\title{
AN INVESTIGATION INTO A DIGITAL STRATEGY FOR INDUSTRIAL DESIGN EDUCATION
}

BY

NOOR NABEEL ALDOY, BA (Hons.), MSC

\begin{abstract}
A Doctoral Thesis
Submitted in partial fulfilment of the requirements for the award of Doctor of Philosophy of Loughborough University
\end{abstract}

10 August 2011

(C) Noor Nabeel Aldoy 2011 
Digital design tools and techniques facilitate efficiency gains, shorten development times, and aid collaboration between members of product development teams. As the range of digital tools available to the industrial designer increases, the aim of this research was to investigate the viability of a totally digital industrial design strategy and opportunities to employ the methods in design education.

Published literature indicated a general lack of research in the use of digital design tools and media by industrial design students and practitioners. This research employed empirical surveys, which indicated that whilst the use of digital methods increased as the design solution progressed, practitioners were using digital tools/media more extensively than the students. The findings also revealed a negative reaction to a completely digital industrial design strategy and curriculum, despite the fact that the majority of practitioners believed in the capacity of digital tools/media to replace conventional methods. Losing the spontaneity of paper-based sketching was identified as the main concern about a totally digital process and this issue was further investigated through a case study in which industrial/product design students employed the Tablet PC as a tool for concept generation. Student responses indicated overwhelmingly positive attitudes towards the use and capabilities of the Tablet PC as a tool for digital sketching and its use as a self-contained design tool. Following the first phase of empirical studies, a draft digital industrial design strategy was devised and presented to graduating students, academics and practitioners for feedback. Findings revealed that the majority of graduating students were receptive to the strategy and modifications applied in response to feedback.

The research concludes that industrial design programmes are failing to fully avail of the breadth of advanced and emerging digital technologies that can be used during practice. Despite the fact that the majority of interviewees felt that the digital industrial design strategy was feasible, cost and the resistance of academics who had an interest in the use of conventional tools was holding back educational progress. Recommendations for curriculum development have been identified for a more extensive introduction to, and use of, digital tools. 


\section{KEYWORDS}

Digital design, digital design strategy, digital sketching, industrial design, media, Tablet PC, tools. 


\section{EXAMINERS}

The external examiner for this PhD thesis was Professor Michael Tovey and the internal examiner was Dr Steve Summerskill. 


\section{ACKNOWLEDGMENTS}

This thesis would not have been possible without the supervision and support of Dr Mark Evans. I am sincerely grateful for his encouragement throughout the research years. He has always made himself available when I needed guidance.

I am indebted to all the industrial design practitioners, academics and students who participated in the research studies and provided valuable feedback and information that helped shaping the thesis.

I gratefully acknowledge the funding that facilitated undertaking the research by Loughborough Design School and Engineering Centre for Excellence in Teaching and Learning (engCETL) at Loughborough University.

Special thanks to my dear friends whom I met in Loughborough while undertaking the research for the happy times and for being thoughtful and caring. Thank you for making so many special memories.

Last but not least, I owe my deepest gratitude to my family, especially my parents for their emotional support throughout my life. Their endless love, care and encouragement made it possible for me to complete my PhD journey. 


\section{ABBREVIATIONS}

2D

3D

CAD

CAID

CAS

CFD

CNC

DID

FEA

HIS

HP

IDSA

IT

MIT

NPD

PDS

RE

RP

UK

VP

VR
- Two-dimensional

- Three-dimensional

- Computer aided design

- Computer aided industrial design

- Computer aided sketching

- Computational fluid dynamics

- Computer numerical control

- Digital industrial design

- Finite element analysis

- Hybrid ideation space

- Hewlett Packard

- Industrial Designers Society of America

- Information technology

- Massachusetts Institute of Technology

- New product development

- Product design specification

- Reverse engineering

- Rapid prototyping

- United Kingdom

- Virtual prototyping

- Virtual reality 


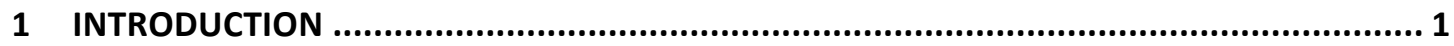

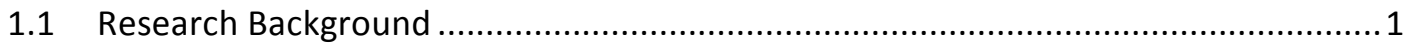

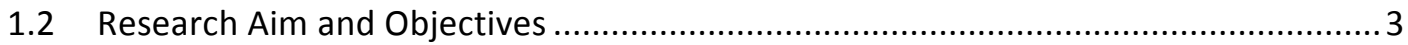

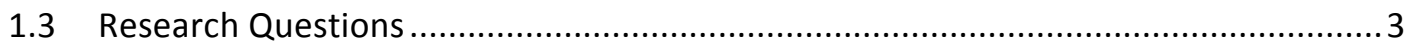

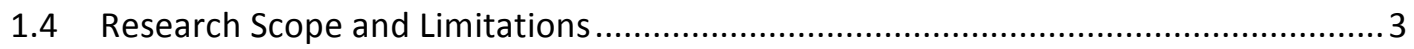

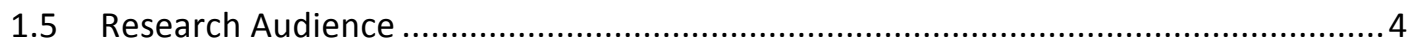

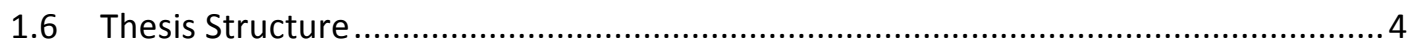

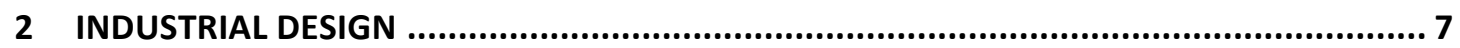

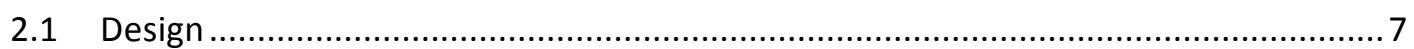

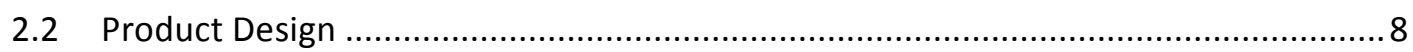

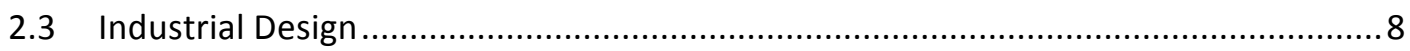

2.4 Distinction between Industrial Design and Engineering Design ............................... 10

2.5 Industrial Design within New Product Development .............................................. 11

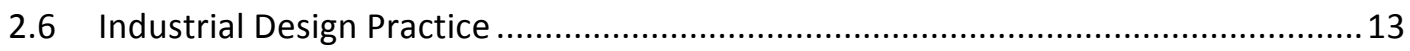

2.7 Generic Activities of Industrial Design .................................................................... 19

2.7.1 Concept Generation .......................................................................................

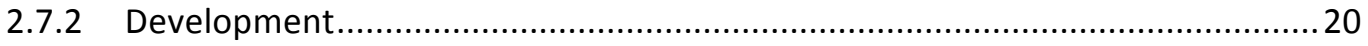

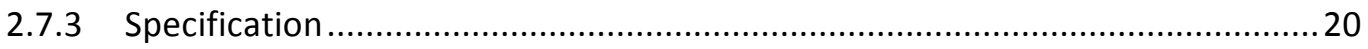

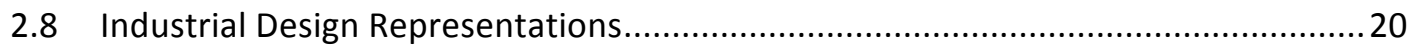

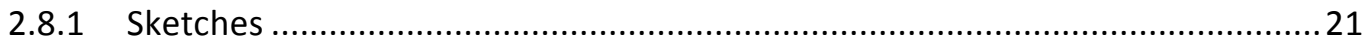

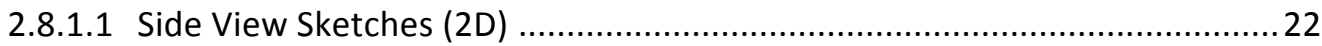

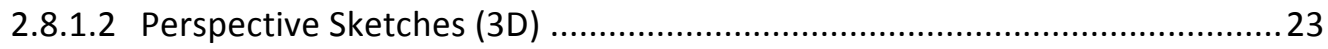

2.8.1.3 Investigative and Exploration Sketches ..................................................23

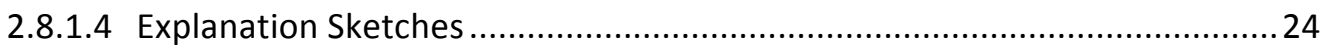

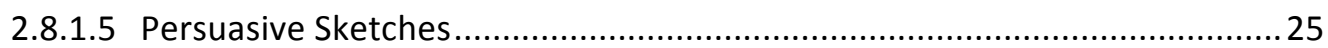

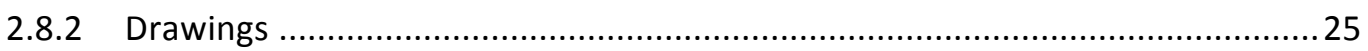

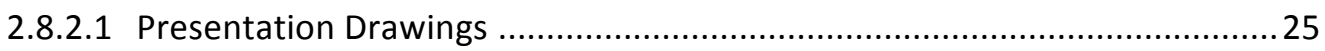

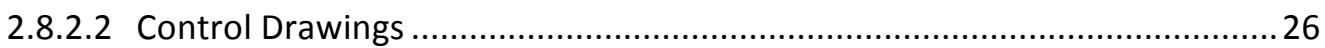

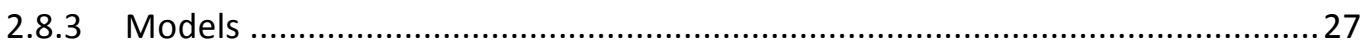

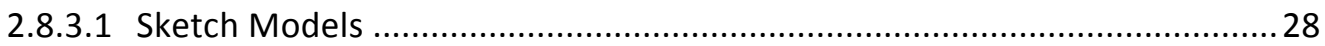

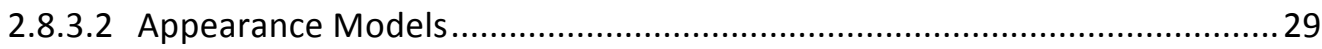




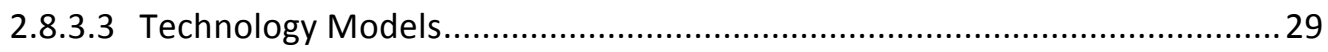

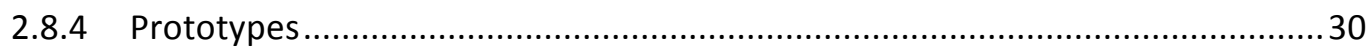

2.8.4.1 Appearance Prototypes ................................................................ 30

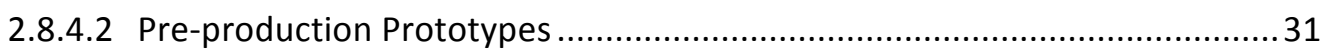

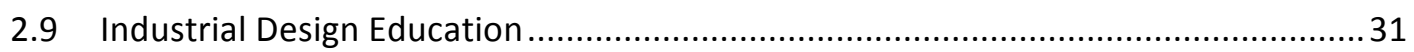

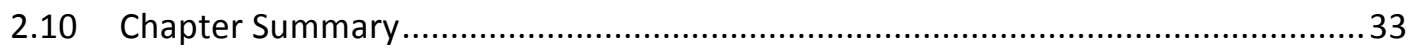

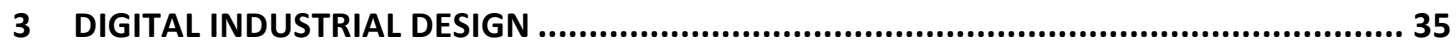

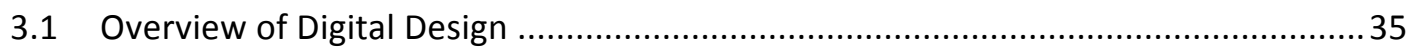

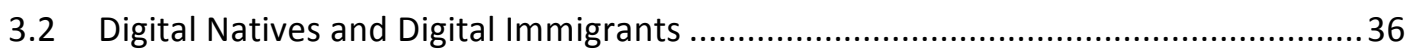

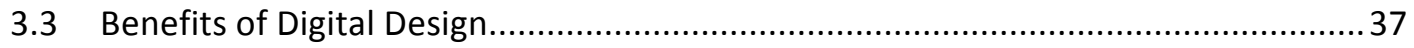

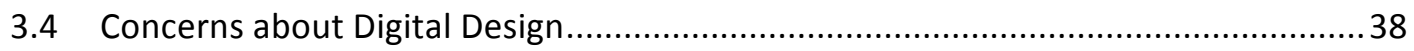

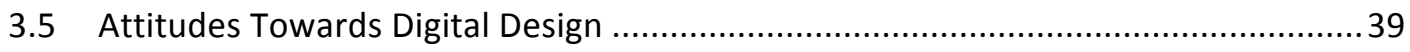

3.6 Digital Tools/Media .............................................................................. 41

3.6.1 Digital Sketching Tools/Media ...................................................... 41

3.6.1.1 Digitising Tablet without a Built-in Display ........................................ 43

3.6.1.2 Digitising Tablet with an Interactive Display....................................... 43

3.6.1.3 2D Visualisation Software ............................................................. 47

3.6.1.4 Pen Input Device ................................................................ 49

3.6.1.5 Digital Design Journal ............................................................. 51

3.6.1.6 Computer Aided Sketching (CAS) .................................................... 53

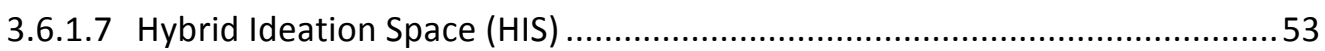

3.6.1.8 3D Sketching System ................................................................ 54

3.6.2 Digital Modelling/Prototyping Tools/Media .................................................56

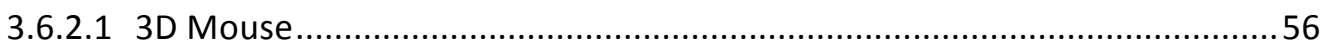

3.6.2.2 Computer Aided Design ................................................................. 57

3.6.2.3 3D Scanning/Reverse Engineering (RE) .........................................60

3.6.2.4 Haptic Modelling.......................................................................... 61

3.6.2.5 Computer Numerical Control Machining...........................................63

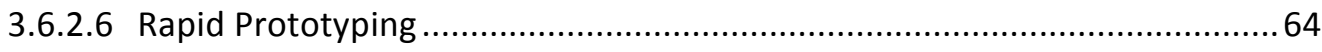

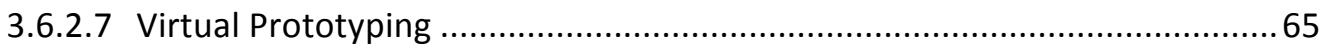

3.6.2.8 Virtual Reality ........................................................................... 66

3.7 Digital Industrial Design Practice ...............................................................67

3.8 Digital Industrial Design Education...........................................................6 68

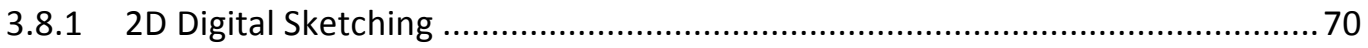




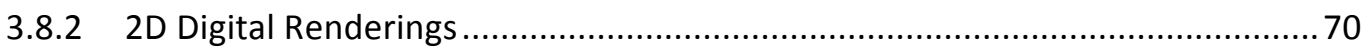

3.8.3 3D Sketch Modelling …............................................................................ 70

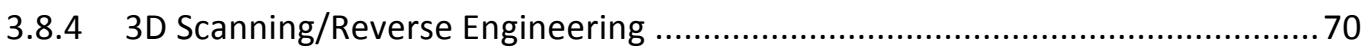

3.8.5 3D Computer Aided Design Modelling ......................................................... 71

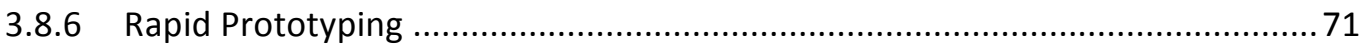

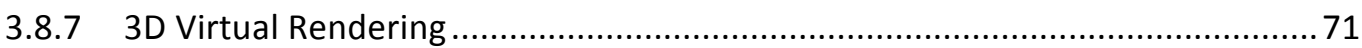

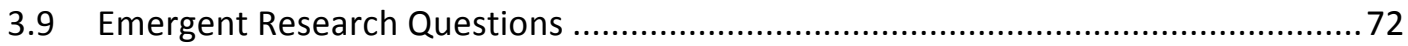

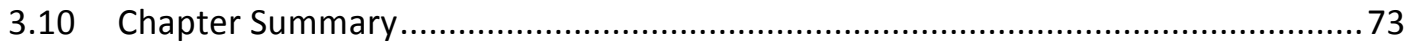

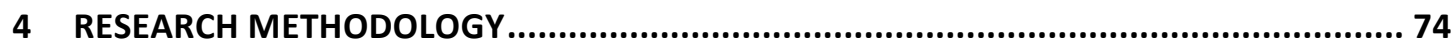

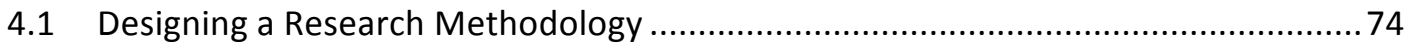

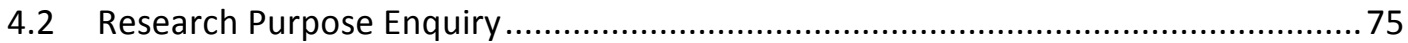

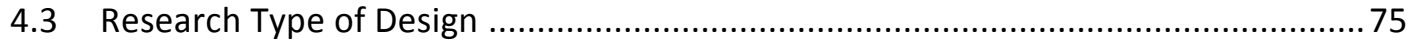

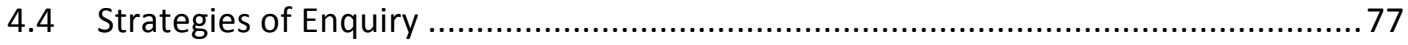

4.4.1 Survey as a Research Strategy........................................................................ 78

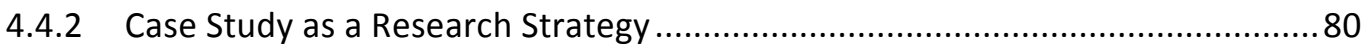

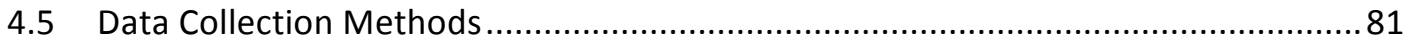

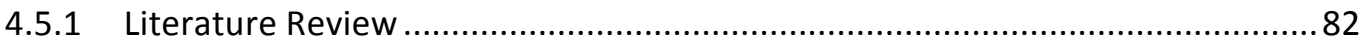

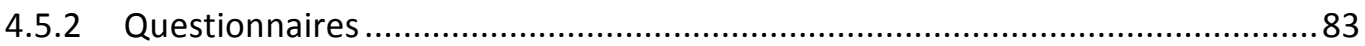

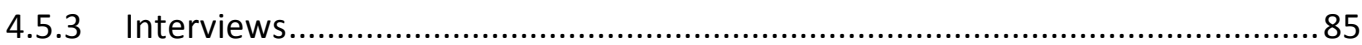

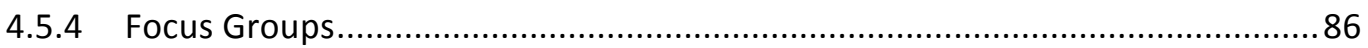

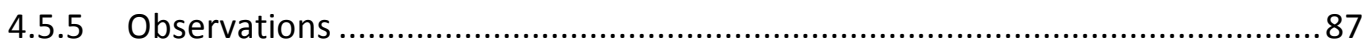

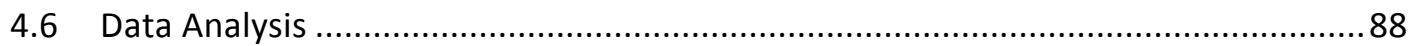

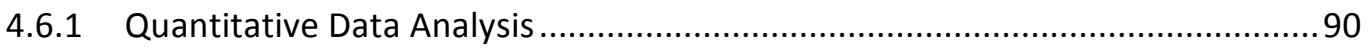

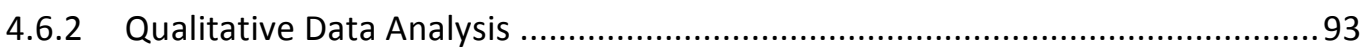

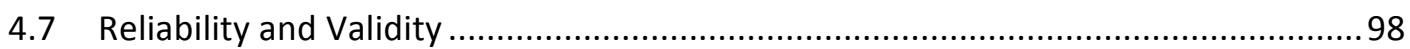

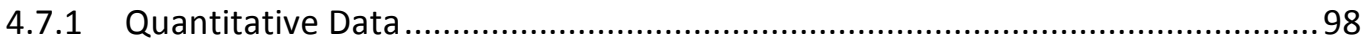

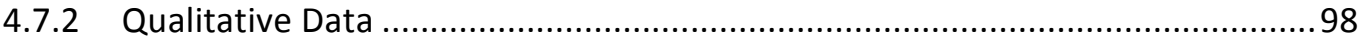

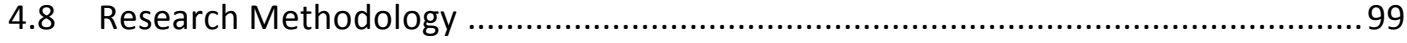

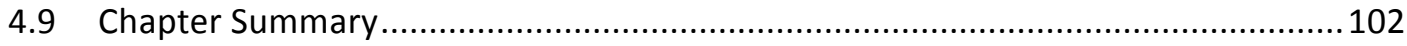

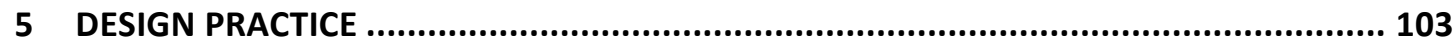

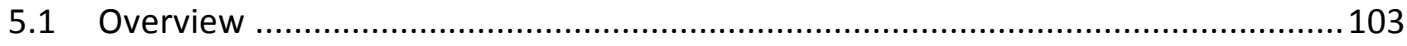

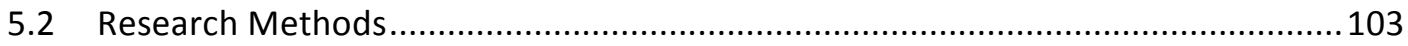

5.2.1 2007/2008 Graduating Student Supervised Collective Questionnaire ............104

5.2.2 Industrial Placement Student Online Questionnaire .....................................107 


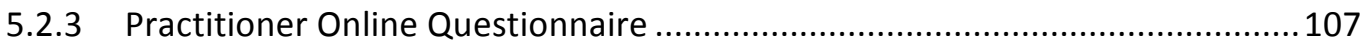

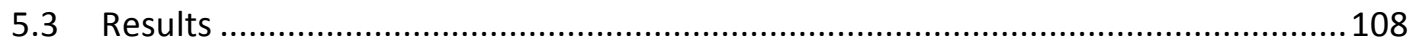

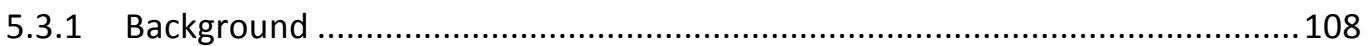

5.3.2 Use of Traditional and Digital Design Methods............................................... 109

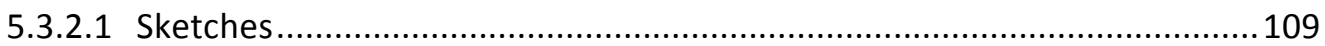

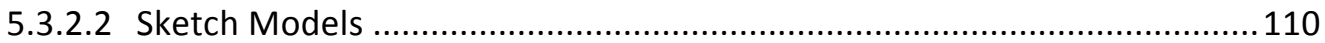

5.3.2.3 Appearance Models.......................................................................... 112

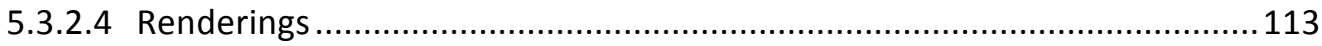

5.3.2.5 Control/Engineering Drawings...........................................................115

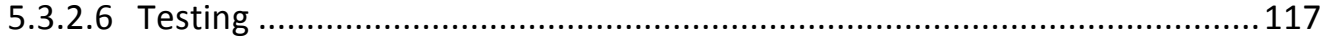

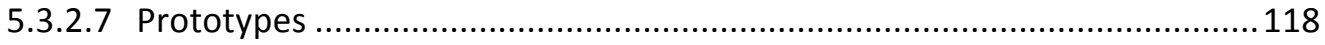

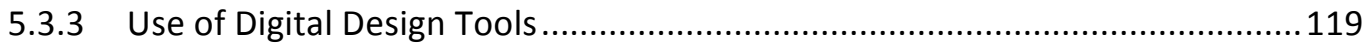

5.3.3.1 2D Computer Visualisation Software .....................................................120

5.3.3.2 3D Solid Modelling Computer Aided Design Software .............................120

5.3.3.3 3D Surface Modelling Computer Aided Design Software ............................ 121

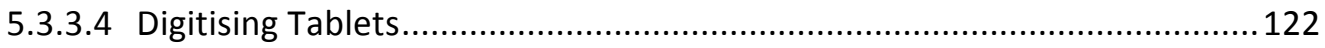

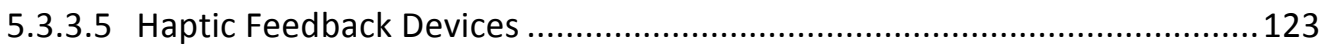

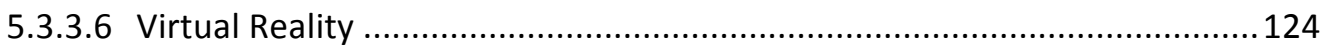

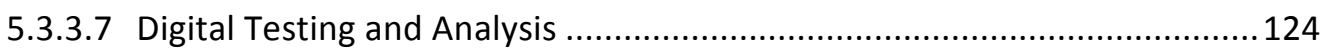

5.3.3.8 Computer Numerical Control Machining ...............................................125

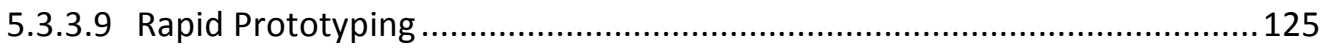

5.3.4 Digital Tools/Media Used during Each Phase of the Design Process ................126

5.3.5 Use of Digital Methods during Different Phases of the Design Process...........127

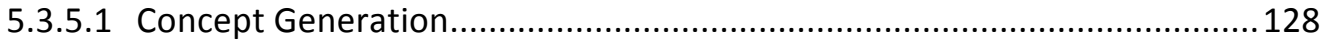

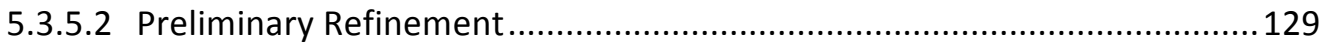

5.3.5.3 Further Refinement and Final Concept Selection .....................................130

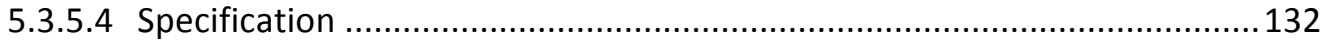

5.3.6 Thoughts on Employing Digital Techniques ..................................................134

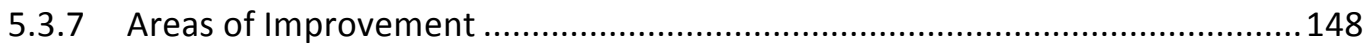

5.3.8 Reflection on a Completely Digital Process ..................................................149

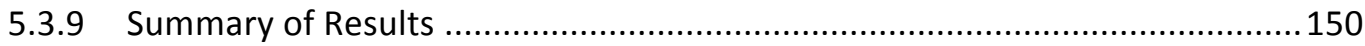

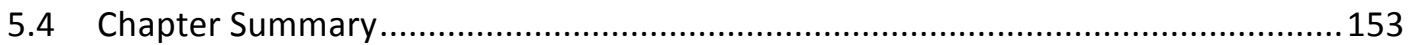

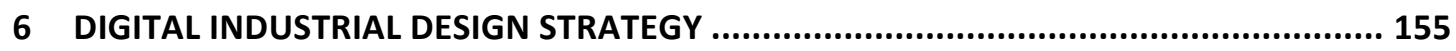

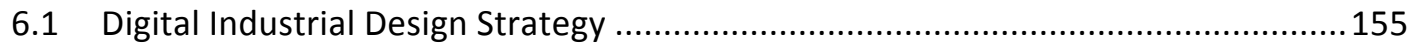


6.2.1 Background

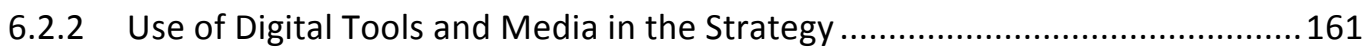

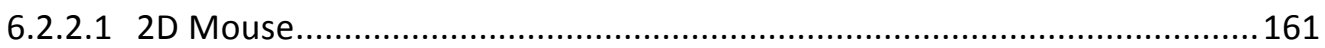

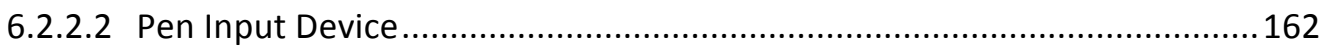

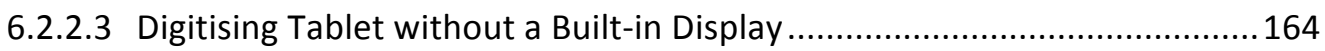

6.2.2.4 Digitising Tablet with an Interactive Pen Display.......................................166

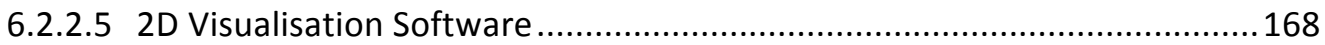

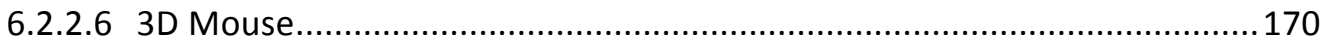

6.2.2.7 3D Scanning/Reverse Engineering ....................................................... 171

6.2.2.8 3D Computer Aided Design (Solid and Surface) …....................................173

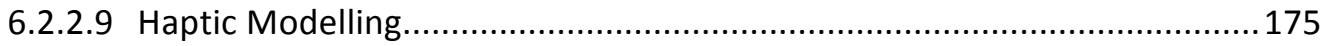

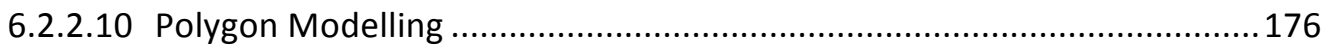

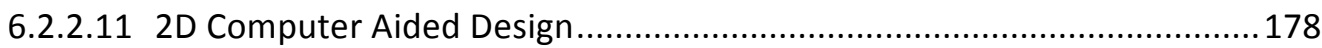

6.2.2.12 2D Computer Numerical Control Machining.........................................179

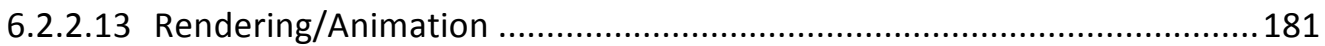

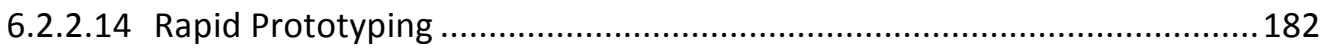

6.2.2.15 3D Computer Numerical Control Machining..........................................184

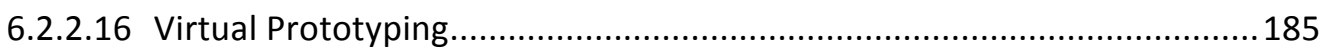

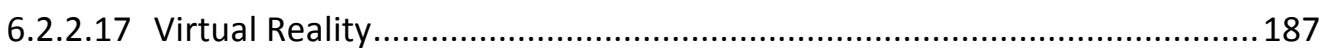

6.2.3 Thoughts on the Digital Industrial Design Strategy ........................................188

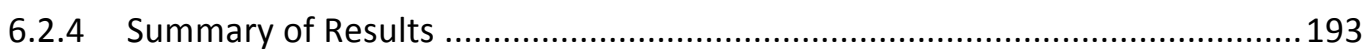

6.3 Academic and Practitioner Feedback on the Digital Industrial Design Strategy .....195

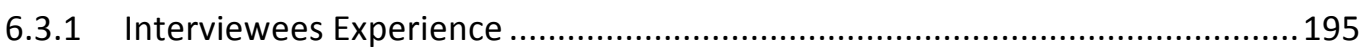

6.3.2 Tools/Media Used within Design Practice.....................................................196

6.3.3 Initial Thoughts on Designing Digitally ..........................................................198

6.3.4 Thoughts on the Digital Industrial Design Strategy ...........................................2201

6.3.5 Improvements Suggested to the Digital Industrial Design Strategy.................207

6.3.6 Viability of the Digital Industrial Design Strategy .........................................2. 211

6.3.7 Employed Elements of the Digital Industrial Design Strategy .........................212

6.3.8 Interest in Employing the Digital Industrial Design Strategy ...........................2214

6.3.9 Interest in Hiring Digital Industrial Design Graduates ...................................215

6.3.10 Thoughts on a Completely Digital Industrial Design Curriculum ....................215

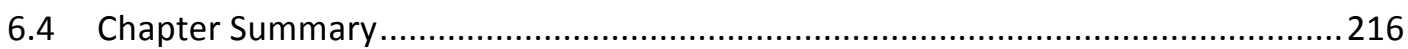




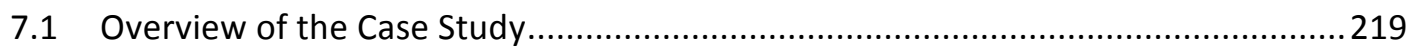

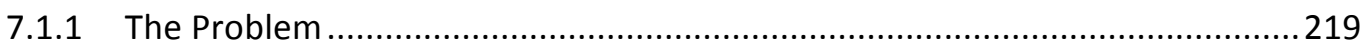

7.1.2 Hewlett Packard Innovation in Education Grant .......................................... 221

7.1.3 Case Study Participants ................................................................. 221

7.1.4 Steps Taken to Address the Problem .................................................... 222

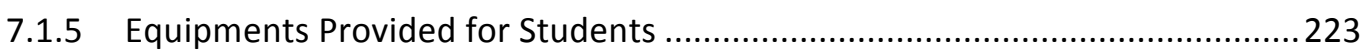

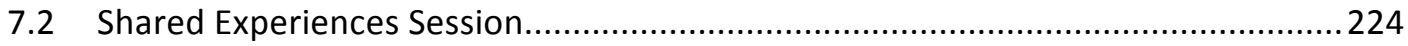

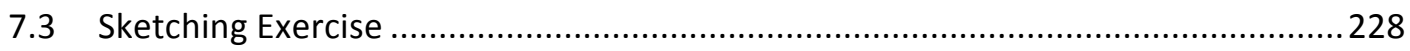

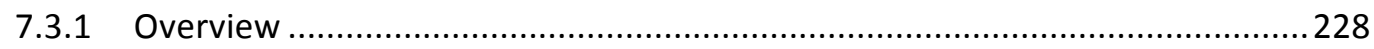

7.3.2 Sketching Exercise Questionnaire .................................................... 231

7.3.3 Assessing the Output of the Sketching Exercise Questionnaire....................237

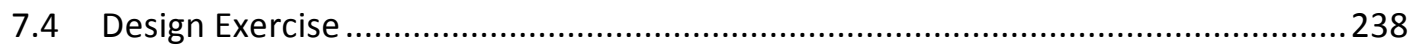

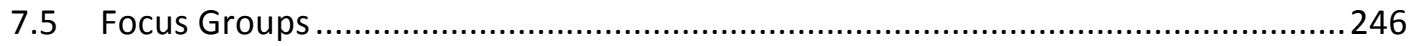

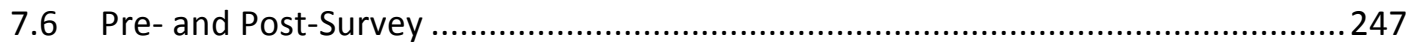

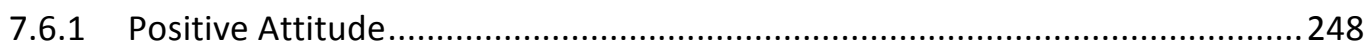

7.6.2 Neutral Attitude ......................................................................... 252

7.6.3 Negative Attitude .......................................................................... 253

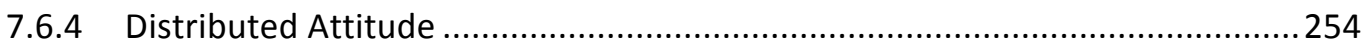

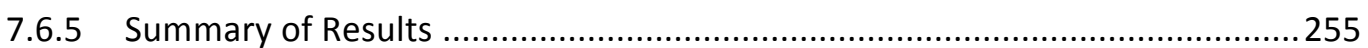

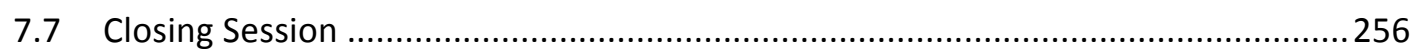

7.7.1 Key Benefits..................................................................................... 256

7.7.2 Limitations................................................................................. 271

7.7.3 Recommendations for Learning and Teaching....................................... 279

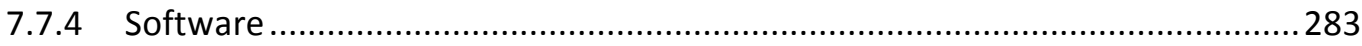

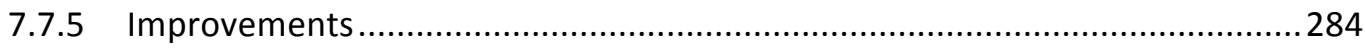

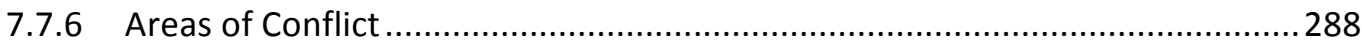

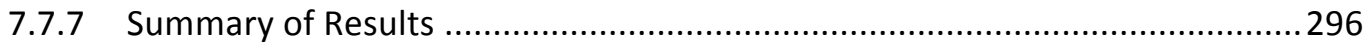

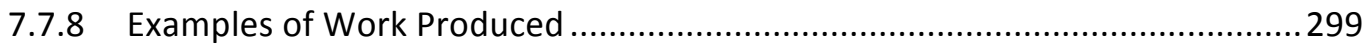

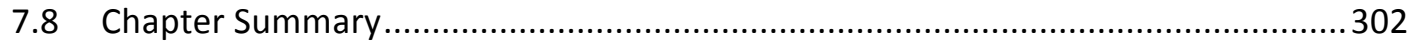

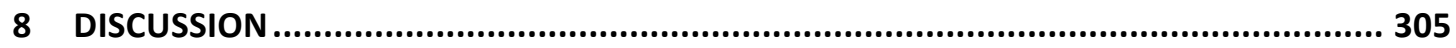

8.1 Nature of Education and Professional Industrial Design Practice in Terms of Digital

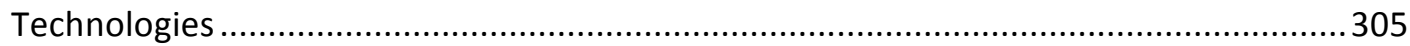

8.1.1 Balance between Conventional and Digital Design Methods ........................305 
8.1.2 Dominant Design Methods 306

8.1.3 Percentages Employing Digital Design Methods within the Design Process....306

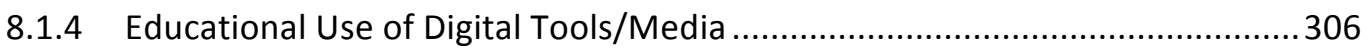

8.1.5 Digital Design Tools/Media Used in Professional Practice ...............................307

8.1.6 Use of Digital Design Tools/Media in Professional and Educational Practice ..307

8.2 Attitudes Towards a Totally Digital Industrial Design Practice ..............................310

8.2.1 Graduating Student Attitude............................................................... 310

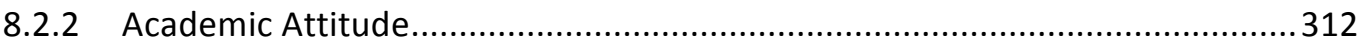

8.2.3 Practitioner Attitude ................................................................. 314

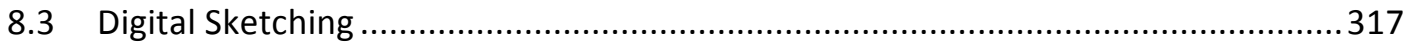

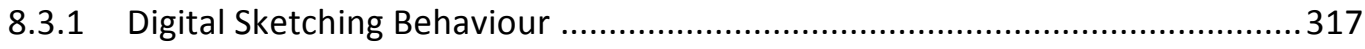

8.3.2 Difference between Digital Sketching and Paper-based Sketching ...............317

8.3.3 Tablet PC as a Tool for Concept Generation .............................................318

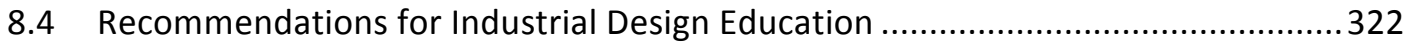

8.4.1 Industrial Design Education Should Increase Student Exposure of Digital Technologies

8.4.2 Students Should be Taught Conventional Methods Before Digital Methods ..323

8.4.3 Tablet PCs Should be Introduced to All Industrial Design Students 324

8.5 Considerations of a Digital Industrial Design Process............................................324

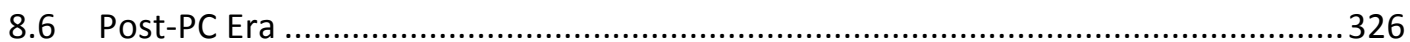

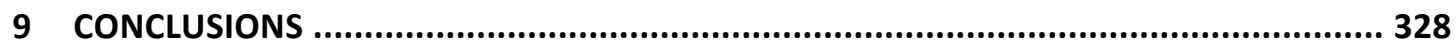

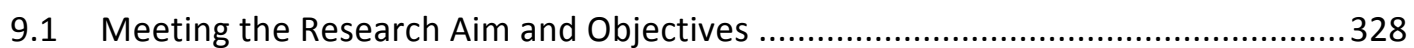

9.1.1 Identify the Nature of Industrial Design Practice and Education Using Published Literature 328

9.1.2 Undertake a Literature Review in the Field of DID and Identify Available Digital

Tools that Can be Used Within Industrial Design Practice 328

9.1.3 Explore the Nature of Contemporary Industrial Design Practice and Education in Terms of Employing Digital Technologies 328

9.1.4 Identify the Attitudes of Industrial Design Practitioners, Academics and Students Towards DID 329

9.1.5 Investigate How Digital Tools/Media Can be Employed to Form a Totally DID Strategy 329

9.1.6 Seek Opinion from Industrial Design Practitioners, Academics and Students on the Use of a Totally DID Strategy. 329 
9.1.7 Investigate Issues Relating to the Activity of Digital Sketching

9.2 Answering the Research Questions

9.2.1 What is the Nature of Educational and Professional Industrial Design Practice in Terms of Digital Technologies?

9.2.2 How Do Students, Academics and Practitioners Feel Towards Undertaking Design Practice Entirely Digitally?

9.2.3 How Can Digital Design Tools/Media be Integrated to Form a DID Strategy?.333

9.2.4 How Can Digital Tools be Used to Support Concept Generation Through Sketching?

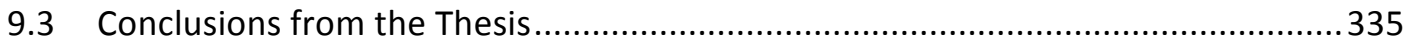

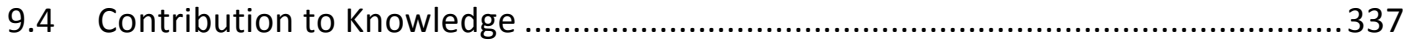

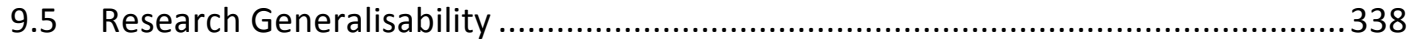

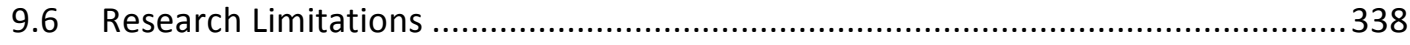

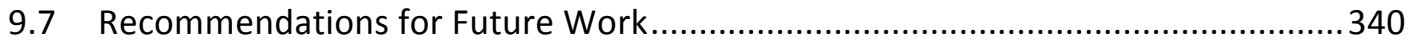

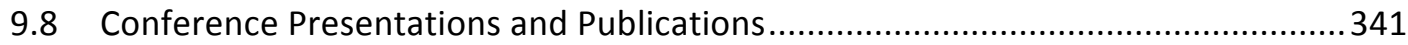

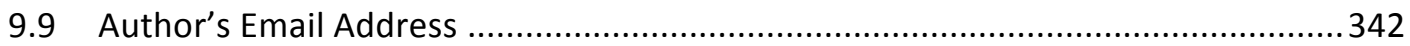

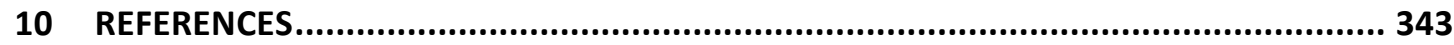

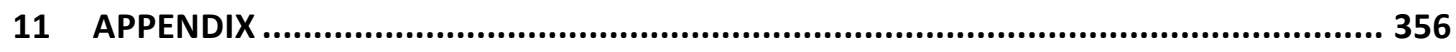

11.1 2007/2008 Graduating Student Digital Industrial Design Questionnaire .............356

11.2 Industrial Placement Student Online Questionnaire on Digital Industrial Design.360

11.3 Online Discussion with Design Practitioners on the IDSA LinkedIn Group 367

11.4 2008/2009 Graduating Student Digital Industrial Design Strategy Questionnaire 378

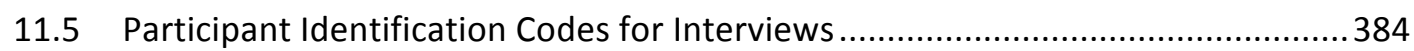

11.6 Practitioner Interview Transcript Sample .................................................... 384

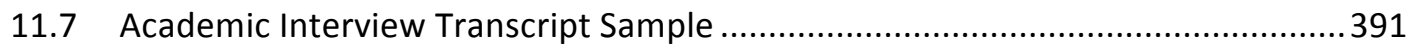

11.8 Student Sketching Exercise Questionnaire ............................................... 400

11.9 Academic Assessing the Output of the Sketching Exercise Questionnaire ..........401

11.10 Student Design Exercise Questionnaire ............................................. 428

11.11 Student Focus Group Transcript Sample .................................................... 429

11.12 Student Pre- and Post-Using the Tablet PC Questionnaire .............................442

11.13 Student Use of the Tablet PC for Designing Questionnaire.............................445 


\section{LIST OF FIGURES}

Figure 2-1: Conceptual mapping of NPD inputs, outputs, financial results, and financial performance (Hertenstein et al., 2005: 6) 12

Figure 2-2: Relative timing of the industrial design process for two types of products (Ulrich and Eppinger, 2003: 202) 12

Figure 2-3: Stages of systematic design (Jones, 1963: 11) 14

Figure 2-4: The main phases of design (Archer, 1965: 64) 14

Figure 2-5: External productive process of design (Cooper and Press, 1995: 38) ...................15

Figure 2-6: The design process (Holmes et al., 1995: 105). 15

Figure 2-7: Block diagram of the industrial design process (Holmes et al., 1995: 109) ...........16

Figure 2-8: The industrial design process (Ulrich and Eppinger, 2003: 219-220)...................17

Figure 2-9: Total design activity model (Pugh, 1991: 11) .......................................................18

Figure 2-10: Side view sketches of hairdryer concepts (Eissen and Steur, 2007: 26) .............23

Figure 2-11: Perspective sketches of hand drill concepts (Olofsson and Sjölén, 2005: 23) ....23

Figure 2-12: Investigative and explorative sketches of domestic iron concepts (Olofsson and Sjölén, 2005: 21).

Figure 2-13: Explanation sketches of journalist's tool concepts (Olofsson and Sjölén, 2005:

53) 24

Figure 2-14: Persuasive sketch of goggles concept (Olofsson and Sjölén, 2005: 73) 25

Figure 2-15: Presentation drawing of a fabric care system concept (Cullen et al., 2004: 141)

Figure 2-16: General arrangement drawing for the rear frame of a folding bicycle (Pipes, 2007: 158) 27

Figure 2-17: Exploded view of an autorotor drawing (Pipes, 2007: 190) ..............................27

Figure 2-18: Sketch model of a head immobiliser (Cullen et al., 2004: 188)...........................28

Figure 2-19: Appearance model of a pocket digital camera (Cullen et al., 2004: 92) 29

Figure 2-20: Technology model of a manual citrus juicer concept (Industrial Designers Society of America, 2001: 26)

Figure 2-21: Appearance prototype of a mixing station and syringe components (Industrial Designers Society of America, 2001: 199).....

Figure 2-22: Pre-production prototype of a Segway Human Transporter (Cullen et al., 2004:

16) 31 
Figure 2-23: Elements of design education (Cooper and Press, 1995: 21)......

Figure 3-1: Wacom Bamboo Pen \& Touch (PC Pro, 2009)

Figure 3-2: The Wacom Cintiq tablet (Pipes, 2007: 97)

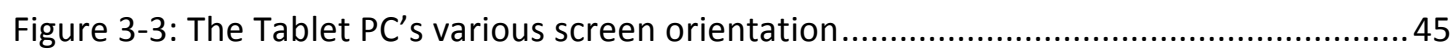

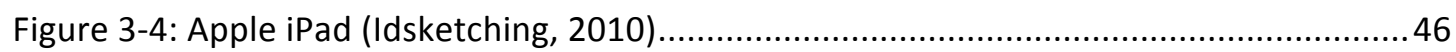

Figure 3-5: Pogo Sketch pen used with Apple iPad (Ten One Design, 2010) ..........................46

Figure 3-6: Screenshot that illustrates the use of layers in SketchBook Pro application for

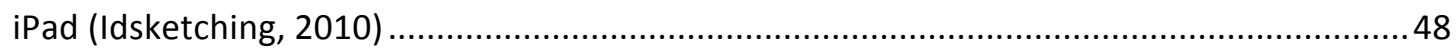

Figure 3-7: Screenshot of SketchBook Pro interface for iPad (Idsketching, 2010) ...................48

Figure 3-8: InkBoard main user interface (Ning et al., 2004: 5) .............................................49

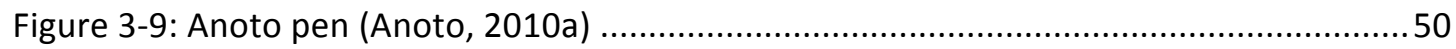

Figure 3-10: Digital ink pen and e-pens base unit (e-pens, 2010a) ........................................50

Figure 3-11: Windows Journal used by MIT mechanical design students for collaborative design work (student work is colour coded) (Microsoft, 2004: 3) .........................................52

Figure 3-12: The Digital Sketchbook prototype (Hoeben and Stappers, 2005: 410)................53

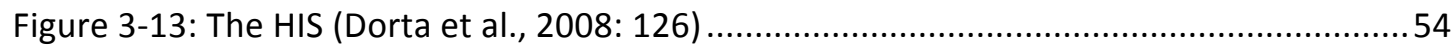

Figure 3-14: Immersive sketching in action within the HIS system (Dorta et al., 2008: 127).. 54

Figure 3-15: ILoveSketch used by a professional designer (Bae et al., 2008: 151)..................55

Figure 3-16: The Napkin Sketch system that creates 3D sketches on top of a physical napkin (Xin et al., 2008: 223) 56

Figure 3-17: SpaceNavigator 3D mouse movements (3Dconnection, 2010) .........................57

Figure 3-18: SpacePilot PRO 3D mouse (3Dconnection, 2011) ...............................................57

Figure 3-19: Screenshot of a 3D car seat concept modelled using Alias Studio Tools (IDSA and

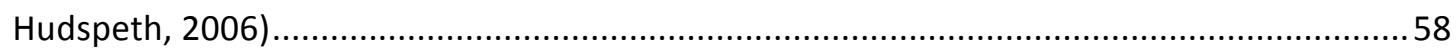

Figure 3-20: Screenshot of Pro/Engineer of a rendered vase (Pipes, 2007: 122) ...................58

Figure 3-21: Use of Autodesk Moldflow software to design a water meter by Arad (Wilde, 2011) 59

Figure 3-22: Polygon meshes in a 3D dinosaur head modelled in Autodesk Maya (Autodesk, 2011a) 60

Figure 3-23: Example of sequences in reverse engineering (Sokovic and Kopac, 2006: 401).61

Figure 3-24: The SensAble PHANTOM haptic device (SensAble Technologies, 2010a) 62

Figure 3-25: FreeForm virtual clay models of handle design and grip pattern of a razor produced by Gillette (SenSAble Technologies, 2006) 
Figure 3-26: Vinyl sign cutter used to cut paper surfaces using 2D files from CAD models (Sass and Oxman, 2006: 329) . 63

Figure 3-27: A 3D wax model being cut on a milling machine (Pipes, 2007: 102). 63

Figure 3-28: Automobile wheel prototype being created on a 3D Stereolithography machine (Pipes, 2007: 103). 64

Figure 3-29: Toothbrush produced in colour using Z Corporation printing (top toothbrush) compared to the real product (Z Corporation, 2010) 64

Figure 3-30: Virtual prototyping of metro interiors (Papitypes, 2010) ..................................66

Figure 3-31: Use of virtual reality to evaluate a train (Siemens, 2010) ..................................66

Figure 3-32: Digital product design system (Yan et al., 2006) .................................................68

Figure 3-33: Digital Rapid Visualisation for Industrial Design course curriculum (Shin, 2009: 2)

Figure 3-34: 2D digital sketch example (Shin, 2009: 3) .................................................... 70

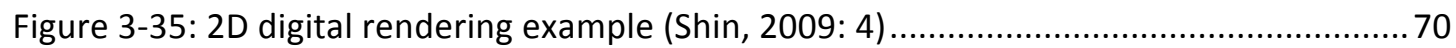

Figure 3-36: 3D scanned image of 3D sketch model (Shin, 2009: 4) .......................................71

Figure 3-37: Rapid prototype models (Shin, 2009: 5) …………........................................ 71

Figure 3-38: Virtual rendering example (Shin, 2009: 6) ................................................... 71

Figure 4-1: Illustrations of different scenarios for combining qualitative and quantitative methods ((Ulin et al., 1996) cited in (Tashakkori and Teddlie, 1998: 44)) 77

Figure 4-2: Methods of data collection developed by the author based on Kumar (2005: 118)

Figure 4-3: Screenshot of EndNote X4 software

Figure 4-4: Sample of the coding system (in red) used in one of the questionnaires employed in the research 91

Figure 4-5: Quantitative data entering in Microsoft Excel 92

Figure 4-6: Using Microsoft Excel to key in the results of the calculations. 92

Figure 4-7: Example of the use of memos in NVivo 9 to summarise the feedback from each participant and record thoughts in the academic interviews analysis. 95 Figure 4-8: Example of the use of tree nodes in NVivo 9 to help organise the data in the practitioner interviews analysis 96

Figure 4-9: Example of the use of general category (parent node) and more specific categories (child nodes) in NVivo 9 to analyse the academic interviews. 97 Figure 4-10: Five phase research methodology 101 
Figure 5-1: First visual aid card used to illustrate non-digital and digital methods of designing

Figure 5-2: Second visual aid card used to show the current practice of industrial design (unused tools and outputs ghosted)

Figure 5-3: Third visual aid card used to show the proposed digital way of designing (unused tools and outputs ghosted) 106

Figure 5-4: Graduating student responses to Questions B1.1 and B1.2: "How often do you use freehand paper-based sketches and digital sketches?" 110

Figure 5-5: Industrial placement student responses to Questions 10 and 11: "How often did your design organisation use freehand paper-based sketches and digital sketches?" 110 Figure 5-6: Graduating student responses to Questions B2.1 and B2.2: "How often do you use workshop-based sketch models and digital sketch models?" 111 Figure 5-7: Industrial placement student responses to Questions 12 and 13: "How often did your design organisation use workshop-based sketch models and digital sketch models?" 112 Figure 5-8: Graduating student responses to Questions B3.1 and B3.2: "How often do you use workshop-based appearance models and digital appearance models?" 113 Figure 5-9: Industrial placement student responses to Questions 14 and 15: "How often did you design organisation use workshop-based appearance models and digital appearance models?" 113

Figure 5-10: Graduating student responses to Questions B4.1 and B4.2: "How often do you use manual paper-based renderings and computer renderings?"

Figure 5-11: Industrial placement student responses to Questions 16 and 17: "How often did your design organisation use manual paper-based renderings and computer renderings?"

Figure 5-12: Graduating student responses to Questions B5.1 and B5.2: "How often do you use manual control/engineering drawings and digital control/engineering drawings?"......116 Figure 5-13: Industrial placement student responses to Questions 18 and 19: "How often did your design organisation use manual control/engineering drawings and digital control/engineering drawings?" 116

Figure 5-14: Graduating student responses to Questions B6.1 and B6.2: "How often do you use physical testing and digital testing?"

Figure 5-15: Industrial placement student responses to Questions 20 and 21: "How often did your design organisation use physical testing and digital testing?" 118 
Figure 5-16: Graduating student responses to Questions B7.1 and B7.2: "How often do you use workshop-based prototypes and digital prototypes?".

Figure 5-17: Industrial placement student responses to Questions 22 and 23: "How often did you design organisation use workshop-based prototypes and digital prototypes?".

Figure 5-18: Graduating student responses to Question C1: "How do you rate using 2D visualisation software?"

Figure 5-19: Graduating student responses to Question C2: "How do you rate using 3D solid modelling CAD software?"

Figure 5-20: Graduating student responses to Question C3: "How do you rate using 3D surface modelling CAD software?"

Figure 5-21: Graduating student responses to Question C4: "How do you rate using digitising tablets?" 123

Figure 5-22: Graduating student responses to Question C5: "How do you rate using haptic feedback devices?"

Figure 5-23: Graduating student responses to Question C6: "How do you rate using virtual reality?".

Figure 5-24: Graduating student responses to Question C8: "How do you rate using computer numerical control machining?" 125

Figure 5-25: Graduating student responses to Question C9: "How do you rate using rapid prototyping?" 126

Figure 5-26: Graduating student responses to Question D1: "To what extent do you employ digital methods in the concept generation phase (creating the product's form and user interfaces)?" 128

Figure 5-27: Industrial placement student responses to Question 24: "To what extent does the design organisation you worked for employ digital methods in the concept generation phase (creating the product form and translating ideas into visual representation)?". 129 Figure 5-28: Graduating student responses to Question D2: "To what extent do you employ digital methods in the preliminary refinement phase (building soft models of the most promising concepts)?” 130

Figure 5-29: Industrial placement student responses to Question 25: "To what extent does the design organisation you worked for employ digital methods in preliminary refinement phase (most promising ideas being developed and presented to clients as rendering or foam models)?" 130 
Figure 5-30: Graduating student responses to Question D3: "To what extent do you employ digital methods in the further refinement and final concept selection phase (building hard models and making renderings)?"

Figure 5-31: Industrial placement student responses to Question 26: "To what extent does the design organisation you worked for employ digital methods in the further refinement and final concept selection phase (chosen idea being developed and appearance models and prototypes are expected to be produced)?" 132

Figure 5-32: Graduating student responses to Question D4: "To what extent do you employ digital methods in the specification phase (making control drawings of the final concept to enable building prototypes)?" 133

Figure 5-33: Industrial placement student responses to Question 27: "To what extent does the design organisation you worked for employ digital methods in the specification phase (making control drawings of the final concept required for production tooling by the manufacturer)?" 133

Figure 5-34: Average (mean) amount of time spent using digital methods in each phase by graduating students 134

Figure 5-35: Graduating student responses to Question E1: "To what extent do you agree or disagree that you will be able to achieve the same outcome from your project if the entire process was done using digital tools?" 135 Figure 5-36: Industrial placement student responses to Question 32: "Do you believe that the design organisation you worked for will be able to achieve the same outcome from projects if the entire process was done using digital tools?"

Figure 5-37: Practitioner responses to Question E1: "To what extent do you agree or disagree that you will be able to achieve the same outcome from your project if the entire process was done using digital tools?" 138 Figure 5-38: Graduating student responses to Question E2: "To what extent do you agree or disagree that digital technologies have the potential to replace conventional workshops and the hands-on experience?" 139 Figure 5-39: Industrial placement student responses to Question 34: "Do you think that digital technologies have the potential to replace conventional workshops and hands-on experience completely in the design organisation you worked for?" 141 Figure 5-40: Practitioner responses to Question E2: "To what extent do you agree or disagree that digital technologies have the potential to replace conventional workshops and the hands-on experience?" 
Figure 5-41: Graduating student responses to Question E3: "To what extent do you agree or disagree that your design practice will improve if you used a completely digital process?" 143 Figure 5-42: Industrial placement student responses to Question 36: "Do you think that the organisation's design practice will improve if a complete digital process was used?" 144 Figure 5-43: Practitioner responses to Question E3: "To what extent do you agree or disagree that your design practice will improve if you used a completely digital process?" 145 Figure 5-44: Graduating student responses to Question E4: "To what extent do you agree or disagree that it would be appropriate to have a totally digital industrial/product design course?" 146

Figure 5-45: Practitioner responses to Question E4: “To what extent do you agree or disagree that it would be appropriate to have a totally digital industrial/product design course?" 147

Figure 5-46: Graduating student responses to Question F: "Do you think that there are any areas of the industrial/product design course that can be improved in the curriculum of your course?" 149

Figure 6-1: Digital industrial design strategy..... 156

Figure 6-2: First visual aid used to compare the non-digital and digital design processes ...158 Figure 6-3: Second visual aid used to explain the current practice of industrial design (unused tools and outputs ghosted) 159

Figure 6-4: Third visual aid card used to show the anticipated digital way of designing (unused tools and outputs ghosted) 159

Figure 6-5: Fourth visual card used to illustrate the DID strategy 160

Figure 6-6: Graduating student responses to Question B1a: "How often do you use a 2D mouse (e.g. Apple wireless Mighty Mouse, Microsoft Explorer) when designing?". 161 Figure 6-7: Graduating student responses to Question B1b: "How easy is the 2D mouse to use?"

Figure 6-8: Graduating student responses to Question B1c: "How useful is the 2D mouse in making a contribution to practice?" 162 Figure 6-9: Graduating student responses to Question B2a: "How often do you use a pen input device (e.g. Livescribe Plus Smartpen, Dane-elec zPen Light) when designing?" ........163 Figure 6-10: Graduating student responses to Question B2b: “How easy is the pen input device to use?" 163

Figure 6-11: Graduating student responses to Question B2c: "How useful is the pen input device in making a contribution to practice?" 164 
Figure 6-12: Graduating student responses to Question B3a: "How often do you use a digitising tablet without a built-in display (e.g. Wacom Bamboo, Wacom Intuos) when designing?". 165

Figure 6-13: Graduating student responses to Question B3b: "How easy is the digitising tablet without a built-in display to use?" 165

Figure 6-14: Graduating student responses to Question B3c: "How useful is the digitising tablet without a built-in display in making a contribution to practice?" 166 Figure 6-15: Graduating student responses to Question B4a: "How often do you use a digitising tablet with an Interactive pen display (e.g. Wacom Cintiq 12WX, Wacom Cintiq 21UX) when designing?"

Figure 6-16: Graduating student responses to Question B4b: "How easy is the digitising tablet with an interactive pen display to use?" 167 Figure 6-17: Graduating student responses to Question B4c: "How useful is the digitising tablet with an interactive pen display in making a contribution to practice?" 168 Figure 6-18: Graduating student responses to Question B5a: "How often do you use 2D visualisation software (e.g. Adobe Photoshop, Adobe Illustrator, SketchBook Pro) when designing?" 169

Figure 6-19: Graduating student responses to Question B5b: "How easy is the 2D visualisation software to use?" 169 Figure 6-20: Graduating student responses to Question B5C: “How useful is the 2D visualisation software in making a contribution to practice?". 170 Figure 6-21: Graduating student responses to Question B6a: "How often do you use a 3D mouse (e.g. Space Navigator, space Explorer) when designing?" 170 Figure 6-22: Graduating student responses to Question B6b: "How easy is the 3D mouse to use?" 171

Figure 6-23: Graduating student responses to Question B6c: "How useful is the 3D mouse in making a contribution to practice?" 171 Figure 6-24: Graduating student responses to Question B7a: "How often do you use 3D scanning (reverse engineering) (e.g. Konica Minolta V1-910 laser scanner, 3Shape, Scantech) when designing?" 172 Figure 6-25: Graduating student responses to Question B7b: "How easy is the 3D scanning (reverse engineering) to use?" 172 Figure 6-26: Graduating student responses to Question B7c: "How useful is the 3D scanning (reverse engineering) in making a contribution to practice?" 173 
Figure 6-27: Graduating student responses to Question B8a: "How often do you use 3D CAD (surface and solid) (e.g. Rhino, Autodesk Alias Studio, Pro/Engineer, SolidWorks) when designing?"

Figure 6-28: Graduating student responses to Question B8b: “How easy is the 3D CAD (solid and surface) to use?"

Figure 6-29: Graduating student responses to Question B8c: "How useful is the 3D CAD (solid and surface) in making a contribution to practice?"

Figure 6-30: Graduating student responses to Question B9a: "How often do you use haptic modelling (e.g. SensAble PHANTOM FreeForm system) when designing?" 175 Figure 6-31: Graduating student responses to Question B9b: "How easy is haptic modelling to use?" 176

Figure 6-32: Graduating student responses to Question B9c: "How useful is haptic modelling in making a contribution to practice?" 176 Figure 6-33: Graduating student responses to Question B10a: "How often do you use polygon modelling (e.g. Autodesk 3ds Max, Autodesk Maya) when designing?" 177

Figure 6-34: Graduating student responses to Question B10b: "How easy is polygon modelling to use?"

Figure 6-35: Graduating student responses to Question B10c: "How useful is polygon modelling in making a contribution to practice?".

Figure 6-36: Graduating student responses to Question B11a: "How often do you use 2D CAD (e.g. 2D Design, 2D application in AutoCAD) when designing?"

Figure 6-37: Graduating student responses to Question B11b: "How easy is 2D CAD to use?"

Figure 6-38: Graduating student responses to Question B11c: "How useful is 2D CAD in making a contribution to practice?"

Figure 6-39: Graduating student responses to Question B12a: "How often do you use 2D CNC machining (e.g. Laser cutting machine, Water Jet Cutter) when designing?" 180 Figure 6-40: Graduating student responses to Question B12b: "How easy is 2D CNC machining to use?" 180

Figure 6-41: Graduating student responses to Question B12c: "How useful is 2D CNC machining in making a contribution to practice?" 181

Figure 6-42: Graduating student responses to Question B13a: "How often do you use rendering/animation (e.g. Autodesk ImageStudio, Adobe Flash) when designing?" 181 
Figure 6-43: Graduating student responses to Question B13b: "How easy is rendering/animation to use?".

Figure 6-44: Graduating student responses to Question B13c: "How useful is rendering/animation in making a contribution to practice?"

Figure 6-45: Graduating student responses to Question B14a: “How often do you use rapid prototyping (e.g. Invision, Z Crop, Stereolithography) when designing?"

Figure 6-46: Graduating student responses to Question B14b: “How easy is rapid prototyping to use?" 183

Figure 6-47: Graduating student responses to Question B14c: "How useful is rapid prototyping in making a contribution to practice?" 184 Figure 6-48: Graduating student responses to Question B15a: “How often do you use 3D CNC machining (e.g. milling machine) when designing?" 184 Figure 6-49: Graduating student responses to Question B15b: "How easy is 3D CNC machining to use?" 185

Figure 6-50: Graduating student responses to Question B15c: "How useful is 3D CNC machining in making a contribution to practice?" 185

Figure 6-51: Graduating student responses to Question B16a: “How often do you use virtual prototyping (e.g. Finite Element Analysis, Pro/Engineer Mechanica) when designing?” ..... 186 Figure 6-52: Graduating student responses to Question B16b: “How easy is virtual prototyping to use?" 186

Figure 6-53: Graduating student responses to Question B16c: "How useful is virtual prototyping in making a contribution to practice?"

Figure 6-54: Graduating student responses to Question B17a: “How often do you use virtual reality (e.g. computer screen, Stereoscopic displays) when designing?" 187 Figure 6-55: Graduating student responses to Question B17b: "How easy is virtual reality to use?" 188

Figure 6-56: Graduating student responses to Question B17c: "How useful is virtual reality in making a contribution to practice?" 188 Figure 6-57: Graduating student responses to Question C1: “Do you agree or disagree that the digital industrial/product design strategy has the potential to replace the existing conventional (non-digital) and hybrid (mixture of digital and non-digital) process of designing?" 189

Figure 6-58: Graduating student responses to Question C2: "How do you feel about the efficiency of the digital industrial/product design strategy?" 191 
Figure 6-59: Graduating student responses to Question C3: "Would you like to try the digital industrial/product design strategy?"

Figure 6-60: Graduating student responses to Question C4: "Are there any other digital tools/media that you would like to add to the strategy? If yes can you please identify the tools/media?"

Figure 6-61: Revised DID strategy after feedback and implementing the required changes 210

Figure 6-62: Use of digital design tools/media employed in DID strategy in professional and educational design practice 214

Figure 7-1: HP EliteBook 2730p Notebook PC (Hewlett Packard, 2010) 224

Figure 7-2: Use of the Tablet PC to produce simple elevational sketches 225

Figure 7-3: Use of the Tablet PC to produce sketches over imported photos of physical sketch models 226

Figure 7-4: Use of the Tablet PC to introduce colour when sketching concepts 226

Figure 7-5: Use of the Tablet PC to produce images of users as an underlay to help sketch user scenarios 227

Figure 7-6: Use of video to capture the student sketching activity during the exercise $\ldots . . . .228$

Figure 7-7: Geometric shape torch used for sketching exercise 228

Figure 7-8: Organic shape child's spoon used for sketching exercise 229

Figure 7-9: Participant 2 sketch of the torch using paper-based media 229

Figure 7-10: Participant 2 sketch of the torch using the Tablet PC. 230

Figure 7-11: Participant 2 sketch of the child's spoon using paper-based media 230

Figure 7-12: Participant 2 sketch of the child's spoon using the Tablet PC 231

Figure 7-13: Student responses to Question 1: "How would you rate your ability to sketch using line only during design activity with the following media ( 1 being low and 5 being high)?". 232

Figure 7-14: Student results for Question 3.1: "Most accurate representation of product" 233

Figure 7-15: Student results for Question 3.2: "Most confidence in use of line" 233

Figure 7-16: Student results for Question 3.5: "Quickest to produce" 234

Figure 7-17: Student results for Question 3.6: "Easiest to use". 234

Figure 7-18: Student results for Question 3.3: "Most expressive" 235

Figure 7-19: Student results for Question 3.4: "Most enjoyable" 235

Figure 7-20: Student results for Question 3.7: "Required most error corrections" 236 Figure 7-21: Student results for Question 3.8: "Preferred final sketch" 236 
Figure 7-22: Graph showing the average (mean) percentage of academics in response to Question: "Please indicate which sketch is most effective in the communication of product form"

Figure 7-23: Examples of pepper mills used to brief students (1 of 3) 239

Figure 7-24: Examples of pepper mills used to brief students (2 of 3 ) 240

Figure 7-25: Examples of pepper mills used to brief students (3 of 3) 240

Figure 7-26: Use of virtual keyboard whilst undertaking the design exercise 241

Figure 7-27: Loose application of colour during the design exercise

Figure 7-28: Sketch rendered output from design exercise

Figure 7-29: Sketch rendered output from design exercise

Figure 7-30: Sketch rendered output from design exercise

Figure 7-31: Students using the Tablet PCs in the design exercise

Figure 7-32: Use of addition keyboard to help in using shortcuts when sketching

Figure 7-33: Sharing knowledge during the design exercise

Figure 7-34: Focus group on the use of Tablet PC undertaken with BSc students. 247

Figure 7-35: Student responses to Question B2: "To what extent do you agree or disagree that digital design methods offer more portability than non-digital design methods?" 248 Figure 7-36: Student responses to Question B4: "To what extent do you agree or disagree that digital design methods provide more opportunities to explore alternative solutions than non-digital design methods?"

Figure 7-37: Student responses to Question B6: "To what extent do you agree or disagree that digital design methods are more productive than the non-digital design methods?"..249 Figure 7-38: Student responses to Question B7: "To what extent do you agree or disagree that digital design methods facilitate the collaboration more than non-digital design methods?" 250

Figure 7-39: Student responses to Question B10: "To what extent do you agree or disagree that digital design methods contribute to the design development phase more than nondigital design methods?". 250

Figure 7-40: Student responses to Question B13: "To what extent do you agree or disagree that it is now viable to design products using digital tools/media only?" 251 Figure 7-41: Student responses to Question B1: "To what extent do you agree or disagree that digital design methods are quicker than non-digital design methods?" 251 
Figure 7-42: Student responses to Question B3: "To what extent do you agree or disagree that digital design methods are more effective for presentation of proposals than non-digital design methods?"

Figure 7-43: Student responses to Question B12: "To what extent do you agree or disagree that it is now viable to use a digital logbook whilst designing?"

Figure 7-44: Student responses to Question B5: "To what extent do you agree or disagree that digital design methods facilitate creativity more than non-digital design methods?"..253 Figure 7-45: Student responses to Question B9: "To what extent do you agree or disagree that digital design methods contribute to the concept generation phase more than nondigital design methods?".

Figure 7-46: Student responses to Question B8: "To what extent do you agree or disagree that digital design methods are easier to learn than non-digital design methods?". 254 Figure 7-47: Student responses to question B11: "To what extent do you agree or disagree that digital design methods contribute to the specification phase more than non-digital design methods?" 255

Figure 7-48: Student responses to Question B16: "To what extent do you agree or disagree that it was easier to remove mistakes using the Tablet PC than when paper-based sketching?" 258

Figure 7-49: Student responses to Question B15: "To what extent do you agree or disagree that you felt more confident using the Tablet PC compared to paper-based sketching because of the ability to "undo'?" 258

Figure 7-50: Student responses to Question B24: "To what extent do you agree or disagree that the Tablet PC layering facility was very helpful?".

Figure 7-51: Student responses to Question B31: "To what extent do you agree or disagree that the quality of your renderings produced using computer drawing packages (e.g. SketchBook Pro) improved using the Tablet PC?"

Figure 7-52: Student responses to Question B38: "To what extent do you agree or disagree that the Tablet PC was easy to use for tracing and producing basic outlines?" 260 Figure 7-53: Student responses to Question B52: “To what extent do you agree or disagree that after sketching for some time, you got used to the smoothness of the Tablet PC screen?" 260

Figure 7-54: Student responses to Question B14: "To what extent do you agree or disagree that the line quality of the Tablet PC was better than that for paper-based sketching?" ....261 
Figure 7-55: Student responses to Question B46: "To what extent do you agree or disagree that if you had to work when visiting friends and family, you would prefer to take the Tablet PC rather than an $\mathrm{A} 3$ pad?"

Figure 7-56: Student responses to Question B60: "To what extent do you agree or disagree that using the Tablet PC for designing introduced an element of fun?"

Figure 7-57: Student responses to Question B67: "To what extent do you agree or disagree that the Tablet PC is pressure sensitive?"

Figure 7-58: Student responses to Question B20: “To what extent do you agree or disagree that you were able to make quick amendments to your designs using the Tablet PC?". 263 Figure 7-59: Student responses to Question B22: "To what extent do you agree or disagree that the colours used on the Tablet PC were more vibrant than those available with paperbased techniques?" 263

Figure 7-60: Student responses to Question B23: "To what extent do you agree or disagree that the Tablet PC made you more adventurous when generating concepts and developing them?" 264

Figure 7-61: Student responses to Question B26: "To what extent do you agree or disagree that applying colour and tone to your line work was quicker and easier with the Tablet PC?"

Figure 7-62: Student responses to Question B66: "To what extent do you agree or disagree that the battery life of the Tablet PC was acceptable?" 265 Figure 7-63: Student responses to Question B7: "To what extent do you agree or disagree that the ability to 'undo' previous work during concept generation hindered creativity?" .265 Figure 7-64: Student responses to Question B36: "To what extent do you agree or disagree that the visual quality and appearance of your designs were enhanced by the use of the Tablet PC?" 266 Figure 7-65: Student responses to Question B17: "To what extent do you agree or disagree that the quality of outcome is greater using the Tablet PC than when paper-based sketching?" 266

Figure 7-66: Student responses to Question B37: "To what extent do you agree or disagree that the work produced using the Tablet PC was of a higher level of presentation than that undertaken using paper-based techniques?" 267

Figure 7-67: Student responses to Question B35: "To what extent do you agree or disagree that the use of the Tablet PC increased your excitement when collaborating through sketching with other people?" 
Figure 7-68: Student responses to Question B42: "To what extent do you agree or disagree that being able to browse the Internet whilst generating ideas was a significant advantage of using the Tablet PC?"

Figure 7-69: Student responses to Question B2: "To what extent do you agree or disagree that it was difficult to create faint lines and use them as a guide when using the Tablet PC?"

Figure 7-70: Student responses to Question B8: "To what extent do you agree or disagree that the stylus was too short for comfortable use?"

Figure 7-71: Student responses to Question B30: "To what extent do you agree or disagree that the ability to 'undo' using the Tablet PC increased creativity?" 269 Figure 7-72: Student responses to Question B32: "To what extent do you agree or disagree that you became more productive when you used the Tablet PC?" 270 Figure 7-73: Student responses to Question B19: "To what extent do you agree or disagree that the Tablet PC helped you quickly communicate your ideas to other people?" 270 Figure 7-74: Student responses to Question B45: "To what extent do you agree or disagree that you were uneasy about sketching in public with the Tablet PC because of the potential for it to be stolen?"

Figure 7-75: Student responses to Question B39: "To what extent do you agree or disagree that the size of the Tablet PC screen limited your ability to see numerous previous ideas on the same page?"

Figure 7-76: Student responses to Question B1: "To what extent do you agree or disagree that it was difficult to match the position of the tip of the stylus with the cursor?" 273 Figure 7-77: Student responses to Question B9: "To what extent do you agree or disagree that you were not able to sketch with the stylus at low angle on the screen?" Figure 7-78: Student responses to Question B44: "To what extent do you agree or disagree that if not already in use, the Tablet PC was less convenient when short amounts of time were available for sketching?" 274

Figure 7-79: Student responses to Question B58: "To what extent do you agree or disagree that the Tablet PC screen was too small for 3D CAD work?" 274 Figure 7-80: Student responses to Question B27: "To what extent do you agree or disagree that rendering using 3D CAD was quicker and easier with the Tablet PC?" 275 Figure 7-81: Student responses to Question B5: "To what extent do you agree or disagree that the Tablet PC screen was too small for effective sketching?" 275 
Figure 7-82: Student responses to Question B28: "To what extent do you agree or disagree that sketches produced using the Tablet PC had a tendency to be less detailed?"

Figure 7-83: Student responses to Question B47: "To what extent do you agree or disagree that the weight of the Tablet PC affected its portability?"

Figure 7-84: Student responses to Question B4: "To what extent do you agree or disagree that the rubber feet on the Tablet PC made it difficult to rotate when sketching?"

Figure 7-85: Student responses to Question B10: "To what extent do you agree or disagree that you faced problems with screen glare while sketching?"

Figure 7-86: Student responses to Question B11: "To what extent do you agree or disagree that the Tablet PC was more difficult to use than pencil and paper?" 278 Figure 7-87: Student responses to Question B12: "To what extent do you agree or disagree that you were not able to use the full size of the Tablet PC screen because matching the position of the top of the stylus with the cursor became more difficult towards the edges?"

Figure 7-88: Student responses to Question B57: "To what extent do you agree or disagree that the Tablet PC was not powerful enough for 3D CAD work?"

Figure 7-89: Student responses to Question B69: "To what extent do you agree or disagree that using the stylus was useful with 3D CAD work?"....

Figure 7-90: Student responses to Question B56: "To what extent do you agree or disagree that students should always have the option for using paper-based techniques to sketch in addition to the Tablet PC?" 280

Figure 7-91: Student responses to Question B50: "To what extent do you agree or disagree that students should be taught sketching using paper-based techniques before using the Tablet PC?"

Figure 7-92: Student responses to Question B53: "To what extent do you agree or disagree that students should not be taught paper-based rendering techniques as the Tablet PC makes them redundant?" 281

Figure 7-93: Student responses to Question B54: "To what extent do you agree or disagree that students need to be taught how to use the virtual keyboard on the Tablet PC desktop?"

Figure 7-94: Student responses to Question B55: "To what extent do you agree or disagree that the introduction of the Tablet PC to all industrial/product design students would have a motivating effect?" 
Figure 7-95: Student responses to Question B51: "To what extent do you agree or disagree that students should be taught paper-based rendering before using the Tablet PC?" 283 Figure 7-96: Student responses to Question B48: "To what extent do you agree or disagree that you need to have $2 \mathrm{D}$ visualisation software experience to be able to use the Tablet PC effectively?" 283

Figure 7-97: Student responses to Question B62: "To what extent do you agree or disagree that SketchBook Pro was more suitable than Photoshop for the generation of line work?"284 Figure 7-98: Student responses to Question B63: "To what extent do you agree or disagree that SketchBook Pro was easier to use than Photoshop for the generation of line work?" .284 Figure 7-99: Student responses to Question B72: "To what extent do you agree or disagree that having an additional 'control' button that can be used when the screen covers the keyboard would be beneficial?" 285

Figure 7-100: Student responses to Question B70: "To what extent do you agree or disagree that having a device that enables you to adjust the angle of the Tablet PC screen while sketching would be beneficial?" 286

Figure 7-101: Student responses to Question B3: "To what extent do you agree or disagree that you would prefer it if the surface of the screen on the Tablet PC had a similar level of resistance to paper?" 286

Figure 7-102: Student responses to Question B65: "To what extent do you agree or disagree that connecting the Tablet PC to a larger external screen was beneficial during 3D CAD work?" 287

Figure 7-103: Student responses to Question B71: "To what extent do you agree or disagree that it would be beneficial if the Tablet PC could sit in a recess on a desk to make the screen flush with the surface?"

Figure 7-104: Student responses to Question B61: "To what extent do you agree or disagree that it was useful to use an external keyboard with the Tablet PC when sketching?" 288 Figure 7-105: Student responses to Question B13: "To what extent do you agree or disagree that leaning over the Tablet while sketching created an uncomfortable posture?" 290 Figure 7-106: Student responses to Question B18: "To what extent do you agree or disagree that it was quicker to sketch with the Tablet PC than with paper?" 290 Figure 7-107: Student responses to Question B25: "To what extent do you agree or disagree that using the Tablet PC increased the speed of your sketching?" 291 
Figure 7-108: Student responses to Question B29: "To what extent do you agree or disagree that your ability to sketch and draw using paper-based techniques has declined since using the Tablet PC?"

Figure 7-109: Student responses to Question B33: "To what extent do you agree or disagree that sketching using the Tablet PC encouraged you to employ construction techniques such as crating when sketching in perspective?"

Figure 7-110: Student responses to Question B34: “To what extent do you agree or disagree that sketching using the Tablet PC improved your perspective?"

Figure 7-111: Student responses to Question B40: "To what extent do you agree or disagree that the size of the Tablet PC screen encouraged you to think more carefully about what you sketch?" 293

Figure 7-112: Student responses to Question B41: "To what extent do you agree or disagree that sketches produced using the Tablet PC appeared to be more precious in concept generation, which limited creativity?"

Figure 7-113: Student responses to Question B43: "To what extent do you agree or disagree that the Tablet PC represented a stand-alone design tool that contained all that was required for effective designing?"

Figure 7-114: Student response to Question B49: "To what extent do you agree or disagree that you need to know the shortcuts in the $2 \mathrm{D}$ visualisation software to be able to use the Tablet PC effectively?"

Figure 7-115: Student responses to Question B59: "To what extent do you agree or disagree that students about to start undergraduates degrees in industrial/product design should be encouraged to purchase Tablet PCs rather than laptops?"

Figure 7-116: Student responses to Question B64: "To what extent do you agree or disagree that Photoshop was more suitable for rendering the line work than SketchBook Pro?" .....295 Figure 7-117: Student responses to Question B68: "To what extent do you agree or disagree that Microsoft Journal software represented a viable alternative to a paper-based logbook?" 296

Figure 7-118: Simple sketches during concept generation ..... 299

Figure 7-119: Integration of line and tone during concept generation 300

Figure 7-120: Use of loosely applied lines and colours 300

Figure 7-121: Descriptive visual that shows how the product functions 301

Figure 7-122: Controlled sketch for presentation..... 301 Figure 7-123: 3D CAD rendering using the Tablet PC. 302 


\section{LIST OF TABLES}

Table 2-1: Stages of the design process (Baxter, 1995: 263-264)

Table 3-1: Comparison between digital sketching and paper-based sketching (Ronning, 2008)

Table 3-2: Comparison between CAD software and CAID software (Ye et al., 2008: 3) .........58

Table 3-3: Classification of rapid prototyping systems (Choi and Chan, 2003: 237) .............65

Table 3-4: Summary of VR-based interaction paradigms strengths and weaknesses (Ye et al., 2006: 80)

Table 4-1: Classification of the purposes of enquiry (Robson, 2002: 59-60). 75

Table 4-2: Difference between qualitative, quantitative and mixed methods research (Creswell, 2009: 4) 76

Table 4-3: Alternative strategies of enquiry (Creswell, 2009: 12) 77

Table 4-4: A summary of the strategies of enquiry used in the research 78

Table 4-5: Aims of data collection methods used within the surveys carried out in the research 79

Table 4-6: The aims of data collection methods used within the Tablet PC case study 81

Table 4-7: Strengths and weaknesses of using collective questionnaire (Fowler, 2002: 73-74)

Table 4-8: Strengths and Weaknesses of e-mail, online and postal questionnaire (unsupervised) (Bourque and Fielder, 2003: 9).

Table 4-9: Strengths and weaknesses of face-to-face interviews (Fowler, 2002: 71)..... 86

Table 4-10: Strengths and weaknesses of focus groups (Litosseliti, 2003: 18-21)..... 87

Table 4-11: Strengths and weaknesses of observation (Foster, 1996: 58-60) 88

Table 4-12: Sources of quantitative data (Denscombe, 2007: 254) .89

Table 4-13: Sources of qualitative data (Denscombe, 2007: 287) 89

Table 4-14: The five main stages of data analysis adapted from Creswell and Clark (2007: 129)

Table 5-1: Industrial placement student responses to Questions 28, 29, 30 and 31: "What are the main digital media/tools used at the design organisation you worked for in the concept generation phase, preliminary refinement phase, further refinement and final concept selection phase and specification phase?" 127 
Table 5-2: Graduating student reasons behind responses to Question E1: "To what extent do you agree or disagree that you will be able to achieve the same outcome from your project if the entire process was done using digital tools?" 136

Table 5-3: Industrial placement student reasons behind responses to Question 32: "Do you believe that the design organisation you worked for will be able to achieve the same outcome from projects if the entire process was done using digital tools?"

Table 5-4: Practitioner reasons behind responses to Question E1: "To what extent do you agree or disagree that you will be able to achieve the same outcome from your project if the entire process was done using digital tools? 138

Table 5-5: Graduating student reasons behind responses to Question E2: "To what extent do you agree or disagree that digital technologies have the potential to replace conventional workshops and the hands-on experience?" 140

Table 5-6: Industrial placement student reasons behind responses to Question 34: "Do you think that digital technologies have the potential to replace conventional workshops and hands-on experience completely in the design organisation you worked for?" 141

Table 5-7: Practitioner reasons behind responses to Question E2: "To what extent do you agree or disagree that digital technologies have the potential to replace conventional workshops and the hands-on experience?"

Table 5-8: Graduating student reasons behind responses to Question E3: "To what extent do you agree or disagree that your design practice will improve if you used a completely digital process?"

Table 5-9: Industrial placement student reasons behind responses to Question 36: "Do you think that the organisation's design practice will improve if a complete digital process was used?" 144

Table 5-10: Practitioner reasons behind responses to Question E3: "To what extent do you agree or disagree that your design practice will improve if you used a completely digital process?". 145

Table 5-11: Graduating student reasons behind responses to Question E4: "To what extent do you agree or disagree that it would be appropriate to have a totally digital industrial/product design course?" 146

Table 5-12: Practitioner reasons behind responses to Question E4: "To what extent do you agree or disagree that it would be appropriate to have a totally digital industrial/product design course?" 148 
Table 5-13: Areas identified by graduating students in response to Question F: "Do you think that there are any areas of the industrial/product design course that can be improved in the curriculum of your course?"...

Table 5-14: Graduating student responses to Question G: "What would you feel about a completely digital industrial/product design process?" 150

Table 5-15: Graduating student responses to quantitative questions within the supervised collective questionnaire $(n=96)$.

Table 5-16: Industrial placement student responses to the quantitative questions within the online questionnaire $(n=17)$.

Table 5-17: Practitioner responses to quantitative questions within the online questionnaire $(n=10)$ 152

Table 6-1: Graduating student reasons behind responses to Question C1: "Do you agree or disagree that the digital industrial/product design strategy has the potential to replace the existing conventional (non-digital) and hybrid (mixture of digital and non-digital) process of designing?" 190

Table 6-2: Graduating student reasons behind responses to Question C2: "How do you feel about the efficiency of the digital industrial/product design strategy?" 191

Table 6-3: Graduating student reasons behind responses to Question C3: "Would you like to try the digital industrial/product design strategy?"

Table 6-4: Summary of the closed-ended questions responses used in the 2008/2009 graduating student questionnaire 194

Table 7-1: Steps taken in the case study with final year students to explore the use of the Tablet PC for sketching.

Table 7-2: Benefits, challenges and relevant points identified by the students during the shared experiences session 225

Table 7-3: Summary of the student responses to the quantitative questions in the sketching exercise questionnaire $(n=15)$ 237

Table 7-4: Summary of the Tablet PC strengths and weakness identified by students after undertaking the design exercise 246

Table 7-5: Overall quantitative data results of the pre- and post-questionnaire used to examine student attitude towards digital design methods $(n=16)$. 256

Table 7-6: Summary of the Use of Tablet PC for Designing Questionnaire results $(n=16) . .298$ 
Table 8-1: Summary of the use of digital design tools/media within professional design practice and educational design practice according to academics and graduating students

Table 8-2: Graduating student negative and positive opinions on employing only digital tools/media for their design practice.

Table 8-3: Academic opinions on students designing using digital tools/media only 314 Table 8-4: Summary of the of negative and positive opinions shared by practitioners and industrial placement students 316

Table 8-5: Defining features of interactive pen display sketching behaviour in collaborative design (Lee and Wei, 2007: 305) . 317

Table 8-6: Key benefits the Tablet PC identified by the majority of students. 321

Table 8-7: Limitations of the Tablet PC identified by the majority of students 321 Table 8-8: Recommendations for teaching and learning the use of Tablet PC identified by the majority of students. 322

Table 9-1: Meeting the objectives of the research 330 


\section{INTRODUCTION}

This chapter introduces the research presented in the thesis. It identifies the aim and objectives of the research along with the research questions. It also provides an overview of the thesis structure.

\subsection{Research Background}

Industrial design is the practice of generating concepts and developing/detailing them to produce products and systems that appeal to users in terms of function and appearance while making profit for the manufacturer (Industrial Designers Society of America, 2010: 1). The term 'industrial design' has associations with styling and ergonomics and can also be referred to as 'product design'. "Product designers design things we use in our daily lives from vacuum cleaners to cars. They consider how to make items easier to use, more efficient, cheaper to produce or better looking" (Unver, 2006: 323).

Industrial design practice has undergone enormous change since the introduction of computer aided design (CAD) in the late 1980's (Sener and Wormald, 2001: 358). From its beginnings as two-dimensional (2D) drafting, digital techniques have now evolved to support a wide range of design activities such as three-dimensional (3D) CAD; 3D rendering; computer-based drawing; haptic feedback modelling; technical evaluation (e.g. mould flow analysis, finite element analysis (FEA)); image manipulation; animation and rapid prototyping (RP). The impact is summed up by Oxman (2006: 225): "Digital technology is a force that has begun to profoundly affect design culture". Yan et al. (2006: 1) state that modern digital design tools are now key tools used within industrial design practice.

Digital industrial design (DID) tools and techniques provide opportunities to reduce the time from product planning to product sale (Fraunhofer Magazine, 2000: 16, Lynn, 2006: 107, Pipes, 2007: 35, Wilson and Fauscette, 2008: 4). Computer-based design tools facilitate efficiency gains leading to faster product development and enhanced design output (Chen and Owen, 1998: 331). Furthermore, using a digital model, which is a common language between members of the new product development (NPD), can ease the collaboration between designers, engineers, marketing and management team by allowing them to 
communicate efficiently (Lynn, 2006: 107, Evans, 1998: 1). The digital design process allows elements of the design to be easily changed and manipulated when compared with traditional methods that require rebuilding models and redrawing (Marx, 2000: 21). It has an appeal to clients because it provides greater realism through the high resolution rendering without having to build a physical model (Marx, 2000: 21). In addition to appealing to clients, virtual prototyping (VP) saves time and the materials needed to build models in conventional ways (Yan et al., 2006: 4). VP cannot entirely replace the need for physical models, but it can reduce the overall number of physical models required (Bordegoni et al., 2006: 377, Wilson and Fauscette, 2008: 13, Catalano et al., 2002: 11). As a result, a number of companies have started to rely heavily on digital tools/media when designing (Siemens, 2008: 1).

When industrial design graduates apply for their first professional positions, the ability to use digital design methods has become a key feature of the selection process (Lynn, 2006: 111). Despite the range of skills and knowledge that must be acquired by undergraduates, evidence suggests that the enthusiasm to employ digital tools/media is generally greater amongst the younger generation of designers (Lynn, 2006: 108). Digital technology allows a high level of remote interaction on product development via the web, which provides opportunity for universities to have live project briefs with companies operating on a global scale (Unver, 2006: 325). In a study by Yang et al. (2005: 174), 55.1\% of industrial design job openings request candidates with ability in 3D graphic software. As a result, the authors suggested decreasing industrial design student training in drawing renderings and model making. Malins et al. (2007: 438) state that "traditional studio-based model of design education is in the process of being replaced by a laptop on the kitchen table".

It is clear that technological infrastructure has changed extensively over the past 20 years and so have designers' practices and expectations (Oehlberg et al., 2009: 239). As the range and impact of digital tools available to the industrial designer increases, it is now timely to investigate how close we are to a totally DID strategy that can be employed in practice and education. This belief is supported by Munson (2004: 8) when stating that "technology is changing all of the time, and the impacts of technology on product design are also always changing. The potential, opportunity, and impact of technology on product design/designing must constantly be assessed". 


\subsection{Research Aim and Objectives}

The aim of the research is to investigate the potential for a totally digital strategy for industrial design education that would be suitable for professional practice. The research aim will be achieved by addressing the following objectives:

- Identify the nature of industrial design practice and education using published literature

- Undertake a literature review in the field of DID and identify available digital tools that can be used within industrial design practice

- Explore the nature of contemporary industrial design practice and education in terms of employing digital technologies

- Identify the attitudes of industrial design practitioners, academics and students towards DID

- Investigate how digital tools/media can be employed to form a totally DID strategy

- Seek opinion from industrial design practitioners, academics and students on the use of a totally DID strategy

- Investigate issues relating to the activity of digital sketching

\subsection{Research Questions}

The research questions to be answered in the thesis are as follows:

- What is the nature of educational and professional industrial design practice in terms of digital technologies?

- How do students, academics and practitioners feel towards undertaking design practice entirely digitally?

- How can digital design tools/media be integrated to form a DID strategy?

- How can digital tools be used to support concept generation through sketching?

\subsection{Research Scope and Limitations}

The research focused on DID practice and education. A review of the literature on the nature of industrial design practice and education; the field of DID; and digital design tools/media 
was undertaken. The current educational and professional practice in terms of employing digital technologies was examined through surveys. The findings were collated to form a draft DID strategy that was presented to graduating students, academics and practitioners of industrial design for feedback and modifications. Results indicated that the activity of digital sketching was a major concern and a case study was employed that investigated the use of the Tablet PC as a tool for concept generation. Final year industrial design students undertook the case study.

With a global reputation for industrial design education, the research has a focus on undergraduate education in the United Kingdom (UK). The term 'digital industrial design' includes the translation of a virtual design into a physical representation through RP and computer numerical control (CNC) machining to support evaluation. Furthermore, industrial design and product design have been interpreted as having the same meaning.

The professional activities associated with industrial design are broad, so the DID strategy in this research focuses only on the core activities of form generation and design development, which are sketching, drawing, modelling and prototyping.

\subsection{Research Audience}

The research should be of interest to:

- Academics aiming to develop an industrial design curriculum that employs the latest thinking in the use of digital tools/media

- Industrial design practitioners aiming to employ digital design tools/media during their practice

- Researchers interested in digital technologies within industrial design practice and education

- Software and hardware developers aiming to improve digital sketching

\subsection{Thesis Structure}

In addition to the introduction, the thesis consists of a further 10 chapters. An overview of each chapter will now be discussed. 
- Chapter 2: Industrial Design

This chapter is the first part of the literature review. It provides an overview of the terms 'design', 'industrial design', 'product design', and 'NPD'. It presents a description of an investigation of the differences between industrial design and engineering design and reviews the roles of industrial design within NPD. The chapter discusses the activities associated with industrial design, the representations used during practice and provides an overview of industrial design education.

- Chapter 3: Digital Industrial Design

This chapter is the second part of the literature review. It reviews the phenomenon of employing digital techniques in professional and educational contexts. It illustrates the current and emerging digital tools and media that can be used for sketching/drawing and modelling/prototyping. The potential of undertaking design practice entirely digitally is reviewed.

- Chapter 4: Research Methodology

This chapter describes the research methodology employed to answer the research questions. It outlines the methodology in terms of purpose, type, strategies of enquiry, data collection methods, and data analysis. It provides justification for the choices made in the research design and illustrates issues of reliability and validity.

- Chapter 5: Design Practice

This chapter focuses on the nature of educational and professional industrial design practice. It investigates the conventional and digital methods used and focuses on the extent to which digital technologies are employed. It demonstrates initial opinions towards having a completely digital workflow.

- Chapter 6: Digital Industrial Design Strategy

This chapter presents the DID strategy that was developed from the literature review and feedback from graduating students, academics and practitioners.

- Chapter 7: Use of the Tablet PC for Concept Generation

This chapter explores the capabilities of the Tablet PC to facilitate creative concept generation during industrial design practice. It begins with an overview of the case 
study undertaken with final year industrial design students, followed by results from sketching and design exercises. Results from the pre- and post-questionnaire that compares digital design methods with non-digital design methods are discussed. It concludes with the results of the questionnaire that was generated from focus groups on the use of the Tablet PC as a design tool.

- Chapter 8: Discussion

This chapter brings together the data and findings from the previous chapters. It discusses the outcomes in relation to the nature of education and professional practice by focusing on digital technologies, attitudes towards undertaking design practice entirely digitally, and digital sketching. It identifies recommendations for industrial design education based on the research findings and discusses the potential for devices in the 'post-PC era'.

- Chapter 9: Conclusions

This chapter brings together the general findings from the research. It describes how the research aim and objectives were achieved; provides answers to the research questions; and gives overall conclusions. It identifies the contribution to knowledge; presents limitations of research; and provides suggestions for further work.

- Chapter 10: References

This chapter provides a list of the references used within the thesis.

- Chapter 11: Appendix

This chapter collates additional documents used in the research. 


\section{INDUSTRIAL DESIGN}

This chapter is the first part of the literature review. It provides an overview of the terms 'design', 'industrial design', 'product design', and 'NPD'. It presents a description of an investigation of the differences between industrial design and engineering design and reviews the roles of industrial design within NPD. The chapter discusses the activities associated with industrial design, the representations used during practice and provides an overview of industrial design education.

\subsection{Design}

Every manufactured object around us has been designed (Marcus, 2002: 17, Cross, 2007: 15). The word 'design' can be used in many disciplines, such as fashion design, interior design, furniture design, industrial design and engineering design. According to the New Oxford American Dictionary, design has been defined as a plan or a drawing produced to demonstrate the appearance and function of objects (Oxford Dictionaries, 2005). Dumas (2002: 3) believes that the word tends to be used to describe the functionality and style of physical objects as opposed to its reference to the activity of planning. Archer (1965: 58) notes that it is the act of having a perception of the finished work before its embodiment that differentiates designers from a sculptor.

In defining design, Jones (1992: 3-4) gathers 11 definitions and descriptions from a variety of authors. These definitions differ considerably and do not refer to the end result of designing but to its components. He identifies design as "the intention of change in man-made things" and proposes that design is a blend of art, science and mathematics (Jones, 1992: 15). Nevertheless, the only difference between design and these three fields is the timing, as designers propose foreseen things while the others operate in present or historical time.

The principle of predicting a future state continues in Dumas' (2002: 1) definition when he states that "it is the process of turning ideas into material things". This process involves creative thinking and problem solving (Ye et al., 2008: 812, International Council of Societies of Industrial Design, 2010: 1). 
The International Council of Societies of Industrial Design (2010: 1) describes design as "a creative activity whose aim is to establish the multi-faceted qualities of objects, processes, services and their systems in whole life cycles. Therefore, design is a central factor of innovative humanisation of technologies and the crucial factor of cultural and economic exchange". The aim of the creative activity is to increase consumer appeal/satisfaction profits by enhancing design elements such as performance, appearance and cost (Kotler and Rath, 1993: 13). Design is an essential factor in gaining competitive advantage.

\subsection{Product Design}

"Product design is a generic term for the creation of an object that originates from design ideas-in the form of drawings, sketches, prototypes, or models- through a process of design that can extend into the object's production, logistics, and marketing" (Slack, 2006: 6). It focuses on function, structure, appearance, and ergonomics of products (Cooper and Press, 1995: 28). "Product design ranges from realising wholly new product concepts, through to restyling existing concepts for enhanced differentiation in the market" (Cooper and Press, 1995: 28). It is a complex process that involves a combination of different skills and understandings such as engineering, industrial design, manufacturing and marketing (Eppinger et al., 1990: 3, Slappendel, 1996: 3). While industrial design, according to Eppinger et al. (1990: 3), Cooper and Press (1995: 28) and Slappendel (1996: 3) is part of product design, some literature states that the terms product design and industrial design are pretty much interchangeable in some cases (Unver, 2006: 323, Pei, 2009: 48, Core 77, 2007: 2). The term 'industrial design' will be used through out this thesis to avoid confusion. However, when conducting surveys the term 'industrial/product design' will be used as some participants may relate to either 'industrial' or 'product' to describe their discipline.

\subsection{Industrial Design}

"Despite the upswing in its popularity, ID [industrial design] is still one of the least understood professions" (Amit, 2010: 1). Industrial design has been defined in numerous ways. However, the lack of a universally accepted definition is still apparent, which indicates the different perspectives on the function of industrial design (Gemser and Leenders, 2001: 29, Sener, 2004: 34). 
During the $20^{\text {th }}$ century, the term 'industrial design' was used to describe objects that were manufactured by industrial processes rather than crafted by hand (Caplan, 1969: 1, Industrial Designers Society of America, 2004: 1, Tovey, 1997: 6). Despite the importance of this definition to separate an industrial designer and a craftsman, it is no longer a sufficient definition (Caplan, 1969: 1).

Van Doren ((1940) cited in (Tovey, 1997: 8)) identifies industrial design as "the practice of analysing, creating and developing products for mass manufacture. It's goal is to achieve forms which are assured of acceptance before extensive capital investment has been made, and which can be manufactured at a price permitting wide distribution and reasonable profits". While this contributes to the notion that industrial design makes profits for the manufacturer, it does not distinguish industrial design from engineering design.

Archer (1965: 59) is more specific when he states that "industrial design covers a class of design problems which ranges from domestic appliances, office machinery, and public service equipment on the one hand to typography, textiles, and wallpaper on the other. All industrial design is characterised by the importance of the visual element in the design of the end product and by the fact that the end product is made or reproduced by industrial methods". Even though this definition emphasises the role of the industrial designer in the appearance of products, it does not highlight other important aspects highlighted by Gemser and Leenders (2001: 29), such as ergonomics, function and ease of manufacture. "Industrial design therefore implies a visual and conscious process to develop physical objects with functional ergonomic, economic and expressive concerns" (Svengren, 1997: 4).

"No industrial designer would regard appearance as unimportant. But appearance might be subordinate to any or all of a number of other design factors: safety, convenience, cost of production, ease of maintenance, wise choice of materials. Appearance might lead a customer to buy, but it could not itself lead to a satisfied customer. A successful design must integrate performance with appearance, while appealing to the customer and making a profit for the manufacturer" (Caplan, 1969: 3). It is important to note that industrial designers aim to generate desirable products that can increase the profitability for the manufacturer and when successfully applied, makes an essential contribution to the success of firms, such as Philips Electronics and Apple (Gemser and Leenders, 2001: 28).

A more focused definition of industrial design and the one applied within this thesis is provided by Industrial Designers Society of America (IDSA) (2010: 1); "industrial design (ID) is the professional service of creating and developing concepts and specifications that optimise 
function and appearance of products and systems for the mutual benefit of both user and manufacturer".

Industrial designers are thus required to be both visual and creative and can sometimes be regarded as 'artists' within a design team (engineers, industrial designers, manufacturing personnel and marketing staff) (Tovey, 1989: 27). Tovey (1989: 27) identifies some particular skills that industrial designers require. These skills include drawing and presentation techniques, and sufficient understanding of engineering and market requirements to ensure that the designed product is feasible (Tovey, 1989: 27). The industrial designer will also have knowledge in ergonomics and appreciate form giving (Eppinger et al., 1990: 302, Tovey, 1997: 27). Powell (1990: 6) and Olofsson and Sjölén (2005: 5) believe that out of all these skills, the most important is drawing as it enables designers to externalise their ideas and develop them to solve identified problems.

\subsection{Distinction between Industrial Design and Engineering Design}

Engineering design is "the use of scientific principles, technical information and imagination in the definition of the mechanical structure, machine or system to perform specified functions with maximum economy and efficiency" ((DSIR, 1963) cited in (Moody, 1980: 329)). It is the "development of a product from its technical conception through detail design, and the design of the related manufacturing process and tooling" (Dumas, 2002: 3).

In the design team, industrial designers work on the "desirability" factor while engineer designers make sure that the product has "quality and reliability" (Tovey, 1997: 9). Industrial designers determine the appearance and human factors and tend to delegate performance and production methods to engineers (Naveiro and de Souza Pereira, 2008: 305, Evans, 1998: 5). Therefore, industrial design focuses on the user-driven features of products, while engineering design focuses on the technology-driven features of products (Lofthouse, 2004: 219).

Since the field of engineering design is mainly taught as science, and industrial design is mostly taught within an art school-type environment (Dumas, 2002: 4, Tovey, 1997: 6), a difference in the style of learning is recognised (Lofthouse, 2004: 219). The industrial designer "tends to be subjective in his judgment of concepts and ideas, whereas the 
engineering designer can implement systematic design tools or methods to make formal judgments" (Holmes et al., 1995: 112).

A difference noted by Bates and Pedgley ((1998) cited in (Lofthouse, 2004: 220)) is that industrial designers require a wider range of skills compared to those of the engineer designers. The industrial designer, typically, has knowledge in areas such as form giving, mechanical design, anthropometrics, psychology and marketing, whereas the engineer designer has skills sets in mechanical design, materials and manufacturing.

\subsection{Industrial Design within New Product Development}

The term 'product development' is defined as "the set of activities beginning with the perception of a market opportunity and ending in the production, sale, and delivery of a product" (Ulrich and Eppinger, 2003: 2). It is the entire set of activities needed to bring a new product to the market (Otto and Wood, 2001: 5). The aim of product development is to meet the customer needs as quickly as possible and at the lowest cost possible (Otto and Wood, 2001: 5).

Van Doren ((1954) cited in (Caplan, 1969: 4)) states that "modern product design is almost never the work of one individual". Within NPD, industrial designers work with marketing professionals, electronics designers, mechanical engineers, manufacturing engineers, production specialists engineers, and human factors specialists (Hertenstein et al., 2005: 4, Lofthouse, 2001: 18, Ulrich and Eppinger, 2003: 4). Industrial designers are known as the artists/stylists among the team (Tovey, 1997: 9). Gemser and Leenders (2001: 28) note that there is an increasing belief that the involvement of industrial design in NPD can make an essential contribution to a company's success. Industrial design contributes to NDP by presenting solutions that meet user needs, determines the ergonomics and appearance of products and creates a product identity (Hertenstein et al., 2005: 4, Svengren, 1997: 4, Tovey, 1997: 9).

Figure 2-1 presents a conceptual model of how industrial design relates to the NDP process and how that process translates into financial performance. 


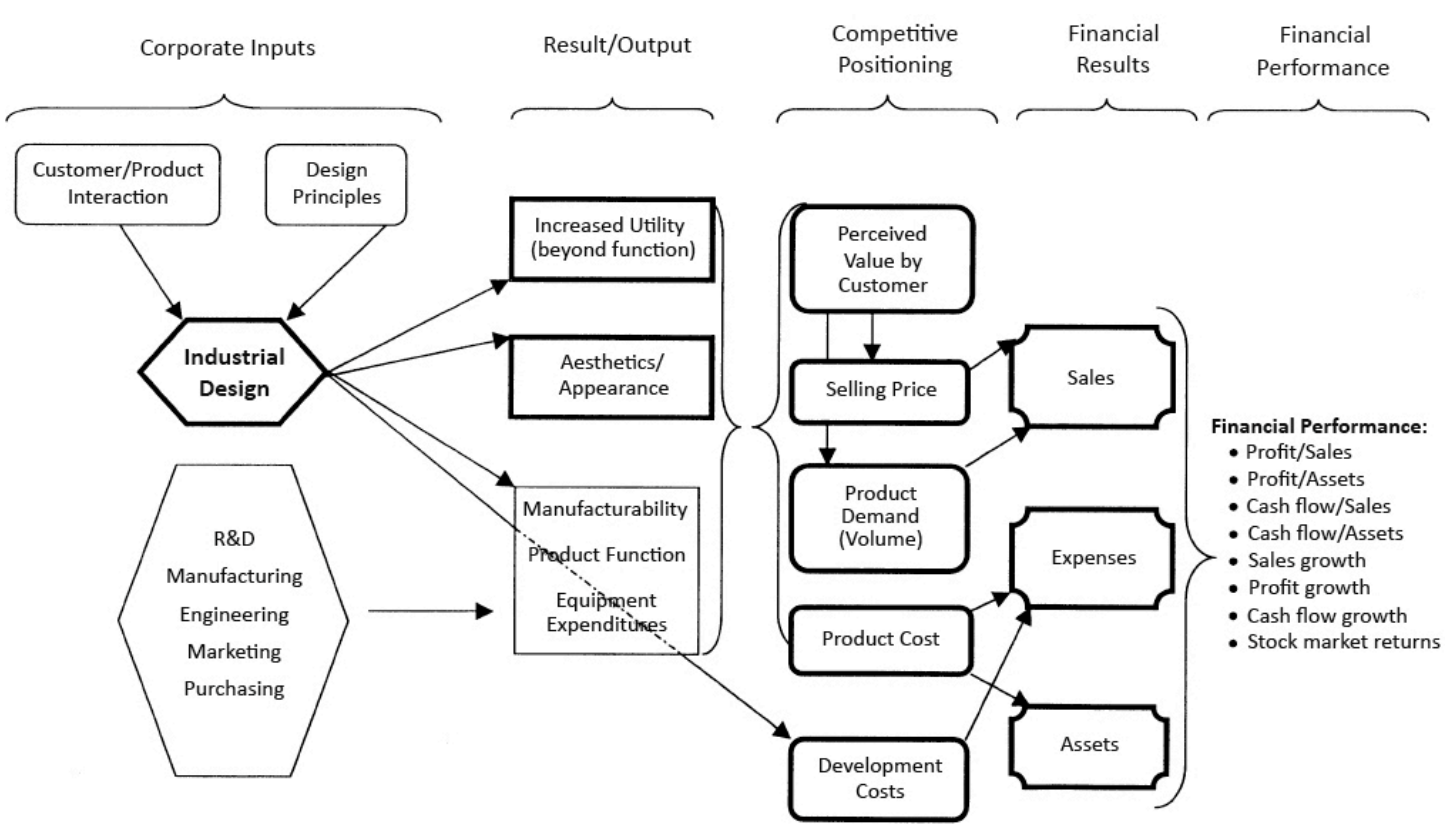

Figure 2-1: Conceptual mapping of NPD inputs, outputs, financial results, and financial performance (Hertenstein et al., 2005: 6)

The timing of industrial design involvement during NPD depends upon the type of product being designed. If the product is technology-driven, such as a laptop computer, then the role of industrial designers will be during the latter stages and will focus on the enclosure and interface issues after the engineers have solved the technical problems (Ulrich and Eppinger, 2003: 202). If the product was a user-driven product, such as a non-electrical kitchen tool, the industrial designer would be involved throughout the entire development process (Tovey, 1989: 26, Ulrich and Eppinger, 2003: 202). Figure 2-2 shows that for a technologydriven product, industrial design activities may begin relatively late during NDP, whereas for a user-driven product, industrial design is involved during most of the process.

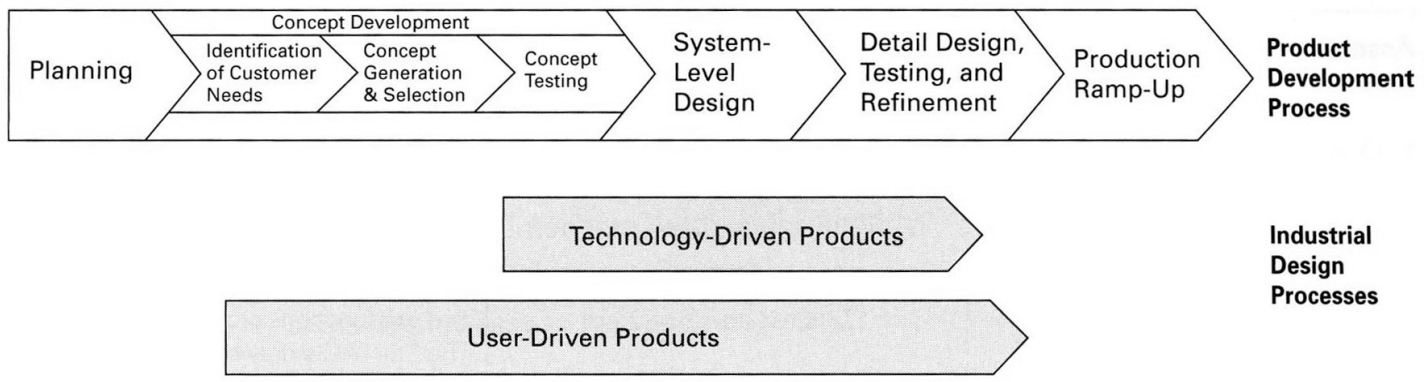

Figure 2-2: Relative timing of the industrial design process for two types of products (Ulrich and Eppinger, 2003: 202) 
It could be argued that it is sometimes difficult to distinguish between a product being technology-driven or user-driven as products could contain elements of both. Furthermore, in technology-driven products industrial designers work closely with design engineers and then pass over their work to production engineers (Tovey, 1989: 26). For example, even though iPad 2 is considered a technology-driven product, industrial designers created a smart cover that can be attached magnetically at the same time of designing the product (Ive, 2011). The cover automatically aligns and controls the device being awaken or in sleep mode (Ive, 2011). It would not have been feasible to design the iPad 2 with its smart cover if the input of industrial design was at later stages of the product development process after the engineers have worked out all the technical issues. The device shows the successful cooperation work between industrial designers and engineers through out the process.

\subsection{Industrial Design Practice}

"The process of design is the translation of information in the form of requirements, constraints, and experience into potential solutions which are considered by the designer to meet required performance characteristics" (Luckman, 1967: 84). This process has to involve creativity or originality (Luckman, 1967: 84). Tovey (1997: 7) points out that the importance of describing the design process is of limited benefit to the individual designer. However, it is beneficial to those responsible for the management of the design process, who might be unfamiliar with the activity and also educators who develop design courses (Tovey, 1997: 78). Attempts have been made to identify the design process although there is not one generic model that has been universally adopted (Evans, 2002: 12, Archer, 1965: 63). There appears to be difficulty in identifying the various stages involved due to the fact that there is more than one approach to solving a design problem (Evans, 2002: 12) and the financial resources and equipment differs from one organisation to another (Catalano et al., 2002: 11). While some researchers believe that requiring designers to follow a systematic method can hinder creativity, Holmes et al. (1995: 108) argue that it does not.

One of the simplest divisions of the design process is illustrated by Jones (1963: 11, 1992: 63) when he proposes three stages. These are analysis, synthesis and evaluation. In the analysis stage, designers break the problem down into component parts and study requirements for the product. In the synthesis stage, they develop solutions to each 
problem. Finally in the evaluation stage, they assess the new solutions developed and select the one that best fulfils the requirements (Jones, 1963: 11, Jones, 1992: 63) (Figure 2-3).

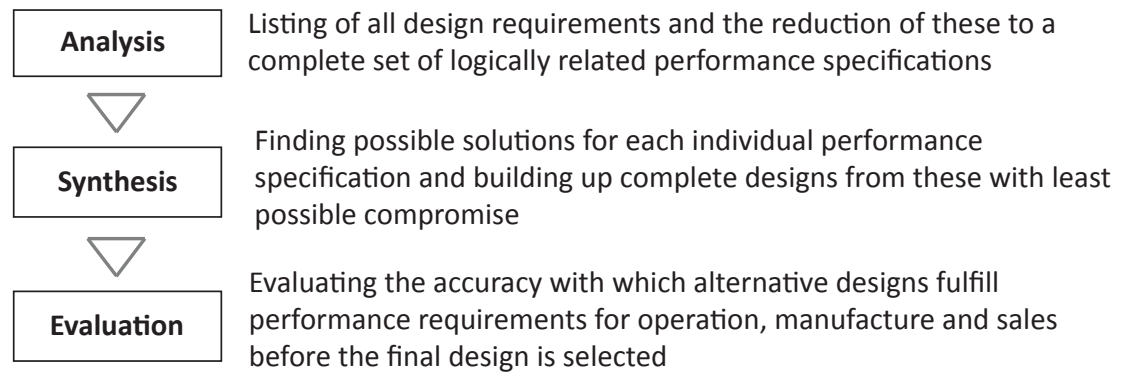

Figure 2-3: Stages of systematic design (Jones, 1963: 11)

Archer (1965: 64) uses a similar division to that of Jones (1963: 11) when he identifies three main phases of the design process. These are an analytical phase, creative phase and an executive phase. However, he then breaks down the design activity into a further six stages. These are: programming; data collection; analysis; synthesis; development; and communication (Archer, 1965: 64). Archer (1965: 64) clarifies that the design process is like a sandwich, the bread of analysis can be thin or thick, but the creative phase is the filling which will always be in the middle of the process (Figure 2-4).

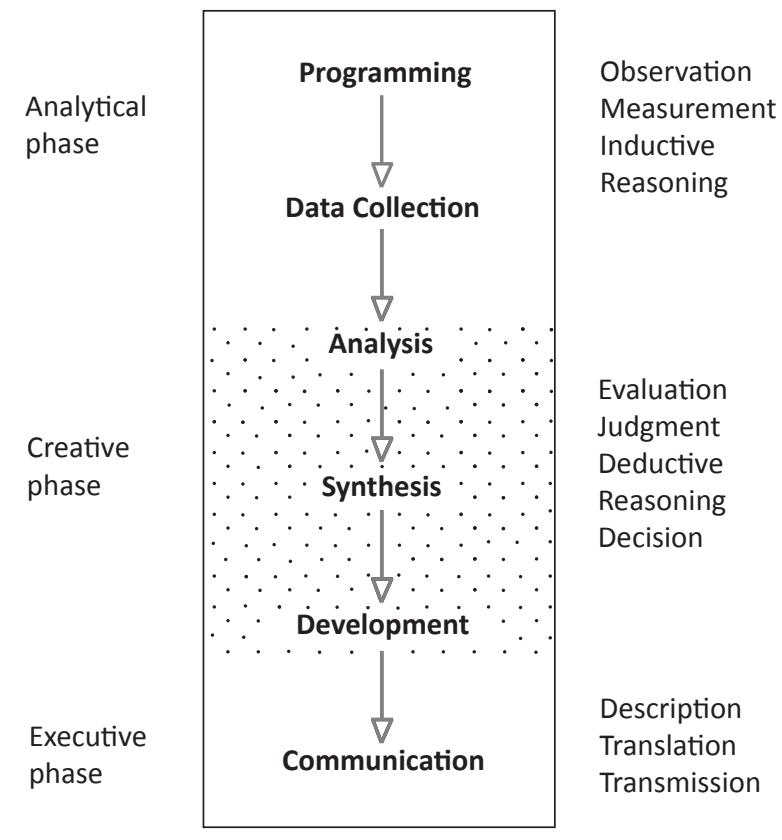

Figure 2-4: The main phases of design (Archer, 1965: 64)

Cooper and Press (1995: 37-38) suggest that the design process for products comprises four phases. These are concept, embodiment, detail and production. The design process starts 
with a brief which identifies the problem to be solved. The designer then starts generating concepts, developing these and then detailing the most suitable solution(s). By the end of the process, the designer should end up with a product or service as an output of the production phase (Cooper and Press, 1995: 37-38) (Figure 2-5).

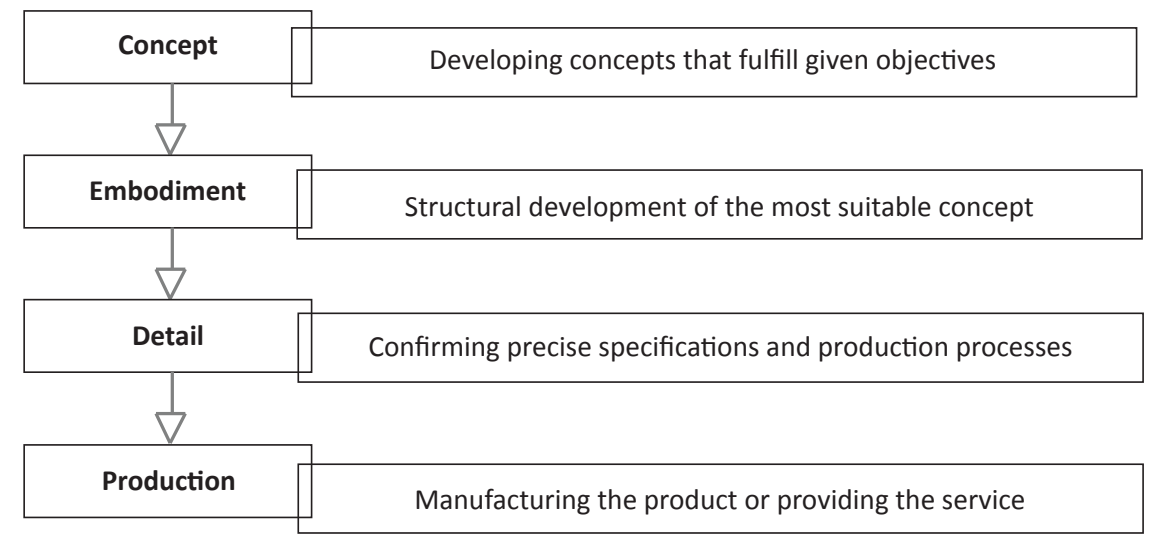

Figure 2-5: External productive process of design (Cooper and Press, 1995: 38)

Holmes et al. (1995: 105) agree with Cooper and Press (1995: 37) that the design process should be simplified to four stages. However, Holmes et al. (1995: 105) process starts with an absorption stage to help understand the problem thoroughly instead of generating concepts (Figure 2-6).

\section{Absorption}

The accumulation of information relevant to gain understanding of the problem at hand

Investigation

The investigation of the problem and all criterial affecting the problem

The investigation of a solution or the means for a solution

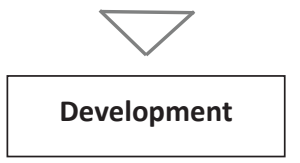

The development and refinement of one or more of the proposed solutions

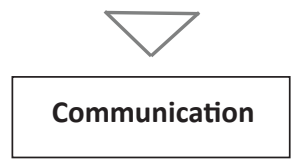

The communication, by whatever means, of the solution to others

Figure 2-6: The design process (Holmes et al., 1995: 105) 
Marcus (2002: 24) also divides the design process to four stages. These are research, concept, design and production. The design stage in Marcus' (2002: 24) process defines the product's form, function, materials and manufacturing process. It is a combination of the embodiment and detail stages from Cooper and Press' (1995: 38) model of the design process.

In terms of having a design model specifically for industrial design, Holmes et al. (1995: 109) propose a nine phase process (Figure 2-7). Their model involves a range of statements and four actions. The actions are research, conceptual design, embodiment and detailing. The Holmes et al. (1995: 109) model includes some loops to help in the evaluation of the design and going back to the previous stage when needed.

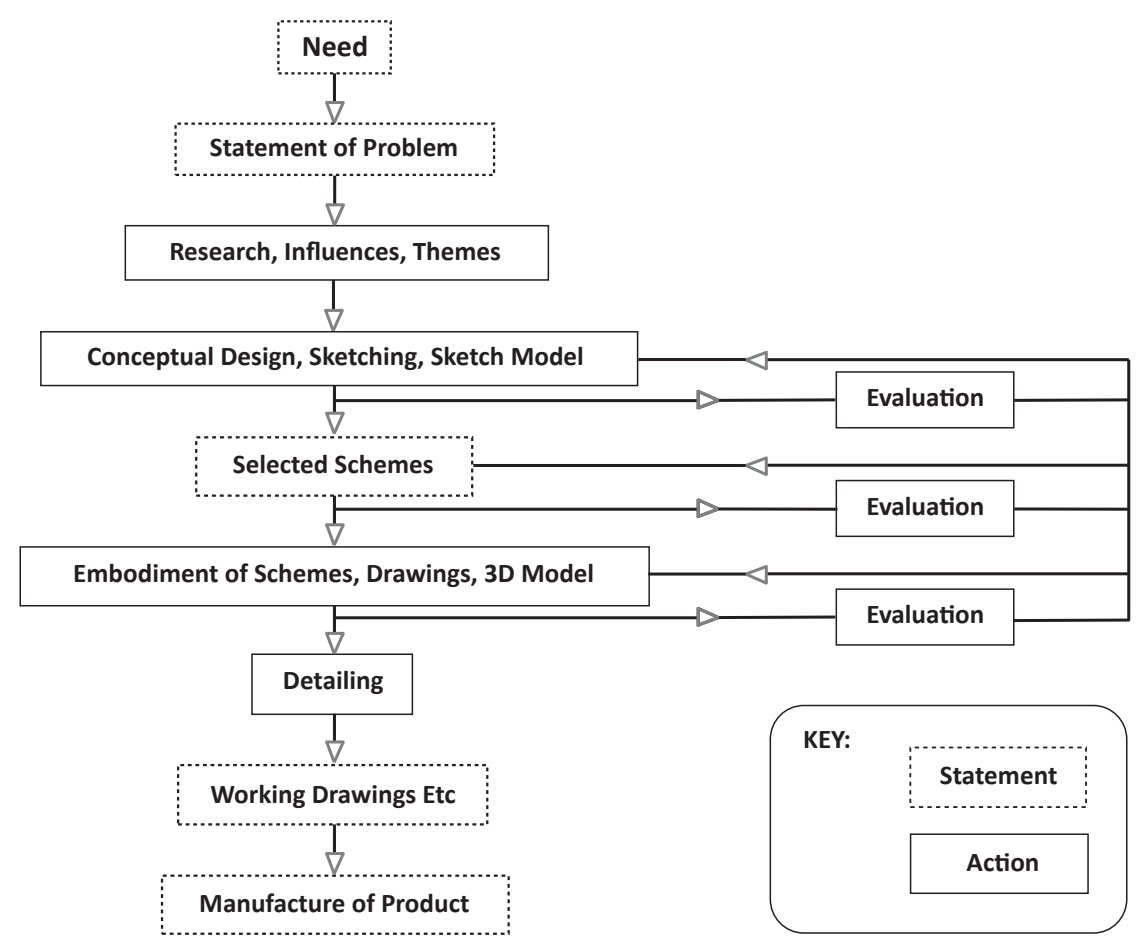

Figure 2-7: Block diagram of the industrial design process (Holmes et al., 1995: 109)

Ulrich and Eppinger (2003: 219-220) propose a six phase process for industrial design (Figure 2-8). According to this process, industrial designers identify customer needs; generate concepts to develop form and user interface; build models of the concepts with the most potential; refine and select a final concept; make control drawings; and finally work with the engineering and manufacturing team to complete the product development process (Ulrich and Eppinger, 2003: 220-223). 


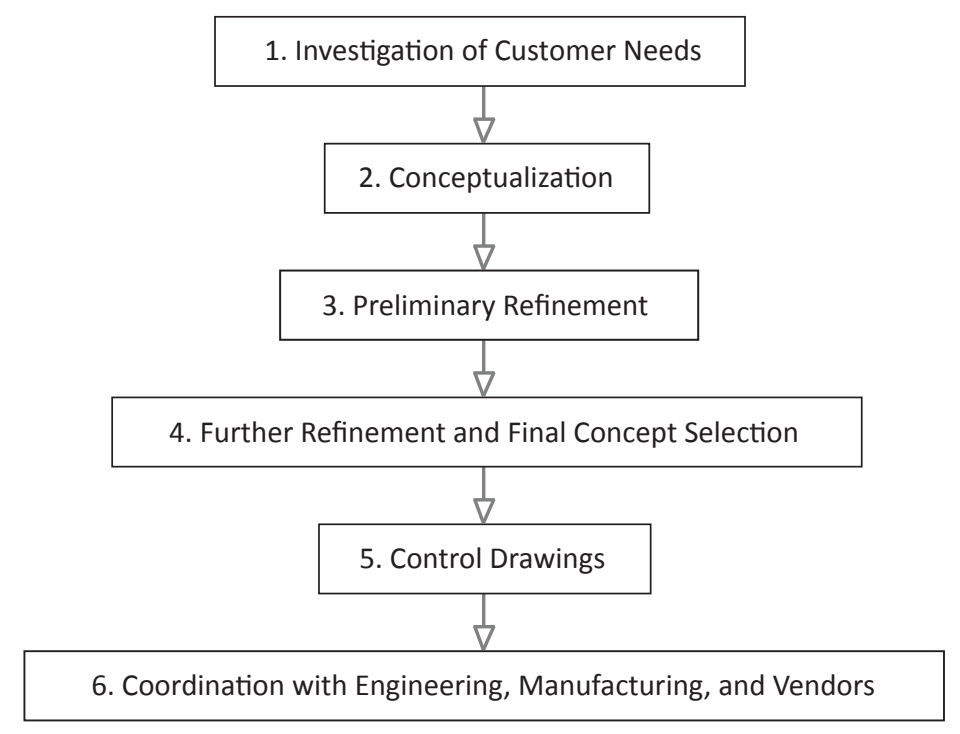

Figure 2-8: The industrial design process (Ulrich and Eppinger, 2003: 219-220)

Pugh (1991: 5) prescribes a model for NPD that begins by identifying market needs that meet user requirements and defines this as 'total design'. The total design activity model involves a central design core, which consists of studying market needs; formulating product design specification (PDS); generating concepts; detail design; manufacturing; and finally selling the product (Pugh, 1991: 5-6) (Figure 2-9). The design activity in the design core is iterative and the PDS controls the designing (Pugh, 1991: 6). The total design model also includes a range of activities, which act as inputs, such as market analysis, synthesis, decision-making, optimisation, data handling and costing (Pugh, 1991: 8). Technological knowledge, which might consist of materials information, stress analysis and electronic analysis also forms an essential input into the design core (Pugh, 1991: 8). 


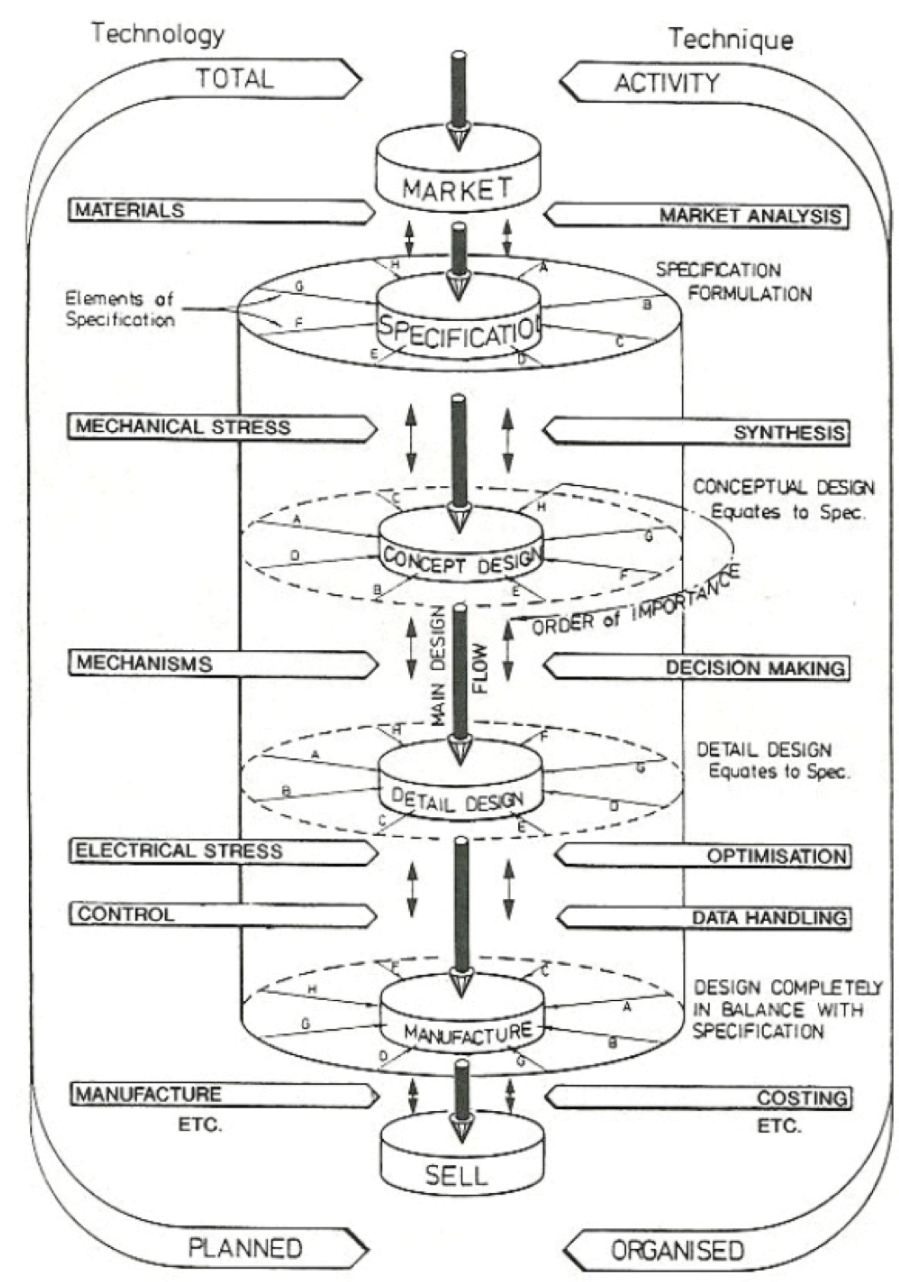

Figure 2-9: Total design activity model (Pugh, 1991: 11)

Baxter (1995: 263) simplifies the design process into three stages; concept design, embodiment design and detail design. Table 2-1 identifies the expected outcomes, aims and design thinking that takes place in each of the three design stages. 


\begin{tabular}{|c|c|c|c|c|}
\hline Stage & Outcome & Purpose & Design thinking & Example \\
\hline \multirow{3}{*}{$\begin{array}{l}\text { Concept } \\
\text { Design }\end{array}$} & \multirow{3}{*}{$\begin{array}{l}\text { Design } \\
\text { principles }\end{array}$} & \multirow{3}{*}{$\begin{array}{l}\text { Sufficient to deliver } \\
\text { the required core } \\
\text { benefit }\end{array}$} & $\begin{array}{l}\text { Design principles for } \\
\text { whole product }\end{array}$ & $\begin{array}{l}\text { Hand-helds or desk- } \\
\text { top adhesive tape } \\
\text { dispenser? }\end{array}$ \\
\hline & & & $\begin{array}{l}\text { Preliminary ideas for } \\
\text { embodiment design } \\
\text { for the whole } \\
\text { product }\end{array}$ & $\begin{array}{l}\text { Main body of } \\
\text { moulded plastic or } \\
\text { cast metal? }\end{array}$ \\
\hline & & & $\begin{array}{l}\text { Design pronciples for } \\
\text { product components }\end{array}$ & $\begin{array}{l}\text { Alternative general } \\
\text { forms and functions } \\
\text { for tape holder }\end{array}$ \\
\hline \multirow{3}{*}{$\begin{array}{l}\text { Embodiment } \\
\text { Design }\end{array}$} & \multirow{3}{*}{$\begin{array}{l}\text { Full working } \\
\text { prototype }\end{array}$} & \multirow{3}{*}{$\begin{array}{l}\text { Sufficient to check } \\
\text { 'manufacturability' } \\
\text { and fitness for } \\
\text { purpose }\end{array}$} & $\begin{array}{l}\text { Design principles for } \\
\text { product components }\end{array}$ & $\begin{array}{l}\text { Alternative general } \\
\text { forms and functions } \\
\text { for tape holder }\end{array}$ \\
\hline & & & $\begin{array}{l}\text { Embodiment design } \\
\text { of product } \\
\text { compnents }\end{array}$ & $\begin{array}{l}\text { Specific form, } \\
\text { function material and } \\
\text { process for } \\
\text { compenents }\end{array}$ \\
\hline & & & $\begin{array}{l}\text { Prelimniary ideas on } \\
\text { detail design for } \\
\text { product components }\end{array}$ & $\begin{array}{l}\text { Simple two-part } \\
\text { injection mould tool? }\end{array}$ \\
\hline \multirow{2}{*}{ Detail Design } & \multirow{2}{*}{$\begin{array}{l}\text { Complete } \\
\text { product } \\
\text { specification }\end{array}$} & \multirow{2}{*}{$\begin{array}{l}\text { Sufficient for } \\
\text { manufacture }\end{array}$} & $\begin{array}{l}\text { Design principles for } \\
\text { detailing product } \\
\text { components }\end{array}$ & $\begin{array}{l}\text { Increase wall } \\
\text { thickness or add ribs } \\
\text { or bosses? }\end{array}$ \\
\hline & & & $\begin{array}{l}\text { Detail design of } \\
\text { product components }\end{array}$ & $\begin{array}{l}\text { Full technical } \\
\text { drawings and product } \\
\text { specification }\end{array}$ \\
\hline
\end{tabular}

Table 2-1: Stages of the design process (Baxter, 1995: 263-264)

\subsection{Generic Activities of Industrial Design}

In line with Baxter's (1995: 263) approach, a three stage process was adopted in this research to simplify the process. The name of each stage was selected based on the on the first part of the IDSA's (2010: 1) definition of industrial design, which focuses on "creating and developing concepts and specifications". These stages of concept generation, development and specification will now be disscussed:

\subsubsection{Concept Generation}

After undertsanding the customer needs, industrial designers start to generate concepts (Ulrich and Eppinger, 2003: 197). These concepts are usually a set of styling and functional proposals (Baxter, 1995: 262). They can be represeted in the form of 2D sketches and drawings or 3D sketch models that are fast to produce in order to test the basic feasiability (Lofthouse, 2004: 218). A considerable amount of sketches are produced at this stage to 
generate ideas and engage in a process of reflection (Tovey et al., 2003: 140, Chen et al., 2003: 1).

\subsubsection{Development}

In the development stage, designers and clients select their preferred concept and develop it further by determining how it can be manufactured (Baxter, 1995: 263). They represent proposals in the form of renderings which are more informative-intensive drawings (Ulrich and Eppinger, 2003: 197). They also produce some further models to ensure that the concept is viable (Ulrich and Eppinger, 2003: 197, Baxter, 1995: 262). Materials and finish selection takes place at this stage of the process (Baxter, 1995: 263, Lofthouse, 2004: 219).

\subsubsection{Specification}

Details of each compenent is defined at this stage to facilitate manufacture (Baxter, 1995: 262). Industrial designers complete their contribuation to the NPD process by making engineering drawings and passing them over to engineers (Lofthouse, 2004: 219, Ulrich and Eppinger, 2003: 199).

\subsection{Industrial Design Representations}

Design representations are the way in which designers externalise ideas and enable them to be communicated to others (Goldschmidt and Porter, 2003: xi). They are important in the ideation phase to help the designer visualise concepts and solve problems (Dorta et al., 2008: 123). Saddler (2001: 19) defines a design representation as "a perceptible expression of a design idea, proposal, or fact".

Industrial designers use a variety of techniques, such as sketches, drawings, models and prototypes, to communicate ideas (Evans, 1992: 42, Pei, 2009: 385, Bodker, 1998: 111, Logan and Radcliffe, 2003: 127, Dorta et al., 2008: 124, Archer and Roberts, 1992: 4), but describing objects that do not yet exist is the common role of design representations (Bodker, 1998: 109). The design process normally starts with freehand sketching of concepts, then more structured design representations such as drawings, with models appearing as the process progresses (Pei et al., 2010: 141). Sketches and drawings are regarded as $2 \mathrm{D}$ visual design representations while models and prototypes are regarded as 3D visual design representations (Pei, 2009: 154). Evans and Wormald (1993: 97) summarise the representations used within industrial design practice by stating that it "generally 
involves the production of 2D sketches for the rapid generation of ideas; 3D sketch models for a more detailed manipulation of form; $2 \mathrm{D}$ renderings to present the proposal(s) to a client; 3D block model(s) as an exact representation of the proposal; 3D prototypes to define internal detail and undertake performance testing".

Pei (2009: 156) presented a taxonomy that is composed of 35 forms of design representations used by industrial designers and engineer designers. However, this section will focus on those used by industrial designers and the definitions that will be illustrated are generic; they apply to digital, analogue (conventional/traditional) and hybrid (use of both digital and conventional) design representations.

\subsubsection{Sketches}

Concept design takes place during initial stages of the design process. It involves generating a wide range of concepts to solve a design problem and meet project requirements (Peng, 2006: 439). Concept design requires $2 \times$ A0 area of inspiration illustrations and many simultaneous A2 or A3 design sketches (around 50 sketches) (Tovey, 1997: 17, Tovey et al., 2003: 142). Sketches are regarded as a key form of design representation used within concept design (McGown et al., 1998: 432, Prats and Garner, 2006: 1, Soufi and Edmonds, 1996: 451, Burton, 2005: 40, Tovey, 1997: 17). A concept sketch is defined as "a collection of visual cues sufficient to suggest a design to an informed observer" (Pipes, 2007: 19, Tovey, 1997: 25). Fish's (1996: 25) definition of sketching adds that the object being sketched is usually ambiguous or imaginary. (Tovey, 1997: 17).

While the initial sketches might only be understood by the original designer (McGown et al., 1998: 432), sketches produced at a later stage can be informative to clients and members of the new product development team (McGown et al., 1998: 443). Tovey et al. (2003: 141) state that sketches move from "a hazy vague picture to one that is in crisp focus". Therefore, sketches "can be loose or informal or dimensionally rigorous" (Tovey, 1997: 17).

Sketches are used to propose ideas and solutions quickly (Saddler, 2001: 20, Prats et al., 2009: 505, Evans, 2002: 214) while enabling reflective conversations between the designer and representation (Prats and Garner, 2006: 4, Verstijnen et al., 1998: 520, Prats et al., 2009: 503, Dorta et al., 2008: 123). Designers create sketches "not just to record an idea, but to help generate it" (Menezes and Lawson, 2006: 571). Sketches are also used to remind the designer of the initial concepts that can be developed further at a later stage (Faber, 2009: 2485, Prats et al., 2009: 505) or used to explore other alternative concepts (Prats et al., 
2009: 503). They are usually vague and ambiguous (Prats and Garner, 2006: 5, Evans, 2002: 47), but it is this uncertainly that allows designers to generate further concepts (Soufi and Edmonds, 1996: 451). Verstijnen et al. (1998: 520) suggest that sketches are essential for the designers' creative process and, without them, creativity can be impeded.

Menezes and Lawson (2006: 572) highlight the importance of sketches on design thinking when stating that "conceptual sketches are thus central to the phenomena of emergence and reinterpretation during early design activity. Emergence refers to new thoughts and ideas that could be anticipated or planned before sketching. Reinterpretation refers to the ability to transform, develop and generate new images in the mind while sketching".

The aim of producing sketches from designers' perspective is to help "generating concepts"; "externalising and visualising problems", "facilitating perception and translation of ideas"; "representing real world artefacts that can be manipulated"; and "revising and refining ideas" (Tovey et al., 2003: 137). From design managers' perspective, sketches are used for communication and evaluation purposes of design proposals so they have to be clearly understood by members of the design team (Tovey et al., 2003: 141).

The key components in concept sketches are lines, shading and colour (Tovey et al., 2003: 142). Tovey et al. (2003: 142) state that while lines are considered the most important component, shading and colour are used less often in early concept sketches. Sketches can be divided into types that are 2D and 3D. In addition, Olofsson and Sjölén (2005: 5) suggest that sketches can be categorised based on their role to investigation and exploration sketches, explanation sketches, and persuasive sketches. Sketches types will now be discussed.

\subsubsection{Side View Sketches (2D)}

2D sketching takes the form of side or orthographic views. Side views speed up the ideation of concepts in the early stages of the design process by providing a relatively simple way of representing a concept in a basic form (Eissen and Steur, 2007: 9) (Figure 2-10). 

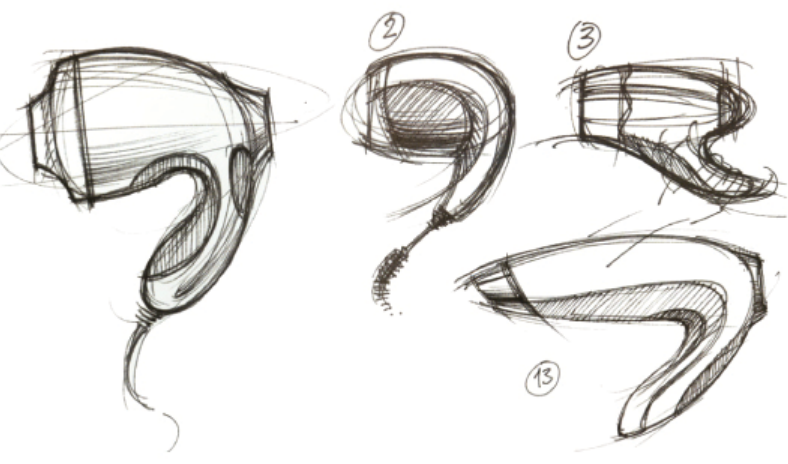

Figure 2-10: Side view sketches of hairdryer concepts (Eissen and Steur, 2007: 26)

\subsubsection{Perspective Sketches (3D)}

3D sketches are produced using a perspective technique that adds realism through the application of foreshortening (Olofsson and Sjölén, 2005: 9, Pipes, 2007: 46) thereby giving an indication of the proposed form and proportions (Evans, 2002: 51, Olofsson and Sjölén, 2005: 9, Pipes, 2007: 46). Designers normally use two-point perspective with two vanishing points as this facilitates views of the top and sides of a product (Pipes, 2007: 46) (Figure 2-11).

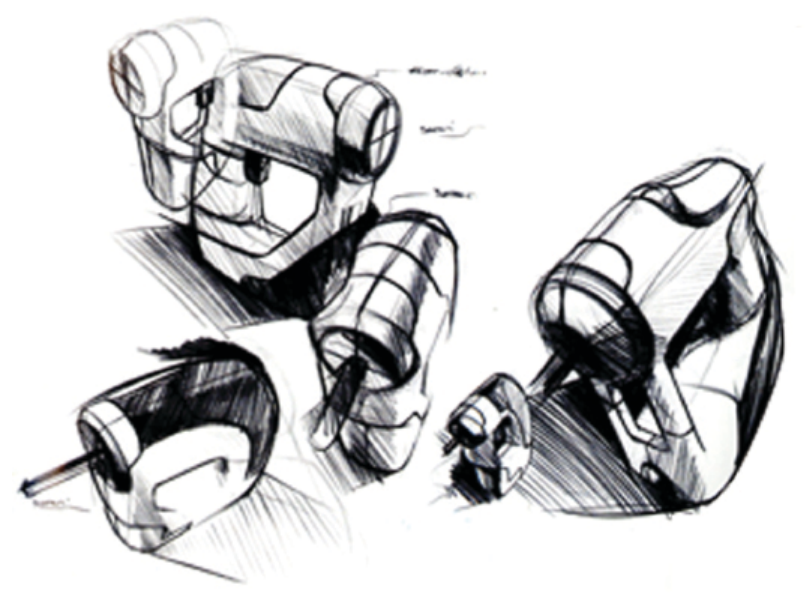

Figure 2-11: Perspective sketches of hand drill concepts (Olofsson and Sjölén, 2005: 23)

\subsubsection{Investigative and Exploration Sketches}

This type of sketch is normally used at the beginning of a design project to help identify solutions quickly and explore form and function (Olofsson and Sjölén, 2005: 5). The speed with which these sketches are produced allows the designer to explore a large number of concepts (Olofsson and Sjölén, 2005: 20). An example of investigative and exploration sketches can be seen in Figure 2-12. 


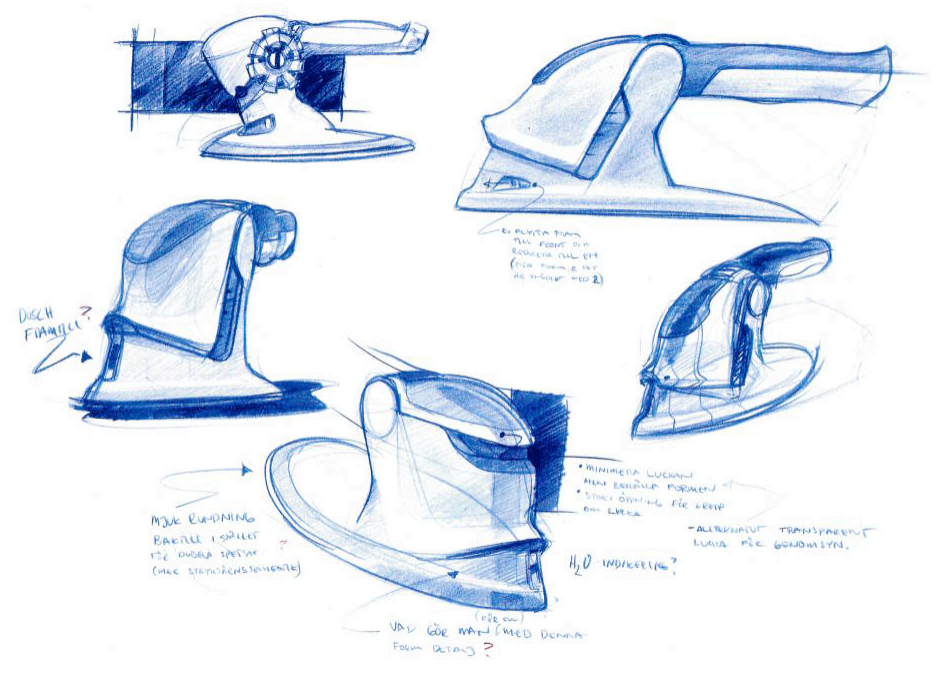

Figure 2-12: Investigative and explorative sketches of domestic iron concepts (Olofsson and Sjölén, 2005: 21)

\subsubsection{Explanation Sketches}

The main focus of an exploration sketch is to explain the proposed idea rather than promoting it (Olofsson and Sjölén, 2005: 46). They simply describe the "form, function and structure" (Olofsson and Sjölén, 2005: 46) after investigating the context and exploring possible solutions (Olofsson and Sjölén, 2005: 5). They represent uncompleted concepts that could be presented to others for feedback and further development (Olofsson and Sjölén, 2005: 46). Figure 2-13 shows an example of explanation sketches.
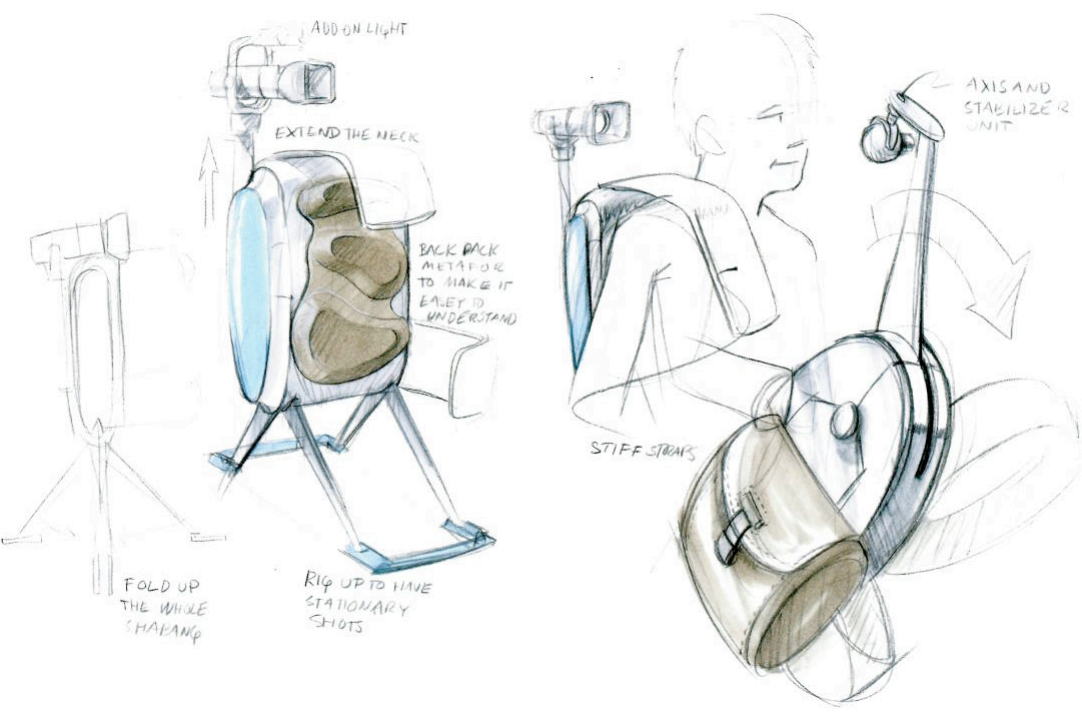

Figure 2-13: Explanation sketches of journalist's tool concepts (Olofsson and Sjölén, 2005: 


\subsubsection{Persuasive Sketches}

Persuasive sketches are "realistic 2D visual design representations in full colour, illustrating how the final product would look" (Pei, 2009: 168). They illustrate the proposed concept and persuade stakeholders to select the concept (Olofsson and Sjölén, 2005: 72, Pei, 2009: 168). As a result, persuasive sketches take longer to produce compared to investigative and exploration sketches, and explanation sketches (Olofsson and Sjölén, 2005: 5). An example of a persuasive sketch can be seen in Figure 2-14.

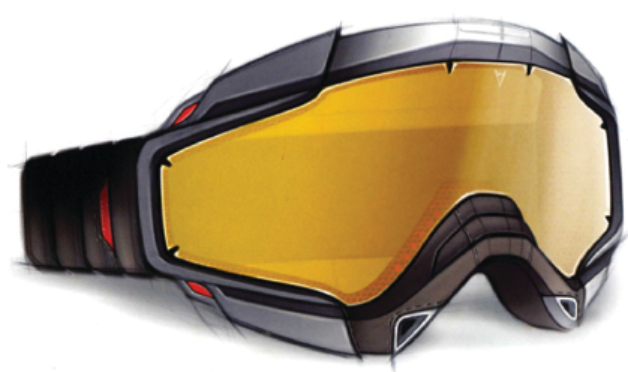

Figure 2-14: Persuasive sketch of goggles concept (Olofsson and Sjölén, 2005: 73)

\subsubsection{Drawings}

Drawing from pre-existing objects is different from design sketches, as the latter activity externalises forms that do not already exist (Tovey et al., 2003: 136, Archer, 1992: 8). Ullman et al. (1990: 263) clarifies the difference further by stating that drawings are "made in accordance with a set of widely accepted rules", whereas sketches are normally produced freehand without consideration to scale. Drawings presented towards the end of the design process communicate the form details of the proposed concept in scale (Ullman et al., 1990: 264).

Presentation drawings and control drawings (general arrangements and exploded views) are examples of drawings used within the industrial design process. A description of each will now be given.

\subsubsection{Presentation Drawings}

Presentation drawings are more formal when compared to sketches and are used to present work to clients and stakeholders before developing the proposals further (Burton, 2005: 39, Pipes, 2007: 20). They require the designer to apply colour/tone and detail to drawings (Evans, 2002: 49). Presentation drawing/renderings usually offer a high degree of realism, 
which requires a considerable amount of time and effort by the designer to be able to produce high quality representations of a design proposal (Burton, 2005: 39). They are normally produced in perspective to describe the object's form accurately (Pei, 2009: 174). Figure 2-15 illustrates an example of a presentation drawing.

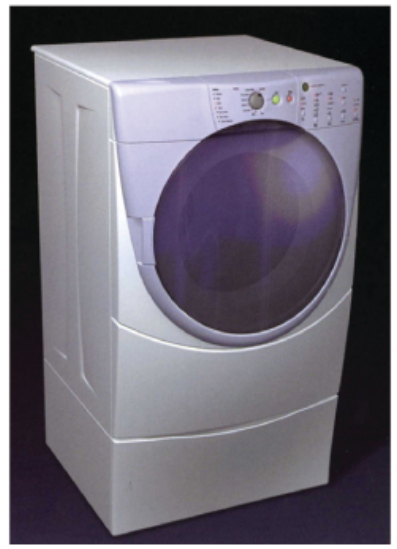

Figure 2-15: Presentation drawing of a fabric care system concept (Cullen et al., 2004: 141)

\subsubsection{Control Drawings}

Control drawings are the last type of drawing produced by in the industrial designers which get passed to other members of the product development team (Ulrich and Eppinger, 1995: 165). Ulrich and Eppinger (1995: 165) note that "control drawings document functionality, features, sizes, colors, surface finishes, and key dimensions". Two types of control drawings are general arrangement drawings and exploded views.

General arrangement drawings are also known as 'assembly drawings' (Pipes, 2007: 156) and 'engineering design' (Pipes, 2007: 20). This type of drawing is usually executed in orthographic projection (Evans, 2002: 53) and takes place in the specification phase of the design process, after approving the concept and developing it so it is ready for manufacture (Pipes, 2007: 20). General arrangement drawings are detailed drawings that specify dimensions; the arrangement of parts; materials; tolerances; and finish that are required for manufacture and assembly (Pipes, 2007: 159-160). An example of a general arrangement drawing can be seen in Figure 2-16. 


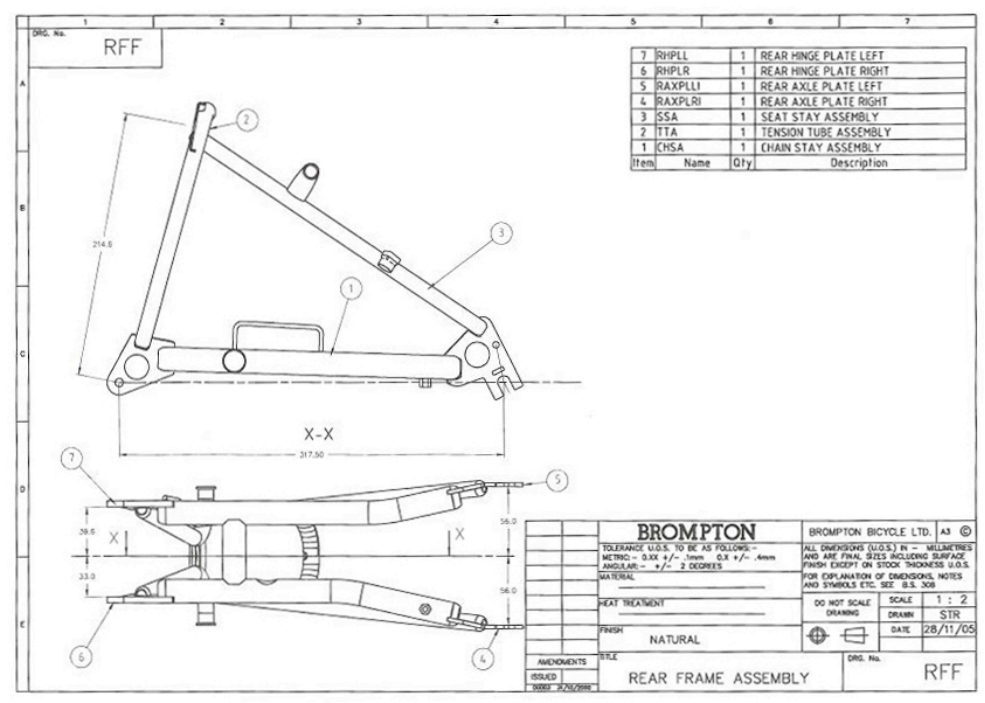

Figure 2-16: General arrangement drawing for the rear frame of a folding bicycle (Pipes,

2007: 158)

Exploded views are used to demonstrate how components fit together (Eissen and Steur, 2007: 182). Exterior and interior parts are typically separated in one direction to illustrate the links between them and how they are assembled (Eissen and Steur, 2007: 182) (Figure 2-17).

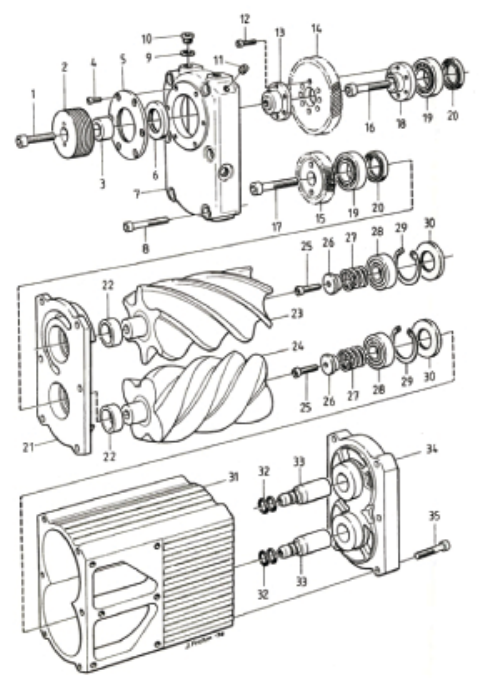

Figure 2-17: Exploded view of an autorotor drawing (Pipes, 2007: 190)

\subsubsection{Models}

Despite the usefulness of sketching and drawing within the design process, they do not effectively represent the proposal in true 3D. Powell (1990: 11) states that "it is through the 
model, of course, that an idea reaches three dimension for the first time, and both designer and client can truly assess the design".

Models are an essential part of industrial design practice (Evans and Campbell, 2003: 344, Tovey, 1997: 19, Archer, 1992: 7, Baynes, 1992: 12) as they allow designers to externalise their thoughts and communicate them to others (Shimizu et al., 1991: 38, Andreasen, 1994: 103, Burton, 2005: 40). Investing in models enables concepts to be fully assessed after creating 2D representations (Powell, 1990: 11, Evans, 2002: 56). Models provide an opportunity to solve problems and ensure that the design is feasible before proceeding further in the process and help prevent financial loss caused by design errors (Evans, 2002: 56, Sener, 2004: 46). Shimizu et al. (1991: 83) believe that models offer an opportunity for testing ideas and developing them rapidly.

Models are produced quickly using basic equipment with minimum effort and can be discarded after use (Powell, 1990: 45). If appropriate, they may be produced to scale (Evans, 1992: 42). The three key types of models will now be discussed.

\subsubsection{Sketch Models}

Sketch models are produced quickly with relatively little 2D information (Evans, 2002: 59). They are known as 'mock-ups', 'shape models', 'development models' (Sener, 2004: 50) and 'soft models' (Ulrich and Eppinger, 2003: 198). Sketch models are regarded as the first form of modelling that takes place after sketching and are used to assess and develop ideas (Sener, 2004: 50, Shimizu et al., 1991: 38, Evans, 1992: 43). Evans (1992: 43) states that industrial designers employ sketch models widely within their design practice, using card or foam. Figure 2-18 shows an example of a sketch model.

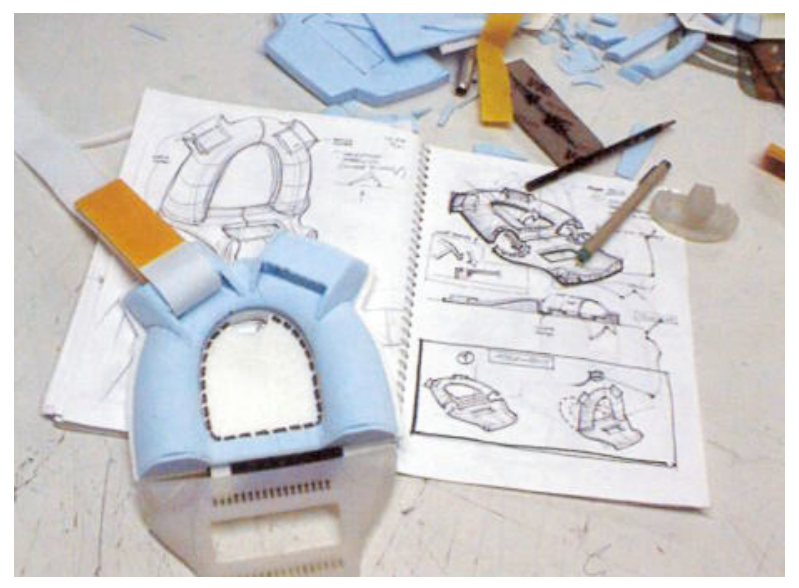

Figure 2-18: Sketch model of a head immobiliser (Cullen et al., 2004: 188) 


\subsubsection{Appearance Models}

Appearance models are also known as 'block models', 'qualitative models' and 'presentation models' (Evans, 2002: 57, Sener, 2004: 51). They represent the external features (materials, colours and finish) of a proposed product in detail (Evans, 1992: 43, Sener, 2004: 51). Evans (2002: 57) defines appearance models as "non-working physical representations of industrial design proposals that fully define exterior form and finish". Appearance models are usually expensive and take an extensive amount of time to produce (Powell, 1990: 11, Sener, 2004: 52). They are normally used to evaluate the form and ergonomics and to test the proposed product in the market (Shimizu et al., 1991: 38, Sener, 2004, Evans, 1992: 44). Figure 2-19 shows an example of an appearance model.

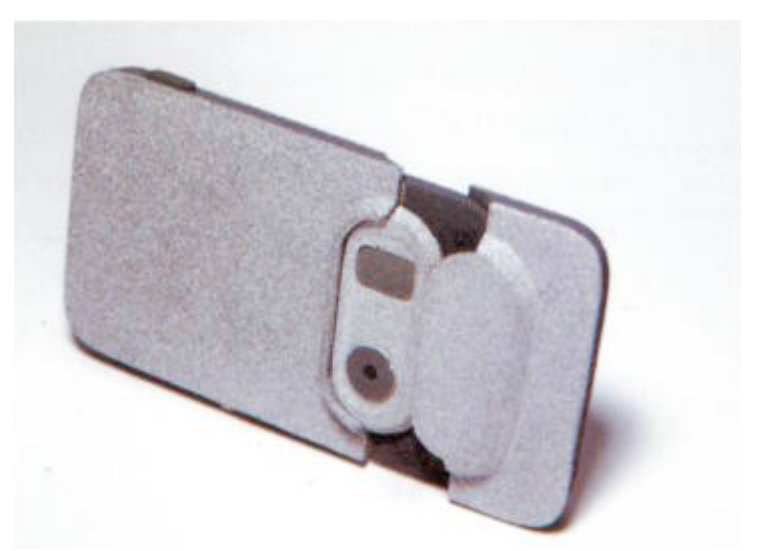

Figure 2-19: Appearance model of a pocket digital camera (Cullen et al., 2004: 92)

\subsubsection{Technology Models}

Technology models are concerned with the proposed product performance as opposed to appearance. They demonstrate how the proposed product works by modelling its structure, mechanisms and electronics (Sener, 2004: 51) (Figure 2-20). 


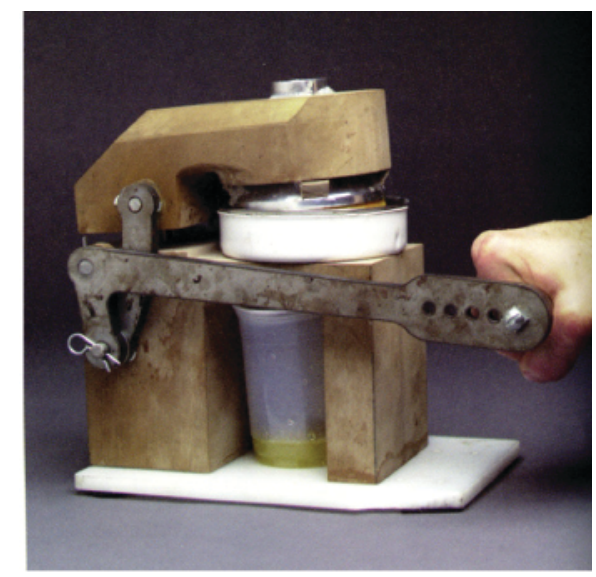

Figure 2-20: Technology model of a manual citrus juicer concept (Industrial Designers Society of America, 2001: 26)

\subsubsection{Prototypes}

The term prototype is defined as "a full-size, working representation of a design proposal" (Evans, 2002: 58). This definition clarifies that scale is a distinction between models and prototypes, with the latter typically being produced to the same scale as the product they represent (Evans, 1992: 43). Prototypes are mainly used as a learning tool to confirm that the product will work; to communicate to other members of the NPD team; to guarantee that parts of the product will work well when integrated; and to ensure that proposed product performs as required (Ulrich and Eppinger, 1995: 220-222, Saddler, 2001: 21).

Appearance prototypes and preproduction prototypes extend the level of communication further.

\subsubsection{Appearance Prototypes}

Appearance prototypes are also called 'working prototypes' (Sener, 2004: 51). They illustrate the exterior form (appearance) of the designed product as well as its functionality (Sener, 2004: 51, Evans, 2002: 58). An example of an appearance prototype can be seen in Figure $2-21$ 


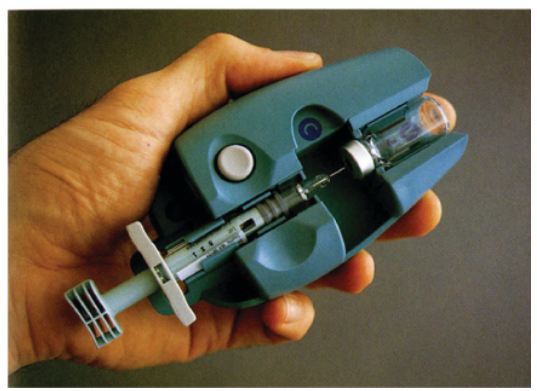

Figure 2-21: Appearance prototype of a mixing station and syringe components (Industrial Designers Society of America, 2001: 199)

\subsubsection{Pre-production Prototypes}

Pre-production prototypes are also known as 'pilot production prototypes' (Ulrich and Eppinger, 1995: 229). They are the first products produced using the specified production techniques in low volumes to ensure that the production process is capable of producing products to the required quality (Ulrich and Eppinger, 1995: 229, Sener, 2004: 52, Evans, 1992: 45). Figure 2-22 illustrates an example of a pre-production prototype.

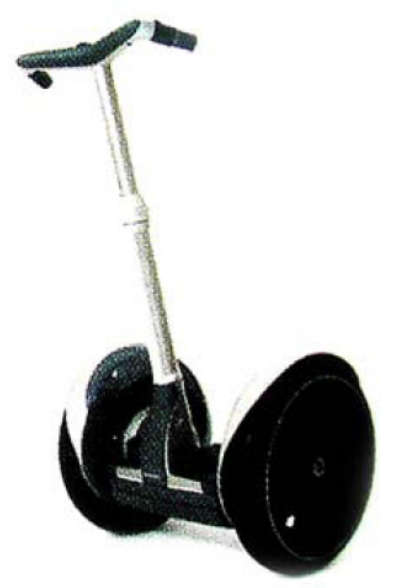

Figure 2-22: Pre-production prototype of a Segway Human Transporter (Cullen et al., 2004:

16)

\subsection{Industrial Design Education}

Industrial design was mainly taught in art schools in the UK (Tovey, 1997: 6, Kolko, 2005: 2, Unver, 2006: 323) and it is usually based in new universities because of the transformations in higher education (Tovey, 1997: 6). Two different disciplines come into conflict when educating industrial designers; those of art and engineering (Council for National Academic 
Awards, 1992: 9). Tovey (1997: 6) believes that although industrial design originated in art schools, it has stronger links with engineering as the two cultures (industrial design and engineering) relate to the manufacturing of products.

In the UK, industrial designers are typically educated through three-year full-time undergraduate degrees or four-year programmes if a placement/sandwich year is included (UCAS, 2011). Cooper and Press (1995: 21) suggest that in order for students to succeed in industry, design courses must equip students with the fundamental design knowledge, design skills and a contextual understanding (Figure 2-23).

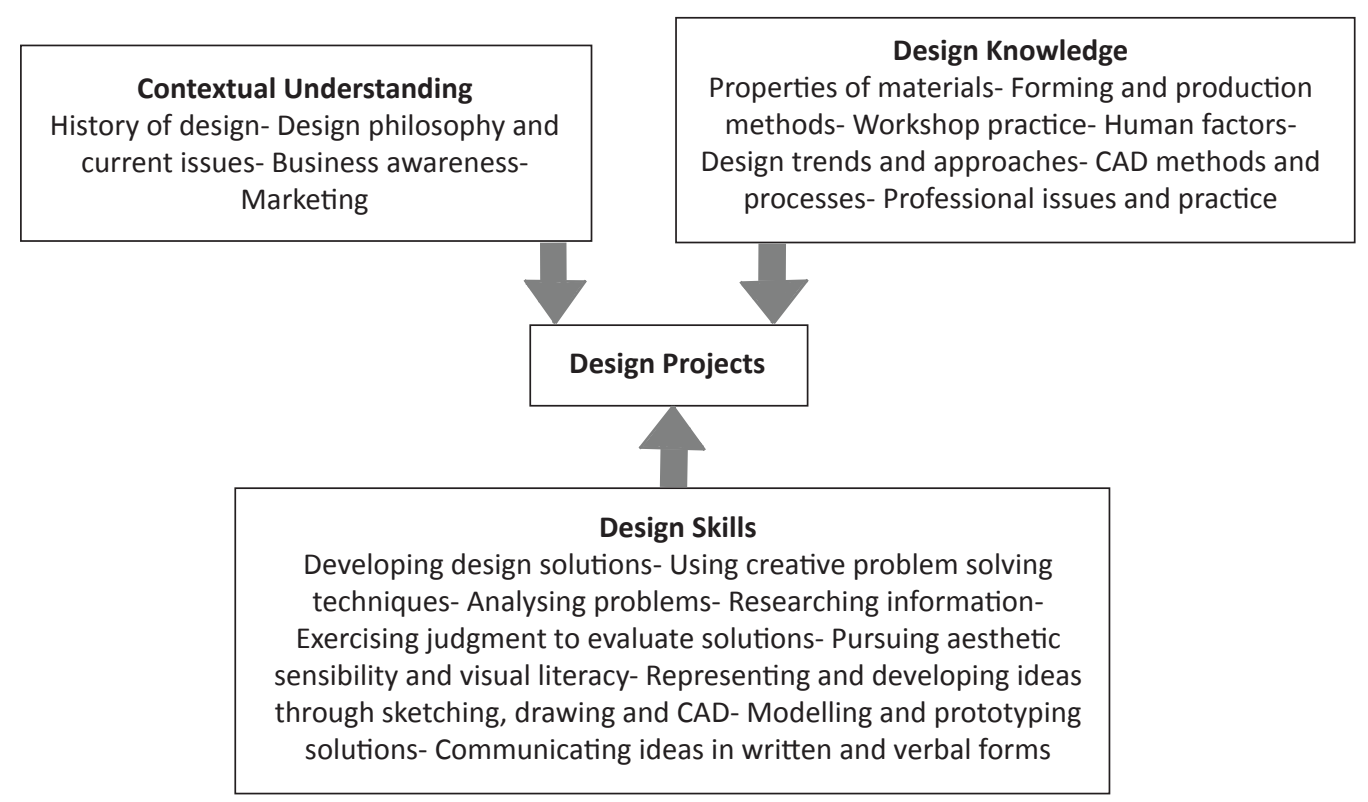

Figure 2-23: Elements of design education (Cooper and Press, 1995: 21)

During an industrial design course, core skills and knowledge focus on form giving, sketching, model making, materials, finish and manufacturing (Ulrich and Eppinger, 2003: 191, Kolko, 2005: 2). Yang et al. (2005: 162) suggest that design education has been evolving to meet the new trends. One of these changes is the increasing use of digital media and tools which have impacted on the output of sketching and model making activities within student design practice. However, these authors also argue that "computer aided industrial design (CAID), rapid prototyping (RP), online learning, interaction design, interface design, experience design, sustainable design, universal design, etc. have not been extensively brought into the formal design curriculum" (Yang et al., 2005: 162-163). The Council for National Academic Awards (1992: 26) suggest that a three-year industrial design course is not long enough to 
meet the demands required of the profession, which in part, explains the longer duration of industrial design courses in Europe of four or five years.

While the top-rated competency required for design jobs has been identified as 3D CAD skills (Yang et al., 2005: 178), there is a tension between obtaining hands-on modelling and digital skills in design education (Malins et al., 2007: 440). Malins et al. (2007: 440) anticipate that the conventional design tools will be replaced with digital equivalents so new pedagogies should emerge to make the most of the advantages offered by emerging technologies.

\subsection{Chapter Summary}

Design is the creative process of transforming ideas into solutions that stand out in terms of appearance and function to gain a competitive advantage. Industrial design is the practice of generating concepts and developing/detailing them to produce products and systems that appeal to users in terms of function and appearance while making profit for the manufacturers. Although in some literature, the term product design was identical to industrial design, others considered industrial design as an element within product design. To avoid misunderstanding, the term 'industrial design' will be used throughout the thesis but in surveys, the term 'industrial/product design' will be used.

NPD is the collection of activities undertaken to bring a new product to market to meet a demand as quickly and as cost effectively as possible. Within the NPD team, industrial designers typically focus on appearance and user interface while engineering designers address the performance and manufacturing.

Many attempts have been made to define the various stages of the design process. Some authors divide the process into three, four or six stages. In this research, the industrial design process will consist of three stages: generating concepts, developing the chosen concept, and specification for manufacture.

Industrial designers use a variety of 2D and 3D visual design representations to externalise their ideas. 2D representations consist of sketches (investigative and exploration sketches, explanation sketches and persuasive sketches) and drawings (presentation drawings and control drawings). 3D representations include models (sketch models, appearance models 
and technology models) and prototypes (appearance prototypes and pre-production prototypes).

In the UK, industrial designers are typically educated on a three-year programme or a fouryear programme if it includes a placement year. During their studies, industrial designers develop capability in form, sketching, modelling, materials and manufacturing. The ability to use 3D CAD modelling was the most important quality that design firms required from students.

The literature review undertaken in this chapter ensured that the background and context of industrial design practice and education is understood before examining the impact of digital designing and the available digital tools/media that can be employed in design practice. It was necessary to examine the role of industrial design, its practice, the representations used within it and education to understand the changes that digital design tools/media might bring to industrial design. 


\section{DIGITAL INDUSTRIAL DESIGN}

This chapter is the second part of the literature review. It reviews the phenomenon of employing digital techniques in professional and educational contexts. It illustrates the current and emerging digital tools and media that can be used for sketching/drawing and modelling/prototyping. The potential of undertaking design practice entirely digitally is reviewed.

\subsection{Overview of Digital Design}

In the last 20 years, design practice has undergone enormous change through the introduction and development of digital technologies (Ramduny-Ellis et al., 2008: 167/1, Oehlberg et al., 2009: 239, Shin, 2009: 1, Unver, 2006: 323). Computers are now considered as an essential tool within design practice, being employed, to various extents, during every stage of the design process (Pipes, 2007: 17).

In terms of industrial design, Shin (2009: 1) states that "industrial design practice has been changing due to the rapid growth of the software industry and the development of various computer-based design tools. As the scope and applications of design technology grow, designers are relying more and more on computers to aid the design process".

As digital technology continues to advance and the number of tools increases, design practitioners, academics and students are questioning the role of conventional tools such as paper-based drawing and workshop-based modelling (Anderson, 2005: 9). It is important to "educate a new generation of digital design specialists" as technology advances and becomes increasingly sophisticated (Oxman, 2008: 117).

Bass and Senyapih (2005: 258) believe that even though CAD is used to present concepts, design education is maintaining the use of manual paper-based skills. This situation leads to tension between physical and digital media (Basa and Senyapih, 2005: 258) as some believe that computers restrict creativity and should only be used for repetitive tasks (Chapman, n.d.: 2). Chapman (n.d.: 1-3) identifies five main problems that prevent the smooth introduction of information technology (IT) within design education. These are: hostility to 
technology, lack of lead from industry, limitation in expertise and time, reservations on the educational value and the cost of implementing technology (Chapman, n.d.: 1-3).

It is important to note that despite an increasing amount of literature on digital design generally and architectural design specifically (Marx, 2000, Oxman, 2008, Mark et al., 2001, Cil and Pakdil, 2007, Pektas and Erkip, 2006, Basa and Senyapih, 2005, Kvan et al., 2004), few studies only focus on industrial design practice and education (Shin, 2009, Yan et al., 2006).

\subsection{Digital Natives and Digital Immigrants}

According to Prensky (2001: 1-2), technology divides people into digital natives and digital immigrants. Digital natives are the native speakers of digital language who are used to being surrounded by computers, the Internet and video games and have not known a world without immediate digital interaction (Prensky, 2001: 1, The Sunday Times, 2006: 1). Digital immigrants, on the other hand, are those to whom digital technology appeared at a later point in their lives and they have had to adapt to using it within their environment (Prensky, 2001: 1-2). The difference between digital natives and immigrants is not only categorised by age but also by acceptance of rapid digital change (The Sunday Times, 2006: 2). Therefore, it could be argued that older people who adopted the digital language and are continuously keeping up to date with emerging technologies are digital natives as well.

Prensky (2001: 1-2) highlights a problem in education caused by the fact that students are digital natives while teachers are digital immigrants by stating that "our students have changed radically. Today's students are no longer the people our education system was designed to teach... Our digital immigrant instructors, who speak an outdated language (that of the pre-digital age), are struggling to teach a population that speaks an entirely new language". This issue is emphasised more recently by Delacruz (2009: 264), who believes that its common nowadays for students to know more about emerging technology than their teachers.

Current students are enthusiastic about accessing and obtaining information. They are good at multitasking and operate best when networked (Prensky, 2001: 2). Prensky (2001: 3) argues that in order to fully engage with students, educators should change their methods of teaching and learn to adopt technology as it is unlikely that students will change their behaviour and stop embracing new digital technologies. 


\subsection{Benefits of Digital Design}

The use and uptake of digital design techniques is being widely discussed (Oxman, 2008: 117, Cil and Pakdil, 2007: 123) as they offer many opportunities to designers. For instance, implementing digital technologies in industrial design practice enables the designer to manage the design process without the need for a number of specialists to make prototypes or undertake basic analytical tests (Unver, 2006: 323). Advances in communication technology enable remote interaction between members of the product development team to assess the design and ensure that the process is running smoothly (Unver, 2006: 325, Pipes, 2007: 35, Lee, 2006: 2). While digital tools/media assist communication between stakeholders, it also facilitates communication with clients (Lau et al., 2003: 402).

Digital tools/media allow concepts to be relatively easily modified through the use of undo, redo, copy, paste, resize and save as options that immediately apply changes (Marx, 2000: 21, Dorta et al., 2008: 125, Lee, 2006: 2). Scale issues can be resolved when using computers by providing the designer with the opportunity to immerse themselves in the representations of the design concepts (Dorta et al., 2008: 125). Digital tools/media allow the designer to create products that are complex in shape (Shih, 2006: 137, Sequin, 2005: 737) and at the same time, reduce the number of physical models required to decrease product development time and cost (Catalano et al., 2002: 14, Unver, 2006: 323, Ye et al., 2008: 1-2, Bucolo and Brereton, 2004: 1). They facilitate global collaboration and offer an opportunity for mass customisation (Munson, 2004: 3-4). Examples of companies that offer customisation include Nike (NIKEiD), Trek (Project One) and Lego (Lego Digital Designer) (Nike, 2011, Trek, 2011, Lego, 2011).

Digital formats are easier to handle compared to physical items as data can be stored in different locations with unlimited numbers of copies that can be accessed remotely (Weightman and McDonagh, 2007: 272). Marx (2000: 21) notes that clients prefer to see realistic images of the proposed product at an early stage of the design process and digital tools/media facilitate clarifying and presenting concepts. CAD represents concepts with a high degree of realism which enables effective concept evaluation (Loosschilder, 1997: 44, Hodgson, 2006: 10). It allows materials, colours and graphic details to be incorporated into the 3D model (Loosschilder, 1997: 45). 
"CAD can help designers avoid errors, predict potential pitfalls and prevent them occurring, and control the escalating amount of complex data" (Pipes, 2007: 35). It speeds the design process by merging different design stages and smoothing the transition of initial concepts to models and engineering drawings (Pipes, 2007: 35, Kvan et al., 2004: 8). It produces accurate, reliable, detailed and complex models (van Elsas and Vergeest, 1998: 81, Loosschilder, 1997: 51-52, Pipes, 2007: 35, Unver, 2006: 323). CAD facilitates efficiency gains (Chen and Owen, 1998: 331) and increases the collaboration between industrial designers, design engineers, marketing and manufacturing people (Evans, 1998: 1, Lynn, 2006: 107). It supports creative thinking when conceptualising by aiding the exploration of alternative options whilst designing (Hanna and Barber, 2001: 278, Jonson, 2005: 622). Unver (2006: 325) places emphasis on the use of CAD as "the broader parameters of design can be integrated, moving designers from just stylists to a more effective role in the development of products from concept to manufacture". The 3D CAD model can be used for animation and simulation or to produce a physical 3D model using RP and CNC machining (Loosschilder, 1997: 45-46, Hodgson, 2006: 10, Evans, 2002: 76). Advances in genetic programming offers designers the opportunity to use evolutionary CAD, where the designer can explore the use of different breeds of a single design automatically in a creative way (Hanna and Barber, 2001: 256).

Whilst operating digitally should be a natural process for students who are already fully immersed in a digital world that utilises the Internet along with social and instant massaging software (Beetham and Sharpe, 2007: 5), CAD provides an opportunity for students with limited abilities in sketching, drawing and producing sketch models to fully engage in the design activity (Unver, 2006: 325, Hodgson, 2006: 11).

\subsection{Concerns about Digital Design}

As discussed, there are numerous benefits to employing digital methods, although McCullough (1998) notes that computers prohibit the opportunity for designers to have tactile interaction with their work. Pedagogic issues have also been identified in terms of balancing the need to learn digital design techniques with a fundamental understanding of form: "There is a tension between acquiring haptic and digital skills that arise from the need for students to acquire an understanding of elements of form, colour and spatial awareness, 
skills which are acquired through making, whilst at the same time acquiring digital skills" (Malins et al., 2007: 437).

Although DID has advantages over conventional (non-digital) processes, opinion suggests that conventional sketching can illustrate the thinking process while digital tools limit creativity (Dorta, 2008: 393, van Elsas and Vergeest, 1998: 82, Verstijnen et al., 1998: 544, Dorta et al., 2008: 121, Chapman, n.d.: 2). Prats et al. (2009: 504) and Company et al. (2009: 592) note that current computer systems demand too much precision too soon in the design process and Dorta et al. (2008: 121) state that "the discrepancy between the creative impulse and the input needed to activate digital commands often leaves the designer bound to a process that steers him away from design thinking". Lynn (2006: 109) also notes that computers may generate issues with the interpretation of scale and proportion. Longson (1999: 2) comments that the constant updating of software can hinder the capacity to learn. Within design practice, the use of CAD forces design managers to adapt to new processes and introduce new jobs (Westin, 1998: 51). Marx (2000: 22) and Radclyffe-Thomas (2008: 163) suggest that the cost of digital tools/media puts off investors, especially within design education. Students face problems when designing and computers can over complicate the situation as educators may not be ready for change (Marx, 2000: 22). Furthermore, designers and academics who have made a career using traditional tools have concerns about the use of digital tools as they believe they have the capacity to somehow 'steal the soul' or degrade the quality of designing (Lynn, 2006: 108).

On a physiological level, using the computer for long periods of time increases the risk of eyestrain and cumulative trauma disorder which is caused by making small repetitive movements with the input device over long periods of time (Chapman and Chapman, 2007: $6)$.

\subsection{Attitudes Towards Digital Design}

According to Robertson et al. (1995: 73-74), student attitude towards IT is affected by gender, with males being more positive than females; experience of using computers (more experienced students have more positive feelings); and the owners of computers having a more positive attitude. 
The attitude of teachers towards computers is not affected by gender but, overall, they have been noted as being more anxious about using computers compared to students (Robertson et al., 1995: 77) who enjoyed using technology more than their teachers (Robertson et al., 1995: 79). Robertson et al. (1995: 78-79) suggest three reasons for the negative attitude of teachers towards IT: opposition to change; anxiety of the challenges that might require new methods of teaching; and interpreting computers differently to students (Robertson et al., 1995: 78-79).

While the results from Robertson et al. (1995) are concerned with the IT side of digital media rather than the design activity, it serves as an indication of the correlations of these issues, especially that there is a lack in studies that identify the student attitude towards the use of digital technologies in design (Pektas and Erkip, 2006: 80). The studies that will be described next focus on student and academic attitudes within architecture.

A survey was undertaken by Bilkent University with senior students from the Department of Interior Architecture and Environmental Design to investigate the student attitude towards the use of computers in design (Pektas and Erkip, 2006: 79). The results revealed that student thoughts about the use of computers in design were influenced by their use of computers in general. In addition, while the attitude towards the use of computers in design was extensively positive, students were not as enthusiastic about the use of computers to generate design concepts as they were about other areas of design (Pektas and Erkip, 2006: 84). Male students were more positive about the use of computers than female students (Pektas and Erkip, 2006: 84). Petkas and Erkip (2006: 93) proposed that in order to close the gap between academic and student attitudes, academics should understand the advantages that computers offer, especially as the field of technology is consistently advancing.

Radclyffe-Thomas (2008: 159) states that "technology provides a new medium that presents both opportunities and threats to educators". To investigate this matter further, Cil and Pakdil (2007: 126) carried out a case study that involved a survey and semi-structured interviews with architecture instructors who had more than 10 years experience to examine their views on the contribution of computers. Results indicated that 20 out of the 28 respondents believed that 3D CAD software enhanced the student perceptual skills, while 11 out of the 20 stressed the importance of continuing to teach hand sketching (Cil and Pakdil, 2007: 130). Furthermore, $66 \%$ of the instructors felt that computers were not used to their full potential within the student and instructor practice, with the instructors regarding computers as a tool to be used for drafting, aiding visualisation and 3D modelling, thereby 
indicating that other aspects of digital design activity have not been embraced (Cil and Pakdil, 2007: 133).

Within interior architecture design, "practice seems to welcome computer aid in presentation, whereas in academia there seems to be a dilemma" (Basa and Senyapih, 2005: 257). Basa and Senyapih (2005: 259-261) identify three reasons for the academic negative opinion towards the use of computers in design presentation. These are: lack of identity and characteristic features in the produced work; difficulties in tracing authenticity; and academic competency and skills in computer technologies (Basa and Senyapih, 2005: 259261).

\subsection{Digital Tools/Media}

Computers are brought "into design studios with an ever-increasing role in design activities" (Sener and Wormald, 2001: 358). Compared to conventional tools, digital tools/media act as an entire workshop that combines the performance of several conventional tools (Chapman and Chapman, 2007: 4). Emerging and available digital design tools/media used within the core design activity of concept generation and design development are categorised in this chapter according to their purpose and ambiguity/refinement. The categories used are digital sketching tools/media (ambiguous), and digital modelling/prototyping tools/media (refined).

\subsubsection{Digital Sketching Tools/Media}

Digital sketching tools/media refer to the tools/media that allow users to sketch digitally while maintaining ambiguity and intuitiveness when generating concepts. The software used usually takes the form of 2D, but some 3D software has been developed recently that facilitates the intuitive nature of sketching activity.

While there is a lack of digital tools that support initial concept generation (Dorta et al., 2008: 121, Bilda and Demirkan, 2003: 49), published literature suggested concerns towards generating concepts digitally. Designers might find it difficult to generate creative ideas whilst adapting to the use of computers (Hanna and Barber, 2001: 261). Dorta et al. (2008: 123) indicate that the lack of digital tools that can be used to generate concepts has led designers to use 3D CAD for ideation purposes when they have not been built for that purpose. Company et al. (2009: 592) point out that the introduction of CAD led some 
designers to discard sketching. Tang et al. (2011: 2-3) state that many computer aided conceptual design systems have been established, but a common problem with them is that they are still not as good as paper-based sketching in terms of visual resolution and they have not been widely evaluated. Sener (2004: 113) addresses the same issue and notes that "digital sketching tools do not fully replicate the qualitative satisfaction and experience of pen-on-paper sketching". Ronning (2008) suggests that paper-based sketching is more spontaneous and convenient compared to digital sketching. Paper-based sketching tools/media are cheaper, more portable and instant so ideas do not fade away while trying to boot up a computer (Ronning, 2008). Paper resistance means that paper-based sketching offer more tactile response (Ronning, 2008). It provides a direct connection with the paper surface so the tip of the pen/pencil touches the exact point on paper, while digital sketching suffer from parallax (Ronning, 2008). Paper based sketching allows the designer to view a number of ideas next to each other as opposed to digital sketching, which is limited because of the screen size (Ronning, 2008). Table 3-1 shows a comparison between digital sketching and paper-based sketching.

\begin{tabular}{|l|l|l|}
\hline \multicolumn{1}{|c|}{ Criteria } & \multicolumn{1}{|c|}{ Digital sketching } & \multicolumn{1}{|c|}{ Paper-based sketching } \\
\hline Access & $\begin{array}{l}\text { Computer needs to boot up/few clicks } \\
\text { away }\end{array}$ & Tools are always readily accessible \\
\hline Tangibility & Does not provide subtle haptic feedback & Tactile and responsive \\
\cline { 2 - 3 } & $\begin{array}{l}\text { Size of the stylus nib does not define } \\
\text { the stroke size }\end{array}$ & $\begin{array}{l}\text { Size of the pen/pencil/marker/brush nib } \\
\text { defines the stroke size accurately }\end{array}$ \\
\hline Parallax & $\begin{array}{l}\text { Tip of stylus appears to be at a slightly } \\
\text { different location from where it is } \\
\text { making a mark in screen }\end{array}$ & $\begin{array}{l}\text { Tip of the pen/pencil/market/brush makes } \\
\text { marks in the location placed accurately }\end{array}$ \\
\hline Commitment & $\begin{array}{l}\text { Demands saving files and following a } \\
\text { folder filing system commitment }\end{array}$ & Does not require saving \\
\hline Canvas & $\begin{array}{l}\text { Size of screen limits viewing to one or a } \\
\text { few sketches at a time }\end{array}$ & $\begin{array}{l}\text { Design sheets can be laid out next to each } \\
\text { other and compared }\end{array}$ \\
\hline Portability & $\begin{array}{l}\text { Concerns about battery life, size and } \\
\text { weight }\end{array}$ & $\begin{array}{l}\text { Easy to carry around as they are light and } \\
\text { handy }\end{array}$ \\
\hline Price & $\begin{array}{l}\text { Expensive and can reach \$2000 price } \\
\text { tag }\end{array}$ & Cheap \\
\hline
\end{tabular}

Table 3-1: Comparison between digital sketching and paper-based sketching (Ronning, 2008)

On the other hand, compared to paper-based sketching, digital sketching offers an easy way to store concepts and pass them on to other members of the design team (Company et al., 2009: 595). It allows amendments (erasing, copying and resizing for example) while providing a limitless canvas that can be altered in terms of size and used along with the zooming feature (Company et al., 2009: 595).

The digital tools that are currently available for concepts sketching will now be discussed. 


\subsubsection{Digitising Tablet without a Built-in Display}

Shin (2009: 3) believes that the introduction of digital tablet technology enables designers to sketch digitally while benefitting from quick modification and communication with others. A digitising tablet without a built-in display is "a flat electromagnetic grid that captures positional data via an input device, such as a stylus" (Sener, 2004: 97). This type of digitising tablet provides indirect interaction by requiring the user to control the movement of the hand with the stylus and the design representation being created/modified on screen (Lee and Wei, 2007: 305). Examples include the Wacom Intuos and Wacom Bamboo. The Wacom Bamboo Pen \& Touch also includes a multi-touch sensor that enables the use of fingertip gestures to write, rotate, flip, zoom and scroll (Wacom, 2011a) (Figure 3-1).

While digitising tablet without a built-in display is one of the available tools that could be used for sketching purposes, it could be argued that the indirect interaction does not facilitate having a natural sketching experience.

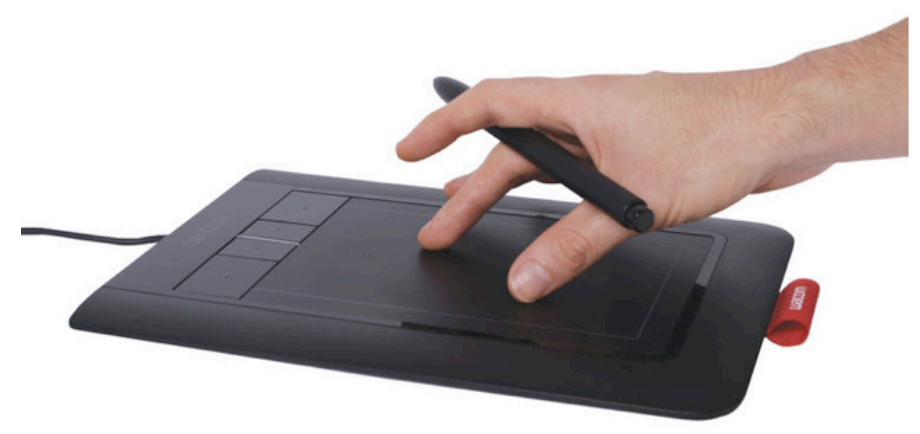

Figure 3-1: Wacom Bamboo Pen \& Touch (PC Pro, 2009)

\subsubsection{Digitising Tablet with an Interactive Display}

The digitalising tablet with an interactive pen display offers greater control by providing direct interaction with the screen while sketching to make the process more natural and productive (Lee and Wei, 2007: 305). An interactive pen display digitising tablet, such as Wacom Cintiq and Wacom PL Series, is pressure sensitive and allows the designer to rotate the display into suitable position for sketching (Wacom, 2011b) (Figure 3-2). The stylus comes with three different nibs (Standard Nib, Stroke Nib and Felt Nib) to get a brush-like feel or marker-like feel (Wacom, 2011b). 


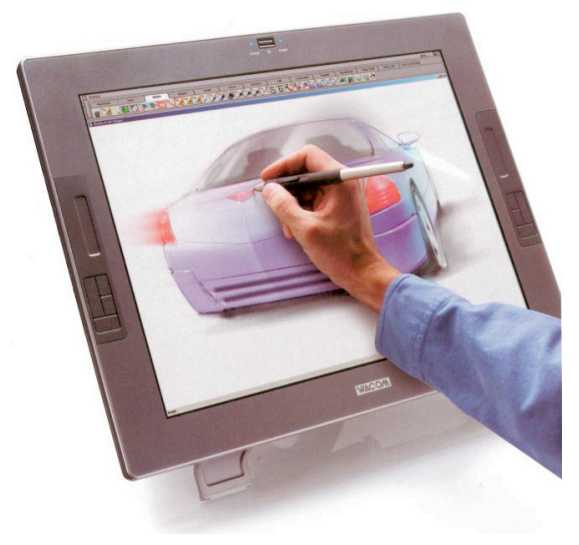

Figure 3-2: The Wacom Cintiq tablet (Pipes, 2007: 97)

The Wacom Cintiq comes in two screen sizes (12.1 inches and 21.3 inches) (Wacom, 2011b). The Wacom Cintiq 21UX provides a sketching area that is big enough to fit an A3 page that industrial designers are used to sketch on. However, the size, weight and the fact that the Cintiq has to be connected to a computer, makes it more of a static digital tool that cannot be carried around easily to be used when inspiration strikes.

While the Wacom Cintiq and PL Series have to be connected to a computer, the Tablet PC is a self-contained portable computer that effectively combines a digitising tablet (Sener, 2004: 102). Tablet PCs attracted users in the 1990s and Atkinson (2008: 11) notes that "even though their popularity then underwent a massive decline, they did not disappear altogether, and still are manufactured today in limited quantities".

The Tablet PC uses a touch screen that allows input by a stylus or fingertip and can recognise handwriting (Atkinson, 2008: 3, Chin, 2007: 11). The screen can change its orientation from being a normal laptop that uses the keyboard, to being configured so that the screen covers the keyboard allowing pen input (Atkinson, 2008: 11) (Figure 3-3). Frolik and Zurn state that (2004: 5) "the Tablet PC is a relatively new technology and thus a broad set of experiences are not yet available". 

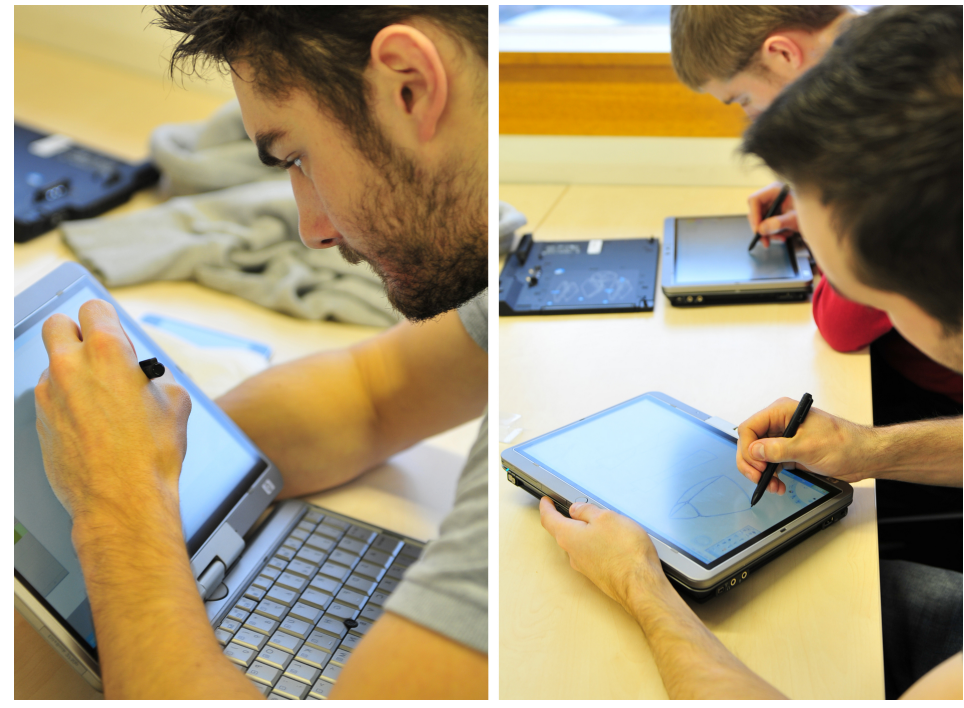

Figure 3-3: The Tablet PC's various screen orientation

With appropriate software, the Tablet PC is a suitable tool for freehand sketching as it is pressure sensitive. When the tip of the stylus touches the screen, a digital 'ink' can appear on the screen (Ning et al., 2004: 4, Chin, 2007: 11, Hoeben and Stappers, 2005: 409). Massachusetts Institute of Technology (MIT) piloted the use of Tablet PC for two weeks in the 2002 International Design Competition and then used it with 40 mechanical design students for different projects (Microsoft, 2004: 2). Results indicated that the Tablet PC helped students generate ideas anytime and anywhere; it facilitated drawing and making notes while designing; and increased the collaboration between the team members (Microsoft, 2004: 2-3).

When using the Tablet PC, students did not have to carry additional items for designing and responded well to its portability (Frolik and Zurn, 2004: 4). Ning et al. (2004: 4) note that despite the fact that the Tablet PC offers a smooth surface to sketch on, digital sketching using the Tablet PC was similar to sketching using pen and paper. While sketches were easier to sort and retrieve using the Tablet PC, the sketching output can be imported into CAD software for full 3D modelling (Ning et al., 2004: 4). Nevertheless, the Tablet PC provides a limited area for viewing the work produced (Frolik and Zurn, 2004: 3).

Developments in tablets with interactive displays led to the launch of the Apple iPad which has a large, multi-touch screen that covers the processor unit. It is a very portable tablet that can operate in any orientation (Apple, 2011) (Figure 3-4). 

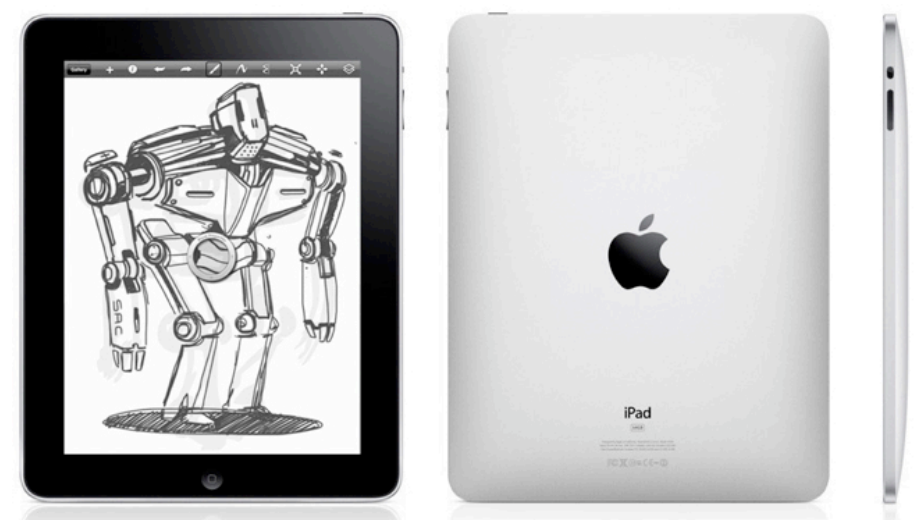

Figure 3-4: Apple iPad (Idsketching, 2010)

While there is a lack of published research on the use of the iPad for design sketching, two reviews were noted in a blog and on a forum (Konigi, 2010, Idsketching, 2010). Konigi (2010) believes that "pen and paper are still superior". Using a finger/nail to draw is not efficient so a stylus helps with the iPad but pens that are available have a fat foam tip that prevents the process feeling as natural as paper-based sketching (Konigi, 2010) (Figure 3-5). However, Konigi (2010) argues that it is still usable for quick initial sketching when you do not need to be too precise.

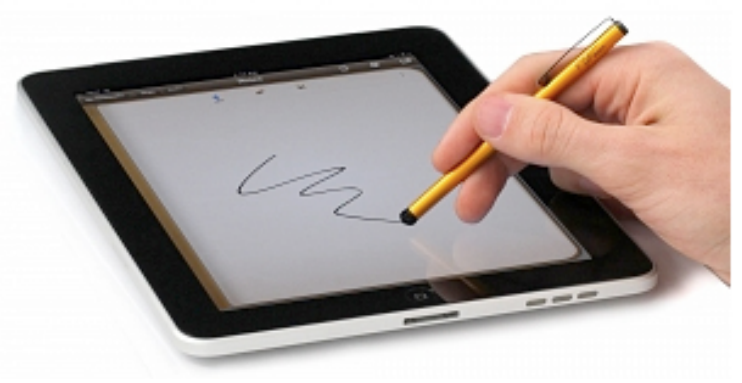

Figure 3-5: Pogo Sketch pen used with Apple iPad (Ten One Design, 2010)

Sketching with an iPad has been identified as being enjoyable and its battery life facilitates heavy usage (Idsketching, 2010). On the negative side, the Pogo Sketch stylus needs more pressure when compared to a normal Wacom stylus and the screen size is considered small for sketching (Idsketching, 2010). Furthermore, exporting and importing sketches to the iPad can only be done wirelessly through e-mail and websites (Idsketching, 2010). The iPad is not as pressure sensitive as the Wacom Cintiq, but has been described as being elegantly designed, portable, cheaper and does not require cables and large space to store (Idsketching, 2010). 


\subsubsection{2D Visualisation Software}

2D visualisation software can be divided into draw/vector and paint/bitmap programs (Pipes, 2007: 137). Vector images are constructed from lines and circles, while bitmap images are composed of pixels or dots (Pipes, 2007: 137, Foxit Software Company, 2004: 1). Vector-based programs, such as Adobe Illustrator and Adobe FreeHand MX, allow objects to be selected and modified separately (Pipes, 2007: 137). Bitmap programs, such as Adobe Photoshop and Corel Painter, are powerful in having the capacity to create images with a high degree of realism (Foxit Software Company, 2004: 4-7, Pipes, 2007: 137). The fact that the resolution of bitmap images depends on the number of pixels used to create it, resizing (larger or smaller) images effects the resolution while vector images can sustain it (Foxit Software Company, 2004: 4).

Adobe Photoshop has the flexibility to work in layers (Pipes, 2007: 142). Each layer can be arranged and treated separately in terms of activation and visibility (Pipes, 2007: 142). Adobe Illustrator uses an overlay feature and has the ability to apply changes to individual elements within the drawing (Pipes, 2007: 142).

Autodesk SketchBook Pro provides a relatively simple 2D application for freehand sketching (Pipes, 2007: 119). The Idsketching forum (2010) reviewed the use of SketchBook Pro with the iPad. The article illustrated that on the negative side, SketchBook Pro did not allow the use of new customised brushes and trying to bring all the brushes up on the screen was not particularly easy (Idsketching, 2010). The software limits the user to a maximum of six layers and these cannot be merged (Idsketching, 2010) (Figure 3-6). This is limited due to the size of the iPad (Idsketching, 2010). Also, while shape tools (such as ellipses and lines tools) are available in SketchBook Pro for Tablet PCs and computers, the iPad version lacks this feature (Idsketching, 2010). 


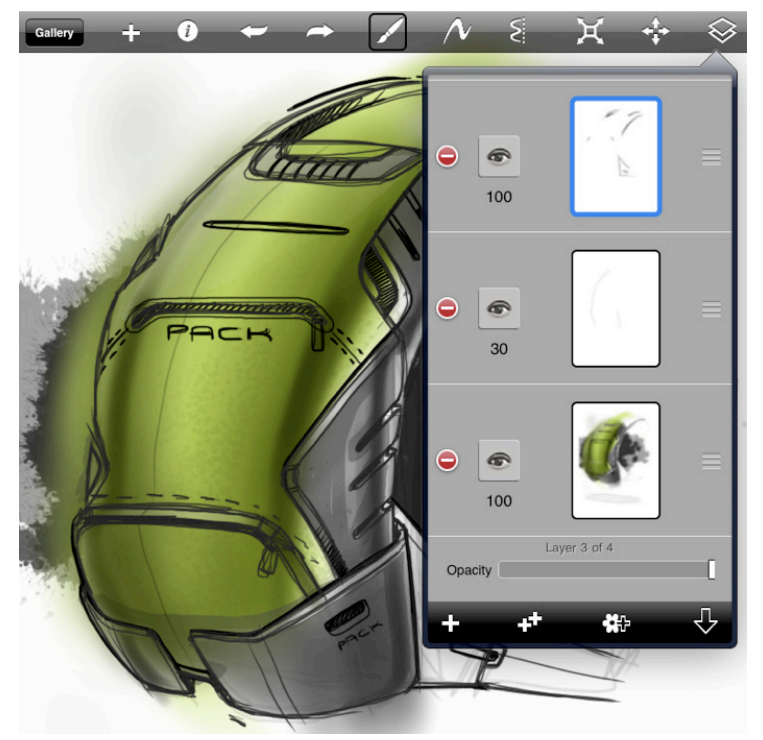

Figure 3-6: Screenshot that illustrates the use of layers in SketchBook Pro application for iPad (Idsketching, 2010)

On the positive side, SketchBook Pro in the iPad facilitates symmetrical sketching and is considered to have a simple interface when it comes to applying colours (Idsketching, 2010) (Figure 3-7). It mimics the pressure sensitivity that the iPad does not provide by the generation of faux taper to the lines (Idsketching, 2010).

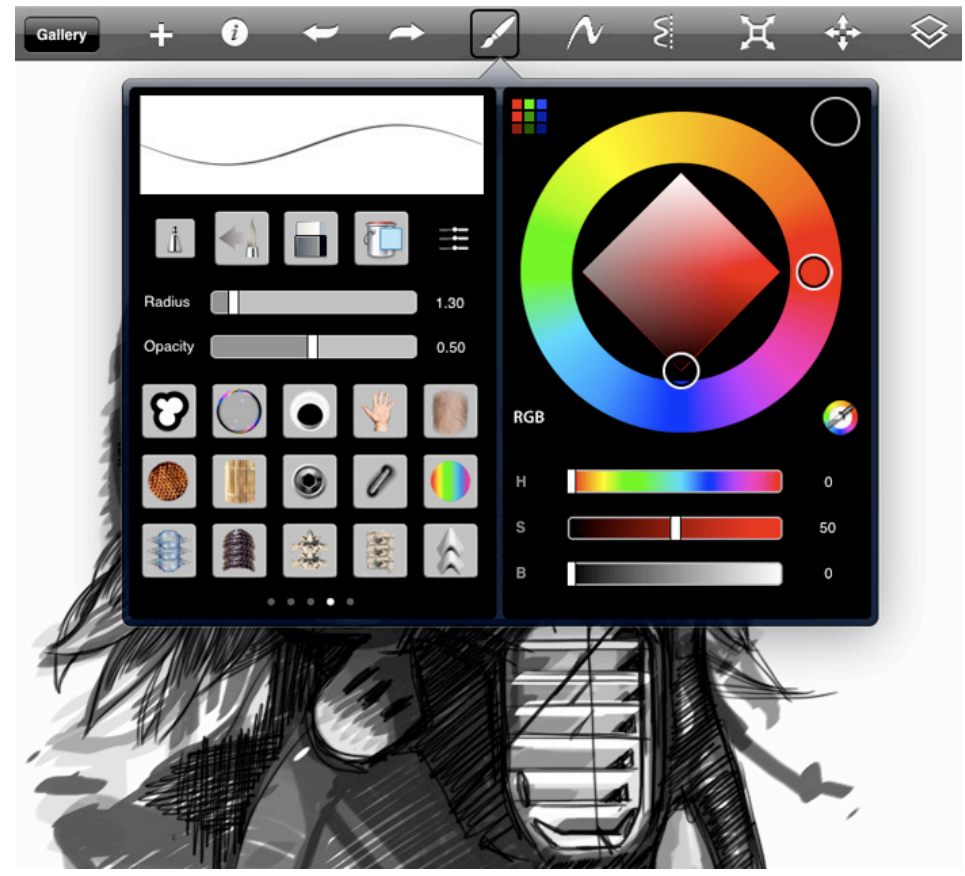

Figure 3-7: Screenshot of SketchBook Pro interface for iPad (Idsketching, 2010)

InkBoard is an emerging application for Tablet PCs that facilitates collaborative network sketching between industrial designers (Ning et al., 2004: 5, Microsoft, 2004: 5). It supports 
a group of users working on the same sketch in real-time and allows the sequence of strokes to be replayed using the timeline feature (Ning et al., 2004: 5). The use of various colours within the software helps differentiate the work done by each participant (Microsoft, 2004: 5). The interface includes a main drawing area and list of 10 buttons to avoid the use of a keyboard (Ning et al., 2004: 5) (Figure 3-8). The user has to sign in using the stylus to log into the program that employs conference technology to facilitate the interaction of up to four users at a time (Ning et al., 2004: 5-7). InkBoard has potential for use within a design teaching environment and an experimental version of the software can be downloaded from MIT (http://ender.mit.edu/inkboard/) (Ning et al., 2004: 7). As professional design practice has more collaborative nature, InkBoard might be more beneficial for industry than student design practice.

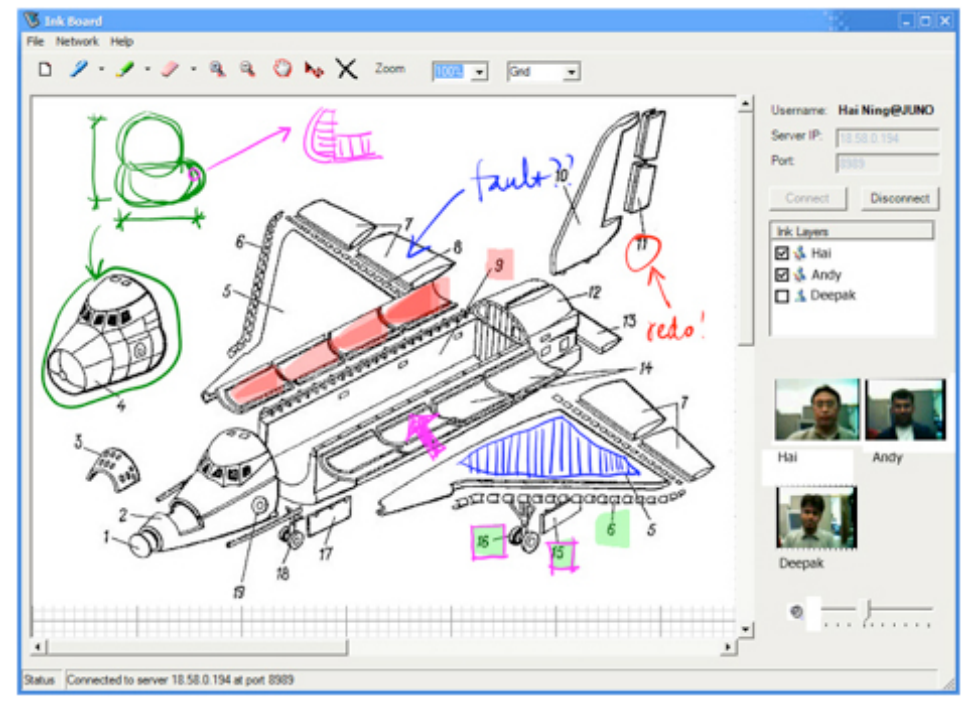

Figure 3-8: InkBoard main user interface (Ning et al., 2004: 5)

\subsubsection{Pen Input Device}

Compared to digital tablets, digital pens offer more portability and convenience (Cheng and Mckelvey, 2005: 291). An example of a digital pen and paper is the Anoto digital pen and paper. The Anoto pen can be used with any paper type as long as it has a pattern of dots printed on top to enable the gathering of data on the position of the pen (Koutamanis, 2005: 323, Sener, 2004: 99). The pen is equipped with a camera that captures what is being written or drawn on the paper (Anoto, 2010a) (Figure 3-9). The captured data is then stored within the pen memory and can be transferred to a computer wirelessly using Bluetooth or a USB port (Anoto, 2010b). When assessing the use of Anoto technology within architecture, users noted its limitations in terms of stroke weight and pen orientation (Koutamanis, 2005: 
324). Furthermore, the camera did not capture the strokes when users sketched at an angle lower than 60 degrees (Koutamanis, 2005: 324).

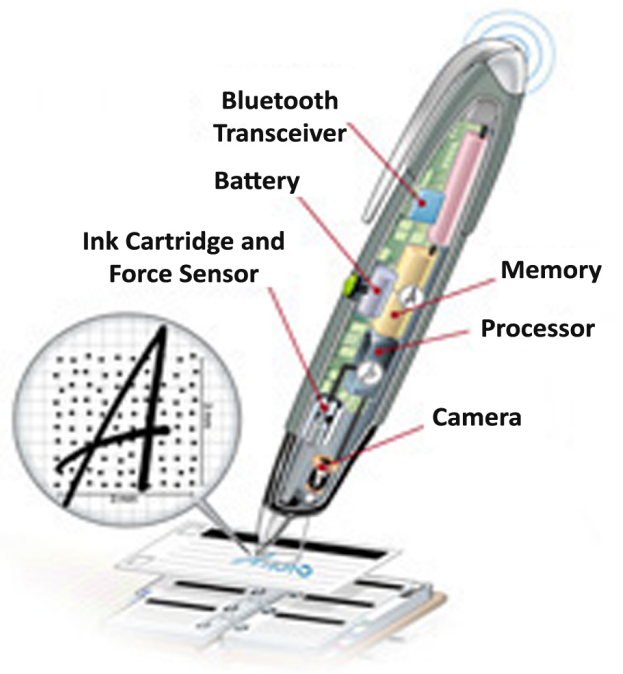

Figure 3-9: Anoto pen (Anoto, 2010a)

The Logitech lo digital pen uses Anoto digital technology and can be used to record the strokes of sketching activity. Researches have reported on its capacity to trigger memories of the drawing and thinking process when playing back the video (Cheng, 2004: 393).

Another system is the e-pens, which allows data to be captured while writing/sketching on normal paper, without requiring a pattern of dots (e-pens, 2010b: 1). The device can be used as a pen and a mouse when connected to the computer via a USB cable (e-pens, 2010b: 1). The e-pens has a base unit that should be attached to the top of the paper while using the pen to enable it to capture data (e-pens, 2010b: 2) (Figure 3-10).

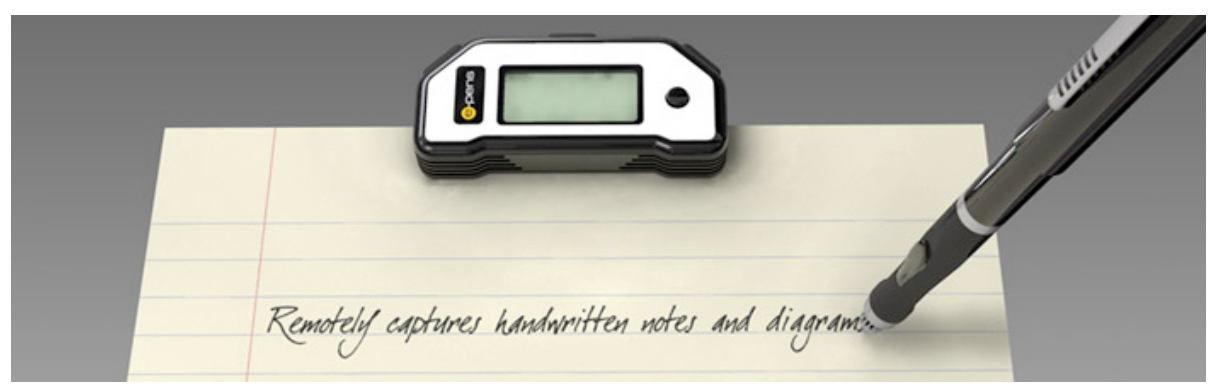

Figure 3-10: Digital ink pen and e-pens base unit (e-pens, 2010a)

It is important to note that these digitising pens, plus the iNote and Nokia Digital Pen, have not been specifically produced for use by industrial designers. In addition, the digitising pens 
use within design practice has not been evaluated so there is uncertainty about their contribution.

\subsubsection{Digital Design Journal}

Designers use design logbooks/journals/sketchbooks to record ideas, information and thoughts (Oehlberg et al., 2009: 239, Hoeben and Stappers, 2005: 409). Logbooks are normally paper-based notebooks or a range of individual sheets attached together using a binder (McAlpine et al., 2006a: 492-498). They are used to document information throughout the entire design process beginning at the point of inspiration for personal record and as a reminder of the work in progress (Hoeben and Stappers, 2005: 409, McAlpine et al., 2006a: 483-491). The information recorded can be in the format of notes or sketches (McAlpine et al., 2006a: 483), which enables understanding of the design (McAlpine et al., 2006a: 485). "Logbooks may contain considerably more than design rationale (for example, contact information, calculations, notes of meetings and notes not related to design activities, etc.)" (McAlpine et al., 2006a: 484).

Logbooks provide an opportunity to illustrate the background research; understand the design thinking behind a concept; and collate notes and sketches in a single source when undertaking the design activity (McAlpine et al., 2006b: 565). They are "valued for their legal authority in providing proof of invention for the purpose of securing and maintaining patent rights for the designs contained therein" (Currano and Leifer, 2009: 9-323).

In academia, students' logbooks usually contain ideas, sketches, important information, annotations, images, reflection and thoughts addressed during the entire duration of the design project (Product Design Forums, 2007). Students are asked to employ logbooks to demonstrate their progress in the design project (Middle East Technical University, n.d.). Students are required to submit their logbooks to be marked by the end of their project. Logbooks play an important role when writing reports as they remind the student about decisions made and the important issues addressed (Middle East Technical University, n.d.).

Digital logbooks allow designers to access information and ideas stored wirelessly and support the management of data (Oehlberg et al., 2009: 238). They facilitate collaboration over the Internet between members of a design team while permitting users to engage with multimedia (Oehlberg et al., 2009: 239). McApline et al. (2006b: 569) state that digital logbooks provide "immediate and substantial advantages for specific tasks, particularly the embedding of complete computer models, large data sets and dynamic content, more 
effective searching, and better support for multiple authors and sharing/collaboration in a distributed environment" (McAlpine et al., 2006b: 569)

Microsoft Journal facilitates digital hand-written notes and the embedding of images (Frolik and Zurn, 2004: 2) but does not allow the incorporation of URL links (Frolik and Zurn, 2004: 4) (Figure 3-11). It offers a search facility for specific hand-written words and the speed of note taking is not affected by the use of the software (Frolik and Zurn, 2004: 4). Diagrams can be produced and information can be copied and pasted in a number of colours (Frolik and Zurn, 2004: 4). Windows Journal has been identified as being useful when making design notes in student design practice and it facilitates the distribution of notes when required (Microsoft, 2004: 2).

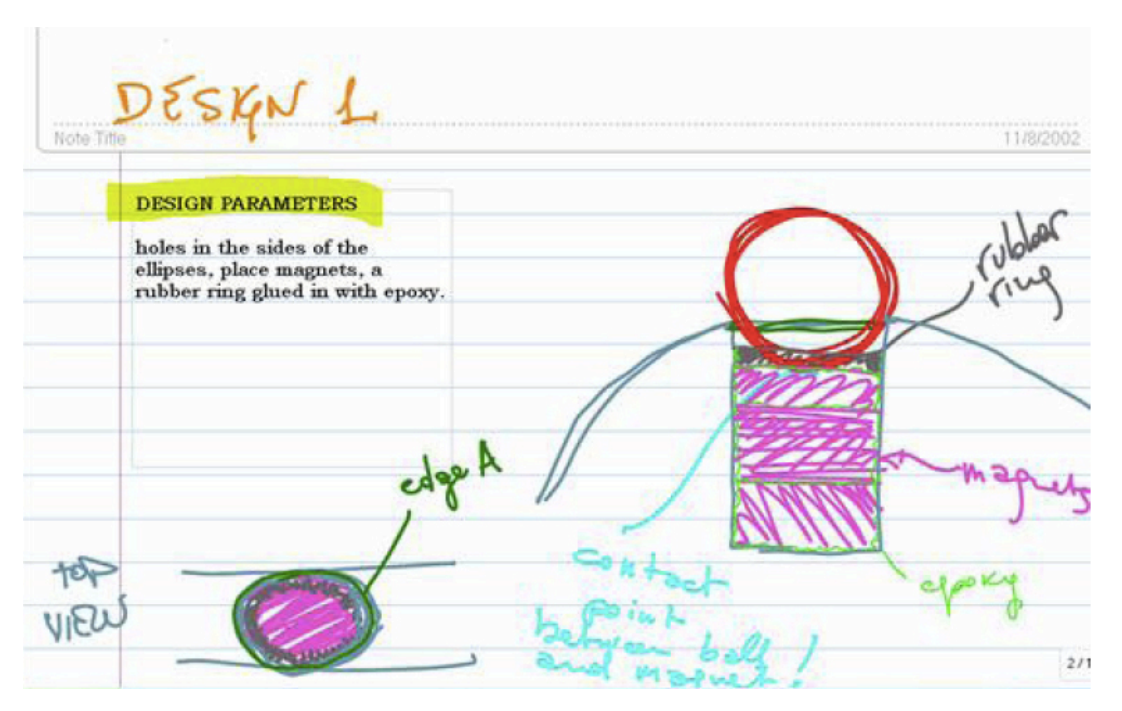

Figure 3-11: Windows Journal used by MIT mechanical design students for collaborative design work (student work is colour coded) (Microsoft, 2004: 3)

The Digital Sketchbook is a project developed by Delft University of Technology to support the externalisation of ideas and dialogues (Hoeben and Stappers, 2005: 408). The Digital Sketchbook is in the size of an A5 book and combines a readily available Tablet PC with the Digital Sketchbook software that was developed by the University to aid sketching and browsing ideas (Hoeben and Stappers, 2005: 409-410) (Figure 3-12). It has a relatively simple interface and the application uses only five pen styles selected by the designer (Hoeben and Stappers, 2005: 410-411). The software allows page browsing through the use of a thumbnail-slider (Hoeben and Stappers, 2005: 411). While the Digital Sketchbook has been shown to have a positive effect on productivity, especially in the first six months of use, results indicated that the size of the display and pen limit the number of sketches produced on one page (Hoeben and Stappers, 2005: 412). Furthermore, the digital sketchbook does 
not offer more than conventional techniques when meeting clients (Hoeben and Stappers, 2005: 412).

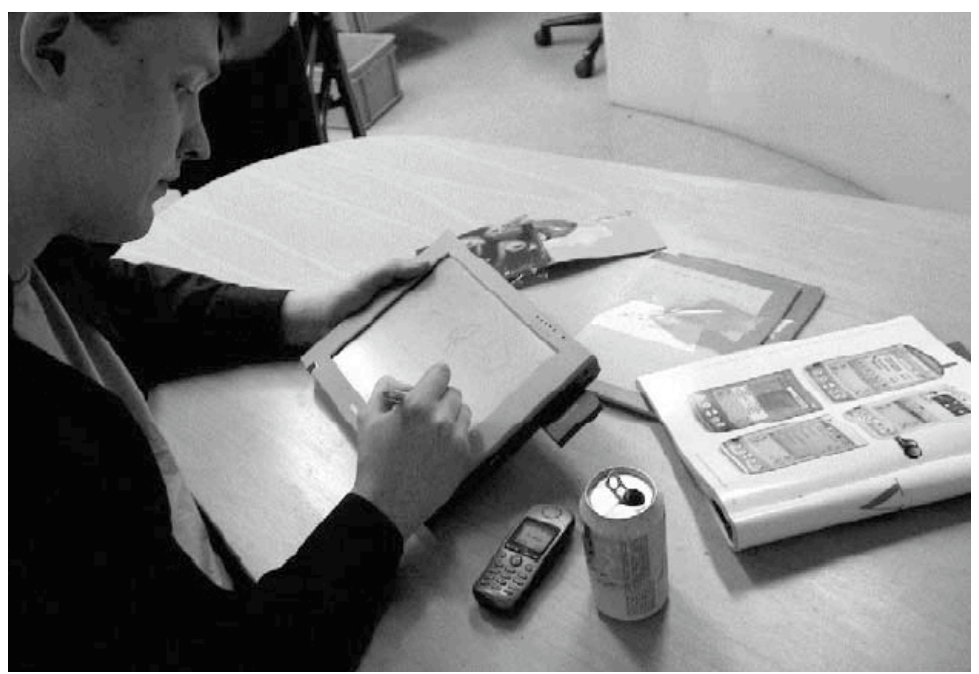

Figure 3-12: The Digital Sketchbook prototype (Hoeben and Stappers, 2005: 410)

\subsubsection{Computer Aided Sketching (CAS)}

Company et al. (2009: 592) argue that paper-based sketching is "disconnected from the rest of the design process". The rationale behind this is that the output of conventional paperbased sketching does not help when designers move to CAD as they usually find themselves forced to start the modelling process all over again. This lead to the development of CAS tools that integrate with the subsequent phases of CAD (Company et al., 2009: 592). However, Company et al. (2009: 600) conclude that even though CAS is viable, it still needs refinement to improve its limited capabilities with curved surfaces or free-form curves.

\subsubsection{Hybrid Ideation Space (HIS)}

HIS was developed to enable designers to have reflective conversations with their representations while generating ideas individually or in a team (Dorta et al., 2008: 121122). The system puts the designer inside the representation through the use of immersive sketching and immersive model making with the option of using digital or conventional tools (Dorta et al., 2008: 125). It consists of a spherical mirror that allows immersive projection (Dorta et al., 2008: 125) (Figure 3-13). The HIS was tested with small sample of three interior designers and one industrial designer (Dorta et al., 2008: 132) (Figure 3-14). While the industrial designer experienced considerable frustration and anxiety as he was not able to create accurate representations, Dorta et al. (2008: 138) concluded that HIS enhances ideation by providing a high design flow for interior designers. 
As industrial design practice mainly deals with products that would fit on top of a table, immersing into design representations using HIS might not be seen as useful as it is for other fields of design such as interior design and architecture design.

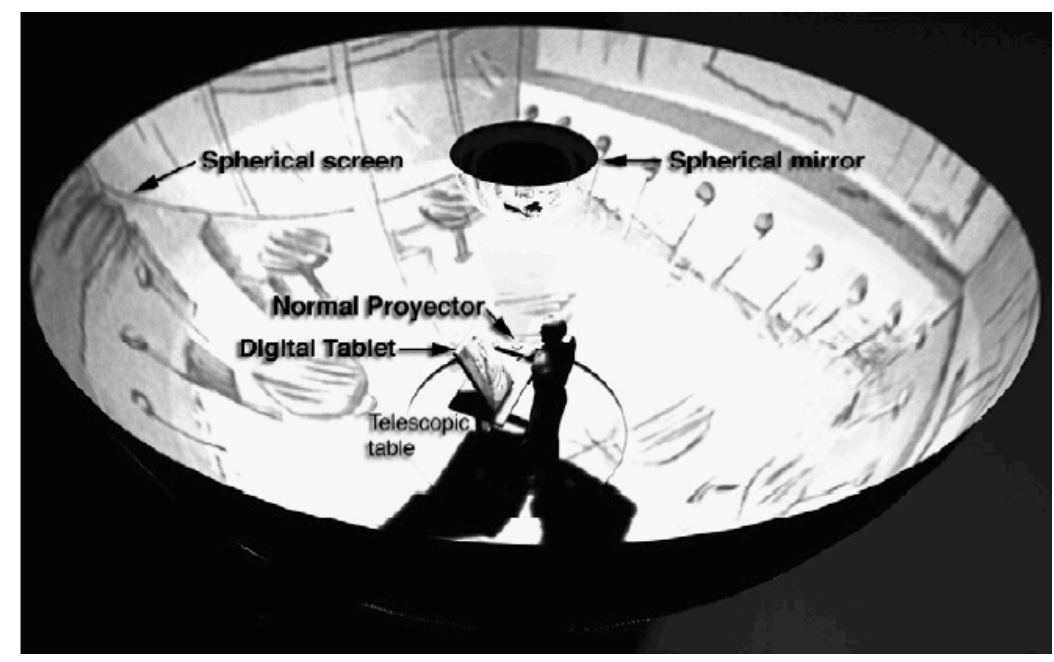

Figure 3-13: The HIS (Dorta et al., 2008: 126)
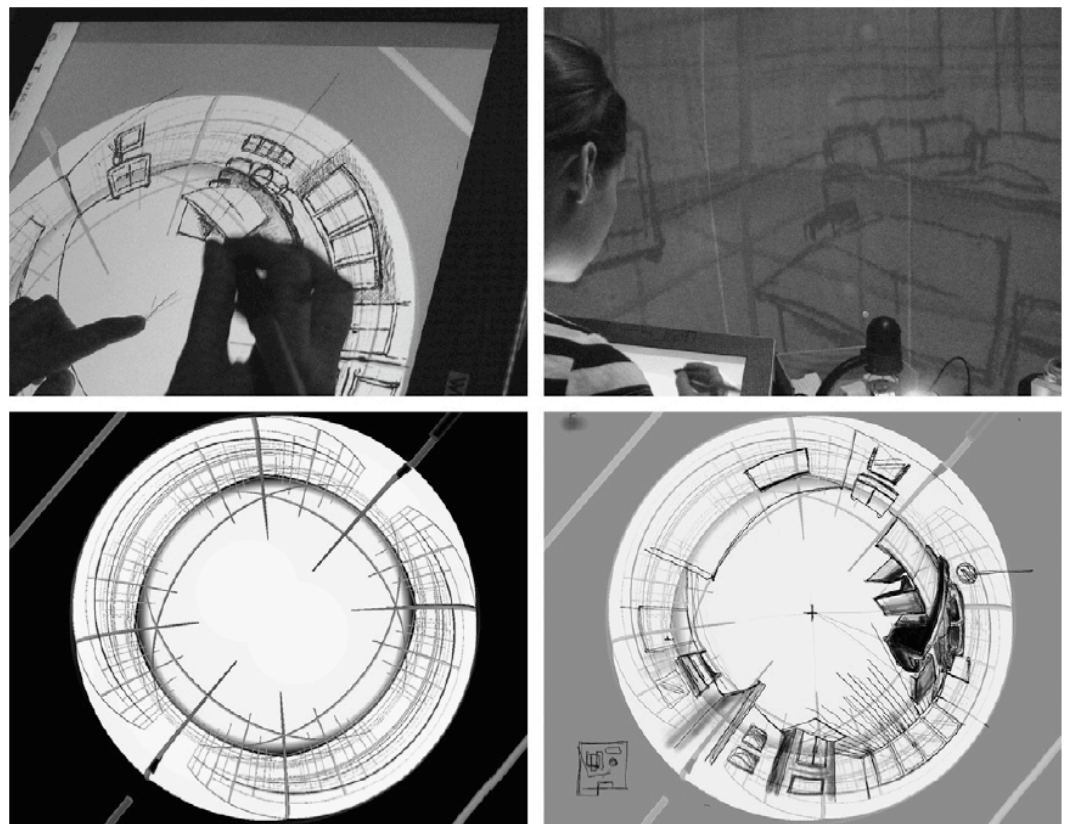

Figure 3-14: Immersive sketching in action within the HIS system (Dorta et al., 2008: 127)

\subsubsection{3D Sketching System}

ILoveSketch is an example of a sketch-based 3D curve modelling system developed by the University of Toronto to ease the designers transition from 2D sketches to 3D models (Bae et al., 2008: 152). The system utilises a pen input device to maintain a sketch-like workflow while enabling designers to produce 3D curve networks (Bae et al., 2008: 151) (Figure 3-15). 
The system provides a similar experience to paper-based sketching as it uses a set of gestures to enable flipping, tearing, rotating, panning and zooming (Bae et al., 2008: 152). The system is simple and does not use menus or tool palettes in an attempt to allow the designer to concentrate on sketch activity (Bae et al., 2008: 152). Feedback on the tool was generally positive regarding the ease and intuitive nature of making 3D curves for modelling, but some features were regarded as drawbacks, such as the automatic rotation of paper (Bae et al., 2008: 157).

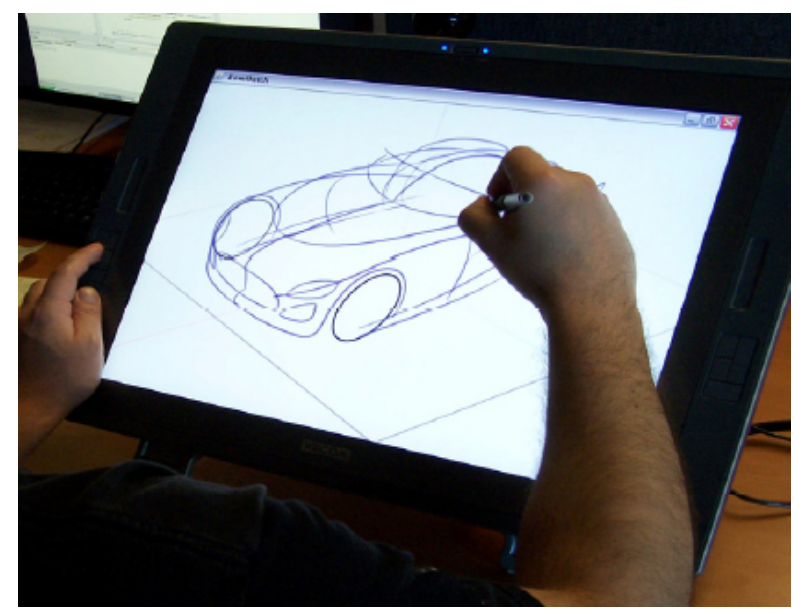

Figure 3-15: ILoveSketch used by a professional designer (Bae et al., 2008: 151)

Another example of a 3D sketching interface is the Napkin Sketch that allows 3D sketches to be projected on top of a physical napkin-size piece of paper (Xin et al., 2008: 223) (Figure 3-16). The system consists of a Tablet PC with a camera attached to capture video of the physical space. Before sketching, users have to define the surface they are going to sketch in the physical space (napkin). They then sketch on the Tablet PC with the sketch being projected in 3D on the physical napkin (Xin et al., 2008: 224). When evaluated by a number of users, the system proved to support a natural sketching experience that was similar to pen and paper (Xin et al., 2008: 225). However, results also indicated difficulties when sketching in perspective and trying to connect lines (Xin et al., 2008: 225). 


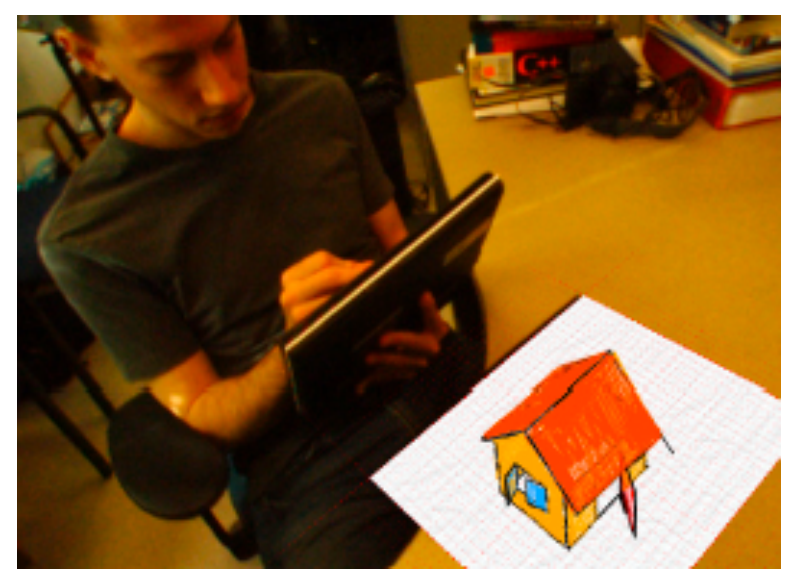

Figure 3-16: The Napkin Sketch system that creates 3D sketches on top of a physical napkin (Xin et al., 2008: 223)

\subsubsection{Digital Modelling/Prototyping Tools/Media}

Digital modelling/prototyping tools/media focus mainly on transferring the $2 \mathrm{D}$ concepts generated using digital sketching tools/media to 3D digital models on screen or to physical 2D/3D models/prototypes. Digital models "offer distinct advantages in terms of the ease of repetition and scaling of some design elements, or the quick generation of perspective or axonometric projection, or even the rendering of the model in various lighting or light energy algorithms. These modelling techniques may offer advantages in terms of the speed of generating and changing three-dimensional forms" (Kvan et al., 2004: 7-8). The digital tools/media that facilitate producing models and prototypes will now be discussed.

\subsubsection{3D Mouse}

As well as functioning as a traditional 2D mouse, a 3D mouse provides opportunities to rotate, zoom and pan a 3D model by twisting, elevating and pressing movements (3Dconnection, 2010) (Figure 3-17). It is a valuable tool when dealing with 3D CAD models as it eases navigation and interaction (Pipes, 2007: 98).

A range of 3D mouse input devices are currently available. The selection varies in terms of complexity, from being a controller cap (such as the SpaceNavigator), to the SpacePilot PRO 3D which has more advanced functionalities (3Dconnection, 2011) (Figure 3-18). The SpacePilot PRO has six degrees of freedom sensing and employs an LCD to assist with navigation (3Dconnection, 2011). It provides access to 32 views and has five customisable buttons (3Dconnection, 2011). 


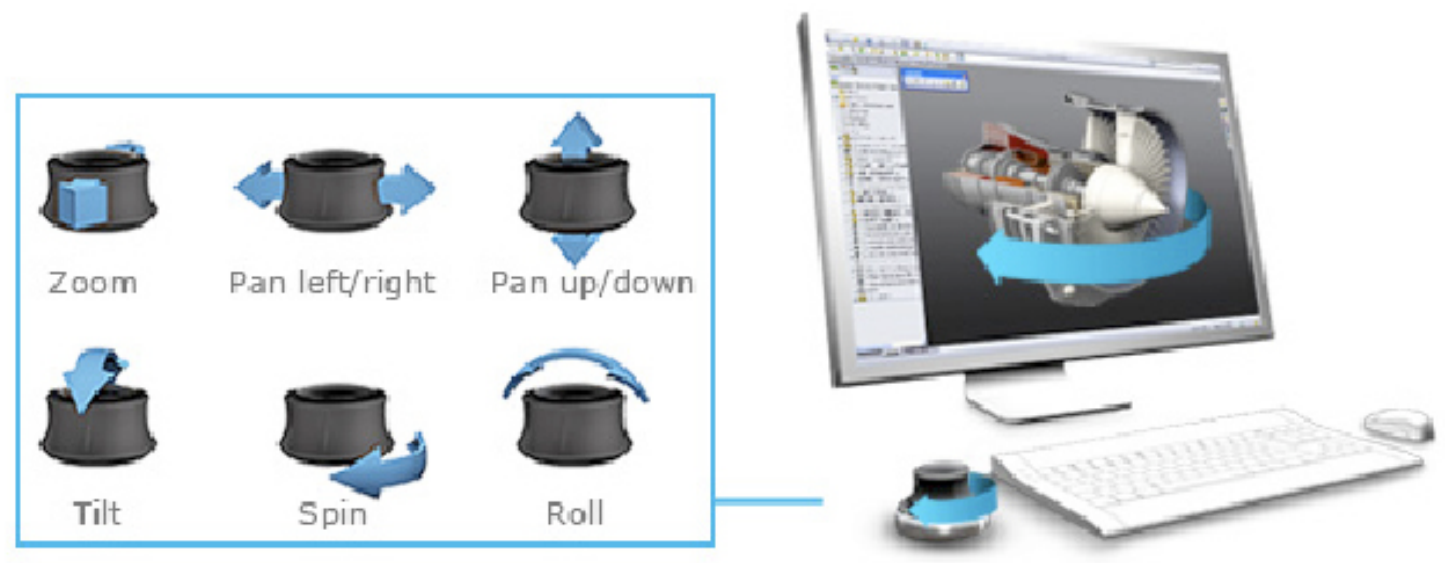

Figure 3-17: SpaceNavigator 3D mouse movements (3Dconnection, 2010)

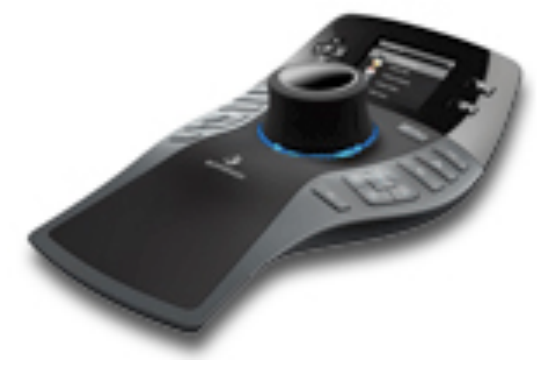

Figure 3-18: SpacePilot PRO 3D mouse (3Dconnection, 2011)

\subsubsection{Computer Aided Design}

The use of CAD is widespread within industrial design practice (Schodek et al., 2005: ix). In its early days, it was used to produce wireframe models that defined the edges of objects through the construction of points, lines and curves (Schodek et al., 2005: 6). CAD systems then developed to include surface (Shih, 2009: 5-2, Schodek et al., 2005: 6). While surface models can be used for visualisation when rendered, neither of these model types is suitable for streaming activity as they lack the thickness, mass and weight (volume) that exists in solid models (Shih, 2009: 5-2, Schodek et al., 2005: 6). Industrial designers use surface modelling software as it is more flexible when creating organic forms (Figure 3-19), while engineers tend to use solid modelling software because it is more precise (Hartman, 2004: 121) (Figure 3-20). Examples of surface modelling software are Alias Studio Tools and Rhino, while Pro/Engineer and SolidWorks are solid modelling software (Shin, 2009: 4). 


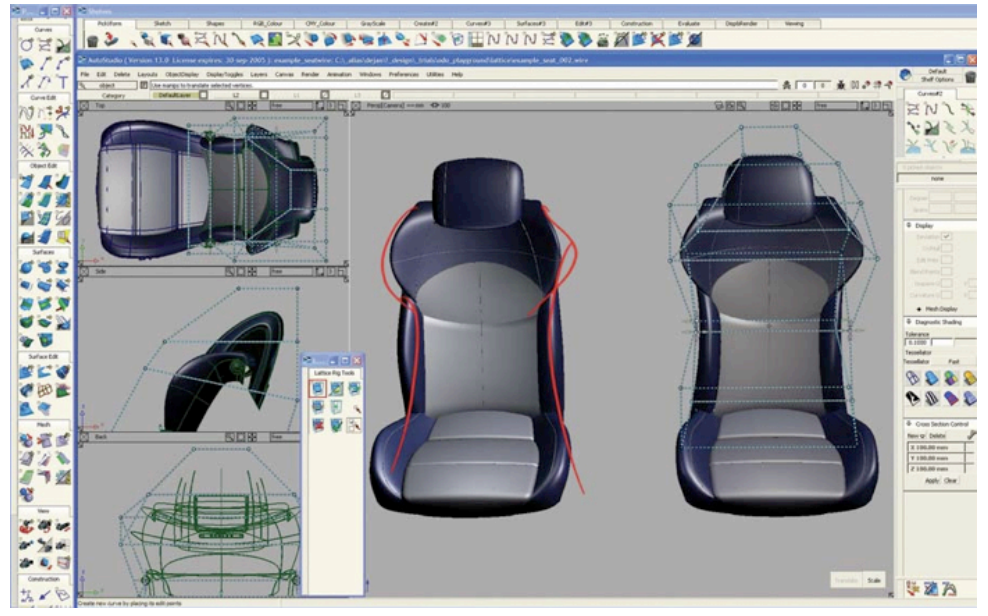

Figure 3-19: Screenshot of a 3D car seat concept modelled using Alias Studio Tools (IDSA and Hudspeth, 2006)

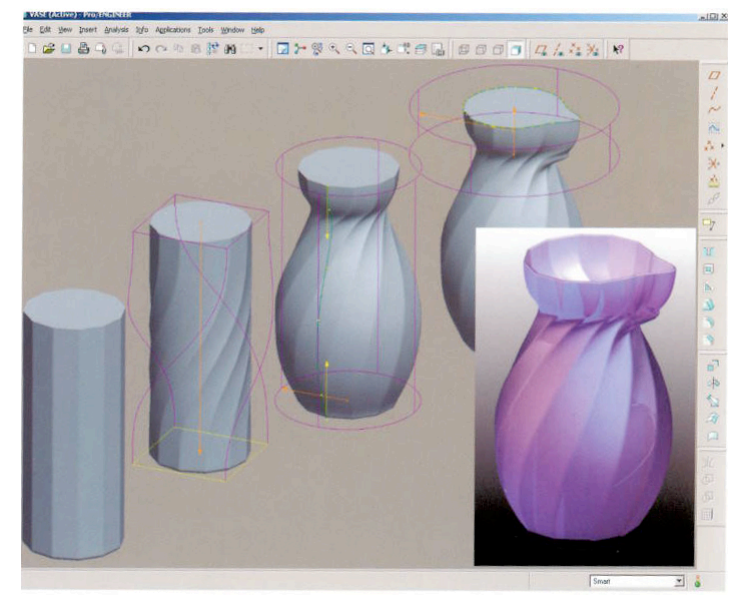

Figure 3-20: Screenshot of Pro/Engineer of a rendered vase (Pipes, 2007: 122)

The term 'computer aided industrial design (CAID) software' is commonly used to describe software that was designed specifically for industrial designers by effectively supporting the definition of form and high quality rendering (Ye et al., 2008: 3, Westin, 1998: 49, Evans, 2004: 68, Sener and Wormald, 2001: 358). Table 3-2 highlights the difference in the characteristics of CAD and CAID software.

\begin{tabular}{|l|l|}
\hline \multicolumn{1}{|c|}{ CAD software } & \multicolumn{1}{c|}{ CAID software } \\
\hline $\begin{array}{l}\text { 1. Offers more constraints and precision } \\
\text { 2. Less suitable for creating organic shapes }\end{array}$ & $\begin{array}{l}\text { 1. Allows modifications to be easily applied } \\
\text { 3. The material library focuses on engineering } \\
\text { parameters for engineering computation }\end{array}$ \\
& $\begin{array}{l}\text { 2olour } \\
\text { 3. Creates high quality renderings for } \\
\text { presentation }\end{array}$ \\
\hline
\end{tabular}

Table 3-2: Comparison between CAD software and CAID software (Ye et al., 2008: 3) 
Parametric 3D CAD systems share four common characteristics. These are: any operation made would be saved as a feature; dimensions and geometric constraints set the parameters; features and parameters are recorded in the history to facilitate changes at any time; and allowing design variables to drive the parameters when needed (Ye et al., 2008: 3).

Advanced 3D CAD modelling software facilitates digital analysis and simulations to increase efficiency and reliability (Hodgson, 2006: 12, Yan et al., 2006: 4). Finite element analysis, for example, assess the forces and stress on the 3D CAD models and presents the data in various colours on the model (Santos et al., 2005: 1, Hodgson, 2006). Computational Fluid Dynamics (CFD), through software such as Autodesk Moldflow, simulates the way in which material fills the mould tool (Hodgson, 2006: 12). This software also has the capacity to suggest the most suitable location to feed the material from and the area that will require a riser (Hodgson, 2006: 13). Figure 3-21 shows the use of Autodesk Moldflow software when designing.
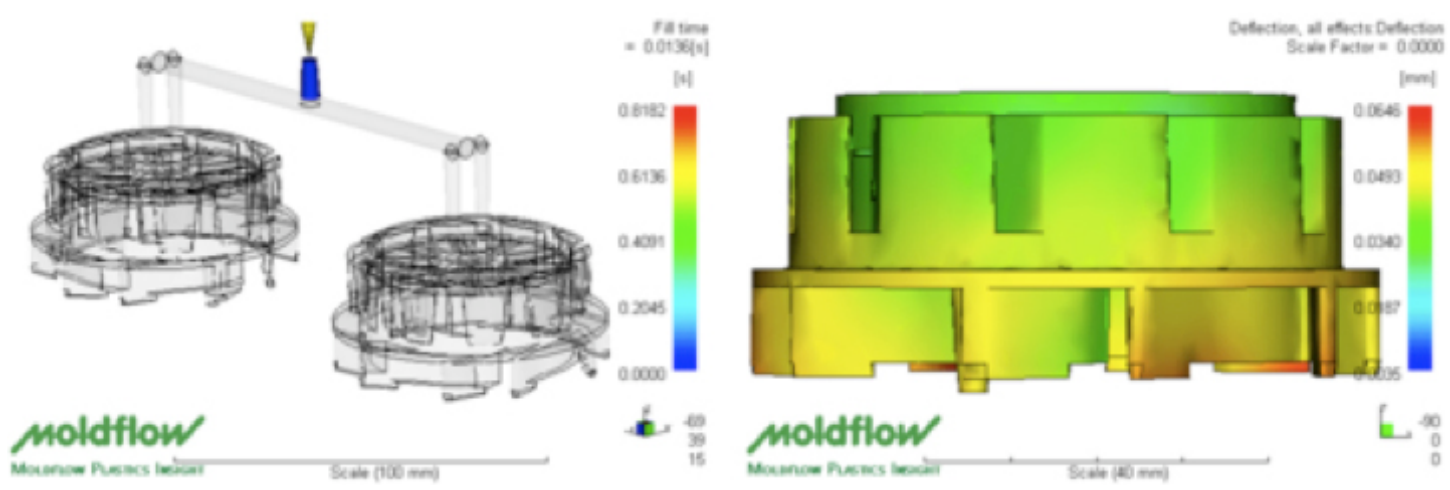

Figure 3-21: Use of Autodesk Moldflow software to design a water meter by Arad (Wilde, 2011)

Poylgon modelling is a 3D computer graphics application. A polygon is a plane with a minimum of three sides (Merriam-Webster Online Dirctionary, 2009). It is mainly used in computer games design (low poly models), for realistic rendering, and by film makers (McGregor, 2008: 2) (Figure 3-22). When using polygon modelling, a 3D model can use a minimum number of faces (McGregor, 2008: 2) so the files tend to be small in size which makes them suitable to use with virtual reality (VR).

3D polygon modelling software varies in complexity (McGregor, 2008: 1). Autodesk Maya, Autodesk Studio Max and Maxon Cinema 4D are examples of polygon modelling software 
(Isenburg and Alliez, 2002: 141, McGregor, 2008: 1). Despite this capability for visualisation and rendering, Kuhnen (2009: 1) states that "polygons are in general ignored in industrial design because of their lack of precision. Also trimming is not yet possible with polygons".

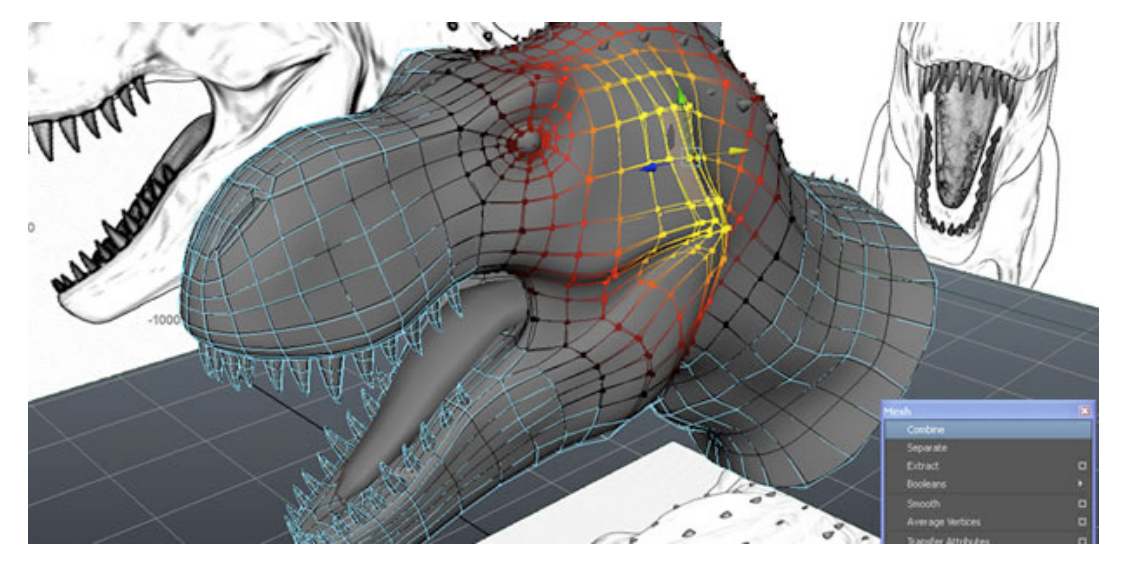

Figure 3-22: Polygon meshes in a 3D dinosaur head modelled in Autodesk Maya (Autodesk, 2011a)

\subsubsection{3D Scanning/Reverse Engineering (RE)}

3D scanning/digitising is "the process of gathering data from an undefined threedimensional surface" (Sokovic and Kopac, 2006: 400). It was generated to avoid the expense of generating a 3D CAD model from scratch (Willis et al., 2007: 1174). When the scanning process takes place, the scanning probe moves forwards and backwards while recording surface information to produce a point cloud matrix (Sokovic and Kopac, 2006: 400). The scanning process can take place without contact with the object by using a laser or by making physical contact via an articulated robotic arm (Sokovic and Kopac, 2006: 401, Willis et al., 2007: 1175). Willis et al. (2007: 1176) point out that the internal hidden parts of the product are difficult to capture with 3D scanning and clear or translucent surfaces lead to illdefined meshes.

Reverse engineering is a digital method that is gaining more popularity within design (Yan et al., 2006: 1, Sokovic and Kopac, 2006: 398). The aim of RE is to create a 3D CAD replica of physical objects that can be used for downstreaming operations (Schodek et al., 2005: 14, Ye et al., 2008: 5) that are undertaken towards the end of the design process; i.e. "closer to the point of sale" after production and manufacture (American Heritage Dictionaries, 2000). Designers mainly use RE when a CAD model is not available (Schodek et al., 2005: 14). RE software outputs data as surface models, but the freeform surfaces created are usually not 
detailed enough for downstreaming and do not express the deign entirely (Ye et al., 2008: 2).

RE involves the following sequence of operation: 3D scanning of objects to create a point cloud or mesh models; repairing the data; and reconstructing the surfaces (Sokovic and Kopac, 2006: 400, Ye et al., 2008: 5, Yan et al., 2006: 1) (Figure 3-23). The output of RE is typically surfaces that have to be put together by sewing, trimming or extending to create solid 3D models (Ye et al., 2008: 5).

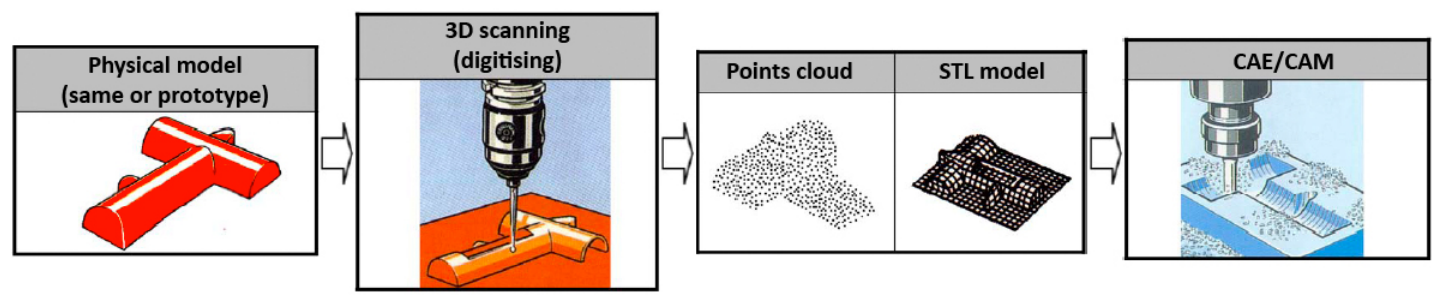

Figure 3-23: Example of sequences in reverse engineering (Sokovic and Kopac, 2006: 401)

\subsubsection{Haptic Modelling}

Haptic technology facilitates the integration of conventional hands-on model making skills within a digital environment by allowing a designer to touch, feel and manipulate 3D digital models (Bordegoni et al., 2006: 378, Ye et al., 2006: 84).

SensAble Technologies were the first company to introduce a commercialised haptic device called the PHANTOM (Bordegoni et al., 2006: 378). The SensAble PHANTOM offers three to six degrees of freedom sensing (Pipes, 2007: 99, Bordegoni et al., 2006: 378) and can be used with FreeForm which is the only software currently available to produce 3D models using a digital clay (Bordegoni et al., 2006: 379) (Figure 3-24). Other haptic devices are available, such as HapticMaster, Sarcos Dextrous ArmMaster, CyberForce and PERCRO, but SensAble PHANTOM is the most commonly used (Bordegoni et al., 2006: 378-379). A number of companies have utilised SensAble FreeForm in their design practice, for example Black \& Decker, Converse and Gillette (SensAble Technologies, 2010b) (Figure 3-25). 


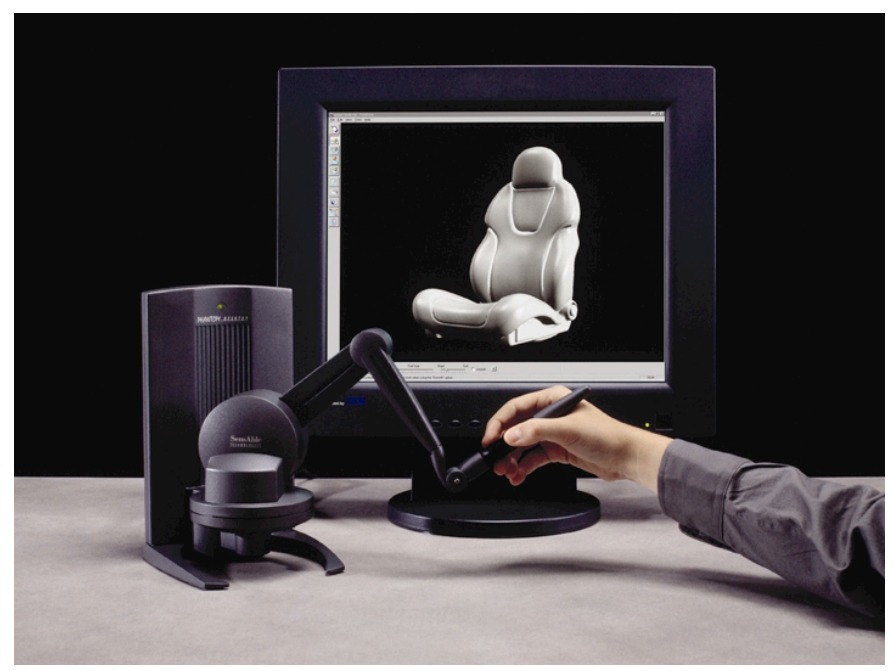

Figure 3-24: The SensAble PHANTOM haptic device (SensAble Technologies, 2010a)

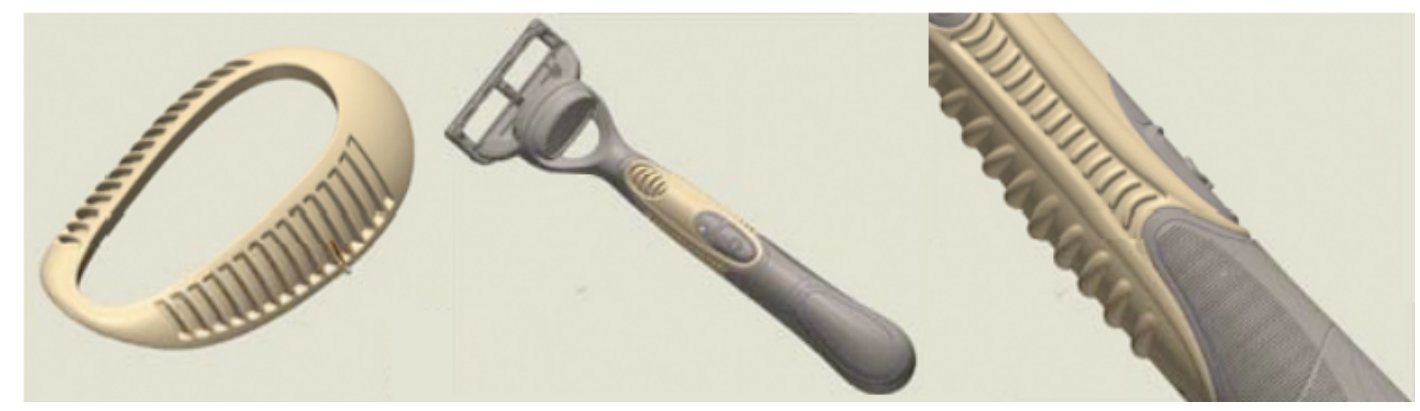

Figure 3-25: FreeForm virtual clay models of handle design and grip pattern of a razor produced by Gillette (SenSAble Technologies, 2006)

Using FreeForm modelling software with a SensAble PHANTOM enables designers to engage in tactile interaction with form, but also editing the model in real-time and easily correct mistakes (Evans et al., 2005: 501). The surface hardness of the clay models and its texture can be easily changed and it is possible to "work from inside out by pulling and deforming the shape" (Bordegoni et al., 2006: 379). Furthermore, the opportunity to interact with form can influence the decision-making (Evans et al., 2005: 488).

Evans et al. (2005: 506) conclude their study on the use of haptic feedback modelling within industrial deign practice by stating that it offered limited contribution to practice. Designers are used to a multisensory process that supports direct hands-on model making. When using haptic feedback modelling, designers struggle to get used to the tool and its feedback forces (Bordegoni et al., 2006: 379). Haptic feedback modelling does not facilitate creating geometrically smooth surfaces (Evans et al., 2005: 499). In addition, a major drawback when using SensAble FreeForm and the PHANTOM haptic device for interactive sculpting is the 
low quality surface finish that prevents the file from being used directly for rendering or downstreaming operations (Bordegoni et al., 2006: 379, Evans et al., 2005: 499).

\subsubsection{Computer Numerical Control Machining}

CNC machining forms an essential and integrated part of manufacturing ( $\mathrm{Xu}$ and Newman, 2006: 141). It has "evolved from the automated machine tools of the 1960s to the modern multi-process multi-axis machining centres" (Newman and Nassehi, 2007: 459). This development resulted in the CNC machine becoming more difficult to program and its tools less adaptable (Xu and Newman, 2006: 142). Two types of CNC machining exist, these are 2D CNC cutting (such as vinyl and laser cutters) (Figure 3-26) and CNC milling (Sass and Oxman, 2006: 330) (Figure 3-27). Milling machines are based on subtracting materials to create a 3D model (Willis et al., 2007: 1176, Pipes, 2007: 102, Evans, 2002: 78).

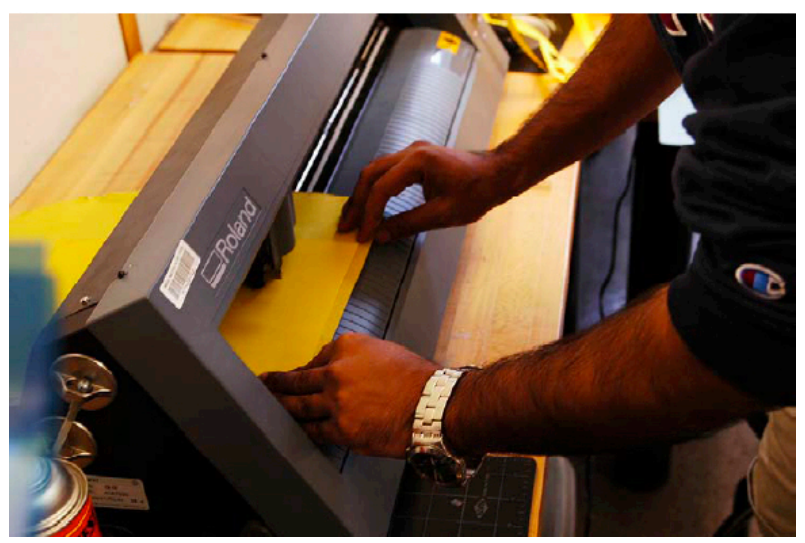

Figure 3-26: Vinyl sign cutter used to cut paper surfaces using 2D files from CAD models (Sass and Oxman, 2006: 329)

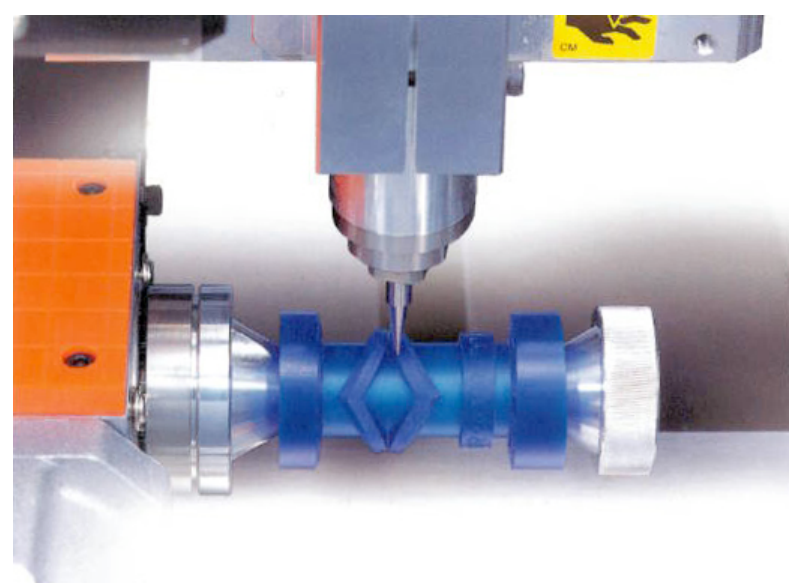

Figure 3-27: A 3D wax model being cut on a milling machine (Pipes, 2007: 102) 


\subsubsection{Rapid Prototyping}

RP makes an essential contribution to design practice (Sass and Oxman, 2006: 31). It is defined as "the use of $3 D$ computer geometry in the production of components using a layer-based additive build process in condensed time-scales" (Evans et al., 2005: 488-489). RP uses 3D CAD models as an input to produce physical models (Willis et al., 2007: 1176). The process of RP involves creating a 3D CAD file and saving it in STL format (a series of small triangular planes); automatically slicing the $3 \mathrm{D}$ model into layers (five to ten layers in a millimetre); and building the model layer by layer using the chosen material to form a 3D object (Pipes, 2007: 102, Yan et al., 2006: 2).

A range of RP systems are commercially available, with examples of built components seen in Figure 3-28 and Figure 3-29. Table 3-3 illustrates a classification of RP systems based on build materials.

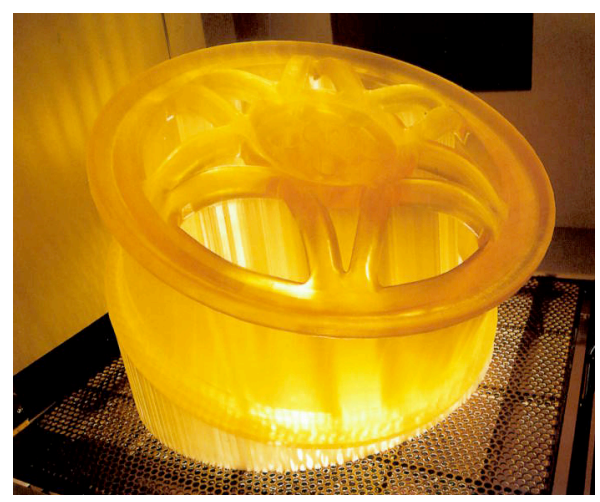

Figure 3-28: Automobile wheel prototype being created on a 3D Stereolithography machine (Pipes, 2007: 103)

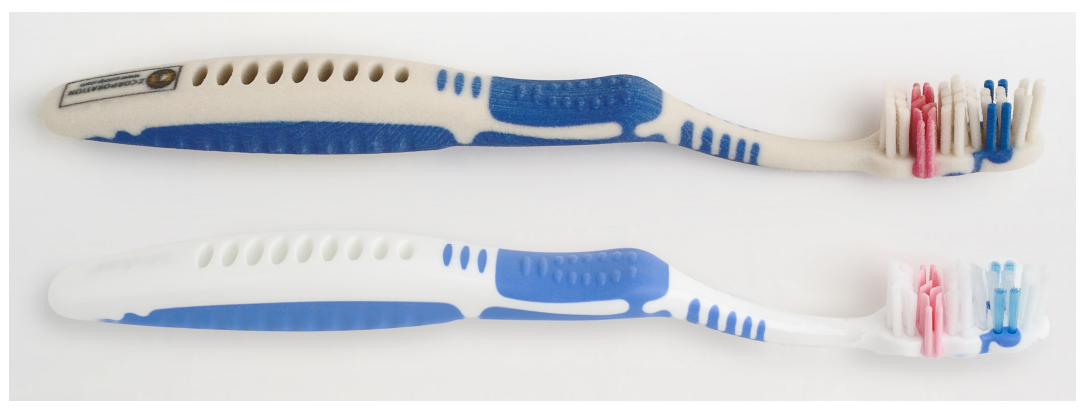

Figure 3-29: Toothbrush produced in colour using Z Corporation printing (top toothbrush) compared to the real product (Z Corporation, 2010) 


\begin{tabular}{|c|c|c|}
\hline \multicolumn{3}{|c|}{ RP systems } \\
\hline 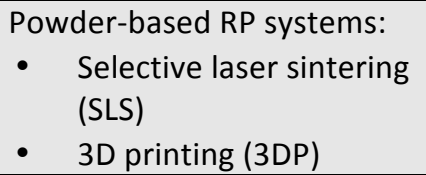 & $\begin{array}{l}\text { Resin-based RP systems: } \\
\text { - } \quad \text { Stereolithography } \\
\text { apparatus (SLA) }\end{array}$ & $\begin{array}{l}\text { Laminated sheet-based RP } \\
\text { systems: } \\
\text { - Laminated object } \\
\text { manufacturing (LOM) }\end{array}$ \\
\hline
\end{tabular}

Table 3-3: Classification of rapid prototyping systems (Choi and Chan, 2003: 237)

In industrial design practice, RP facilitates the evaluation of appearance, ergonomics and function before committing to downstream activity (Choi and Chan, 2003: 237). RP plays an important role in producing the tooling parts required for production (Choi and Chan, 2003: 238). It shortens product development lead times (Yan et al., 2006: 2, Evans, 2002: 102, Sener, 2004: 50) and facilitates the cost construction of complex forms (Sass and Oxman, 2006: 328, Shih, 2006: 137, Yan et al., 2006: 2). Furthermore, the price of the model does not raise when increasing the complexity of the design (Evans and Campbell, 2003: 348) and it empowers students with limited hands-on skills in building physical models (Shih, 2006: 137).

On the less positive side, RP models can take extensive time to produce and large models have to be divided into parts to fit in a RP machine (Shih, 2006: 137). RP models are limited in their range of colours for build materials (Shih, 2006: 137, Burton, 2005: 32). Models produced using RP still face problems in terms of surface quality finish and dimensional accuracy (Burton, 2005: 69, Choi and Chan, 2003: 238).

\subsubsection{Virtual Prototyping}

CAD software plays an essential role for VP. The aim of VP is to create digital models with a high degree of detail to demonstrate the product's form, functions and environment which facilitates product evaluation without the need for producing physical models (Choi and Chan, 2003: 238, Sener, 2004: 52, Bell, 2010: 3) (Figure 3-30). Zorriassatine et al. (2003: 513) note the importance of VP by stating that "VP is becoming very advanced and may eventually dominate the product development process".

The process of VP typically involves assembly, interface and interaction testing (Sener, 2004: 52). VP enables designers and stakeholders to visualise and evaluate the designed product which helps to shorten product development timescales and reduces costs (Choi and Chan, 2003: 255, Munson, 2004: 2). It defines detail and allows data to be sent to manufacturers electronically (Choi and Chan, 2003: 239). VP allows the client to be integrated in the design process for feedback (Munson, 2004: 2). Compared to physical models, VP supports the use 
of various simulations on the same model and generates results immediately (Bordegoni et al., 2006: 377).

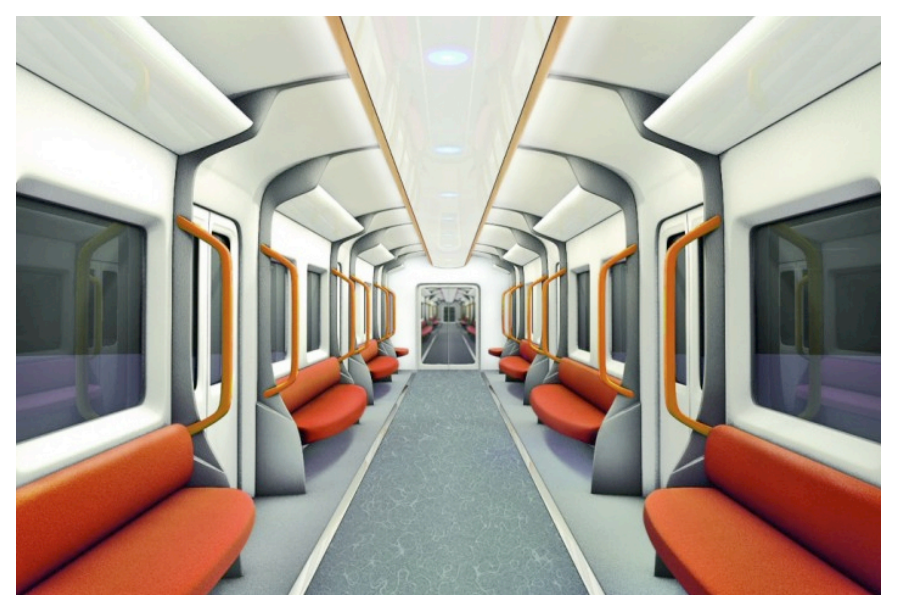

Figure 3-30: Virtual prototyping of metro interiors (Papitypes, 2010)

\subsubsection{Virtual Reality}

VR technology was introduced more than 30 years ago (Talaba et al., 2010: 361). VR is a 3D real-time believable environment that allows users to visualise and manipulate $3 D$ CAD models using interactive devices (Choi and Chan, 2003: 238, Yan et al., 2006: 2) (Figure 3-31). VR technology can simulate sound, appearance and feel (Ye et al., 2006: 78, Yan et al., 2006: 2). It can be used along with VP for further evaluation (Sener, 2004: 52) and supports the development of human user interfaces (Ye et al., 2006: 78).

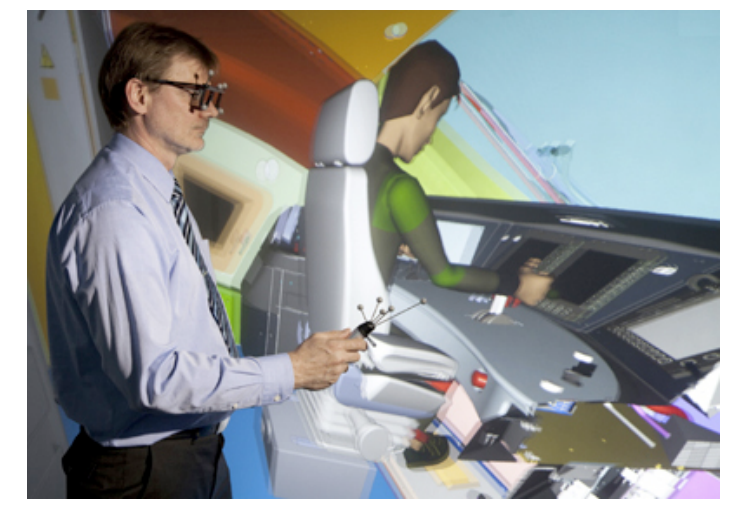

Figure 3-31: Use of virtual reality to evaluate a train (Siemens, 2010)

VR design systems are categorised into VR-enhanced 3D visualisation and analysis systems that facilitate visualising and examining CAD models in the environments without being able to modify them; and VR-based CAD systems, which enable designers to construct and alter 
3D models in the virtual environment (Ye et al., 2006: 79). Table 3-4 outlines the strengths and weaknesses of the main VR-based interaction systems.

VR has been identified as being relatively expensive and not realistic or accurate enough (Catalano et al., 2002: 13), although it has been acknowledged as having the capacity to support industrial design (Ye et al., 2006: 78). "The need to integrate VR technologies with the product design process is generally recognised, especially at the conceptual design stage and as such will provide new advances in the field of CAD" (Ye et al., 2006: 78).

\begin{tabular}{|c|c|c|}
\hline $\begin{array}{c}\text { VR-based interaction } \\
\text { paradigms }\end{array}$ & Strengths & Weaknesses \\
\hline Glove type devices & $\begin{array}{l}\text { - } \quad \text { Enable to use both hands } \\
\text { - Use the hand with more } \\
\text { degrees of freedom } \\
\text { - } \quad \text { Allow a natural interaction by } \\
\text { gesture input }\end{array}$ & $\begin{array}{l}\text { - } \\
\text { geed pre-defined complex } \\
\text { gesture language } \\
\text { Need fast and precise gesture } \\
\text { recognition } \\
\text { Need user-specific calibration } \\
\text { to work }\end{array}$ \\
\hline Voice input methods & $\begin{array}{l}\text { - Free both hands for other } \\
\text { operations } \\
\text { - Need simple hardware devices } \\
\text { (i.e. a microphone) } \\
\text { - Specify verbal commands } \\
\text { flexibly }\end{array}$ & $\begin{array}{ll}\text { - } & \text { Need different language } \\
\text { support } \\
\text { - } \\
\text { Need different pronunciation } \\
\text { recognition } \\
\text { - Need different accent } \\
\text { recognition }\end{array}$ \\
\hline $\begin{array}{l}\text { Position tracking } \\
\text { devices }\end{array}$ & $\begin{array}{l}\text { Provide spatial information for } \\
\text { interaction (i.e. view control, } \\
\text { object selection and } \\
\text { manipulation) } \\
\text { - Allow users to feel 'presence' in } \\
\text { a virtual world }\end{array}$ & $\begin{array}{l}\text { - } \\
\text { calibration } \\
\text { - Need complex algorithm to } \\
\text { reduce noise disturbance } \\
\text { - Cable connection limits } \\
\text { freedom of operation }\end{array}$ \\
\hline $\begin{array}{l}\text { Fully immersive virtual } \\
\text { environments }\end{array}$ & $\begin{array}{l}\text { Create a more realistic } \\
\text { environment } \\
\text { Increase the user's feeling of } \\
\text { immersion }\end{array}$ & $\begin{array}{l}\text { - Make the system } \\
\text { infrastructure more complex } \\
\text { - Cause uncomfortable intrusive } \\
\text { viewing problems } \\
\text { - Make the system more } \\
\text { expensive to use }\end{array}$ \\
\hline
\end{tabular}

Table 3-4: Summary of VR-based interaction paradigms strengths and weaknesses (Ye et al., 2006: 80)

\subsection{Digital Industrial Design Practice}

In a paper titled "Digital Technology \& Digital Product Design", Yan et al. (2006) examined the digital technologies applied during industrial/product design practice, such as digital modelling, RE, tactile design, RP and VR. This paper supports the use of digital technology during design practice and illustrates a digital product design system (Figure 3-32). The 
system demonstrates the use of some digital design technologies that support the use of 3D digital models for digital simulation and testing before manufacture. However, the system omits the conceptual phase of the design process, as it does not employ 2D visualisation software to enable the designers to sketch ideas and develop concepts.

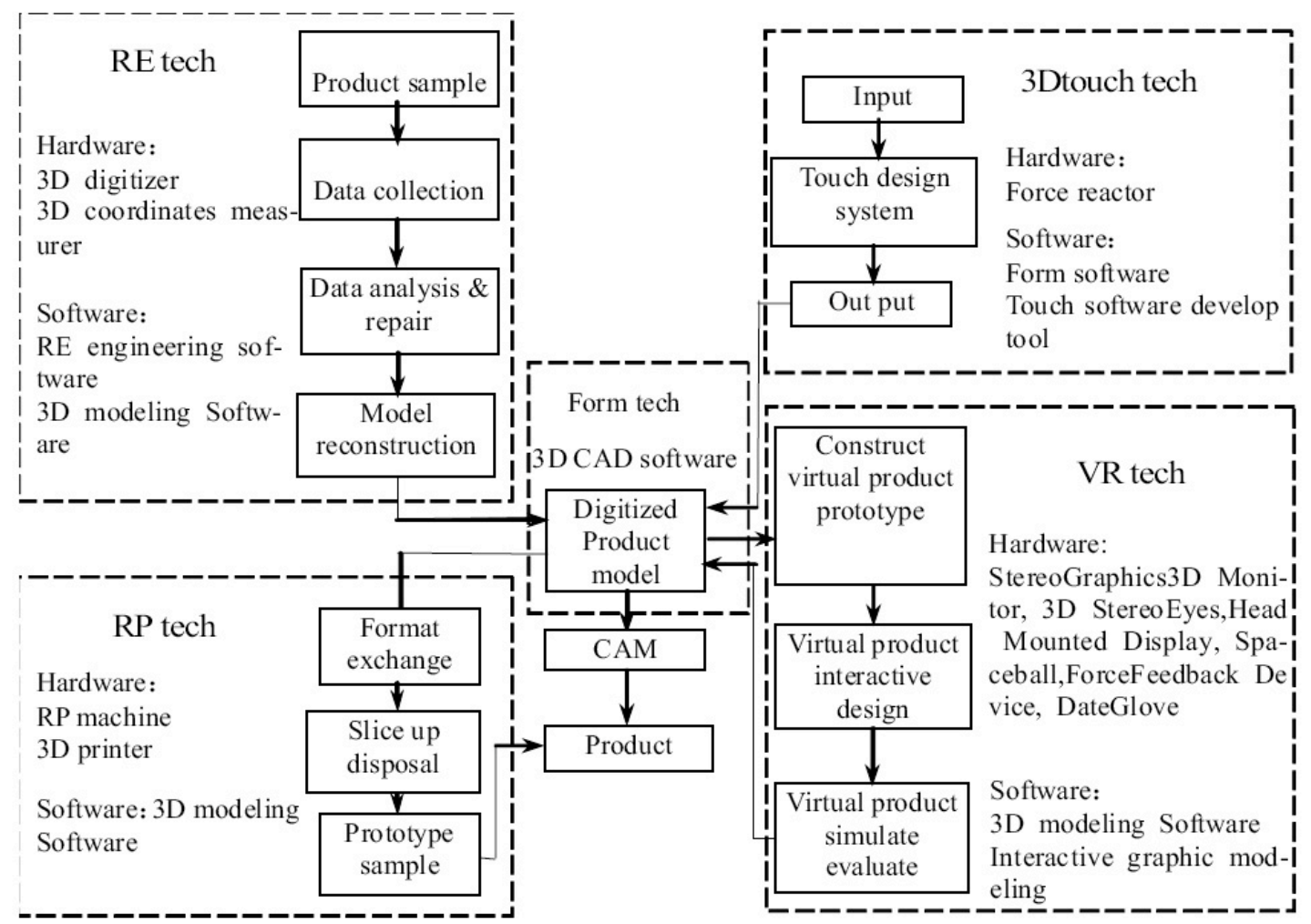

Figure 3-32: Digital product design system (Yan et al., 2006)

\subsection{Digital Industrial Design Education}

Examining the available undergraduate courses in the UK with a bias towards DID revealed that none of the courses available provided a fully DID practice. Although, in 2008, there were six universities that offered a Computer Aided Product Design course (Bournemouth University, Northumbria University, Swansea Metropolitan University, University of Portsmouth, Nottingham Trent University and Coventry University), this number reduced to one university in 2011 (University of Portsmouth) (UCAS, 2011). The reasons behind the changes are not clear. Information available on the University of Portsmouth website regarding the Computer Aided Product Design course points out that the students share first year classes with students on the Product Design and Innovation course. In terms of the development of knowledge and skills, the University of Portsmouth (2010) states that 
students will "spend more time working on artworks development and physical 3D modelling, while students on the Computer Aided Product Design course will concentrate on high performance computer imaging and rendering". This indicates that students were not expected to have a physical output by the end of a design project when undertaking the Computer Aided Product Design course.

Shin (2009) has explored the potential of using digital technologies within industrial design practice through a case study that involved an intense three-week course (Digital Rapid Visualisation for Industrial Design) with 17 undergraduate and graduate design students in the USA. An overview of the course can be seen in Figure 3-33.

\begin{tabular}{|c|c|c|c|c|}
\hline & Class & Class date & Program & Topics / Assignments \\
\hline \multirow{5}{*}{$\begin{array}{r}2 \mathrm{D} \text { digital } \\
\text { sketch }\end{array}$} & 1 & $12 / 30$ & Painter & $\begin{array}{l}\text { Course overview (theme, goals, expectations, schedule, etc.) } \\
\text { Introduction of digital design technologies } \\
\text { Exploration of dgital sketch and methodology } \\
\text { Digital sketch practice using Wacom Cintiq LCD monitor in Painter } \\
\text { Assignment } 1 \text { (basic digital sketch) }\end{array}$ \\
\hline & 2 & $12 / 31$ & Painter & $\begin{array}{l}\text { Exploration of digital sketch with scanned line drawings using Cintiq monitor } \\
\text { Assignment } 2 \text { (digital design sketch practice using line drawings) }\end{array}$ \\
\hline & 3 & $1 / 1$ & & New Year Holiday \\
\hline & 4 & $1 / 2$ & Painter & $\begin{array}{l}\text { Introduction and basic tools of Rhino modeling } \\
\text { Exploration of digital sketch with Rhino model } \\
\text { Assignment } 3 \text { (digital design sketch practice using 3D models) }\end{array}$ \\
\hline & 5 & $1 / 5$ & & $\begin{array}{l}\text { Digital sketches of existing products and design modifications } \\
\text { Assignment } 4 \text { (applications of digital design sketch) }\end{array}$ \\
\hline $\begin{array}{l}2 D \text { digital } \\
\text { line drawing }\end{array}$ & 6 & $1 / 6$ & Rhino & $\begin{array}{l}\text { Line \& curve tools of Rhino } \\
\text { Line drawings in Rhino for } 2 \mathrm{D} \text { digital rendering }\end{array}$ \\
\hline $\begin{array}{l}2 \mathrm{D} \text { digital } \\
\text { rendering }\end{array}$ & 7 & $1 / 7$ & $\begin{array}{l}\text { Photoshop CS } \\
\text { Illustrator CS }\end{array}$ & $\begin{array}{l}\text { 2D digital rendering demonstration and practice in Photoshop CS3 } \\
\text { Assignment } 5 \text { (Photoshop digital rendering in projection viewS) } \\
2 D \text { digital rendering demonstration and practice in Illustrator CS3 } \\
\text { Assignment } 6 \text { (Illustrator digital rendering in projection vews) }\end{array}$ \\
\hline $\begin{array}{l}\text { 3D sketch } \\
\text { 3D scan }\end{array}$ & 8 & $1 / 8$ & $\begin{array}{l}\text { 3D sketch } \\
\text { 3D scanner } \\
\text { Rhino }\end{array}$ & $\begin{array}{l}\text { Exploration of } 3 \mathrm{D} \text { form study model } \\
\text { Introduction of } 3 \mathrm{D} \text { scanner technology and practice with the study model } \\
\text { Basic surface tools of Rhino }\end{array}$ \\
\hline \multirow{3}{*}{$\begin{array}{l}\text { 3D computer } \\
\text { modeling }\end{array}$} & 9 & $1 / 9$ & Rhino & Rhino modeling of the scanned 3D study model and form development \\
\hline & 10 & $1 / 12$ & Rhino & Rhino modeling of the scanned 3D study model and form development \\
\hline & 11 & $1 / 13$ & SolidWorks & $\begin{array}{l}\text { Introduction of SolidWorks (part split, wall thickness, shell, corner radius, etc.) } \\
\text { Assignment } 7 \text { ( } 3 D \text { CAD modeling) }\end{array}$ \\
\hline 30 print & 12 & $1 / 14$ & $\begin{array}{l}\text { 3D print } \\
\text { 3D Max Studio V-Ray }\end{array}$ & $\begin{array}{l}\text { Introduction of rapid prototype technologies } \\
3 D \text { printing practice in Dimension SST and Z-Printer } 450 \\
\text { Introduction of 3D Max Studio V-ray rendering }\end{array}$ \\
\hline \multirow{2}{*}{$\begin{array}{l}30 \text { virtual } \\
\text { rendering }\end{array}$} & 13 & $1 / 15$ & 3D Max Studio V-Ray & Virtual rendering practice in 3D Max Studio V-ray \\
\hline & 14 & $1 / 16$ & $\begin{array}{l}\text { 3D Max Studio V-Ray } \\
\text { HyperShot }\end{array}$ & $\begin{array}{l}\text { Virtual rendering practice in 3D Max Studio V-ray \& HyperShot } \\
\text { Assignment } 8 \text { (product presentation board with virtual rendering images) }\end{array}$ \\
\hline
\end{tabular}

Figure 3-33: Digital Rapid Visualisation for Industrial Design course curriculum (Shin, 2009: 2)

During the course, students explored the following digital design methods: 


\subsubsection{D Digital Sketching}

Students started the course with 2D sketching classes, where they used Painter software and a Cintiq digitising tablet to generate design concepts (Shin, 2009: 3) (Figure 3-34).

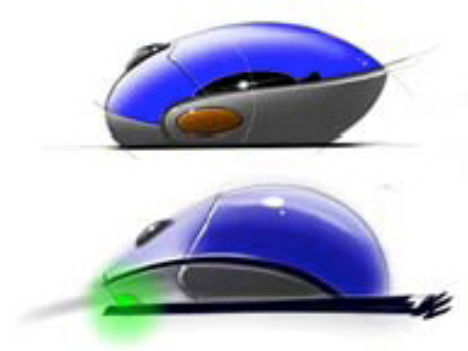

Figure 3-34: 2D digital sketch example (Shin, 2009: 3)

\subsubsection{D Digital Renderings}

Students practiced producing 2D orthographic line work of a mouse and then used Illustrator CS3 software to render the line drawings (Shin, 2009: 3) (Figure 3-35).

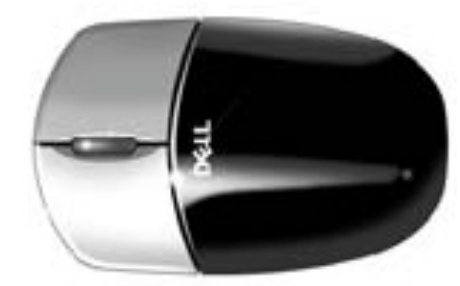

Figure 3-35: 2D digital rendering example (Shin, 2009: 4)

\subsubsection{D Sketch Modelling}

2D data from the line work was used to cut out shapes using a laser cutter to produce a 3D sketch model when assembled (Shin, 2009: 4).

\subsubsection{D Scanning/Reverse Engineering}

The 3D sketch model of the mouse was scanned and data was used to help build a 3D CAD model (Shin, 2009: 4) (Figure 3-36). 


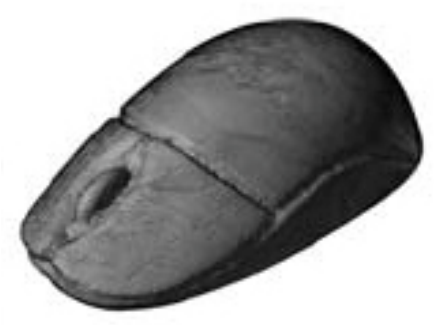

Figure 3-36: 3D scanned image of 3D sketch model (Shin, 2009: 4)

\subsubsection{D Computer Aided Design Modelling}

The data captured using the 3D scanner was imported into 3D CAD surface modelling software to build features of the mouse and add thickness to the parts (Shin, 2009: 5).

\subsubsection{Rapid Prototyping}

STL files from the 3D solid modelling files were used to build 3D models of the designed products using RP (FDM and 3D printer) (Shin, 2009: 5) (Figure 3-37).

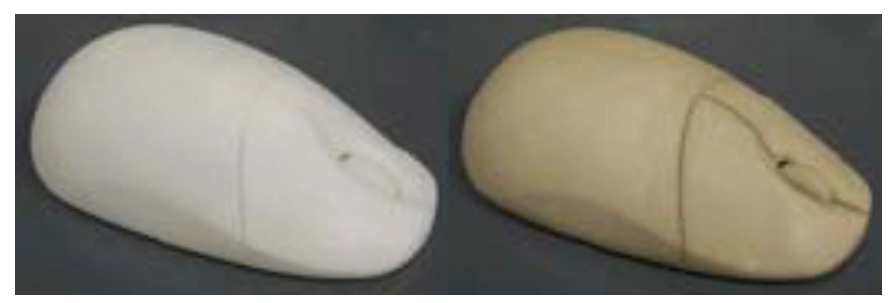

Figure 3-37: Rapid prototype models (Shin, 2009: 5)

\subsubsection{D Virtual Rendering}

In order to provide a realistic appearance of the 3D mouse models in the intended colours, materials and graphics, 3D virtual rendering was used (Shin, 2009: 5) (Figure 3-38).

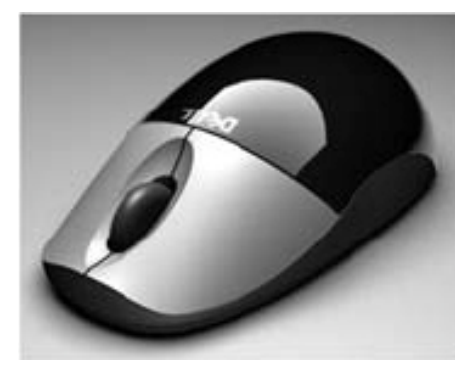

Figure 3-38: Virtual rendering example (Shin, 2009: 6)

The study concluded that the course succeeded in terms of making the students aware of new industrial design technologies and how these tools can be used when designing (Shin, 
2009: 6). While the course demonstrated the use of available digital technologies, it did not make students aware of haptic modelling or VR.

\subsection{Emergent Research Questions}

In order to investigate the potential for a totally digital strategy for industrial design education that would also be suitable for professional practice, it was necessary to review the literature in terms of digital design. The benefits and concerns of designing products digitally had to be explored as well as the attitudes towards digital design. A lack of information on the attitude of academics, students and practitioners towards undertaking industrial design practice entirely digitally was identified. This has led to the development of the following research question:

- How do students, academics and practitioners feel towards undertaking design practice entirely digitally?

The information related to the current industrial design education and professional practice in terms of employing digital technologies was also limited. Many digital tools/media that have the potential to be employed during the core industrial design activities of sketching, drawing, modelling and prototyping were reviewed.

With the exception of one attempt that lacked the creative process of generating concepts through sketching, there were not any strategies that illustrate the way that currently available digital tools/media can be integrated to form a completely DID strategy that have the potential to be employed in education and professional practice. Another finding was the lack of confidence in the capabilities of digital sketching; so many designers preferred paper-based sketching for initial concept generation. This was due to the fact that current computer systems demand too much precision too soon in the process while paper-based sketching offer more freedom and facilitates the thinking process and creativity. As a result, it was considered essential to investigate the issues related to the activity of digital sketching. These literature review findings supported the definition of the other three research questions:

- What is the nature of educational and professional industrial design practice in terms of digital technologies?

- How can digital design tools/media be integrated to form a DID strategy? 
- How can digital tools be used to support concept generation through sketching?

\subsection{Chapter Summary}

Digital technology plays an important role in a changing world. It divides people into digital natives, who are familiar with computers; and digital immigrants, who have had to adapt to technology at a later stage of in life. The nature of international competition is necessitating shorter product development timescales and an increasing trend towards customisation. This places greater emphasis on reducing time to market as a key feature of competitive advantage. DID tools and techniques provide opportunities to reduce the time from product planning to product sale. They facilitate efficiency gains through the use of computer-based methods to support concept sketching, visualisation, detailing, and prototyping. Despite the fact that DID offers many advantages to users, some concerns about its use in practice and education were revealed. These include the possibility of hindering creativity; reducing the haptic interaction with physical objects; the need for constant upgrading; and cost of digital tools/media.

The digital tools/media available had been categorised into digital sketching tools/media (maintain ambiguity while generating concepts) and modelling/prototyping tools/media (facilitate creating refined models/prototypes). Digital sketching tools/media include digitising tablets with and without a built-in display, 2D visualisation software, pen input devices, Digital Design Journal, CAS, HIS and 3D sketching systems. Examples of modelling/prototyping tools/media are 3D mouse, CAD, 3D scanning/RE, haptic modelling, CNC machining, RP, VP and VR.

The literature review revealed a distinct lack of studies that focus on practitioner, academic and student opinions towards the use of entirely digital techniques within industrial design practice and education. It demonstrated a single attempt to identify a digital product design system but the system lacked the front-end conceptualisation stage of the design process. Within education, only one university offered a course with an extensive amount of digital content, but the course did not required students to produce a physical representation of their design as it focused on computer visualisation. An intense three-week course was developed in the USA to make students aware of the digital methods that can be employed within industrial design practice. This included 2D digital sketching and renderings, 3D scanning/RE, 3D CAD modelling, RP and VP. 


\section{RESEARCH METHODOLOGY}

This chapter describes the research methodology employed to answer the research questions. It outlines the methodology in terms of purpose, type, strategies of enquiry, data collection methods, and data analysis. It provides justification for the choices made in the research design and illustrates issues of reliability and validity.

\subsection{Designing a Research Methodology}

The word 'research' can be described as "an original contribution to the existing stock of knowledge making for its advancement" (Kumar, 2008: 2). Research is an organised process of gathering data to provide an understanding of the unknown (Davies, 2007: 17, Kumar, 2008: 1). Merriam-Webster Online Dictionary (2010) defines methodology as "a body of methods, rules, and postulates employed by a discipline: a particular procedure or set of procedures". In a research context, a methodology is the general approach of investigating the research focus (Silverman, 2004: 53). It provides an understanding of how the research was conducted and systematically organised in order to achieve the aims of research (Kumar, 2008: 4). The research methodology is the path the investigator takes to find answers for the set research questions (Kumar, 2005: 16). Designing a suitable research methodology is essential for the success of the research. This chapter will address the research methodology in terms of:

- Purpose of enquiry (exploratory, descriptive, explanatory, or emancipatory)

- Type of design (quantitative, qualitative, or mixed methods research)

- Strategies of enquiry (quantitative strategies, qualitative strategies or mixed methods strategies)

- Data collection methods (interviews, questionnaires, observations and literature review)

- Analysis (quantitative data analysis, qualitative data analysis, coding, clustering, content analysis) 


\subsection{Research Purpose Enquiry}

Neuman (2005: 33-35) suggests that the purpose of research could be to explore a little understood issue or phenomenon, to describe a situation or event, or to explain why events occur. Robson (2002: 58-60) agrees with Neuman (2005) and adds another reason that is to emancipate to create opportunities. Table 4-1 provides descriptions of the possible research purposes that one might carry out a research study for.

\begin{tabular}{|c|c|}
\hline Purpose of enquiry & Aims \\
\hline Exploratory & $\begin{array}{l}\text { - To find out what is happening, particularly in little-understood situations } \\
\text { - To seek new insights } \\
\text { - To ask questions } \\
\text { - To assess phenomena in a new light } \\
\text { - To generate ideas and hypotheses for future research }\end{array}$ \\
\hline Descriptive & $\begin{array}{l}\text { - To portray an accurate profile of persons, events or situations } \\
\text { - Requires extensive previous knowledge of the situation to be researched } \\
\text { or described, so that you know appropriate aspects on which to gather } \\
\text { information }\end{array}$ \\
\hline Explanatory & $\begin{array}{l}\text { - To explore a situation or problem, traditionally but not necessarily in the } \\
\text { form of casual relationships } \\
\text { - To explain patterns relating to the phenomenon being researched } \\
\text { - To identify relationships between aspects of the phenomenon }\end{array}$ \\
\hline Emancipatory & - To create opportunities and the will to engage in social action \\
\hline
\end{tabular}

Table 4-1: Classification of the purposes of enquiry (Robson, 2002: 59-60)

As discussed in Chapter 1, the research focuses on DID. It investigates design practice in professional and educational contexts. It also examines how digital design tools could be integrated to form a totally DID strategy. While undertaking the research, the capabilities of digital sketching in replacing conventional paper-based sketching techniques was doubted by most participants. This then led the researcher to explore the use of the Tablet PC for concept generation through sketching. This research could therefore be described as having an exploratory nature.

\subsection{Research Type of Design}

Three types of research design have been identified. These are: qualitative, quantitative, and mixed methods research (Creswell, 2009: 4, Davies, 2007: 9-11). Table 4-2 presents definitions of each type. 


\begin{tabular}{|l|l|}
\hline \multicolumn{1}{|c|}{ Research type of design } & \multicolumn{1}{c|}{ Description } \\
\hline Qualitative research & $\begin{array}{l}\text { - } \\
\text { It is a means for exploring and understanding the meaning } \\
\text { individuals or groups ascribe to a social or human problem }\end{array}$ \\
\hline Quantitative research & $\begin{array}{l}\text { The process of research involves emerging questions and } \\
\text { procedures } \\
\text { Data typically collected in the participant's setting, data analysis } \\
\text { inductively building from the meaning of the data }\end{array}$ \\
\hline Mixed methods research & $\begin{array}{l}\text { It is a means for testing objectives theories by examining the } \\
\text { relationship among variables } \\
\text { Variables can be measured, typically on instruments, so that } \\
\text { numbered data can be analysed using statistical procedures }\end{array}$ \\
\hline $\begin{array}{l}\text { It is an approach to enquiry that combines or associates both } \\
\text { qualitative and quantitative forms } \\
\text { The overall strength of a study is greater than either qualitative or } \\
\text { quantitative }\end{array}$ \\
\hline
\end{tabular}

Table 4-2: Difference between qualitative, quantitative and mixed methods research

(Creswell, 2009: 4)

While quantitative and qualitative methods have advantages and limitations (Spicer, 2004: 298), it was decided that a mixed methods research approach, also known as 'multi-strategy' (Bryman, 2006: 98), 'mixed methodology' (Tashakkori and Teddlie, 1998: 5), and 'combined methods research' (Spicer, 2004: 294) would be used to answer the research questions and go beyond what qualitative and quantitative research methods offer individually (Creswell, 2009: 4). Greene et al. (1989: 255-259) identify five justifications for integrating qualitative and quantitative research: triangulation (convergence of results), complementarity (explanations of the results from one method with the results from another), development (use the results of one method to develop another method), initiation (discovery of paradox, contradiction and new perspectives) and expansion (adding breadth) .

In this research, qualitative methods were used to explain the findings from the quantitative methods to clarify opinions and provide detailed insights into the participants' perceptions in surveys. In addition, focus groups were used to investigate individuals' views and experiences (Litosseliti, 2003: 1) and then the data collected helped to generate a questionnaire that was used to collect quantitative data. Combining methods in this case helped solve the issue of "limited quantification of qualitative studies" (Spicer, 2004: 299). Figure 4-1 illustrates the different routes that can be taken to combine the use of qualitative and quantitative methods when designing a research. 
Qualitative measures to develop quantitative tools

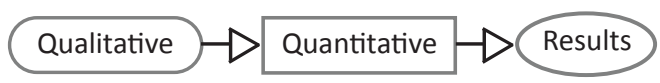

Quantitative methods to enlarge on qualitative study

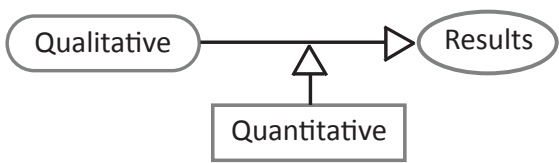

Qualitative methods to explain quantitative results

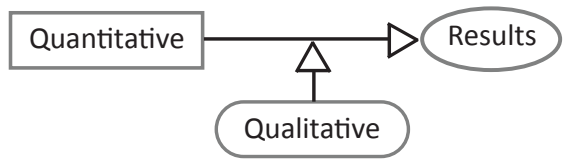

Quantitative and qualitative methods equal and parallel

Figure 4-1: Illustrations of different scenarios for combining qualitative and quantitative methods ((Ulin et al., 1996) cited in (Tashakkori and Teddlie, 1998: 44))

\subsection{Strategies of Enquiry}

While Robson (2002: 87) clusters research strategies into fixed (quantitative) and flexible (qualitative), Creswell (2009: 14) adds a mixed methods category (Table 4-3).

\begin{tabular}{|c|c|c|}
\hline Qualitative & Quantitative & Mixed methods \\
\hline $\begin{array}{ll}\text { - } & \text { Narrative research } \\
\text { - } & \text { Phenomenology } \\
\text { - } & \text { Ethnographies } \\
\text { - } & \text { Grounded theory studies } \\
\text { - } & \text { Case study }\end{array}$ & $\begin{array}{ll} & \text { Experimental designs } \\
\text { - } & \text { Non-experimental design } \\
\text { such as surveys }\end{array}$ & $\begin{array}{ll}\text { - } & \text { Sequential } \\
\text { - } & \text { Concurrent } \\
\text { - } & \text { Transformative }\end{array}$ \\
\hline
\end{tabular}

Table 4-3: Alternative strategies of enquiry (Creswell, 2009: 12)

Selecting the appropriate strategies of enquiry was influenced by the purpose and research questions. Surveys were used to understand the current design practice in professional and educational contexts; evaluate the DID strategy; and seek opinion towards employing completely digital techniques when designing a product. Results from the surveys indicated reservations about digital sketching, as participants expressed their preference for paperbased sketching in terms of its freedom, speed, and ease. In order to understand the interviewees concerns in great detail, a case study approach was selected to evaluate the use of the Tablet PC as a tool for concept generation.

As a result of selecting surveys and a case study for the research strategies of enquiry, mixed methods strategies were selected to illustrate how the two methods would be combined. A 
sequential mixed methods approach was used through the use of focus groups to investigate the use of the Tablet PC for sketching. The information was then used to design a questionnaire that was employed to generalise the results. Furthermore, a concurrent mixed methods approach was employed to more fully understand the situation, experiences, and feedback. In general, applying a mixed methods approach can improve the accuracy of data; provide a more complete picture; overcome the intrinsic bias; and develop the analysis (Denscombe, 2007: 109-111). Table 4-4 provides a brief summary of the combined strategies used in this research.

\begin{tabular}{|l|l|}
\hline \multicolumn{1}{|c|}{ Strategy of enquiry } & \multicolumn{1}{c|}{ Description } \\
\hline Case study & \begin{tabular}{l} 
- $\begin{array}{l}\text { It "is an empirical enquiry that investigates a contemporary } \\
\text { phenomenon in depth and within its real-life context, especially when } \\
\text { the boundaries between phenomenon and context are not clearly } \\
\text { evident" (Yin, 2009: 19) } \\
\text { "Case studies employ various methods. These can include interviews, } \\
\text { participant observation, and field studies. Their goals are to reconstruct } \\
\text { and analyse a case from a sociological perspective" (Hamel et al., 1993: } \\
\text { 1) }\end{array}$ \\
\hline Survey
\end{tabular}$\quad \begin{array}{l}\text { It is a "collection of information in standardised form from groups of } \\
\text { people" (Robson, 1993: 40) } \\
\text { The "three techniques used most often to collect data in survey research } \\
\text { are face-to-face interviews, the self completion questionnaire and } \\
\text { telephone interviews" (Bloch, 2004: 165) }\end{array}$ \\
\hline $\begin{array}{l}\text { Sequential mixed } \\
\text { methods }\end{array}$ & $\begin{array}{l}\text { They "are those in which the researcher seeks to elaborate on or expand } \\
\text { on the findings of one method with another method" (Creswell, 2009: } \\
\text { 14) }\end{array}$ \\
\hline $\begin{array}{l}\text { Concurrent mixed } \\
\text { methods }\end{array}$ & $\begin{array}{l}\text { They "are those in which the researcher converges or merges } \\
\text { quantitative and qualitative data in order to provide a comprehensive } \\
\text { analysis of the research problem" (Creswell, 2009: 14) }\end{array}$ \\
\hline
\end{tabular}

Table 4-4: A summary of the strategies of enquiry used in the research

\subsubsection{Survey as a Research Strategy}

Surveys were carried out as an approach to doing the research. The surveys were undertaken mainly to obtain a broad perspective of industrial design practice in professional and educational contexts; seek opinion on designing using completely digital tools/media; and gather feedback on the DID strategy. Table 4-5 provides an overview of the surveys carried out with practitioners, academics and students. This table excludes the surveys carried out as part of the Tablet PC case study. 


\begin{tabular}{|c|c|c|c|}
\hline \multicolumn{2}{|r|}{ Survey focus } & $\begin{array}{l}\text { Data collection } \\
\text { method }\end{array}$ & Aims \\
\hline 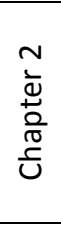 & Industrial design & $\begin{array}{l}\text { Literature } \\
\text { review }\end{array}$ & $\begin{array}{l}\text { To obtain an understanding of: } \\
\text { - } \quad \text { Industrial design } \\
\text { - } \quad \text { Industrial design practice } \\
\text { - } \quad \text { Industrial design representations } \\
\text { - } \quad \text { Industrial design education }\end{array}$ \\
\hline $\begin{array}{l}m \\
\frac{m}{0} \\
\stackrel{2}{0} \\
\frac{0}{\pi} \\
\frac{\tau}{U}\end{array}$ & $\begin{array}{l}\text { Digital industrial } \\
\text { Design }\end{array}$ & $\begin{array}{l}\text { Literature } \\
\text { review }\end{array}$ & $\begin{array}{l}\text { To review the following: } \\
\text { - } \quad \text { Benefits and concerns about digital design } \\
\text { - } \quad \text { Attitude towards digital design } \\
\text { - } \quad \text { Digital design tools/media } \\
\text { - } \quad \text { DID practice } \\
\text { - } \quad \text { DID education }\end{array}$ \\
\hline \multirow{3}{*}{ 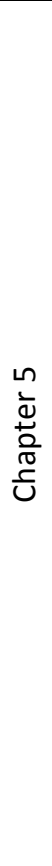 } & $\begin{array}{l}\text { Industrial design } \\
2007 / 2008 \text { graduating } \\
\text { students (UK) }\end{array}$ & $\begin{array}{l}\text { Supervised } \\
\text { collective } \\
\text { questionnaire } \\
\text { ( } 96 \text { fully } \\
\text { completed) }\end{array}$ & $\begin{array}{l}\text { To identify the following: } \\
\text { - The digital and conventional design methods } \\
\text { currently used } \\
\text { - Extent to which digital tools are currently } \\
\text { being employed } \\
\text { - Ease of using some of the digital tools } \\
\text { - Opinion about a completely digital design } \\
\text { process }\end{array}$ \\
\hline & $\begin{array}{l}\text { Industrial design } \\
\text { students who had } \\
\text { successfully completed } \\
\text { an industrial } \\
\text { placement year in } \\
2007 / 2008 \text { (UK) }\end{array}$ & $\begin{array}{l}\text { Online } \\
\text { questionnaire } \\
\text { (17 fully } \\
\text { completed) }\end{array}$ & $\begin{array}{l}\text { To investigate the following: } \\
\text { - } \quad \text { Digital and conventional methods used } \\
\text { within design organisations } \\
\text { - Digital design methods used during design } \\
\text { process phases } \\
\text { - } \quad \text { Extent of employing digital methods during } \\
\text { the different phases of the design process } \\
\text { - Opinion about designing totally digitally }\end{array}$ \\
\hline & $\begin{array}{l}\text { Industrial design } \\
\text { practitioners }\end{array}$ & $\begin{array}{l}\text { Online } \\
\text { questionnaire } \\
\text { (10 fully } \\
\text { completed) } \\
\end{array}$ & $\begin{array}{l}\text { To obtain: } \\
\text { - Opinion regarding employing completely } \\
\text { digital design techniques }\end{array}$ \\
\hline \multirow{3}{*}{ 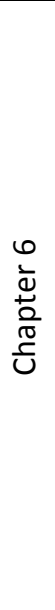 } & $\begin{array}{l}\text { Industrial design } \\
2008 / 2009 \text { graduating } \\
\text { students (UK) }\end{array}$ & $\begin{array}{l}\text { Supervised } \\
\text { collective } \\
\text { questionnaire } \\
\text { (117 fully } \\
\text { completed) }\end{array}$ & $\begin{array}{l}\text { To identify the following: } \\
\text { - Frequency of use, ease of use and } \\
\text { contribution to practice of the } 17 \text { digital } \\
\text { tools/media employed in DID strategy } \\
\text { - Opinion on the DID strategy }\end{array}$ \\
\hline & $\begin{array}{l}\text { Industrial design } \\
\text { practitioners }\end{array}$ & $\begin{array}{l}8 \text { semi- } \\
\text { structured face- } \\
\text { to-face } \\
\text { interviews }\end{array}$ & $\begin{array}{l}\text { To validate DID strategy through obtaining: } \\
\text { - } \quad \text { Thoughts on DID strategy } \\
\text { - } \quad \text { Reservations on DID strategy } \\
\text { - } \quad \text { Suggestions to improve DID strategy }\end{array}$ \\
\hline & $\begin{array}{l}\text { Industrial design } \\
\text { academics }\end{array}$ & $\begin{array}{l}9 \text { semi- } \\
\text { structured face- } \\
\text { to-face } \\
\text { interviews }\end{array}$ & $\begin{array}{l}\text { To validate DID strategy through identifying: } \\
\text { - } \quad \text { Thoughts on DID strategy } \\
\text { - } \quad \text { Reservations on DID strategy } \\
\text { - } \quad \text { Suggestions to improve DID strategy } \\
\text { - } \quad \text { Thoughts on DID curriculum }\end{array}$ \\
\hline
\end{tabular}

Table 4-5: Aims of data collection methods used within the surveys carried out in the research 


\subsubsection{Case Study as a Research Strategy}

A case is defined by Miles and Huberman (1994: 25) as "a phenomenon of some sort occurring in a bounded context" and it is an element that could be analysed. A case study is a detailed study of the case (Hamel et al., 1993: 1). Yin (2009: 13) states that a case study is suitable when "a 'how' or 'why' question is being asked about a contemporary set of events, over which the investigator has little or no control". In this research, the fourth research question (How can digital tools be used to support concept generation through sketching?) fits well within the context of a case study. While case studies give deep understanding, surveys were used within the case study to provide quantitative and qualitative attitudes and opinions. This integrated approach is supported by several authors, such as Yin (2009: 13) and Neale et al. (2006: 4).

On the negative side, a case study can persuade researchers to investigate very broad subjects (Baxter and Jack, 2008: 546). To avoid this problem, boundaries were set to investigate the use of the Tablet PC as a tool for concept generation.

Table 4-6 illustrates the data collection methods (questionnaires, focus groups and observations) used for the Tablet PC case study. All of the data collection methods were carried out with the 16 students that participated, apart from the postal questionnaire that aimed to assess sketching output and was undertaken with academics. 


\begin{tabular}{|c|c|c|}
\hline \multicolumn{2}{|r|}{ Data Collection Method } & Aims \\
\hline 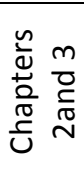 & Literature review & $\begin{array}{l}\text { To obtain more information about: } \\
\text { - Tablet PCs } \\
\text { - } \quad \text { Sketching activity } \\
\text { - } \quad \text { Sketching software }\end{array}$ \\
\hline \multirow{10}{*}{$\begin{array}{l}N \\
\bar{d} \\
\stackrel{2}{0} \\
\frac{0}{U}\end{array}$} & $\begin{array}{l}\text { Pre Digital Industrial/Product } \\
\text { Design Strategy Questionnaire } \\
\text { (supervised collective) }\end{array}$ & $\begin{array}{l}\text { - To investigate opinions on digital design methods } \\
\text { before using the Tablet PC }\end{array}$ \\
\hline & $\begin{array}{l}\text { Tablet PC as a Design Tool } \\
\text { Focus Groups }\end{array}$ & $\begin{array}{l}\text { To understand the following: } \\
\text { - Impact of Tablet PC on sketching ability, creativity and } \\
\text { productivity } \\
\text { - Key skills that need to be taught to use the Tablet PC } \\
\text { effectively } \\
\text { - Thoughts on the introduction of the Tablet PC to all } \\
\text { industrial design students }\end{array}$ \\
\hline & $\begin{array}{l}\text { Sketching Exercise Non- } \\
\text { participant Observation }\end{array}$ & $\begin{array}{l}\text { - To observe the behaviour and techniques used when } \\
\text { sketching organic and geometric products digitally } \\
\text { compared to paper-based techniques }\end{array}$ \\
\hline & $\begin{array}{l}\text { Sketching Exercise } \\
\text { Questionnaire (supervised } \\
\text { collective) }\end{array}$ & $\begin{array}{l}\text { To identify the following: } \\
\text { - Differences in sketching strategies when using non- } \\
\text { digital media and Tablet PC } \\
\text { - Compare opinions on the sketching activity and } \\
\text { outcome using non-digital media and Tablet PC }\end{array}$ \\
\hline & $\begin{array}{l}\text { Assessing the Output of the } \\
\text { Sketching Exercise } \\
\text { Questionnaire (postal) with } 12 \\
\text { academics }\end{array}$ & $\begin{array}{l}\text { To gather expert opinion on the effectiveness of the } \\
\text { digital and non-digital sketches produced by students } \\
\text { in the sketching exercise }\end{array}$ \\
\hline & $\begin{array}{l}\text { Design Exercise Non- } \\
\text { participant Observation }\end{array}$ & - To observe student use of the Tablet PC for designing \\
\hline & $\begin{array}{l}\text { Design Exercise Questionnaire } \\
\text { (supervised collective) }\end{array}$ & $\begin{array}{l}\text { - To identify strengths, weaknesses and software used } \\
\text { when undertaking the pepper mill design exercise with } \\
\text { the Tablet PC }\end{array}$ \\
\hline & $\begin{array}{l}\text { Post Digital Industrial/Product } \\
\text { Design Strategy Questionnaire } \\
\text { (supervised collective) }\end{array}$ & $\begin{array}{l}\text { - To investigate opinions on digital design methods after } \\
\text { using the Tablet PC }\end{array}$ \\
\hline & $\begin{array}{l}\text { Use of Tablet PC for Designing } \\
\text { Questionnaire (supervised } \\
\text { collective) }\end{array}$ & $\begin{array}{l}\text { - To evaluate the use of the Tablet PC for as a design } \\
\text { tool in general and for sketching specifically }\end{array}$ \\
\hline & \multicolumn{2}{|c|}{$\begin{array}{l}\text { Case study participants (16 students in total): } \\
\text { - } \quad 9 x \text { final year students from BSc Product Design course } \\
\text { - } \quad 7 x \text { final year students from BA Industrial Design and Technology course }\end{array}$} \\
\hline
\end{tabular}

Table 4-6: The aims of data collection methods used within the Tablet PC case study

\subsection{Data Collection Methods}

Maxwell (1996: 74) argues that research questions cannot be transformed automatically or logically to data collection methods as they are considered to be techniques for answering research questions. However, the selection process for appropriate data collection methods depends on the research questions and context that will provide with the data needed. 
A variety of qualitative and quantitative data collection techniques were available to the researcher. Figure 4-2 illustrates the different data collection methods and highlights methods employed in this research.

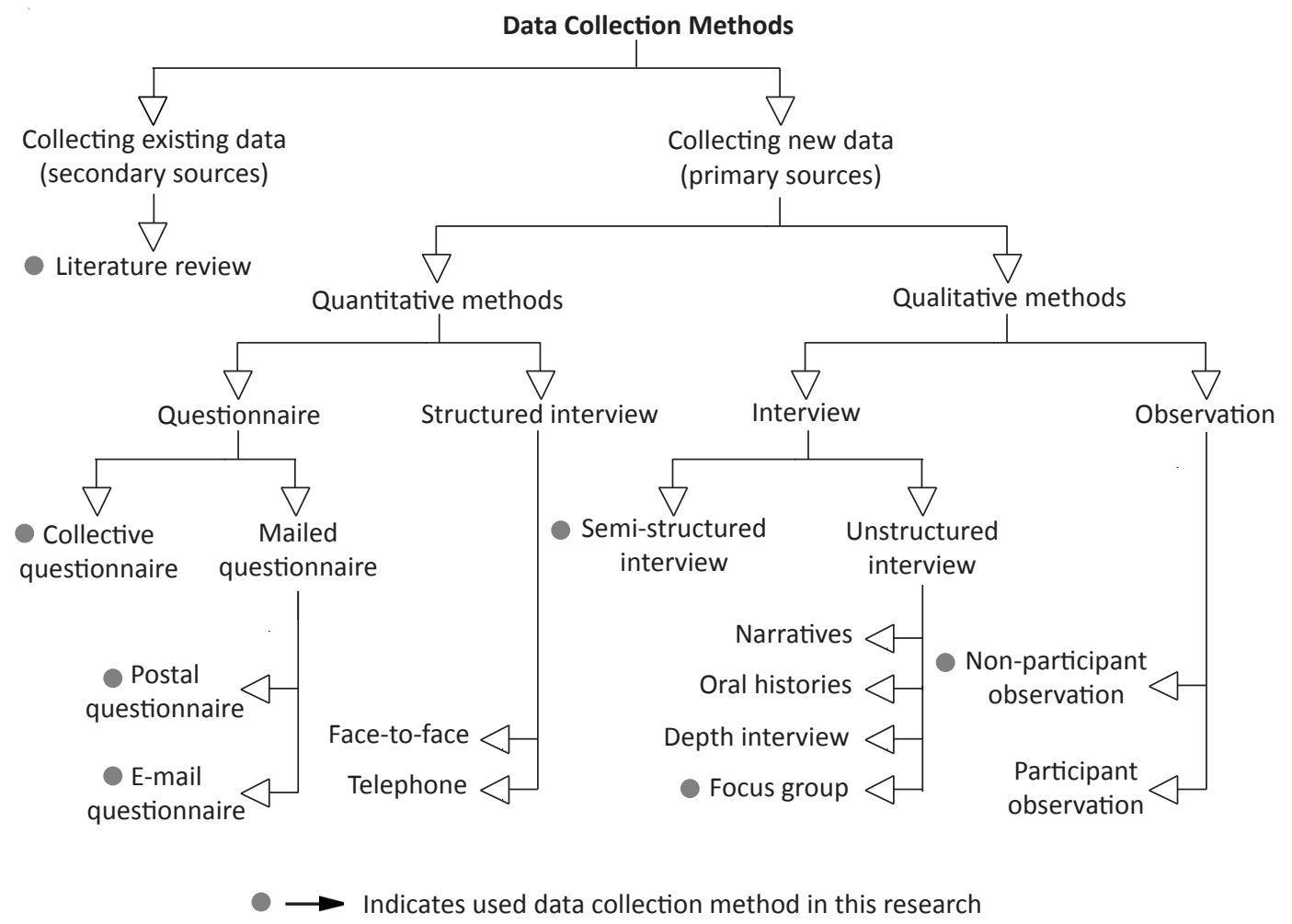

Figure 4-2: Methods of data collection developed by the author based on Kumar (2005: 118)

The selected data collection methods will now be described along with their strengths and weaknesses:

\subsubsection{Literature Review}

The starting point of data collection in most research projects involves collecting new or primary data and existing or secondary information through the use of literature review (Moore, 2006: 106). Finnegan (1996: 138) emphasises the importance and requirement of information data gathering using documents, despite the significance of all other techniques of data collection. Literature review is defined as "the selection of available documents (both published and unpublished) on the topic, which contain information, ideas, data and evidence written from a particular standpoint to fulfil certain aims or express certain views on the nature of the topic and how it is to be investigated, and the effective evaluation of these documents in relation to the research being proposed" (Hart, 1998: 13). 
To provide a solid background for the initial investigation of this research, a literature review method was implemented. A list of keywords was identified and a search for relevant literature was undertaken using MetaLib, Loughborough University's Online Public Access Catalogue (OPAC) and Google Scholar. A selection of published and unpublished documents on industrial design practice, education and digital tools were analysed (Chapter 2 and Chapter 3). To help find, analyse, and manage the information, EndNote X4 software was used. EndNote X4 allowed references in this thesis to be inserted and organised automatically in Microsoft Word with Harvard Style (Figure 4-3).

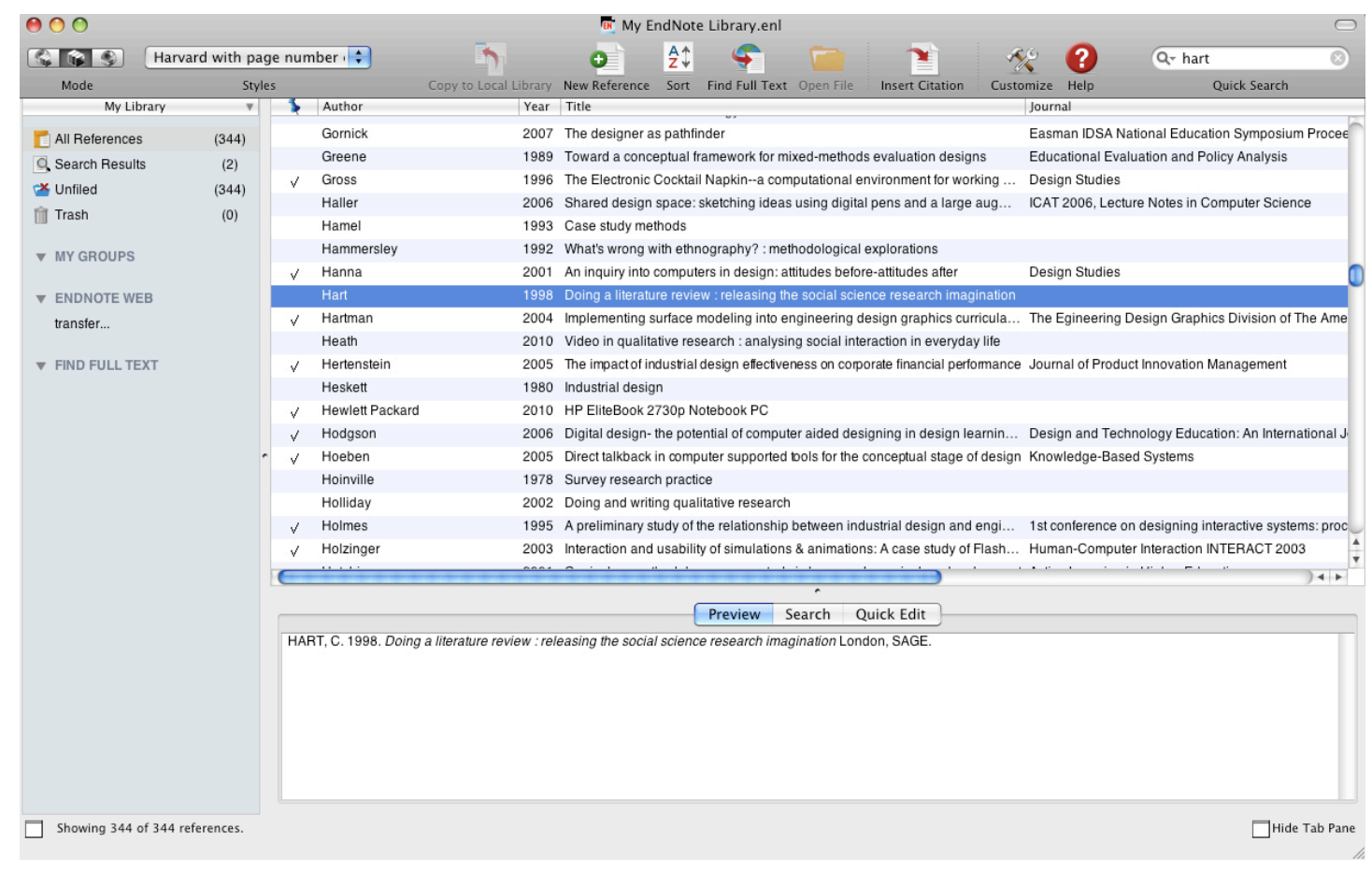

Figure 4-3: Screenshot of EndNote X4 software

\subsubsection{Questionnaires}

Respondent-completed questionnaires are one of the most commonly used data collection methods (Bourque and Fielder, 2003: 1). A questionnaire can be distributed and then collected by the researcher, which provides the opportunity to respond directly to questions. It can be also be in e-mail, online, and postal formats. Each method has its strengths and weaknesses. Table 4-7 illustrates the strengths and weaknesses of a collective questionnaire, which involves handing the questionnaire personally to participants and collecting it when completed. Table 4-8 highlights the strengths and weaknesses of an email, online, and postal questionnaire. 


\begin{tabular}{|c|c|}
\hline Strengths & Weaknesses \\
\hline $\begin{array}{l}\text { The researcher can explain the study, } \\
\text { answer questions and designate a } \\
\text { household respondent in contrast to mail } \\
\text { - Response rates tend to be like those in face- } \\
\text { to-face interviews methods } \\
\text { - Provides more opportunity to give } \\
\text { thoughtful answers } \\
\text { - Does not require trained interviewing staff }\end{array}$ & - A field staff is needed \\
\hline
\end{tabular}

Table 4-7: Strengths and weaknesses of using collective questionnaire (Fowler, 2002: 73-74)

\begin{tabular}{|l|ll|}
\hline \multicolumn{1}{|c|}{ Strengths } & \multicolumn{1}{c|}{ Weaknesses } \\
\hline - $\begin{array}{l}\text { Allows for consistent stimulus to all } \\
\text { respondents }\end{array}$ & - Lack of control over who responds \\
Allows for the possibility of more & Provides no direct information on the \\
representative samples & answerability of questions \\
\hline
\end{tabular}

Table 4-8: Strengths and Weaknesses of e-mail, online and postal questionnaire (unsupervised) (Bourque and Fielder, 2003: 9)

Bourque and Fielder (2003: 8-9) propose four ways of administrating self-completed questionnaires. These are one-to-one, group, semi-supervised, or unsupervised administration.

Group administrated questionnaires were selected as a collection method within this research. These questionnaires are self-completed and managed on a group basis (Robson, 2002: 236). Although the researcher might introduce the study and answer questions, participants are expected not to consult with each other whilst completing the questionnaire (Bourque and Fielder, 2003: 4). To ensure that all respondents receive the same briefing, the researcher used pre-prepared information to introduce the study (Bourque and Fielder, 2003: 5). Supervising the collective paper-based questionnaires provided an opportunity to check that each questionnaire was completely filled in by the respondents.

The cost and occasional inconvenience (geographical boundaries) of group administered questionnaires led to the use of unsupervised (postal and online) questionnaires in this research. However, to ensure that the respondents were provided with clarification or additional information, the researcher's details (e-mail and telephone number) were provided with the questionnaire (Bourque and Fielder, 2003: 7).

Most of the questionnaires designed in this research involved the use of closed-ended questions (answers provided in a number of fixed alternatives) and open-ended questions 
(no answers included) to allow respondents to express themselves in more detail and accuracy (Bourque and Fielder, 2003: 64). To measure the attitude of participants, a fivepoint Likert scale was used to give the respondents the option of a mid-point (Edwards and Talbot, 1999: 89). This approach is most frequently used by researchers (Robson, 2002: 294). Furthermore, the wording used in questionnaires was precise and the layout was simple and clear to ensure accurate responses (Hoinville and Jowell, 1978: 50).

A random sampling technique was used when collecting the data to ensure fairness (Fink, 2003: 36). Random sampling can provide an unbiased sample, but it can sometimes have limitations in covering all subjects of interest (Fink, 2003: 37).

Piloting the questionnaire was essential "both to gauge the length of time which it takes and to investigate whether the questions are properly understood by the respondent" (Wilson, 1996: 102). Edwards and Talbot (1999: 37) suggest that a pilot study should be carried out with an average of $10 \%$ of the sample size to provide an indicative figure of the results.

Questionnaire responses tend to be relatively low (Wilson, 1996: 102, Bloch, 2004: 166), with online questionnaires having response rates of $10 \%$ to $20 \%$ (Bourque and Fielder, 2003: 17) and postal questionnaires should expect around a $20 \%$ response rate (Fink, 2003: 43). However, making sure that the participants were interested in the content of questionnaire, sending reminders, and giving incentives can help increase the response rate (Bourque and Fielder, 2003: 16, Bloch, 2004: 166, Wilson, 1996: 102, Fink, 2003: 43). Schonfield (1996: 51) notes that even if non-responders are followed up, achieving $80 \%$ response rate to questionnaires is rare.

In this research, the supervised collective questionnaires achieved a high response rate. This was because the group-administrated questionnaires were completed at the New Designers Exhibition in London where graduating students had the time and motivation to undertake the questionnaire. In contrast, the online questionnaire had a low response rate despite sending following up e-mails. Only the questionnaires that were fully completed were included in the analysis to keep the data accurate.

\subsubsection{Interviews}

An interview is a conversation carried out for specific purposes by two participants (interviewer and respondent) (Gillham, 2000: 1) to provide a deeper understanding of a study (Silverman, 1993: 15). Interviews can deliver rich, vivid and interesting data (Gillham, 2000: 10). Researchers should aim to generate reliable and valid data when undertaking 
interviews. This can be achieved by the "random selection of the interview sample and the administration of standardised questions with multiple-choice answers which can be readily tabulated" (Silverman, 1993: 91).

A face-to-face interview, also known as an 'in-person interview' and 'personal interview', is a focused conversation between two people that is carried in the same location (Oishi, 2003: 1). While face-to-face interviews can be time consuming (Gillham, 2000: 9), they were selected to provide detailed feedback on the DID strategy. Gillham (2000: 15) notes that even though questionnaires take less time to complete when compared to an interview, participants preferred to undertake an interview because they respond to being listened to, especially if they felt that their suggestions and opinions were taken into consideration. Table 4-9 provides a summary of the strengths and weaknesses of using face-to-face interviews.

\begin{tabular}{|c|c|}
\hline Strengths & Weaknesses \\
\hline $\begin{array}{l}\text { - } \\
\text { moffective way of enlisting cooperation for } \\
\text { - } \quad \text { Interviewer administration } \\
\text { - } \\
\text { Rapport and confidence building are } \\
\text { possible } \\
\text { - Longer survey instruments are possible in } \\
\text { person rather than any other mode }\end{array}$ & $\begin{array}{l}\text { - Likely to be more costly than alternatives } \\
\text { - } \text { trained interviewer who is geographically } \\
\text { near the sample is needed } \\
\text { Data collection period is likely to be longer } \\
\text { than telephone procedures } \\
\text { - Difficulty in accessing some samples }\end{array}$ \\
\hline
\end{tabular}

Table 4-9: Strengths and weaknesses of face-to-face interviews (Fowler, 2002: 71)

The face-to-face interviews were undertaken with a relatively small sample in this research (eight practitioners and nine academics). This research practice is acceptable (Silverman, 1993: 10) as it avoids increasing "the complexity of data collection, management, and analysis without necessarily improving the quality or credibility of the results" (Fink, 2003: 67). Practitioners and academics with a background in industrial design were invited by email to participate in the study. The author visited those who accepted the offer to conduct the interview.

\subsubsection{Focus Groups}

Another form of qualitative interview method is the focus group (Oishi, 2003: 178). "A focus group is a special type of group in terms of purpose, size, composition and procedures" (Krueger and Casey, 2009: 2). The aim of a focus group is to better understand a topic through gathering information about people's opinion and perception (Krueger and Casey, 2009: 2). The number of participants in a single focus group is typically six to eight people (Krueger and Casey, 2000: 73) with some shared characteristics (Litosseliti, 2003: 32). 
Increasing the size of the group can lead to difficulties in managing the group and the danger of changing the group dynamic, especially when respondents are not provided with an opportunity to express their opinion (Krueger and Casey, 2000: 73). The strengths and weaknesses of using focus groups as a data collection method are discussed in Table 4-10.

\begin{tabular}{|c|c|}
\hline Strengths & Weaknesses \\
\hline $\begin{array}{l}\text { - Useful in discovering new information } \\
\text { - } \quad \text { Provides a number of different perspectives } \\
\text { on the same topic } \\
\text { pelpful in gaining information on } \\
\text { - } \text { responses, motivations and perceptions } \\
\text { - Useful for brainstorming and generating } \\
\text { - } \quad \text { ideas } \\
\text { - Helpful in exploring controversial issues and } \\
\text { complex or sensitive topics }\end{array}$ & $\begin{array}{l}\text { - Potential bias and manipulation } \\
\text { - Participants with strong personalities may } \\
\text { dominate the discussion while others may } \\
\text { - } \quad \text { Difficulty in distinguishing between an } \\
\text { individual view and a group view } \\
\text { - Difficulty in making generalisations } \\
\text { - Difficulty of analysis and interpretation of } \\
\text { results }\end{array}$ \\
\hline
\end{tabular}

Table 4-10: Strengths and weaknesses of focus groups (Litosseliti, 2003: 18-21)

As focus groups provide clues and insights into the possible reactions to the research questions (Oishi, 2003: 178), they were used to help the researcher to more fully understand how the Tablet PC was perceived as a design tool for generating concepts prior to creating a detailed questionnaire. Two focus groups were undertaken in this research, each with seven participants (BSc final year students and BA final year students).

\subsubsection{Observations}

"Observation is a purposeful, systematic and selective way of watching and listening to an interaction or phenomenon as it takes place" (Kumar, 2005: 119). Nevertheless, as the observation might be different from one observer to another, qualitative researchers argue on its credibility as a data collection method (Silverman, 1993: 9). This lead to a tendency of using observations at the beginning of research for an exploration of issues or towards the end to confirm the data collected using other methods (Foster, 1996: 58, Silverman, 1993: 9). While the main benefit of observation is its directness in collecting data without asking questions, the actions and behaviour of the participants might change as result of being observed (Robson, 2002: 310-311). The advantages and limitations of observations are summarised in Table 4-11. 


\begin{tabular}{|c|c|}
\hline Strengths & Weaknesses \\
\hline $\begin{array}{l}\text { - Information can be recorded directly } \\
\text { without having to rely on retrospective or } \\
\text { anticipatory accounts of others that may be } \\
\text { inaccurate } \\
\text { - Possibility of observing what participant } \\
\text { cannot } \\
\text { - Providing information of those who are busy } \\
\text { or cannot speak for themselves } \\
\text { Useful in checking the information obtained } \\
\text { from other data collection methods }\end{array}$ & $\begin{array}{l}\text { - Inaccessibility of some environments, events } \\
\text { or behaviours } \\
\text { - Possibility of participants behaviour changes } \\
\text { as a result of being observed } \\
\text { - Observations are filtered by the observer's } \\
\text { interpretation } \\
\text { - Time consuming and therefore costly }\end{array}$ \\
\hline
\end{tabular}

Table 4-11: Strengths and weaknesses of observation (Foster, 1996: 58-60)

Kumar (2005: 120) suggests two types of observation: participant observation (investigator gets involved in the activities with the participants) and non-participant observation (researcher just observes the participants). In this research, non-participant observation was chosen to examine the student use of the Tablet PC as a sketching tool without interfering with their design activity. This allowed the investigator to watch, follow and record the tasks undertaken and become aware of any issues that were not previously raised by students.

\subsection{Data Analysis}

The process of analysis includes exploring things behind the surface content of data (Denscombe, 2007: 247). It involves transferring complex phenomena into basic elements to provide a clearer understanding (Denscombe, 2007: 97). Swift (1996: 153) states that it is "the process of transforming 'raw' data into variables that can be analysed to produce the information found in the results sections of such reports".

In this research, two types of data analysis were used: quantitative (use of numbers as the unit of analysis) and qualitative (use of words and images as the unit for analysis) (Denscombe, 2007: 248). Swift (1996: 153) comments that the use of numbers in quantitative data analysis provides more accurate analysis without misinterpretations while qualitative data use words to provide "breadth and uniqueness" (Fink, 2003: 68).

Coding is an essential aspect of data analysis, but "coding and analysis are not synonymous" (Basit, 2003: 145). In general, coding or categorising (Basit, 2003: 144) is used to simplify responses by grouping them into a limited number of categories to allow statistical analysis and simple explanation of the data (Robson, 2002: 257, Gibbs, 2002: 3, Miles and Huberman, 1994: 56). 
Table 4-12 identifies the research methods that generate quantitative data, while Table 4-13 illustrates the sources for qualitative data. The general phases in quantitative and qualitative data analysis can be found in Table 4-14.

\begin{tabular}{|c|c|}
\hline Numbers & Research method \\
\hline - Answers to closed-ended questions & Questionnaires \\
\hline - $\quad$ Content analysis of transcripts & Interviews \\
\hline $\begin{array}{l}\text { - } \quad \text { Measurements from experiments } \\
\text { - Observations schedule used with events }\end{array}$ & Observation \\
\hline 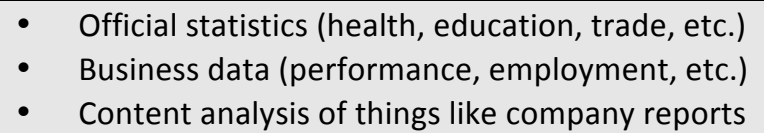 & Documents \\
\hline
\end{tabular}

Table 4-12: Sources of quantitative data (Denscombe, 2007: 254)

\begin{tabular}{|c|c|}
\hline Words and visual images & Research method \\
\hline $\begin{array}{ll}- & \text { Interview talk } \\
\cdot & \text { Narratives (for life histories) }\end{array}$ & Interviews \\
\hline $\begin{array}{l}\text { - } \quad \text { Diaries, minutes of meetings } \\
\text { - Scripts (e.g. for political speeches or media programmes) }\end{array}$ & Documents \\
\hline $\begin{array}{l}\text { - Interactions between people (including naturally occurring actions, } \\
\text { - } \text { - Events (e.g. ceremononies, rituals, performances) } \\
\text { - }\end{array}$ & Observation \\
\hline - Answers to open-ended questions & Questionnaires \\
\hline
\end{tabular}

Table 4-13: Sources of qualitative data (Denscombe, 2007: 287) 


\begin{tabular}{|c|c|c|}
\hline Stage & Quantitative data & Qualitative data \\
\hline 1. Data preparation & $\begin{array}{l}\text { - } \quad \text { Coding (which normally takes } \\
\text { place before data collection) } \\
\text { - } \quad \text { Categorising the data } \\
\text { - Checking the data }\end{array}$ & $\begin{array}{l}\text { - } \quad \text { Transcribing the text } \\
\text { - } \quad \text { Cataloguing the text or visual } \\
\text { data } \\
\text { - } \\
\text { Preparation of data and loading } \\
\text { to software (if applicable) }\end{array}$ \\
\hline $\begin{array}{l}\text { 2. Initial exploration of } \\
\text { the data }\end{array}$ & $\begin{array}{l}\text { - Look for obvious trends or } \\
\text { correlations }\end{array}$ & $\begin{array}{l}\text { - Look for obvious recurrent } \\
\text { themes or issues } \\
\text { - } \quad \text { Add notes to the data } \\
\text { - Write memos to capture ideas }\end{array}$ \\
\hline 3. Analysis of the data & $\begin{array}{l}\text { Use of statistical test, e.g. } \\
\text { descriptive statistics, factor } \\
\text { analysis, cluster analysis } \\
\text { - Link to research questions or } \\
\text { hypotheses }\end{array}$ & $\begin{array}{l}\text { - } \text { Code the data } \\
\text { - Group the codes into categories } \\
\text { or themes } \\
\text { - Comparison of categories and } \\
\text { themes } \\
\text { Quest for concepts (or fewer, } \\
\text { more abstract categories) that } \\
\text { encapsulate the categories }\end{array}$ \\
\hline $\begin{array}{l}\text { 4. Representation and } \\
\text { display of the data }\end{array}$ & $\begin{array}{ll}\text { - } & \text { Tables } \\
\text { - } & \text { Figures } \\
\text { - } & \text { Written interpretation of the } \\
& \text { statistical findings }\end{array}$ & $\begin{array}{l}\text { Written interpretation of the } \\
\text { findings } \\
\text { - Illustration of points by quotes } \\
\text { and pictures } \\
\text { Use of visual models, figures } \\
\text { and tables }\end{array}$ \\
\hline $\begin{array}{l}\text { 5. Validation of the } \\
\text { data }\end{array}$ & $\begin{array}{ll}\text { - } & \text { External benchmarks } \\
\text { - } & \text { Internal consistency } \\
\text { - } & \text { Comparison with alternative } \\
\text { explanations }\end{array}$ & $\begin{array}{l}\text { - } \quad \text { Data and method triangulation } \\
\text { - } \quad \text { Member validation } \\
\text { - } \quad \text { explanations } \\
\text { expith alternative }\end{array}$ \\
\hline
\end{tabular}

Table 4-14: The five main stages of data analysis adapted from Creswell and Clark (2007:

The processes used in quantitative and qualitative data analysis will now be discussed.

\subsubsection{Quantitative Data Analysis}

The process of quantitative data analysis usually starts with coding (2007: 129). Codes are usually numbers that are assigned to identify specific answer categories (Robson, 2002: 256). Coding "consists of applying a preestablished set of categories to the data according to explicit, unambiguous rules, with the primary goal being to generate frequency counts of the items in each category" (Maxwell, 1996: 78). Figure 4-4 is an example of the numerical coding system used in a questionnaire that employed closed-ended questions. 
B. Design Methods Usage:

How often do you use each method when designing a product?

1. Sketches (e.g. 2D side view sketches, 3D perspective sketches, investigative and explorative sketches, explanatory sketches):

1.1 Freehand paper-based sketches (produced on paper using pencils, pens, ink, airbrush, pastels, markers, etc)

1.2 Digital sketches (produced using Alias Sketchbook, Corel Painter, Adobe Photoshop, digitizing tablets, etc)

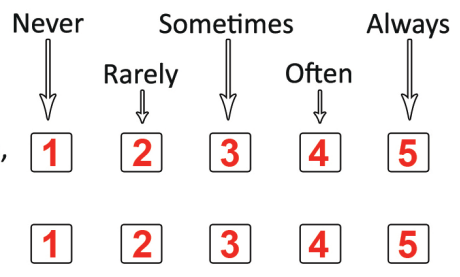

2. Sketch models also known as 'mock up models', 'soft models' and 'development models' (e.g. 2D card models, 3D Styrofoam, wax models):

2.1 Norkshop-based sketch models (produced using cutting knife, sanding paper, rule, saw, pencil, etc)

2.2 Digital sketch models (produced using Z Corp rapid prototype machine, Haptic feedback device with Sensable Phantom Freeform system, computer numerical control machines, etc)

3. Appearance models (models that communicates the form only):
3.1 Workshop-based appearance models (produced using conventional workshop techniques)
3.2 Digital appearance models (produced using modelling software, rapid prototyping, computer numerical control machines, etc)
4. Renderings also known as 'presentation drawings' and 'persuasive sketches' (e.g. 2D side view renderings, 3D isometric renderings):

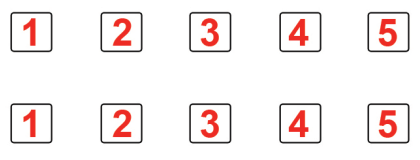

4.1 Manual paper-based renderings (produced using pencils, pens, papers, boards, ink, airbrush, pastels, markers, etc)

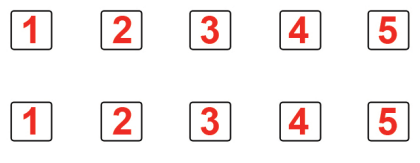

Figure 4-4: Sample of the coding system (in red) used in one of the questionnaires employed in the research

While the use of nominal data (originating from counting and grouping) was limited in this research, ordinal data (from counting and placing in ordered and ranked categories) was largely employed (Denscombe, 2007: 255). As the coding system provided a simple statistical text, spreadsheet software (Microsoft Excel) was used to perform the required tasks (Robson, 2002: 392). The numbers (codes) representing the data were keyed into the spreadsheet software (Figure 4-5). The data was printed and occurrences calculated manually before entering in Microsoft Excel. After identifying the occurrence of each reply category, the percentage was calculated by dividing the number of the occurrence by the total number of participants and then multiplying the result by 100 (Occurrence $\div$ Total number of participants $\times 100=$ Percentage) $($ Figure 4-6). 


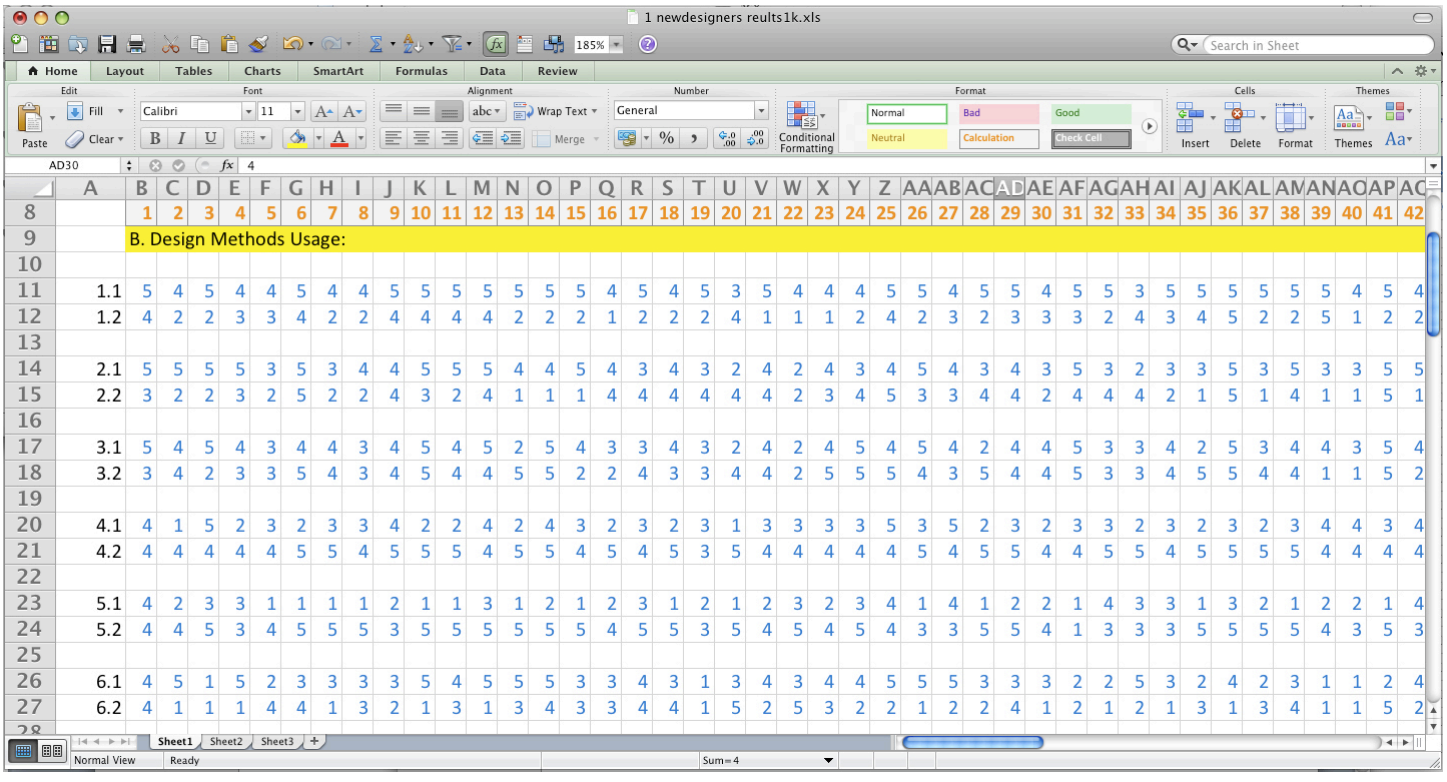

Figure 4-5: Quantitative data entering in Microsoft Excel

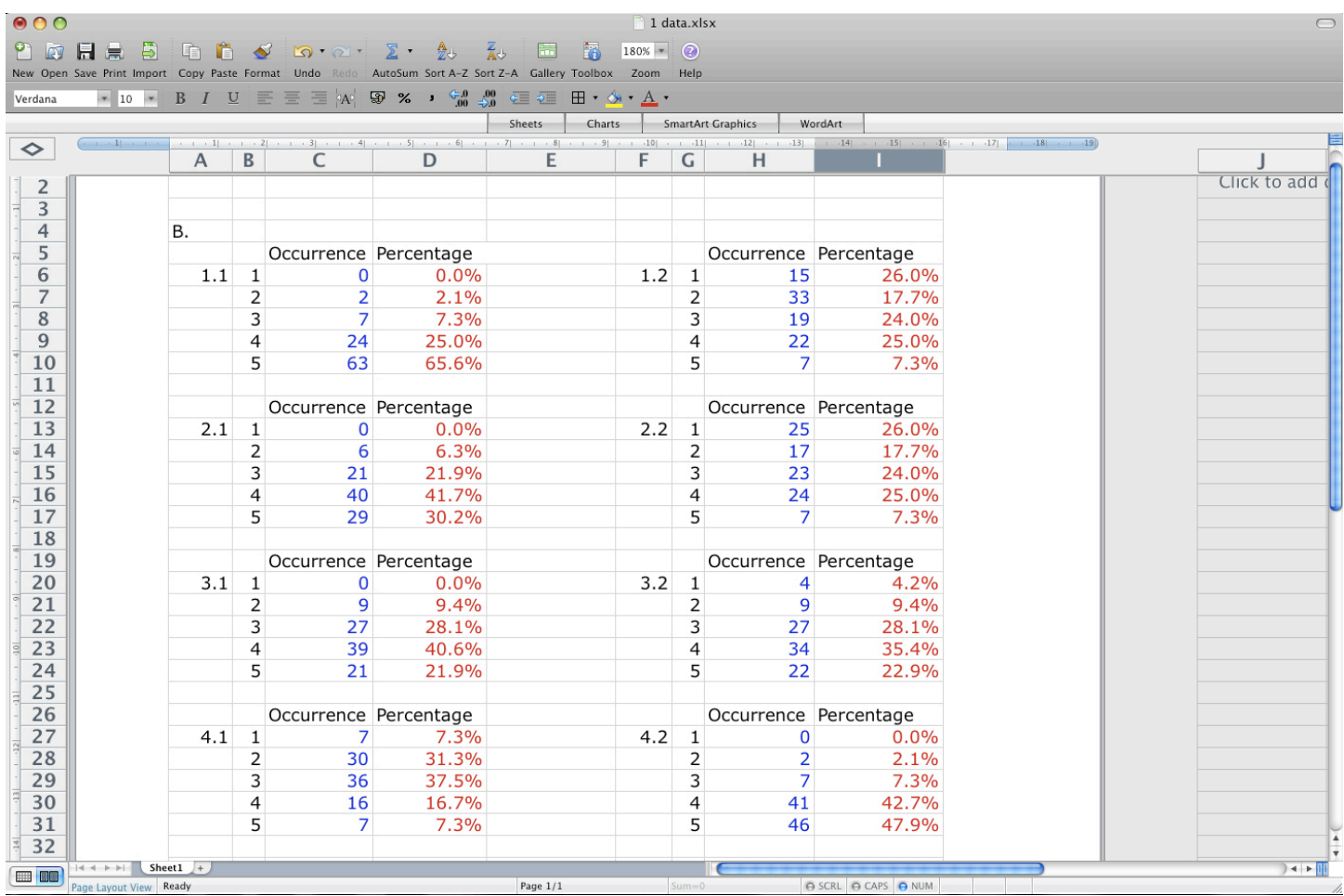

Figure 4-6: Using Microsoft Excel to key in the results of the calculations

In this research, quantitative data results were represented using charts within the same spreadsheet package (Microsoft Excel) and bar charts were selected to show the amounts or frequencies data in an effective and simple way (Denscombe, 2007: 274). 


\subsubsection{Qualitative Data Analysis}

In quantitative analysis, computers undertake calculations needed to create the statistics. In qualitative data, "the real heart of the analysis requires an understanding of the meaning of the texts, and that is something that computers are still a long way from being able to do" (Gibbs, 2002: 10).

The first step of qualitative data analysis involves preparing the data by producing transcripts of the recorded or written information. Swift (1996: 169) argues that taking notes and listening is not always sufficient for this process. Transcripts are beneficial in making the researcher get closer to the data by listening to the recordings several times while typing the transcript, thereby providing an opportunity to reveal features that were not previously acknowledged (Silverman, 2000: 150).

The coding applied is different when dealing with qualitative data as apposed to quantitative data. In qualitative data (open questions), a code "is most often a word or short phrase that symbolically assigns a summative, salient, essence-capturing, and/or evocative attribute for a portion of language-based or visual data" (Saldana, 2009: 3). The categorising should enable the research to compare the data between the assigned categories (Maxwell, 1996: 78) and data could also be sorted into boarder themes (Maxwell, 1996: 79). Saldana (2009: 10) suggests that coding and recoding is a common practice when dealing with qualitative data as it is rare to get the coding right the first time due to the special attention required for language and interpretations.

Content analysis is mainly used to analyse interviews and questionnaire (open-ended questions) textual data (Robson, 2002: 351, Tonkiss, 2004: 368, Silverman, 1993: 59). It is built on the researchers' assumptions and understanding of the text meaning (Edwards and Talbot, 1999: 121). "It involves establishing categories and then counting the number of instances when those categories are used in a particular item of text" (Silverman, 1993: 59). When used in small surveys, content analysis is usually carried out by hand, but in larger surveys it is usually undertaken with computers as they help in the organisation of data and coding (Fink, 2003: 73).

A word processing package (Microsoft Word 2008) was used to transcribe the qualitative data. However, because of the substantial amount of qualitative data collected in the research, it was decided that a specialist qualitative data analysis package (NVivo) would be beneficial to increase efficiency (Robson, 2002: 456). NVivo software, which is a version of 
NUD*IST (Non-numerical Unstructured Data, Indexing Searching and Theorising) (Basit, 2003: 148), was chosen due to its capacity to provide a simple application of codes for a selection of text, plus the facility to retrieve the similar coded text (Gibbs, 2002: 11). Furthermore, it was used to assist in managing the collection of documents (transcribed data, annotations, images and memos), which can all be coded to nodes (tree nodes, child nodes and free nodes) (Gibbs, 2002: 17).

After transferring the textual data from Microsoft Word to NVivo 9, memos were created to summarise feedback and insights from each interview. Units that dealt with the same topic were clustered and then divided into topics and subtopics. Codes generated at the start of the analysis were developed and revised as the process continued which is a natural approach to coding (Miles and Huberman, 1994: 61). Figure 4-7, Figure 4-8 and Figure 4-9 illustrate the different components and features used in Nvivo 9 to analyse the data. 


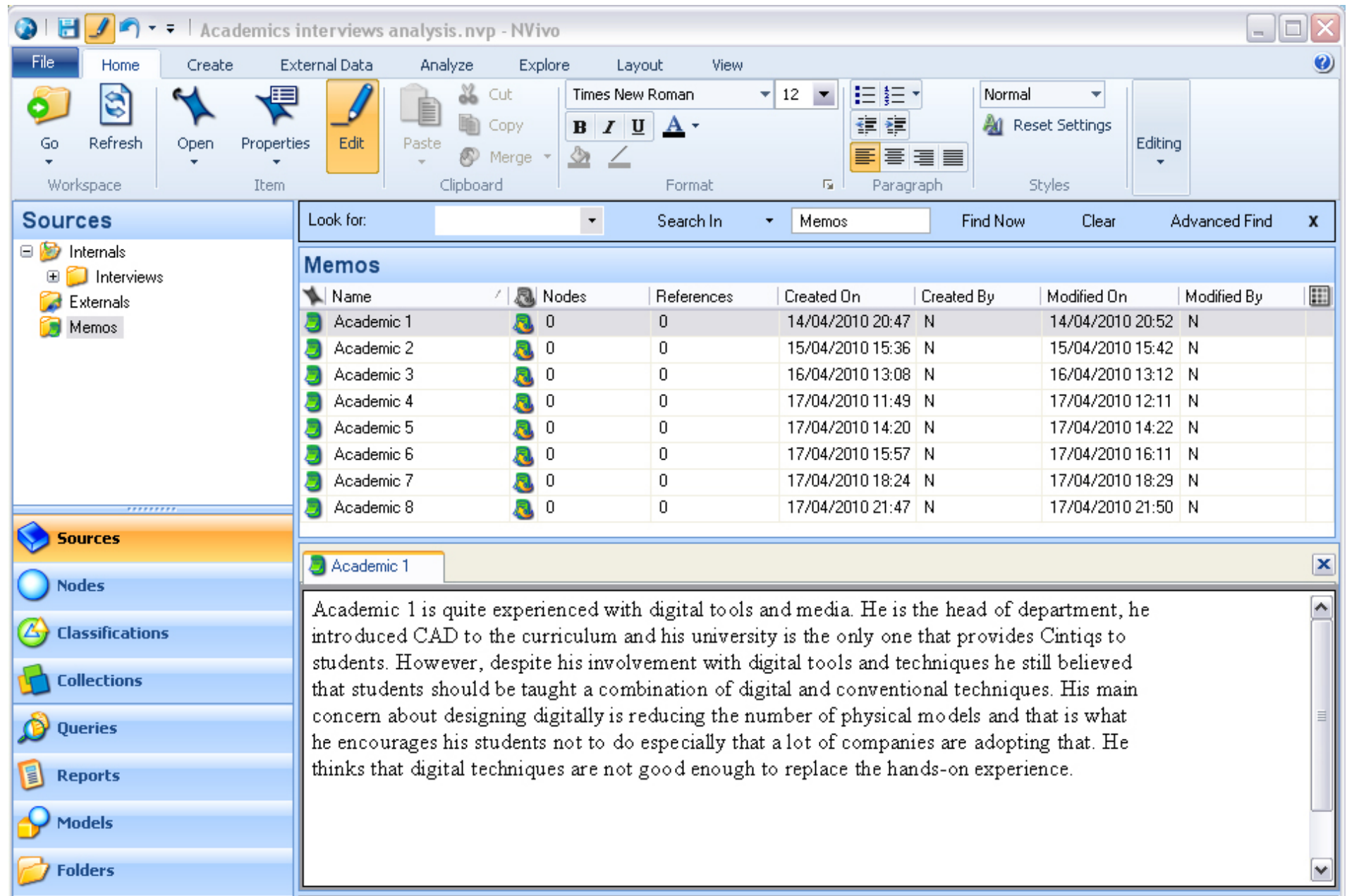

Figure 4-7: Example of the use of memos in NVivo 9 to summarise the feedback from each participant and record thoughts in the academic interviews

analysis 


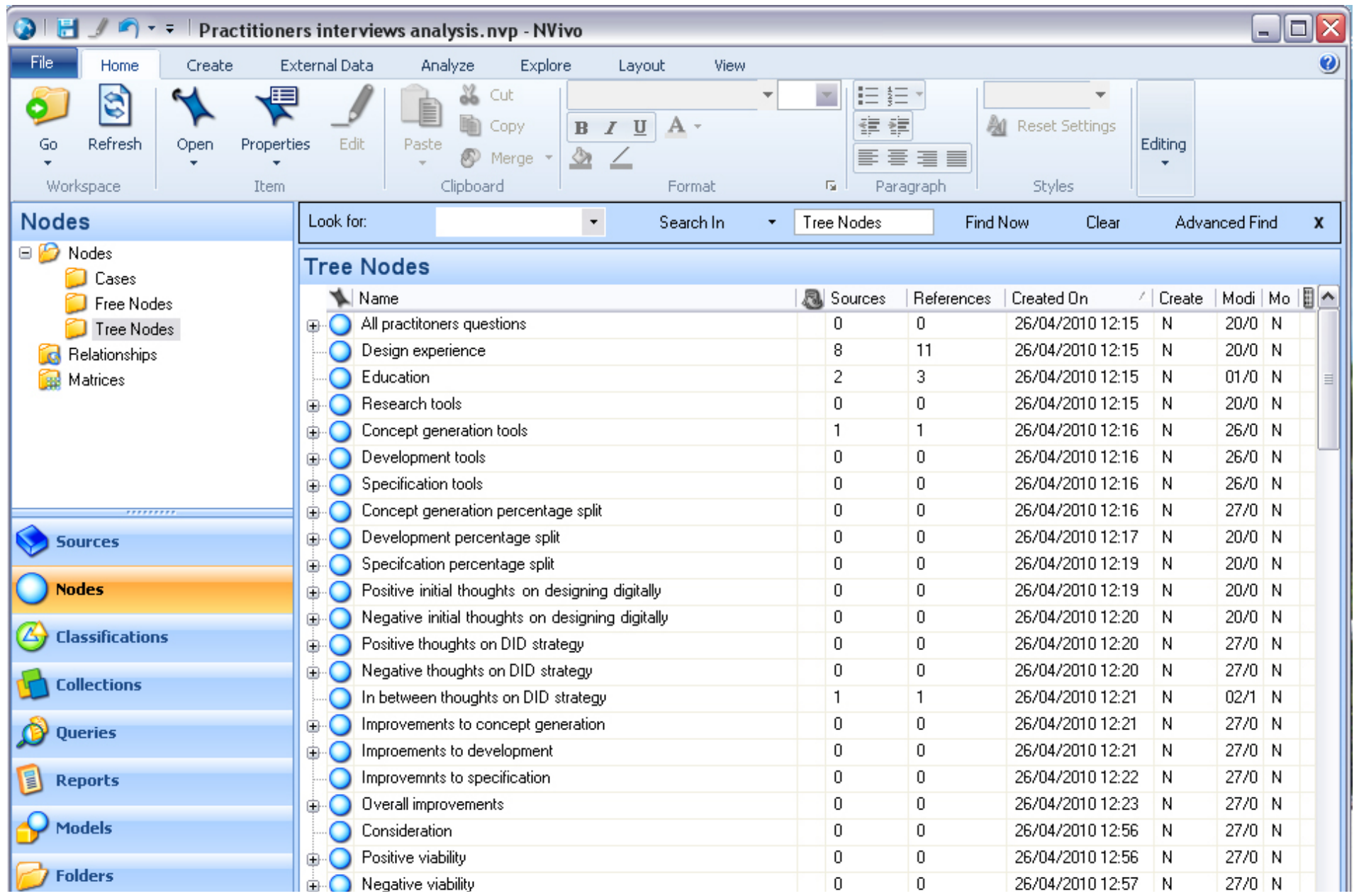

Figure 4-8: Example of the use of tree nodes in NVivo 9 to help organise the data in the practitioner interviews analysis 


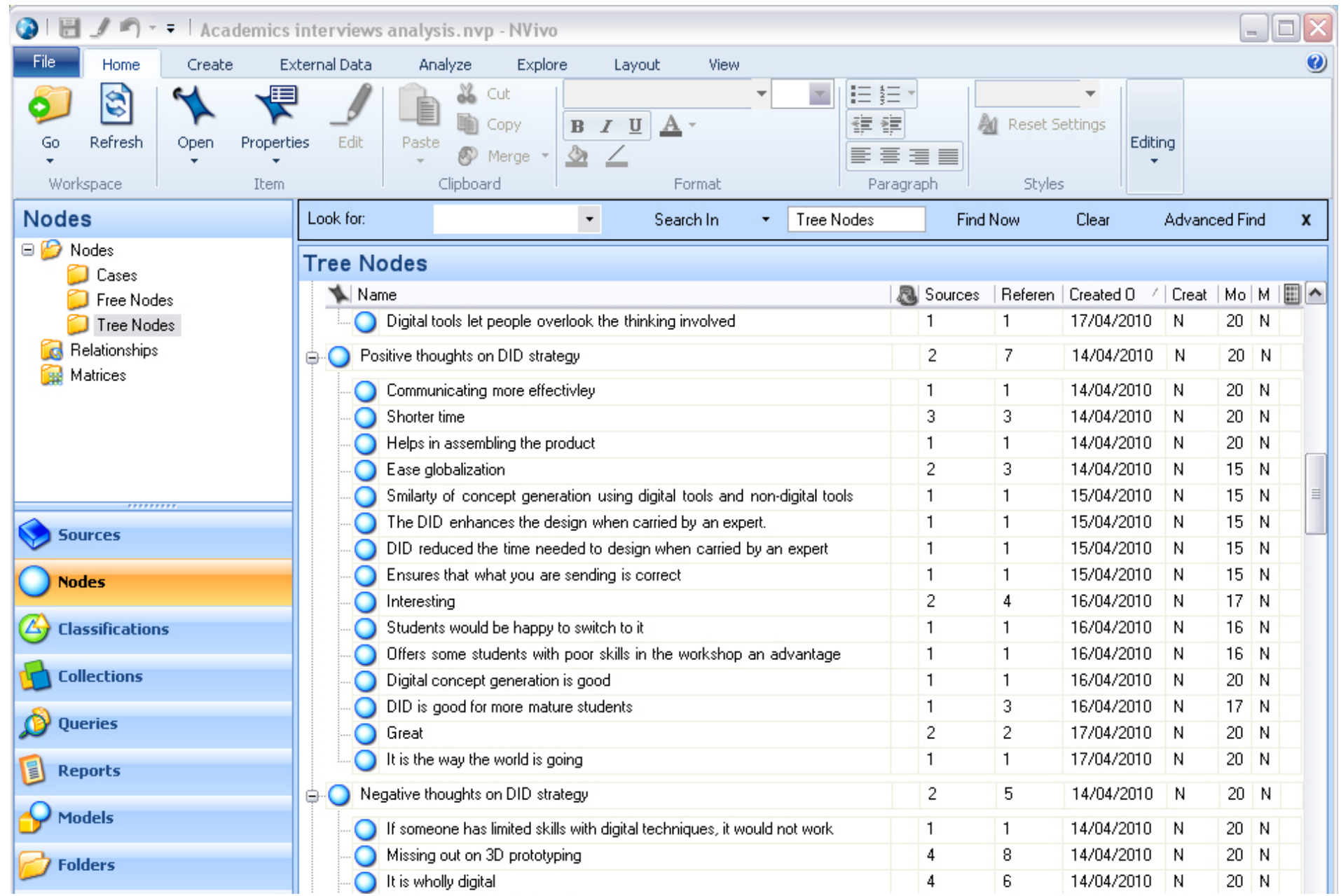

Figure 4-9: Example of the use of general category (parent node) and more specific categories (child nodes) in NVivo 9 to analyse the academic interviews 


\subsection{Reliability and Validity}

Reliability "refers to the degree of consistency with which instances are assigned to the same category by different observers or by the same observer on different occasions" (Hammersley, 1992: 67). In other words, reliability is concerned with reproducing similar results from the data collection methods used when the procedures are repeated again (Seale, 2004: 72, Wilson, 1996: 117-118). Reliability is different from validity as "validity refers to the degree to which a survey instrument actually measures what it purports to measure" (Fink, 2003: 50). Validity is dependable on the "relationship of your conclusions to the real world" (Maxwell, 1996: 86). Silverman (2000: 188) suggests that when a very limited number of instances are detailed; criteria for including specific instances and not others is not clear; or when the original form of material is not included, the research is not valid. To ensure that the data collected and results were reliable and viable, the following procedures were taken in terms of quantitative and qualitative data:

\subsubsection{Quantitative Data}

From the beginning of design phase of quantitative research, reliability and validly should be taken into account (Kelly, 2004: 131). "This may involve specifying a sample size sufficient to perform the statistical analysis necessary to answer the research question" (Kelly, 2004: 131). When reviewing the current strategies for design practice in education and receiving feedback from students regarding the DID strategy, a sample size that included students from at least 15 UK-based universities was targeted to ensure that the data reflected a large enough sample from different educational institutes.

In general, the context to which participants are asked to answer questions can affect their responses (Wilson, 1996: 118). Therefore, to match the context to the participants' experience, only industrial design students completed the questionnaires.

Apart from the online questionnaire that was undertaken by students who had successfully completed a placement where data was constructed automatically, all of the data collected whilst undertaking the research was entered manually. This required the researcher to check the data to ensure that no mistakes were made during data entry (Denscombe, 2007: 282).

\subsubsection{Qualitative Data}

"The contemporary search for reliability in qualitative observation revolves around detailing the relevant context of observation" (Kirk and Miller, 1986: 52). During the non-participant 
observation in the Tablet PC case study, short notes were made at the time and then expanded notes were made when required. These notes included the problems faced, ideas identified by students to solve the problems, and benefits of using the Tablet PC.

Silverman (1993: 148) emphasises the importance of making sure that the interviewees understand the questions clearly and that coding of the data is done without any ambiguity. Piloting the interviews and double-checking the data analysis of the interviews fulfilled this issue.

In terms of qualitative data validity, Maxwell (1996: 89) suggests that the main cause of invalid descriptions is the inaccuracy and incompleteness of the data. In order to avoid this, interviews and focus group data were recorded then transcribed at a later stage. Another threat identified by Maxwell (1996: 89-90) is "imposing one's own framework or meaning, rather than understanding the perspective of the people studied and the meanings they attach to their words and actions". This potential problem was avoided by summarising the participant opinion whenever required during the interview or focus group before asking the next question.

According to Silverman (1993: 92) the aim of an interview "is to generate data which hold independently of both the research setting and the researcher or interviewer". In order to achieve this, semi-structured interviews were undertaken with a list of standard questions that were asked precisely as worded and in the same order. This allowed data collected from one interview to be compared with another.

\subsection{Research Methodology}

The findings from the previous sections in this chapter facilitated the generation of a five phase research methodology to answer the research questions.

Phase 1 of the research methodology is the literature review to provide a solid background for the research. It investigates the field of industrial design practice and education. It illustrates the nature of DID practice and addresses its strengths and weaknesses along with the attitude towards it. It defines the existing and emerging digital design tools and reviews data collection methods and analysis to provide the basis for the development of the draft DID strategy. 
Phase 2 is student/practitioner feedback on digital design methods. It defines the current conventional and digital design methods used in education and professional practice. It identifies the extent to which digital methods were recently employed and seeks opinion on a totally DID process and programme of study through a supervised collective questionnaire with graduating students and online questionnaires with industrial placement students and practitioners.

Phase 3 is the development and appraisal of the DID strategy. It defines a draft DID strategy based on the findings from Phases 1 and 2 . In addition, semi-structured interviews are conducted with academics and practitioners to assess the DID strategy. Feedback is sought from graduating students through a supervised collective questionnaire. This phase ends with modifications to the draft DID strategy based on the analysis of data collected, to produce a revised DID strategy.

Phase 4 is the evaluation of the Tablet PC as a tool for concept generation. It implements a case study approach with industrial design students. Within the case study, non-participant observations are undertaken while students are using the Tablet PCs for sketching and designing. Focus groups are carried out to provide a greater understanding of the use of the Tablet PC from a student perspective. The phase implements four different supervised collective questionnaires with students to investigate their opinion towards DID and evaluate the use of the Tablet PC as a design tool for concept generation. A postal questionnaire is employed with academics to assess the digital and non-digital sketches produced by students during the case study.

Phase 5 is the discussion and conclusions. It collates and discusses the research materials to draw together recommendations for industrial design education. The five phase research methodology is illustrated in Figure 4-10. 
PHASE 1: LITERATURE REVIEW

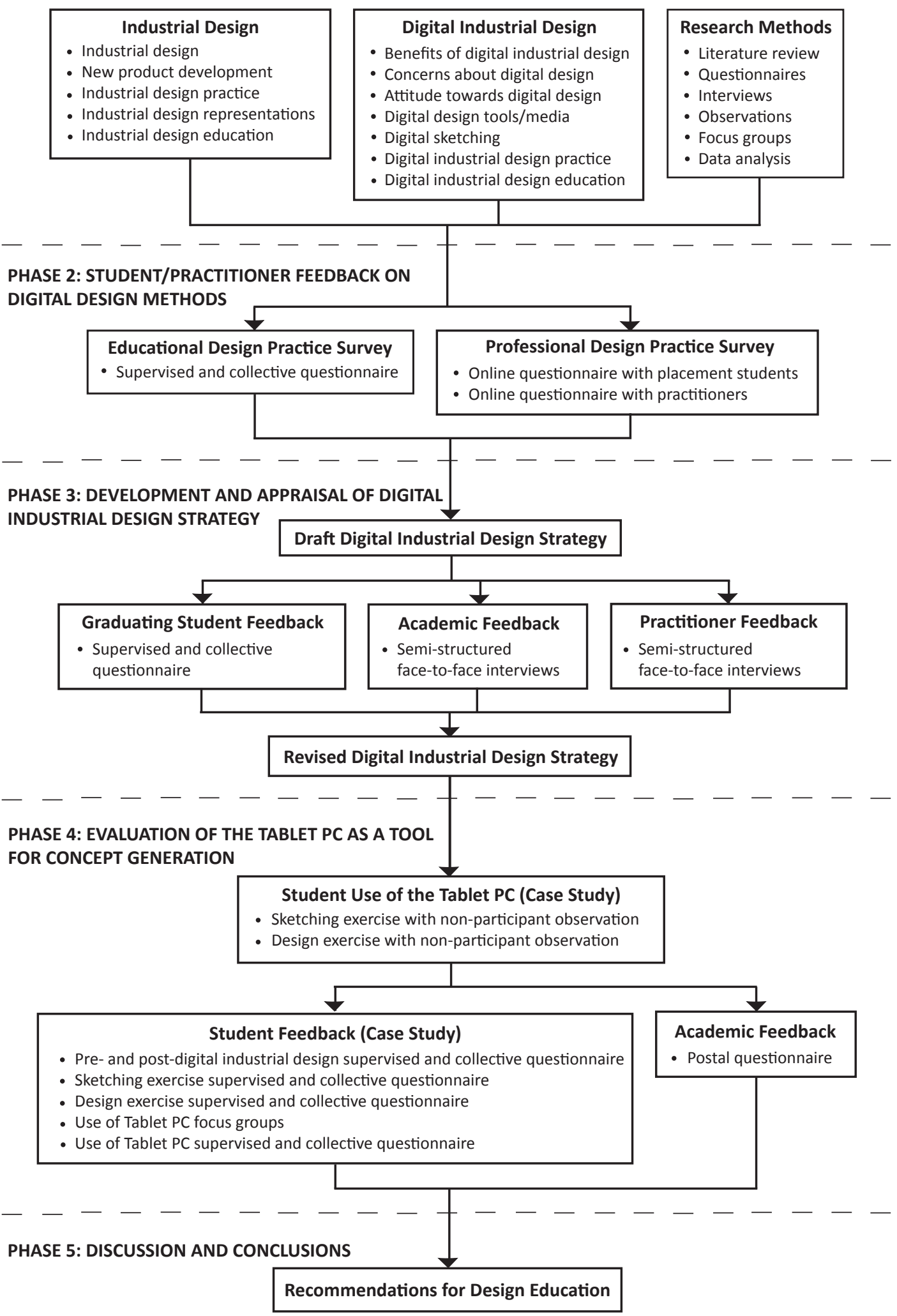

Figure 4-10: Five phase research methodology 


\subsection{Chapter Summary}

The research purpose of enquiry was of an exploratory nature to provide insights into the viability of DID. Mixed methods research approach, that integrates quantitative and qualitative research, was selected as the research type of design to broaden the outcome. Case study, surveys and sequential and concurrent mixed methods were employed as strategies of enquiry.

Data in this research was collected from a literature review, supervised collective questionnaires, online and postal questionnaires, face-to-face interviews, focus groups and observations. In terms of data analysis, quantitative data was analysed using coding with the support of Microsoft Excel and manual calculations, while qualitative data was analysed after being transcribed using coding and content analysis with NVivo software.

In order to meet the research aim and objectives, the data collection methods were integrated into a five phase research methodology, involving literature review; student/practitioner feedback on digital design methods; development and appraisal of DID strategy; evaluation of the Tablet PC as a tool for concept generation; and discussion and conclusions. 


\section{DESIGN PRACTICE}

This chapter focuses on the nature of educational and professional industrial design practice. It investigates the conventional and digital methods used and focuses on the extent to which digital technologies are employed. It demonstrates initial opinions towards having a completely digital workflow.

\subsection{Overview}

The studies in this chapter were undertaken to more fully understand the current use of digital tools in undergraduate education and professional practice. The aim of the studies was to:

- Identify the conventional and digital design methods used by graduating students and professional designers.

- Establish how easy it was for graduating students to use digital tools.

- Determine the extent to which digital tools were employed during different stages of the design process in educational and professional practice.

- Highlight areas of the industrial design curriculum that might be improved through the use of digital methods.

- Gather opinion on the potential of employing entirely digital techniques during industrial design practice.

\subsection{Research Methods}

Opinion was sought from three groups of industrial designers: graduating students (one month after completion of their degree); final year students who had completed an industrial placement; and practitioners with three or more years experience. The research methods used will now be discussed. 


\subsubsection{7/2008 Graduating Student Supervised Collective Questionnaire}

The population of graduating students comprised industrial design graduating students who had completed their degree at a university in the UK and probability samples were used in the study. To give each person an equal chance of being included in the samples and to facilitate all possible combinations, a random selection from the sampling frame was undertaken (simple random sampling) (Robson, 2002: 261). Two visits to the New Designers Exhibition in London were made in July 2008, where graduating industrial design students were asked to participate in the study that took approximately 10 minutes to complete. A total of 100 graduating students responded to the survey. Four questionnaires out of the 100 were not completely filled in by the respondents and removed from the survey.

A group administered self-completed questionnaire, that allowed the researcher to introduce the study and clarify needed issues, was undertaken by graduating students (Bourque and Fielder, 2003: 8). Based on the type of information required, the questionnaire was divided into seven sections: background; design methods usage; digital design tool use; use of digital methods; thoughts on employing digital techniques; areas of improvements; and reflections on a completely digital process. In order to capture both quantitative and qualitative data, a mixed methods research approach was employed. This was used to generalise the findings to a population and develop a detailed view of a concept for individuals (Creswell, 2003: 22). A combination of closed-ended questions and open-ended questions were used. Five point Likert scale enabled respondents to have a 'neutral' middle point thereby increasing the accuracy of responses (Intelligent Measurements, 2008).

Robson (2002: 238) proposes the use of cards as visual aids to assist when carrying out a questionnaire and this was undertaken using three $A 4$ cards which were shown before the interviewees were asked to complete the questionnaire. The literature review revealed that authors divide the design process into three, four, five or six phases. In the visual aids four phases were used to show the industrial design process based on the main phases identified by Ulrich and Eppinger (2003: 196-197). These phases were conceptualisation, preliminary refinement, further refinement and final concept selection, and specification. The phases were specifically chosen because they simplified the industrial design practice without being too general. It also avoided overlapping or neglecting the main types of representation used at each phase. Examples of the tools and outputs used at the different phases were extracted mainly from a range of books such as 'Design Secrets' (Cullen et al., 2004, Industrial Designers Society of America, 2001), 'Drawing for Designers' (Pipes, 2007) and 
'Sketching: Drawing Techniques for Product Designers' (Eissen and Steur, 2007). The visual aids illustrated comparative analysis between non-digital and digital methods of designing (Figure 5-1); current design practice (Figure 5-2); and a schematic diagram for a totally DID process (Figure 5-3). During the questionnaire briefing, graduating students were asked to complete the questionnaire based on the project being presented at New Designers Exhibition. The questionnaire can be found in Appendix 11.1.

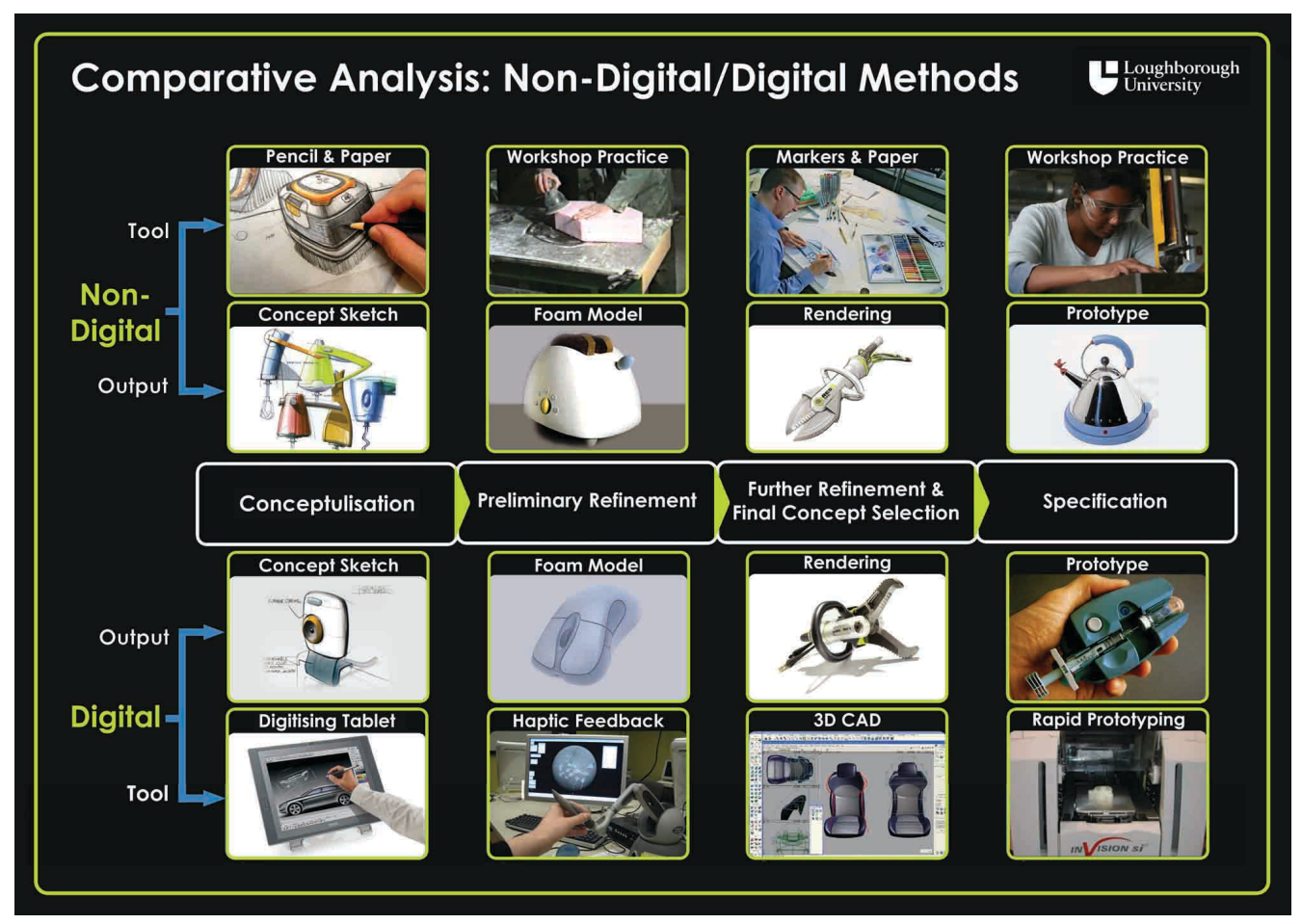

Figure 5-1: First visual aid card used to illustrate non-digital and digital methods of designing 


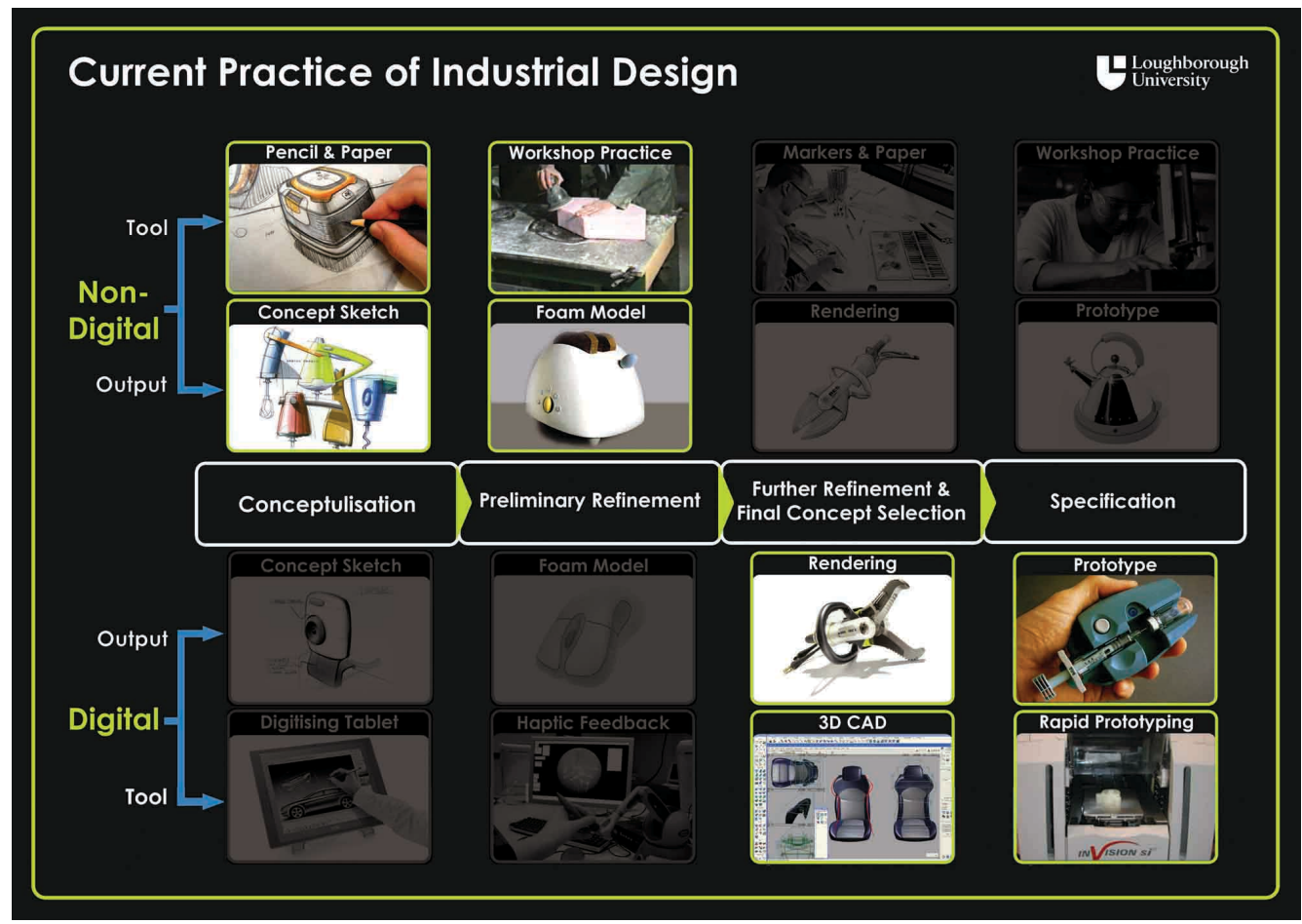

Figure 5-2: Second visual aid card used to show the current practice of industrial design (unused tools and outputs ghosted)

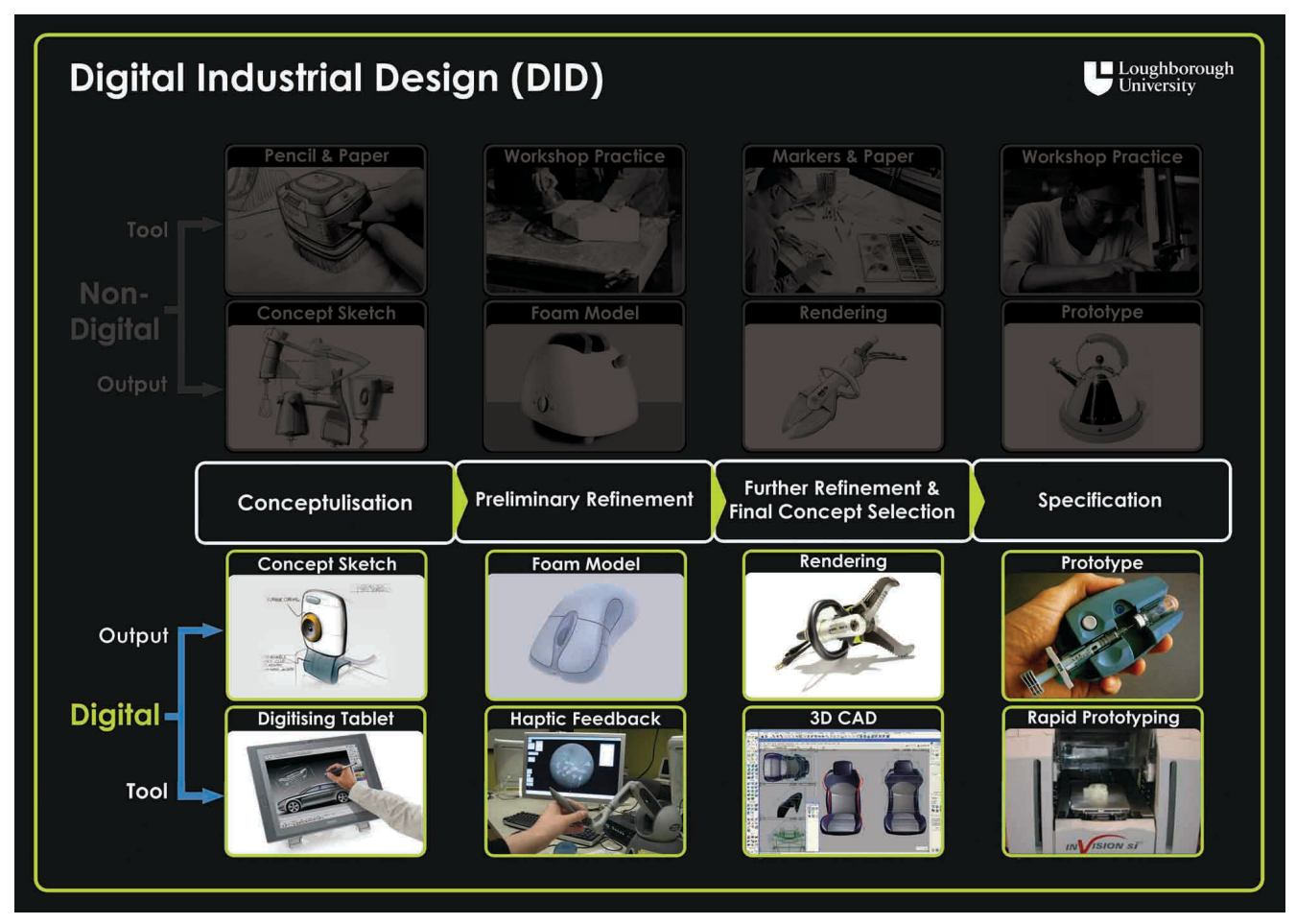

Figure 5-3: Third visual aid card used to show the proposed digital way of designing (unused tools and outputs ghosted) 
A pilot study was undertaken to gauge the length of time required for completion and to investigate whether the questions were properly understood by the respondents (Wilson, 1996: 102). Ten finalist industrial design undergraduates were invited to fill in the questionnaire, which was then revised by making minor changes to the language and format used to make it easier to understand (Robson, 2002: 254). An example of the changes made was asking a general question in the beginning of Section C. Thoughts on Employing Digital Techniques: "To what extent do you agree or disagree with the following?". The general question was followed by four statements instead of repeating the question for each statement made.

\subsubsection{Industrial Placement Student Online Questionnaire}

The population of this study was 2008/2009 final year students in the UK who had successfully completed a placement year in $2007 / 2008$. It was decided that surveying these students after they had spent a year in industrial design organisations would be efficient to report the methods used in professional practice. An e-mail was sent to all final year industrial design placement students at Loughborough University with a link to an online questionnaire. A total of 26 students responded to the questionnaire but only 17 were fully completed.

The Survey Methods website was used to create the online questionnaire. The website was free of charge and selected due to its ease of use and the ability to automatically analyse the responses to the closed-ended questions. The full questionnaire can be found in Appendix 11.2 .

The questionnaire involved 37 questions that were of similar content to the 2007/2008 graduating student questionnaire, covering a range of sections depending on the type of information gathered. These sections are: background; design methods usage; digital design tools; use of digital methods in the design process; and thoughts on employing digital techniques. A mixed methods approach was adopted in this questionnaire through the use of a range of closed-ended questions with five Likert categories along with open-ended question to identify reasons or list the digital tools and media used.

\subsubsection{Practitioner Online Questionnaire}

A third source of data came from the IDSA LinkedIn group. As the author is not a member of the IDSA, Dr Mark Evans published an online questionnaire on behalf of the researcher. In order to identify the thoughts of practitioners on employing digital techniques in their 
design practice, practitioners were asked to respond to four key questions. These questions asked for thoughts on achieving the same outcome if the entire process was done digitally; potential of digital technologies in replacing the conventional techniques; improvements in design practice if a completely digital process was employed; and finally appropriateness of having a totally DID course. Ten fully completed questionnaires were received from practitioners. Whilst the sample size was smaller than that for the graduating students or the final year students with work experience, the opinions expressed were based on extensive use of digital tools for commercial professional practice. The results from the practitioners facilitated a comparison with the opinions of the graduating students. The full responses to the questions can be found in Appendix 11.3.

\subsection{Results}

The supervised collective and online questionnaires were sub-divided into sections to make completing them easier. The rationale and findings for each section will now be discussed with reference to two previous studies that have some relevance to the work discussed in this chapter. These studies explored the use of virtual and physical modelling by 39 secondyear industrial design students (Charlesworth, 2007) and the significance of external design representations in a survey of 106 engineering designers and industrial designers (Romer et al., 2001). Results from the three groups of industrial designers will be compared and contrasted.

\subsubsection{Background}

The graduating student survey generated responses from 22 different universities with the highest number from any single institution being 11 . The majority of the respondents were male (75\%) and all respondents had completed an industrial design degree.

In the industrial placement student online questionnaire, 17 responses were received. All respondents had undertaken a placement as industrial designer during the 2007/2008 academic year in design organisations that included Nokia Design, Bombardier Transportation, Triumph Motorcycles, Hodges and Drake Design, Protean Design, Black and Blum, FSW Design and K6 Design Group. A majority of 14 students had spent 10-12 months on placement and five students were still working part time with the same placement organisation when the questionnaires were completed. The range and calibre of these 
organisations provided a high degree of credibility in terms of commercial industrial design practice.

Industrial design practitioners with 3, 7, 10, 10, 11, 16, 19, 20, 21 and 39 years of experience completed the online IDSA discussion. These practitioners were working in design organisations such as Fluke Corporation, Redpoint Studios, US Marine/Meridian Yachts, Hawking Technologies and IsoTech Design.

\subsubsection{Use of Traditional and Digital Design Methods}

\subsubsection{Sketches}

Pipes (2007) notes that most designers begin the design process by producing sketches (e.g. 2D side view sketches, 3D perspective sketches, investigative and explorative sketches, explanatory sketches) using pen and paper. This was confirmed in the survey as more than $90 \%$ of the graduating students said that they always/often used freehand paper-based sketches; $50 \%$ never/rarely used digital sketches that were produced using $2 \mathrm{D}$ computer visualisation software (e.g. Adobe Photoshop, Autodesk SketchBook Pro, Corel Painter); and only $7 \%$ always used digital sketches. Overall, freehand paper-based sketches were used considerably more than digital sketches but, despite the fact that digital sketching was not identified by Romer et al. (2001) and Charlesworth (2007), the results from the supervised collective questionnaire indicate extensive use of this technique in education (Figure 5-4). In terms of professional practice, the number of designers using freehand paper-based sketches and digital sketches often/always was similar with nine design organisations using freehand paper-based sketches and eight design organisations using digital sketches often/always (Figure 5-5). This could be due to the collaborative nature of professional practice. The implication for these findings is that education practice is not following professional practice and education may wish to explore the potential to reduce this imbalance by supporting/encouraging greater use of digital sketching. 


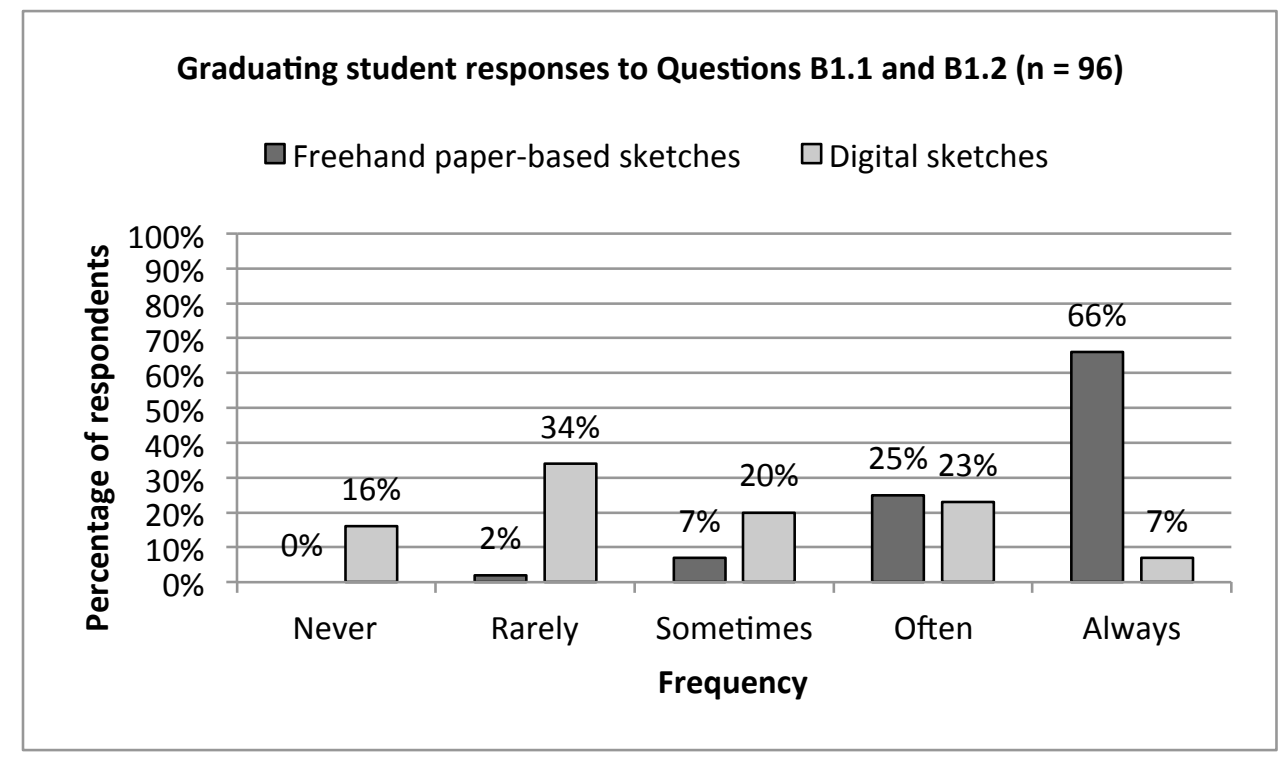

Figure 5-4: Graduating student responses to Questions B1.1 and B1.2: "How often do you use freehand paper-based sketches and digital sketches?"

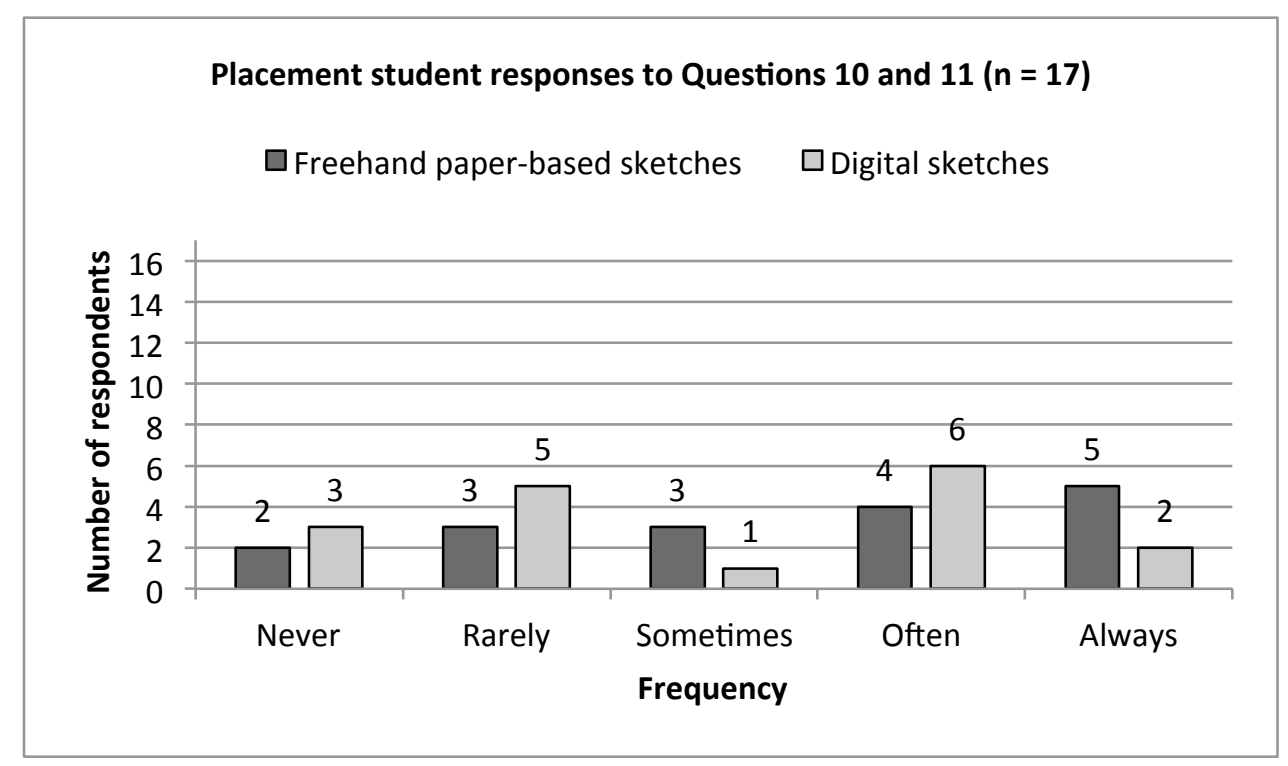

Figure 5-5: Industrial placement student responses to Questions 10 and 11: "How often did your design organisation use freehand paper-based sketches and digital sketches?"

\subsubsection{Sketch Models}

Sketch models are generally made from card and/or foam to enable designers to get a feel for concepts as 3D forms (Evans, 1992: 43). Results from the supervised collective questionnaire indicated that workshop-based sketch models were used more than digital sketch models since all of the graduating students had experience in using them. 
Extensive use of sketch models during concept design was identified by Romer et al. (2001: 483) where over $50 \%$ of the practitioners employed sketch models during concept generation. This contrasts with Charlesworth's (2007: 42) survey of final year undergraduate students in which "all respondents had omitted the sketch modelling phase" although further questioning revealed that this was not always the case. Why the students would not wish to declare their use of sketch models is unclear as results from the author's study indicate that all respondees had used physical sketch models and $74 \%$ had used digital sketch models. The number of the respondents that said that they always/often used workshop-based sketch models was $72 \%$. In contrast to this, $26 \%$ had never used any digital sketch models such as those produced using a Z-Corp RP machine or haptic feedback device (e.g. SensAble PHANTOM) and 32\% had used them on a regular basis (Figure 5-6).

When the industrial placement students were asked about the use of sketch models in their design organisation, results highlighted that two design organisations had never used workshop-based sketch models and another five had never used digital sketch models. However, most design organisations appeared to use a combination of workshop-based and digital sketch models and only one design organisation always used workshop-based sketch models (Figure 5-7).

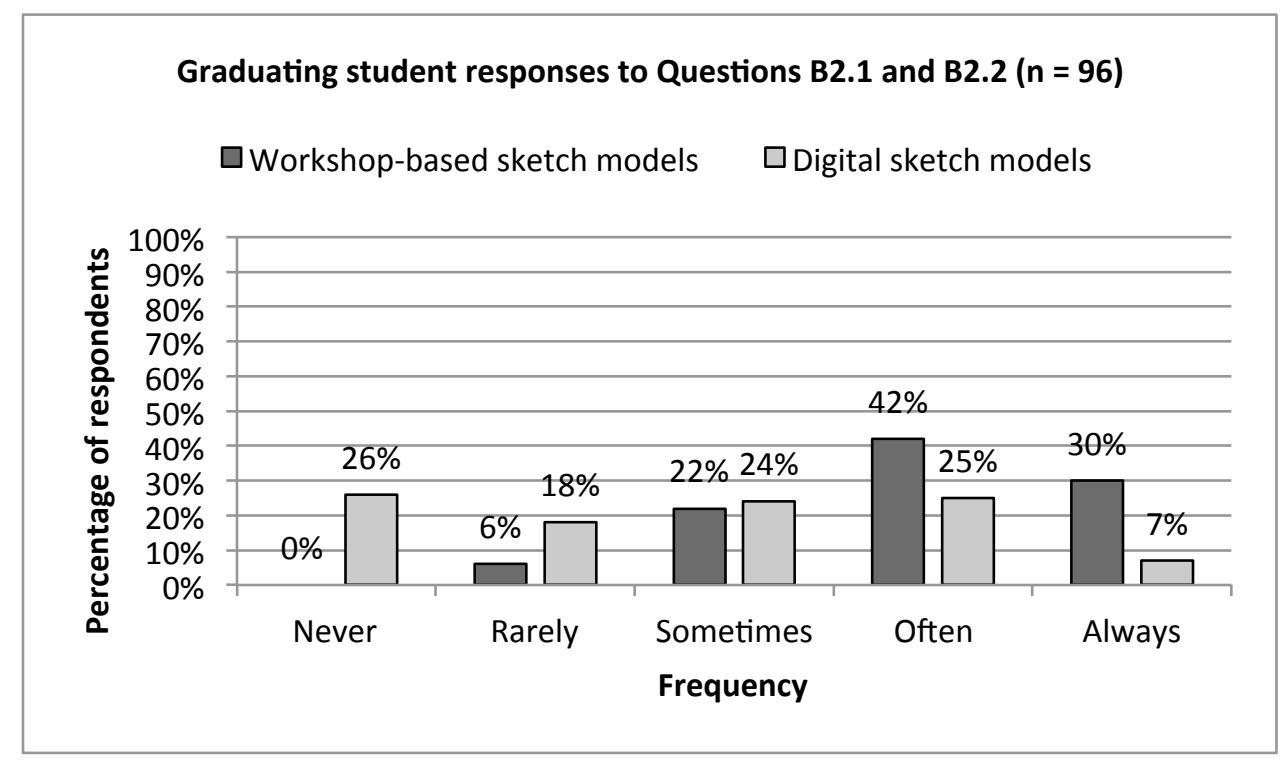

Figure 5-6: Graduating student responses to Questions B2.1 and B2.2: "How often do you use workshop-based sketch models and digital sketch models?" 


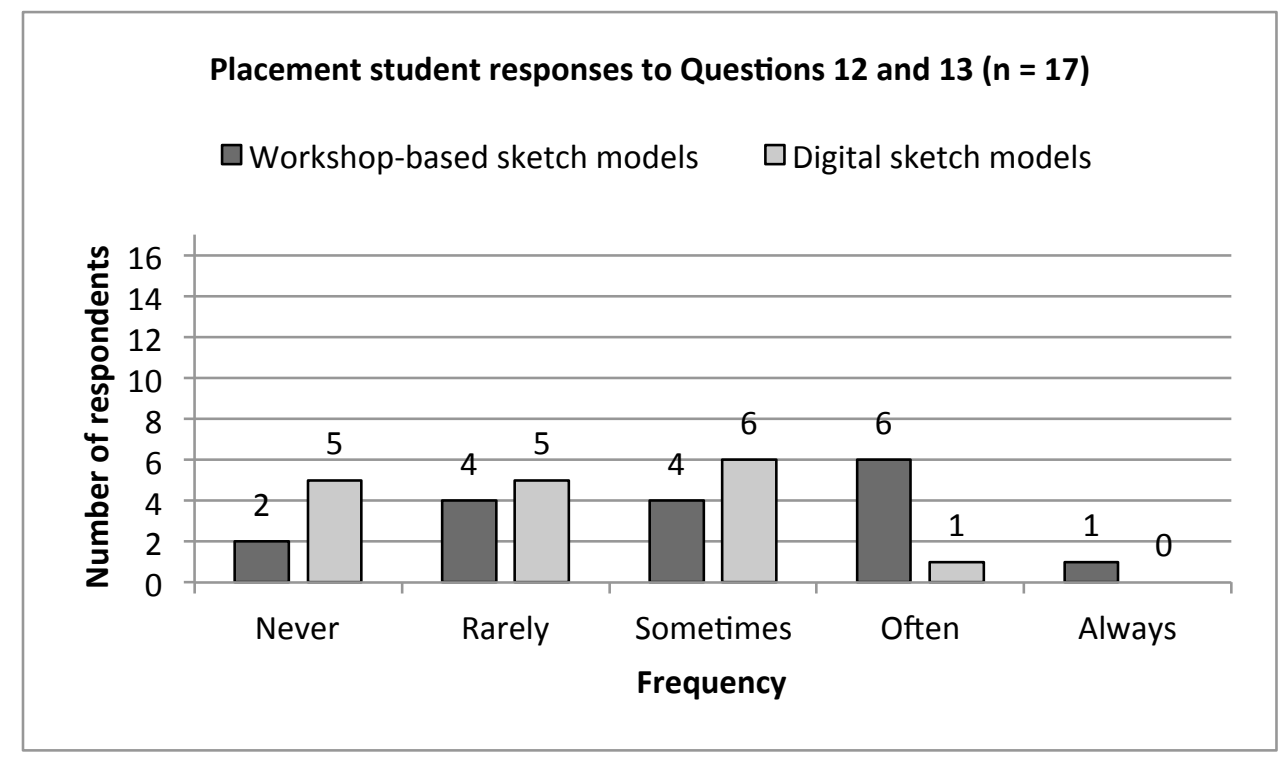

Figure 5-7: Industrial placement student responses to Questions 12 and 13: "How often did your design organisation use workshop-based sketch models and digital sketch models?"

\subsubsection{Appearance Models}

Industrial designers typically use appearance models to define and approve product form and physical size (Pei, 2009: 187). The questionnaire results indicated that in education, workshop-based appearance models were used more than digital appearance models that had been produced using techniques such as RP and CNC machining. The percentage of respondents who often/always used workshop-based appearance models and the ones who used digital appearance models was relatively close, with 63\% always/often employing workshop-based appearance models and 59\% using digital appearance models (Figure 5-8).

The industrial placement student questionnaire results revealed an extensive use of digital appearance models. The greater number of design organisations (seven design organisations) always used digital appearance models and only one design organisation had never used workshop-based appearance models (Figure 5-9).

Substantial efficiency gains have been identified for the use of RP when compared to workshop-based methods (Evans and Campbell, 2003: 350) which helps explain the high percentage of graduating students and the large number of design organisations that employed digital appearance models. 


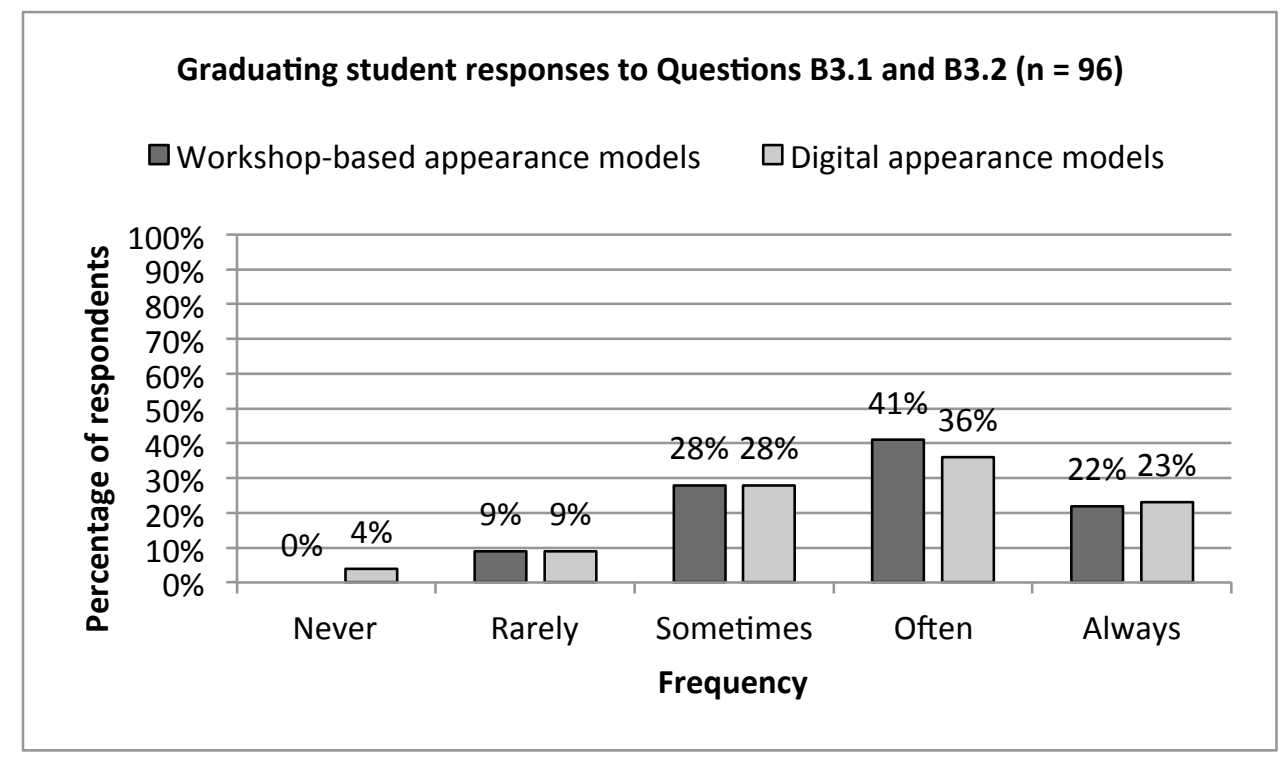

Figure 5-8: Graduating student responses to Questions B3.1 and B3.2: "How often do you use workshop-based appearance models and digital appearance models?"

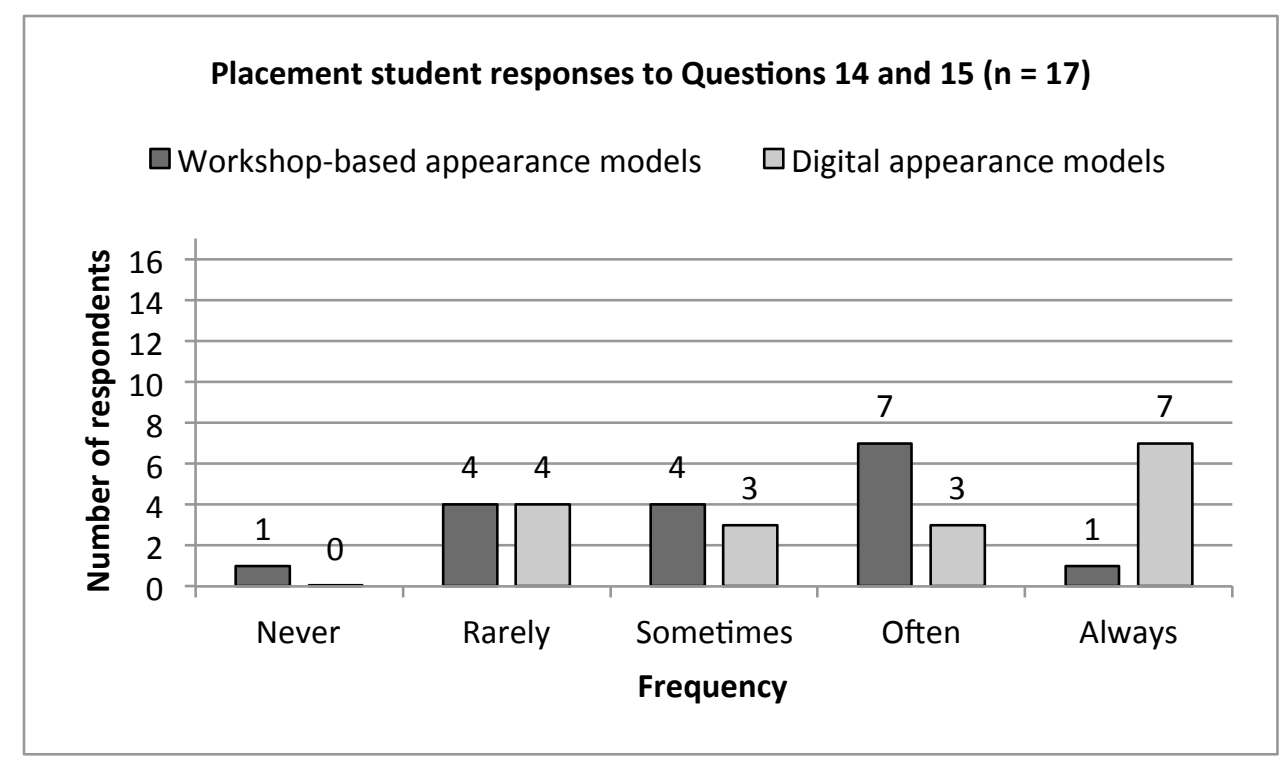

Figure 5-9: Industrial placement student responses to Questions 14 and 15: "How often did you design organisation use workshop-based appearance models and digital appearance models?"

\subsubsection{Renderings}

Renderings can be in the form of $2 \mathrm{D}$ side view renderings or 3D perspective renderings. Pipes (2007: 119) notes that a large number of designers begin the design process using pen/paper and then scan the resulting drawing, refine it, and then tone/colour using programs such as Adobe Photoshop. This was evident in the graduating student 
questionnaire and industrial placement student questionnaire responses, which indicated that computer renderings produced using software such as Adobe Photoshop, Pro/Engineer, Alias Studio Tools and Rhino were used considerably more than manual paper-based renderings. Ninety-one percent of graduating students used computer renderings often/always and only $24 \%$ used manual paper-based renderings on a regular basis (Figure 5-10). Seven percent had never used manual paper-based renderings. The majority of the design organisations (13 out of 17) used computer renderings often/always compared to three design organisations that used manual paper-based renderings on a similar basis. Seven design organisations did not use manual paper-based renderings (Figure 5-11).

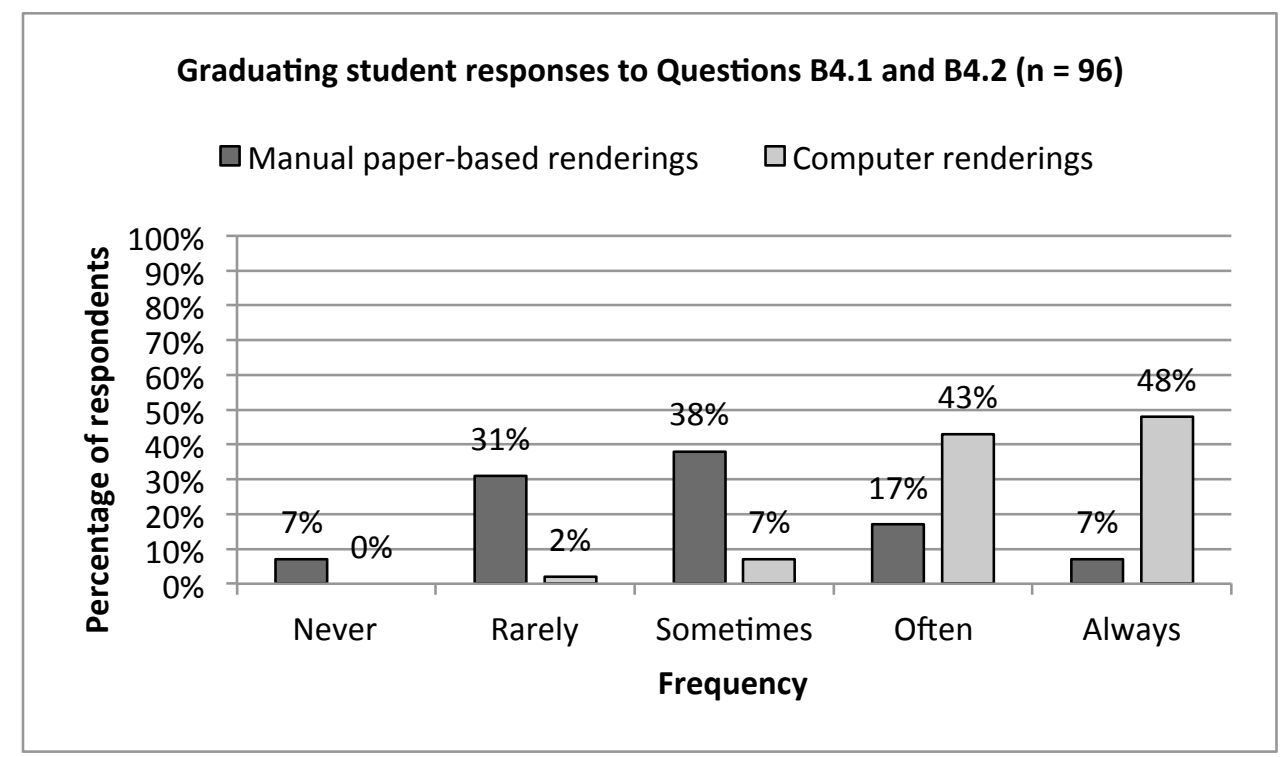

Figure 5-10: Graduating student responses to Questions B4.1 and B4.2: "How often do you use manual paper-based renderings and computer renderings?" 


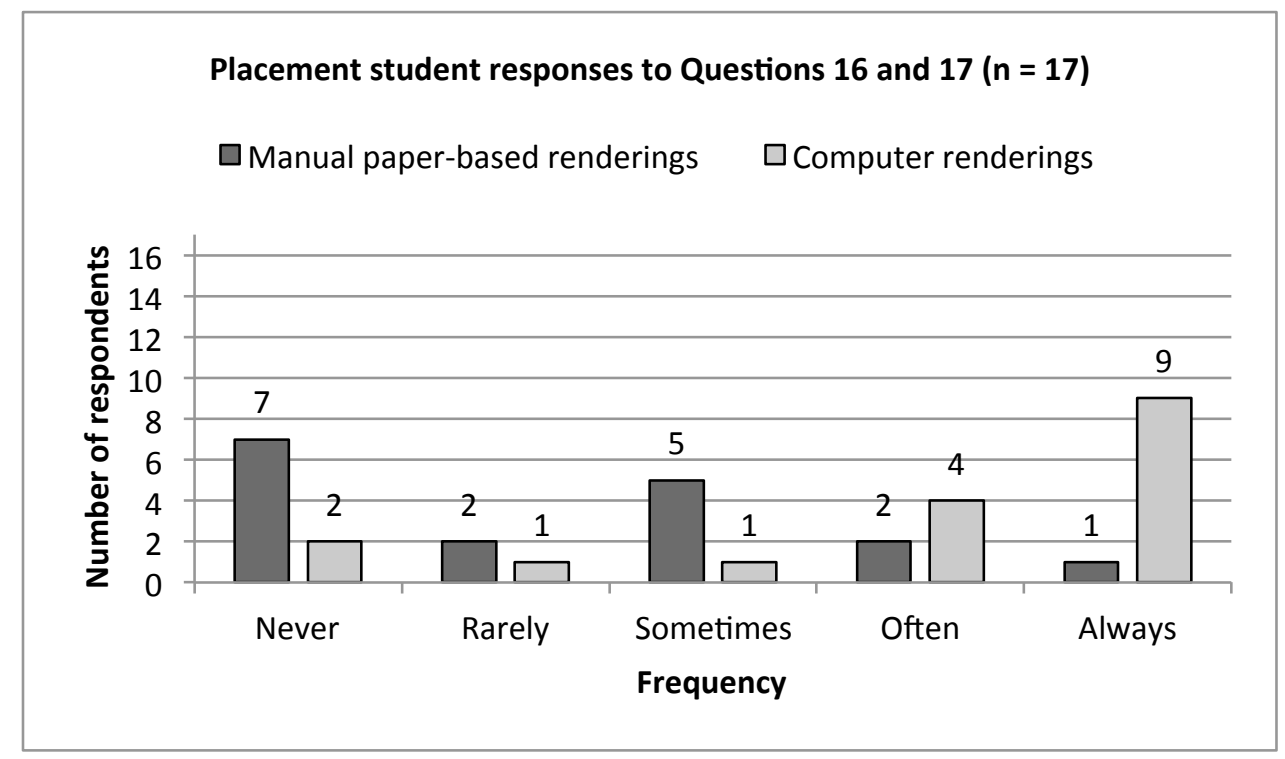

Figure 5-11: Industrial placement student responses to Questions 16 and 17: "How often did your design organisation use manual paper-based renderings and computer renderings?"

\subsubsection{Control/Engineering Drawings}

Although 3D computer geometry is used to specify form and support the production of tooling for manufacture, a role remains for the preparation of schematic drawings that define product and component detail in a 2D format. This is reiterated by Pipes (2007: 156) who states that "designers and engineers will continue to use 2D drafts - whether manually produced (rare, these days) or computer-generated at some point, to communicate their designs to those responsible for production and manufacturing". Control drawings may be used to support communication within the design team or as part of the quality control process for individual components. As such, instruction in the production of these control or engineering drawings remains part of the curriculum for industrial design courses. Conventional control/engineering drawings were historically produced using a drawing board but the functionality of 3D CAD software packages enables them to be generated from 3D geometry by extracting 2D profiles. The effectiveness of this process depends on the level of skill of the operator but the 3D CAD models produced are flexible enough to generate 2D profiles with dimensions being added either automatically or manually.

Seventy-two percent of graduating students used digital control/engineering drawings often/always and only $14 \%$ used manual paper-based drawings. Thirty-eight percent said that they had never used manual control/engineering drawings and $2 \%$ had never used digital control/engineering drawings (Figure 5-12). 
The majority of the design organisations (16 out of 17) used digital control/engineering drawings on regular basis and all 17 organisations had used them at some stage. Out of the 17 design organisations, 13 confirmed that they did not use manual paper-based control/engineering drawings (Figure 5-13).

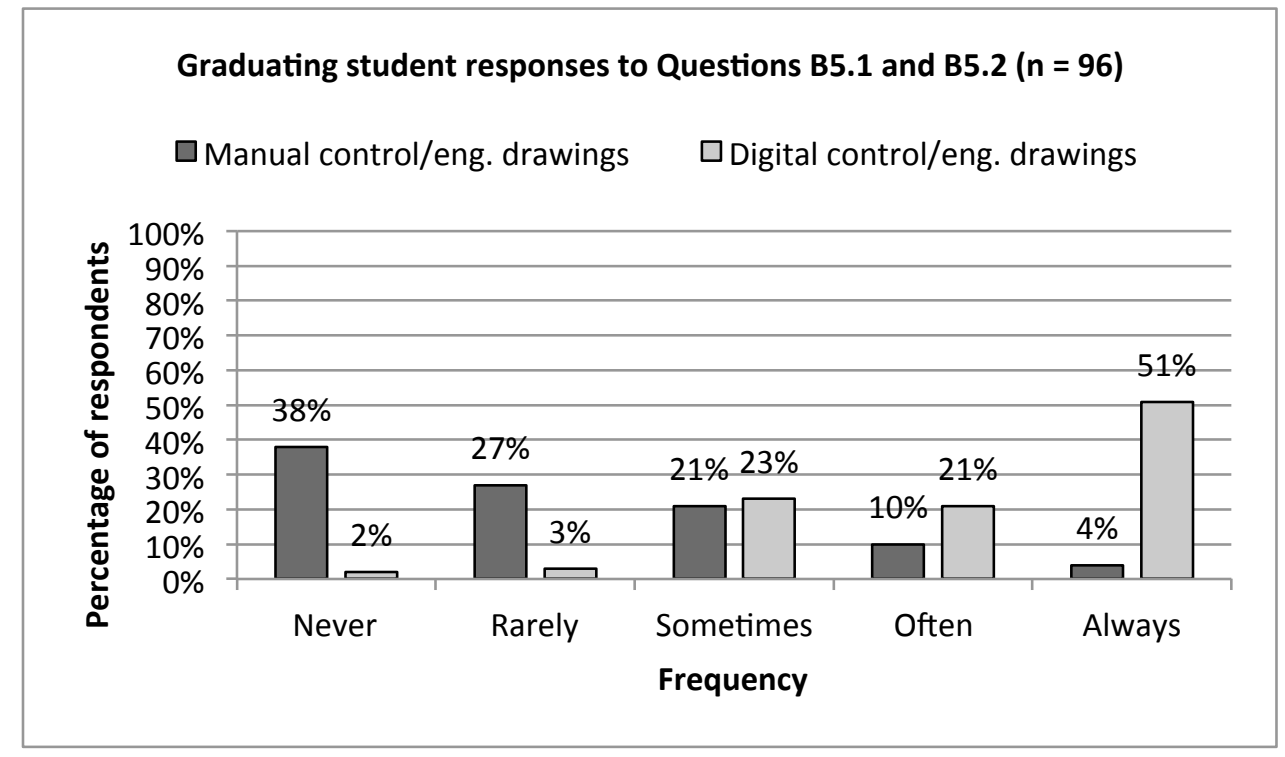

Figure 5-12: Graduating student responses to Questions B5.1 and B5.2: "How often do you use manual control/engineering drawings and digital control/engineering drawings?"

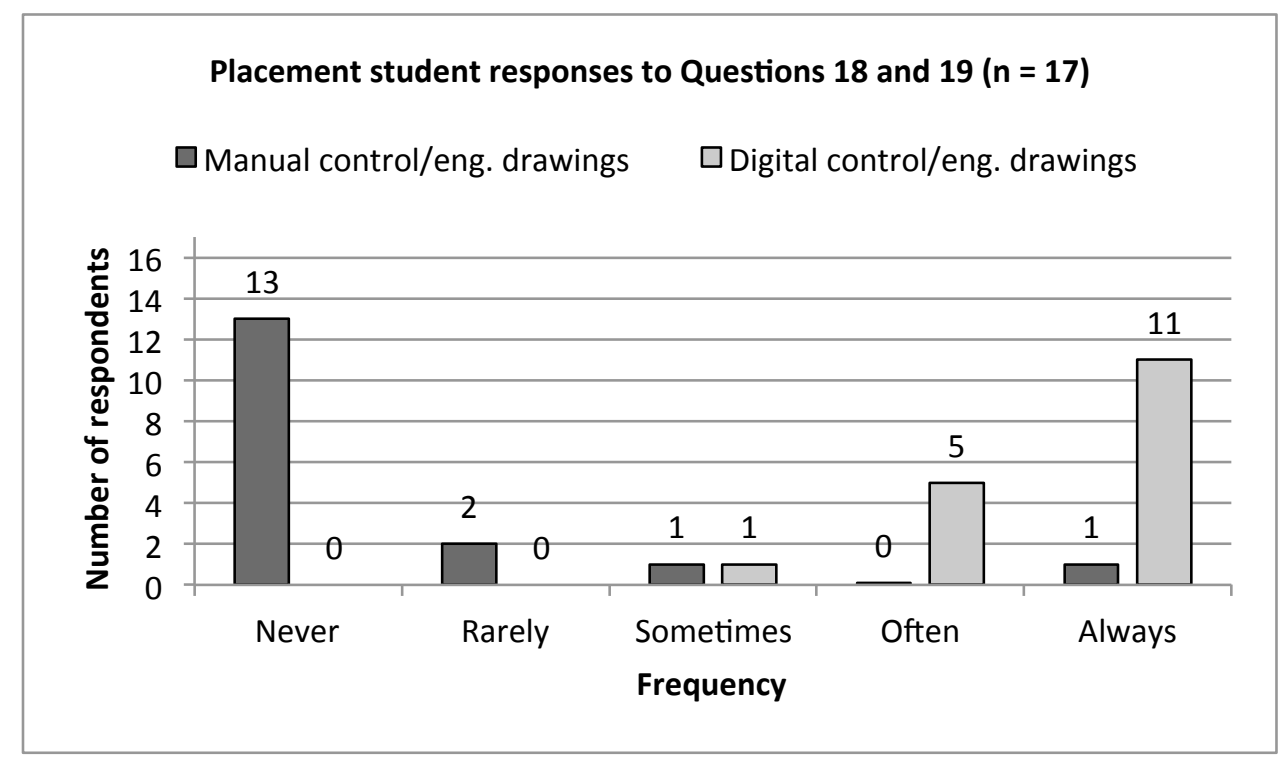

Figure 5-13: Industrial placement student responses to Questions 18 and 19: "How often did your design organisation use manual control/engineering drawings and digital control/engineering drawings?" 


\subsubsection{Testing}

Testing during design activity can involve testing ergonomics (Mavrikios et al., 2007: 533), usability and interface (Bruno and Muzzupappa, 2010: 255). Forty-six percent of graduating students and 11 out of 17 design organisations always/often used physical testing using techniques such as user trials, Breadboard circuits and load testing rigs. In contrast, only $22 \%$ of graduating students and four design organisations always/often used digital testing using simulation through VP using software such as Pro/Engineer Mechanica and applications for FEA. The overall figure for the use of digital testing by graduating students was $77 \%$ which was comparable with $72 \%$ in the survey by Romer et al. (2001: 482). Forty-five percent of graduating students and 7 out of 17 design organisations never/rarely used digital analysis (Figure 5-14 and Figure 5-15). In general, physical testing was used more than digital testing in education and professional practice with the professional designers implementing physical testing considerably more than graduating students as reported by the industrial placement students. This could be due to the fact that professionals did not believe that digital testing was efficient enough to replace physical testing yet. Also, in professional practice products have to be fully tested with users for reliability, health and safety reasons before introducing them in the market so an extensive amount of testing is required compared to the limited graduating student practice when it comes to testing.

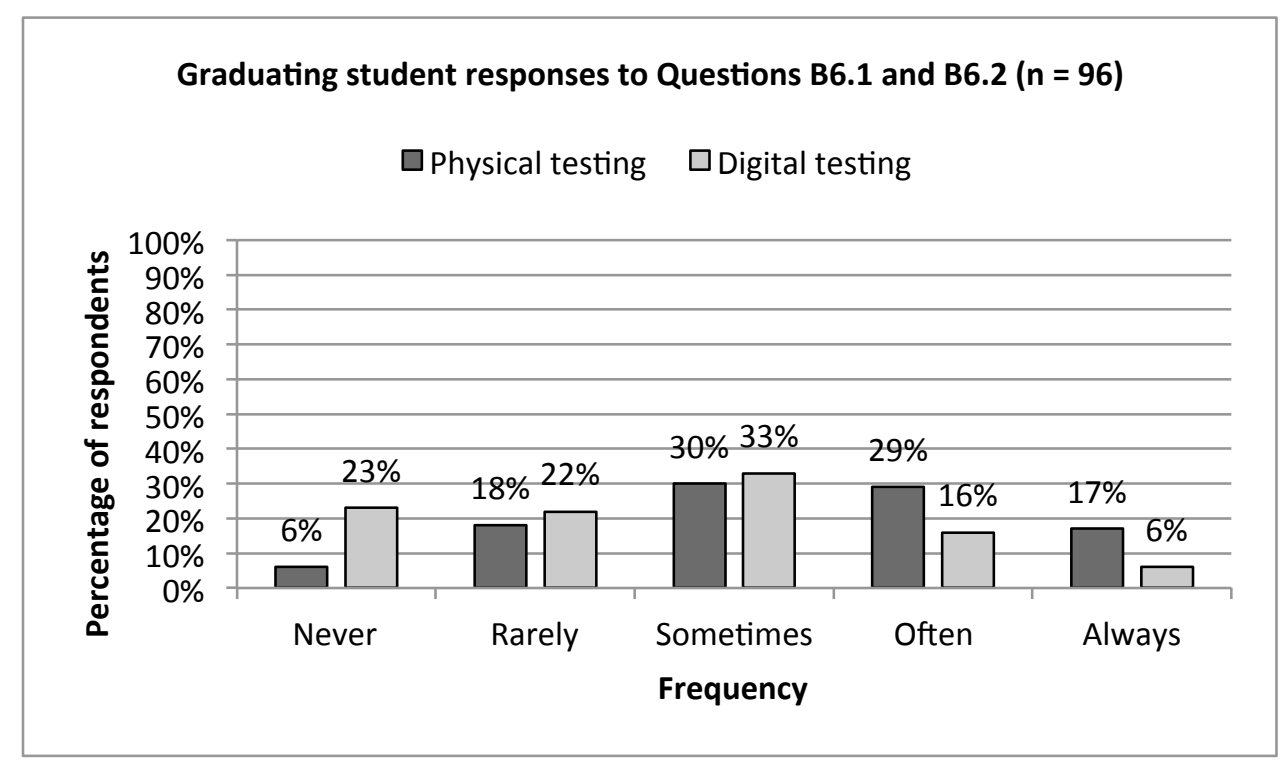

Figure 5-14: Graduating student responses to Questions B6.1 and B6.2: "How often do you use physical testing and digital testing?" 


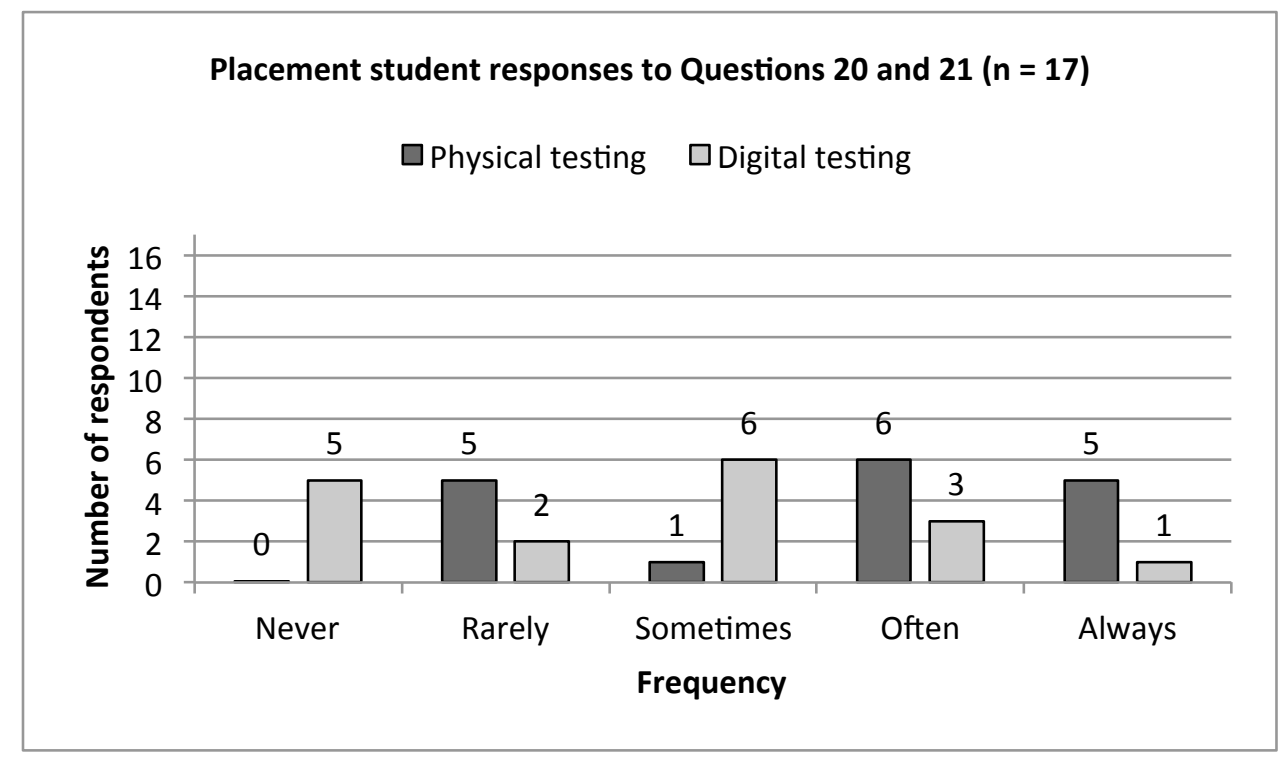

Figure 5-15: Industrial placement student responses to Questions 20 and 21: "How often did your design organisation use physical testing and digital testing?"

\subsubsection{Prototypes}

Prototypes are full-size working design representations that are used to simulate some or all of the features for a proposed product. All of the graduating students had used workshopbased prototypes and $66 \%$ confirmed using them on a regular basis. Forty-two percent often/always used digital prototypes that were produced using RP and/or CNC machining and $6 \%$ never used them (Figure 5-16). Digital prototypes were used more than workshopbased prototypes in professional practice as 7 out of 17 design organisations used digital prototypes on a regular basis compared to 6 who used workshop-based prototypes. Two design organisations never used workshop-based prototypes and another six used them sometimes (Figure 5-17). These findings show that educational practice is not keeping up with professional practice when it comes to prototyping. Education should optimise the use of digital prototypes in their teaching and students practice with the advances in digital technologies to fully prepare students for industry. 


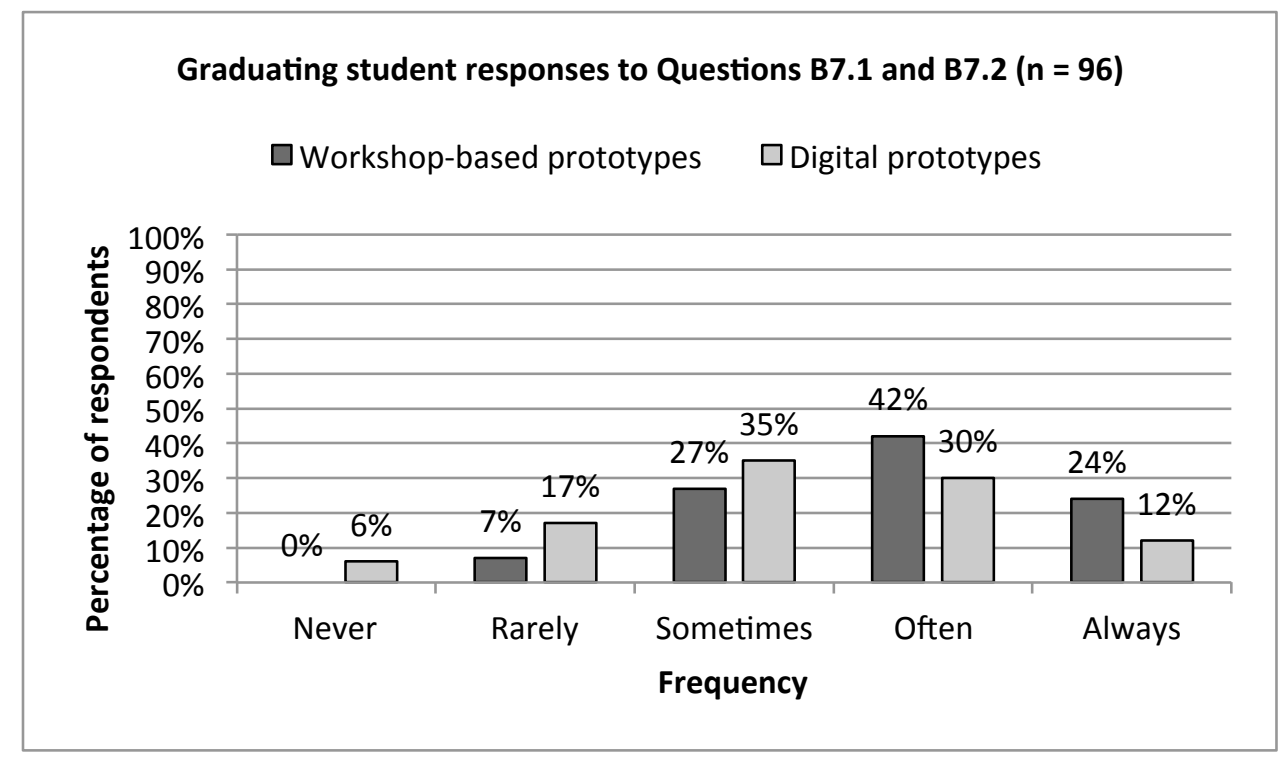

Figure 5-16: Graduating student responses to Questions B7.1 and B7.2: "How often do you use workshop-based prototypes and digital prototypes?"

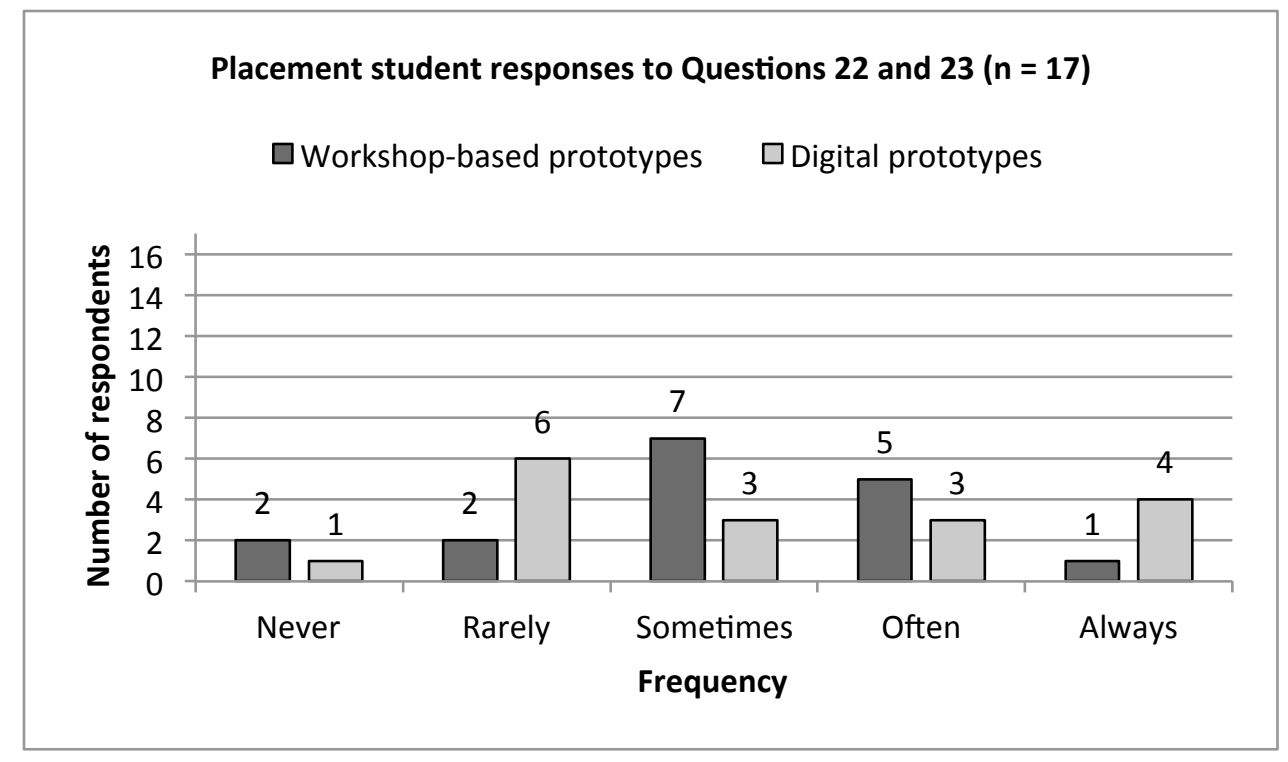

Figure 5-17: Industrial placement student responses to Questions 22 and 23: "How often did you design organisation use workshop-based prototypes and digital prototypes?"

\subsubsection{Use of Digital Design Tools}

This section of the supervised collective questionnaire explored graduating student opinion on the ease or difficulty in using a range of digital tools that had been identified as having the potential to contribute to the design process. These were $2 \mathrm{D}$ computer visualisation software; 3D solid modelling CAD software; 3D surface modelling CAD software; digitising tablets; haptic feedback devices; VR; CNC machining; and RP. The industrial placement 
student questionnaire did not explore this issue as this group was not considered reliable in rating the ease of using digital design tools on behalf of the design organisation they worked for due to their limited experience and because there was no guarantee that they used each digital tool as part of their design practice in the design organisation.

\subsubsection{2D Computer Visualisation Software}

Sixty-three percent of the graduating students stated that 2D computer visualisation software (e.g. Autodesk SketchBook Pro, Corel Painter, Adobe Photoshop) was easy/very easy to use, with $8 \%$ believing that it was difficult to use and a minority of $4 \%$ having never used any 2D computer visualisation software (Figure 5-18).

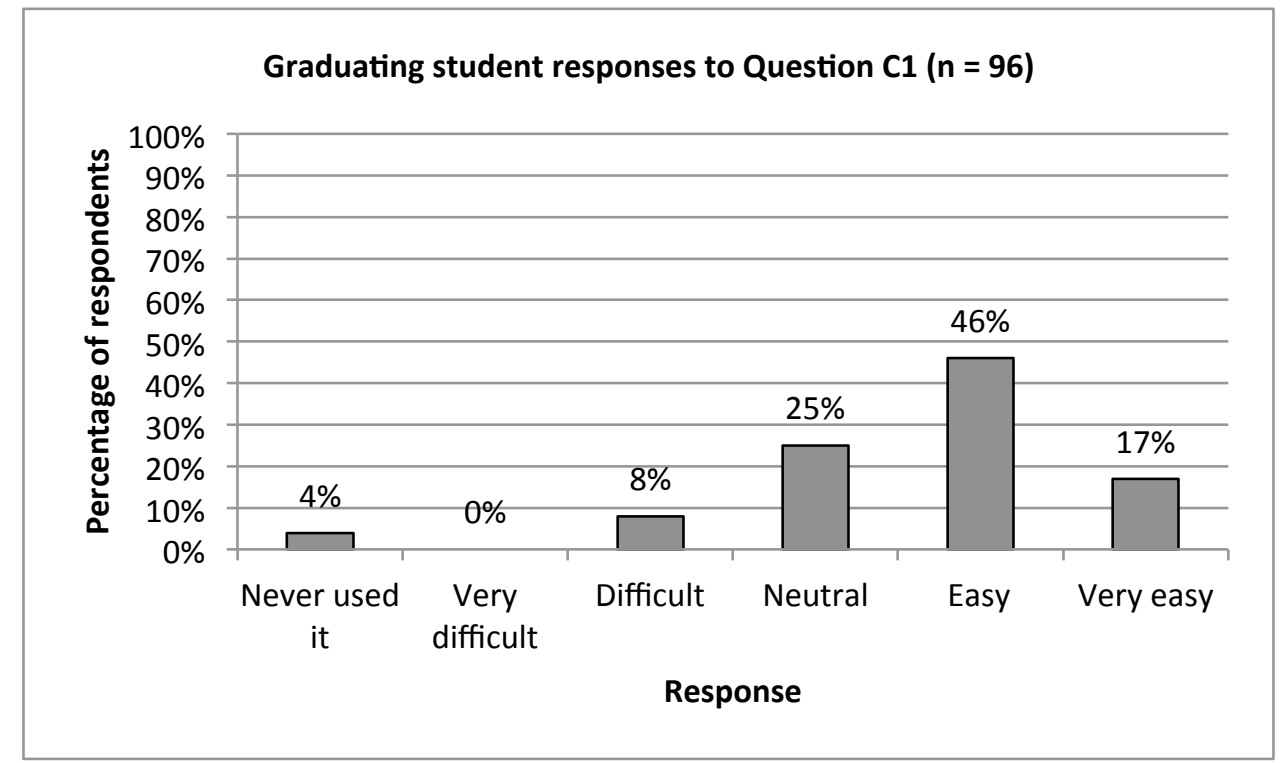

Figure 5-18: Graduating student responses to Question C1: "How do you rate using 2D visualisation software?"

\subsubsection{3D Solid Modelling Computer Aided Design Software}

CAD has moved from being a secondary component of design education to a central tool in design development (Unver, 2006: 324) with students using a range of 3D solid modelling CAD software such as Pro/Engineer, SolidWorks, and Pro/Desktop. The majority of respondents (57\%) felt that 3D solid modelling software was easy/very easy to use, and $14 \%$ felt that it was difficult or very difficult to use (Figure 5-19).

With such a high percentage of students finding solid modelling CAD systems easy to use, it is no surprise that students have a tendency to use this technology during the early stages of 
design activity. Cases have been made to restrict access in order to facilitate the development of broader design capability (Charlesworth, 2007: 43).

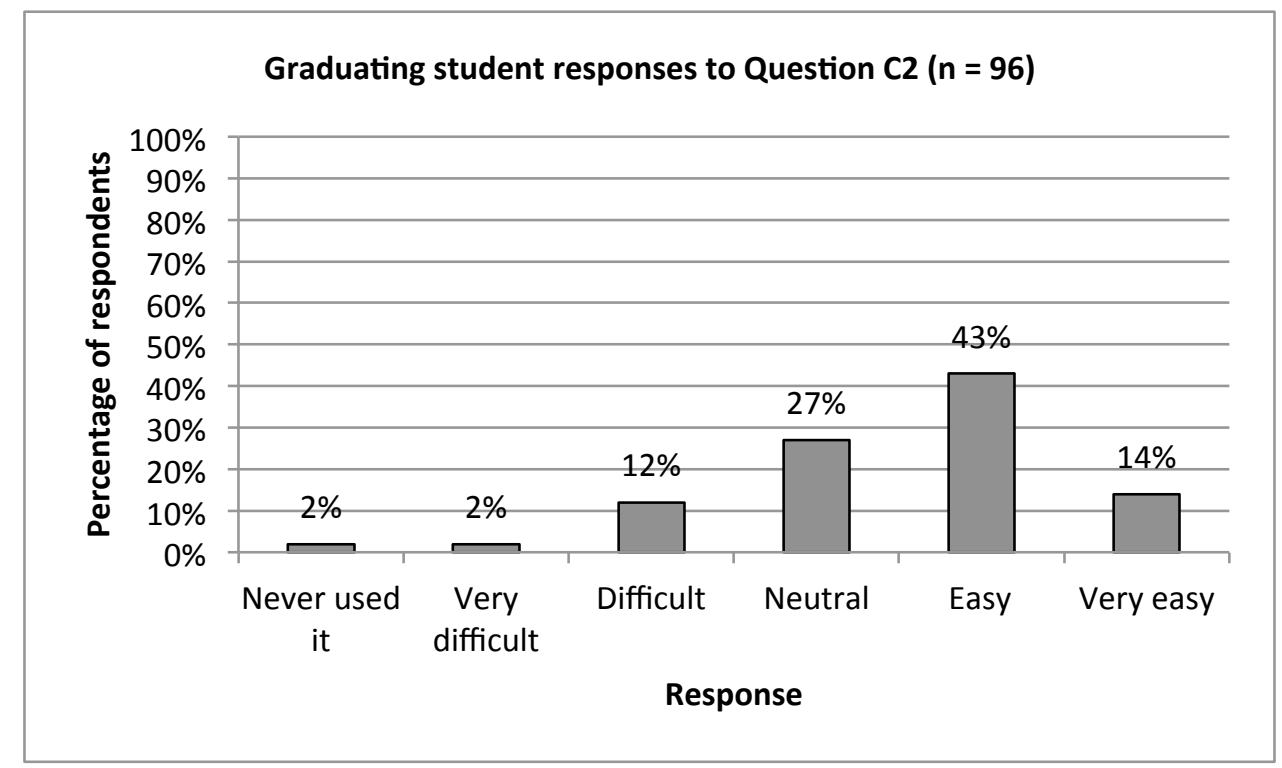

Figure 5-19: Graduating student responses to Question C2: "How do you rate using 3D solid modelling CAD software?"

\subsubsection{3D Surface Modelling Computer Aided Design Software}

Feedback relating to the ease of using 3D surface modelling CAD software (e.g. Rhino, Autodesk Alias Studio Tools) was less positive than that for solid modelling. Thirty-three percent (the largest group) felt neutral towards it while $29 \%$ thought that it was easy/very easy to use and another $21 \%$ noted that it was difficult to use overall (Figure 5-20). 


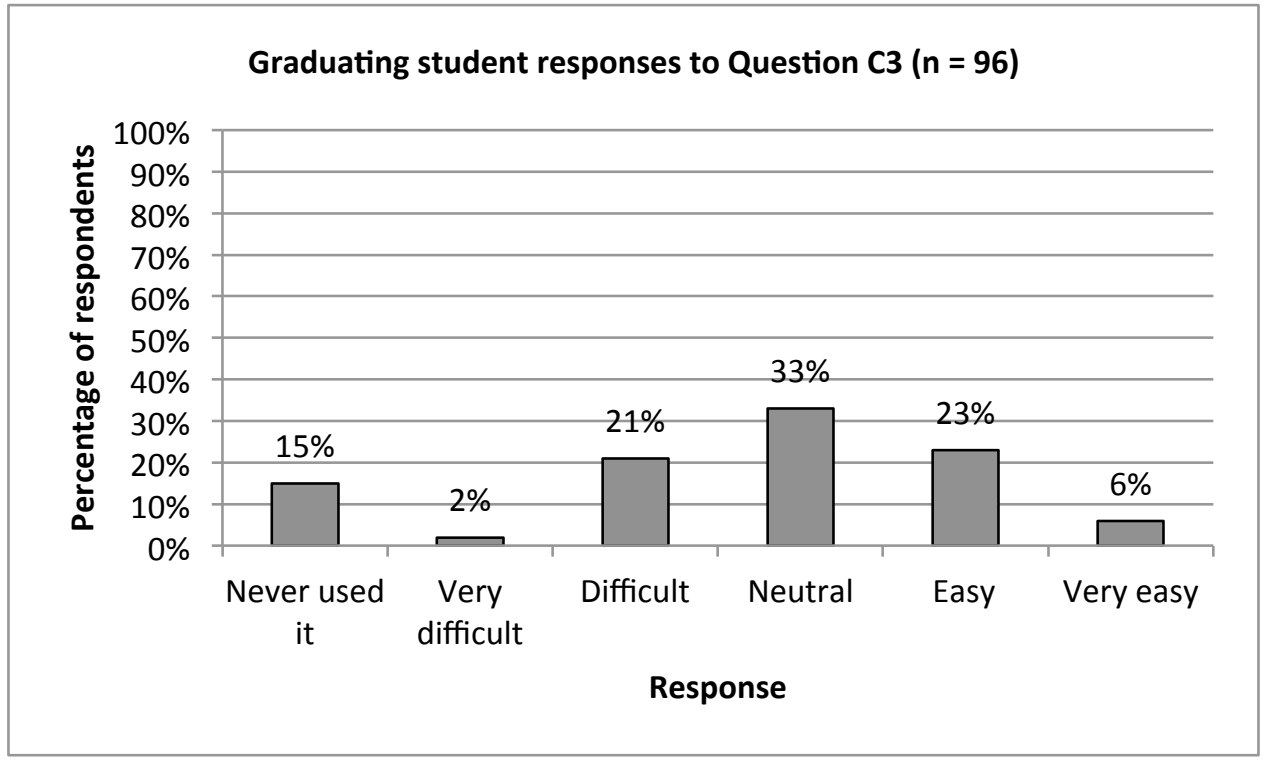

Figure 5-20: Graduating student responses to Question C3: "How do you rate using 3D surface modelling CAD software?"

\subsubsection{Digitising Tablets}

Digitising tablets, such as the Wacom Intuos and Cintiq, can perform a dual role. They can be used to point and pick software commands when using 3D CAD or for sketching. The Cintiq has a built-in display so the designer can draw directly onto the screen. When students were asked to rate using digitising tablets their responses were spread throughout the full range; $25 \%$ had not used them; $28 \%$ felt that they were easy/very easy to use; $28 \%$ were neutral; and $19 \%$ said that they were difficult/very difficult to use (Figure 5-21). 


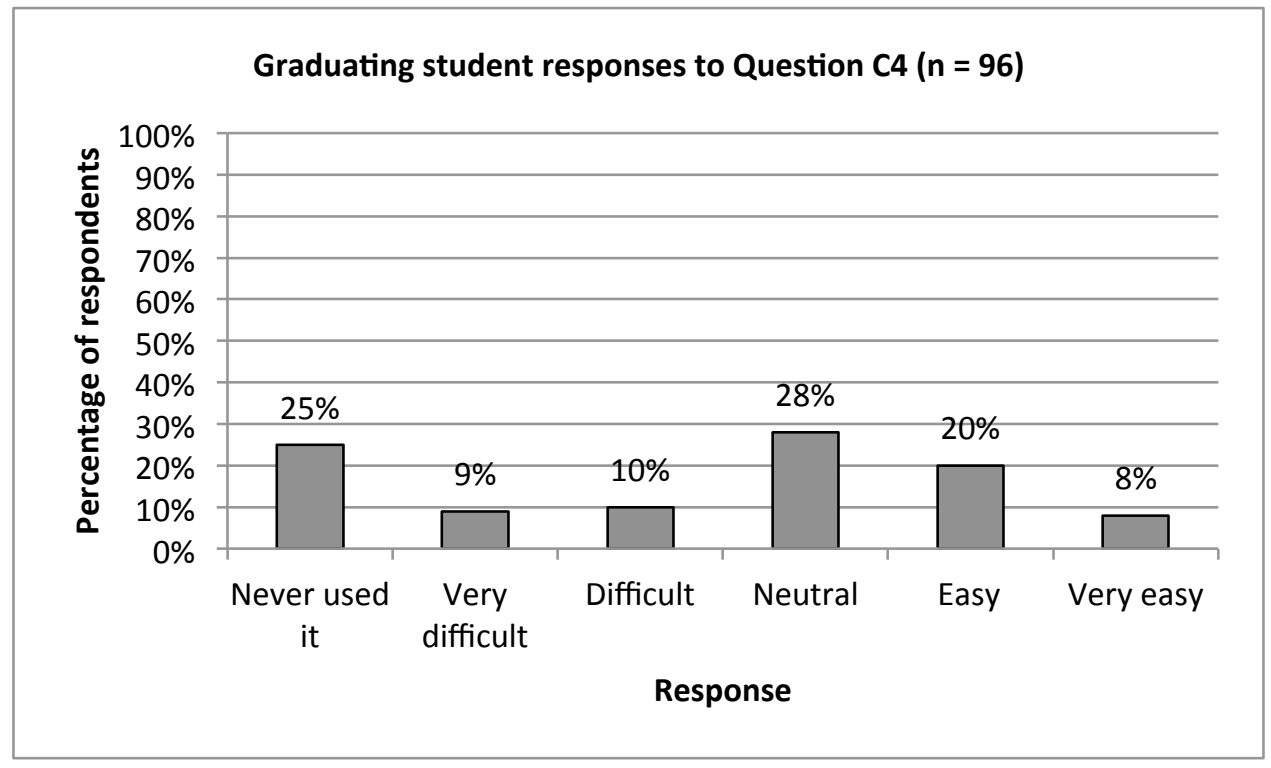

Figure 5-21: Graduating student responses to Question C4: "How do you rate using digitising tablets?"

\subsubsection{Haptic Feedback Devices}

When the graduating students were asked to comment on how they rated using haptic feedback devices (e.g. SensAable PHANTOM FreeForm system), $88 \%$ of the respondents said that they had never used them while $8 \%$ said that they were difficult to use; $3 \%$ felt neutral and only $1 \%$ confirmed that they were very easy to use (Figure $5-22$ ).

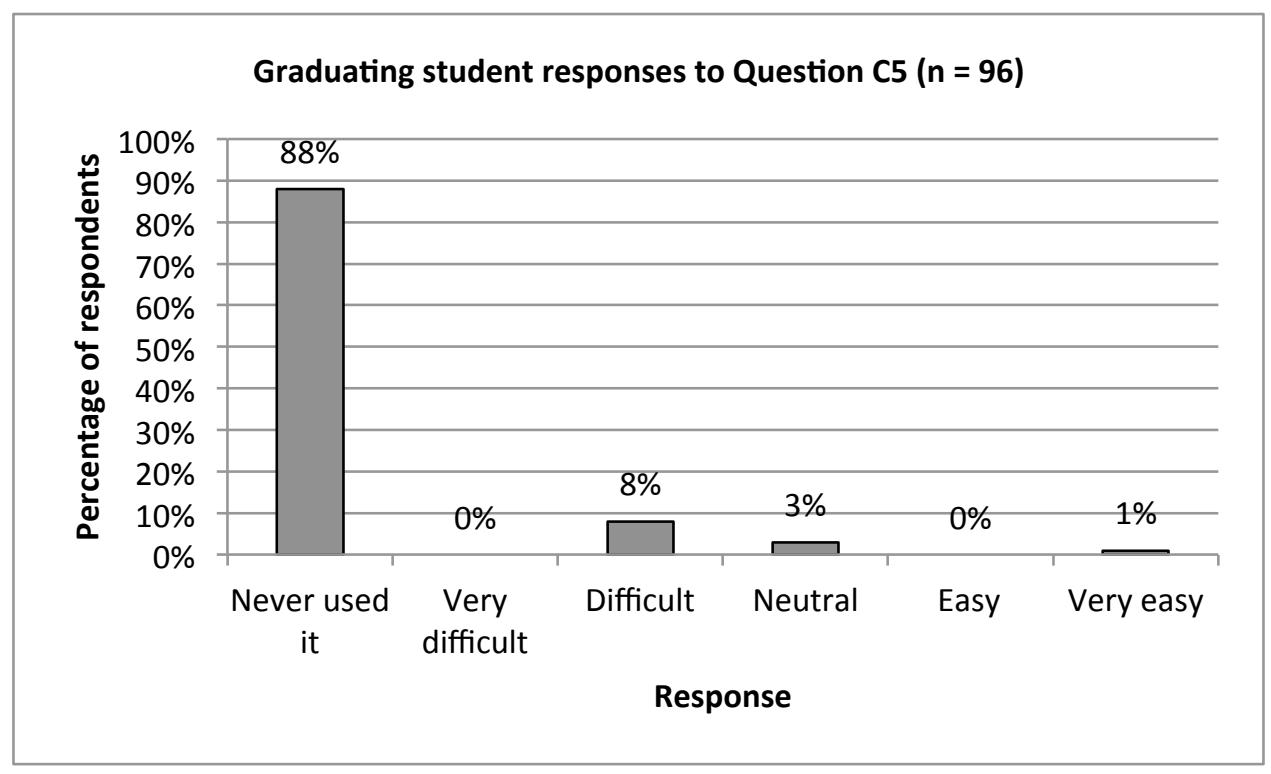

Figure 5-22: Graduating student responses to Question C5: "How do you rate using haptic feedback devices?" 


\subsubsection{Virtual Reality}

VR (e.g. head-mounted displays, stereographic projection to room size screens) allows designers to immerse themselves in a digital environment that mimics reality. This is achieved to varying degrees of realism. Eight-eight percent of graduating students had never used VR, $2 \%$ felt that it was difficult/very difficult to use and $7 \%$ had a neutral response (Figure 5-23).

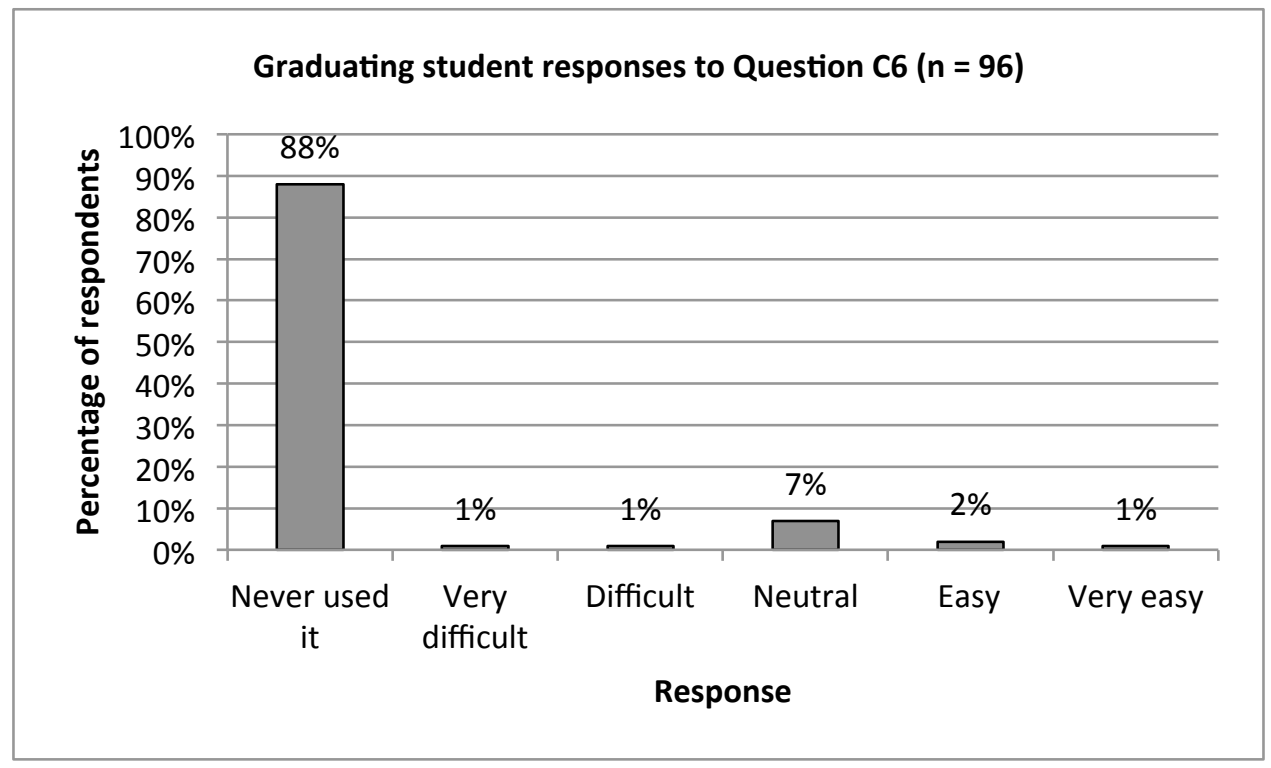

Figure 5-23: Graduating student responses to Question C6: "How do you rate using virtual

$$
\text { reality?" }
$$

\subsubsection{Digital Testing and Analysis}

An anomaly was identified in the responses to Question B6, "How often do you use physical testing and digital testing?" and Question C7, "How do you rate using digital testing and analysis?". In Question B6, 23\% claimed not to have used digital testing and analysis and in Question C7, 44\% claimed not to have used digital testing and analysis. The contrast in the results were generated despite the fact that identical wording was used for questions B6 and C7 to describe what was meant by "digital testing and analysis" apart from including FEA in Question B7. It could be because graduating students found it difficult to rate digital testing and analysis ease of use, especially as it could include a range of software and skills needed, so students found it easier to tick the 'never used it' box. As a question on frequency of use, Question B6 is considered as having greater significance to the research and Question C7 has been removed. 


\subsubsection{Computer Numerical Control Machining}

The largest number of graduating students $(46 \%)$ considered CNC machining (e.g. laser cutting, milling and water-jet cutting) easy/very easy to use; $29 \%$ felt neutral and $16 \%$ found it difficult/very difficult to use (Figure 5-24).

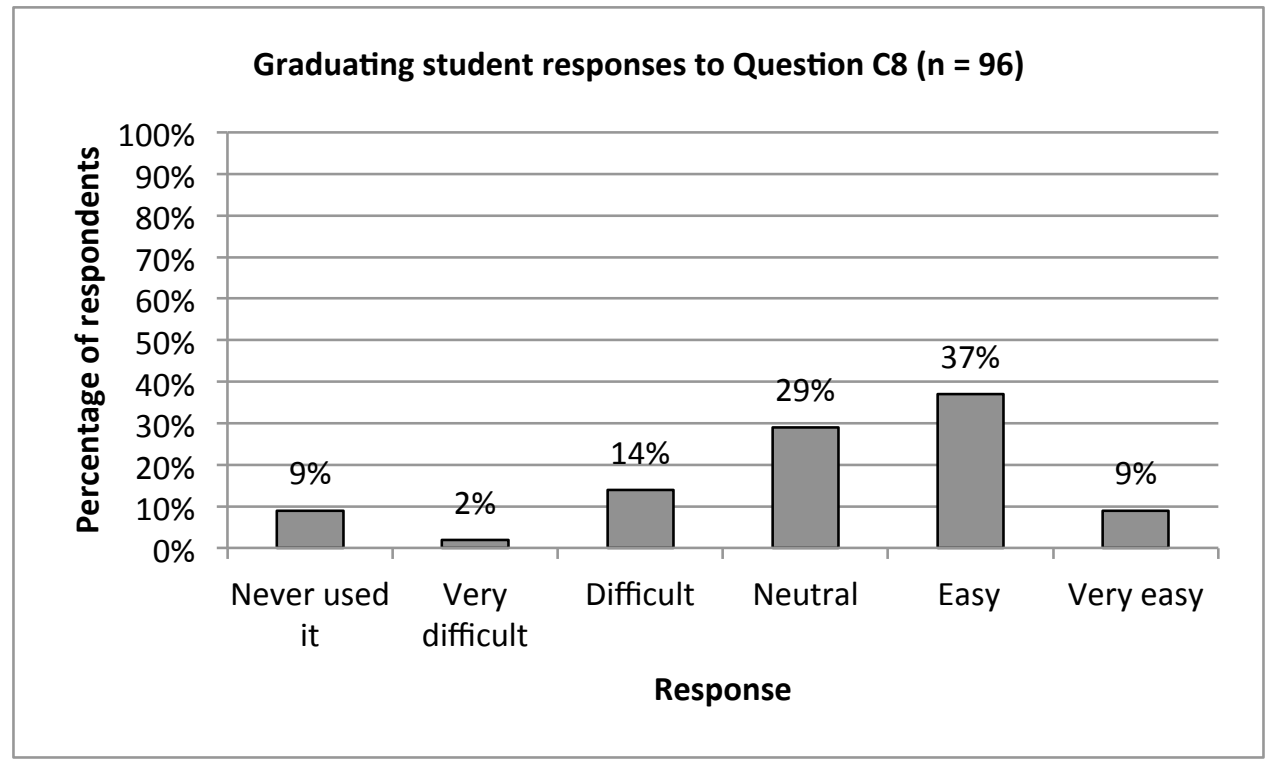

Figure 5-24: Graduating student responses to Question C8: “How do you rate using computer numerical control machining?"

\subsubsection{Rapid Prototyping}

RP is "becoming a major facilitator of design production for product designers. Typically used to view products at all phases of the process, rapid prototyping can be used to demonstrate a product's functional and ergonomic makeup" (Sass and Oxman, 2006: 337). The models produced using RP machines at an early stage in the development process can be used to confirm fit, aesthetic and ergonomics issues; to share the model with other members of the team; and to carry out physical amendments in some occasions (Prieto et al., 2003: 696). The use of RP (e.g. stereolithography, selective laser sintering, fused deposition modelling) appeared to be a relatively straightforward according to the survey results, with $55 \%$ finding it easy/very easy. However, $14 \%$ had never used it and $27 \%$ felt neutral about it (Figure 5-25). 


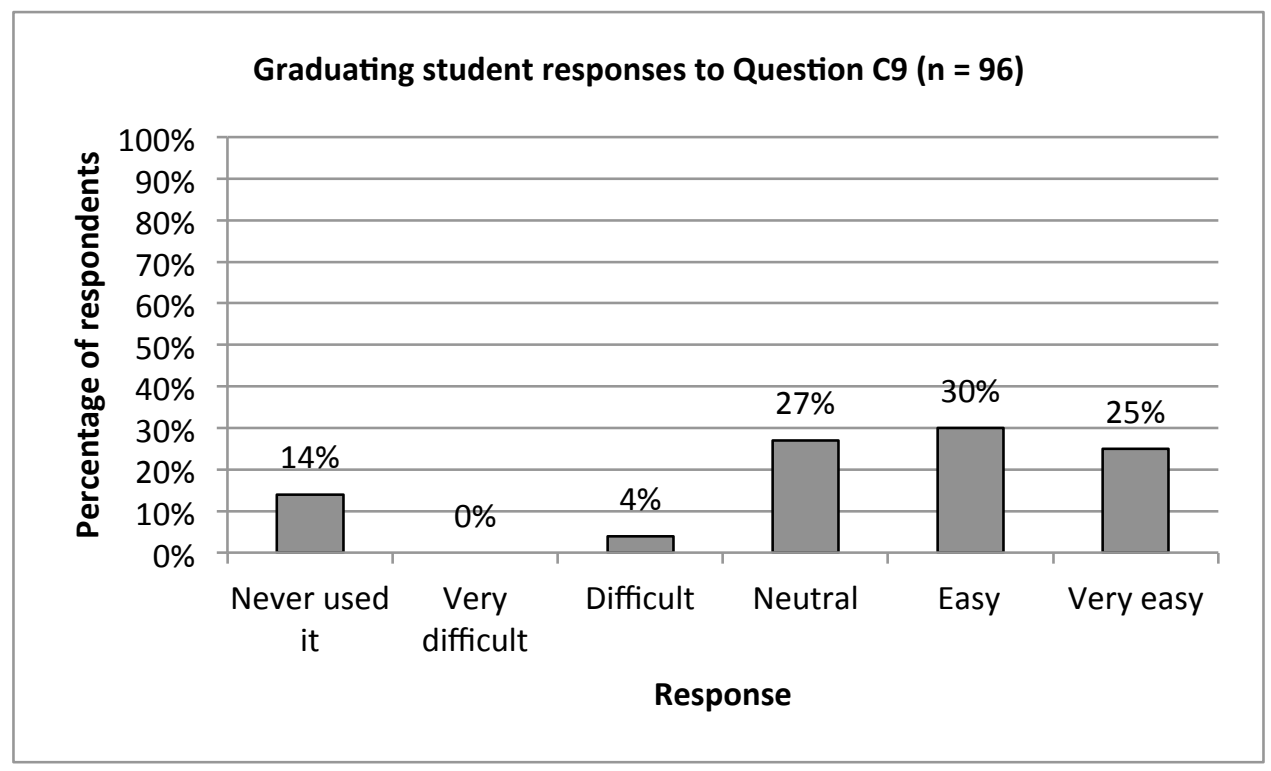

Figure 5-25: Graduating student responses to Question C9: "How do you rate using rapid prototyping?"

\subsubsection{Digital Tools/Media Used during Each Phase of the Design Process}

To ensure that all of the digital tools and media that are currently used in professional practice are included in the DID strategy, this section of the industrial placement student online questionnaire employed open-ended questions for listing the digital tools and media used in concept generation, preliminary refinement, further refinement and final concept selection and specification.

The results of Section $D$ of the online questionnaire revealed that in the concept generation phase, most design organisations used 2D visualisation software such as Adobe Photoshop (nine design organisations), Adobe Illustrator (five design organisations), AutoCAD (one design organisation) and SketchBook Pro (one design organisation). Other design organisations used 3D solid modelling software such as SolidWorks (four design organisations) and Pro/Engineer (two design organisations). Only one design organisation confirmed using Wacom tablets and another design organisation did not use any digital tools and media in the conceptualisation phase.

The employment of 2D visualisation software increased in the preliminary refinement stage through the use of Adobe Photoshop (10 design organisations) and Adobe Illustrator (six design organisations). The use of solid modelling software such as SolidWorks (six design organisations) and Pro/Engineer (three design organisations) also increased. 
In the further refinement and final concept selection phase and specification, design organisations tended to increase their use of solid and surface modelling software. Only one industrial placement student identified the use of RP technology in the design company he worked for.

Table 5-1 illustrates the range of digital tools/media used at the four different phases of the design process.

\begin{tabular}{|c|c|c|c|c|c|c|c|}
\hline $\begin{array}{c}\text { Concept } \\
\text { generation }\end{array}$ & 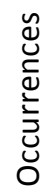 & $\begin{array}{l}\text { Preliminary } \\
\text { refinement }\end{array}$ & 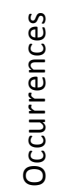 & $\begin{array}{c}\text { Further refinement } \\
\text { and final concept } \\
\text { selection }\end{array}$ & 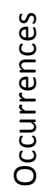 & Specification & 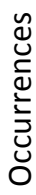 \\
\hline Photoshop & 9 & Photoshop & 10 & SolidWorks & 7 & SolidWorks & 6 \\
\hline Illustrator & 5 & Illustrator & 6 & Pro/Engineer & 4 & Pro/Engineer & 5 \\
\hline SolidWorks & 4 & SolidWorks & 6 & Photoshop & 3 & AutoCAD & 5 \\
\hline Pro/Engineer & 2 & Pro/Engineer & 3 & AutoCAD & 3 & Inventor & 2 \\
\hline SketchBook Pro & 1 & AutoCAD & 2 & Illustrator & 2 & Photoshop & 1 \\
\hline AutoCAD & 1 & Autodesk VIZ & 1 & Inventor & 2 & Illustrator & 1 \\
\hline CATIA & 1 & Inventor & 1 & Alias & 2 & CATIA & 1 \\
\hline None & 1 & CATIA & 1 & Autodesk VIZ & 1 & Autodesk VIZ & 1 \\
\hline \multirow[t]{6}{*}{ Wacom tablets } & 1 & Alias renders & 1 & 3ds Max & 1 & eDrawings & 1 \\
\hline & & & & CATIA & 1 & Rhino & 1 \\
\hline & & & & Rhino & 1 & Mia & 1 \\
\hline & & & & Cinema 4D & 1 & Easy PC & 1 \\
\hline & & & & eDrawings & 1 & SLA prototypes & 1 \\
\hline & & & & SLA prototypes & 1 & & \\
\hline
\end{tabular}

Table 5-1: Industrial placement student responses to Questions 28, 29, 30 and 31: "What are the main digital media/tools used at the design organisation you worked for in the concept generation phase, preliminary refinement phase, further refinement and final concept selection phase and specification phase?"

\subsubsection{Use of Digital Methods during Different Phases of the Design Process}

This section of the questionnaire explored the extent to which digital methods were employed during the four design phases (concept generation, preliminary refinement, further refinement and final concept selection, and specification). In the graduating students supervised questionnaire, the percentages of the phase were absolute as $0 \%, 20 \%, 40 \%$, $60 \%, 80 \%$, and $100 \%$. However, it was then realised that it might be difficult for respondents to pick a certain percentage, especially as it discards the in between percentages. Therefore, in the industrial placement student questionnaire, percentage ranges replaced most of the absolute percentages. These were $0 \%, 1 \%-25 \%, 26 \%-50 \%, 51 \%-75 \%, 76 \%-99 \%$ and $100 \%$. 


\subsubsection{Concept Generation}

Once the client's needs and constraints are understood, industrial designers undertake concept generation. Sketching is extensively used during this phase to externalise, manipulate and evaluate ideas. The questionnaire sought to gather data on the extent to which digital methods were used as a percentage of the concept generation phase. The results indicated that $6 \%$ of graduating students did not employ digital methods during the concept generation phase when undertaking the project presented at New Designers Exhibition. Twenty-six percent employed them during $20 \%$ of the time, while $23 \%$ employed them during $60 \%$ of the same stage. The highest percentage (31\%) utilised digital tools during $40 \%$ of this phase (Figure $5-26$ ).

In terms of professional practice, the final year students who had completed industrial placement reported that one design organisation was relying solely on digital methods when generating concepts. Three employed digital methods $76 \%-99 \%$ of the time, another five during $51 \%-75 \%$ of the time and five during $1 \%-25 \%$ of the phase. When comparing the results from student practice with professional practice, it is noted that the professional practice employed more digital tools and media in the conceptualisation phase (Figure 5-27).

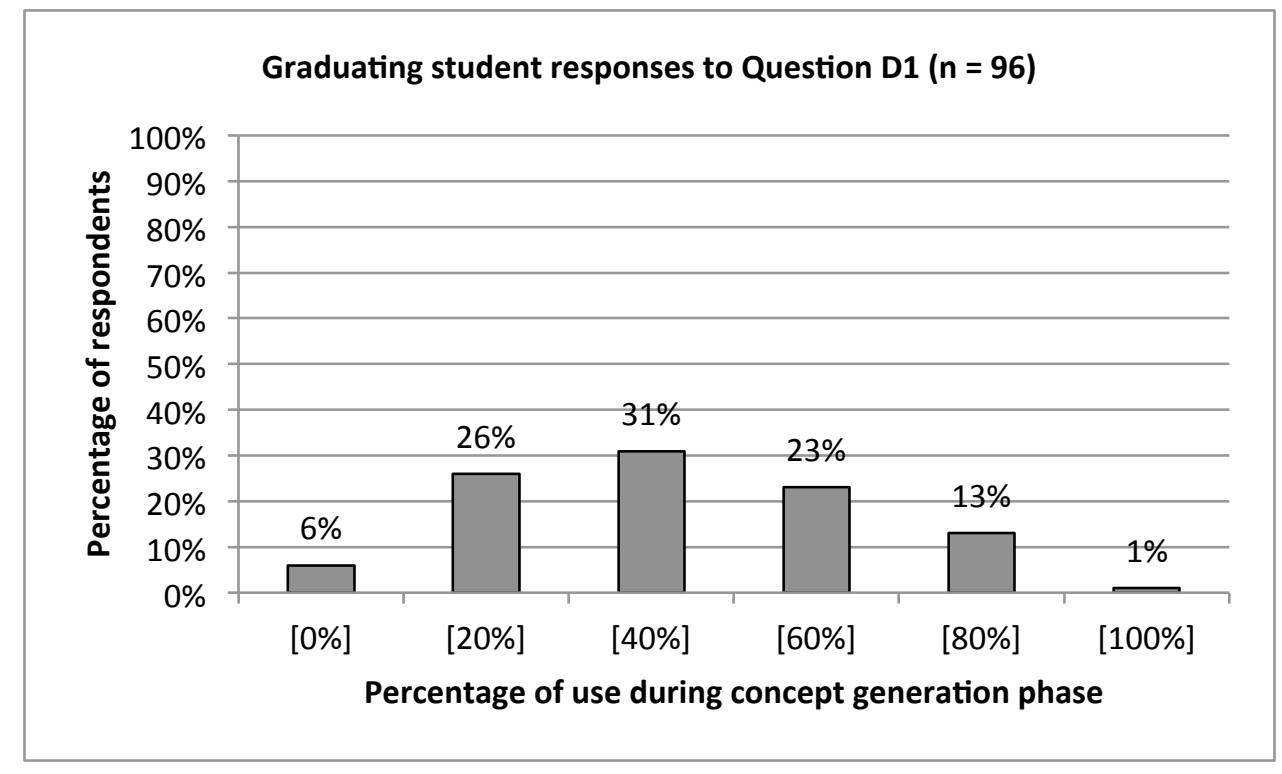

Figure 5-26: Graduating student responses to Question D1: "To what extent do you employ digital methods in the concept generation phase (creating the product's form and user interfaces)?" 


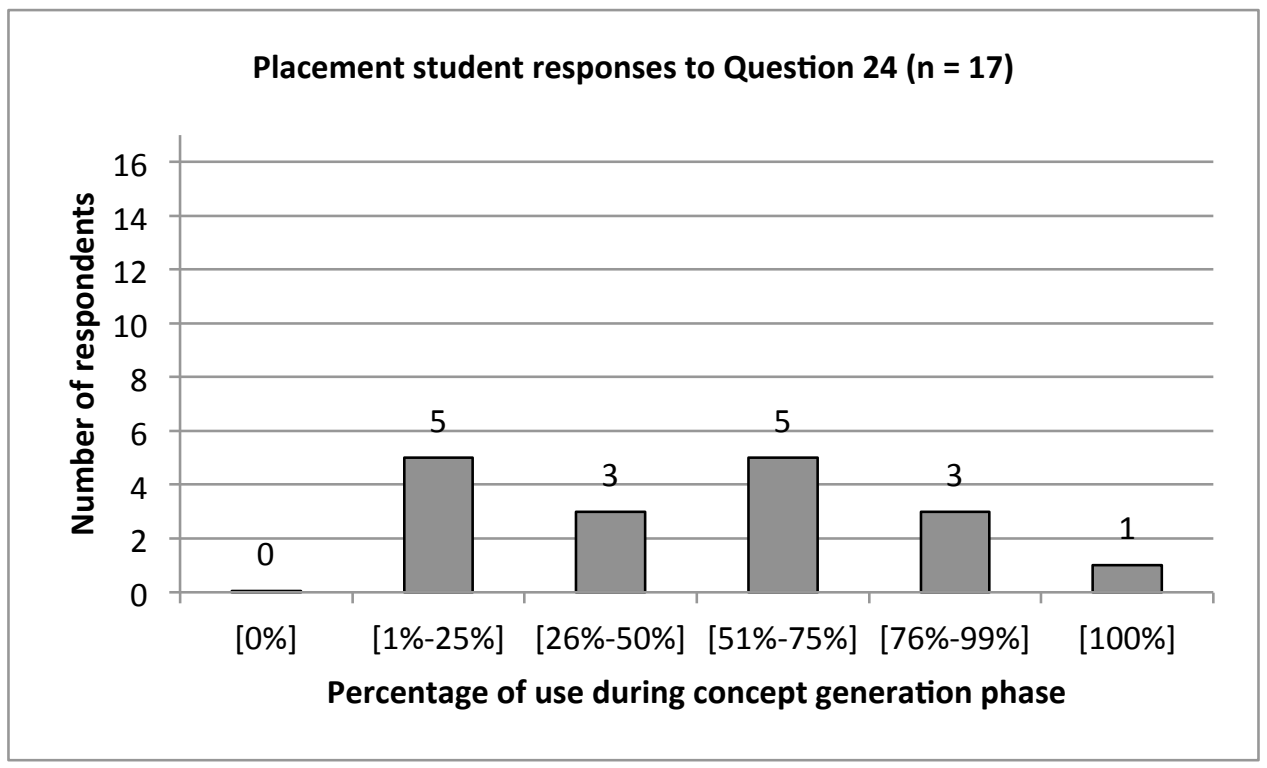

Figure 5-27: Industrial placement student responses to Question 24: "To what extent does the design organisation you worked for employ digital methods in the concept generation phase (creating the product form and translating ideas into visual representation)?"

\subsubsection{Preliminary Refinement}

In the preliminary refinement phase, industrial designers build soft models of the most promising concepts to explore form and interface. Graduating student responses were scattered in terms of the use of digital methods during $20 \%, 40 \%, 60 \%$ and $80 \%$ of this phase. The largest group (27\%) employed digital methods during $60 \%$ of this phase and $2 \%$ employed them all the time (Figure 5-28). The majority of the design organisations (15 in total) used digital tools and media more than $50 \%$ of the time with seven design organisations utilising them $76 \%-99 \%$ of the phase and three design organisations employing them all the time (Figure 5-29). It was apparent from these findings that practitioners were utilising digital methods more than students during design practice. 


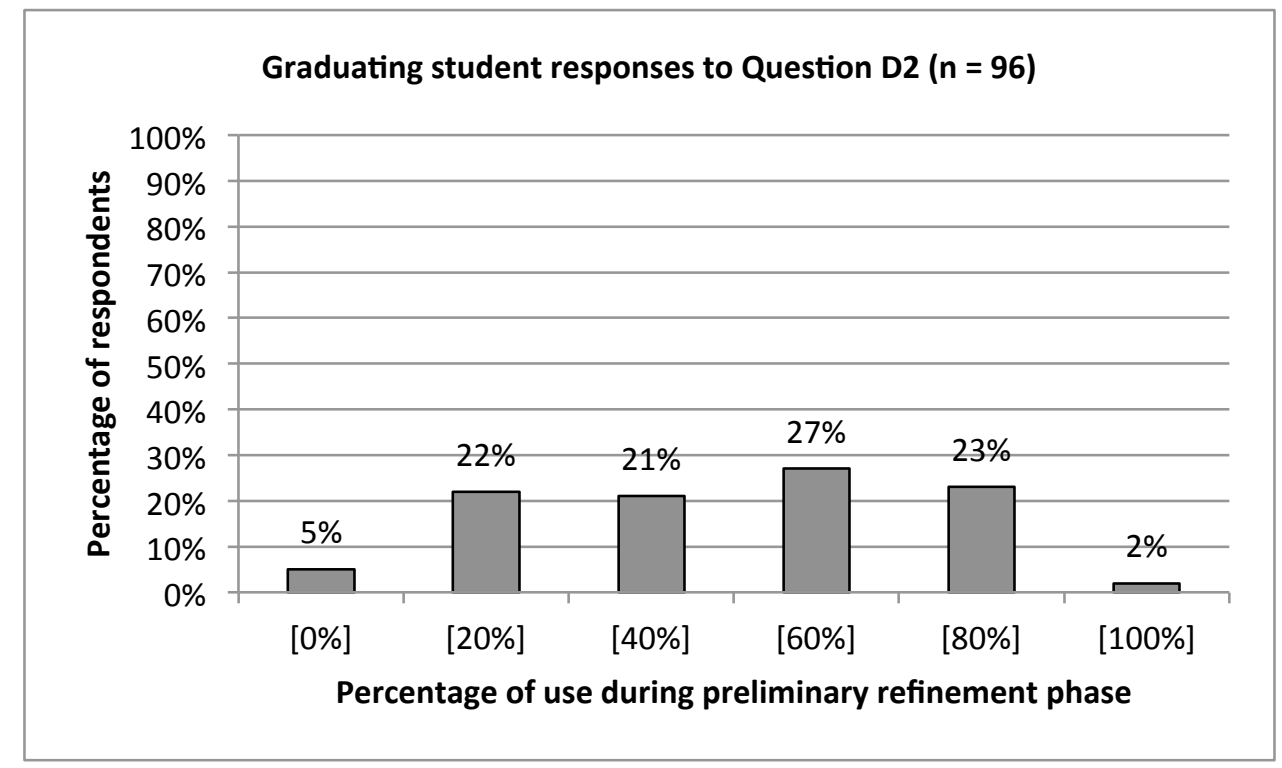

Figure 5-28: Graduating student responses to Question D2: "To what extent do you employ digital methods in the preliminary refinement phase (building soft models of the most promising concepts)?"

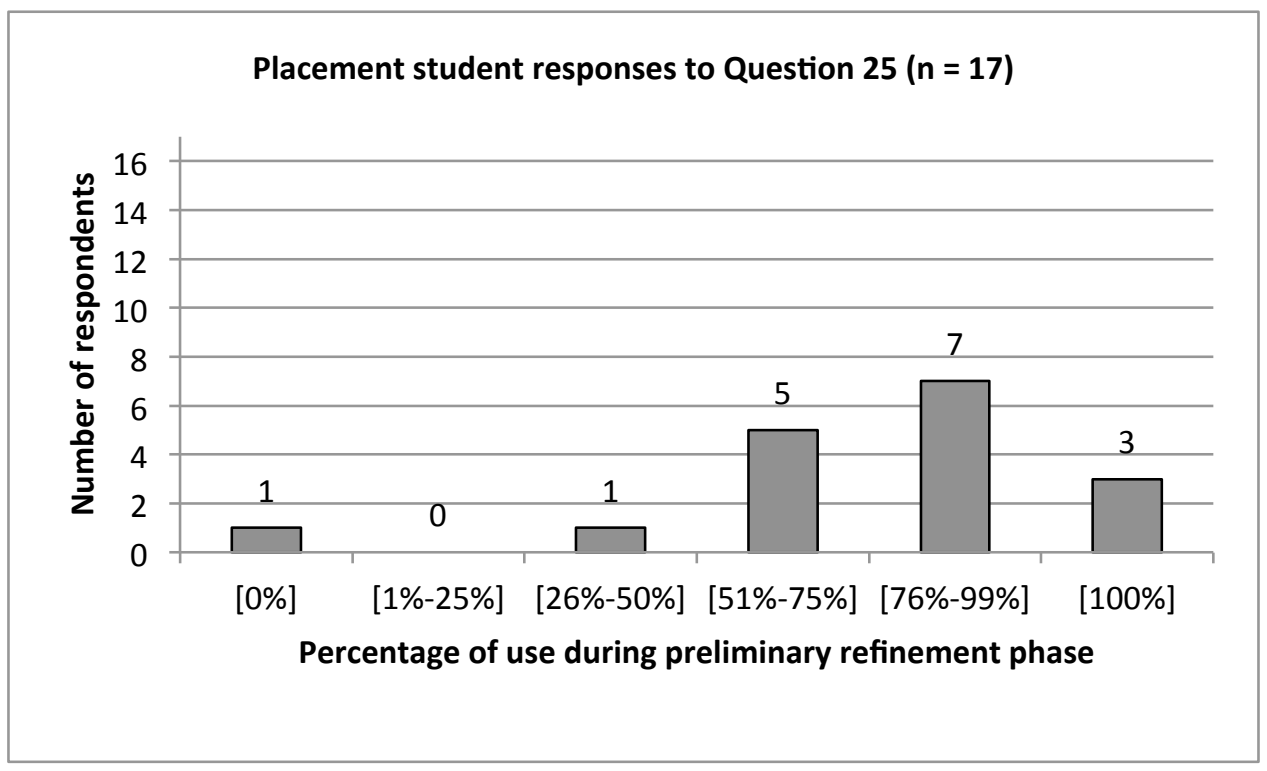

Figure 5-29: Industrial placement student responses to Question 25: "To what extent does the design organisation you worked for employ digital methods in preliminary refinement phase (most promising ideas being developed and presented to clients as rendering or foam models)?"

\subsubsection{Further Refinement and Final Concept Selection}

During this phase, industrial designers generally select concepts and explore details such as materials and manufacture. They switch from soft models and sketches to appearance 
models and information-intensive drawings (renderings). A relatively large number of the graduating students (44\%) confirmed that they employed digital methods during $80 \%$ of the further refinement and final concept selection phase; $26 \%$ employed digital methods during $60 \%$ of this stage and $15 \%$ employed them during the entire phase (Figure $5-30$ ). According to the final year students who completed a placement, almost all of the design organisations they worked for (apart from one) applied digital methods in more than half the phase. Four design organisations employed them all the time, seven in $76 \%-99 \%$ of the phase and the remaining five design organisations used them in $51 \%-75 \%$ of the same phase (Figure 5-31).

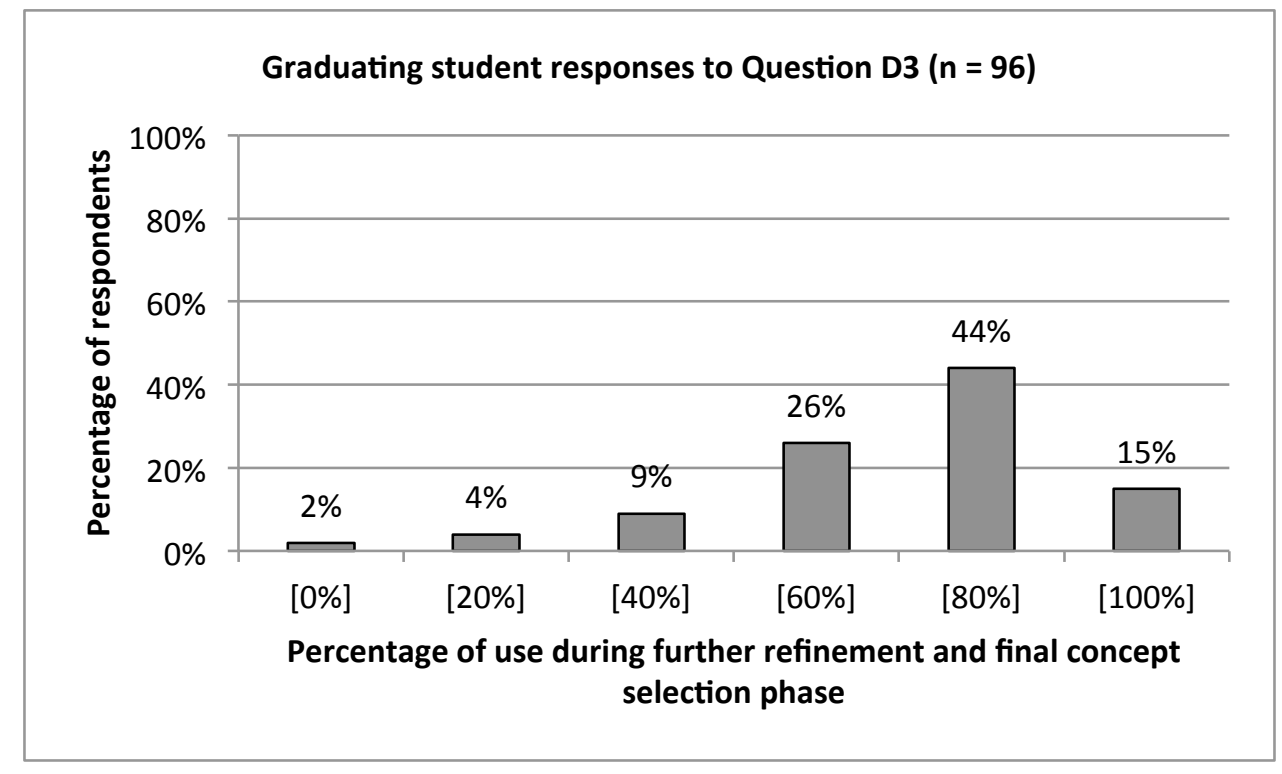

Figure 5-30: Graduating student responses to Question D3: "To what extent do you employ digital methods in the further refinement and final concept selection phase (building hard models and making renderings)?" 


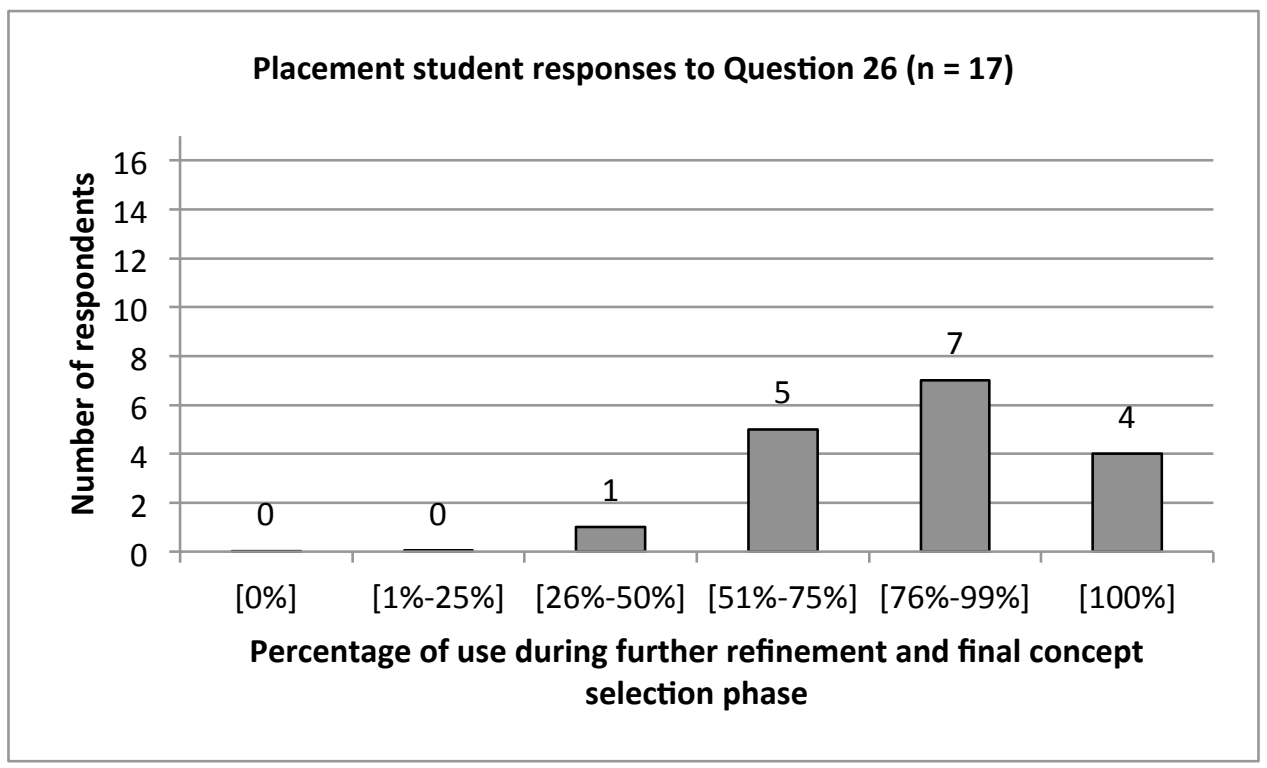

Figure 5-31: Industrial placement student responses to Question 26: "To what extent does the design organisation you worked for employ digital methods in the further refinement and final concept selection phase (chosen idea being developed and appearance models and prototypes are expected to be produced)?"

\subsubsection{Specification}

Industrial designers generally undertake the detailing of components during the specification phase and complete their development process by making control/engineering drawings and 3D CAD geometry for the final design. The greatest percentage of graduating students (40\%) utilised digital methods during $80 \%$ of this phase and $33 \%$ employed them during the entire phase (Figure 5-32). The use of digital methods in the specification phases increased in the professional practice as the majority (12 out of 17 design organisations) employed digital methods along the entire phase (Figure 5-33). This indicates that educators should encourage students to increase the use of digital methods in the detailing phase of the design process to follow professional practice. 


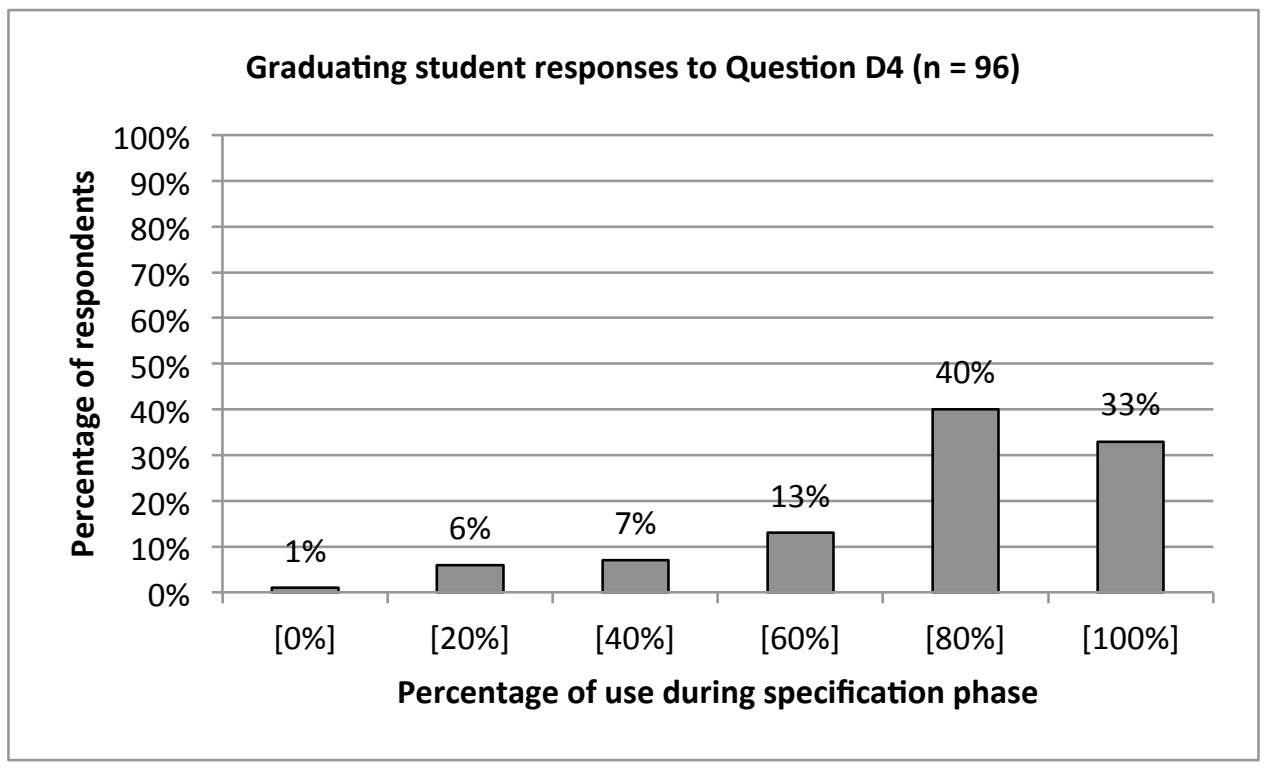

Figure 5-32: Graduating student responses to Question D4: "To what extent do you employ digital methods in the specification phase (making control drawings of the final concept to enable building prototypes)?"

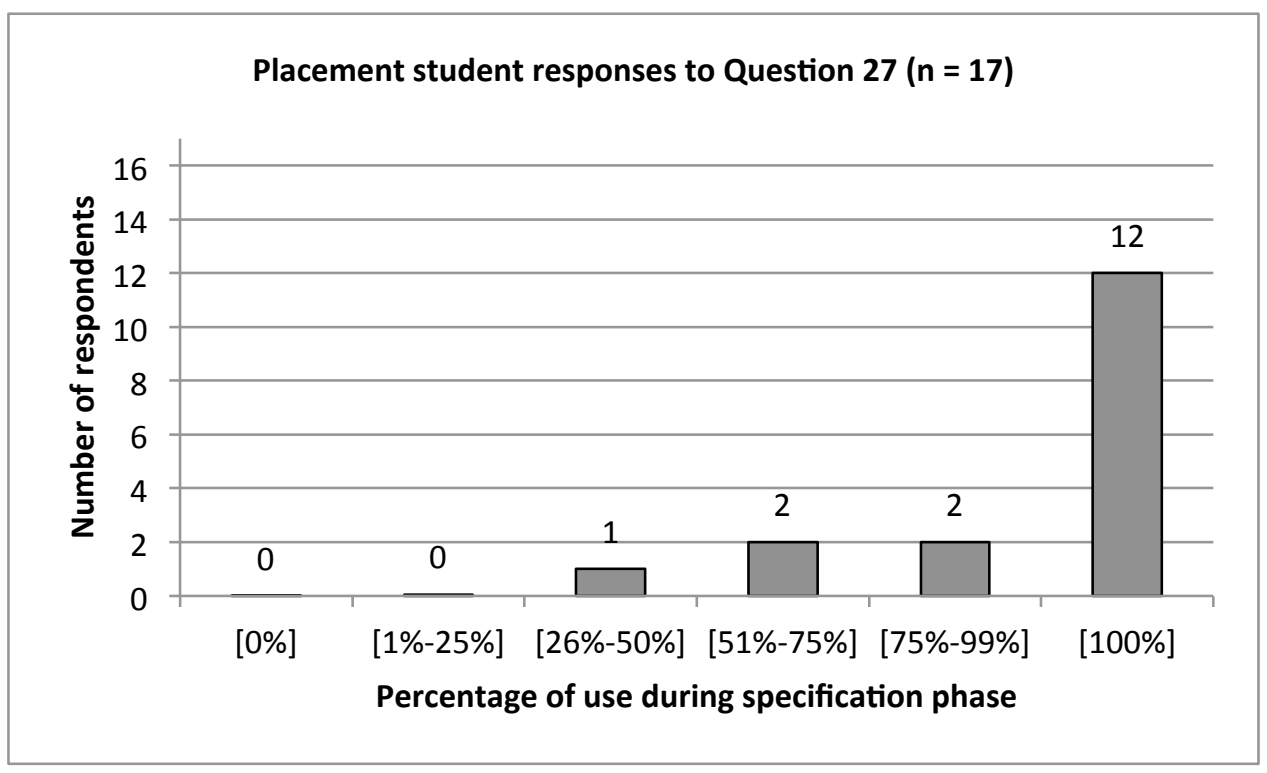

Figure 5-33: Industrial placement student responses to Question 27: "To what extent does the design organisation you worked for employ digital methods in the specification phase

(making control drawings of the final concept required for production tooling by the manufacturer)?"

An indication of the average amount of time spent by graduating students using digital methods within each phase was calculated by multiplying each group's percentage value by its number of respondents; summing these six sub-totals; and then dividing by the total 
number of participants to give a numerical mean. These mean percentage values increased for subsequent phases of the design process confirming that, as the design process progresses, the proportion of time spent using digital methods increased extensively (Figure 5-34).

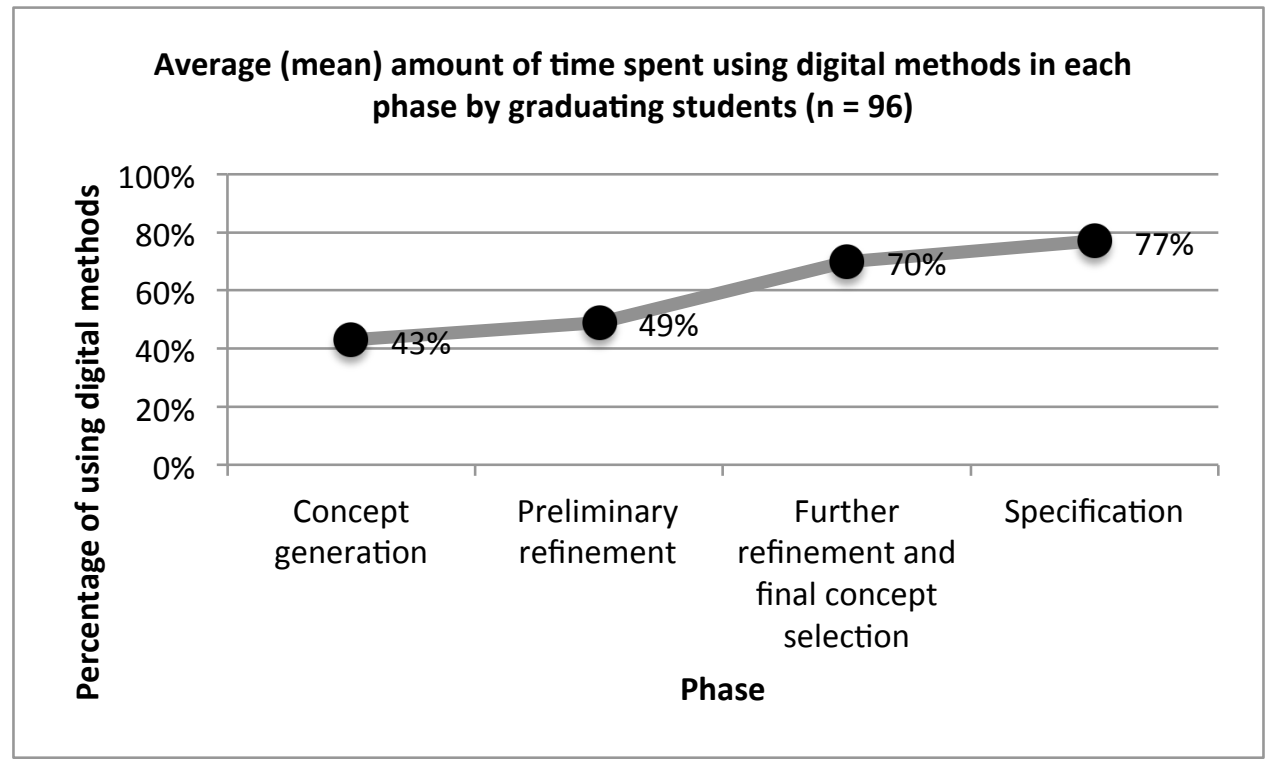

Figure 5-34: Average (mean) amount of time spent using digital methods in each phase by graduating students

\subsubsection{Thoughts on Employing Digital Techniques}

This section of the questionnaire gathered opinion on the possibility of achieving the same outcome from projects if an entirely digital design process was employed and if digital technologies had the potential to replace conventional workshops and hands-on activity. It also examined whether graduating students and practitioners thought that their design practice would improve if a completely digital process was used and if it would be appropriate to have a totally DID course. The reasons identified by respondents for disagreeing/strongly disagreeing; agreeing/strongly agreeing; and feeling neutral were data condensed into tables after clustering the responses. Due to the large amount of data collected from graduating students, their tables highlight the reasons occurring two or more times to summarise the most important data (for example Table 5-2), while the practitioner and industrial placement student tables illustrate all the reasons mentioned since the number of participants is relatively small compared to the graduating students (for example Table 5-3 and Table 5-4). 
Question E1 asked, "To what extent do you agree or disagree that you will be able to achieve the same outcome from your project if the entire process was done using digital tools?". Responses to this question indicated that $23 \%$ of graduating students agreed/strongly agreed that they could achieve the same outcome from their projects if they used digital tools only while $58 \%$ disagreed/strongly disagreed (Figure 5-35). It is important to note that some of the graduating students who disagreed/strongly disagreed believed that they could achieve a better outcome when designing totally digitally rather than similar outcome, while the majority had negative feelings towards the capabilities of digital tools/media. A breakdown of the responses can be seen in Table 5-2.

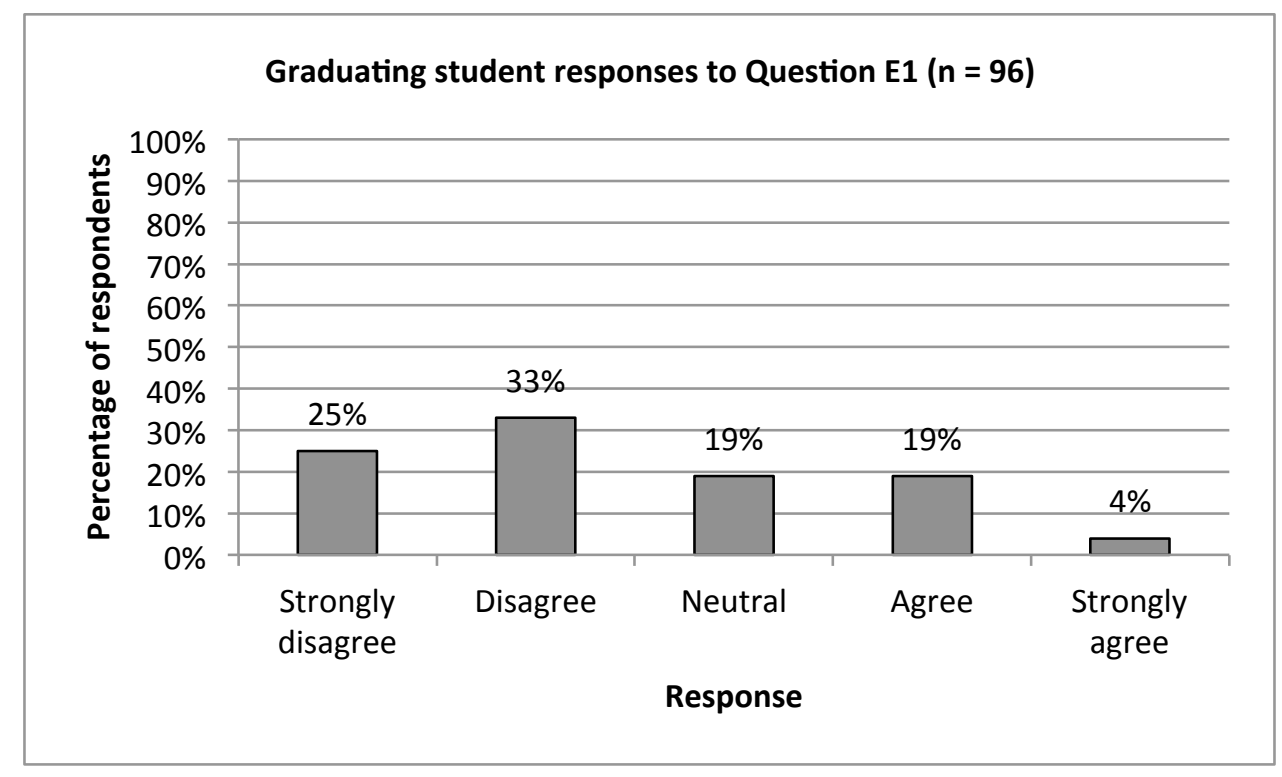

Figure 5-35: Graduating student responses to Question E1: "To what extent do you agree or disagree that you will be able to achieve the same outcome from your project if the entire process was done using digital tools?" 


\begin{tabular}{|l|l|l|c|}
\hline \multicolumn{1}{|c|}{ Response } & \multicolumn{1}{|c|}{ Reason } & Occurrences \\
\hline & 1 & Digital tools/media does not allow sketching quickly & 13 \\
& 2 & Concept generation is better with pen and paper & 12 \\
& 3 & Restriction in freedom & 7 \\
& 4 & More efficient and easier to carry around a pencil & 6 \\
& 5 & Difficulties in being creative with digital techniques & 6 \\
Strongly & 6 & A physical model is needed to interact with the product & 5 \\
disagree/disagree & 7 & Software can slow you down if it is not familiar & 3 \\
& 8 & Cost of digital equipments & 3 \\
& 9 & Limitation in the sense of scale & 3 \\
& 10 & Manual modelling teaches how the product functions & 2 \\
& 11 & Less understanding of product emotive cues (texture) & 2 \\
& 12 & Better products can be designed digitally (POSITIVE) & 2 \\
& 13 & Hands-on experience is important & 2 \\
\hline Neutral & 1 & Ease of use and speed & 3 \\
\hline Strongly & 2 & Depends on preference & 2 \\
agree/agree & 1 & Technology has advanced enough & 3 \\
\hline
\end{tabular}

Table 5-2: Graduating student reasons behind responses to Question E1: "To what extent do you agree or disagree that you will be able to achieve the same outcome from your project if the entire process was done using digital tools?"

Industrial placement student responses to Question 32, "Do you believe that the design organisation you worked for will be able to achieve the same outcome from projects if the entire process was done using digital tools?" was close with seven disagreed/strongly disagreed and six agreed/strongly agreed (Figure 5-36). Table 5-3 shows a breakdown of the reasons of each group. 


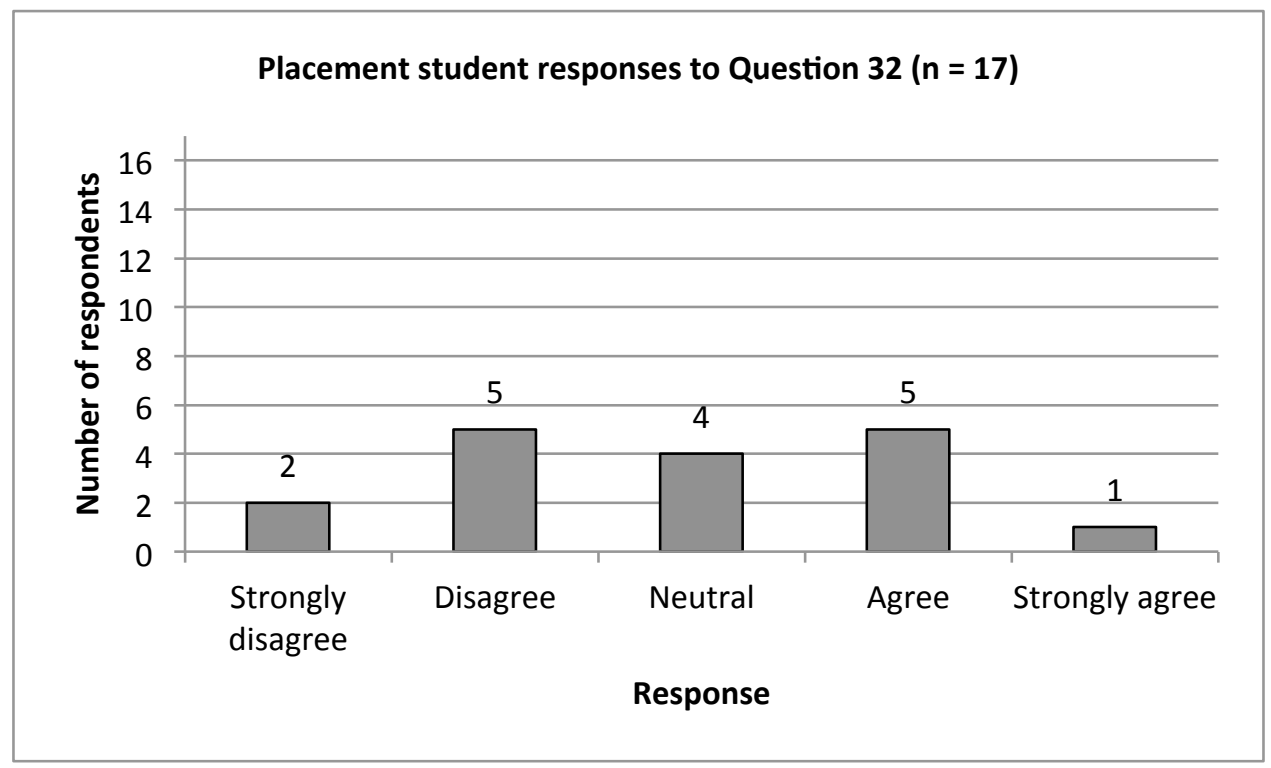

Figure 5-36: Industrial placement student responses to Question 32: “Do you believe that the design organisation you worked for will be able to achieve the same outcome from projects if the entire process was done using digital tools?"

\begin{tabular}{|c|c|c|c|}
\hline Response & & Reason & Occurrences \\
\hline \multirow{6}{*}{$\begin{array}{l}\text { Strongly } \\
\text { disagree/disagree }\end{array}$} & 1 & Quicker to sketch on paper & 3 \\
\hline & 2 & Poor tactile and visual feedback when designing entirely & 3 \\
\hline & & digital & \\
\hline & 3 & Concepts flow more easily on paper & 3 \\
\hline & 4 & Designs can be verified with digital tools later on after & 2 \\
\hline & 5 & $\begin{array}{l}\text { sketching on paper } \\
\text { Cheaper to sketch on paper }\end{array}$ & 1 \\
\hline & 1 & The design organisation used digital tools already & 4 \\
\hline agree/agree & 2 & $\begin{array}{l}\text { Technology has advanced enough to reduce the learning } \\
\text { curve }\end{array}$ & 1 \\
\hline
\end{tabular}

Table 5-3: Industrial placement student reasons behind responses to Question 32: “Do you believe that the design organisation you worked for will be able to achieve the same outcome from projects if the entire process was done using digital tools?"

When practitioners in the IDSA LinkedIn group were asked if they would be able to achieve the same outcome if a project was undertaken entirely using digital tools (Question E1), the results indicated a similar opinion to that of the majority of graduating students and the greatest number of final year students that had completed industrial placement i.e. it would not be possible (Figure 5-37).

Two of the four respondents that strongly disagreed included comments on the loss of personality when designing digitally. Another two practitioners expressed the lack of flexibility of digital tools when compared to pencil/paper and that "the ability to quickly 
draw out a gesture or mechanical concept on a napkin has yet to be replaced electronically". These were similar to the most common reasons cited by the other two groups, which focused on efficiency and flexibility (Table 5-4).

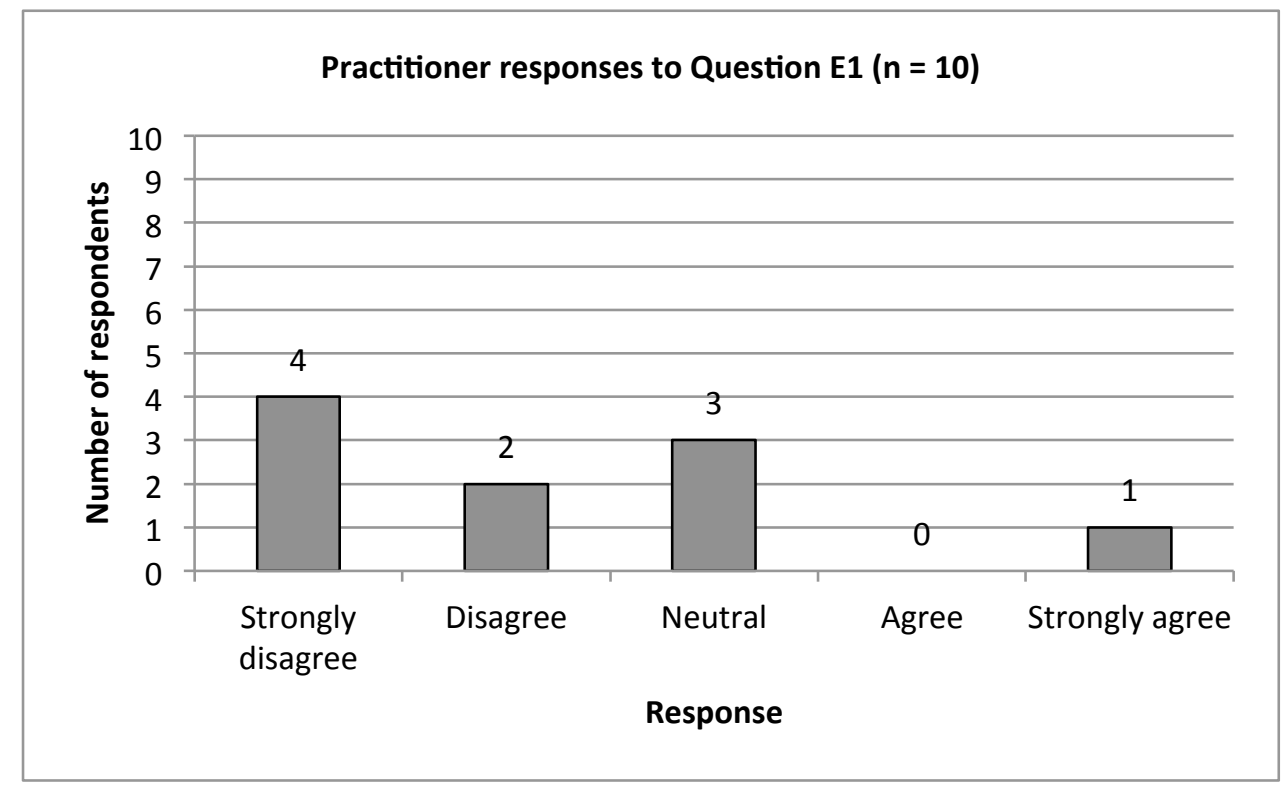

Figure 5-37: Practitioner responses to Question E1: "To what extent do you agree or disagree that you will be able to achieve the same outcome from your project if the entire process was done using digital tools?"

\begin{tabular}{|l|l|l|c|}
\hline \multicolumn{1}{|c|}{ Response } & \multicolumn{1}{|c|}{ Reason } & Occurrences \\
\hline $\begin{array}{l}\text { Strongly } \\
\text { disagree/disagree }\end{array}$ & 1 & $\begin{array}{l}\text { Digital sketching tools are not as flexible as pencil and } \\
\text { paper } \\
\text { Loss of personality as the end results of digital process } \\
\text { could be similar } \\
\text { No substitute for working in 1:1 real 3D } \\
\text { Designers are influenced by what they are able to achieve } \\
\text { with a particular software or a particular technique }\end{array}$ & 2 \\
\hline Neutral & 1 & $\begin{array}{l}\text { It depends on the nature of the product (tech. driven/user } \\
\text { driven) and the nature of the project } \\
\text { CAID has great advantages and disadvantages } \\
\text { 2D digital sketch or 3D CAD rendering can be very } \\
\text { impressive but often generate stiff or overly simple designs } \\
\text { When digital photography came on to the scene, traditional } \\
\text { artists were threatened and influenced by it at the same } \\
\text { time. Similarly is digital designing }\end{array}$ & 1 \\
& 2 & 1 \\
\hline
\end{tabular}

Table 5-4: Practitioner reasons behind responses to Question E1: "To what extent do you agree or disagree that you will be able to achieve the same outcome from your project if the entire process was done using digital tools?

While the High Tech Computer Corporation (HTC) has been able to reduce the number of physical prototypes from up to five sets to one per product through the use of 3D CAD 
software (Wilson and Fauscette, 2008: 8), Coyne et al. (2002: 265) indicated that $90 \%$ of designers believed that gesturing (bold hand movement) is important for effective design and all of the respondents agreed that digital media supplements manual media rather than replaces it. Ramduny-Ellis et al. (2008: 1) note that although the design process is becoming increasingly digital, our bodies and minds are still naturally conceived to interact with the physical things. Mahoney (2000: 13) states that "designers are a notoriously touchy-feely lot to whom the ideal creative process is a multi-sensory one that support direct, physical control of the media".

In the supervised collective questionnaire, when graduating students were asked if they agreed or disagreed that digital technologies had the potential to replace conventional workshops and the hands-on experience, the majority (55\%) strongly disagreed/disagreed while $27 \%$ of respondents agreed/strongly agreed (Figure 5-38). A breakdown of the responses can be seen in Table 5-5.

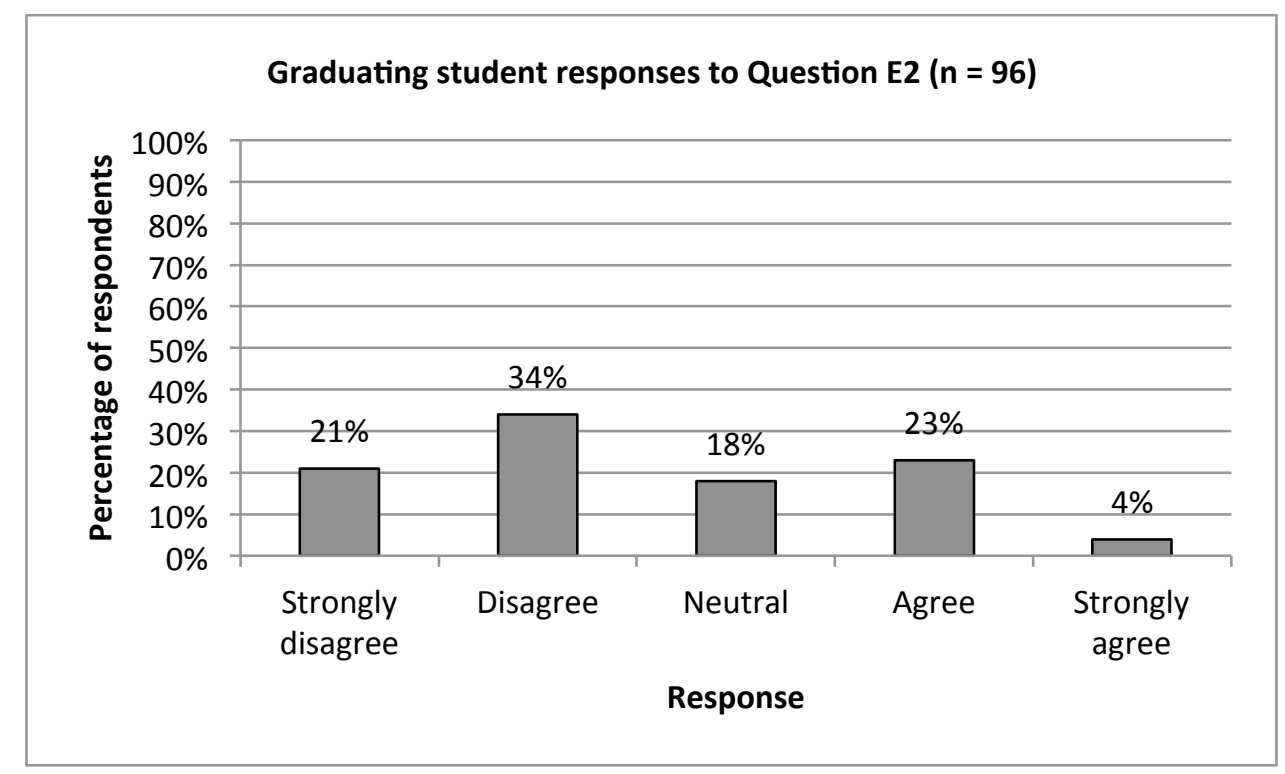

Figure 5-38: Graduating student responses to Question E2: “To what extent do you agree or disagree that digital technologies have the potential to replace conventional workshops and the hands-on experience?" 


\begin{tabular}{|c|c|c|c|}
\hline Response & & Reason & Occurrences \\
\hline \multirow{11}{*}{$\begin{array}{l}\text { Strongly } \\
\text { disagree/disagree }\end{array}$} & 1 & Hands-on experience is needed when designing & 7 \\
\hline & 2 & $\begin{array}{l}\text { Workshop model making skills are vital to understand the } \\
\text { design properly and develop it }\end{array}$ & 6 \\
\hline & 3 & Digital tools are expensive compared to conventional ones & 5 \\
\hline & 4 & Conventional tools such as pen and paper are more & 5 \\
\hline & 5 & It is best to feel the product in its true form and texture to & 4 \\
\hline & 6 & $\begin{array}{l}\text { There will always be a place for traditional methods and } \\
\text { workshops }\end{array}$ & 3 \\
\hline & 7 & $\begin{array}{l}\text { It would be a loss to the design craft skills and fabrication } \\
\text { process }\end{array}$ & 3 \\
\hline & 8 & Physical models are important for assessment and input & 2 \\
\hline & 9 & Hands-on models made in the workshop enhance creativity & 2 \\
\hline & 10 & Digital design wastes time & 2 \\
\hline & 11 & $\begin{array}{l}\text { The design process can be seen and documented easier by } \\
\text { hand }\end{array}$ & 2 \\
\hline Neutral & 1 & Hands-on work will always be needed & 5 \\
\hline \multirow{4}{*}{$\begin{array}{l}\text { Strongly } \\
\text { agreed/agreed }\end{array}$} & 1 & Saves time & 6 \\
\hline & 2 & Technology has advanced enough & 3 \\
\hline & 3 & More accurate and efficient & 3 \\
\hline & 4 & Possibly with future technologies & 2 \\
\hline
\end{tabular}

Table 5-5: Graduating student reasons behind responses to Question E2: "To what extent do you agree or disagree that digital technologies have the potential to replace conventional workshops and the hands-on experience?"

Question 34 in the industrial placement student questionnaire asked, "Do you think that digital technologies have the potential to replace conventional workshops and hands-on experience completely in the design organisation you worked for?". Four out of 17 final year students that had completed industrial placement felt neutral about it and the number of students who disagreed/strongly disagreed and agreed/strongly agreed was fairly close, seven and six respectively (Figure 5-39). A breakdown of the reasons can be seen in Table 5-6. 


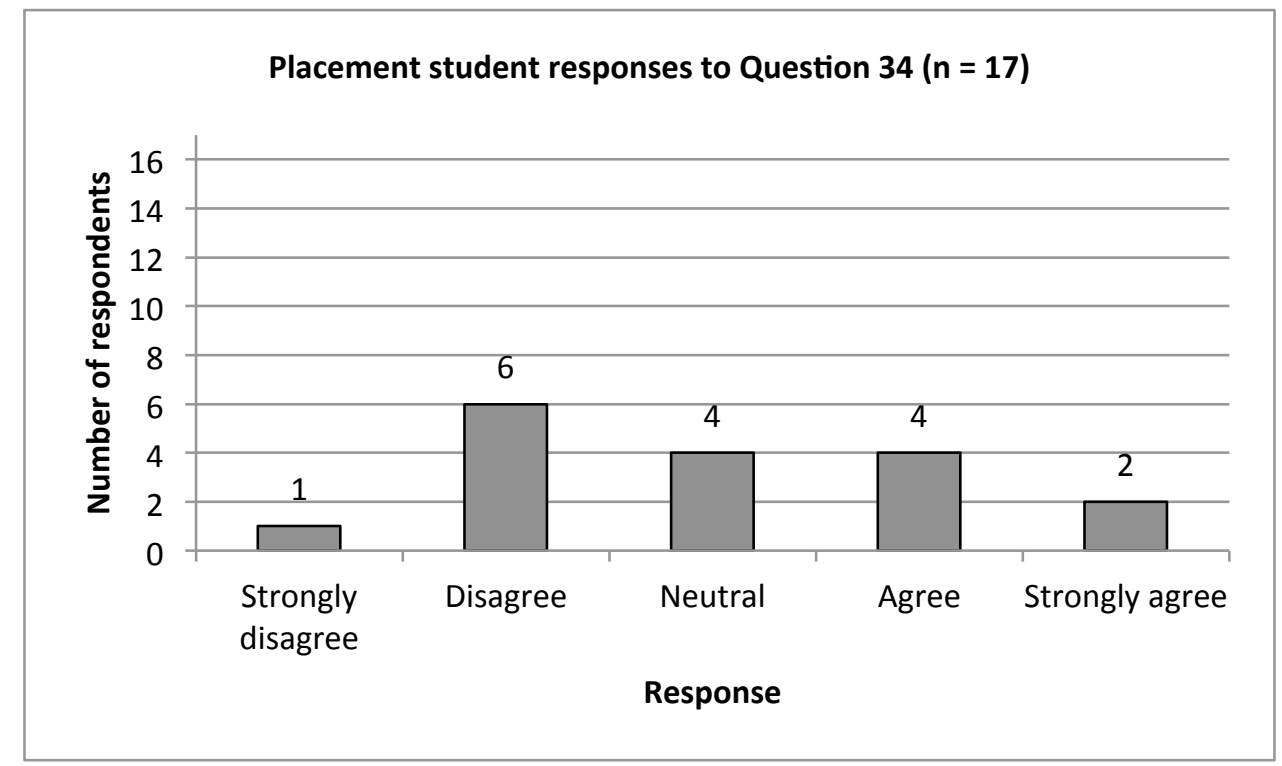

Figure 5-39: Industrial placement student responses to Question 34: "Do you think that digital technologies have the potential to replace conventional workshops and hands-on experience completely in the design organisation you worked for?"

\begin{tabular}{|l|l|l|c|}
\hline \multicolumn{1}{|c|}{ Response } & \multicolumn{1}{|c|}{ Reason } & Occurrences \\
\hline $\begin{array}{l}\text { Strongly } \\
\text { disagree/disagree }\end{array}$ & 1 & $\begin{array}{l}\text { Holding and analysing a physical 3D model is important } \\
\text { It is easier and quicker to communicate through paper- } \\
\text { based sketches } \\
\text { 3D software needs to come a long way before it can replace } \\
\text { real physical design strategies }\end{array}$ & 5 \\
& 3 & 1 \\
\hline Neutral & 1 & 3D printing is great but expensive & 1 \\
\hline & 1 & Digital design provides more precision & 2 \\
Strongly & 2 & RP is proving the digital data before tooling & 1 \\
agree/agree & 3 & RP saves time & 1 \\
& 4 & Changes are easier to make when designing digitally & 1 \\
& 5 & The design organisation works digitally already & 1 \\
\hline
\end{tabular}

Table 5-6: Industrial placement student reasons behind responses to Question 34: "Do you think that digital technologies have the potential to replace conventional workshops and hands-on experience completely in the design organisation you worked for?"

When asked if digital tools had the potential to replace conventional workshops and the hands-on experience (Question E2), only 3 out of the 10 practitioners strongly disagreed/disagreed compared to $55 \%$ of the graduating students and 7 out of 17 placement students. Reasons given by the practitioners as to why the hands-on experience might be replaced included the ability of digital tools to prevent the loss of design intent and that digital tools will eventually replace conventional tools (Table 5-7). It is possible that experience of using digital tools during a wide range of commercial projects has 
demonstrated to practitioners the capability of such methods to deliver results. The findings for Question E3 for the practitioners can be seen in Figure 5-40.

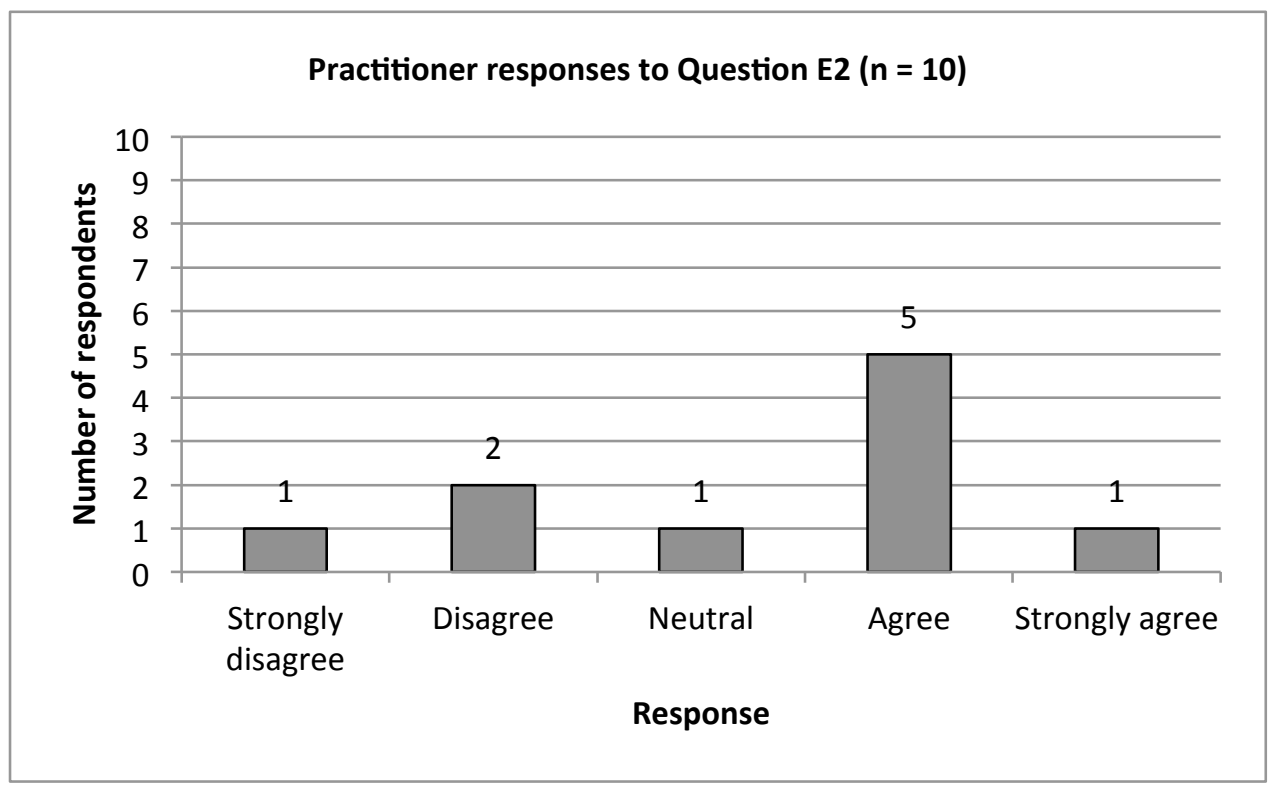

Figure 5-40: Practitioner responses to Question E2: "To what extent do you agree or disagree that digital technologies have the potential to replace conventional workshops and the hands-on experience?"

\begin{tabular}{|l|l|l|c|}
\hline \multicolumn{1}{|c|}{ Response } & \multicolumn{1}{|c|}{ Reason } & Occurrences \\
\hline $\begin{array}{l}\text { Strongly } \\
\text { disagree/disagree }\end{array}$ & 1 & $\begin{array}{l}\text { Good design is all about designing a customer experience } \\
\text { (visual, tactile, experiential, etc.) and that type of skill is } \\
\text { difficult to translate through a computer monitor } \\
\text { Being face-to-face with other designers and contributors } \\
\text { helps you to sharpen your skills } \\
\text { At least for a number of years }\end{array}$ & 1 \\
\hline Neutral & 1 & Tools are tools and you use what is available & 1 \\
\hline $\begin{array}{l}\text { Strongly } \\
\text { agree/agree }\end{array}$ & 1 & $\begin{array}{l}\text { Digital tools have the potential to replace analogue tools, } \\
\text { but not yet } \\
\text { Digital technology has the potential to 100\% mimic the } \\
\text { paper and pen interface } \\
\text { 3D interfaces will be improved to a point where form can } \\
\text { be evaluated effectively } \\
\text { It is viable now to make blind people see by stimulating the } \\
\text { cerebral cortex with head implants }\end{array}$ & 1 \\
\hline
\end{tabular}

Table 5-7: Practitioner reasons behind responses to Question E2: "To what extent do you agree or disagree that digital technologies have the potential to replace conventional workshops and the hands-on experience?"

"Today, the effects of computer-based technological advances are widespread and that they have brought computers into design studios with an ever-increasing role in design activities" (Sener and Wormald, 2001: 358). However, the negative feeling towards a digital process 
reached $58 \%$ when graduating students were asked: "To what extent do you agree or disagree that your design practice will improve if you used a completely digital process?" (Figure 5-41). A breakdown of the responses can be seen in Table 5-8.

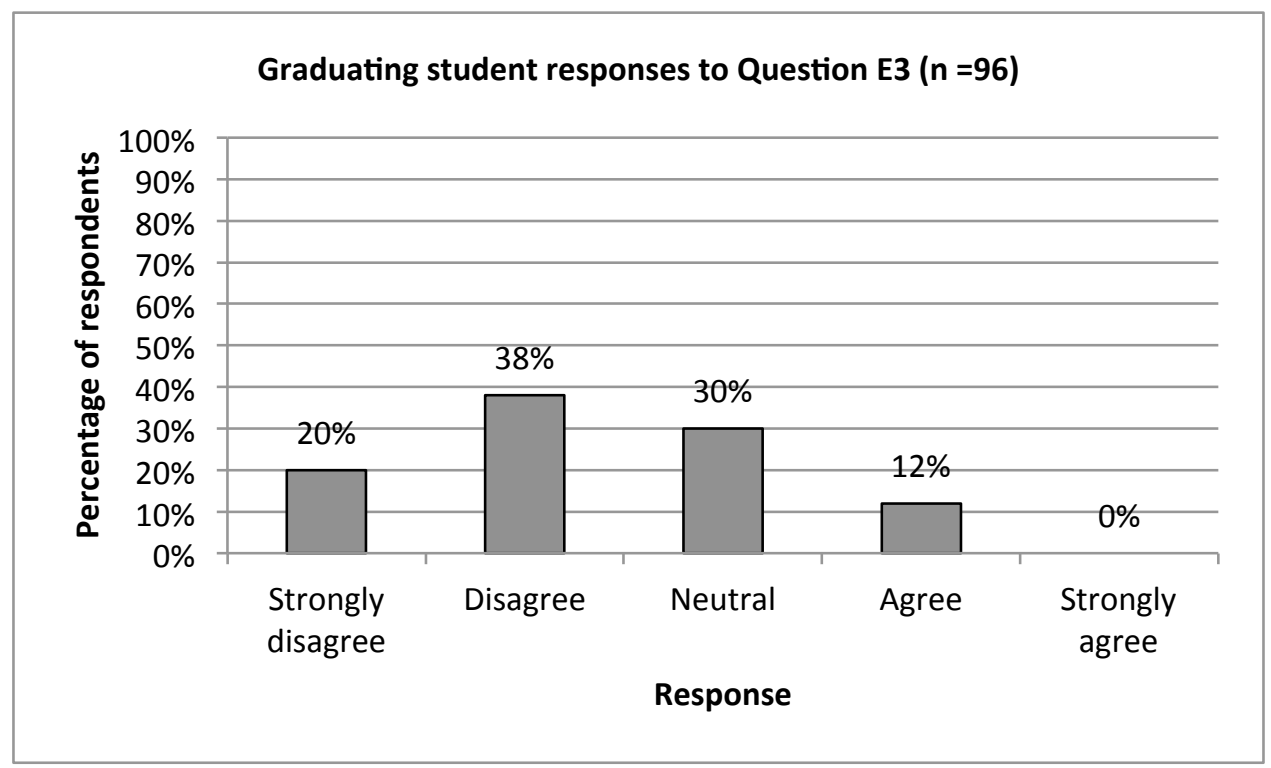

Figure 5-41: Graduating student responses to Question E3: "To what extent do you agree or disagree that your design practice will improve if you used a completely digital process?"

\begin{tabular}{|l|l|l|c|}
\hline \multicolumn{1}{|c|}{ Response } & \multicolumn{1}{|c|}{ Reason } & Occurrences \\
\hline & 1 & Generating ideas is quicker with a pen/pencil & 6 \\
& 2 & Sketching supports appreciation of form and styling & 5 \\
& 3 & Physical models are needed to understand the design & 4 \\
Strongly & 4 & Workshop craft is an important skill & 3 \\
disagree/disagree & 5 & Being static behind a computer screen is a bad practice & 2 \\
& 7 & More efficient to use pen/pencil to sketch ideas anywhere & 2 \\
& 8 & Creativity is enhanced more with paper-based sketches & 2 \\
& 9 & Dimits the acquired skills of industrial design & 2 \\
& 10 & Lose the connection between project and designer & 2 \\
& 1 & Need to test the digital processes to decide & 2 \\
\hline Neutral & 2 & Digital technologies have the potential to improve certain & 2 \\
& & areas & 2 \\
\hline Strongly & 3 & There will always be a place for a manual process & 2 \\
agree/agree & 1 & More accurate & 2 \\
\hline
\end{tabular}

Table 5-8: Graduating student reasons behind responses to Question E3: "To what extent do you agree or disagree that your design practice will improve if you used a completely digital

$$
\text { process?" }
$$

The majority of the final year students that had completed industrial placement (9 out of 17) felt neutral when asked: “Do you think that the organisation's design practice will improve if 
a complete digital process was used?". The remaining eight students were equally divided between disagreeing/strongly disagreeing and agreeing/strongly agreeing (Figure 5-42). Reasons behind their responses can be seen in Table 5-9.

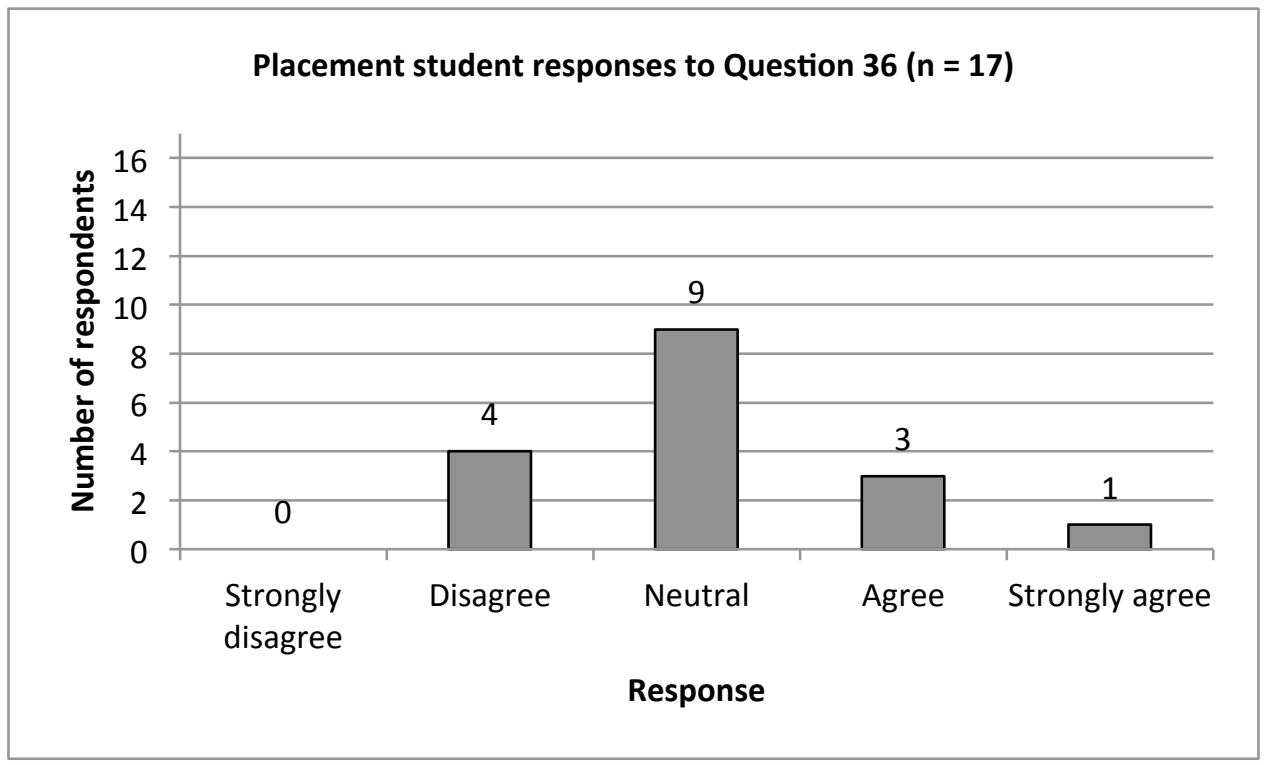

Figure 5-42: Industrial placement student responses to Question 36: "Do you think that the organisation's design practice will improve if a complete digital process was used?"

\begin{tabular}{|c|c|c|c|}
\hline Response & & Reason & Occurrences \\
\hline $\begin{array}{l}\text { Strongly } \\
\text { disagree/disagree }\end{array}$ & $\begin{array}{l}3 \\
4\end{array}$ & $\begin{array}{l}\text { Waste of money at concept phase (price of a Wacom tablet } \\
\text { and software compare to pen and paper) } \\
\text { Convenience of pen and paper } \\
\text { Mock ups can be made quickly by hand } \\
\text { A full size prototype was always needed to confirm the } \\
\text { design process } \\
\text { CAD is slow in the early stages of design } \\
\text { Finding it hard to organise the work when designing } \\
\text { digitally }\end{array}$ & $\begin{array}{l}1 \\
1 \\
1 \\
1 \\
1\end{array}$ \\
\hline Neutral & $\begin{array}{l}1 \\
2\end{array}$ & $\begin{array}{l}\text { Depends on nature of process/cost of setup } \\
\text { It may speed the whole design process up but the initial } \\
\text { design work could be limited } \\
\text { Possibly if the digital process was detailed enough }\end{array}$ & $\begin{array}{l}1 \\
1 \\
1\end{array}$ \\
\hline $\begin{array}{l}\text { Strongly } \\
\text { agree/agree }\end{array}$ & $\begin{array}{l}2 \\
3\end{array}$ & $\begin{array}{l}\text { Could make the process of taking a sketch to a more } \\
\text { refined design a bit more fluent } \\
\text { Less time wasted on restarting designs } \\
\text { CAD features are substantial to improve designing products }\end{array}$ & $\begin{array}{l}1 \\
1 \\
1\end{array}$ \\
\hline
\end{tabular}

Table 5-9: Industrial placement student reasons behind responses to Question 36: "Do you think that the organisation's design practice will improve if a complete digital process was

$$
\text { used?" }
$$

The delivery of improvements/enhancements to professional practice is cited as the reason for employing digital methods but total use does not appear to be the preferred option. 
Fifty-nine percent of the graduating students and 7 out of 10 of the practitioners believed that design practice would not improve if a completely digital process was employed (Figure 5-43). The reason given by the one practitioner who supported a totally digital process was similar to that of the graduating students who cited accuracy and reduced lead times. This practitioner commented that, "it provides more control over the data accumulated during a project, which means more efficiency" (Table 5-10).

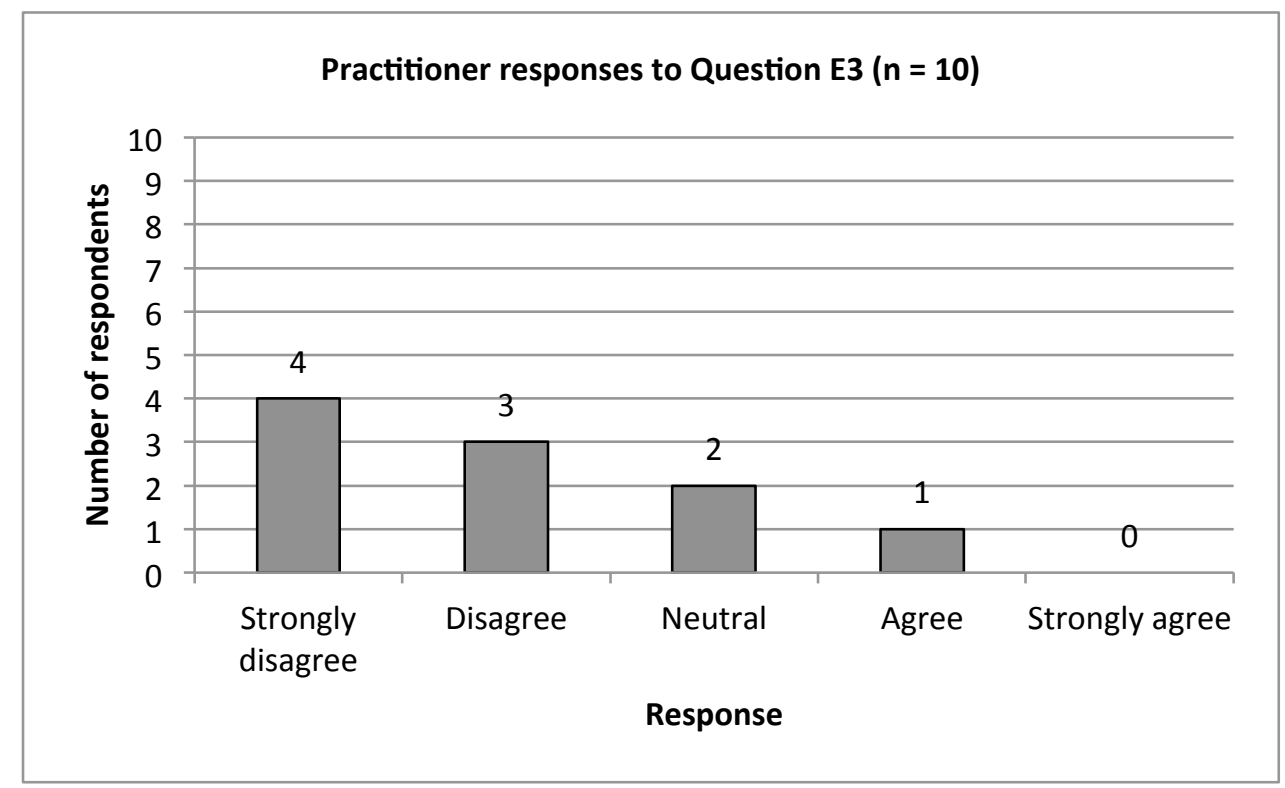

Figure 5-43: Practitioner responses to Question E3: "To what extent do you agree or disagree that your design practice will improve if you used a completely digital process?"

\begin{tabular}{|l|l|l|c|}
\hline \multicolumn{1}{|c|}{ Response } & \multicolumn{1}{|c|}{ Reason } & Occurrences \\
\hline $\begin{array}{l}\text { Strongly } \\
\text { disagree/disagree }\end{array}$ & 1 & $\begin{array}{l}\text { Using digital tools only is too limiting in the initial stages of } \\
\text { a project } \\
\text { It could facilitate information flow to production, but } \\
\text { humans will still be humans and therefore cannot be } \\
\text { substituted digitally } \\
\text { It will not create the same level of sophistication that a } \\
\text { combination of analogue and digital process will create } \\
\text { taking advantage of the strengths of both } \\
\text { Computers are tools and they cannot replace knowledge } \\
\text { itself }\end{array}$ & 1 \\
\hline Neutral & 1 & $\begin{array}{l}\text { It is not about what you buy, it is what you build. The talent } \\
\text { of the mind shines through } \\
\text { It depends on the firms philosophy (training for employees, } \\
\text { desire for learning new tools and methods) }\end{array}$ & 1 \\
\hline $\begin{array}{l}\text { Strongly } \\
\text { agree/agree }\end{array}$ & 1 & $\begin{array}{l}\text { It provides more control over data accumulated during a } \\
\text { project, which means more efficiency }\end{array}$ & 1 \\
\hline
\end{tabular}

Table 5-10: Practitioner reasons behind responses to Question E3: "To what extent do you agree or disagree that your design practice will improve if you used a completely digital process?" 
Having recently completed an industrial design course, $57 \%$ of the graduating students felt that it would not be appropriate to have a totally DID course and only $23 \%$ agreed/strongly agreed that it would be viable (Figure 5-44). A breakdown of the responses can be seen in Table 5-11.

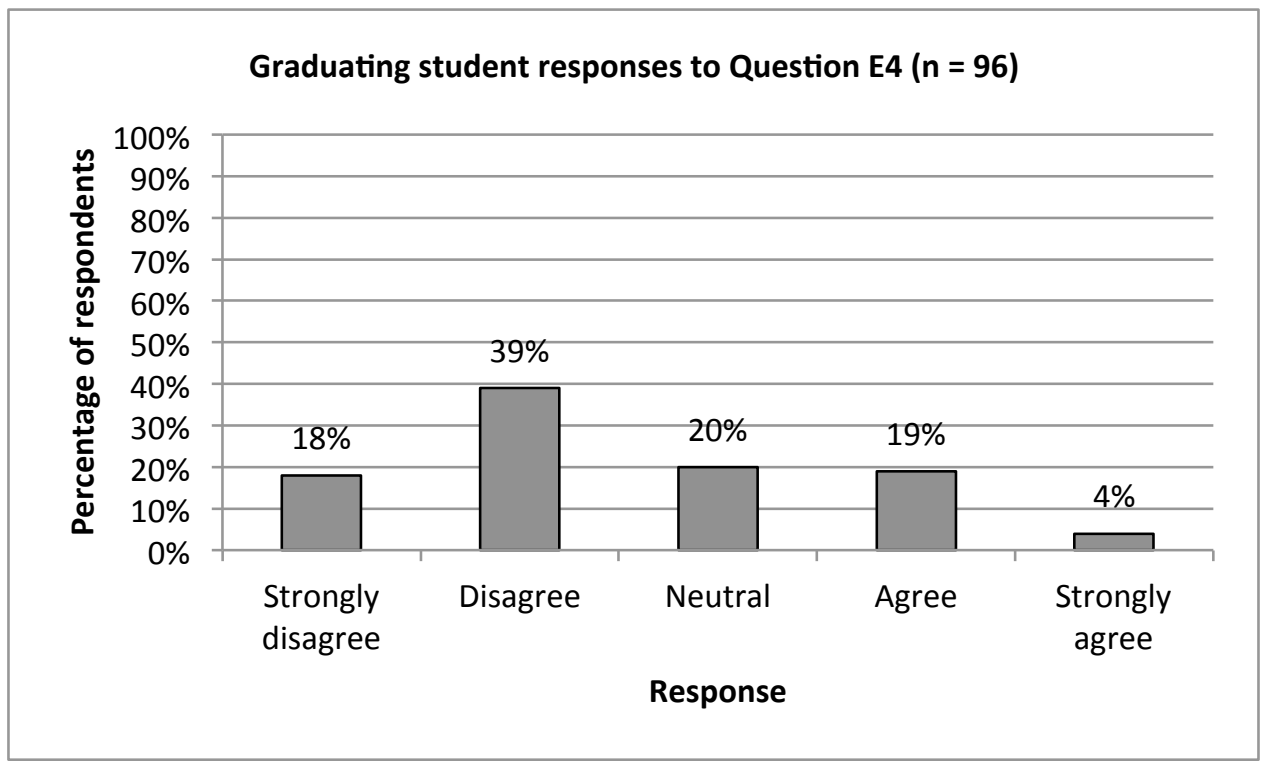

Figure 5-44: Graduating student responses to Question E4: "To what extent do you agree or disagree that it would be appropriate to have a totally digital industrial/product design course?"

\begin{tabular}{|l|l|l|c|}
\hline \multicolumn{1}{|c|}{ Response } & \multicolumn{1}{|c|}{ Reason } & Occurrences \\
\hline & 1 & Hands-on experience will always be needed & 6 \\
& 2 & Sketch work is essential & 3 \\
& 3 & Pen and paper are easier to carry around and use & 3 \\
Strongly & 4 & Cost & 3 \\
disagree/disagree & 5 & Overall design process compromised & 2 \\
& 6 & It is not what the industry wants or requires & 2 \\
& 7 & Quick sketching skill will be lost & 2 \\
& 8 & Some manual sketch work should be taught & 2 \\
& 9 & Best to know both & 2 \\
& 10 & Does not support creativity & 2 \\
\hline \multirow{3}{*}{ Neutral } & 1 & Might be best for some people (personal preference) & 3 \\
& 2 & Paper-based sketching skills should not be diminished & 3 \\
\hline \multirow{5}{*}{ Strongly } & 3 & It would benefit some companies & 2 \\
agree/agree & 1 & It is the future of industrial design & 3 \\
& 2 & Specialists are always needed in industry & 3 \\
& 3 & It is using the most advanced technology to its full potential & 2 \\
& 4 & Some people can utilise a digital process better than a & 2 \\
& & physical process & \\
\hline
\end{tabular}

Table 5-11: Graduating student reasons behind responses to Question E4: "To what extent do you agree or disagree that it would be appropriate to have a totally digital industrial/product design course?" 
The majority of practitioners also expressed a similar opinion to the graduating students negative opinion with 8 out of 10 believing that it would not be appropriate (Figure 5-45). One of the reasons given by practitioners in support of a totally DID course focused on the perception that one of the roles of higher education is to push the boundaries of design thinking/methods (Table 5-12).

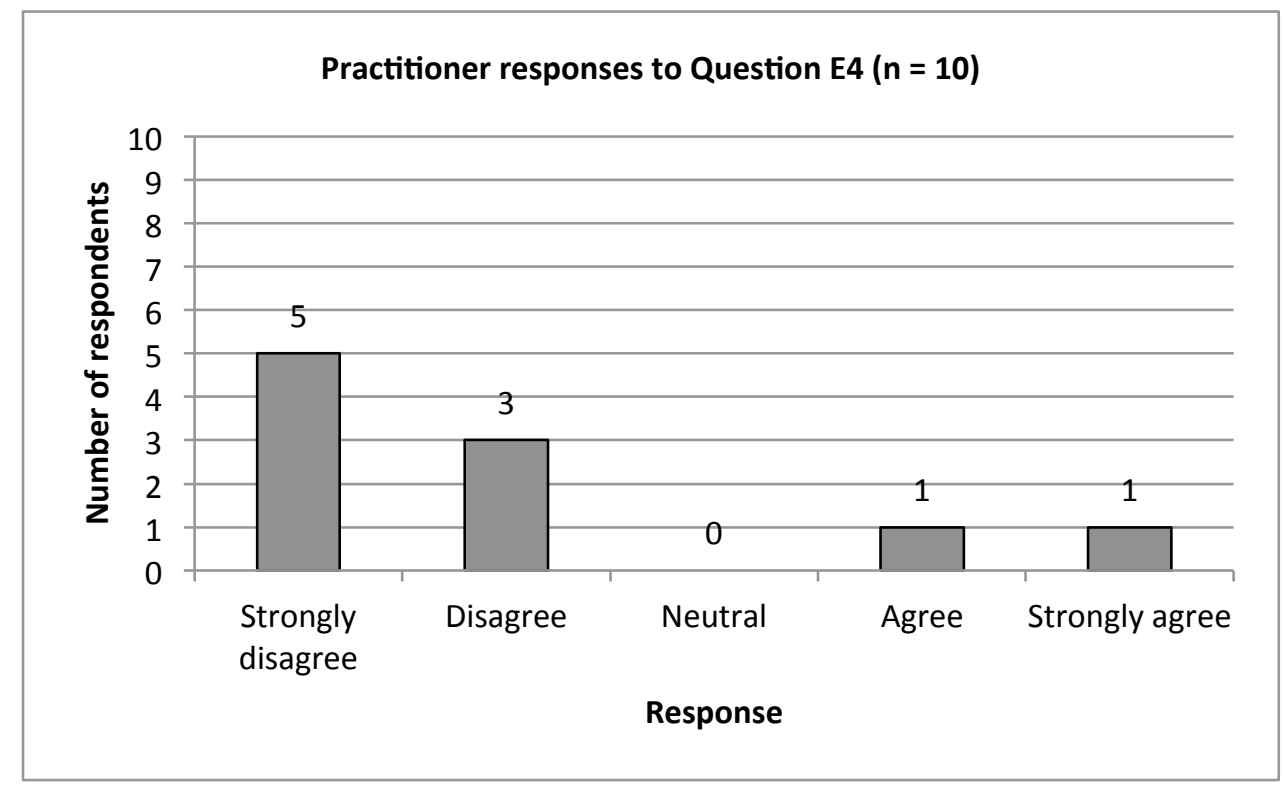

Figure 5-45: Practitioner responses to Question E4: "To what extent do you agree or disagree that it would be appropriate to have a totally digital industrial/product design course?" 


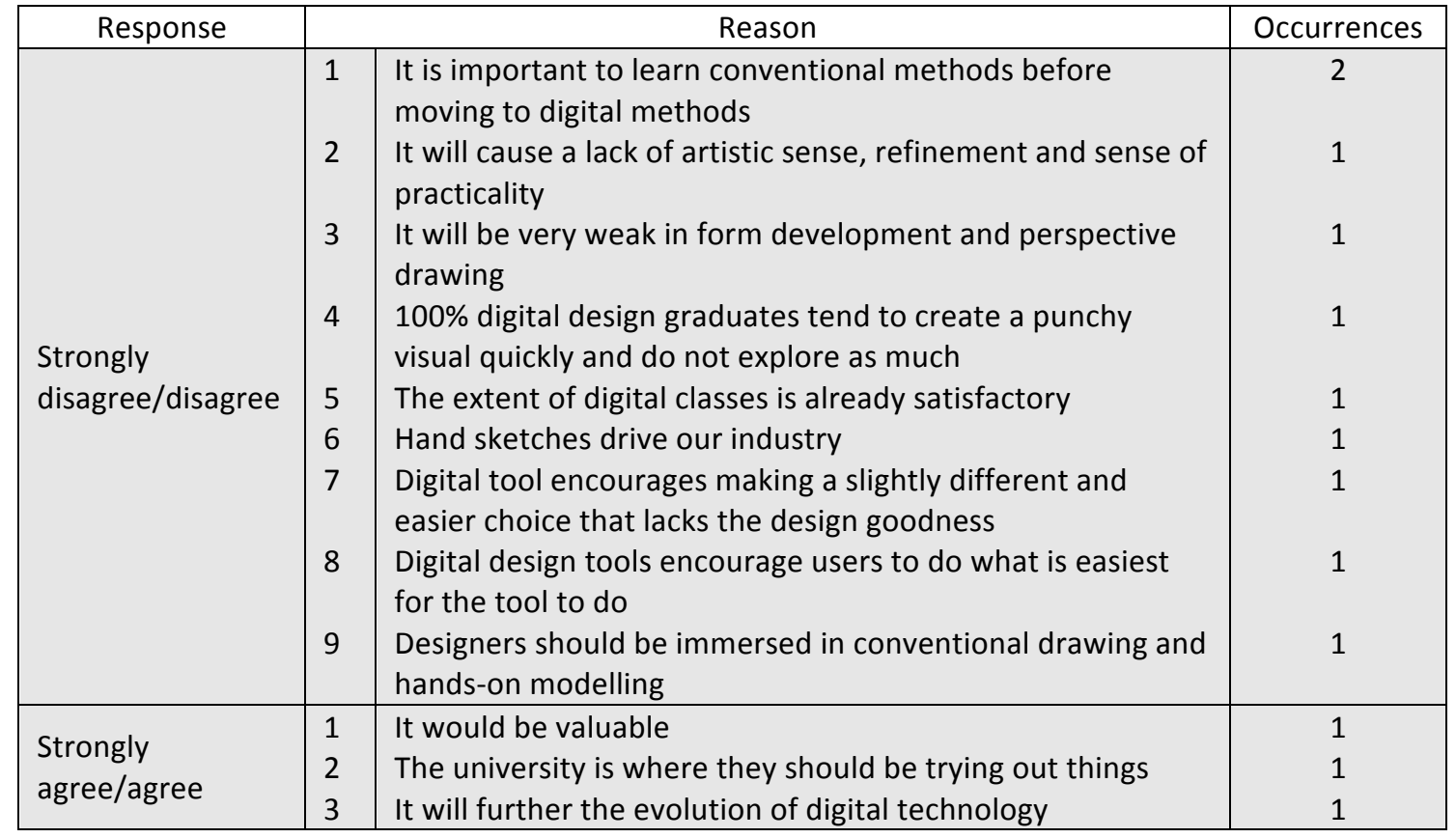

Table 5-12: Practitioner reasons behind responses to Question E4: "To what extent do you agree or disagree that it would be appropriate to have a totally digital industrial/product design course?"

\subsubsection{Areas of Improvement}

The aim of this section of the 2007/2008 graduating student supervised collective questionnaire was to highlight areas that could be improved within the curriculum of an industrial design course.

Fifty-eight percent of the graduating students believed that there were some areas of the industrial design process that could be improved in the curriculum of their course (Figure 5-46). Some of the key areas identified were related to greater use of digital tools and media, such as more emphasis on 3D CAD and digital rendering; the use of a wider variety of 2D and 3D CAD software; and increasing the use of digital prototyping through CNC machining and RP. A breakdown of the responses can be seen in Table 5-13. 


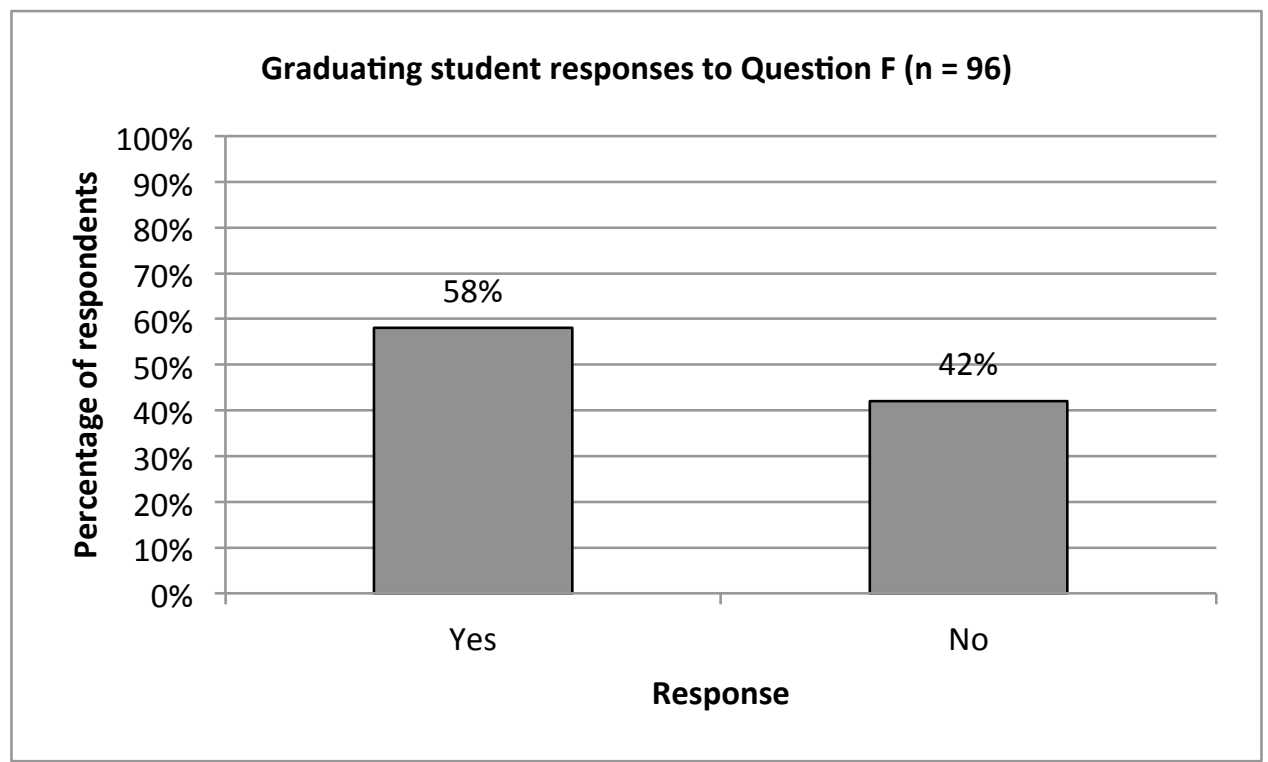

Figure 5-46: Graduating student responses to Question F: "Do you think that there are any areas of the industrial/product design course that can be improved in the curriculum of your course?"

\begin{tabular}{|l|l|c|}
\hline \multicolumn{2}{|c|}{ Areas of Improvement } & Occurrences \\
\hline 1 & More and better tutoring on CAD software & 7 \\
2 & More tutorials on digital rendering for presentation & 7 \\
3 & More sketching & 7 \\
4 & Industry practice (real-life projects) & 6 \\
5 & Greater emphasis on materials & 6 \\
6 & Use of wider variety of 2D and 3D modelling packages & 5 \\
7 & Greater emphasis on manufacturing processes & 4 \\
8 & More hands-on experience (workshop activities) & 4 \\
9 & More use of RP and CNC machining & 4 \\
10 & More emphasis on visualisation methods and aesthetics & 3 \\
11 & More prototyping (creating accurate prototypes) & 3 \\
12 & Sustainability awareness & 2 \\
13 & More information on business and protection side of design & 2 \\
14 & Design history & 2 \\
15 & More focus on animation & 2 \\
16 & Explore more digital media & 2 \\
17 & Use of digitising tables in concept generation phase & 2 \\
18 & More funding & 2 \\
19 & More emphasis on conceptual design & 2 \\
\hline
\end{tabular}

Table 5-13: Areas identified by graduating students in response to Question F: "Do you think that there are any areas of the industrial/product design course that can be improved in the curriculum of your course?"

\subsubsection{Reflection on a Completely Digital Process}

This section of the supervised collective questionnaire focused on graduating students feelings towards an entirely DID process. An open-ended question was used in this section 
to give the graduating students an opportunity to respond spontaneously and avoid the potential for bias from suggesting responses (Reja et al., 2003).

While a number of respondents held negative feelings towards a totally DID process (occurring 29 times), some held positive feelings towards it (occurring 24 times). A number of graduating students had concerns about the absence of paper-based sketching and conventional model making. A breakdown of the responses can be seen in Table 5-14.

\begin{tabular}{|l|l|c|}
\hline \multicolumn{1}{|c|}{ Feelings towards a totally DID process } & Occurrences \\
\hline 1 & Not a good idea and not interested (negative feeling) & 29 \\
3 & Good, interesting and useful idea (positive feeling) & 24 \\
4 & It should not prevent hands-on model making & 11 \\
& Enjoyment of research and development in the real world (hand modelling and & 10 \\
5 & paper sketching) & \\
6 & Lack of sketch work (freehand sketching skill) & 9 \\
& Designers are comfortable sketching using pen and paper to produce quick idea & 9 \\
7 & development whenever they like & \\
8 & Digital and conventional methods should both be employed & 7 \\
9 & Digital design is the future of the design industry & 7 \\
10 & Design process would become too impersonal & 6 \\
11 & Limitation of design skills & 5 \\
12 & Absence of flare & 4 \\
13 & Possibly in the future & 3 \\
14 & Absence of freedom of using any media & 3 \\
15 & It could benefit people/industry & 3 \\
16 & Need more sense of scale & 3 \\
17 & Cost of digital design tools/media & 3 \\
18 & Designs would be limited by the software capabilities & 2 \\
19 & Some people will lose their professionalism & 2 \\
\hline
\end{tabular}

Table 5-14: Graduating student responses to Question G: "What would you feel about a completely digital industrial/product design process?"

\subsubsection{Summary of Results}

Results from the closed-ended questions in the 2007/2008 graduating student supervised collective questionnaire used are illustrated in Table 5-15. Table 5-16 summarises the industrial placement student responses to quantitative data in the online questionnaire and Table 5-17 collates the results from the practitioner online questionnaire. 


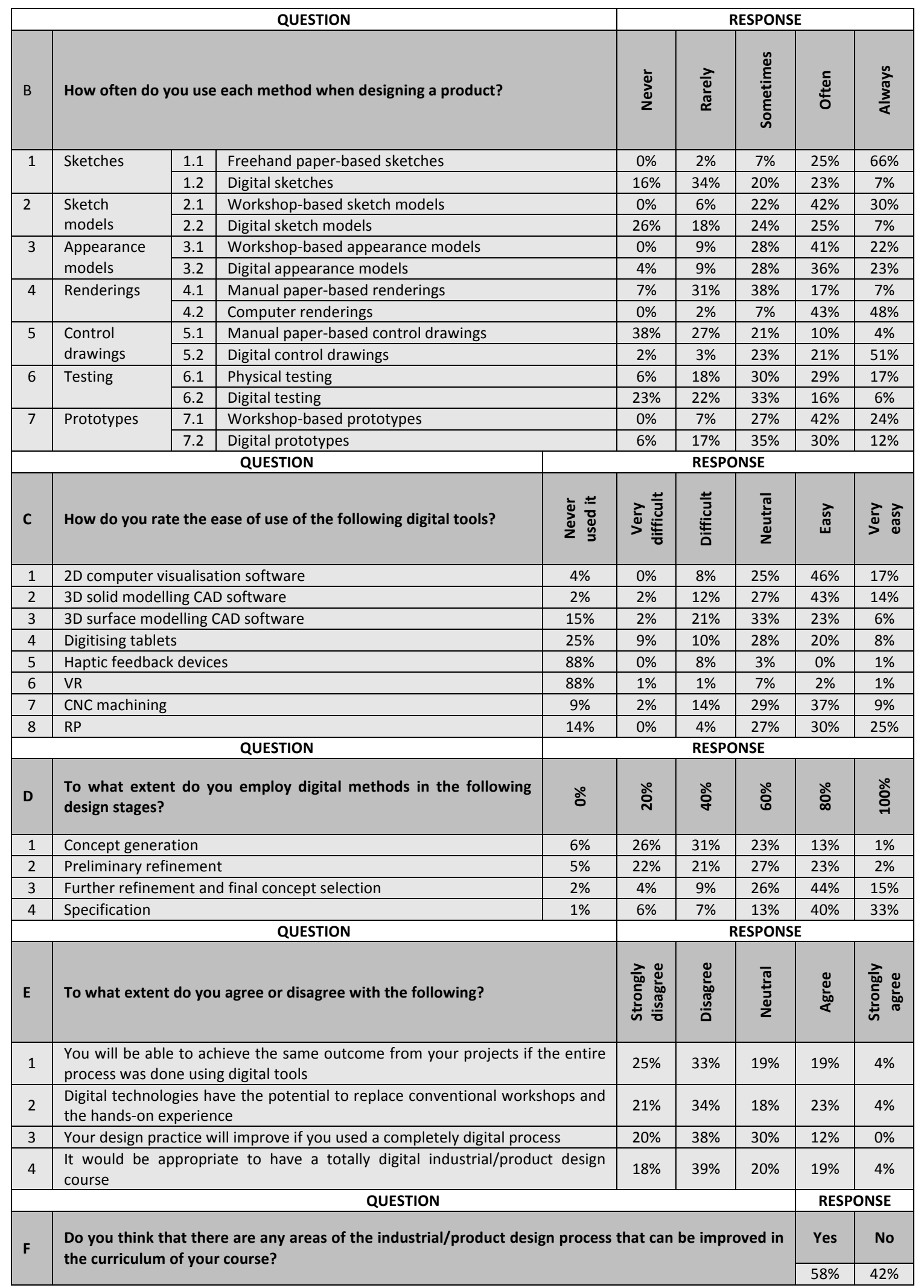

Table 5-15: Graduating student responses to quantitative questions within the supervised collective questionnaire $(n=96)$ 


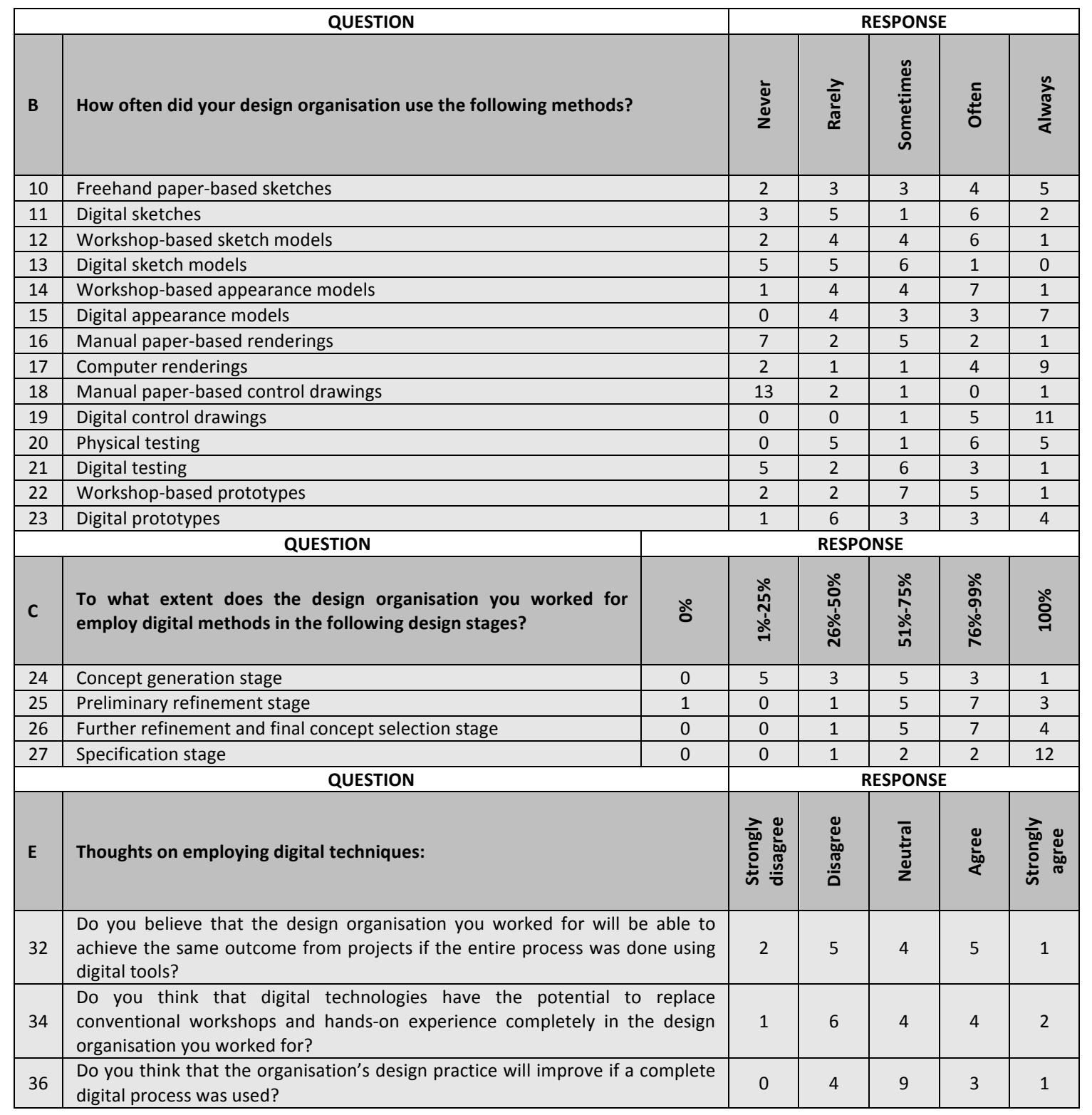

Table 5-16: Industrial placement student responses to the quantitative questions within the online questionnaire $(n=17)$

\begin{tabular}{|c|c|c|c|c|c|c|}
\hline & QUESTION & & & PON & & \\
\hline $\mathbf{E}$ & To what extent do you agree or disagree with the following? & 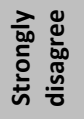 & 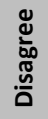 & $\begin{array}{l}\bar{\pi} \\
\stackrel{5}{3} \\
\text { ż }\end{array}$ & 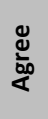 & 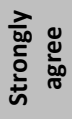 \\
\hline 1 & $\begin{array}{l}\text { You will be able to achieve the same outcome from your projects if the entire } \\
\text { process was done using digital tools }\end{array}$ & 4 & 2 & 3 & 0 & 1 \\
\hline 2 & $\begin{array}{l}\text { Digital technologies have the potential to replace conventional workshops and } \\
\text { the hands-on experience }\end{array}$ & 1 & 2 & 1 & 5 & 1 \\
\hline 3 & Your design practice will improve if you used a completely digital process & 4 & 3 & 2 & 1 & 0 \\
\hline 4 & $\begin{array}{l}\text { It would be appropriate to have a totally digital industrial/product design } \\
\text { course }\end{array}$ & 5 & 3 & 0 & 1 & 1 \\
\hline
\end{tabular}

Table 5-17: Practitioner responses to quantitative questions within the online questionnaire

$$
\text { ( } n=10)
$$




\subsection{Chapter Summary}

This chapter provided an insight into the conventional and digital design methods used when designing in educational and professional contexts. Despite similar numbers of design organisations employing conventional paper-based sketches (nine organisations) and digital sketches (eight organisations), the studies revealed that freehand paper-based sketching, workshop-based sketch models and physical testing were all used more than their digital equivalents in practitioner and student design activity. However, when it came to renderings and control/engineering drawings, the digital formats were used more in both contexts. The differences between the educational and professional design practices were noted in the use of appearance models and prototypes. Design organisations used digital modelling and prototyping more than graduating students who utilised workshop-based appearance models and prototypes more often. This could be due to the limited availability of digital design tools and media in education or the use of RP machines in professional practice.

According to the final year students who completed an industrial placement, Photoshop and Illustrator were the main tools employed in their design organisations for concept generation and preliminary refinement phases, while SolidWorks and Pro/Engineer were used mainly in the further refinement and final concept selection phase and specification phase.

The studies also confirmed that the extent of employing digital methods increased as the design process progressed from concept generation phase to reach its peak in the specification phase. Nevertheless, it was apparent that practitioners employed more digital tools and media than students during each of the design phases. This could be possibly explained by the collaborative nature of professional design practice.

The results for graduating students indicated that the majority felt that $2 \mathrm{D}$ computer visualisation software, 3D solid modelling CAD software and RP were easy/very easy to employ. However, many graduating students had never used digitising tablets, haptic feedback devices and VR. This resulted in a lack of awareness and confidence in the potential of some digital tools. The study highlighted the restrictive nature of some industrial design courses in terms of making students aware of advanced and emerging design technologies. 
When the three groups of participants were asked about the potential of digital technologies to replace conventional workshops and hands-on experience, the majority of graduating students disagreed/strongly disagreed. Although, the numbers of final year students that completed industrial placement who agreed/strongly agreed and disagreed/strongly disagreed were very close (six and seven respectively), a greater number of practitioners agreed/strongly agreed on the capabilities of digital technologies substituting conventional workshops.

Twenty-three percent of the graduating students agreed/strongly agreed that they would be able to achieve the same outcome if the entire process was done using digital tools, only believing that technology had advanced enough to do. In spite of this, most graduating students and practitioners and the greatest number of final year students that had completed an industrial placement did not believe in the capacity of digital tools to achieve identical results. In fact, most of the graduating students and practitioners also disagreed/strongly disagreed that their design practice would improve by using a completely digital process while the majority of placement students felt neutral. The main reason identified for disagreeing was the freedom, ease, efficiency and speed of paper-based sketching.

The negative reaction from graduating students and practitioners included disagreeing/strongly disagreeing on the introduction of a completely digital industrial course. On the other hand, $23 \%$ of graduating students agreed/strongly agreed, believing that designing entirely digitally would be the future of industrial design and specialists would always be needed in industry.

Regardless of the negative response towards an entirely DID course, graduating students identified a range of issues to improve their course that were related to digital methods, such a greater emphasis on 3D CAD software and the use of wider variety of CAD software. 


\section{DIGITAL INDUSTRIAL DESIGN STRATEGY}

This chapter presents the DID strategy that was developed from the literature review and feedback from graduating students, academics and practitioners.

\subsection{Digital Industrial Design Strategy}

Chapter 3, Section 3.3, identified the benefits of digital design. Digital design techniques support collaboration between members of a NPD team. They facilitate efficiency gains and reduce product development time and cost. Employing an entirely DID strategy enables the designer to be more in control of the process and assists making modifications when required. In addition, it reduces the number of physical models required to develop a concept and opens up more opportunities for global collaboration.

It is important to note that while DID might imply virtualisation (use of 2D and 3D digital design software), the DID strategy facilitates the production of physical objects through the use of RP and CNC machining. Including such tools supports the translation of a virtual design into a physical representation and the evaluation of ergonomics, form, purpose, and scale. The strategy only focuses on the main activities of designing, i.e. sketching, drawing, modelling and prototyping and should typically start after completing the preliminary activities of market analysis and refinement of the brief.

The literature review for digital tools/media supported the production of a diagrammatic representation for a totally DID workflow that is divided into the three main phases (concept generation, development and specification) and allows the designer to take various routes according to need (Figure 6-1). The strategy consists of two types of routes: two-way (black dotted line) that permits the designer to go forward and backward when using the digital tools; and a one-way route (black solid line).

In the concept generation phase, four digital input devices are included along with 2D visualisation software, such as SketchBook Pro or Adobe Photoshop, to enable the designer to externalise ideas through sketching. The input devices include a 2D mouse, pen input device, digitising tablet without a built-in display and digitising tablet with an interactive pen display. 
The development phase employs a 3D scanner to scan an existing product for modification; haptic modelling to provide tactile cues during product modelling; a range of $2 \mathrm{D}$ and $3 \mathrm{D} C \mathrm{CAD}$ software (e.g. surface modelling, solid modelling and polygon modelling); and 2D CNC cutting to product sketch models.

The final phase of the DID strategy focuses on the more detailed models and prototypes produced by RP, CNC machining (2D and 3D), VP for product testing, and VR to enable the user to interact with the product in a computer simulated environment.

\section{Digital Industrial Design Strategy}

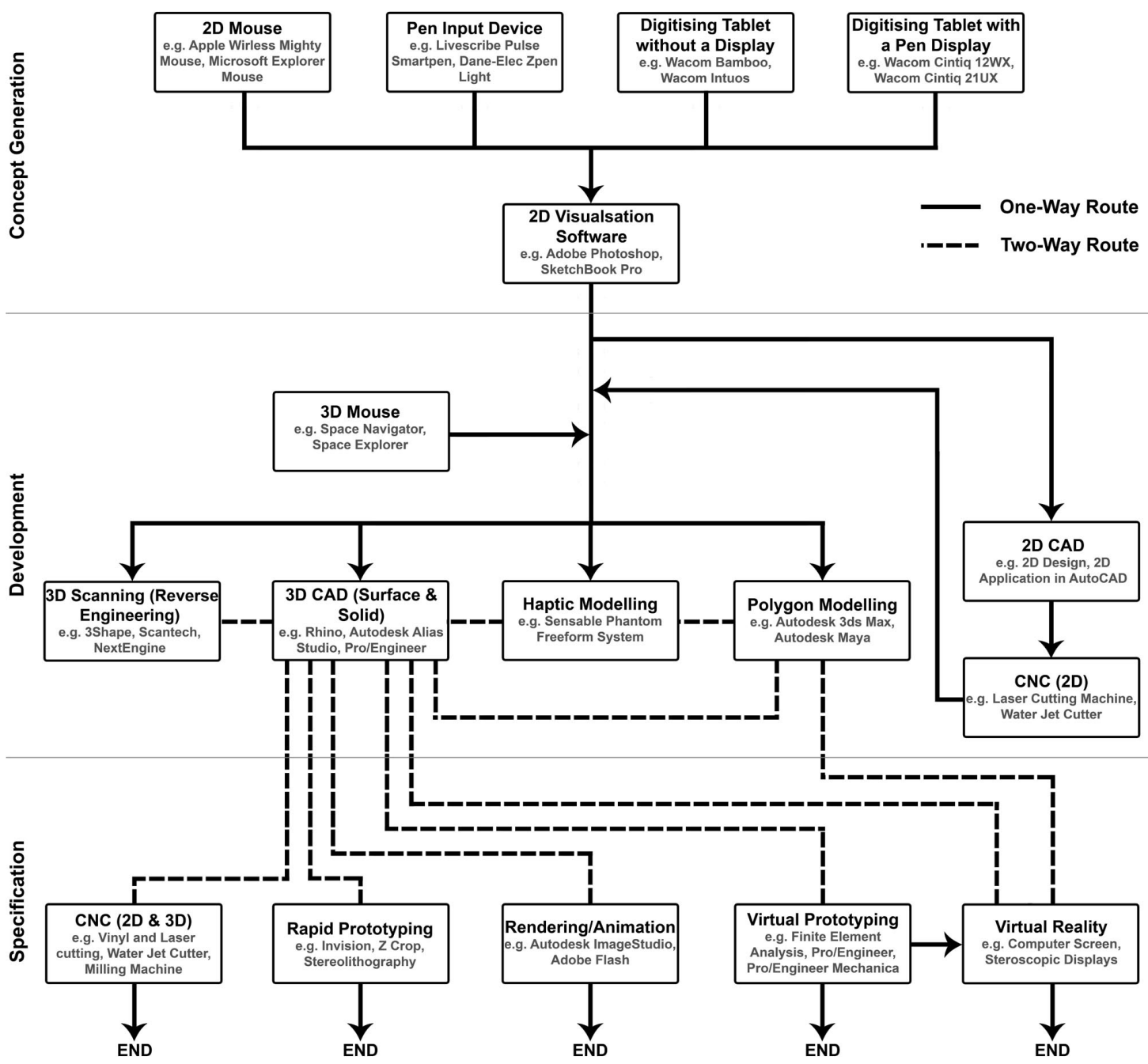

Figure 6-1: Digital industrial design strategy 


\subsection{Graduating Student Feedback on the Digital Industrial Design Strategy}

To receive feedback from students regarding the DID strategy, a survey was carried out at the New Designers Exhibition in London between the $16^{\text {th }}$ and $18^{\text {th }}$ of July 2009 . In order to test the feasibility of the DID strategy within an education context, the following aims were selected:

- Investigate the frequency of using the digital design tools/media employed in the DID strategy; their ease of use; and contribution to the student design practice

- Examine the viability of the DID strategy

- Investigate the efficiency of the DID strategy

- Identify if graduating students were interested in employing the DID strategy

- Add other suitable digital design tools/media to the DID strategy

The DID strategy questionnaire was originally designed for academics and graduating students to complete. However, finding academics that had time to fill out the questionnaire at New Designers event proved difficult. Only three academics completed the questionnaire, so the data from academics had to be discarded.

The questionnaire was piloted with six industrial design students at Loughborough University which lead to minor modification in the layout to increase clarity plus minor amendments in the wording. The pilots also helped in calculating the time needed to fill out the questionnaire.

The questionnaire contained three sections: background; use of digital tools and media in the strategy; and thoughts on the DID strategy. Closed-ended questions were extensively employed with five Likert scales. However, open-ended questions were also used along with closed-ended questions in the third section to identify the reasons behind opinions and to identify the tools/media that respondents would like to add to the strategy. The questionnaire can be seen in Appendix 11.4.

Four A4 visual aid cards were shown prior to completing the questionnaire to explain the research and the purpose of the questionnaire. Three of the visual aids had similar content to the ones used in the New Designers 2008 study (Chapter 5). However, the cards used in the New Designers 2009 study divided the design process into three phases (conceptualisation, development, and specification) while the previous visual aids divided it into four phases (conceptualisation, preliminary refinement, further refinement and final 
concept selection, and specification). Whilst developing the DID strategy based on the literature review and survey data, a decision was made to get rid of the preliminary refinement phase and further refinement and final concept selection phase and replace them with the development phase, which technically combines the two removed phases as it shares the same digital design tools/media and it avoids complications caused by having two separate phases. Figure 6-2 Illustrates the non-digital and digital strategies; Figure 6-3 explains the current design process based on the literature and questionnaire findings; and Figure 6-4 shows the digital process with examples of tools and digital outputs used in every phase. The fourth visual aid card illustrates the DID strategy and was left with the graduating students to refer to whilst filling in the questionnaire (Figure 6-5).

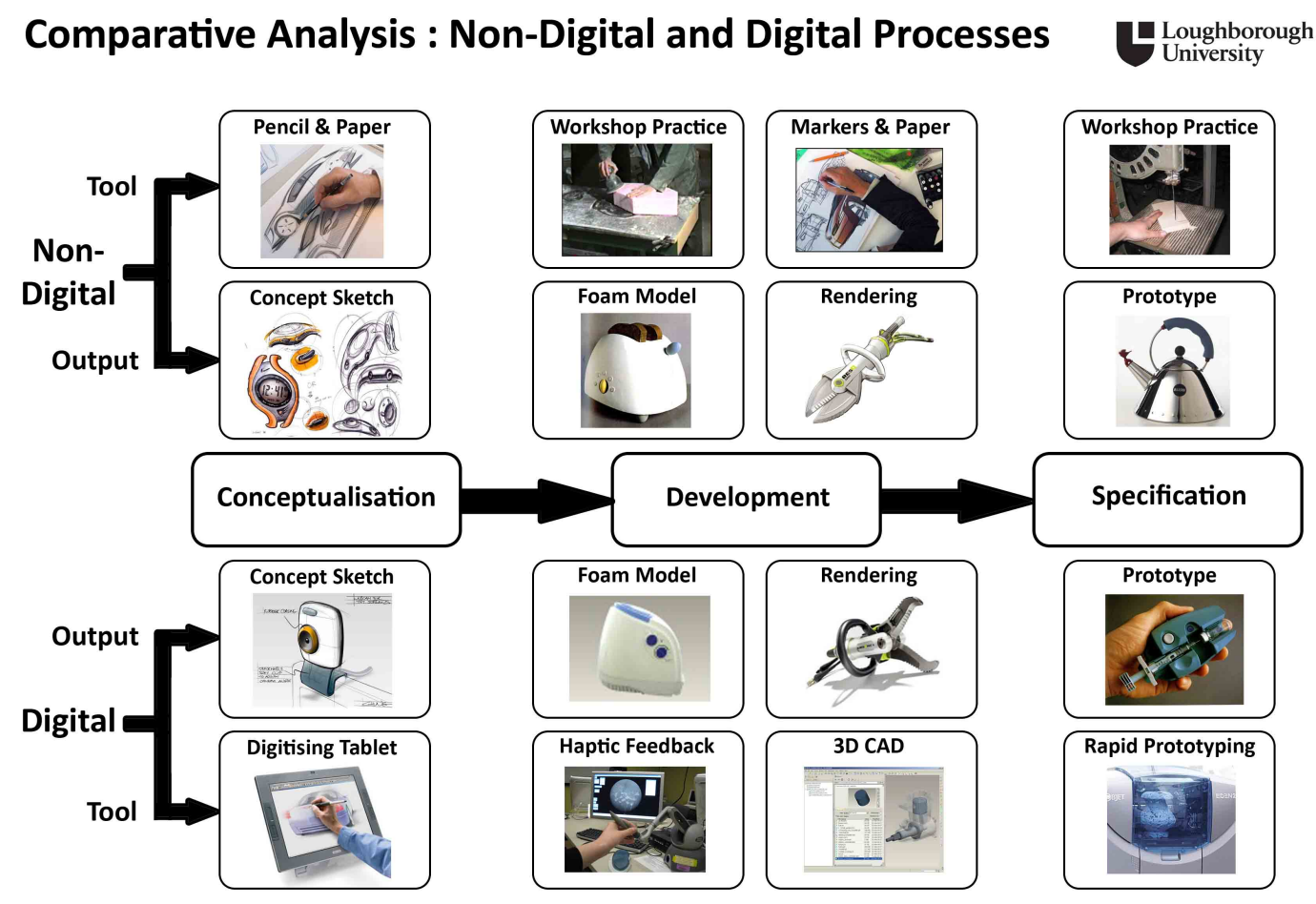

Figure 6-2: First visual aid used to compare the non-digital and digital design processes 


\section{Current Practice of Industrial Design}
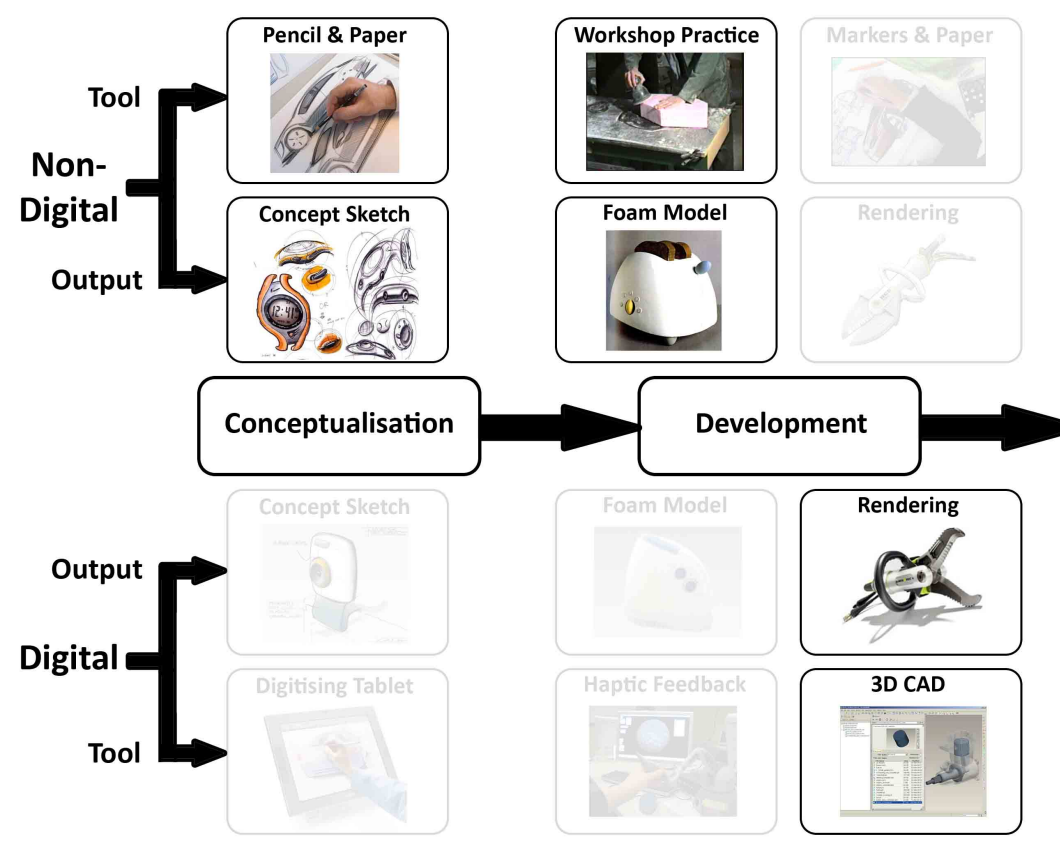

Specification
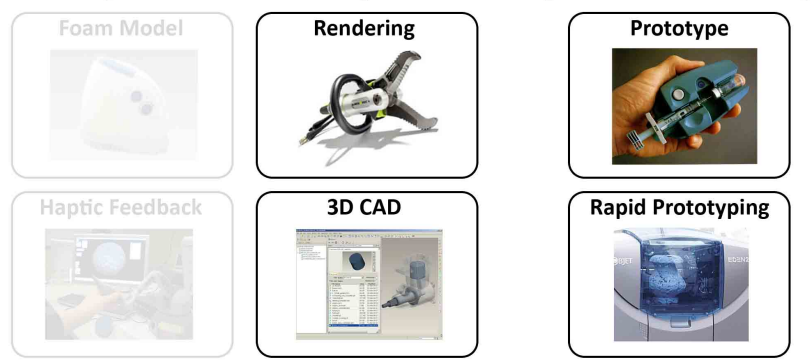

Figure 6-3: Second visual aid used to explain the current practice of industrial design (unused tools and outputs ghosted)

\section{Digital Industrial Design (DID)}

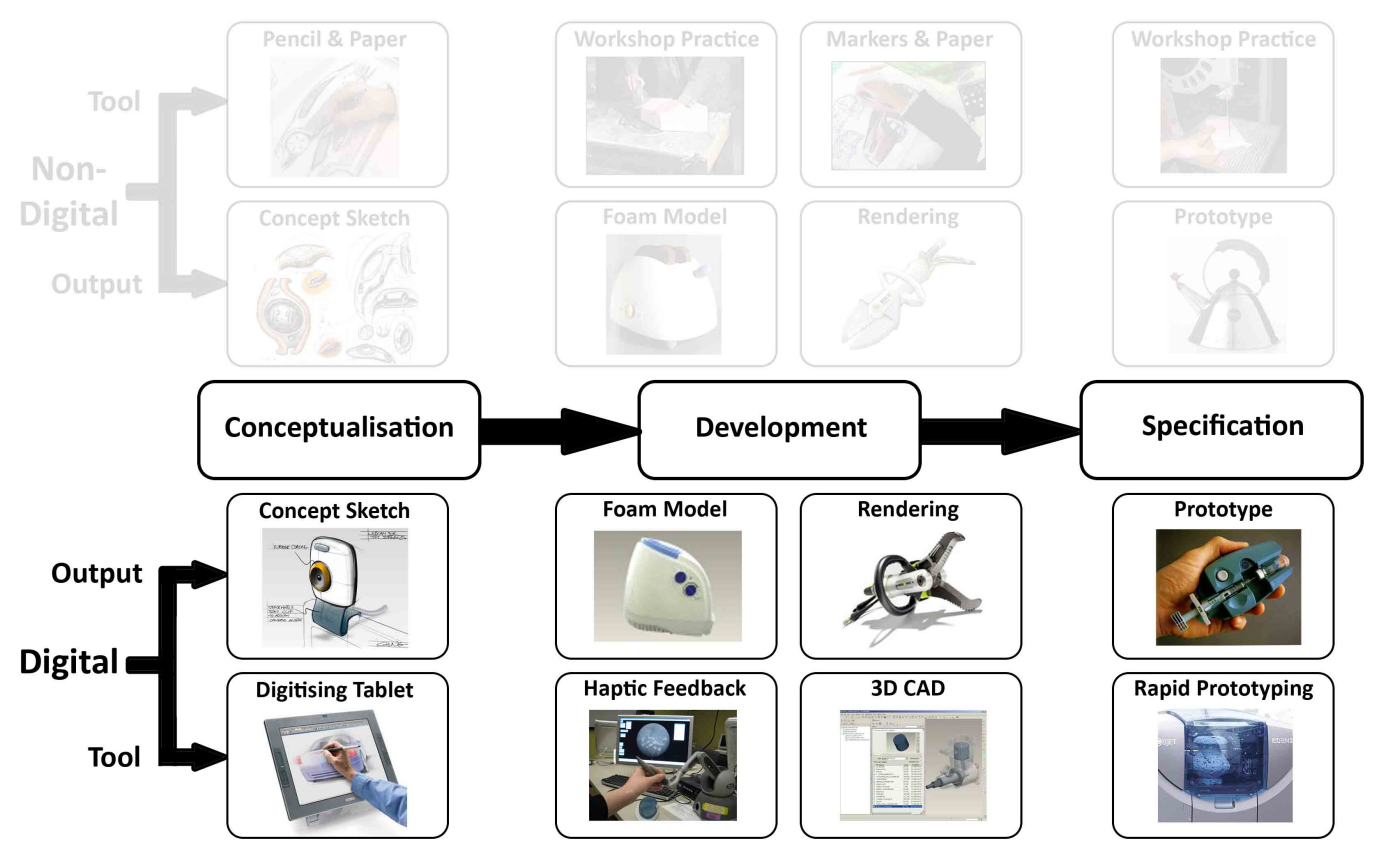

Figure 6-4: Third visual aid card used to show the anticipated digital way of designing (unused tools and outputs ghosted) 


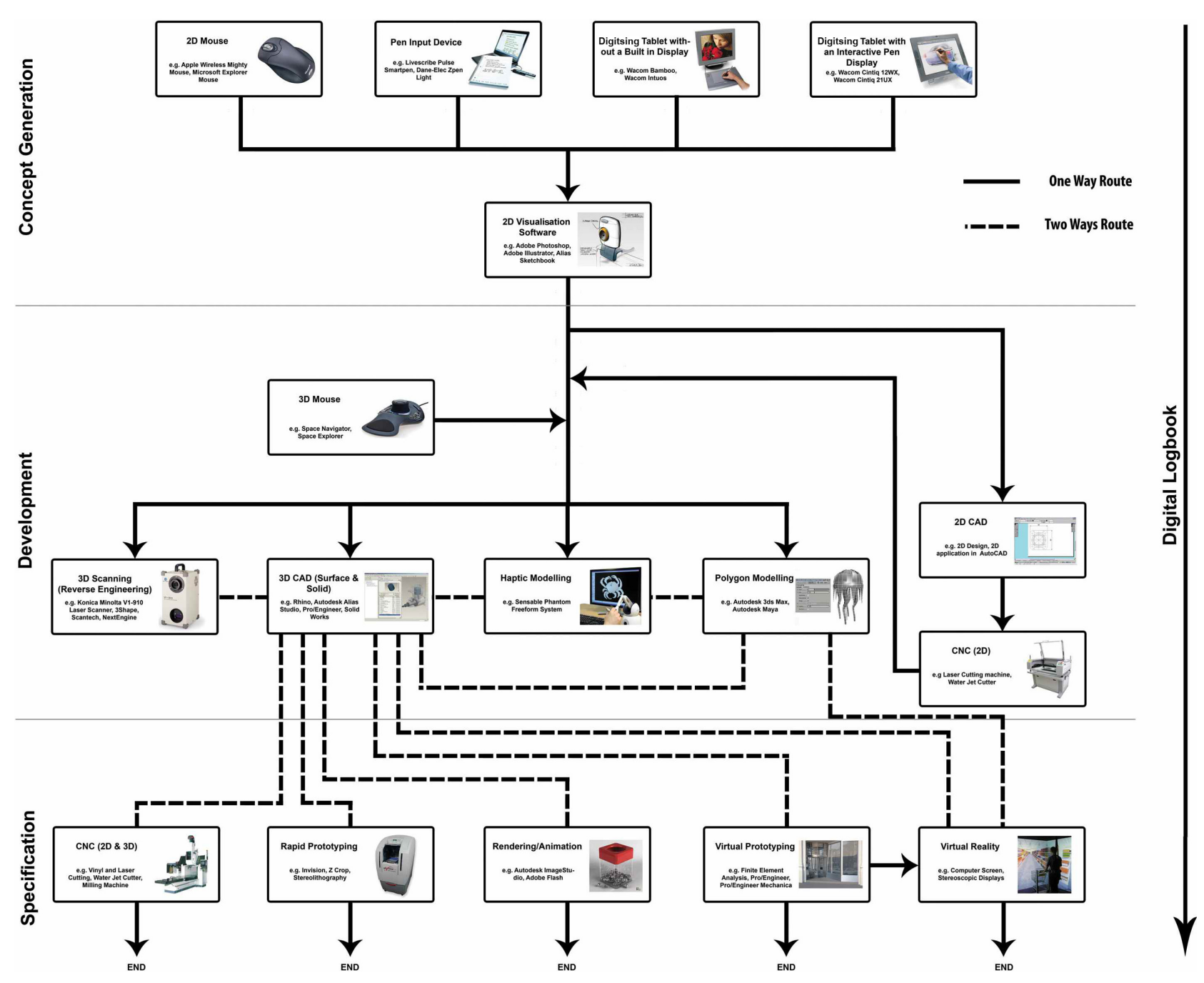

Figure 6-5: Fourth visual card used to illustrate the DID strategy 
The structure and content of the questionnaire will now be discussed.

\subsubsection{Background}

In 2009, 117 industrial design graduating students were randomly selected to complete the questionnaire. The questionnaire generated responses from 28 UK universities with the maximum of eight participants from a single university.

\subsubsection{Use of Digital Tools and Media in the Strategy}

This section of the questionnaire was aimed at examining student experience using the digital tools/media employed in the DID strategy. It investigated the frequency of use, ease of use and contribution to practice of each of the 17 digital design tools/media.

\subsubsection{2D Mouse}

The majority of graduating students (88\%) used a 2D mouse on regular basis (Figure 6-6) as most of them (78\%) thought that it was easy/very easy to use (Figure 6-7). Sixty-five percent felt that contribution of the $2 \mathrm{D}$ mouse was significant/essential to their design practice and only $6 \%$ felt that it has limited or no contribution at all (Figure 6-8).

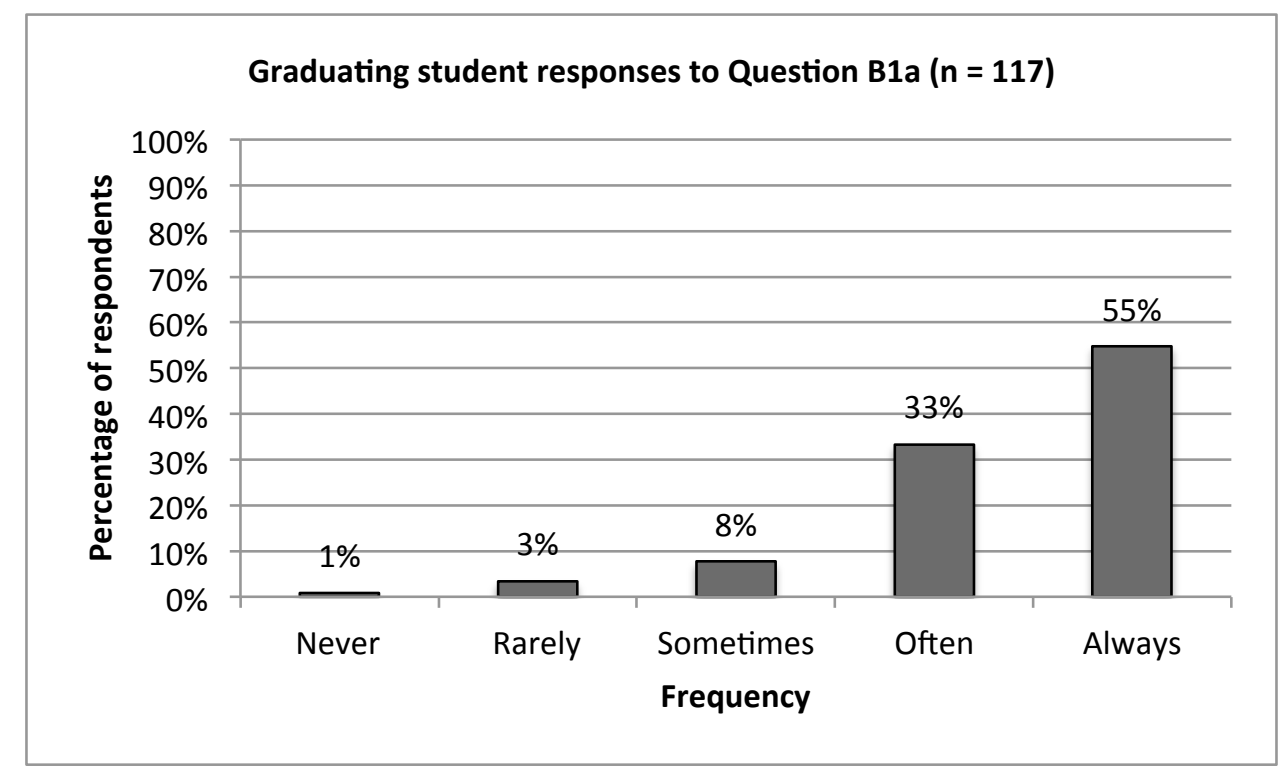

Figure 6-6: Graduating student responses to Question B1a: "How often do you use a 2D mouse (e.g. Apple wireless Mighty Mouse, Microsoft Explorer) when designing?" 


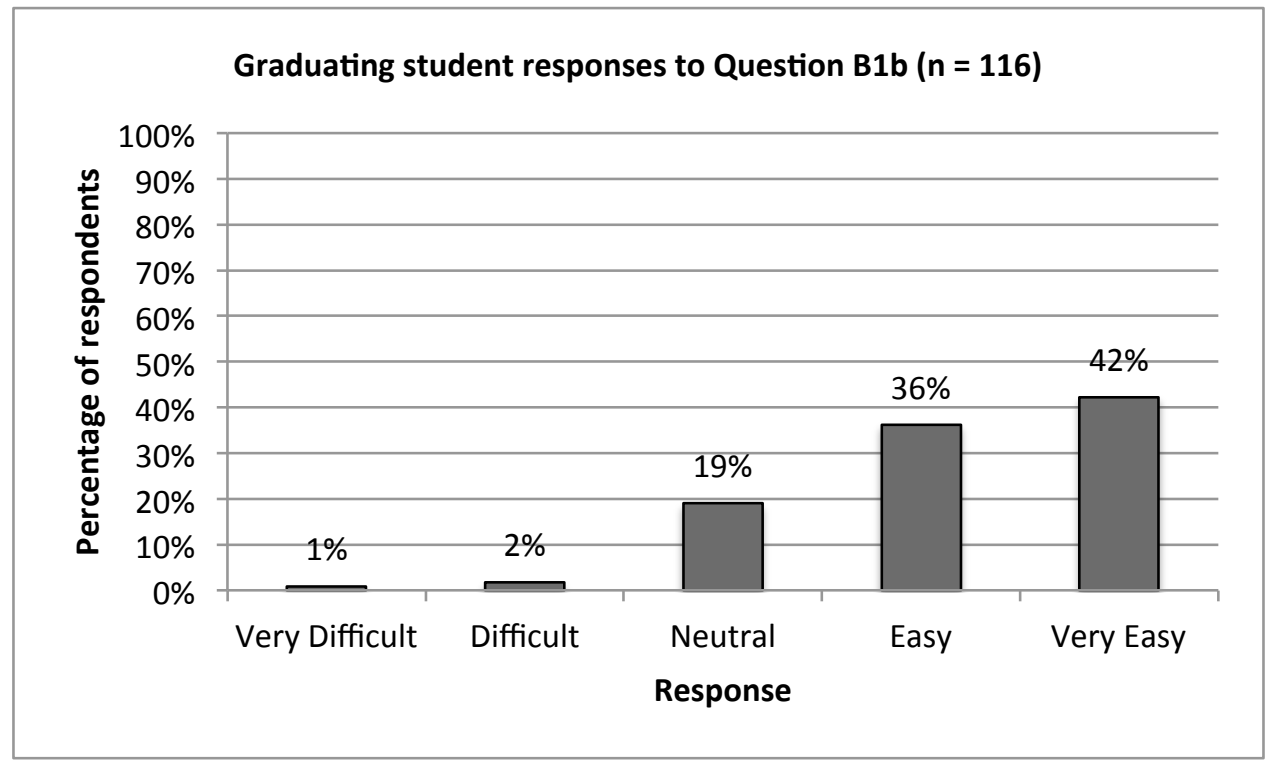

Figure 6-7: Graduating student responses to Question B1b: "How easy is the 2D mouse to use?"

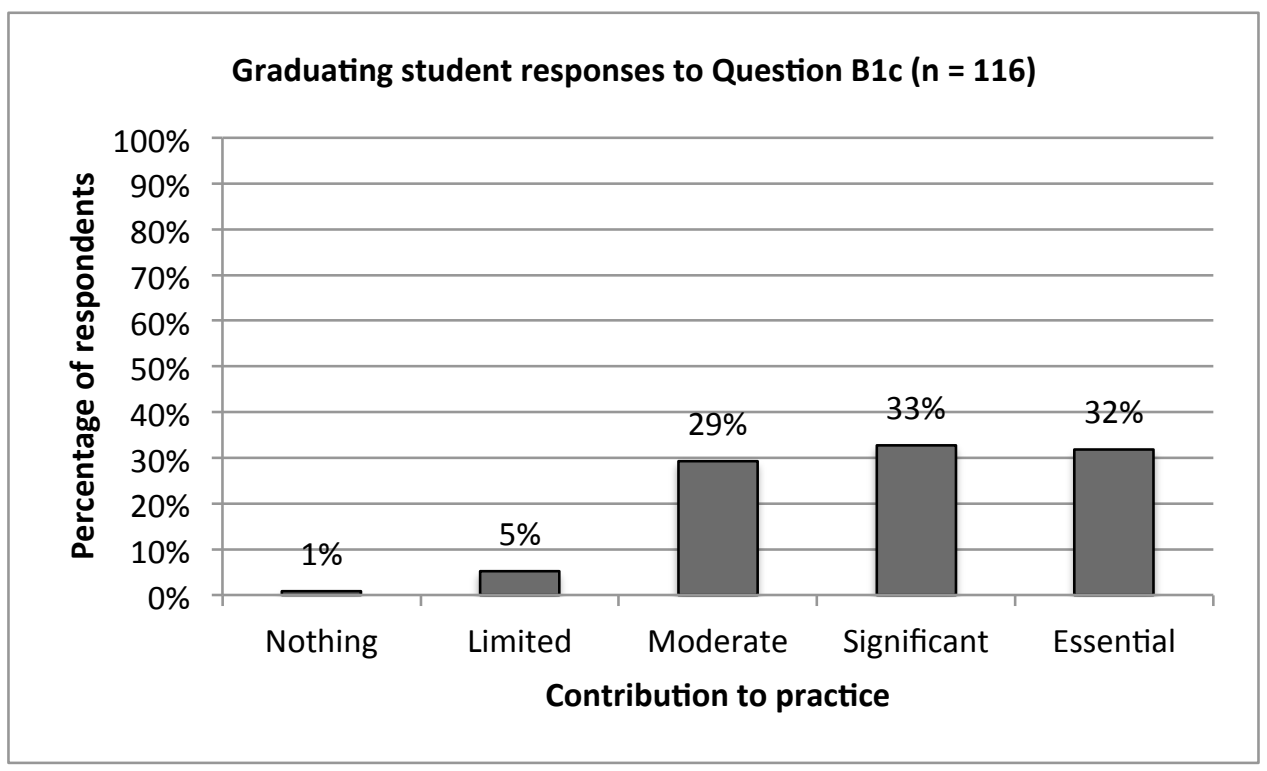

Figure 6-8: Graduating student responses to Question B1c: "How useful is the 2D mouse in making a contribution to practice?"

\subsubsection{Pen Input Device}

Most of the graduating students (66\%) had never used a pen input device such as Livescribe Pulse smartpen and e-pen (Figure 6-9). Only participants who used the device (44\%) were then able to answer questions related to the ease of use and contribution to practice. The greatest percentage of graduating students (42\%) thought that pen input devices were 
easy/very easy to use (Figure 6-10), but their contribution to design practice was mostly distributed between limited (35\%), moderate (37\%) and significant (20\%) (Figure 6-11).

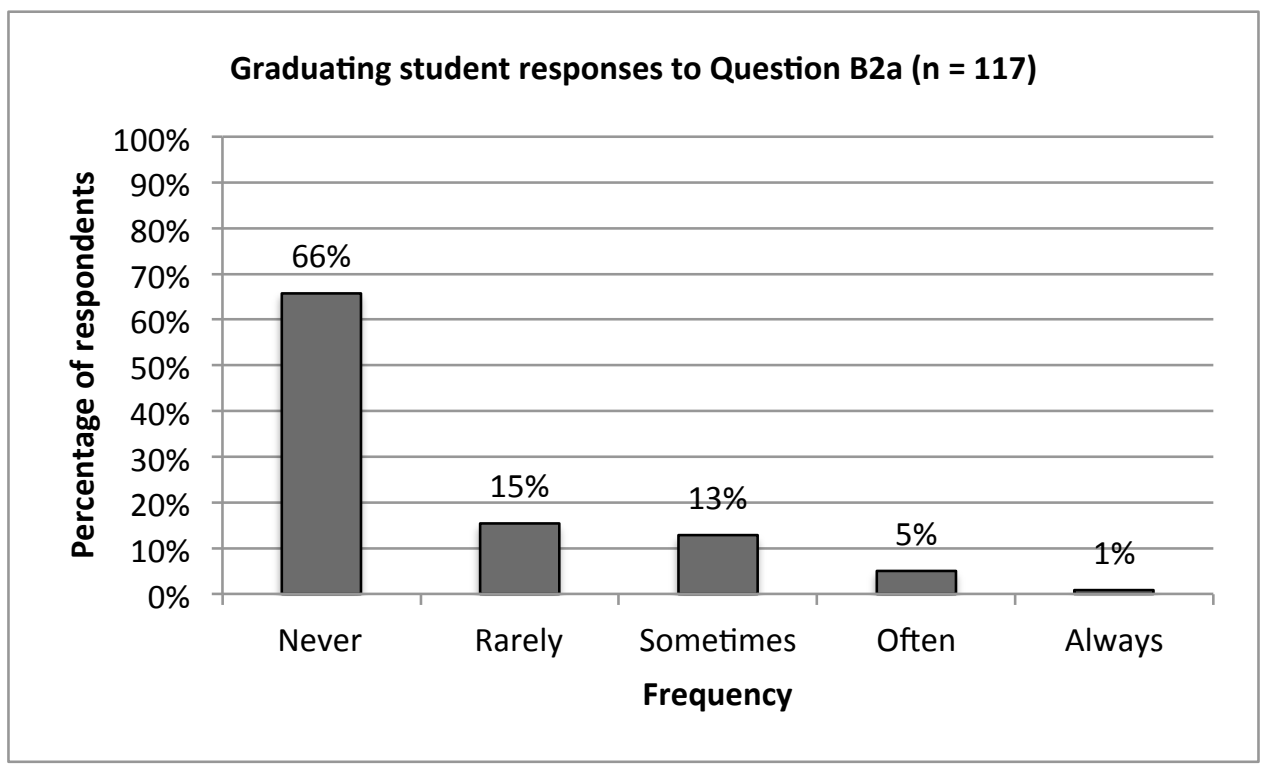

Figure 6-9: Graduating student responses to Question B2a: "How often do you use a pen input device (e.g. Livescribe Plus Smartpen, Dane-elec zPen Light) when designing?"

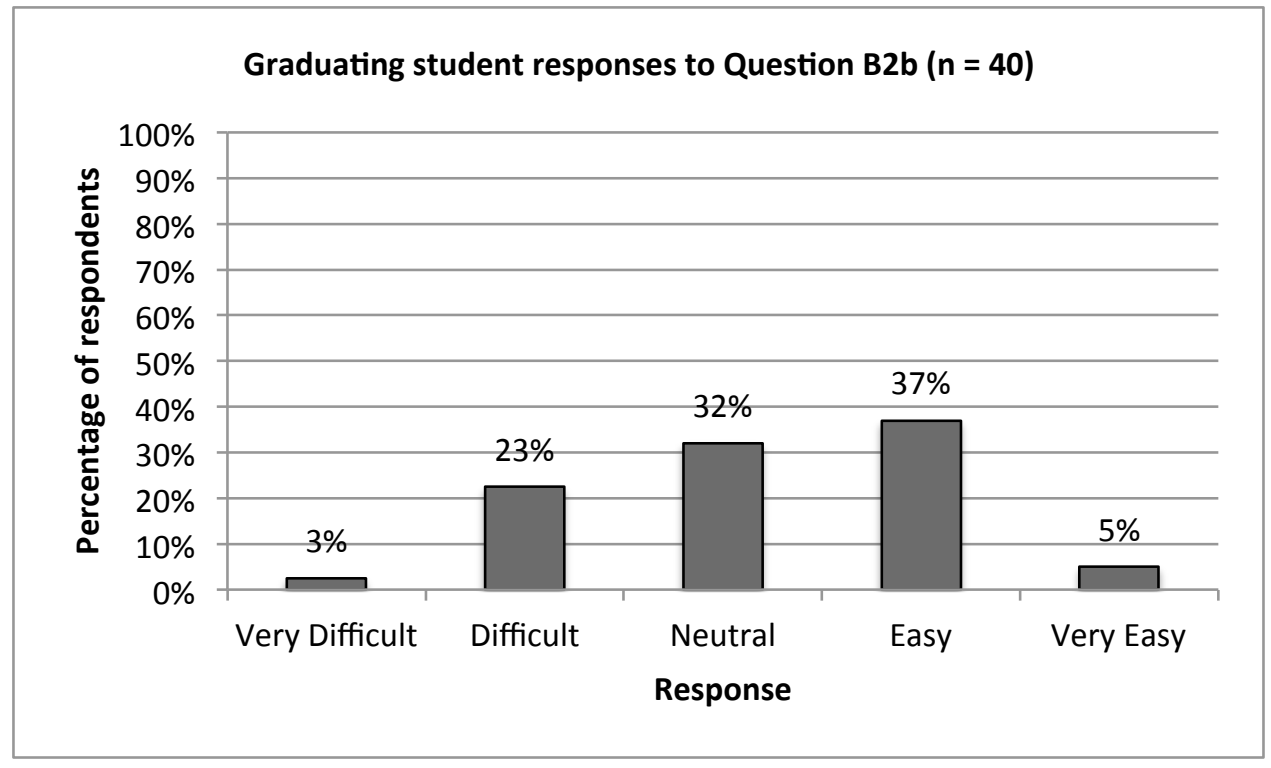

Figure 6-10: Graduating student responses to Question B2b: "How easy is the pen input device to use?" 


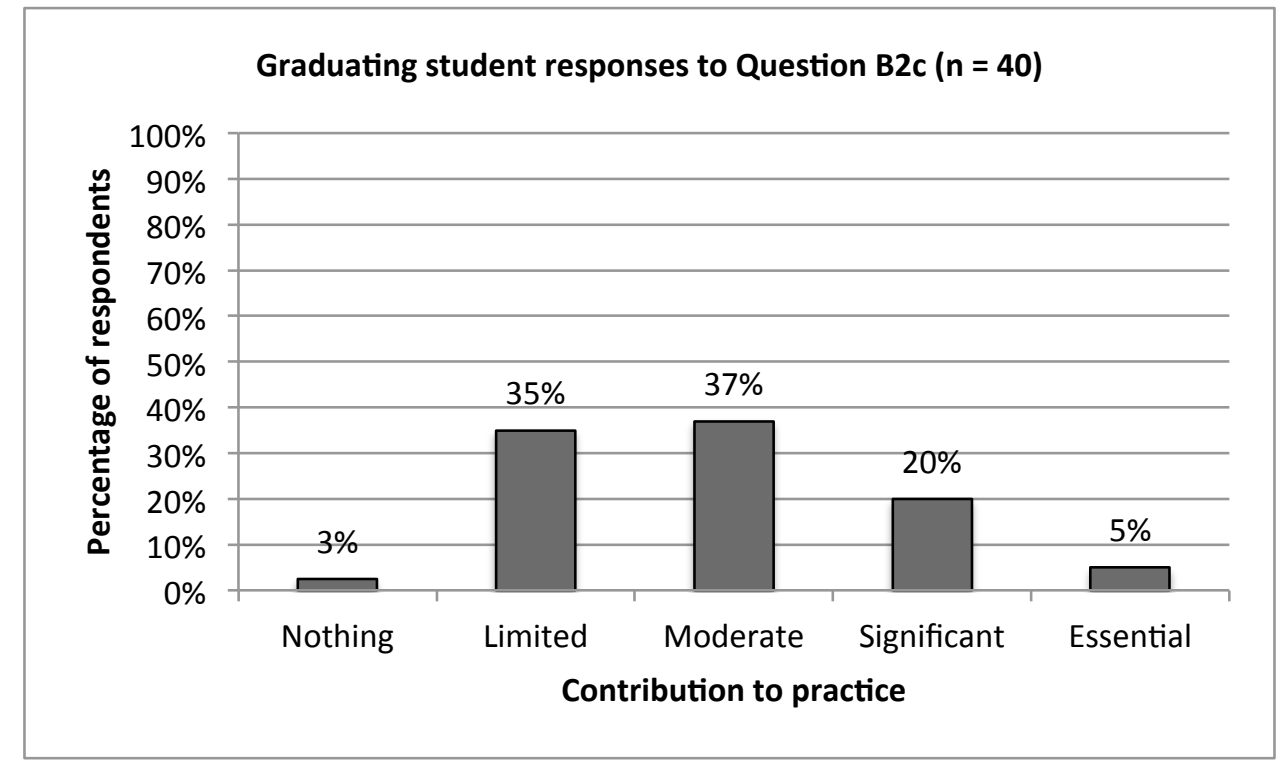

Figure 6-11: Graduating student responses to Question B2c: "How useful is the pen input device in making a contribution to practice?"

\subsubsection{Digitising Tablet without a Built-in Display}

The majority of graduating students (51\%) had never used a graphic/digitising tablet without a built-in display such as the Wacom Bamboo and Wacom Intuos; 22\% used it sometimes and $18 \%$ employed it on regular basis (Figure 5-12). When using the graphic tablet, the drawing does not appear on the tablet itself but on a computer monitor and $48 \%$ of the graduating students who used it felt that it was easy/very easy to use compared to $26 \%$ who felt that it was difficult/very difficult (Figure 6-13). The contribution of the graphic tablet to the graduating student design practice was scattered, with $40 \%$ considering that it was significant/essential; $28 \%$ thought that it was moderate; $30 \%$ believed that it was limited; and only $2 \%$ felt that it did not have any contribution to their design practice (Figure 6-14). 


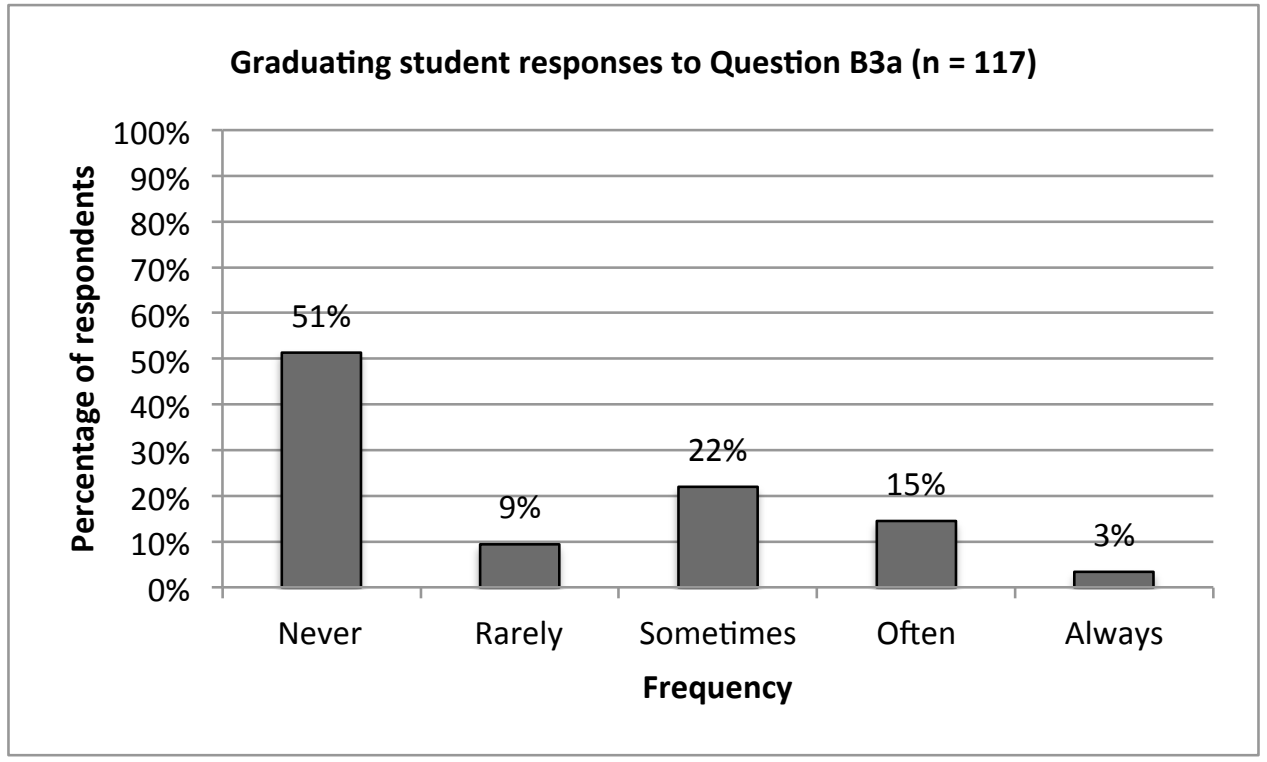

Figure 6-12: Graduating student responses to Question B3a: "How often do you use a digitising tablet without a built-in display (e.g. Wacom Bamboo, Wacom Intuos) when designing?"

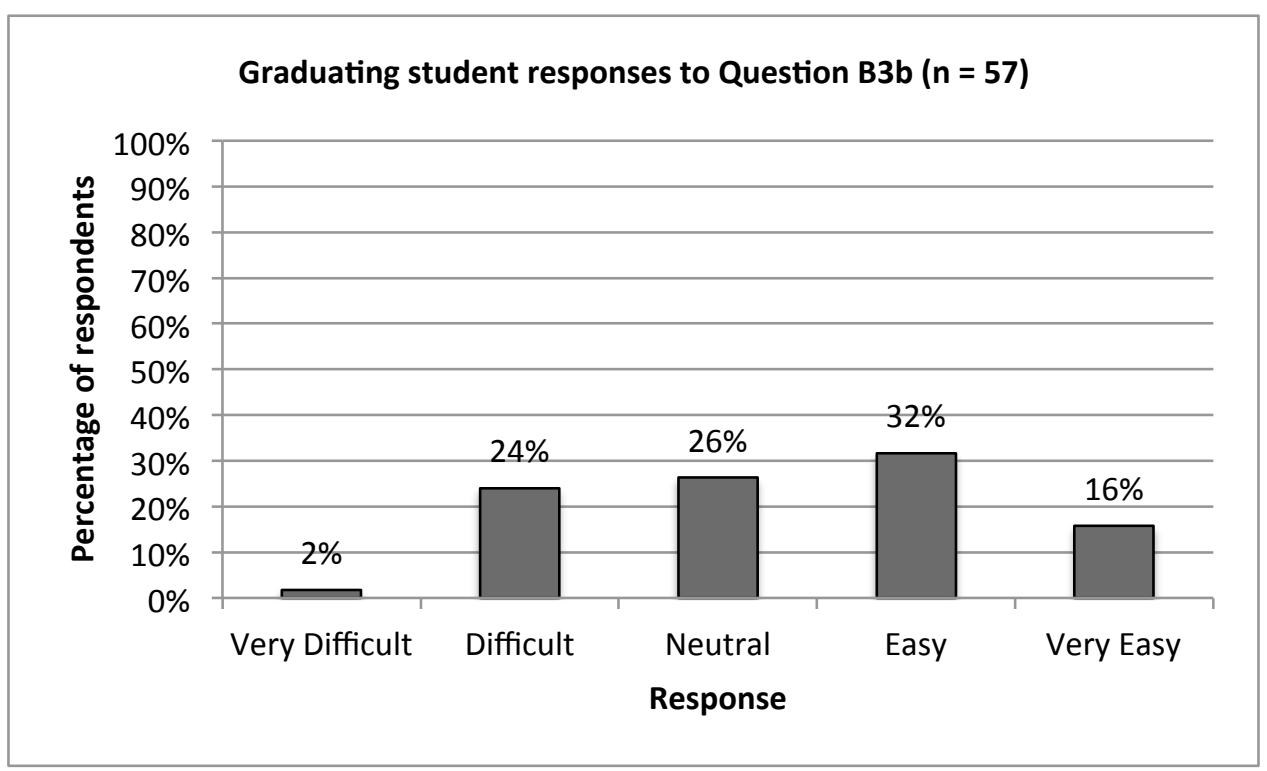

Figure 6-13: Graduating student responses to Question B3b: "How easy is the digitising tablet without a built-in display to use?" 


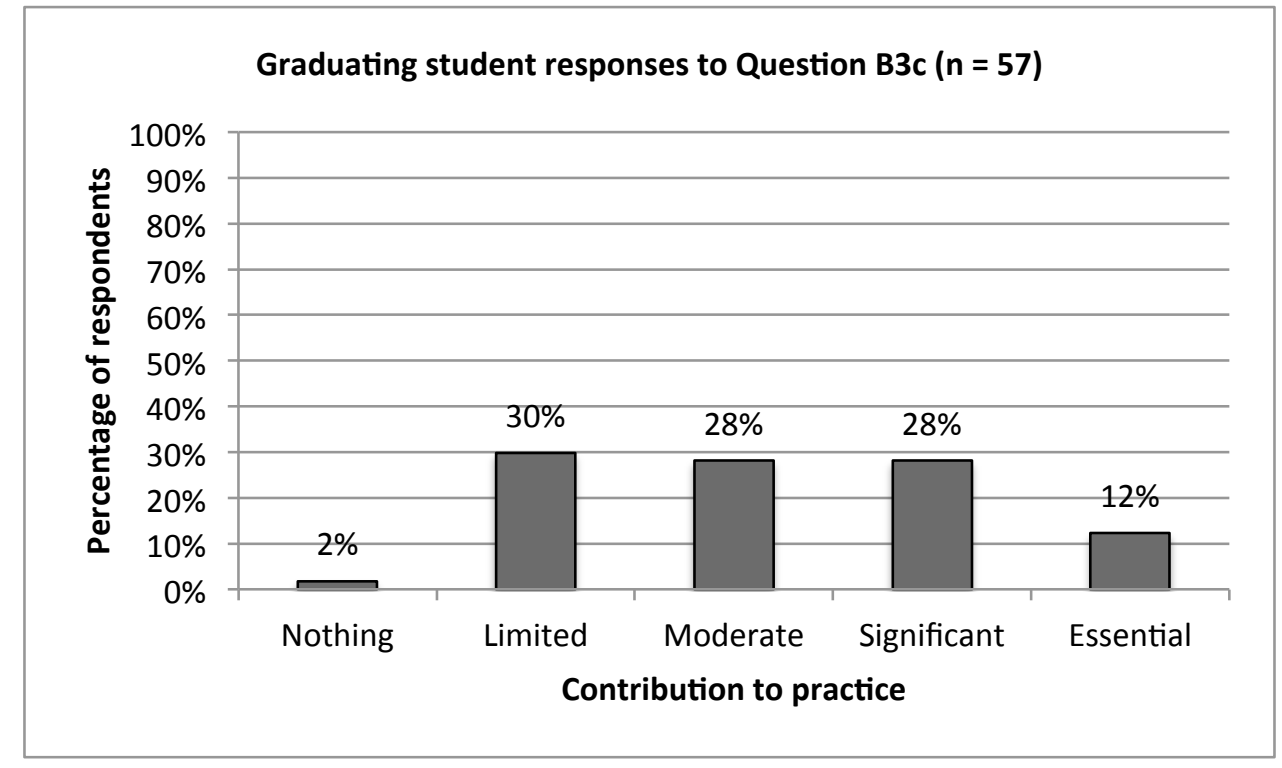

Figure 6-14: Graduating student responses to Question B3c: "How useful is the digitising tablet without a built-in display in making a contribution to practice?"

\subsubsection{Digitising Tablet with an Interactive Pen Display}

Unlike the digitising tablet without a built-in display, a digitising tablet with an interactive pen display such as Wacom Cinitiq and a Tablet PC offer a natural hand-eye coordination as it allows the user to draw on the screen (Wacom, 2011b). While the greater number of graduating students (79\%) had never used a digitising tablet with an interactive pen display (Figure 6-15), 64\% of graduating students who used it thought that it was easy/very easy to use, compared with $48 \%$ when it came to graphic tablets (Figure 6-16). Most of the graduating students $(72 \%)$ felt that the digitising tablet with an interactive pen display offered a moderate contribution to their design practice (Figure 6-17). 


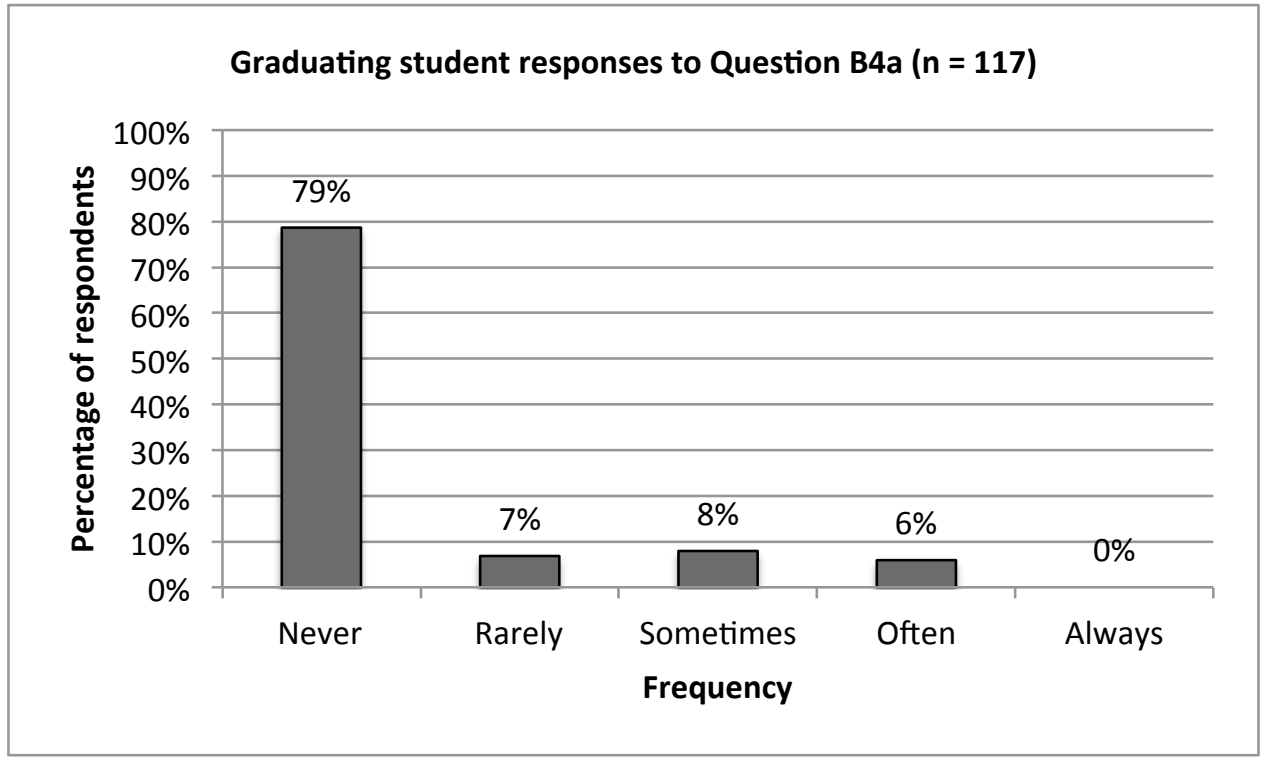

Figure 6-15: Graduating student responses to Question B4a: "How often do you use a digitising tablet with an Interactive pen display (e.g. Wacom Cintiq 12WX, Wacom Cintiq 21UX) when designing?"

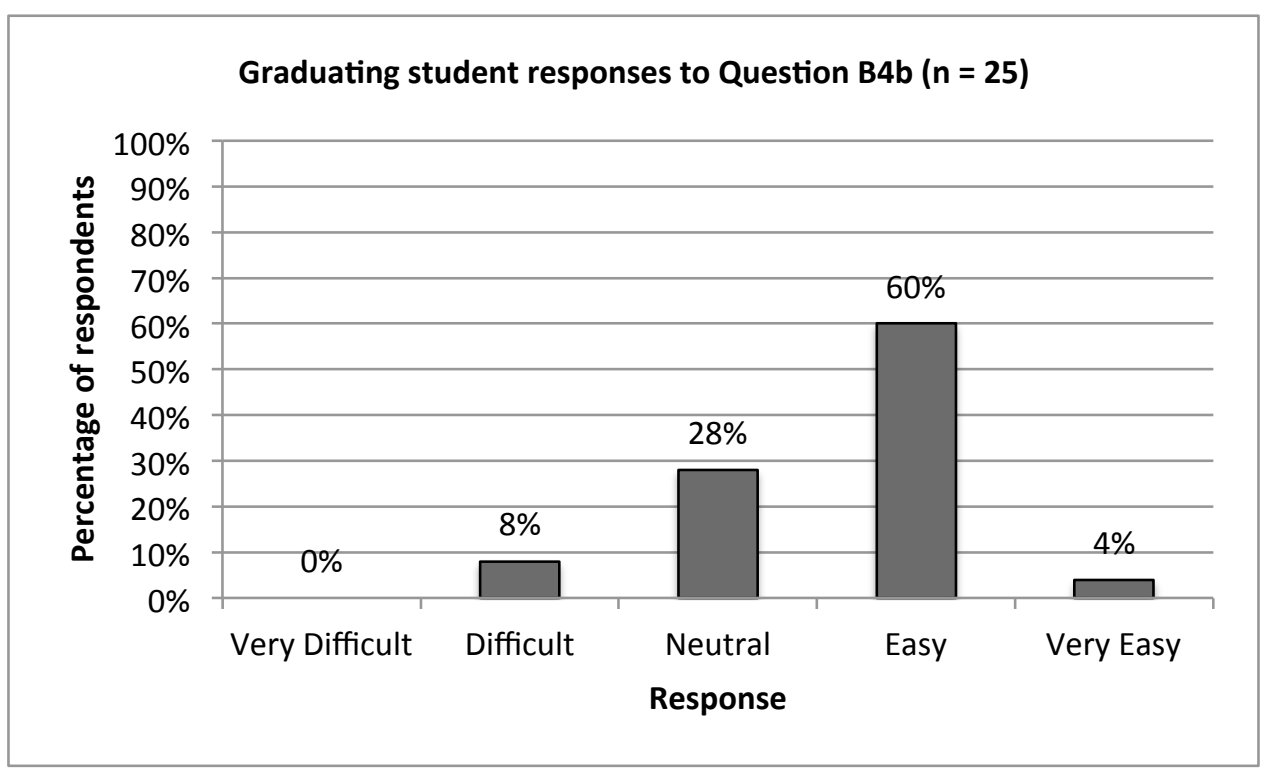

Figure 6-16: Graduating student responses to Question B4b: "How easy is the digitising tablet with an interactive pen display to use?" 


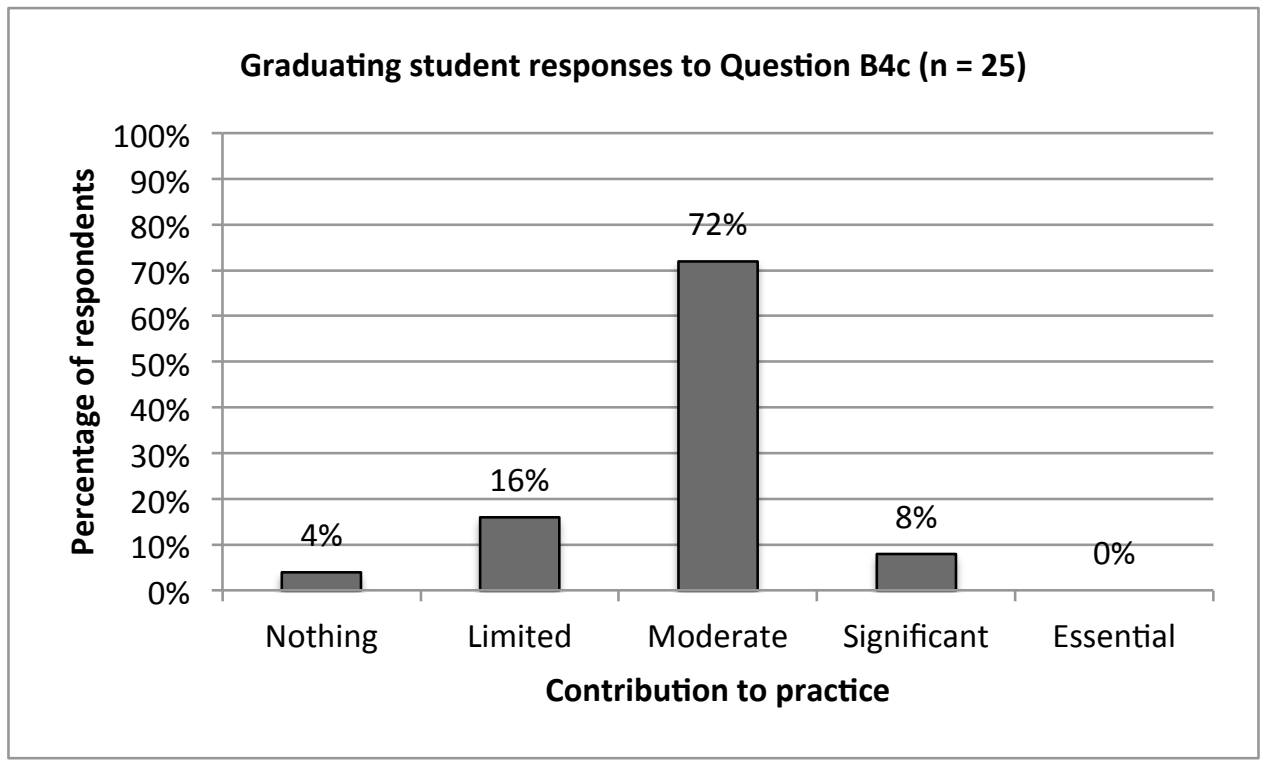

Figure 6-17: Graduating student responses to Question B4c: "How useful is the digitising tablet with an interactive pen display in making a contribution to practice?"

\subsubsection{2D Visualisation Software}

2D visualisation software proved to be a popular digital design tool amongst graduating students, with $86 \%$ using it often/always (Figure $6-18$ ); $73 \%$ of graduating students who used it felt that it was easy/very easy to use (Figure 6-19); and the majority of $87 \%$ confirmed that it had significant/essential contribution to their design practice (Figure 6-20). 


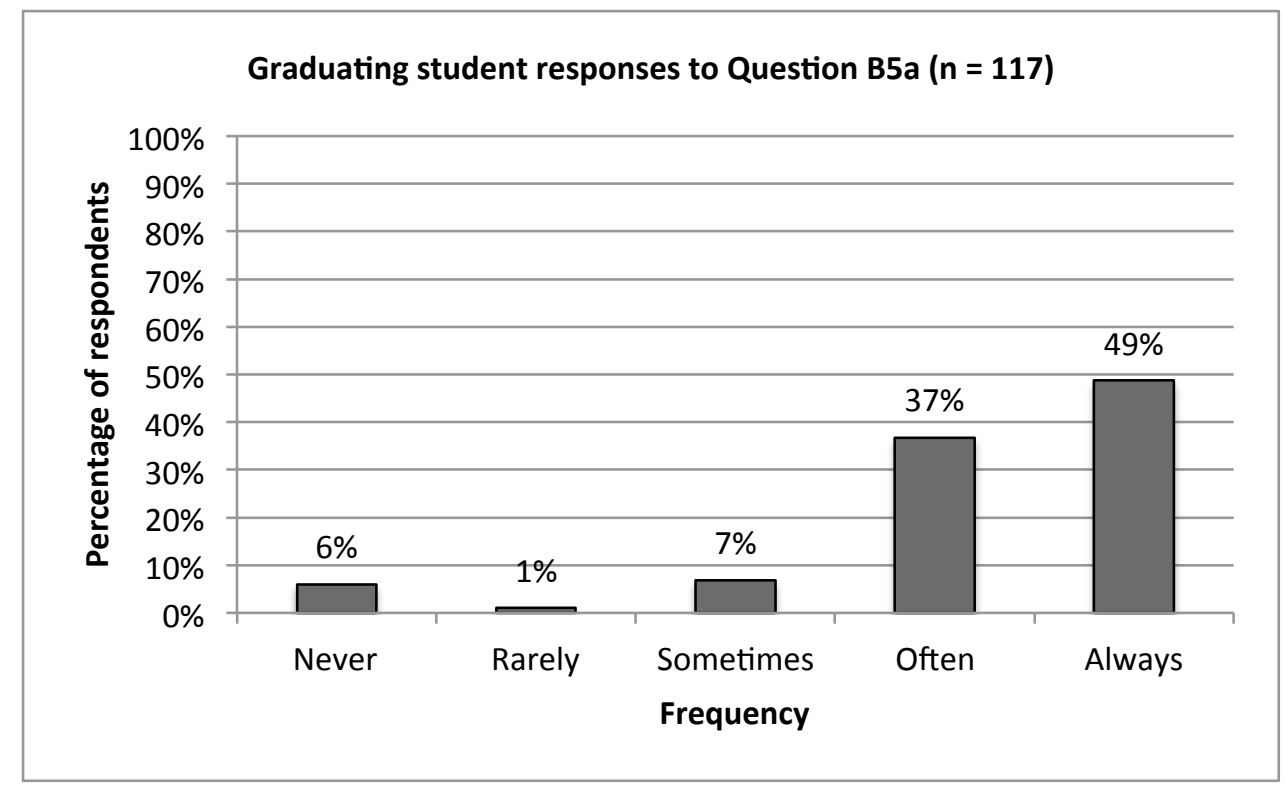

Figure 6-18: Graduating student responses to Question B5a: "How often do you use 2D visualisation software (e.g. Adobe Photoshop, Adobe Illustrator, SketchBook Pro) when designing?"

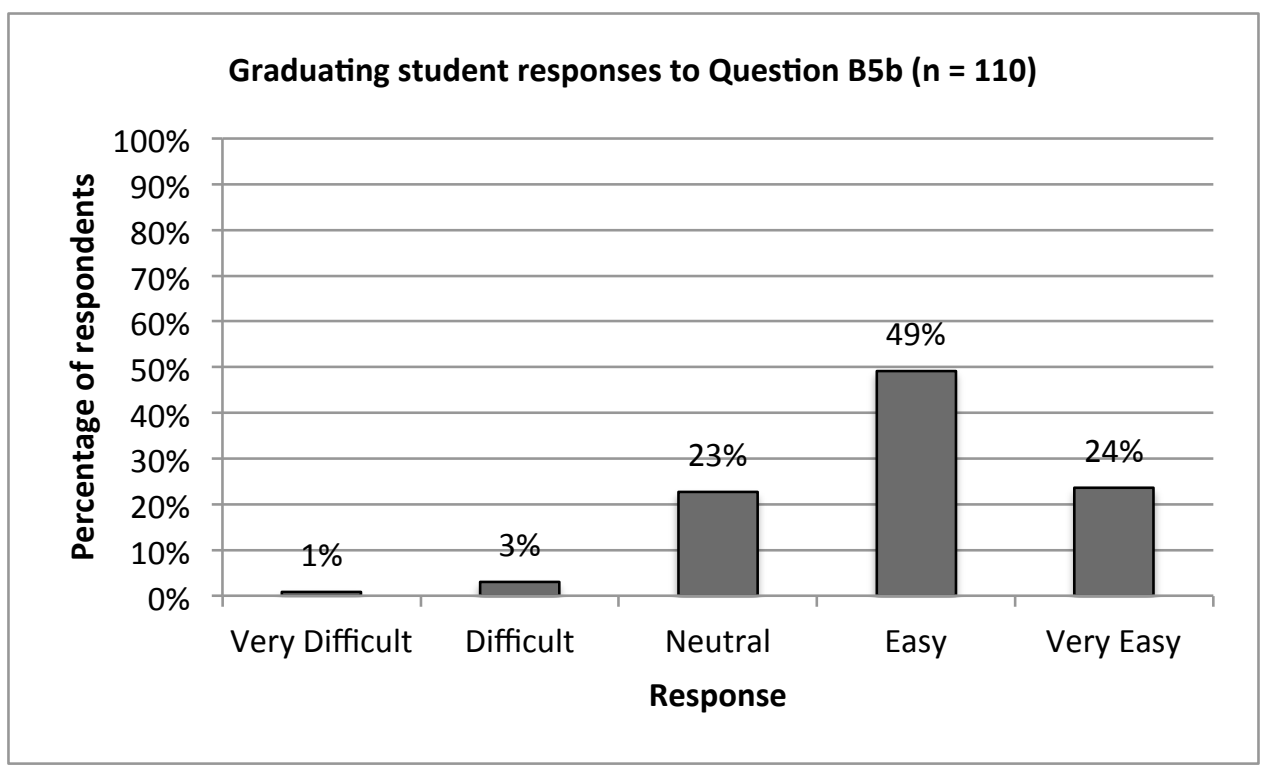

Figure 6-19: Graduating student responses to Question B5b: "How easy is the 2D visualisation software to use?" 


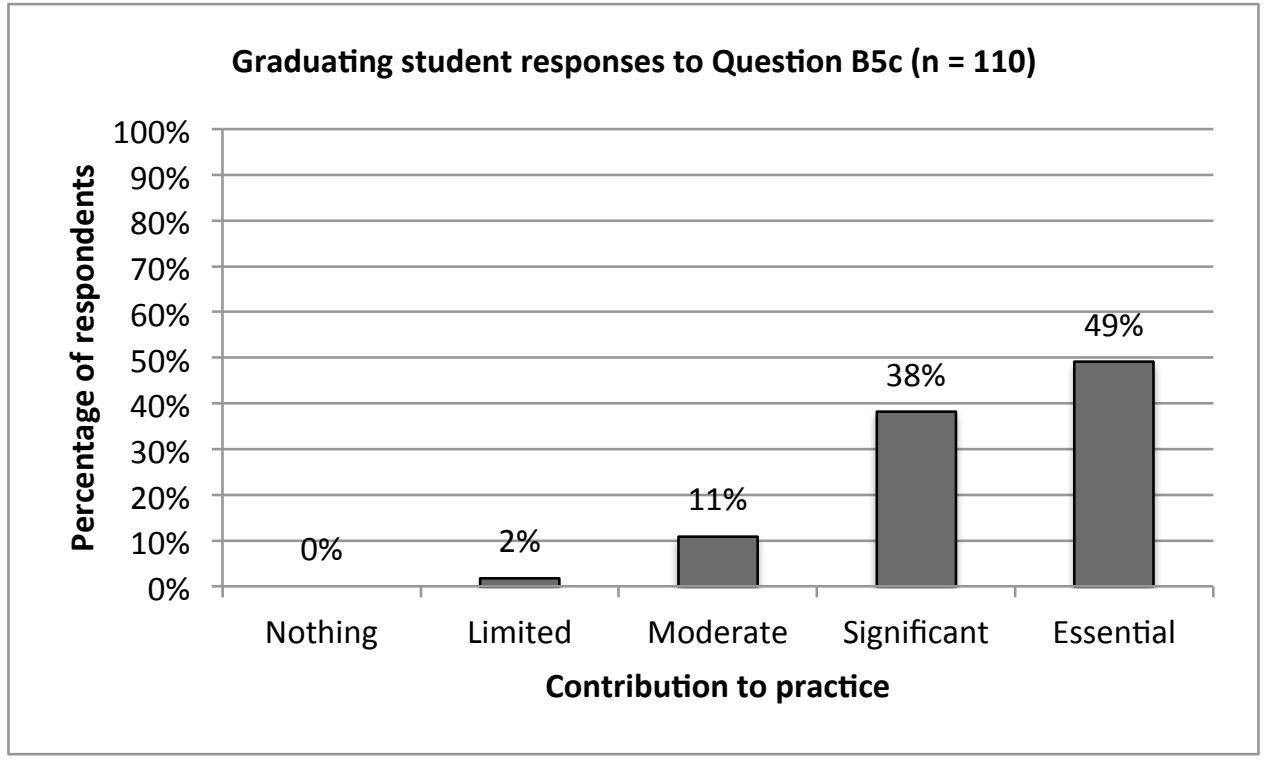

Figure 6-20: Graduating student responses to Question B5c: "How useful is the 2D visualisation software in making a contribution to practice?"

\subsubsection{3D Mouse}

Eighty-five percent of graduating students had never used a 3D mouse and only 5\% used it on regular basis (Figure 6-21). While 50\% of graduating students who used it felt that it was easy/very easy to use, 22\% thought that it was difficult/very difficult to use (Figure 6-22). Most of the graduating students (56\%) believed that it offered a moderate contribution to their design practice (Figure 6-23).

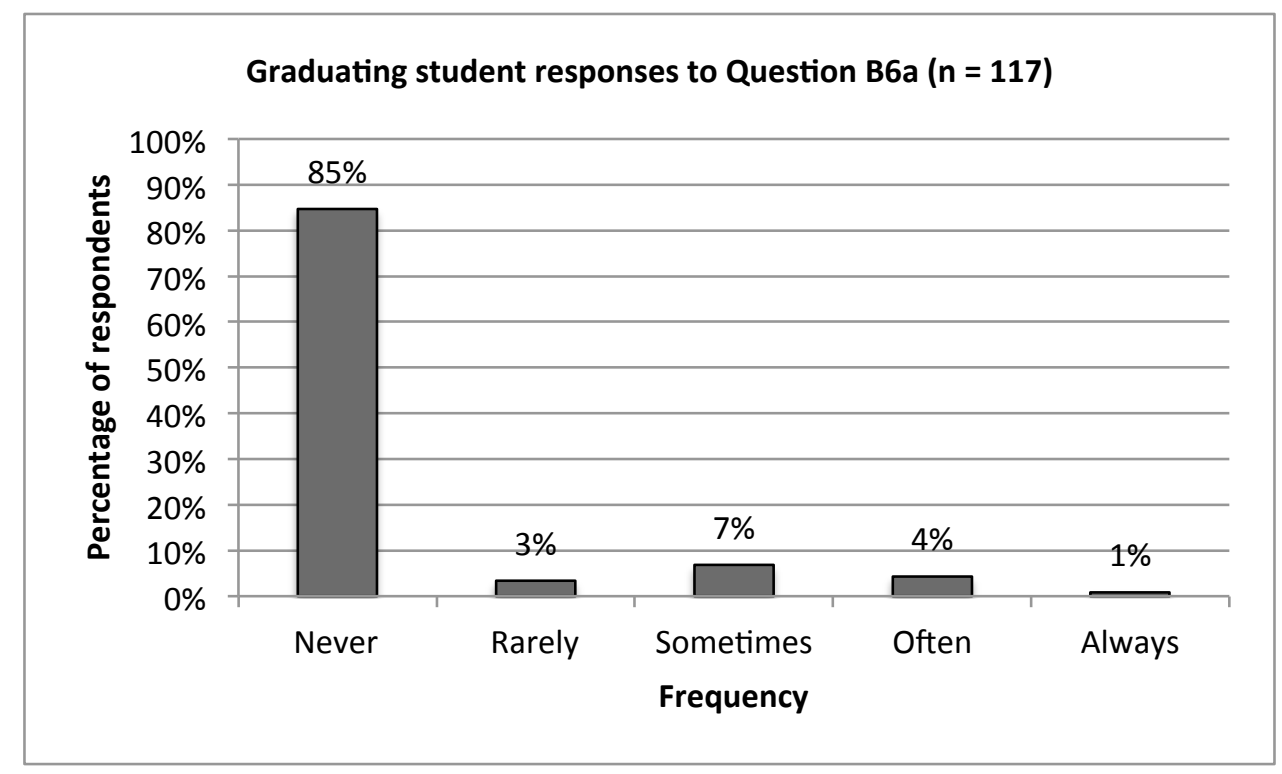

Figure 6-21: Graduating student responses to Question B6a: "How often do you use a 3D mouse (e.g. Space Navigator, space Explorer) when designing?" 


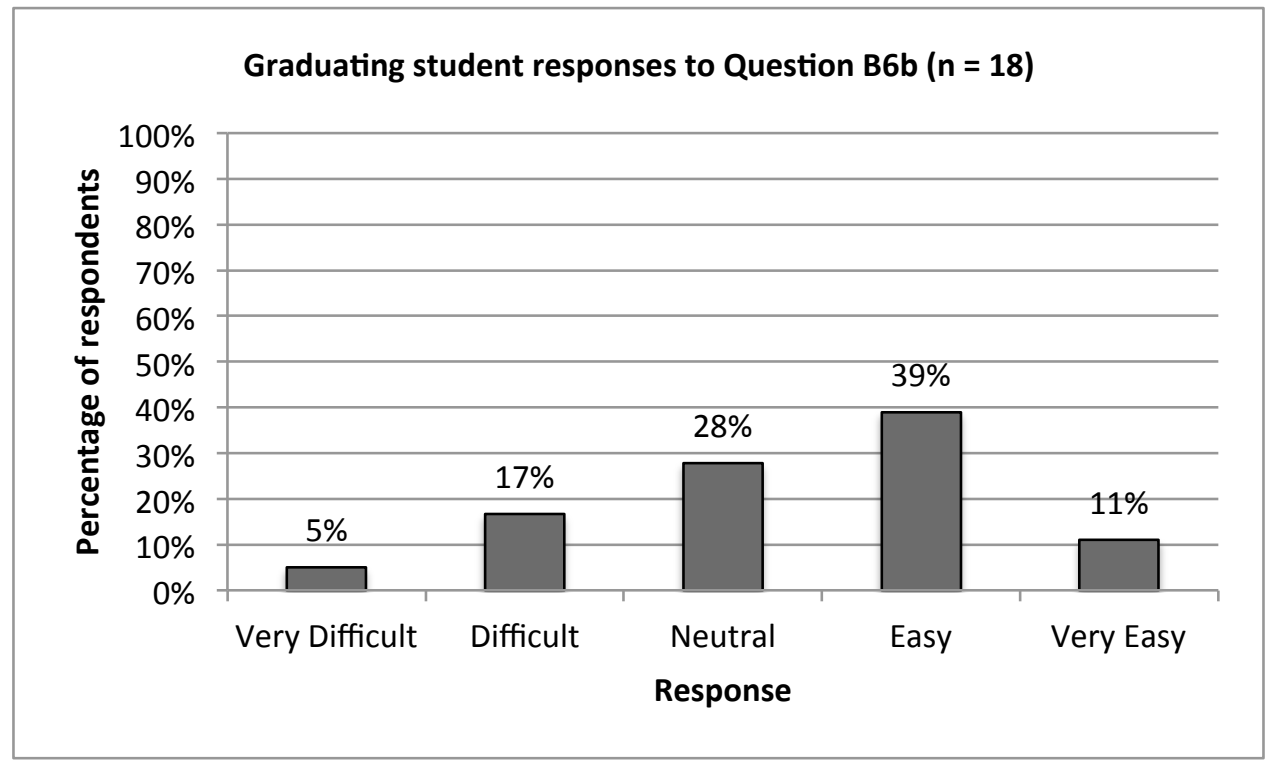

Figure 6-22: Graduating student responses to Question B6b: “How easy is the 3D mouse to use?"

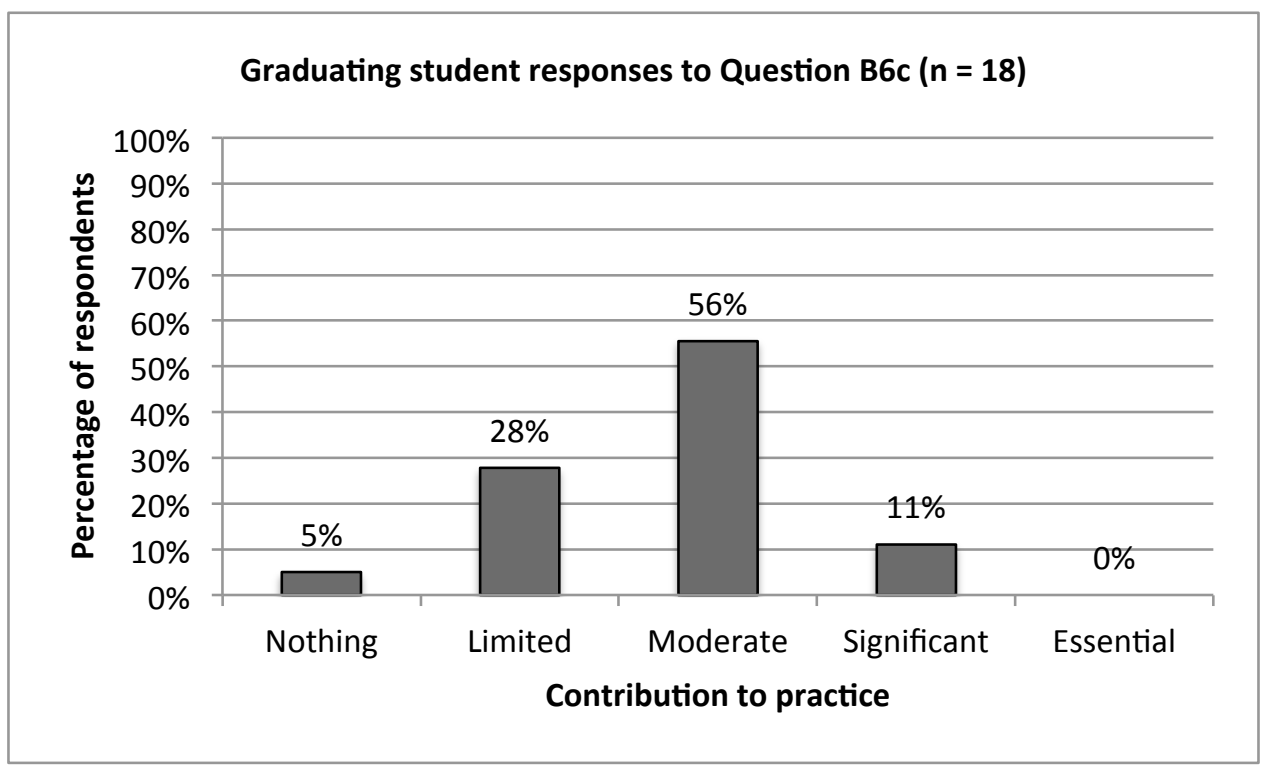

Figure 6-23: Graduating student responses to Question B6c: "How useful is the 3D mouse in making a contribution to practice?"

\subsubsection{3D Scanning/Reverse Engineering}

For 3D scanning/RE, the majority of graduating students (73\%) had never used it; $17 \%$ used it rarely; and 5\% used it often/always (Figure 6-24). The responses on the ease of use were spread between difficult/very difficult (32\%), neutral (39\%) and easy/very easy (29\%) (Figure 6-25). While $10 \%$ of graduating students who used 3D scanning thought that it did not add 
anything to their design practice and 39\% thought that it had limited contribution, $32 \%$ felt that it provided significant/essential contribution (Figure 6-26).

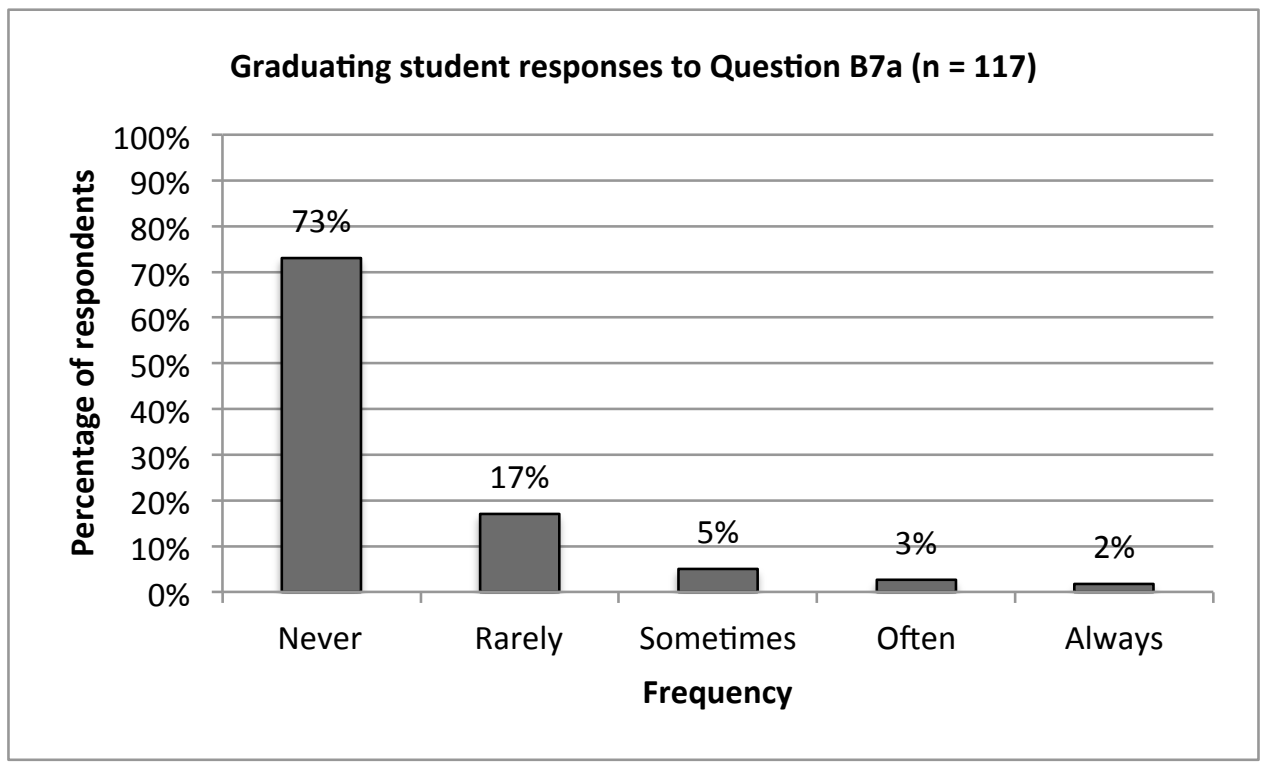

Figure 6-24: Graduating student responses to Question B7a: "How often do you use 3D scanning (reverse engineering) (e.g. Konica Minolta V1-910 laser scanner, 3Shape, Scantech) when designing?"

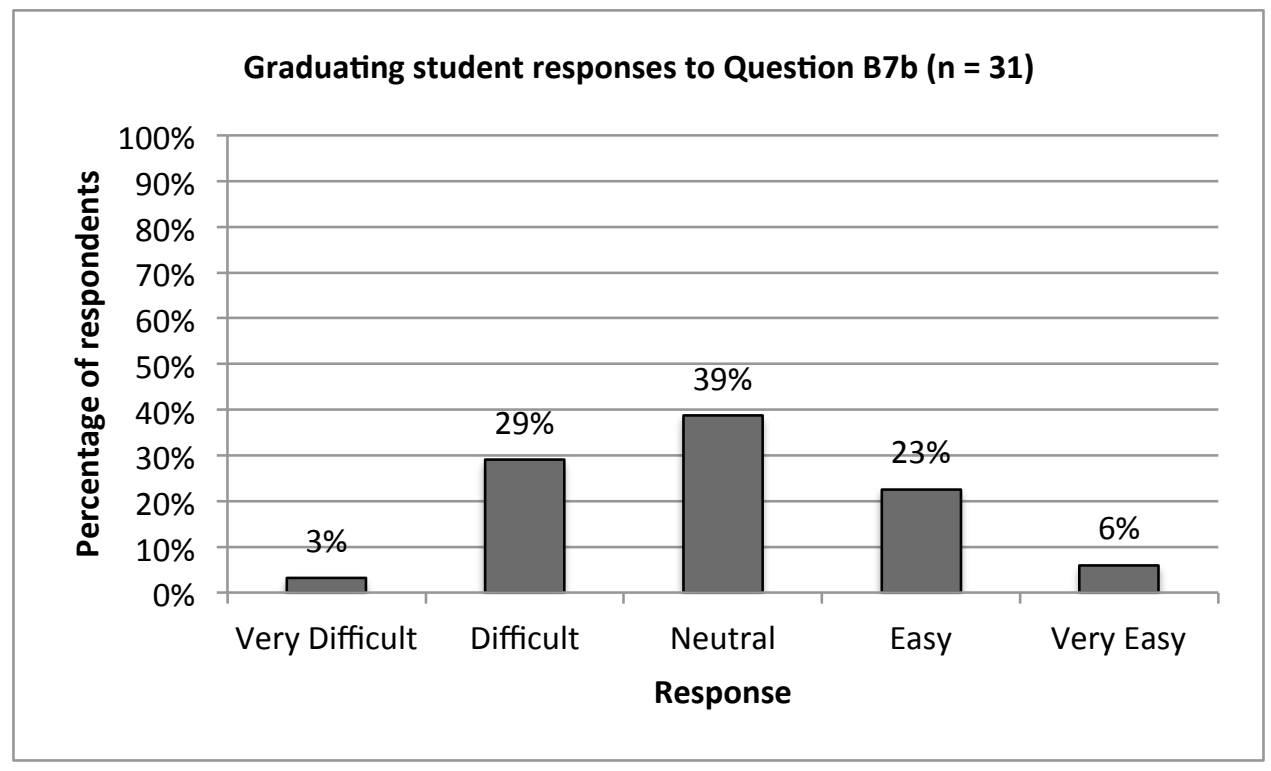

Figure 6-25: Graduating student responses to Question B7b: "How easy is the 3D scanning (reverse engineering) to use?" 


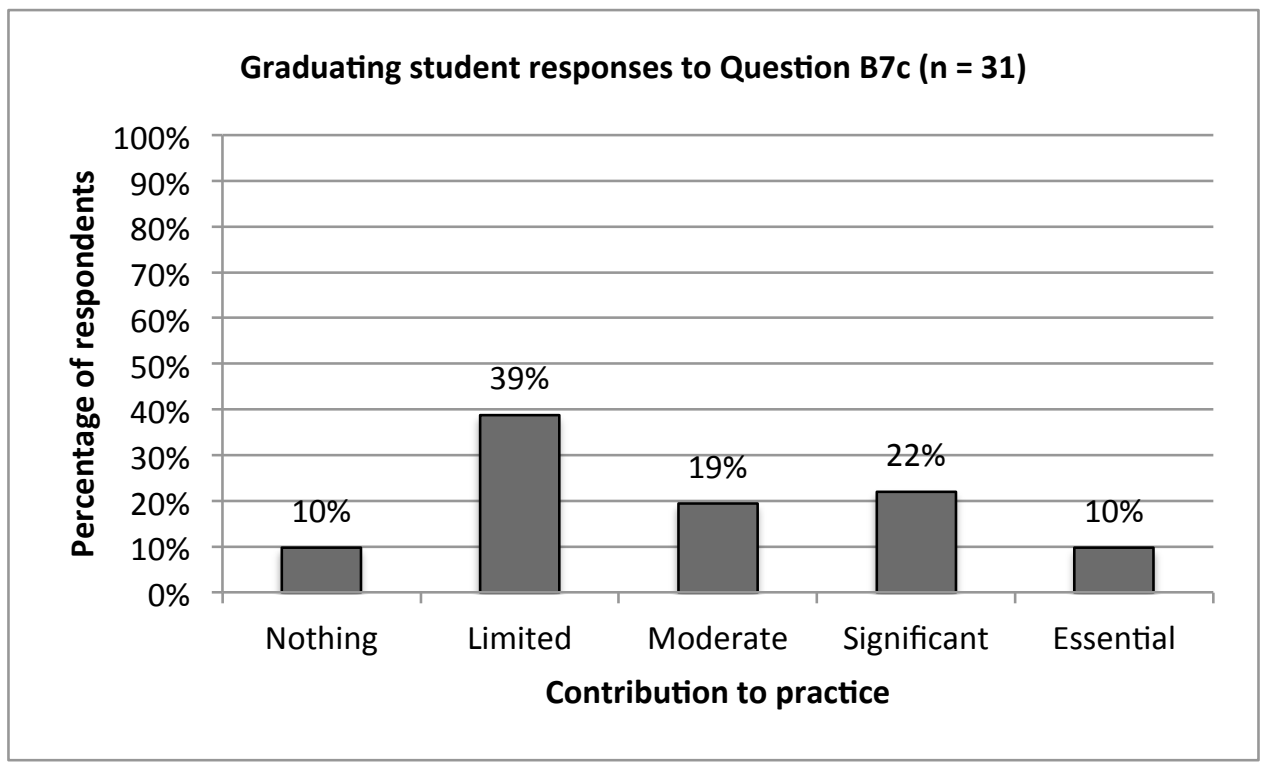

Figure 6-26: Graduating student responses to Question B7c: "How useful is the 3D scanning (reverse engineering) in making a contribution to practice?"

\subsubsection{3D Computer Aided Design (Solid and Surface)}

As with 2D visualisation software, 3D CAD (surface and solid) was another commonly used digital design tool with $84 \%$ of the graduating students using it on regular basis (Figure 6-27); $59 \%$ of graduating students who used it felt that it was easy/very easy to use and only $15 \%$ felt that it was difficult/very difficult to use (Figure 6-28). The feedback on the contribution of $3 \mathrm{D}$ CAD to practice was overwhelmingly positive, with $82 \%$ feeling that it made significant/essential contribution (Figure 3-28). 


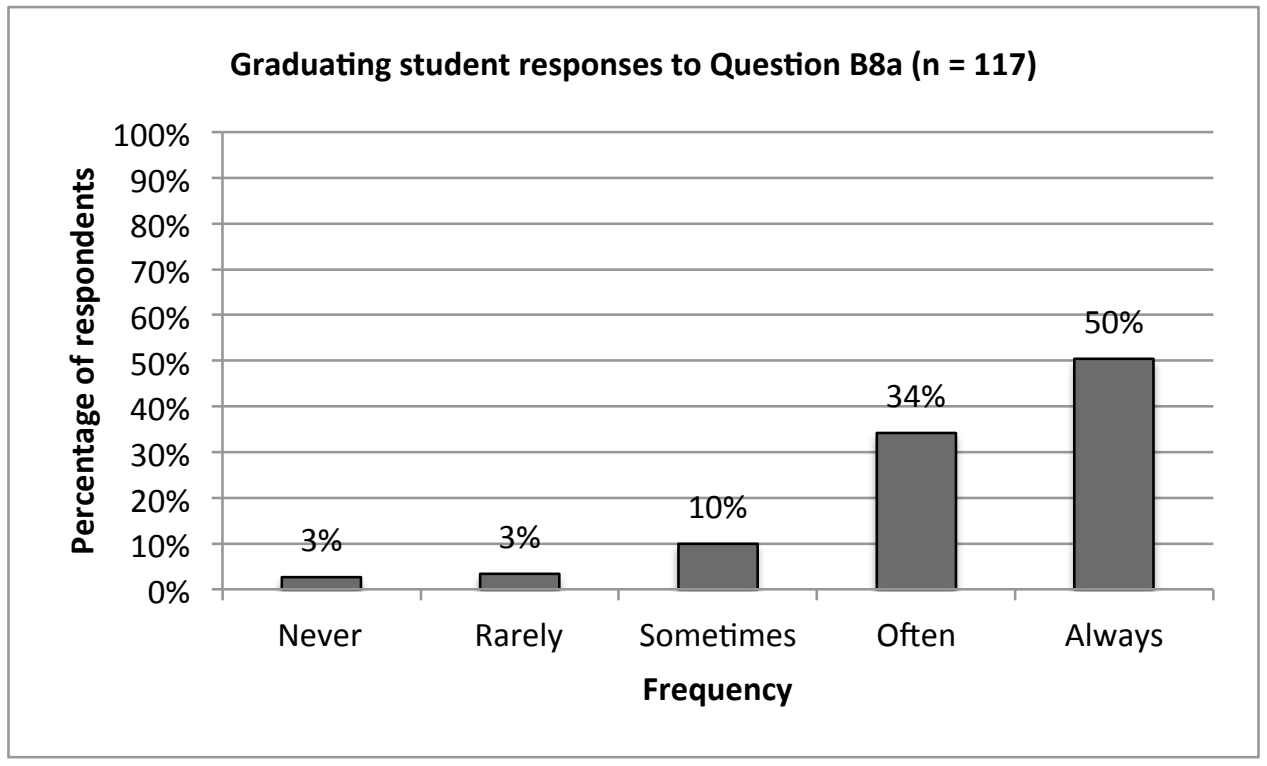

Figure 6-27: Graduating student responses to Question B8a: "How often do you use 3D CAD (surface and solid) (e.g. Rhino, Autodesk Alias Studio, Pro/Engineer, SolidWorks) when designing?"

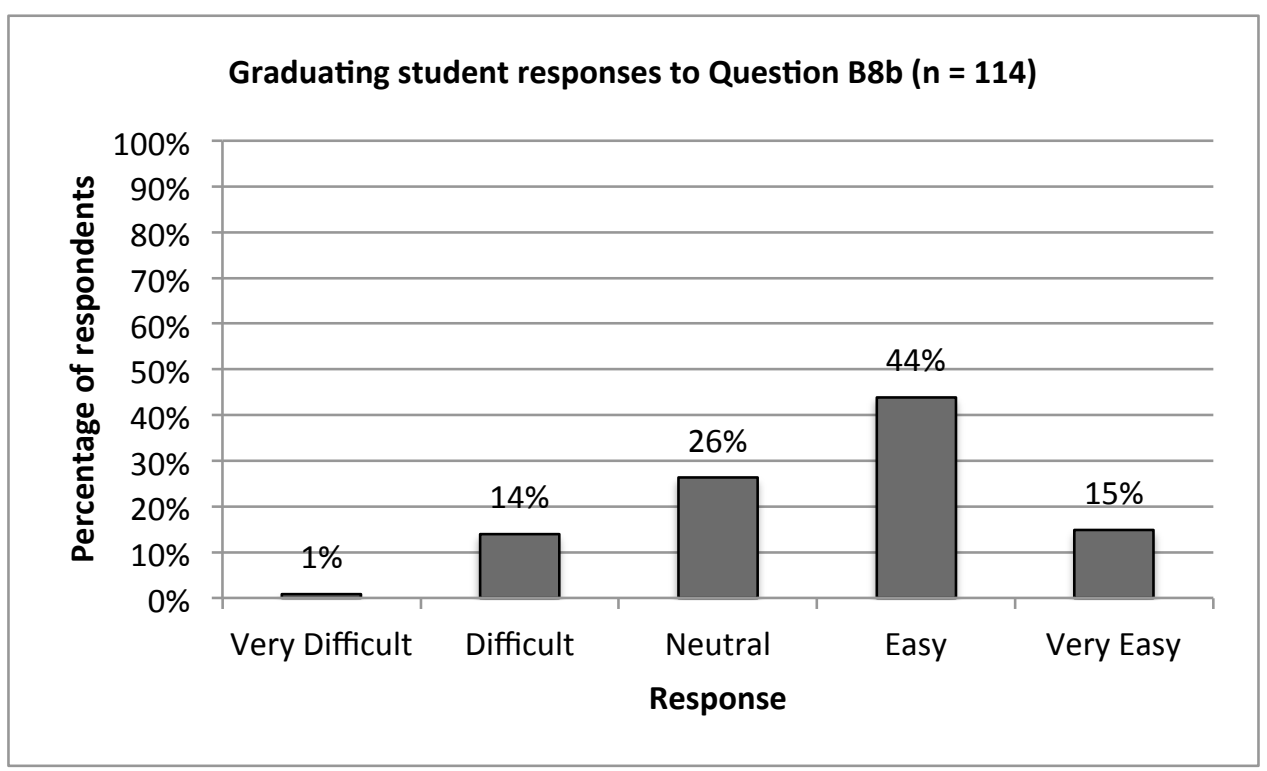

Figure 6-28: Graduating student responses to Question B8b: "How easy is the 3D CAD (solid and surface) to use?" 


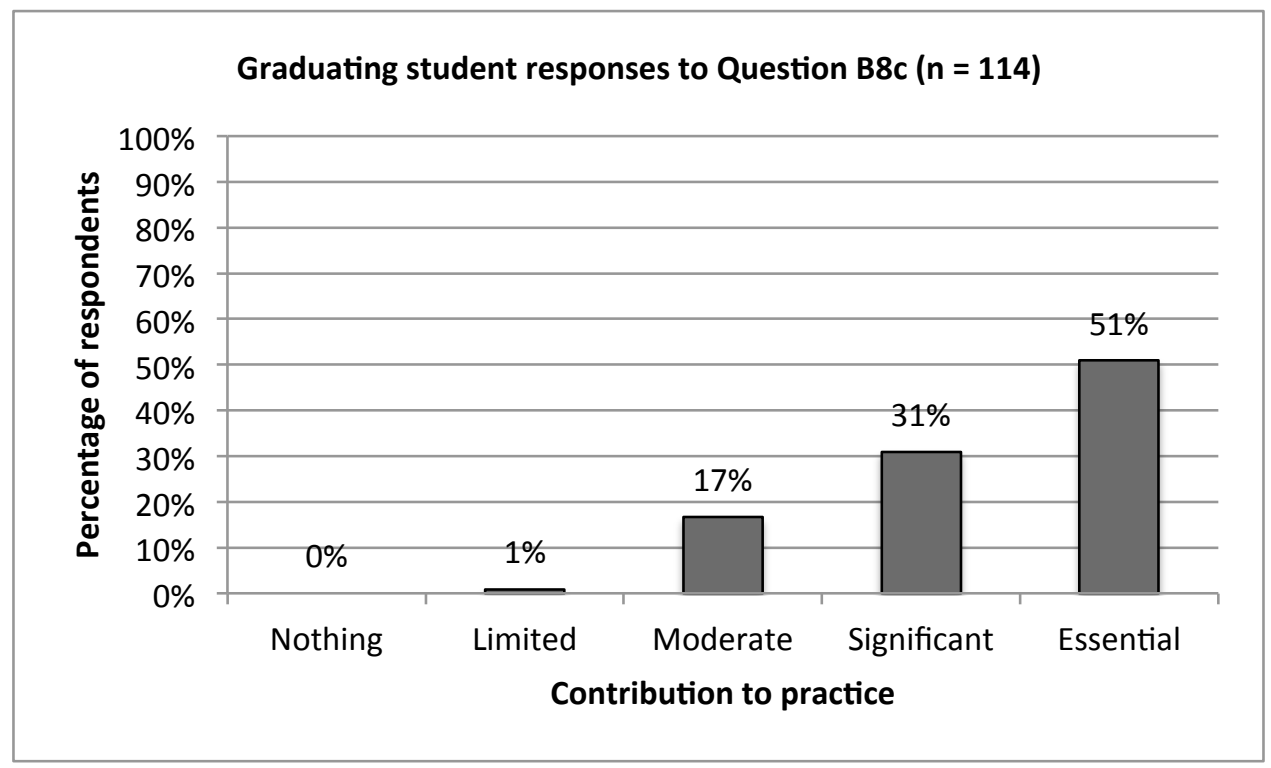

Figure 6-29: Graduating student responses to Question B8c: "How useful is the 3D CAD (solid and surface) in making a contribution to practice?"

\subsubsection{Haptic Modelling}

Graduating students were less familiar with haptic modelling as $87 \%$ had not used it (Figure 6-30). Most of the remaining $13 \%$ that used it felt that it was difficult/very difficult (46\%) or neutral (47\%) to use (Figure 6-31). Its contribution to the graduating student design practice was minimal, with $66 \%$ stating that it made limited/no contribution (Figure 6-32).

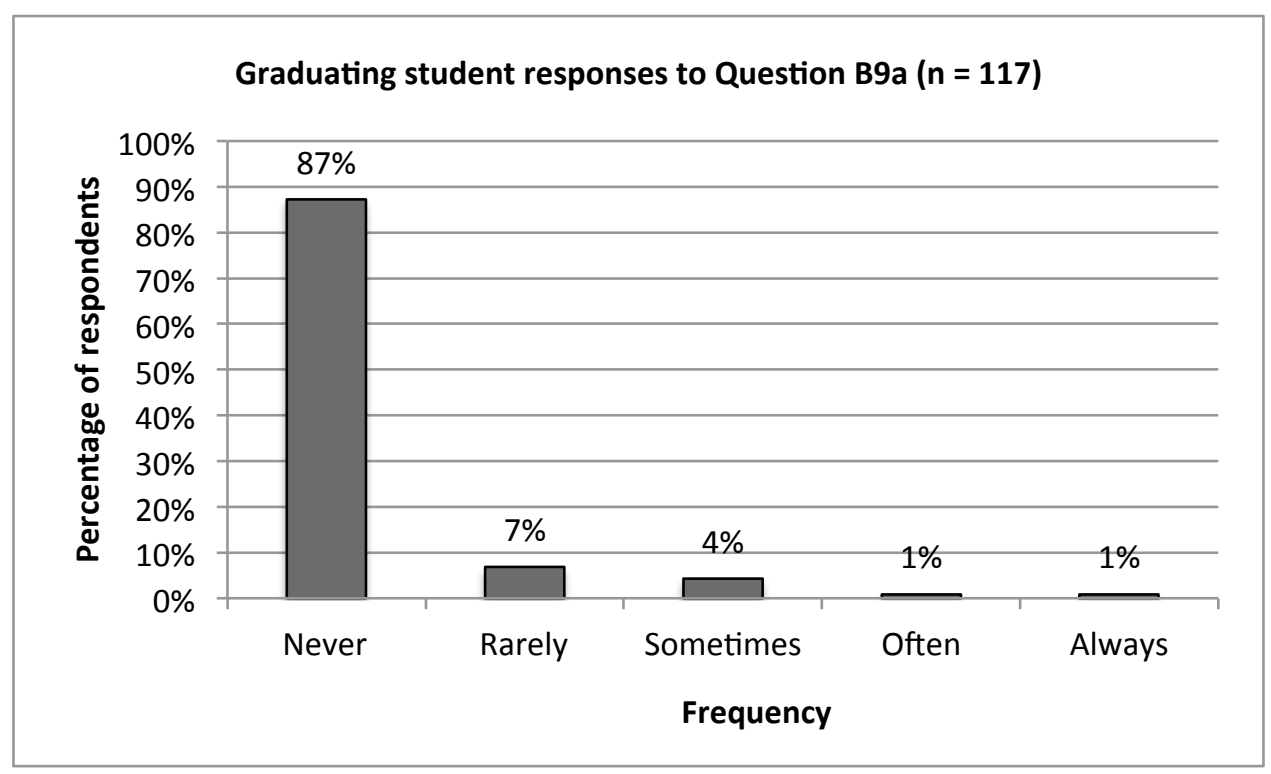

Figure 6-30: Graduating student responses to Question B9a: "How often do you use haptic modelling (e.g. SensAble PHANTOM FreeForm system) when designing?" 


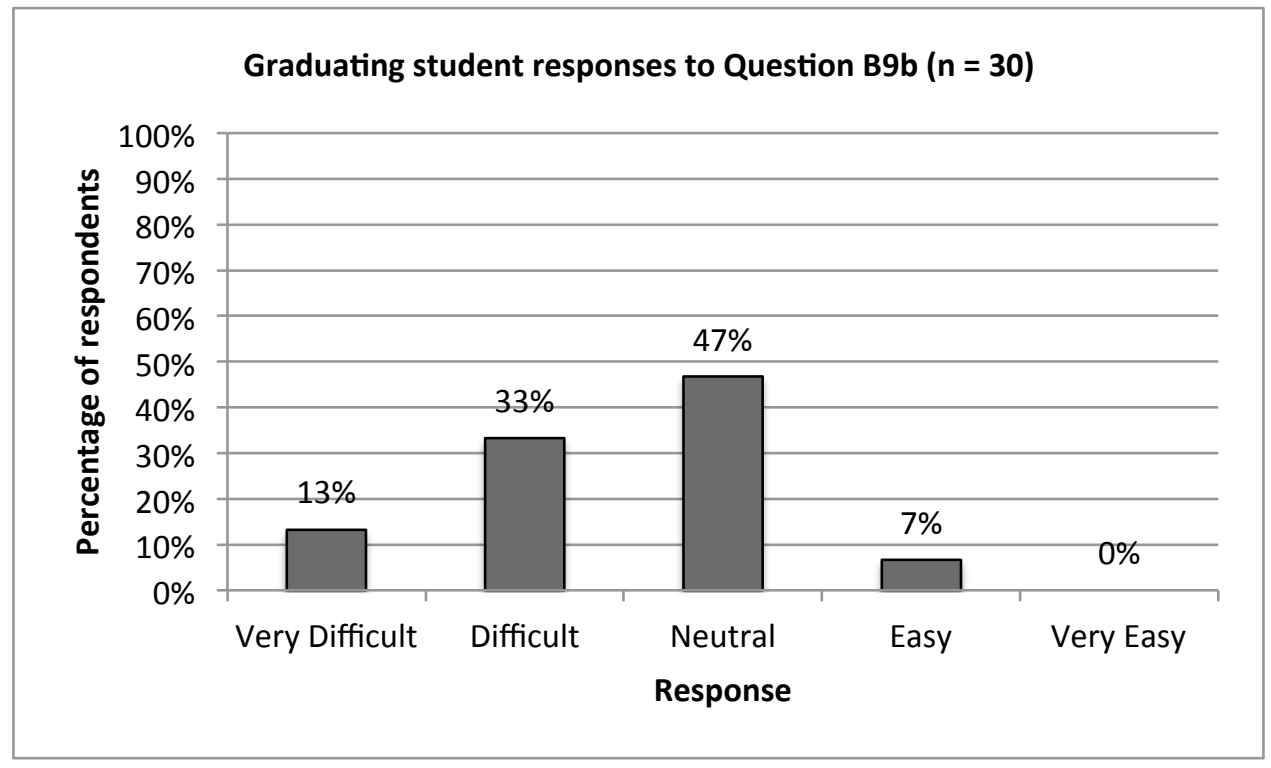

Figure 6-31: Graduating student responses to Question B9b: "How easy is haptic modelling to use?"

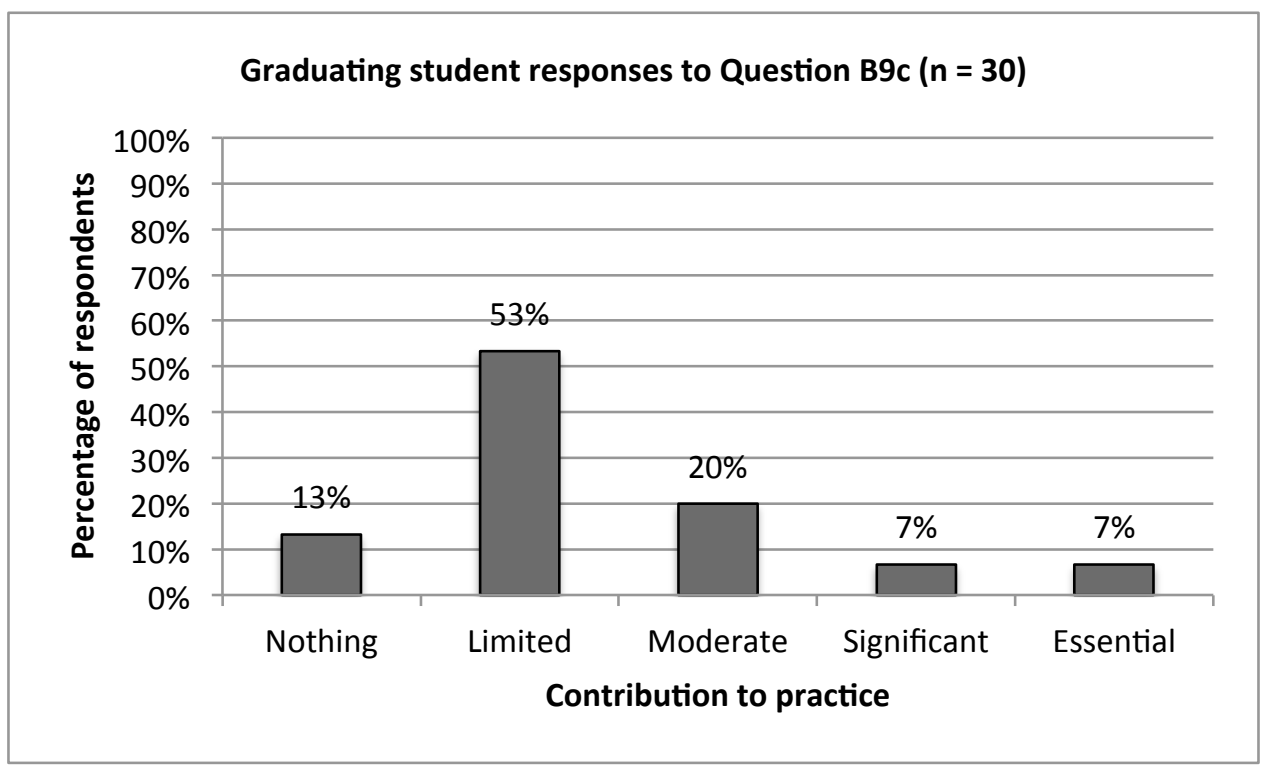

Figure 6-32: Graduating student responses to Question B9c: "How useful is haptic modelling in making a contribution to practice?"

\subsubsection{Polygon Modelling}

While half of the graduating students had never experienced polygon modelling, $21 \%$ used it on a regular basis (Figure 6-33). Graduating students who had experienced it (46\%) felt neutral towards employing it (Figure 6-34); 41\% regarded it as having a significant/essential contribution to their design practice and another 37\% thought that it provided moderate contribution (Figure 6-35). 


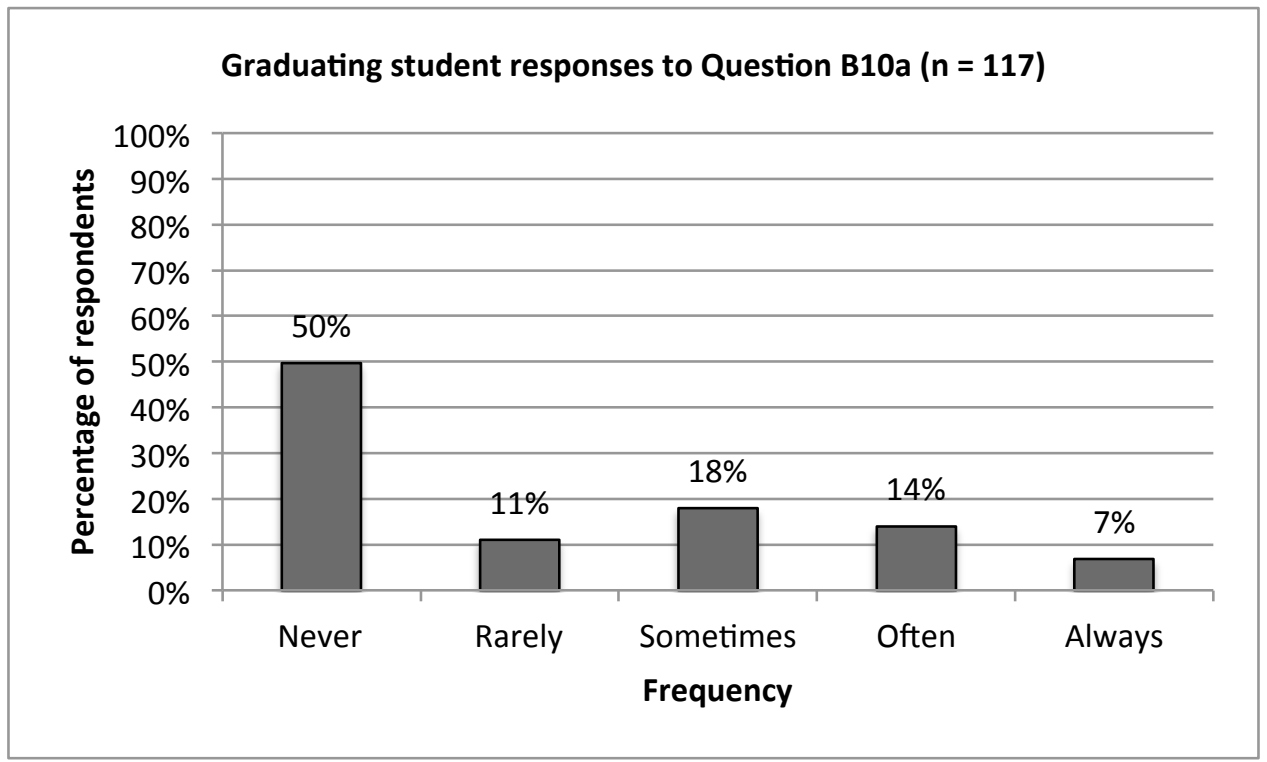

Figure 6-33: Graduating student responses to Question B10a: "How often do you use polygon modelling (e.g. Autodesk 3ds Max, Autodesk Maya) when designing?"

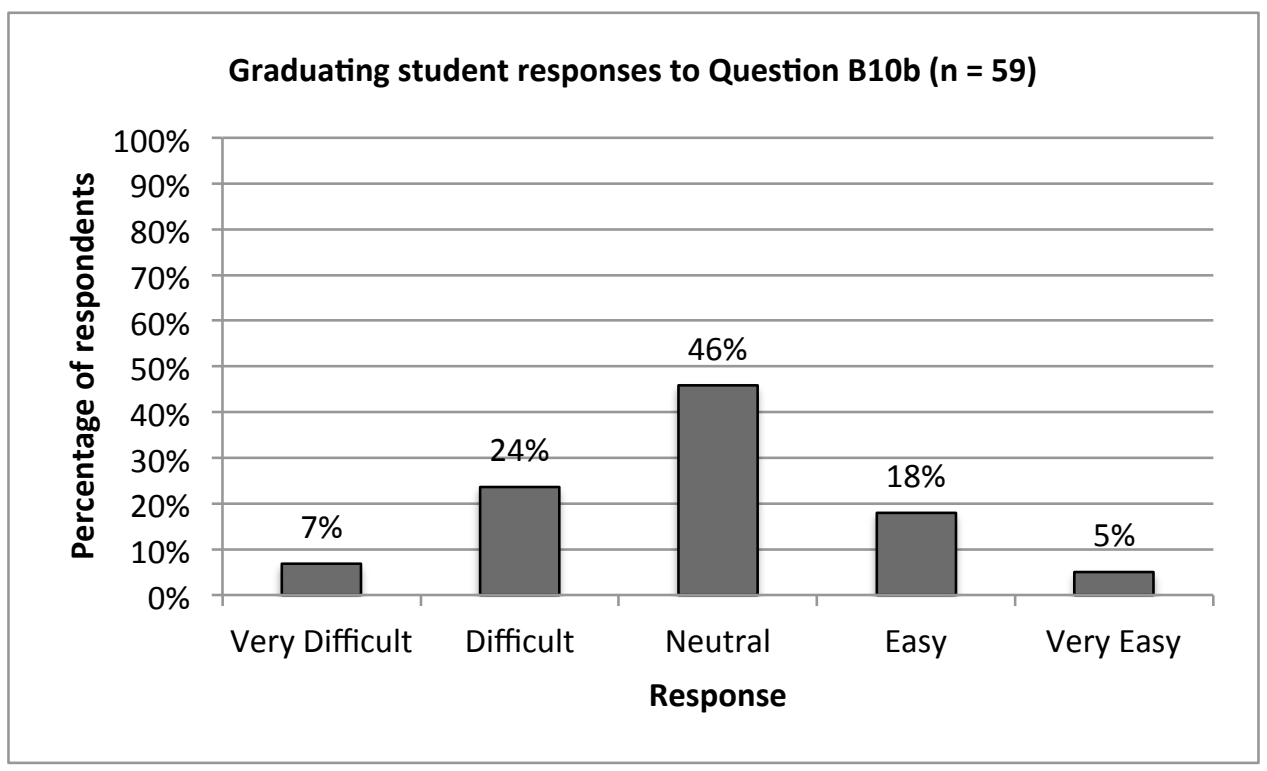

Figure 6-34: Graduating student responses to Question B10b: "How easy is polygon modelling to use?" 


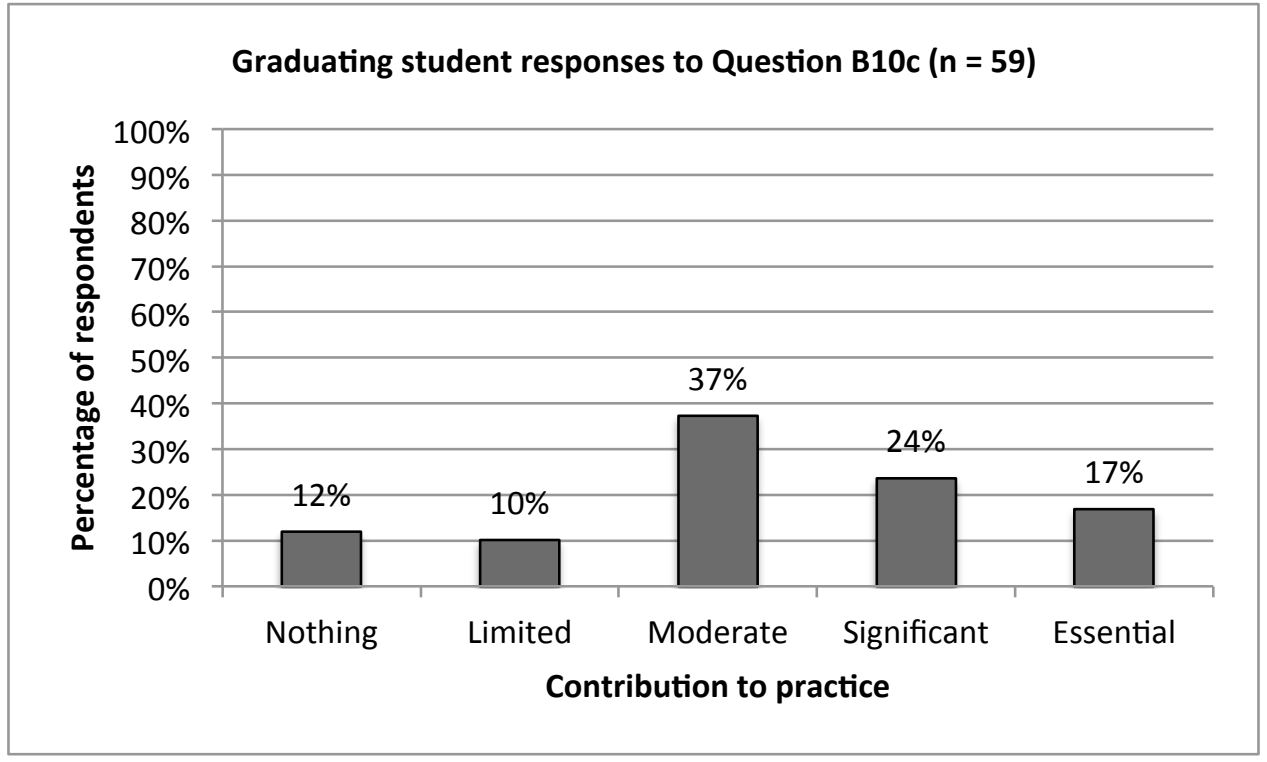

Figure 6-35: Graduating student responses to Question B10c: "How useful is polygon modelling in making a contribution to practice?"

\subsubsection{2D Computer Aided Design}

Of those questioned, $19 \%$ of graduating students had never used 2D CAD; $22 \%$ used it rarely; and $36 \%$ used it often/always (Figure $6-36$ ); $61 \%$ of respondents who used 2D CAD confirmed that it was easy/very easy to use (Figure 6-37); 47\% thought that it provided significant/essential addition to their design practice and $24 \%$ felt that it offered a limited contribution (Figure 6-38).

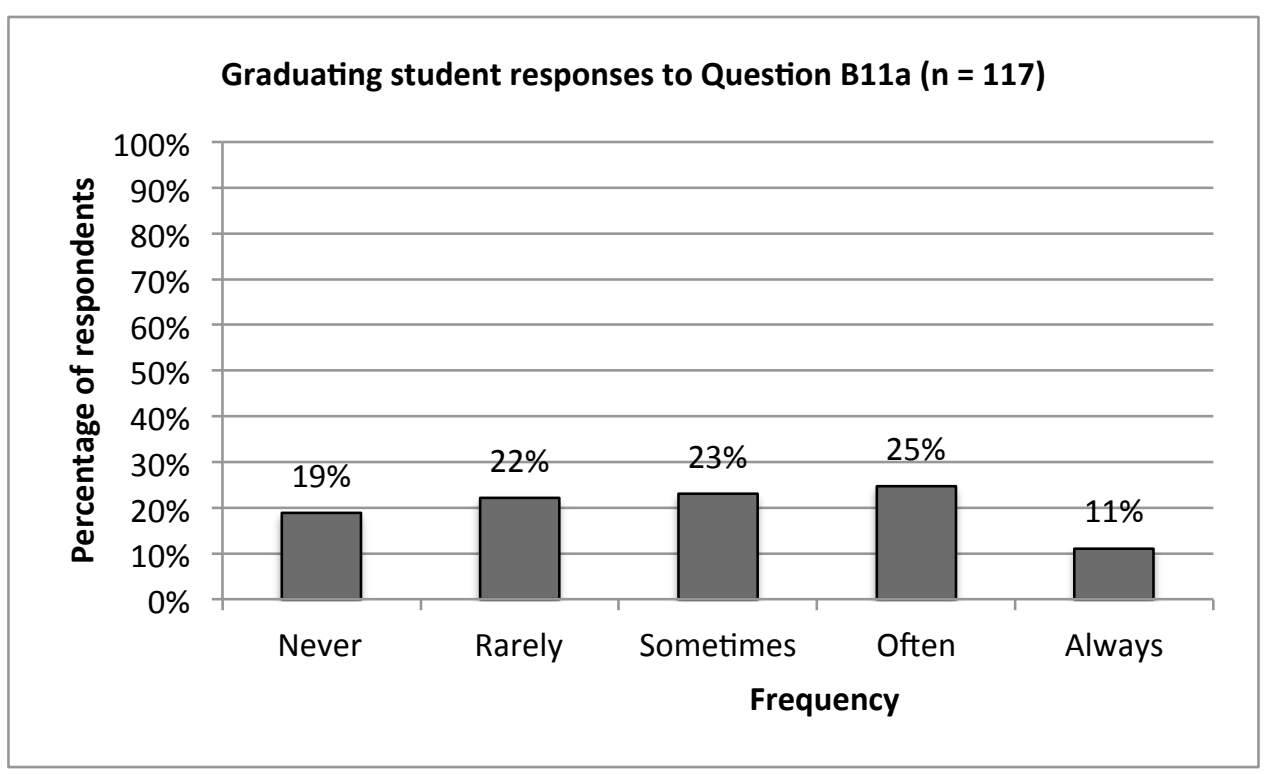

Figure 6-36: Graduating student responses to Question B11a: “How often do you use 2D CAD (e.g. 2D Design, 2D application in AutoCAD) when designing?" 


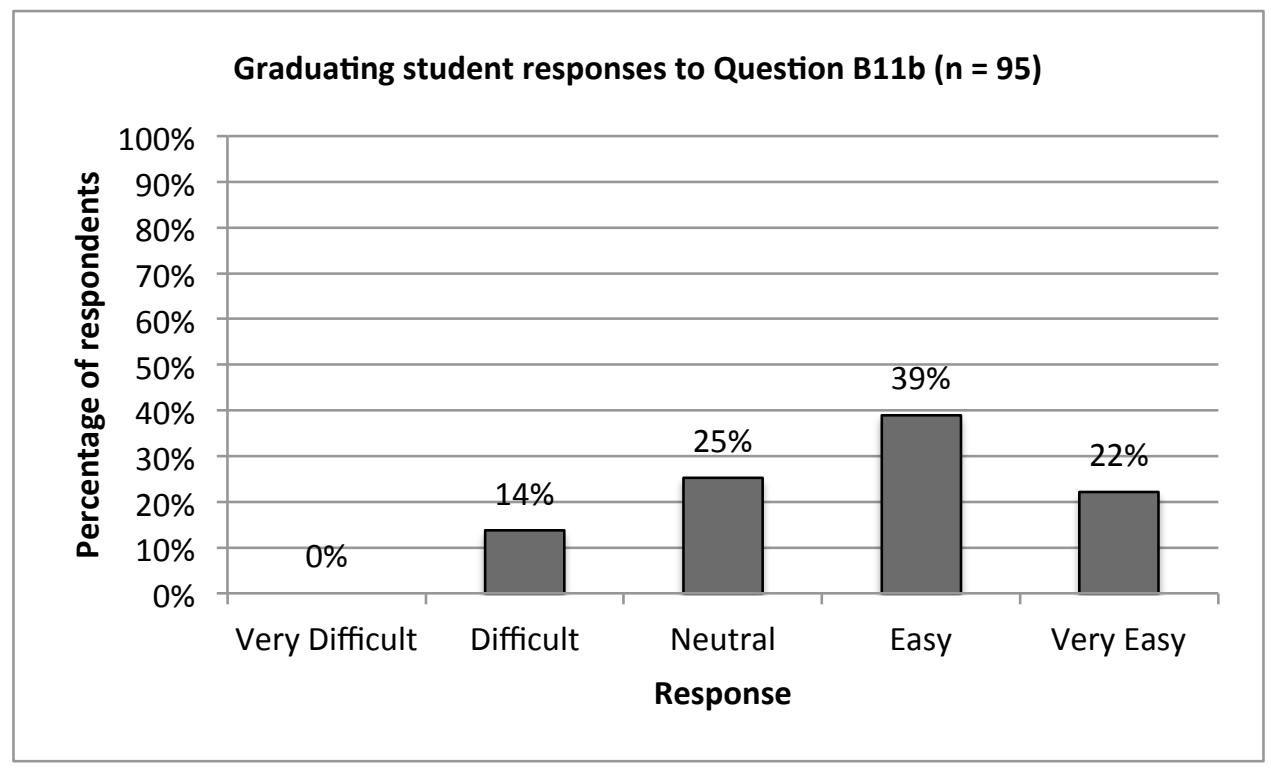

Figure 6-37: Graduating student responses to Question B11b: "How easy is 2D CAD to use?"

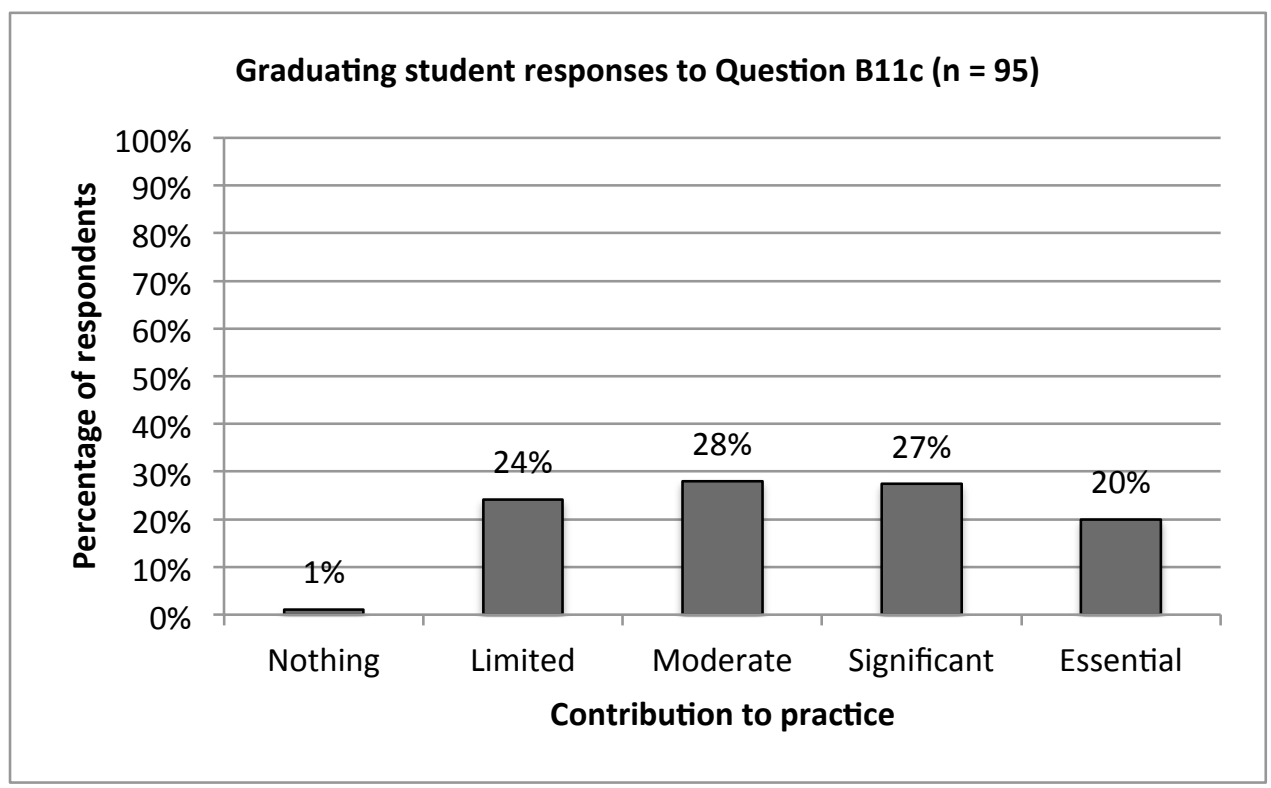

Figure 6-38: Graduating student responses to Question B11c: "How useful is 2D CAD in making a contribution to practice?"

\subsubsection{2D Computer Numerical Control Machining}

Of the graduating students, $40 \%$ used 2D CNC machining sometimes and $34 \%$ used it often/always (Figure 6-39). Although the majority of graduating students (53\%) felt that it was easy/very easy to use, $40 \%$ felt neutral about it (Figure 6-40). It was apparent that $2 \mathrm{D}$ CNC machining offered a significant/essential contribution to the design practice as confirmed by the majority (51\%) (Figure 6-41). 


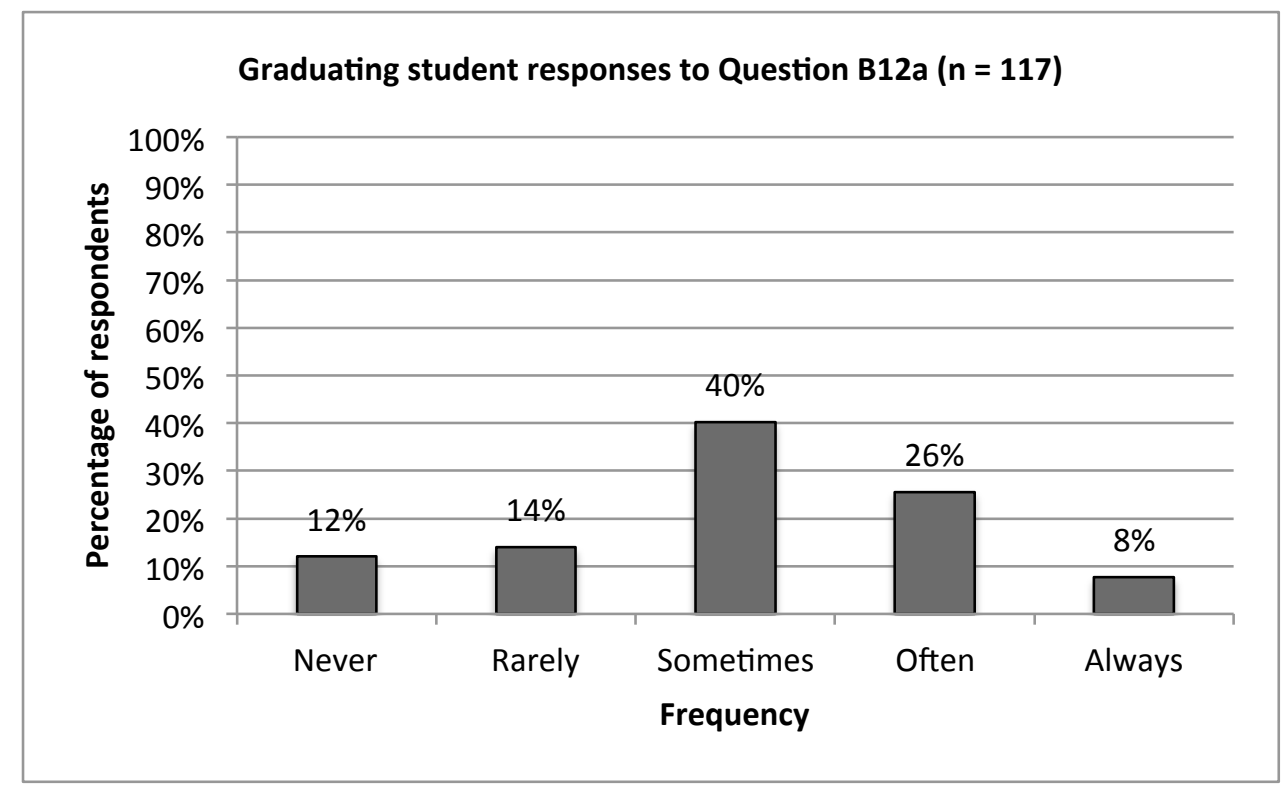

Figure 6-39: Graduating student responses to Question B12a: "How often do you use 2D CNC machining (e.g. Laser cutting machine, Water Jet Cutter) when designing?"

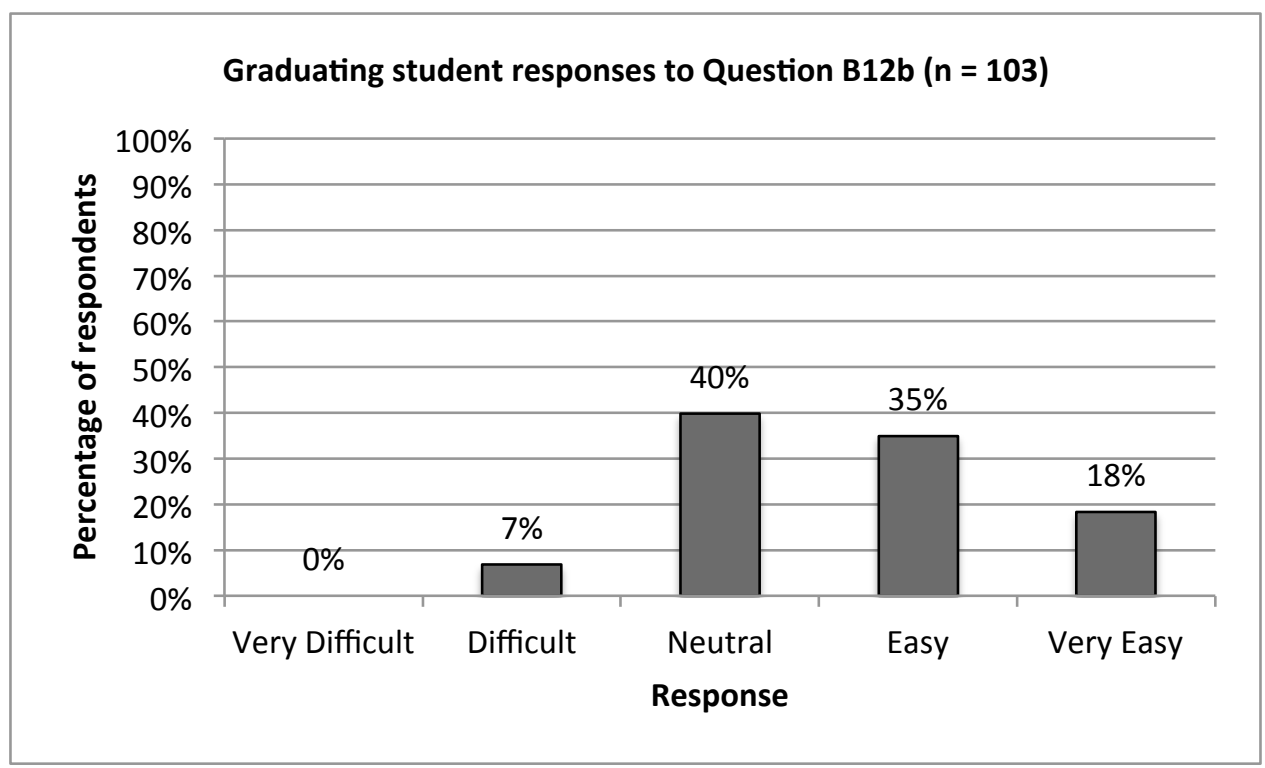

Figure 6-40: Graduating student responses to Question B12b: "How easy is 2D CNC machining to use?" 


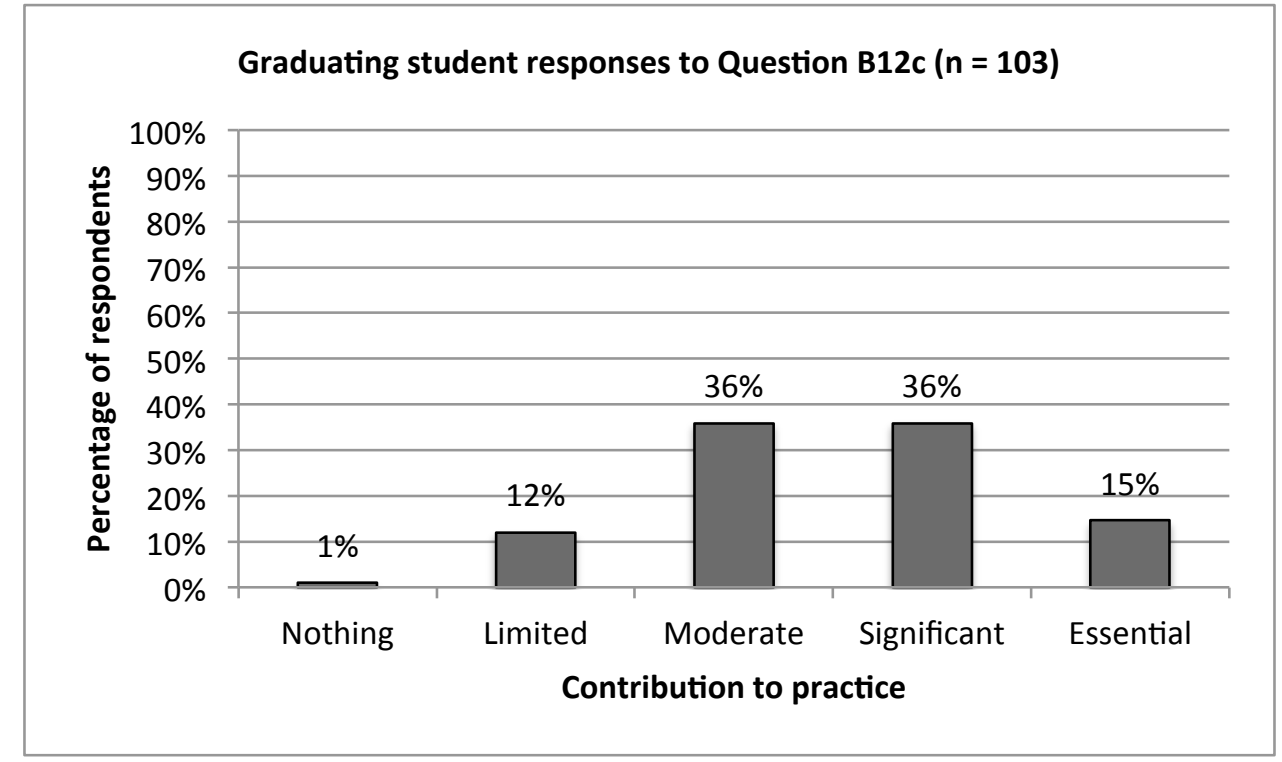

Figure 6-41: Graduating student responses to Question B12c: "How useful is 2D CNC machining in making a contribution to practice?"

\subsubsection{Rendering/Animation}

Forty-nine percent of graduating students used rendering/animation on a frequent basis and $17 \%$ had never used it (Figure 6-42); 42\% who used rendering/animation thought that it was easy/very easy to use and 33\% felt neutral about it (Figure 6-43). Most of the respondents (62\%) felt that it had a significant/essential contribution to their design practice (Figure 6-44).

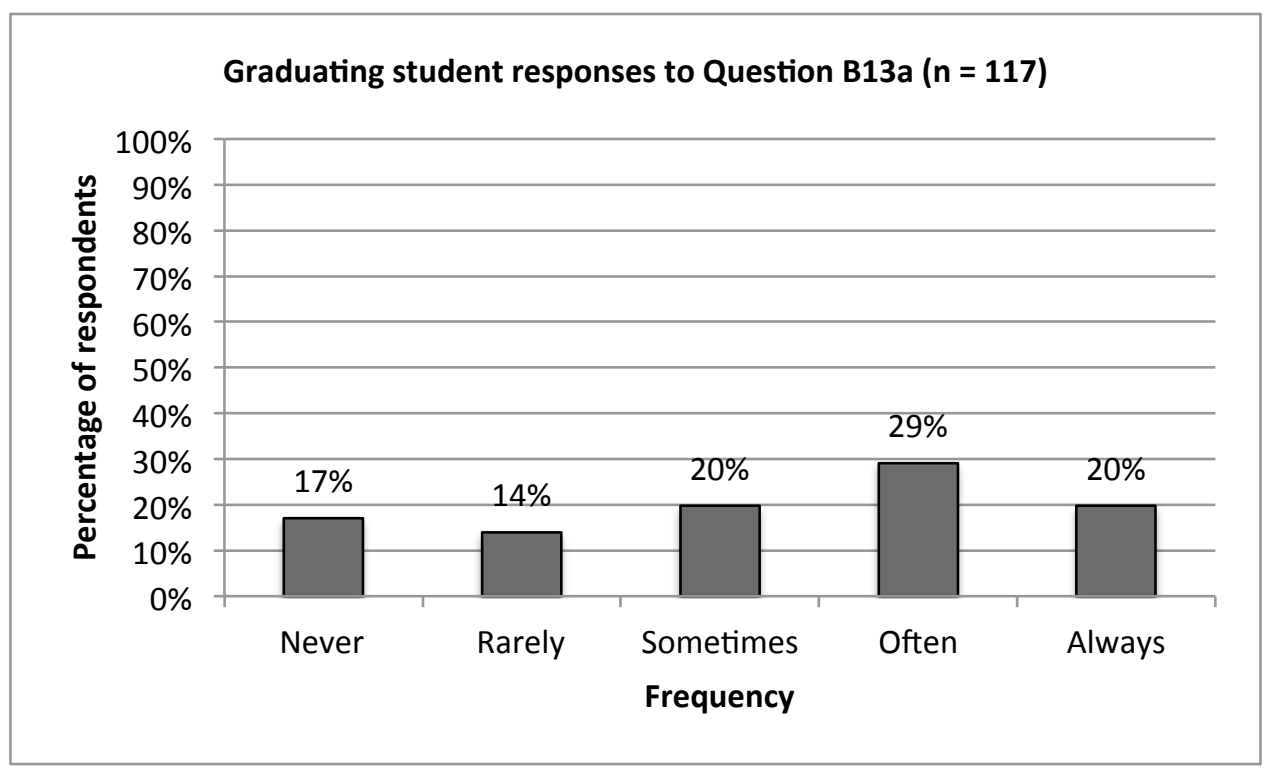

Figure 6-42: Graduating student responses to Question B13a: “How often do you use rendering/animation (e.g. Autodesk ImageStudio, Adobe Flash) when designing?" 


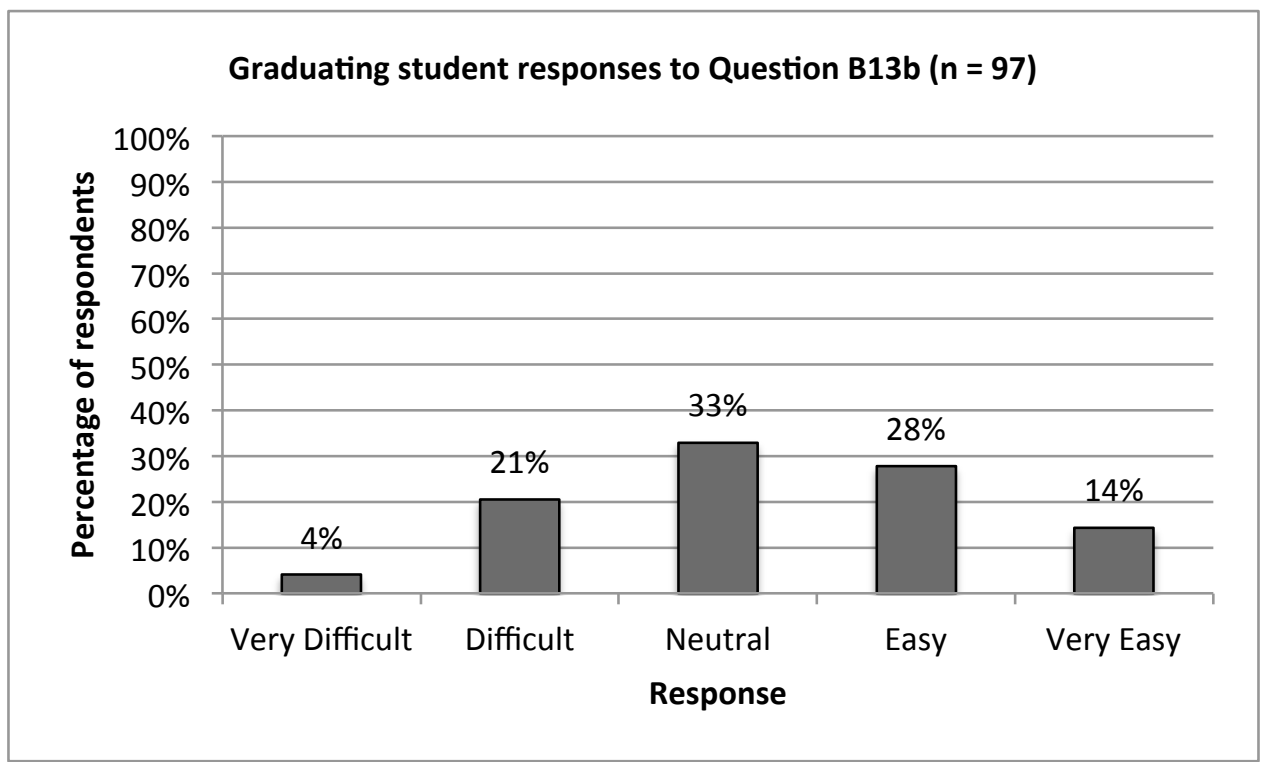

Figure 6-43: Graduating student responses to Question B13b: “How easy is rendering/animation to use?"

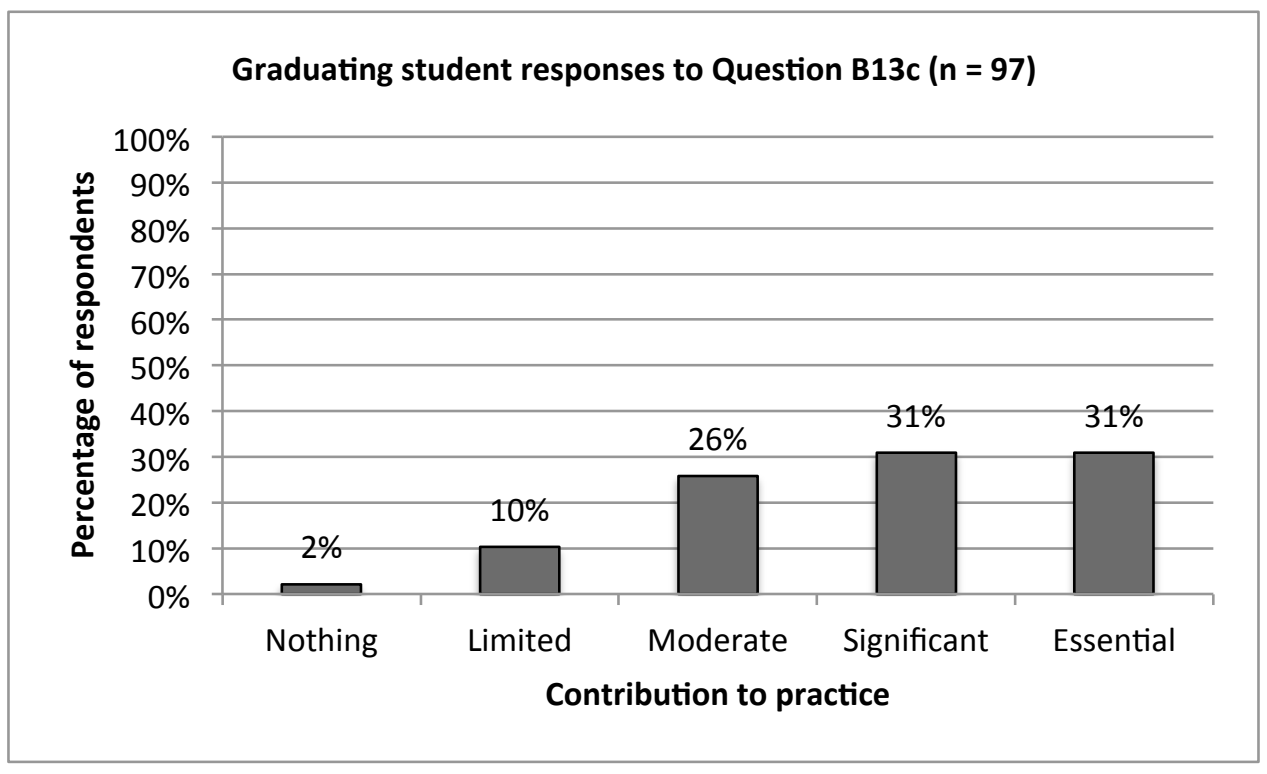

Figure 6-44: Graduating student responses to Question B13c: "How useful is rendering/animation in making a contribution to practice?"

\subsubsection{Rapid Prototyping}

The majority of graduating students considered RP to be easy/very easy to use (55\%) (Figure 6-46) and a tool that offered a significant/essential contribution to design practice (65\%) (Figure 6-47). However, 28\% of graduating students had never used it or used it rarely (Figure 6-45). 


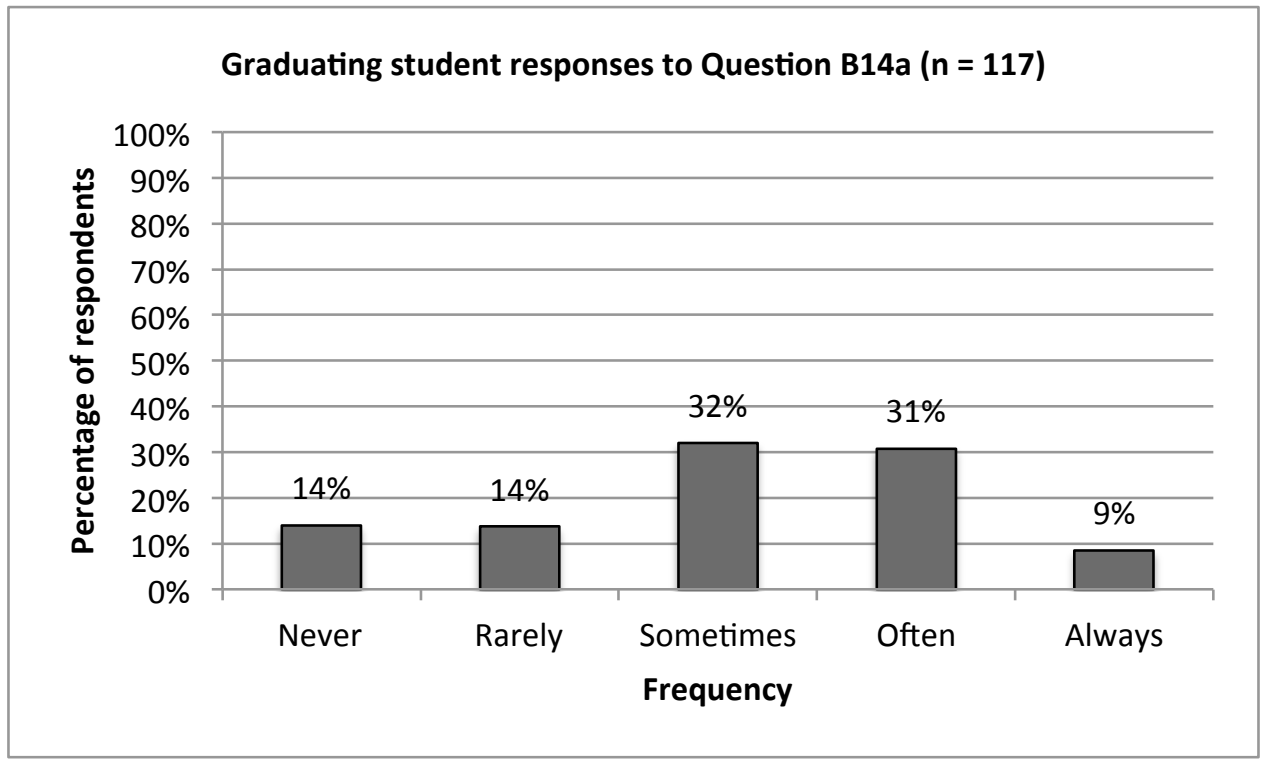

Figure 6-45: Graduating student responses to Question B14a: “How often do you use rapid prototyping (e.g. Invision, Z Crop, Stereolithography) when designing?"

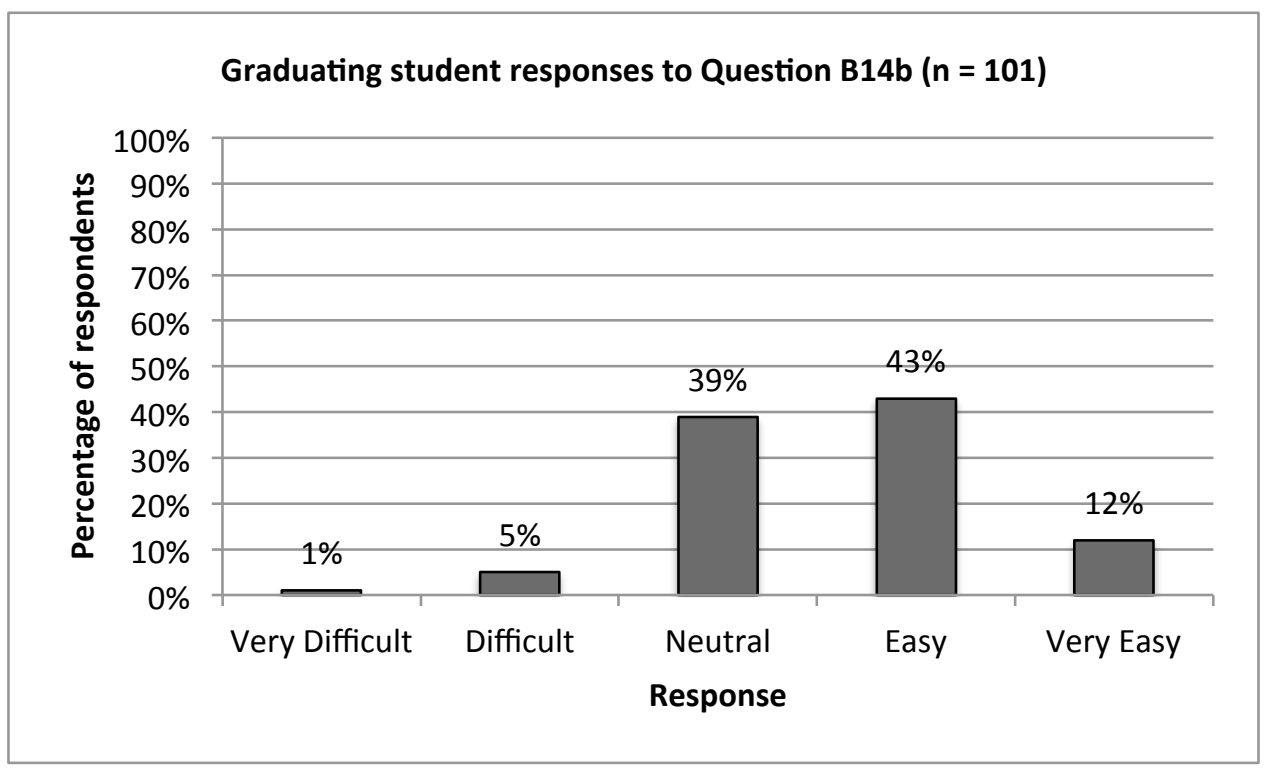

Figure 6-46: Graduating student responses to Question B14b: “How easy is rapid prototyping to use?" 


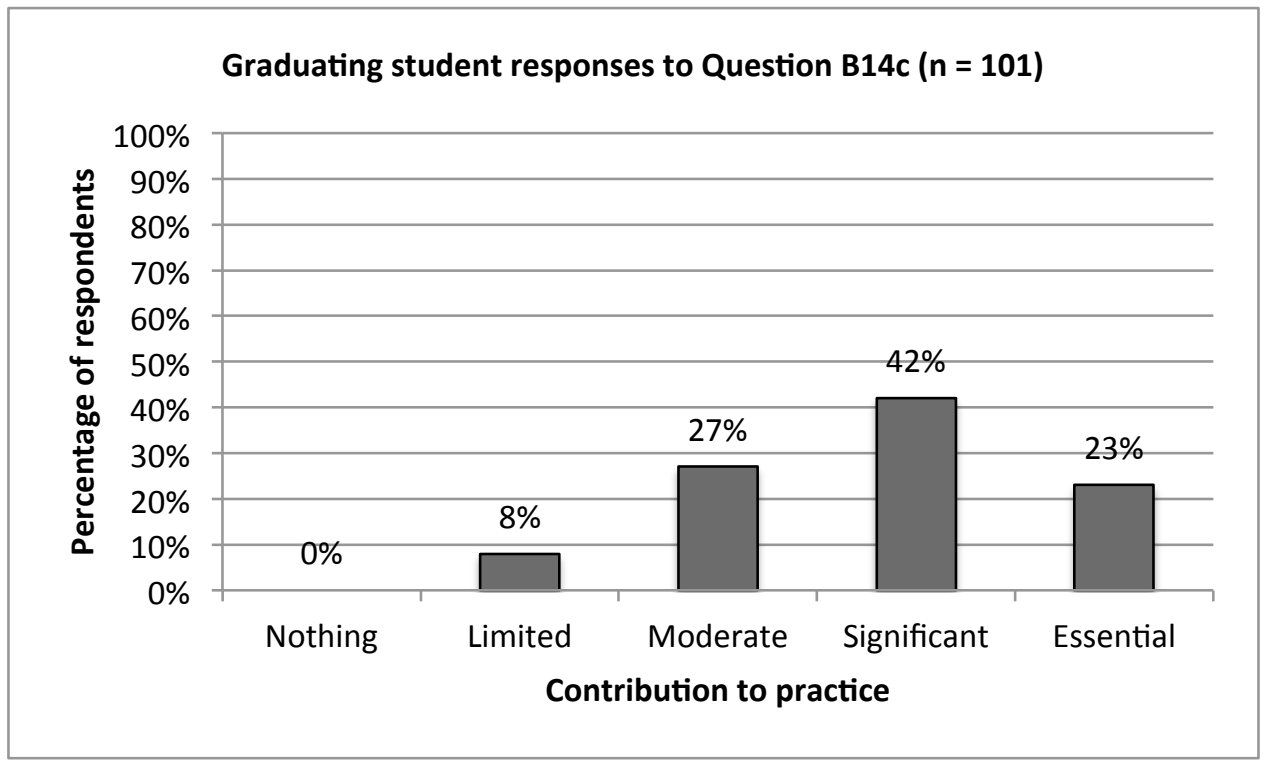

Figure 6-47: Graduating student responses to Question B14c: "How useful is rapid prototyping in making a contribution to practice?"

\subsubsection{3D Computer Numerical Control Machining}

Despite the fact that more than half of the graduating students (51\%) who experienced 3D CNC machining felt that its contribution to their design practice was significant/essential (Figure 6-50), 33\% had never used it (Figure 6-48). Furthermore, when it came to the ease of use, the majority felt neutral (51\%) and 39\% felt that it was easy/very easy to use (Figure 6-49).

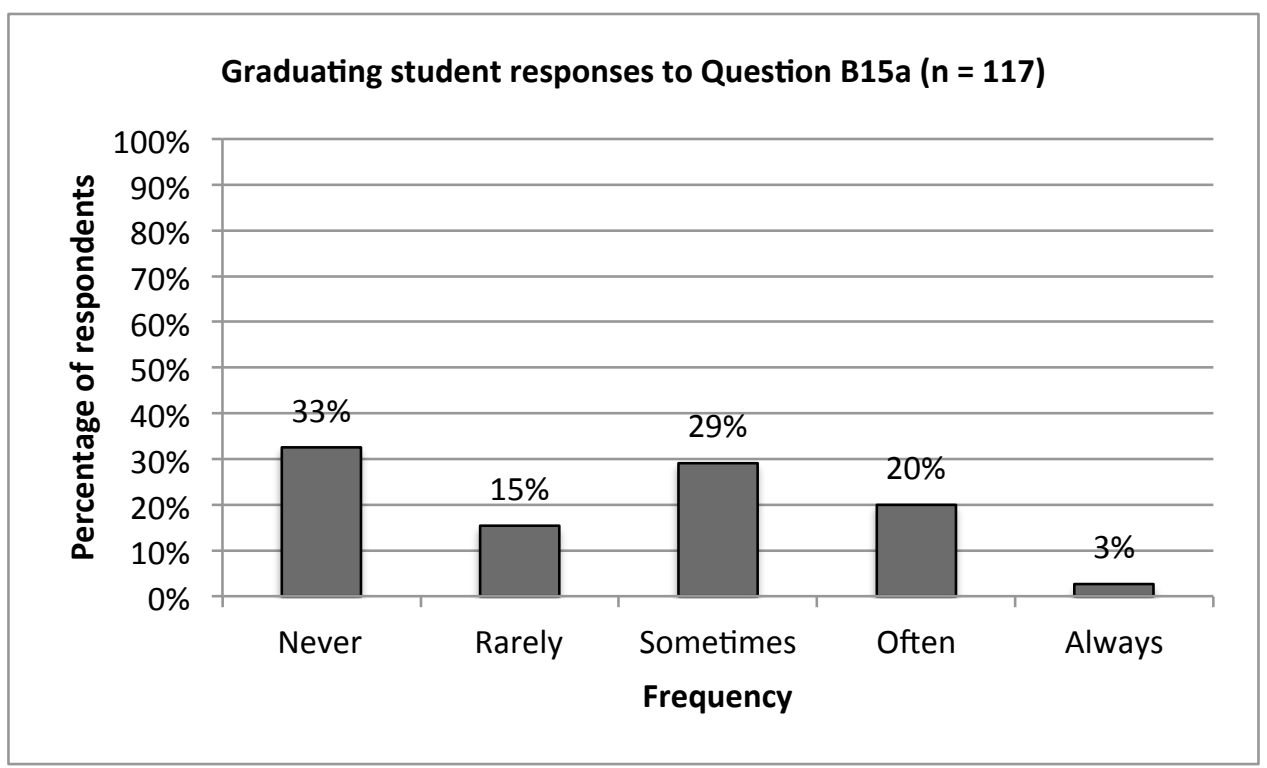

Figure 6-48: Graduating student responses to Question B15a: "How often do you use 3D CNC machining (e.g. milling machine) when designing?" 


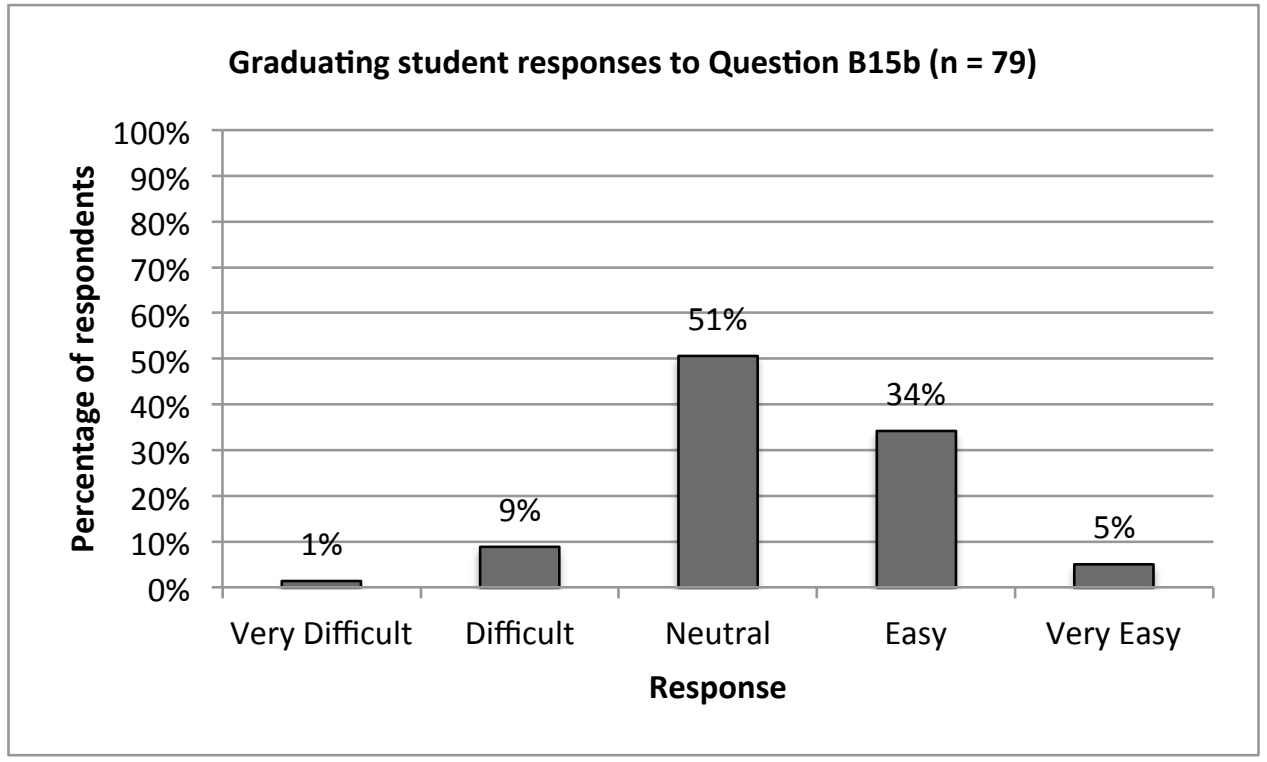

Figure 6-49: Graduating student responses to Question B15b: "How easy is 3D CNC machining to use?"

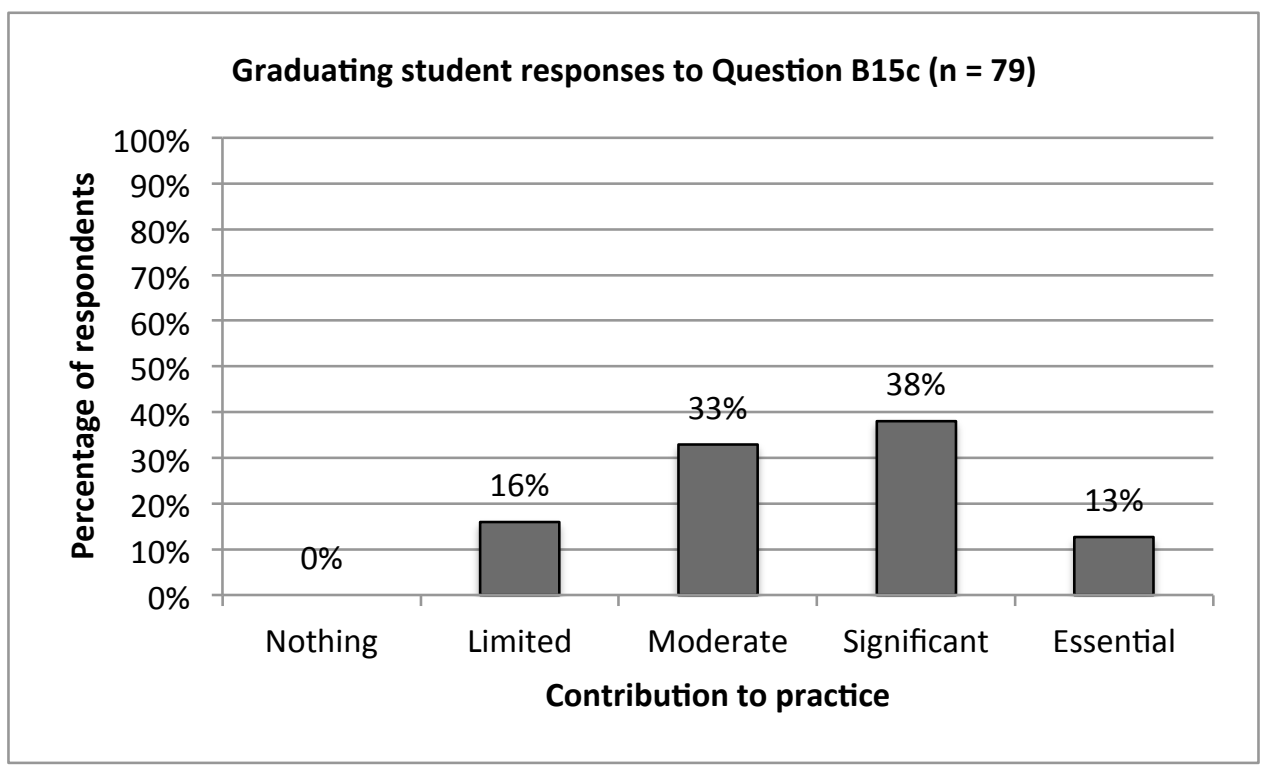

Figure 6-50: Graduating student responses to Question B15c: "How useful is 3D CNC machining in making a contribution to practice?"

\subsubsection{Virtual Prototyping}

Most of the graduating students (56\%) had never used VP and only $17 \%$ used it on a regular basis (Figure 6-51). Thirty percent declared that it was easy/very easy to use and another $43 \%$ were neutral (Figure 6-52). The greatest percentage, 49\%, said that the contribution of VP to their design practice was significant/essential (Figure 6-53). 


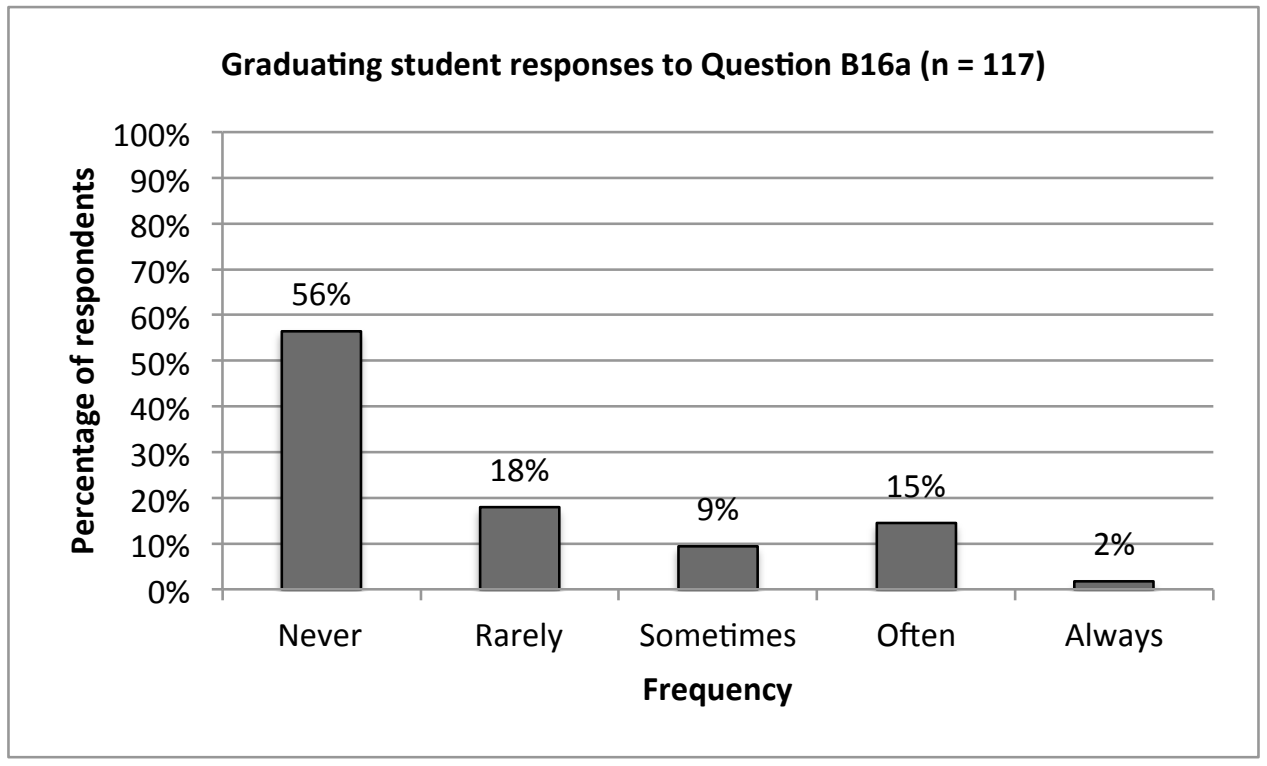

Figure 6-51: Graduating student responses to Question B16a: "How often do you use virtual prototyping (e.g. Finite Element Analysis, Pro/Engineer Mechanica) when designing?"

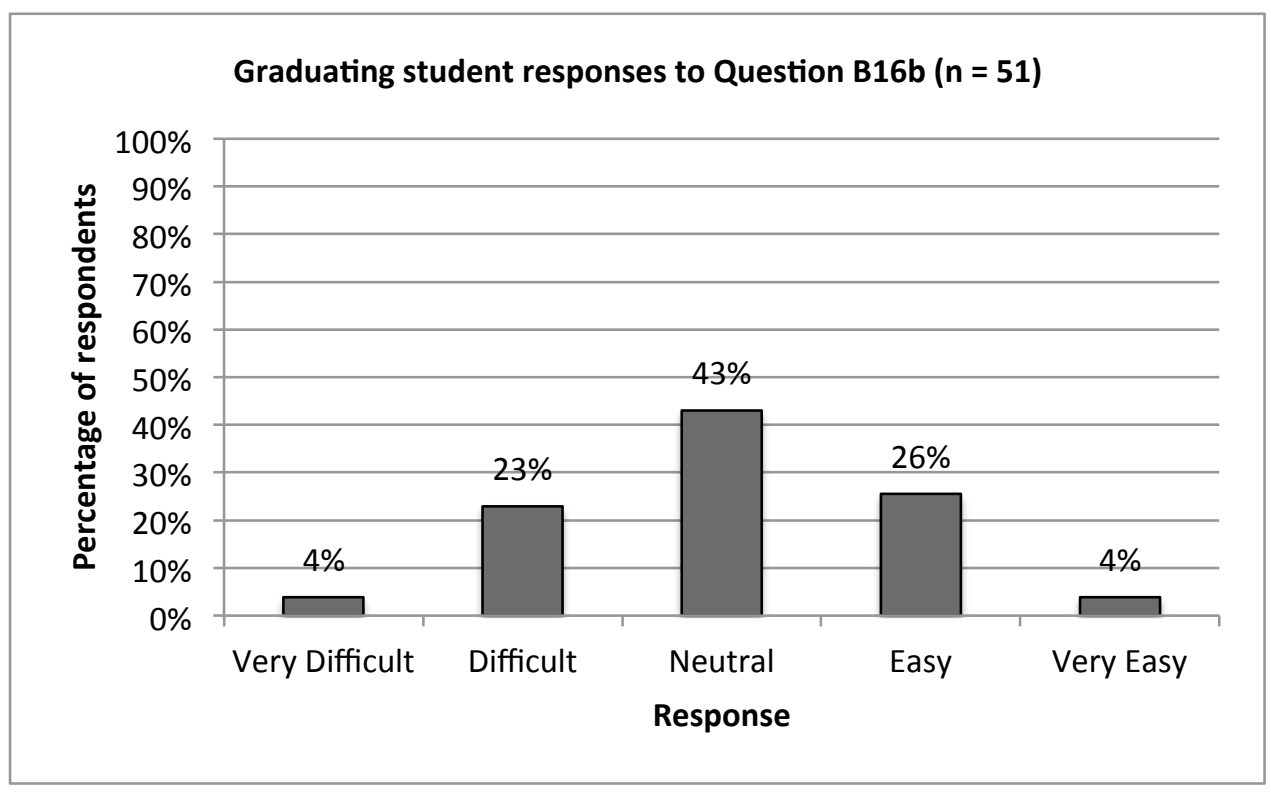

Figure 6-52: Graduating student responses to Question B16b: “How easy is virtual prototyping to use?" 


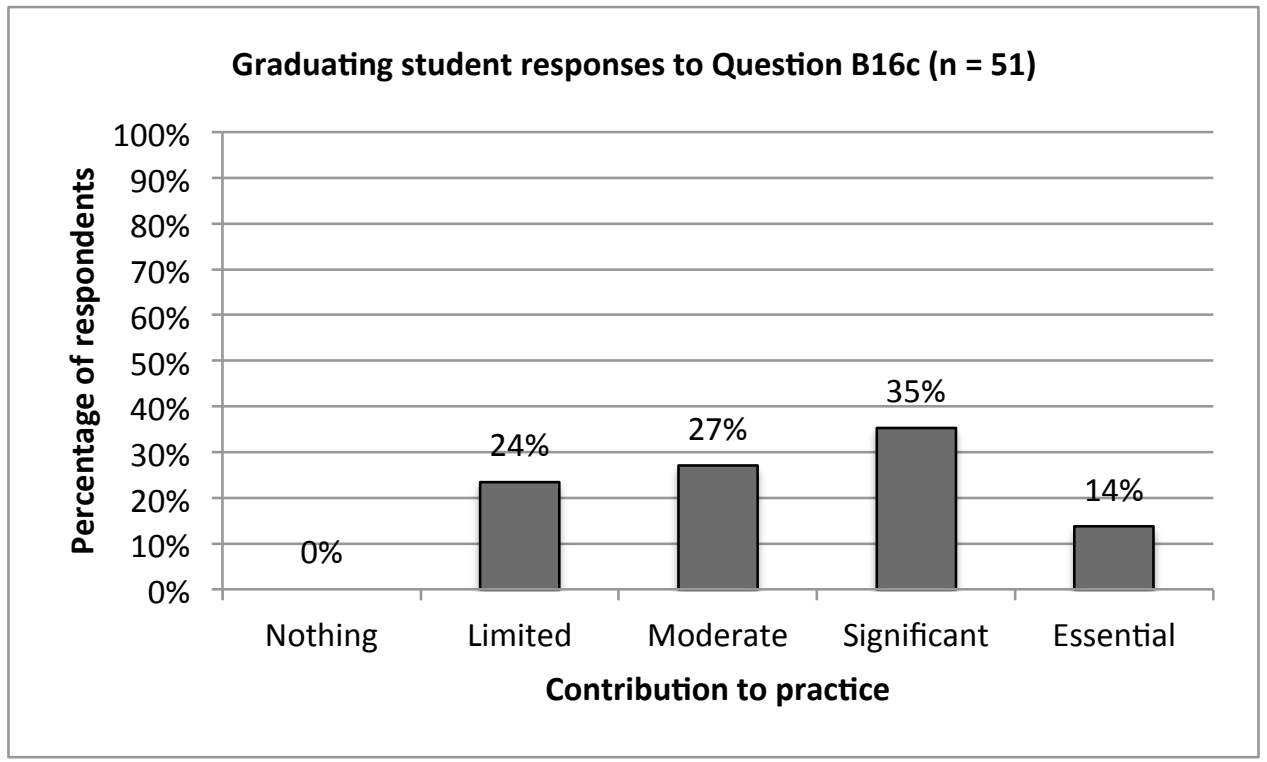

Figure 6-53: Graduating student responses to Question B16c: "How useful is virtual prototyping in making a contribution to practice?"

\subsubsection{Virtual Reality}

VR was one of the least used digital tools within the graduating student design practice as $85 \%$ never used it (Figure 6-54); 67\% of graduating students who employed it felt neutral towards using it (Figure 6-55) and $45 \%$ responded that it offered a moderate contribution to their practice (Figure 6-56).

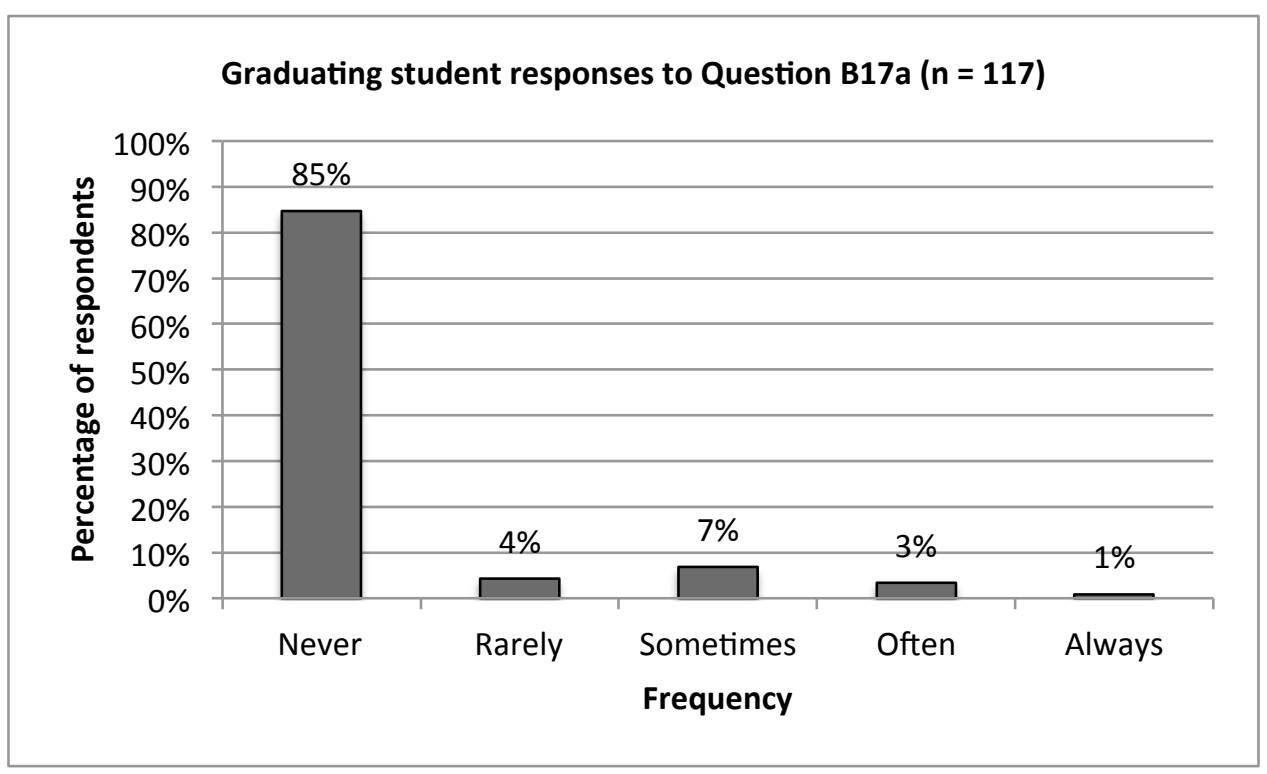

Figure 6-54: Graduating student responses to Question B17a: "How often do you use virtual reality (e.g. computer screen, Stereoscopic displays) when designing?" 


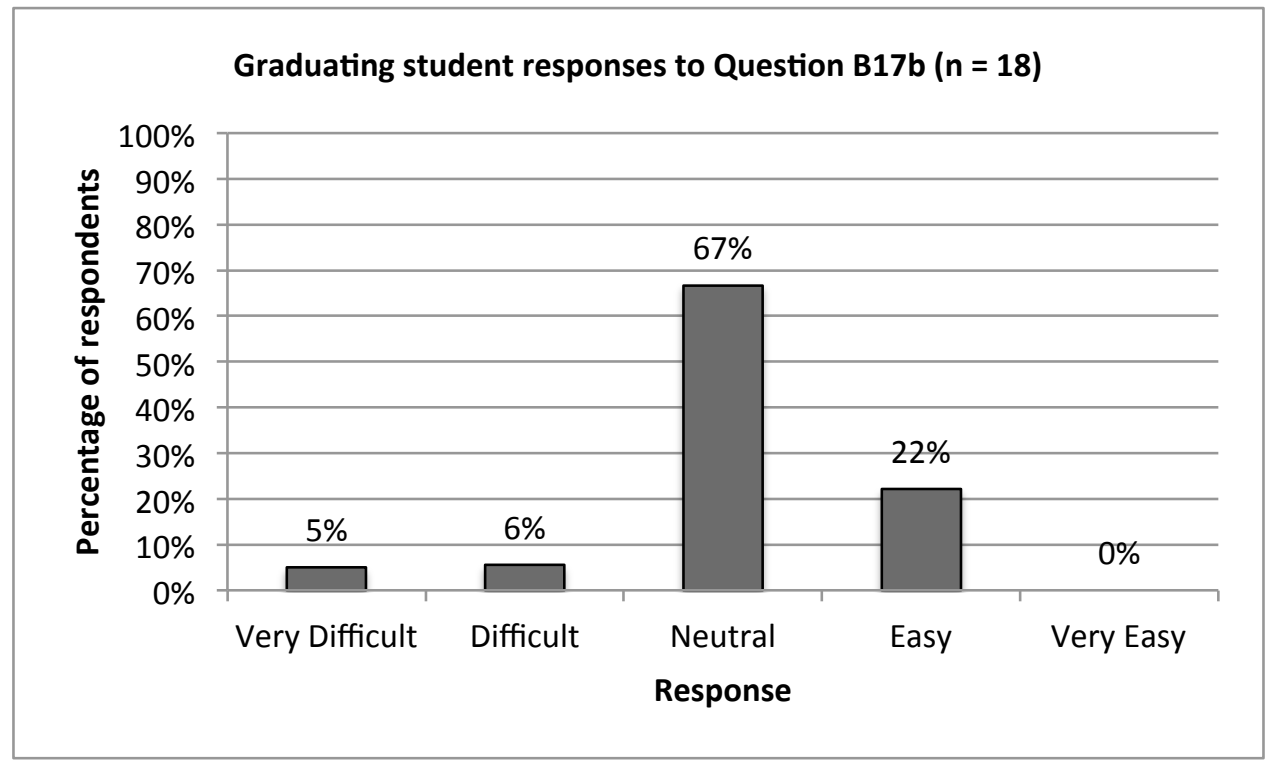

Figure 6-55: Graduating student responses to Question B17b: "How easy is virtual reality to use?"

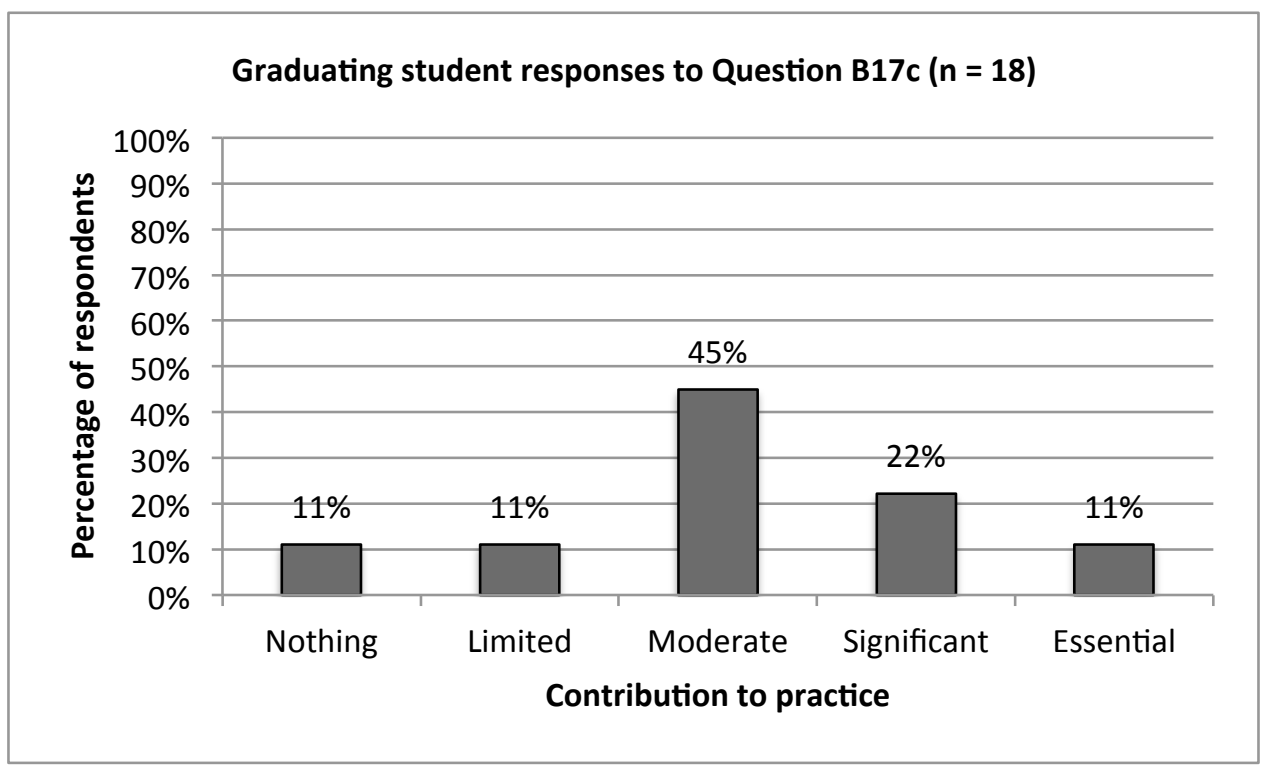

Figure 6-56: Graduating student responses to Question B17c: "How useful is virtual reality in making a contribution to practice?"

\subsubsection{Thoughts on the Digital Industrial Design Strategy}

This section of the questionnaire investigated graduating student opinions on the efficiency of the DID strategy and its potential to replace existing conventional and hybrid processes of designing. It also examined if graduating students would be interested in employing the DID strategy and provided the opportunity for graduating students to add other digital design 
tools/media to the strategy. In the open-ended questions, issues raised by the participants that occurred only once were discarded to focus on the more widely cited points.

Question C1 asked: "Do you agree or disagree that the digital industrial/product design strategy has the potential to replace the existing conventional (non-digital) and hybrid (mixture of digital and non-digital) process of designing?". Responses to this question were mainly negative with $63 \%$ stating that they disagreed/strongly disagreed and only $22 \%$ agreed/strongly agreed (Figure 6-57). The most popular reason (occurring 41 times) cited by those who strongly disagreed/disagreed was related to the absence of paper-based sketching. Many graduating students thought that paper-based techniques were quicker and easier. Other reasons included the opinion that traditional techniques would always be needed when designing (occurring 11 times) and the importance of hands-on modelling to get a better feel of the designed product (occurring 10 times). On the other hand, students with a positive reaction to the DID strategy thought that it would save time (occurring five times) and provide a more effective way of designing (occurring three times). Table 6-1 provides a breakdown of the reasons behind the responses identified by the participants.

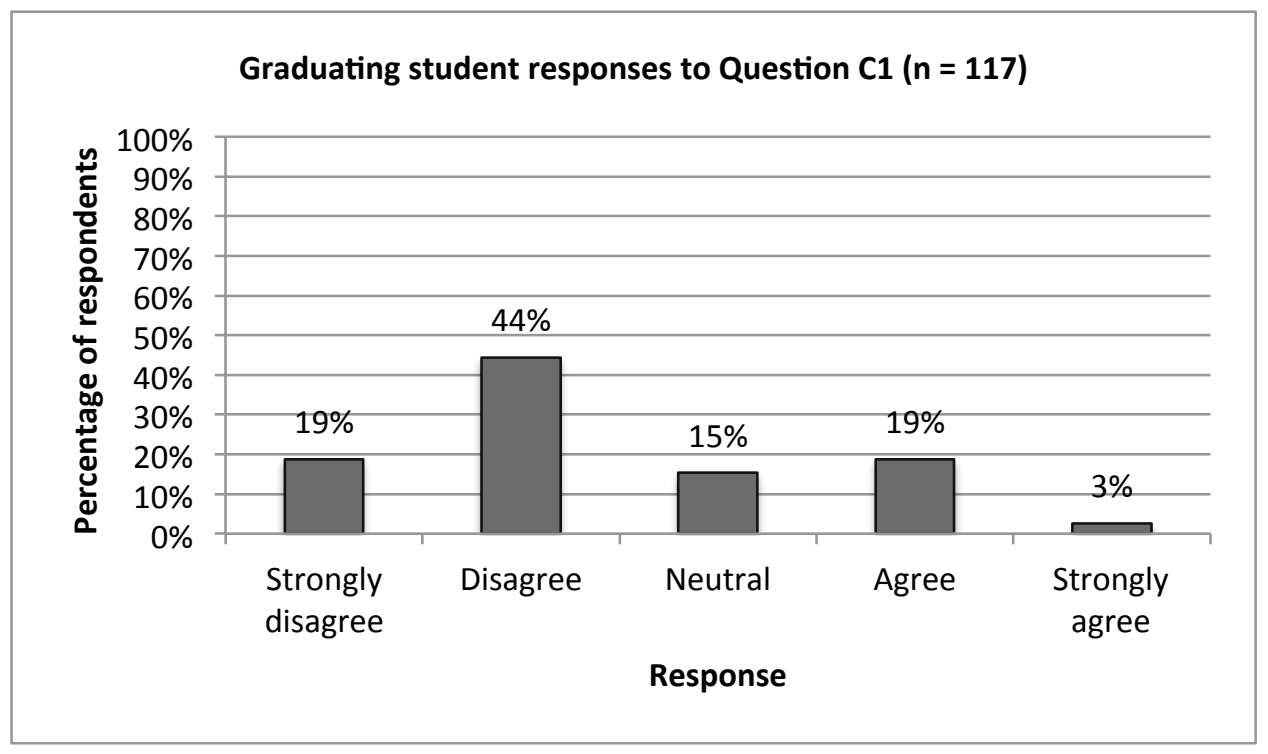

Figure 6-57: Graduating student responses to Question C1: "Do you agree or disagree that the digital industrial/product design strategy has the potential to replace the existing conventional (non-digital) and hybrid (mixture of digital and non-digital) process of designing?" 


\begin{tabular}{|c|c|c|c|}
\hline Response & \multicolumn{2}{|r|}{ Reason } & Occurrences \\
\hline \multirow{13}{*}{$\begin{array}{l}\text { Strongly } \\
\text { disagree/disagree }\end{array}$} & 1 & Conventional sketching is important, easy and quicker & 41 \\
\hline & 2 & Conventional techniques will always be needed & 11 \\
\hline & 3 & Hands-on modelling is important to get a real feel for the & 10 \\
\hline & & product & \\
\hline & 4 & Cost of digital tools & 5 \\
\hline & 5 & Design needs freedom & 5 \\
\hline & 6 & Digital tools waste time & 5 \\
\hline & 7 & Working with materials and processing personally is vital & 3 \\
\hline & 8 & Digital tools limit creativity & 2 \\
\hline & 9 & $\begin{array}{l}\text { Products have to be tested in reality through user } \\
\text { interaction }\end{array}$ & 2 \\
\hline & 10 & Sitting in front of a computer all the time is not good & 2 \\
\hline & 11 & Takes away the fundamental skill of design practice & 2 \\
\hline & 12 & Lack of experience in using digital tools & 2 \\
\hline \multirow{4}{*}{ Neutral } & 1 & Digital and non-digital processes are both important & 6 \\
\hline & 2 & Personal preference of conventional methods & 6 \\
\hline & 3 & Use of conventional methods is still a useful skill & 2 \\
\hline & 4 & $\begin{array}{l}\text { Paper-based sketching is useful and the quickest way to } \\
\text { generate concepts }\end{array}$ & 2 \\
\hline \multirow{5}{*}{$\begin{array}{l}\text { Strongly } \\
\text { agree/agree }\end{array}$} & 1 & Saves time & 5 \\
\hline & 2 & It has potential & 4 \\
\hline & 3 & $\begin{array}{l}\text { Digital technologies are very effective and give some good } \\
\text { results }\end{array}$ & 3 \\
\hline & 4 & More companies are designing digitally & 3 \\
\hline & 5 & The ease of doing modification and developing a design & 2 \\
\hline
\end{tabular}

Table 6-1: Graduating student reasons behind responses to Question C1: "Do you agree or disagree that the digital industrial/product design strategy has the potential to replace the existing conventional (non-digital) and hybrid (mixture of digital and non-digital) process of

$$
\text { designing?" }
$$

Question C2 asked: "How do you feel about the efficiency of the digital industrial/product design strategy?". Forty-five percent of graduating students responded that it was efficient/very efficient. Reasons identified were that it would save time (occurring six times) and help improve design visuals (occurring six times). Another $43 \%$ felt neutral about the DID efficiency (Figure 6-58). Table 6-2 illustrates the main reasons identified by the respondents. 


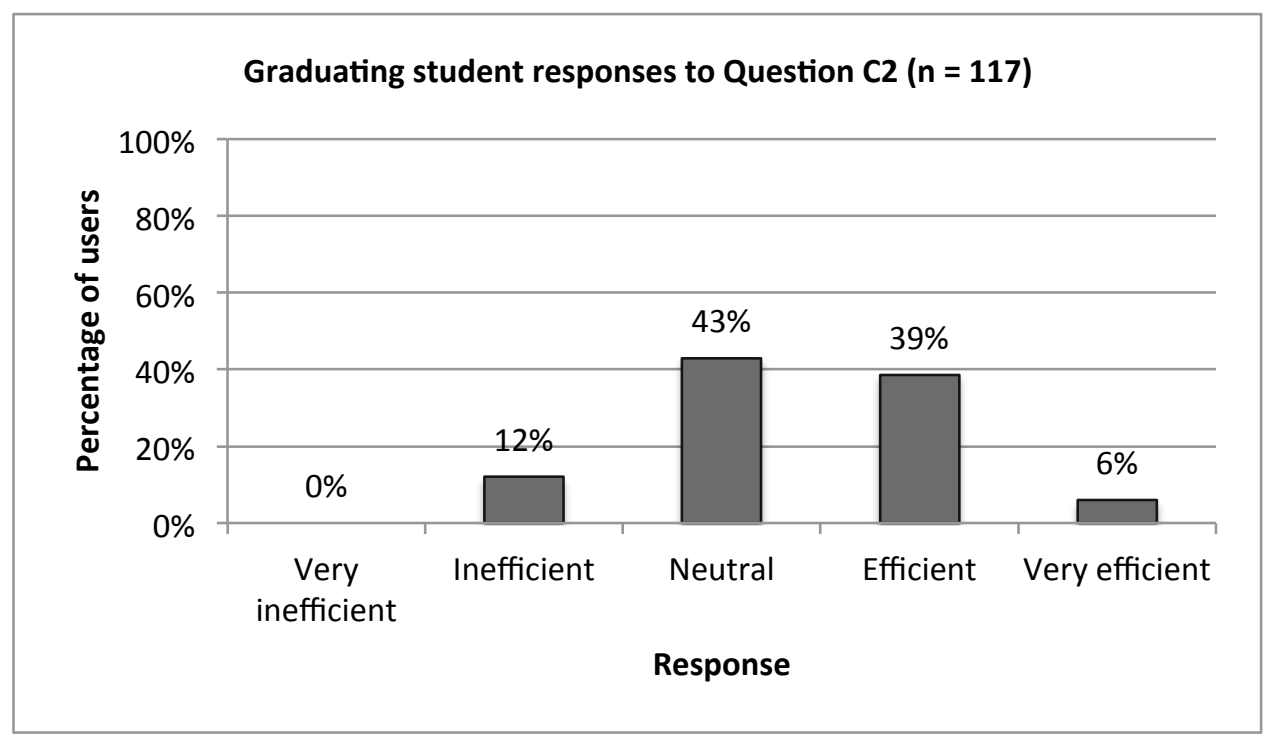

Figure 6-58: Graduating student responses to Question C2: "How do you feel about the efficiency of the digital industrial/product design strategy?"

\begin{tabular}{|l|l|l|c|}
\hline \multicolumn{1}{|c|}{ Response } & \multicolumn{1}{|c|}{ Reason } & Occurrences \\
\hline Very & 1 & Conventional sketching is important, quick and easy & 4 \\
inefficient/inefficient & 2 & Digital sketching takes a long time & 3 \\
& 3 & Computers can go wrong all the time & 2 \\
\hline & 1 & Depends on the project & 7 \\
& 2 & Slows down the design process & 4 \\
Neutral & 3 & Limits creativity & 3 \\
& 4 & Limits the options & 3 \\
& 5 & Need to trial the digital design strategy & 3 \\
& 6 & Hybrid process is better & 2 \\
& 7 & Speeds up the design process & 2 \\
\hline \multirow{5}{*}{ Very } & 1 & Provides good aesthetic and improved visuals & 6 \\
efficient/efficient & 2 & Saves time & 4 \\
& 3 & Ability to change, update and save old files & 2 \\
& 4 & Versatility of many of the computer software packages & 2 \\
& 5 & Saves money & 2 \\
\hline
\end{tabular}

Table 6-2: Graduating student reasons behind responses to Question C2: “How do you feel about the efficiency of the digital industrial/product design strategy?"

When the graduating students were asked Question C3: "Would you like to try the digital industrial/product design strategy?", 54\% replied yes (Figure 6-59). Graduating student reasons were: mainly enhancing experience (occurring 17 times), personal interests in new technologies (occurring 10 times) and to explore the affect of the DID strategy on productivity (occurring six times). The remaining $46 \%$ that did not want to try the strategy provided a range of reasons: enjoyment and importance of paper-based sketching (occurring 
13 times); personal preference of a mixture of digital and non-digital processes of designing (occurring nine times); and enjoyment of hands-on conventional approach (occurring four times). Table 6-3 illustrates the reasons behind responses to Question C3.

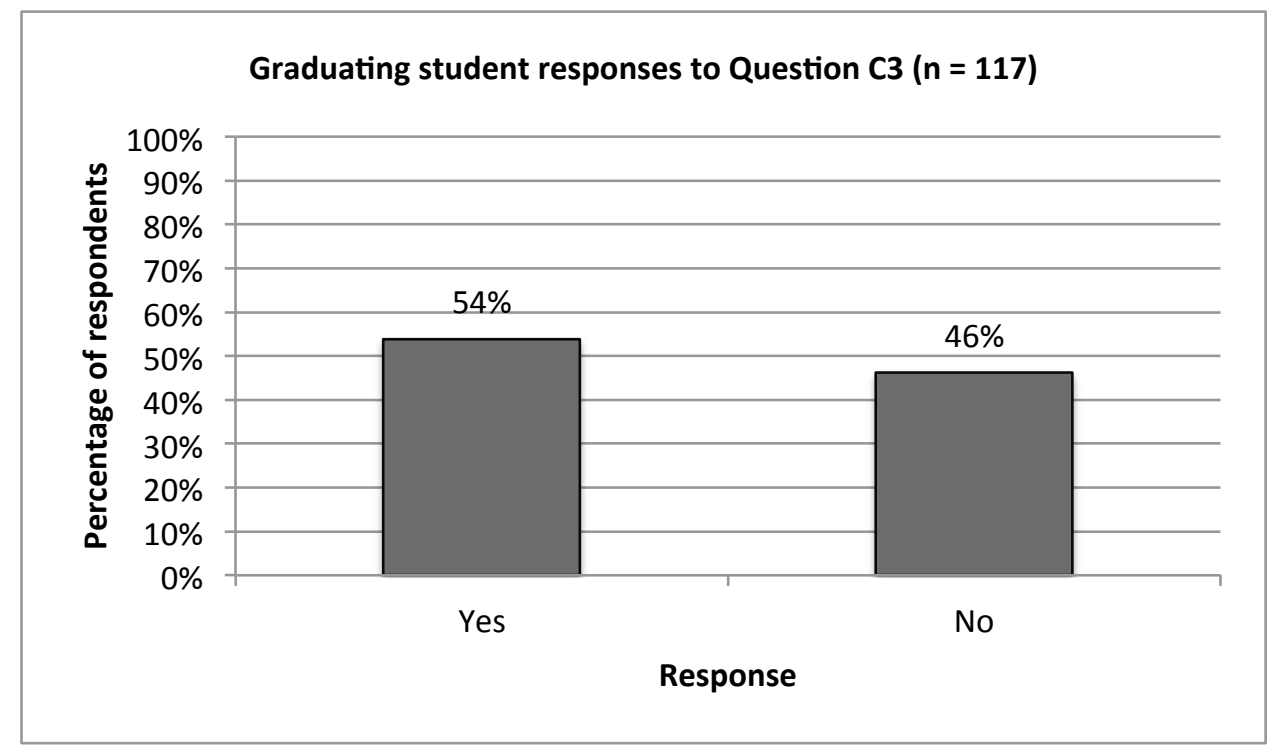

Figure 6-59: Graduating student responses to Question C3: "Would you like to try the digital industrial/product design strategy?"

\begin{tabular}{|l|l|l|c|}
\hline \multicolumn{1}{|c|}{ Response } & \multicolumn{1}{|c|}{ Reason } & Occurrences \\
\hline \multirow{4}{*}{ Yes } & 1 & $\begin{array}{l}\text { To try different methods of working and enhance } \\
\text { experience }\end{array}$ & 17 \\
& 2 & $\begin{array}{l}\text { Interested in new technologies } \\
\text { To see how it would differ and affect productivity }\end{array}$ & 10 \\
& 3 & 6 \\
& 4 & Interesting & 4 \\
& 5 & Importance of technology is undeniable & 3 \\
& 6 & Already implementing the digital strategy & 2 \\
\hline \multirow{4}{*}{ No } & 1 & Manual drawing skill is vital and enjoyable & 13 \\
& 2 & Personal preference of combination of techniques & 9 \\
& 3 & Enjoyment of hands-on methods when prototyping & 4 \\
& 4 & Finished university and about to start work & 2 \\
& 5 & Limits creativity & 2 \\
& 6 & Drawing digitally is not easy & 2 \\
& 7 & Looking at a computer screen all the time is not good & 2 \\
& 8 & Out of individual comfort zone & 2 \\
& 9 & Consumes time & 2 \\
& 10 & Reluctant to change & 2 \\
\hline
\end{tabular}

Table 6-3: Graduating student reasons behind responses to Question C3: "Would you like to try the digital industrial/product design strategy?"

The final question (C4) asked: "Are there any other digital tools/media that you would like to add to the strategy? If yes, can you please identify the tools/media?". Eleven percent of graduating students replied yes (Figure 6-60) but none of the tools mentioned occurred 
more than once. Some of the tools/media suggested by the graduating students were not digital in fact and others were already mentioned in the DID strategy such as FEA. As a result, the responses to this question were discarded.

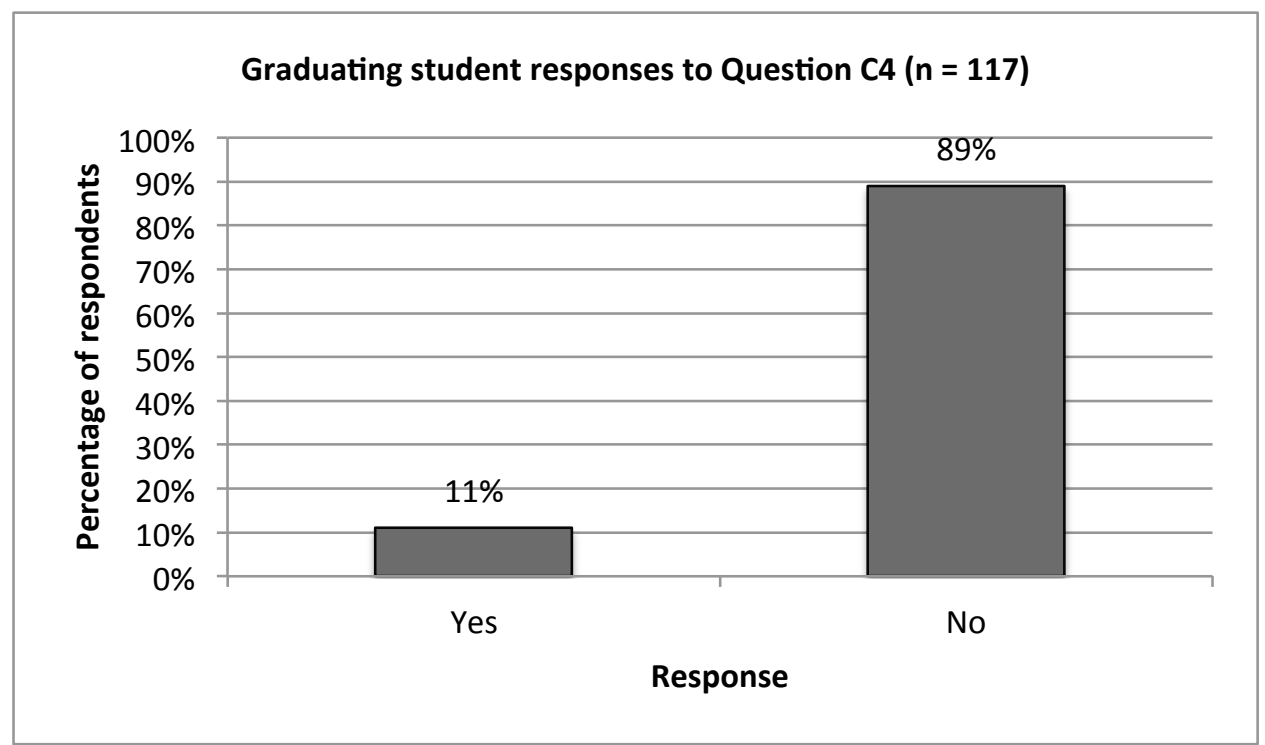

Figure 6-60: Graduating student responses to Question C4: "Are there any other digital tools/media that you would like to add to the strategy? If yes can you please identify the tools/media?"

\subsubsection{Summary of Results}

The results of the quantitative data collected from the 2008/2009 graduating student questionnaire is summarised below in Table 6-4.

\begin{tabular}{|c|c|c|c|c|c|c|}
\hline \multirow{2}{*}{\multicolumn{2}{|c|}{$\begin{array}{l}\text { QUESTION } \\
\text { B. How often do you use the following digital } \\
\text { design media/tools when designing digitally? }\end{array}$}} & \multicolumn{5}{|c|}{ RESPONSE } \\
\hline & & \multirow{2}{*}{\begin{tabular}{c|} 
Never \\
$1 \%$ \\
\end{tabular}} & \multirow{2}{*}{$\begin{array}{c}\text { Rarely } \\
3 \% \\
\end{array}$} & \multirow{2}{*}{$\begin{array}{c}\text { Sometimes } \\
8 \% \\
\end{array}$} & \multirow{2}{*}{$\begin{array}{l}\text { Often } \\
33 \% \\
\end{array}$} & \multirow{2}{*}{$\begin{array}{r}\text { Always } \\
55 \% \\
\end{array}$} \\
\hline $1 \mathrm{a}$ & 2D mouse & & & & & \\
\hline $2 a$ & Pen input device & $66 \%$ & $15 \%$ & $13 \%$ & $5 \%$ & $1 \%$ \\
\hline $3 a$ & Digitising tablet without a built-in display & $51 \%$ & $9 \%$ & $22 \%$ & $15 \%$ & $3 \%$ \\
\hline $4 a$ & $\begin{array}{l}\text { Digitising tablet with an interactive pen } \\
\text { display }\end{array}$ & $79 \%$ & $7 \%$ & $8 \%$ & $6 \%$ & $0 \%$ \\
\hline $5 a$ & 2D visualisation software & $6 \%$ & $1 \%$ & $7 \%$ & $37 \%$ & $49 \%$ \\
\hline $6 a$ & 3D mouse & $85 \%$ & $3 \%$ & $7 \%$ & $4 \%$ & $1 \%$ \\
\hline $7 a$ & 3D scanning/RE & $73 \%$ & $17 \%$ & $5 \%$ & $3 \%$ & $2 \%$ \\
\hline $8 a$ & 3D CAD (surface and solid) & $3 \%$ & $3 \%$ & $10 \%$ & $34 \%$ & $50 \%$ \\
\hline $9 a$ & Haptic modelling & $87 \%$ & $7 \%$ & $4 \%$ & $1 \%$ & $1 \%$ \\
\hline $10 a$ & Polygon modelling & $50 \%$ & $11 \%$ & $18 \%$ & $14 \%$ & $7 \%$ \\
\hline $11 a$ & 2D CAD & $19 \%$ & $22 \%$ & $23 \%$ & $25 \%$ & $11 \%$ \\
\hline $12 a$ & CNC (2D) & $12 \%$ & $14 \%$ & $40 \%$ & $26 \%$ & $8 \%$ \\
\hline $13 a$ & Rendering/animation & $17 \%$ & $14 \%$ & $20 \%$ & $29 \%$ & $20 \%$ \\
\hline $14 a$ & $\mathrm{RP}$ & $14 \%$ & $14 \%$ & $32 \%$ & $31 \%$ & $9 \%$ \\
\hline $15 a$ & CNC (3D) & $33 \%$ & $15 \%$ & $29 \%$ & $20 \%$ & $3 \%$ \\
\hline $16 a$ & VP & $56 \%$ & $18 \%$ & $9 \%$ & $15 \%$ & $2 \%$ \\
\hline $17 a$ & VR & $85 \%$ & $4 \%$ & $7 \%$ & $3 \%$ & $1 \%$ \\
\hline
\end{tabular}




\begin{tabular}{|c|c|c|c|c|c|c|c|c|}
\hline \multirow{2}{*}{\multicolumn{2}{|c|}{$\begin{array}{l}\text { QUESTION } \\
\text { B. How easy is it to use the following digital } \\
\text { medial/tool? }\end{array}$}} & \multicolumn{7}{|c|}{ RESPONSE } \\
\hline & & $\begin{array}{c}\begin{array}{c}\text { Very } \\
\text { difficult }\end{array} \\
1 \% \\
\end{array}$ & $\begin{array}{l}\text { Difficult } \\
2 \%\end{array}$ & \multicolumn{2}{|c|}{ Neutral } & $\begin{array}{l}\text { Easy } \\
36 \%\end{array}$ & \multicolumn{2}{|c|}{$\begin{array}{c}\text { Very easy } \\
42 \% \\
\end{array}$} \\
\hline $2 b$ & Pen input device & $3 \%$ & $23 \%$ & \multicolumn{2}{|l|}{$32 \%$} & $37 \%$ & \multicolumn{2}{|c|}{$5 \%$} \\
\hline $3 b$ & Digitising tablet without a built-in display & $2 \%$ & $24 \%$ & \multicolumn{2}{|l|}{$26 \%$} & $32 \%$ & \multicolumn{2}{|r|}{$16 \%$} \\
\hline $4 \mathrm{~b}$ & $\begin{array}{l}\text { Digitising tablet with an interactive pen } \\
\text { display }\end{array}$ & $0 \%$ & $8 \%$ & \multicolumn{2}{|l|}{$28 \%$} & $60 \%$ & \multicolumn{2}{|r|}{$4 \%$} \\
\hline $5 b$ & $2 \mathrm{D}$ visualisation software & $1 \%$ & $3 \%$ & \multicolumn{2}{|l|}{$23 \%$} & $49 \%$ & \multicolumn{2}{|r|}{$24 \%$} \\
\hline $6 b$ & 3D mouse & $5 \%$ & $17 \%$ & \multicolumn{2}{|l|}{$28 \%$} & $39 \%$ & \multicolumn{2}{|r|}{$11 \%$} \\
\hline $7 \mathrm{~b}$ & 3D scanning/RE & $3 \%$ & $29 \%$ & $39 \%$ & & $23 \%$ & \multicolumn{2}{|r|}{$6 \%$} \\
\hline $8 \mathrm{~b}$ & 3D CAD (surface and solid) & $1 \%$ & $14 \%$ & $26 \%$ & & $44 \%$ & & $15 \%$ \\
\hline $9 b$ & Haptic modelling & $13 \%$ & $33 \%$ & $47 \%$ & & $7 \%$ & & $0 \%$ \\
\hline $10 \mathrm{~b}$ & Polygon modelling & $7 \%$ & $24 \%$ & $46 \%$ & & $18 \%$ & & $5 \%$ \\
\hline $11 \mathrm{~b}$ & 2D CAD & $0 \%$ & $14 \%$ & $25 \%$ & & $39 \%$ & & $22 \%$ \\
\hline $12 \mathrm{~b}$ & CNC (2D) & $0 \%$ & $7 \%$ & $40 \%$ & & $35 \%$ & & $18 \%$ \\
\hline $13 \mathrm{~b}$ & Rendering/animation & $4 \%$ & $21 \%$ & $33 \%$ & & $28 \%$ & & $14 \%$ \\
\hline $14 \mathrm{~b}$ & $\mathrm{RP}$ & $1 \%$ & $5 \%$ & $39 \%$ & & $43 \%$ & & $12 \%$ \\
\hline $15 \mathrm{~b}$ & CNC (3D) & $1 \%$ & $9 \%$ & $51 \%$ & & $34 \%$ & & $5 \%$ \\
\hline $16 \mathrm{~b}$ & VP & $4 \%$ & $23 \%$ & $43 \%$ & & $26 \%$ & & $4 \%$ \\
\hline $17 \mathrm{~b}$ & VR & $5 \%$ & $6 \%$ & $67 \%$ & & $22 \%$ & & $0 \%$ \\
\hline & QUESTION & & & RESPONS & & & & \\
\hline $\begin{array}{l}\text { B. } \mathrm{r} \\
\text { me }\end{array}$ & $\begin{array}{l}\text { w useful are the following digital } \\
\text { a/tools? }\end{array}$ & Nothing & Limited & Moderat & & Significant & & ssential \\
\hline $1 \mathrm{c}$ & 2D mouse & $1 \%$ & $5 \%$ & $29 \%$ & & $33 \%$ & & $32 \%$ \\
\hline $2 c$ & Pen input device & $3 \%$ & $35 \%$ & $37 \%$ & & $20 \%$ & & $5 \%$ \\
\hline $3 c$ & Digitising tablet without a built-in display & $2 \%$ & $30 \%$ & $28 \%$ & & $28 \%$ & & $12 \%$ \\
\hline $4 c$ & $\begin{array}{l}\text { Digitising tablet with an interactive pen } \\
\text { display }\end{array}$ & $4 \%$ & $16 \%$ & $72 \%$ & & $8 \%$ & & $0 \%$ \\
\hline $5 c$ & 2D visualisation software & $0 \%$ & $2 \%$ & $11 \%$ & & $38 \%$ & & $49 \%$ \\
\hline $6 c$ & 3D mouse & $5 \%$ & $28 \%$ & $56 \%$ & & $11 \%$ & & $0 \%$ \\
\hline 7c & 3D scanning/RE & $10 \%$ & $39 \%$ & $19 \%$ & & $22 \%$ & & $10 \%$ \\
\hline $8 c$ & 3D CAD (surface and solid) & $0 \%$ & $1 \%$ & $17 \%$ & & $31 \%$ & & $51 \%$ \\
\hline $9 c$ & Haptic modelling & $13 \%$ & $53 \%$ & $20 \%$ & & $7 \%$ & & $7 \%$ \\
\hline $10 c$ & Polygon modelling & $12 \%$ & $10 \%$ & $37 \%$ & & $24 \%$ & & $17 \%$ \\
\hline $11 \mathrm{c}$ & 2D CAD & $1 \%$ & $24 \%$ & $28 \%$ & & $27 \%$ & & $20 \%$ \\
\hline $12 c$ & CNC (2D) & $1 \%$ & $12 \%$ & $36 \%$ & & $36 \%$ & & $15 \%$ \\
\hline $13 c$ & Rendering/animation & $2 \%$ & $10 \%$ & $26 \%$ & & $31 \%$ & & $31 \%$ \\
\hline $14 \mathrm{c}$ & $\mathrm{RP}$ & $0 \%$ & $8 \%$ & $27 \%$ & & $42 \%$ & & $23 \%$ \\
\hline $15 c$ & CNC (3D) & $0 \%$ & $16 \%$ & $33 \%$ & & $38 \%$ & & $13 \%$ \\
\hline $16 c$ & VP & $0 \%$ & $24 \%$ & $27 \%$ & & $35 \%$ & & $14 \%$ \\
\hline $17 \mathrm{c}$ & VR & $11 \%$ & $11 \%$ & $45 \%$ & & $22 \%$ & & $11 \%$ \\
\hline & QUESTION & & & & & RESPONSE & & \\
\hline $\begin{array}{l}\text { C1. } \\
\text { has } \\
\text { (mi }\end{array}$ & $\begin{array}{l}\text { o you agree or disagree that the digital ind } \\
\text { he potential to replace the existing conven } \\
\text { ure of digital and non-digital) process of d }\end{array}$ & $\begin{array}{l}\text { /product } \\
\text { (non-digit } \\
\text { g? }\end{array}$ & $\begin{array}{l}\text { n strategy } \\
\text { id hybrid }\end{array}$ & 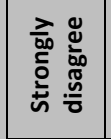 & 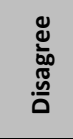 & $\begin{array}{l}\overline{0} \\
\overline{2} \\
\overline{0} \\
2\end{array}$ & 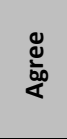 & 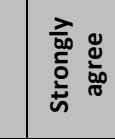 \\
\hline & & & & $19 \%$ & $44 \%$ & \begin{tabular}{l|l}
$15 \%$ \\
\end{tabular} & $19 \%$ & $3 \%$ \\
\hline & QUESTION & & & & & RESPONSE & & \\
\hline $\begin{array}{l}\text { C2. } \\
\text { stra }\end{array}$ & $\begin{array}{l}\text { ow do you feel about the efficiency of the } \\
\text { egy? }\end{array}$ & industrial & duct design & 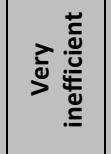 & 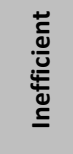 & $\begin{array}{l}\bar{\pi} \\
\stackrel{0}{\frac{2}{3}} \\
\frac{0}{2}\end{array}$ & 蒙 & 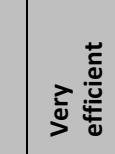 \\
\hline & & & & $0 \%$ & $12 \%$ & $43 \%$ & $39 \%$ & \begin{tabular}{l|l} 
& $6 \%$ \\
\end{tabular} \\
\hline & & IION & & & & & RES & SPONSE \\
\hline & Jould you like to try the digital industrial & & & & & & Yes & No \\
\hline & oula you iाke to try the aigital industrial/p & aesign si & & & & & $54 \%$ & $46 \%$ \\
\hline & & IION & & & & & RES & SPONSE \\
\hline & re tnere any otner algital tools/meala tn & & to the str & & & & Yes & No \\
\hline & 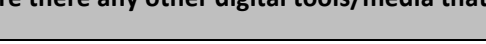 & 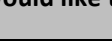 & 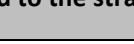 & & & & $11 \%$ & $89 \%$ \\
\hline
\end{tabular}

Table 6-4: Summary of the closed-ended questions responses used in the 2008/2009 graduating student questionnaire 


\subsection{Academic and Practitioner Feedback on the Digital Industrial Design Strategy}

In order to test the validity of the DID strategy, interviews were carried out with practitioners and academics. The aims of the interviews were to identify the initial views on designing digitally; explore thoughts on DID strategy; establish any reservations; and suggest ways to improve it. Also, to identify reasons for not utilising each digital design tool/media employed within the strategy.

A total of 17 participants (eight industrial design practitioners and nine industrial design academics) participated in the interviews after piloting. The interviews were recorded, with the exception of two where the industrial designers objected for reasons of confidentiality. Notes were therefore taken during those interviews and the information was double checked with the interviewees to make sure that the correct response was captured. The recorded, face-to-face, semi-structured interviews were transcribed and the data was inserted in NVivo 9 software which was used to assist in the analysis of the qualitative data. Codes were used to identify the participants (Appendix 11.5). An example of practitioner interviews is illustrated in Appendix 11.6 and an example of academic interviews is given in Appendix 11.7. The academic responses were examined separately from the practitioner interviews data to discover any differences between the two groups opinions and practices.

\subsubsection{Interviewees Experience}

The eight practitioners interviewed varied in their design experience, with one person designing for five years (minimum years of experience amongst the practitioners) and most designing for over 20 years, with the maximum number of years experience being 39 years. The interviews generated responses from different parts of the world (one practitioner based in America, one based in Sweden and six based in the UK). Three of the practitioners worked in their own design consultancies while others worked in well-known design organisations. The areas covered by the designers were broad, such as safety, fitness, medical and consumer electronics.

All of the academics interviewed had at least eight years experience teaching industrial design and eight out of the nine had some industrial experience before joining their universities to teach. The majority of the academics taught in UK universities, with two in 
the United States and one in Australia. One of the nine academics was the head of an Industrial Design Department and another was the Course Director for Industrial Design.

\subsubsection{Tools/Media Used within Design Practice}

After asking the interviewees about their experience, Question 2 asked the practitioners: "Can you describe how non-digital and digital tools/media are used in your design practice?". One participant cited the use of web blogging, search engines, online interviews and face-to-face interviews to find existing knowledge before starting to generate the concepts. All of the interviewees mentioned the use of paper-based sketching or white board sketching to generate concepts and most cited the use of 2D visualisation software such us Illustrator or Photoshop in this phase. For some, concept generation involved making workshop-based mock up models out of foam or card; but for others it involved the use of 3D CAD. One designer explained:

- "More and more there is a requirement to get into CAD sooner. So I have to. You know, very often I have to get into CAD sooner than you would really want." (ID-P4)

Another practitioner highlighted that the design company he worked for had been working on using a digital tool to store ideas. The digital tool should act as a catalogue of the unused concepts due to limitation of funding or materials in order to reuse them, possibly when the issues get resolved in the future. To store the ideas, all the unused ideas must be scanned first. This extra task would not be needed if the concepts were sketched digitally.

In the development phase of the design process, practitioners mentioned the use of workshop-based models to test ideas; 2D CAD for packaging; 3D CAD; and on some occasions the use of RP and CNC machining to produce a physical prototype.

The specification phase involved specifying the model using 3D CAD software and sending it to vendors to make a model or producing prototypes using in-house RP and CNC machining.

In terms of student design practice, few academics mentioned the research phase before concept generation. Digital and conventional techniques such as video and paper-based drawing were used in this phase to provide insight into a particular context. As with the practitioners, all of the academics mentioned the use of paper-based sketching as the main activity in concept generation. One academic explained a particular strategy employed by students: 
- "They use pen and paper in their sketching quite a lot. And after that they will scan it and put it in the computer and they enhance it, you know, clean it up. We call it the clean up." (ID-A3)

The use of 2D visualisation software was also apparent in student design practice. Three academics talked about the use of digitising tablets without a built-in display while one academic cited the use of a digitising tablet with an interactive pen display (Cintiq) within student design practice. Furthermore, some academics noted the use of line work software (Vellum); 3D CAD; and workshop-based mock ups in the concept generation phase.

3D CAD software and workshop-based models were used mainly in the development phase and a small number of academics cited the use of animation and digital models by employing RP and CNC machining.

In professional design practice the entire specification phase was digitalised, but student design practice seemed to take a more hybrid approach through the use of workshop-based modelling and digital modelling (RP and CNC machining):

- "Some components within the final object might be produced using the rapid prototyping facilities but on the whole, an awful lot is still produced manually using milling machines, lathes, hand fettling stuff." (ID-A8)

Several academics emphasised the importance of workshop-based modelling compared to RP:

- "Normally, if someone had has some kind of manual, non-digital input into that, you think very carefully before you go from one to that one, because you invest your time in that thing." (ID-A2)

- 'So what we try to do again is we want to build the students' skill set so that they actually know how to use these 10 digits and so we still emphasise model making." (ID-A4)

Regarding RP, a number of interviewees said that it was mainly used for research purposes in the beginning then had been employed by more mature students as the price dropped:

- "Rapid Prototyping is a sort of developing thing as we bought the equipment. We bought some low cost Rapid Prototyping equipment and in the early days of it, that was some years ago, the cost of the material...you know, meant that it was not open 
to undergraduate students because we could not afford to do it. Really, it was...we were trying to encourage industry to use our Rapid Prototype machine. I think the maintenance cost was $£ 10,000$ a year, just to have the thing checked out. So, that was not open to the students. But, obviously, as the years have gone by and we now have machines that are open to the students, but not in the first year, to my knowledge." (ID-A2)

- "We do have rapid prototyping tools but they are kind of kept away from that in early stages. So, with the hope that when they do come to use that, it will be in an informed way." (ID-A2)

Similar to the practitioner design practice, student design practice was mainly hybrid during the concept generation phase. However, differences appeared as they progressed, with the practitioners increasing the use of digital to reach a completely digital state in the specification phase, while students continued to have more of a hybrid process through all phases.

\subsubsection{Initial Thoughts on Designing Digitally}

Before showing the DID strategy to participants, practitioners were asked: "What are your thoughts on designing using digital tools/media only?" and academics were asked: "What are your thoughts on students designing using digital tools/media only?". A mix of positive, negative and neutral responses was generated.

One of the main concerns about having a completely digital process was the loss of the sense of scale when designing digitally:

- "You get surprised by the scale, for example, when you take things out of the digital world and the real world." (ID-P5)

Another point mentioned was constraints caused due to the limitation of the knowledge of using the digital tools and the restrictions of the tools themselves. Few practitioners revealed that not having any conventional tools within the design process would reduce the opportunity for creative enrichment and would make the process dull. A small number of practitioners also highlighted the importance of physicality when designing:

- "Working in three dimensions physically allows you to look at things in a way that you do not really see them on a screen." (ID-P5)

- "I do not think there is any substitute for the real experience." (ID-P6) 
- "Haptic technology is fine for replicating what has already been thought of. It is not part of the creative process. It is not enriching the creative process. It will make what has been previously thought of but it does not feed, in real time simultaneity, the ideas as they come through the making because the time lag is too slow. And it can only have one user at a time." (ID-P6)

One practitioner thought that the feasibility of designing digitally depends on the generation you were educated in:

- "I am a digital immigrant. I grew up without any digital tools. I started my career without any digital tools. It was half way through my career that digital tools came into play. You [author], on the other hand, from the day you were born digital tools were available. From the day you started school digital tools were available. So you are the digital native." (ID-P1)

Some practitioners expressed their excitement and willingness to convert to a completely digital design process:

- "I cannot wait. I would love to just be able to do it." (ID-P3)

- "I can see a time where you just have a digital pad and what you create is in a digital format. So I am completely at home with that because you are still sketching something immediately, getting your ideas down. So I would be happy with that." (ID-P4)

In terms of students using a completely digital design process, some academics felt that it could be limiting because of the difficulty faced in realising 3D objects and the importance of a mixed method approach. The success of implementing the DID strategy with students would depend on their ability to use the software:

- "I really doubt if they can achieve a sense of 3-dimension with just digital tools because I think a lot of times if you can not touch it, if you can not manipulate it with your hands I really doubt if you can actually feel it." (ID- A3)

- "I cannot train a student to go out into the real world and assume that they are going to be in the optimum position where they are working for a firm that has three or four CAD softwares, has two or three RP machines or has a full-time model maker there." (ID-A4) 
- "I see it as being very restrictive for undergraduate students when they do not necessarily have the skills. So I am still a firm believer that students need a grounding and an understanding of form and how things work before or alongside gaining the digital skills to then be able to apply them." (ID-A1)

Some academics felt that designing using digital techniques only would depend on the student design skills; ability to use digital tools; and the project undertaken. Furthermore, the feeling that a fully digital design process with students could be viewed as being positive and negative was agreed on by a number of academics:

- "It is very limiting, but then of course, it opens up new possibilities to actually configure things that we could not do prior to them, so it is a double-edged problem." (ID-A7)

- "I think there is an awful lot of flexibility offered by that sort of process. But I also think the pitfall might be that the students are convinced, perhaps, by the quality of the look of their line work rather than the content, of the thinking involved... Style over content." (ID-A8)

The same academic felt that it is the concept stage that would be difficult with the use digital tools only. He clarified this point by saying that:

- "Unless you are in control of the software, then actually it is better to take your pen and draw and work things out on paper, because you can work far more quickly, you can produce more options more quickly." (ID-A8)

- "So I think once you get past that first concept stage, I think the digital work is a prerequisite, in many ways. I think you may, with that first stage, I think it will be some time before anybody chooses to put their pen down." (ID-A8)

Positive feedback was obtained from a number of academics:

- "As long as there is some physical [models and prototypes produced using RP and CNC machines], and it is not just onscreen, then yes, I think that is great." (ID-A5)

Another academic thought that a completely digital process for student design practice would be very suitable if the tools allowed them to express their thinking effectively:

- "As long as they do not rely on these tools as a crutch to hide their own thinking or to shy away from really testing an idea out, so long these tools do not slow them 
down in their development process in carrying ideas through and investigating them, then it could be incredibly appropriate." (ID-A6)

\subsubsection{Thoughts on the Digital Industrial Design Strategy}

An A3 visual aid card that illustrated the DID strategy was presented to industrial design practitioners and academics for review during the interviews. The card was similar to the one used in the 2008/2009 graduating student supervised collective questionnaire (Figure 6-5). The feedback regarding the DID strategy generated mixed responses from practitioners and academics that could be grouped into positive and negative thoughts.

A number of participants thought that the DID strategy was carefully thought through:

- "In principle it looks well considered." (ID-P8)

- "Overall it seems like a fairy logical approach to doing what people have been doing for many, many years but in a total digital environment." (ID-P1)

- "This looks like a good description of the digital tools that are available to support the various stages of concept generation, development and specification." (ID-A6)

- "I think it [DID strategy] is a picture of possible ways to do it. Indeed I think it is a good picture of different options you have as it is today." (ID-P2)

One practitioner expressed enthusiasm towards the strategy, especially as the design process would then flow easily between coming up with concepts, developing them and finally specifying the design for manufacturing:

- "I think it is a great idea, going digitally, creating your ideas, developing it and then manufacturing it." (ID-P3)

Some academics expressed interests in the DID strategy:

- "It would be interesting to see if it could be implemented and I believe in a lot of the programmes, a lot of them [digital tools/media] actually have been implemented." (ID-A3)

- "It would be really interesting to monitor. I think there are some other benefits as well because I think the way the world is going, more people, students, have access to media creation technology whether it is the tablets or the SolidWorks or HyperShot or Maxwell or whatever, and I think they are doing more mature presentation work earlier in the process. I think certainly this year, I am more aware 
than I have been that actually, there are people in the big wide world that do not look past that." (ID-A8)

The speed and ease of employing digital techniques was a key reason for the positive responses:

- "It is the quick, easier way to go. It is more immediate gratification because technology in general, not just these kinds of digital tools, bring everything into focus instantly." (ID-P1)

- "The digital gives you some options there that the analogue does not, which is the speed at which you can go back to the concept." (ID-A7)

Designing digitally would support the globalisation and collaboration between members of the NPD team. It would also increase efficiency by assuring that the data sent to the manufacturers was correct:

- "I just watched a presentation on globalisation of design and how people in different parts of the world were working on elements of a rapid prototype and have it. And so, because everyone in the partnership could hold up these things, they discovered what looked great in the digital world... And also, in terms of the manufacturing, a lot of manufacturing happens in the Far East. That is as a way of ensuring that what you send is correct." (ID-A2)

Another academic suggested that if an expert rather than a novice employed the DID strategy, it could enhance elements of the design process and speed it up:

- "For certain aspects of design, it does enhance. It can help you to get there more quickly. But I still think, when carried out by somebody who is expert, has a certain level of expertise." (ID-A2)

The feedback from some academics also suggested that the DID strategy would be more suitable for mature students who are adept and skilled with 3D visualisation.

- "If this strategy was at the third or the forth year, I would say it is a great strategy." (ID-A4)

It was felt that the strategy would help students with poor hands-on model making skills: 
- "I am sure a lot of students probably would be happy to switch to this model because some people are intimated by the shop [workshop]. They are not very good working with their hands-on." (ID-A3)

One designer and owner of a small design firm pointed out that the DID strategy is only suitable for big design organisations:

- "I think it sounds as though it is suitable for large organisations. It is more difficult to do all that in a small organisation." (ID-P5)

The same practitioner felt that the cost of all the digital tools and media used within the strategy and having to rely on other people to use the technology were responsible for thoughts on stepping back from the strategy:

- "What I could not afford to do is lots of different software and lots of different hardware as a small organisation. I would be relying on other people and that is something that I step back from, relying on other people." (ID-P5)

The issue of cost was also raised by the academics responsible for managing budgets:

- "From an administrative point of view, it is really also a cost problem that I would have to have a lot of staff actually, taking care of all those machines." (ID-A3)

Some practitioners expressed their concerns about limitation of concept generation when designing using digital techniques compared to using pen and paper:

- "Right now, you know, there is the Cintiq, there is Wacom tablet and you will have to do a fair bit of training to get quite good on them, you know, get used to that. So really there is nothing here that is as good as pen and paper for getting you initial ideas down." (ID-P4)

- "You are limited only by your knowledge to the tool and the limits of the tool. And when it comes to drawing [paper-based sketching] you have zero limits more or less." (ID-P2)

One practitioner suggested that paper-based sketching offered designers the opportunity to personalise their sketch compared to digital sketching that offered the same tools to everyone. 
- "You could always tell whose sketch [paper-based sketches] was whose because everyone had a personal style. With the digital tools in many ways have created parody among the way things happen because everyone has access to that exact same ellipse tool. There is no distinct personality in that ellipse tool. It is the tool provided by the software. Whereas old school people based upon the selection of the tool you picked, and not that you cannot vary line weight with a digital tool, but there was just something more personal about it." (ID-P1)

While some interviewees had issues with a completely digital concept generation phase, one academic did not:

- "I do not have a problem with you having a concept generation phase all digital." (ID-A3)

Haptic modelling was a source of disagreement between the participants. While some believed in its capabilities in providing the user with tactile feedback, others felt that it was just a waste of time:

- "We have used haptic modelling with companies where we have done prototyping of mobile phones where we could actually create the geometry and the software, the UI [user interface], in a haptic model and then bring in users for usability testing. So I have found that to be an interesting tool for speeding up things because, by the time you build a functional prototype, you are really far down the path of development and you have got a lot of money wrapped up into it." (ID-P1)

- "I think we are still at a stage now where that real tactile, 3D experience about assemblies and form still is not good enough in a digital environment to replace what is the real world." (ID-A1)

One academic was not aware of haptic feedback devices:

- "It requires a lot of equipment for one thing, but you know, I have never heard of this haptic modelling." (ID-A3)

Some interviewees had concerns about the rigidity of the strategy. They pointed out that the design process, in reality, is full of iterations and usually goes in loops rather than in linear:

- "Well my instinct at first response is, it looks very linear, very computer coded." (IDP6) 
- "There is a very neat process that you see. It is not like that at all, no. It is quite, it is much more fluid. So I would say too rigid. In actual fact it is more fluid than this." (ID-P4)

- "It is a natural way to show a design process if you have to but of course in reality it is not the case. It is not like that and you have enormous iterations back and forth between this." (ID-P2)

- "My main thing is that it is not necessarily linear. This is an ideal world, where you have designed it, and it is perfect, and it comes out the other end, and that is OK, and it does not really normally work like that, you are going back and forward a few times." (ID-A5)

Digital tools could sometimes convince the clients that concepts are finalised when in reality they are not, which could influence clients' response:

- "So that is another challenge with the digital tools, that it is very soon looking finished even though it is not." (ID-P2)

Some participants were not happy about the prospect of removing the conventional tools and media, thinking that it could complicate the process and possibly hinder creativity:

- "To ignore non-digital tools sometimes over complicate the process." (ID-P8)

- "Limiting the quantity of tools that are available perhaps limits that and limits their creativity and limits their ability to develop ideas." (ID-A6)

Others were concerned about removing the 3D workshop model making skills to build mockups, models and prototypes:

- "3D form, a manipulation of 3D form, purely from an aesthetic point of view, I think is still something that needs to be done by hand. And very quick foam models, real quick ones at the beginning, for me are still an important part of the industrial design process." (ID-A1)

- "It does make me nervous that you have completely eliminated the hand made model part." (ID-A2)

Students would have to limit their options when graduating from a programme that employed the DID strategy to joining a large design company that provided the digital tools/media students employed during their course: 
- "I am concerned that if students are used to this model, that would require the professional practice to have the same level machinery." (ID-A3)

Students would face problems with the scale of the product as most of the time they would be designing on the screen before they rapid prototyped a concept:

- "It is the size issue. On CAD everything looks wonderful and everything will work but once you actually get into the physical world you have some issues." (ID-A9)

An academic highlighted that the DID strategy would require a huge amount of learning to help the students employ the digital tools/media to their full potential while designing:

- "I think there is a fairly large amount of learning in there [DID strategy]." (ID-A8)

Based on the practitioners and academics interviews analysis, the success of implementing the DID strategy would depend on the following issues:

1. The type of project:

- "With a major project, I could see it. Given that we have a diversity of major projects and maybe some people would be on that one, depending on what the major project is." (ID-A2)

2. The user skill in using the digital design tools/media:

- "The whole picture here represents the new generation of designers because, again, it is very dependent on your skills with different tools and the tools available like 3D scanner, 3D printer and virtual reality." (ID-P2)

- "The problem with it is that if you have somebody who is limited within the process, then it does not work, or it does not work as well. But I think this kind of strategy supposes that there is an ideal person that does not expose any weaknesses, for instance, at concept generation stage, that what comes out of here will be absolutely fine." (ID-A1)

- "So as good as the software is, it is only as good as the person that is driving it." (ID-A8)

3. The creativeness of the user:

- "It is wholly dependent upon the skill base and experience and creativeness of the person who is using it." (ID-A1)

4. Investing resources to provide the tools and learn how to use them properly: 
- "The theory of a total digital system is fine as long as you have got enough investment to be able to do these things at the end, where you can manufacture something you can get hold of, or you could walk around it with virtual reality. That is all great." (ID-A5)

- "There is 120 of them [undergraduate students]... how would you provide these resources?" (ID-A2)

5. Students being in control of conventional (non-digital) tools and media to enhance their visualisation skills in the beginning:

- "But the problem is if they have not mastered manual - what I refer to as analogue in the first or second year - there is no possibility that they are going to get mastery with the digital tools because they do not understand how to create form in the first place." (ID-A4)

\subsubsection{Improvements Suggested to the Digital Industrial Design Strategy}

The feedback from interviewees generated the following points to develop the DID strategy further:

1. 3D modelling techniques and $3 D$ CAD should be included in the concept generation phase:

- "Concept generation contains a lot of 3D when you make a sketch model. And also concept generation is done on CAD a lot as well...I introduce CAD quite a lot for concept generation." (ID-P4)

- "There should be some 3D software, that is simple within the concept generation phase." (ID-P2)

- "So within your concept generate selection stage, it may not be paper-based, it will be 3D-based as well." (ID-A1)

2. Interface design should be included in concept generation phase:

- "I think the interaction design, the interface and the form should all be done at the same time." (ID-P6)

3. Rendering/animation, RP and 3D CNC machining should also be included in the development phase:

- "Rendering animation. Again it depends very much on the skills, but I know a lot of people that already here [pointing at development phase] start to do simple animations, especially when they work in interaction design and interface." (IDP2) 
- "I mean a lot of this information here [RP and 3D CNC machining] needs to be within the development stage as well." (ID-A1)

4. The input devices in the concept generation phase should also be incorporated when using 3D CAD in development phase:

- "A lot of the guys I used to work with, they might have a Cintiq, or they would have this kind of thing, they would be doing the 2D sketch in Photoshop, but then they would be using exactly the same things to do the Pro/Engineer on, or Alias, or 3D Max." (ID-A5)

5. The design phases in the DID strategy should not be separated by lines as some of the tools in the specification phase could be used in the concept generation phase:

- "I do not think there is, there is no line here. There is a blending because you could be coming right down to and in fact, in fact, you know, sometimes you rapid prototype concepts." (ID-P4)

6. There is often modification required when designing, so every step of the DID strategy should give the option of going back to the sketching phase when needed after reflection:

- "I think, pretty much at every stage, you end up jumping back and doing some sketching stuff." (ID-A5)

- "We have always linked everything in design back to concept, constantly, everything loops back." (ID-A7)

7. The physical outputs from $2 \mathrm{D}$ and $3 \mathrm{D}$ CNC machining and RP could be used as input for 3D scanning:

- "The mock-ups here and the physical prototypes here and physical prototypes could be as input for 3D scanning." (ID-P2)

8. Interface interaction would be needed because rendering and animation would be more of one-way that does not allow testing:

- "You obviously need some interface interaction side of stuff in there so you may want to do some Flash or Director of some sort where you can test out buttons and so forth." (ID-A9)

9. The strategy should be used with more mature students who mastered the conventional design skills needed:

- "If you want to implement it [DID strategy], maybe at a very high level of study, like senior or even graduate school, after they have already obtained all those basic techniques and they are familiar with what the machines they are building 
with and they are comfortable with switching in and out of analogue and digital. Then this will make total sense to me." (ID-A3)

Interpretation of the interviewees responses lead to a revised DID strategy (Figure 6-61). 
(5)
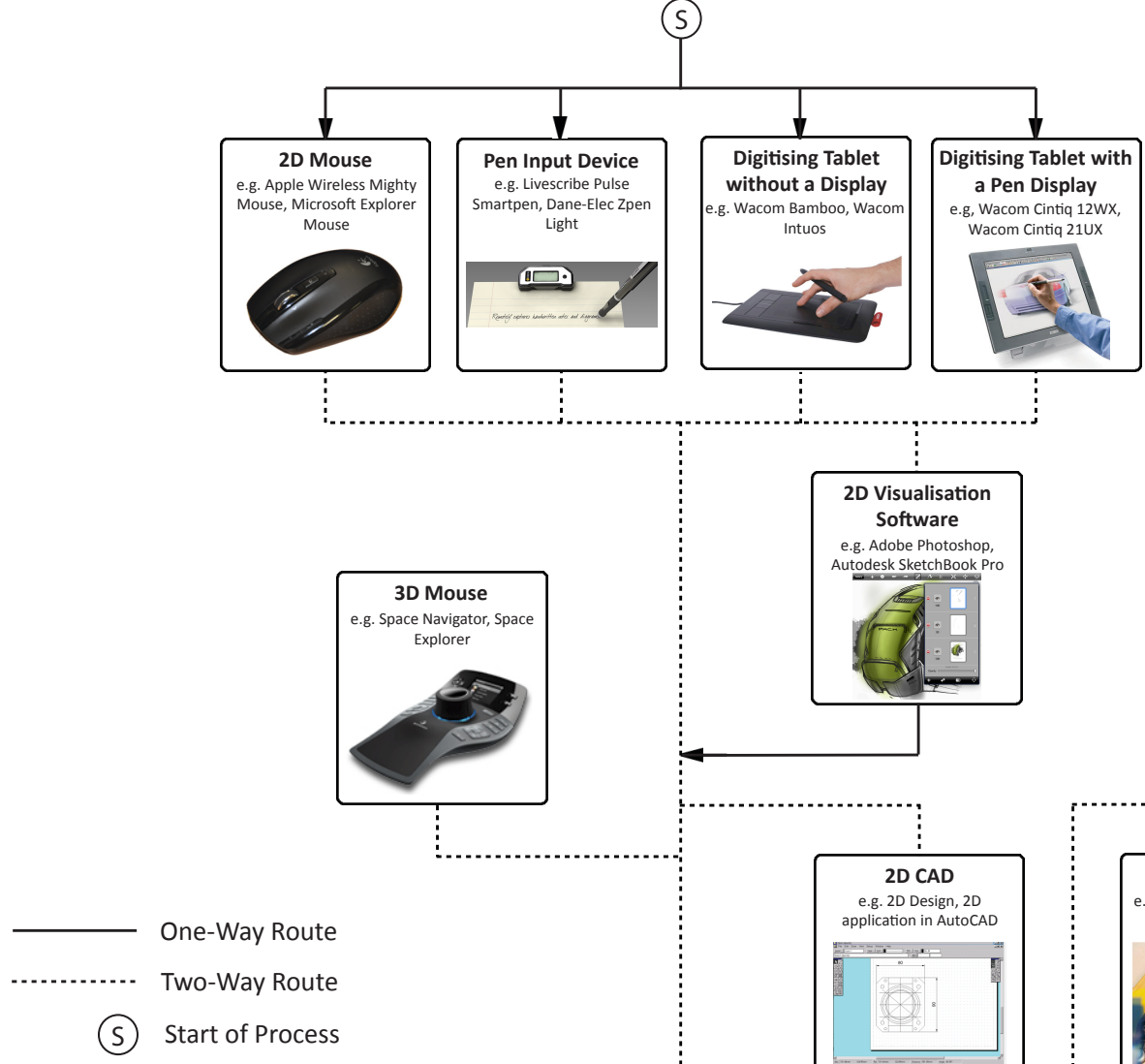

2D Visualisation

Software

e.g. Adobe Photoshop,
Autodesk SketchBook Pro

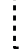

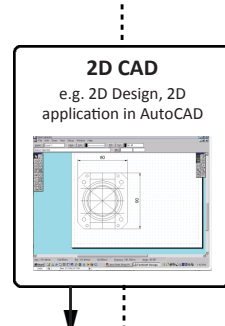

(5)
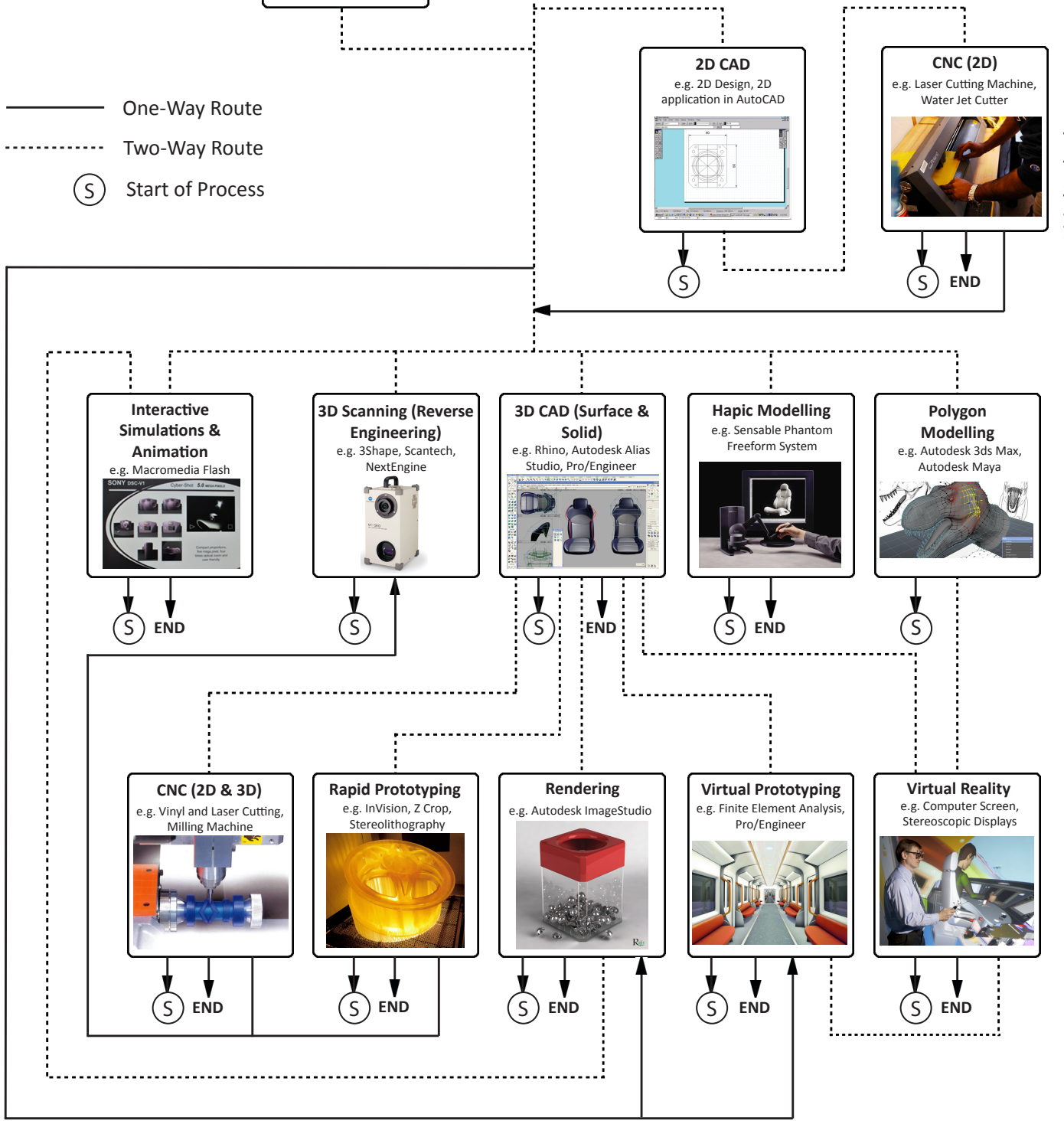

Figure 6-61: Revised DID strategy after feedback and implementing the required changes 


\subsubsection{Viability of the Digital Industrial Design Strategy}

While one academic thought that it would be important to see the outcomes of the students before using the strategy and then be able to decide its viability, the majority of the interviewees agreed that the strategy was feasible:

- "I think it is totally viable. I think, again, this kind of strategy is first of all totally doable, it is viable and the only thing I would ask in some of the earlier phases, I was saying once we go through here basically everybody is now forced to work digitally by the nature of manufacturing." (ID-P1)

- "It is perfectly viable as a strategy and there is nothing in there that one would not use in the right circumstances." (ID-P5)

- "It is viable but I think it is a technology and expense thing. RP is getting cheaper and cheaper all the time and Cintiqs will get cheaper so I think if you have all the technology there to assist you, then you are fine." (ID-A9)

One academic considered two ways of judging the viability of the DID strategy. The first was an idealistic approach where the strategy would be used along with non-digital strategy. The second was the route to market and reducing costs within the design process influenced by manufacturing from the Far East and which could implement the DID strategy. The same academic suggested:

- "But whether one is better than the other, you know, in terms of the product is questionable." (ID-A1)

Few participants thought that the DID was not viable. In education, it was mainly due to cost of the digital tools/media employed in the DID strategy and the resistance of academics used to conventional tools:

- "I do not think we would be able to do it for a number of reasons. I think the cost would be inhibitive, I am not sure we would be able to afford all of the equipment for each student to be able to do that. And I think you would find a lot of resistance amongst the staff team to actually engage with it and to let go of the conventional ways that industrial designers enquire and develop ideas. And I think they may be right to have those reservations." (ID-A6) 


\subsubsection{Employed Elements of the Digital Industrial Design Strategy}

The digital tools that were used by all of the practitioners and students (according to their academics) were 2D mouse; 2D visualisation software; and 3D CAD. While all of the academics used rendering/animation and 3D CNC machining as part their teaching, the majority of the practitioners used the same tools. One practitioner provided a reason for not using 3D CNC machining:

- "I think rapid prototyping presents us with the finished thing. So it is perfect. So all of these become redundant, because it is perfect" (ID-P3)

All of the designers and the six out of the nine academics used RP. The cost of RP and the fact that RP machines keep updating and improving meant that some academics were not employing them in the curriculum.

Other popular tools included 2D CNC machining and 2D CAD. As 2D CAD could also be extracted from 3D CAD, one academic said that: "I think it is a bit of a waste of time these days." (ID-A5).

Whilst only two academics and one practitioner confirmed the use of a digitising tablet with an interactive pen display (Wacom Cintiq for example), the majority of participants had used digitising tablets without built-in display. The main reason for not using the digitising tablet with a built-in interactive display was cost:

- "The main issue with Cintiqs is to buy enough, so that every student had one, we would be spending a lot of money. So I think cost is an issue with those." (ID-A5)

- "Well, a little bit of cost, I mean, they are about $\$ 2,000$ for the tablet. We would probably need to buy more than one." (ID-P1)

One practitioner was critical of the delayed flow of the cursor with the tablet pen when using digitising tablet with a built-in display compared to pen and paper:

- "There is pen lag and really for the way I work it is must quicker just to get a feel for a design just by using pen and paper." (ID-P4)

While five designers confirmed the use of the 3D mouse when designing using 3D CAD, none of the academics mentioned the use of it in student design practice. While few academics had never used one, an academic thought that even though a 3D mouse might be beneficial 
when using SolidWorks, it did not work well with Alias. In order not to confuse the students, the 3D mouse was not used in that university.

None of the academics used pen input devices such as Livescribe Pulse Smartpen, Dane-Elec Zpen Light in their teaching mainly because they did not feel it was needed. Practitioners also shared same feelings.

Limited number of interviewees were using haptic modelling and many academics did not believe in the capabilities of haptic modelling in industrial design.

- "I have to interact with my object and I do not want to interact with it on a screen and I personally do not want to interact with it, I have played with the software, I just do not find it useful at all... the fact that they call it haptic software I think is a joke." (ID-A4)

Few academics felt that it was mainly an issue of investment in time as well as money:

- "The amount of input needed to get the skill level high enough to benefit from it is too high for undergraduate teaching on a product design course." (ID-A1)

Cost was also the reason of not employing 3D scanning as much as other digital design tools, with some commenting on the poor quality of the surface created using 3D scanning:

- "But then, the CAD systems were not very good, and you tended to get a lot of noise, when things were scanned, it does not come in as a beautiful surface, there will be all sorts of points just sticking up randomly." (ID-A5)

The amount of learning required to employ VP and VR limited the use of it in some universities:

- "Finite Element Analysis takes a lot of training and quite a bit of physics and maths understanding to actually get any use of it. It is not just a case of sticking a model in and asking the computer what to do. You have to set up forces and position the forces and how they affect it and so on." (ID-A9)

- "VR set up that we have here is a research facility and within education that would be a module in itself on how to test, evaluate, present using VR because you are taking your computer model, you are then putting it into a completely different piece of software and different environment." (ID-A1) 
The use of VR was only noted in one design firm. Many participants thought that it was mainly suitable for interiors of buildings rather than products that would largely fit on a table:

- "I think it has application but in the kind of work we are doing, we do a lot of table top kind of design. We are not doing like environments." (ID-P1)

Figure 6-62 illustrates the number of practitioners (a total of eight) and academics (a total of nine) interviewed that employed the digital design tools/media used in the DID strategy in their practices.

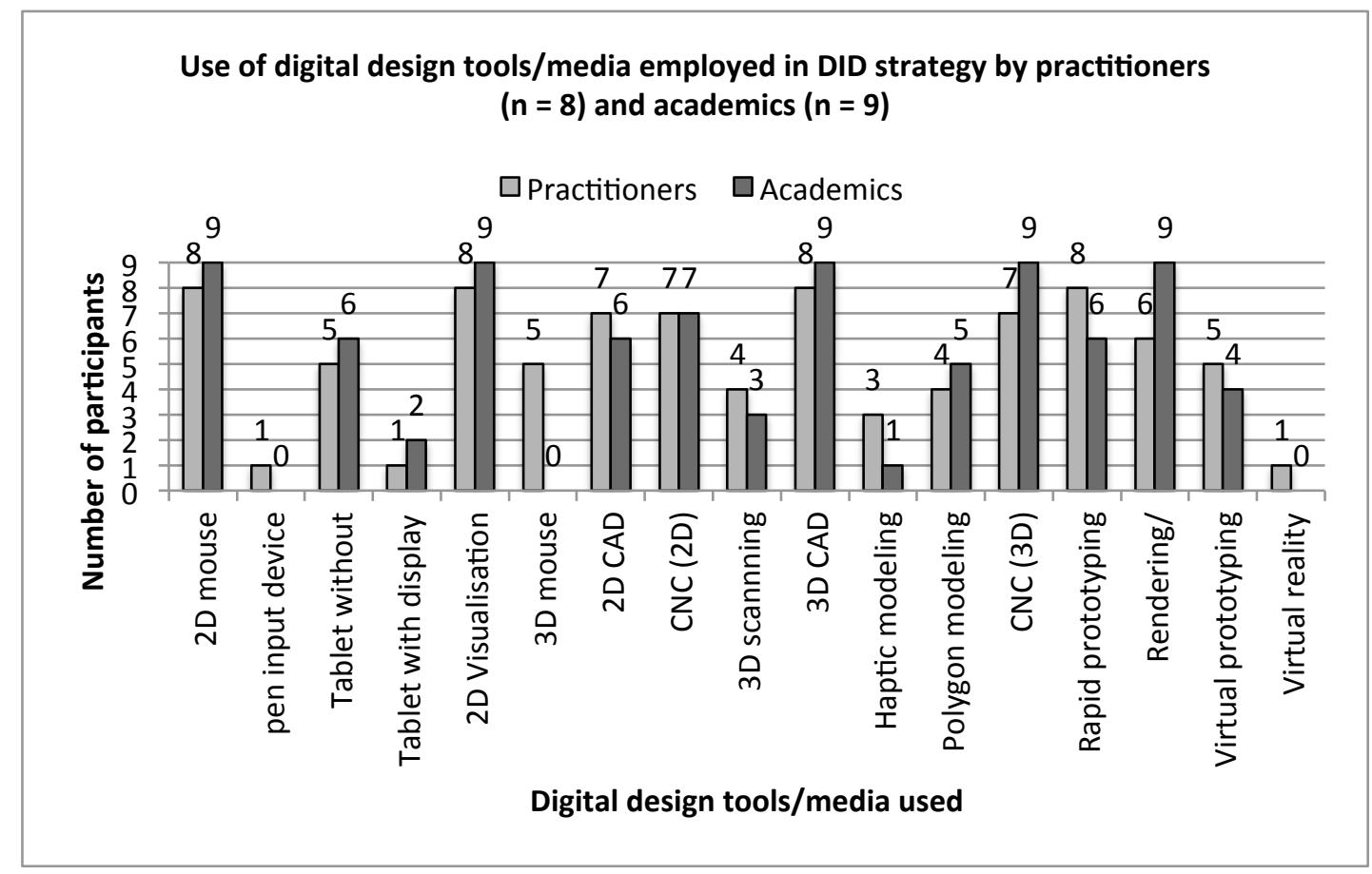

Figure 6-62: Use of digital design tools/media employed in DID strategy in professional and educational design practice

\subsubsection{Interest in Employing the Digital Industrial Design Strategy}

When practitioners were asked about employing the DID strategy within their design practice, many of them said that their design organisations already implemented elements, in some cases it was $50 \%$ of it and in some $80 \%-90 \%$. However, the owners of small design firms did not show interest in employing it because of the substantial costs involved. 


\subsubsection{Interest in Hiring Digital Industrial Design Graduates}

Practitioners were asked: "Would you be interested in hiring students who came from a totally digital industrial design background?". A variety of positive, neutral and negative responses were received:

- "Yes, I would be as interested as in any other student. I do not think that would be a limiting factor, really. Because you would not be looking for, I do not think you would be looking for a student to do the whole design process anyway. You are always looking for them to fill in a job, you do not have the time to do." (ID-P4)

- "It would not affect me one way or the other. Meaning if they had strong skills and a solid understanding of process, whether they did it all digitally or whether they did it a combination of digital and - I do not know, what do we call the other one? Analogue or whatever - that to me would have no real significant bearing." (ID-P1)

- "No, graduates need to have a balanced skill set both traditional and digital." (ID-P8)

\subsubsection{Thoughts on a Completely Digital Industrial Design Curriculum}

"What are your thoughts on a totally digital industrial design curriculum?" was the final question asked to the academics.

Two academics were totally opposed a completely DID education system:

- "I think that the good use of these [digital and non-digital tools] is proportional to your skill based in using them. So if someone can still draw particularly quickly by hand in a sketchbook, rather than using a Tablet PC, then that is fine. As time goes on and they get better and it becomes more natural through early years education to go down that digital route then I think it will become more and more digital. But I still think there is areas of it which would still retain the real world in which we live in." (ID-A1)

Another academic thought that the DID curriculum would face resistance from the university staff themselves, as they are digital immigrants when it comes to designing:

- "I think it is probably staff that are going to be troubled because it is different to what is a longstanding tradition." (ID-A2)

The cost of all the equipment needed for the course was another issue highlighted by an academic: 
- "And also from a schools point of view, unless the school is building this programme from the ground up... then it will take significantly more, larger amount of money to start up this programme than just a normal design programme." (ID-A3)

While one academic expressed concerns about the physicality of designing, since the DID strategy would not allow any conventional workshop model making, few thought this issue could be solved with the use of RP:

- "I think it would miss out on some hand modelling but maybe that is because I am just an old fogey and come from a traditional product side." (ID-A9)

- "I think we will probably eventually have a totally digital system, but I think you might miss out. Well, again, with all of these things, we have to somehow get into the physical world quite soon, so as long as we are rapid prototyping, I do not see that there is a huge issue." (ID-A5)

- "If it does not already exist, is probably very close to coming into existence and seems to make sense to me. I do not see why anyone needs to sit in a workshop and make something by hand anymore." (ID-A7)

In general, despite the issues raised, the majority of academics believed that in the future, industrial design courses would be digital:

- "I think in the future, the way that things are moving will certainly see industrial design curriculums that are more digital...I would imagine that digital will become something that is more pronounced within industrial design curriculum that is currently evidenced. I would imagine it is just that there will be more tools available for the design students to learn and to use, and also it will echo the way that industry goes as well." (ID-A6)

\subsection{Chapter Summary}

This chapter presented the DID strategy and explored its validity mainly from graduating students, academics and practitioners perspectives. A total of 117 graduating students took part in the DID strategy questionnaire and semi-structured interviews were carried with nine academics and eight designers. 
Findings from the questionnaire revealed that the majority of students had never used pen input device, digitising tablet without a built-in display, digitising tablet with an interactive pen display, 3D mouse, 3D scanning, haptic modelling, polygon modelling, VP and VR.

A 2D mouse, digitising tablet with an interactive pen display, 2D visualisation software, 3D mouse, 3D CAD, 2D CAD, 2D CNC machining and RP were considered easy/very easy to use by the greater part of graduating students.

Most of the graduating students also felt that the contribution of the $2 \mathrm{D}$ mouse, $2 \mathrm{D}$ visualisation software, 3D CAD, 2D and $3 D$ CNC machining, RP and rendering/animation were significant/essential to their design practice, while digitising tablet with an interactive pen display and 3D mouse offered moderate contribution and haptic modelling provided limited or no contribution at all.

Despite the fact that $45 \%$ of graduating students felt that the DID strategy was efficient/very efficient, $63 \%$ disagreed/strongly disagreed that it has the potential to replace the existing conventional and hybrid process of designing. The rationale behind the negative response was the absence of paper-based sketching. However, a majority of $54 \%$ would like to try the strategy to enhance their experience and satisfy their personal interest in new technologies.

The academic and practitioner interviews explored views and opinions about the DID strategy in more detail. Findings indicated that on the positive side, the DID strategy was well considered; it would speed up the process of designing; ease globalisation; and facilitate collaboration between members of NPD team. Some interviewees pointed out that the DID strategy would be more suitable for larger design firms, experts, and mature students. In addition, the interviews revealed some concerns about the cost of digital tools/media employed within the strategy and potential limitations in concept generation by replacing the hands-on model making skills with haptic modelling.

The findings also indicated that the success of employing the DID would depend on the type of project being undertaken; having enough investment to provide the digital tools/media; and the user's creativeness and skills in using the digital tools/media. One academic felt that it would depend on students mastering and being in control of the non-digital tools before using the DID strategy.

The changes made to the first draft of DID strategy were: removing the three phases separation, adding interactive simulations, giving the user the option to go back to the 
sketching phase when ever needed, linking the outputs of 3D CNC machining and RP to 3D scanning and allowing the user to use the input devices after sketching concepts as well.

The majority of the interviewees believed that the DID is feasible and few thought that it was not suitable for education, mainly due to cost and resistance of academics who depend on conventional tools.

In terms of implementing the strategy in a professional design practice, owners of small design firms were not interested although some practitioners said that their design firms were already implementing aspects of the strategy.

When practitioners were asked if they would be interested in hiring students graduated from a DID course, some were keen, some were not interested and others felt that it would not affect their preference, as they would be purely judging on their design skills.

While two academics were completely against a totally DID curriculum due to cost, lack of physicality and staff resistance, the majority of academics thought that future of industrial design courses would be more digital. 


\section{USE OF TABLET PC FOR CONCEPT GENERATION}

This chapter explores the capabilities of the Tablet PC to facilitate creative concept generation during industrial design practice. It begins with an overview of the case study undertaken with final year industrial design students, followed by results from sketching and design exercises. Results from the pre- and post-questionnaire that compares digital design methods with non-digital design methods are discussed. It concludes with the results of the questionnaire that was generated from focus groups on the use of the Tablet PC as a design tool.

\subsection{Overview of the Case Study}

It was noted during data collection activity carried out with graduating students, practitioners and academics, that digital sketching was a major concern if used within a totally DID process. The speed, portability, flexibility and freedom that paper-based sketching offered was the main reason for this response. To explore the issue further, a case study was employed to provide detailed information on digital sketching (Neale et al., 2006: 4). This chapter focuses on the use of the Tablet PC as an ideation tool in a DID process, as it has the capacity to emulate paper-based techniques in a digital and portable environment.

\subsubsection{The Problem}

The findings from Chapter 5 and Chapter 6 indicated that digital sketching was a major concern to participants.

In Chapter 5, findings indicated that when graduating students were asked if they thought that they would be able to achieve the same outcome from their project if the entire process was undertaken using digital tools, a majority of 58\% disagreed/strongly disagreed. The two top-rated reasons identified were related to sketching; digital tools/media would not allow quick sketching (occurring 13 times) and concept generation was more effective/efficient with pen and paper (occurring 12 times). When final year students who had completed an industrial placement were asked the same question in relation to the design firm where they worked, 7 out of 17 disagreed/strongly disagreed. Again speed of sketching on paper (occurring three times) and the belief that concepts were generated 
more easily on paper (occurring three times) were recorded as the top reasons. Practitioners highlighted that digital sketching lacked a degree of freedom and the Cintiq was not as flexible as paper-based sketching.

Furthermore, when graduating students were asked: "To what extent do you agree or disagree that your design practice will improve if you used a completely digital process?", the majority (59\%) disagreed/strongly disagreed and again the most cited reasons were related to sketching. Some graduating students believed that concept generation was quicker when using a paper-based sketching technique and others thought that paper-based sketching supported the appreciation of form and styling. Final year students who completed an industrial design placement suggested that paper-based sketching was more convenient and cheaper than digital sketching. Again, the top-rated reason identified by practitioners with negative feelings towards a completely digital process was that digital sketching was too limiting for concept generation.

Question E4 asked: "To what extent do you agree or disagree that it would be appropriate to have a totally digital industrial/product design course?". Two of the three main reasons identified by the graduating students with negative feelings were related to the sketching activity. They felt that paper-based sketch work was essential and its tools were easier to carry around and use. When the same question was asked to designers, one stated that "hand sketches drive our industry. They work, they can be fluid and organic and convey an emotion that can easily get lost once your results are confined by computerised tools. I watch industrial designers struggle with digital tools to keep that fluid element to designs". Another practitioner commented that "the number one issue I have with junior designers that do not have enough analogue sketching and study model making experience (i.e., CAD jocks), is that they do not have a solid sense of scale. Sketching a handheld product full scale does not really have the same affect on an interface where you can constantly zoom in and out".

In Chapter 6, after presenting the DID strategy to graduating students, they were asked about the potential of the DID strategy to replace the exiting conventional and hybrid process of designing. Results indicated that 41 graduating students (greatest number) identified conventional paper-based sketching as being important, easier and quicker to produce when compared to digital sketching.

Some of the academics and practitioners interviewed in Chapter 6 also revealed their reservations towards losing the skill of being able to sketch with conventional tools. A 
number of design practitioners felt that pen and paper were easier and more flexible to use than digital design tool/media. One designer stated that "so far I have not met any digital tool for sketching that is as flexible as having pen and paper" (ID-P2). Another said that "there is the Cintiq, there is Wacom tablet and you will have to do a fair bit of training to get quite good on them, you know, get used to that. So really there is nothing that is as good as pen and paper for getting your initial ideas down" (ID-P4). One practitioner interviewed explained that there appeared to be an issue with the personalisation that paper-based media offered to designers when compared to a digital tool.

Finally an academic referred to the fact that the sketches produced by a digitising tablet tended to be less detailed but with high quality lines, which lead to student satisfaction without showing an understanding of form or detail. The academic stated that he is "seeing more and more drawings that have obviously been done with a digitising tablet where the student seems quite happy with a few lines to describe an object or an intent. But because the quality of the lines that is created by the computer has a fantastic feel to it, it has got a lot of tension and it is really nice line, somehow it is seen as success" (ID-A8).

\subsubsection{Hewlett Packard Innovation in Education Grant}

Digital sketching had been identified as a major issue through both literature review and empirical studies and it was necessary to explore the means by which this technique could be explored further. The problem was, however, that the equipment for digital sketching was at the time, relatively expensive.

In March 2009, an opportunity arose to apply for a Hewlett Packard (HP) Innovation in Education Grant to support the PhD research. A proposal was submitted entitled "Creative Concept Generation in a Digital Design Curriculum" and in August 2009, the $\$ 100,000$ grant was awarded to Loughborough University. The funding included a range of HP products, such as 22 HP Tablet PCs, 22 docking stations, 22 secondary battery slices, 22 security locks for tablets, $\$ 10,000$ cash grant to fund the project, and attendance at the $2010 \mathrm{HP}$ Innovation in Education Conference in San Francisco. For the PhD research, the key contribution was the Tablet PCs which provided the capacity to engage in digital sketching. A case study was devised to explore the issue of digital sketching in some detail.

\subsubsection{Case Study Participants}

An e-mail was sent to all final year industrial design students in Loughborough Design School at the beginning of the $2009 / 2010$ academic year. A total of 20 students expressed interest 
in participating but only 16 were selected. The students were selected based on their skills using 2D visualisation software and 3D CAD. Each student had to send two sketch visuals and two CAD renderings to be considered in the study. Seven students studying on the BA in Industrial Design and Technology course and nine on the BSc in Product Design and Technology course were chosen. All of the BA and BSc students selected had successfully completed a placement in a design firm.

\subsubsection{Steps Taken to Address the Problem}

The Tablet PC case study was undertaken during 2009/2010 academic year. The case study involved many data collection methods such as questionnaires, observations and focus groups. This approach is confirmed by Neale et al. (2006: 4) when they state that "case studies also allow one to present data collected from multiple methods (i.e., surveys, interviews, document review, and observation) to provide the complete story".

Final year students were invited to take part in the study at the beginning of the year. Selected participants were then provided with Tablet PCs that had the required software installed. The Digital Industrial/Product Design Strategy Questionnaire was handed to students to complete twice; before using the Tablet PC and again the day it was returned; to examine any changes in perceptions about digital design methods.

After a month of using the Tablet PCs, a shared experiences session was planned to ensure that students are getting on well with the Tablet PC and to share thoughts about its use for designing. Non-participant observation was undertaken while students were carrying out the sketching exercise to compare paper-based sketching with digital sketching using the Tablet PC after three months of use. A design exercise was also employed with nonparticipant observation to identify issues that were not previously raised by students. Feedback from the sketching and design exercises was sought through supervised collective questionnaires.

Focus groups were undertaken with students to investigate further opinions and thoughts on the use of the Tablet PC as a tool for conceptualisation design. The responses recorded facilitated the generating of the Use of Tablet PC for Designing Questionnaire that was handed to students on the last day (end of academic year). The questionnaire allowed for the collection of quantitative data of the students thoughts about the use of the Tablet PC for designing. 
Table 7-1 identifies the range of activities that were employed to investigate the use of the Tablet PC as a tool for generating concepts.

\begin{tabular}{|c|c|}
\hline Date & Task taken \\
\hline 6 October 2009 & - Invitation to participate in the case study (e-mail) \\
\hline 20 October 2009 & - $\quad$ Selected participants informed (e-mail) \\
\hline 21 October 2009 & $\begin{array}{l}\text { - } \\
\text { - } \\
\text { - } \\
\text { - } \\
\text { - } \\
\text { "Distribitital Industed Tablet PCs } \\
\text { collective) }\end{array}$ \\
\hline 25 November 2009 & - $\quad$ Shared experiences session \\
\hline 20 January 2010 & $\begin{array}{l}\text { - } \quad \text { Sketching exercise } \\
\text { - } \quad \text { Non-participant observation of sketching exercise } \\
\text { - } \quad \text { "Sketching Exercise Questionnaire" (supervised collective) } \\
\text { - } \quad \text { Design exercise } \\
\text { - } \quad \text { Non-participant observation of design exercise } \\
\text { - } \quad \text { Design Exercise Questionnaire" (supervised collective) }\end{array}$ \\
\hline 01 February 2010 & $\begin{array}{l}\text { - } \quad \text { Focus group with BA students "Use of Tablet PC for Designing" } \\
\text { - } \quad \text { Focus group with BSc students "Use of Tablet PC for Designing" }\end{array}$ \\
\hline 14 June 2010 & $\begin{array}{l}\text { - } \quad \text { "Digital Industrial/Product Design Strategy Questionnaire" (supervised } \\
\text { collective) } \\
\text { - } \quad \text { "Use of Tablet PC for Designing Questionnaire" (supervised collective) } \\
\text { - } \quad \text { Returned Tablet PCs }\end{array}$ \\
\hline
\end{tabular}

Table 7-1: Steps taken in the case study with final year students to explore the use of the Tablet PC for sketching

\subsubsection{Equipments Provided for Students}

Each student that agreed to participate in the case study was provided with an HP EliteBook 2730p Notebook PC with duo low voltage processor; 12.1 inch display; $1.86 \mathrm{GHz}$ processor speed; and Windows XP (Figure 7-1). An expansion base with integrated DVD+/-RW drive, USB optical mouse, secondary battery slice, case and a security lock were also provided to the students. Each Tablet PC had MS Office, Pro/Engineer and SketchBook Pro installed. Students had full use of the Tablet PC and its accessories whilst undertaking design activity for their major projects and supporting modules for the entire 2009/2010 academic year. The researcher provided support on demand. 


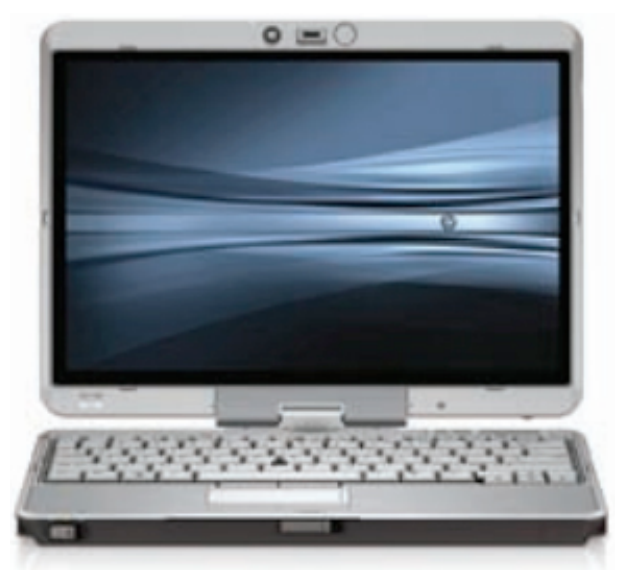

Figure 7-1: HP EliteBook 2730p Notebook PC (Hewlett Packard, 2010)

\subsection{Shared Experiences Session}

A shared experiences session was undertaken to discuss the benefits and challenges faced when using the Tablet PC. The session ensured that the students were using the Tablet PCs while designing without any difficulties. Students were asked to bring some visuals that demonstrated their use of the Tablet PC. Points raised in the discussion are summarised in Table 7-2. Figure 7-2, Figure 7-3, Figure 7-4 and Figure 7-5 show examples of student work that were shared during the session. 
- The battery life of the Tablet PC is really good

- The Tablet PC is pressure sensitive

- The Tablet PC works very well with SketchBook Pro

- $\quad$ Ease of concept generation

- Convenience of rendering straight away without having to scan a manual sketch

- Being able to follow what is on the screen with the pen input device

- $\quad$ Being able to have the screen in different orientations

- Microsoft OneNote is helpful to make manual notes and search among the document

- The Tablet PC is powerful to use for design work

- $\quad$ Sketches looked better after using the Tablet PC

- Microsoft Journal is useful to make notes

\section{Challenges}

- The screen is not finger sensitive

- The screen hides the keyboard when sketching so shortcuts cannot be used

- The design of the Tablet PC is not impressive

- The touch pad is small

- The performance of the Tablet PC is not that good

- There is not enough space in the Tablet PC to rest your hand while sketching

- The Tablet PC is slow for rendering

- The CD drive is attached to the docking station and not built into the Tablet PC itself

- The screen is so glassy, which makes sketching between two lines a bit problematic

- The screen is not big enough

- Problem in the collaboration of the pen and the arrow displayed in the screen Interesting comments

- Use of a manual ruler to help drawing a straight line with the Tablet PC

- Dropping pictures in a layer to sketch on top (images of hands and people) then hide them

- $\quad$ Pictures of models were imported and sketches were made on top to explore concepts

Table 7-2: Benefits, challenges and relevant points identified by the students during the shared experiences session
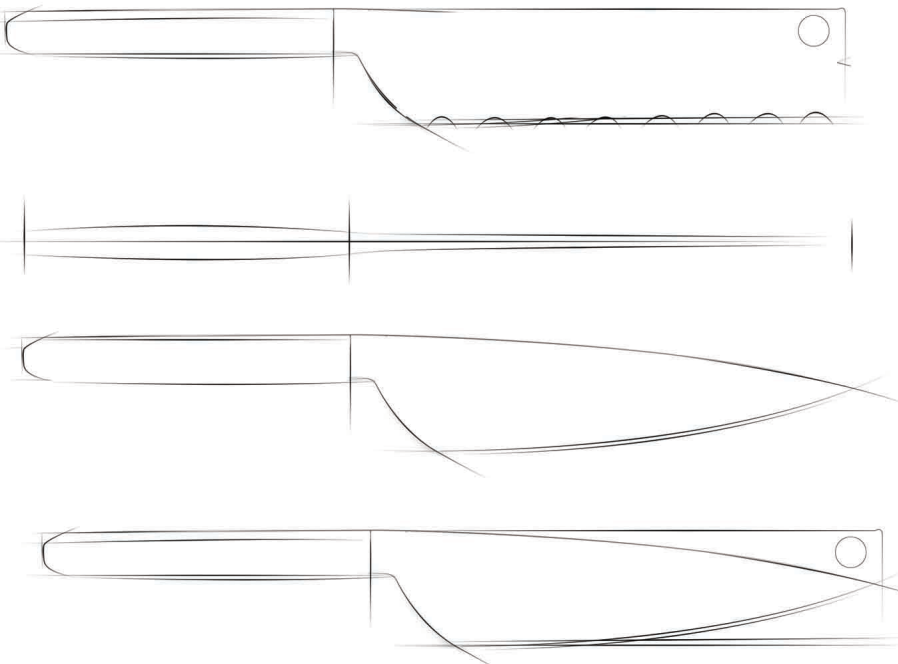

Figure 7-2: Use of the Tablet PC to produce simple elevational sketches 


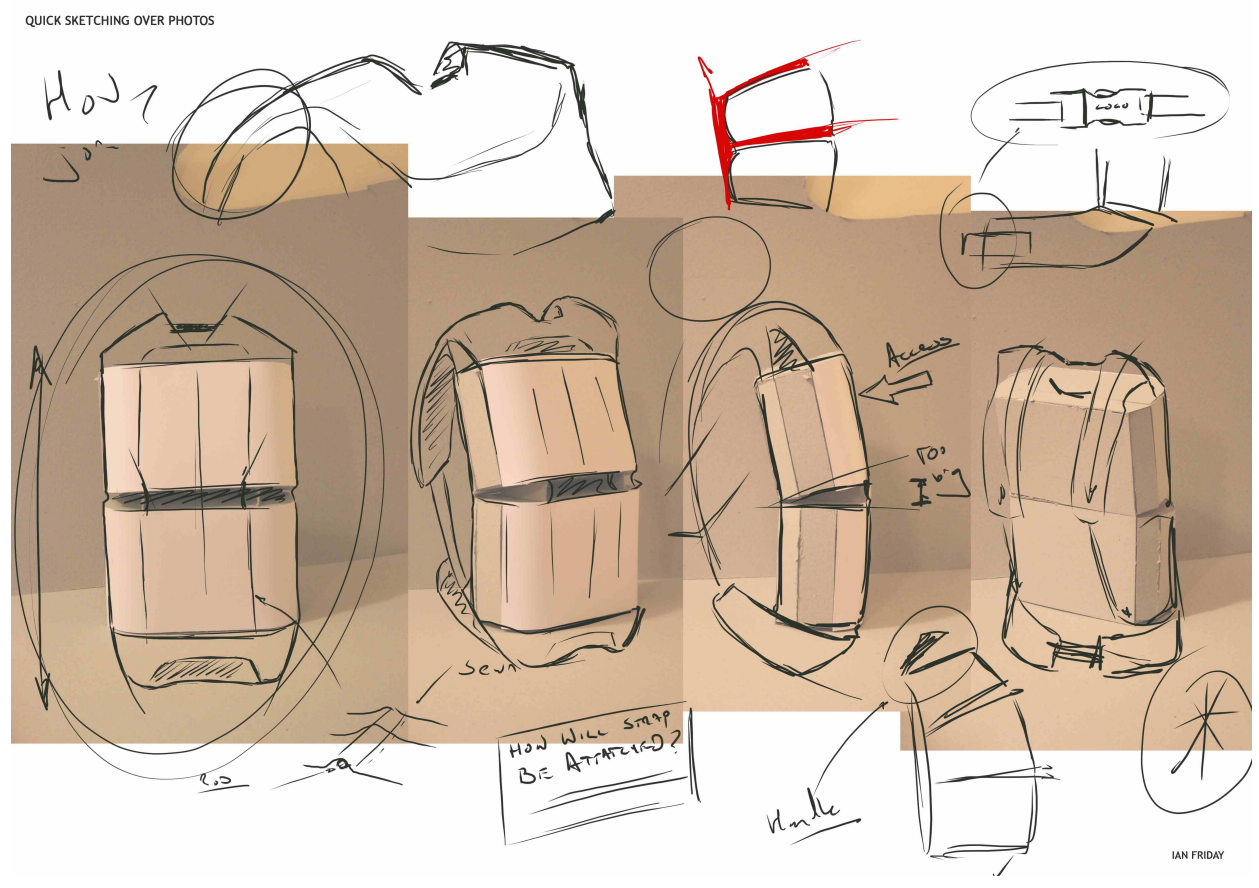

Figure 7-3: Use of the Tablet PC to produce sketches over imported photos of physical sketch models

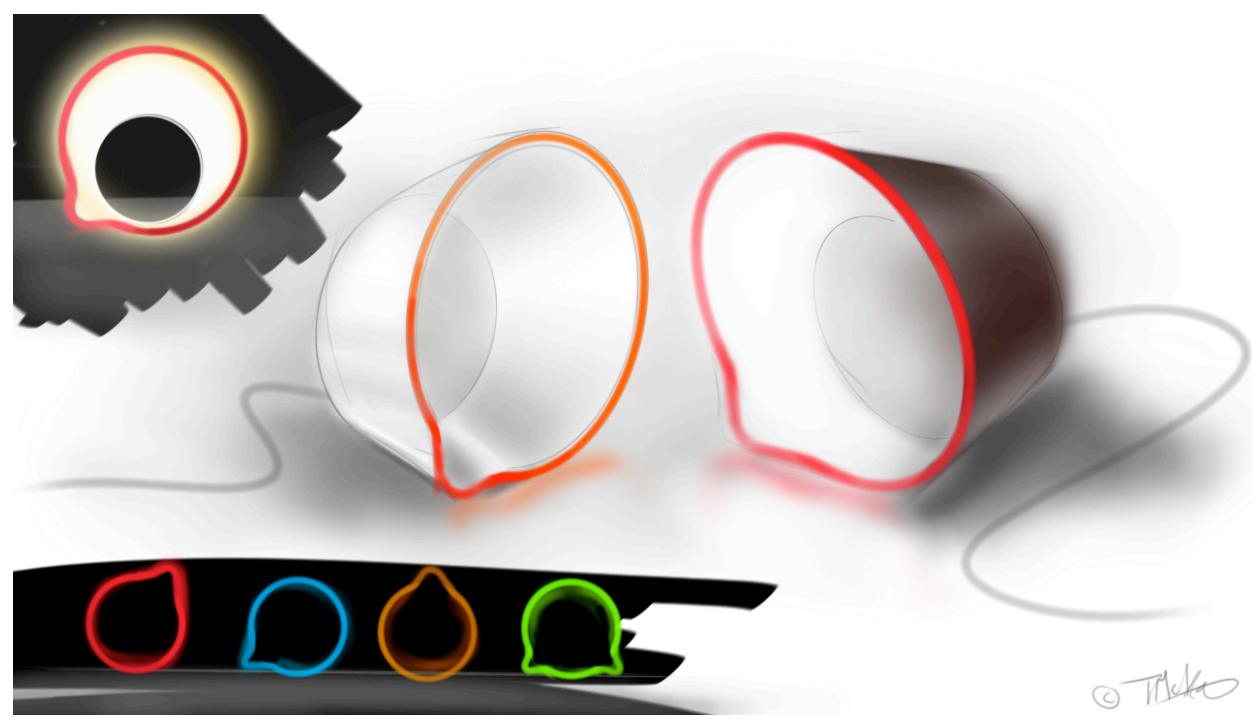

Figure 7-4: Use of the Tablet PC to introduce colour when sketching concepts 
The Scenario
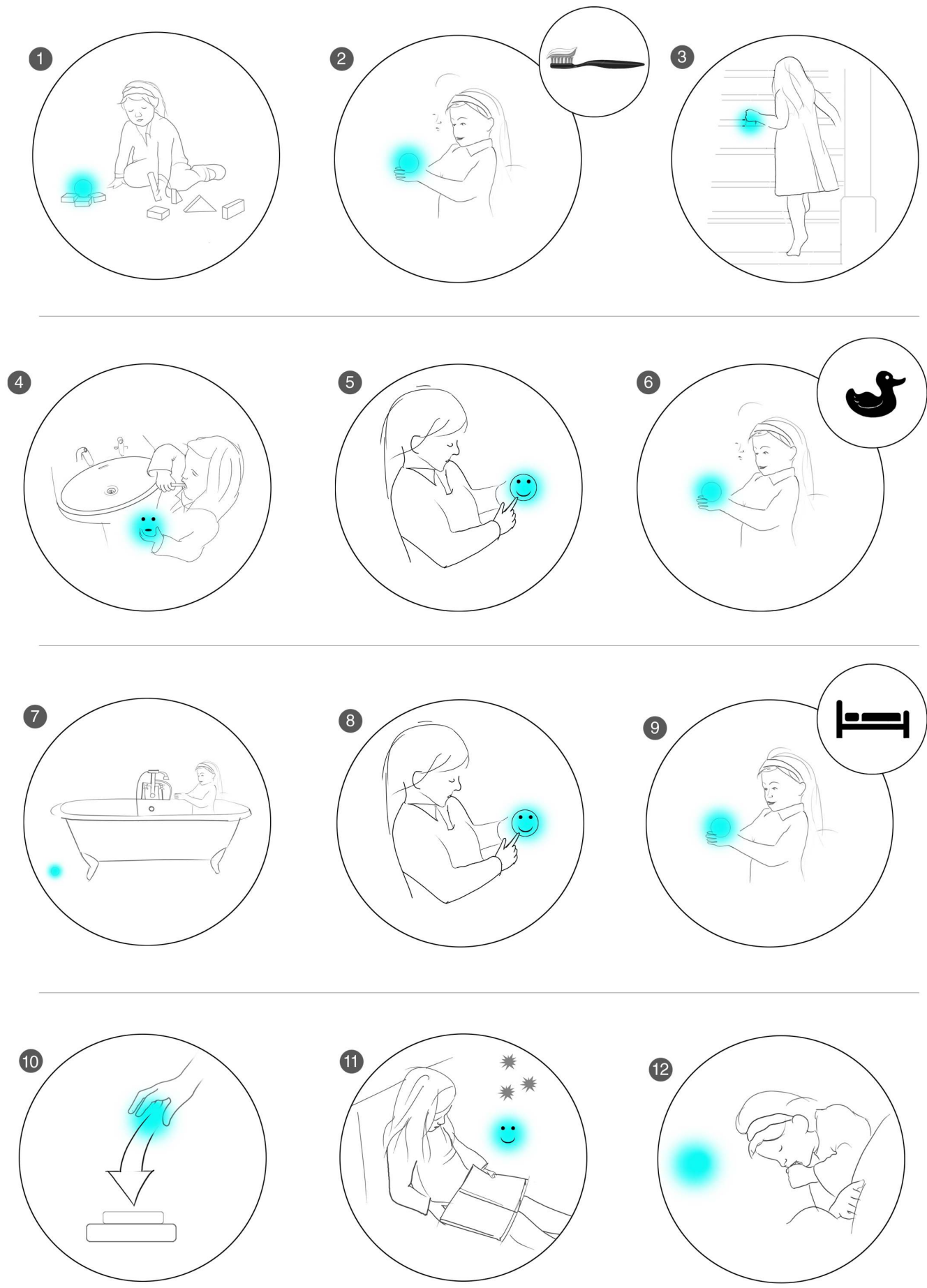

Figure 7-5: Use of the Tablet PC to produce images of users as an underlay to help sketch user scenarios 


\subsection{Sketching Exercise}

\subsubsection{Overview}

A sketching exercise was undertaken to collect data on the student attitude towards the use of the Tablet PC for sketching and expert feedback was sought to evaluate the student outcomes. The exercise required students to sketch two products using paper-based techniques and the Tablet PC. The process was recorded on video for analysis (Figure 7-6).

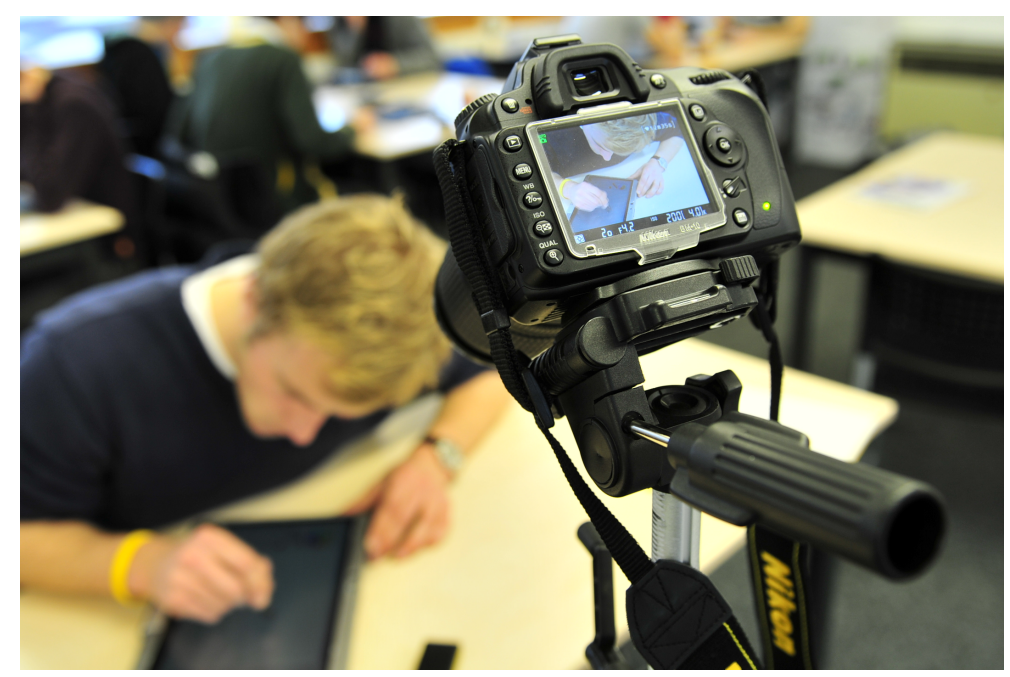

Figure 7-6: Use of video to capture the student sketching activity during the exercise

The nature of product form that is to be sketched generally determines the techniques employed. Ellipses and crating are used for forms of primitive geometry while contour lines and bulkheads are used for those with more organic form. In the sketching exercise, in order to explore different sketching strategies, a geometric torch and an organic toddler's spoon were chosen as the objects to be sketched (Figure 7-7 and Figure 7-8).

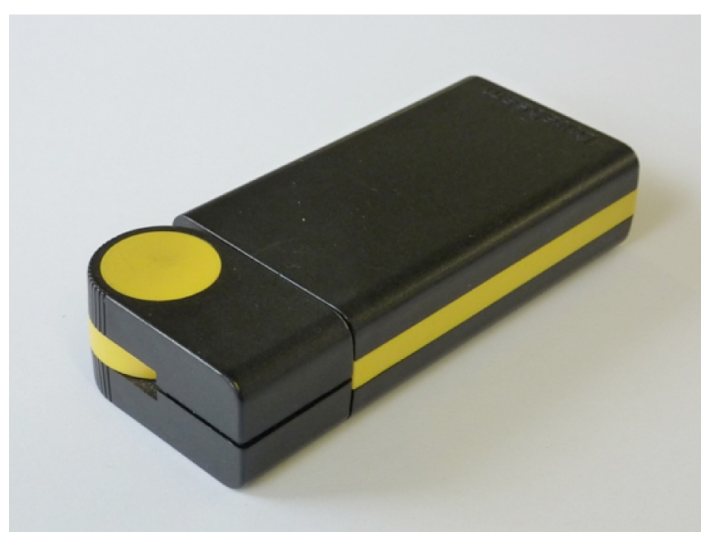

Figure 7-7: Geometric shape torch used for sketching exercise 


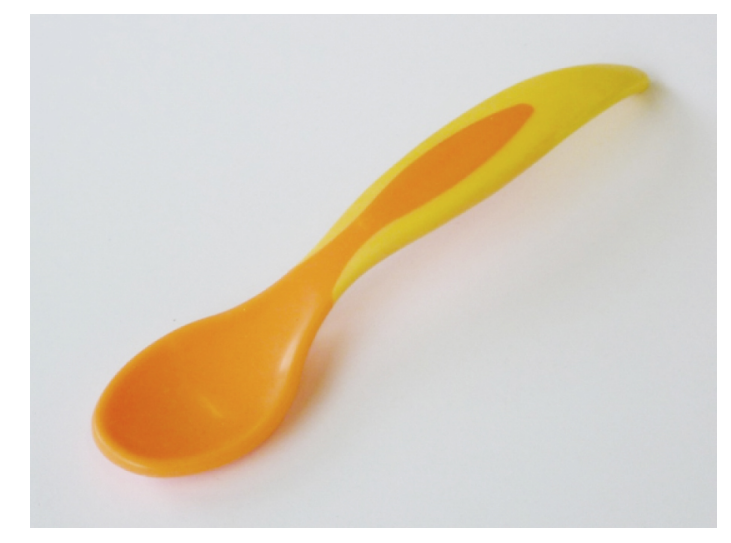

Figure 7-8: Organic shape child's spoon used for sketching exercise

After three months of using the Tablet PC, 15 out of the 16 students who signed up for the case study took part in the sketching exercise. Every student was allowed five minutes for each sketch and they were required to produce two sketches for the torch (one using paperbased techniques and one using the Tablet PC) and another two sketches for the child's spoon. The sequence of product sketched (torch or spoon) and media used (paper and Tablet PC) was randomised to avoid order effects. Examples of the sketches produced by one of the students can be found in Figure 7-9, Figure 7-10, Figure 7-11 and Figure 7-12.

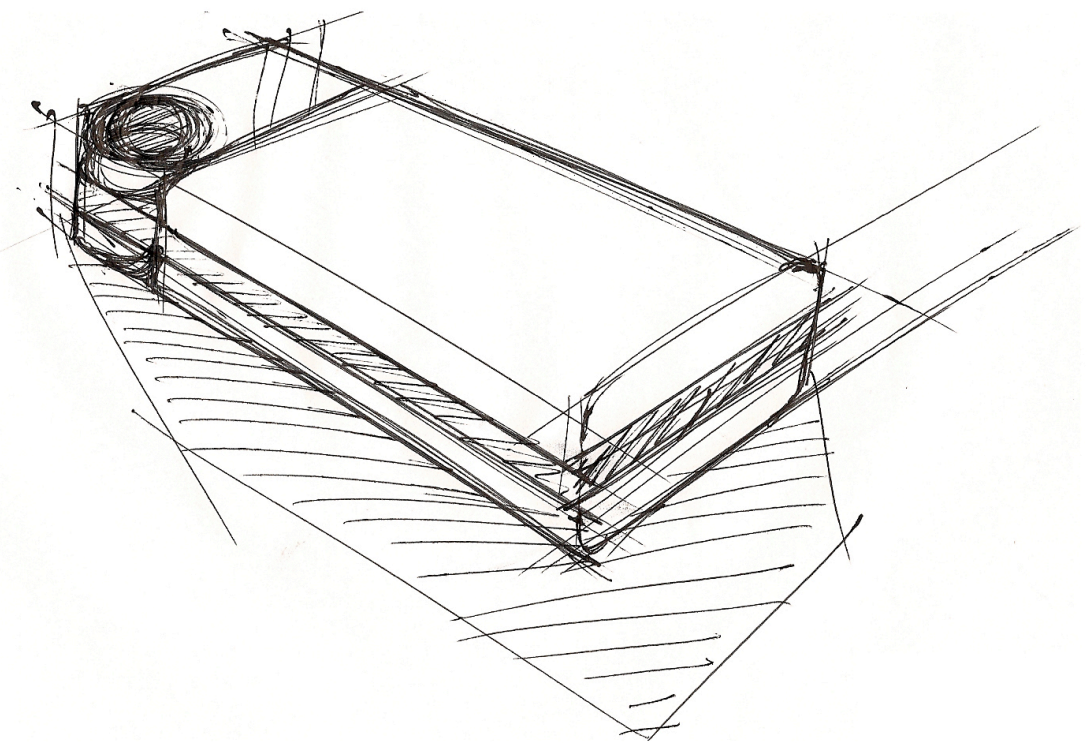

Figure 7-9: Participant 2 sketch of the torch using paper-based media 


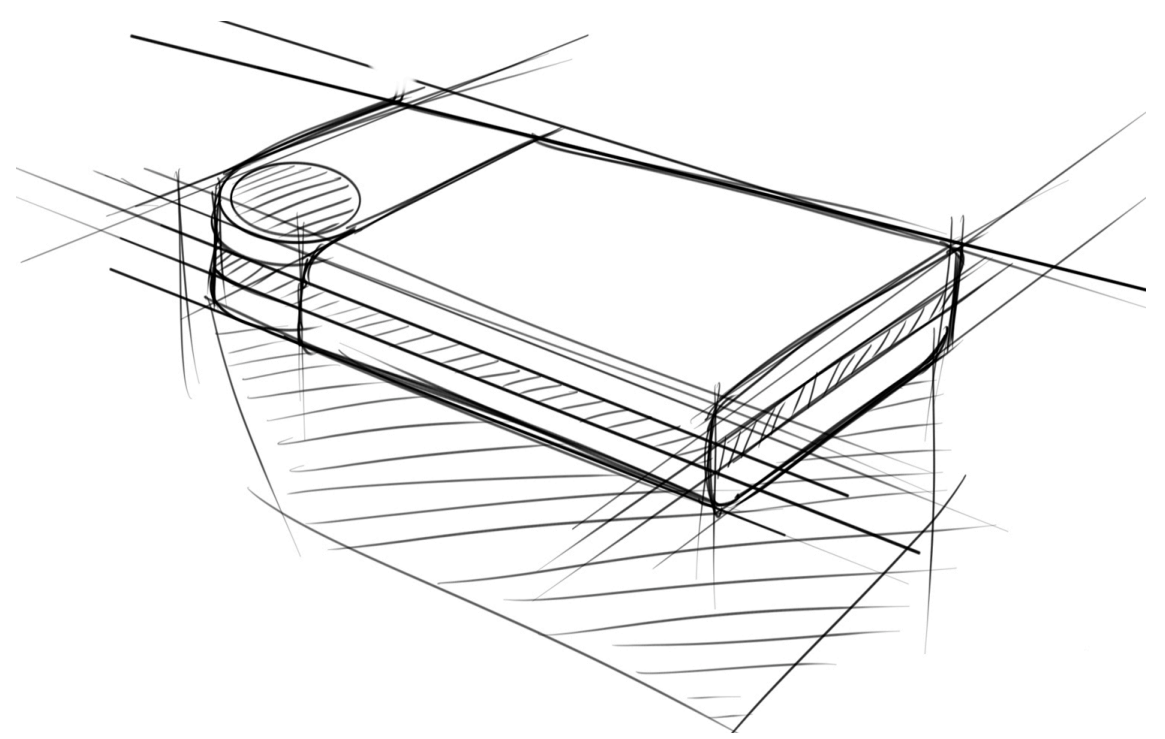

Figure 7-10: Participant 2 sketch of the torch using the Tablet PC

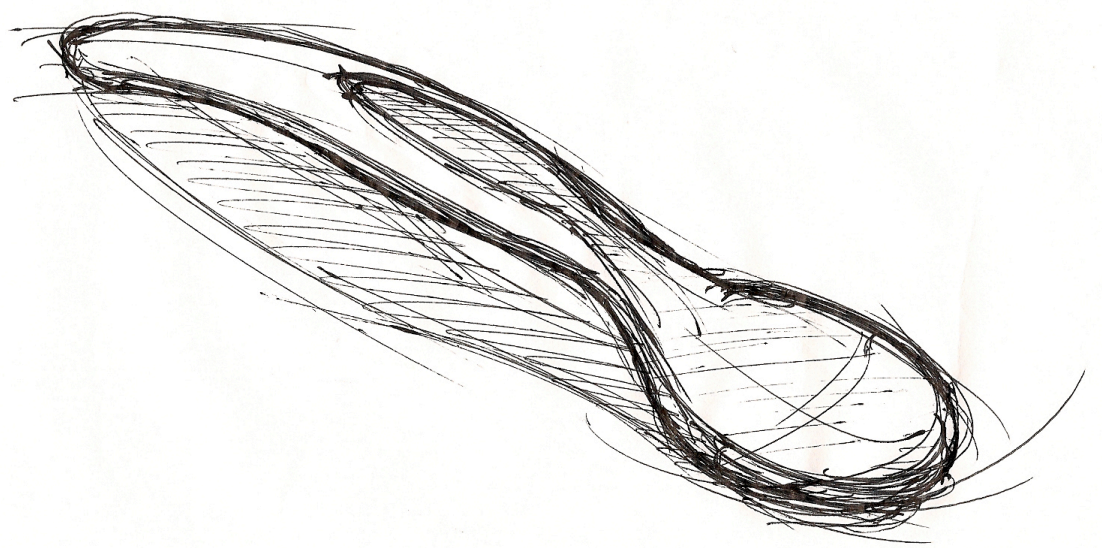

Figure 7-11: Participant 2 sketch of the child's spoon using paper-based media 


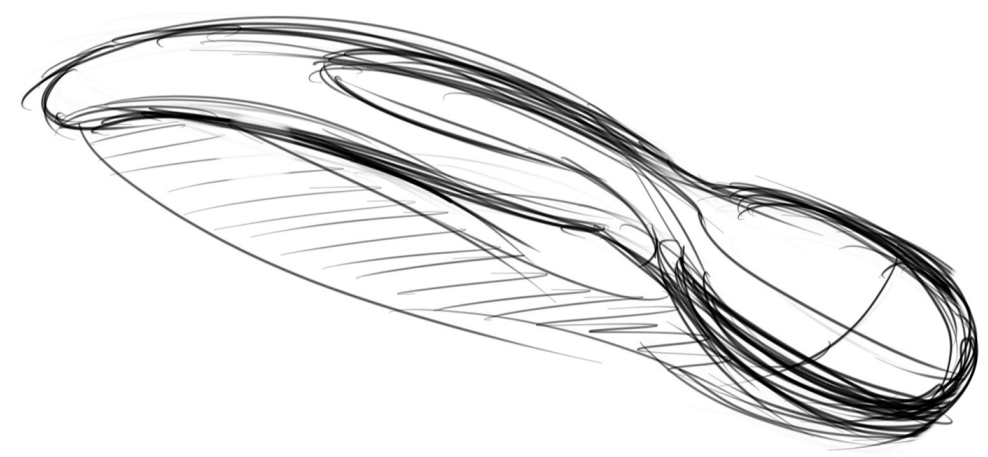

Figure 7-12: Participant 2 sketch of the child's spoon using the Tablet PC

\subsubsection{Sketching Exercise Questionnaire}

On completion of the sketching exercise, students were asked to complete a questionnaire that explored the experiences afforded through the use of paper-based sketching and digital sketching using the Table PC.

The questionnaire consisted of three main questions. The first question explored student perception on their sketching capability when using the two media. The second question requested open-ended responses to ways in which the product sketching strategies differed between paper-based techniques and the Tablet PC requiring a list in rank order with a maximum of five responses. The final question sought opinion on a series of statements that could apply to product sketching using either paper-based techniques or the Tablet PC (Appendix 11.8).

When students were asked to rate their ability using non-digital (paper-based) and digital media, it was apparent that students felt that their sketching ability using non-digital media was higher than using digital media (Tablet PC) (Figure 7-13). This could be due to the fact that none of the students had used a Tablet PC before enrolling in the study while they had been sketching products using paper-based media for at least three years. 


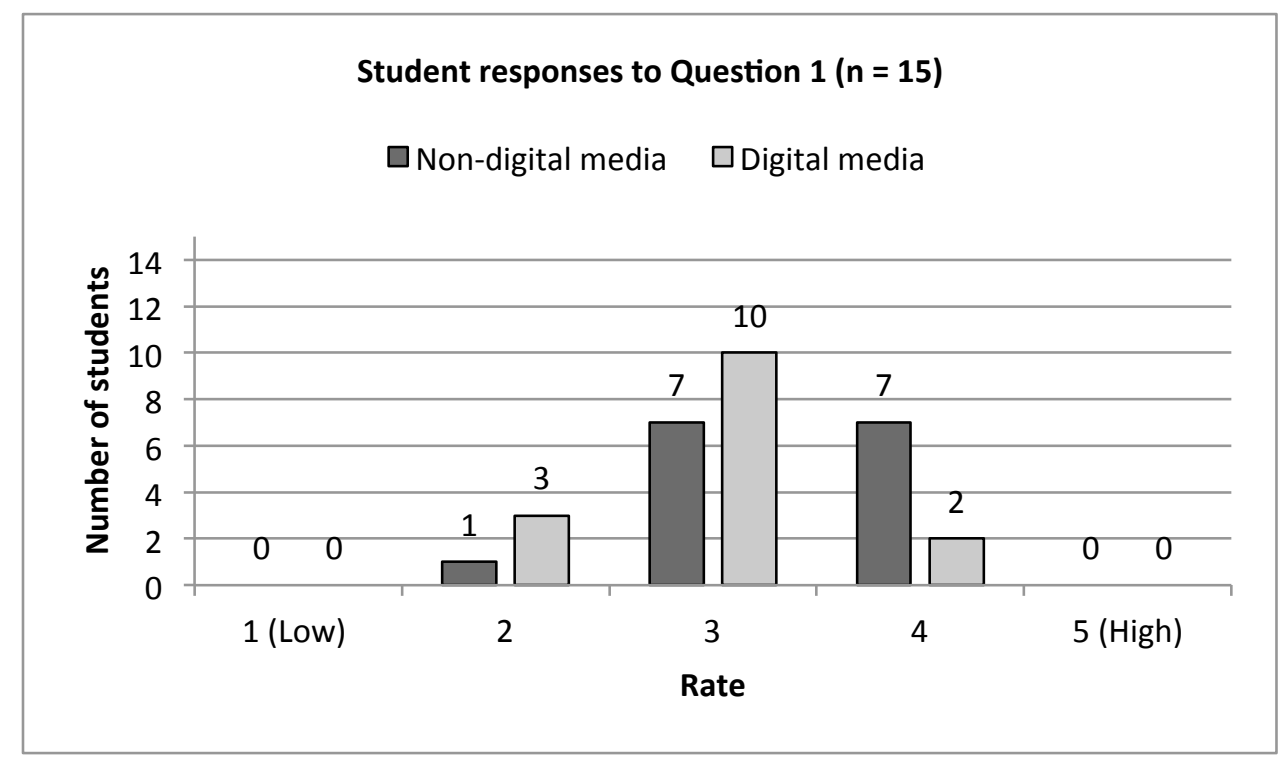

Figure 7-13: Student responses to Question 1: "How would you rate your ability to sketch using line only during design activity with the following media ( 1 being low and 5 being high)?"

Question 2 was open-ended and asked: "How did the sketching strategies differ between non-digital and digital media? Please list them in rank order with the most significant difference first?". Responses to this question was analysed using NVivo 9 software. Findings showed that the ease of using the layers feature when using the Tablet PC was the most important feature. While some students felt that they were more in control when using paper-based techniques in terms of line weight and flow, students felt that the Tablet PC increased the amount of quick experimental shading. Some students declared an ease of creating perfect lines and applying colour when using the Tablet PC compared to using the paper-based media for sketching.

Question 3 required students to indicate the statements that applied the most to non-digital sketching, digital sketching or equally to both. Findings indicated that the majority of students agreed that non-digital sketching was better than its digital equivalent in producing sketches quickly. Paper-based sketching was easier to use, providing more confidence in the use of line and offering the most accurate representation of the product (Figure 7-14, Figure 7-15, Figure 7-16 and Figure 7-17).

When students were asked to identify the most expressive sketch, responses were close. Seven students selected the non-digital sketching, six selected digital sketching and the remaining two thought that it applied to both equally (Figure 7-18). 
On the other hand, most students felt that digital sketching required more error corrections and was more enjoyable (Figure 7-19 and Figure 7-20). Eight out of the 15 students preferred the final sketch produced using the Tablet PC to the paper-based sketch (Figure 7-21).

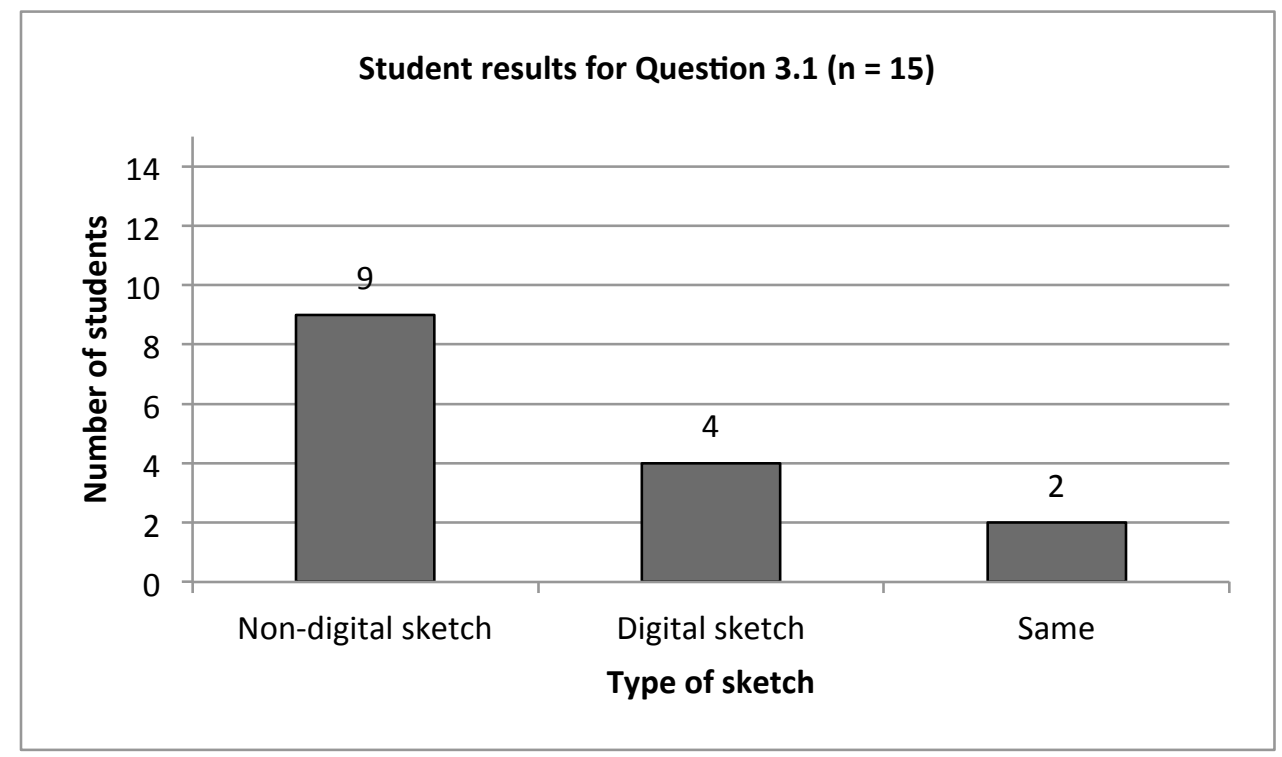

Figure 7-14: Student results for Question 3.1: "Most accurate representation of product"

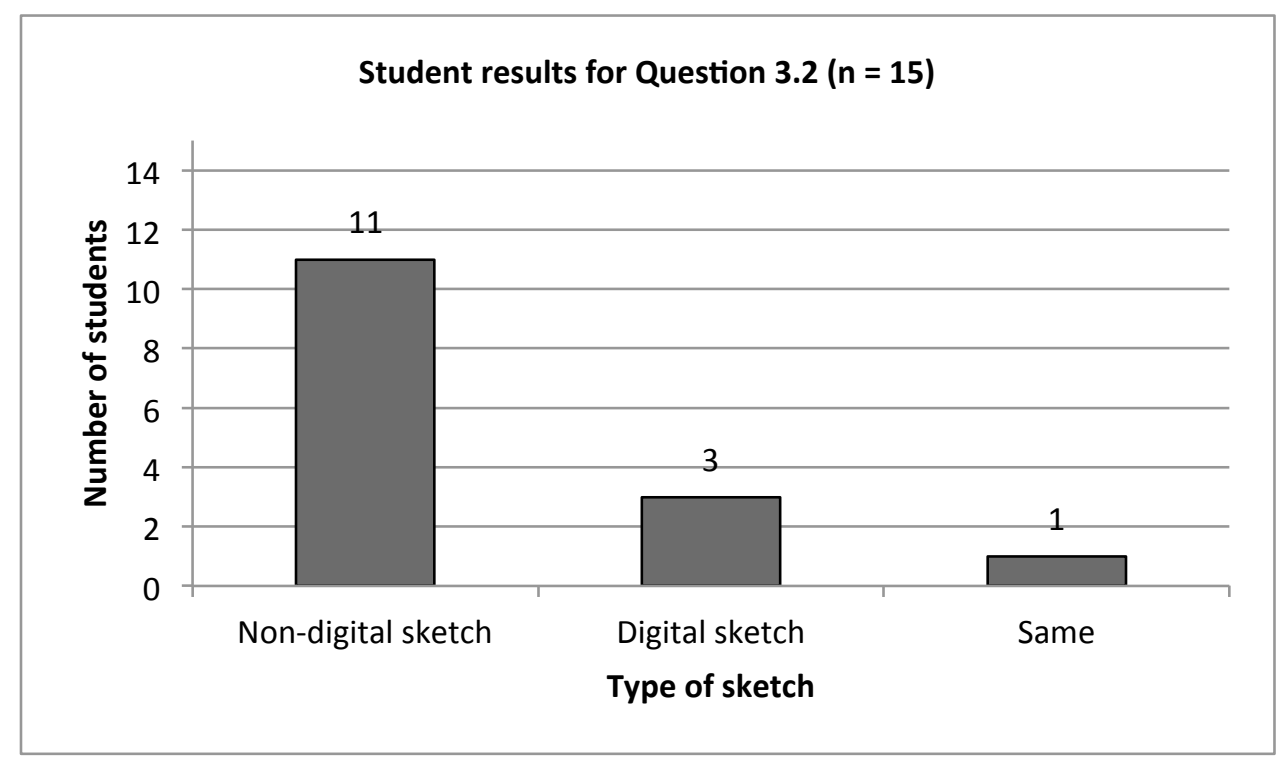

Figure 7-15: Student results for Question 3.2: "Most confidence in use of line" 


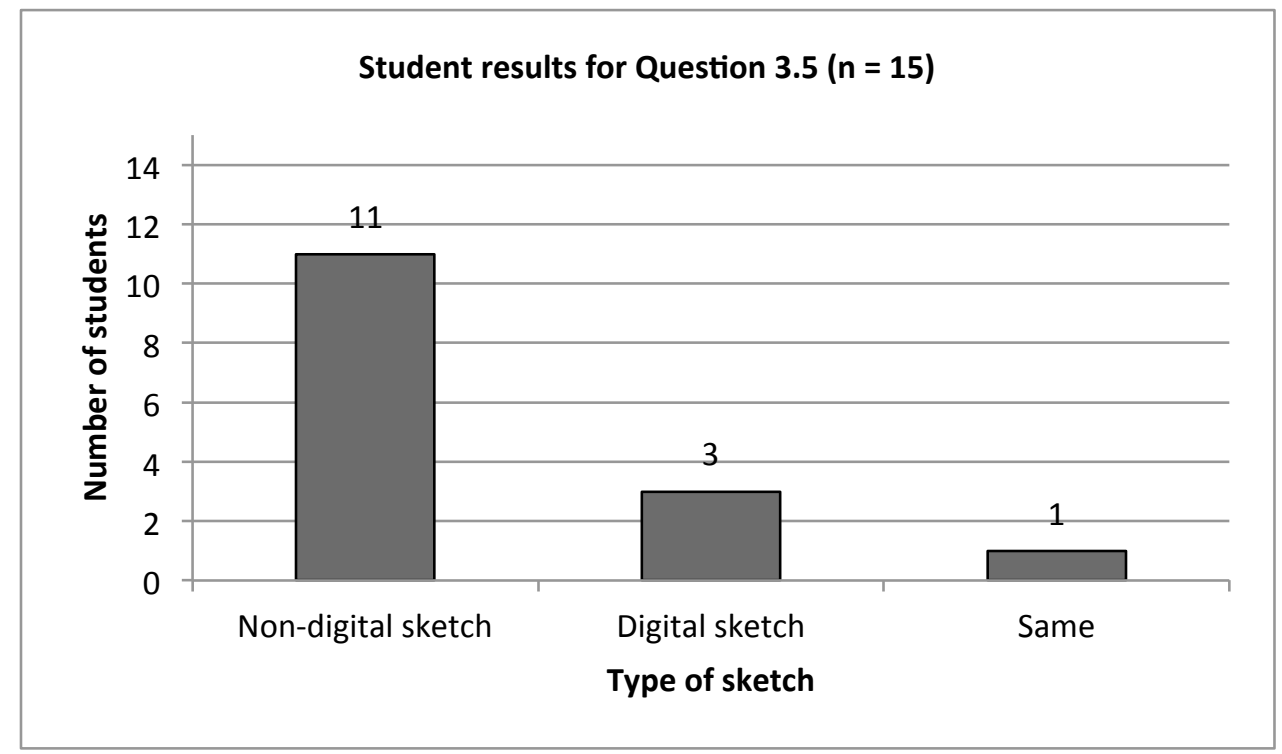

Figure 7-16: Student results for Question 3.5: "Quickest to produce"

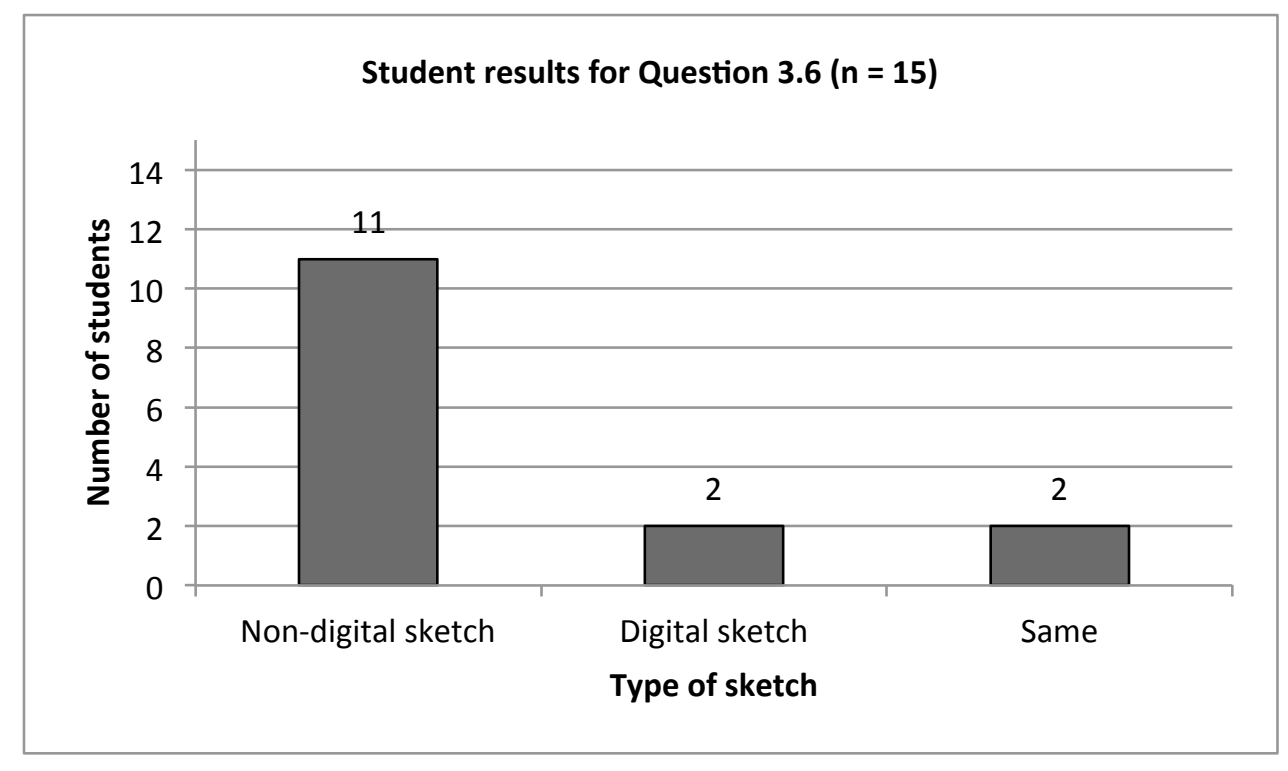

Figure 7-17: Student results for Question 3.6: "Easiest to use" 


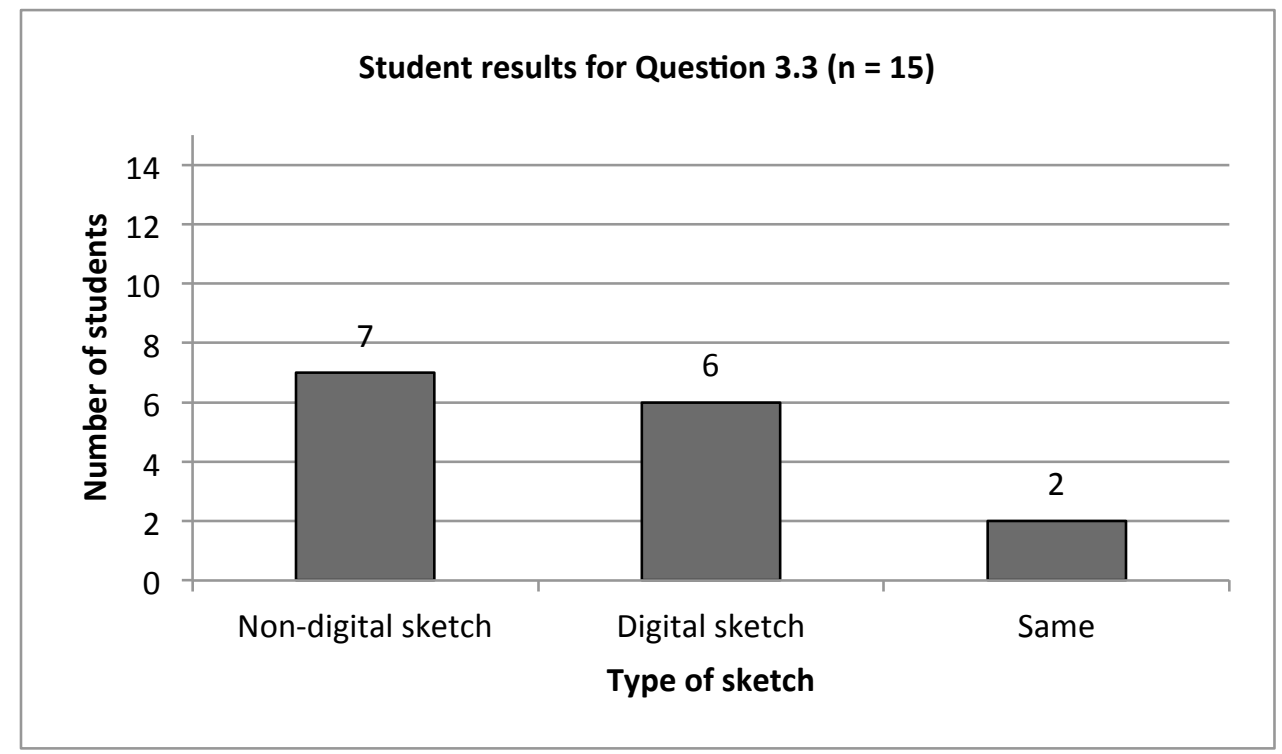

Figure 7-18: Student results for Question 3.3: "Most expressive"

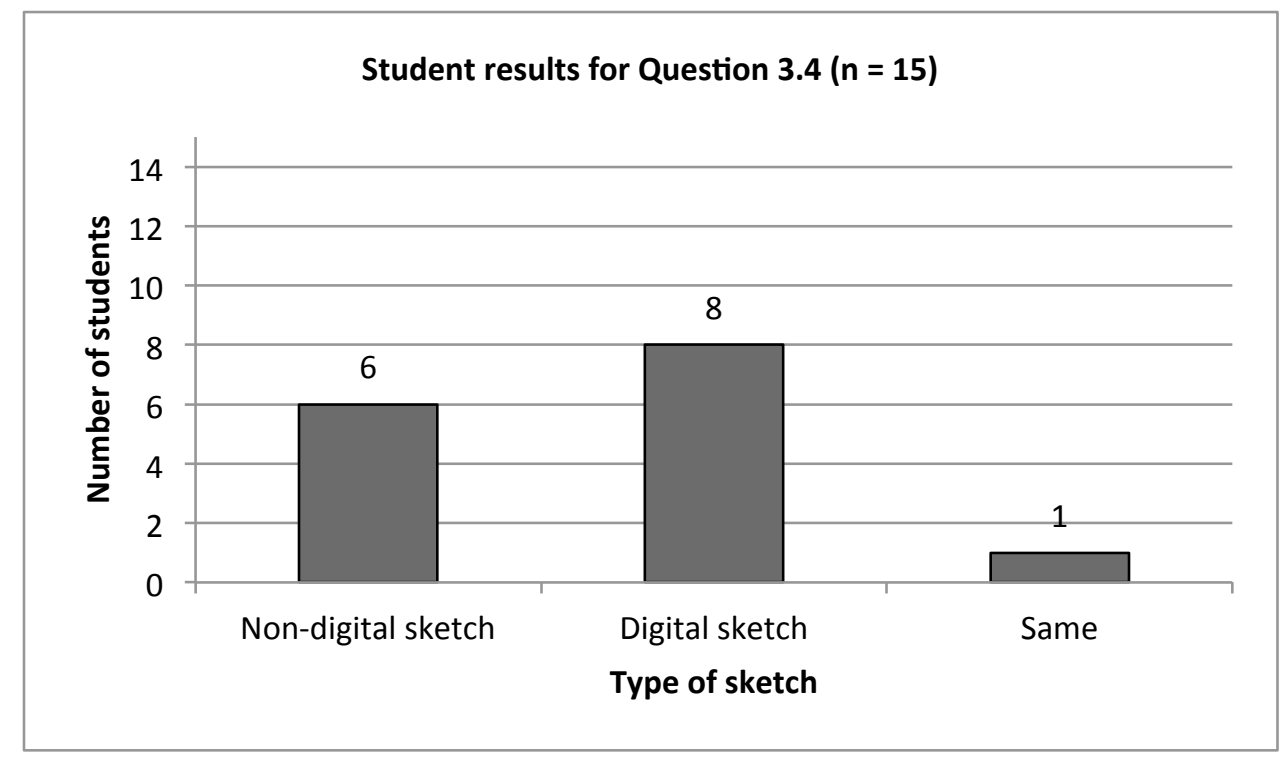

Figure 7-19: Student results for Question 3.4: "Most enjoyable" 


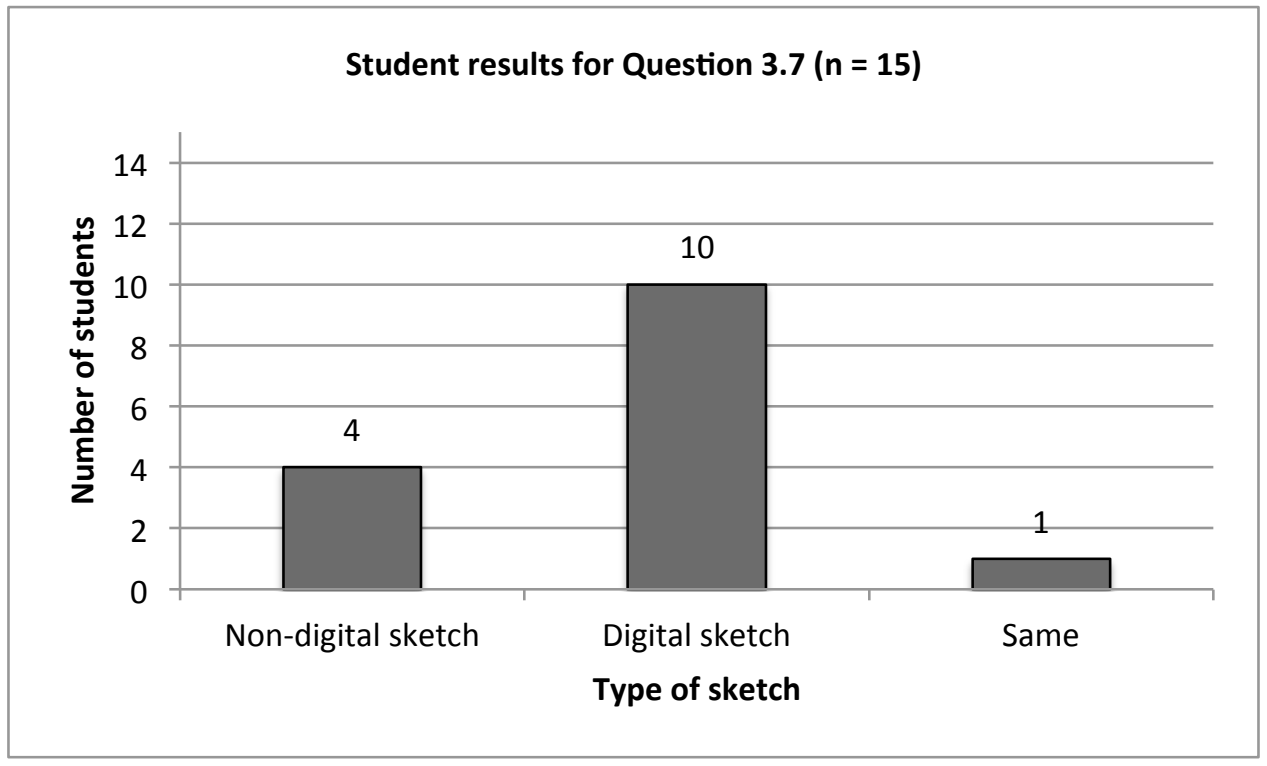

Figure 7-20: Student results for Question 3.7: "Required most error corrections"

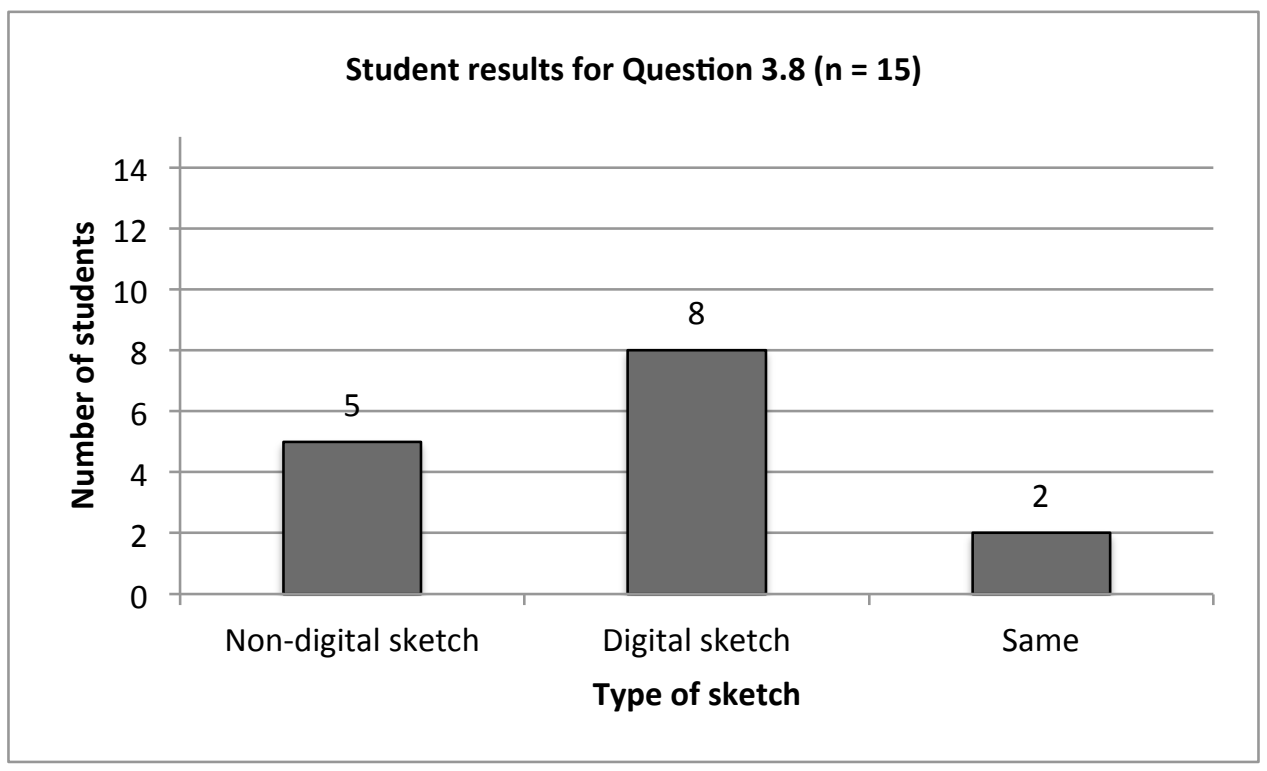

Figure 7-21: Student results for Question 3.8: "Preferred final sketch"

A summary of the sketching exercise responses to the closed-ended questions (Question 1 and Question 3) is illustrated in Table 7-3. 


\begin{tabular}{|c|c|c|c|c|c|c|}
\hline \multicolumn{2}{|r|}{ QUESTION } & \multicolumn{5}{|c|}{ RESPONSE } \\
\hline 1 & $\begin{array}{l}\text { How would you rate your ability to sketch using line only } \\
\text { during the design activity with the following media ( } 1 \text { being } \\
\text { low and } 5 \text { being high)? }\end{array}$ & $\begin{array}{c}1 \\
\text { (Low) }\end{array}$ & 2 & 3 & 4 & $\begin{array}{c}5 \\
\text { (High) }\end{array}$ \\
\hline 1 & Non-digital media & 0 & 1 & 7 & 7 & 0 \\
\hline 2 & Digital media & 0 & 3 & 10 & 2 & 0 \\
\hline \multicolumn{2}{|r|}{ QUESTION } & \multicolumn{5}{|c|}{ RESPONSE } \\
\hline 3 & $\begin{array}{l}\text { Indicate which of the following statements applies most to either } \\
\text { your non-digital sketching; your digital sketching; or equally to } \\
\text { both (tick both boxes). }\end{array}$ & \multicolumn{2}{|c|}{$\begin{array}{l}\text { Non-digital } \\
\text { sketching }\end{array}$} & $\begin{array}{c}\text { Digital } \\
\text { sketching }\end{array}$ & & $\begin{array}{l}\text { Digital and } \\
\text { non-digital } \\
\text { sketching }\end{array}$ \\
\hline 1 & Most accurate representation of product & \multicolumn{2}{|c|}{9} & 4 & & 2 \\
\hline 2 & Most confidence in use of line & \multicolumn{2}{|c|}{11} & 3 & & 1 \\
\hline 3 & Most expressive & \multicolumn{2}{|c|}{7} & 6 & & 2 \\
\hline 4 & Most enjoyable & \multicolumn{2}{|c|}{6} & 8 & & 1 \\
\hline 5 & Quickest to produce & \multicolumn{2}{|c|}{11} & 3 & & 1 \\
\hline 6 & Easiest to use & \multicolumn{2}{|c|}{11} & 2 & & 2 \\
\hline 7 & Required most error corrections (erase/undo) & \multicolumn{2}{|c|}{4} & 10 & & 1 \\
\hline 8 & Preferred final sketch & \multicolumn{2}{|c|}{5} & 8 & & 2 \\
\hline
\end{tabular}

Table 7-3: Summary of the student responses to the quantitative questions in the sketching exercise questionnaire $(n=15)$

\subsubsection{Assessing the Output of the Sketching Exercise Questionnaire}

In addition to student feedback on the sketching exercise, expert opinion was gathered via a postal questionnaire on the effectiveness of the sketches to represent product form. The questionnaire utilised the sketches produced by individual students by pairing them for each product and presenting them on an A4 sheet of paper. Tick boxes were used to enable the respondent to indicate which of the two sketches most accurately represented the product form or if a difference could not be distinguished. The respondents were provided with photographs of the torch and spoon to help them in their judgment (Appendix 11.9). Despite the fact that 15 students took part in the sketching exercise, only 13 students sketches were used in the questionnaire, as two digital sketches were lost when data was transferred.

The questionnaire was completed by 12 academic staff who had taught sketching to undergraduate students and were qualified industrial designers with commercial experience. Whilst the number of questionnaire responses was relatively low, as experts in industrial design sketching there was a high degree of reliability in the responses.

Results from the student sketching exercise questionnaire revealed that the majority of students thought that the non-digital sketch was more accurate when compared to the digital. However, most of the students preferred the digital sketch, which could be due to their enjoyment and enthusiasm for the process. When academics were asked to indicate the most effective sketch, the majority (51.9\%) selected the non-digital sketch when it came 
to the child's spoon and $49.4 \%$ chose the non-digital sketch of the torch over its digital equivalent. Almost a quarter of the academics preferred the digital sketches of the organic and geometric products (Figure 7-22).

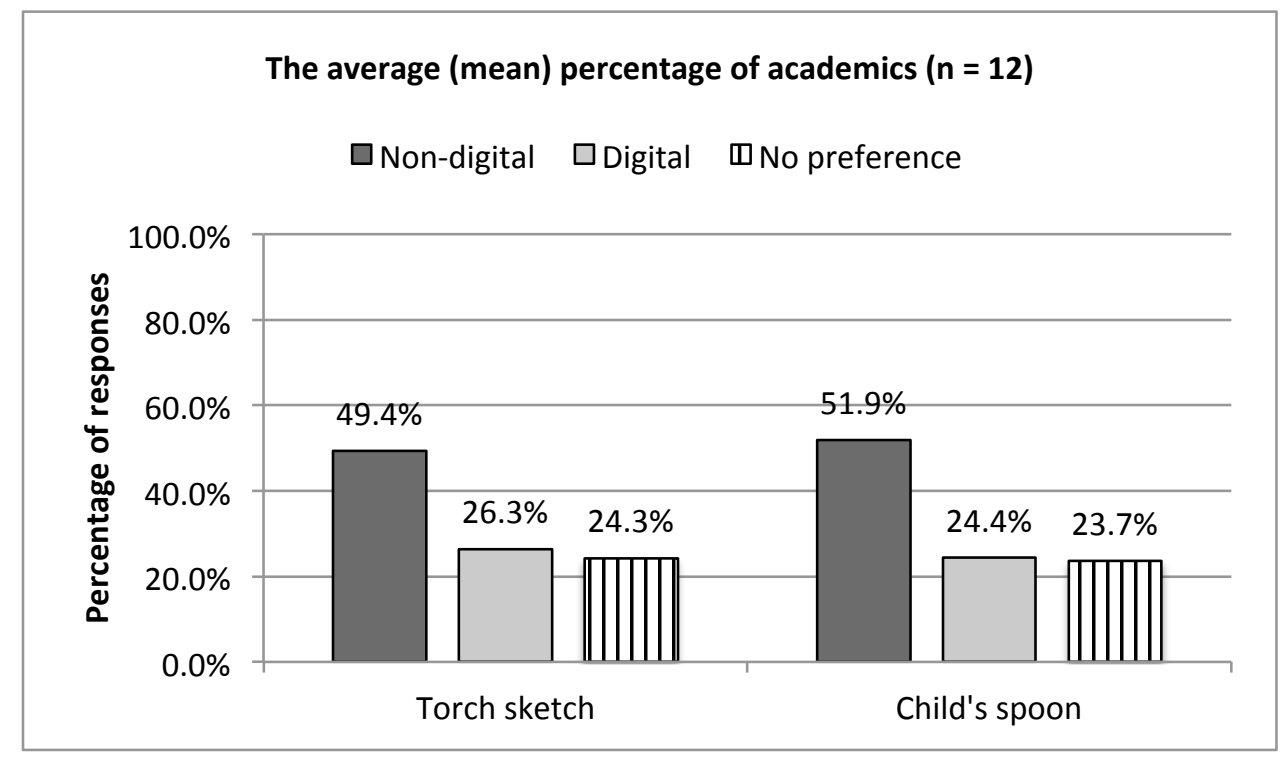

Figure 7-22: Graph showing the average (mean) percentage of academics in response to Question: "Please indicate which sketch is most effective in the communication of product form"

The average (mean) of the academics preferring a specific sketch (digital torch sketch, nondigital torch sketch, digital child's spoon sketch, non-digital child's spoon sketch) was calculated by adding the number of academics that preferred the sketch for all of the 13 students. The total was then divided by the result of multiplying the number of academics (12 academics) by the number of students (13 students), making the result of 156 . Finally, to get the percentage, the result was divided by 100 .

The questionnaire results indicate that within student practice, conventional tools/media produce more effective sketches (line work mainly) than digital sketching when it comes to geometric and organic shape products

\subsection{Design Exercise}

The aim of the design exercise was to evaluate the use of the Tablet PC for concept generation. The exercise allocated two hours for the design of a new product (a pepper mill) using the Tablet PC only. Sixteen students were given a detailed briefing on what was 
required for the pepper mill design which was supported by examples of existing products

(Figure 7-23, Figure 7-24 and Figure 7-25).

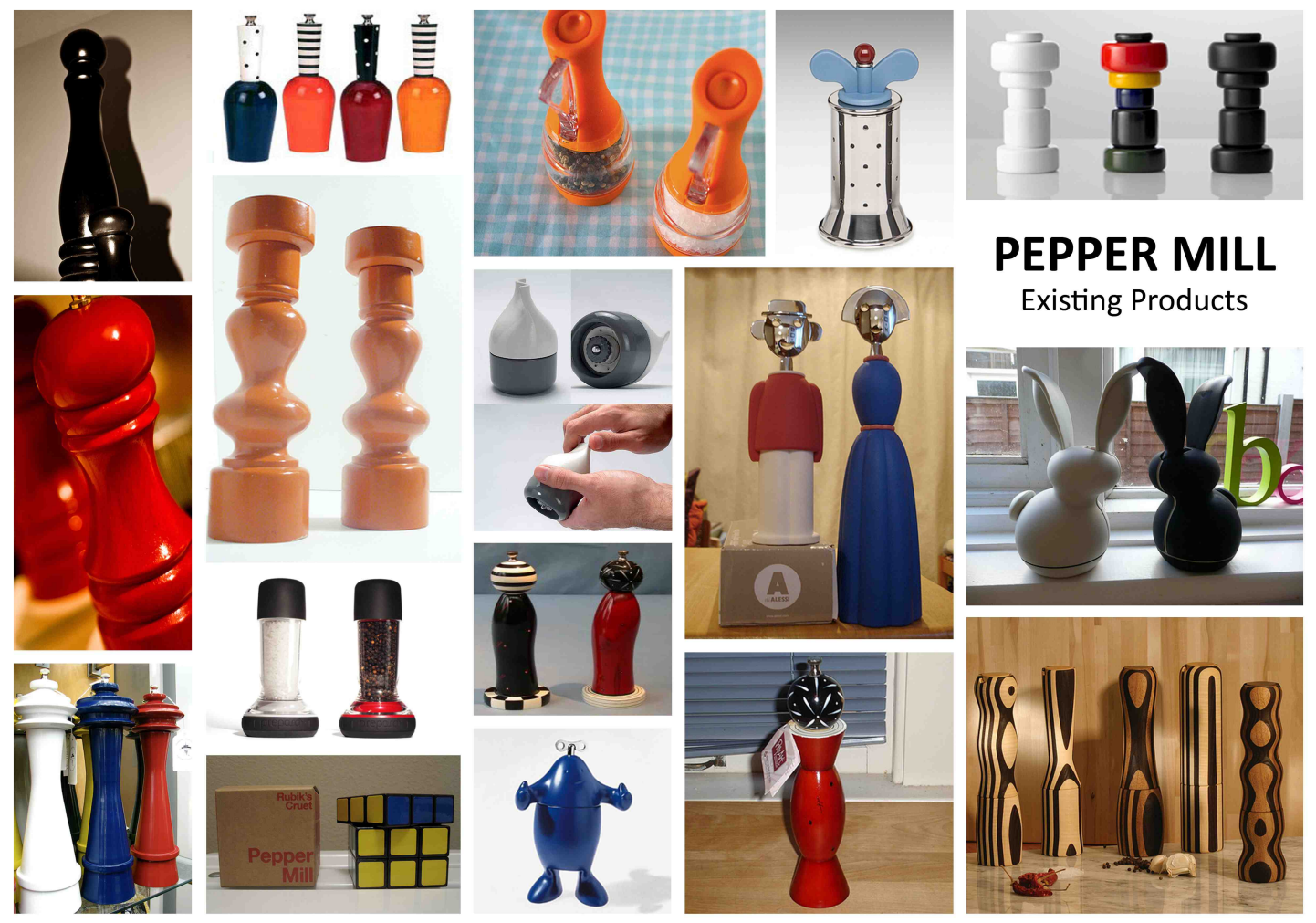

Figure 7-23: Examples of pepper mills used to brief students (1 of 3) 

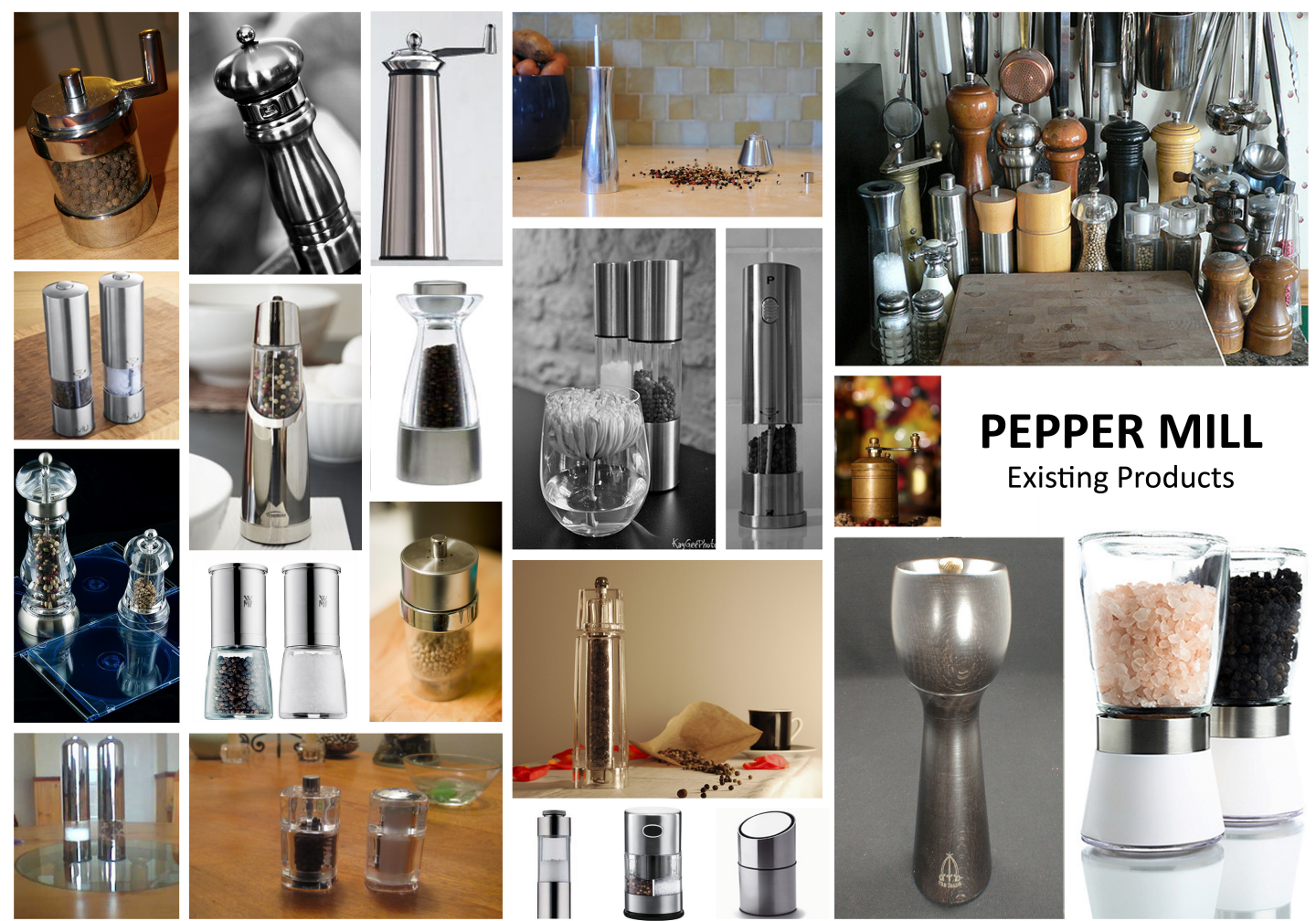

PEPPER MILL

Existing Products

Figure 7-24: Examples of pepper mills used to brief students (2 of 3)
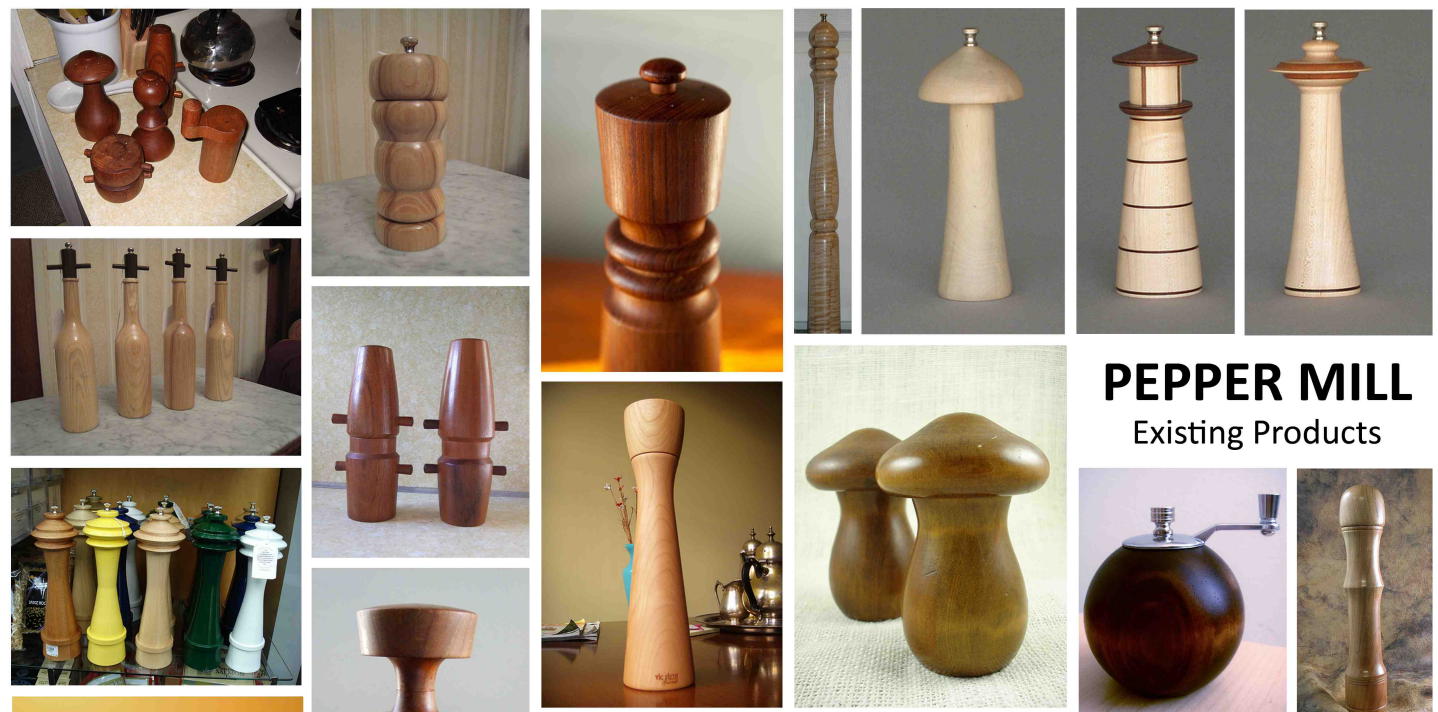

PEPPER MILL

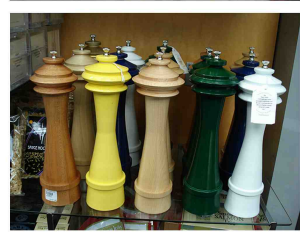

1
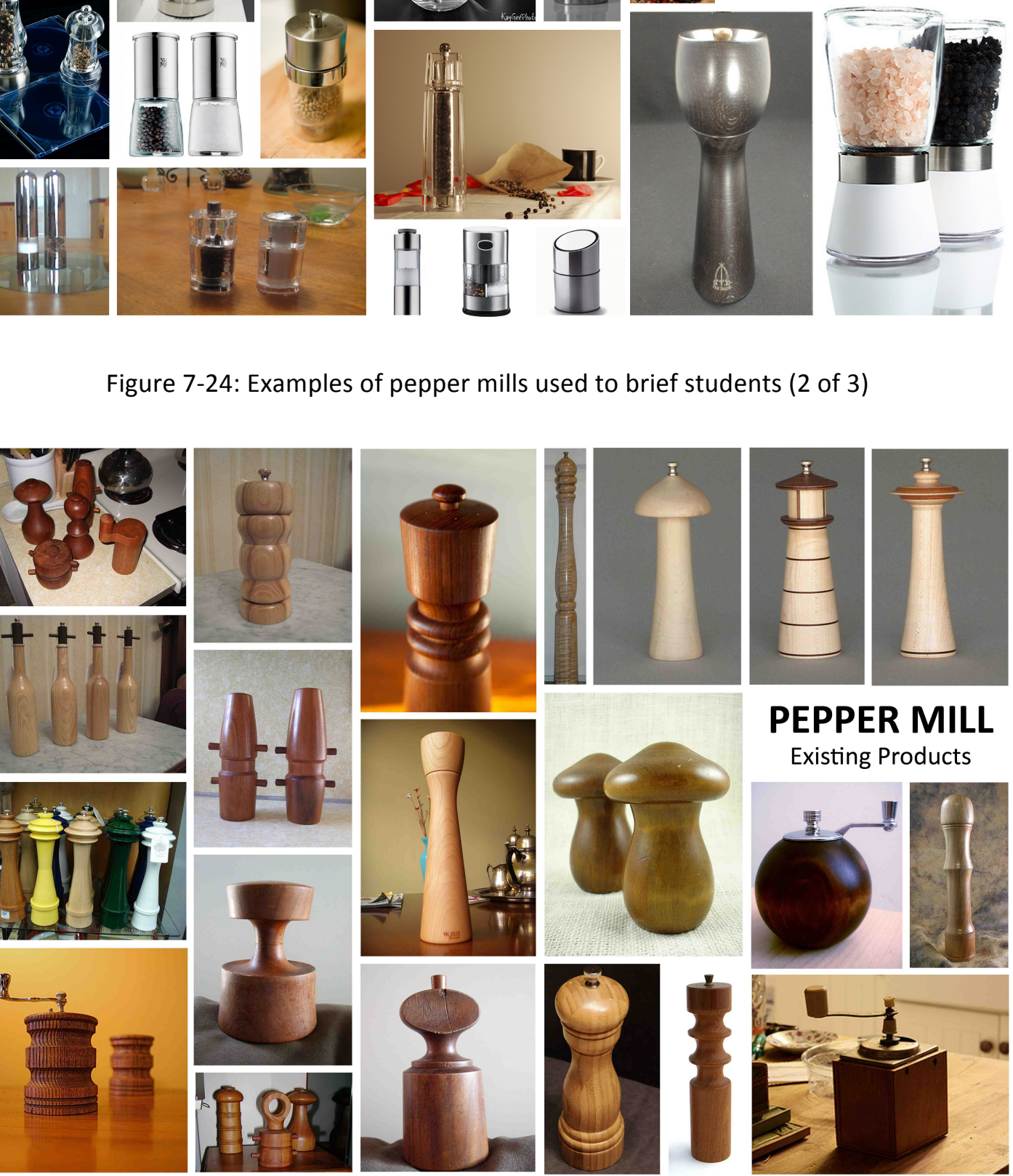

Existing Products

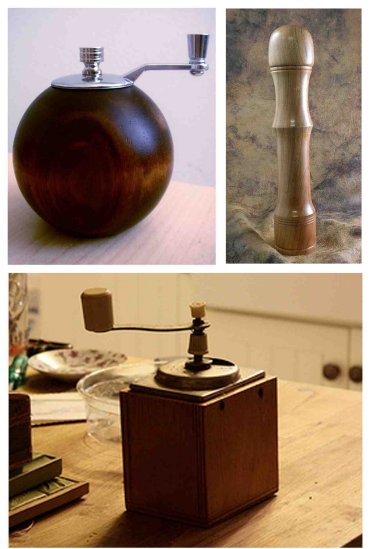

Figure 7-25: Examples of pepper mills used to brief students (3 of 3) 
Students were required to produce a single perspective view of the proposal plus two elevational views. The application of colour/shade was optional and the use of 3D CAD was not allowed, i.e. it had to be sketches produced using the interactive tablet and $2 \mathrm{D}$ visualisation software. During the design exercise, the students employed the full functionality of the interactive screen whilst sketching, including use of the virtual keyboard and capacity to loosely apply tone and colour (Figure 7-26 and Figure 7-27).

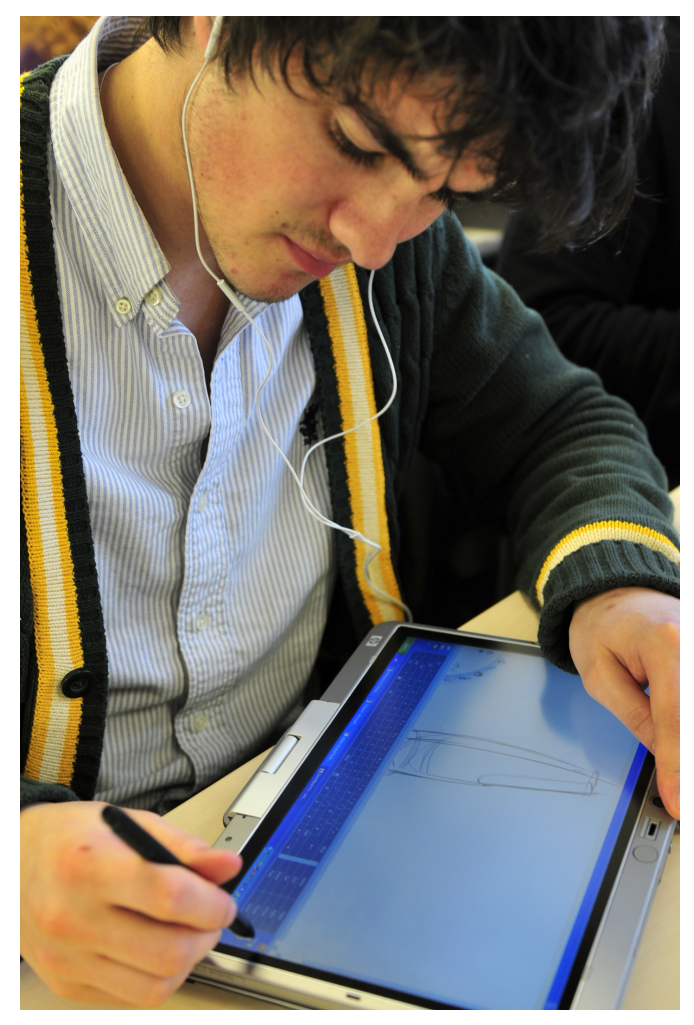

Figure 7-26: Use of virtual keyboard whilst undertaking the design exercise 


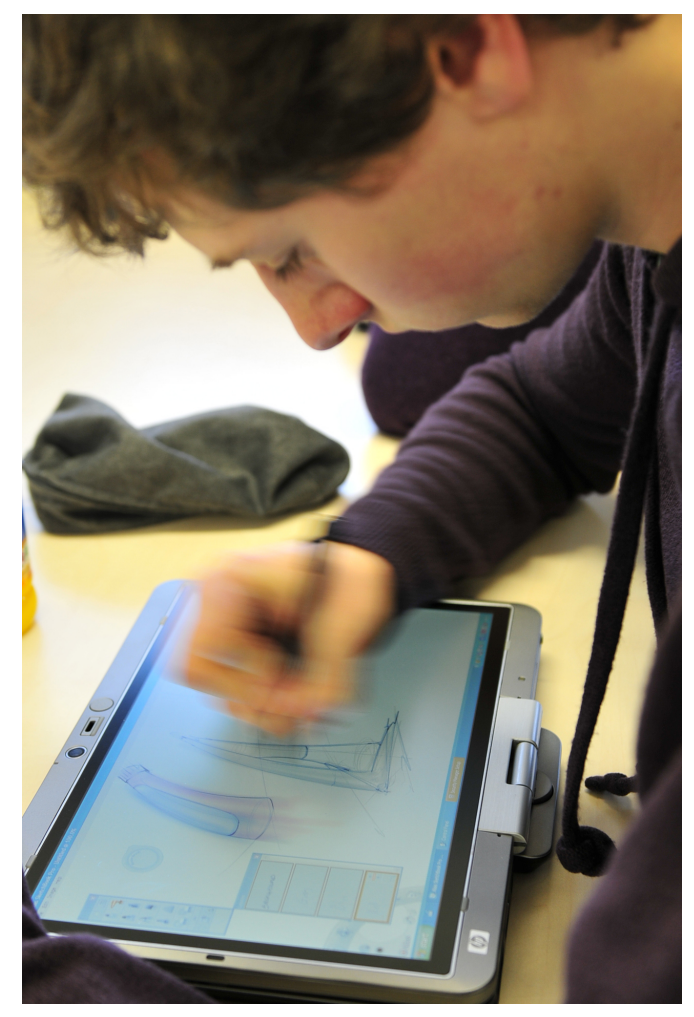

Figure 7-27: Loose application of colour during the design exercise

At the end of the design exercise, the proposals were collected using a memory stick. Examples of design the diversity of proposals can be seen in Figure 7-28, Figure 7-29 and Figure 7-30.

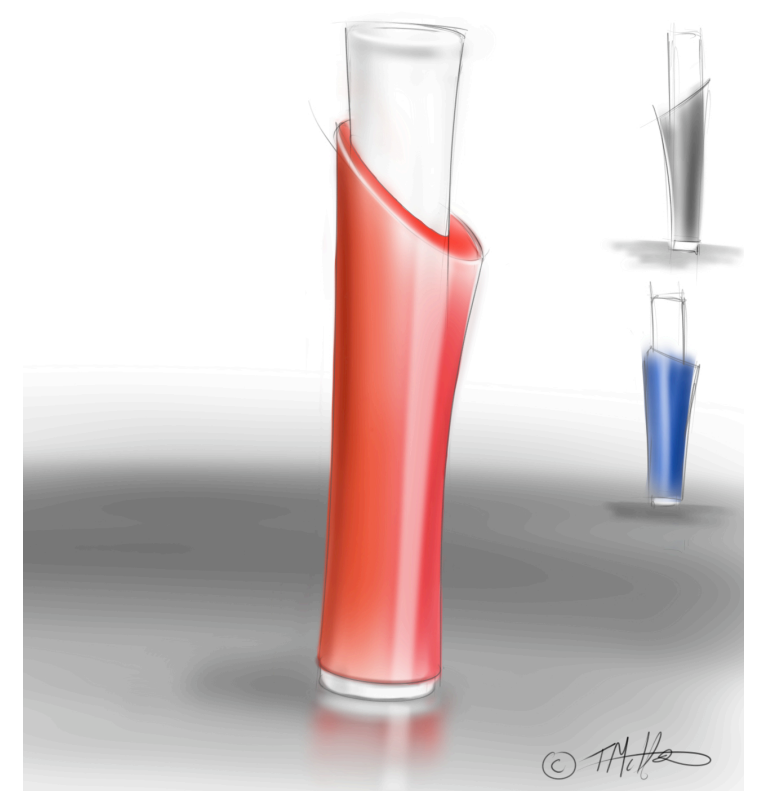

Figure 7-28: Sketch rendered output from design exercise 

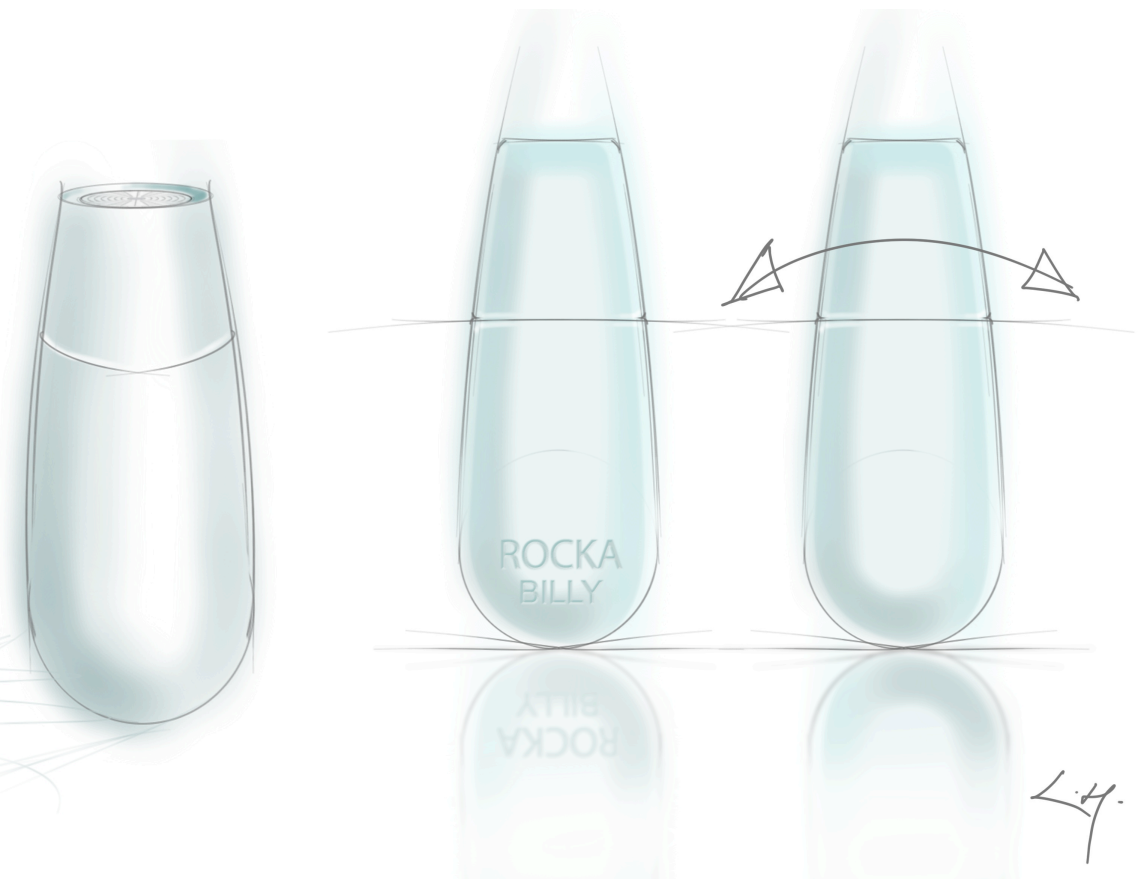

Figure 7-29: Sketch rendered output from design exercise
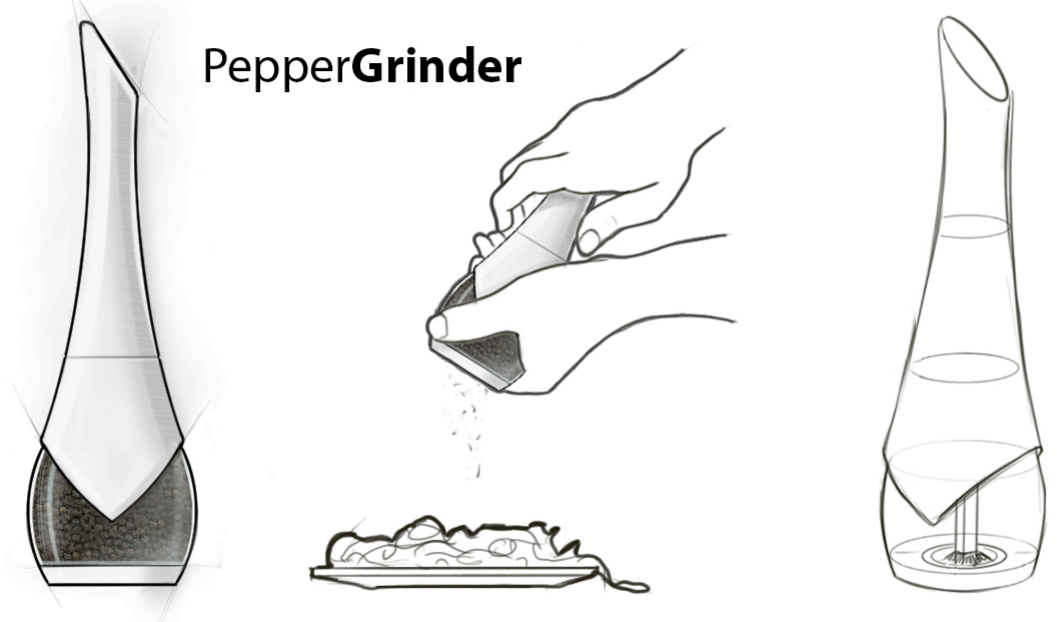

Figure 7-30: Sketch rendered output from design exercise

When observing the design exercise, it was noted that students were rapidly switching between design sketching and accessing supporting material on the Internet. Whilst such activity would be possible when using a computer and paper-based techniques, it was apparent that the Tablet PC facilitated a seamless transition to support design activity. This went beyond the more typical searches for examples of related products and stylistic direction and was the case with the proposal illustrated in Figure 7-30 where the student 
accessed images of pepper and hands in the pose required for the visualisation. The images of hands were imported and traced for use in the proposal in Figure 7-30.

It was noted that while some students preferred sketching with the Tablet PC laying flat on the table, others preferred to sketch with it fixed at an angle using the hand to support it, or in some cases by using an item of clothing (Figure 7-31). Students tended to use the undo feature and zoom in and out to get more accurate line work and shading. When the Tablet PC was set flat to be used for sketching, the screen covers the keyboard so students tended to attach another keyboard to enable them to use software shortcuts (Figure 7-32).

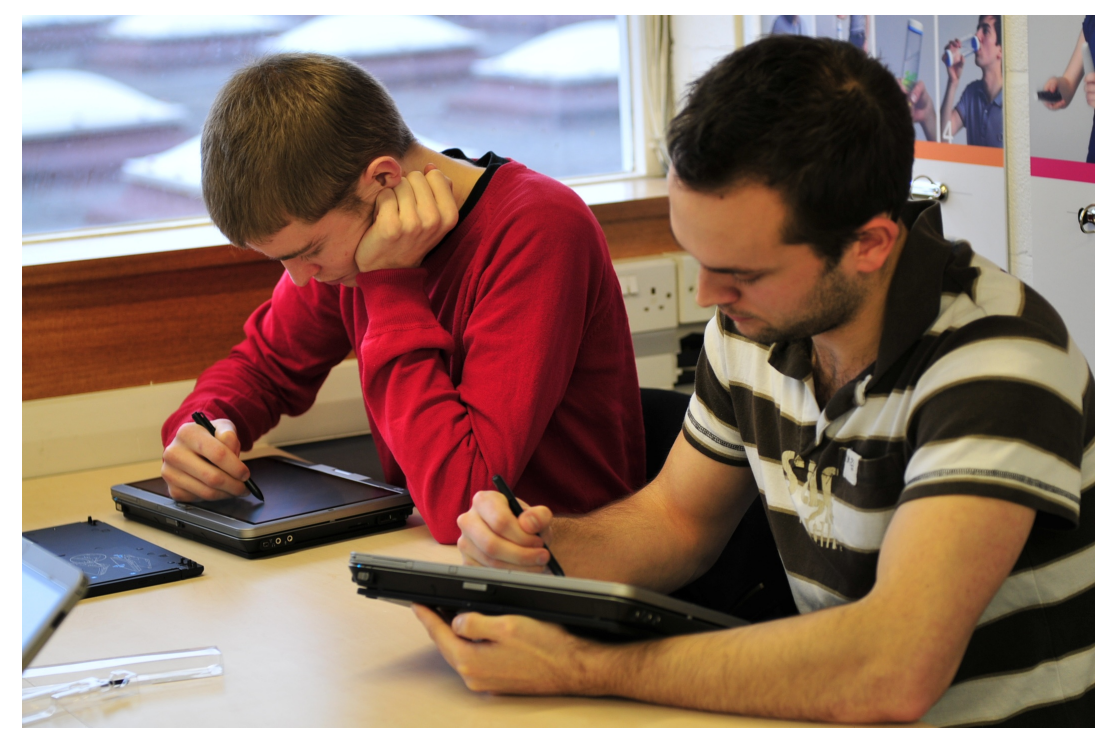

Figure 7-31: Students using the Tablet PCs in the design exercise

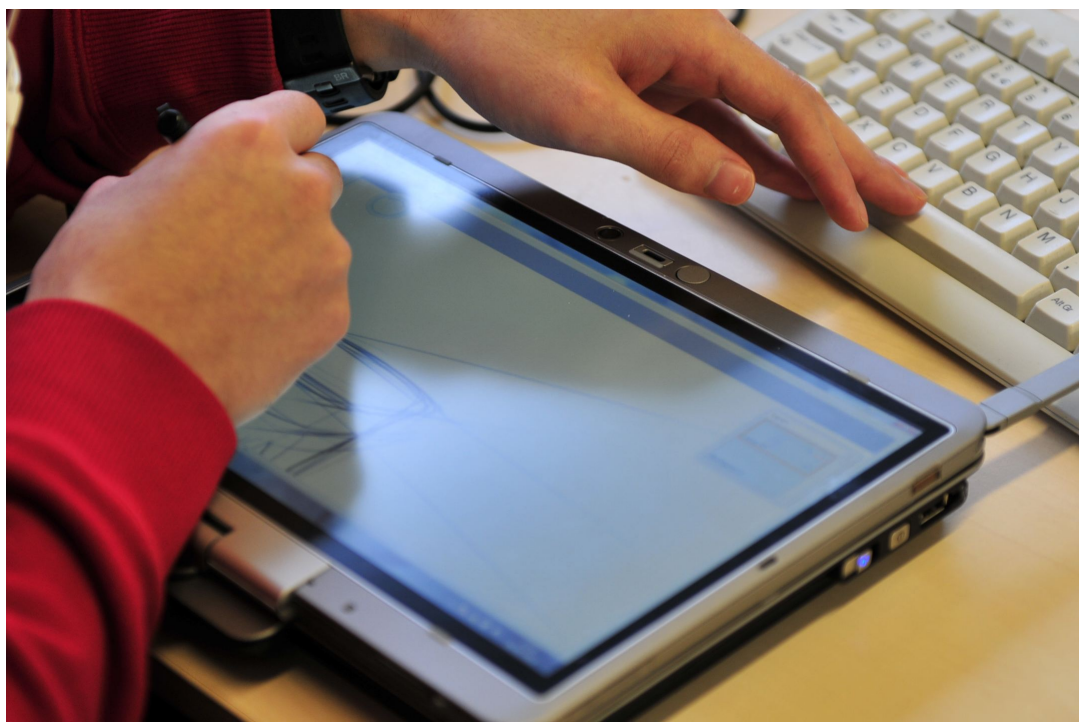

Figure 7-32: Use of addition keyboard to help in using shortcuts when sketching 
The pepper mill design exercise was undertaken to help develop capability in using the interactive screen. The exercise was an opportunity for the students to address problems and share expertise (Figure 7-33).

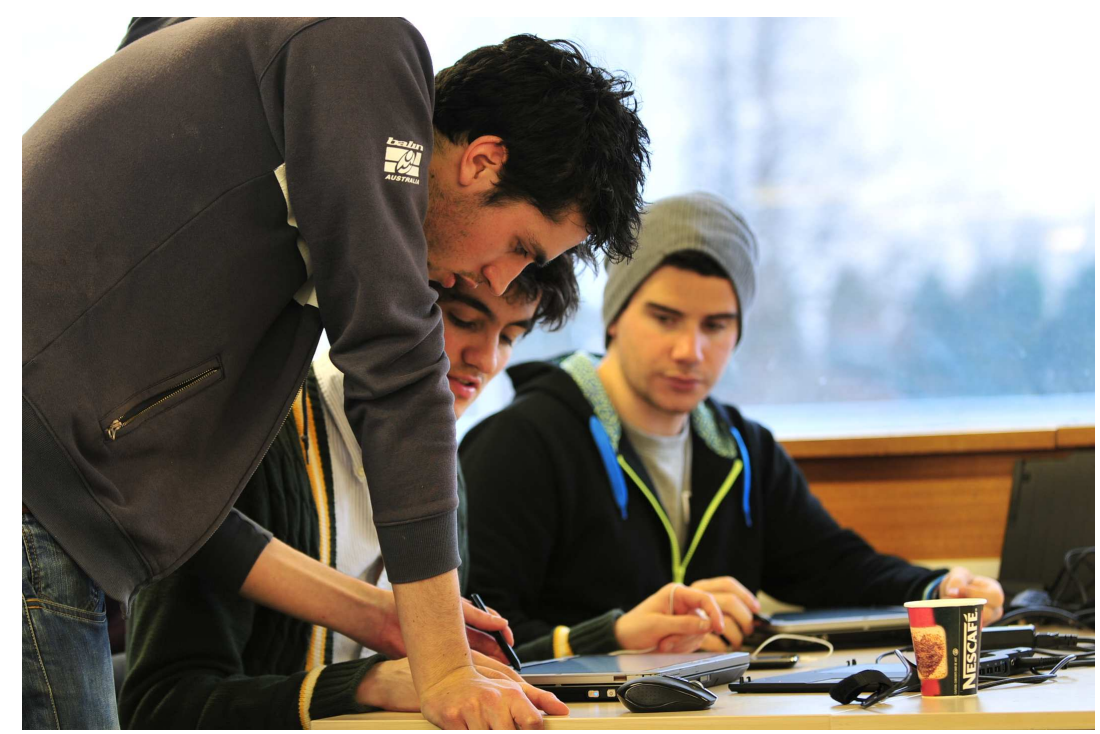

Figure 7-33: Sharing knowledge during the design exercise

On completion of the pepper mill design exercise, the students completed a Design Exercise Questionnaire that involved listing three strengths and three weaknesses in using the Tablet PC for the task (Appendix 11.10). The students were also asked about the software they used during the design of the pepper mill.

Collation of the data revealed that Autodesk SketchBook Pro and Photoshop were the software packages used by the majority of students during the exercise. Students noted that the ability to undo mistakes was the most important advantage as some mentioned that this increased their confidence and improved the quality of line work. The Tablet PC facilitated quick rendering and shading, especially as it offered a range of tools in one device. The use of layers supported a quick workflow and ease of producing slight variation of concepts.

A key weakness was the precision of the stylus caused by the thickness of the screen or calibration of the pen tool. Students also had problems with the screen, considering it to be too small and others mentioned screen glare from overhead lights. Four students felt that rotating the Tablet PC was relatively difficult and the same number had issues with the height of the Tablet PC, which prevented the elbow from being flat when sketching. The fact that the keyboard was unusable when sketching annoyed some students as it prevented them from using the software shortcuts. A small number of students thought that sketching 
activity was slower and the stylus often slipped because of the lack of resistance. Table 7-4 provides a summary of the strengths and weaknesses of the Tablet PC mentioned by the students.

\begin{tabular}{|lc|lc|}
\hline \multicolumn{1}{|c|}{ Strengths } & Occurrences & \multicolumn{1}{c|}{ Weaknesses } & Occurrences \\
\hline Ability to undo & 9 & Poor calibration of the stylus tool & 9 \\
Quick rendering and shading & 7 & Size of the screen & 6 \\
Layers advantage & 5 & Screen glare & 5 \\
Variety of tools to hand & 5 & Difficult to rotate screen & 4 \\
Easy access & 3 & Height of tablet & 4 \\
Producing slight variation quickly & 3 & Lack of friction & 3 \\
Ease of creating straight & 3 & Keyboard unusable when & 2 \\
lines/shapes & & Sketching & \\
Quality of rending & 2 & Slows down sketching & 2 \\
Outcome looks good & 2 & Not good without a mouse & 1 \\
Pressure sensitive & 1 & Stylus does not feel like a pen & 1 \\
Ability to change size and & Difficult to compare a range of & 1 \\
orientation & 1 & ideas & \\
Sketching & 1 & Pop-ups disturbes workflow & 1 \\
Smoothness of line & 1 & Screen at an uncomfortable angle & 1 \\
& & Easy to 'slip' on small details & 1 \\
& & Encourages undoing & 1 \\
& & Constrictive & 1 \\
& & Takes a while to get used to & 1 \\
\hline
\end{tabular}

Table 7-4: Summary of the Tablet PC strengths and weakness identified by students after undertaking the design exercise

\subsection{Focus Groups}

After using the Tablet PCs for more than three months, the students participated in a focus group during which seven semi-structured questions were used to elicit open-ended feedback on their general experience; its impact on sketching, creativity and productivity; what skills the students thought were required to teach the use of the Tablet PC; if they felt that the Tablet PC should be introduced to all industrial design students; and any other comments. Two focus groups of seven students each (BA group and BSc group) took place. An industrial design academic (Dr Mark Evans) who had experience of professional practice, teaching product sketching and digital design methods facilitated the focus groups (Figure 7-34). Appendix 11.11 provides a sample transcription of one of the focus groups carried out with students. 


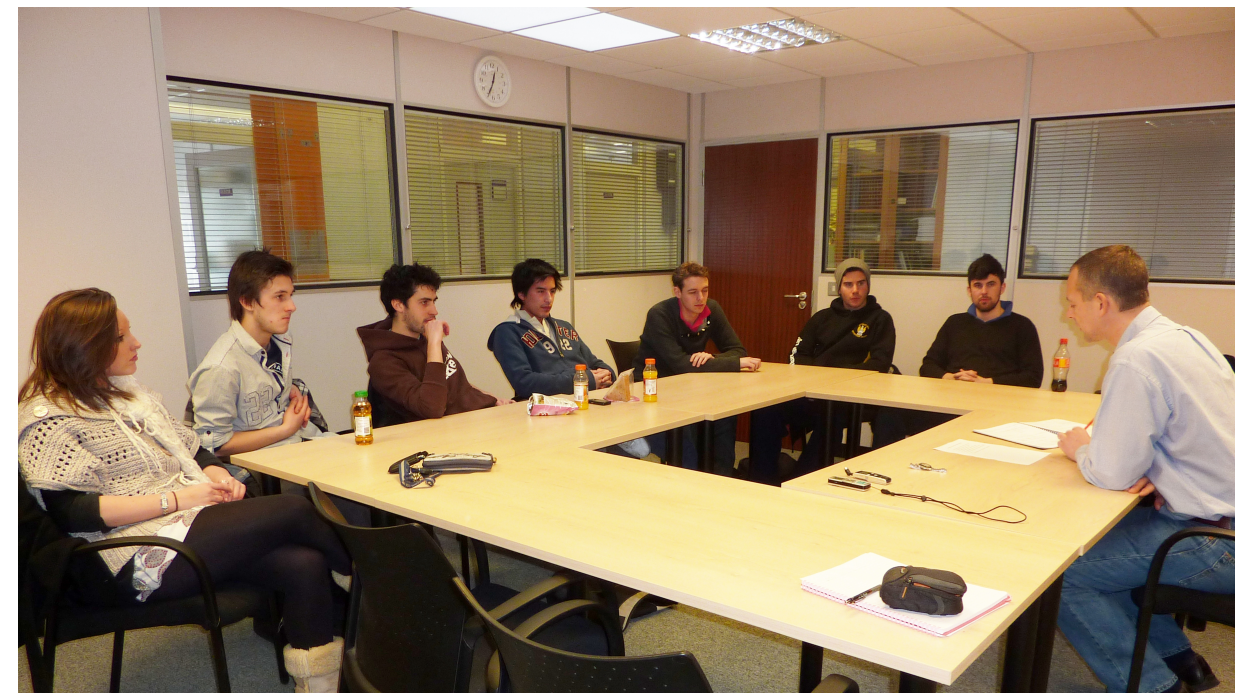

Figure 7-34: Focus group on the use of Tablet PC undertaken with BSc students

Seventy-two distinctive responses were recorded and translated into a final questionnaire for use when the students returned the computers four-and-a-half months later. The open nature of the focus group provided a forum in which the widest possible range of issues could be elicited. This supported the aim of the final use of Tablet PC Questionnaire which was to identify the wide range of issues raised in the focus group.

Litosselitie (2003: 92) suggests that while analysing focus groups, the investigator should consider the "balance of positive and negative comments about an issue or idea". After analysing the BSC and BA students' focus groups, it was noticed that the BSc group mentioned more positive points about the use of the Tablet PC as a design tool than the BA group especially when it came to the sketching activity.

\subsection{Pre- and Post-Survey}

Having had experience of using a Tablet PC with the capacity to be used as a design tool that integrated sketching and 3D CAD in a highly portable format, it was expected that changes might arise in the student feelings towards digital design methods. The pre- and post-survey was mainly designed to identify any accrued changes in the attitudes of students and their opinion on the potential of industrial designers to operate using entirely digital methods after using the Tablet PC (Appendix 11.12). All of the students that participated in the case study completed a questionnaire before being handed the Tablet PC and again on the last day of the case study when the Tablet PC was returned. 
The questionnaire asked the students "To what extent do you agree or disagree with the following statements?" using 13 statements comparing digital design methods to non-digital design.

\subsubsection{Positive Attitude}

The findings indicate a general increase in the positive attitude of the students to employ digital design methods after using the Tablet PC, this being particularly apparent in terms of its portability (Figure 7-35); exploration of alternative solutions (Figure 7-36); productivity (Figure 7-37); facilitating collaboration (Figure 7-38); contribution to the design development phases (Figure 7-39); and viability of designing product entirely digitally (Figure 7-40).

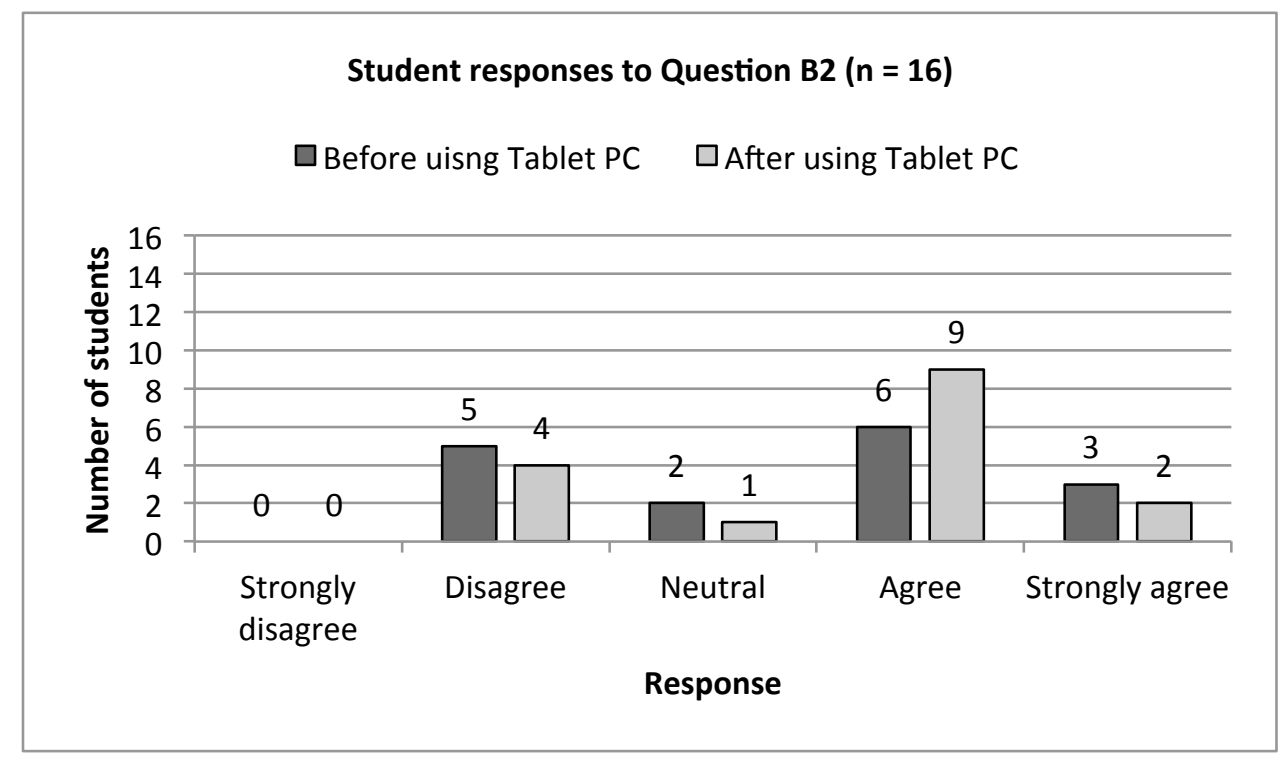

Figure 7-35: Student responses to Question B2: "To what extent do you agree or disagree that digital design methods offer more portability than non-digital design methods?" 


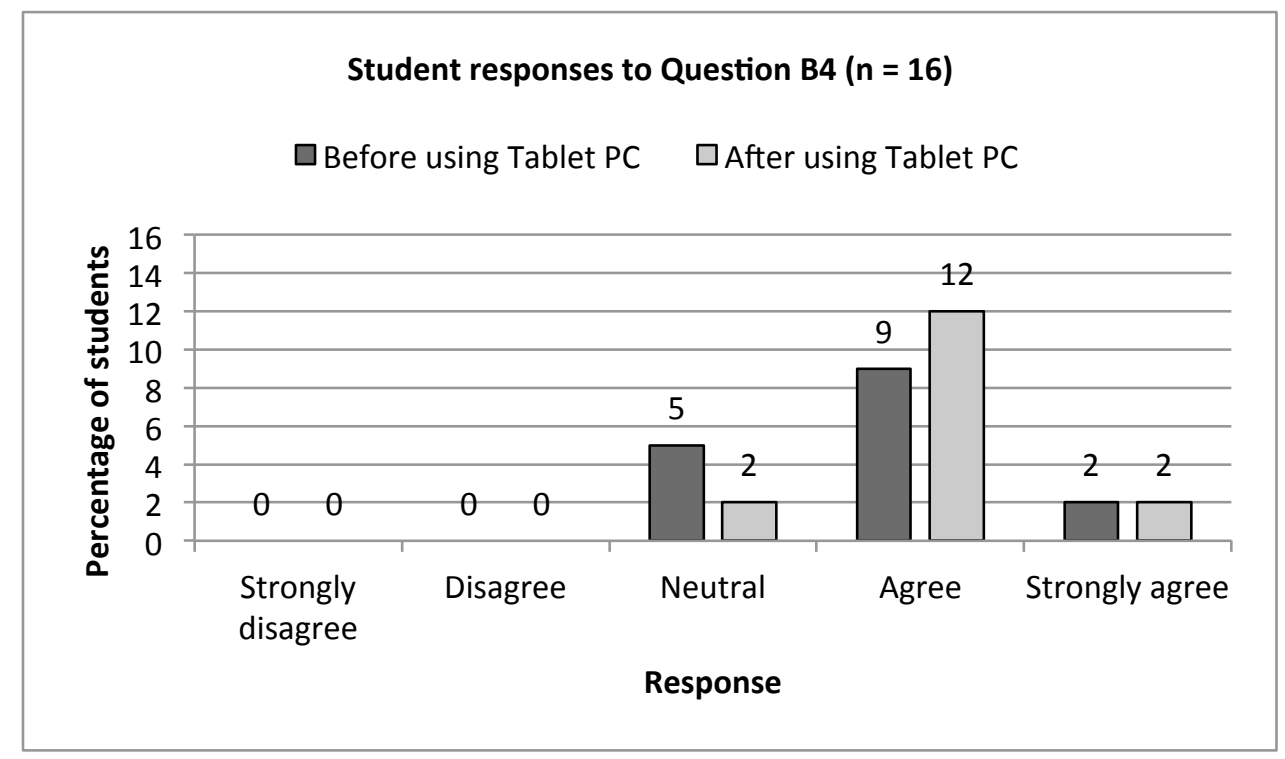

Figure 7-36: Student responses to Question B4: "To what extent do you agree or disagree that digital design methods provide more opportunities to explore alternative solutions than non-digital design methods?"

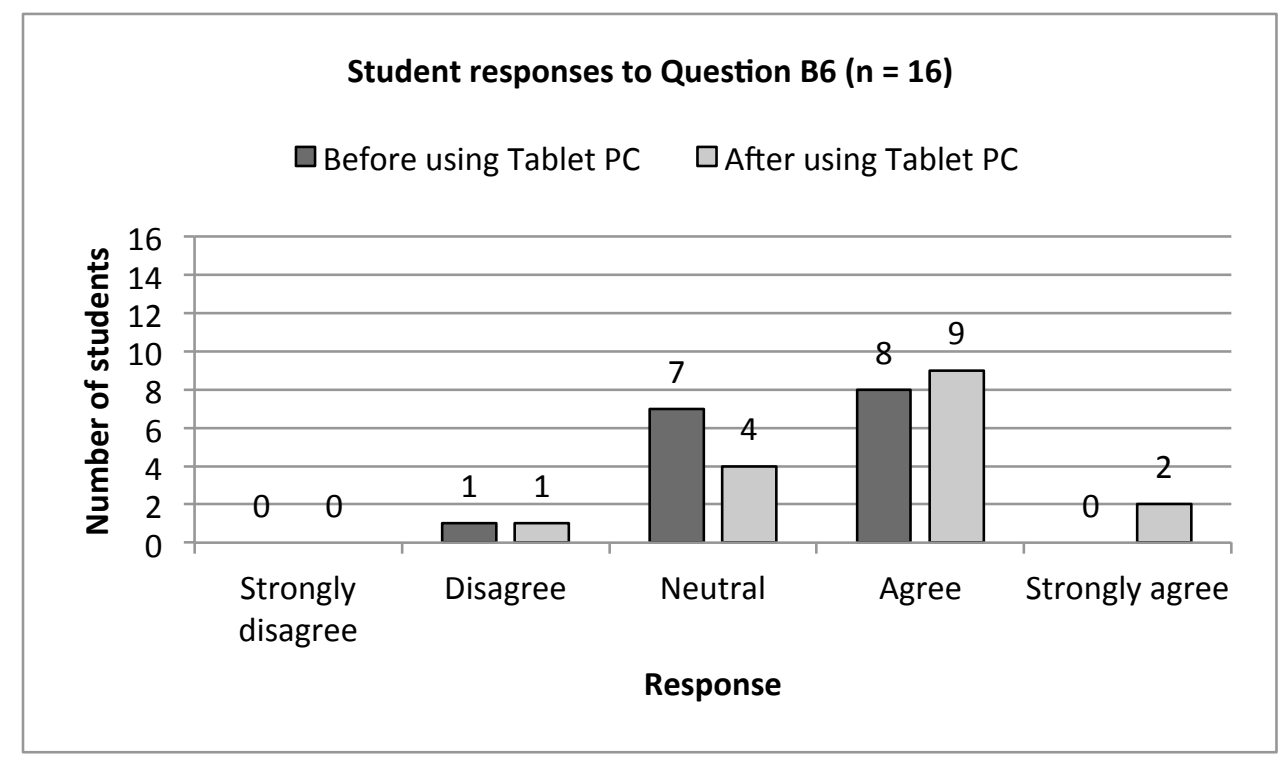

Figure 7-37: Student responses to Question B6: "To what extent do you agree or disagree that digital design methods are more productive than the non-digital design methods?" 


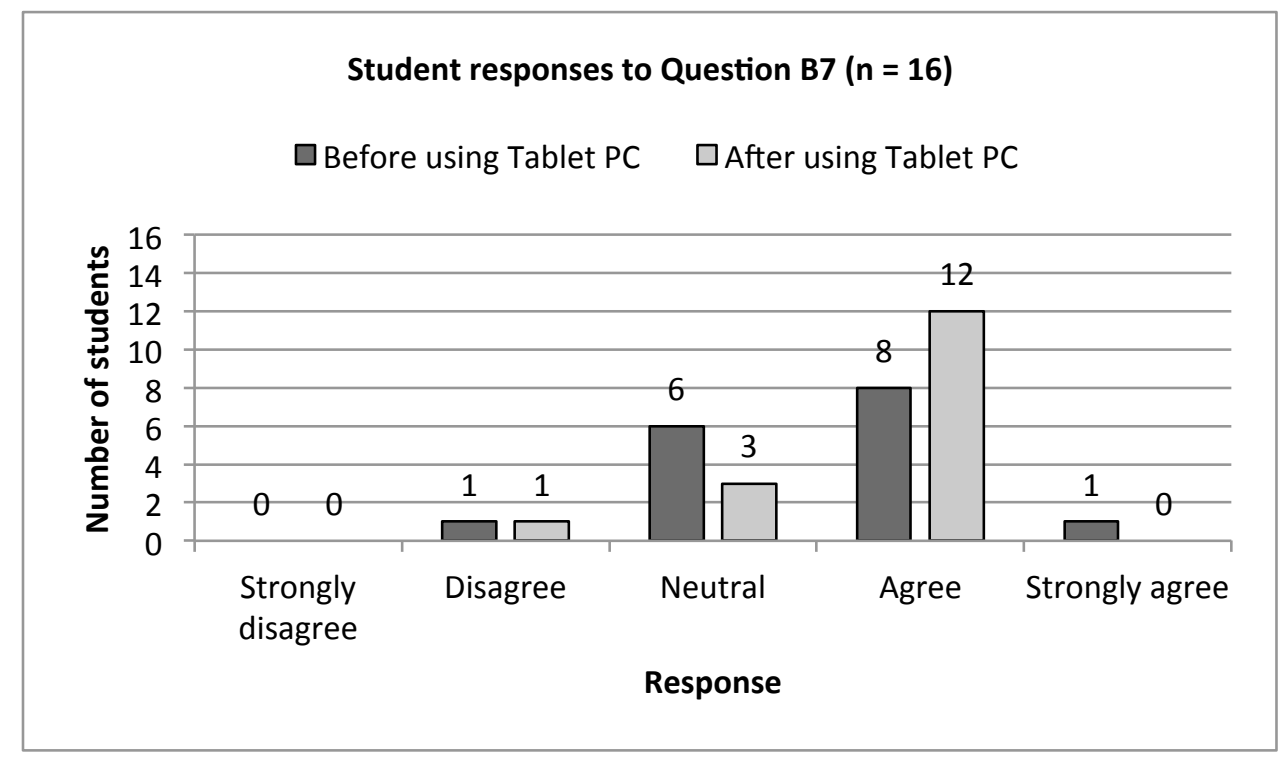

Figure 7-38: Student responses to Question B7: "To what extent do you agree or disagree that digital design methods facilitate the collaboration more than non-digital design methods?"

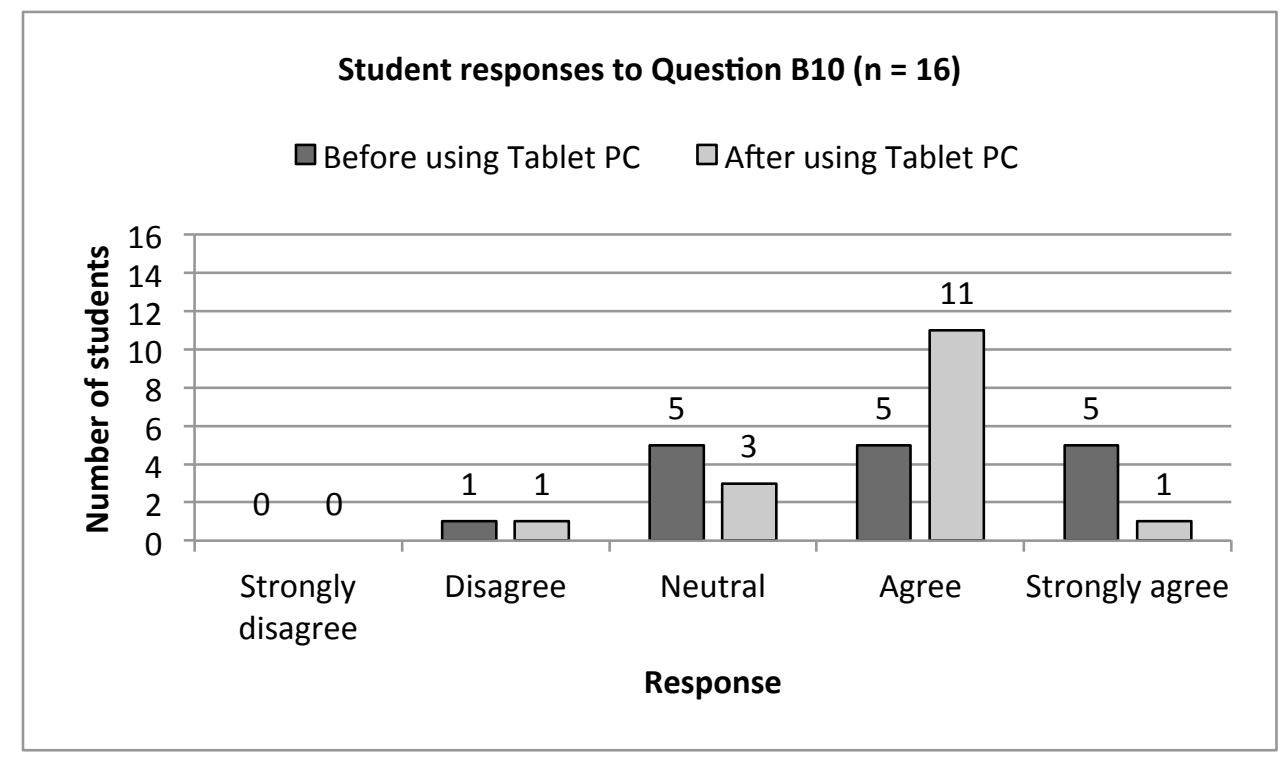

Figure 7-39: Student responses to Question B10: "To what extent do you agree or disagree that digital design methods contribute to the design development phase more than nondigital design methods?" 


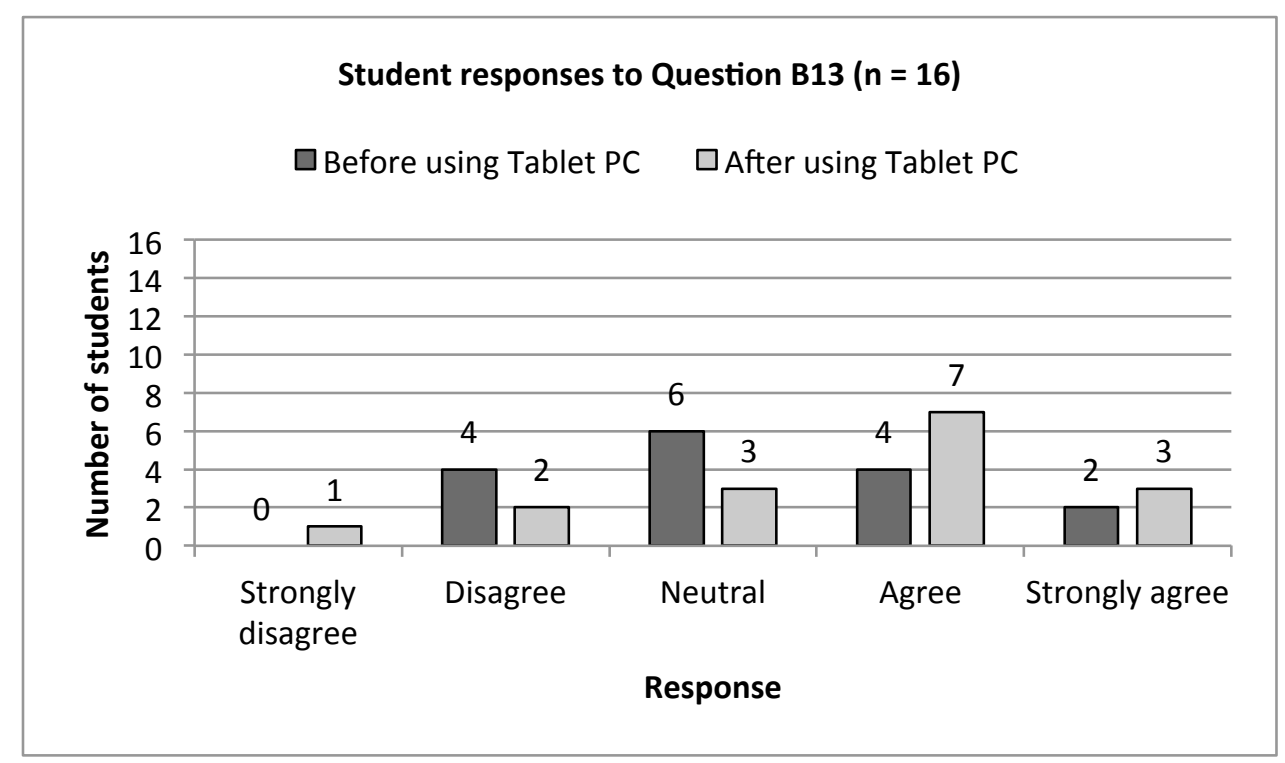

Figure 7-40: Student responses to Question B13: "To what extent do you agree or disagree that it is now viable to design products using digital tools/media only?"

There were some areas that retained the positive attitude but a slight decrease occurred after using the Tablet PC. These areas were the speed and effectiveness compared to nondigital design methods (Figure 7-41 and Figure 7-42) and viability of using a digital logbook whilst designing (Figure 7-43).

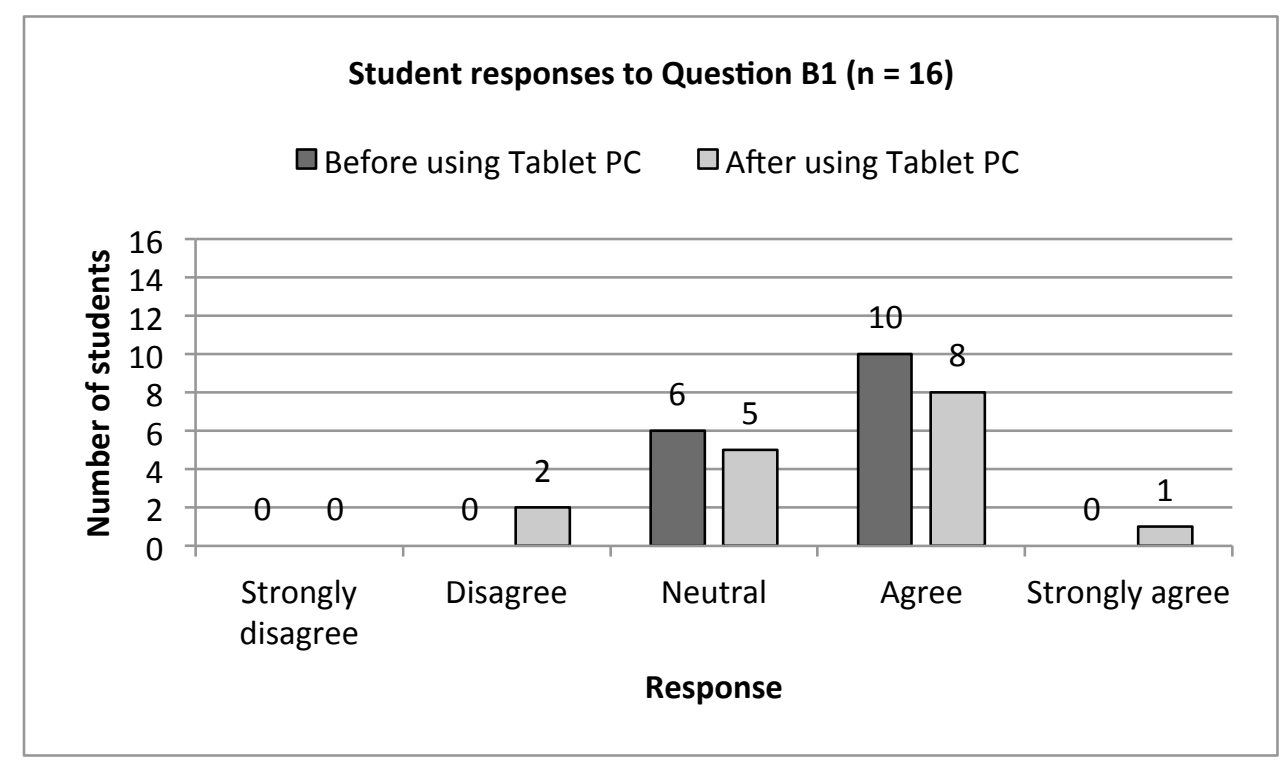

Figure 7-41: Student responses to Question B1: "To what extent do you agree or disagree that digital design methods are quicker than non-digital design methods?" 


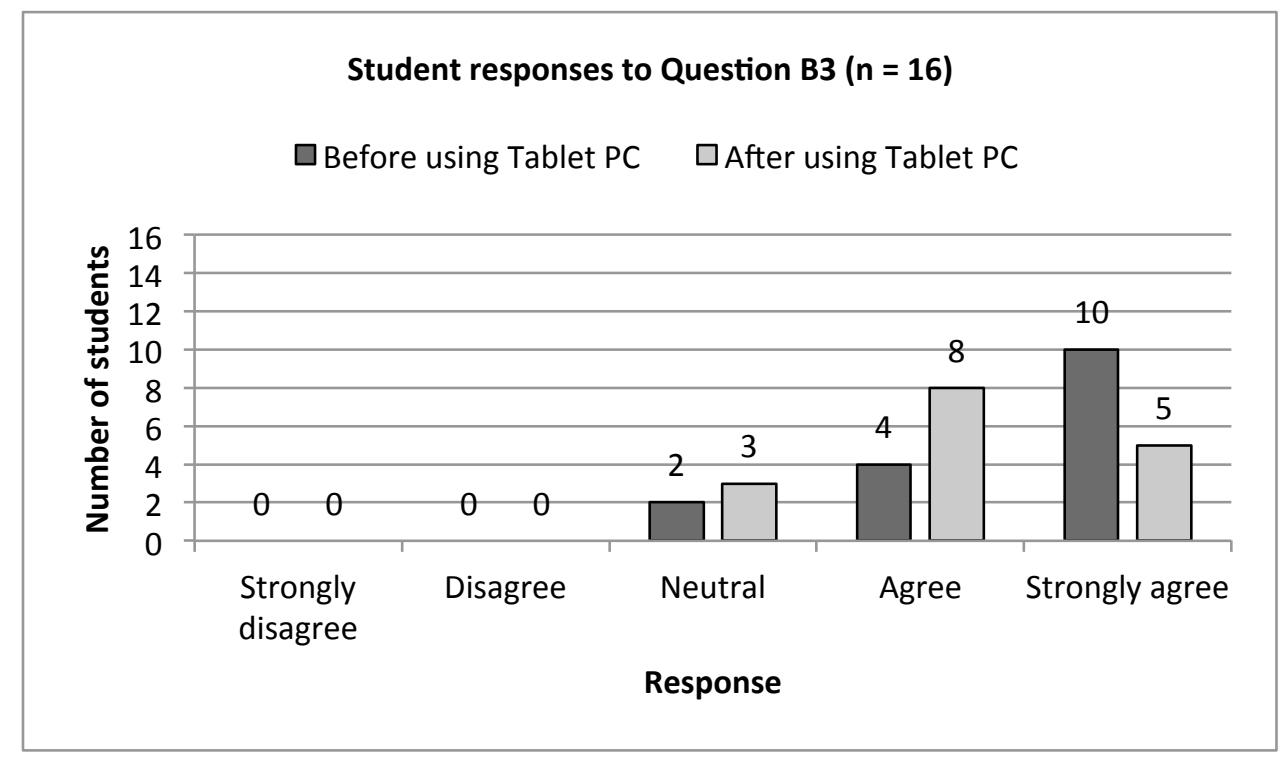

Figure 7-42: Student responses to Question B3: "To what extent do you agree or disagree that digital design methods are more effective for presentation of proposals than non-digital design methods?"

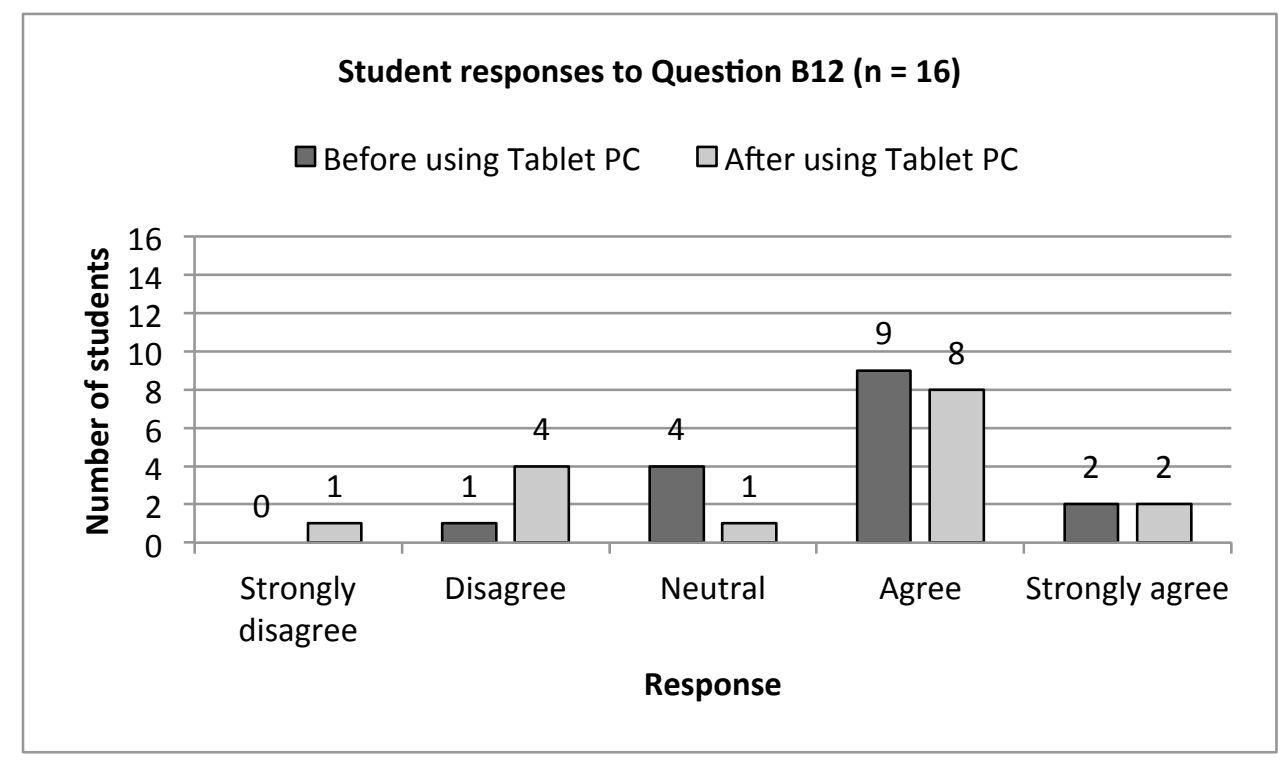

Figure 7-43: Student responses to Question B12: "To what extent do you agree or disagree that it is now viable to use a digital logbook whilst designing?"

\subsubsection{Neutral Attitude}

When students were asked about the capacity of digital design methods to facilitate creativity more than non-digital design methods, most were neutral before and after using the Tablet PC (Figure 7-44). However, whilst student responses were distributed between disagreeing and being neutral, when they were asked if digital design methods contributed 
to the concept generation phase more than non-digital design methods, the majority felt neutral after using the Tablet PC (Figure 7-45).

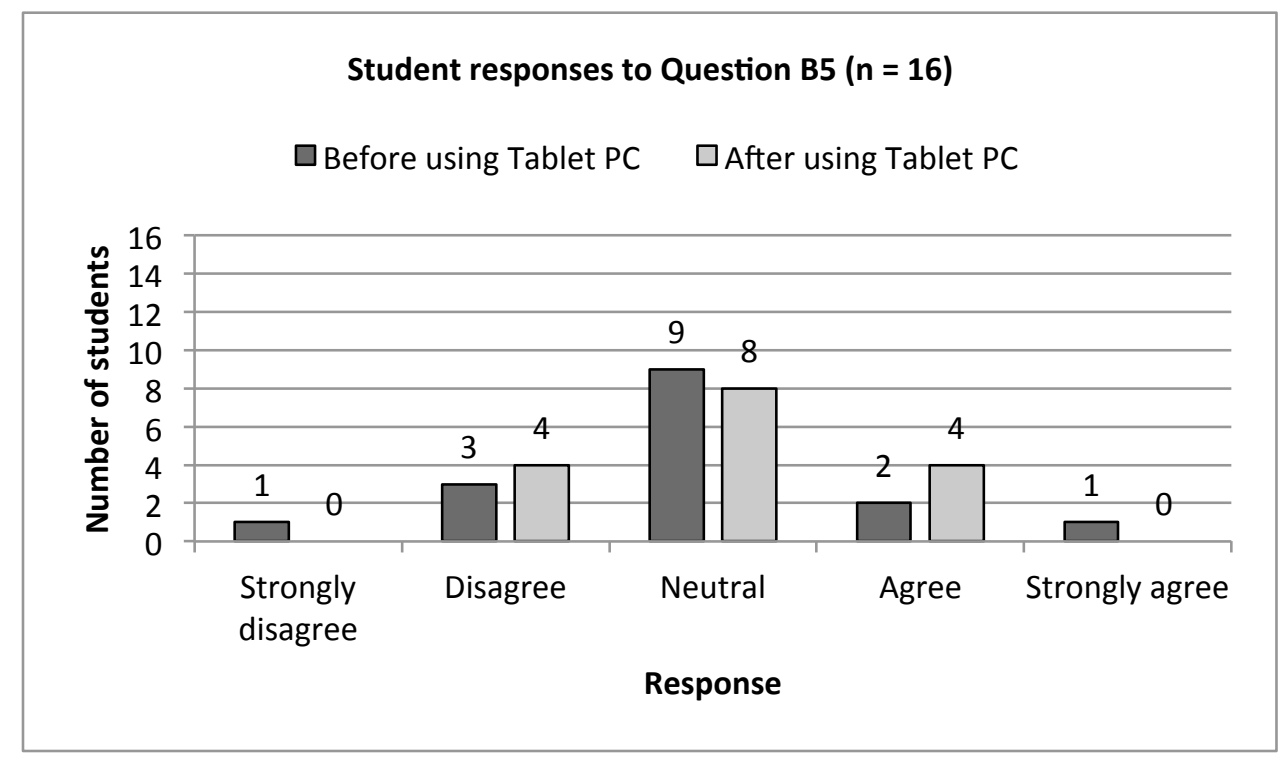

Figure 7-44: Student responses to Question B5: "To what extent do you agree or disagree that digital design methods facilitate creativity more than non-digital design methods?"

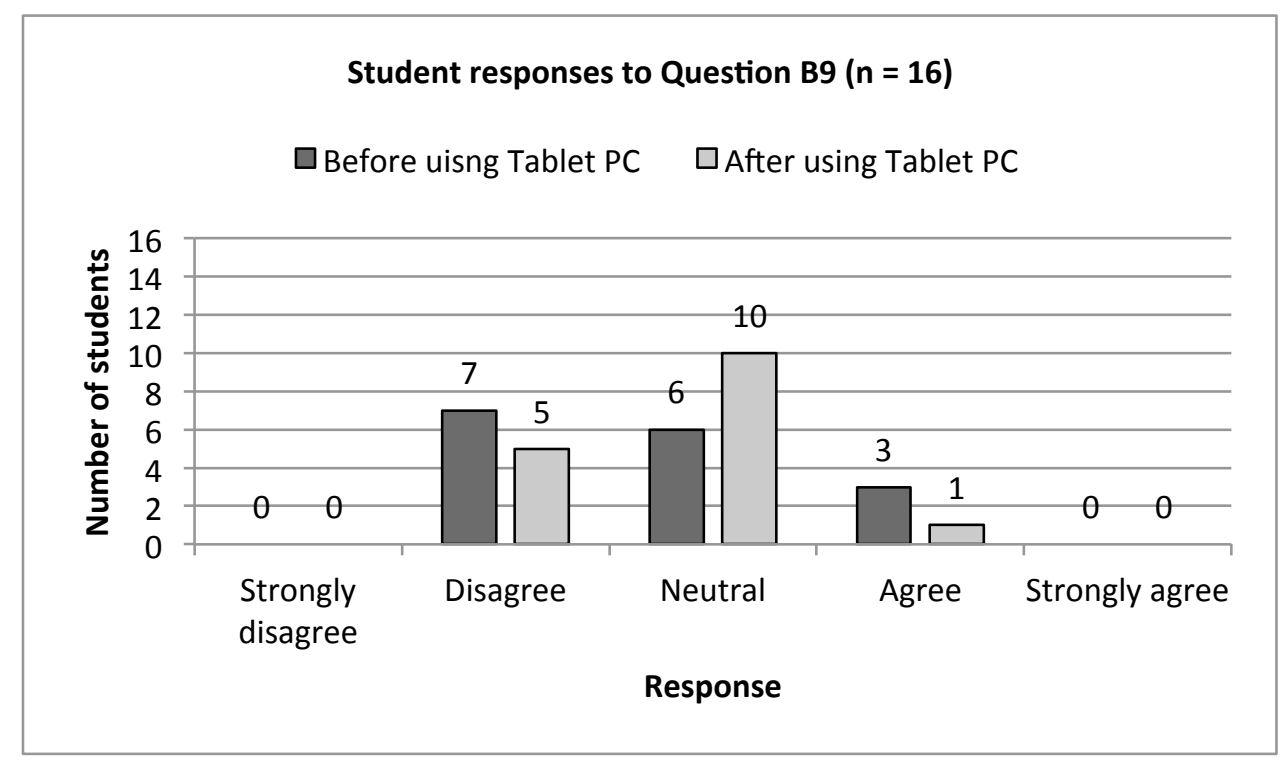

Figure 7-45: Student responses to Question B9: "To what extent do you agree or disagree that digital design methods contribute to the concept generation phase more than nondigital design methods?"

\subsubsection{Negative Attitude}

The majority of the students felt negative after using the Tablet PC in response to the statement that "digital design methods are easier to learn than non-digital design methods". 
Seven students disagreed/strongly disagreed to the statement before using the Tablet PC and then the number increased to 10 after using the Tablet PC. While four students agreed/strongly agreed to the statement before using the Tablet PC, three students continued to agree after using it (Figure 7-46).

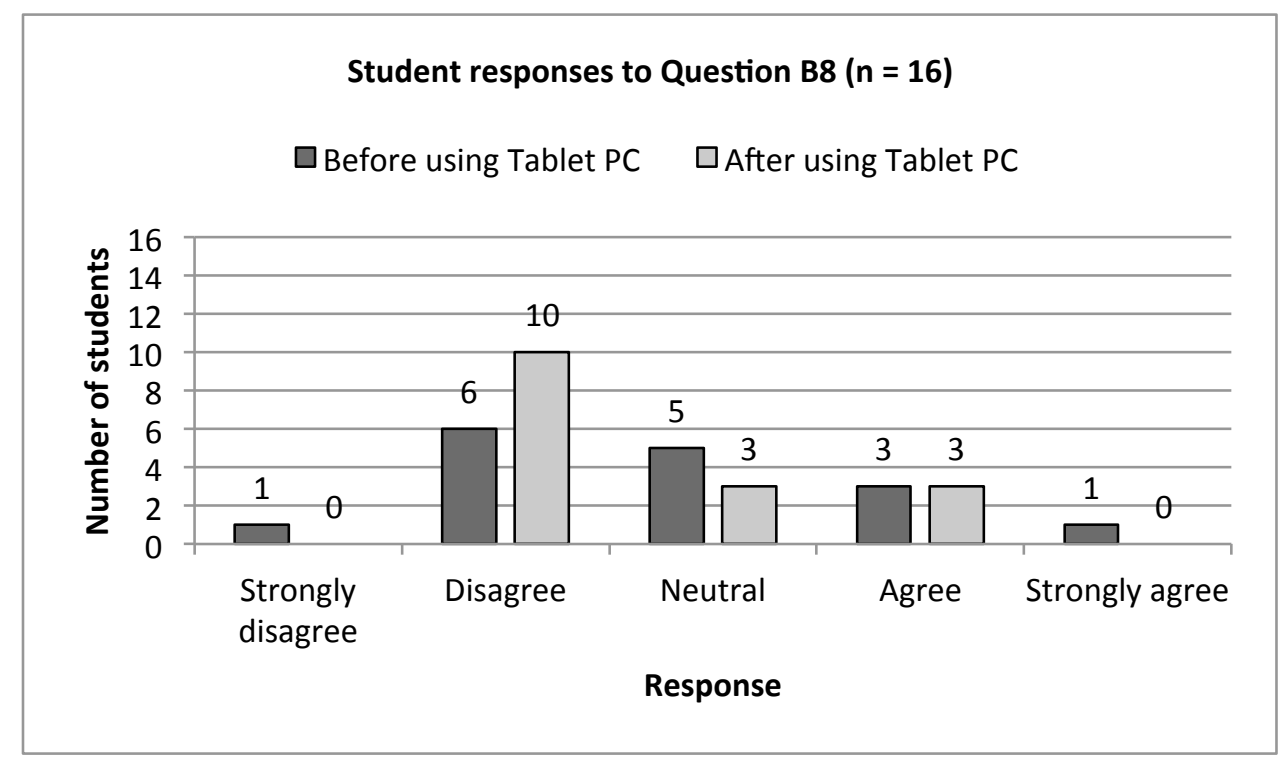

Figure 7-46: Student responses to Question B8: "To what extent do you agree or disagree that digital design methods are easier to learn than non-digital design methods?"

\subsubsection{Distributed Attitude}

Despite the fact that half of the students felt positive towards the contribution of digital design methods to the specification phase of the design process when compared to nondigital before using the Tablet PC, the responses were distributed between being neutral and disagreeing/strongly disagreeing after using it (Figure 7-47). Reasons for the change were unknown, as the students did not add anything in the additional comments box. 


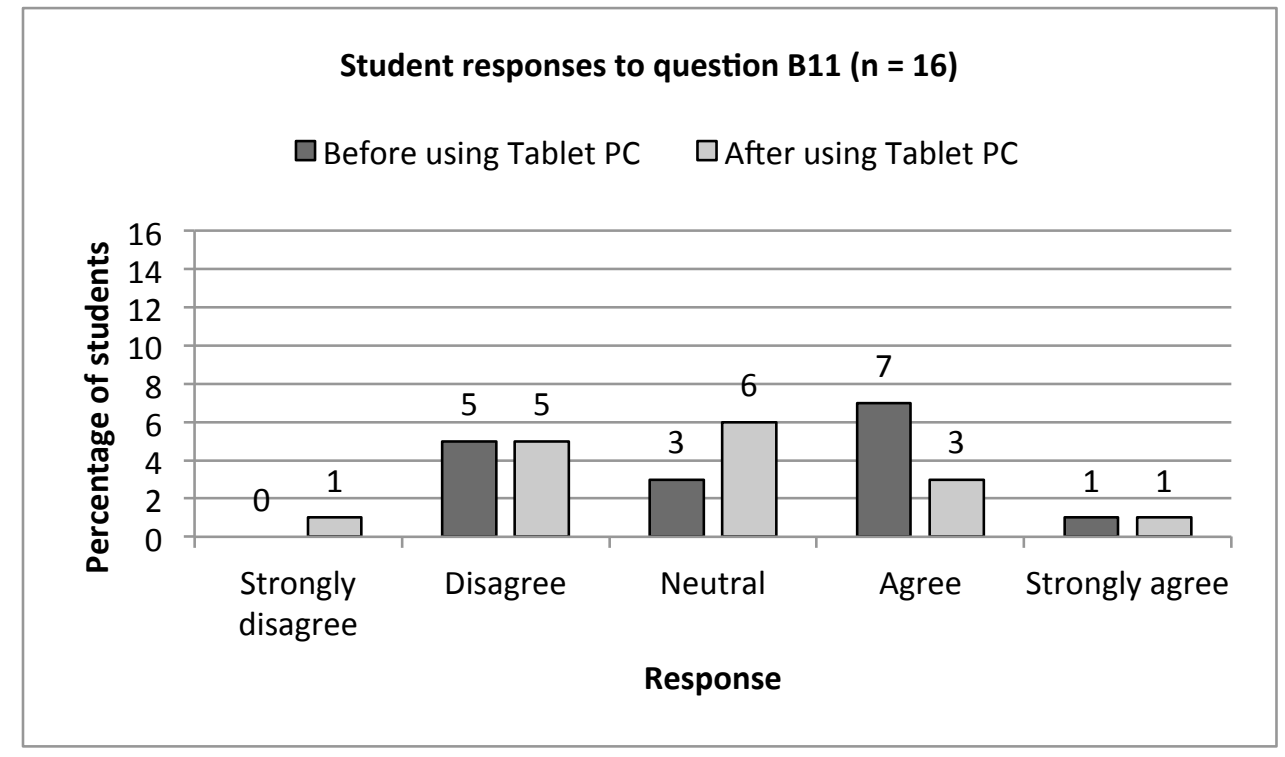

Figure 7-47: Student responses to question B11: "To what extent do you agree or disagree that digital design methods contribute to the specification phase more than non-digital design methods?"

\subsubsection{Summary of Results}

Table 7-5 provides a summary of the questionnaire results for the 13 closed-ended questions before and after using the Tablet PC. 


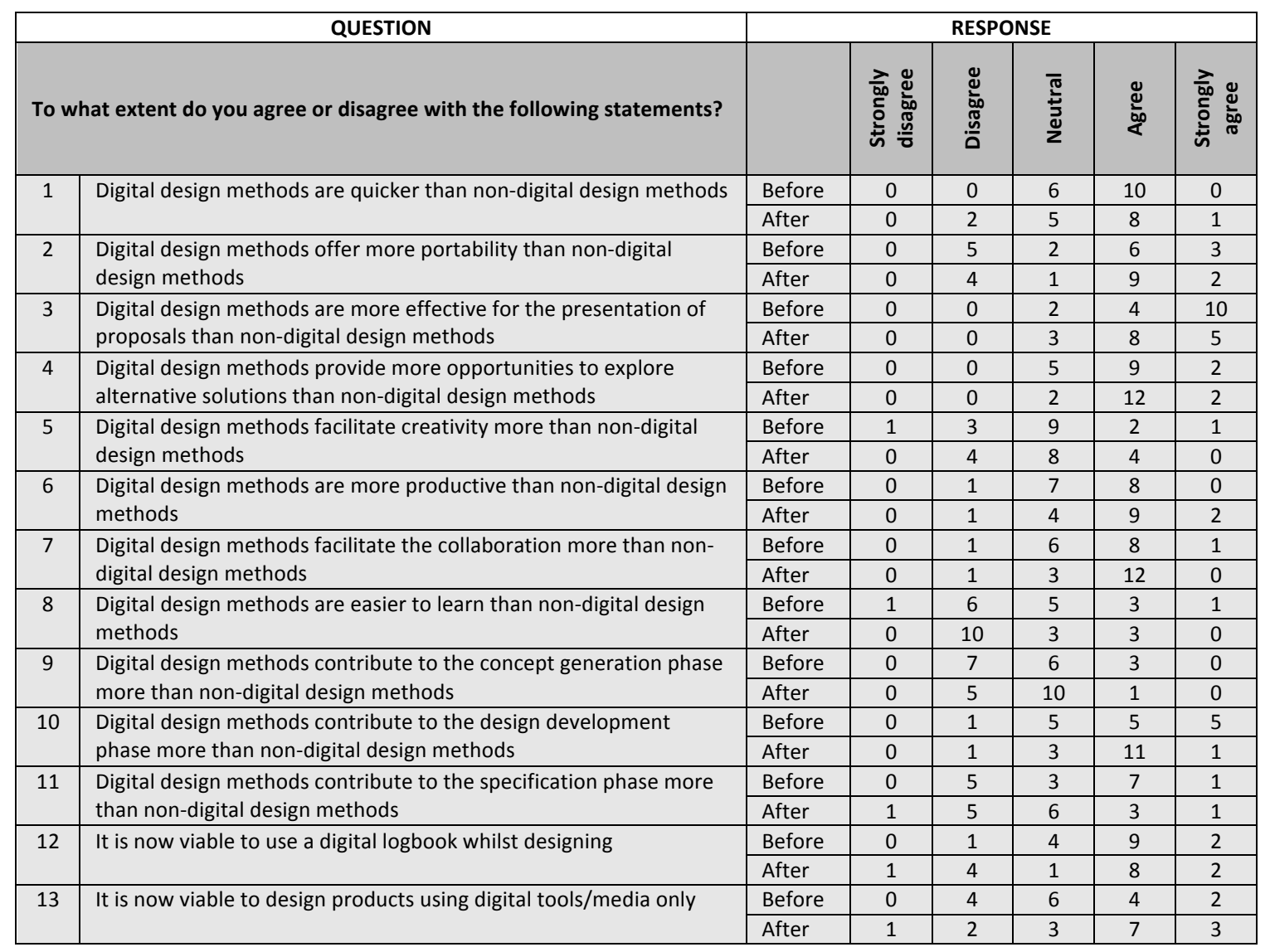

Table 7-5: Overall quantitative data results of the pre- and post-questionnaire used to examine student attitude towards digital design methods $(n=16)$

\subsection{Closing Session}

After almost eight months of using the Tablet PCs for a wide variety of design activity, including their major project, the students were asked to complete a final Use of Tablet PC Questionnaire that evaluated the use of the Tablet PC as a digital design tool (Appendix 11.13). The questionnaire was based on the 72 issues that had been raised during the focus groups. The issues were arranged randomly and all of 16 students completed the questionnaire. Findings were clustered into key benefits, limitations, learning recommendations, software, improvements and areas of conflict. Examples of the student design work produced using the Tablet PC were also included.

\subsubsection{Key Benefits}

Almost all of the students felt that their confidence in digital sketching using the Tablet PC was greater than when using paper-based sketching because the Tablet PC enabled them to 
'undo' mistakes easily (Figure 7-48 and Figure 7-49). Fifteen students felt that the layering facility in the Tablet PC was helpful when sketching or creating presentation concepts (Figure 7-50) and improved the quality of the renderings produced using drawing packages (Figure 7-51), enabling them to trace and produce basic outlines easily (Figure 7-52). Even though some students in the focus groups pointed out that they had problems with the smooth surface of the screen when using the stylus, the majority adapted (Figure 7-53).

Fourteen out of the 16 students felt that the Tablet PC enabled them to produce lines of better quality when compared with paper-based techniques (Figure 7-54). The same number also preferred taking the Tablet PC to sketch ideas when visiting friends and family to an A3 pad (Figure 7-55). Students enjoyed using the Tablet PC as it introduced an element of fun while working (Figure 7-56) and felt that it was pressure sensitive (Figure 7-57) and a useful device to make quick changes to designs (Figure 7-58). In terms of the output, the majority of students confirmed that the colours used on the Tablet PC were more vibrant (Figure 7-59); the concepts were more adventurous (Figure 7-60); applying colour and tone to the line work was quicker and easier (Figure 7-61); and the visual quality and appearance of designs was enhanced (Figure 7-64). Students had definitely considered the ability to 'undo' previous work as an advantage since that the majority disagreed that undoing previous work during concept generation hindered creativity (Figure 7-63).

The battery life of the Tablet PC was acceptable (Figure 7-62) and the quality of outcome using the Tablet PC and level of presentation was considered greater and higher than paperbased techniques (Figure 7-65 and Figure 7-66). The largest number of students did not find it difficult to create faint lines and use them as a guide when using the Tablet PC (Figure 7-69) and did not consider the stylus too short for comfortable use (Figure 7-70). Eleven students agreed/strongly agreed that the Tablet PC increased their excitement when collaborating on sketches with clients or colleagues (Figure 7-67). The majority of students felt that having the Tablet PC provided them with a substantial benefit in terms of browsing the Internet while generating concepts (Figure 7-68).

Whilst some of the academics interviewed (Chapter 6) felt strongly that students should not erase their mistakes when sketching, the majority of students thought that the ability to 'undo' mistakes increased creativity when using the Tablet PC (Figure 7-71). Students also thought that the Tablet PC had a positive effect on productivity (Figure 7-72) and speed of communicating their ideas to other people (Figure 7-73). The fact that the Tablet PC was an expensive device did not seem to affect the students in terms of sketching in public with it 
because of its potential to be stolen (Figure 7-74). However, it should be noted that three machines were stolen from students' rooms during the research and had to be replaced.

The figures have been arranged in rank order so that the statements in which the majority of students agreed/strongly agreed or in some cases disagreed/strongly agreed on appear first.

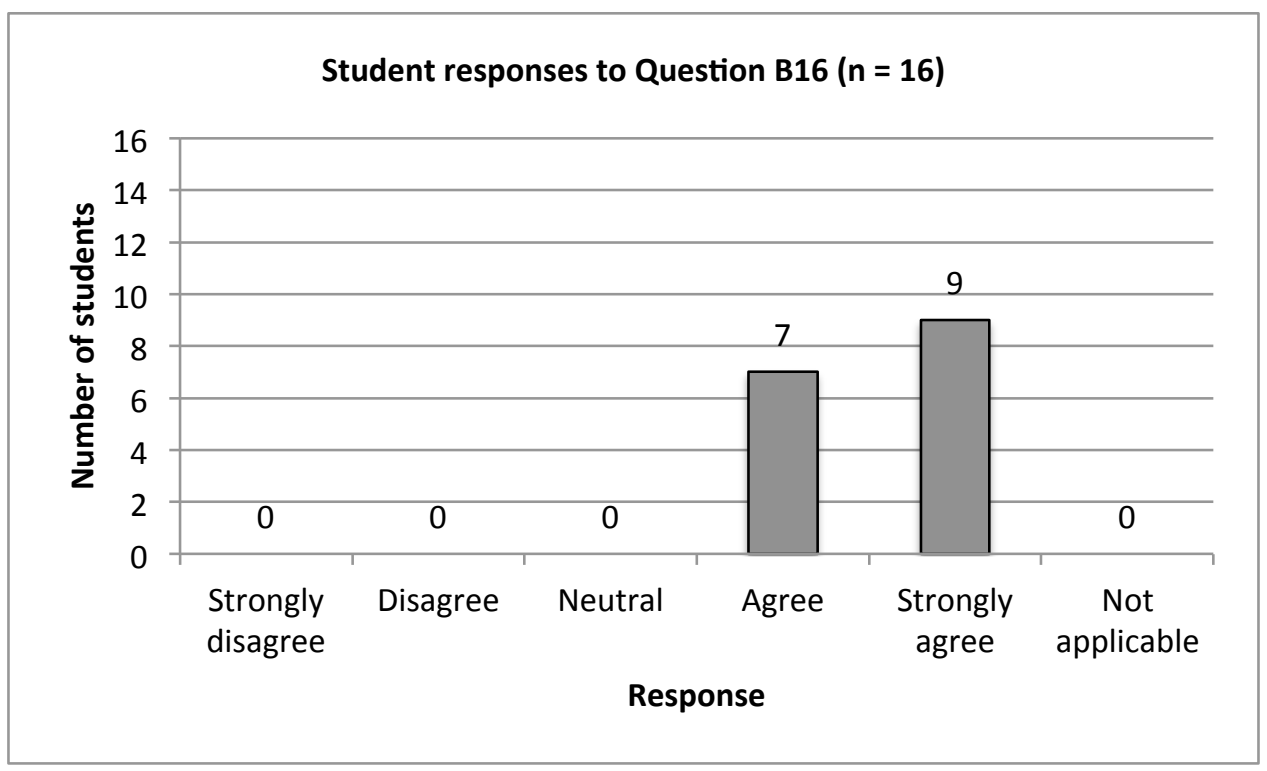

Figure 7-48: Student responses to Question B16: "To what extent do you agree or disagree that it was easier to remove mistakes using the Tablet PC than when paper-based sketching?"

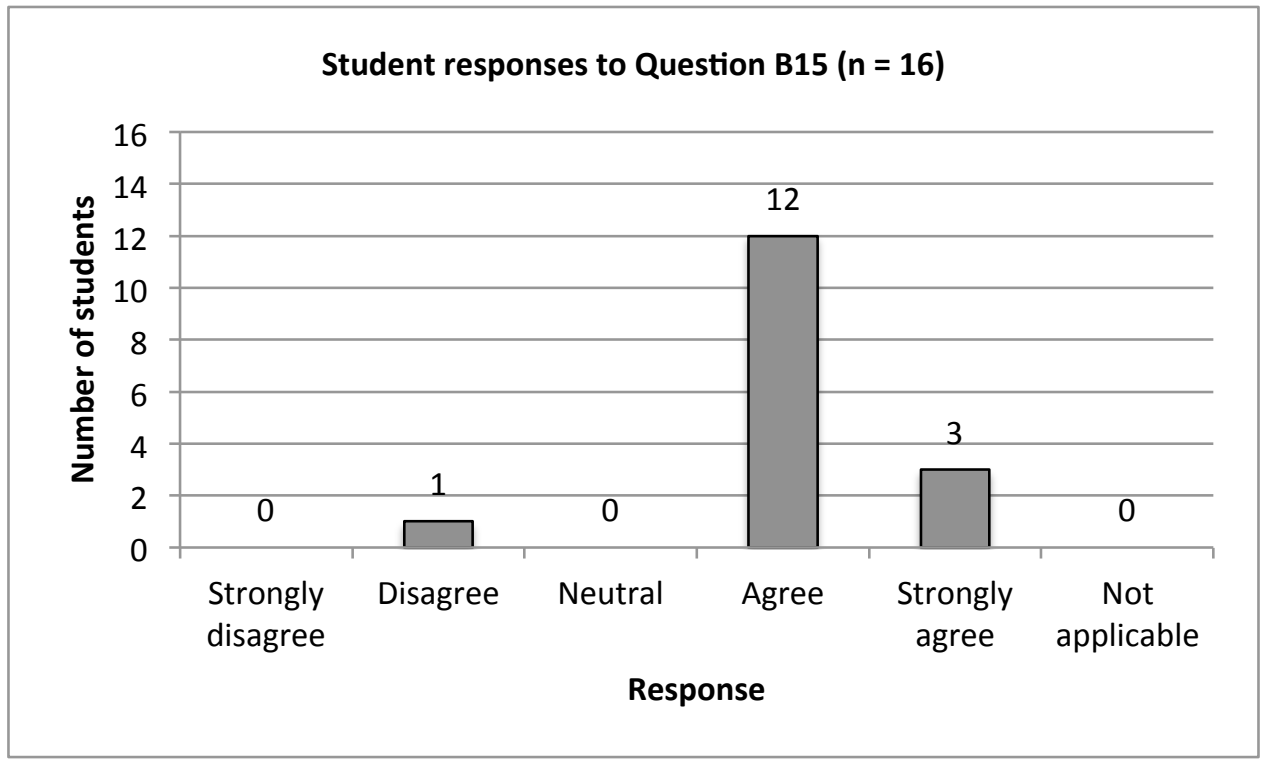

Figure 7-49: Student responses to Question B15: "To what extent do you agree or disagree that you felt more confident using the Tablet PC compared to paper-based sketching because of the ability to "undo'?" 


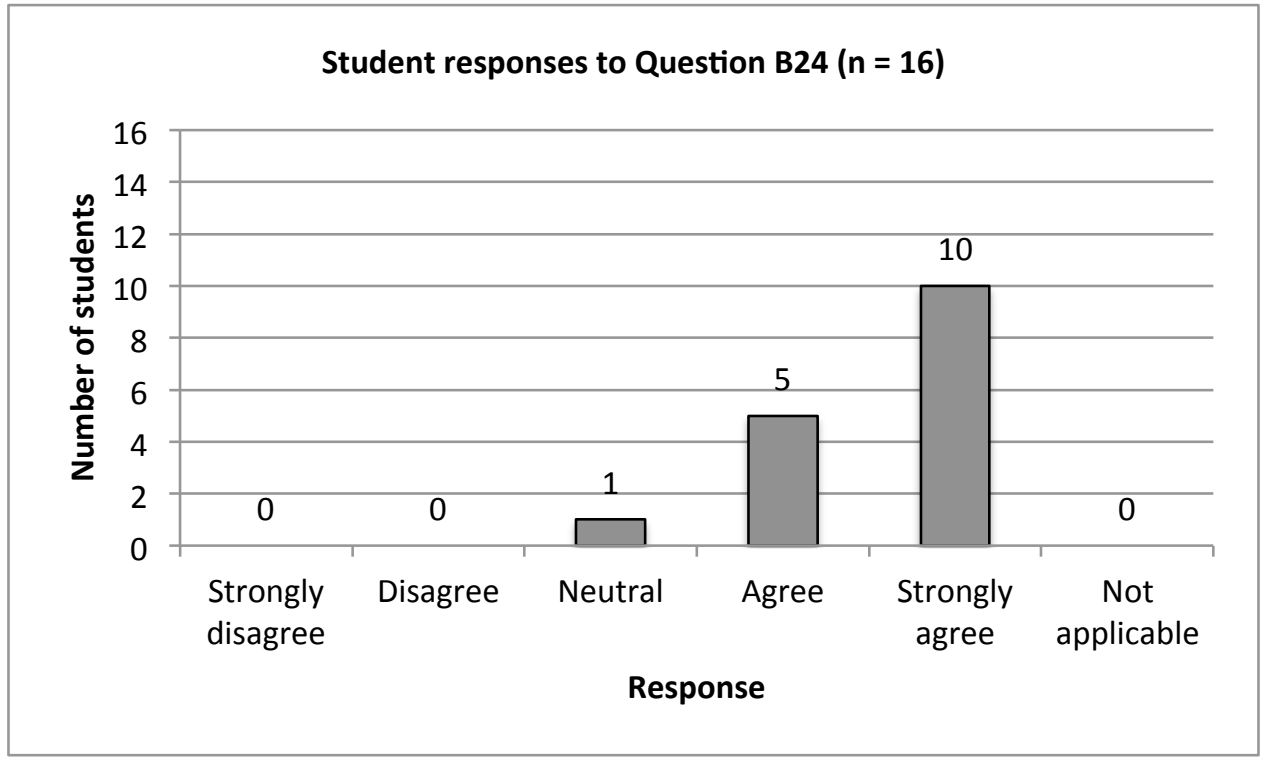

Figure 7-50: Student responses to Question B24: "To what extent do you agree or disagree that the Tablet PC layering facility was very helpful?"

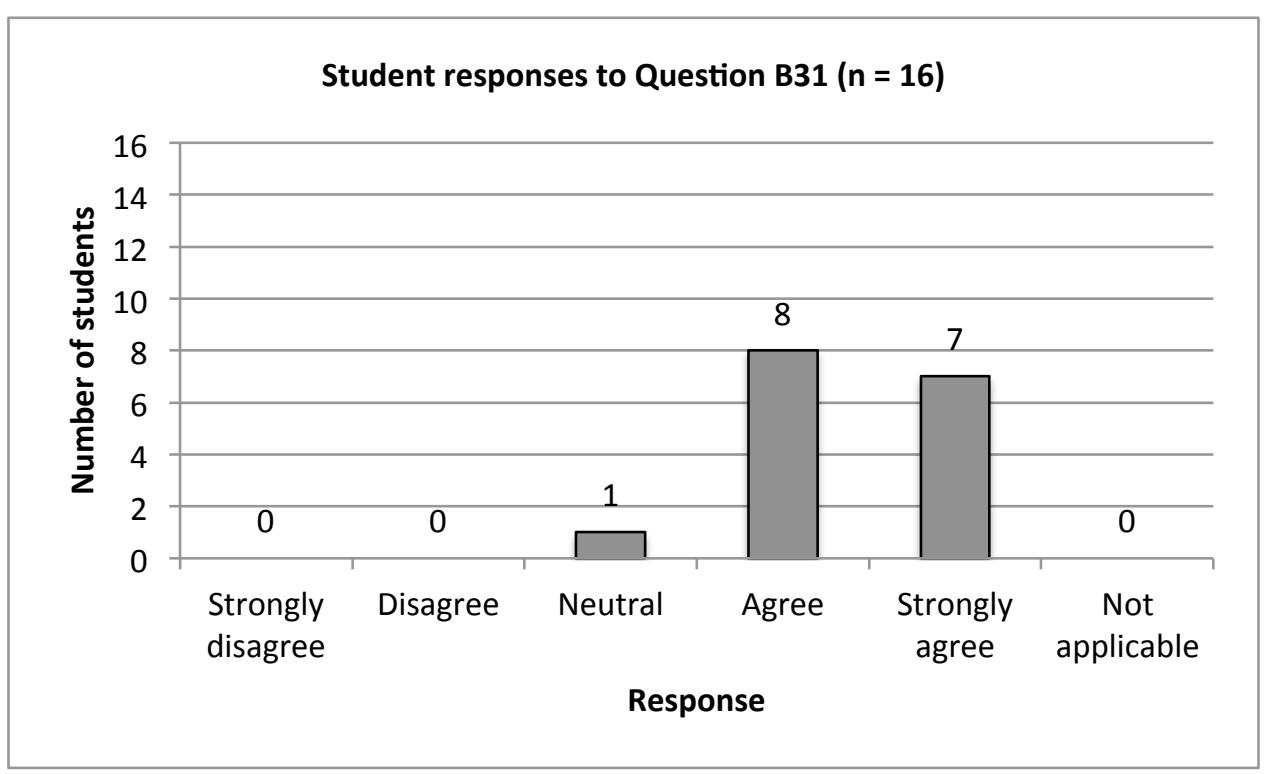

Figure 7-51: Student responses to Question B31: "To what extent do you agree or disagree that the quality of your renderings produced using computer drawing packages (e.g.

SketchBook Pro) improved using the Tablet PC?" 


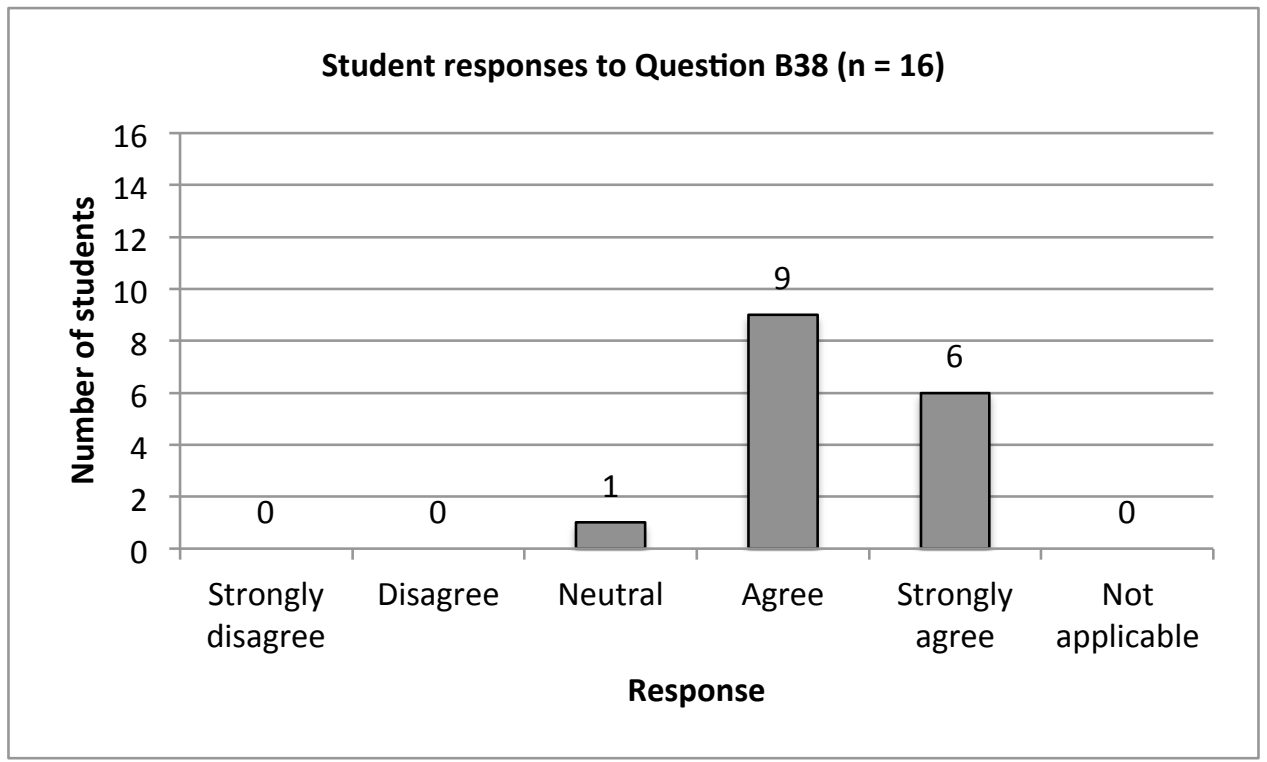

Figure 7-52: Student responses to Question B38: "To what extent do you agree or disagree that the Tablet PC was easy to use for tracing and producing basic outlines?"

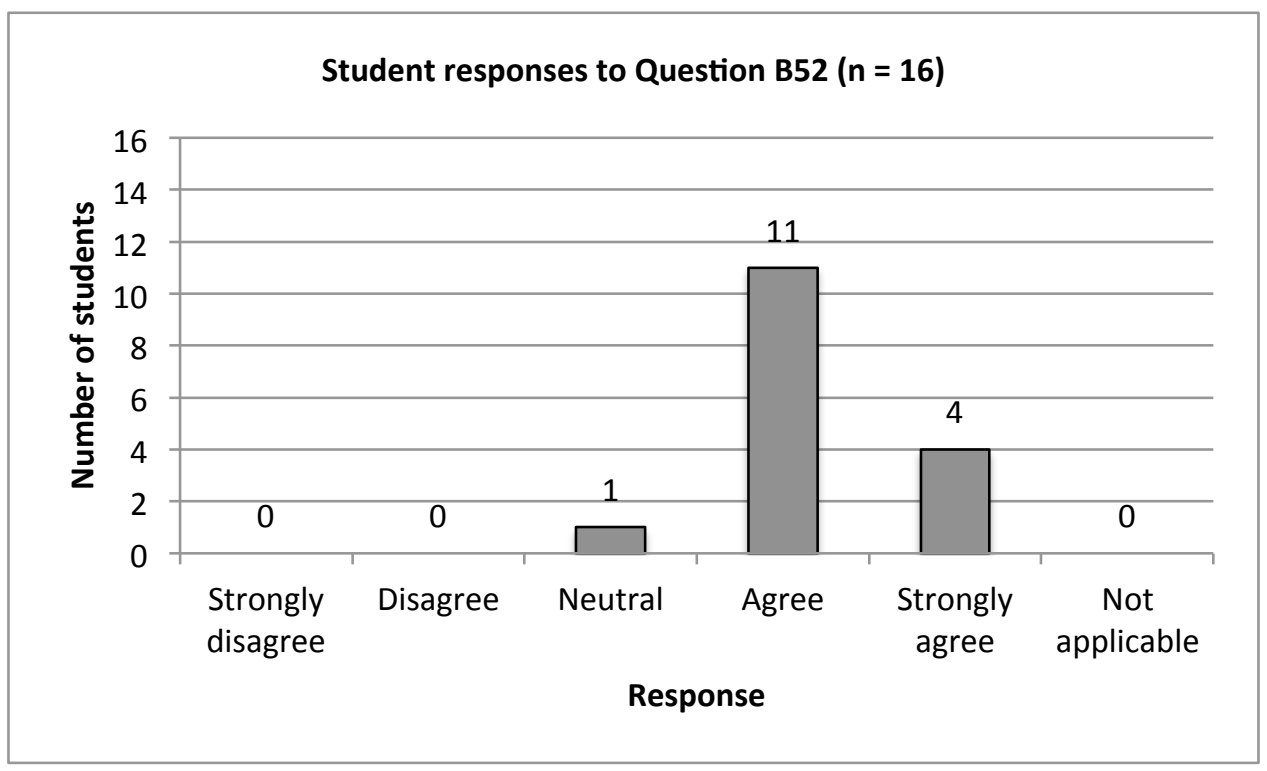

Figure 7-53: Student responses to Question B52: "To what extent do you agree or disagree that after sketching for some time, you got used to the smoothness of the Tablet PC screen?" 


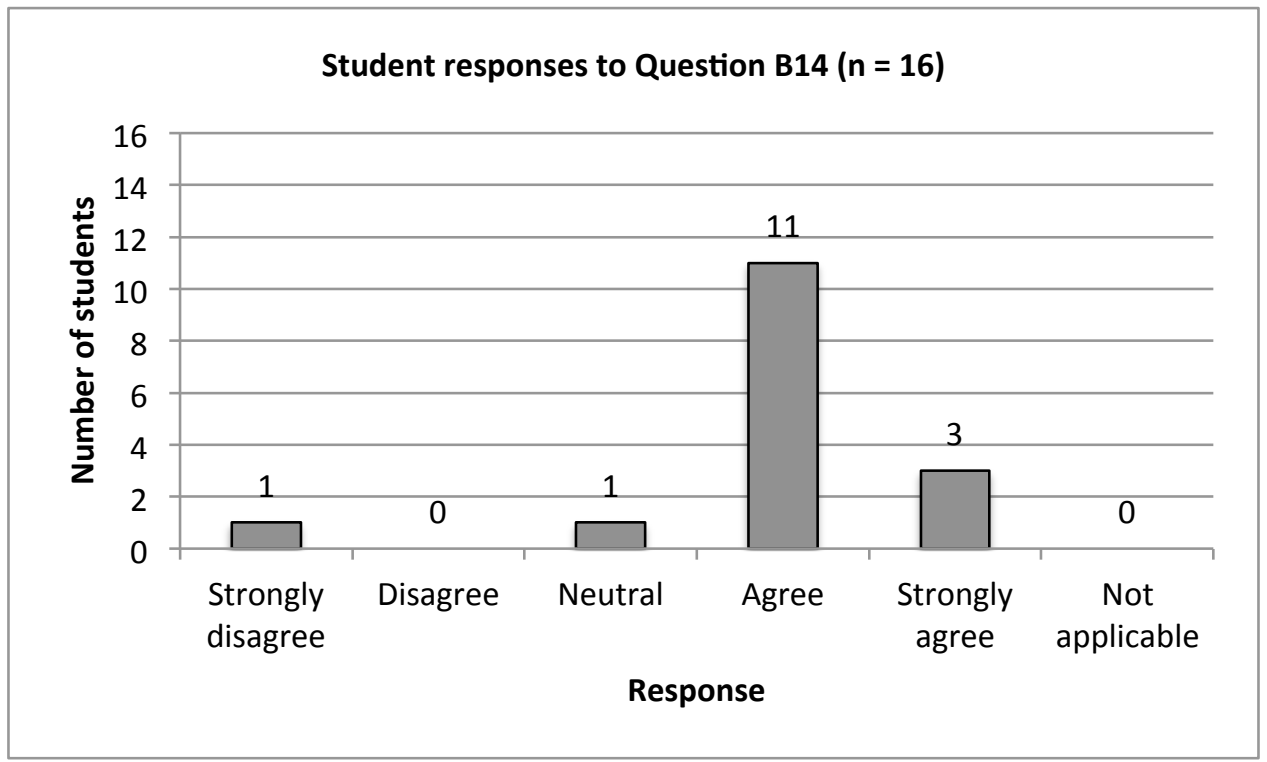

Figure 7-54: Student responses to Question B14: "To what extent do you agree or disagree that the line quality of the Tablet PC was better than that for paper-based sketching?"

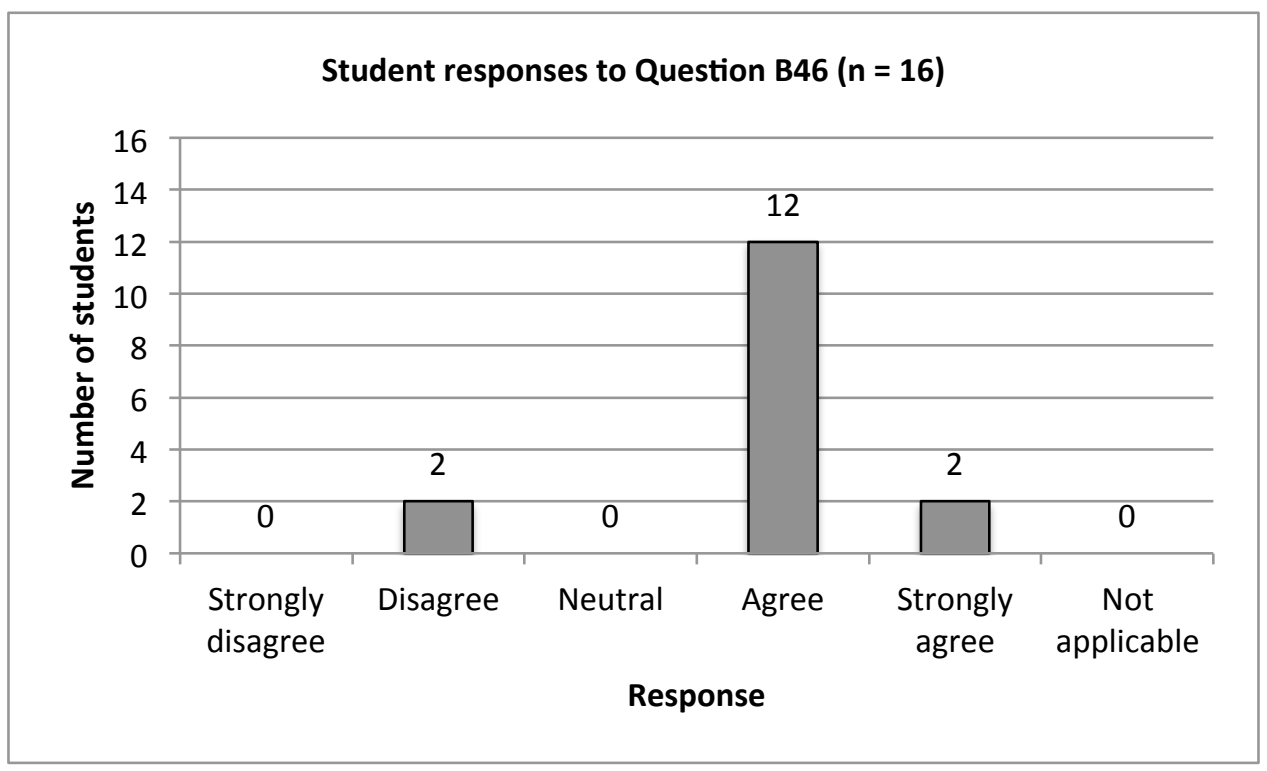

Figure 7-55: Student responses to Question B46: "To what extent do you agree or disagree that if you had to work when visiting friends and family, you would prefer to take the Tablet PC rather than an $\mathrm{A} 3$ pad?" 


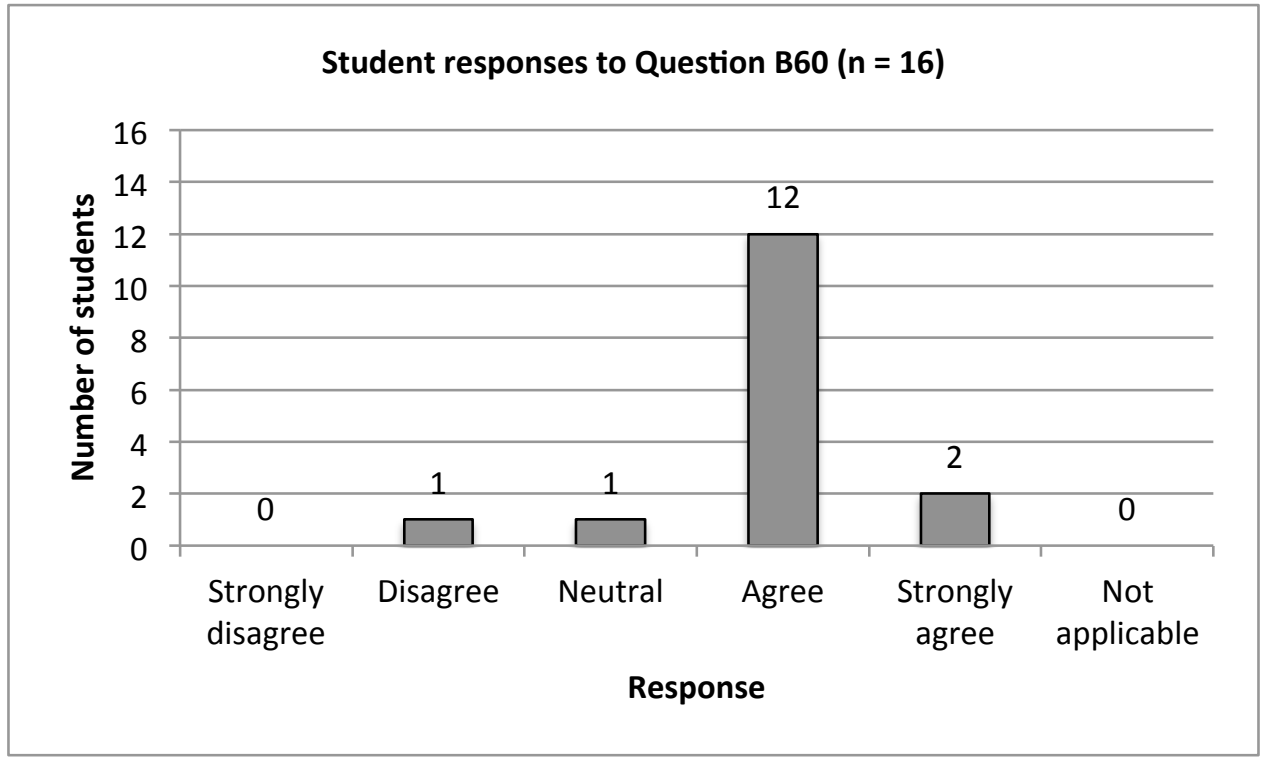

Figure 7-56: Student responses to Question B60: "To what extent do you agree or disagree that using the Tablet PC for designing introduced an element of fun?"

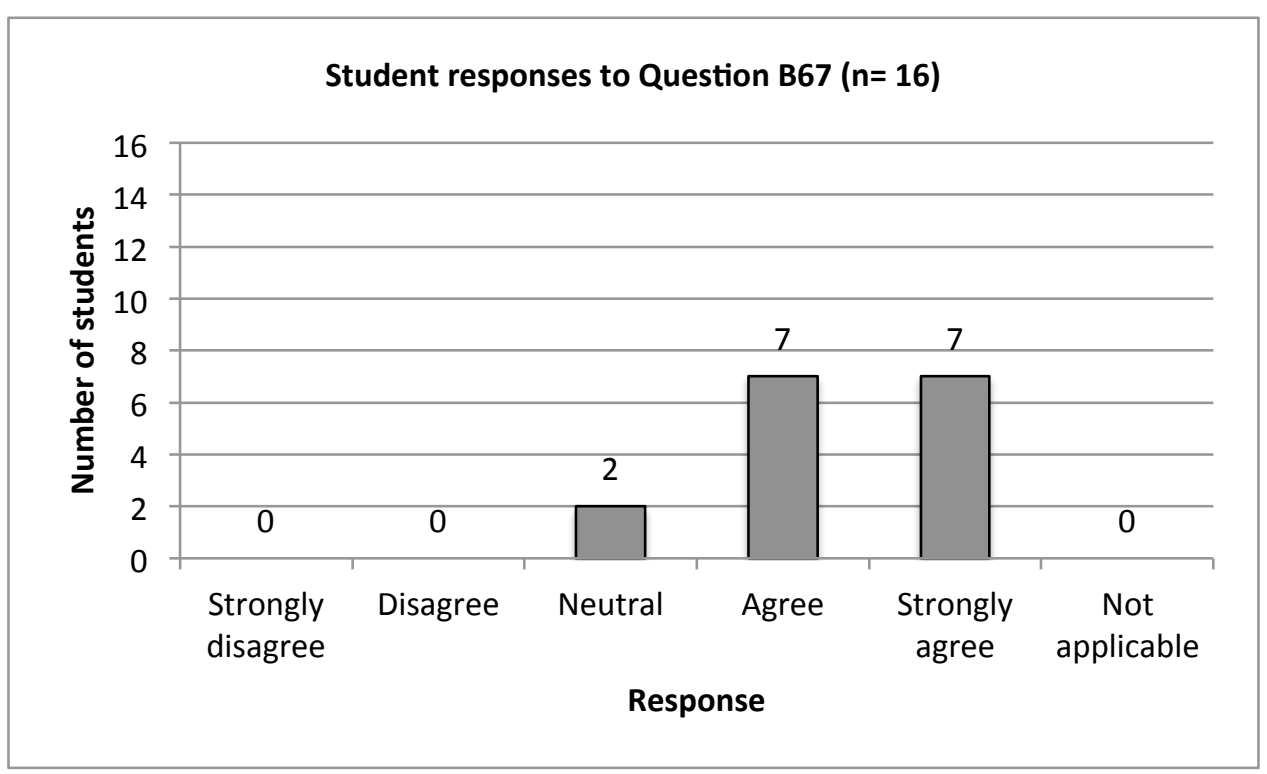

Figure 7-57: Student responses to Question B67: "To what extent do you agree or disagree that the Tablet PC is pressure sensitive?" 


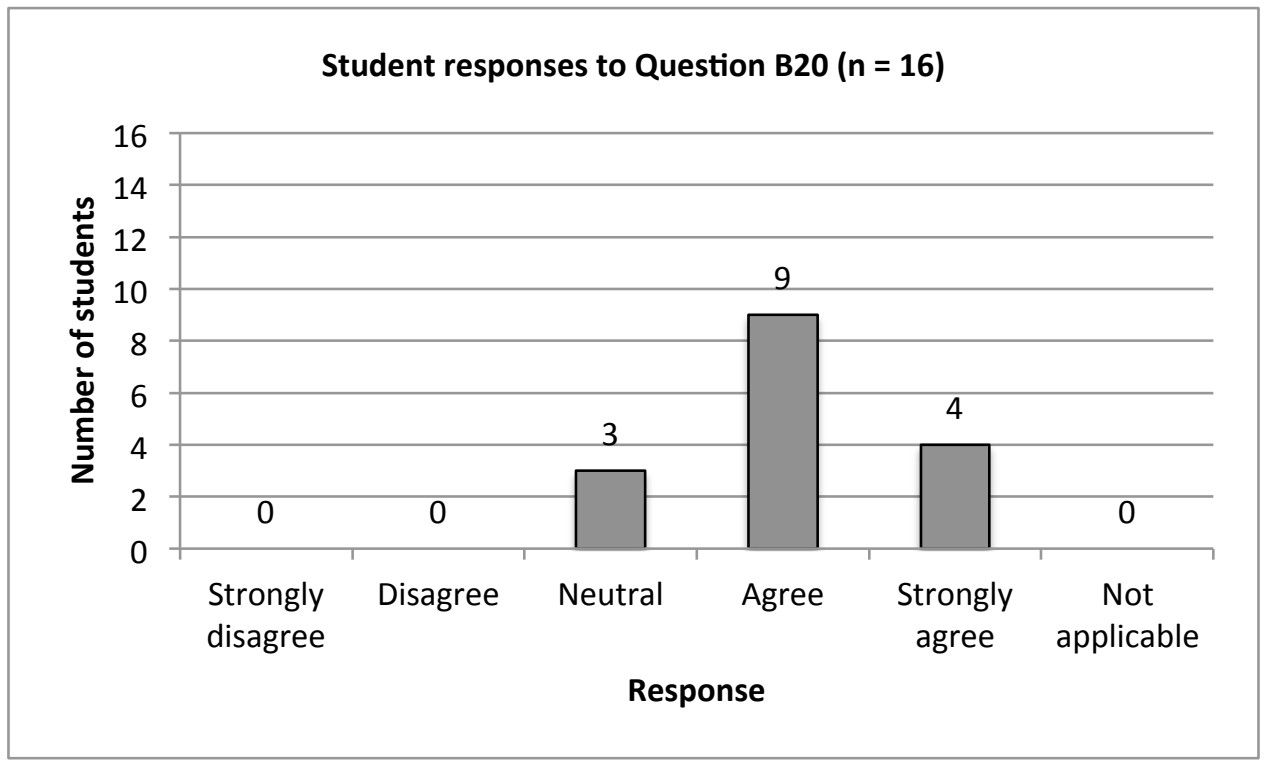

Figure 7-58: Student responses to Question B20: "To what extent do you agree or disagree that you were able to make quick amendments to your designs using the Tablet PC?"

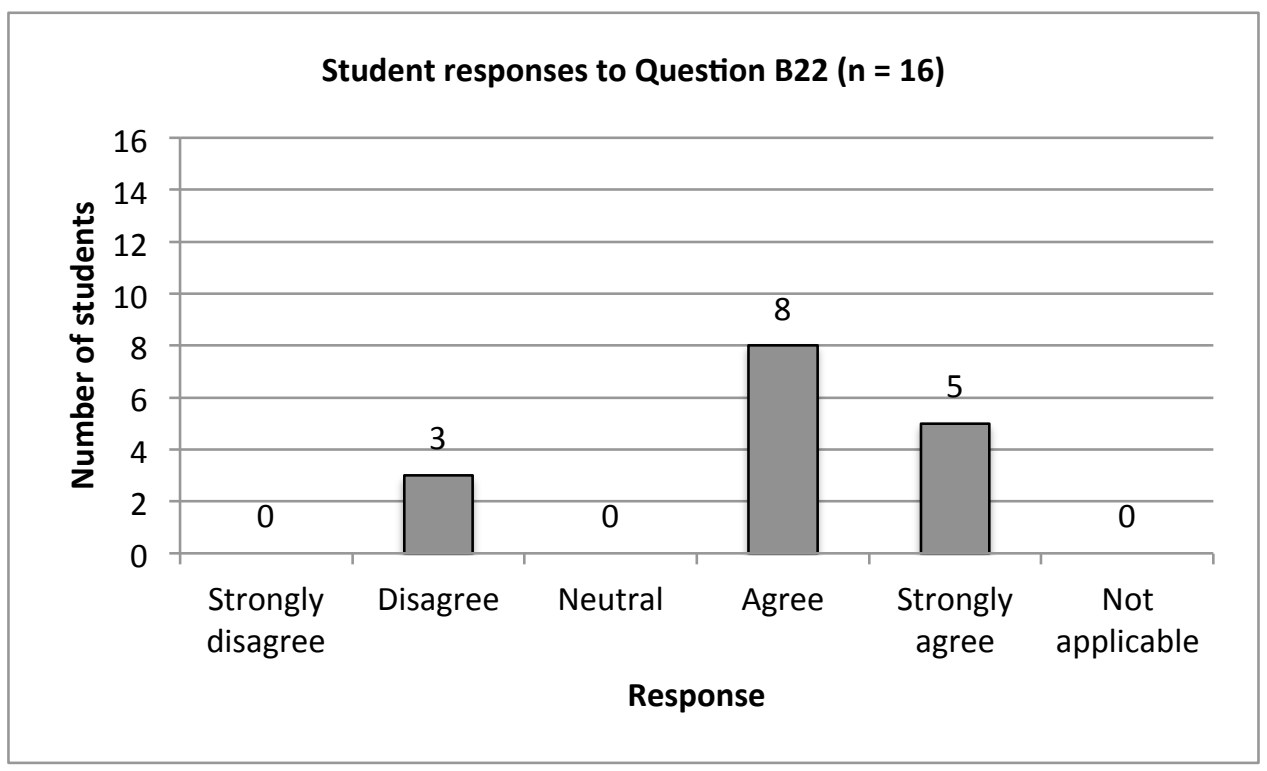

Figure 7-59: Student responses to Question B22: "To what extent do you agree or disagree that the colours used on the Tablet PC were more vibrant than those available with paperbased techniques?" 


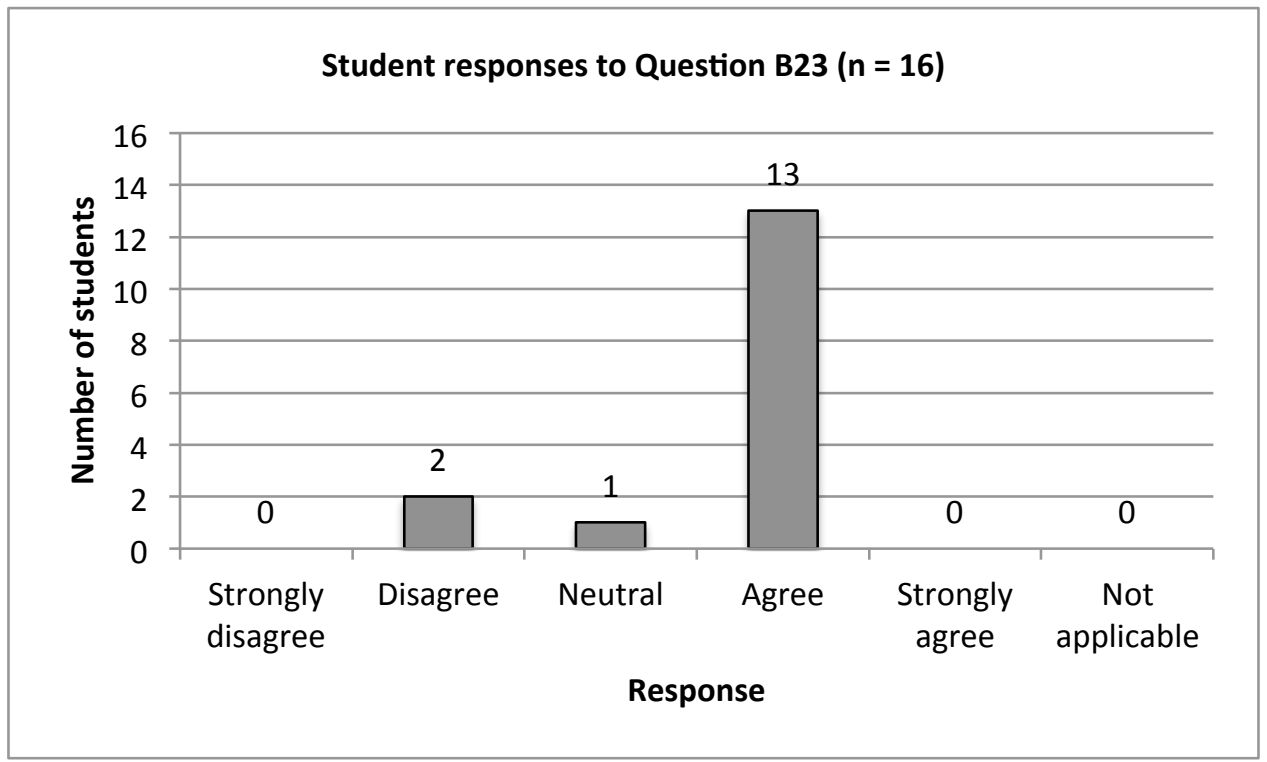

Figure 7-60: Student responses to Question B23: "To what extent do you agree or disagree that the Tablet PC made you more adventurous when generating concepts and developing them?"

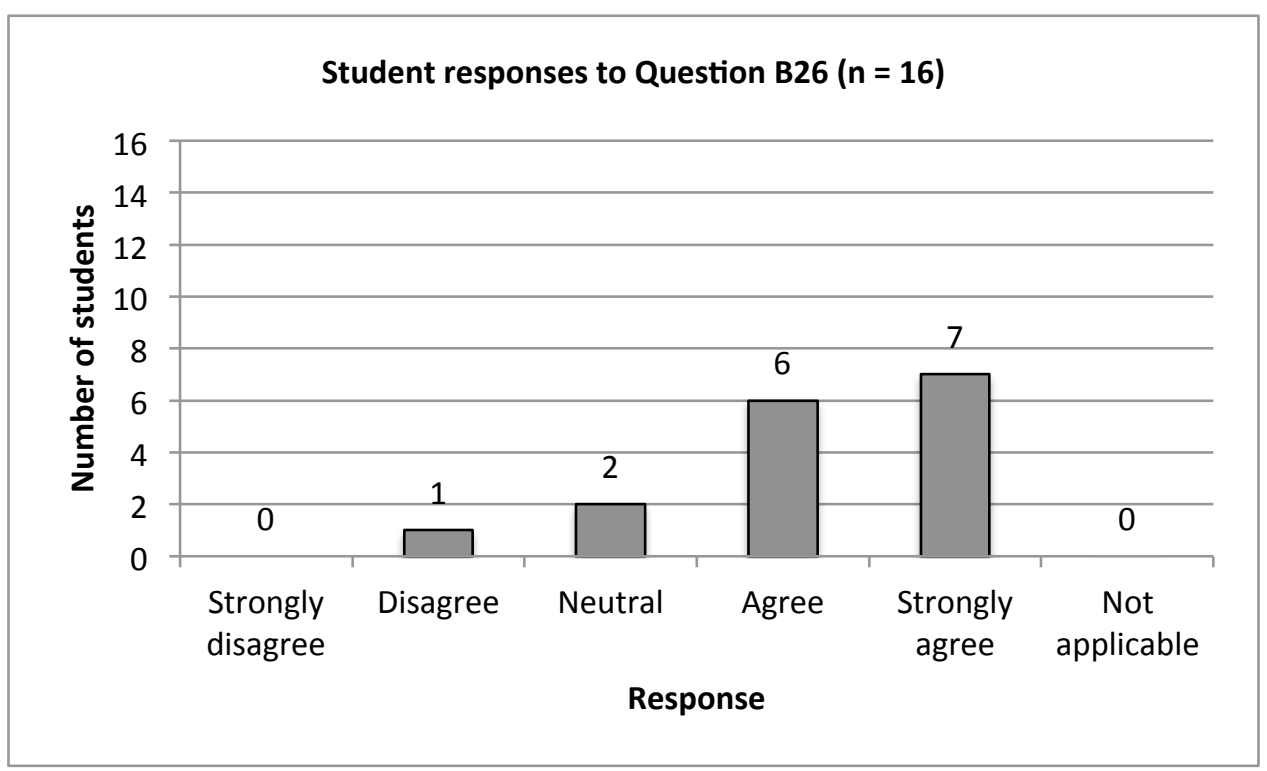

Figure 7-61: Student responses to Question B26: "To what extent do you agree or disagree that applying colour and tone to your line work was quicker and easier with the Tablet PC?" 


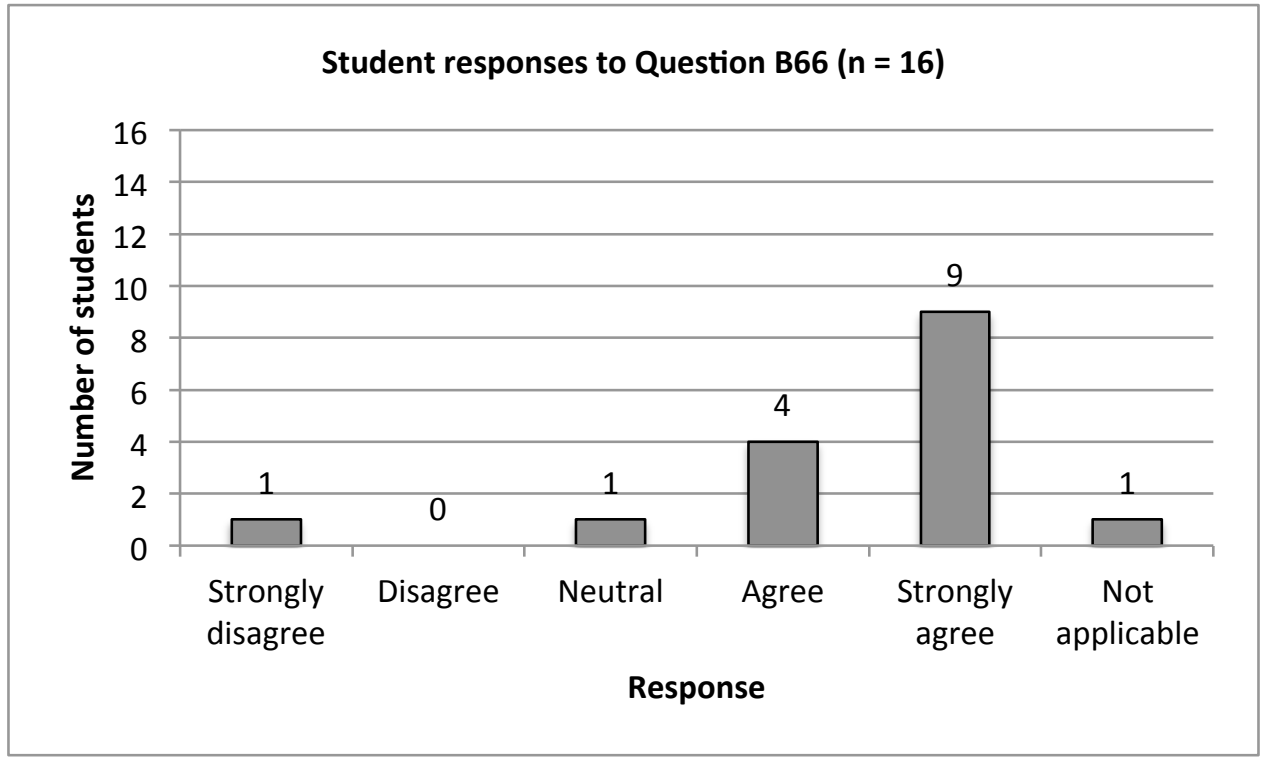

Figure 7-62: Student responses to Question B66: "To what extent do you agree or disagree that the battery life of the Tablet PC was acceptable?"

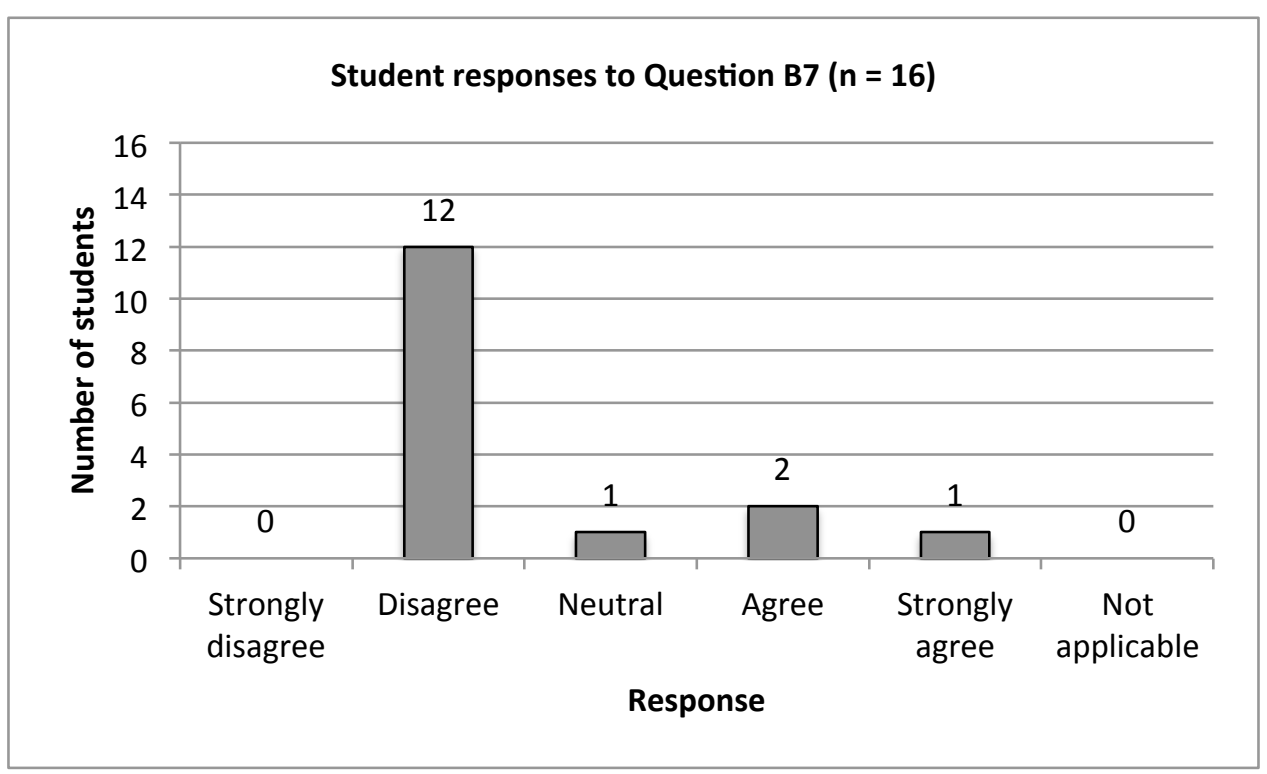

Figure 7-63: Student responses to Question B7: "To what extent do you agree or disagree that the ability to 'undo' previous work during concept generation hindered creativity?" 


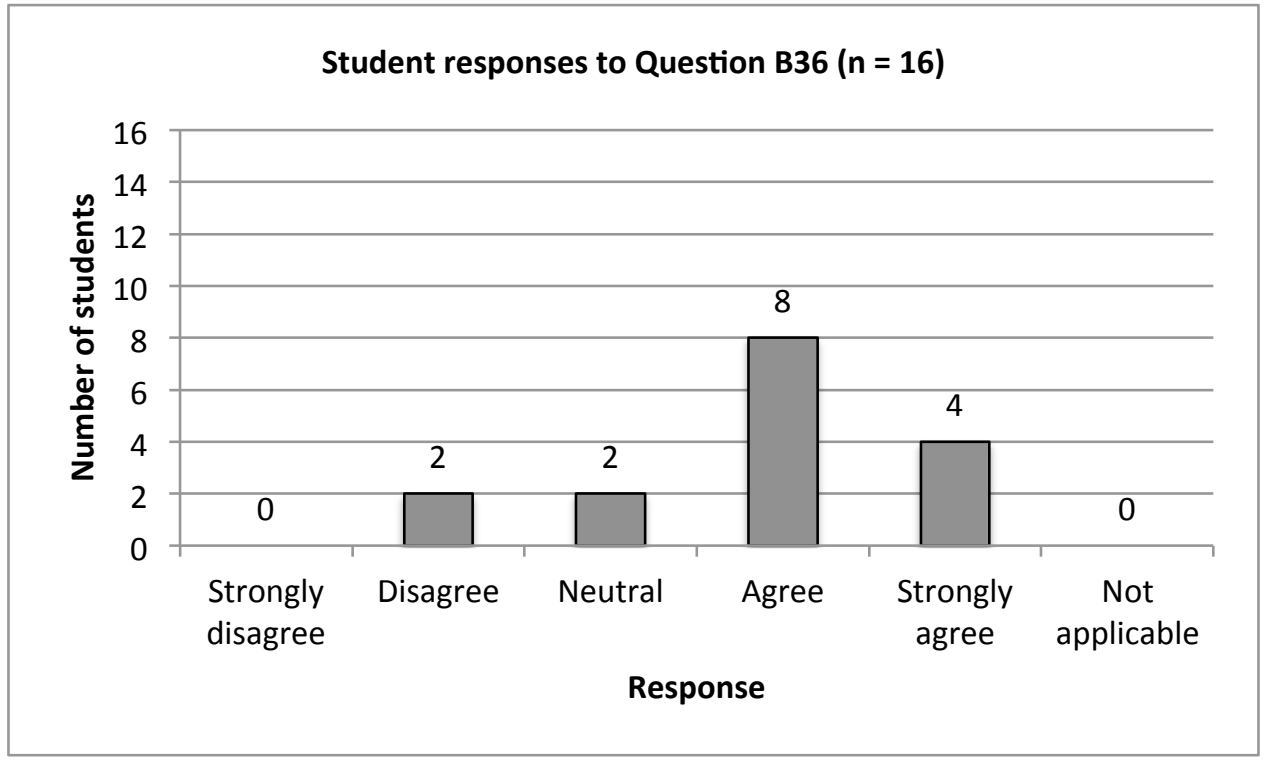

Figure 7-64: Student responses to Question B36: "To what extent do you agree or disagree that the visual quality and appearance of your designs were enhanced by the use of the

Tablet PC?"

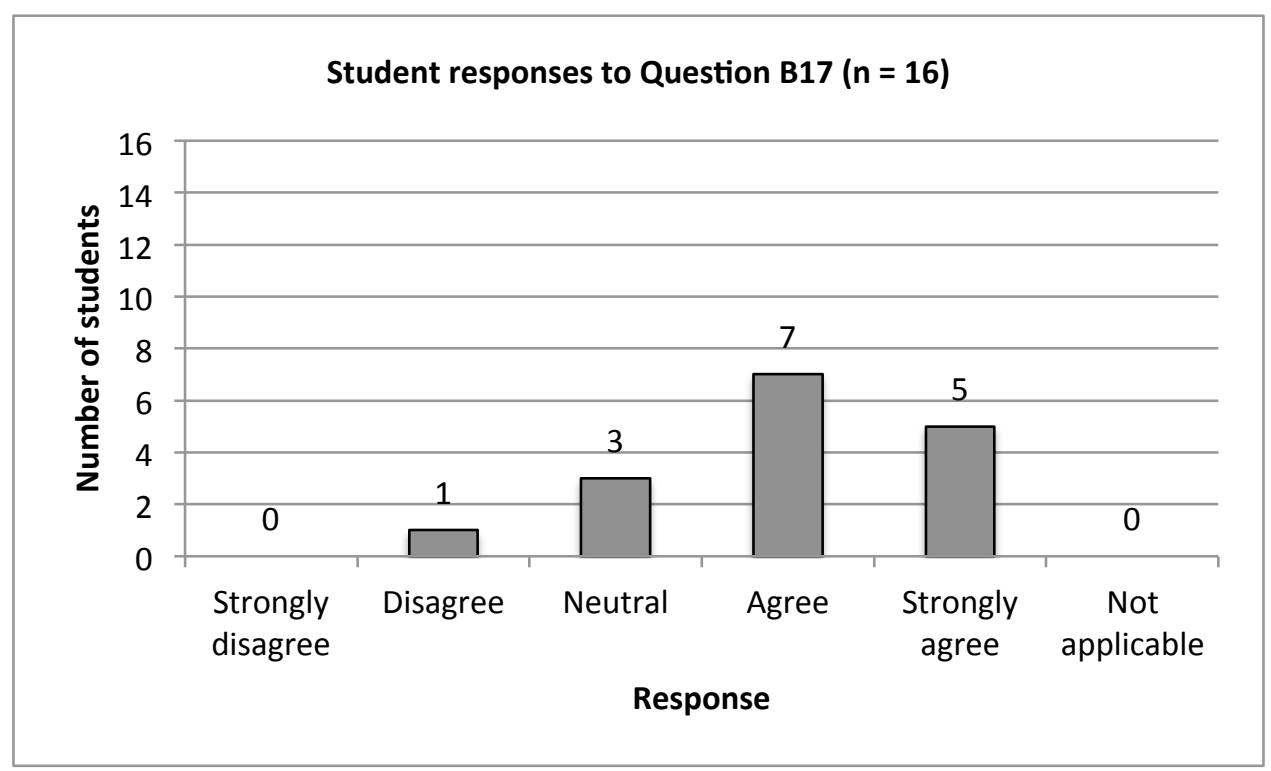

Figure 7-65: Student responses to Question B17: "To what extent do you agree or disagree that the quality of outcome is greater using the Tablet PC than when paper-based sketching?" 


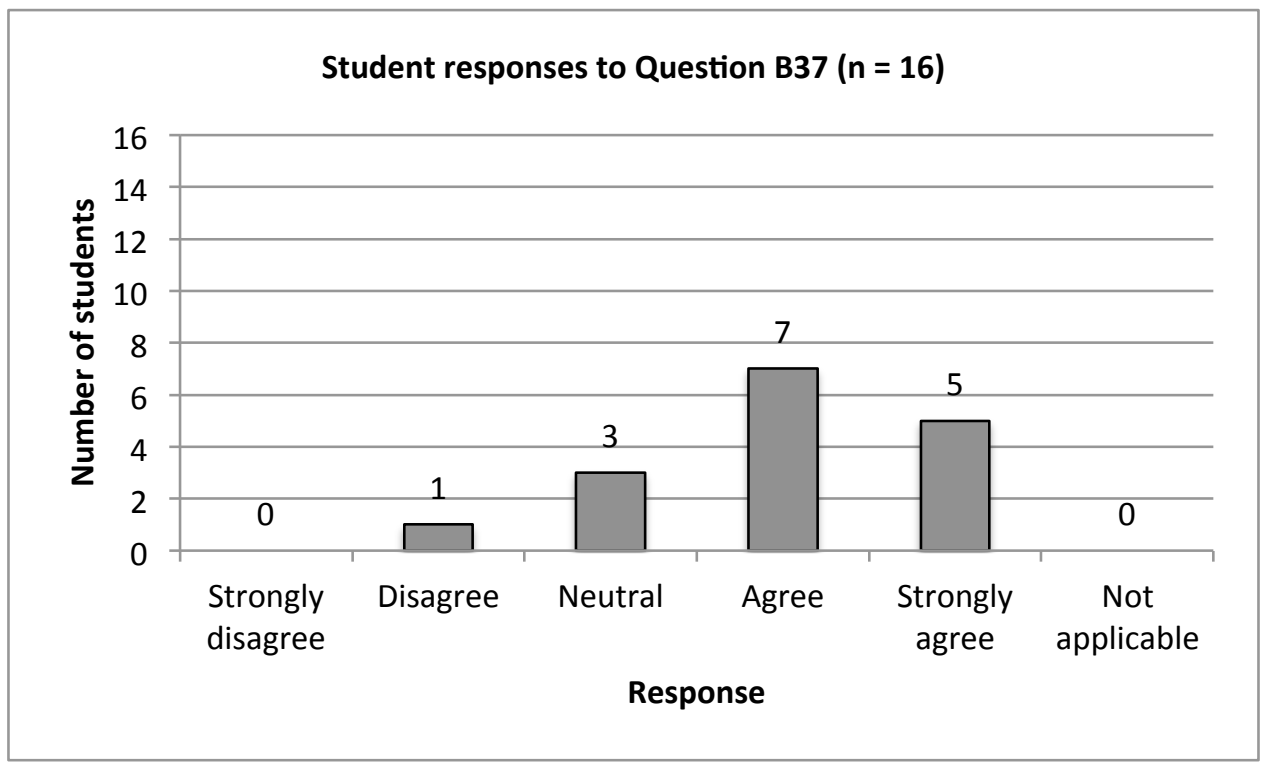

Figure 7-66: Student responses to Question B37: "To what extent do you agree or disagree that the work produced using the Tablet PC was of a higher level of presentation than that undertaken using paper-based techniques?"

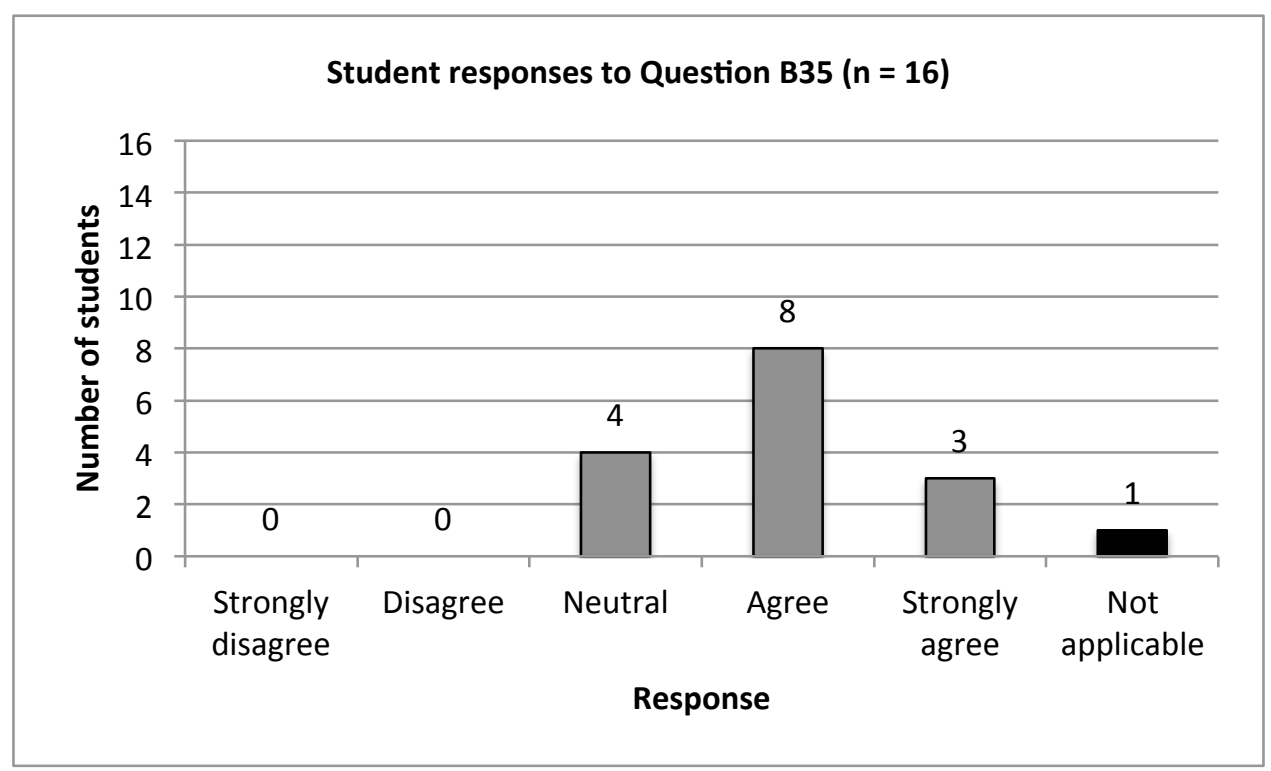

Figure 7-67: Student responses to Question B35: "To what extent do you agree or disagree that the use of the Tablet PC increased your excitement when collaborating through sketching with other people?" 


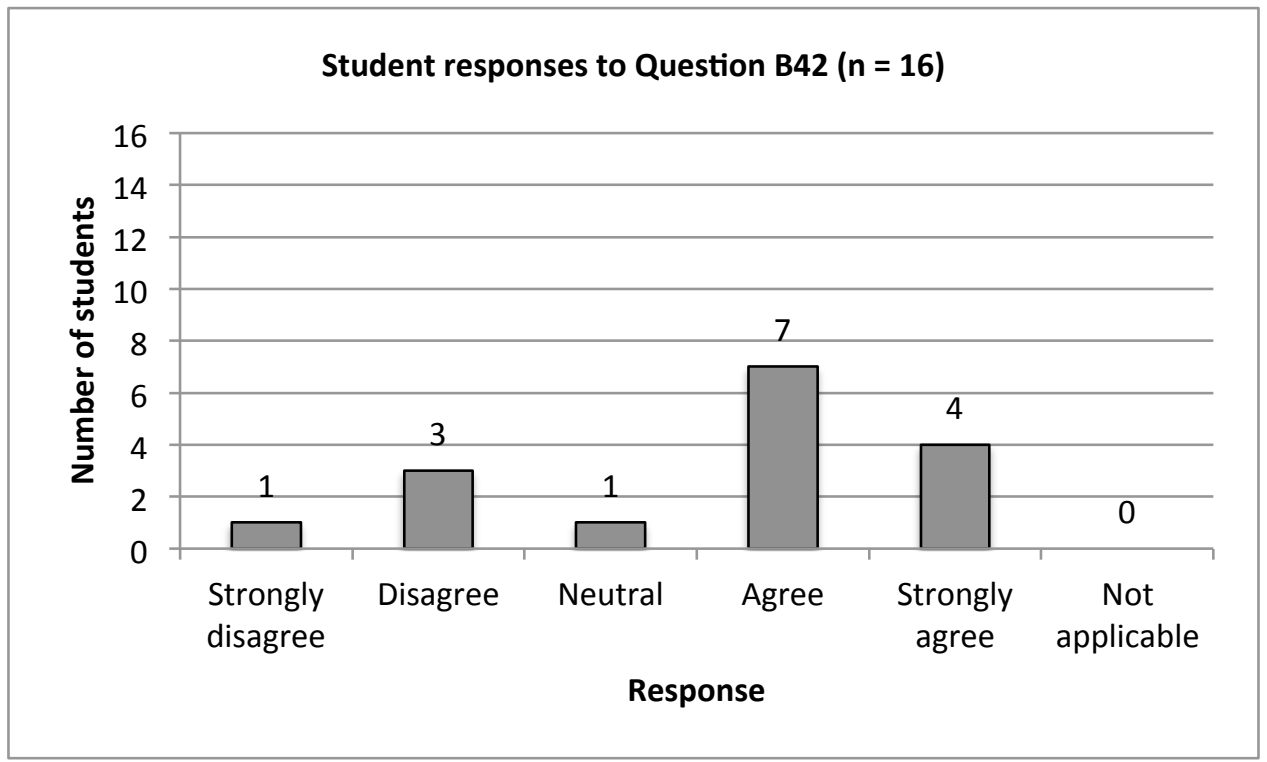

Figure 7-68: Student responses to Question B42: "To what extent do you agree or disagree that being able to browse the Internet whilst generating ideas was a significant advantage of using the Tablet PC?"

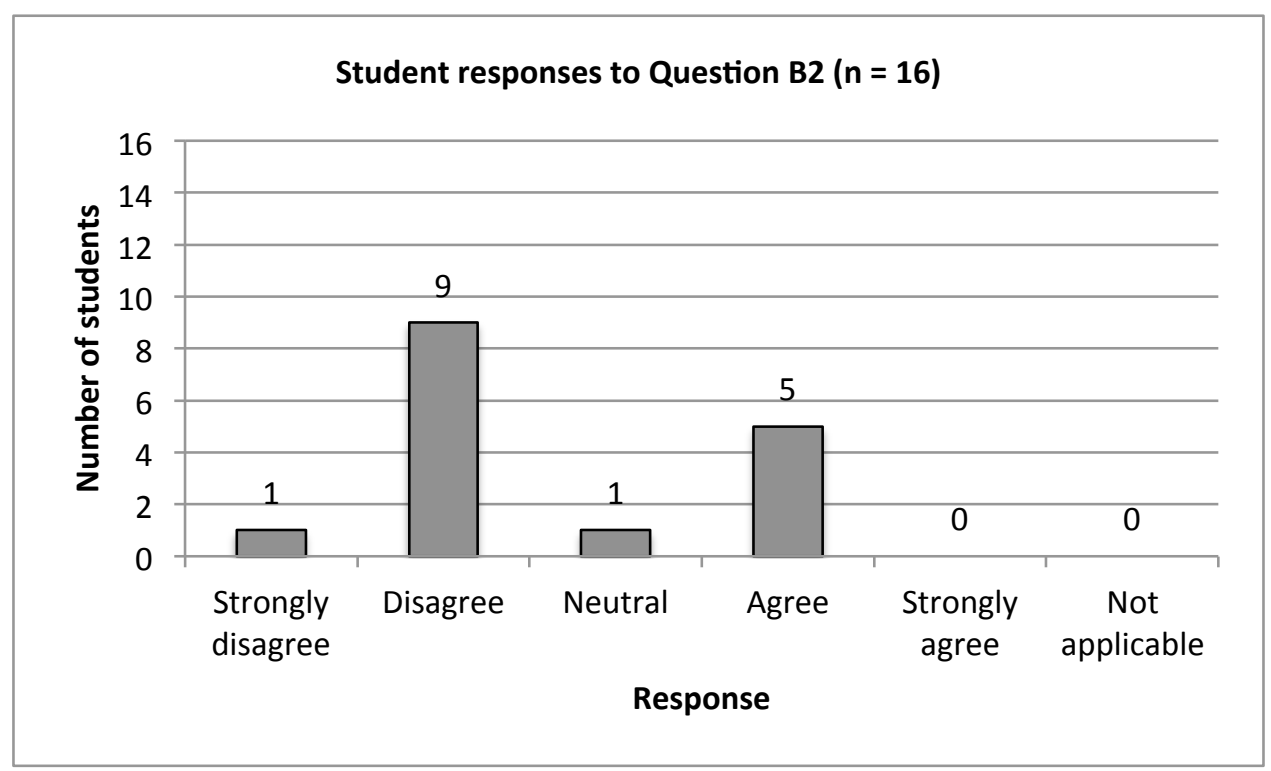

Figure 7-69: Student responses to Question B2: "To what extent do you agree or disagree that it was difficult to create faint lines and use them as a guide when using the Tablet PC?" 


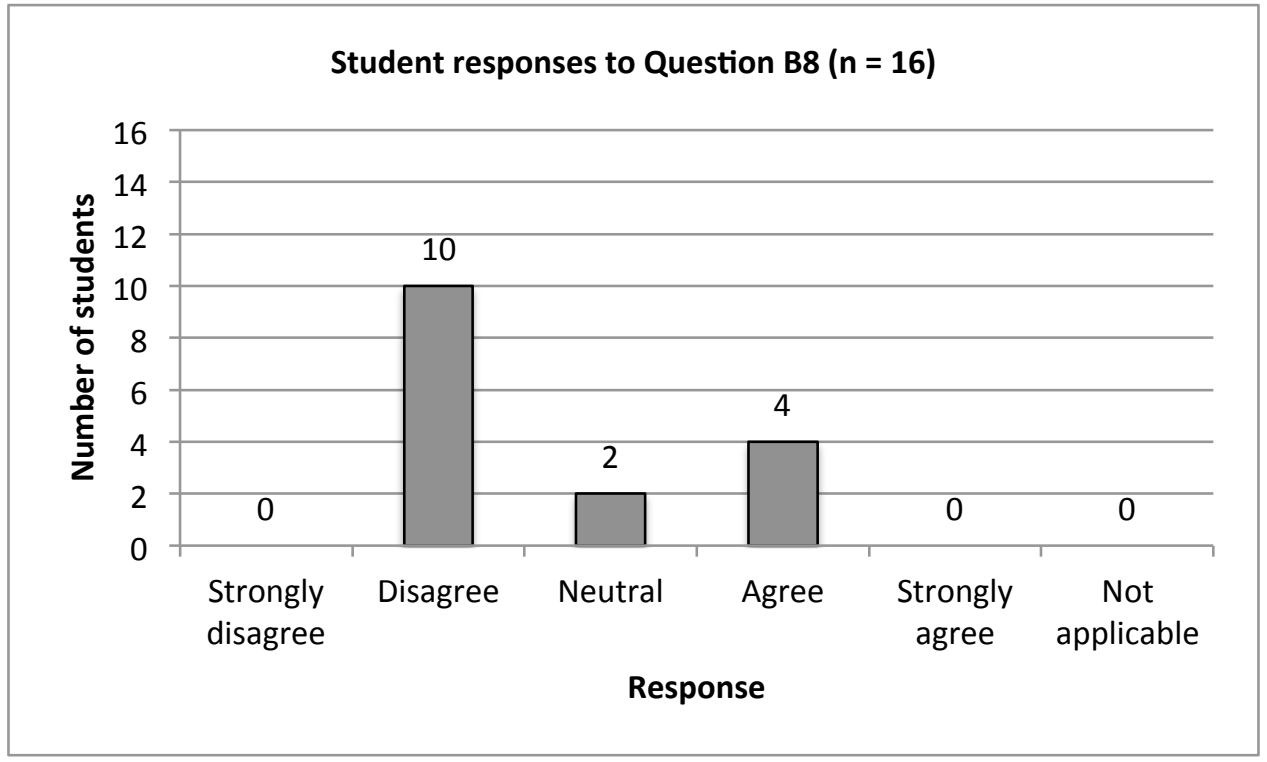

Figure 7-70: Student responses to Question B8: "To what extent do you agree or disagree that the stylus was too short for comfortable use?"

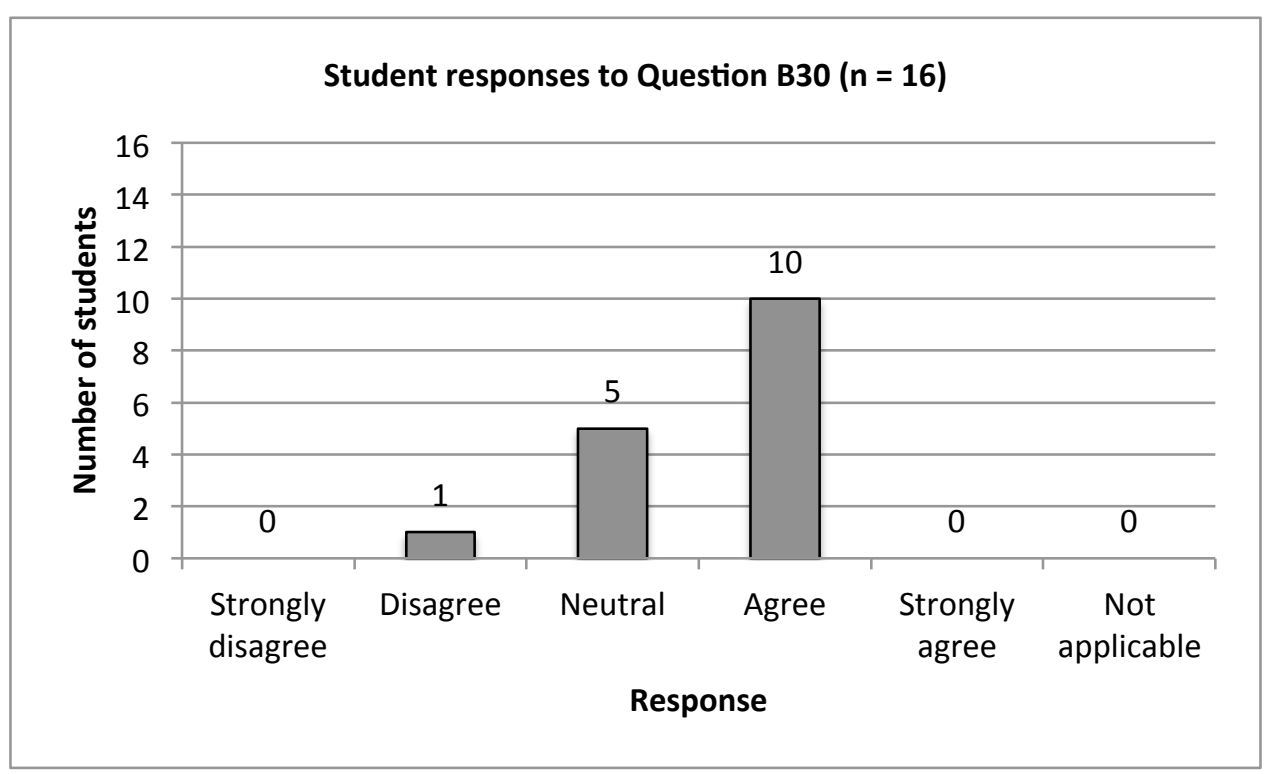

Figure 7-71: Student responses to Question B30: "To what extent do you agree or disagree that the ability to 'undo' using the Tablet PC increased creativity?" 


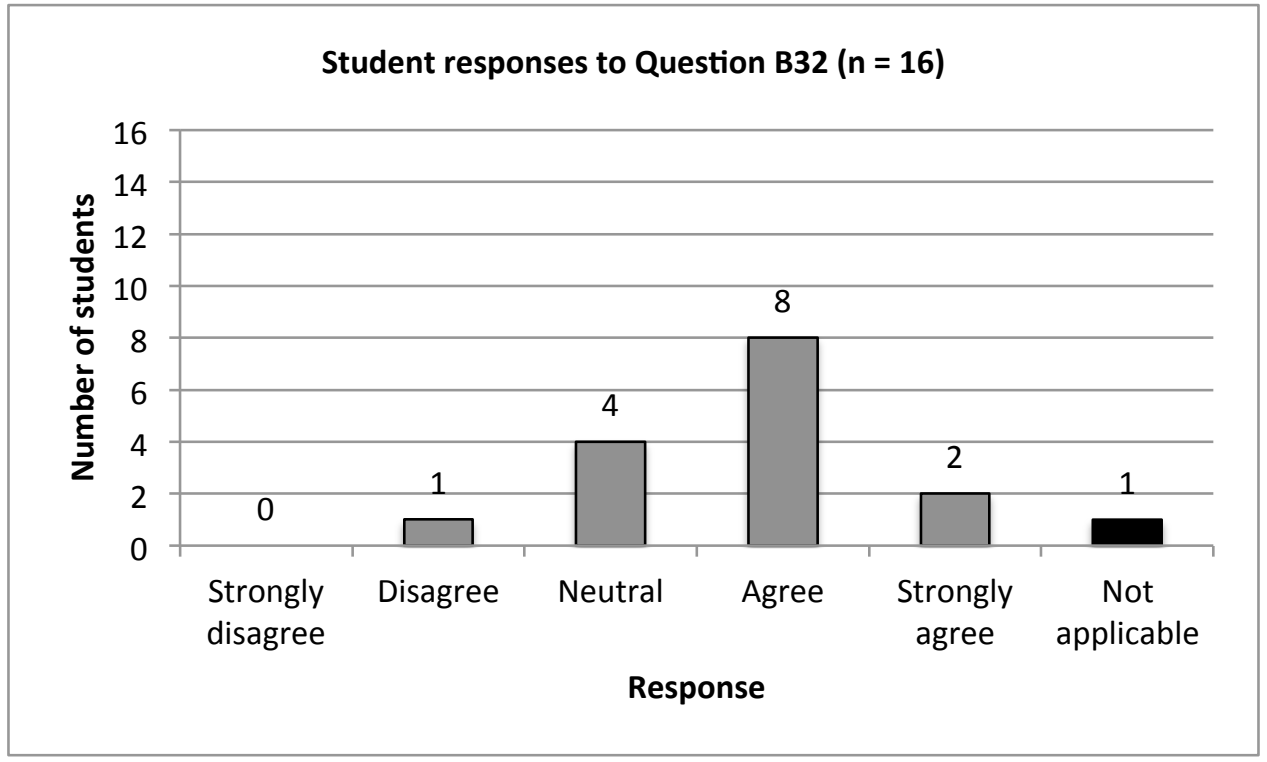

Figure 7-72: Student responses to Question B32: "To what extent do you agree or disagree that you became more productive when you used the Tablet PC?"

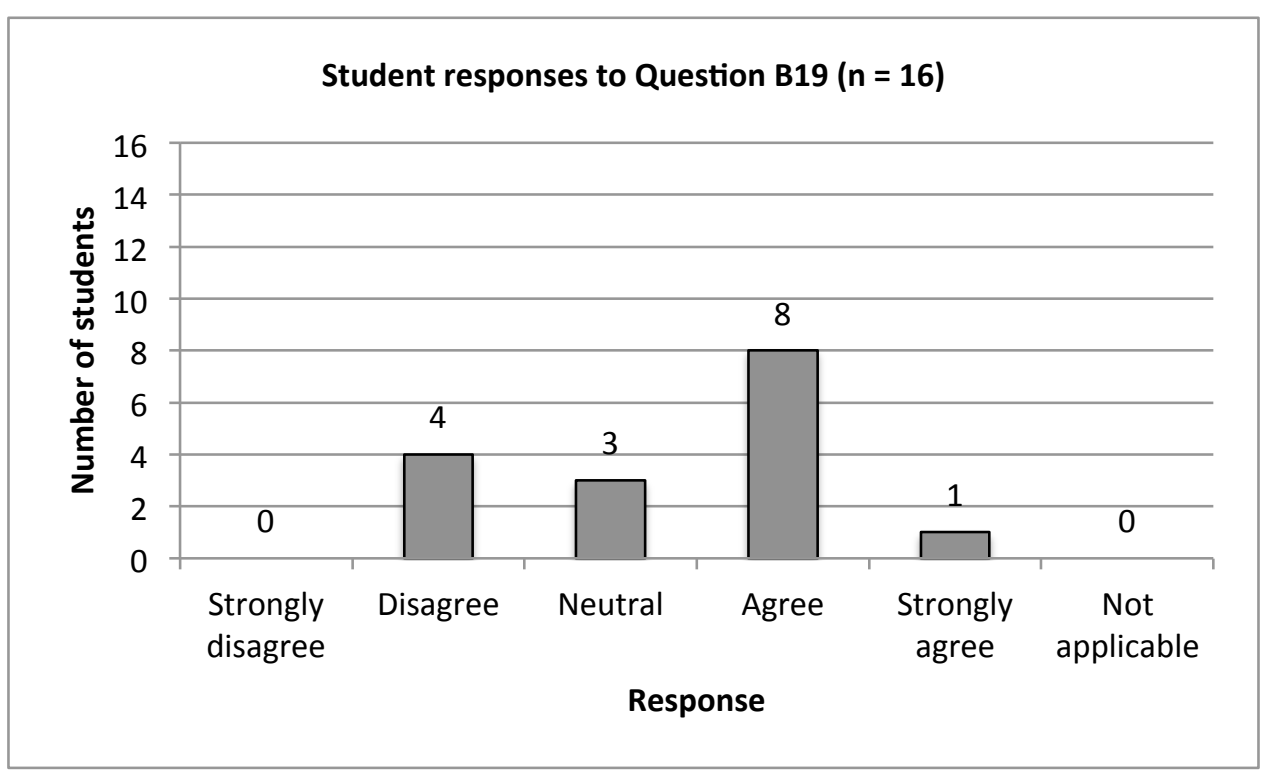

Figure 7-73: Student responses to Question B19: "To what extent do you agree or disagree that the Tablet PC helped you quickly communicate your ideas to other people?" 


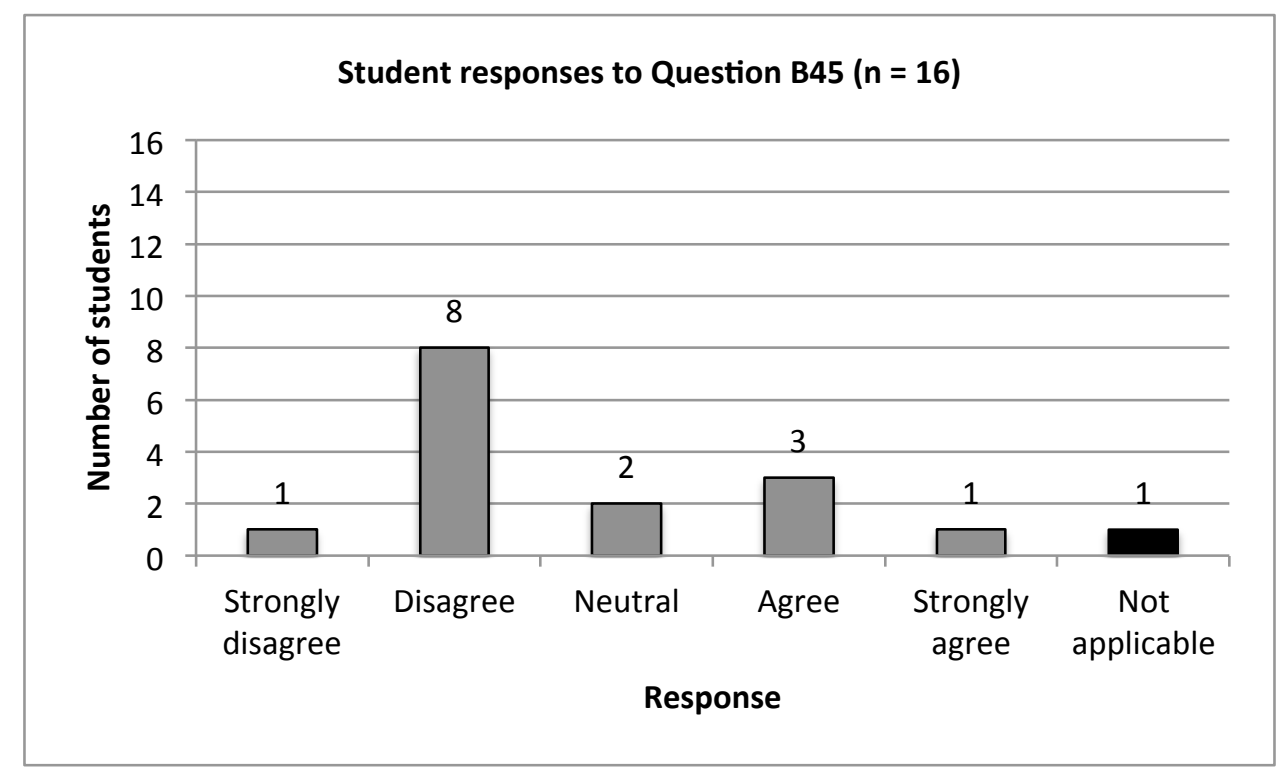

Figure 7-74: Student responses to Question B45: “To what extent do you agree or disagree that you were uneasy about sketching in public with the Tablet PC because of the potential for it to be stolen?"

\subsubsection{Limitations}

The biggest drawback in using the Tablet PC identified by most students was the size of the screen as it limited their ability to preview previous concepts on the same page (Figure 7-75). Students also expressed some concerns about calibrating the stylus. Students found it difficult to match the position of the tip of the stylus with the cursor (Figure 7-76). They were not able to sketch with the stylus at a low angle on the screen, which is possible when sketching using paper-based techniques (Figure 7-77). Twelve students thought that when short amounts of time were available for sketching, the Tablet PC was less convenient (Figure 7-78). Also, the majority of students confirmed that the Tablet PC screen was too small for 3D CAD work (Figure 7-79) and effective sketching (Figure 7-81). Eleven students disagreed/strongly disagreed that rendering using 3D CAD was quicker and easier with the Tablet PC (Figure 7-79). Students felt that the sketches produced using the Tablet PC had a tendency to be less detailed (Figure 7-82).

The Tablet PC's weight affected its portability (Figure 7-83) and its rubber feet interfered in rotating it whilst sketching (Figure 7-84). The screen glare (Figure 7-85) and difficulty in using the Tablet PC compared to pen and pencil were other limitations identified by the students (Figure 7-86). The Tablet PC screen size had negative effects when using it for sketching and 3D CAD. However, what made the issue worse was that the majority of students believed 
that they were not able to use the Tablet PC full size because matching the position of the top of the stylus with the cursor became more difficult towards the edges (Figure 7-87) and the Tablet PC was not powerful enough to be used for 3D CAD (Figure 7-88). Half of the students also disagreed/strongly disagreed that using the stylus was useful with 3D CAD work (Figure 7-89).

The figures are arranged in order of concern, with the most substantial appearing first.

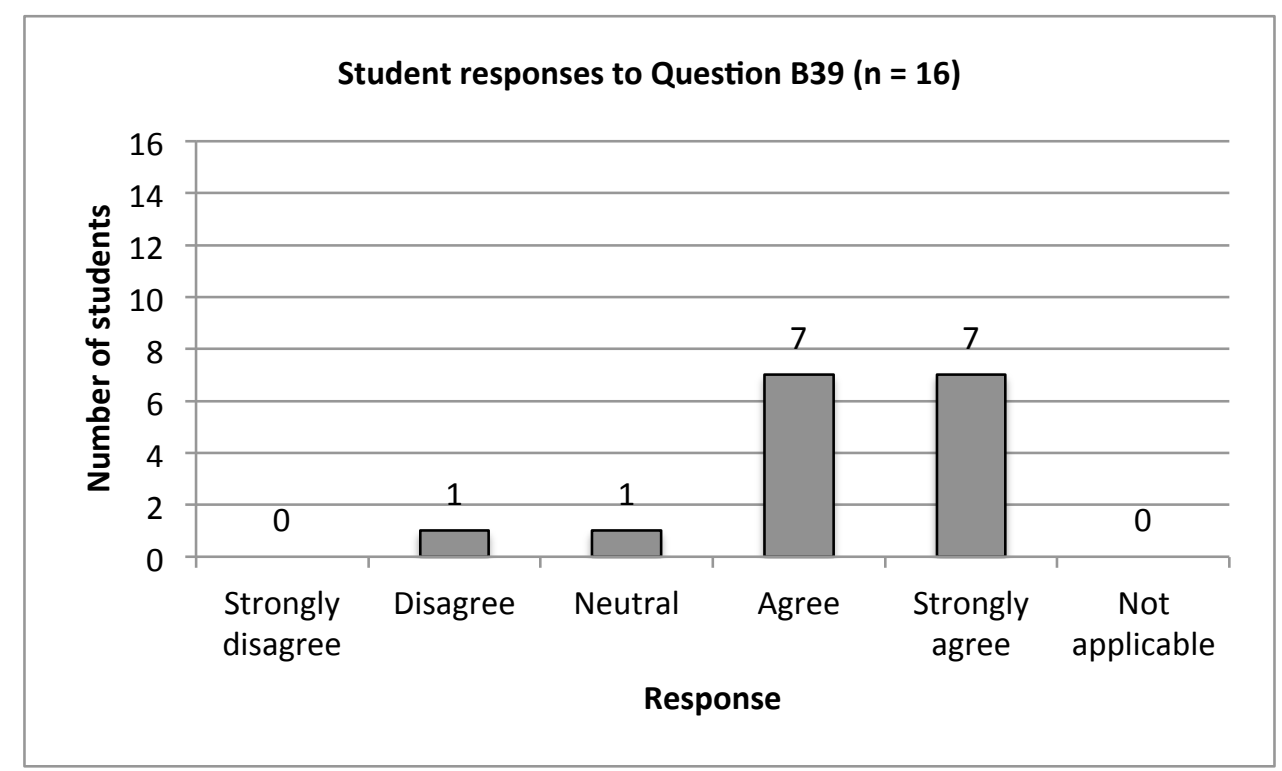

Figure 7-75: Student responses to Question B39: "To what extent do you agree or disagree that the size of the Tablet PC screen limited your ability to see numerous previous ideas on the same page?" 


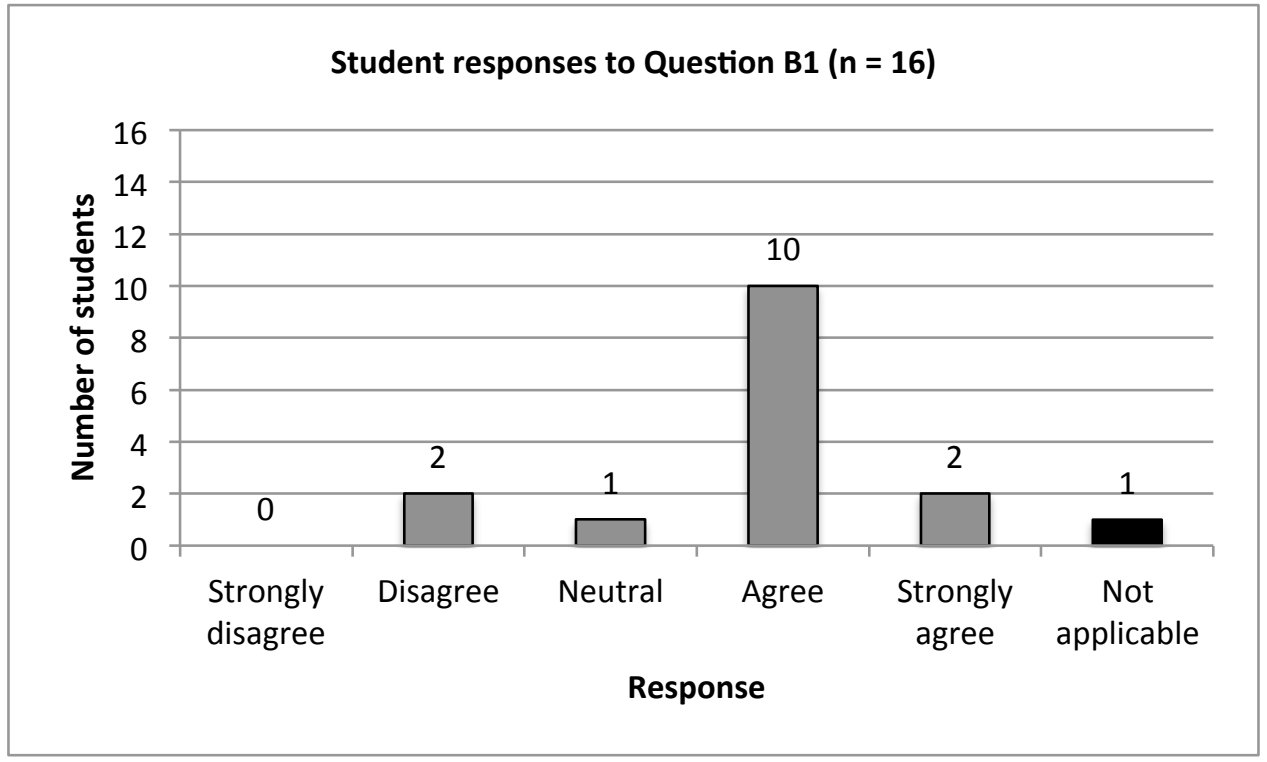

Figure 7-76: Student responses to Question B1: "To what extent do you agree or disagree that it was difficult to match the position of the tip of the stylus with the cursor?"

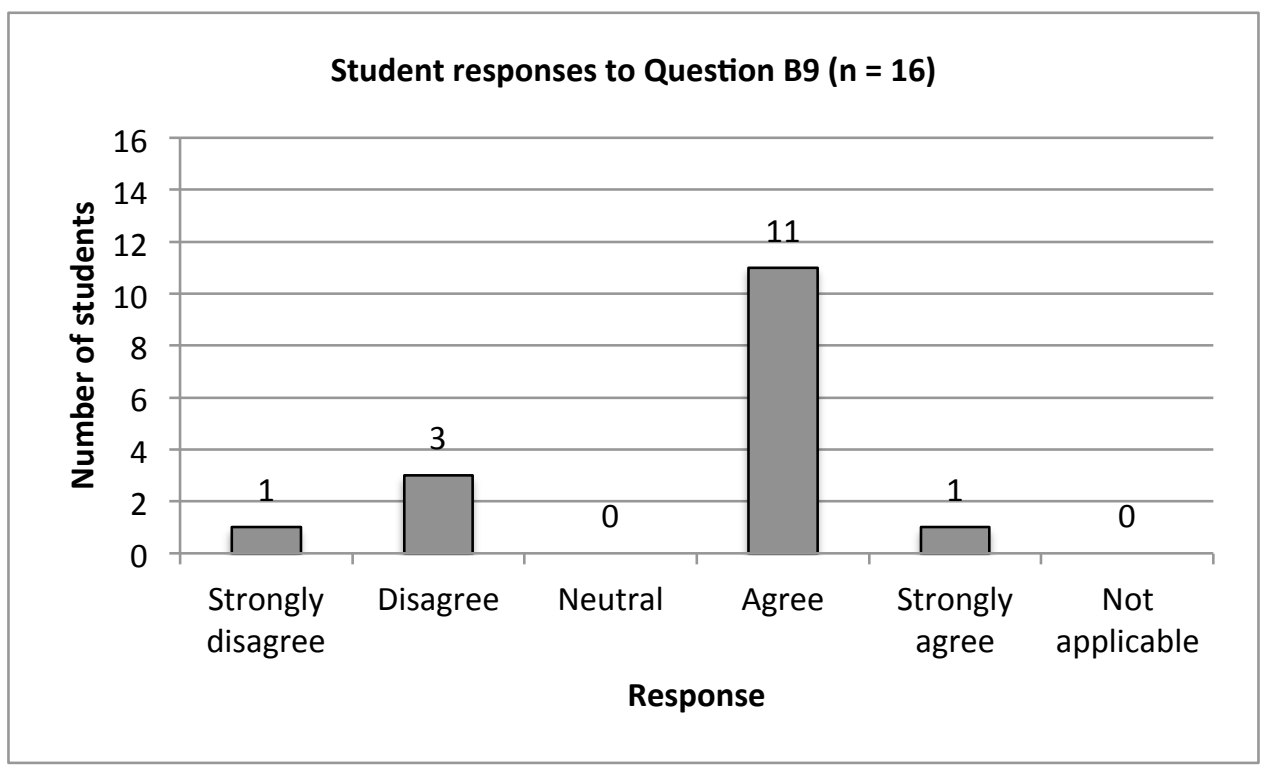

Figure 7-77: Student responses to Question B9: "To what extent do you agree or disagree that you were not able to sketch with the stylus at low angle on the screen?" 


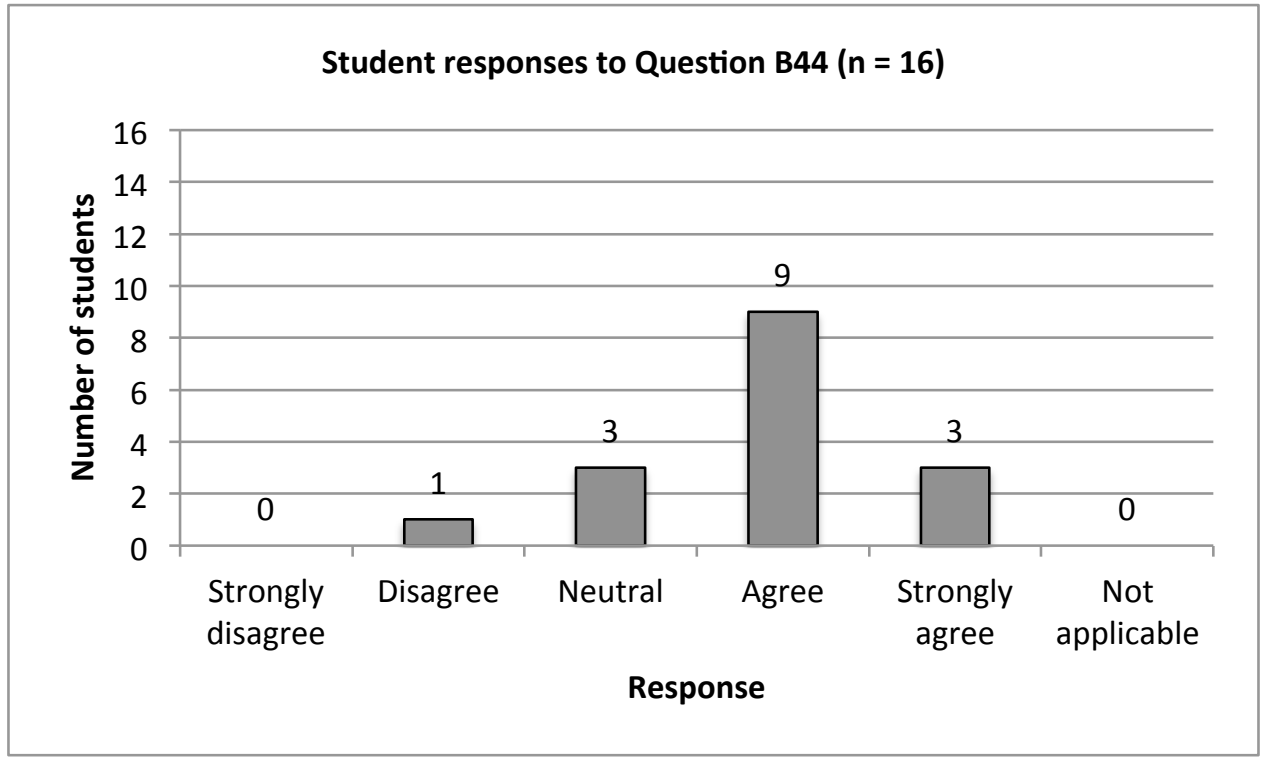

Figure 7-78: Student responses to Question B44: "To what extent do you agree or disagree that if not already in use, the Tablet PC was less convenient when short amounts of time were available for sketching?"

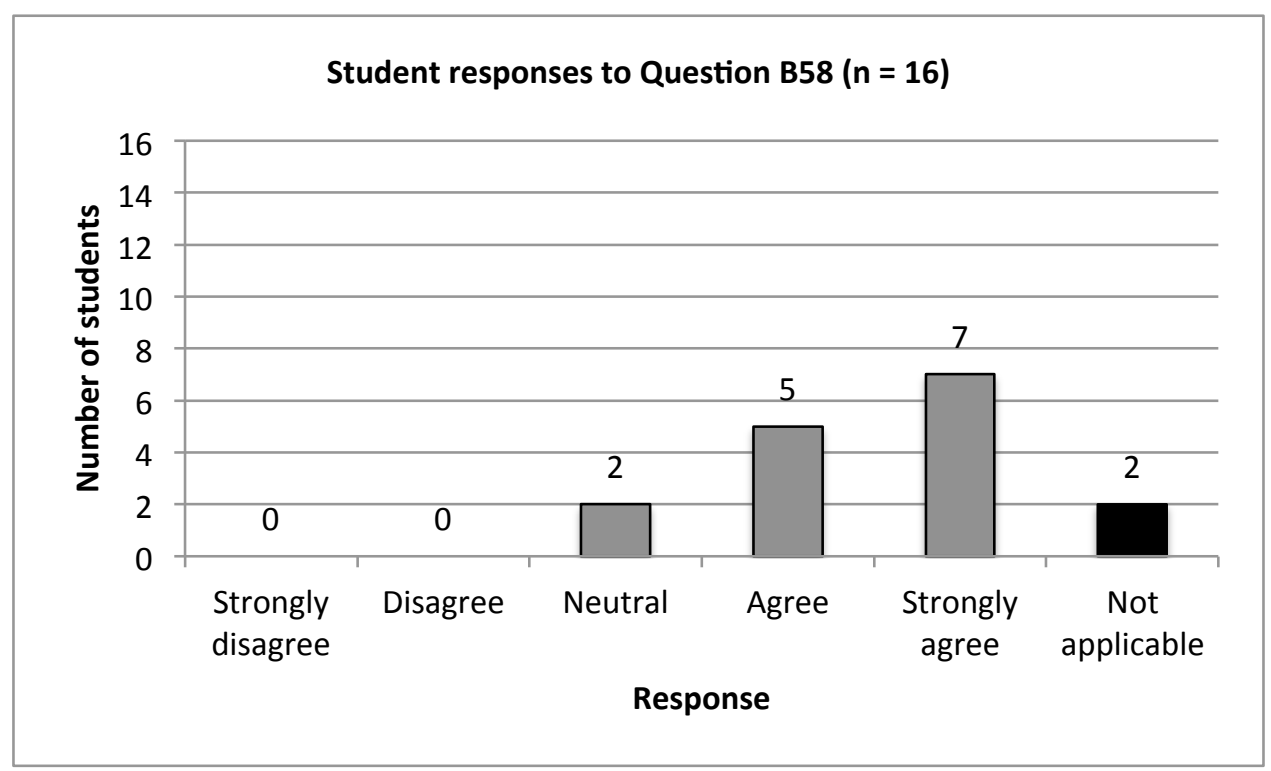

Figure 7-79: Student responses to Question B58: "To what extent do you agree or disagree that the Tablet PC screen was too small for 3D CAD work?" 


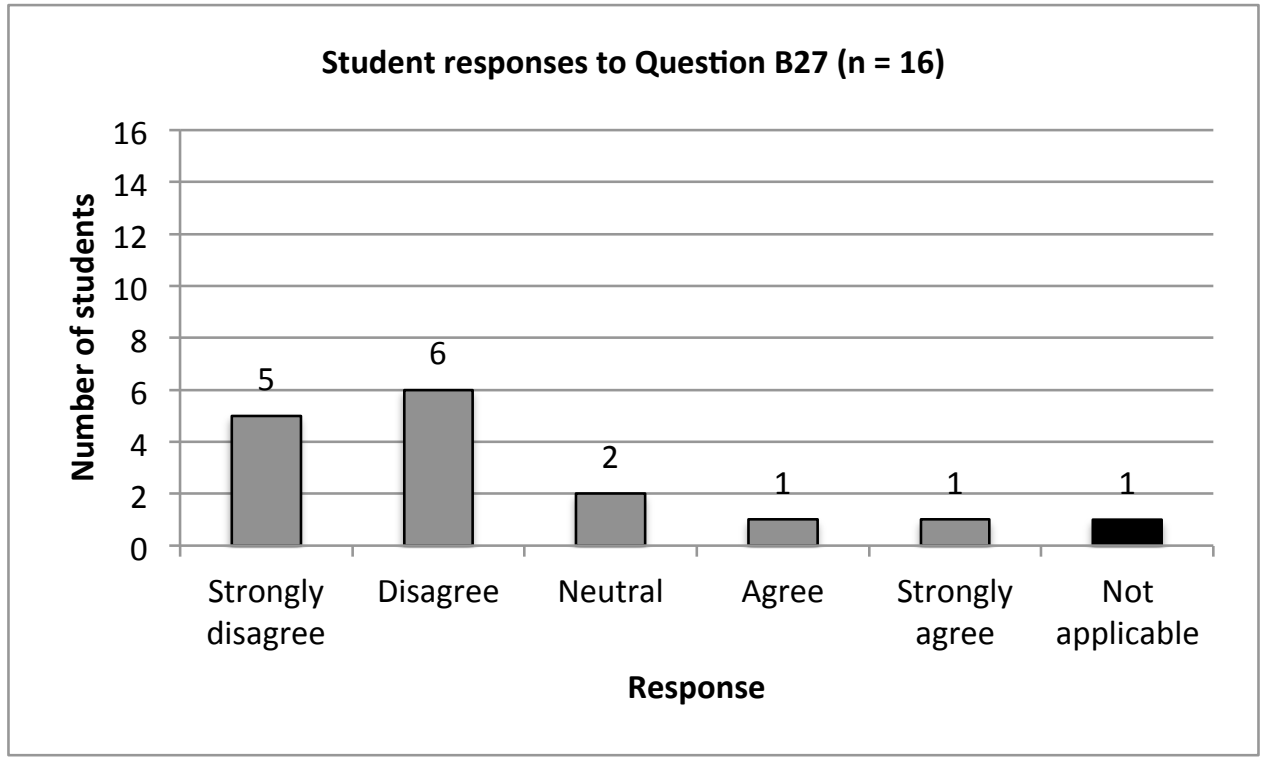

Figure 7-80: Student responses to Question B27: "To what extent do you agree or disagree that rendering using 3D CAD was quicker and easier with the Tablet PC?"

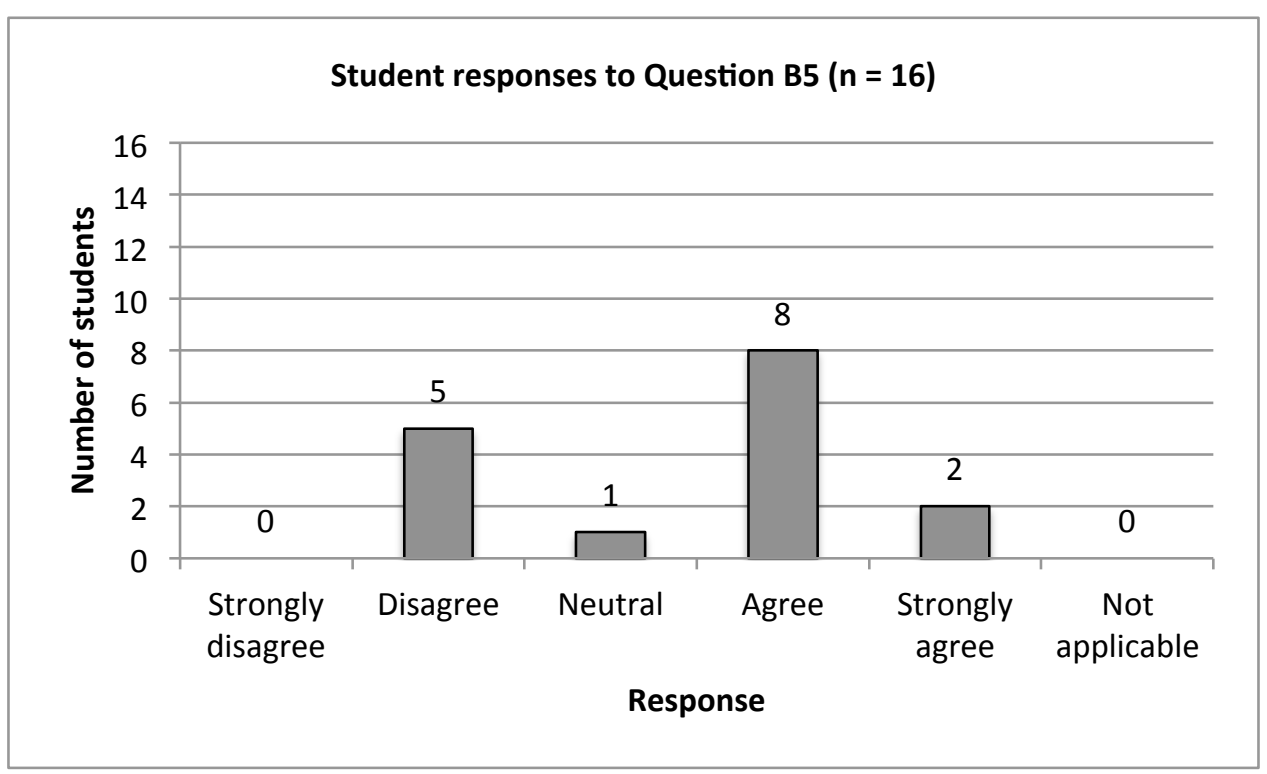

Figure 7-81: Student responses to Question B5: "To what extent do you agree or disagree that the Tablet PC screen was too small for effective sketching?" 


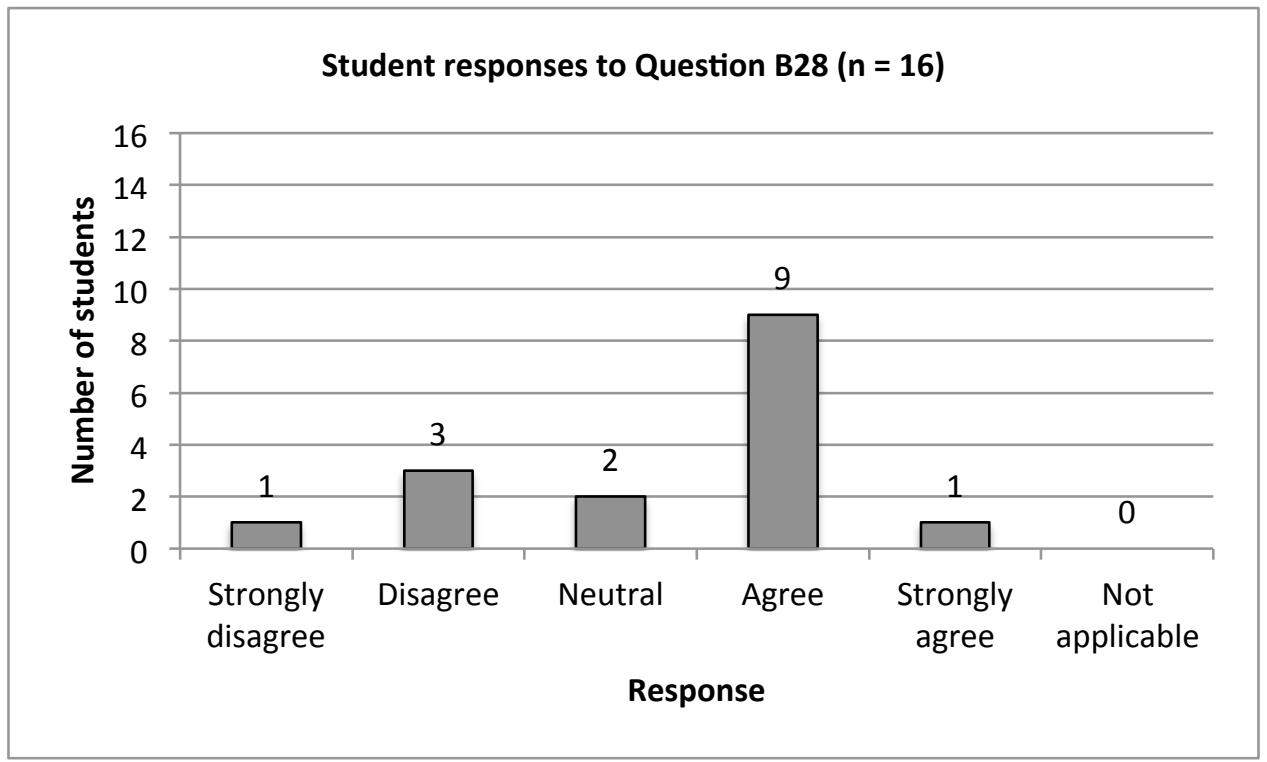

Figure 7-82: Student responses to Question B28: "To what extent do you agree or disagree that sketches produced using the Tablet PC had a tendency to be less detailed?"

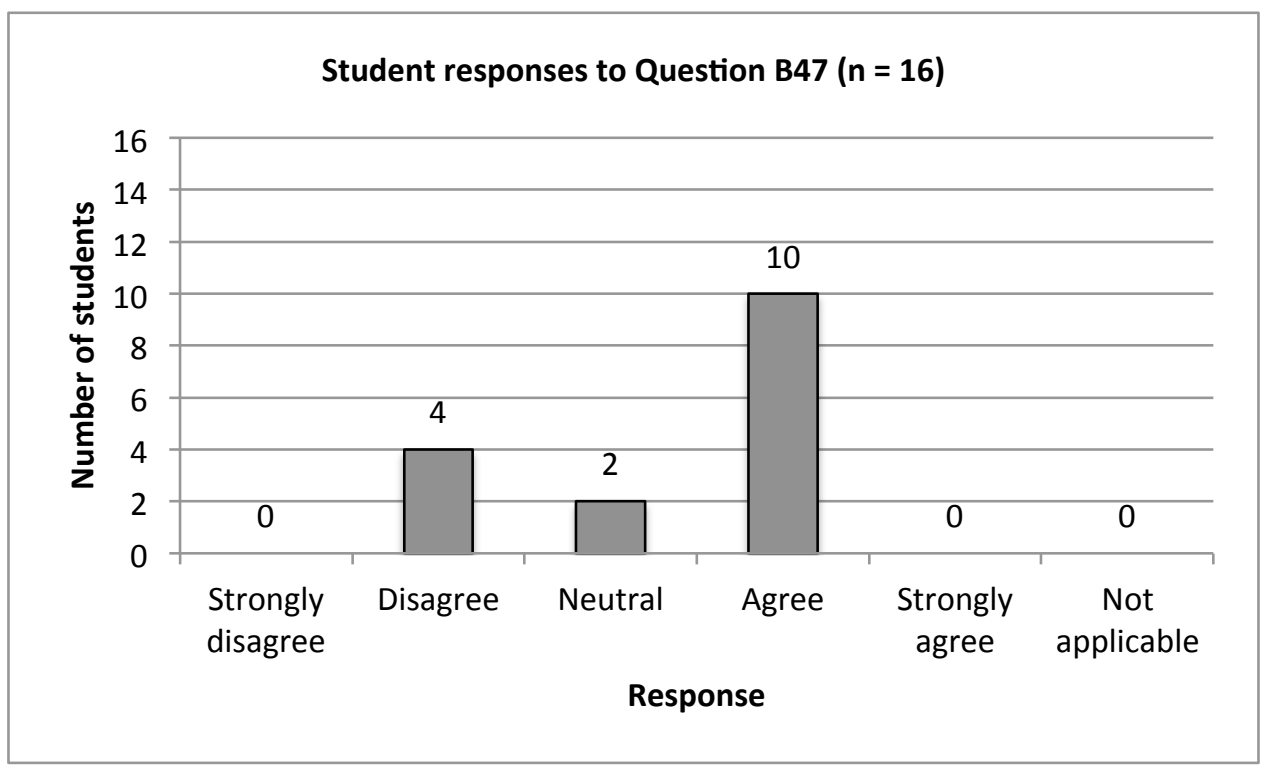

Figure 7-83: Student responses to Question B47: "To what extent do you agree or disagree that the weight of the Tablet PC affected its portability?" 


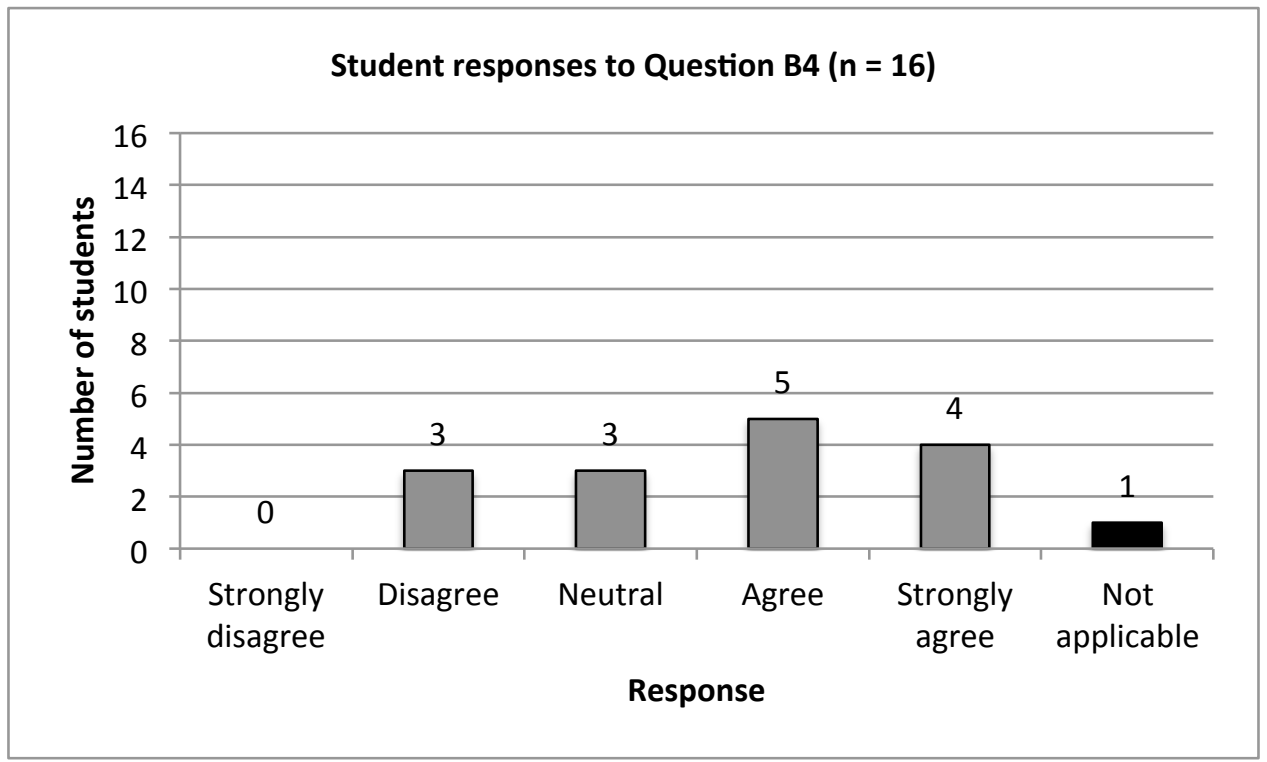

Figure 7-84: Student responses to Question B4: "To what extent do you agree or disagree that the rubber feet on the Tablet PC made it difficult to rotate when sketching?"

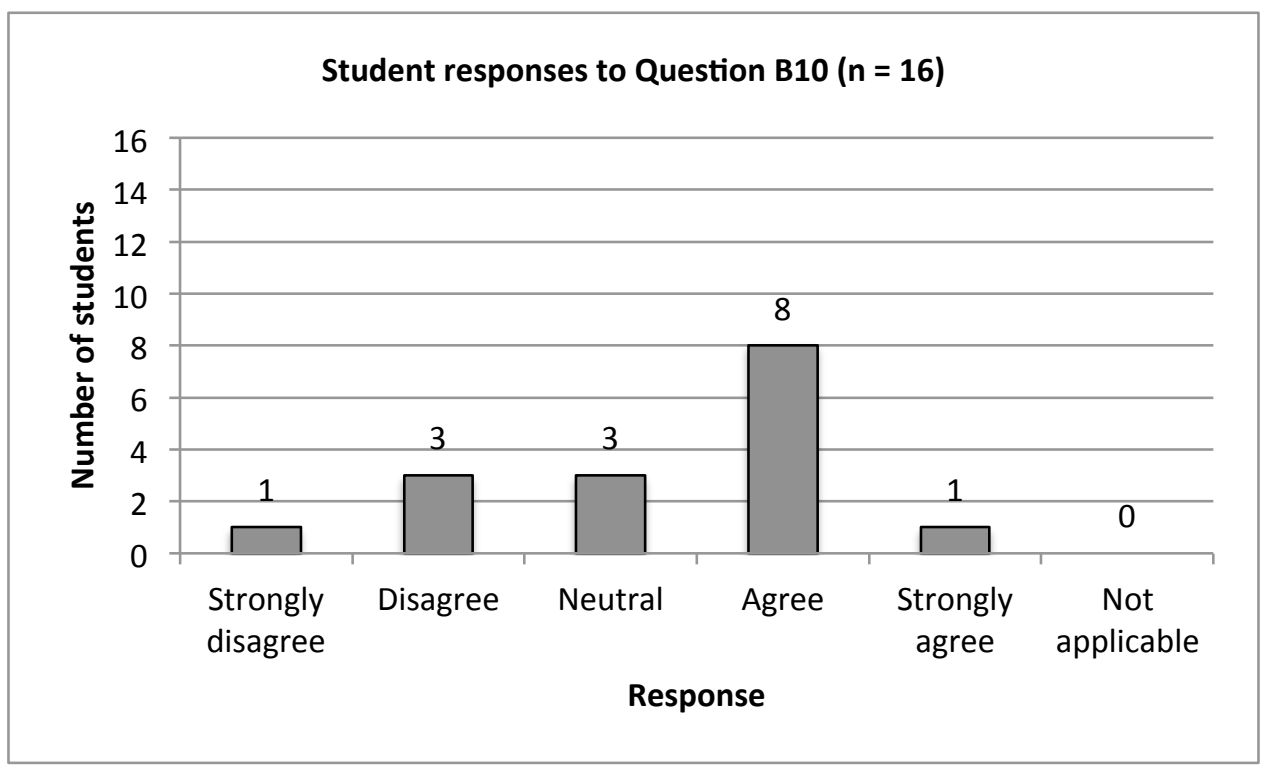

Figure 7-85: Student responses to Question B10: "To what extent do you agree or disagree that you faced problems with screen glare while sketching?" 


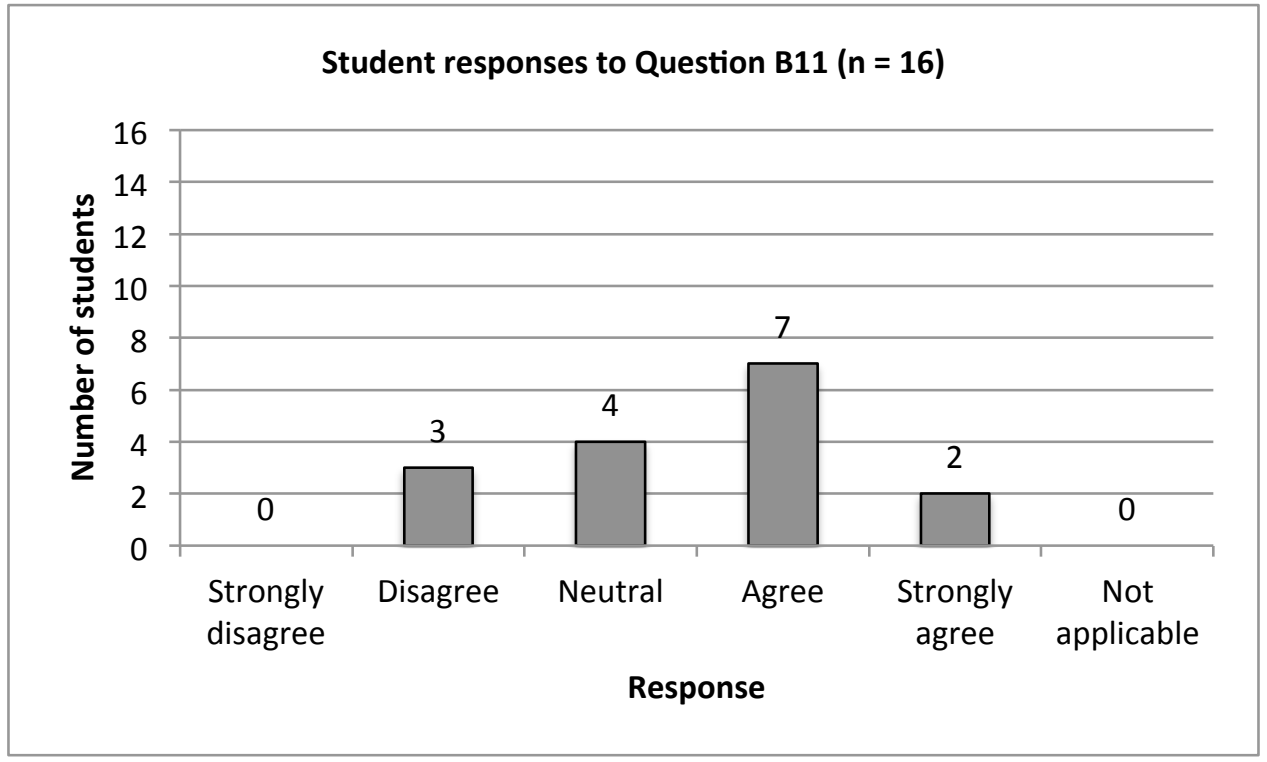

Figure 7-86: Student responses to Question B11: "To what extent do you agree or disagree that the Tablet PC was more difficult to use than pencil and paper?"

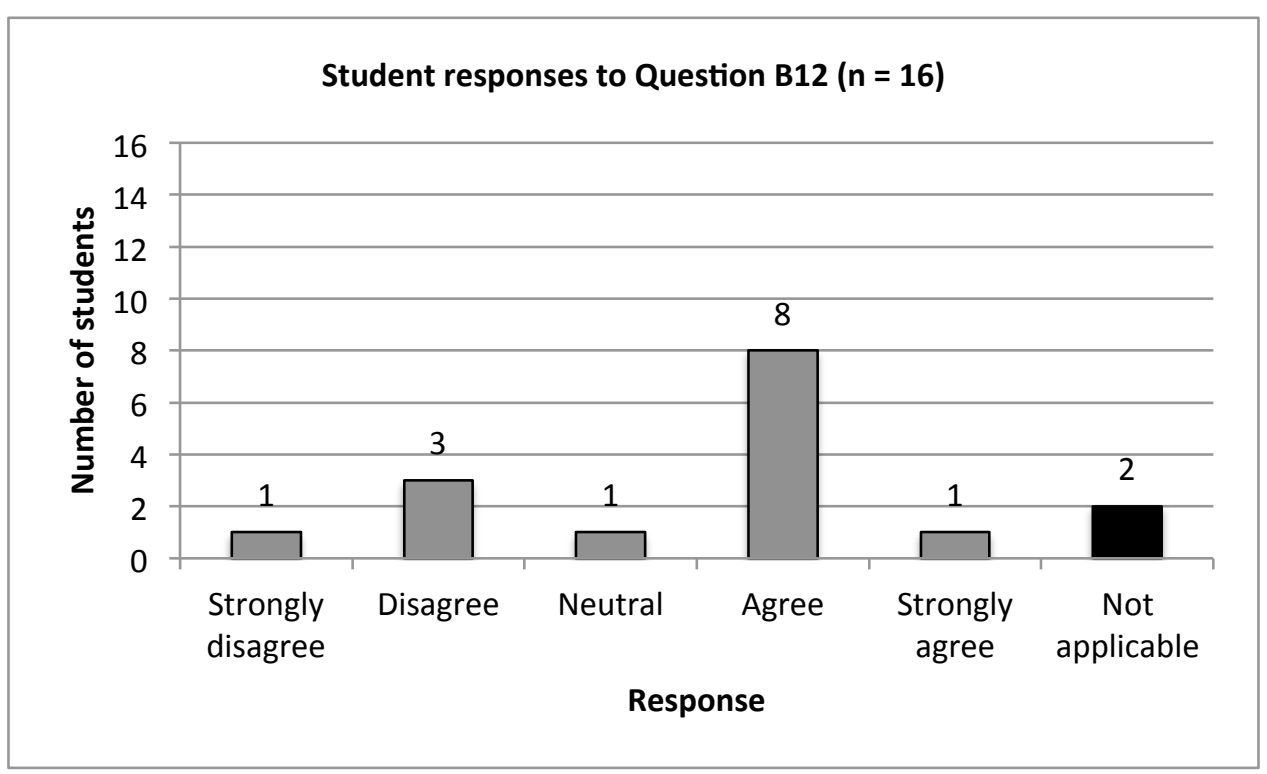

Figure 7-87: Student responses to Question B12: "To what extent do you agree or disagree that you were not able to use the full size of the Tablet PC screen because matching the position of the top of the stylus with the cursor became more difficult towards the edges?" 


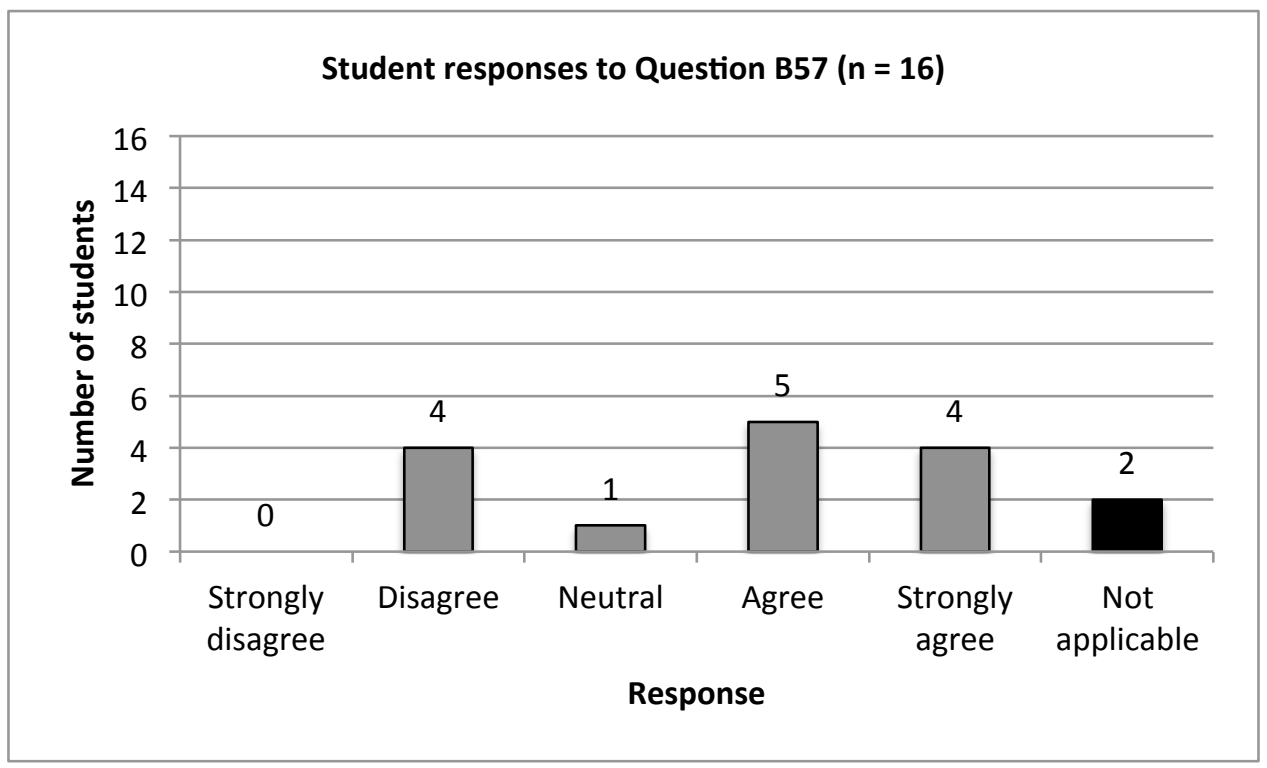

Figure 7-88: Student responses to Question B57: "To what extent do you agree or disagree that the Tablet PC was not powerful enough for 3D CAD work?"

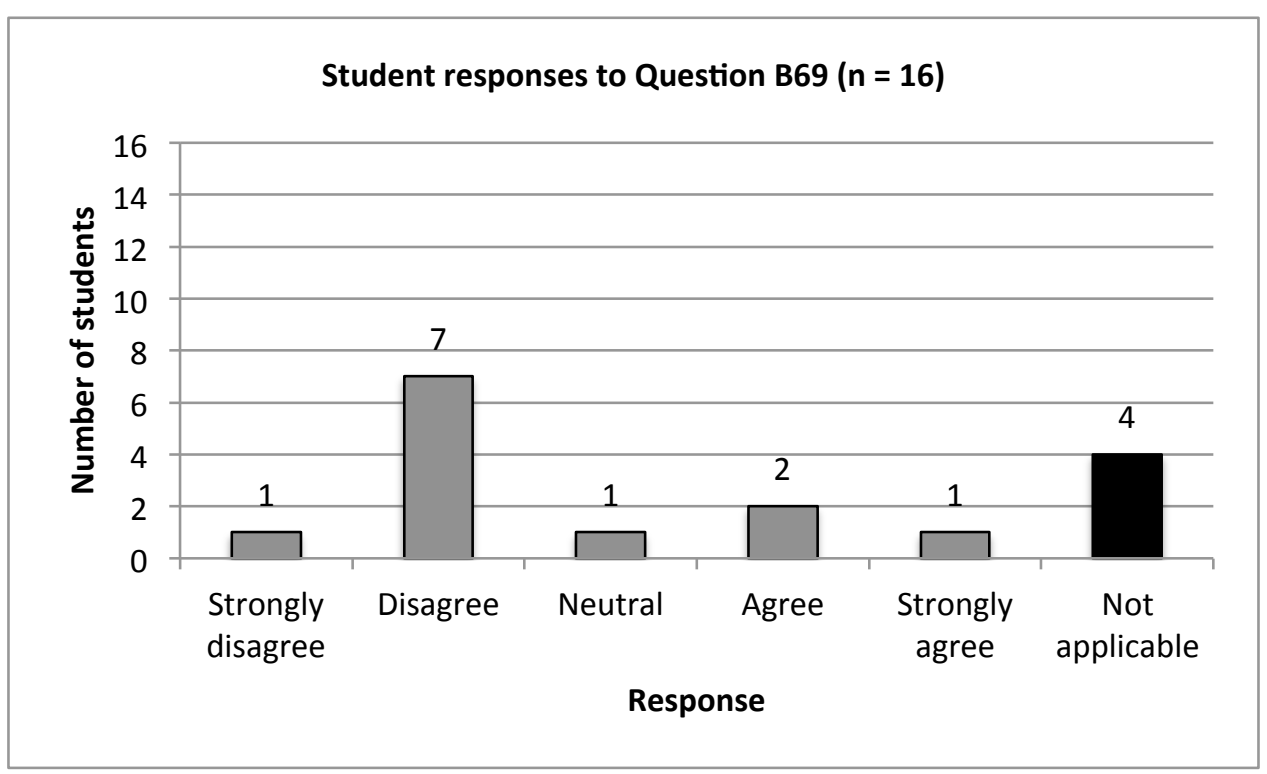

Figure 7-89: Student responses to Question B69: "To what extent do you agree or disagree that using the stylus was useful with 3D CAD work?"

\subsubsection{Recommendations for Learning and Teaching}

Despite the advantages of using the Tablet PC, all students felt that it should be used in conjunction with paper-based techniques (Figure 7-90) and that paper-based sketching techniques should be taught before using the Tablet PC (Figure 7-91). Strong feelings towards the importance of paper-based techniques continued with a desire to retain the 
teaching of paper-based rendering (Figure 7-92). In fact, the majority of students felt that they should be taught paper-based rendering before using the Tablet PC (Figure 7-95).

Thirteen students disagreed/strongly disagreed that they should be taught how to use the virtual keyboard on the Tablet PC desktop appropriately (Figure 7-93). Furthermore, the majority of students felt that introducing the Tablet PC to all industrial design students should have a motivating effect on them (Figure 7-94). Half of the students felt that in order to use the Tablet PC effectively, students must have been taught how to use 2D visualisation software (Figure 7-96).

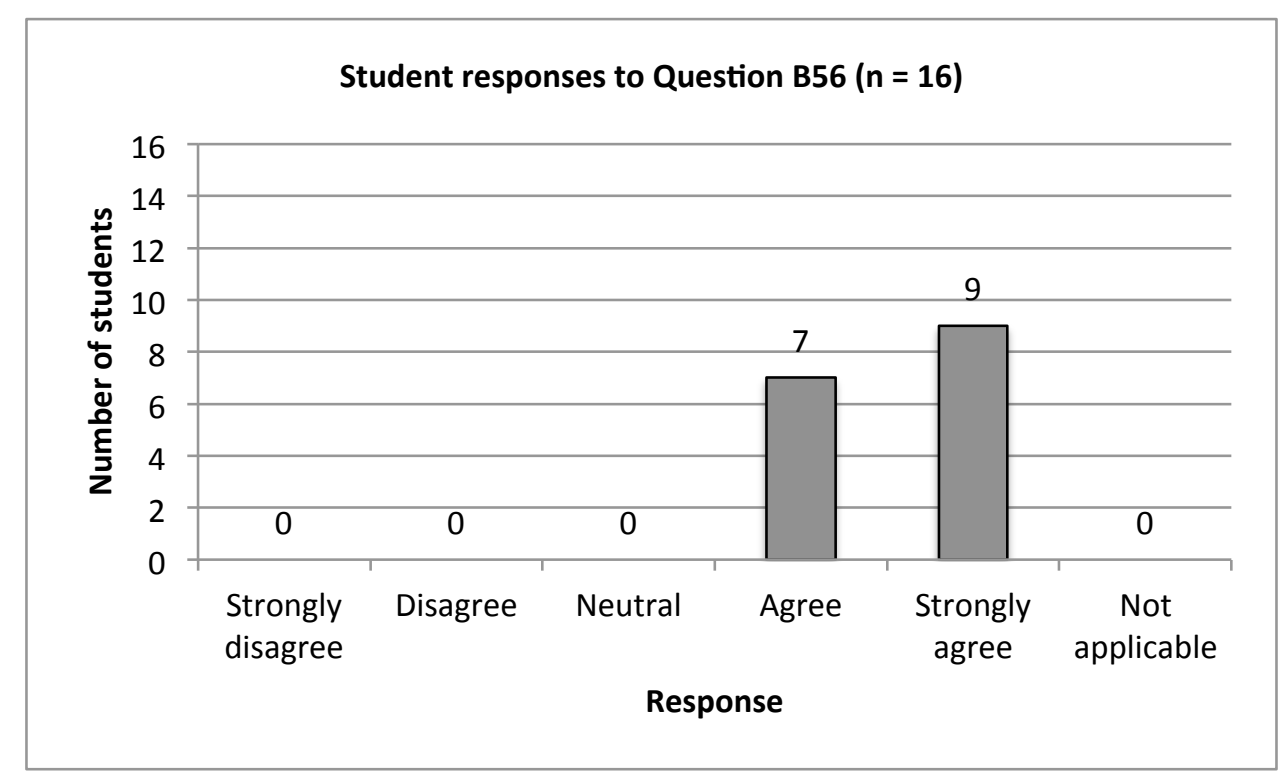

Figure 7-90: Student responses to Question B56: "To what extent do you agree or disagree that students should always have the option for using paper-based techniques to sketch in addition to the Tablet PC?" 


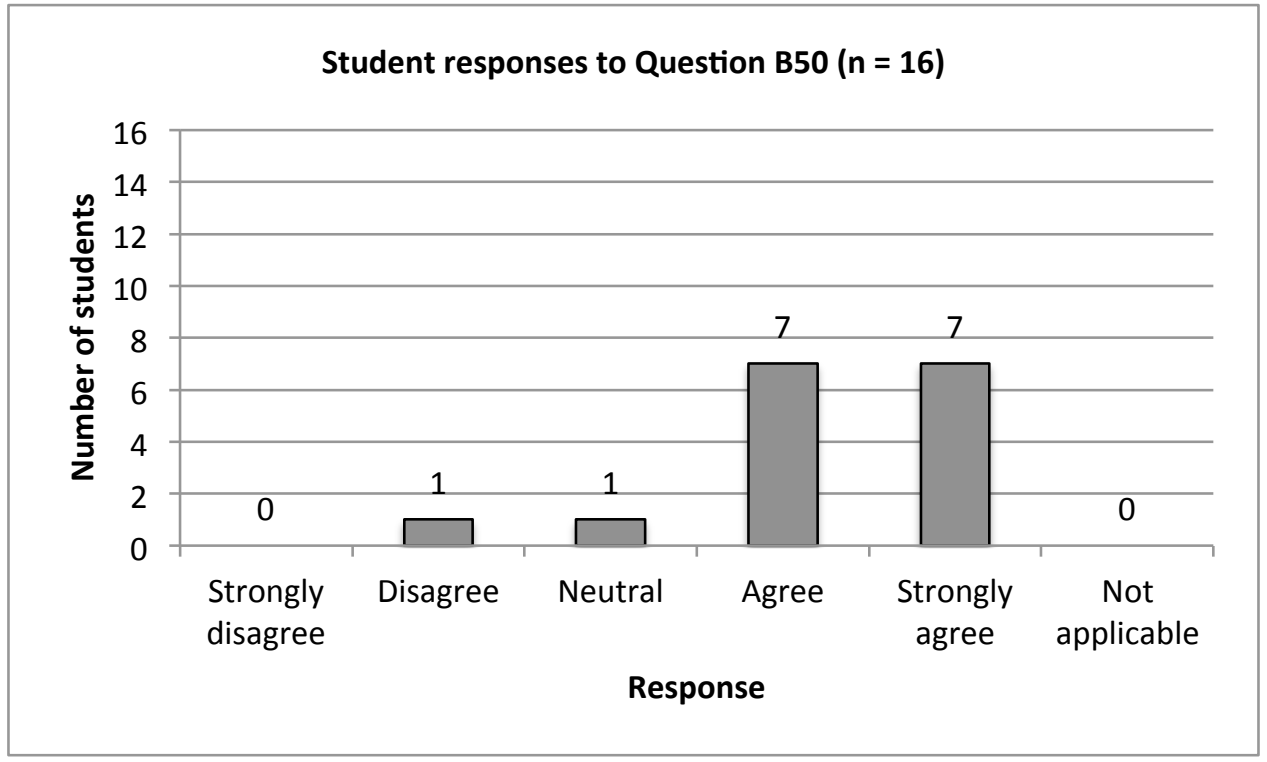

Figure 7-91: Student responses to Question B50: "To what extent do you agree or disagree that students should be taught sketching using paper-based techniques before using the Tablet PC?"

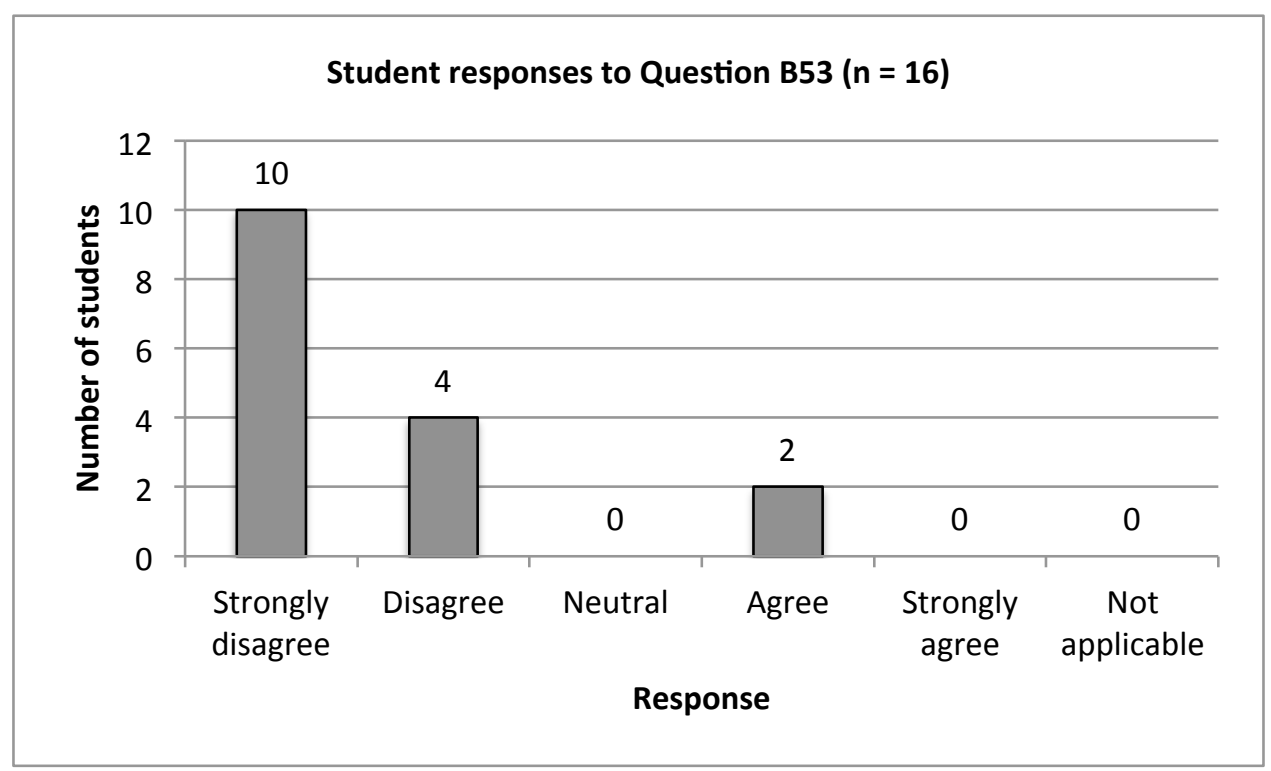

Figure 7-92: Student responses to Question B53: "To what extent do you agree or disagree that students should not be taught paper-based rendering techniques as the Tablet PC makes them redundant?" 


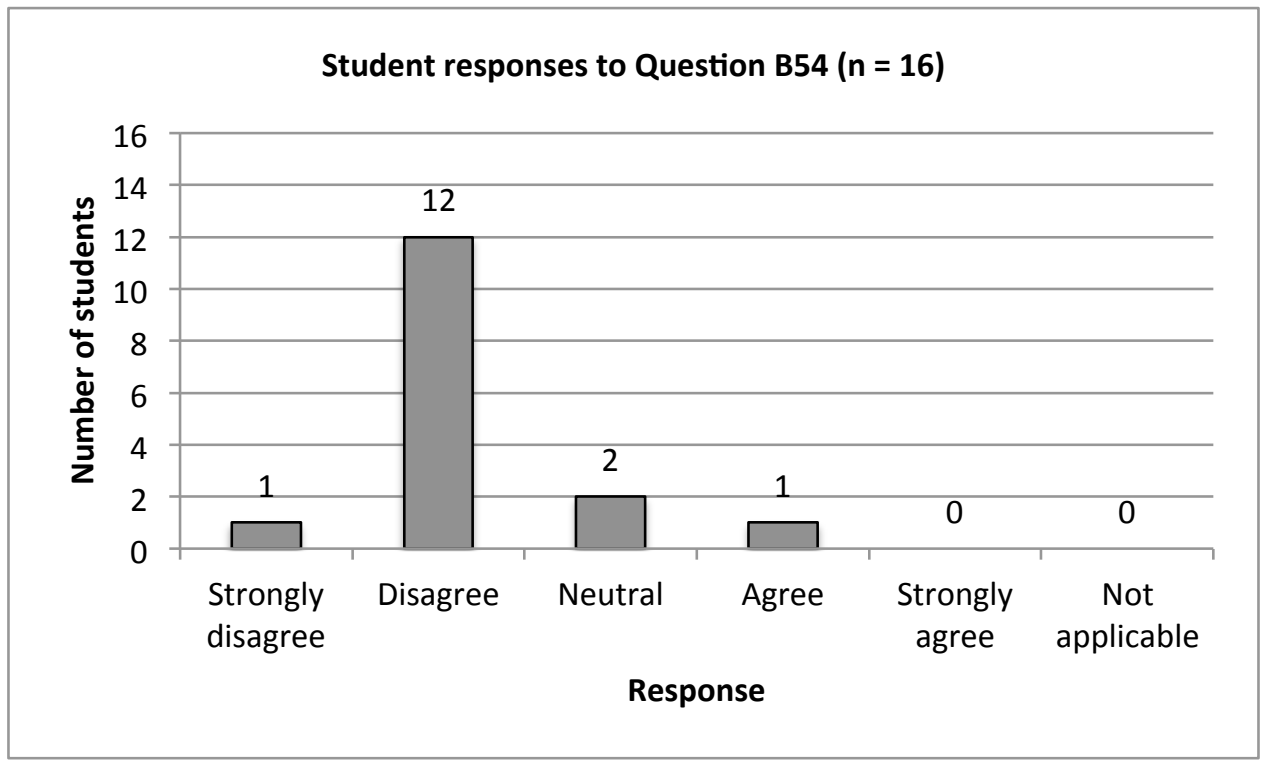

Figure 7-93: Student responses to Question B54: "To what extent do you agree or disagree that students need to be taught how to use the virtual keyboard on the Tablet PC desktop?"

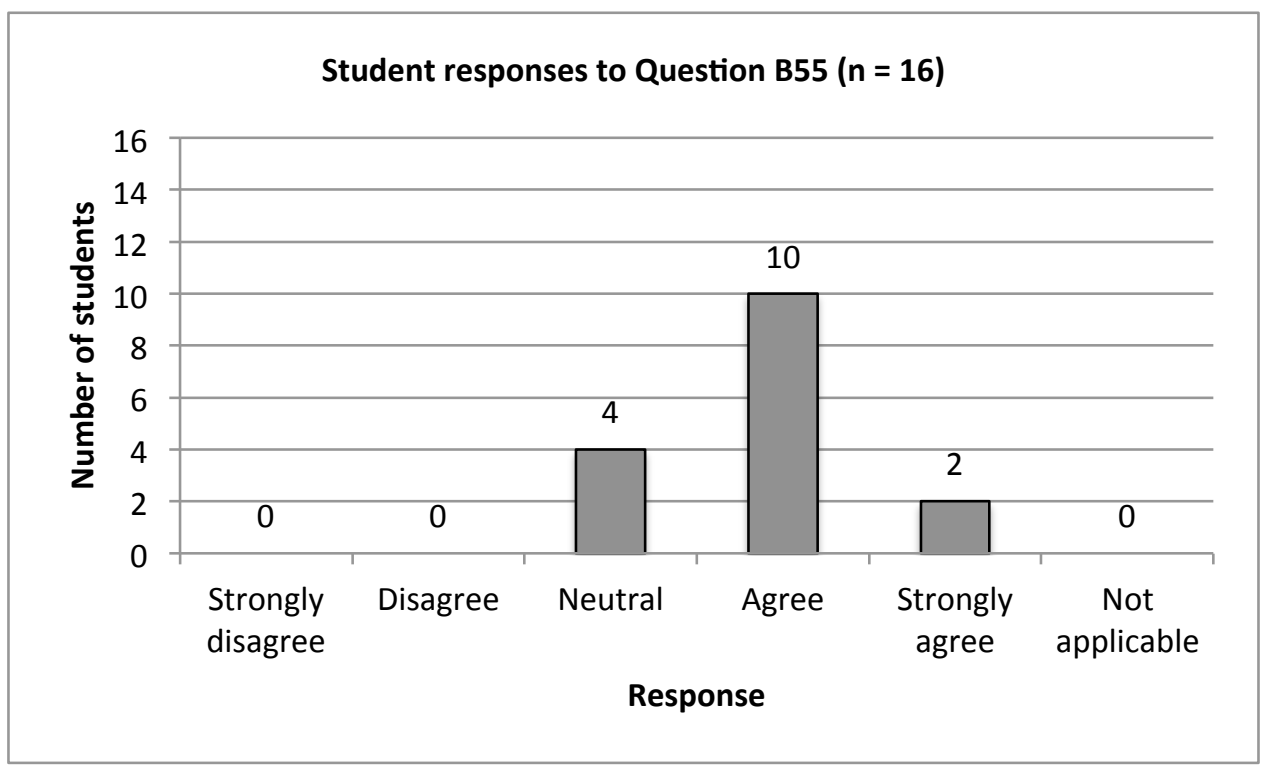

Figure 7-94: Student responses to Question B55: "To what extent do you agree or disagree that the introduction of the Tablet PC to all industrial/product design students would have a motivating effect?" 


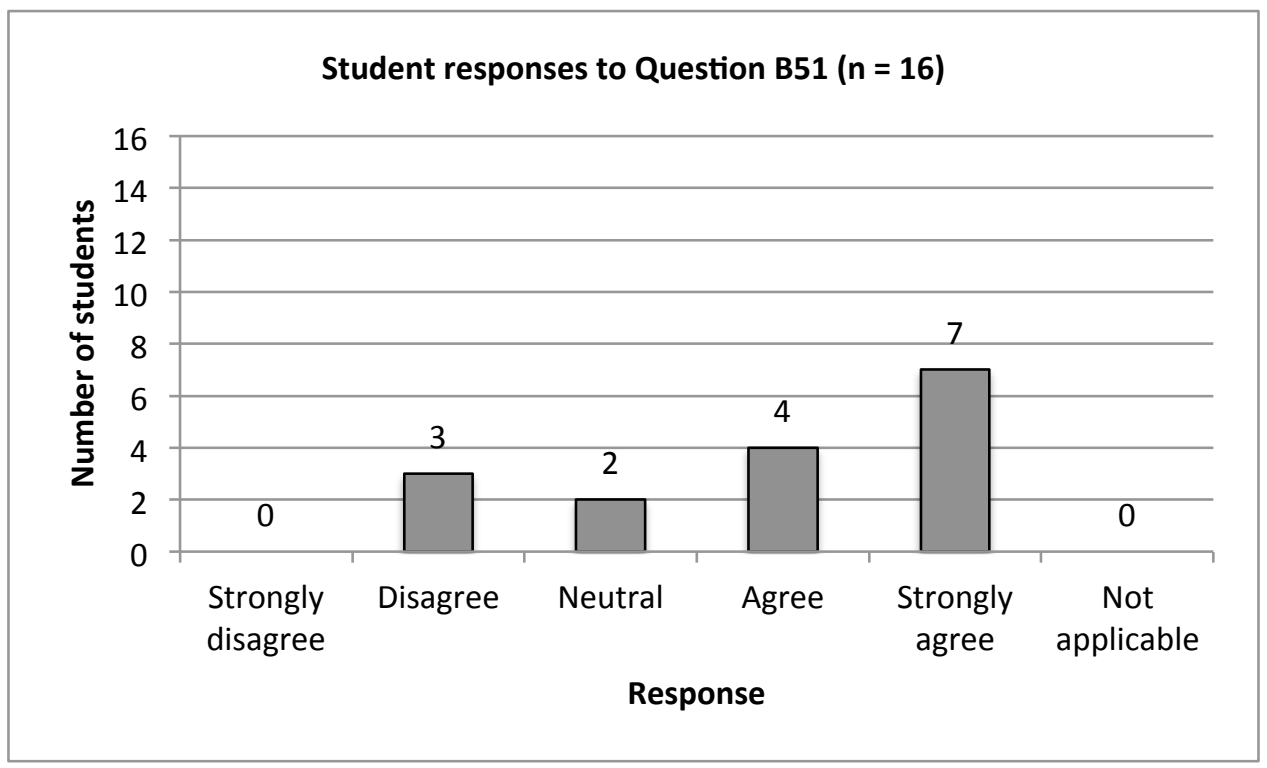

Figure 7-95: Student responses to Question B51: "To what extent do you agree or disagree that students should be taught paper-based rendering before using the Tablet PC?"

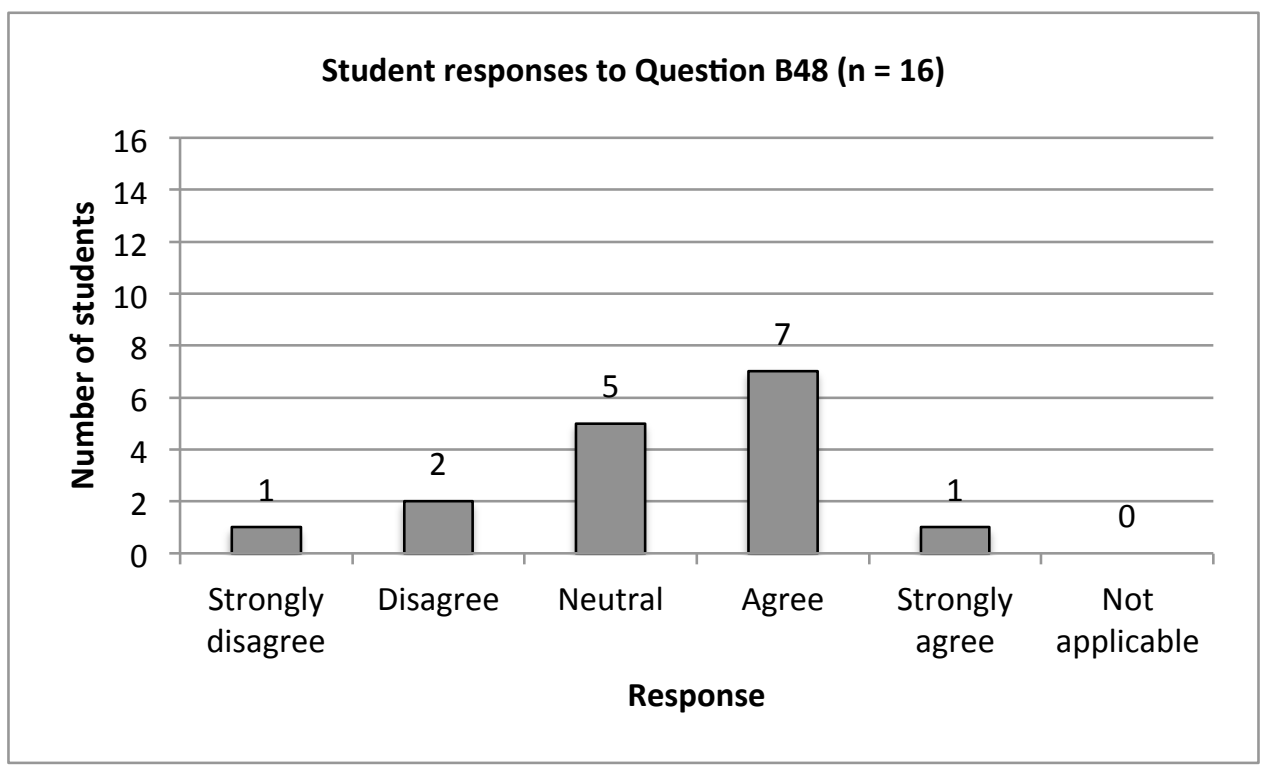

Figure 7-96: Student responses to Question B48: "To what extent do you agree or disagree that you need to have $2 \mathrm{D}$ visualisation software experience to be able to use the Tablet PC effectively?"

\subsubsection{Software}

Before using the Tablet PC, students used Photoshop or Illustrator most of the time. After undertaking the case study, SketchBook Pro proved to be preferable over Photoshop software for the generation of line work (Figure 7-97) because of its ease to use (Figure 7-98). 


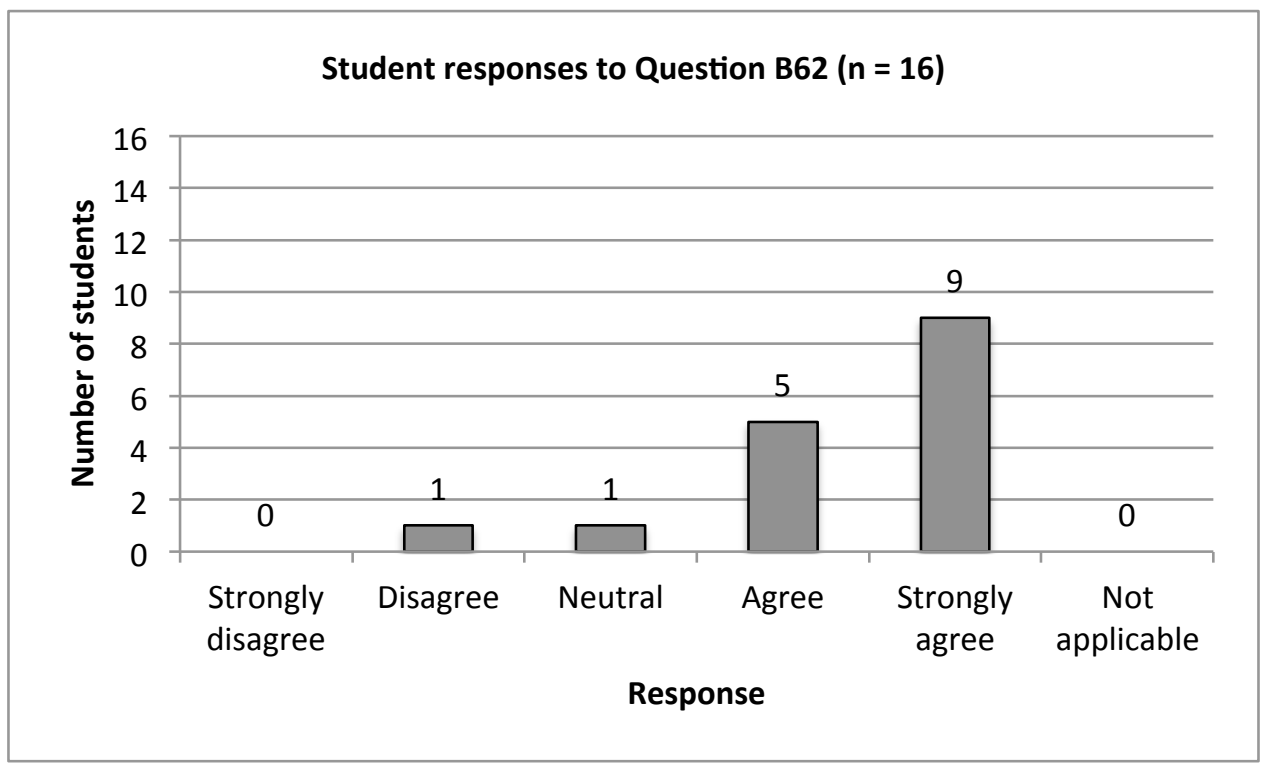

Figure 7-97: Student responses to Question B62: "To what extent do you agree or disagree that SketchBook Pro was more suitable than Photoshop for the generation of line work?"

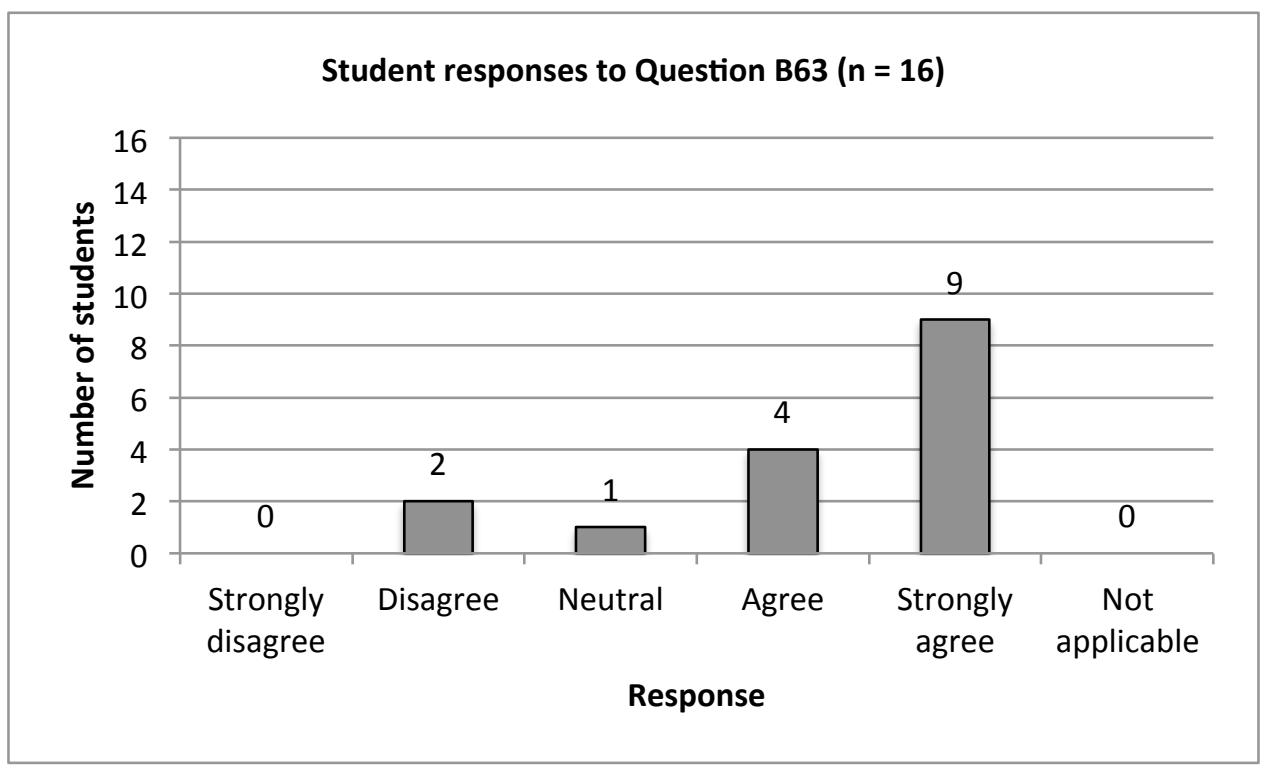

Figure 7-98: Student responses to Question B63: "To what extent do you agree or disagree that SketchBook Pro was easier to use than Photoshop for the generation of line work?"

\subsubsection{Improvements}

The improvement that the greatest number of students (12) agreed/strongly agreed with was in having an additional 'control' button that could be used when the keyboard was covered by the screen (Figure 7-99). This would enable students to use some shortcuts whilst sketching without having to connect an additional keyboard. The majority of students also agreed that having a device that enabled them to adjust the angle of the screen while 
sketching would be beneficial (Figure 7-100). In order to keep the wrist and elbow at one level, the majority felt that it would be useful if the Tablet PC could sit in a recess on a desk to make the screen flush with the surface (Figure 7-103).

Even though students felt that they adapted to the smoothness of the screen when using the stylus after sometime (Figure 7-53), some would prefer it if the surface of the screen on the Tablet PC had a similar level of resistance to that of paper (Figure 7-101).

Most students felt that the size of Tablet PC screen was small (Figure 7-79) and 10 students confirmed that connecting a larger external screen to the Tablet PC was beneficial during 3D CAD work (Figure 7-102). To enable the use of software shortcuts while sketching, the majority of students agreed/strongly agreed that it was useful to use an external keyboard (Figure 7-104).

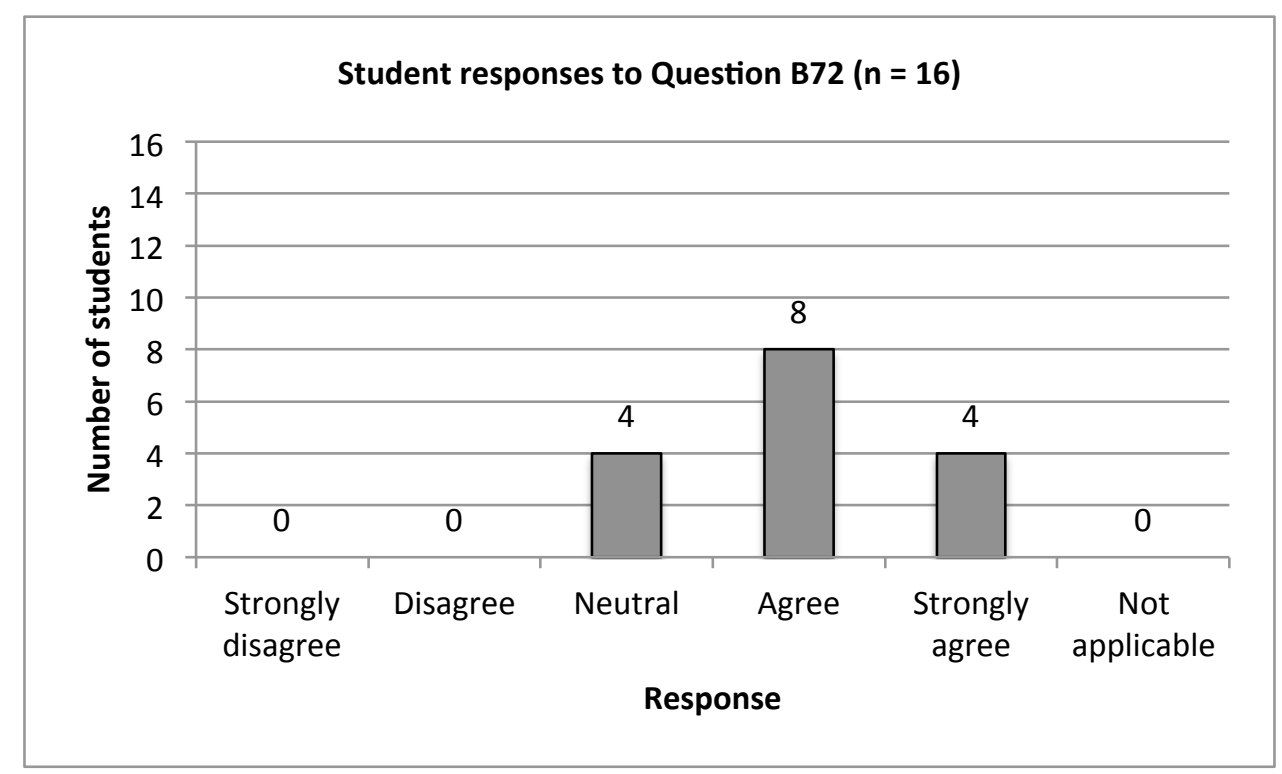

Figure 7-99: Student responses to Question B72: "To what extent do you agree or disagree that having an additional 'control' button that can be used when the screen covers the keyboard would be beneficial?" 


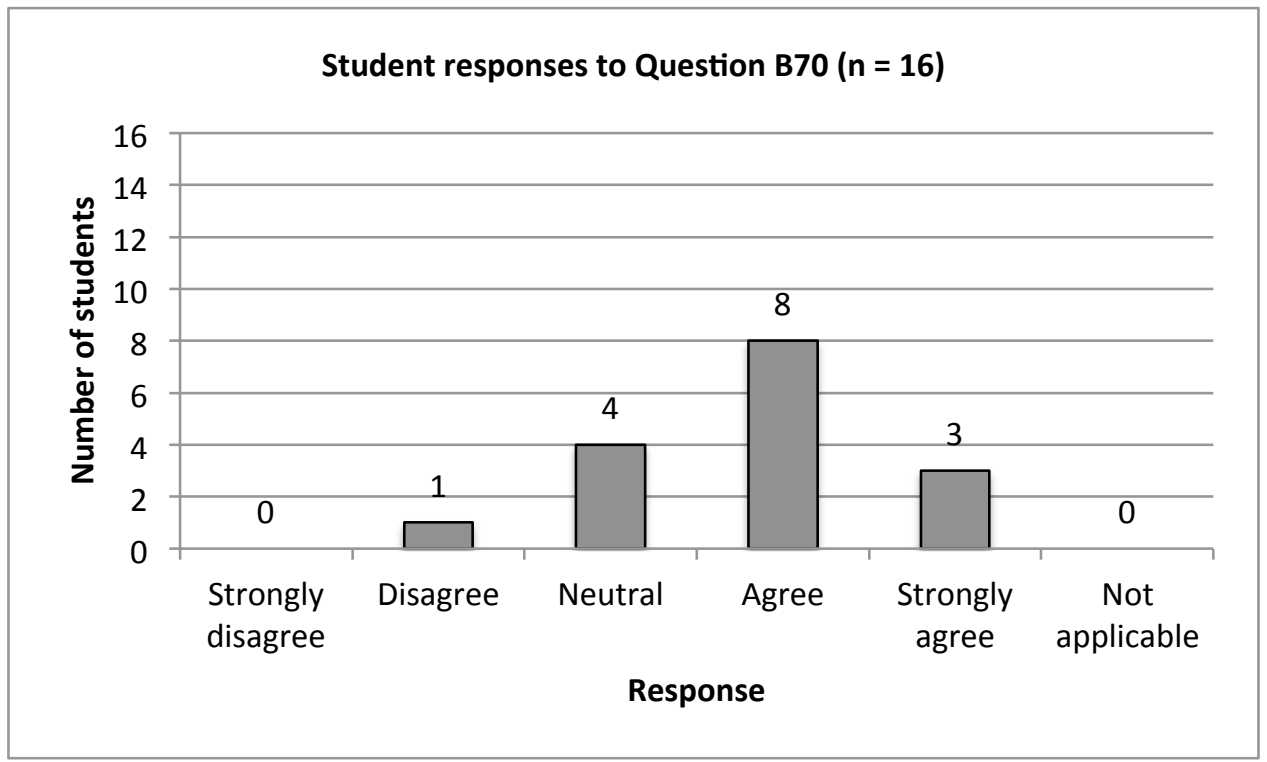

Figure 7-100: Student responses to Question B70: "To what extent do you agree or disagree that having a device that enables you to adjust the angle of the Tablet PC screen while sketching would be beneficial?"

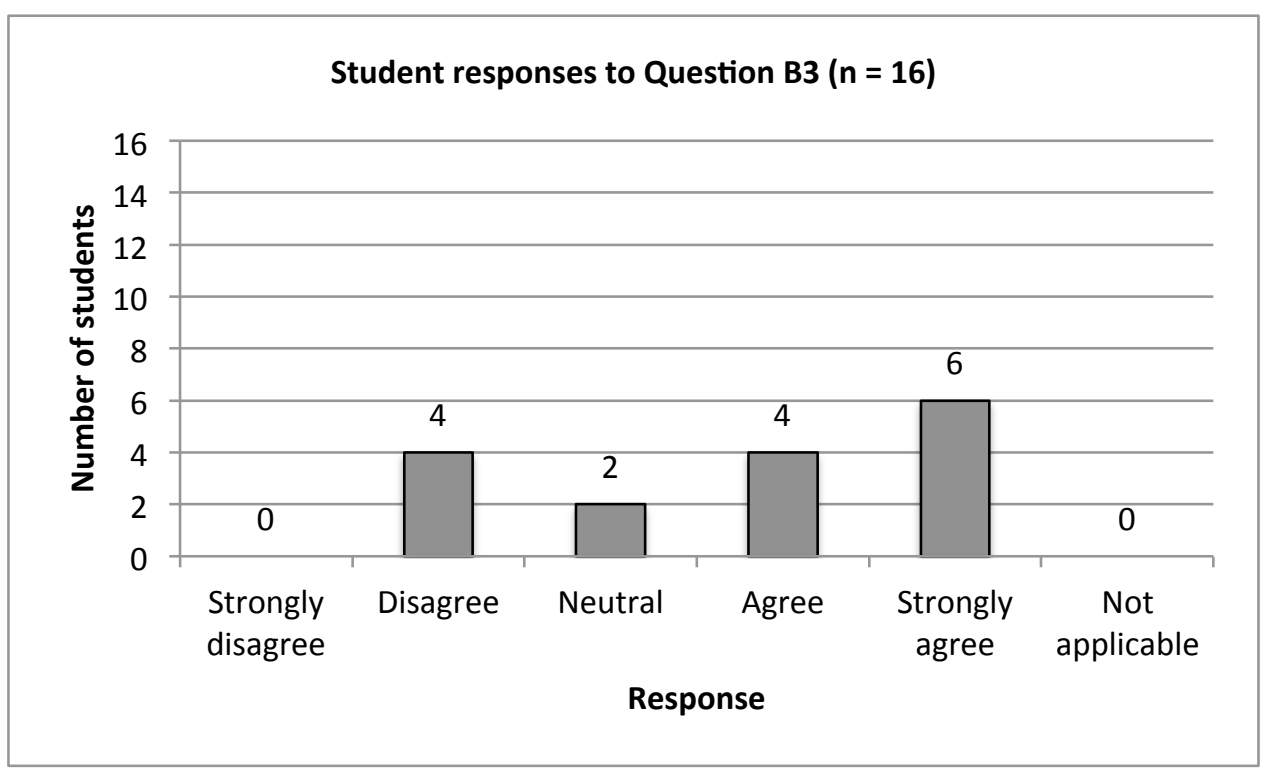

Figure 7-101: Student responses to Question B3: "To what extent do you agree or disagree that you would prefer it if the surface of the screen on the Tablet PC had a similar level of resistance to paper?" 


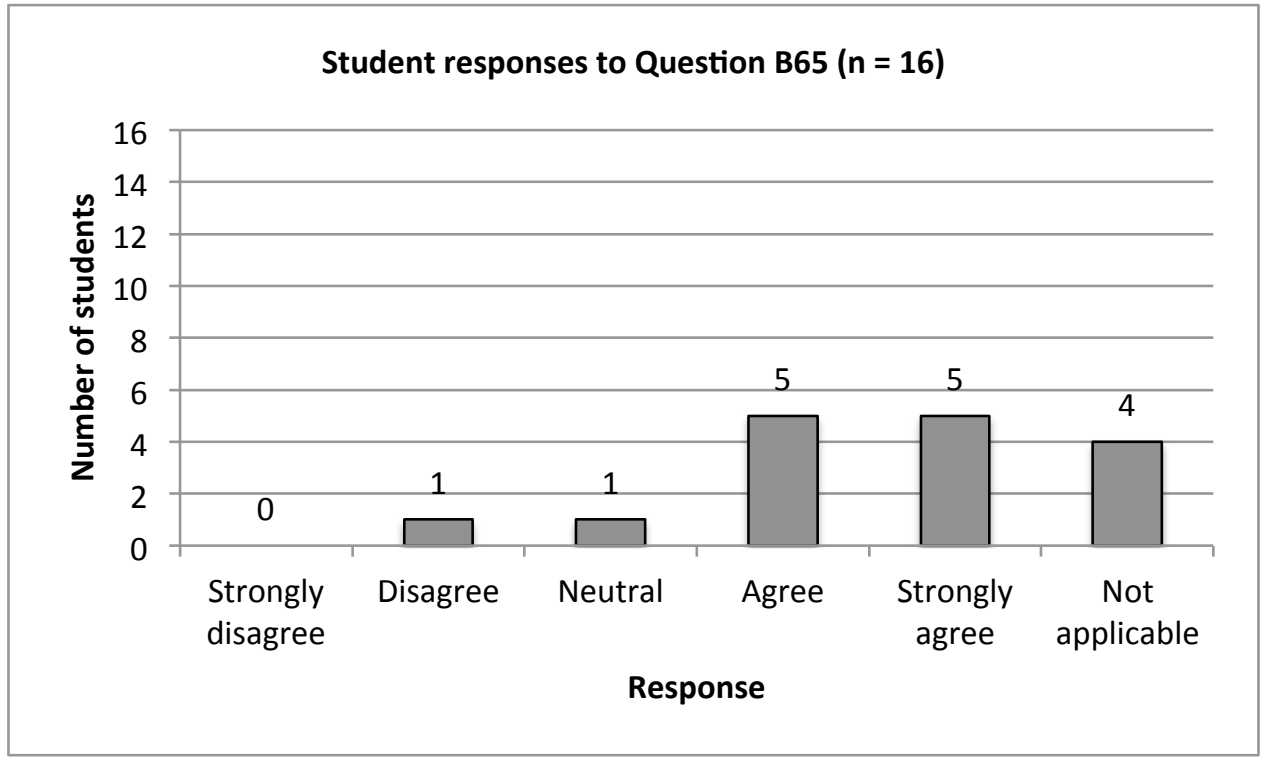

Figure 7-102: Student responses to Question B65: "To what extent do you agree or disagree that connecting the Tablet PC to a larger external screen was beneficial during 3D CAD work?"

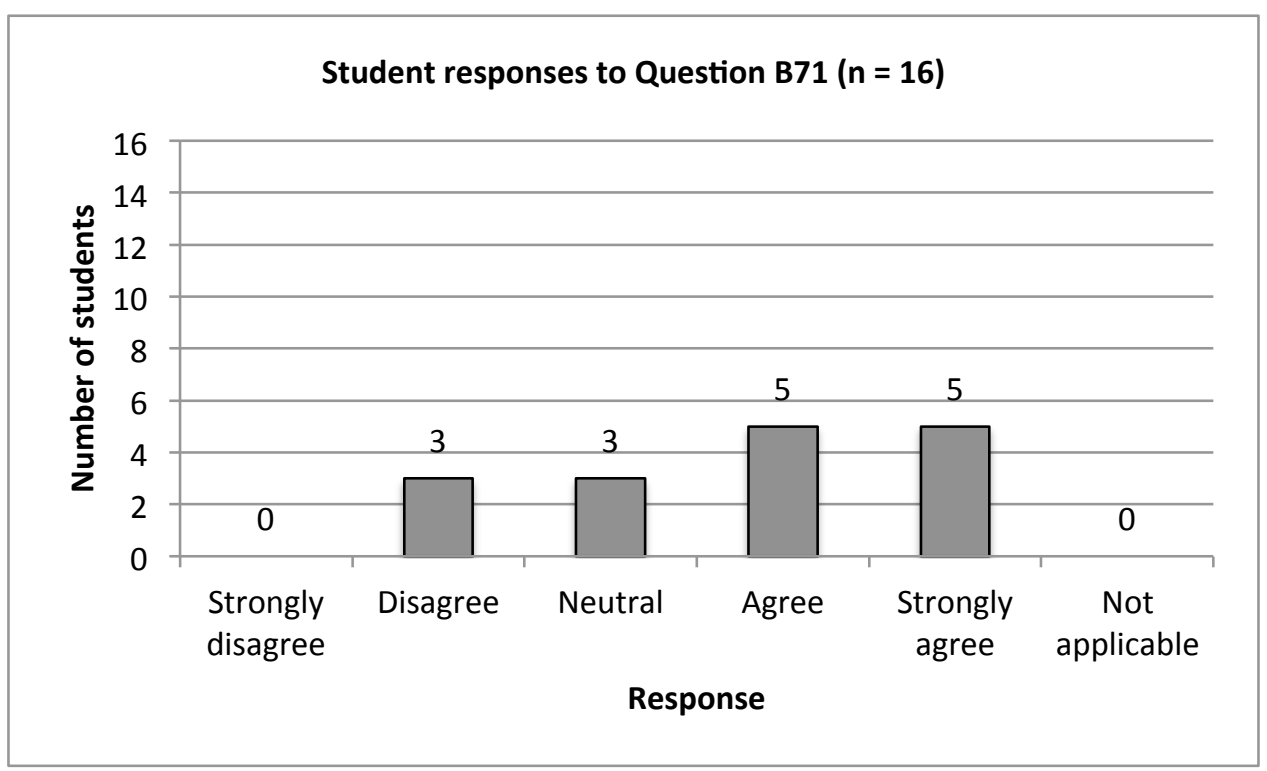

Figure 7-103: Student responses to Question B71: "To what extent do you agree or disagree that it would be beneficial if the Tablet PC could sit in a recess on a desk to make the screen flush with the surface?" 


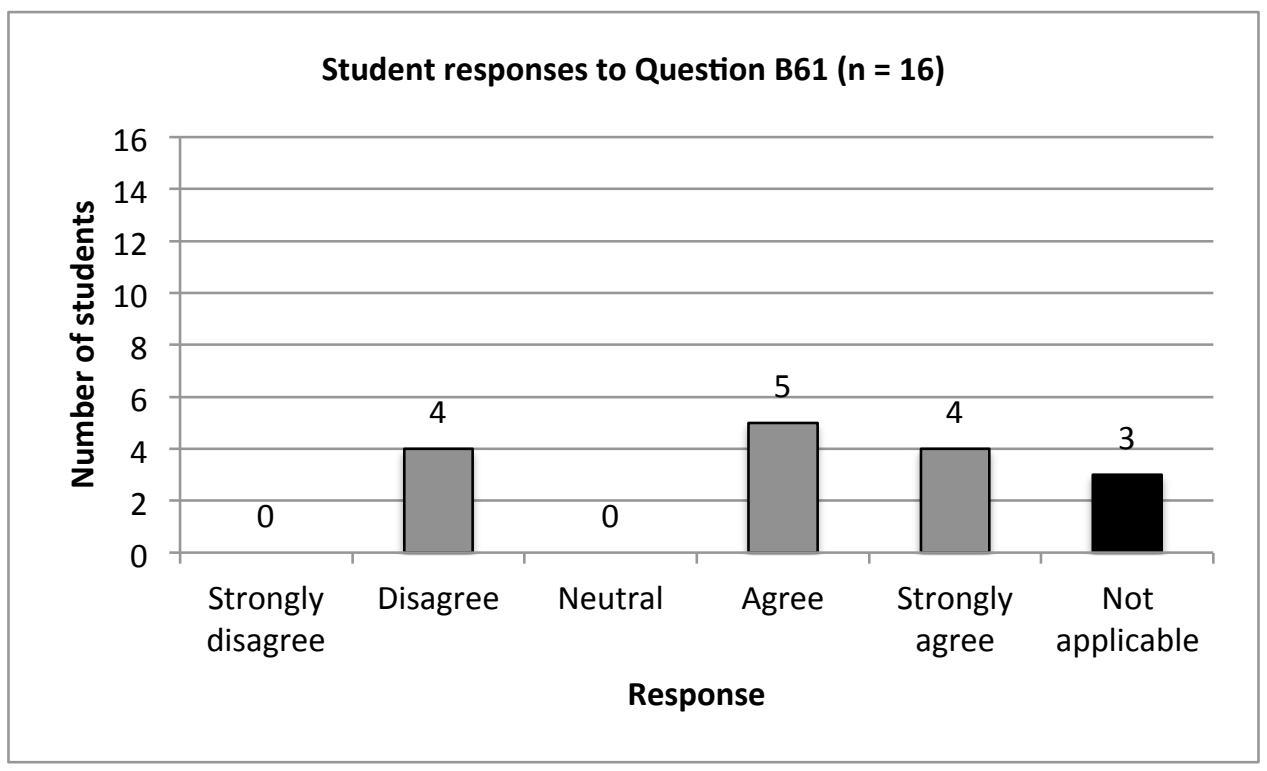

Figure 7-104: Student responses to Question B61: "To what extent do you agree or disagree that it was useful to use an external keyboard with the Tablet PC when sketching?"

\subsubsection{Areas of Conflict}

This section collated the findings of questions where students had issues of conflict. It was difficult to conclude on the general feeling of students for these issues as the replies were distributed on a number of answers without a single one getting eight responses or more.

When students were asked if leaning over the Tablet PC while sketching created an uncomfortable posture, seven students agreed/strongly agreed and another six disagreed (Figure 7-105). It was also uncertain if, in general, students thought that sketching with the Tablet PC was quicker than paper-based media, as six students agreed/strongly agreed and seven disagreed (Figure 7-106). This level of response continued when the students were asked if the Tablet PC increased the speed of their sketching (Figure 7-107).

Whilst seven students disagreed that their ability to sketch and draw using paper-based techniques had declined since using the Tablet PC, five students felt neutral about it (Figure 7-108). Whether the Tablet PC encouraged the students to employ construction techniques, such as crating, when sketching in perspective was inconclusive with five students agreeing, five feeling neutral, and four disagreeing (Figure 7-109). Only three students agreed that the Tablet PC improved their perspective sketching and seven students disagreed (Figure 7-110).

Previously, the majority of students confirmed that the size of the Tablet PC limited their ability to view a number of previous ideas on the same page (Figure 7-75). However, the 
responses were close between students who disagreed (seven students) and agreed (six students) when they were asked if the Tablet PC size encouraged them to think more carefully about what they sketch (Figure 7-111). Six students disagreed and another six agreed/strongly agreed that sketches produced using the Tablet PC appeared to be 'more precious' when generating concepts (Figure 7-112).

Close results were identified when students were asked if the Tablet PC represented a stand-alone design tool that contained all that was required for effective designing; seven students agreed/strongly agreed and six students disagreed/strongly disagreed (Figure 7-113). Knowing the shortcuts in the 2D visualisation software to be able to use the Tablet PC effectively was another point that was uncertain, since six students agreed/strongly agreed and the same number felt neutral (Figure 7-114). The same reaction (seven agreed/strongly agreed and five felt neutral) continued when students were asked if those that were about to start undergraduate degrees in industrial design should be encouraged to purchase a Tablet PC as apposed to a conventional laptop (Figure 7-115).

Although most of the students preferred SketchBook Pro to Photoshop for line work (Figure 7-97), it was difficult to conclude if the majority felt that Photoshop was more suitable for rendering than SketchBook Pro because six students disagreed and another six agreed/strongly agreed (Figure 7-116). Microsoft Journal software was an alternative to a paper-based logbook but whether this was viable was questionable, as four students did not use it and six students agreed/strongly agreed (Figure 7-117). 


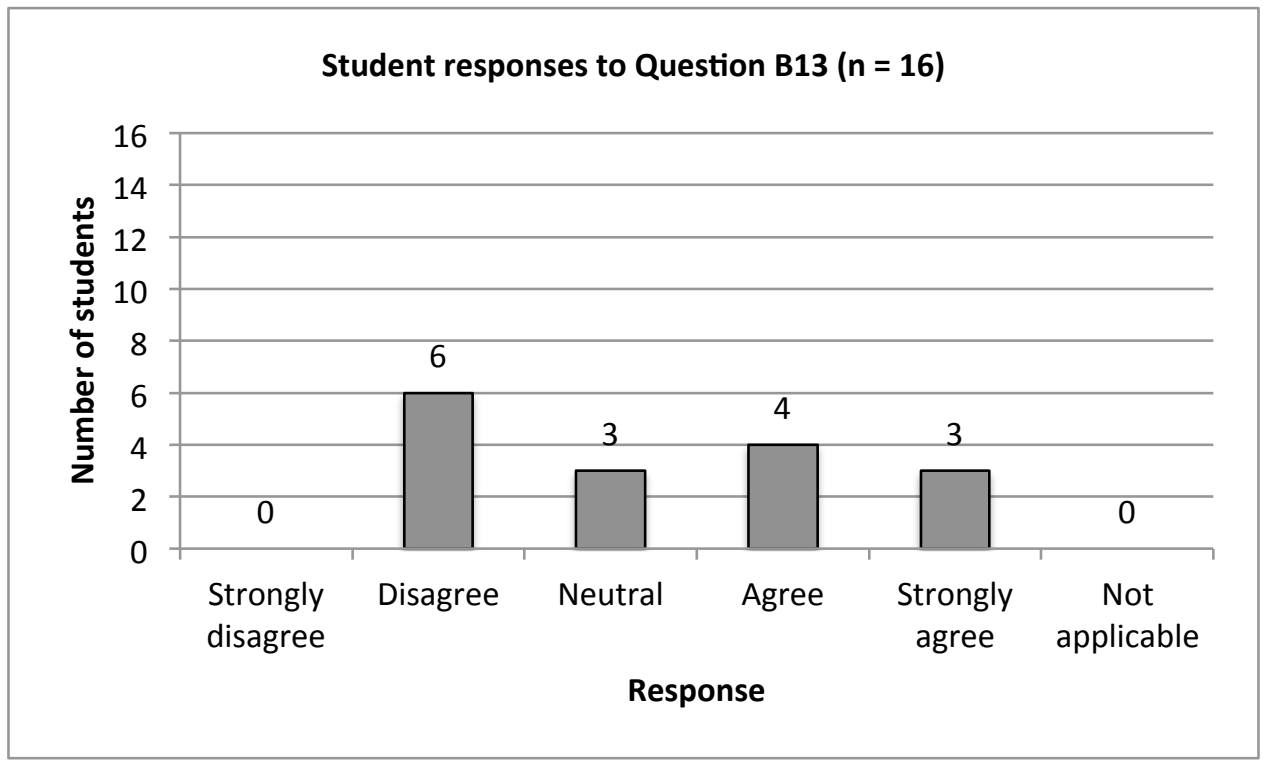

Figure 7-105: Student responses to Question B13: "To what extent do you agree or disagree that leaning over the Tablet while sketching created an uncomfortable posture?"

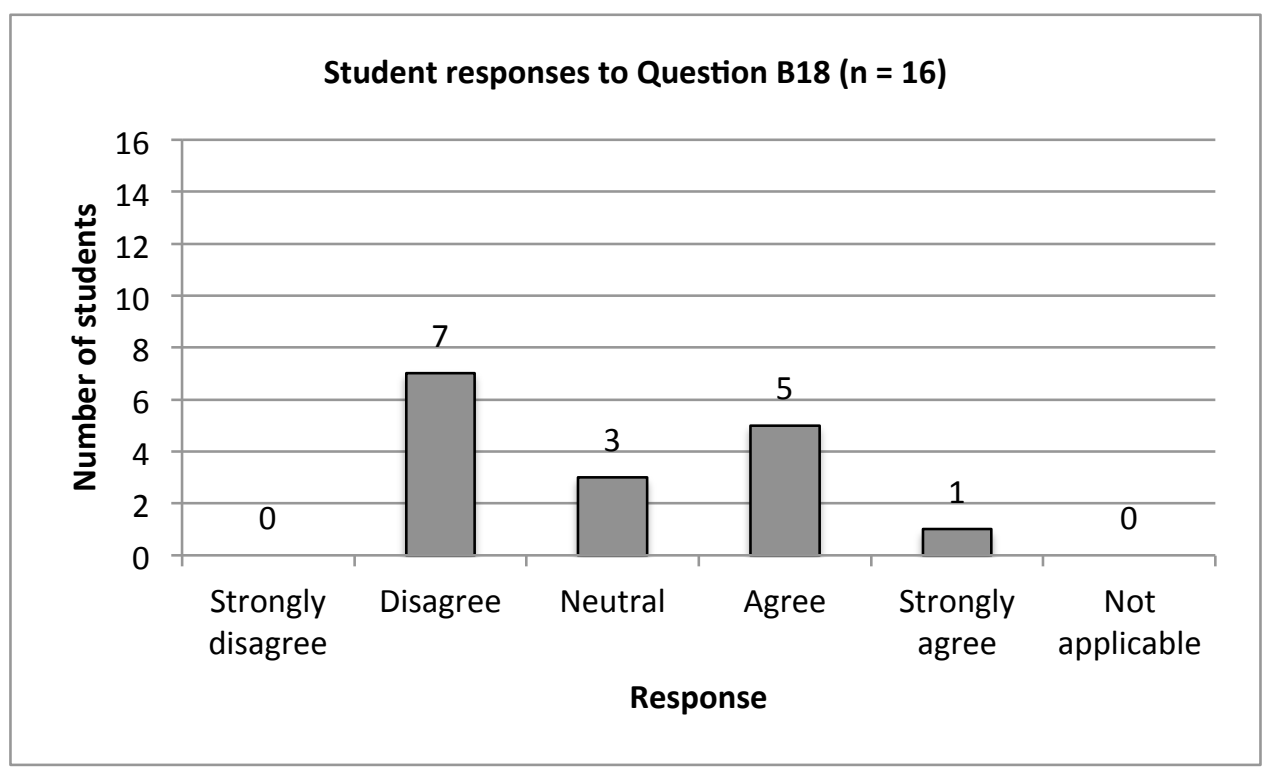

Figure 7-106: Student responses to Question B18: "To what extent do you agree or disagree that it was quicker to sketch with the Tablet PC than with paper?" 


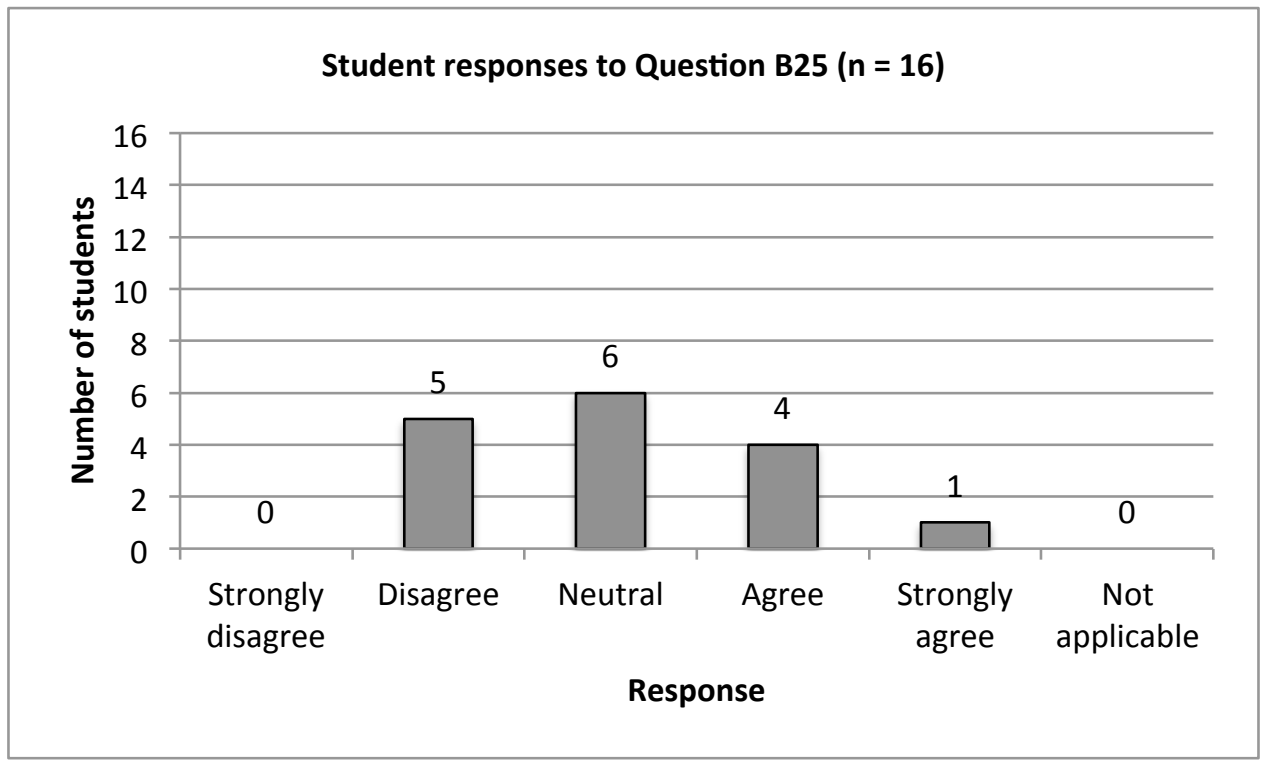

Figure 7-107: Student responses to Question B25: "To what extent do you agree or disagree that using the Tablet PC increased the speed of your sketching?"

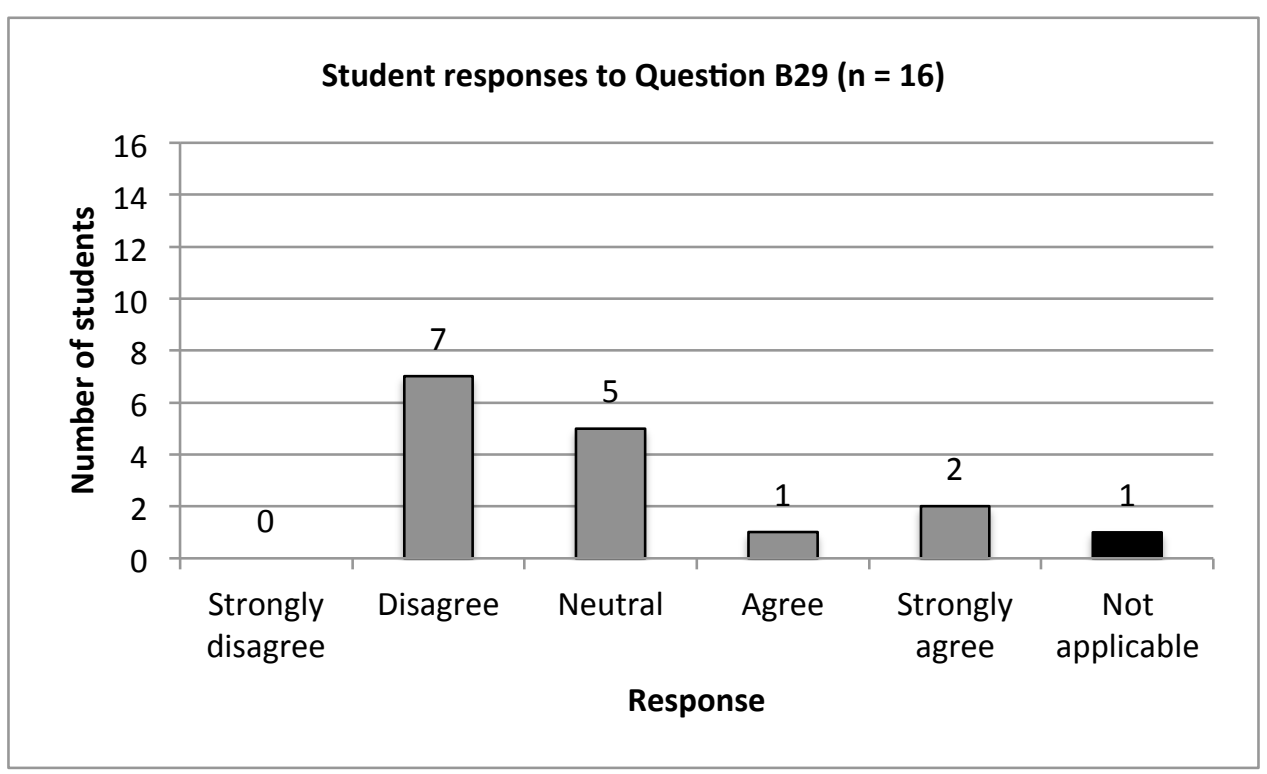

Figure 7-108: Student responses to Question B29: "To what extent do you agree or disagree that your ability to sketch and draw using paper-based techniques has declined since using the Tablet PC?" 


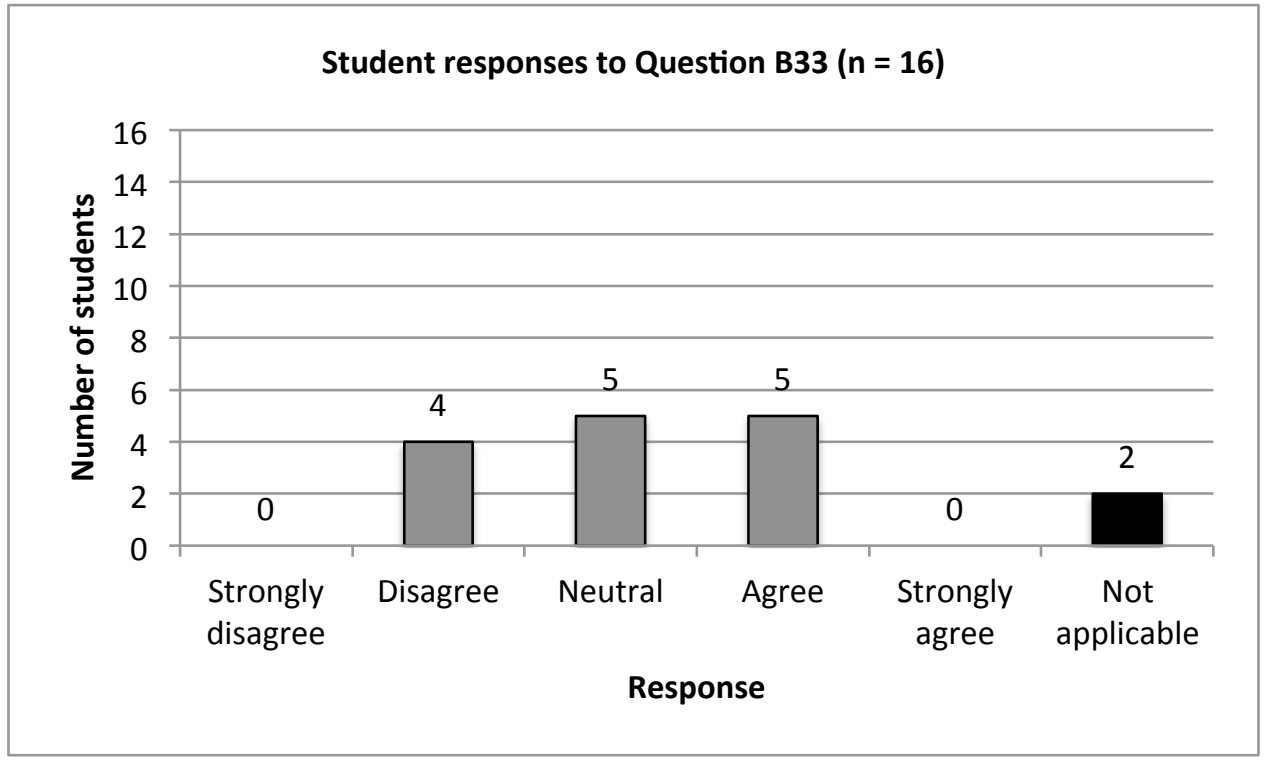

Figure 7-109: Student responses to Question B33: "To what extent do you agree or disagree that sketching using the Tablet PC encouraged you to employ construction techniques such as crating when sketching in perspective?"

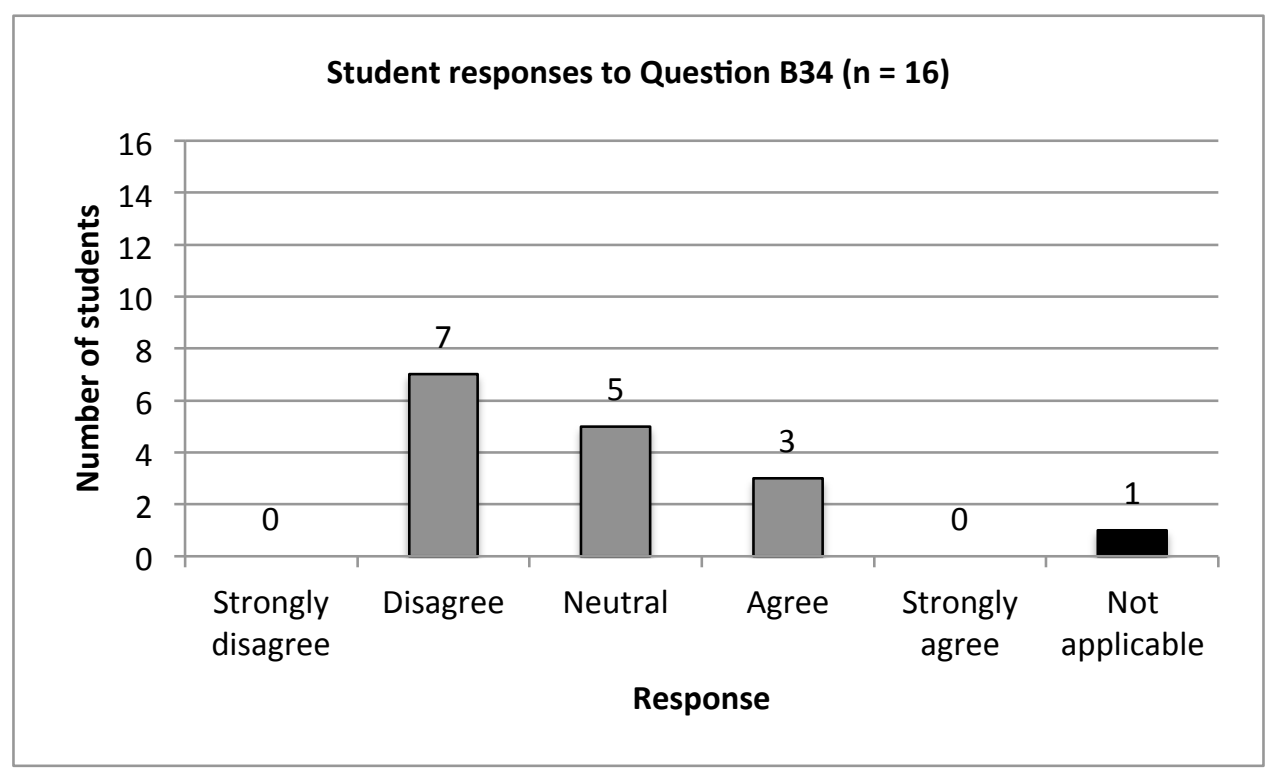

Figure 7-110: Student responses to Question B34: "To what extent do you agree or disagree that sketching using the Tablet PC improved your perspective?" 


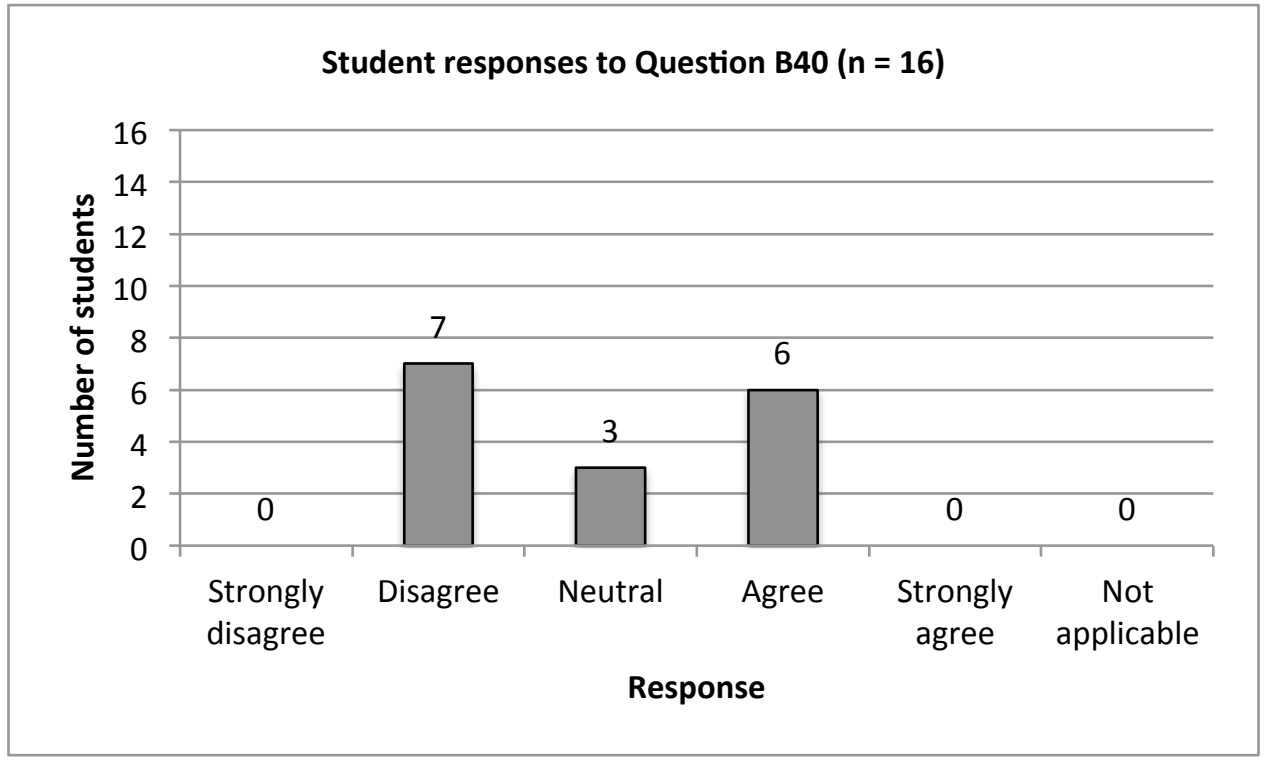

Figure 7-111: Student responses to Question B40: "To what extent do you agree or disagree that the size of the Tablet PC screen encouraged you to think more carefully about what you sketch?"

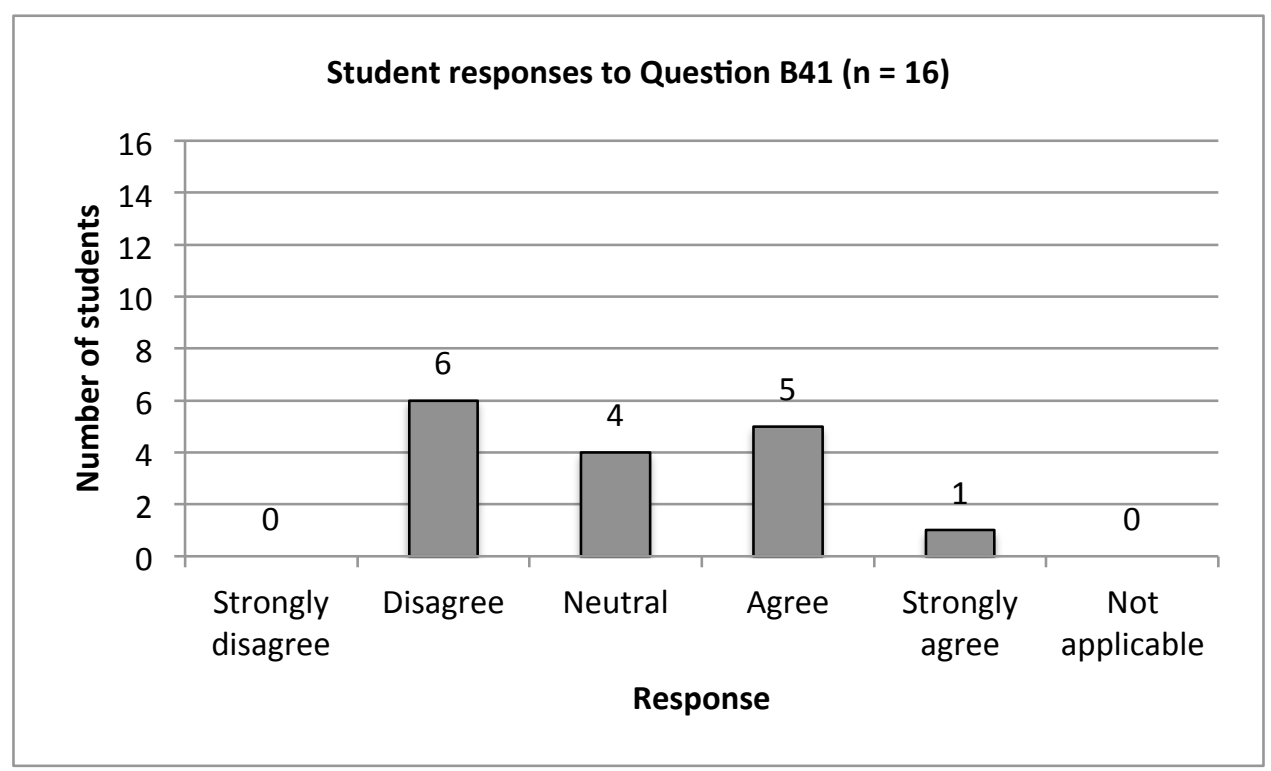

Figure 7-112: Student responses to Question B41: "To what extent do you agree or disagree that sketches produced using the Tablet PC appeared to be more precious in concept generation, which limited creativity?" 


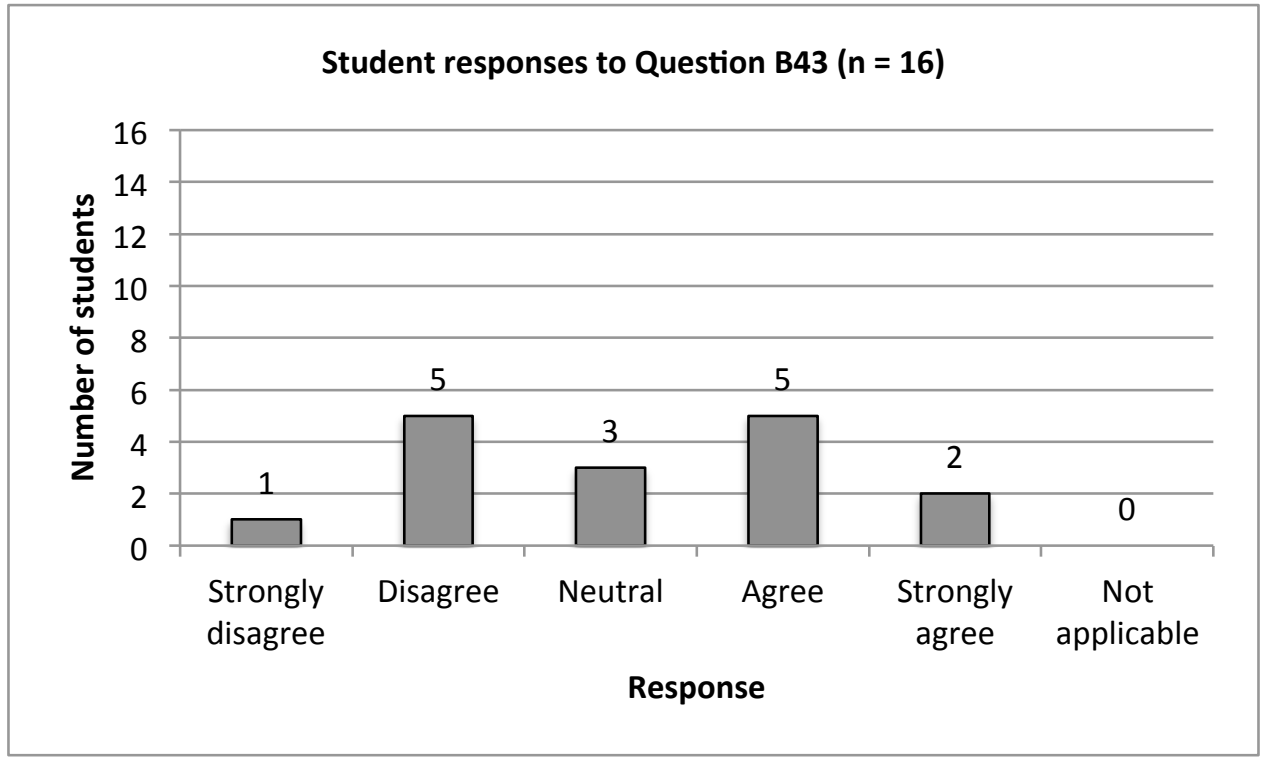

Figure 7-113: Student responses to Question B43: "To what extent do you agree or disagree that the Tablet PC represented a stand-alone design tool that contained all that was required for effective designing?"

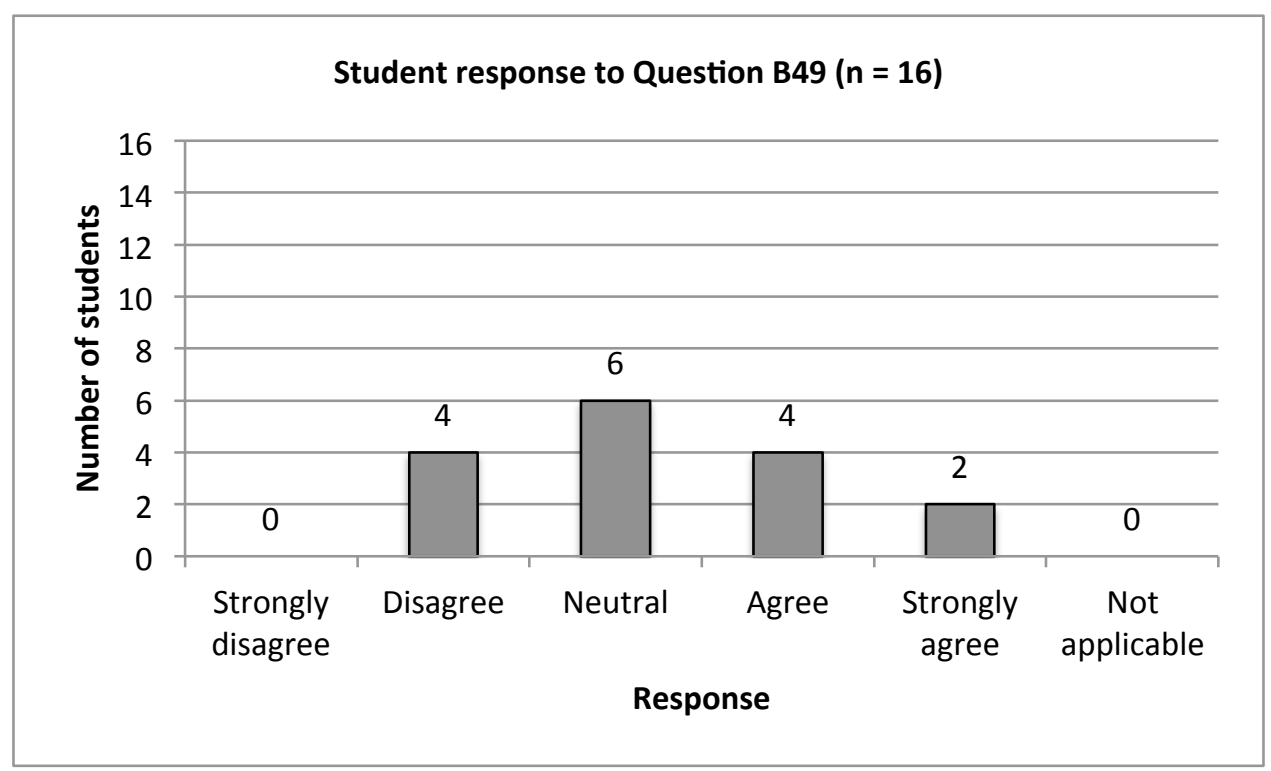

Figure 7-114: Student response to Question B49: "To what extent do you agree or disagree that you need to know the shortcuts in the $2 \mathrm{D}$ visualisation software to be able to use the Tablet PC effectively?" 


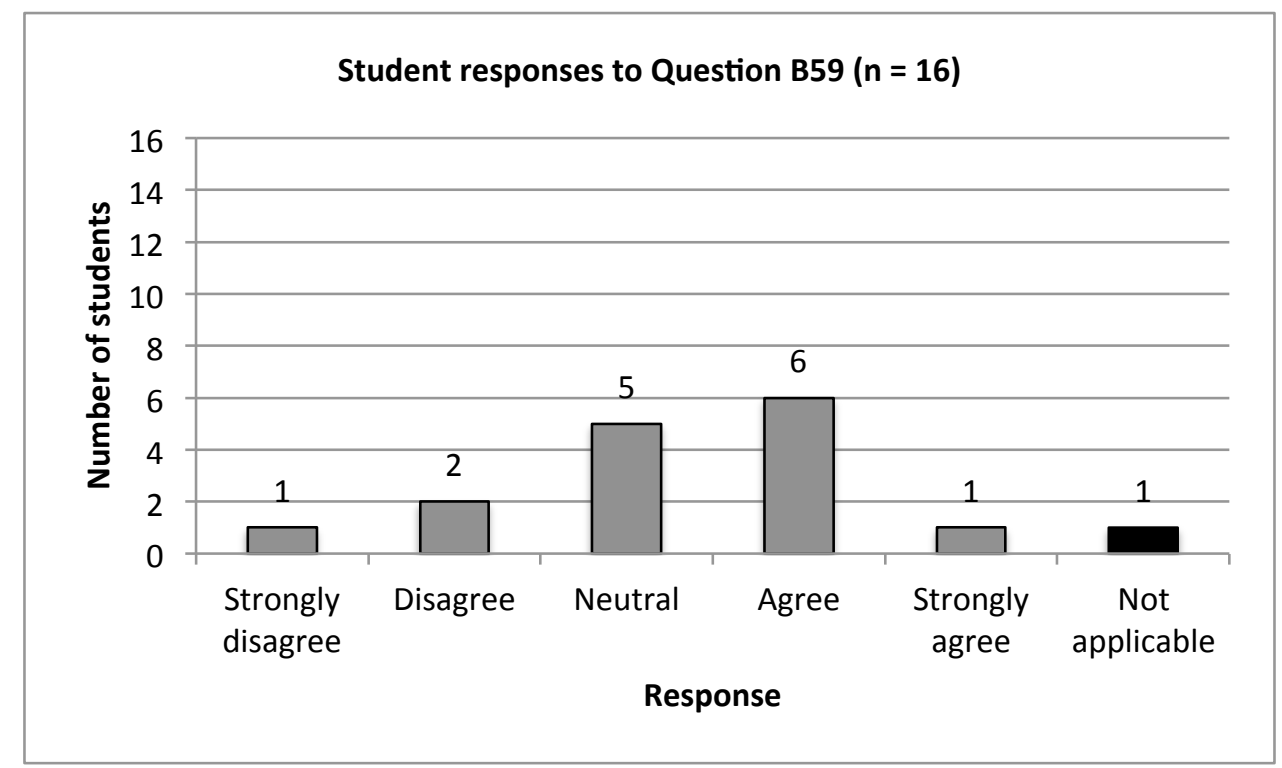

Figure 7-115: Student responses to Question B59: "To what extent do you agree or disagree that students about to start undergraduates degrees in industrial/product design should be encouraged to purchase Tablet PCs rather than laptops?"

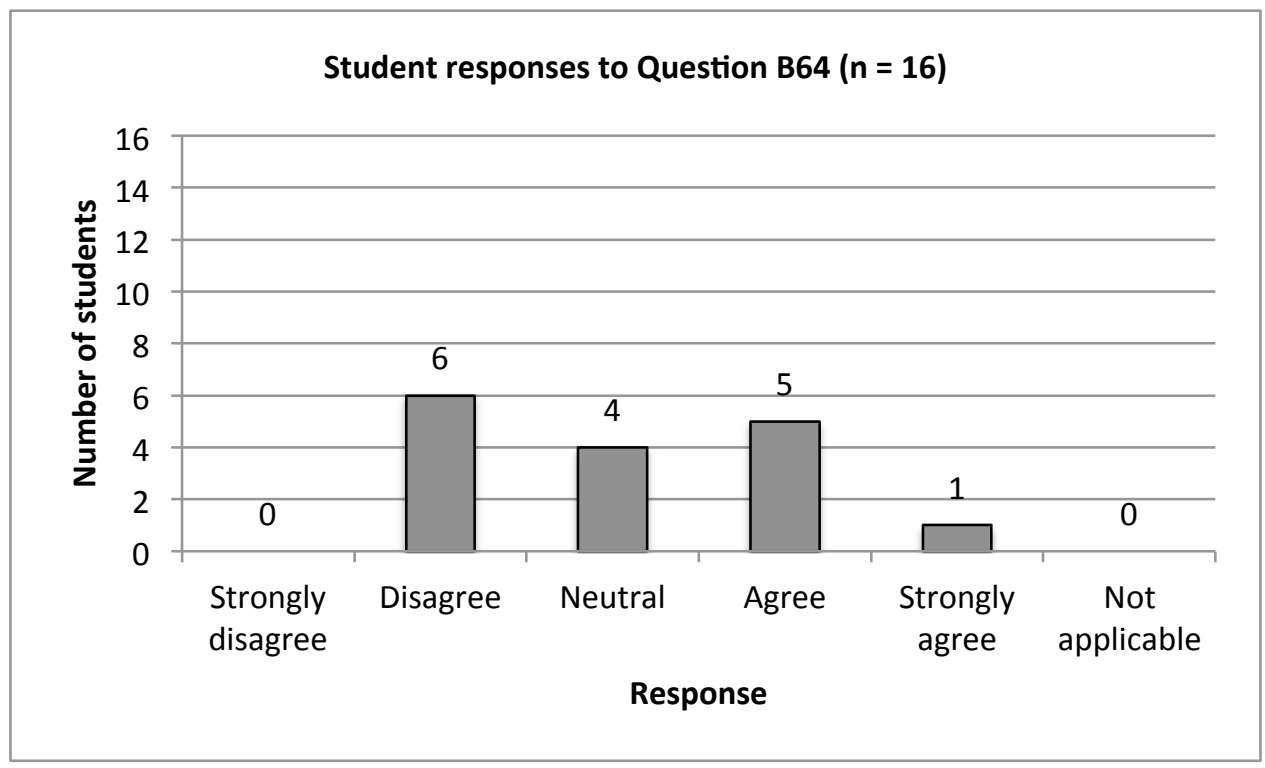

Figure 7-116: Student responses to Question B64: "To what extent do you agree or disagree that Photoshop was more suitable for rendering the line work than SketchBook Pro?" 


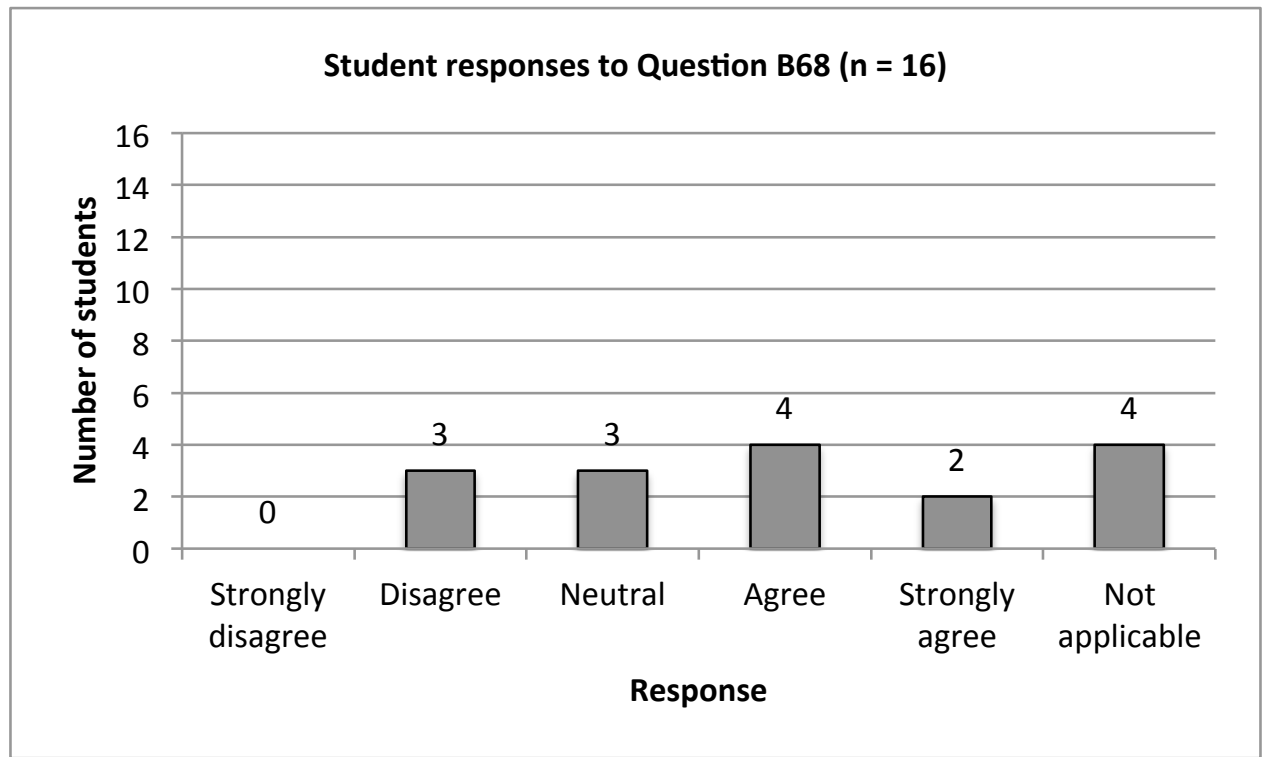

Figure 7-117: Student responses to Question B68: "To what extent do you agree or disagree that Microsoft Journal software represented a viable alternative to a paper-based logbook?"

\subsubsection{Summary of Results}

A summary of the student responses to the 72 statements regarding the use of Tablet PC for designing is illustrated in Table 7-6. 


\begin{tabular}{|c|c|c|c|c|c|c|c|}
\hline \multicolumn{2}{|c|}{ QUESTION } & \multicolumn{6}{|c|}{ RESPONSE } \\
\hline \multicolumn{2}{|r|}{ To what extent do you agree or disagree with the following statements? } & \multirow{2}{*}{$\frac{\frac{0}{0}}{2} \frac{\frac{0}{0}}{\frac{0}{0}}$} & \multirow{2}{*}{ 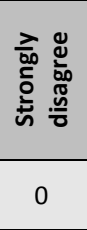 } & \multirow{2}{*}{ 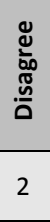 } & \multirow{2}{*}{$\begin{array}{l}\frac{\bar{\pi}}{\frac{2}{3}} \\
\frac{0}{2} \\
1\end{array}$} & \multirow{2}{*}{$\begin{array}{l}\frac{0}{\frac{1}{40}} \\
10\end{array}$} & \multirow{2}{*}{ 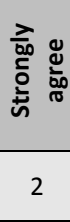 } \\
\hline 1 & $\begin{array}{l}\text { It was difficult to precisely match the position of the tip of the stylus } \\
\text { with the cursor }\end{array}$ & & & & & & \\
\hline 2 & $\begin{array}{l}\text { It was difficult to create faint lines and use them as a guide when } \\
\text { using the Tablet PC }\end{array}$ & 0 & 1 & 9 & 1 & 5 & 0 \\
\hline 3 & $\begin{array}{l}\text { You would prefer it if the surface of the screen on the Tablet PC had a } \\
\text { similar level of resistance to paper }\end{array}$ & 0 & 0 & 4 & 2 & 4 & 6 \\
\hline 4 & $\begin{array}{l}\text { The rubber feet on the Tablet PC made it difficult to rotate when } \\
\text { sketching }\end{array}$ & 1 & 0 & 3 & 3 & 5 & 4 \\
\hline 5 & The Tablet PC screen was too small for effective sketching & 0 & 0 & 5 & 1 & 8 & 2 \\
\hline 6 & $\begin{array}{l}\text { The thickness of the Tablet PC made it uncomfortable to sketch with } \\
\text { as it put pressure on your wrist }\end{array}$ & 0 & 0 & 5 & 5 & 2 & 4 \\
\hline 7 & $\begin{array}{l}\text { The ability to 'undo' previous work during concept generation } \\
\text { hindered creativity }\end{array}$ & 0 & 0 & 12 & 1 & 2 & 1 \\
\hline 8 & The stylus was too short for comfortable use & 0 & 0 & 10 & 2 & 4 & 0 \\
\hline 9 & You were not able to sketch with the stylus at low angle on the screen & 0 & 1 & 3 & 0 & 11 & 1 \\
\hline 10 & You faced problems with screen glare while sketching & 0 & 1 & 3 & 3 & 8 & 1 \\
\hline 11 & The Tablet PC was more difficult to use than pencil and paper & 0 & 0 & 3 & 4 & 7 & 2 \\
\hline 12 & $\begin{array}{l}\text { You were not able to use the full size of the Tablet PC screen because } \\
\text { matching the position of the tip of the stylus with the cursor became } \\
\text { more difficult towards the edges }\end{array}$ & 2 & 1 & 3 & 1 & 8 & 1 \\
\hline 13 & $\begin{array}{l}\text { Leaning over the Tablet while sketching created an uncomfortable } \\
\text { posture }\end{array}$ & 0 & 0 & 6 & 3 & 4 & 3 \\
\hline 14 & $\begin{array}{l}\text { The line quality of the Tablet PC was better than that for paper-based } \\
\text { sketching }\end{array}$ & 0 & 1 & 0 & 1 & 11 & 3 \\
\hline 15 & $\begin{array}{l}\text { You felt more confident using the Tablet PC compared to paper-based } \\
\text { sketching because of the ability to 'undo' }\end{array}$ & 0 & 0 & 1 & 0 & 12 & 3 \\
\hline 16 & $\begin{array}{l}\text { It was easier to remove mistakes using the Tablet PC than when } \\
\text { paper-based sketching }\end{array}$ & 0 & 0 & 0 & 0 & 7 & 9 \\
\hline 17 & $\begin{array}{l}\text { The quality of outcome was greater using the Tablet PC than when } \\
\text { paper-based sketching }\end{array}$ & 0 & 0 & 1 & 3 & 7 & 5 \\
\hline 18 & It was quicker to sketch with the Tablet PC than with paper & 0 & 0 & 7 & 3 & 5 & 1 \\
\hline 19 & $\begin{array}{l}\text { The Tablet PC helped you to quickly communicate your ideas to other } \\
\text { people }\end{array}$ & 0 & 0 & 4 & 3 & 8 & 1 \\
\hline 20 & $\begin{array}{l}\text { You were able to make quick amendments to your designs using the } \\
\text { Tablet PC }\end{array}$ & 0 & 0 & 0 & 3 & 9 & 4 \\
\hline 22 & $\begin{array}{l}\text { The colours used on the Tablet PC were more vibrant than those } \\
\text { available with paper-based techniques }\end{array}$ & 0 & 0 & 3 & 0 & 8 & 5 \\
\hline 23 & $\begin{array}{l}\text { The Tablet PC made you more adventurous when generating concepts } \\
\text { and developing them }\end{array}$ & 0 & 0 & 2 & 1 & 13 & 0 \\
\hline 24 & The Tablet PC layering facility was very helpful & 0 & 0 & 0 & 1 & 5 & 10 \\
\hline 25 & Using the Tablet PC increased the speed of your sketching & 0 & 0 & 5 & 6 & 4 & 1 \\
\hline 26 & $\begin{array}{l}\text { Applying colour and tone to your line work was quicker and easier } \\
\text { with the Tablet PC }\end{array}$ & 0 & 0 & 1 & 2 & 6 & 7 \\
\hline 27 & Rendering using 3D CAD was quicker and easier with the Tablet PC & 1 & 5 & 6 & 2 & 1 & 1 \\
\hline 28 & $\begin{array}{l}\text { Sketches produced using the Tablet PC had a tendency to be less } \\
\text { detailed }\end{array}$ & 0 & 1 & 3 & 2 & 9 & 1 \\
\hline 29 & $\begin{array}{l}\text { Your ability to sketch and draw using paper-based techniques has } \\
\text { declined since using the Tablet PC }\end{array}$ & 1 & 0 & 7 & 5 & 1 & 2 \\
\hline 30 & The ability to 'undo' using the Tablet PC increased creativity & 0 & 0 & 1 & 5 & 10 & 0 \\
\hline 31 & $\begin{array}{l}\text { The quality of your renderings produced using computer drawing } \\
\text { packages (e.g. SketchBook Pro) improved using the Tablet PC }\end{array}$ & 0 & 0 & 0 & 1 & 8 & 7 \\
\hline 32 & You became more productive when you used the Tablet PC & 1 & 0 & 1 & 4 & 8 & 2 \\
\hline 33 & $\begin{array}{l}\text { Sketching using the Tablet PC encouraged you to employ construction } \\
\text { techniques such as crating when sketching in perspective }\end{array}$ & 2 & 0 & 4 & 5 & 5 & 0 \\
\hline 34 & Sketching using the Tablet PC improved your perspective & 1 & 0 & 7 & 5 & 3 & 0 \\
\hline 35 & $\begin{array}{l}\text { Use of the Tablet PC increased your excitement when collaborating } \\
\text { through sketching with other people }\end{array}$ & 1 & 0 & 0 & 4 & 8 & 3 \\
\hline 36 & $\begin{array}{l}\text { The visual quality and appearance of your designs were enhanced by } \\
\text { the use of the Tablet PC }\end{array}$ & 0 & 0 & 2 & 2 & 8 & 4 \\
\hline 37 & $\begin{array}{l}\text { The work produced using the Tablet PC was of a higher level of } \\
\text { presentation than that undertaken using paper-based techniques }\end{array}$ & 0 & 0 & 1 & 3 & 7 & 5 \\
\hline 38 & The Tablet PC was easy to use for tracing and producing basic outlines & 0 & 0 & 0 & 1 & 9 & 6 \\
\hline 39 & The size of the Tablet PC screen limited your ability to see numerous & 0 & 0 & 1 & 1 & 7 & 7 \\
\hline
\end{tabular}




\begin{tabular}{|c|c|c|c|c|c|c|c|}
\hline & previous ideas on the same page & & & & & & \\
\hline 40 & $\begin{array}{l}\text { The size of the Tablet PC screen encouraged you to think more } \\
\text { carefully about what you sketch }\end{array}$ & 0 & 0 & 7 & 3 & 6 & 0 \\
\hline 41 & $\begin{array}{l}\text { Sketches produced using the Tablet PC appeared to be more precious } \\
\text { in concept generation, which limited creativity }\end{array}$ & 0 & 0 & 6 & 4 & 5 & 1 \\
\hline 42 & $\begin{array}{l}\text { Being able to browse the Internet whilst generating ideas was a } \\
\text { significant advantage of using the Tablet PC }\end{array}$ & 0 & 1 & 3 & 1 & 7 & 4 \\
\hline 43 & $\begin{array}{l}\text { The Tablet PC represented a stand-alone design tool that contained } \\
\text { all that was required for effective designing }\end{array}$ & 0 & 1 & 5 & 3 & 5 & 2 \\
\hline 44 & $\begin{array}{l}\text { If not already in use, the Tablet PC was less convenient when short } \\
\text { amounts of time were available for sketching }\end{array}$ & 0 & 0 & 1 & 3 & 9 & 3 \\
\hline 45 & $\begin{array}{l}\text { You were uneasy about sketching in public with the Tablet PC because } \\
\text { of the potential for it to be stolen }\end{array}$ & 1 & 1 & 8 & 2 & 3 & 1 \\
\hline 46 & $\begin{array}{l}\text { If you had to work when visiting friends and family, you would prefer } \\
\text { to take the Tablet PC rather than an A3 pad }\end{array}$ & 0 & 0 & 2 & 0 & 12 & 2 \\
\hline 47 & The weight of the Tablet PC affected its portability & 0 & 0 & 4 & 2 & 10 & 0 \\
\hline 48 & $\begin{array}{l}\text { You need to have 2D visualisation software experience to be able to } \\
\text { use the Tablet PC effectively }\end{array}$ & 0 & 1 & 2 & 5 & 7 & 1 \\
\hline 49 & $\begin{array}{l}\text { You need to know the shortcuts in the 2D visualisation software to be } \\
\text { able to use the Tablet PC effectively }\end{array}$ & 0 & 0 & 4 & 6 & 4 & 2 \\
\hline 50 & $\begin{array}{l}\text { Students should be taught sketching using paper-based techniques } \\
\text { before using the Tablet PC }\end{array}$ & 0 & 0 & 1 & 1 & 7 & 7 \\
\hline 51 & $\begin{array}{l}\text { Students should be taught paper-based rendering before using the } \\
\text { Tablet PC }\end{array}$ & 0 & 0 & 3 & 2 & 4 & 7 \\
\hline 52 & $\begin{array}{l}\text { After sketching for some time, you get used to the smoothness of the } \\
\text { Tablet PC screen }\end{array}$ & 0 & 0 & 0 & 1 & 11 & 4 \\
\hline 53 & $\begin{array}{l}\text { Students should not be taught paper-based rendering techniques as } \\
\text { the Tablet PC makes them redundant }\end{array}$ & 0 & 10 & 4 & 0 & 2 & 0 \\
\hline 54 & $\begin{array}{l}\text { Students need to be taught how to use the virtual keyboard on the } \\
\text { Tablet PC desktop }\end{array}$ & 0 & 1 & 12 & 2 & 1 & 0 \\
\hline 55 & $\begin{array}{l}\text { The introduction of the Tablet PC to all industrial/product design } \\
\text { students would have a motivating effect }\end{array}$ & 0 & 0 & 0 & 4 & 10 & 2 \\
\hline 56 & $\begin{array}{l}\text { Students should always have the option for using paper-based } \\
\text { techniques to sketch in addition to the Tablet PC }\end{array}$ & 0 & 0 & 0 & 0 & 7 & 9 \\
\hline 57 & The Tablet PC was not powerful enough for 3D CAD work & 2 & 0 & 4 & 1 & 5 & 4 \\
\hline 58 & The Tablet PC screen was too small for 3D CAD work & 2 & 0 & 0 & 2 & 5 & 7 \\
\hline 59 & $\begin{array}{l}\text { Students about to start undergraduates degrees in industrial/product } \\
\text { design should be encouraged to purchase Tablet PCs rather than } \\
\text { laptops }\end{array}$ & 1 & 1 & 2 & 5 & 6 & 1 \\
\hline 60 & Using the Tablet PC for designing introduced an element of fun & 0 & 0 & 1 & 1 & 12 & 2 \\
\hline 61 & $\begin{array}{l}\text { It was useful to use an external keyboard with the Tablet PC when } \\
\text { sketching }\end{array}$ & 3 & 0 & 4 & 0 & 5 & 4 \\
\hline 62 & $\begin{array}{l}\text { SketchBook Pro was more suitable than Photoshop for the generation } \\
\text { of line work }\end{array}$ & 0 & 0 & 1 & 1 & 5 & 9 \\
\hline 63 & $\begin{array}{l}\text { SketchBook Pro was easier to use than Photoshop for the generation } \\
\text { of line work }\end{array}$ & 0 & 0 & 2 & 1 & 4 & 9 \\
\hline 64 & $\begin{array}{l}\text { Photoshop was more suitable for rendering the line work than } \\
\text { SketchBook Pro }\end{array}$ & 0 & 0 & 6 & 4 & 5 & 1 \\
\hline 65 & $\begin{array}{l}\text { Connecting the Tablet PC to a larger external screen was beneficial } \\
\text { during 3D CAD work }\end{array}$ & 4 & 0 & 1 & 1 & 5 & 5 \\
\hline 66 & The battery life of the Tablet PC was acceptable & 1 & 1 & 0 & 1 & 4 & 9 \\
\hline 67 & The Tablet PC is pressure sensitive & 0 & 0 & 0 & 2 & 7 & 7 \\
\hline 68 & $\begin{array}{l}\text { Microsoft Journal software represented a viable alternative to a } \\
\text { paper-based logbook }\end{array}$ & 4 & 0 & 3 & 3 & 4 & 2 \\
\hline 69 & Using the stylus was useful with 3D CAD work & 4 & 1 & 7 & 1 & 2 & 1 \\
\hline 70 & $\begin{array}{l}\text { Having a device that enables you to adjust the angle of the Tablet PC } \\
\text { screen while sketching would be beneficial }\end{array}$ & 0 & 0 & 1 & 4 & 8 & 3 \\
\hline 71 & $\begin{array}{l}\text { It would be beneficial if the Tablet PC could sit in a recess on a desk to } \\
\text { make the screen flush with the surface }\end{array}$ & 0 & 0 & 3 & 3 & 5 & 5 \\
\hline 72 & $\begin{array}{l}\text { Having an additional 'control' button that can be used when the } \\
\text { screen covers the keyboard would be beneficial }\end{array}$ & 0 & 0 & 0 & 4 & 8 & 4 \\
\hline
\end{tabular}

Table 7-6: Summary of the Use of Tablet PC for Designing Questionnaire results $(n=16)$ 


\subsubsection{Examples of Work Produced}

On completion of the Use of Tablet PC for Designing Questionnaire, examples of projectbased design activity undertaken by students using the Tablet PC were collected to provide evidence of progression of design capability. The examples ranged from simple sketches (Figure 7-118) to the use of line with the application of tone (Figure 7-119); the use of loosely applied colour (Figure 7-120); descriptive visuals (Figure 7-121); formal sketches for presentation (Figure 7-122); and 3D CAD rendering (Figure 7-123).
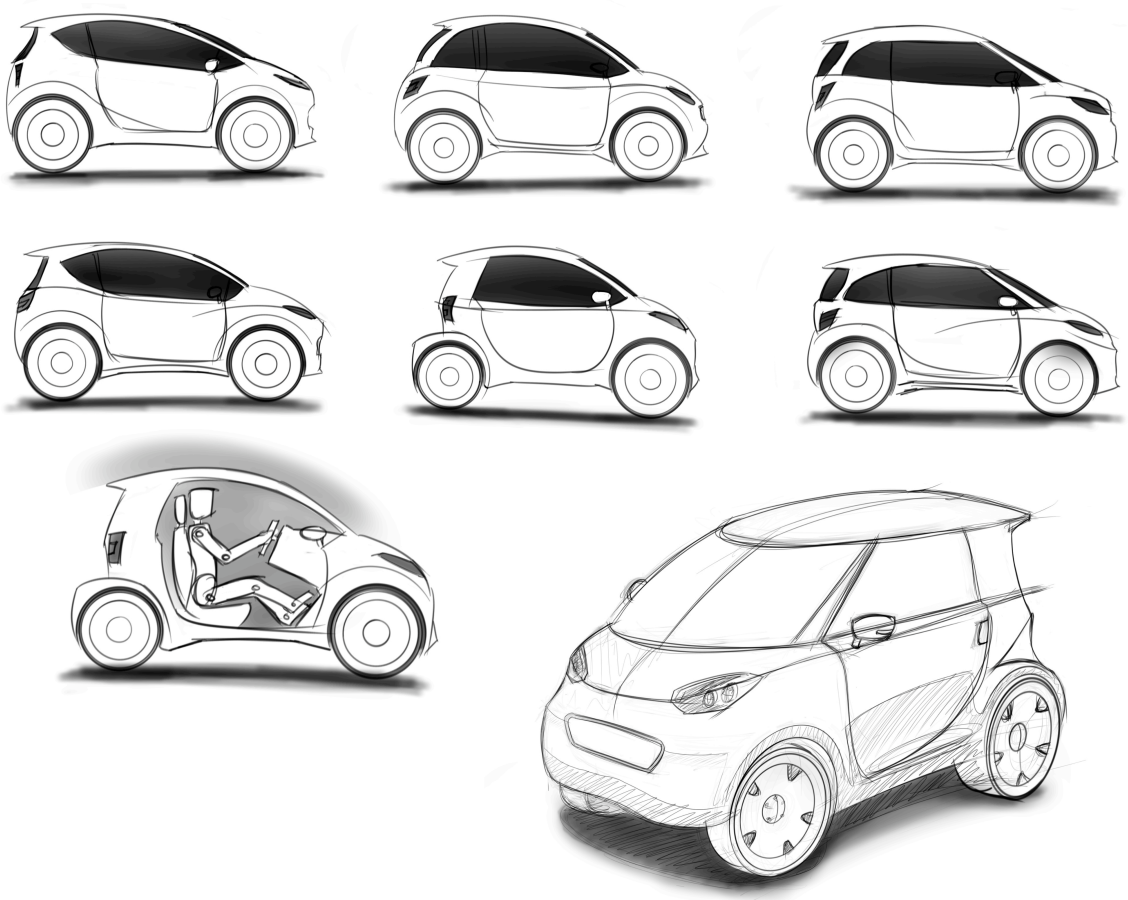

Figure 7-118: Simple sketches during concept generation 


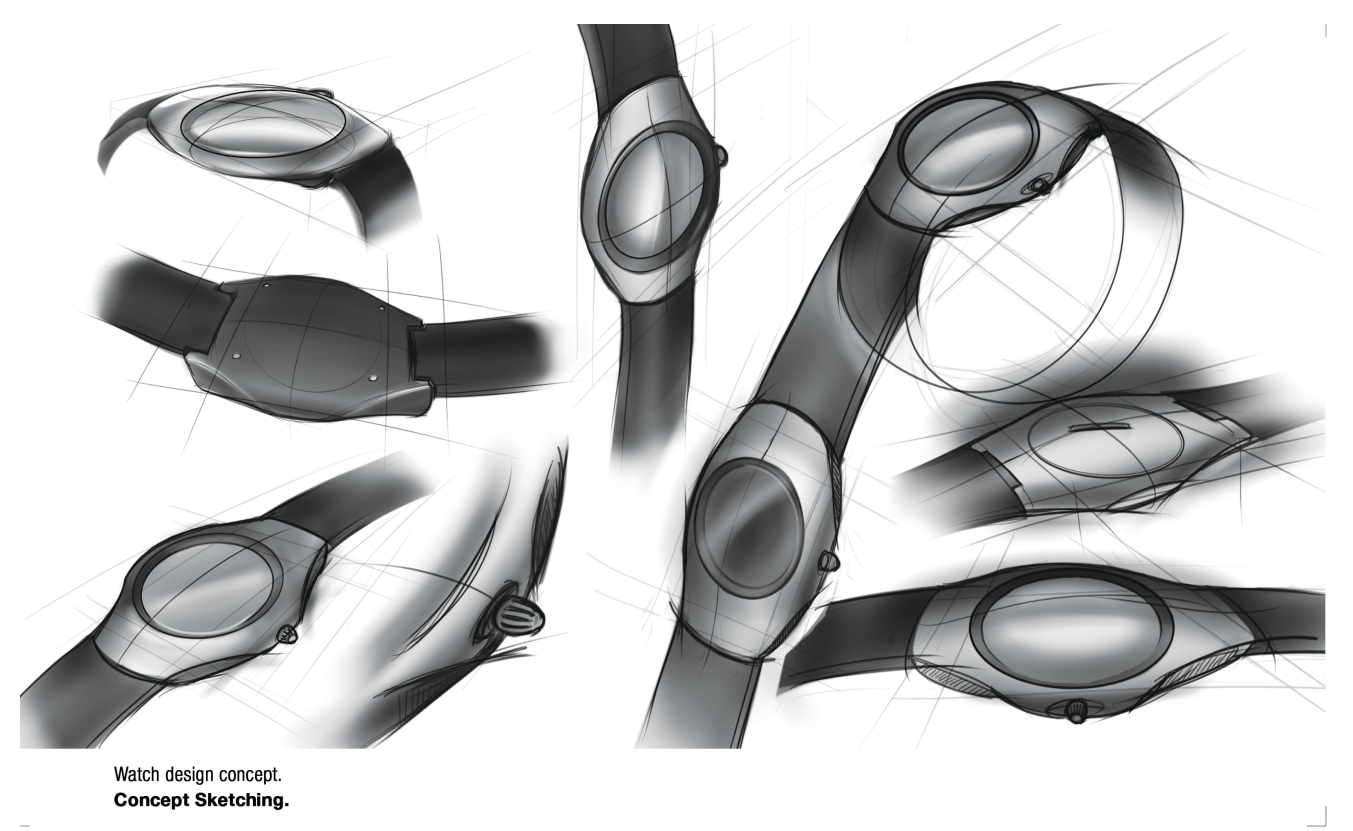

Figure 7-119: Integration of line and tone during concept generation

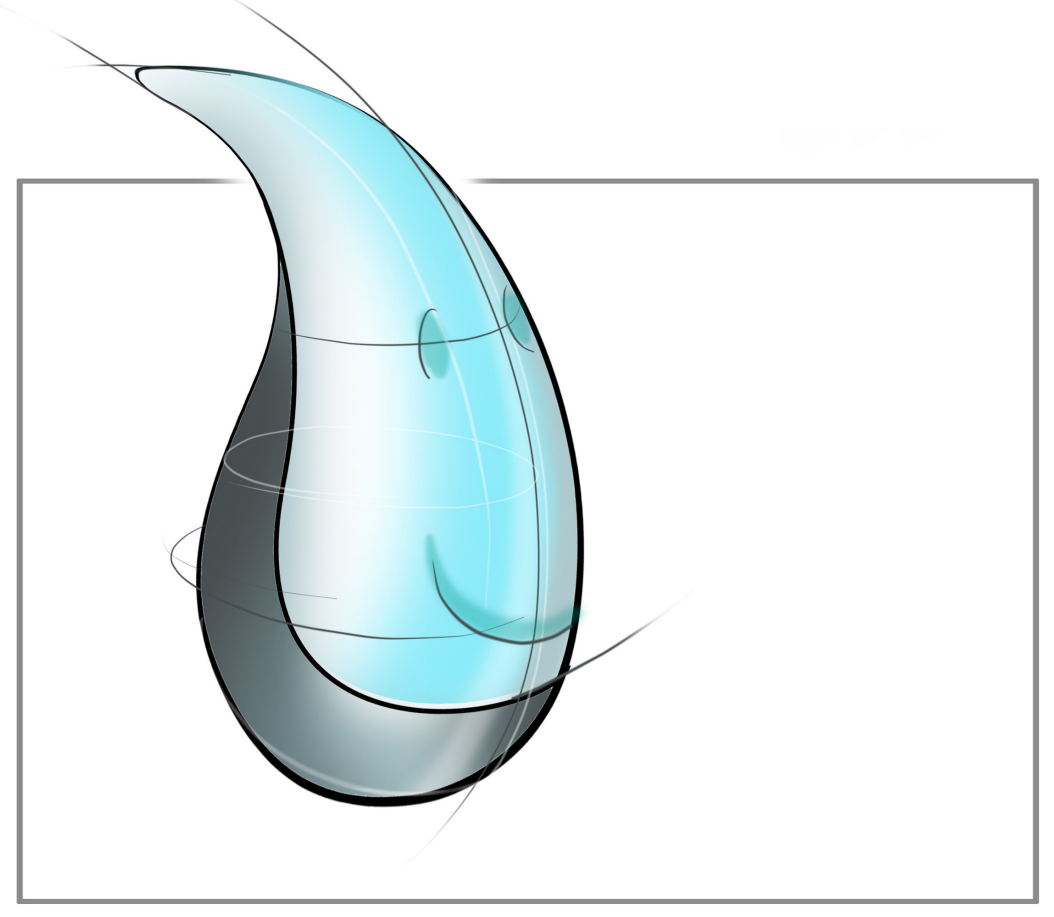

Figure 7-120: Use of loosely applied lines and colours 


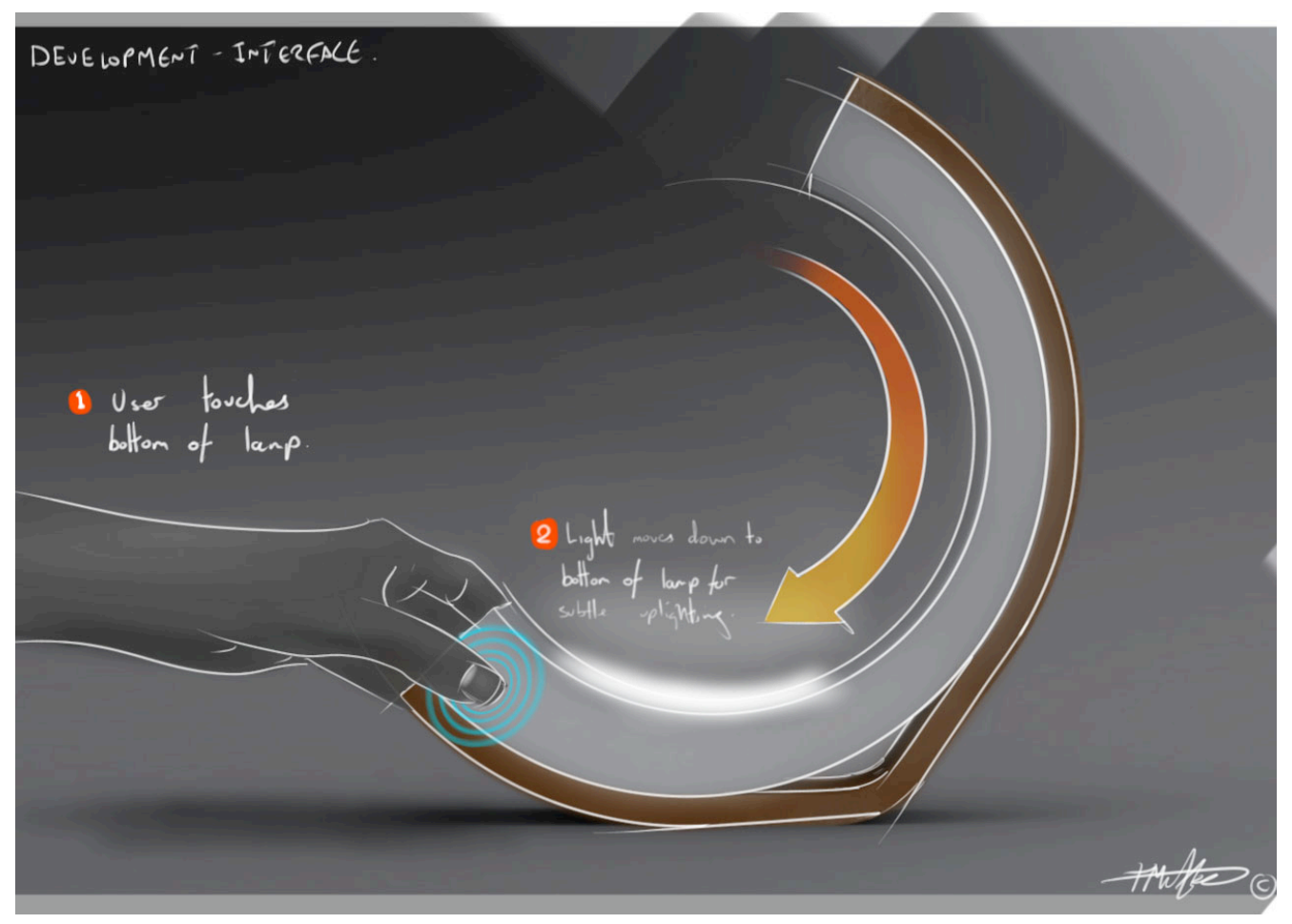

Figure 7-121: Descriptive visual that shows how the product functions

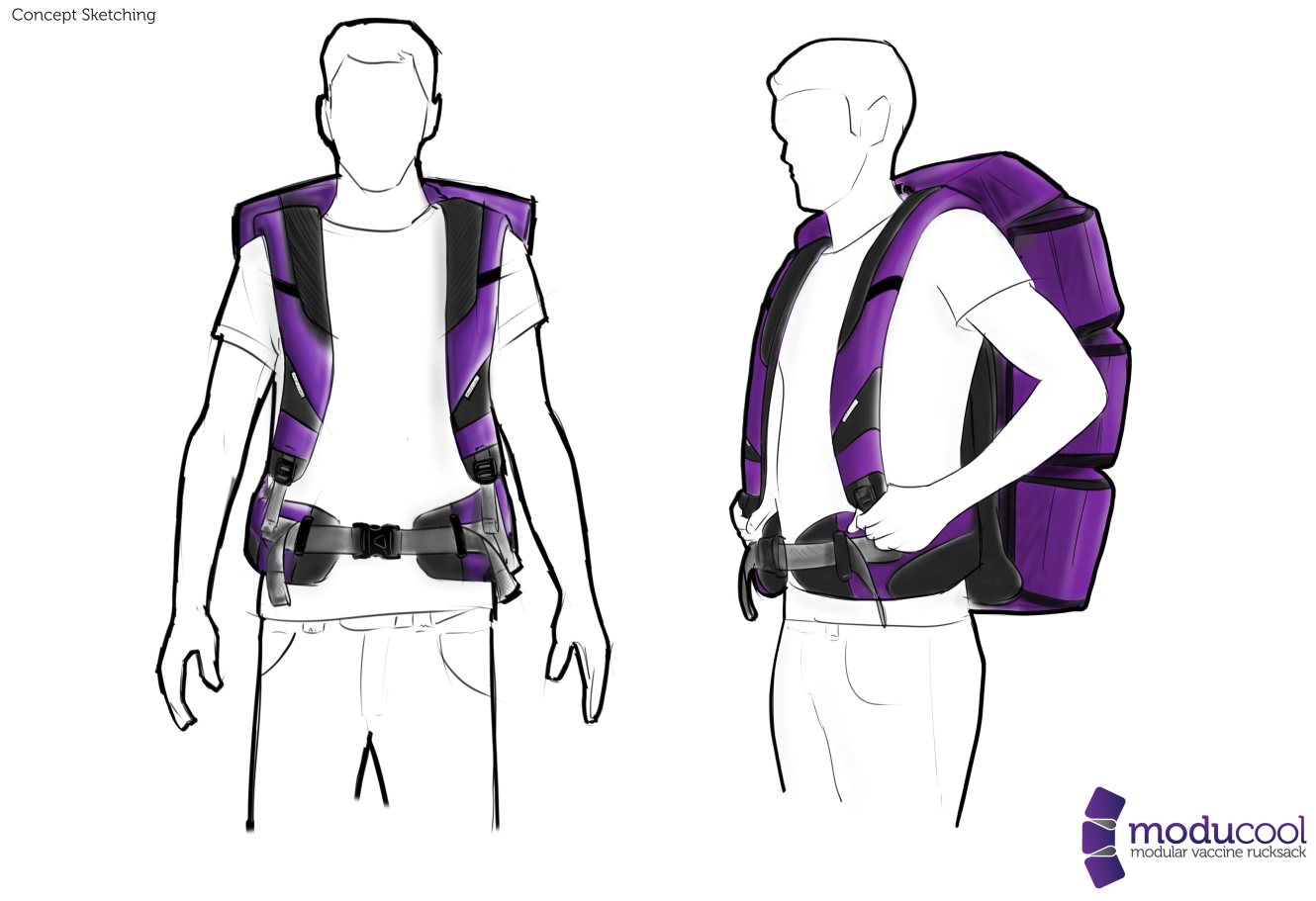

Figure 7-122: Controlled sketch for presentation 


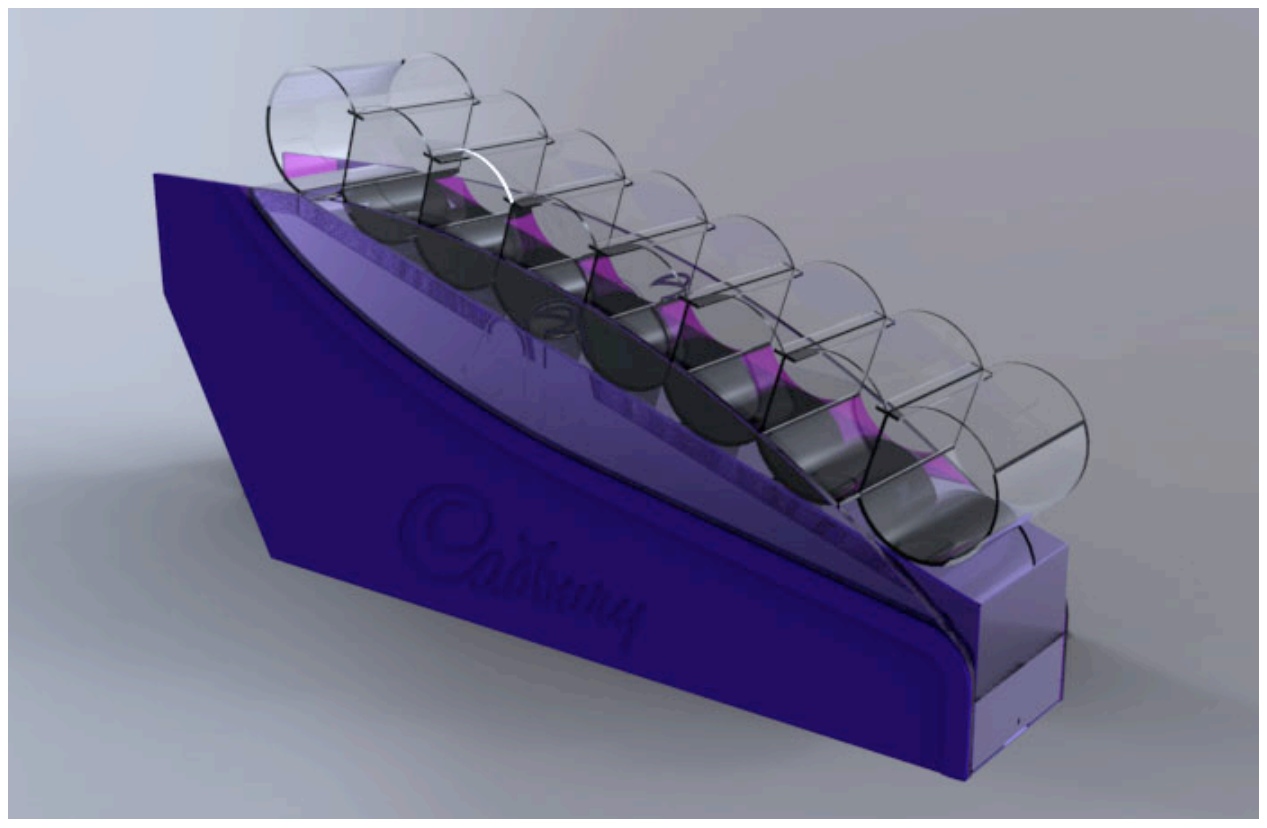

Figure 7-123: 3D CAD rendering using the Tablet $P C$

\subsection{Chapter Summary}

After undertaking the initial data collection (Chapter 5 and Chapter 6), digital sketching appeared to be a main concern for graduating students, industrial placement students and practitioners. Responders had strong feelings towards the portability, speed, flexibility, and freedom that paper-based media offered compared to digital methods. Some academics and practitioners felt that digital sketching required considerable training and could lead to less personalised and less detailed sketches.

To address these concerns and with the support of an HP Innovation in Education Grant, this chapter discusses the Tablet PC case study that investigated the use of the Tablet PC for designing. The grant was valued at $\$ 100,000$ and included 22 Tablet PCs, 22 docking stations and $\$ 10,000$ cash to be invested in the research.

Sixteen of the Tablet PCs were provided to students $(7 \times$ BA Industrial Design and Technology course students and 9 x BSc Product Design and Technology course students) at the beginning of the 2009/2010 academic year. The case study lasted for an entire academic year and included different data collection methods such as questionnaires, a sketching exercise, a design exercise, focus groups and observations. 
To compare sketching using the Tablet PC with paper-based techniques, a sketching exercise was undertaken by students. The exercise required students to produce two sketches (one using paper-based media and another using the Tablet PC) of a geometric torch and another two sketches of an organic child's spoon. Each sketch had to be produced in five minutes. After completing the exercise, students were asked to complete a questionnaire. Results indicated that, overall, students rated their ability to sketch using paper-based techniques higher than using digital media. The majority of students felt that non-digital sketching was quicker, easier, offered more confidence in the use of line and was more accurate than the digital sketches produced using the Tablet PC. However, the students also stated that digital sketching was more enjoyable, required more error correction and produced the preferred type of final sketch.

When academics were asked to assess the outcome of the student sketching exercise, the greatest number preferred the conventional sketch of the torch and child's spoon in terms of effectiveness and almost quarter of them favoured the digital sketches.

A design exercise was undertaken with the students to evaluate and observe the use of the Tablet PC for designing. Each student produced a single perspective and two elevational views of a pepper mill concept design. During the exercise, it was noted that some students used an external keyboard and the zoom function when adding detail. Students often used the 'undo' button and imported images from the Internet to use as underlays for tracing. The ability to undo and produce quick shading were listed as the main strengths when undertaking the exercise, while the poor calibration of the pen tool and the size of screen were the key weaknesses identified by students.

A pre- and post-survey that compared digital design methods to non-digital design methods was also undertaken with the students, before and after using the Tablet PC, over an entire academic year. In general, student attitude towards digital design methods was optimistic. The key changes noted in the student responses before and after using the Tablet PC were mainly in favour of digital design tools. Students were positive about digital design methods when it came to the speed, portability, productivity, capability of facilitating collaboration, effectiveness for presentation, exploration of alternative solutions and contribution to development compared to non-digital design methods. In contrast, the majority of students felt neutral towards the capability of digital design methods in contributing to creativity and its contribution to concept generation. The majority of students disagreed/strongly disagreed that digital design methods were easier to learn than the non-digital equivalent. 
Focus groups were employed to explore the widest possible range of issues related to the use of Tablet PC for designing. The 72 distinctive issues raised in the focus group were translated into a final questionnaire to evaluate the use of the Tablet PC as a design tool.

This chapter concludes with the results of a survey that evaluated the Tablet PC as a design tool. The responses to the questionnaire indicated a positive attitude towards the use and capabilities of the Tablet PC when employing digital design methods. Key benefits of the Tablet PC were an increase in the quality of design output, making the students more adventurous when designing, and a major improvement in the speed of rendering and visual quality of designs. The Tablet PC helped the student to quickly communicate ideas with other people. It also increased the student excitement when collaborating through sketches. The ability to 'undo' mistakes boosted student confidence and creativity. The Tablet PC had a positive effect on student productivity when designing and introduced a degree of 'fun'.

In terms of negative attitudes, students had problems with the screen glare and its size which prevented previewing concepts on the same page. It was considered too small for effective sketching and 3D CAD. Sketches were less detailed and the Tablet PC was not powerful enough to be used for 3D CAD. The majority of students also found it difficult to match the position of the tip of the stylus with the cursor and rotating the tablet because of the rubber feet. While the sketching produced using the Tablet PC had a tendency to be less detailed, sketching at a low angle using the stylus was not possible. In addition, the Tablet PC was considered less convenient for sketching when short amount of time was available.

Areas for potential improvement included increasing the resistance of the screen to make it more like paper; having removable rubber feet or covers to allow easy reorientation; a system that would allow the stylus to be used at a lower angle on the screen; and greater sensitivity towards the edges of the screen.

Despite the advantages that the Tablet PC offered students, they believed that paper-based sketching and rendering should be taught before using the Tablet PC. Students also thought that introducing the Tablet PC to all industrial design students should have a motivating effect and should be encouraged. 


\section{DISCUSSION}

This chapter brings together the data and findings from the previous chapters. It discusses the outcomes in relation to the nature of education and professional practice by focusing on digital technologies, attitudes towards undertaking design practice entirely digitally, and digital sketching. It identifies recommendations for industrial design education based on the research findings and discusses the potential for devices in the 'post-PC era'.

\subsection{Nature of Education and Professional Industrial Design Practice in Terms of Digital Technologies}

This section brings together findings from the literature review, Chapter 5 and Chapter 6 .

\subsubsection{Balance between Conventional and Digital Design Methods}

A study by Jonson (2005: 613) on the impact of digital technology on tools for concept generation, especially sketching, concluded that students across design domains use less computing during the ideation stage (generating, developing and conveying ideas) when compared with design practitioners (Jonson, 2005: 622). This was identified as being due to the lack of student experience in digital technology (Jonson, 2005: 622).

In Chapter 5, results from the 2007/2008 graduating student supervised collective questionnaire and the online questionnaire with industrial placement students indicated that paper-based sketching was used more in education and professional design practice than digital sketching. However, in professional practice, the results for use of paper-based sketching and digital sketching were very close, confirming Jonson's (2005: 613) findings that practicing designers tend to use more digital sketching than students. This could be due to the collaborative nature of professional design practice that benefits from the speed of transfer between individuals. In addition, results from the questionnaire undertaken in Chapter 5 indicated that students were encouraged to employ paper-based sketching, especially as half of the graduating students never/rarely used digital sketching. A similar practice of encouraging paper-based sketching techniques was noted within interior design education (Basa and Senyapih, 2005: 262). 
The same online questionnaire along with the $2007 / 2008$ graduating student questionnaire revealed that workshop-based sketch models and physical testing were used more than digital sketch models and digital testing in both education and professional design practice. Students and practitioners employed more digital methods in terms of control/engineering drawings and renderings. An obvious difference between the two practices took place when it came to producing appearance models and prototypes. Design organisations used digital appearance models and prototypes more than workshop-based appearance models and prototypes; whereas student practice was more conventional than digital.

\subsubsection{Dominant Design Methods}

In terms of the dominant design methods that were used by the majority of graduating students all of the time during design practice, paper-based sketching received the highest score (66\% always using it) followed by digital control drawings (51\% always using it). Results also indicated that digital control drawings were dominant within professional practice, with 11 out of 17 design organisations always using it. These results support McLaren's (2007: 176) findings that four out of five companies utilised digital control drawings through CAD, and Pipe's (2007: 92) statement that the use of drawing boards within a design studio is reducing dramatically with the introduction of CAD.

\subsubsection{Percentages Employing Digital Design Methods within the Design Process}

Results from the first supervised collective questionnaire used with 2007/2008 graduating students and the online questionnaire with industrial placement students indicated that while practitioners were employing more digital methods than students, the percentage using digital methods increased as graduating students and practitioners progressed during the design process, reaching its peak in the specification phase. Analysis of the practitioner and academic interviews in Chapter 6 indicated that the specification phase utilised completely digital methods during professional practice, while student practice remained hybrid. The findings from professional practice are supported by Pipes (2007: 35): "a designer may still use a pencil and paper right at the beginning of a project, but a computer will be used for the remainder of the process".

\subsubsection{Educational Use of Digital Tools/Media}

The number of graduating students that had never used CNC machining increased from $9 \%$ in the $2007 / 2008$ graduating student questionnaire to $12 \%$ for 2D CNC machining and $33 \%$ for 3D CNC machining in the 2008/2009 graduating student questionnaire, despite the fact 
that the majority of graduating students pointed out that their contribution to practice is significant/essential.

Results from the $2007 / 2008$ questionnaire with graduating students indicated that $25 \%$ had never used digitising tablets. In the second questionnaire of $2008 / 2009$, this percentage increased to $51 \%$ for digitising tablets without a built-in display and $79 \%$ for digitising tablets with an interactive pen display.

The 2008/2009 survey results indicated that the majority of graduating students who used a digitising tablet with an interactive pen display felt that it was easy/very easy to use and its contribution to practice was moderate. Even though digitising tablets without a built-in display were considered less easy to use than the digitising tablets with an interactive pen display ( $48 \%$ felt that it was easy/very easy), they contributed more to graduating student design practice as $40 \%$ felt that it had significant/essential contribution and $26 \%$ pointed out that it had moderate contribution. Despite the digitising tablets' contribution to design practice and ease of use, design education appears to be failing to make students aware of these digital devices.

\subsubsection{Digital Design Tools/Media Used in Professional Practice}

When industrial placement students were asked to report on the digital tools/media used within the design organisation they worked for, through open-ended questions, responses focused mainly on software used rather than the tools/media in general. Even though the results indicated that 8 out of 17 design organisations used digital sketches always/often, only one industrial placement student indicated the use of Wacom tablets during concept generation. This result was repeated in the use of digital output machines, such as RP machine and CNC machining. Despite the fact that 10 out of 17 design organisations used digital appearance models (produced using RP and CNC machining) always/often and seven design organisations utilised digital prototypes, only one used RP and none reported the use of CNC machining. This conflicts with results from the interviews undertaken with practitioners, where many mentioned the use of RP and CNC machining within their practice. However, there is a possibility that the design organisations that placement students worked in outsource RP and CNC machining.

\subsubsection{Use of Digital Design Tools/Media in Professional and Educational Practice}

This section analyses results collected from practitioners and academics interviews, plus the $2008 / 2009$ graduating student questionnaire. It is important to note that the sample size of 
practitioner (eight in total) and academic (nine in total) interviews was too small to be converted to percentages when compared to graduating students (117 in total).

Results from the interviews undertaken with practitioners and academics revealed that the 2D mouse, 2D visualisation and 3D CAD (solid and surface) were used within the practice of each university and design organisation. The 2008/2009 graduating student questionnaire findings also showed that these digital tools were the ones used most frequently within their own practice, with $88 \%, 86 \%$ and $84 \%$ respectively using them always/often. Graduating students identified these digital tools/media as the ones that contributed the most to their design practice, with $65 \%, 87 \%$ and $82 \%$ respectively believing that they offered essential/significant contribution to their practice.

The interviews also revealed that all academics reported employing digital rendering/animation and 3D CNC machining within educational design practice. However, findings from the graduating student questionnaire showed that $17 \%$ of graduating students never used rendering/animation and 33\% never used 3D CNC machining. These results may have been impacted by the fact that the academics and students were from different institutions. The academics interviewed were lecturing in English, American and Australian universities while all of the graduating students were in UK higher education.

All of the practitioners interviewed utilised RP in their practice. Six out of nine academics employed RP within student design practice and $86 \%$ of graduating students were using it. Other tools/media that were extensively employed within education and professional practice were 2D CNC machining and 2D CAD. Results of graduating students were roughly similar, with $88 \%$ using 2D CNC and $81 \%$ employing 2D CAD.

The digitising tablet without a built-in display was used within the design practice of five out of eight practitioners and six out of nine academics reported its use in education practice. However, results from the 2008/2009 graduating student questionnaire indicated that the majority had never used it. This could be linked to the fact that academics represented data from around the world while the graduating student survey involved UK-based students only or that the digitising tablet without a built-in display is used in some UK institutions and not others.

The number of professionals and academics who employed polygon modelling and VP were similar. Four out of eight practitioners used polygon modelling and five mentioned the use of VP. In education practice, five out of nine academics reported the use of polygon 
modelling and four cited employing VP. Results from the graduating students indicated that $50 \%$ used polygon modelling and $44 \%$ used VP.

Differences between professional and educational design practices became more apparent in terms of employing a 3D mouse, where none of the academics reported its use in student design practice and five practitioners were using when designing; $85 \%$ of graduating students confirmed that they had never used it, despite the fact that the majority of graduating students who had used felt that it was easy/very easy and it provided moderate contribution to their design practice.

While half of the designers interviewed (four in total) used 3D scanning, three out of the nine academics cited its use in education, but $73 \%$ of the graduating students said that they never used it in their design practice. This could be due to the fact that 3D scanning is generally used for reverse engineering that is more common in industry than education.

Three designers used haptic modelling and one academic only used it in education which is comparable to the graduating student response of $13 \%$. An assumption for these results could be that haptic modelling contribution to industrial design practice is limited and the output would not be sufficient enough to be used for downstreaming.

One out of eight designers and two out of nine academics used a tablet with a built-in interactive display, such as the Cintiq, within student design practice. This result was comparable with the 2008/2009 graduating student questionnaire, as $79 \%$ of graduating students never used it.

The digital design tools that were used by one designer only and were not used within education design practice as reported by academics were the pen input device and VR. The $2008 / 2009$ graduating student questionnaire results indicated that $34 \%$ of graduating students used a pen input device and 15\% utilised VR.

A summary of the interview results for practitioners and academics, plus the 2008/2009 graduating student questionnaire results on the use of digital design tools/media are illustrated in Table 8-1. 


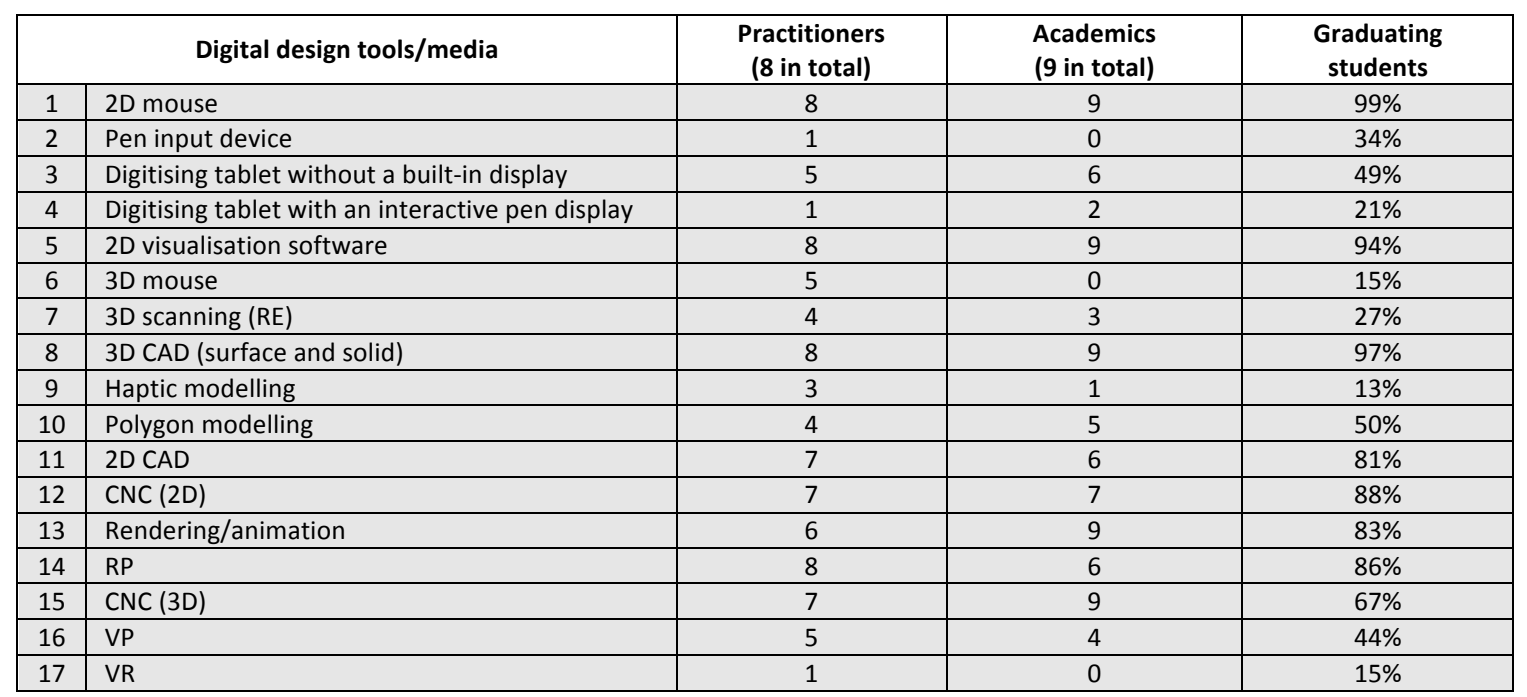

Table 8-1: Summary of the use of digital design tools/media within professional design practice and educational design practice according to academics and graduating students

\subsection{Attitudes Towards a Totally Digital Industrial Design Practice}

The researcher has identified a variety of opinions expressed by graduating students, academics and practitioners. These attitudes will now be discussed.

\subsubsection{Graduating Student Attitude}

The supervised collective questionnaire carried out with 2007/2008 graduating students provided a valuable insight into attitude towards digital designing.

The students who undertook the study were all 'digital natives', according to Prensky (2001), which makes them native speakers of the digital language. However, the results indicated that the majority of graduating students disagreed/strongly disagreed that they would be able to achieve the same outcome from projects if the entire process was undertaken using digital tools and that digital technologies had the potential to replace conventional workshops and the hands-on experience. This attitude continued to include a negative response to their design practice improving if they used a completely digital process and being apprehensive about the appropriateness of having a totally DID course.

The absence of paper-based sketching was one of the major concerns raised by graduating students. In a questionnaire that was carried with 91 design academics and students at Brunel University, results revealed that the two main reasons for using paper-based sketching were that it allowed spontaneous expression of ideas and its ease of use to record 
impulsive ideas (Lim et al., 2004: 395-396). The 2007/2008 graduating student questionnaire cited similar reasons plus the freedom that paper-based techniques offered along with the cheap cost of pen and paper compared to the digital sketching tools/media.

Students have claimed that revealing a designer's identity which is defined as the "traceable features in a drawing that distinguish the author of the design/drawing from the other" was difficult with computer drawing (Basa and Senyapih, 2005: 259-262). Results from the $2007 / 2008$ graduating student questionnaire indicated that the loss of personalisation when designing using digital tools only was a concern. Graduating students expressed the importance of workshop-based model making to understand the design and develop it further.

In a paper exploring the use of digital technology in art and design education, RadclyffeThomas (2008: 163) states that "some colleges cannot afford to buy appropriate industry standard equipment or software; students may feel disappointed and disadvantaged if they perceive their education institution is not teaching them the most relevant skills and keeping up with the rapid pace of technological change in the commercial sector". Graduating students who participated in the $2007 / 2008$ questionnaire did not directly state that they felt disappointed or disadvantaged because of the limited use of digital tools/media within their education practice. However, many of the key areas of improvement suggested by graduating students were related to the extensive use of digital design tools/media, such as more tutoring on $C A D$; digital rendering for presentation; use of wider variety of $2 D$ and $3 D$ packages; and more use of RP and CNC machining. This indicates that some graduating students felt disadvantaged in terms of the use of digital design technologies.

Table 8-2 provides a summary of the negative and positive opinions of graduating students on using only digital tools/media for their design practice. 


\begin{tabular}{|l|l|}
\hline \multicolumn{2}{|c|}{ Negative thoughts } \\
\hline 1 & Digital tools are not effective for concept generation in terms of ease of use, speed, and cost \\
\hline 2 & Restriction in freedom \\
\hline 3 & Hinders creativity \\
\hline 4 & Hands-on experience is needed when designing \\
\hline 5 & Software can slow you down if you are not familiar with it \\
\hline 6 & Cost of digital equipments \\
\hline 7 & Limitation in the sense of scale \\
\hline 8 & Less understanding of product emotive cues (texture) \\
\hline 9 & Workshop model making skills are vital to understand the design properly and develop it \\
\hline 10 & It would be a loss to the design craft skills and fabrication process \\
\hline 11 & Physical models are important for assessment and input \\
\hline 12 & Digital design wastes time \\
\hline 13 & Being static behind a computer screen is a bad practice \\
\hline 14 & Lose the connection between project and designer \\
\hline \multicolumn{2}{|l|}{ Positive thoughts } \\
\hline 1 & Technology has advanced enough \\
\hline 2 & Digital design tools exist to replace conventional design process \\
\hline 3 & Same outcome can be achieved from projects if the entire process was done using digital tools \\
\hline 4 & Reduces lead time \\
\hline 5 & Using digital tools/media is more accurate and efficient \\
\hline 6 & $\begin{array}{l}\text { Digital technologies have the potential to replace conventional workshops and hands-on } \\
\text { experience possibly with future technologies }\end{array}$ \\
\hline
\end{tabular}

Table 8-2: Graduating student negative and positive opinions on employing only digital tools/media for their design practice

\subsubsection{Academic Attitude}

The opinion of academics towards designing using only digital tools/media was sought through interviews with nine academics. Responses indicated that employing entirely DID tools when designing depends on the skill of the student to use the digital tools and the type of project undertaken.

The positive benefits arising from change in the education system has been summarised by Malins et al. (2007: 438) who state that "the existing models of academic structure are the 'scared cows' of contemporary education, acting as artificial barriers which if overcome might offer distinct advantages to the next generation of design practitioners". Some academics expressed concern about the idea of students designing only using digital tools/media as students should have the freedom to use digital or conventional design techniques: "I guess the first thing is one of shock and horror that that might be something that would be imposed on students" (ID-A6).

Academics interviewed in Basa's and Senyapih's (2005: 265-266) study noted that revealing the designers identity and tracing student authorship of the work are two main concerns for computer drawings and renderings compared to hand drawings and renderings. Design 
instructors felt that teaching students hand drawing was a priority. Basa and Senyapih (2005: 267) reported that when design instructors compared hand versus computer drawings, four problems were raised with computer drawings: they looked too refined and finished; students believed that computers created the best representations when this was not always the case; computers could be used to cover up poor drawing capability; and the effort of re-plotting computer drawings puts students off altering mistakes that they were aware of. Interestingly, within the same study, instructors agreed that computers would dominate design practice in the near future, but not in design education and that manual skills would continue (Basa and Senyapih, 2005: 266).

In this research, none of the academics interviewed mentioned problems associated with revealing the student designers' identity and tracing authorship. One academic raised the issue of computers encouraging students to focus on style over content when stating "I also think the pitfall might be that the students are convinced, perhaps, by the quality of the look of their line work rather than the content, of the thinking involved. So almost back to the, 'I have done a lovely drawing,' rather than, 'I have solved a great problem here and here is a fantastic solution that has got a lot of content to it.' Style over content" (ID-A8). Few academics mentioned the ease of using paper-based sketching and its importance to externalise ideas. They preferred a hybrid approach and emphasised that students should learn design using conventional techniques, as the digital tools/media might not always be available in practice. The importance of workshop-based model making was also cited, especially as students found it difficult to realise objects in 3D form. Results confirmed that academics had concerns about the educational value of introducing digital technologies as pointed out by Chapman (Chapman, n.d.: 3).

On the positive side, some academics believed in the capabilities of digital design tools and thought that they could offer flexibility and opportunities when designing. Table 8-3 illustrates the negative and positive opinions cited by academics about students designing using digital tools/media only. 


\begin{tabular}{|l|l|}
\hline \multicolumn{2}{|c|}{ Negative opinion } \\
\hline 1 & $\begin{array}{l}\text { Students face difficulty realising objects in 3D and designing entirely digitally will just make it } \\
\text { more complicated }\end{array}$ \\
\hline 2 & A combination of digital and conventional methods is important \\
\hline 3 & Students should learn with basic equipments as they might not find digital tools in practice \\
\hline 4 & Computers encourage students to focus on style over content \\
\hline 5 & Limiting and restricting \\
\hline 6 & Danger that students will create designs that can not be manufactured \\
\hline 7 & There is a lack on the material side \\
\hline 8 & Concern of not being able to touch and feel the model \\
\hline 9 & Access to technology does not necessarily make students better designers \\
\hline 10 & Paper-based sketching is vital \\
\hline 11 & Shock and horror at imposing digital design methods only on students \\
\hline 12 & Can not imagine students designing using digital tools/media now \\
\hline \multicolumn{2}{|c|}{ Positive opinion } \\
\hline 1 & As long as students can produce a physical object then it is great \\
\hline 2 & Opens up new possibilities \\
\hline 3 & Offers flexibility \\
\hline 4 & Good when you have a Cintiq to sketch \\
\hline 5 & Digital methods are dominating after concept generation \\
\hline 6 & As long as it does not hide students thinking and slows them down it is completely appropriate \\
\hline
\end{tabular}

Table 8-3: Academic opinions on students designing using digital tools/media only

\subsubsection{Practitioner Attitude}

The attitude of practitioners towards digital designing was gathered from the following research methods: online questionnaire with final year students that had completed an industrial placement; online questionnaire with IDSA practitioners; and interviews with practitioners.

The majority of the IDSA practitioners disagreed/strongly disagreed that they would be achieving the same outcome from their projects if the entire process was done using digital tools. Reasons for this could be that some were familiar with conventional tools/media and had to adapt to the use of new technology, especially as some had up to 39 years of design experience. Industrial placement student responses were not clear, with 7 out of 17 students disagreeing/strongly disagreeing that the design organisation they worked for would be able to achieve the same outcome if digital tools were used and six students agreed/strongly agreed.

This lack of clear opinion continued when industrial placement students were asked if digital technologies had the potential to replace conventional workshops and the hands-on experience completely in the design organisation they worked for, where seven students disagreed/strongly disagreed and six agreed/strongly agreed. IDSA members were more positive, as the majority agreed/strongly agreed that digital tools/media had the potential to 
replace conventional workshops and the hands-on experience. This positive response of the practitioners could be due to their experience of many commercial projects that could contribute to a reduction in the number of physical models required.

The majority of industrial placement students felt neutral when asked if the work produced for the design organisation they worked for would improve if a complete digital process was used. Seven out of the 10 IDSA members who took part in the online questionnaire disagreed/strongly disagreed that their design practice would improve if a completely digital process was used. The top reason cited for this was that digital tools were considered to be too limiting during concept generation.

As the majority of industrial placement students did not agree or disagree on any of the statements, it could be assumed that they did not have a sufficient experience to fully understand the design process used in the placement design organisation.

Results from interviews undertaken with industrial design practitioners indicated that that major concern of practitioners about designing entirely digitally was losing the sense of scale and proportion for the products being designed (four out of eight designers), which was also cited as one of the concerns by Lynn (2006: 109). Designers interviewed and industrial placement students felt that hands-on modelling allowed them to see things differently when compared with the lack of tactile feedback when using digital methods.

Lynn (2006: 108) states that designers and educators were concerned that digital technologies would "steal the soul" of their designs. Few designers interviewed shared their concern that designing entirely digitally might lead to the loss of personality, although practitioners felt that using entirely digital techniques when designing depended on the generation you were raised in and knowledge in using the specific tools.

While many industrial placement students and IDSA members cited losing the freedom, and speed offered by paper-based techniques when generating concepts, none of the other practitioners interviewed mentioned this concern.

Table 8-4 provides an outline of the positive and negative opinions of designing using entirely digital techniques as mentioned by the IDSA members and industrial placement students who undertook the online questionnaire, plus interviews with practitioners. 


\begin{tabular}{|c|c|}
\hline \multicolumn{2}{|r|}{ Negative opinion } \\
\hline 1 & $\begin{array}{l}\text { Digital sketching is not as flexible as paper-based sketching that offers ease of use, speed and } \\
\text { freedom and it is cost effective }\end{array}$ \\
\hline 2 & Limitation in tactile and visual feedback when designing entirely digitally \\
\hline 3 & Scale problem \\
\hline 4 & Designers will be limited to what they can achieve (knowledge) with the digital tool \\
\hline 5 & Loss of personality as the end result of digital process could be similar \\
\hline 6 & Hands-on workshop-based model making is important to understand the design \\
\hline 7 & 3D CAD software need to come a long way before it can replace real physical model making \\
\hline 8 & $\begin{array}{l}\text { Good design is all about designing a customer experience (visual, tactile, experiential, etc.) and } \\
\text { that type of skill is difficult to translate through a computer monitor }\end{array}$ \\
\hline 9 & Being face-to-face with other designers and contributors helps you to sharpen your skills \\
\hline 10 & Sketch models can be made quickly by hand \\
\hline 11 & CAD is slow in early stages of design \\
\hline 12 & Digital design tools are just tools that can not replace the knowledge itself \\
\hline 13 & Limits creativity \\
\hline 14 & Limitation of the digital tools/media can affect the design process \\
\hline \multicolumn{2}{|r|}{ Positive opinion } \\
\hline 1 & Design organisation already uses digital tools/media \\
\hline 2 & Technology has advanced enough to reduce the learning curve \\
\hline 3 & Changes are easier to make when using digital design tools/media \\
\hline 4 & Digital design tools provide more precision \\
\hline 5 & RP saves time and is proving the digital data before tooling \\
\hline 6 & Digital tools have the potential to replace analogue tools, but not yet \\
\hline 7 & Digital technology has the potential to $100 \%$ mimic the paper and pen interface \\
\hline 8 & Could make the process of taking a sketch to a more refined design a bit more fluent \\
\hline 9 & CAD features are substantial to improve designing products \\
\hline 10 & $\begin{array}{l}\text { Digital design methods provide more control over the data accumulated during a project, which } \\
\text { means more efficiency }\end{array}$ \\
\hline 11 & Designing totally digitally is the future of design \\
\hline
\end{tabular}

Table 8-4: Summary of the of negative and positive opinions shared by practitioners and industrial placement students

When industrial design practitioners from the IDSA were asked for their opinion on the appropriateness of having a totally DID course, the majority felt that it was inappropriate. Reasons for this included: the importance of learning conventional methods before moving to digital; a negative influence on exploration while designing; the importance of paperbased sketching; existing industrial design courses were already applying enough digital tools/media; weaknesses in form development and perspective drawing when using digital techniques; and digital design tools encouraged students to be 'lazy'.

Practitioners who agreed/strongly agreed in having a totally DID course believed that it would be valuable because university was the place to explore new strategies and this would help develop digital technologies. 


\subsection{Digital Sketching}

The findings from the Tablet PC case study undertaken with final year students will now be discussed with reference to existing literature and findings on digital sketching.

\subsubsection{Digital Sketching Behaviour}

When observing student sketching using the Tablet PC, it was noted that they tended to draw lines, zoom in and out, use the 'undo' button, modify lines and shading, add handwritten signatures, use the mirror feature to avoid repetitive line work and access supporting material on the Internet. The observations of the digital sketching behaviour during the case study confirms Lee and Wei (2007) findings (Table 8-5).

\begin{tabular}{|l|l|}
\hline $\begin{array}{c}\text { Sketching behaviour } \\
\text { categories }\end{array}$ & \multicolumn{1}{c|}{ Defining features } \\
\hline Creation & $\begin{array}{l}\text { Draw any kind of elements, lines and features of objects. In order to explain } \\
\text { and suggest ideas, designers need to create and generate something on the } \\
\text { board. }\end{array}$ \\
\hline Modification & $\begin{array}{l}\text { To add on new features and delete original line and features, modify and } \\
\text { change sketch line and features. }\end{array}$ \\
\hline Annotation & Using text and graphics to annotate the idea function and comments. \\
\hline Indication & $\begin{array}{l}\text { Using symbols, arrows, square and cycle lines, underlines to emphasise the } \\
\text { speaker's concern direction, location and scope of features, or repetitive } \\
\text { draw on the sketches to point out features. }\end{array}$ \\
\hline $\begin{array}{l}\text { Application } \\
\text { operations }\end{array}$ & $\begin{array}{l}\text { Except the drawing behaviour, designers need to operate the application } \\
\text { (SketchBook Pro), such as browse websites, open files, save files, change } \\
\text { drawing tools, change colour, use layers and zoom in/out etc. }\end{array}$ \\
\hline
\end{tabular}

Table 8-5: Defining features of interactive pen display sketching behaviour in collaborative design (Lee and Wei, 2007: 305)

\subsubsection{Difference between Digital Sketching and Paper-based Sketching}

In comparing paper-based sketching with digital sketching, the Tablet PC case study indicated that students rated their ability in using non-digital (paper-based) media for sketching higher than digital media. Faber (2009: 2487) noted that students with more experience in digital sketching using digitising tablets without a built-in display, such as Wacom Intuos, were inclined to sketch with similar speed or faster than conventional paperbased sketching. This was not the case with one student in the Tablet PC study. Whilst only 1 out 16 students had experienced the use of digitising tablets with an interactive pen display before undertaking the case study, the student still felt that the non-digital sketching was quicker when compared with digital sketching. However, it is difficult to generalise, as it was the case with just one student. Faber (2009: 2489) cites that unfamiliarity with digital 
sketching was the main reason for the slow speed of sketching when compared with conventional paper-based techniques. The findings in this research revealed that the majority of students, who rated their ability in digital sketching lower than paper-based sketching, pointed out that paper-based sketching was quicker which could, in part, be explained by their unfamiliarity with the Tablet PC or sketching software. Other reasons could be problems faced with the screen parallax and glare, difficulties in sketching with the stylus at a low angle and the size of the screen was too small for effective sketching.

Even though the findings from Lee and Wei (2007: 307) revealed that there was no major differences in the modification behaviour between paper-based and interactive pen display using Cintiq sketching, questionnaire results from Faber's (2009: 2488) study and the sketching exercise undertaken with students in this research indicated that digital sketching required most error corrections. Bilda and Demirkan (2003: 49) also stated that "modify actions were more frequently used in digital media". However, an important outcome from the Tablet PC case study was that the majority of students believed that the ability to 'undo' increased creativity and confidence.

Other findings from the sketching exercise included paper-based sketching being easier to use and more expressive than digital sketching, even though Faber (2009: 2488) noted that digital sketching generated "more expressive marks in backgrounds". When assessing the outcome of the sketching exercise undertaken in the Tablet PC case study to compare digital sketching to non-digital sketching, the greatest number of academics thought that the nondigital sketches produced by students were more effective in the communication of product form than digital sketches produced using the Tablet PC. Furthermore, half of the students preferred the final sketch produced using the Tablet PC rather than paper-based media. This could be explained by the students' reference to them enjoying using the Tablet PC when compared with non-digital sketching, or their satisfaction of line quality over the content as expressed by one academic who stated "I am seeing more and more drawings that have obviously been done with a digitising tablet where the student seems quite happy with a few lines to describe an object or an intent. But because the quality of the lines created by the computer has a fantastic feel to it, it has got a lot of tension and it is a really nice line, somehow it is seen as success" (ID-A8).

\subsubsection{Tablet PC as a Tool for Concept Generation}

The Tablet PC offered numerous advantages to students, some of which were similar to the ones provided by the digitising tablets without a built-in display as addressed by Faber 
(2009: 2488-2489) . For example, browsing the Internet while generating concepts and being more adventurous in terms of taking risks through experimentation. Pipes (2007: 141) gives reasons for being more experimental when stating that "the computer allows you to play around with ideas- trying out different type for captions, alternative positioning of elements, another background colour and so on- for as long as your schedule will allow... And so long as you save the different versions, there is no chance of ever spoiling the original".

The ease of applying and blending colours in the study by Faber (2009: 2489) was dependent on the experience of the user, those having more experience feeling that it was easier to undertake than when using paper-based techniques. The Tablet PC case study concluded that the majority of students believed that applying colour and tone to line work was quicker and easier. Colours were more vibrant and the line quality, visual quality, appearance and renderings were enhanced.

Lee and Wei (2007: 307) and Tang et al. (2011) suggested that the use of a Cintiq facilitated collaboration. The Tablet PC study indicated an increment in student excitement when collaborating with other people. Microsoft (2004: 1) cites "the built-in wireless capabilities and portability of the lightweight Tablet PC increased student productivity, simplified team work, and improved access to web-base services, including an essential online peer-review process for completing coursework". A study by Chin (2007: 15) proposed that the use of Tab-Sketch (Tablet PC used along with SketchBook Pro) increased the number of visual representations produced by Design and Technology students. Chin (2007: 15) believes that this could be due to students enjoying using the Tab-Sketch and the ease, speed and flexibility it offered. Findings from the HP Tablet PC study indicated that the majority of students thought that the Tablet PC facilitated being more productive. Reasons could be the fact that the majority enjoyed using it and an increase in confidence and creativity due to the ability to modify easily using the Tablet PC.

The digitising tablet without a built-in display has been cited as causing problems with coordination. Faber (2009: 2489) states that "tablet to screen and hand-eye coordination was a struggle for everyone within his or her experience levels". This was not an issue for students when using the Tablet PC, but the majority pointed out the difficulty in matching the position of the tip of stylus with the cursor, which could be because of the thickness of the screen glass or the "offset between LCD and the top of surface of the display" (Ronning, 2008). 
The weight of the Tablet PC affected its portability but students still preferred taking it rather an A3 pad if work had to be done when travelling. While Faber (2009: 2489) notes that "digital drawing had less set up and clean up time than traditional drawing", results from the HP Tablet PC study indicated that the Tablet PC was less convenient when short amounts of time were available for sketching if not already in use. The size of the digitising tablet without a display limited students (Faber, 2009: 2489). In the case of the Tablet PC, the majority of students expressed concern that the Tablet PC was too small for viewing numerous pervious ideas on the same page, for effective sketching and 3D CAD work.

Students in Faber's (2009: 2488) study indicated that drawing skills learnt using conventional paper-based media were transferable to digital sketching. These included "cross-hatching, sketching from residual lines, and creating more interesting linear qualities in general" (Faber, 2009: 2488). Baskinger (2008: 36) adds that "hand-generated drawings can also provide a basis for transitioning into digital sketching in a variety of tools". In the HP Tablet PC study, results indicated that students valued the experience of paper-based sketching and rendering before using the Tablet PC. They suggested that the option of using paperbased techniques for sketching in addition to the Tablet PC should always be available.

A study by Oehlberg et al. (2009: 242) revealed that, in 2007, none of the industrial design students used a digital design journal to write down comments on their design activity. All students utilised a tangible logbook, apart from one student who used a hybrid (tangible and digital content) design journal. The Tablet PC had Microsoft Journal software pre-installed, but Frolik and Zurn (2004: 4) explained that "due to the similarity between the Journal interface and a traditional sheet of notepaper, there is no loss in note-taking speed, even on the first day of use". The Tablet PC case study identified mixed reactions from students towards the use Microsoft Journal software as an alternative to a paper-based logbook, with six students agreeing/strongly agreeing and three disagreeing on its suitability.

A summary of the Tablet PC results identified by the majority of students who undertook the Tablet PC case study are outlined in Table 8-6 (key benefits), Table 8-7 (limitations) and Table 8-8 (recommendations for teaching and learning). 


\begin{tabular}{|l|l|}
\hline \multicolumn{2}{|c|}{ Key benefits } \\
\hline 1 & Tablet PC was easier to use to remove mistakes when compared with paper-based media \\
\hline 2 & Increased confidence compared to paper-based sketching because of the ability to 'undo' \\
\hline 3 & Tablet PC layering facility was very helpful \\
\hline 4 & Quality of renderings produced improved using the Tablet PC \\
\hline 5 & Tablet PC was easy to use for tracing and producing basic outlines \\
\hline 6 & Smoothness of the Tablet PC was not an issue after sketching for some time \\
\hline 7 & Line quality of the Tablet PC was better than that for paper-based sketching \\
\hline 8 & $\begin{array}{l}\text { Preference to take Tablet PC rather than an A3 pad when work had to be done while visiting } \\
\text { friends and family }\end{array}$ \\
\hline 9 & Using the Tablet PC for designing introduced an element of fun \\
\hline 10 & Tablet PC was pressure sensitive \\
\hline 11 & Tablet PC facilitated making quick amendments to the designs \\
\hline 12 & $\begin{array}{l}\text { Colours used on the Tablet PC were more vibrant than those available with paper-based } \\
\text { techniques }\end{array}$ \\
\hline 13 & Tablet PC made students more adventurous when generating concepts and developing them \\
\hline 14 & Applying colour and tone to line work was quicker and easier with the Tablet PC \\
\hline 15 & Battery life of the Tablet PC was acceptable \\
\hline 16 & Ability to 'undo' previous work during concept generation did not hinder creativity \\
\hline 17 & Visual quality and appearance of designs were enhanced by the use of the Tablet PC \\
\hline 18 & Quality of outcome was greater using the Tablet PC than when using paper-based media \\
\hline 19 & $\begin{array}{l}\text { Work produced using the Tablet PC was of a higher level of presentation than that undertaken } \\
\text { using paper-based techniques }\end{array}$ \\
\hline 20 & Use of Tablet PC increased excitement when collaborating through sketching with other people \\
\hline 21 & Being able to browse the Internet whilst generating ideas \\
\hline 22 & Creating faint lines and using them as a guide when using the Tablet PC was not difficult \\
\hline 23 & Tablet PC stylus was not too short for comfortable use \\
\hline 24 & Ability to 'undo' using the Tablet PC increased creativity \\
\hline 25 & Tablet PC facilitated being more productive \\
\hline 26 & Tablet PC helped in quickly communicating ideas to other people \\
\hline 27 & The potential for the Tablet PC to be stolen did not affect students ability to sketch in public \\
\hline
\end{tabular}

Table 8-6: Key benefits the Tablet PC identified by the majority of students

\begin{tabular}{|l|l|}
\hline \multicolumn{2}{|c|}{ Limitations } \\
\hline 1 & Tablet PC screen limited the ability to see numerous previous ideas on the same page \\
\hline 2 & It was difficult to match the position of the tip of the stylus with the cursor \\
\hline 3 & Students were not able to sketch with the stylus at a low angle on the screen \\
\hline 4 & $\begin{array}{l}\text { Tablet PC was less convenient when short amounts of time were available for sketching when } \\
\text { not already in use }\end{array}$ \\
\hline 5 & Tablet PC screen was too small for 3D CAD work \\
\hline 6 & Rendering using 3D CAD was not quicker and easier with the Tablet PC \\
\hline 7 & Tablet PC screen was too small for effective sketching \\
\hline 8 & Sketches produced using the Tablet PC had a tendency to be less detailed \\
\hline 9 & Weight of the Tablet PC affected its portability \\
\hline 10 & Rubber feet on Tablet PC made it difficult to rotate when sketching \\
\hline 11 & Students faced problems with screen glare while sketching \\
\hline 12 & Tablet PC was more difficult to use than pencil and paper \\
\hline 13 & $\begin{array}{l}\text { Students were not able to use the full size of the Tablet PC screen because matching the } \\
\text { position of the top of the stylus with the cursor became more difficult towards the edges }\end{array}$ \\
\hline 14 & Tablet PC was not powerful enough for 3D CAD work \\
\hline 15 & Tablet PC stylus was not useful with 3D CAD work \\
\hline
\end{tabular}

Table 8-7: Limitations of the Tablet PC identified by the majority of students 


\begin{tabular}{|l|l|}
\hline \multicolumn{2}{|c|}{ Recommendations for learning and teaching } \\
\hline 1 & $\begin{array}{l}\text { Students should always have the option to using paper-based techniques to sketch in addition to } \\
\text { the Tablet PC }\end{array}$ \\
\hline 2 & Students should be taught sketching using paper-based techniques before using the Tablet PC \\
\hline 3 & $\begin{array}{l}\text { Students should be taught paper-based rendering techniques as the Tablet PC does not make } \\
\text { them redundant }\end{array}$ \\
\hline 4 & Students do not need to be taught how to use the virtual keyboard on the Tablet PC desktop \\
\hline 5 & Introduction of the Tablet PC to all industrial design students would have a motivating effect \\
\hline 6 & Students should be taught paper-based rendering before using the Tablet PC \\
\hline 7 & $\begin{array}{l}\text { Students need to have 2D visualisation software experience to be able to use the Tablet PC } \\
\text { effectively }\end{array}$ \\
\hline
\end{tabular}

Table 8-8: Recommendations for teaching and learning the use of Tablet PC identified by the majority of students

\subsection{Recommendations for Industrial Design Education}

The collated and discussed data facilitated four recommendations for industrial design education that will now be discussed.

\subsubsection{Industrial Design Education Should Increase Student Exposure of Digital Technologies}

Shin (2009: 6) states that "it is crucial that students be kept abreast of new technological developments that shape industrial design practice". In order for students to be fully exposed to digital technologies it is important that academics are aware, and immersed in, the capabilities of digital technology. The research revealed that some academics were not aware of some of the available digital design tools/media, such as haptic modelling. The top rated suggestion identified by graduating students to improve the curriculum of their industrial design course was that universities should place more emphasis on CAD software and digital rendering for presentations.

Findings from the surveys undertaken highlighted the restrictive nature of some industrial design courses in terms of making students aware of advanced and emerging design technologies. The number of graduating students who never used some digital tools/media, such as CNC machining and digitising tablets, increased during the academic years $2007 / 2008$ to $2008 / 2009$. Industrial design education should aim to increase student awareness of the digital technologies employed within industrial design practice. It should expose students to the key tools of digitising tablets, 3D mouse, 3D scanning, haptic 
modelling, RP, 3D CNC machining and VP as they are all used to a greater extent within professional practice than design education.

\subsubsection{Students Should be Taught Conventional Methods Before Digital Methods}

One practitioner and most of the academics emphasised the importance of teaching industrial design using conventional tools/media before employing digital techniques, with the following reasons being cited:

- "Children need to learn to use a slide rule, then they get a calculator." (IDSA Linkedln group online questionnaire participant)

- "When carried out [DID strategy] by somebody who is expert, has a certain level of expertise. I am still troubled about letting novices go all digital, really." (ID-A2)

- "If it is [DID strategy] in senior year then it might work. If it is earlier, the freshman year, I can tell you right now, even though they are citizens, digital citizens, a lot of times they do not understand the very basic functions of a computer because they did not have to, they do not have to because everything is made very well for them already." (ID-A3)

- "We [academics] do a tremendous amount in that early phase of just getting them [first year students] competent with the standard sorts of visualisations that occur for me to get an idea out - not to get it into a computer, but just to get it out of my head." (ID-A4)

- "If you do not have a workshop, if you do not have a 3D fettling workshop where you have got a bandsaw and lots of blocks of foam and things, then the students would have to learn all of this stuff [tools/media employed in the DID strategy] before they are able to make anything. Now how are you going to teach them 2D drawing software, 3D shaping software, 3D surface solid modelling software in effectively a 12-month period or something similar, before they can even have something physical?" (ID-A8)

- "I think you have to have a bit of an understanding of how things are made, physically made, to get a good grasp on what you should be designing." (ID-A9)

Results from the Tablet PC case study indicated that students prefer to be taught paperbased sketching and rendering before using the Tablet PC with visualisation software for digital sketching and rendering. This research has led to the conclusion that a completely DID course was not fully endorsed by academics and students. As a result, academics should 
teach students industrial design with conventional methods in the early stages of a course and introduce digital techniques into existing modules where appropriate during the second and third year of the programme. For example, digital sketching could be presented within design communication module while the use of virtual prototyping and virtual reality relate to CAD module. This would create a generation of industrial designers that are able to succeed in professional practice, as some of the conventional skills learnt are transferable to digital methods. Therefore, the conventional design tools/media employed within industrial design education should not be removed completely and certainly not during the first year of study.

\subsubsection{Tablet PCs Should be Introduced to All Industrial Design Students}

While the Tablet PC was only one of the digital tools/media that could be used along with 2D visualisation software to generate concepts, its introduction to final year students within the case study proved to be successful. The student questionnaire results on the use of the Tablet PC indicated that its use increased student confidence, excitement, enjoyment, productivity, creativity and motivation. The Tablet PC provided an opportunity for correcting mistakes easily through using the 'undo' button, which facilitated experimental work within student design practice. It improved the quality of renderings and line work produced by students and eased producing basic outline using the layer feature. It offered the advantage of browsing the Internet for supporting materials while designing. Students recommended the introduction of the Tablet PC to all industrial design students because of its motivating effect. As a result of the positive student feedback, the use of the Tablet PC within industrial design education should be encouraged.

\subsection{Considerations of a Digital Industrial Design Process}

While sketches serve many roles for the original designer, design managers use sketches as the main initial design representation to communicate and evaluate design proposals. Students in the Tablet PC case study confirmed that digital sketching using the Tablet PC enhanced the visual quality and appearance of designs. Digital sketching offers a greater quality of outcome and level of presentation, which could possibly make it more desirable for design managers. 
Paper-based sketching on an A3 page gives the designer the opportunity to sketch a number of concepts on the same page quickly. With digital tablets, the screen size limits the number of sketches that can be generated on one page. In addition, having a completely digital design process might not be compatible with displaying a range of 50 sketches in the same time for concepts to be assessed quickly, which can be achieved easily when using paperbased sketching.

In terms of using a digital logbook when designing products, a number of strengths and weakness could be assumed. On the positive side, a digital logbook offers the facility to store data easily; to send copies to other members of the design teams; to retrieve information needed without having to go through every page of the logbook; to import videos, images and website links; and to annotate external documents. At the end of the design activity, its normal for the logbook to be kept for record of the work done or to be referred to for specific reasons in the future (McAlpine et al., 2006a: 486) and when using a digital logbook managing and storing logbooks could be much easier. Despite the advances in technology, a paper-based logbook remains quicker to use, more affordable and portable when compared to its digital equivalent. Furthermore, a digital logbook does not provide tactile feedback from turning pages. One of the practitioners interviewed stated that "with this [paper-based logbook] I do not have to worry about charging a battery, I do not have to have access to an outlet, it is a lot lighter, lightweight and I can put it in my pocket. Is digital moving in that direction? Absolutely. I mean, battery life keeps getting longer, the computing power gets more powerful, things get thinner, more lightweight. Yes, it is all moving in that direction" (ID-P1).

The DID strategy has the potential to enhance collaborative working, which is the nature of professional practice. Industrial designers can be working on a certain part/feature within the product and then send the files to other team members. The DID strategy also facilitates globalisation so team members can work together on a project without being physically in the same location. This also enables files to be sent to manufacturers in the Far East easily. The DID strategy has the potential to increase efficiency and reduce time to market by reducing the number of physical models required. It could be assumed that these advantages assist the DID strategy to be more suitable for professional design practice than education. 


\subsection{Post-PC Era}

When the research presented in this thesis commenced in October 2007, the Tablet PC was a new technology that had potential within design practice. Currently, with the continuous advancements in technology, the Tablet PC is considered old. While undertaking the Tablet PC case study with industrial design students (academic year 2009/2010), Apple introduced the iPad as the modern Tablet PC in the post-PC era (Jobs, 2011a). Fifteen million iPads were sold within the first nine months, which is more than every Tablet PC ever sold according to Jobs (2011a). In 2011, Apple lunched the second generation iPad (iPad 2) and announced that the iPad is the fastest growing new product in history (Jobs, 2011a, Schiller, 2011). Compared to the first iPad, iPad 2 is 33\% thinner, lighter, faster and integrates a camera on the front and back of the device (Jobs, 2011a).

Nowadays, numerous tablets are available in the market. Apart from the iPad and BlackBerry PlayBook, most of the tablets feature Android operating system such as Samsung Galaxy Tab, Motorola Xoom and Acer Iconia Tab (Samsung, 2011, Motorola, 2011, Acer, 2011). These post-PC devices facilitate gesture and touch interaction, so many sketching software programmes are currently available at reasonable prices when compared to conventional tools/media. Autodesk developed two drawing applications: Autodesk SketchBook Mobile that is priced at $\$ 1.99$ and is available for iOS and specific Android devices (Autodesk, 2011d) and Autodesk SketchBook Pro, which has been designed for industrial designers and is only available for iPad (Autodesk, 2011c). Compared to SketchBook Pro that is designed for Tablet PCs or digitised pen tablets, Autodesk SketchBook Pro for iPad is considerably cheaper ( $\$ 4.99$ compared to $f 60$ ) but have some limitations, which were addressed in the literature review (Autodesk, 2011b, Autodesk, 2011c).

Other sketching applications that are available for iPad include Adobe Ideas, SketchPad HD and Layers for iPad (Adobe, 2011, Raizlabs Corporation, 2011, Benjamin Gotow, 2010). For BlackBerry PlayBook, examples include Sketch Professional, Sketch Book, and Sketch On (BlackBerry, 2011). In addition, Sketch Notes, TabNotes and MaplePaint are obtainable for tablets with the Android operating system (Google, 2011).

The new post-PC tablets could potentially solve some of the problems identified by students on the use of Tablet PC for sketching. These new tablets are considerably lighter and smaller than the Tablet PCs, which makes them more portable to be used for sketching when ideas strike. The fact that they can be rebooted easily and quickly makes them more convenient 
for sketching when short amount of time is available. Students found it difficult to rotate the Tablet PC because of the rubber feet, the new tablets are easy to rotate physically when needed and the screen automatically orientates depending on the way the tablet is held or used. Compared to paper-based sketching, the use of the new tablets allows the designer to adjust the brightness of the screen and give the opportunity to sketch in a dark setting.

On the negative side, the new tablets are not pressure sensitive to facilitate a natural sketching experience and CAD applications are currently not available. In addition, it is expected that their use for sketching will encounter a similar problem to that have been addressed when using the Tablet PC, which is the size of the screen is too small for effective sketching.

The price of the new tablets is relatively cheaper than the Tablet PC used in the case study with students and it is expected for the cost to reduce with time. For instance, a basic electronic paper tablet has been developed to replace paper-based sketching and note taking should soon be available in the market for the price of $\$ 99$ (NoteSlate, 2011).

While viewing a number of sketches on Tablet PC screen was a bit problematic because of the size of the screen, AirPlay and Apple TV allow images on iPad 2 to be presented on a wide screen TV wirelessly and automatically (Jobs, 2011a). This feature would support viewing a number of sketches on the same page or presenting them in a slide show on a bigger screen to offer an opportunity for inspiration and decision-making. Last but not least, the introduction of iCloud by Apple that facilitates wirelessly and automatically uploading content, storing it and pushing it to all other devices shared by the same person (Jobs, 2011b), would possibly enhance the digital sketching experience. A designer could be making notes using his/her iPhone, the notes get to be uploaded, saved and stored automatically in his/her iPad and MacBook. While the designer is on the train, an idea strikes so he/she picks up the iPad to sketch. The sketches produced which are automatically pushed to the rest of the devices could be used as an under layer for building 3D CAD models with the MacBook when the designer reaches home. Similar to the scenario described, iCould could possibly improve collaborative work between members of the design team. 


\section{CONCLUSIONS}

This chapter brings together the general findings from the research. It describes how the research aim and objectives were achieved; provides answers to the research questions; and gives overall conclusions. It identifies the contribution to knowledge; presents limitations of research; and provides suggestions for further work.

\subsection{Meeting the Research Aim and Objectives}

The aim of the research was to examine the potential of employing digital design tools/media during all stages of industrial design practice leading to the definition of a DID strategy that could be implemented in education and professional practice. This aim was achieved through the completion of the research objectives. The research activities that were carried out to meet the research objectives will now be described.

\subsubsection{Identify the Nature of Industrial Design Practice and Education Using Published Literature}

A literature review was undertaken to provide an understanding of industrial design, NPD, industrial design process, industrial design representations and industrial design education.

\subsubsection{Undertake a Literature Review in the Field of DID and Identify Available Digital Tools that Can be Used Within Industrial Design Practice}

Published literature was reviewed on the benefits of DID; concerns about DID; attitude towards digital design; digital sketching tools/media; digital modelling/prototyping tools/media; DID practice; and DID education.

\subsubsection{Explore the Nature of Contemporary Industrial Design Practice and Education in Terms of Employing Digital Technologies}

Supervised collective questionnaires were carried out with 2007/2008 and 2008/2009 graduating students to examine the use of digital tools/media in industrial design education. An online questionnaire with final year students who had successfully completed an industrial placement year provided an overview on the use of digital technologies in 
professional practice. In addition, semi-structured interviews with industrial design practitioners and academics were undertaken to confirm the findings.

\subsubsection{Identify the Attitudes of Industrial Design Practitioners, Academics and Students Towards DID}

In education, opinion on undertaking design practice entirely digitally was sought through a supervised collective questionnaire with 2007/2008 graduating students and semistructured face-to-face interviews with academics. Practitioner attitudes were sought through an online questionnaire with IDSA members and semi-structured face-to-face interviews with designers.

\subsubsection{Investigate How Digital Tools/Media Can be Employed to Form a Totally DID Strategy}

The literature review undertaken on the digital design tools/media that could be used during core design activity (sketching, drawing, modelling and prototyping) facilitated the generation of a DID strategy that had the potential to be employed in professional practice and education.

\subsubsection{Seek Opinion from Industrial Design Practitioners, Academics and Students on the Use of a Totally DID Strategy}

Semi-structured interviews were conducted with industrial design practitioners and academics to assess the DID strategy. The graduating student supervised collective questionnaire, which was undertaken at the 2009 New Designers Exhibition, provided feedback on the DID strategy. A revised DID strategy was developed based on the feedback collated from academics, graduating students and practitioners.

\subsubsection{Investigate Issues Relating to the Activity of Digital Sketching}

Digital sketching was explored through a case study with final year students on the use of the Tablet PC as a tool for concept generation. Within the case study, sketching and design exercises were carried out with students while the author was observing their sketching behaviour. Focus groups were conducted to more fully understand the student experience of sketching using the Tablet PC. In addition, supervised collective questionnaires were undertaken by students to compare digital sketching to paper-based sketching and to evaluate the use of Tablet PC as a tool for concept generation. Table 9-1 illustrates the chapters that addressed each research objective. 


\begin{tabular}{|c|l|c|}
\hline \multicolumn{1}{|c|}{ Objective } & Chapter \\
\hline 1 & $\begin{array}{l}\text { Identify the nature of industrial design practice and education using published } \\
\text { literature }\end{array}$ & Chapter 2 \\
\hline 2 & $\begin{array}{l}\text { Undertake a literature review in the field of DID and identify available digital tools } \\
\text { that can be used within industrial design practice }\end{array}$ & Chapter 3 \\
\hline 3 & $\begin{array}{l}\text { Explore the nature of contemporary industrial design practice and education in } \\
\text { terms of employing digital technologies }\end{array}$ & $\begin{array}{c}\text { Chapters 5, } \\
6 \text { and } 8\end{array}$ \\
\hline 4 & $\begin{array}{l}\text { Identify the attitudes of industrial design practitioners, academics and students } \\
\text { towards DID }\end{array}$ & $\begin{array}{c}\text { Chapters 5, } \\
6,7 \text { and 8 }\end{array}$ \\
\hline 5 & Investigate how digital tools/media can be employed to form a totally DID strategy & Chapter 6 \\
\hline 6 & $\begin{array}{l}\text { Seek opinion from industrial design practitioners, academics and students on the } \\
\text { use of a totally DID strategy }\end{array}$ & Chapter 6 \\
\hline 7 & $\begin{array}{l}\text { Investigate issues relating to the activity of digital sketching } \\
\text { Chapters 7 } \\
\text { and } 8\end{array}$ \\
\hline
\end{tabular}

Table 9-1: Meeting the objectives of the research

\subsection{Answering the Research Questions}

This section will discuss the answers to the four research questions that were identified at the beginning of research.

\subsubsection{What is the Nature of Educational and Professional Industrial Design Practice in Terms of Digital Technologies?}

Conventional design methods still dominate industrial design education, with freehand paper-based sketches, workshop-based sketch models, workshop-based appearance models and workshop-based prototypes dominating student design activity. However, digital design methods are used more than conventional methods in education when producing renderings and control drawings. In terms of industrial design practice, even though the use of digital sketches is comparable to paper-based sketches, freehand paper-based sketches, workshop-based sketch models, digital renderings and digital control drawings are being increasingly used.

The extent of employing digital methods in the design process increased as the students and practitioners progressed through the design process, reaching its peak during specification stage, with practitioners stating that the specification stage utilised entirely digital tools/media while student design practice continued to employ hybrid methods.

In terms of the digital tools/media used during practice, all of the practitioners and academics that were interviewed cited the use of a 2D mouse, 2D visualisation software and 3D CAD (solid and surface). These tools/media were the only ones reported by graduating 
students to be used often/always. Graduating students felt that the 2D mouse, 2D visulisation software, 3D CAD, 2D and 3D CNC machining and RP were easy/very easy to use and offered significant/essential contribution to their design practice. In addition, rendering/animation provided a significant/essential contribution to their design practice. Other digital tools that were regarded as being easy/very easy to use included digitising tablets with interactive pen display and the 3D mouse.

The majority of graduating students had never used pen input devices, digitising tablets without a built-in display, digitising tablets with interactive pen display, 3D mouse, 3D scanning, haptic modelling, polygon modelling, VP and VR despite the fact that graduating students did not regard the use of any of the digital tools/media as being difficult/very difficult. In contrast, the majority of the design firms interviewed reported the extensive use of digitising tablets without built-in display, 3D mouse, 3D scanning, polygon modelling and VP during design practice. The only tools that were not used extensively during professional practice were the pen input device, digitsing tablets with interactive pen display, VR and haptic modelling.

Among all the digital tools/media employed in the DID strategy, graduating students felt that haptic modelling was the only tool that offered no/limited contribution to their design practice. Results also indicated that the percentage of graduating students who never used CNC machining increased slightly from 2007/2008 to 2008/2009 and the ones who never used digitising tablets increased extensively. The research highlighted the restrictive nature of industrial design education in terms of making students aware of the diverse range of digital tools/media.

\subsubsection{How Do Students, Academics and Practitioners Feel Towards Undertaking Design Practice Entirely Digitally?}

An understanding of the student, academic and practitioner attitudes towards a totally DID process was established by undertaking questionnaires and interviews. The initial student opinion towards a totally digital practice for industrial design was negative. Graduating students did not believe that they would be able to achieve a similar outcome from their project if an entirely digital process was used or if their practice would improve. The majority of graduating students disagreed/strongly disagreed that digital technology had the potential to replace conventional workshops and hands-on experience. This attitude continued with a negative reaction to having a totally DID course. The opinion of practitioners was similar to graduating students, apart from agreeing/strongly agreeing on 
the capabilities of digital technology to replace the conventional hands-on experience. This could, possibly, be explained by their extensive experience in using digital tools during practice. The feedback from final year students who had successfully completed an industrial placement was scattered on the five-point Likert scale when they were asked similar questions. Nevertheless, the majority felt neutral about the possibility of improving design practice at the design organisation they worked for if a complete digital process was used.

When students, academics and practitioners were asked to express their negative thoughts on undertaking design practice entirely digitally, some commonality was found. This included: paper-based sketching was an important skill that participants regarded as being easier, quicker, more flexible and more cost effective when compared to digital sketching; workshop-based model making was vital to fully understand the design; there were limitations in tactile interaction when using digital methods; and using digital tools restricted the designer's/student's freedom and creativity. Graduating students and practicing designers agreed that digital practice limited the sense of scale and led to the loss of personality in the outcome. Academics and practitioners shared the view that digital design tools were just tools that could not replace the designers' knowledge or produce better designers/students.

Some academics expressed 'shock and horror' at the idea of a totally DID process for design education. They felt that students should learn with conventional tools, as the more advanced ones might not be available when they go into professional practice. In addition, academics mentioned that students tend to have problems realising form in $3 \mathrm{D}$ and using digital techniques would compound the existing problem. They felt that employing digital techniques would encourage students to focus on style rather than content and create designs that could not be manufactured. Other concerns that were raised by graduating students were the cost of digital equipment; digital design practice would waste time; and the idea of being static behind a computer screen was not particularly appealing. Practitioners highlighted the importance of having face-to-face contact with other designers and the issue of being limited to what the designer can achieve due to his/her knowledge in using the digital tool.

On the positive side, graduating students and designers mentioned the accuracy and efficiency that digital design tools/media offer, along with reduced lead times. Both groups 
cited recent advancement in technology has made it possible for digital tools/media to replace some existing conventional tools/media.

Some designers indicated that their design firm already employed a wide range of digital design tools/media. A number of designers believed in digital technology's ability to mimic paper-based sketching and its capacity to translate a sketch into a more developed design. They pointed out the advantage of using RP to confirm the digital data before tooling and the use of CAD in offering substantial benefits that improved design activity. Designers stated that digital design enabled modifications to be made which facilitated the design process and that practicing DID process was the future of design.

The academic positive feedback indicated that having a DID process was acceptable as long as students could produce a physical object; that digital design tools/media opened up new possibilities/flexibility; that the DID process was achievable with a Cintiq; and that digital methods were dominating after concept generation.

\subsubsection{How Can Digital Design Tools/Media be Integrated to Form a DID Strategy?}

Apart from the work of Yan et al. (2006) who explored the capabilities of a digital product design system without any recognition of creative concept generation, there were no other studies of direct relevance to this PhD research. The literature facilitated the identification of 17 digital design tools/media that were available and could be used within industrial design practice. The digital tools/media were the 2D mouse; pen input device; digitising tablet without a built-in display; digitising tablet with an interactive pen display; 2D visualisation software; 3D mouse; 3D scanning/RE; 3D CAD (surface and solid); haptic modelling; polygon modelling; 2D CAD; 2D CNC machining; 3D CNC machining; RP; rendering/animation; VP; and VR.

While $22 \%$ of the graduating students felt that the DID strategy had the potential to replace the existing conventional and hybrid process, the majority disagreed/strongly disagreed. The main reasons for this disagreement were the ease and speed of paper-based sketching and the importance of conventional techniques when designing, especially hands-on model making. When assessing the efficiency of the DID strategy, $45 \%$ (the greatest percentage) of graduating students felt that it was efficient/very efficient as it saved time and provided enhanced opportunities for creative form and visualisation. The majority of graduating students agreed that they would like to try the DID strategy to increase their experience and further their interest in new technologies. 
Contrasting responses were received when interviews were conducted with practitioners to provide feedback on the DID strategy. On the positive side, practitioners felt that the DID strategy was a good idea that provided a logical approach to the design of a product. They expressed their concerns about concepts looking overly finished when, in reality, they were not; and the cost of digital tools that made the DID suitable only for larger design companies.

Some of the academics interviewed mentioned that the DID strategy was an interesting approach that provided a useful summary of available digital tools/media; it offered the speedy modification of concepts; and presented the potential for students to use such methods in the more advanced stages of their industrial design degree.

When compared to practitioners, academics had more reservations regarding the use of the DID strategy by students. Reasons for this included: the 3D digital experience did not replace the capabilities of hands-on model making; the cost of providing the digital resources to all students; the loss of the essential tool of paper-based sketching; digital tools/media limiting creativity; the amount of learning required for students to master digital techniques; and the need for extra staff to maintain the equipments. The academics also suggested that the success of implementing the DID depended on being able to provide the digital tools/media and the student skill, experience and creativeness in using them.

Overall, the majority of practitioners and academics felt that the DID strategy was feasible. Feedback from practitioners and academics, through semi-structured interviews, led to modifications to the DID strategy such as removing the three phase division; providing the option of going back to sketching when needed (after using most of digital tools/media); separating renderings from animation; and including interactive simulations. The revised DID strategy can be seen in Chapter 6, Section 6.3.5 (Improvements Suggested to DID Strategy).

\subsubsection{How Can Digital Tools be Used to Support Concept Generation Through Sketching?}

The DID strategy employed a range of four digital tools/media (2D mouse, pen input device, digitising tablet without a display and digitising tablet with an interactive pen display) that could be used along with 2D visualisation software to produce sketches. Due to the limitation of time and resources, the research investigated the activity of digital sketching through a case study with 16 final year students using the Tablet PC with 2D visualisation software (Alias Sketchbook Pro and Adobe Photoshop mainly) for concept generation. In terms of digital sketching, the students were creating lines using a stylus, modifying their 
sketches and annotating. Other sketching operations that were not possible with conventional tools/media were identified, such as zooming in and out the work, utilising the mirror feature to avoid repetitive line work, and browsing websites to access supporting material while generating concepts.

Results indicated that digital sketching using the Tablet PC and 2D visualisation software was an improvement on the capabilities of paper-based conventional sketching in terms of quality of line and outcome; vibrant colours; ease of removing mistakes; enjoyment of sketching process; and the standard of presentation. In contrast, paper-based sketching was considered to be quicker, easier to produce, and created a more accurate representation of products when compared to digital sketching.

Some of the limitations associated with the use of the Tablet PC for digital sketching included the size of the Tablet PC being too small for viewing various ideas on the same page, for effective sketching, and for 3D CAD work. There was difficulty in rotating the Tablet PC, matching the point of the stylus with the cursor and using the stylus at a low angle. Sketches produced had a tendency to be less detailed and there were problems associated with screen glare while sketching. In contrast, students indicated that the Tablet PC increased their productivity and excitement when collaborating through sketches with other people. Digital sketching using the Tablet PC introduced an element of fun and facilitated browsing the Internet to find supporting material. It increased the student's willingness to take risks and be more adventurous when generating concepts as it facilitated quick amendments and undoing mistakes. In addition, when sketching, the ability to 'undo' enhanced student confidence and creativity.

While the case study explored the area of digital sketching and identified the advantages and limitations of using the Tablet PC along with 2D visualisation software, results from the study indicated that the student attitude towards digital sketching was positive overall and students recommended introducing the Tablet PC to all industrial design students because of its motivating effect.

\subsection{Conclusions from the Thesis}

McLaren (2007: 184) states that "the introduction of any new technology creates debate and encourages review of curriculum provision at various levels of education". This research 
has examined published literature in the field of industrial design practice and education along with digital design and digital design tools/media. The literature review revealed that with the exception of a single three-week course taught in America and an undergraduate course offered in the UK that did not require students to produce physical models, there were not any courses that taught students the full use of DID tools/media in sketching, drawing, modelling and prototyping. One attempt has been identified for a totally digital product design system (Yan et al., 2006) but this lacked the front-end of sketching activity that is a central characteristic of design practice. In addition, a lack of studies on the attitudes of industrial design practitioners, academics and students towards digital practice was identified.

The research has explored the use of digital design tools/media within industrial design education and professional practice. The dominance of conventional design methods within student design practice is apparent, especially in terms of the significance of paper-based sketching; workshop-based sketch models; workshop-based appearance models; and workshop-based prototyping, despite the fact that students did not find any of the digital design tools/media difficult/very difficult to use and none were regarded as having no/limited contribution to their design practice apart from haptic modelling. The majority of students had never used many digital tools/media such as digitising tablets without a built-in display; digitising tablets with an interactive pen display; the 3D mouse; 3D scanning; haptic modelling; VR; and VP. The findings indicated that the use of digital technology was greater in professional practice than education. These results led to a recommendation for industrial design education to increase the exposure of digital technologies.

The attitude of practitioners, academics and students towards the use of digital technology has a fundamental effect on the successful integration of digital design tools/media into industrial design in professional and educational contexts. The results from this research indicated that there was a general negative feeling shared by students and practitioners towards the initial appropriateness of having a totally digital industrial course and the capabilities of a totally DID process. However, while practitioners agreed/strongly agreed that digital technology had the potential to replace conventional workshops, students retained a negative attitude towards a more extensive use of digital technology.

The literature review facilitated the definition of a draft DID strategy that focused on the design modelling activities within industrial design and employed a range of 17 digital design tools/media. Feedback from practitioners and academics supported the development of the 
DID strategy to provide the designer/student with more freedom and options. While the DID strategy is feasible and big design firms already implement many of the tools/media employed within it, small design organisations might struggle to keep up with the recourses required to implement the DID strategy within its practice.

Evidence gathered from the research suggests that the even though most students were interested in trying the DID strategy to experiment different methods of working and keep up to date with new technologies, the majority of students and academics shared a negative feeling towards the potential of the DID strategy to replace existing conventional and hybrid process of design products in academia. Industrial design education continues to value the importance of paper-based sketching and workshop-based model making in shaping the students' design skills. Therefore, the adoption of completely digital process in academic practice is questionable at the moment.

As students, academics and practitioners had reservations about losing paper-based sketching, the research investigated the activity of digital sketching through a case study with 16 final year industrial design students. Results from the case study indicated positive feedback on the use of Tablet PC for generating concepts. Furthermore, it was revealed that the introduction of the Tablet PC within student design practice complemented the learning atmosphere. The motivating effect it provided persuaded students to recommend its use within student design practice. Therefore, a recommendation for industrial design education could be to encourage use of the Tablet PC to all students by providing an additional means of expressing and externalising their ideas.

In order for digital techniques to be accepted by industrial design students, academics and practitioners, they should offer benefits over conventional techniques. Digital design tools/media have influenced and changed design practice and they are not going to disappear. While a fully digital industrial design education is not currently ideal without teaching existing conventional methods of designing, the majority of academics believe that the developments in digital technologies will facilitate introducing an entirely digital industrial design course in the future.

\subsection{Contribution to Knowledge}

The research has facilitated the following new knowledge: 
- Identification of the conventional and digital design methods used within education and professional design practice and their frequency of use

- The attitude of students, academics and practitioners towards an entirely DID method of design practice

- Definition of totally DID strategy that employed 18 digital design tools/media to be used in education and professional practice

- Identification of the frequency of use, ease of use and contribution of digital design tools/media to student industrial design practice

- Comparison between digital sketching using the Tablet PC and 2D visualisation software with paper-based sketching in industrial design undergraduate education

- Evaluation of the use of the Tablet PC along with a 2D visualisation software by final year industrial design students

- Recommendations for industrial design undergraduate education on the use of digital methods

\subsection{Research Generalisability}

It should be noted that this research focused on the professional practice of industrial design and education and the findings illustrated are not necessarily transferrable to other fields of design such as furniture design, transport design and interior design.

Although the graduating students who took part in the supervised collective questionnaires were all UK-based (the first questionnaire included 96 graduating students from 22 UK universities and the second involved 117 graduating students from 28 UK universities), they serve as an indication of what is happening in industrial design education in general. Student design practice was investigated further through semi-structured interviews with academics from the UK, USA and Australia.

\subsection{Research Limitations}

While a great deal has been achieved within the duration of research, some of the limitations faced will now be identified. 
A lack of industrial design practitioners and academics collaborating in the research meant that the number was smaller than the number of students. Even though their feedback was based on extensive experience, this research could have compared percentages if a larger number of practitioners and academics had participated.

In the research, the term 'solid modelling' was used to describe software such as Pro/Engineer and SolidWorks. Solid modelling software is parametric and has the capabilities to produce surface modelling which explains the reason why it could also be called hybrid modelling (Anderl and Mendgen, 1995: 1). As a result, there is a possibility that when 2007/2008 graduating students where asked to rate the ease of using 3D surface modelling CAD software, some of them might have referred to parametric surface modelling CAD software. Furthermore, the terms 'surface modelling' and 'polygon modelling' are used to explain 3D CAD software that is more free-form. These two terms could have been replaced by 'polygon surface modelling' to avoid confusion.

New Designers Exhibition provided the opportunity of meeting graduating students from a wide range of industrial design courses across the UK under one roof. However, due to the fact that each university has a limited number of students that could participate in the exhibition, the selection process tends to be based on the quality of the projects. Therefore, it could be argued that the graduating student supervised collective questionnaires were completed by the best students and might not represent the more average or low-level students. It is difficult to speculate how the results would be affected if a wider range of levels were included. One assumption could be that best students who undertook the questionnaire were doing well with the methods they have been taught to use when designing so they might not be interested in changing. It may be that the average students with limited abilities in workshop model making or paper-based sketching might prefer employing digital tools/media to support the design activity. A third assumption could be that the low-level students were already struggling designing using conventional techniques so using digital techniques would complicate the process for them.

The majority of final year industrial placement students were not working at their industrial placement firm when undertaking the online questionnaire. As a result, it could be argued that most of them were not reporting the firm's design practice instantly. However, the questionnaire was completed at the beginning of the academic year that they returned to university. In addition, the duration that students spent in the placement (10-12 months) might not be regarded as sufficient enough to have a complete understanding of the firm's 
design practice, which can possibly limit the results of the online questionnaire and explains the lack of clear opinion towards digital designing.

This research could have been extended further if the DID strategy was tested by undertaking design projects that employed the digital tools/media identified within the strategy. The limited sources of funding and time constraints did not enable this to take place.

The pre- and post-questionnaire had the potential danger of having acquiescence bias that limits the credibility of responses as all the statements mentioned favoured digital methods over non-digital methods. The bias could be caused by the fact that respondents sometimes are inclined to agree with statements to be polite and avoid conflict so the answers might not reflect the students' actual thoughts. However, phrasing the main question so that it asked if the respondent agree or disagree before mentioning the statement reduced the risk of bias. Furthermore, the fact that the majority disagreed and felt neutral towards some statements reduced the chance of having acquiescence bias because of the leading nature of the questions.

Finally, evaluation of the Tablet PC could have been explored further if case studies were undertaken with academics and practitioners, but time constrains within the PhD and the limited number of Tablet PCs provided by HP meant that the Tablet PC could only be evaluated effectively by one group, which restricted evaluation by academics and practitioners.

\subsection{Recommendations for Future Work}

Although this research has investigated the potential for a totally digital strategy of industrial design education within the duration of the $\mathrm{PhD}$ research, further work could be implemented. This research validated the front-end digital tools/media employed within the DID strategy by undertaking the Tablet PC case study with final year students. However, further work could include undertaking practice-based research to evaluate the use of the entire DID strategy when designing products. The evaluation could also be extended by including case studies that employ the DID strategy with practitioners and students.

Another suggestion for future work would be to undertake a long-term case study that lasts for the entire duration of an industrial design course to evaluate the use of the Tablet PC in 
concept generation more effectively. This would enable students to maximise the use of the Tablet PC within their design practice, enabling a comparison of use with the paper-based sketching that most students were so dependent on. In addition, the use of the Tablet PC within professional practice along with the effect of the Tablet PC on design thinking and creativity could be investigated further.

Last but not least, to investigate the capabilities of post-PC devices to support concept generation through sketching as they could potentially overcome some of the problems identified when using the Tablet PC for sketching.

\subsection{Conference Presentations and Publications}

The credibility of the PhD research has been supported by exposing the findings to peer review at a number of international conferences and through academic journal papers. The author presented the research at the following conferences:

- Science, Technology, Engineering and Mathematics (STEM) Pedagogy Research Methods, 30 June 2009, engCETL, Loughborough University, UK.

- The Fourth International Conference on Design Principles and Practices, 13-15 February 2010, University of Illinois at Chicago, Chicago, USA.

- HP Innovations in Education Worldwide Summit, 22-24 February 2010, San Francisco, California, USA.

- The Inaugural Loughborough Design School Research Student (DeSReS) Conference, 16 April 2010, Loughborough Design School, Loughborough University, UK.

In addition, papers were published in the following conferences proceedings and academic journals:

- AL-DOY, N. \& EVANS, M. 2009. The development of a curriculum for the study of digital industrial design. Science, Technology, Engineering and Mathematics (STEM) Pedagogy Research Methods Symposium. Loughborough, UK.

- AL-DOY, N. \& EVANS, M. 2009. Towards a totally digital industrial design curriculum. ICSID Design Education Conference: Design Difference - Design Education 2050. Temasek Polytechnic, Singapore: International Council of Societies of Industrial Design. 
- AL-DOY, N. \& EVANS, M. 2010. The development of a curriculum for the study of digital industrial design. Design Principles \& Practices: An International Journal, 4, 195-217.

- AlDOY, N. \& EVANS, M. 2011. A review of digital industrial and product design methods in UK higher education. The Design Journal, 14.

\subsection{Author's Email Address}

nooraldoy@gmail.com 


\section{REFERENCES}

3DCONNECTION. 2010. What is a 3D mouse? [Online]. Available: http://www.3dconnexion.com/products/what-is-a-3d-mouse.html [Accessed 19 February 2010].

3DCONNECTION. 2011. Product overview [Online]. Available: http://www.3dconnexion.co.uk/buy/shop.html [Accessed 7 February 2011].

ACER. $2011 . \quad$ Iconia Tab [Online]. Available: http://www.acer.co.uk/ac/en/GB/content/iconia-tab-a500 [Accessed 15 June 2011].

ADOBE. $2011 . \quad$ Adobe Ideas [Online]. Available: http://www.adobe.com/products/adobeideas/ [Accessed 17 June 2011].

AMERICAN HERITAGE DICTIONARIES 2000. The American Heritage Dictionary of the English Language. 4th ed.: Houghton Miffin Company.

AMIT, G. 2010. The definition of industrial design? It's right there in the title. Available: http://www.core77.com/reactor/08.06_amit.asp [Accessed 10 July 2010].

ANDERL, R. \& MENDGEN, R. 1995. Parametric design and its impact on solid modeling applications. The third ACM symposium on Solid modeling and applications. New York, USA.

ANDERSON, E. 2005. Visualization in design: Is what we preach being practiced? Exploring visual intelligence and some realities about our tools and how we use them. Eastman IDSA National Education Symposium Proceedings. Virginia: Industrial Designers Society of America.

ANDREASEN, M. M. 1994. Modelling - the language of the designer. Journal of Engineering Design, 5.

ANOTO. 2010a. Digital pen. Available: http://www.anoto.com/the-pen-2.aspx [Accessed 30 October 2010].

ANOTO. 2010b. Transfer data from pen. Available: http://www.anoto.com/transfer-datafrom-pen-2.aspx [Accessed 30 October 2010].

APPLE. 2011. iPad: The best way to experience the web, email, photos and video. Hands down. [Online]. Available: http://www.apple.com/uk/ipad/features/ [Accessed 3 January 2011].

ARCHER, B. 1992. As complex as ABC. In: ROBERTS, P., ARCHER, B. \& BAYNES, K. (eds.) Modelling: The language of designing. Loughborough: Loughborough University.

ARCHER, B. \& ROBERTS, P. 1992. Design and technological awareness in education. In: ROBERTS, P., ARCHER, B. \& BAYNES, K. (eds.) Modelling: The language of designing. Loughborough: Loughborough University.

ARCHER, L. B. 1965. Systematic method for designers. In: CROSS, N. (ed.) Developments in design methodology. Chichester: Wiley.

ATKINSON, P. 2008. A bitter pill to swallow: the rise and fall of the tablet computer. Design Issues, 24, 3-25.

AUTODESK. 2011a. Autodesk Maya [Online]. Available: http://usa.autodesk.com/adsk/servlet/pc/index?sitelD=123112\&id=13583239 [Accessed 7 February 2011].

AUTODESK. 2011b. Autodesk SketchBook Pro [Online]. Available: http://usa.autodesk.com/adsk/servlet/pc/index?id=6848332\&sitelD $=123112$ [Accessed 17 June 2011].

AUTODESK. 2011c. Autodesk SketchBook Pro: Autodesk SketchBook Pro for iPad [Online]. Available: 
http://usa.autodesk.com/adsk/servlet/pc/item?sitelD=123112\&id=15119465\&previ ew=1 [Accessed 17 June 2011].

AUTODESK. 2011d. SketchBook Mobile Express: Experience Sketching on-the-go [Online]. Available: http://m.autodesk.com/sketchbook/sketchbook-mobilex.html [Accessed 17 June 2010].

BAE, S.-H., BALAKRISHNAN, R. \& SINGH, K. 2008. ILoveSketch: as-natural-as-possible sketching system forcreating 3D curve models. 21st Annual ACM symposium on User Interface Software and Technology (UIST). California, USA.

BASA, I. \& SENYAPIH, B. 2005. The (in)secure position of the design jury towards computer generated presentations. Design Studies, 26, 257-270.

BASIT, T. N. 2003. Manual or electronic? The role of coding in qualitative data analysis. Educational Research, 45, 143-154.

BASKINGER, M. 2008. Pencils before pixels: A primer in hand-gnerated sketching. Interactions, 15, 28-36.

BATES, D. J. \& PEDGLEY, O. F. 1998. An industrial design team's approach to engineering design. In: HEPBURN, C. \& HARRIS, D. (eds.) IMC-15: Proceedings of the Fifteenth Conference of the Irish Manufacturing Committee. Jordanstown: University of Ulster.

BAXTER, M. 1995. Product design: a practical guide to systematic methods of new product development, London, Chapman \& Hall.

BAXTER, P. \& JACK, S. 2008. Qualitative case study methodology: study design and implementation for novice researchers. The Qualitative Report, 13, 544-559.

BAYNES, K. 1992. The ethics of representation. In: ROBERTS, P., ARCHER, B. \& BAYNES, K. (eds.) Modelling: The language of designing. Loughborough: Loughborough University.

BEETHAM, H. \& SHARPE, R. 2007. An introduction to rethinking pedagogy for a digital age. In: BEETHAM, H. \& SHARPE, R. (eds.) Rethinking Pedagogy for a Digital Age. London: Routledge.

BELL, L. L. 2010. CAD and virtual prototyping software: continuous development in a challenging economy. Available: http://www.conceptsnrec.com/ConceptsNREC/media/Articles/2010\%20Articles/NA SA_tech_briefs_Jan-2010.pdf [Accessed 20 October 2010].

BENJAMIN GOTOW, J. 2010. Layers for iPad [Online]. Available: http://www.layersforipad.com/ [Accessed 17 June 2011].

BILDA, Z. \& DEMIRKAN, H. 2003. An insight on designers' sketching activities in traditional versus digital media. Design Studies, 24, 27-50.

BLACKBERRY. 2011. BlackBerry App World [Online]. Available: http://appworld.blackberry.com/webstore/search/sketch?lang=en [Accessed 15 June 2011].

BLOCH, A. 2004. Doing social surveys. In: SEALE, C. (ed.) Researching society and culture. 2nd ed. ed. London: SAGE.

BODKER, S. 1998. Understanding representation in design. Human-Computer Interaction, 13, 107-125.

BORDEGONI, M., COLOMBO, G. \& FORMENTINI, L. 2006. Haptic technologies for the conceptual and validation phases of product design. Computers \& Graphics, 30, 377390.

BOURQUE, L. B. \& FIELDER, E. P. 2003. The survey kit. Vol. 3. How to conduct selfadministered and mail surveys, London, Sage.

BRUNO, F. \& MUZZUPAPPA, M. 2010. Product interface design: a participatory approach based on virtual reality. International Journal of Human-Computer Studies, 68, 254269. 
BRYMAN, A. 2006. Integrating quantitative and qualitative research: how is it done? [Online]. SAGE. Available: http://qrj.sagepub.com/content/6/1/97.full.pdf+html [Accessed 29 July 2010].

BUCOLO, S. \& BRERETON, M. 2004. Design activity within immersive design environments. In: AGGeR ERIKSEN, M., MALMBORG, L. \& NIELSEN, J. (eds.) Computers in Art and Design Education Conference, CADE2004. Denmark.

BURTON, M. J. 2005. Design for rapid manufacture : developing an appropriate knowledge transfer tool for industrial designers Ph.D. thesis, Loughborough University.

CAPLAN, R. 1969. Design in America: selected work by members of the Industrial Designers Scoiety of America, McGraw-Hill.

CATALANO, C. E., FALCIDIENO, B., GIANNINI, F. \& MONTI, M. 2002. A survey of computeraided modeling tools for aesthetic design. Journal of Computing and Information Science in Engineering, 2, 11-20.

CHAPMAN, C. n.d. A strategy for the introduction of 3D CAD into industrial design courses [Online]. Available: http://www.agocg.ac.uk/reports/graphics/26/node3.htm [Accessed 13 November 2008].

CHAPMAN, N. \& CHAPMAN, J. 2007. Digital Media Tools, Chichester, John Wiley.

CHARLESWORTH, C. 2007. Student use of virtual and physical modelling in design development - an experiment in 3D design education. The Design Journal, 10, 35-45.

CHEN, H.-H., YOU, M. \& LEE, C.-F. 2003. The sketch in industrial design process. The 6 th Asian Design Conference. Japan.

CHEN, K. \& OWEN, C. L. 1998. A study of computer-supported formal design. Design Studies, 19, 331-359.

CHENG, N. Y.-W. 2004. Stroke sequence in digital sketching. 22nd eCAADe Copenhagen, Denamark.

CHENG, N. Y.-W. \& MCKELVEY, A. 2005. Learning design with digital sketching: copying graphic processes from animation and storyboards. Computer Aided Architectural Design Futures, 6, 291-300.

CHIN, C. S. 2007. Use of SketchBook Pro with Tablet PC (Tab-Sketch) as a design thinking tool in the teaching and learning of Design and Technology. Design and Technology Association Education \& International Research Conference 2007. University of Wolverhampton: DATA.

CHOI, S. H. \& CHAN, A. M. M. 2003. A layer-based virtual prototyping system for product development. Computers in Industry, 51, 237-256.

CIL, E. \& PAKDIL, O. 2007. Design instructor's perspective on the role of computers in architectural education: a case study. Middle East Technical University Journal of the Faculty of Architecture, 24, 123-136.

COMPANY, P., CONTERO, M., VARLEY, P., ALEIXOS, N. \& NAYA, F. 2009. Computer-aided sketching as a tool to promote innovation in the new product development process. Computers in Industry, 60, 592-603.

COOPER, R. \& PRESS, M. 1995. The design agenda: a guide to successful design managment, Chichester, Wiley.

CORE 77. 2007. Difference between product design and industrial design. [Online]. Available: http://boards.core77.com/viewtopic.php?t=12461

[Accessed 19 July 2010].

COUNCIL FOR NATIONAL ACADEMIC AWARDS 1992. Technological change and industrial design education: a review of changing practices on industrial and product design courses in UK higher education, London, Council for National Academic Awards.

COYNE, R., PARK, H. \& WISZNIEWSKI, D. 2002. Design devices: digital drawing and the pursuit of difference. Design Studies, 23, 263-286. 
CRESWELL, J. W. 2003. Research design : qualitative, quantitative, and mixed method approaches, London, SAGE.

CRESWELL, J. W. 2009. Research design : qualitative, quantitative, and mixed methods approaches, Los Angeles, SAGE.

CRESWELL, J. W. \& CLARK, V. L. P. 2007. Designing and conducting mixed methods research, Thousand Oaks, California, Sage.

CROSS, N. 2007. Designerly ways of knowing, London, Springer.

CULLEN, C. D., HALLER, L. \& INDUSTRIAL DESIGNERS SOCIETY OF AMERICA 2004. Design secrets : products $2: 50$ real-life projects uncovered, Gloucester, Rockport

CURRANO, R. \& LEIFER, L. 2009. Understanding idealogging: The use and perception of logbooks within a capstone engineering design course. International Conference on Engineering Design, ICED 09. Stanford, USA.

DAVIES, M. B. 2007. Doing a successful research project : using qualitative or quantitative methods Basingstoke, Palgrave Macmillan.

DELACRUZ, E. 2009. Old world teaching meets the new digital cultural creatives. The International Journal of Art \& Design Education, 28, 261-268.

DENSCOMBE, M. 2007. The good research guide: for small-scale social research projects, New York, Open University Press.

DORTA, T. 2008. Point and sketch: collaboration in the hybrid ideation space [Online]. Available: $\quad$ http://www.hybridlab.umontreal.ca/documents/21-IHM2008.pdf [Accessed 30 July 2010].

DORTA, T. S., PÈREZ, E. \& LESAGE, A. 2008. The ideation gap:: hybrid tools, design flow and practice. Design Studies, 29, 121-141.

DSIR 1963. Engineering Design London, HMSO.

DUMAS, A. 2002. Theory and practice of industrial design. Available: http://www.urenio.org/tools/en/Industrial_Design.pdf [Accessed 10 July 2010].

E-PENS. 2010a. Mobile notes [Online]. Available: http://e-pens.com/mobile_notes.htm [Accessed 30 November 2010].

E-PENS. 2010b. Mobile notes: remotely capture, save and convert handwritten notes to editable text. Available: http://epens.com/downloads/Mobile\%20Notes\%20High\%20Res.pdf [Accessed 30 Novemeber 2010].

EDWARDS, A. \& TALBOT, R. 1999. The hard-pressed researcher: a research handbook for the caring professions, London, Longman.

EISSEN, K. \& STEUR, R. 2007. Sketching: drawing techniques for product designers, Amesterdam, BIS.

EPPINGER, S. D., FINE, C. H. \& ULRICH, K. T. 1990. Interdisciplinary product design education. IEEE Transactions on Engineering Management, 37, 301-305.

EVANS, M. 1992. Model or prototype which, when and why? International Conference on Design and Technology Education Research and Curriculum Development Loughborough University.

EVANS, M. 1998. The potential of computer aided industrial design to act as a catalyst for greater professional collaboration. In: WILDEMUTH, B. M. (ed.) ASIS Midyear Collaboration Across Boundaries: Theories, strategies, and Technology. Orlando.

EVANS, M., WALLACE, D., CHESHIRE, D. \& SENER, B. 2005. An evaluation of haptic feedback modelling during industrial design practice. Design Studies, 26, 487-508.

EVANS, M. A. 2002. The integration of rapid prototyping within industrial design practice. Ph.D. thesis, Loughborough University.

EVANS, M. A. 2004. An investigation into the capabalities of a virtual workshop. Journal of Design and Technology Education, 9, 6-13. 
EVANS, M. A. \& CAMPBELL, R. I. 2003. A comparative evaluation of industrial design models produced using rapid prototyping and workshop-based fabrication techniques. Rapid Prototyping, 9, 344-351.

EVANS, M. A. \& WORMALD, P. W. 1993. The future role of virtual and phyisical modelling in industrial design. International Conference on Design and Technology Educational Research and Curriculum Development. Loughborough Universty.

FABER, C. H. Year. Digital drawing tablet to traditional drawing on paper: a teaching studio comparison. In: IASDR, 18-22 September 20092009 Seoul. 2485-2492.

FINK, A. 2003. The survey kit. Vol. 1. The survey handbook, London, Sage.

FINNEGAN, R. 1996. Using documents. In: SAPSFORD, R. \& JUPP, V. (eds.) Data collection and analysis. London: Sage.

FISH, J. C. 1996. How sketches work: a cognitive theory for improved system design. Ph.D. thesis, Loughborough University.

FOSTER, P. 1996. Observational research. In: SAPSFORD, R. \& JUPP, V. (eds.) Data collection and analysis. London: Sage.

FOWLER, F. J. 2002. Survey research methods, London, Sage.

FOXIT SOFTWARE COMPANY. 2004. Bitmap artwork versus vector artwork. Available: http://www.cbec.rutland.sch.uk/students/documents/bitmapvvectors.pdf [Accessed 30 July 2010].

FRAUNHOFER MAGAZINE 2000. Information technology: digital product design. Fraunhofer. German: Fraunhofer-Gesellschaft.

FROLIK, J. \& ZURN, J. B. 2004. Evaluation of Tablet PCs for engineering content development and instruction. American Society for Engineering Education Annual Confeence \& Exposition. Salt Lake City, Utah.

GEMSER, G. \& LEENDERS, M. A. A. M. 2001. How integrating industrial design in the product development process impacts on company performance. Journal of Product Innovation Management, 18, 28-38.

GIBBS, G. R. 2002. Qualitative data analysis: exploration with NVivo, Buckingham, Open University Press.

GILLHAM, B. 2000. The research interview, London, Continuum.

GOLDSCHMIDT, G. \& PORTER, W. L. 2003. Introduction. In: GOLDSCHMIDT, G. \& PORTER, W. L. (eds.) Design representation. New York: Springer.

GOOGLE. 2011. Android Market [Online]. Available: https://market.android.com/search?q=sketch+tablet+\&so=1\&c=apps [Accessed 15 June 2011].

GREENE, J. C., CARACELLI, V. J. \& GRAHAM, W. F. 1989. Toward a conceptual framework for mixed-methods evaluation designs. Educational Evaluation and Policy Analysis, 11, 255-274.

HAMEL, J., DUFOUR, S. \& FORTIN, D. 1993. Case study methods, London, Sage Publications.

HAMMERSLEY, M. 1992. What's wrong with ethnography? : methodological explorations, London, Routledge.

HANNA, R. \& BARBER, T. 2001. An inquiry into computers in design: attitudes beforeattitudes after. Design Studies, 22, 255-281.

HART, C. 1998. Doing a literature review : releasing the social science research imagination London, SAGE.

HARTMAN, N. W. 2004. Implementing surface modeling into engineering design graphics curricula: Is there room for more than just solids? The Egineering Design Graphics Division of The American Society for Enginerring Education 59th Annual Midyear Meeting. Williamsburg, Virginia. 
HERTENSTEIN, J. H., PLATT, M. B. \& VERYZER, R. W. 2005. The impact of industrial design effectiveness on corporate financial performance. Journal of Product Innovation Management, 22, 3-21.

HEWLETT PACKARD. 2010. HP EliteBook 2730p Notebook PC. Available: http://h20195.www2.hp.com/V2/GetPDF.aspx/4AA2-1049EEE.pdf [Accessed 10 Nov 2010].

HODGSON, A. R. 2006. Digital design- the potential of computer aided designing in design learning environments. Design and Technology Education: An International Journal, 11, 14-17.

HOEBEN, A. \& STAPPERS, P. J. 2005. Direct talkback in computer supported tools for the conceptual stage of design. Knowledge-Based Systems, 18, 407-413.

HOINVILLE, G. \& JOWELL, R. 1978. Survey research practice, London, Gower.

HOLMES, W. P., AZAM, M. A. \& HILLS, P. C. Year. A preliminary study of the relationship between industrial design and engineering design. In: 1st conference on designing interactive systems: processes, practices, methods, \& techniques, 1995 Michigan, United States. ACM, 105-114.

IDSA \& HUDSPETH, M. 2006. Cadalyst labs review: Alias Studio Tools 13. Available: http://www.cadalyst.com/manufacturing/cadalyst-labs-review-alias-studiotools-1310629?page_id=2 [Accessed 20 February 2010].

IDSKETCHING. 2010. SketchBook Pro on the apple iPad- A review. Available: http://www.idsketching.com/news/sketching-on-the-apple-ipad/ [Accessed 30 July 2010].

INDUSTRIAL DESIGNERS SOCIETY OF AMERICA 2001. Design secrets : products : 50 real-life projects uncovered, Gloucester, Rockport.

INDUSTRIAL DESIGNERS SOCIETY OF AMERICA. 2004. What is ID? [Online]. Available: http://www.idsa.org/absolutenm/templates/?a=88\&z=36 [Accessed 30 October 2007].

INDUSTRIAL DESIGNERS SOCIETY OF AMERICA. 2010. Industrial design: defined [Online]. Available: http://www.idsa.org/content/content1/industrial-design-defined [Accessed 10 July 2010].

INTELLIGENT MEASUREMENTS. 2008. Likert scale \& surveys: best practices [Online]. Available: http://intelligentmeasurement.wordpress.com/2007/11/20/likert-scalesurveys-best-practices/ [Accessed 25 June 2008].

INTERNATIONAL COUNCIL OF SOCIETIES OF INDUSTRIAL DESIGN. 2010. Definition of design [Online]. Available: http://www.icsid.org/about/about/articles31.htm [Accessed 20 June 2010].

ISENBURG, M. \& ALLIEZ, P. 2002. Compressing polygon mesh geometry with parallelogram predication. IEEE Visualization.

IVE, J. 2011. Apple Special Event [Online]. Available: http://www.youtube.com/watch?v=qQGOXfU-bFs [Accessed 17 June 2011].

JOBS, S. 2011a. Apple Special Event [Online]. Available: http://www.youtube.com/watch?v=qQGOXfU-bFs [Accessed 17 June 2011].

JOBS, S. 2011b. Worldwide Developers Conefernce (WWDC Keynote Address) [Online]. Available: http://www.youtube.com/user/Apple\#p/u/0/3lsMFzxtSz8 [Accessed 17 June 2011].

JONES, J. C. 1963. A method of systematic design. In: CROSS, N. (ed.) Developments in design methodology. Chichester: Wiley.

JONES, J. C. 1992. Design methods, New York, Wiley.

JONSON, B. 2005. Design ideation: the conceptual sketch in the digital age. Design Studies, 26, 613-624. 
KELLY, M. 2004. Research design and proposals. In: SEALE, C. (ed.) Researching society and culture. 2nd ed. ed. London: Sage.

KIRK, J. \& MILLER, M. L. 1986. Reliability and validity in qualitative research, London, Sage.

KOLKO, J. 2005. New techniques in industrial design education The 6th International Conference of the European Academy of Design. Bremen, Germany.

KONIGI. 2010. iPad sketching. Available: http://konigi.com/notebook/ipad-sketching [Accessed 30 July 2010].

KOTLER, P. \& RATH, G. A. 1993. Design: a powerful but neglected strtegic tool. Journal of Business Strategy, 5, 16-21.

KOUTAMANIS, A. 2005. Sketching with digital pen and paper. Computer Aided Architectural Design Futures, 6, 321-330.

KRUEGER, R. A. \& CASEY, M. A. 2000. Focus groups : a practical guide for applied research Thousand Oaks, Sage Publications.

KRUEGER, R. A. \& CASEY, M. A. 2009. Focus groups: a practical guide for applied research, London, Sage.

KUHNEN, C. 2009. T.Splines: Industrial design with T-Splines, NURBS, and polygons. Available: www.tsplines.com/resources/rhino/T-SplinesInClassroom.pdf [Accessed 23 November 2009].

KUMAR, R. 2005. Research methodology : a step-by-step guide for beginners, London, SAGE.

KUMAR, R. 2008. Research methodology, New Delhi, S.B. Nangia for APH Publishing Corporation

KVAN, T., MARK, E., OXMAN, R. \& MARTENS, B. 2004. Ditching the dinosaur: Redefining the role of digital media in education. International Journal of Design Computing, 7.

LAU, H. Y. K., MAK, K. L. \& LU, M. T. H. 2003. A virtual design platform for interactive product design and visualization. Journal of Materials Processing Technology, 139, 402-407.

LEE, B. 2006. From cognitive artifacts to social artifacts: The ideas design ecology. User Interface Software and Technology (UIST) Conference Montreux, Switzerland.

LEE, L.-C. \& WEI, W.-J. 2007. Behavior analysis between paper sketching and interactive pen display sketching in collaborative design 11th International Conference on Computer Supported Cooperative Work in Design.

LEGO. 2011. Lego Digital Designer [Online]. Available: http://ldd.lego.com/default.aspx [Accessed 5 June 2011].

LIM, S., QIN, S. F., PRIETO, P., WRIGHT, D. \& SHACKLETON, J. 2004. A study of sketching behaviour to support free-form surface modelling from on-line sketching. Design Studies, 25, 393-413.

LITOSSELITI, L. 2003. Using focus groups in research, New York, Continuum.

LOFTHOUSE, V. 2004. Investigation into the role of core industrial designers in ecodesign projects. Design Studies, 25, 215-227.

LOFTHOUSE, V. A. 2001. Facilitating ecodesign in an industrial design context: an exploratory study. Ph.D. thesis, Cranfield University.

LOGAN, G. D. \& RADCLIFFE, D. F. 2003. Impromptu prototyping and artefacting: representing design ideas through things at hand, actions, and talk. In: GOLDSCHMIDT, G. \& PORTER, W. L. (eds.) Design representation. New York: Springer.

LONGSON, T. 1999. Computers in art and design education - past, present and future [Online]. California: California State University. Available: http://old.siggraph.org/education/conferences/GVE99/papers/GVE99.T.Longson.pdf [Accessed 20 March 2010].

LOOSSCHILDER, G. 1997. A picture tells a thousan words. Testing product design concepts using computer-aided design. The Design Journal, 0, 41-57.

LUCKMAN, J. 1967. An approach to the management of design. In: CROSS, N. (ed.) Developments in design methodology. Chichester: Wiley. 
LYNN, D. 2006. Automotive design education embraces the digital age. Eastman IDSA National Education Symposium Texas: Industrial Designers Society of America.

MAHONEY, D. 2000. Hands-on modeling. Computer Graphics World, 23, 13-14.

MALINS, J., PENGELLY, J. \& MARSHALL, J. 2007. The post disciplinary digital practitioner. International conference on engineering and product design education: shaping the future? Northumbria Upon Tyne: Northumbria University.

MARCUS, G. H. 2002. What is design today?, New York, Harry N. Abrams.

MARK, E., MARTENS, B. \& OXMAN, R. 2001. The ideal computer curriculum. The 19th Education for Computer Aided Architectural Design in Europe (ECAADE) Conference. Helsinki, Finland.

MARX, J. 2000. A proposal for alternative methods for teaching digital design. Automation in Construction, 9, 19-35.

MAVRIKIOS, D., KARABATSOU, V., PAPPAS, M. \& CHRYSSOLOURIS, G. 2007. An efficient approach to human motion modelling for the verification of human-centric product design and manufacturing in virtual environments. Robotics and ComputerIntegrated Manufacturing, 23, 533-543.

MAXWELL, J. A. 1996. Qualitative research design: an interactive approach, London, Sage.

MCALPINE, H., HICKS, B. J., HUET, G. \& CULLEY, S. J. 2006a. An investigation into the use and content of the engineer's logbook. Design Studies, 27, 481-504.

MCALPINE, H. C., HICKS, B. J. \& CULLEY, S. J. 2006b. A review of state-of-the-art technologies for supporting a designer's electronic logbook. International Design ConferenceDesign 2006. Dubrovnik, Croatia.

MCCULLOUGH, M. 1998. Abstracting craft: the practiced digital hand, USA, MIT Press.

MCGOWN, A., GREEN, G. \& RODGERS, P. A. 1998. Visible ideas: information patterns of conceptual sketch activity. Design Studies, 19, 431-453.

MCGREGOR, N. 2008. What is 3D polygon modeling? Available: http://www.suite101.com/content/what-is-3d-polygon-modeling-a73217 [Accessed 23 November 2009].

MCLAREN, S. V. 2007. Exploring perceptions and attitudes towards teaching and learning manuael technical drawing in a digital age. International Journal of Technology and Design Education, 1, 167-188.

MENEZES, A. \& LAWSON, B. 2006. How designers perceive sketches. Design Studies, 27, 571585.

MERRIAM-WEBSTER ONLINE DIRCTIONARY. 2009. Poygon [Online]. Available: http://www.merriam-webster.com/dictionary/polygon [Accessed 23 Novemeber 2009].

MERRIAM-WEBSTER ONLINE DIRCTIONARY. 2010. Methodology [Online]. Available: http://www.merriam-webster.com/dictionary/methodology [Accessed 22 July 2010].

MICROSOFT. 2004. University improves collaborative hands-on learning with Tablet PC projects.

Available: http://download.microsoft.com/documents/customerevidence/7147_MIT_Tablet_C S.doc [Accessed 30 August 2009].

MIDDLE EAST TECHNICAL UNIVERSITY. n.d. Designer's log-book [Online]. Available: http://www.eee.metu.edu.tr/ design/logbook.htm [Accessed 12 July 2011].

MILES, M. B. \& HUBERMAN, A. M. 1994. Qualitative data analysis: an expanded sourcebook London, Sage.

MOODY, S. 1980. The role of industrial design in technological innovation. Design Studies, 1, 329-339.

MOORE, N. 2006. How to do research : a practical guide to designing and managing research projects, London, Facet. 
MOTOROLA. 2011. Motorola Xoom [Online]. Available: http://www.motorola.com/staticfiles/Consumers/xoom-android-tablet/usen/experience.html\#/specs [Accessed 15 June 2011].

MUNSON, S. 2004. The role of computing technologies in product design and product design education. 2nd International Engineering and Product Design Education Conference EDPE04. Delft, The Netherlands.

NAVEIRO, R. M. \& DE SOUZA PEREIRA, R. C. 2008. Design education in Brazil. Design Studies, 29, 304-312.

NEALE, P., THAPA, S. \& BOYCE, C. 2006. Preparing a case study: A guide for designing and conducting a case study for evaluation input. Pathfinder International.

NEUMAN, W. L. 2005. Social research methods : qualitative and quantitative approaches, Boston, Allyn and Bacon.

NEWMAN, S. T. \& NASSEHI, A. 2007. Universal Manufacturing Platform for CNC Machining. CIRP Annals - Manufacturing Technology, 56, 459-462.

NIKE. 2011. NIKEiD [Online]. Available: http://store.nike.com/gb/en_GB/?cp=EUID_KW_NS09_UK_Google_B_Category\&l=s hop, nikeid [Accessed 5 June 2011].

NING, H., WILLIAMS, J. R., SLOCUM, A. H. \& SANCHEZ, A. 2004. Inkboard- Tablet PC enabled design-oriented learning. Seventh International Conference on Computers and Advanced Technology in Education (CATE 2004). Kauai, Hawaii, USA.

NOTESLATE. 2011. NoteSlate [Online]. Available: http://www.noteslate.com/products.htm [Accessed 15 June 2011].

OEHLBERG, L., LAU, K. \& AGOGINO, A. 2009. Tangible interactions in a digital age: medium and graphic visualization in design journals. Artificial Intelligence for Engineering Design, Analysis and Manufacturing, 23, 237-249.

OISHI, S. M. 2003. The survey kit. Vol. 5. How to conduct in-person interviews for surveys, London, Sage.

OLOFSSON, E. \& SJÖLÉN, K. 2005. Design sketching, Klippan, KEEOS Design.

OTTO, K. \& WOOD, K. 2001. Product design : techniques in reverse engineering and new product development New Jersey, Prentice Hall.

OXFORD DICTIONARIES 2005. The New Oxford America Dictionary. 2nd ed. New York: Oxford University Press.

OXMAN, R. 2006. Special Issue of Design Studies on Digital Design. Design Studies, 27, 225227.

OXMAN, R. 2008. Digital architecture as a challenge for design pedagogy: theory, knowledge, models and medium. Design Studies, 29, 99-120.

PAPITYPES. 2010. Design support [Online]. Available: http://www.rapitypes.com/activitiesdesignsupport.aspx [Accessed 30 November 2010].

PC PRO. 2009. Wacom Bamboo Pen \& Touch review [Online]. Available: http://www.pcpro.co.uk/reviews/peripherals/352492/wacom-bamboo-pen-touch [Accessed 3 January 2011].

$\mathrm{PEI}, \mathrm{E}$. 2009. Building a common language of design representations for industrial designers \& engineering designers. Ph.D. thesis, Loughborough University.

PEI, E., CAMPBELL, I. R. \& EVANS, M. A. 2010. Development of a tool for building shared representations among industrial designers and engineering designers. CoDesign, 6 , 139-166.

PEKTAS, S. T. \& ERKIP, F. 2006. Attitudes of design students toward computer usage in design. International Journal of Technology and Design Education, 16, 79-95.

PENG, C. 2006. In-situ 3D concept design with a virtual city. Design Studies, 27, 439-455.

PIPES, A. 2007. Drawing for designers, London, Laurence King. 
POWELL, D. 1990. Presentation techniques : a guide to drawing and presenting design ideas, London, Orbis.

PRATS, M. \& GARNER, S. 2006. Observations on ambiguity in design sketches. TRACEY the Online Journal of Contemporary Drawing Research, 1-20.

PRATS, M., LIM, S., JOWERS, I., GARNER, S. W. \& CHASE, S. 2009. Transforming shape in design: observations from studies of sketching. Design Studies, 30, 503-520.

PRENSKY, M. 2001. Digital natives, digital immigrants. On the Horizon, MCB University Press, 9, 1-6.

PRIETO, P. A., WRIGHT, D. K. \& QIN, S. F. 2003. A novel method for early formal developments using computer aided design and rapid prototyping technology. Journal of Engineering Manufacture, 217, 695-698.

PRODUCT DESIGN FORUMS. 2007. Log Book/Sketching Folio [Online]. Available: http://www.productdesignforums.com/topic/7047-log-book-sketching-folio/ [Accessed 12 July 2011].

PUGH, S. 1991. Total design: integrated methods for successful product engineering, Harlow, Pearson Education

RADCLYFFE-THOMAS, N. 2008. White Heat or Blue Screen? Digital Technology in Art \& Design Education. International Journal of art \& Design Education, 27, 158-167.

RAIZLABS CORPORATION. 2011. SketchPad HD [Online]. Available: http://itunes.apple.com/us/app/sketchpad-hd/id364736130?mt $=8$ [Accessed 17 June 2011].

RAMDUNY-ELLIS, D., HARE, J., DIX, A. \& GILL, S. 2008. Exploring physicality in the design process. Undisciplined! Design Research Society Conference 2008. Sheffield: Sheffield Hallam University.

REJA, U., MANFREDA, K. L., HLEBEC, V. \& VeHOVAR, V. 2003. Open-ended vs Close-ended Questions in Web Questionnaires. In: FERLIGOJ, A. \& MRVAR, A. (eds.) Development in Applied Statistics. Lujbljana: University of Ljubljana.

ROBERTSON, S. I., CALDER, J., FUNG, P., JONES, A. \& O'SHEA, T. 1995. Computer attitudes in an English secondary school. Computers \& Education, 24, 73-81.

ROBSON, C. 1993. Real world research: a resource for social scientists and practitionerresearchers Oxford, Blackwell.

ROBSON, C. 2002. Real world research: a resource for social scientists and practitionerresearchers, Oxford, Blackwell.

ROMER, A., PACHE, M., WEIFLHAH, G., LINDEMANN, U. \& HACKER, W. 2001. Effort-saving product representations in design--results of a questionnaire survey. Design Studies, 22, 473-491.

RONNING, O. 2008. Sketching part 2: paper in a digital world. Available: http://www.artefactgroup.com/\#/content/sketching-part-2-paper-in-a-digital-world [Accessed 15 July 2009].

SADDLER, H. J. 2001. Design: Understanding design representations. Ineractions, 8, 17-24.

SALDANA, J. 2009. The coding manual for qualitative researchers, Los Angeles, SAGE.

SAMSUNG. 2011. Samsung Galaxy Tab [Online]. Available: http://www.samsung.com/uk/galaxytab/ [Accessed 15 June 2011].

SANTOS, D. M. C., PERTENCE, A. E. M. \& CETLIN, P. R. 2005. The development of 3D models through rapid prototyping concepts. Journal of Materials Processing Technology, 168, 270-272.

SASS, L. \& OXMAN, R. 2006. Materializing design: the implications of rapid prototyping in digital design. Design Studies, 27, 325-355.

SCHILLER, P. 2011. Apple Special Event [Online]. Available: http://www.youtube.com/watch?v=qQGOXfU-bFs [Accessed 17 June 2011]. 
SCHODEK, D., BECHTHOLD, M., GRIGGS, K., KAO, K. M. \& STEINBERG, M. 2005. Digital design and manufacturing: CAD/CAM applications in architechture and design, Hoboken, New Jersey, John Wiley \& Sons.

SCHONFIELD, W. 1996. Survey sampling. In: SAPSFORD, R. \& JUPP, V. (eds.) Data collection and analysis. London: Sage.

SEALE, C. 2004. Validity, reliability and the quality of research. In: SEALE, C. (ed.) Researching society and culture. 2 nd ed. ed. London: Sage.

SENER, B. 2004. Enhancing the form creation capabilities of digital industrial design tools. Ph.D. thesis, Loughborough University.

SENER, B. \& WORMALD, P. 2001. The future of computer use in product design. CADE conference, computers in art and design education: Digital creativity crossing the border. Glasgow

SENSABLE TECHNOLOGIES. 2006. FreeForm customer spotlight. 19 February 2010. Available: http://www.sensable.com/documents/Galleries/CaseStudies/CustSpotlight_Gillette Nov2006.pdf.

SENSABLE TECHNOLOGIES. 2010a. $3 D$ design \& modeling [Online]. Available: http://www.sensable.com/industries-design-model.htm [Accessed 19 February 2010].

SENSABLE TECHNOLOGIES. 2010b. SensAble case studies \& customer spotlights [Online]. Available: http://www.sensable.com/industries-case-studies.htm [Accessed 19 February 2010].

SEQUIN, C. H. 2005. CAD tools for aesthetic engineering. Computer-Aided Design, 37, 737750.

SHIH, N.-J. 2006. RP-aided computer modeling for architectural education. Computers \& Graphics, 30, 137-144.

SHIH, R. H. 2009. AutoCAD 2010 Tutorial- Second Level: 3D Modeling, Kansas, USA, Schroff Development Corporation.

SHIMIZU, Y., KOJIMA, T., TANO, M. \& MATSUDA, S. 1991. Models \& prototypes : clay, plaster, styrofoam, paper, Tokyo, Graphic-sha Publishing.

SHIN, D. 2009. Exploring digital rapid visualzation in industrial design education. International Conference of Engineering and Product Design Education University of Brighton.

SIEMENS. 2008. Developing innovative, high-tech products 30 percent faster [Online]. Available: http://vmhinternational.com/wpcontent/uploads/2008/11/high_samsung.pdf [Accessed 28 November 2009].

SIEMENS. 2010. New supertrain for Germany: Siemens plans in a 3D laboratory [Online]. Available:

http://www.siemens.com/press/en/presspicture/?press=/en/presspicture/picturesphotonews/2010/pn201006/pn201006-12.htm [Accessed 30 Novemeber 2010].

SILVERMAN, D. 1993. Interpreting qualitative data: methods for analysing talk, text and interaction, London, Sage.

SILVERMAN, D. 2000. Doing qualitative research: a practical handbook, London, Sage.

SILVERMAN, D. 2004. Research and social theory. In: SEALE, C. (ed.) Researching society and culture. 2 nd ed. ed. London: Sage.

SLACK, L. 2006. What is product design? , Mies, RotoVision.

SLAPPENDEL, C. 1996. Industrial design utilization in New Zealand firms. Design Studies, 17, 3-18.

SOKOVIC, M. \& KOPAC, J. 2006. RE (reverse engineering) as necessary phase by rapid product development. Journal of Materials Processing Technology, 175, 398-403.

SOUFI, B. \& EDMONDS, E. 1996. The cognitive basis of emergence: implications for design support. Design Studies, 17, 451-463. 
SPICER, N. 2004. Combining qualitative and quantitative methods. In: SEALE, C. (ed.) Researching society and culture. 2 nd ed. ed. London: Sage.

SVENGREN, L. 1997. Industrial design as a strategic resource: a study of industrial design methods and approaches for companies' strategic development. The Design Journal, $0,3-11$.

SWIFT, B. 1996. Preparing numerical data. In: SAPSFORD, R. \& JUPP, V. (eds.) Data collection and analysis. London: Sage.

TALABA, D., HORV.TH, I. \& LEE, K. H. 2010. Special issue of Computer-Aided Design on virtual and augmented reality technologies in product design. Computer-Aided Design, 42, 361-363.

TANG, H. H., LEE, Y. Y. \& GERO, J. S. 2011. Comparing collaborative co-located and distributed design processes in digital and traditional sketching environments: Atprotocol study using the function-behaviour-structure coding scheme. Design Studies, 32, 1-29.

TASHAKKORI, A. \& TEDDLIE, C. 1998. Mixed methodology : combining qualitative and quantitative approaches, London, SAGE.

TEN ONE DESIGN. 2010. Pogo Sketch for trackpads and touch screens [Online]. Available: http://tenonedesign.com/sketch.php [Accessed 30 July 2010].

THE SUNDAY TIMES. 2006. Report: the next step in brain evolution [Online]. London. Available:

http://entertainment.timesonline.co.uk/tol/arts_and_entertainment/article683193. ece?token=null\&offset=0\&page $=1$ [Accessed 8 August 2010].

TONKISS, F. 2004. Analysing text and speech: content and dicourse analysis. In: SEALE, C. (ed.) Researching society and culture. 2 nd ed. ed. London: Sage.

TOVEY, M. 1989. Drawing and CAD in industrial design. Design Studies, 10, 24-39.

TOVEY, M. 1997. Styling and design: intuition and analysis in industrial design. Design Studies, 18, 5-31.

TOVEY, M., PORTER, S. \& NEWMAN, R. 2003. Sketching, concept development and automotive design. Design Studies, 24, 135-153.

TREK. 2011. Project One [Online]. Available: http://www.trekbikes.com/uk/en/collections/custom_project_one [Accessed 5 June 2011].

UCAS. 2011. Industrial design course search. Available: http://search.ucas.com [Accessed 22 January 2011].

ULIN, P., WASZAK, C. \& PFANNENSCHMIDT, S. 1996. Integrating qualitative and quantitative research. Family Health International's Women's Studies Project Technical Advisory Group Annual Meeting. Raleigh, North Carolina.

ULLMAN, D. G., WOOD, S. \& GRAIG, D. 1990. The importance of drawing in the mechanical design process. Computer \& Graphics, 14, 263-274.

ULRICH, K. T. \& EPPINGER, S. D. 1995. Product design and devlopment, New York, McGrawHill.

ULRICH, K. T. \& EPPINGER, S. D. 2003. Product design and development, Boston, McGrawHill.

UNIVERSITY OF PORTSMOUTH. 2010. BSc (Hons) product design and innovation. Available: http://www.port.ac.uk/courses/coursetypes/undergraduate/BScHonsProductDesign AndInnovation/ [Accessed 22 January 2011].

UNVER, E. 2006. Strategies for the transition to CAD based 3D design education. ComputerAided Design \& Applications, 3, 323-330.

VAN DOREN, H. 1940. Industrial design: a practical guide. New York: McGraw-Hill Book Co.

VAN DOREN, H. 1954. Industrial design : a practical guide to product design and development, New York, McGraw-Hill. 
VAN ELSAS, P. A. \& VERGEEST, J. S. M. 1998. New functionality for computer-aided conceptual design: the displacement feature. Design Studies, 19, 81-102.

VERSTIJNEN, I. M., VAN LEEUWEN, C., GOLDSCHMIDT, G., HAMEL, R. \& HENNESSEY, J. M. 1998. Sketching and creative discovery. Design Studies, 19, 519-546.

WACOM. 2011a. Bamboo Touch: Bringing simplicity to your digital life [Online]. Available: http://www.wacom.eu/index2.asp?pid=294\&lang=en\&spid=3 [Accessed 3 January 2011].

WACOM. 2011b. CINTIQ 21UX- features and benefits [Online]. Available: http://www.wacom.com/cintiq/cintiq-21ux-features-and-benefits.php [Accessed 3 January 2011].

WEIGHTMAN, D. \& MCDONAGH, D. Year. Users connecting with the design process- has the paradigm shifted? In: Eastman IDSA National Education Symposium Proceedings, 2007 San Francisco Industrial Designers Society or America, 271- 277.

WESTIN, S. H. 1998. Computer-aided industrial design. ACM SIGGRAPH Computer Graphics, 32, 49-52.

WILDE. 2011. Arad use Autodesk Moldflow software to design, develop and manufacture top quality precision water meters [Online]. Available: http://wildeanalysis.co.uk/casestudies/autodesk-moldflow-software-designdevelop-manufacture-water-meters [Accessed 7 February 2011].

WILLIS, A., SPEICHER, J. \& COOPER, D. B. 2007. Rapid prototyping 3D objects from scanned measurement data. Image and Vision Computing, 25, 1174-1184.

WILSON, G. D. \& FAUSCETTE, M. 2008. White paper: digital prototyping: Autodesk strengthens competitivness of worldwide SMB manufactures [Online]. Massachusetts: IDC. Available: http://images.autodesk.com/adsk/files/idc_global_white_paper_digital_prototyping .pdf [Accessed 5 March 2010].

WILSON, M. 1996. Asking Questions. In: SAPSFORD, R. \& JUPP, V. (eds.) Data collection and analysis. London: SAGE.

XIN, M., SHARLIN, E. \& SOUSA, M. C. 2008. Napkin sketch- handheld mixed rality 3D sketching. Available: http://pages.cpsc.ucalgary.ca/ mxin/docs/NapkinSketchVRST2008-MX.pdf.

XU, X. W. \& NEWMAN, S. T. 2006. Making CNC machine tools more open, interoperable and intelligent--a review of the technologies. Computers in Industry, 57, 141-152.

YAN, Z., HONGKE, T., LI, G. \& GUANGYU, Z. 2006. Digital technology and digital product design. CAIDCD, 7th international conference on computer-aided industrial design and conceptual design. China: IEEE.

YANG, M.-Y., YOU, M. \& CHEN, F.-C. 2005. Competencies and qualifications for industrial design jobs: implications for design practice, education, and student career guidance. Design Studies, 26, 155-189.

YE, J., CAMPBELL, R. I., PAGE, T. \& BADNI, K. S. 2006. An investigation into the implementation of virtual reality technologies in support of conceptual design. Design Studies, 27, 77-97.

YE, X., LIU, H., CHEN, L., CHEN, Z., PAN, X. \& ZHANG, S. 2008. Reverse innovative design - an integrated product design methodology. Computer-Aided Design, 40, 812-827.

YIN, R. K. 2009. Case study research : design and methods, Los Angeles, SAGE.

Z CORPORATION. 2010. Mechanical design [Online]. Available: http://www.zcorp.com/en/Solutions/Rapid-Prototypes---CAD/spage.aspx [Accessed 30 November 2010].

ZORRIASSATINE, F., WYKES, C., PARKIN, R. \& GINDY, N. 2003. A survey of virtual prototypng techniques for mechanical product development. Proceedings of the Institution of Mechanical Engineers, Part B: Journal of Engineering Manufacture, 217, 513-530. 


\subsection{7/2008 Graduating Student Digital Industrial Design Questionnaire}

Department of Design and Technology

Loughborough University, Leicestershire, UK, LE11 3TU

Loughborough University

\section{Digital Industrial/Product Design Questionnaire}

This is an anonymous questionnaire that will be used as part of a research study aiming to develop a curriculum for the study of digital industrial design (DID). Your honest opinions will be very helpful.

\section{A. Background:}

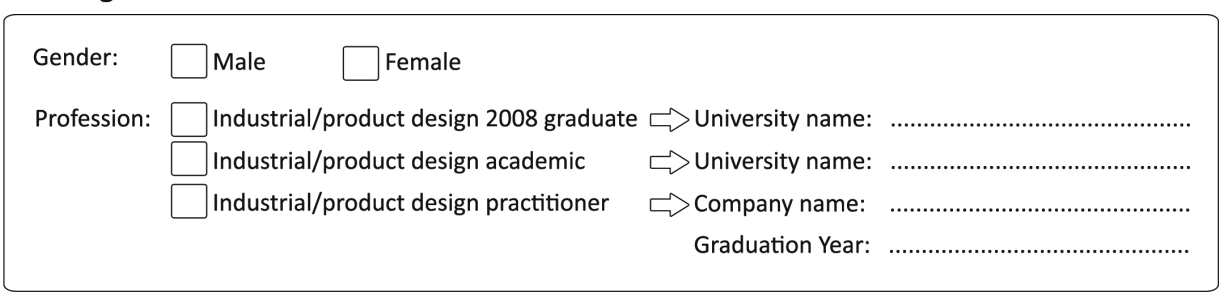

\section{B. Design Methods Usage:}

How often do you use each method when designing a product?

1. Sketches (e.g. 2D side view sketches, 3D perspective sketches, investigative and explorative sketches, explanatory sketches):

1.1 Freehand paper-based sketches (produced on paper using pencils, pens, ink, airbrush, pastels, markers, etc)

1.2 Digital sketches (produced using Alias Sketchbook, Corel Painter, Adobe Photoshop, digitizing tablets, etc)

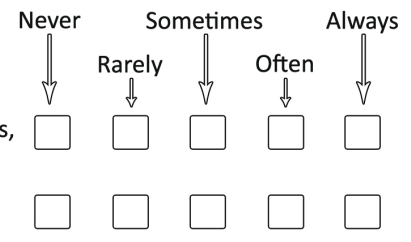

2. Sketch models also known as 'mock up models', 'soft models' and 'development models' (e.g. 2D card models, 3D Styrofoam, wax models):

2.1 Workshop-based sketch models (produced using cutting knife, sanding paper, rule, saw, pencil, etc)

2.2 Digital sketch models (produced using Z Corp rapid prototype machine, Haptic feedback device with Sensable Phantom Freeform system, computer numerical control machines, etc)

3. Appearance models (models that communicates the form only):

3.1 Workshop-based appearance models (produced using conventional workshop techniques)

3.2 Digital appearance models (produced using modelling software, rapid prototyping, computer numerical control machines, etc)

4. Renderings also known as 'presentation drawings' and 'persuasive sketches' (e.g. 2D side view renderings, 3D isometric renderings):

4.1 Manual paper-based renderings (produced using pencils, pens, papers, boards, ink, airbrush, pastels, markers, etc) 
4.2 Computer renderings (produced using Adobe Photoshop, Pro/Engineer, Alias StudioTools, Rhino, Autodesk 3ds Max, etc)

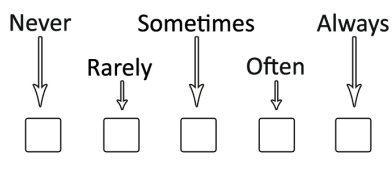

5. Control drawings also known as 'engineering drawing' (e.g. general arrangement, exploded views, cut-away/sections, instructional drawings):

5.1 Manual paper-based control drawings (produced using pencils, pens, papers, ink, rule, protractor, etc)

5.2 Digital control drawings (produced using Pro/Engineer, AutoCAD, SolidWorks, Autodesk 3ds Max, etc)

6. Testing also known as 'analysis' (testing ergonomics, mechanics, electronics, etc):

6.1 Physical testing (using user trials, Breadboard circuits, load testing rigs, etc)

6.2 Digital testing (using simulation, virtual reality, Pro/Engineer Mechninca, Moldflow, Finite Element Analysis (FEA), etc)

7. Prototypes (e.g. appearance prototype, pre-production prototype)

7.1 Workshop-based prototypes (produced using conventional workshop techniques)

7.2 Digital prototypes (produced using rapid prototyping, computer numerical control machines, etc)

\section{Digital Design Tools Usage:}

How do you rate the ease of using of the following digital tools?

1. 2D computer visualisation software (e.g. Alias sketchbook, Corel Painter, Adobe Photoshop)

2. 3D solid modelling CAD software (e.g. Pro/Engineer, SolidWorks, Pro/DESKTOP)

3. 3D surface modelling CAD software (e.g. Rhino, Autodesk Alias Studio)

4. Digitising tablets (e.g. Wacom graphic tablets, Cintiq tablet)

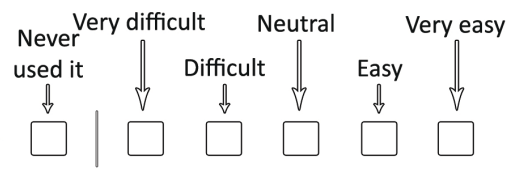

5. Haptic feedback devices (e.g. Sensable Phantom Freeform system)

6. Virtual reality (e.g. head mounted displays, stereographic projection to room size screens) 
7. Digital testing and analysis (using simulation, virtual reality, Pro/Engineer Mechninca, Moldflow, etc)

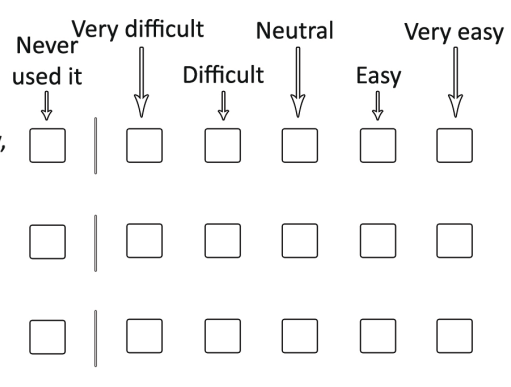

D. Your Use of Digital Methods:

1. To what extent do you employ digital methods in the concept generation stage (creating the product's form and user interfaces)?
$\square 0 \%$
$\square 20 \%$
$40 \%$
$60 \%$
$80 \%$
$100 \%$

2. To what extent do you employ digital methods in the preliminary refinement stage (building soft models of the most promising concepts)?
$\square \%$
$20 \%$
$40 \%$
$60 \%$
$80 \%$
$100 \%$

3. To what extent do you employ digital methods in the further refinement and final concept selection stage (building hard models and making renderings)?
$\square 0 \%$
$\square 20 \%$
$40 \%$
$60 \%$
$80 \%$
$100 \%$

4. To what extent do you employ digital methods in the specification stage (making control drawings of the final concept to enable building prototypes)?
$\square 0 \%$
$\square 20 \%$
$\square 40 \%$
$60 \%$
$80 \%$

\section{E. Thoughts on Employing Digital Techniques:}

To what extent do you agree or disagree with the following?

1. You will be able to achieve the same outcome from your projects if the entire process was done using digital tools.

$\square$ Strongly disagree $\square$ Disagree $\square$ Neutral $\square$ Agree $\square$ Strongly agree
Why?

2. Digital technologies have the potential to replace conventional workshops and the hands-on experience.

$\square$ Strongly disagree $\square$ Disagree $\square$ Neutral $\quad \square$ Agree $\square$ Strongly agree

\section{Why?}


3. Your design practice will improve if you used a completely digital process.

$\square$ Strongly disagree $\square$ Disagree $\square$ Neutral $\square$ Agree $\square$ Strongly agree

Why?

4. It would be appropriate to have a totally digital industrial/product design course.

$\square$ Strongly disagree $\square$ Disagree $\square$ Neutral $\square$ Agree $\square$ Strongly agree

Why?

\section{F. Areas of Improvements:}

Do you think that there are any areas of the industrial/product design process that can be improved in the curriculum of your course?

$\square$ Yes $\square$ No

If yes, can you please identify the areas?

\section{G. Reflections on a Completely Digital Process:}

What would you feel about a totally digital industrial/product design process?

Thank you for your assistance in this research 
11.2 Industrial Placement Student Online Questionnaire on Digital Industrial Design

\section{Digital Industrial/Product Design Questionnaire}

Loughborough

University

A. Background:

1. First name:

2. Surname:

3. Gender:

Male

Female

4. Did you work as a product/industrial designer at your placement design organization? (Please complete the rest of the questionnaire if your answer to this question is yes only).

Yes $\rightarrow$ Please complete the rest of the questionnaire

No $\rightarrow$ Thank you for your time

5. When did you take your placement year?
2005/2006
(2006/2007
$2007 / 2008$
$2008 / 2009$
If other, please specify

6. What is the name of the design organization you worked for as part of your placement?

7. What was your job title at the design organization you worked for? 
8. How long did your placement last?
(1-3 months
4-6 months
7-9 months
10-12 months
If other, please specify

9. Are you still working part/full time with the same design organization?
Yes
No

\section{B. Design Methods Usage:}

10. How often did your design organization use FREE HAND PAPER_BASED SKETCHES (produced using pencils, pens, papers, ink, airbrush, pastels, markers, etc)? Note that examples of sketches are 2D side view sketches, 3D perspective sketches, investigative and explorative sketches, explanatory sketches.
Never
Rarely
Sometimes
Often
Always

11. How often did your design organization use DIGITAL SKETCHES (produced using Alias Sketchbook, Core Painter, Adobe Photoshop, digitizing tablets, etc)?
Never
Rarely
Sometimes
Often
Always

12. How often did your design organization use WORKSHOP-BASED SKETCH MODELS (produced using cutting knives, sanding papers, rules, saws, pencils, etc)? Note that sketch models also known as 'mock up models', 'soft models' and 'development models' (e.g. 2D card models, 3D Styrofoam, wax models).
Never
Rarely
Sometimes
Often
Always 
13. How often did your design organization use DIGITAL SKETCH MODELS (produced using $Z$ Crop rapid prototype machine, Haptic feedback device with Sensable Phantom Freeform system, computer numerical control machines, etc)?
Never
Rarely
Sometimes
Often
Always

14. How often did your design organization use WORKSHOP-BASED APPEARANCE MODELS (produced using conventional workshop techniques)? Note that appearance models are models that communicate the form only.
Never
Rarely
Sometimes
Often
Always

15. How often did your design organization use DIGITAL APPEARANCE MODELS (produced using modeling software, rapid prototyping, computer numerical control machines, etc)?
Never
Rarely
Sometimes
Often
Always

16. How often did your design organization use MANUAL PAPER-BASED RENDERINGS (produced using pencils, pens, papers, boards, ink, airbrush, pastels, markers, etc)? Note that renderings are also known as 'presentation drawings' and 'persuasive sketches' (e.g. 2D side view renderings, 3D isometric renderings).
Never
Rarely
Sometimes
Often
Always

17. How often did your design organization use COMPUTER RENDERINGS (produced using Adobe Photoshop, Pro/Engineer, Alias StudioTools, Rhino, Autodesk 3ds Max, etc)?
Never
Rarely
Sometimes
Often
Always 
18. How often did your design organization use MANUAL PAPER-BASED CONTROL DRAWINGS (produced using pencils, pens, paper, ink, rule, protractor, etc)? Note that control drawings are also known as 'engineering drawings' (e.g. general arrangement, exploded views, cut-away/sections, instructional drawings).
Never
Rarely
Sometimes
Often
Always

19. How often did your design organization use DIGITAL CONTROL DRAWINGS (produced using Pro/Engineer, AutoCAD, SolidWorks, Autodesk 3ds Max, etc)?
Never
Rarely
Sometimes
Often
Always

20. How often did your design organization use PHYSICAL TESTING (using Breadboard circuits, user trials, load testing rigs, etc)? Note that testing is also known as 'analysis' (testing relating to ergonomics, mechanics, electronics, etc).
Never
Rarely
Sometimes
Often
Always

21. How often did your design organization use DIGITAL TESTING (using simulation, virtual reality, Pro/Engineer Mechanica, Moldflow, Finite Element Analysis (FEA), etc)?
Never
Rarely
Sometimes
Often
Always

22. How often did your design organization use WORKSHOP-BASED PROTOTYPES (produced using conventional workshop techniques)? Note that different examples of prototypes include appearance and pre-production.
Never
Rarely
Sometimes
Often
Always 
23. How often did your design organization use DIGITAL PROTOTYPES (produced using rapid prototyping, computer numerical control machines, etc)?
Never
Rarely
Sometimes
Often
Always

C. Design Organization's Usage of Digital Methods:

24. To what extent does the design organization you worked for employ digital methods in the CONCEPT GENERATION stage (creating the product form and translating ideas into visual representation)?
$0 \%$
$1 \%-25 \%$
$26 \%-50 \%$
$51 \%-75 \%$
$76 \%-99 \%$
$100 \%$

25. To what extent does the design organization you worked for employ digital methods in the PRELIMINARY REFINEMENT stage (most promising ideas being developed and presented to clients as rendering or foam models)?
$0 \%$
$1 \%-25 \%$
$26 \%-50 \%$
$51 \%-75 \%$
$76 \%-99 \%$
$100 \%$

26. To what extent does the design organization you worked for employ digital methods in the FURTHER REFINEMENT AND FINAL CONCEPT SELECTION stage (chosen idea being developed to add more to the product's usability and desirability in the same time cut costs, appearance models and prototypes are expected to be produced)?
$0 \%$
$1 \%-25 \%$
$51 \%-75 \%$
$76 \%-99 \%$
$100 \%$ 
27. To what extent does the design organization you worked for employ digital methods in the SPECIFICATION stage (making control drawings of the final concept required for production tooling by the manufacturer)?
$0 \%$
$1 \%-25 \%$
$26 \%-50 \%$
$51 \%-75 \%$
$76 \%-99 \%$
$100 \%$

D. Main Digital Media/Tools:

28. What are the main digital media/tools used at the design organization you worked for in the CONCEPT GENERATION stage?

Digital media/tools

29. What are the main digital media/tools used at the design organization you worked for in the PRELIMINARY REFINEMENT stage?

Digital media/tools

30. What are the main digital media/tools used at the design organization you worked for in the FURTHER REFINEMENT AND FINAL CONCEPT SELECTION stage?

Digital media/tools

31. What are the main digital media/tools used at the design organization you worked for in the SPECIFICATION stage?

Digital media/tools

\section{E. Thoughts on Employing Digital Techniques:}

32. Do you believe that the design organization you worked for will be able to achieve the same outcome from projects if the entire process was done using digital tools?
Strongly disagree
Disagree
Neutral
Agree
Strongly agree 


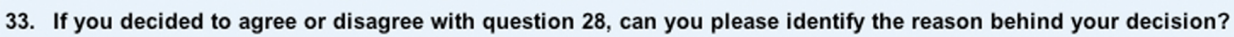
Reason:

34. Do you think that digital technologies have the potential to replace conventional workshops and hands-on experience completely in the design organization you worked for?
Strongly disagree
Disagree
Neutral
Agree
Strongly agree

35. If you decided to agree or disagree with question 30 , can you please identify the reason behind your decision? Reason:

36. Do you think that the organization's design practice will improve if a complete digital process was used?
Strongly disagree
Disagree
Neutral
Agree
Strongly agree

37. If you decided to agree or disagree with question 32, can you please identify the reason behind your decision? Reason: 


\title{
11.3 Online Discussion with Design Practitioners on the IDSA LinkedIn Group
}

\section{IDSA}

Industrial Design | Industrial Designers Society of America...

\author{
Discussions \\ Members \\ Promotions \\ Jobs \\ Search \\ More...
}

Should/could industrial designers operate entirely digitally?

I have a PhD student that is exploring the potential for industrial designers to undertake new product

development entirely digitally e.g. no biros, markers, Styrofoam, bits of card, crude prototypes, painted models.

This will include a review of the state of the art plus insight into the use of digital tools within education.

We have assembled the more popular digital tools into what we are calling a digital industrial design (DID) strategy. This includes solutions for activities that have been slower to digitise, such as sketching (using a Wacom Cick such as SensAble Freerm. We applications and have extended the scope in the DiD strategy to include rapid prototype parts that have had mossible but are physical components that can be handled.

We would very much appreciate feedback from educators and practitioners on four key questions. This can be easily done by copying the section below the dotted line and pasting it into your reply. Your response to the five options (strongly disagree; disagree: neutral; agree; strongly agree) can be indicated by placing with an " $X$ " nex to it. If you would like to elaborate (which is not essential) please do so next to "Because".

We will publish the results on the IDSA section of Linkedin once collated. Many thanks for your support.

1. To what extend do you agree or disagree that you will be able to achieve the same outcome from a project if the entire process was done using digital tools?

Strongly disagree

Disagree

Neutral

Agree

Strongly agree

Because:

2. To what extend do you agree or disagree that digital technologies have the potential to replace conventional workshops and the hands-on experience?

Strongly disagree

Disagree

Neutral

Strongly agree

Because:

3. To what extend do you agree or disagree that design practice will improve if a completely digital process is used?

Strongly disagree

Disagree

Neutral

Agree

Because:

4. To what extend do you agree or disagree that it would be appropriate to have a totally digital industrial design degree course?

Strongly disagree

Disagree

Neutral

Agree

Strongly agree

Because:

7 months ago 
1. To what extend do you agree or disagree that you will be able to achieve the same outcome from a project if the entire process was done using digital tools?

Strongly disagree $\mathrm{X}$

Disagree

Neutral

Agree

Strongly agree

Because: Although Cintiq provides a "sketching-like" experience it is nowhere as flexible as paper and pencil/chalk/graphite/marker - yet!

2. To what extend do you agree or disagree that digital technologies have the potential to replace conventional workshops and the hands-on experience?

Strongly disagree

Disagree

Neutral

Agree

Strongly agree $X$

Because: Someday computers will be so powerful they will be able to replicate any analog experience/

3. To what extend do you agree or disagree that design practice will improve if a completely digital process is used?

Strongly disagree

Disagree $\mathrm{X}$

Neutral

Agree

Strongly agree

Because: Computers and software are not yet anywhere near as efficient for concept work as the human hand/brain.

4. To what extend do you agree or disagree that it would be appropriate to have a totally digital industrial design degree course?

Strongly disagree

Disagree $\mathrm{X}$

Neutral

Agree

Strongly agree

Because: Just as an artist should learn anatomy before drawing from "life" a designer should be immersed in the "craft" of drawing and modeling by hand.

7 months ago

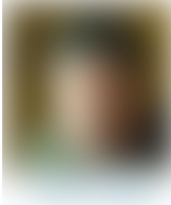

I'm on the same page as , we use Cintiq tablets and all the fantastic apps the are additional tools in our design toolbox but when I want to visually communicate immediately to a colleague sitting across from me technology is here yet that replaces me pulling the pencil out from behind my ear and sketching something on a piece of paper (I do acknowledge that the design studio of the future will have every work surface covered with an digital display interface)

The number one issue I have with junior designers that do not have enough analogue sketching and study model making experience (i.e., CAD jocks), is that they don't have a solid sense of scale. Sketching a handheld product full scale doesn't really have the same affect on an interface where you can constantly zoom in and out.

7 months ago 


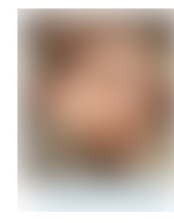

- I do everything digitally. What once, in my early applied arts classes for example, was traditionally done by hand (ie. models, renders, sketches...) is now transferred directly to digital. However, when unexpectedly faced with a potential client in a restaurant, bar, bistro, or any other place where you might not have your laptop handy because it's either impractical or just plain rude, you can simply take your pen out of your pocket and doodle ideas on the napkin or some piece of paper... and I think there is still no replacement for that, not even this (the first video) :

http://www.pranavmistry.com/projects/sixthsense/\#VIDEOS

although the applications shown in that video are rather amazing...

There is also the importance of knowing HOW to sketch because that gives the designer a basis of knowledge. In other words, if you're going to be a designer of any kind, I believe you should learn the analogue sketching basics first.

7 months ago

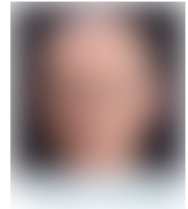

- Architecture would seem to be the first design category to go digital since they never model anything 1:1.

Why do car designers still do full scale clay? Because you really can't evaluate a surface in a computer.

7 months ago

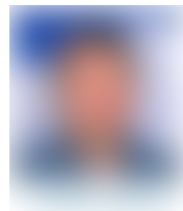

- 1. Neutral Computer Aided Industrial Design has great advantages and disadvantages. The digital Photoshop-style 2D sketch or 3D CAD rendering can be very impressive and packs a visual punch hard to achieve with marker on paper or without endless hours of physical modelling (clay, foamcore, etc). The problem is that these tools tend to generate stiff or overly simple designs that just don't have the flow and "hand" that traditional "analog" techniques generate.

2. Agree Eventually digital tools will replace analog tools, but not yet. CAD modelling software is just not sophisticated enough to do, nicely, a multiple blend surface in the same easy manner as a little modeling clay. The SenseAble tool is years away from being able to combine ruled CAD surfaces and the freeform (uncontrolled) surfaces it currently creates in a truly useful manner. Sorry guys.

3. Strongly disagree $100 \%$ digital is just not ready. It could work, but will not create the same level of sophistication that a combo analog/digital process will create taking advantage of the strengths of both.

4. Strongly disagree $100 \%$ digital design graduates will be very weak in form development and overall comfort level with perspective drawing of complex objects. They also tend to create a punchy visual quickly and don't explore as much. I've seen way too much of this. 7 months ago

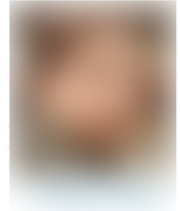

-1. To what extend do you agree or disagree that you will be able to achieve the same outcome from a project if the entire process was done using digital tools?

Strongly disagree

Disagree

Neutral •

Agree

Strongly agree

Because: It depends on the nature of the product (tech. driven/user-end driven) and how complex certain tests and prototypes have to be. It may also depend on the nature of the project, its conditions, circumstances etc... 
2. To what extend do you agree or disagree that digital technologies have the potential to replace conventional workshops and the hands-on experience?

Strongly disagree

Disagree

Neutral

Agree

Strongly agree

Because: I believe they have the potential... just not $100 \%$ yet.

3. To what extend do you agree or disagree that design practice will improve if a completely digital process is used?

Strongly disagree •

Disagree

Neutra

Agree

Strongly agree

Because: Computers are tools and they can't replace knowledge itself. (hehheh! This reminds me of TRON)

4. To what extend do you agree or disagree that it would be appropriate to have a totally digital industrial design degree course?

Strongly disagree •

Disagree

Neutral

Agree

Strongly agree

Because: Agreed if used together and AFTER "analogue" classes on sketching, perspective principles, etc... because of what I mentioned in earlier post. I believe the extent of digital classes is already satisfactory in most design schools. Disagree that it should be part of any separate degree per se, but as an addition into the schools' curriculum.

7 months ag

\section{between}

- Dear Mark, I believe, being part from a generation that was trapped inAutocad on the first versions of Windows, Apple Quadras running 3D programs that constantly went "Quack!") that after being constantly in contact with late technologies from Xeon processors, UNIX systems running NX, or Solid Works, Rhino, Alias, etc. and having SLS or DLS, and digitizing tablets... I still can not find a true substitute for the old Pantone markers, or Staedtler edging markers, or Koh-i-noor sketching tools, my old mechanical pencil is still my most reliable tools, and for me at least nothing beats the feeling of developing a model from scratch, you can imbue a "spirit" into your creation, modify and finally "digitize" according to the result that you expect. I concede it might take more time but... that time saves on remaking models and forms, for me at least it is not the same. 1. To what extend do you agree or disagree that you will be able to achieve the same outcome from a project if the entire process was done using digital tools?

Strongly disagree $\mathrm{X}$

Disagree

Neutral

Agree

Strongly agree

Because: I do not have the contemplative power and presence from developing from hand drawing and representation techniques, I would not be able to take my "sketching" tablet as easily as a sketching pad. I can not express what I want to express the same way. I like to become dirty and filthy with graphite and marker, that makes the design mine.

2. To what extend do you agree or disagree that digital technologies have the potential to replace conventional workshops and the hands-on experience? 
Strongly disagree $X$

Disagree

Neutral

Agree

Strongly agree

Because: First of all costs, for as cheap as digital tools may become, top quality pencils, markers, premium papers and drawing boards will always be cheaper and more versatile. Second there are limits to what digital technologies can provide when it comes to expressivity. We spent years learning how to express freely, why limit that expression through a digital material that if it breaks down you can not show your work?

3. To what extend do you agree or disagree that design practice will improve if a completely digital process is used?

Strongly disagree $\mathrm{X}$

Disagree

Neutral

Agree

Strongly agree

Because: A computer will not have the ability to present without batteries or being on a design studio. I believe that full digital technologies would be like distancing expression from design.

4. To what extend do you agree or disagree that it would be appropriate to have a totally digital industrial design degree course?

Strongly disagree

Disagree $X$

Neutral

Agree

Strongly agree

Because: How would you teach students to become flexible and resourceful when you distance them from the hands on world, sooner or later they will have to get hands on experience, I have been designing for some time and have not bumped into digital only situations, when I need to present a quick idea to a decision making character, there is nothing like my paper and pencil for quick sketching to reach an agreement. That way I have found for Eureka expressions than the deep frown from the "let me turn on my computer" - "do not make me loose my time" retort from busy execs. Later when you come with a printed 3D they say "good, I now precisely see what you mean". If you intend to do some digital only, good luck, I personally do not find it very practical.

7 months ago

1. To what extend do you agree or disagree that you will be able to achieve the same outcome from a project if the entire process was done using digital tools?

\section{Strongly disagree}

Because: We have seen that completely digital processes can often result in shapes and forms that all have a similar aesthetic, i.e. driven by the digital tools instead of a free thinking freedom that comes with pen and paper.

Going digital too soon also seems to result in less design exploration (because it is slower) and the last few quick sketches that you never did may end up being the ones that really too the design to the next level.

2. To what extend do you agree or disagree that digital technologies have the potential to replace conventional workshops and the hands-on experience?

\section{Strongly disagree}

Because: Good design is all about designing a customer experience (visual, tactile,

experiential, etc.) and that type of skill is difficult to translate through a computer monitor. Ultimately a product brings you face-to-face with your end customer. Being face-to-face with other designers and contributor helps you to sharpen your skills something like "so as iron sharpens iron, man sharpens man." 
3. To what extend do you agree or disagree that design practice will improve if a completely digital process is used?

\section{Strongly disagree}

Because: Only using digital tools are too limiting in the initial stages of a project. Hand sketching is quick and easy. Why throw away a tool that just rocks. One day the digita tools may get us to the point where we can throw out hand sketches, but not yet. The digital tools are just too slow and too confining to replace a hand sketch or a napkin sketch. One day that may change, but we aren't there yet.

4. To what extend do you agree or disagree that it would be appropriate to have a totally digital industrial design degree course?

\section{Strongly disagree}

Because: Hand sketches drive our industry. They work, they can be fluid and organic and convey an emotion that can easily get lost once your results are confined by a

computerized tools. I watch industrial designers struggle with digital tools to keep that fluid element to designs. Lets face it, digital design tools encourage users to do what is easiest for the tool to do. In the process of designing anything, the designer makes thousands of choices. If the digital tool pushes you thousands of times to make a slightly different (and easier at the moment) choice it most definitely impacts your design. That changes your design and makes it easier to end up with a vanilla, ho-hum design instead of the design goodness that we all strive for

Cheers

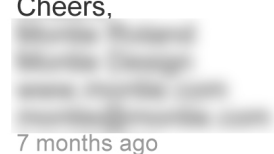

\section{Disagree}

\section{Disagree}

3. Disagree

\section{Disagree}

Because: All of these I disagree but not strongly because I obviously can't tell the future. However, CAD, haptic tools (freeform), and digital sketching still have major limits compared to analog tools. As well analog has alot of limits compared to digital tools as well. I think if we are designing 3 dimensional things we need to be able to make them 3D as early as possible in the design process. Digital can help but is not always the best way. I think David Kelley said once and I'm paraphrasing 'the sooner you get to a crappy prototype the better.' IF you want to design great products you eventually have to make one.

The same question has arisen in fields like woodworking where power tools have kept alot of craftsman from learning the use of age old hand tools. However, if you look into the shops of the finest craftsmen, they still regularly use hand tools in the building process. Tools that have been around for a long time.

The limitations that I see in the digital world is that it is only a symbolic representation of the real world and can only represent a real thing. At the same time this is it's strength. With CGI for example movies help a person to image the possibilities of a realty not yet available.

Ultimately I think good designers have the ability to see in their minds and then use whatever tools to communicate that thought to others and to ultimately make it reality. Even a pencil and paper can limit that ability. The better you can draw the better you can communicate actually what is in your mind, the better CAD modeling skills are the better you can communicate the original design intent to an engineer, tool maker etc. Though digital tools are very helpful, I think we will not get away from analog tools until we are hooked up to computers like in the Matrix, and I hope that never happens.

7 months ago 
- 1. To what extend do you agree or disagree that you will be able to achieve the same outcome from a project if the entire process was done using digital tools?

Neutral

Because: Take a moment to consider the photography analogy. When photography came on the scene traditional artists were threatened and influenced by it at the same time. The camera has now become respected and supported as an artist's tool. A photographer takes many pictures, but the good ones know or can feel when a good shot is about to be taken. Similarly, sketches are "feeling" guided snapshots towards developing a product. But who is to say that designers cannot be guided by feeling while working exclusively in digital?

2. To what extent do you agree or disagree that digital technologies have the potential to replace conventional workshops and the hands-on experience?

Agree

Because: Digital technology has the potential to $100 \%$ mimic the paper and pen interface. In addition, $3 d$ interfaces will be improved to a point where form can be evaluated effectively.

3. To what extend do you agree or disagree that design practice will improve if a completely digital process is used?

Agree

Because: Specifically, it provides more control over the data accumulated during a project, which means more efficiency. Generally, all processes evolve and sometimes undergo a paradigm shift.

4. To what extend do you agree or disagree that it would be appropriate to have a totally digital industrial design degree course?

Agree

Because: It will further the evolution of digital technology and the ways in which we interface with it. It can't hurt because even unsuccessful designs make it out of the clay phase. :)

7 months ago

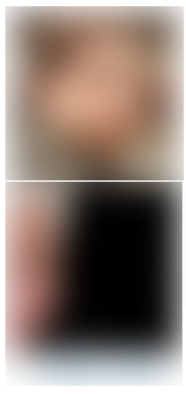

I like your point about "'feeling" guided snapshots"...

sometimes call intermediary sketches "mood studies" (and that may include photoshop intervention with the hand sketch)

7 months ago

- Memory is analog ...

7 months ago

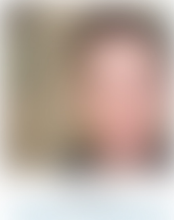

- The Industrial Revolution meant redefining the value of traditional art and hand made objects. The irony is that machines took the process of production out of our hands and now they threaten to put it back. Its a good thing.

7 months ago 


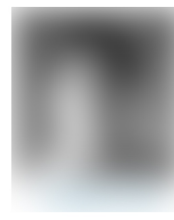

- There is no doubt that the digital explosion of the 90s through today have revolutionized the design business. Back in ' 94 I started with RKS and they were one of the early adopters of "solid" 3D CAD as a design tool. How it allowed us to turn designs around from napkin sketches production ready designs was pronominal. Now, for a few thousand dollars in software and hard ware anyone can create 3D CAD models.

What I think is important to keep in mind is that the computers and software is no more a tool then the calculator or a T-square. Granted it is a very valuable tool, and one that any designer today better be proficient at using, but it is only as good as the designer behind it. I've seen some really horrific designs come out from a computer (yes, even my own), and it is always the designers fault, not the computers.

As good as 3D and 2D soft wares have become, and it is truly dazzling what they can do, they can not replace the human component of the design. As has been pointed out, the ability to quickly draw out a gesture or mechanical concept on a napkin has yet to be replaced electronically. One item that has not been address is the need for quick fast fail models and prototypes. One could spend hours modeling in a computer and it all looks great, but as product designers what we design and eventually have produced has to work here in the real world. I have yet to have a prototype built that did not reveal some aspect to a design that could use refinement. (sometimes for then a little)

We always advise our clients that a prototype should be a must before they invest in hard tooling. Our words are not always heeded, and expensive tooling changes are almost always inevitable. This can cost clients extra cash, and often what is more valuable, time.

So to answer the questions above:

1. Strongly disagree

2. Disagree (at least for a number of years

3. Disagree (but there is no doubt that it will become more and more digital)

4. Strongly agree (I think that a single course that is completely digital would be a valuable lesson. After all, the university is where they should be trying out things)

7 months ago

- To what extend do you agree or disagree that you will be able to achieve the same outcome from a project if the entire process was done using digital tools?

Strongly disagree

Disagree $\mathrm{X}$

Neutral

Agree

Strongly agree

Because: The end result could be similar but not identical. Knowledge, tools and technology all influence the end result. Designers are influenced by what they are able to achieve with a particular software or a particular technique. The digital era as influenced greatly design and to a certain extent is even a precursor of some tendencies.

2. To what extend do you agree or disagree that digital technologies have the potential to replace conventional workshops and the hands-on experience?

Strongly disagree

Disagree

Neutral

Agree $X$

Strongly agree

Because: We can now make blind people see by stimulating the cerebral cortex with head implants. So it's just a matter of time that this could be achievable. But the common interfaces are not there yet.

3. To what extend do you agree or disagree that design practice will improve if a completely digital process is used?

Strongly disagree $X$

Disagree

Neutral

Agree

Strongly agree 
Because: That's an ethical mater of each one belief of a better design. If you design for machines yes but if you design for humans no. In other words it could facilitate information flow to production, but humans will still be humans and therefore can't be substituted digitally. Going straight to production without getting out of the physical world with mock up and prototype is a risky business.

4. To what extend do you agree or disagree that it would be appropriate to have a totally digital industrial design degree course?

Strongly disagree $\mathrm{X}$

Disagree

Neutral

Agree

Strongly agree

Because: Thorough the designers I interview, I perceive more students graduating and lacking of artistic sense, refinement and sense of practicality. Is there a correlation between the fact that there is less and less teaching of classic art techniques such as hand drawing and model making to become more digitalized. Maybe

7 months ago

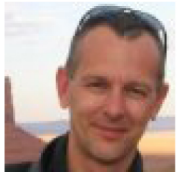

Dr Mark Evans - As it is now four days since I posted the question "Should/could industrial designers operate entirely digitally?" I thought it might be useful to have a heads-up to see where opinion is going. However, I would still like to think that it is early days in terms of the discussion and the more opinion we receive the more representative the final statistics will be. So if you have not yet contributed to the debate, I intend to let it run for another week (ending midnight on Wednesday 24 March) before starting to collate the responses.

The current status of opinion appears to be going in the direction of:

1. It would not be possible to achieve the same results if operating entirely digitally

2. There is no clear consensus on the ability of digital technologies to replace conventional workshops/hands-on experience

3. Practice would not improve if undertaken entirely digitally

4. It would not be appropriate to have a totally digital industrial design degree course

Some very interesting points are being raised in the supporting statements which focus around such issues as:

5. There is a degree of flexibility/spontaneity/flow when undertaking conventional sketching with pens/pencils that is not replicated by digital tools

6. The need for sketching (digitally or conventionally) remains: "The better you can draw the better you can communicate actually what is in your mind"

7. Digital techniques contribute efficiency gains

I also appreciated the comment from

who said, "I think that a single course that is completely digital would be a valuable lesson. After all, the university is where they should by trying out things". That is very much the aim of the PhD and we may use the results to develop a new course.

In terms of sketching, I am currently evaluating the use of Tablet PC's as a design tool and the 16 students using them love the portability and ability to sketch (using SketchBook Pro) whenever they get the urge. It gives them the functionality of a Cintiq combined with a compact laptop PC.

As the number of responses hopefully increases, I would like to clarify a point about rapid prototyping. In terms of the digital industrial design (DID) strategy for the PhD, we consider rapid prototyping to be a digital technology and, as per my original post, the DID strategy will "include rapid prototype parts that have had their support structures removed but not rubbed down i.e. they are as close to the digital model as possible but are physical 
components that can be handled". So, physical components can be included in digital working practices. These rapid prototype builds can include components from production systems such as stereolithography or concept modellers such as Z-Corp 3D printers.

And finally, I would like to mention that last week I visited a company that was using FreeForm to replace what was once undertaken in a workshop. Whilst the company does not engage in what I would call mainstream industrial design, the work was indicative of how conventional practice can be replaced by digital media.

Please keep the opinions coming

Thanks

Mark

7 months ago

\section{- Great exploration Mark!}

1. To what extend do you agree or disagree that you will be able to achieve the same outcome from a project if the entire process was done using digital tools?

X Strongly disagree

Disagree

Neutral

Agree

Strongly agree

Because: There is no substitute for working in 1:1 real 3D to get one's head around a project. Although I love my SLS machine!

2. To what extent do you agree or disagree that digital technologies have the potential to replace conventional workshops and the hands-on experience?

Strongly disagree

Disagree

$x$ Neutral

Agree

Strongly agree

Because: Tools are tools, man. You use what you have and what you need. If you need to carve out a quick set of mockups, or at a later stage need an objet rapid prototype, use what is at hand.

3. To what extend do you agree or disagree that design practice will improve if a completely digital process is used?

Strongly disagree

Disagree

$x$ Neutral

Agree

Strongly agree

Because: It is not about what you buy... it is what you build. The talent of the mind shines through- you can put lipstick on a pig, it is still a pig.

4. To what extend do you agree or disagree that it would be appropriate to have a totally digital industrial design degree course?

Strongly disagree

$x$ Disagree

Neutral

Agree

Strongly agree

Because: As a craftsman, one does not just learn to use a power saw. A screwdriver comes in handy! I believe children need to learn to use a sliderule, then they get a calculator! 
- As someone who has visited countless firms and design departments (from my experience as an Autodesk AE) I've seen the whole landscape from completely analog to completely digital (with the use of rapid prototype machines). I've noticed a strong reoccurring theme. Those who are quick to discount digital technology are usually the ones that haven't invested the time to properly learn the tools. Instead of thinking how technology IS HINDERING creativity I challenge that thought by thinking what else IS POSSIBLE with technology.

I'm so glad to hear schools are starting to focus on technology in design more because I have to tell you... the capabilities of firms that embracing digital technology and utilizing it seamlessly (proper training, etc) are astounding compared to those who are not.

It's going to take some work though. I definitely feel that the misuse of digital tools has had somewhat of a negative impact on our field. Look at most of the IDEA awards. The bulk of the 90's everything was so organic (Alias influence). The last ten years everything has been shifting towards geometric (SWX influence). Are those trends because it was right for the design or is it that that's all we could model and those were the tools available?

Bottom line, good or bad, it's pretty obvious that digital technology has influenced our trade... what's important is HOW we use it, not IF we use it.

\section{Enough rambling:}

1. To what extend do you agree or disagree that you will be able to achieve the same outcome from a project if the entire process was done using digital tools?

Strongly Agree - And more

Because: BUT... it still comes down to the people using the tools and their skill sets

2. To what extend do you agree or disagree that digital technologies have the potential to replace conventional workshops and the hands-on experience?

Agree

Because: Time is money and handing an engineer a foam model is inefficient. Not to mention the potential for lost design intent. HOWEVER, nothing can replace a good sketch model that you can shape with your hands. The technology's coming though.

3. To what extend do you agree or disagree that design practice will improve if a completely digital process is used?

Neutral

Because: Once again, it depends on the firms philosophy (training for employees, desire for learning new tools and methods) but there's huge upside if they do it right.

4. To what extend do you agree or disagree that it would be appropriate to have a totally digital industrial design degree course?

\section{Strongly disagree}

Because: Exposure to any method is good, digital or not. I'd like to highly recommend that part of the course is looking what happens to the digital data as it leaves the designer. Rarely do we consider where it goes or how it's implemented which has HUGE business impacts. In today's world, most likely there's going to be a CAD model generated somewhere along the way and who would you want to control that model? ...the designer or the engineer?

7 months ago

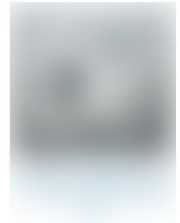

• "Should/could industrial designers operate entirely digitally?"

In the Physical World - Strongly disagree (1-4) because it breeds incompetence. In a Virtual World - Strongly agree (1-4) since it would be the new reality.

Although our technological evolution is beginning to bridge the virtual divide, our human senses will continue to dominate.

That is, until all sensory perception and the soul can be synthesized.

Good luck with the thesis, Dr. Evans

7 months ago 


\subsection{8/2009 Graduating Student Digital Industrial Design Strategy}

\section{Questionnaire}

Department of Design and Technology

Tel: +44 (0) 1509228315 Email: N.Al-Doy@lboro.ac.uk

Loughborough

University

\section{Digital Industrial/Product Design Strategy Questionnaire}

This is an anonymous questionnaire that will be used as part of a research study aiming to develop a curriculum for the study of digital industrial design (DID). Your honest opinions will be very helpful.

\section{A. Background:}

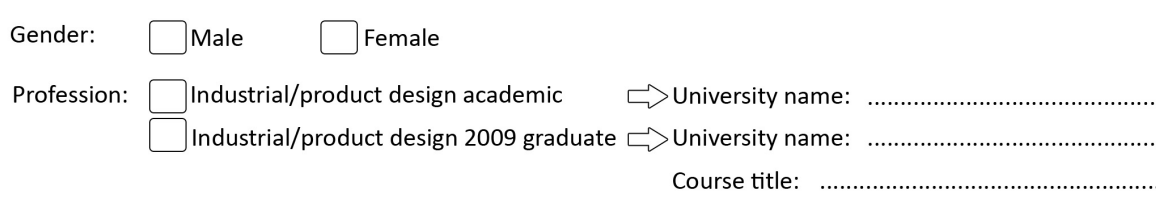

B. Use of Digital Tools and Media in the Strategy:

How often do you use the following digital media/tools when designing digitally? How easy is it to use them? And how useful are they? Please note that if you chose never, you do not have to rate the ease of use and contribution to practice.

\section{2D Mouse}

(e.g. Apple Wireless Mighty Mouse, Microsoft Explorer)

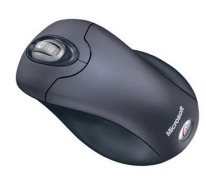

\section{1a. Frequency of use:}

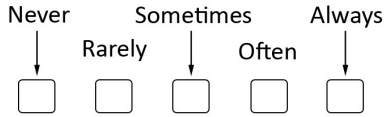

1b. Ease of use:

Very difficult Neutral Very easy

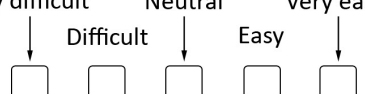

1c. Contribution to practice:

Nothing Moderate Essential $\downarrow$ Limited Significant
2. Pen Input Device

(e.g. Livescribe

Pulse Smartpen,

Dane-Elec Zpen

Light)

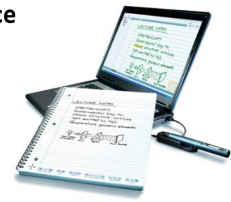

2a. Frequency of use:

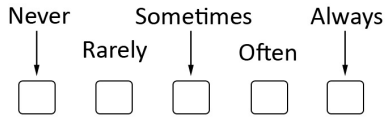

2b. Ease of use:

Very difficult Neutral Very easy

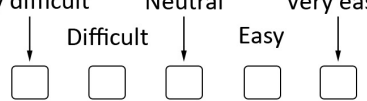

2c. Contribution to practice:

Nothing Moderate Essential

$\downarrow$ Limited \Significant 


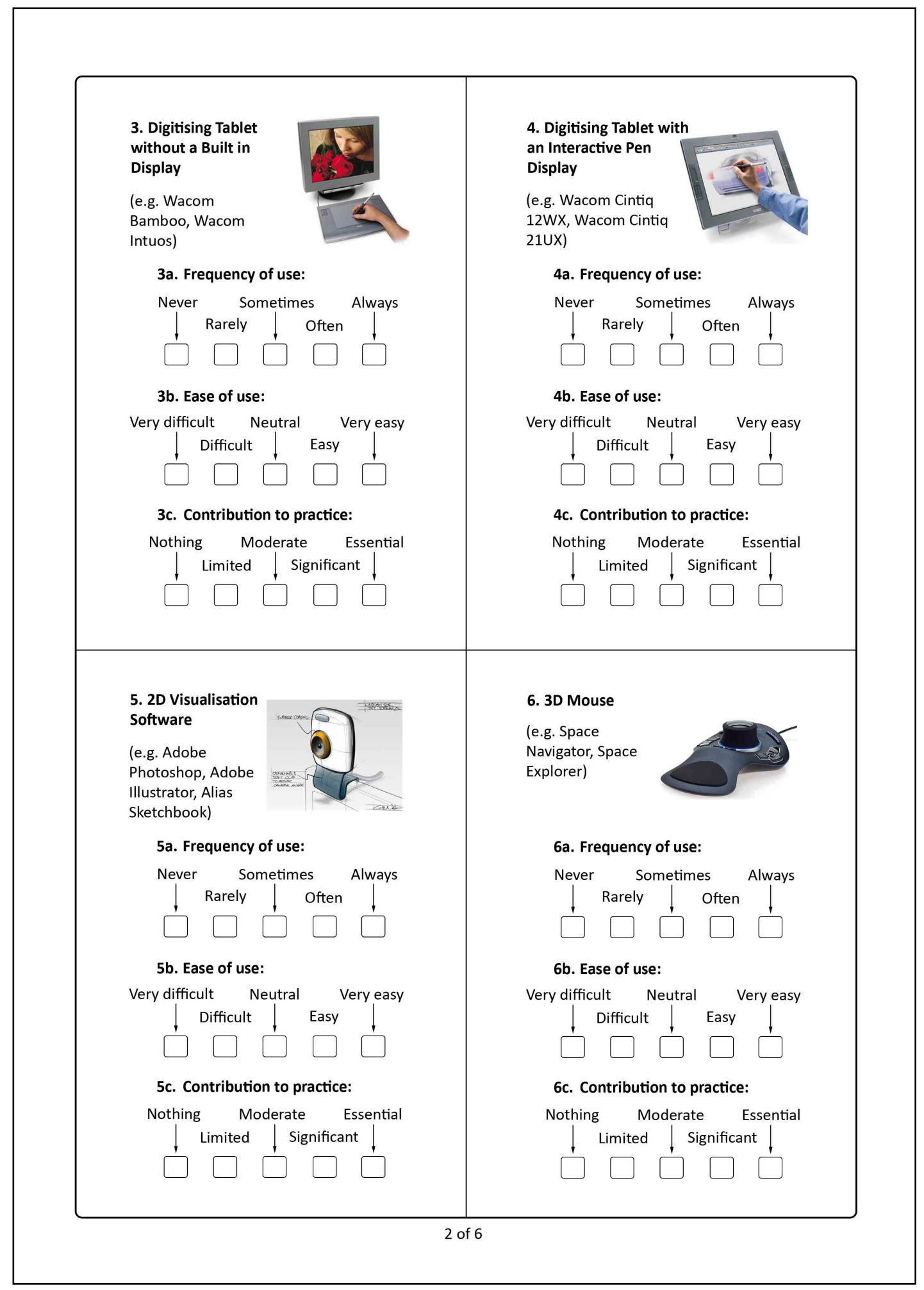




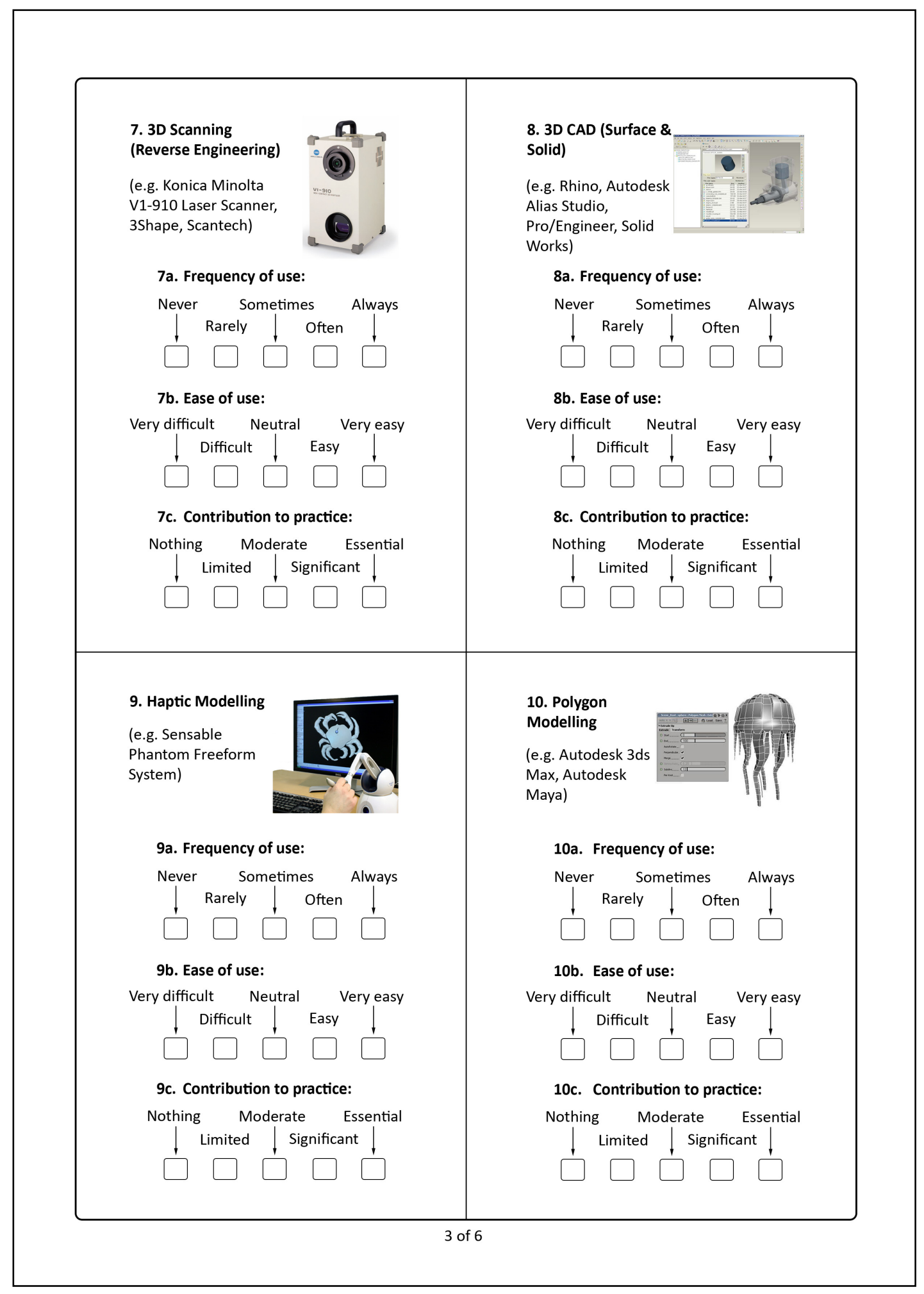




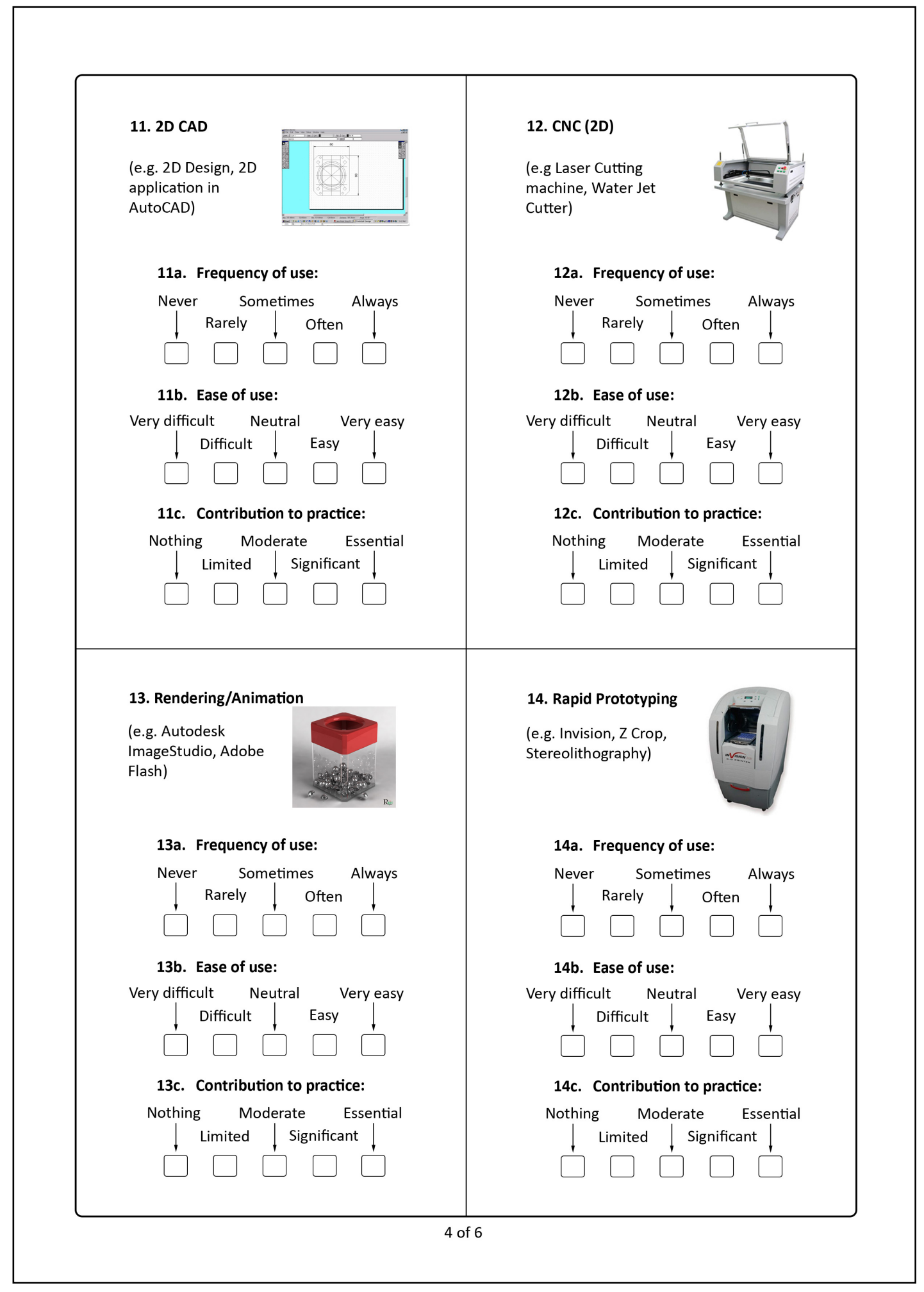




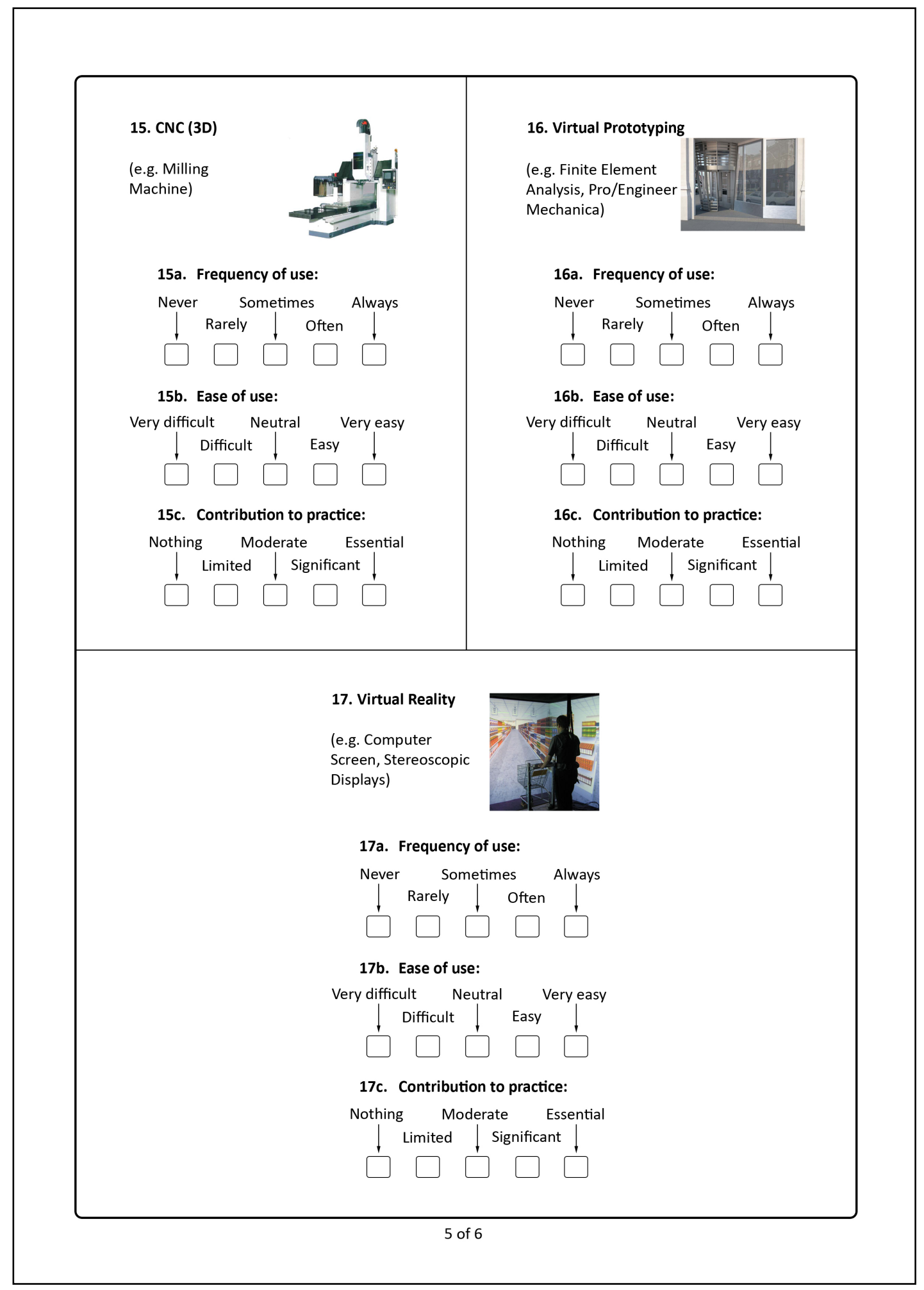


C. Thoughts on the Digital Industrial/Product Design Strategy:

1. Do you agree or disagree that the digital industrial/product design strategy has the potential to replace the existing conventional (non-digital) and hybrid (mixture of digital and non-digital) process of designing?

$\square$ Strongly disagree $\square$ Disagree $\square$ Neutral $\square$ Agree $\square$ Strongly agree
Why?

Why?

2. How do you feel about the efficiency of the digital industrial/product design strategy?

$\square$ Very inefficient $\square$ Inefficient $\square$ Neutral $\square$ Efficient $\square$ very efficient

Why?

3. Would you like to try the digital industrial/product design strategy?

$\square$ Yes

No

Why?

4. Are there any other digital tools/media that you would like to add to the strategy?

Yes

No

If yes, can you please identify the tools/media?

Thank you for your assistance in this research 


\subsection{Participant Identification Codes for Interviews}

\begin{tabular}{|l|l|}
\hline \multicolumn{1}{|c|}{ Code } & \multicolumn{1}{|c|}{ Representation } \\
\hline ID-P1 & Industrial design practitioner \#1 \\
\hline ID-P2 & Industrial design practitioner \#2 \\
\hline ID-P3 & Industrial design practitioner \#3 \\
\hline ID-P4 & Industrial design practitioner \#4 \\
\hline ID-P5 & Industrial design practitioner \#5 \\
\hline ID-P6 & Industrial design practitioner \#6 \\
\hline ID-P7 & Industrial design practitioner \#7 \\
\hline ID-P8 & Industrial design practitioner \#8 \\
\hline ID-A1 & Industrial design academic \#1 \\
\hline ID-A2 & Industrial design academic \#2 \\
\hline ID-A3 & Industrial design academic \#3 \\
\hline ID-A4 & Industrial design academic \#4 \\
\hline ID-A5 & Industrial design academic \#5 \\
\hline ID-A6 & Industrial design academic \#6 \\
\hline ID-A7 & Industrial design academic \#7 \\
\hline ID-A8 & Industrial design academic \#8 \\
\hline ID-A9 & Industrial design academic \#9 \\
\hline NA & Noor Aldoy \\
\hline
\end{tabular}

\subsection{Practitioner Interview Transcript Sample}

Date: 12 February 2010

Location: Chicago, USA

Description of participant: Founder of an American industrial design consultancy that designs a range of sports, electronics, household, health and children products.

\begin{tabular}{|ll|}
\hline NA & Can you summarise your experience as a designer, please? \\
\hline ID-P1 & I have been working in the design field since 1975 or 1976, so a long time. My experience \\
covers working in-house in a cooperate environment for manufacture. I worked in the public \\
sector working in a museum design, doing exhibitions. My cooperate experience was working \\
in a lighting manufacturer and for the last 22 years, I have been one of the founders, with a \\
partner who is originally from Paris, of this design consultancy and have now been working as \\
a design consultant. And in that capacity we have worked in many industries; health, fitness, \\
medical, consumer electronics, house wares, industrial products, research, and blue sky \\
research projects for people like Intel and Procter and Gamble. \\
NA $\begin{array}{l}\text { Can you describe how non-digital and digital tools and media are used within your company } \\
\text { design practice? So in concept generation, what tools do you normally use to come up with } \\
\text { ideas? }\end{array}$ \\
$\begin{array}{l}\text { Typically when a project starts we will assemble the team that is going to be working on that } \\
\text { particular project and we will generally flesh out our general ideas in a group session using } \\
\text { both white board and sketchpad. Everybody has their own preferences on which pen they } \\
\text { like or which pencil they like, but that is basically how we start. That will be step one. } \\
\text { Once we get past the initial brain flash, then we would begin to work with digital tools } \\
\text { depending upon the complexity of the object, depending upon if it is the kind of device that } \\
\text { might have a lot of electronics or a lot of technical requirements. If that is the case then we }\end{array}$
\end{tabular}




\begin{tabular}{|c|c|}
\hline & $\begin{array}{l}\text { would start either in SolidWorks or Illustrator, again, depending upon the complexity of } \\
\text { creating an internal component layout so really understanding what is inside the product, } \\
\text { how that really can be configured because that obviously will determine the size, proportion, } \\
\text { relationships of where things might be on the object. Particularly if it is an object that has } \\
\text { interaction with the human hand or some part of the human body then it needs to be } \\
\text { obviously dealt with in terms of ergonomics and human factors, the issues of usability. So we } \\
\text { will basically create layouts and then we will start to work again either in Illustrator or } \\
\text { SolidWorks depending upon the object. We will start to wrap it, to start to understand how } \\
\text { the design of the object will actually come up, that is our first phase. }\end{array}$ \\
\hline NA & And then what would happen? \\
\hline ID-P1 & $\begin{array}{l}\text { And then let's say, for example, if we were using Illustrator and we have created an internal } \\
\text { component layout and we have created a much more well defined concept that could then } \\
\text { be rendered using Illustrator and Photoshop to present to the client. So now we have maybe } \\
\text { between three and five concepts that we are presenting to the client. Maybe we generated } \\
20 \text { but our policy is to narrow it down before we present to the client, we do not show } \\
\text { everything. And people sometimes might ask why do we do that? So if you did 20, why are } \\
\text { you only showing three? Our attitude is to make a compression. If you went to the doctor } \\
\text { and you said you had a problem and you want a diagnosis, do you want } 20 \text { possibilities or do } \\
\text { you want him to tell you that it is this or this. So we figure that people come to us because } \\
\text { they want the expertise, so we are pre-decided. At that point, once a direction or an option is } \\
\text { picked then all the detailed design development will be done using digital tools. We will use } \\
\text { primary SolidWorks and Cobalt from Ashlar-Vellum, it is a 3D tool and we will encourage the } \\
\text { client to quickly go to models, mock-up models. }\end{array}$ \\
\hline NA & How would you produce those mock-up models? \\
\hline ID-P1 & $\begin{array}{l}\text { Some of those will be made by hand, if it is very rough and quick we have a little model shop. } \\
\text { We will do it out of foam or rein board but we like to quickly generate enough 3D data that } \\
\text { we can output it to get FDM, or a Z Corp or a SLA or whatever it might be, whatever is } \\
\text { appropriate. }\end{array}$ \\
\hline NA & $\begin{array}{l}\text { And then the final prototype that you will show to client would be produced using which } \\
\text { method? }\end{array}$ \\
\hline ID-P1 & $\begin{array}{l}\text { We will be using the same data that has now been further defined, we have defined wall } \\
\text { thicknesses, we have defined internal features of how the things inside are going to be held } \\
\text { together. We have probably defined, at that point, the draft angles for all the parts. And then, } \\
\text { depending upon what material it is, we have determined how we would output the data to } \\
\text { which vendor for having those models made. }\end{array}$ \\
\hline NA & $\begin{array}{l}\text { All right, thank you. So basically to summarise this. In the beginning of the concept } \\
\text { generation you are going to start using pen and paper, manual techniques to produce some } \\
\text { ideas. Then those ideas get to be developed a bit using Illustrator or SolidWorks then you } \\
\text { might go to the workshop to produce some mock-up models, if needed. }\end{array}$ \\
\hline ID-P1 & And by hand. \\
\hline NA & $\begin{array}{l}\text { Yes, by hand. And sometimes you do them digitally as well. And then after that the entire } \\
\text { process will be digital. }\end{array}$ \\
\hline ID-P1 & Correct. \\
\hline NA & $\begin{array}{l}\text { What is the typical percentage split between non-digital and digital tools used within your } \\
\text { design organisation in concept generation, let's say, in the beginning, in each of those three } \\
\text { main phases, in concept generation. }\end{array}$ \\
\hline ID-P1 & I will be guessing, but I would say it is maybe $25 \%$ hand and $75 \%$ digital. \\
\hline NA & OK, and in development? \\
\hline ID-P1 & $\begin{array}{l}\text { The farther we get down the development path, the less we are doing things by hand. So } \\
\text { maybe we go from } 25 \% / 75 \% \text { to } 15 \% / 85 \% \text { and then } 10 \% / 90 \% \text { because every step we take, } \\
\text { even when we are working on the computer, many times we will be sitting together in front } \\
\text { of a computer trying to work something out, we will be sketching how we think we want it to } \\
\text { look or work or interact before we try to work it out on the computer. I can create that sketch } \\
\text { in } 60 \text { seconds and to create that same thing in the computer may take } 10 \text { minutes. So we still, } \\
\text { if we are looking at a detail of how two parts come together, typically will do little thumbnail } \\
\text { sketches before we actually try to figure it out in detail on the computer. So we move more }\end{array}$ \\
\hline
\end{tabular}




\begin{tabular}{|c|c|}
\hline & and more digitally. \\
\hline NA & But it is not completely. \\
\hline ID-P1 & But it is not completely. Not until the very end. \\
\hline NA & $\begin{array}{l}\text { So in development you said it is going to be } 15 \% \text { hand and } 85 \% \text { digital, while in specification it } \\
\text { would be } 10 \% \text { by hand. }\end{array}$ \\
\hline ID-P1 & $\begin{array}{l}\text { Or } 5 \% \text { by hand because it is really just those very little details now that you want to quickly } \\
\text { look at before you model it. }\end{array}$ \\
\hline NA & OK. \\
\hline ID-P1 & $\begin{array}{l}\text { Because it is much faster to communicate between designers or designers and engineers by } \\
\text { doing a little doodle rather than to have to actually build the geometry. That takes longer. }\end{array}$ \\
\hline NA & $\begin{array}{l}\text { I think that is the case if you are using CAD software. But what about a sketching software? } \\
\text { Do you think that pen and paper are still better? }\end{array}$ \\
\hline ID-P1 & $\begin{array}{l}\text { Well, I mean, I personally do not use the sketching software because I am old school. So it is } \\
\text { just the reality - you have probably heard this expression before - what year were you born? }\end{array}$ \\
\hline NA & 1984. \\
\hline ID-P1 & $\begin{array}{l}\text { OK. I have three sons. You are the same age as my oldest. I have 1984, } 1988 \text { and } 1990 \text { and } \\
\text { you are a digital native. I am a digital immigrant. I grew up without any digital tools. I started } \\
\text { my career without any digital tools. It was half way through my career that digital tools came } \\
\text { into play. You, on the other hand, from the day you were born digital tools were available. } \\
\text { From the day you started school digital tools were available. So you are the digital native. For } \\
\text { me, I still - if I can make just a comparison - a lot of people love using Kindle and the Sony } \\
\text { reader. I am old school in that way too. I enjoy holding a book in my hands and having that } \\
\text { very visceral, tactile, very primary experience when I am doing that and I find the same } \\
\text { experience, for me, it is not the same to have a pen of my choosing and sometimes maybe I } \\
\text { am using a Pilot } 0.2 \text { which is that little fine-tipped marker, maybe I am using HB4 lead in a } \\
\text { mechanical pencil. I have my own peculiarities about those tools. And picking the different } \\
\text { kinds of paper to work with. I know a lot of people, a lot of young designers use Cintiq and } \\
\text { Wacom and all the sketching tools. It is great for them. }\end{array}$ \\
\hline NA & $\begin{array}{l}\text { OK. So if I ask you what are your thoughts on designing using digital tools and media only, } \\
\text { that would be your answer. }\end{array}$ \\
\hline ID-P1 & $\begin{array}{l}\text { That would be my answer. And I think a lot of it has to do with the generation you were } \\
\text { raised in. Another example: One of my mentors was a German designer. He did very little } \\
\text { drawing when he started concept generation. He would immediately go into the workshop } \\
\text { and start building stuff. And making mock-ups immediately because he wanted to see stuff ... }\end{array}$ \\
\hline NA & $\ln 3 \mathrm{D}$. \\
\hline ID-P1 & $\begin{array}{l}\text { In 3D. Right away. That was his method and some of that has rubbed off but I realise now you } \\
\text { can see things in 3D using a digital tool but it still not the same. You cannot hold it in your } \\
\text { hand. I do not know if you have experienced this yet but I cannot tell you how many times we } \\
\text { have created the design on a computer without making enough models or mock-ups and } \\
\text { then when the first model gets made there is this realisation - you knew all along what the } \\
\text { dimensions were - wow, that is bigger than I thought it would be. Because now it is a real } \\
\text { thing in front of you. And you know, at these sizes } 5 \mathrm{~mm} \text { or } 10 \mathrm{~mm} \text { per side totally changes the } \\
\text { appearance. So that is my take there. }\end{array}$ \\
\hline NA & $\begin{array}{l}\text { I will be showing you the digital industrial design strategy and then you can give me your } \\
\text { feedback on it if you do not mind. So over here you can see the three main stages of the } \\
\text { design, concept generation, development and specification. There is the one-way route, } \\
\text { which is the black solid line and there is the two-way route, which is the black dotted line, so } \\
\text { you can go from here to here and back again. In concept generation you can see a range of } \\
\text { different input devices, some of which you have actually mentioned just now, like the } \\
\text { Wacom, one way like tablet - a display that has a pen or a stylus and there is the other one } \\
\text { which has a two-way interaction, where you can sketch on the tablet but you cannot see } \\
\text { what you sketch on top of the tablet, you have to see it on the screen. And this is a pen input } \\
\text { device, which is basically a pen with special paper maybe and then you draw on that paper. }\end{array}$ \\
\hline
\end{tabular}




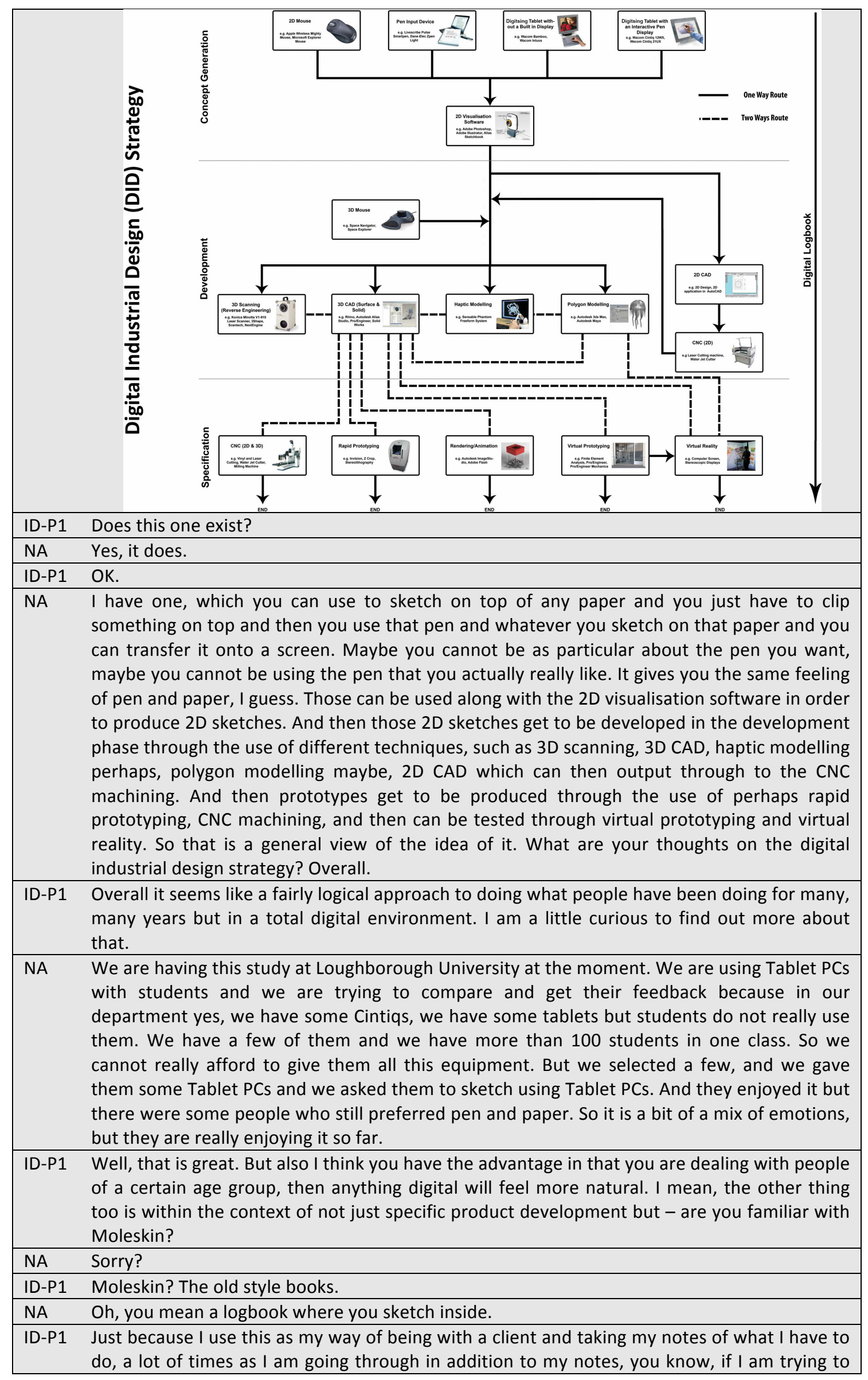




\begin{tabular}{|c|c|}
\hline & $\begin{array}{l}\text { take - for example, if I was trying to record the meeting on a computer using a digital tool, I } \\
\text { could not work this fast. Because just to create like this little sketch note for myself about this } \\
\text { project, to create that geometry on a computer. }\end{array}$ \\
\hline NA & $\begin{array}{l}\text { I think that is the case in some situations- but I had a digital logbook where you can use the } \\
\text { Tablet PC and Microsoft Journal to write, you do not have to type, and you can draw. }\end{array}$ \\
\hline ID-P1 & OK, so it would be like this but it would be in a digital format. \\
\hline NA & Yes, in a digital format. \\
\hline ID-P1 & OK. \\
\hline NA & Yes, that is all. But I know you are saying that you still prefer those. \\
\hline ID-P1 & $\begin{array}{l}\text { Well, needless to say, with this I do not have to worry about charging a battery, I do not have } \\
\text { to have access to an outlet, it is a lot lighter, lightweight and I can put it in my pocket. Is } \\
\text { digital moving in that direction? Absolutely. I mean, battery life keeps getting longer, the } \\
\text { computing power gets more powerful, things get thinner, more lightweight. Yes, it is all } \\
\text { moving in that direction. }\end{array}$ \\
\hline NA & True. Do you have any reservations regarding this strategy? \\
\hline ID-P1 & $\begin{array}{l}\text { Well, I mean again, my initial impression is it is perfectly logical and it follows a clean path to } \\
\text { development. The only thing I would say is that my experience is product development and it } \\
\text { tends to never be quite as neat and clean and it tends to be rather messy, especially when } \\
\text { you have a lot of forces coming to play on how a product should be made. But that really } \\
\text { does not affect your digital progress because those forces may deal with changing } \\
\text { specifications or changing requirements or changing how the product is going to operate. But } \\
\text { how you would implement that could still play into this scenario. }\end{array}$ \\
\hline NA & Right. Do you have any suggestions to improve it? \\
\hline ID-P1 & I am curious. Do you guys use haptic modelling in your school? \\
\hline NA & $\begin{array}{l}\text { Yes, we have it at our school. When I did my Masters at my university we used it just to } \\
\text { experience how does it feel. But then the undergraduates did not really use it. }\end{array}$ \\
\hline ID-P1 & OK. And what were you using it for? \\
\hline NA & $\begin{array}{l}\text { We were just trying to see how does it feel when we try to model like anything, any product } \\
\text { or something. }\end{array}$ \\
\hline ID-P1 & $\begin{array}{l}\text { OK. But I mean, were you trying to determine if it is an object that has buttons on it, what the } \\
\text { feel of ... }\end{array}$ \\
\hline NA & No, we were just trying to drill holes in something so it was really basic. \\
\hline ID-P1 & So you felt the feedback of the drill going through. \\
\hline NA & Yes, but my supervisor is actually involved with haptic modelling so he knows a lot about it. \\
\hline ID-P1 & $\begin{array}{l}\text { We have used haptic modelling with companies where we have done prototyping of mobile } \\
\text { phones where we could actually create the geometry and the software, in a haptic model and } \\
\text { then bring in users for usability testing. So I have found that to be an interesting tool for } \\
\text { speeding up things because, by the time you build a functional prototype, you are really far } \\
\text { down the path of development and you have got a lot of money wrapped up into it. This is } \\
\text { kind of a way to get some feedback earlier on and find out what the problems are. Nothing } \\
\text { jumps out at me as being particularly problematic. }\end{array}$ \\
\hline NA & How do you feel towards the viability of the DID strategy? \\
\hline ID-P1 & $\begin{array}{l}\text { I think it is totally viable. I think, again, this kind of strategy is first of all totally doable, it is } \\
\text { viable and the only thing I would ask is in some of the earlier phases, I was saying once we go } \\
\text { through here basically everybody is now forced to work digitally by the nature of } \\
\text { manufacturing. What do you see as the advantages of, in the very early part of this, being all } \\
\text { digital as opposed to working both digitally and manual? }\end{array}$ \\
\hline NA & $\begin{array}{l}\text { Better collaboration between members of the product development and efficiency. To tell } \\
\text { you the truth, I do not feel very confident when I am sketching. I am not very good at drawing } \\
\text { ellipses, for example, manually, accurately if I am sketching something. I can draw an ellipse } \\
\text { but it would not look right. When I use Alias SketchBook Pro that just increases my } \\
\text { confidence and that was one of the advantages that the students themselves mentioned. } \\
\text { They felt that because they can undo when needed they tended to be more expressive. They } \\
\text { can draw anything and then just click an undo button if they did not like it. They were able to } \\
\text { create more variation. }\end{array}$ \\
\hline ID-P1 & It is an interesting point of view. And a very valid point of view. I think, again I am now \\
\hline
\end{tabular}




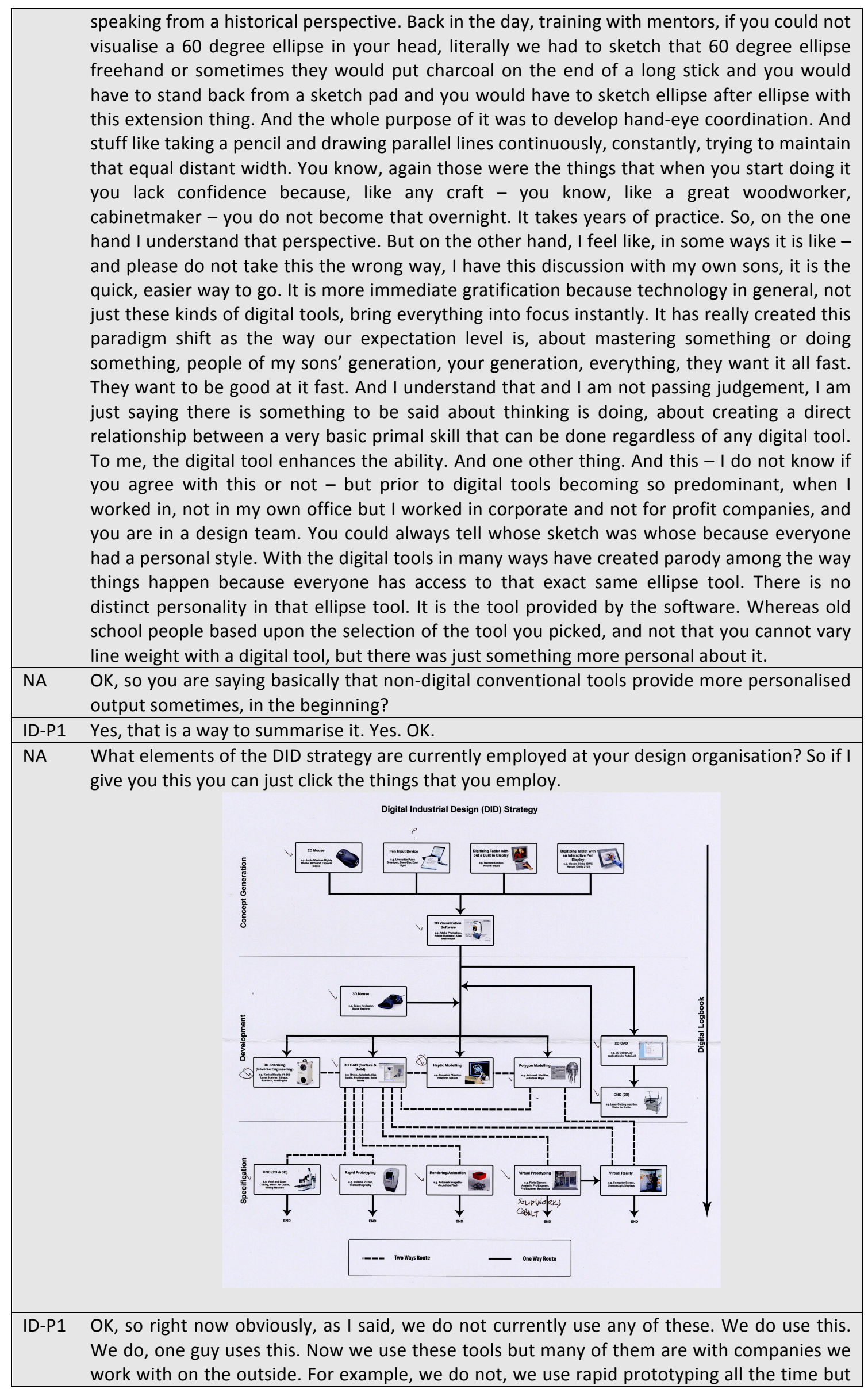




\begin{tabular}{|c|c|}
\hline & ve do not have that equipment here. \\
\hline NA & If you use it, then tick it. \\
\hline ID-P1 & $\begin{array}{l}\text { Yes, that is what I thought I was doing. So, and we use this. We use this. Yes but we do not } \\
\text { use Pro/E, we use SolidWorks. We use - I do not know if you would - we do, because we } \\
\text { develop a lot of Uls, GUIs, graphical user interface. We do not really use virtual reality for that } \\
\text { but, and I do not know where we would fall into, we use flash. We create flash simulations. }\end{array}$ \\
\hline NA & That is in rendering and animation. \\
\hline ID-P1 & $\begin{array}{l}\text { OK. So we tick that. We use this, we use this. This occasionally. So just - no, I do not have this } \\
\text { capability here, this is something I work with at the university. We use this. Again, we have } \\
\text { used this on occasion, not that often. We have done it. So do you want me to tick that or not? }\end{array}$ \\
\hline NA & $\begin{array}{l}\text { Yes, you can. OK. Can you provide reasons for not including the remaining of them? The } \\
\text { remaining tools or media? So if I ask you about those three. }\end{array}$ \\
\hline ID-P1 & $\begin{array}{l}\text { OK. Well, this one - as I said initially - I was totally unfamiliar with. This one I have seen and } \\
\text { the fact that you have to look at the screen and draw down here, that threw me completely. } \\
\text { So that would not work for me. I cannot speak for anybody else. I do not get that weird } \\
\text { relationship. The school, the university that I teach at uses Cintiq. They have some, not many, } \\
\text { there is only two so students have to share those, they are in high demand. I have played } \\
\text { around with the Cintiq a little bit and I can see the value in it but we do not currently have } \\
\text { that tool here. }\end{array}$ \\
\hline NA & And is that because of cost or you just because you do not need it? \\
\hline ID-P1 & $\begin{array}{l}\text { Well, a little bit of cost. I mean, they are about } \$ 2,000 \text { for the tablet. We would probably } \\
\text { need to buy more than one. But I think part of it is the young designers that we work with } \\
\text { have not asked for it. So now, my partner and I, we are old school so, you know, the pen and } \\
\text { paper set. I would think that if some of the young designers really wanted to work with that } \\
\text { we would probably make the investment. }\end{array}$ \\
\hline NA & All right, OK. And what about virtual reality? \\
\hline ID-P1 & $\begin{array}{l}\text { Again, the university has virtual reality so I have had a chance to play with it. I think it has } \\
\text { applications but in the kind of work we are doing, we do a lot of tabletop kind of design. We } \\
\text { are not doing environments so if you are not designing like retail store environments. For } \\
\text { example, we designed this a number of years ago. Now, how would I use virtual reality with } \\
\text { this? }\end{array}$ \\
\hline NA & \\
\hline ID-P1 & $\begin{array}{l}\text { For this. I mean, you know. We did use this because we did the whole UI in flash and then did } \\
\text { usability testing using flash where we had people just come in and navigate but our work } \\
\text { does not really fall into that category. }\end{array}$ \\
\hline NA & $\begin{array}{l}\text { Would you like to employ the digital industrial strategy in the design practice of your design } \\
\text { organisation? }\end{array}$ \\
\hline ID-P1 & My answer would be, we probably employ $80 \%-90 \%$ of it already. \\
\hline NA & $\begin{array}{l}\text { And would you be interested in hiring students who come from an entirely digital industrial } \\
\text { design course? }\end{array}$ \\
\hline ID-P1 & $\begin{array}{l}\text { Lets say this: it would not affect me one-way or the other. Meaning if they had strong skills } \\
\text { and a solid understanding of process, whether they did it all digitally or whether they did a } \\
\text { combination of digital and - I do not know, what do we call the other one? Analogue or } \\
\text { whatever - that to me would have no real significant bearing. }\end{array}$ \\
\hline NA & OK. Thank you. Is there anything more you would like to add? \\
\hline ID-P1 & $\begin{array}{l}\text { I guess my question to you is: All of this strategy takes place once concept generation is about } \\
\text { to begin. How do these digital tools, if at all, affect the background and the research that } \\
\text { goes into determining how you get to the point to actually begin the conceptual design } \\
\text { development? }\end{array}$ \\
\hline NA & $\begin{array}{l}\text { Oh, it does not address that. It focuses on the main design activities, which are sketching and } \\
\text { modelling basically. So it does not address or it does not go into a lot of details on this or } \\
\text { mechanics or ergonomics or sustainability, for example. }\end{array}$ \\
\hline ID-P1 & That is a fair and honest assessment. \\
\hline & nKs d lol tor your time, your leedodek is very vo \\
\hline
\end{tabular}




\title{
11.7 Academic Interview Transcript Sample
}

\author{
Date: 25 January 2010
}

Location: UK

Description of participant: Head of Product and Interior Design Department

\begin{tabular}{|c|c|}
\hline NA & First of all, would you like to summarise your experience as a designer and educator? \\
\hline ID-A1 & $\begin{array}{l}\text { OK. I have been an educator for } 12 \text { years, or involved in design education for } 12 \text { years as a } \\
\text { lecturer and module leader and then getting more involved in course management. So I was } \\
\text { the person who wrote the curriculum to integrate CAD into the design programmes here. }\end{array}$ \\
\hline NA & Into product design? \\
\hline ID-A1 & $\begin{array}{l}\text { Into product and furniture design, yes. And then programme leader and subject leader and } \\
\text { now department head. So my education experience goes from the coalface of face-to-face } \\
\text { teaching students right the way through to the overall structure and direction of the } \\
\text { programmes. So that is the design education. On the consultancy side, alongside some of my } \\
\text { teaching experience, I have worked as a consultant designer and for myself as a freelance } \\
\text { designer for several years. And then as a designer within the university. So I was a practicing } \\
\text { designer on projects here until } 2007, \text { I think was the last piece of commercial design work. So } \\
\text { to make it even more complicated, half of my time at the university, half of it I spent as a } \\
\text { freelance designer and then half as a lecturer for several years. And then I became a full time } \\
\text { academic but part of my role was set aside to do practicing design work until } 2007 \text { and from } \\
2007 \text { onwards I am not doing any design work at all. I am just an academic now. }\end{array}$ \\
\hline NA & OK, right. \\
\hline ID-A1 & OK. Does that summarise it? \\
\hline NA & Yes, it does. \\
\hline ID-A1 & It is not straightforward. It is slightly complicated. \\
\hline NA & $\begin{array}{l}\text { Can you describe how non-digital and digital tools are used by students to design at your } \\
\text { university? So in concept generation what tools do they use, and in development what tools } \\
\text { do they use, and specification basically? }\end{array}$ \\
\hline ID-A1 & $\begin{array}{l}\text { Leaving aside initial research work, I am assuming you are talking about the skill-based side of } \\
\text { design work now, so in concept generation then, probably the key design tool is still the } \\
\text { sketchbook. So it is still using pencil and pen on paper. It still forms a particularly important } \\
\text { part. If the design is, if they are exploring say more tangible elements, such as say, form or a } \\
\text { mechanism then quick models, physical 3D models also will form an important part as well. } \\
\text { Within the first year there are a series of modules that look at skills. So within concept } \\
\text { generation there is, supporting that, there is a module that looks at visual communication. } \\
\text { Part of that will be using pencil and paper and marker pens in a traditional way. But within } \\
\text { the same module they will also be using Photoshop and Illustrator. So they will be generating } \\
\text { original artwork using a pen but also generating original artwork using Wacom interactive } \\
\text { screens so each computer now has an interactive screen. }\end{array}$ \\
\hline NA & Oh, so you have Wacom tablets here, Cintiqs? \\
\hline ID-A1 & $\begin{array}{l}\text { Yes, for each computer. So we are trying to, we firmly believe that drawing is still the core } \\
\text { tool that a designer uses to communicate ideas but we are trying to bridge the gap between } \\
\text { people thinking designing it on a computer is using a mouse and a different skill set than } \\
\text { those using pen and paper. So we still do a chunk of traditional drawing work, but then that } \\
\text { then moves on into using Photoshop and Illustrator Creative Suite basically so they will be } \\
\text { doing very similar exercises that they do with paper and pen but within a digital environment. }\end{array}$ \\
\hline NA & So how many Cintiqs do you have? \\
\hline ID-A1 & 27 , so not a lot but our CAD groups are limited to groups of 25 , so we have 27 Cintiqs. \\
\hline NA & And then in the development phase? \\
\hline ID-A1 & $\begin{array}{l}\text { The development phase again, on the digital side they would have, most students will go on } \\
\text { and define their design within CAD so they will use, say, Solidworks for doing development }\end{array}$ \\
\hline
\end{tabular}




\begin{tabular}{|c|c|}
\hline & $\begin{array}{l}\text { work. Prior to that, as part of the concept generation stage, on the CAD side we use Alias. } \\
\text { Alias Design Studio or AutoStudio for doing surface modelling. So the idea is that, say this } \\
\text { thing here, the concept for and the surface model is created in Alias and then we will export } \\
\text { the surface data into Solidworks and then we will use Solidworks Parametric modelling to do } \\
\text { the internals and all the mechanism behind it. }\end{array}$ \\
\hline NA & So are you saying that in concept generation they are going to use Alias to create the surface? \\
\hline ID-A1 & Yes, depending on what level they are and what year and what project. \\
\hline NA & So they will go straight into CAD in concept generation? Then at some point 3D modelling? \\
\hline ID-A1 & $\begin{array}{l}\text { No, actually. I will pull back a little bit on that because the idea of using Alias is that in } \\
\text { concept generation they will create models over 2D elevations. So they use SketchBook Pro, } \\
\text { PhotoShop or pen and paper, scan them in and use the drawing planes that Alias uses with } \\
\text { the form that they do. So then they will generate the concept form based around original } \\
\text { artwork so that is the process. Now, the original artwork may come wholly from PhotoShop, } \\
\text { SketchBook Pro or from pen and paper, or a combination of all of them, depending on how } \\
\text { the students are working. So with this coverage going straight into concept generation it is in } \\
\text { 3D form but concept generation will start on 2D before moving into 3D. }\end{array}$ \\
\hline NA & What about the development phase? \\
\hline ID-A1 & $\begin{array}{l}\text { Depending again on which year and how substantial a project is, if it is development of form } \\
\text { then it will be done, there will be a lot of development that will be done subtly within CAD, if } \\
\text { it is defined in CAD, you know. So what happens if I increase that radius here, how does it } \\
\text { look? So there will be a lot of using CAD as a developmental tool and alongside that they will } \\
\text { be using maquettes and models to also develop an idea. So I would expect to see within the } \\
\text { development process of that several different 3D versions of it. }\end{array}$ \\
\hline NA & In CAD? \\
\hline ID-A1 & In CAD and in 3D. \\
\hline NA & So like, out of foam? \\
\hline ID-A1 & Yes. \\
\hline NA & OK. \\
\hline ID-A1 & $\begin{array}{l}\text { Yes, so they would go, and this is really important and this is where commercially a lot of } \\
\text { companies are trying to squeeze the design process to go straight to final production and } \\
\text { missing out the stages of 3D development. So at the development stage students, and I am } \\
\text { talking about form now rather than, say, mechanisms approach. I would expect to see several } \\
\text { iterations of a form in 3D, in real 3D, before getting to the final one. The development may be } \\
\text { mechanical. So it may be building a rig and physically testing things which again we would } \\
\text { expect to see done in 3D but being supported by a digital tool as well. }\end{array}$ \\
\hline NA & A digital tool? \\
\hline ID-A1 & $\begin{array}{l}\text { Yes, things like using mechanisms in Solidworks or Pro/E if you are a BSc student. So when } \\
\text { you get to specification, specification in terms of generating a data set for production will be } \\
\text { exclusively done in CAD. So they will generate part drawings, assembly drawings from the } \\
\text { CAD that they have generated. And prototypes will be made using a combination of Rapid } \\
\text { prototyping techniques and 3D, hand made 3D models. So if you were doing something, } \\
\text { again using this phone as an example, if it was an appearance model then there is a 50-50 } \\
\text { chance of them doing it as an RP part or as a foam model, depending on which is easier. } \\
\text { Because sometimes it is actually as quick to make a model in foam by hand, you know, rather } \\
\text { than CNCing it or getting an SLS or FDM or SLA made of it. So you will find that with students, } \\
\text { it will all vary. }\end{array}$ \\
\hline NA & $\begin{array}{l}\text { What would you say is the typical percentage split between non-digital and digital tools used } \\
\text { within the students' design practice at your university? So in concept generation would you } \\
\text { say, for example, they use } 50 \% \text { digital and } 50 \% \text { non-digital? Or } 60 \%-40 \% \text { ? What is the } \\
\text { percentage? }\end{array}$ \\
\hline ID-A1 & $\begin{array}{l}\text { OK, it depends on whether you are counting in, because most concept generation will come } \\
\text { almost exclusively through pen and paper, but the presentation of that concept generation } \\
\text { will be largely digital. You know, so if we were to spend a day on a project, generating a new } \\
\text { concept for this phone, all the ideas, the actual concepts being generated would be done by } \\
\text { hand but then you would perhaps scan those in, use Photoshop and use whatever piece of } \\
\text { software to take the best ones and then present it. So it depends what you want the split to }\end{array}$ \\
\hline
\end{tabular}




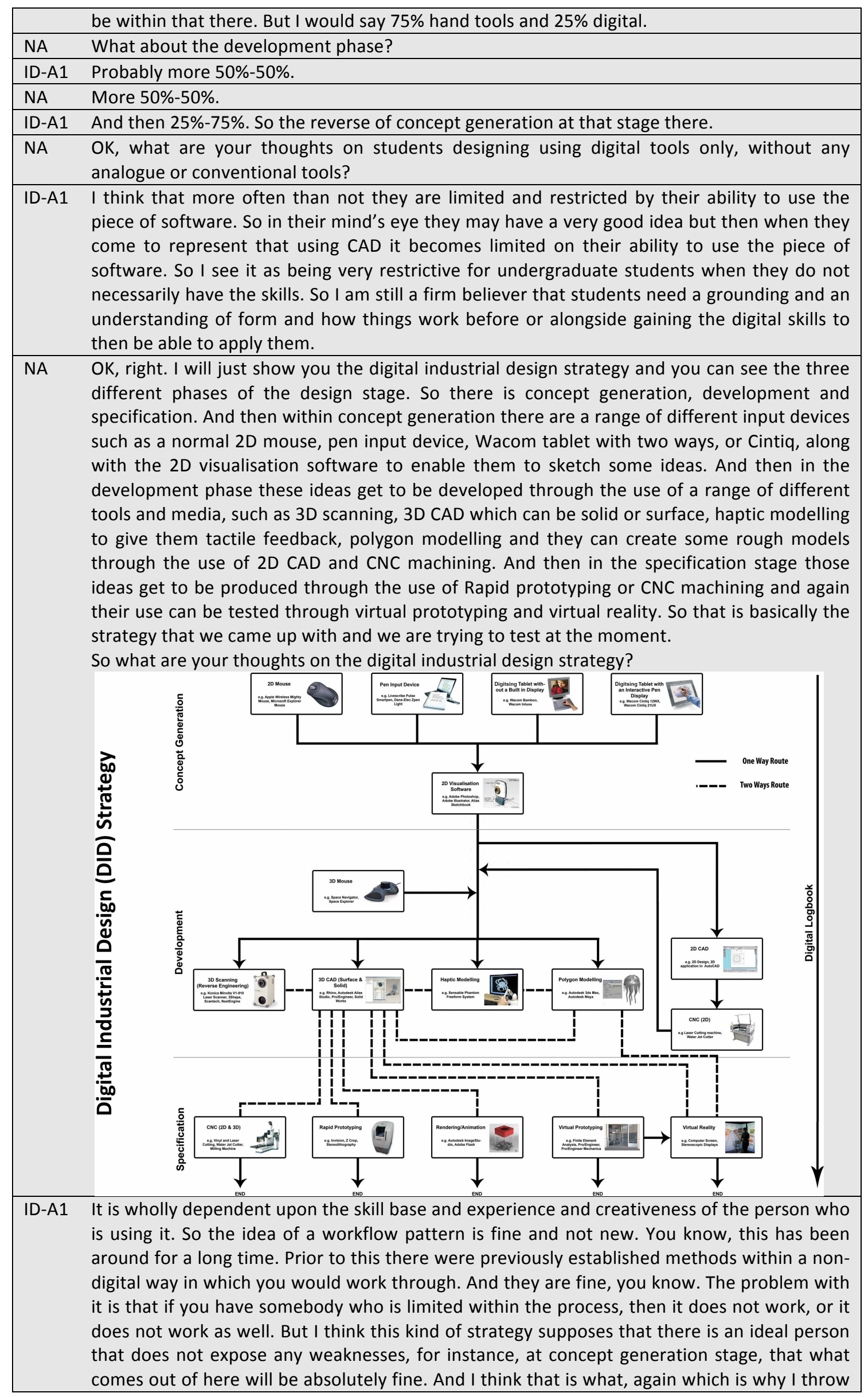




\begin{tabular}{|c|c|}
\hline & $\begin{array}{l}\text { the question back to you: What does this hope to improve over an existing model where } \\
\text { somebody hand-drew something here? }\end{array}$ \\
\hline NA & $\begin{array}{l}\text { To ease the collaboration between designers, engineers and manufacturing team, to save } \\
\text { time and to increase efficiency. At the moment, we have this study as part of the PhD as well, } \\
\text { we have a number of Tablet PCs and we are giving them to students and we are trying to } \\
\text { compare how they actually draw, using pen and paper and draw using the Tablet PC. And a } \\
\text { lot of them actually had fun and preferred the Tablet PC over the output of pen and paper } \\
\text { because they felt that they it improved their sketching, that the tools within, for example, } \\
\text { Alias SketchBook Pro, like the ellipses and things, they felt it was like easier to use it over } \\
\text { sketching with pen and paper. }\end{array}$ \\
\hline ID-A1 & $\begin{array}{l}\text { Yes, OK. Yes, I think we must not confuse the issues here between what is a skill and, within } \\
\text { concept generation, and what is a good idea within concept generation. You know, so you } \\
\text { can be - it is like the scenario, forget about being digital, but you can be the best drawer in } \\
\text { the world but it does not mean you actually come up with any decent ideas. So providing that } \\
\text { the strategy behind concept generation is still in place, then whether you draw it digitally or } \\
\text { whether you draw it by hand. }\end{array}$ \\
\hline NA & It will not affect creativity. \\
\hline ID-A1 & $\begin{array}{l}\text { It will not affect creativity. If the digital tools enable somebody to communicate something } \\
\text { more effectively then you would argue that the digital tool is enhancing the design process } \\
\text { because they can present something more effectively than their drawing skills. So if your } \\
\text { drawing skills are worse than your computer skills then it makes sense to use your computer } \\
\text { skills. Yes? So in that part there I think it is a bit of a no-brainer that this is purely about skill } \\
\text { and with advances in software and input devices now, if you can get to a better result in a } \\
\text { shorter space of time using digital tools, then absolutely fine. I think perhaps the key stage in } \\
\text { this, for me which is a negative about a wholly digital strategy, is the missing out of 3D } \\
\text { prototyping. And that does not come from an idealistic point of view that comes from } \\
\text { commercial experience of working with clients who want you to miss out that stage because } \\
\text { it costs money. So back in the day, you would get to a stage where you would present a } \\
\text { physical model to a client before going to produce tools and, you know, it was used for a } \\
\text { whole range of reasons, verification of the design, is it too big, is it too small, does it look } \\
\text { right? All those kinds of things. And now we are finding increasingly more and more clients, } \\
\text { because of the advancement with software and the whole digital area, are pressurising } \\
\text { people to miss out that stage so we go straight to virtual prototyping and straight to the } \\
\text { actual producing the design, to save money. So this becomes a bit of a victim of its own } \\
\text { success, that people, you know, are starting to miss out that all-important stage. }\end{array}$ \\
\hline NA & $\begin{array}{l}\text { But they can still go through it. Let's say if they want to produce a mock-up, they can go } \\
\text { through to } 2 \mathrm{D} \text { CAD and then CNC machining, for example. Or they can use Rapid prototype to } \\
\text { produce models. }\end{array}$ \\
\hline ID-A1 & $\begin{array}{l}\text { Yes, I mean a lot of this information here needs to be within the development stage as well. } \\
\text { Because, you know, in an ideal process, forgetting about the people who want to miss out on } \\
\text { a stage, before you get to specification and development stage, the conclusions that you will } \\
\text { make, you will produce a master piece of that to check that it fits and, before that you may } \\
\text { produce several different variants of this. }\end{array}$ \\
\hline NA & $\begin{array}{l}\text { Yes, I think that is why I had it as a two-way route over here. So that you can go there and } \\
\text { you can still go back. }\end{array}$ \\
\hline ID-A1 & $\begin{array}{l}\text { Yes. So the idea that a client would miss out on that is worrying. Going back to the } \\
\text { development, if you are using form as an example, there is a reason why, say in automotive } \\
\text { design, they still produce clay models and I have yet to see an argument for somebody who is } \\
\text { being educated wholly digitally to be able to design form particularly effectively. You know, if } \\
\text { I give you an example. I once had a student who was born with a birth defect. He did not } \\
\text { have any legs and only had one hand and on that one hand he had a finger and a thumb, OK. } \\
\text { And he was one of the best drawers that I have ever come across. He could draw beautifully. } \\
\text { As a designer and a visualiser he was absolutely fantastic. When he came to specifying and } \\
\text { assembling how something came together he was absolutely terrible and he had not had, } \\
\text { despite working in a digital environment, he had never had any experience in life of what it is } \\
\text { like to try and fit a fixing on the inside there going through from the back or, you know, he }\end{array}$ \\
\hline
\end{tabular}




\begin{tabular}{|c|c|}
\hline & $\begin{array}{l}\text { did not have the real world examples of experience, of being able to manipulate things } \\
\text { because of his disability. But on a computer and drawing he could show things absolutely } \\
\text { perfectly. But it never translated into a real 3D world and I think there is - I mean, you show } \\
\text { haptic arms which are not that brilliant at the moment are they? Apart from genius people } \\
\text { who know how to use them. And so I think we are still at a stage now where that real tactile, } \\
\text { 3D experience about assemblies and form still is not good enough in a digital environment to } \\
\text { replace what is the real world. So I am not saying that to diss what you have here but I think } \\
\text { this is the fault that I have with it - sorry if I am being too harsh, but as I said it is my opinion. }\end{array}$ \\
\hline NA & No, it is OK. \\
\hline ID-A1 & $\begin{array}{l}\text { Is that it is wholly digital, when the real world is not, we will get into a stage where we are } \\
25 \% \text { digital, } 50 \% \text { digital and we are now approaching, say, } 75 \% \text { digital, rather than proposing } \\
\text { something - well, actually it should be } 100 \% \text { digital. So, you know, there are a few areas } \\
\text { where I think it is still better to do it in the real world, that do fit alongside this, which would } \\
\text { justify it. }\end{array}$ \\
\hline NA & And this area would be building mock-ups and prototypes? \\
\hline ID-A1 & $\begin{array}{l}\text { Yes, 3D form, a manipulation of 3D form, purely from an aesthetic point of view, I think is still } \\
\text { something that needs to be done by hand. And very quick foam models, real quick ones at } \\
\text { the beginning, for me are still an important part of the industrial design process. }\end{array}$ \\
\hline NA & $\begin{array}{l}\text { OK. Do you have any other reservations regarding the strategy? Apart from what you just } \\
\text { mentioned. }\end{array}$ \\
\hline ID-A1 & $\begin{array}{l}\text { No, I think again, for me, my key observation to it really is it is wholly reliant upon digital tools } \\
\text { and I think that makes it look, in terms of a real industrial design process, it is slightly naïve. } \\
\text { You know, so you go to a design consultancy and say: How would this map fit to how you } \\
\text { work? And ask them, you know, because people do not want to hang on to traditional skills } \\
\text { for the sake of hanging on to them. This is business, so if we can invest in capital and lose } \\
\text { staff and reduce the time, then consultancy will do that because that is a business model that } \\
\text { we are all working to. So people do not hang on to traditional model making skills, for } \\
\text { example, for the sake of it. I know you are recording this, are not you, so I cannot tell you } \\
\text { who the client is but a friend of mine is working on a job for a big consultancy, for a big } \\
\text { automotive manufacturer at the moment and they have still gone down a route of using hand } \\
\text { carving techniques to shape the product. Previously they went down a route of doing wholly } \\
\text { CAD, it went through a complete CAD process and the hand modelling was purely finishing } \\
\text { the RP parts. }\end{array}$ \\
\hline NA & Do you mind me asking what product was it? \\
\hline ID-A1 & Yes, a motorbike. \\
\hline NA & A motorbike, OK. \\
\hline ID-A1 & $\begin{array}{l}\text { Yes, so now they have gone back to a different process because they think that they lose } \\
\text { some sort of sensitivity through going through wholly CAD. Having said that, the assembly of } \\
\text { the bike, it is vitally important that it is done in CAD and the fact that many, many different } \\
\text { teams at different locations are working on the product means that this is particularly } \\
\text { important. And I think that is perhaps something that does not come across. I mean, you } \\
\text { cannot explain everything on one page, I know, but the advantages for this are not shown as } \\
\text { clearly, just through the process. Interesting thing on haptic modelling, I went to, you know } \\
\text { the Games Workshop? You know the people that do Dungeons and Dragons and all that sort } \\
\text { of school boy stuff? You know the game Dungeons and Dragons? }\end{array}$ \\
\hline NA & Yes I do. \\
\hline ID-A1 & $\begin{array}{l}\text { They are traditional, they make, manufacture hundred and thousands of little goblins and } \\
\text { fantasy figures for, well I say boys, grown men, OK. And the traditional way of doing it is by } \\
\text { hand modelling because that is how you craft something, which is so complex. And they get } \\
\text { cast in metal, then injection mould them. What they do now is they use a haptic model. They } \\
\text { have re-trained their development team to use haptic modelling. So if you wanted to visit } \\
\text { someone to see, to support something like this - I can email you their contact details if it } \\
\text { helps - but it might be interesting because they fly in the face of what I am saying. You know, } \\
\text { and they are someone that has a very, very traditional, non-CAD design route to embracing a } \\
\text { digital design route. Now, importantly they still do it in conjunction with the real thing. }\end{array}$ \\
\hline NA & What do you mean in conjunction with the real thing? \\
\hline
\end{tabular}




\begin{tabular}{|c|c|}
\hline ID-A1 & $\begin{array}{l}\text { Well, all evaluation will be done by making and SLS or whatever 3D print of the actual object } \\
\text { and appraising it there. Yes, so it is constantly going in and out of the digital route. So there } \\
\text { will be a manual creation, inter-digital, digital manipulation, rapid prototype made, } \\
\text { evaluation, physical change, re-scanning perhaps if appropriate, back into a digital world, } \\
\text { evaluation for moulding, whatever the case, maybe FEA, all those things, before going down } \\
\text { to the tooling element. So they are still dropping in and out and they are using non-digital } \\
\text { tools because it is more appropriate. You know, so this is a company that I think they are mad } \\
\text { for using some of the digital tools that they use. They say: No, it works. But every so often } \\
\text { they still go to a non-digital route because it supports what they need to do. }\end{array}$ \\
\hline NA & All right. OK. And do you have any suggestions to improve it? \\
\hline ID-A1 & $\begin{array}{l}\text { Do not rely wholly on it being digital. As straightforward as that. You know, because it is - I } \\
\text { do not see the advantage - I guess what I am saying is, you know, you talk here about rapid } \\
\text { prototyping, you know, and it ends. }\end{array}$ \\
\hline NA & So there will be physical prototype. \\
\hline ID-A1 & $\begin{array}{l}\text { Yes, it is showing it. I mean why, it does not end at a rapid prototype does it? You could go } \\
\text { from, in this part here, you can go from visualisation here to rapid prototype. So rather than } \\
\text { present in 2D it may be that you are presenting - with this next stage along - that you are } \\
\text { presenting several versions of the phone wholly digitally but using rapid prototyping } \\
\text { technology. So within your concept selection stage, it may not be paper-based, it will be 3D- } \\
\text { based as well. So that feeds in there. Within this thing here, within the development of it, } \\
\text { again you have got this two-way thing going backwards and forwards and for me it would be } \\
\text { exaggerating that a little bit more so you do not present this as being wholly just a digital } \\
\text { route. For instance, you know, if you are showing you have got scanning techniques in here, } \\
\text { then I would make a rapid prototype of that, or a CNC - I would CNC that in foam, OK - and } \\
\text { you have got that sliding line on there and I go: When it reflects there it makes it look a bit } \\
\text { flat. If we extend that line down here and add } 2 \mathrm{~mm} \text { to there, make it not quite so flat there, } \\
\text { slightly more, and I would do that, yes, by hand. I can then re-scan it in, cannot I? }\end{array}$ \\
\hline NA & Yes. \\
\hline ID-A1 & $\begin{array}{l}\text { Yes, and then go back into the parametric system and carry on. But this sort of proposal does } \\
\text { not suggest that that is possible. It sort of shows it only as a digital route. }\end{array}$ \\
\hline NA & OK. \\
\hline ID-A1 & $\begin{array}{l}\text { So it might be your presentation, or perhaps you think that? I had a supervisor of PhD and } \\
\text { she thought that all creativity should come from computers. }\end{array}$ \\
\hline NA & $\begin{array}{l}\text { Even when using rapid prototyping you would still have to sand some parts to get them, } \\
\text { because there would still be some uneven surfaces. So you would still have to sand them. }\end{array}$ \\
\hline ID-A1 & $\begin{array}{l}\text { But what if though, a few years down the line, the striations are so small now that you do not } \\
\text { even need to do that, because that is the aim of rapid prototyping, is not it? That build } \\
\text { becomes smaller and smaller and coloured so you do not even need to do that. I am talking } \\
\text { about changing the design, using my eye and my understanding of form here to make } \\
\text { judgements about the change of design, not relying on seeing that on a screen to make that } \\
\text { judgement but actually holding it in my hand. An iPhone, for example or an iTouch with a } \\
\text { metal back, you know, it feels cold on my hand, does not it? }\end{array}$ \\
\hline NA & Yes. \\
\hline ID-A1 & $\begin{array}{l}\text { It feels heavy. It is not a mistake. You know, that is part of the design process, was to try and } \\
\text { give someone a feeling of quality and solidity in a product. And that is very hard to evaluate } \\
\text { within a computer environment. }\end{array}$ \\
\hline NA & OK. How do you feel towards the viability of the DID? \\
\hline ID-A1 & $\begin{array}{l}\text { I think there are two key elements to it, I think. There is an idealistic approach which I am still } \\
\text { maintaining in design education where a digital strategy is used in conjunction with the } \\
\text { better parts of a manual strategy, non-digital strategy. And then you have got the route to } \\
\text { market and the cost within the design process side of it. So there is two completely separate } \\
\text { ways of looking at it and I think that the influence over manufacturing from the Far East will } \\
\text { mean that you will see this strategy, I think, will be more and more implemented at the } \\
\text { expense of quality form and some quality design as well. So I think there is absolutely no } \\
\text { reason that now - and I have done it - get on a computer and go through a complete design } \\
\text { process, yes, and the last thing I do is email some data for tooling and an average product }\end{array}$ \\
\hline
\end{tabular}




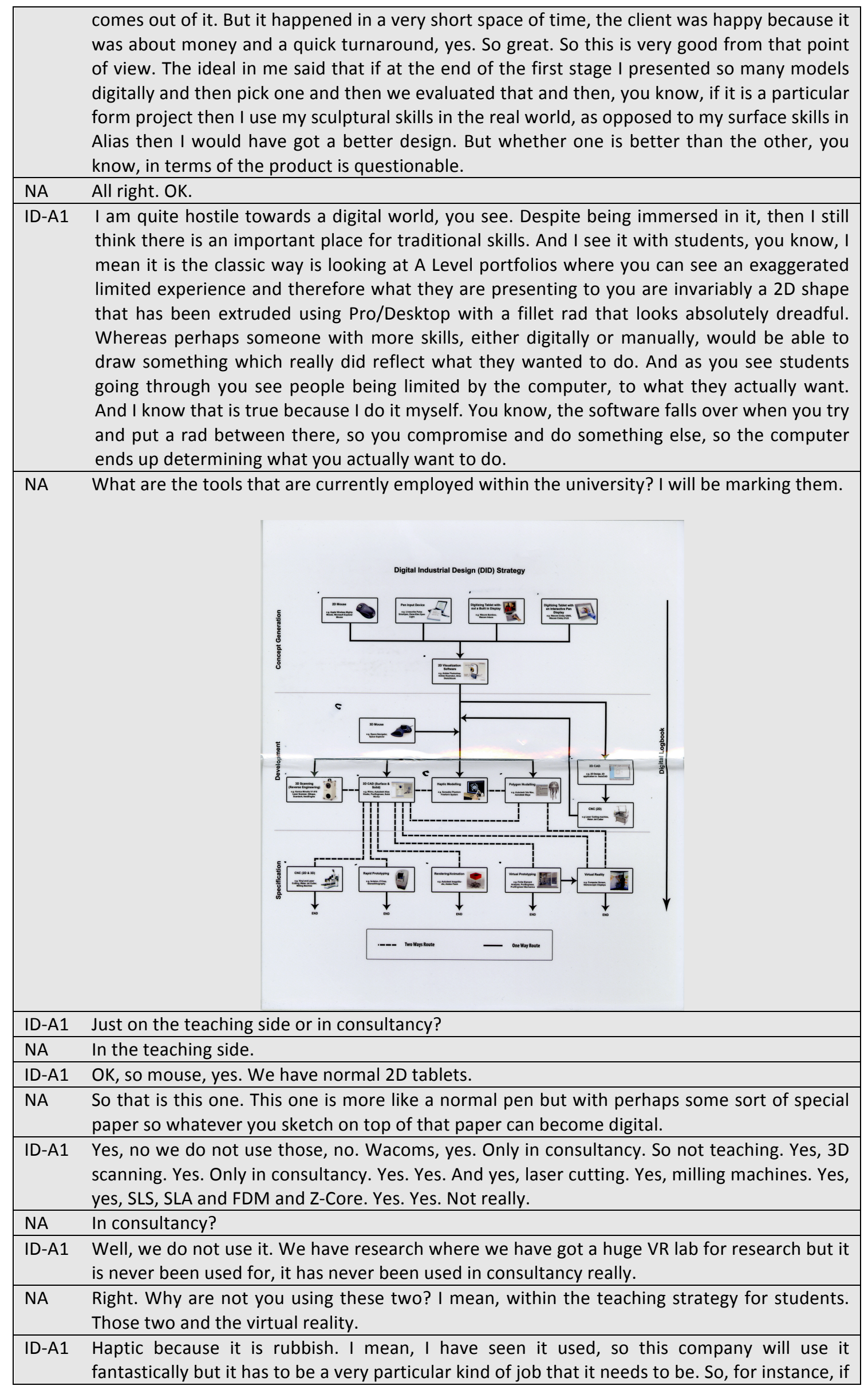




\begin{tabular}{|c|c|}
\hline & $\begin{array}{l}\text { you were designing that, then the wrong tool. You would not do that using haptic modelling. } \\
\text { But if I was modelling a caricature of myself, for something which is far more sculptural, then } \\
\text { it would make sense to do that. But the amount of input needed to get the skill level high } \\
\text { enough to benefit from it is too high for undergraduate teaching on a product design course, } \\
\text { that is why we do not do that. The 3D mouse thing is, there is a very good technical reason } \\
\text { why we do not and that is Alias has its own input system called Marking Menus. Do you know } \\
\text { Alias? }\end{array}$ \\
\hline NA & Yes. I have used it. \\
\hline ID-A1 & $\begin{array}{l}\text { You know it, so you press two buttons and button down and then move up and it brings up a } \\
\text { menu and where you move the mouse, yes. When you try and use a 3D mouse with it, the 3D } \\
\text { mouse does not use a marking menu system so it is actually very hard to use a 3D mouse with } \\
\text { Alias Marking system. So that is the reason why. }\end{array}$ \\
\hline NA & And what about Pro/Engineer or SolidWorks? \\
\hline ID-A1 & $\begin{array}{l}\text { Again, it works very well with SolidWorks and the guys use it in the consultancy but we try } \\
\text { not to confuse students by, you know, one piece of software use this, on another piece of } \\
\text { software use that. So there is not that advantage of productivity that you get from a } \\
\text { commercial environment. }\end{array}$ \\
\hline NA & All right. And what about virtual reality? \\
\hline ID-A1 & $\begin{array}{l}\text { Well, part of the reason is that the VR set up that we have here is a research facility and } \\
\text { within education that would be a module in itself on how to test, evaluate, present using VR } \\
\text { because you are taking your computer model, you are then putting it into a completely } \\
\text { different piece of software and different environment. And so accessibility to it would be an } \\
\text { issue. It is not prevalent in the majority of commercial consultancy so by giving the students } \\
\text { the skills, it is not that they will get an opportunity to practice them, unless you are working } \\
\text { for Ford or somebody like that, you know, some big companies who are experimenting with it } \\
\text { at the moment. So I see it more as a student would go on after getting an underpinning at } \\
\text { Bachelors level, would then go on at Masters level or PhD and explore it more fully. }\end{array}$ \\
\hline NA & OK, and the final one is the pen input device. \\
\hline ID-A1 & $\begin{array}{l}\text { Again, when each student has got their own - or each computer, sorry - has its own Wacom } \\
\text { interactive screen there seems little point in using one of those when we have got those. I } \\
\text { mean, the normal tablets now sort of no-one is bothering using them because that has } \\
\text { superseded it really. }\end{array}$ \\
\hline NA & $\begin{array}{l}\text { But why are you using the Cintiq and not a Tablet PC when the Tablet PC is more portable. I } \\
\text { have personally used both of them and I think the Tablet PC is easier to get around } \\
\text { everywhere you want and the actual sensitivity of it is good as well. }\end{array}$ \\
\hline ID-A1 & $\begin{array}{l}\text { Well, I think you have just answered your own question, the fact that it is easier to get } \\
\text { around would mean that everyone would steal them. You know, as it is now the Cintiqs we } \\
\text { have to chain down to the desk because they are so expensive it would become a security } \\
\text { risk for the university and also I have yet to come across a decent Tablet PC that can run Alias } \\
\text { Auto Studio. You know, they are limited in their powers compared to specific computers. }\end{array}$ \\
\hline NA & So you are saying they are using Cintiq with Alias? Not Alias Sketchbook? \\
\hline ID-A1 & $\begin{array}{l}\text { Yes. No, the third years use Alias Sketchbook. But yes, so they use if for a whole - they use it } \\
\text { for Alias, they use it for Sketchbook, they use it for PhotoShop. So first years will do exercises } \\
\text { in using PhotoShop but using our Cintiq. }\end{array}$ \\
\hline NA & Oh right. OK. And what are your thoughts on a totally digital industrial design curriculum? \\
\hline ID-A1 & $\begin{array}{l}\text { Again it is back to the commercial one really. I still think that although these tools are } \\
\text { excellent, it is wrong to wholly rely upon these tools as opposed to other tools. You know, the } \\
\text { analogy is you have your toolbox, and some of the tools are digital and some of them are } \\
\text { manual. I do not see the point in not using the manual ones if they are better than the digital } \\
\text { ones. You know, the toolbox is made up of many, many tools and I think there is the fashion } \\
\text { of wanting to use wholly digital tools. It does not mean that the process is any quicker or any } \\
\text { better. And I think that the good use of these is proportional to your skill based in using them. } \\
\text { So if someone can still draw particularly quickly by hand in a sketchbook, rather than using a } \\
\text { Tablet PC, then that is fine. As time goes on and they get better and it becomes more natural } \\
\text { through early years education to go down that digital route then I think it will become more } \\
\text { and more digital. But I still think there are areas of it which would still retain the real world in }\end{array}$ \\
\hline
\end{tabular}


which we live in.

NA Do you have anything else to add?

ID-A1 No.

NA Many thanks for your time and valuable feedback, I will get in touch with the results of the study when the thesis gets published. 


\subsection{Student Sketching Exercise Questionnaire}

Department of Design and Technology

UK, LE11 3TU

Tel: +44 (0) 1509228315 Email: N.Al-Doy@lboro.ac.uk

Loughborough

University

\section{Sketching Exercise Questionnaire}

First name: $\quad$................................................... Surname:

Comparison between Non-digital and Digital Sketching:

1. How would you rate your ability to sketch using line only during design activity with the following media (1 being low and 5 being high)?

Non-digital media
Low
\begin{tabular}{|l|l|l|l|l|}
\hline 1 & 2 & 3 & 4 & 5 \\
\hline
\end{tabular}

Digital media
Low
\begin{tabular}{|c|c|c|c|c|}
\hline 1 & 2 & 3 & 4 & 5 \\
\hline
\end{tabular}

2. How did the sketching strategies differ between non-digital and digital media? Please list them in rank order with the most significant difference first.

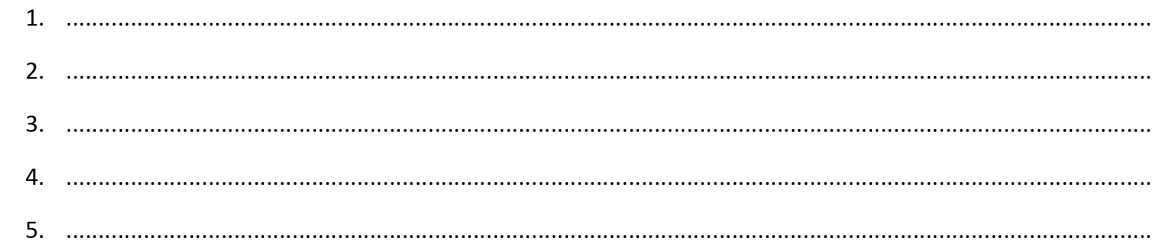

3. Indicate which of the following statements applies most to either your non-digital sketching; your digital sketching; or equally to both (tick both boxes).

\begin{tabular}{l|l|}
\hline 1. Most accurate representation of product & Non-digital sketching \\
\hline 2. Most confidence in use of line & Digital sketching \\
\hline 3. Most expressive & \\
\hline 4. Most enjoyable & \\
\hline 5. Quickest to produce & \\
\hline 6. Easiest to use & \\
\hline 7. Required most error corrections (erase/undo) & \\
\hline 8. Preferred final sketch &
\end{tabular}

Thank you for your assistance in this research 


\subsection{Academic Assessing the Output of the Sketching Exercise}

\section{Questionnaire}

Loughborough Design School

Loughborough University, Leicestershire, UK, LE11 3TU

Tel: +44 (0) 1509222660 Email: N.Al-Doy@lboro.ac.uk

Loughborough

University

\section{Assessing the Output of the Sketching Exercise Questionnaire}

Briefing:

This questionnaire is part of a research project to investigate the use of the Tablet PC for concept generation using its pen-type stylus and interactive screen. After owning a Tablet PC for three months, a sketching exercise was undertaken with 13 undergraduate design and engineering students. The exercise required students to sketch the same product using paper-based media and the Table PC. 5 minutes were allowed for each sketch. Two products were sketched, one with geometric form (a torch) and one with organic form (a child's spoon). The two products can be seen in the photographs below.

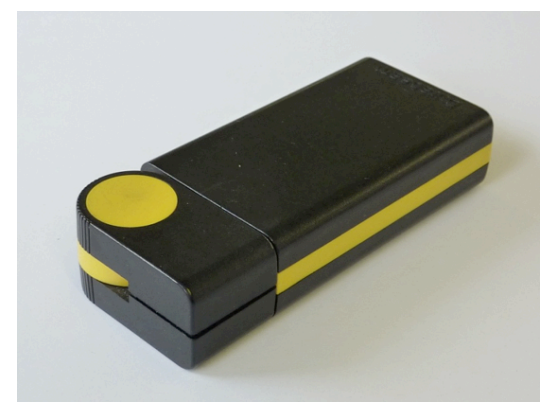

Torch used for sketching exercise

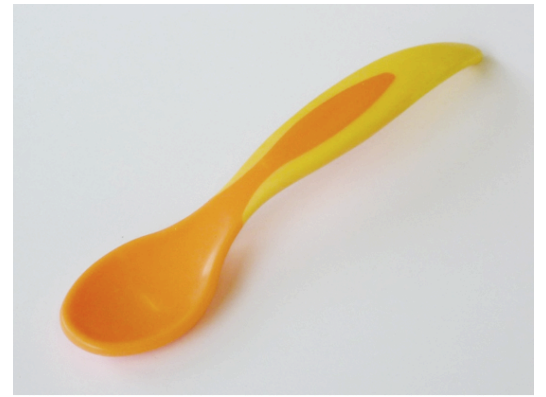

Child's spoon used for sketching exercise

On pages 2 to 27 , please indicate which sketch is most effective in the communication of product form. The application of colour or tone should be ignored as this was not required for the exercise. Each page has two sketches of the same product drawn by one student, one sketch using paper-based media and the other using the Tablet PC. Please select the most effective sketch by ticking the box that is linked to the sketch frame. If you cannot distinguish a difference between the two sketches, please tick the "similar" box. Thank you for your help with this research.

Background:

\begin{tabular}{|c|c|}
\hline First Name: & Surname: \\
\hline Occupation: & University: \\
\hline
\end{tabular}

Email: 
Participant 1:

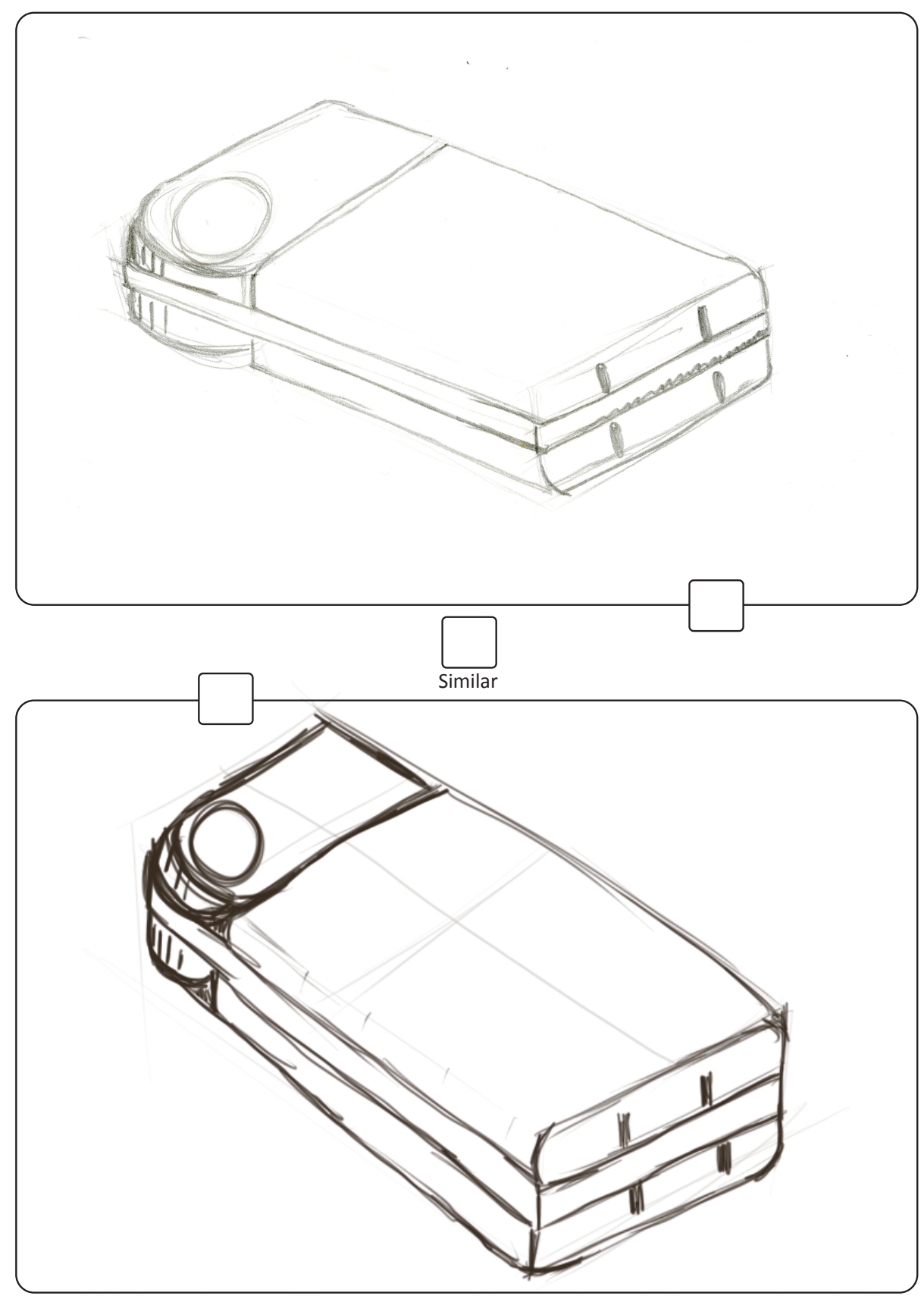

2 of 27 


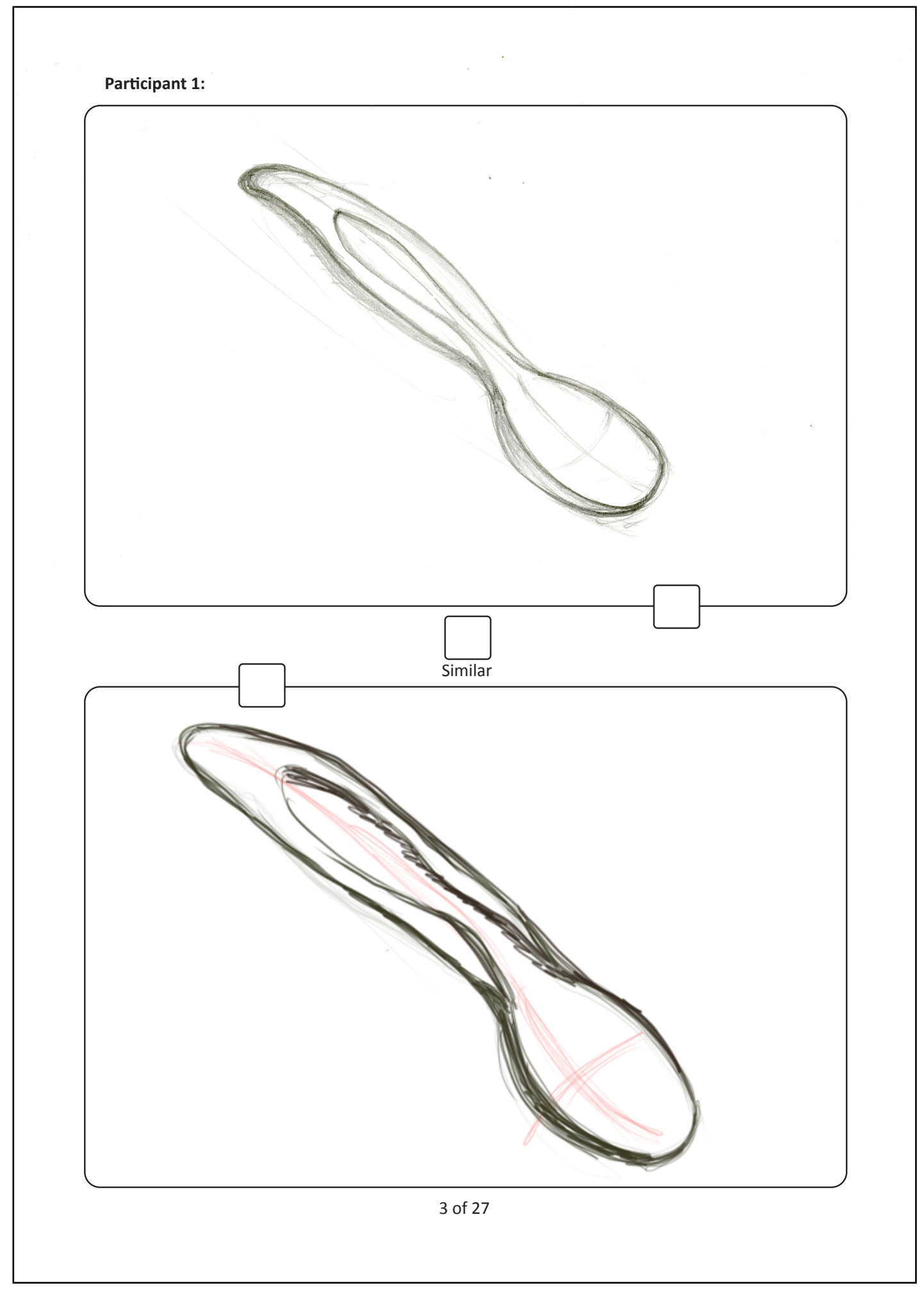


Participant 2:

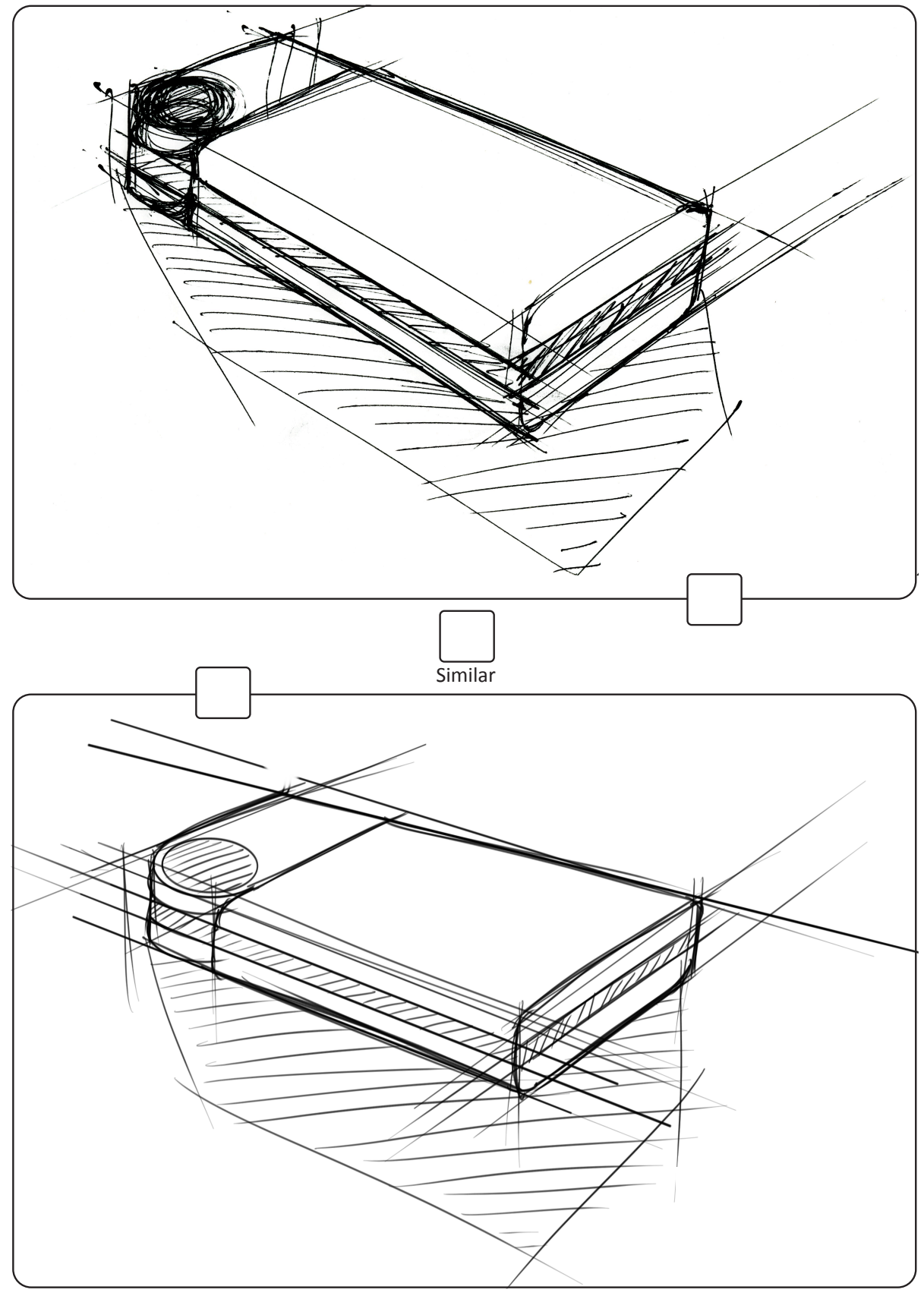

4 of 27 


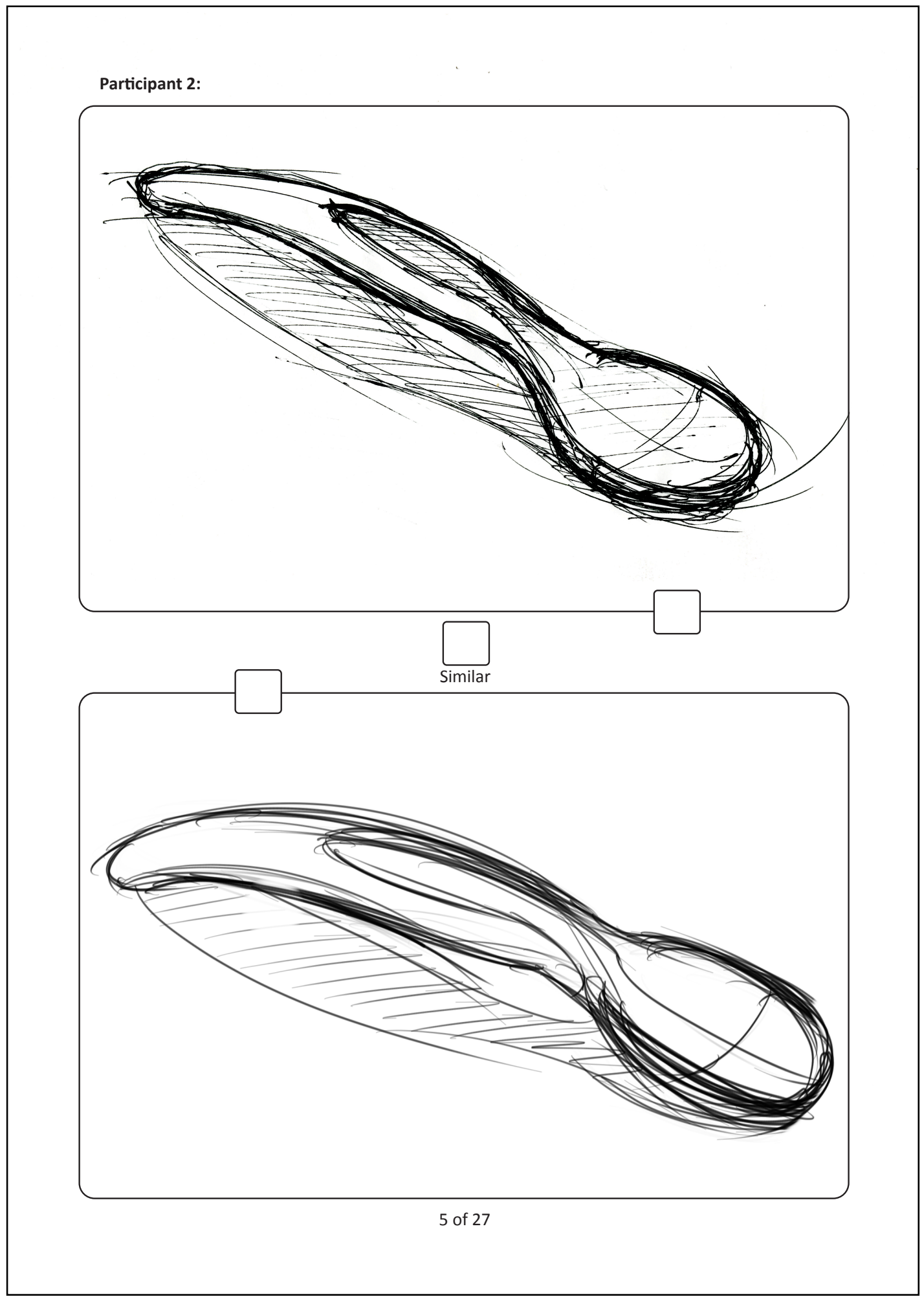




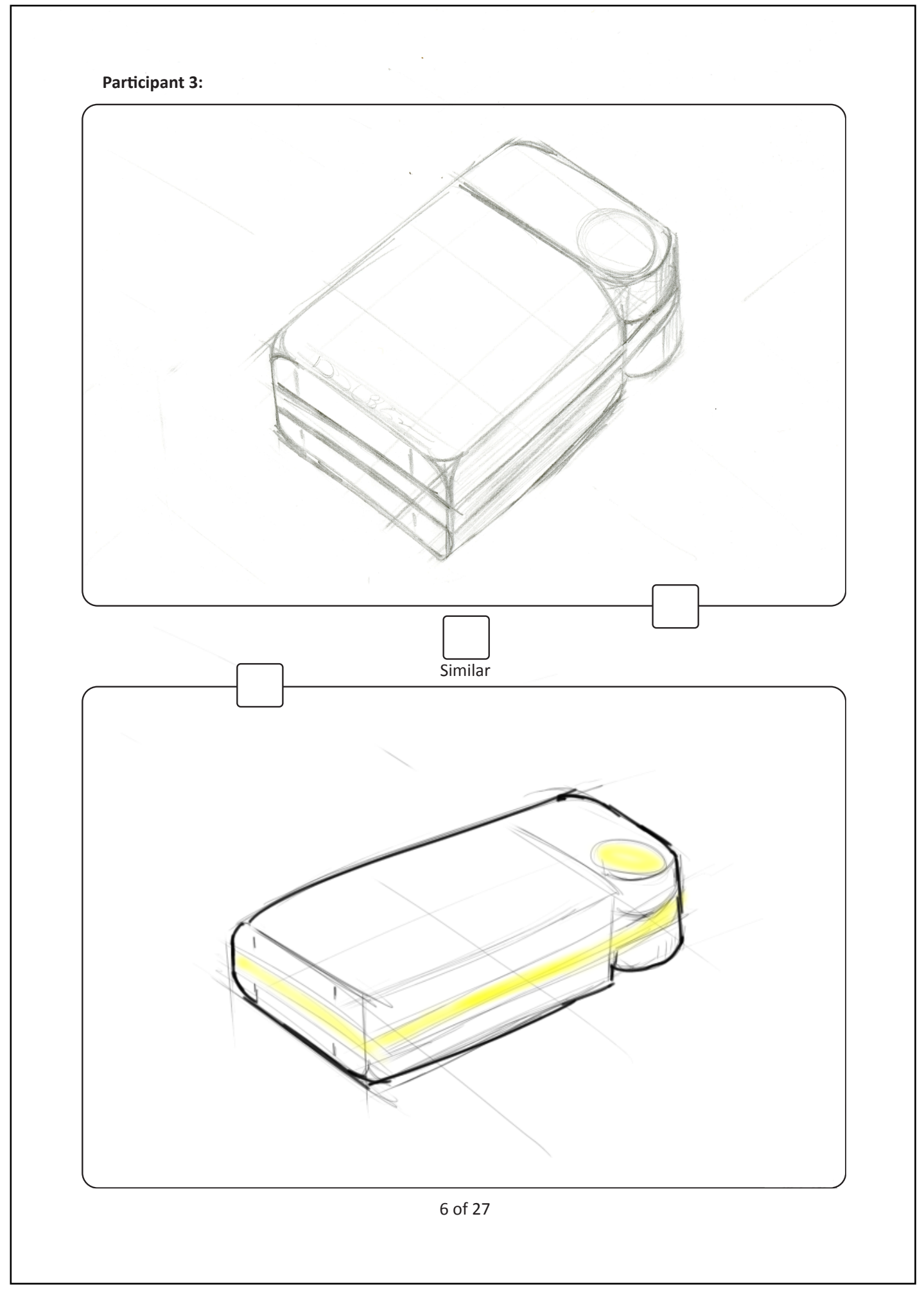




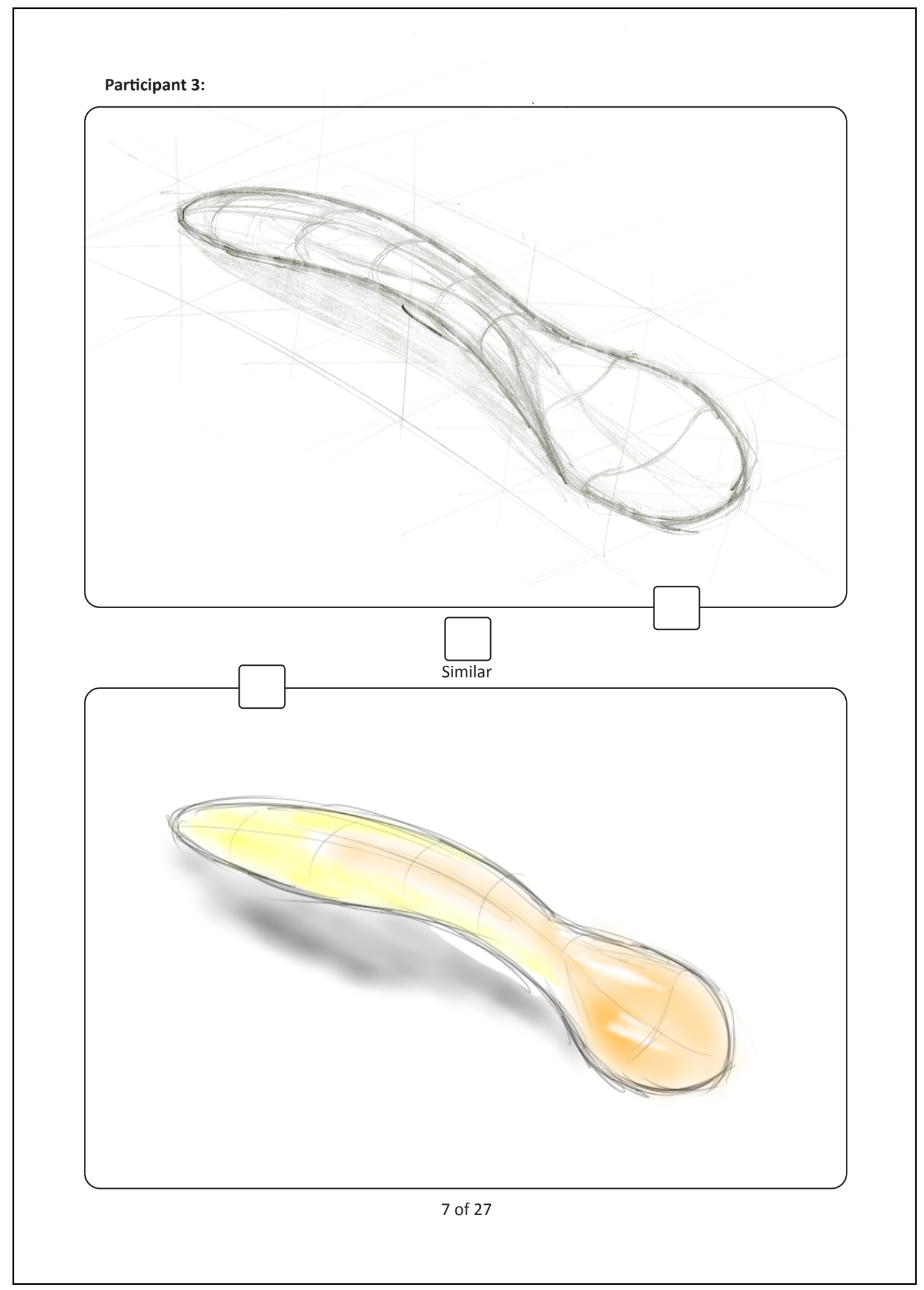




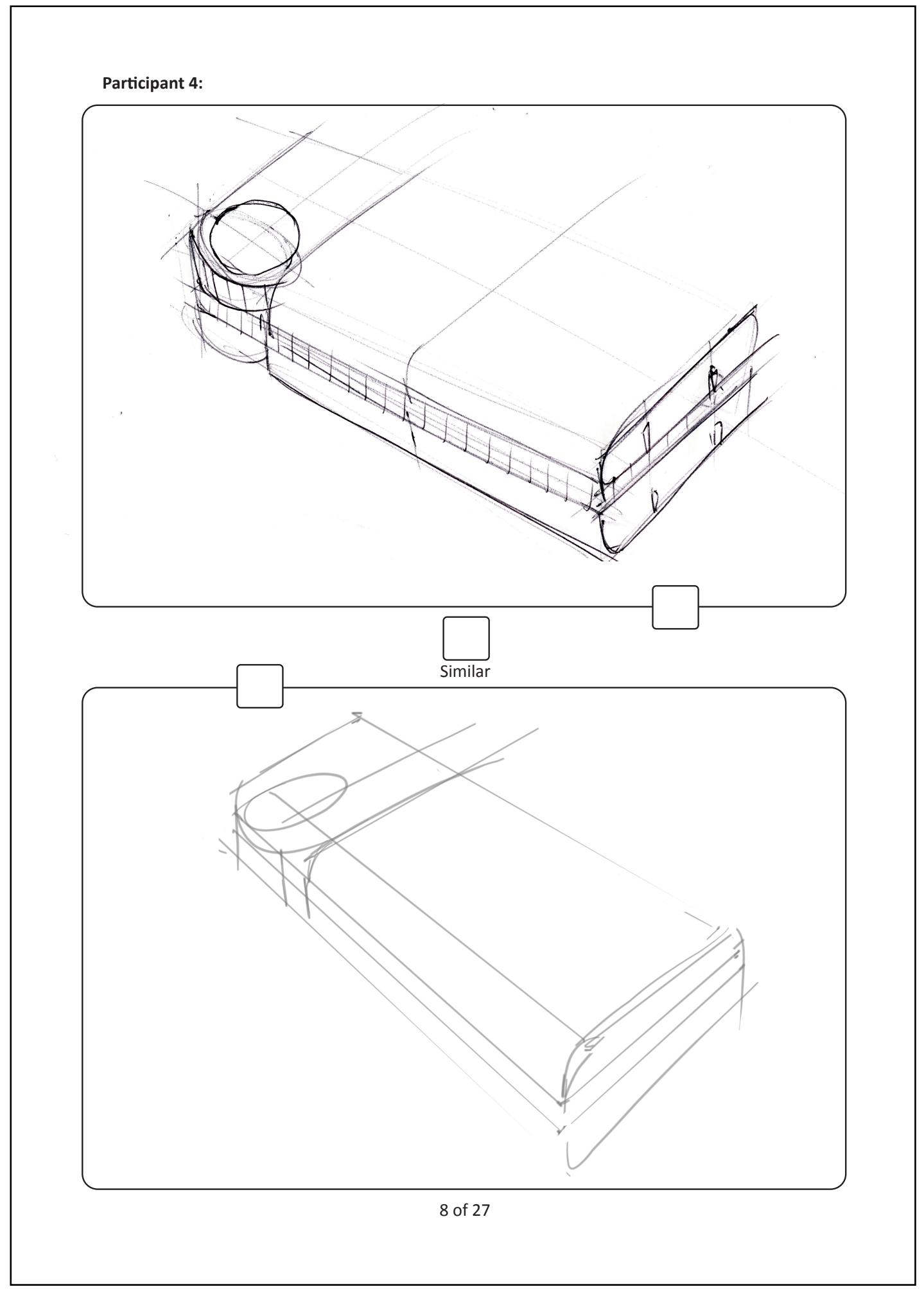


Participant 4:

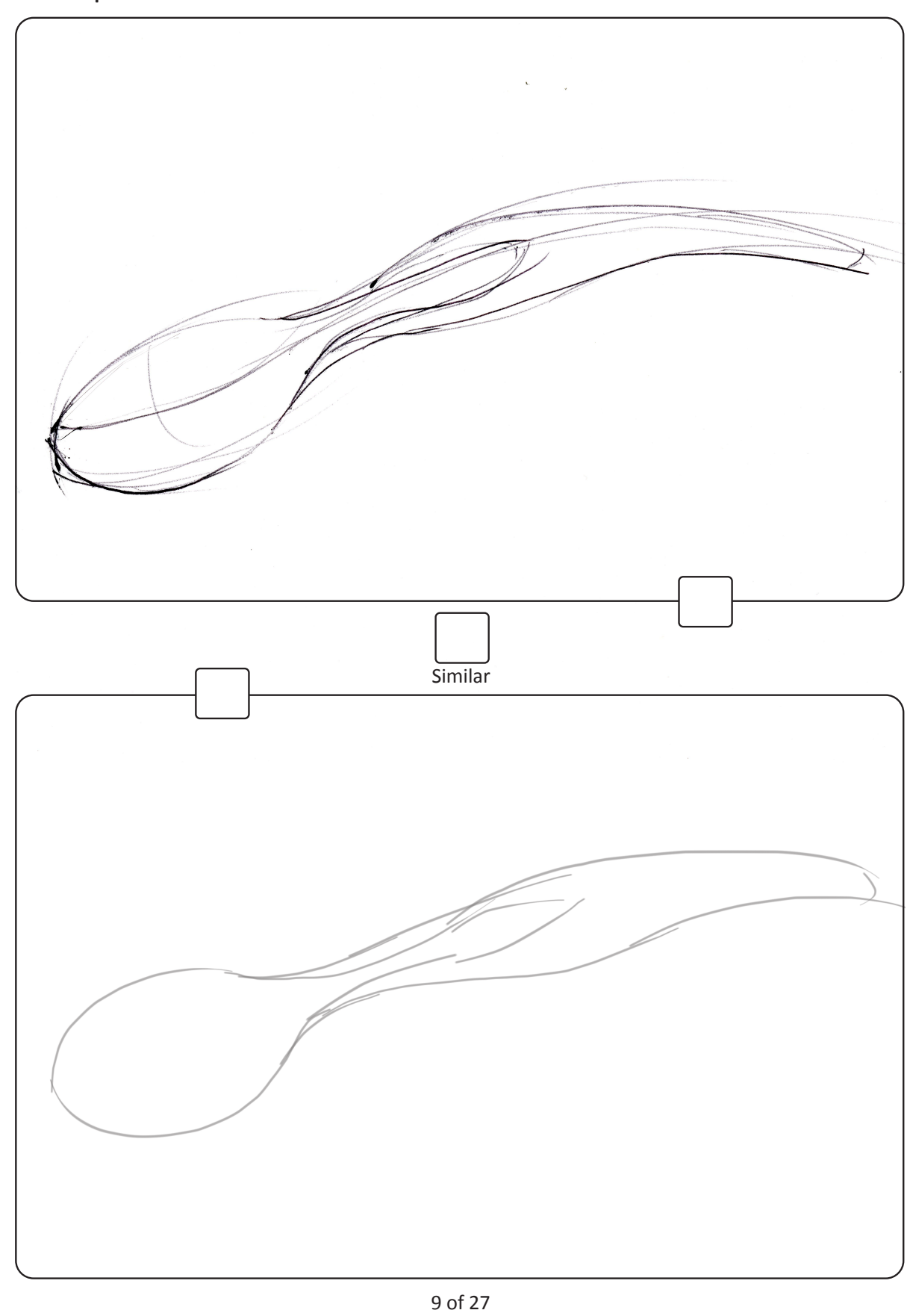


Participant 5:

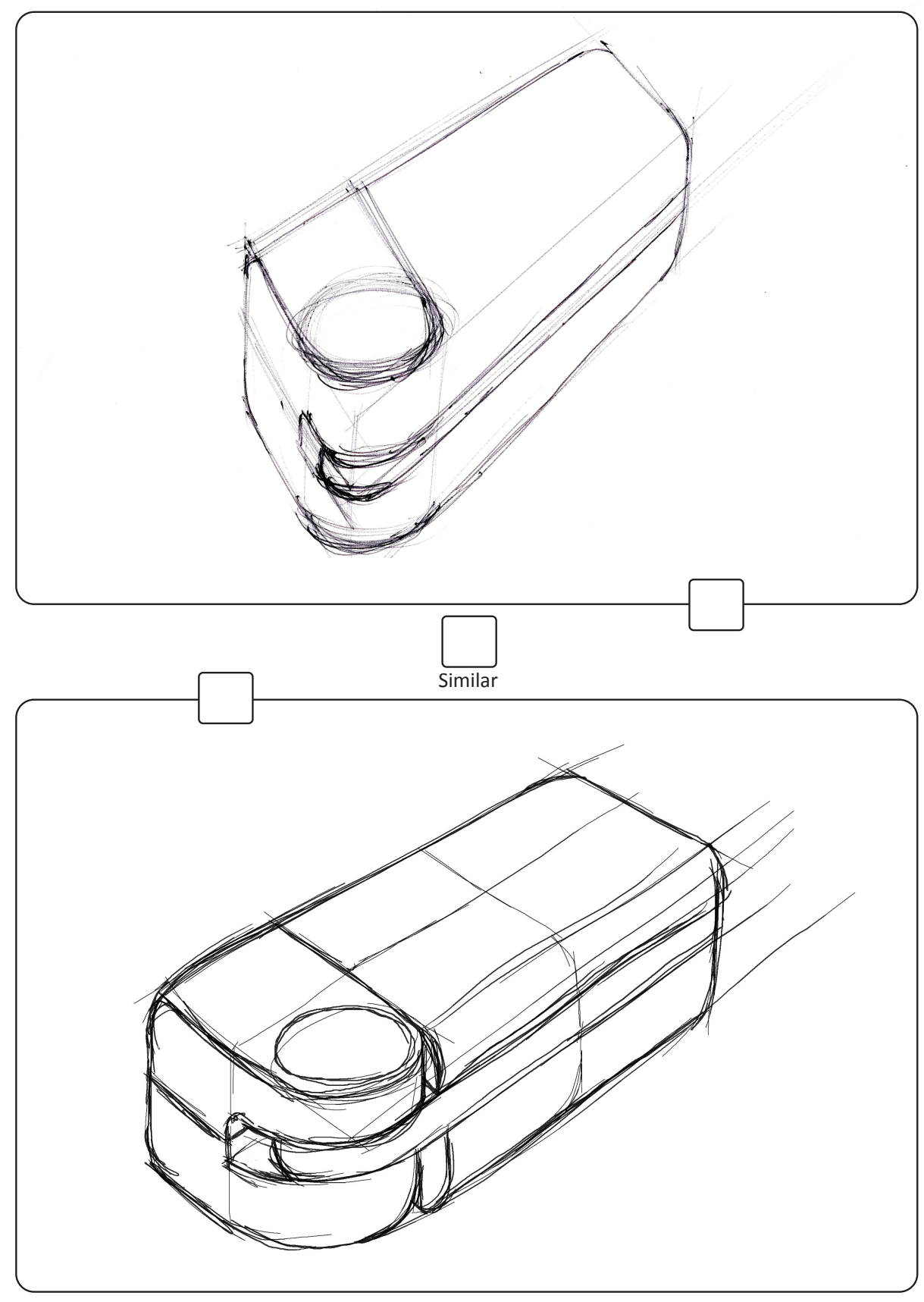

10 of 27 
Participant 5:

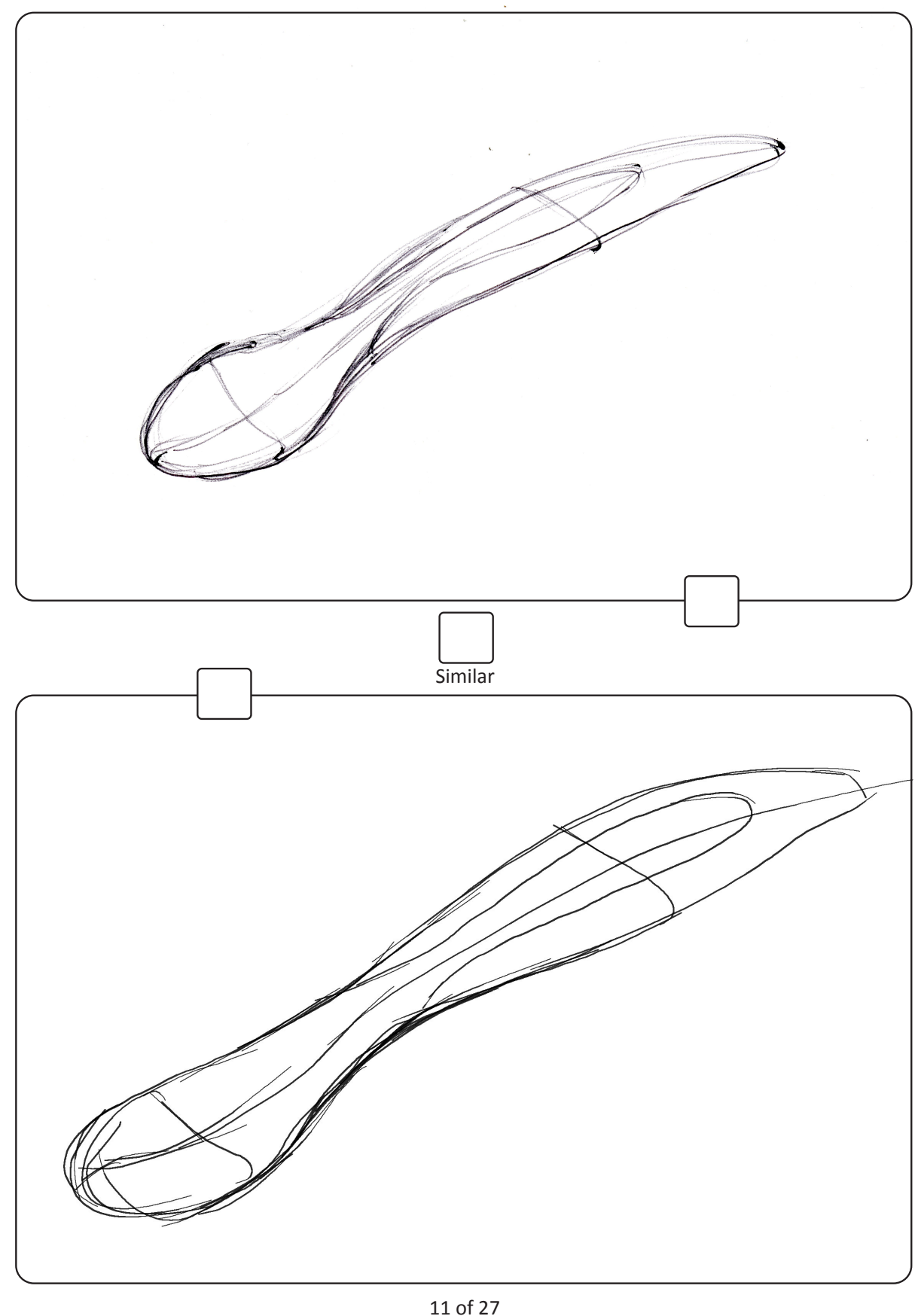


Participant 6:

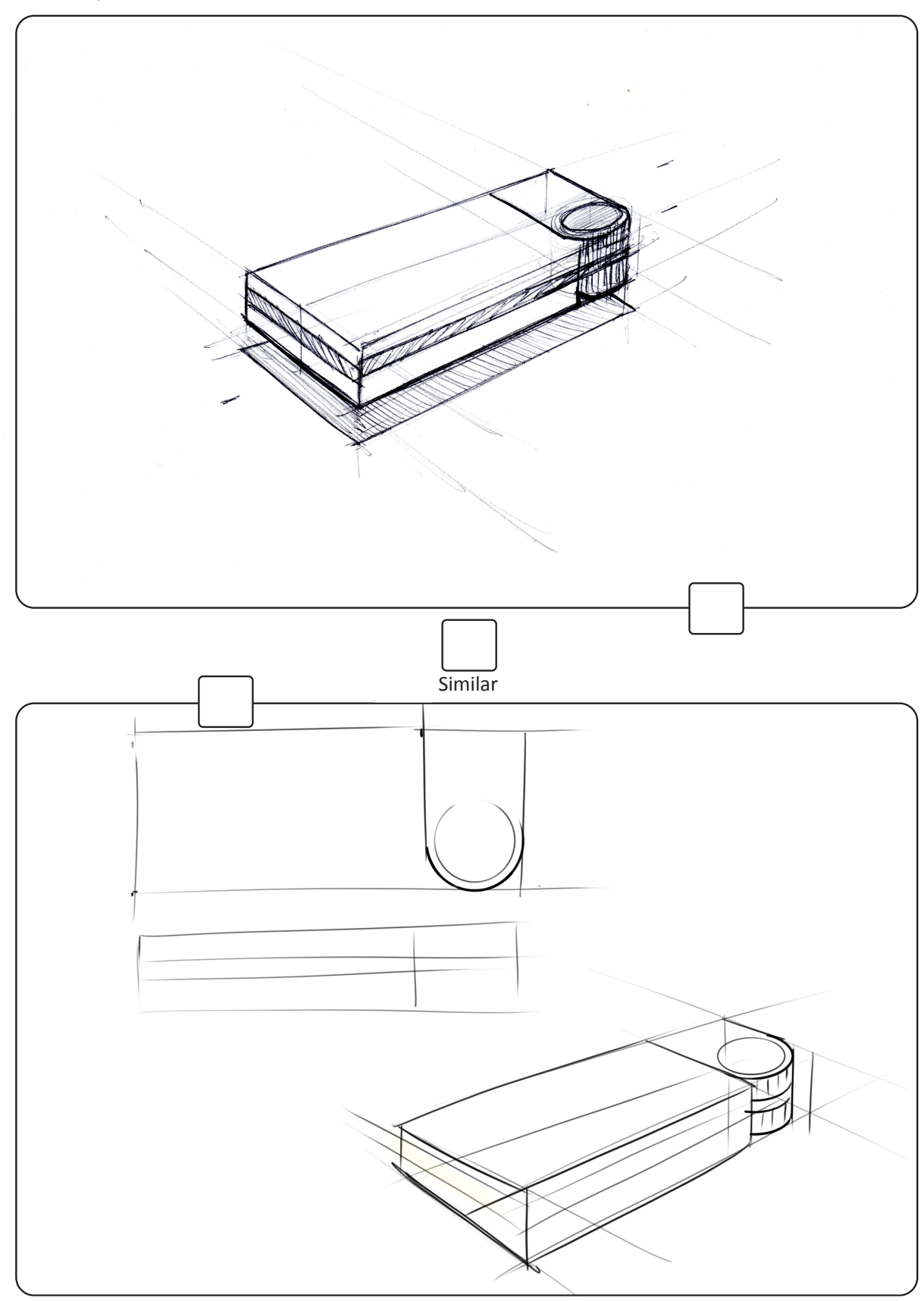

12 of 27 
Participant 6:
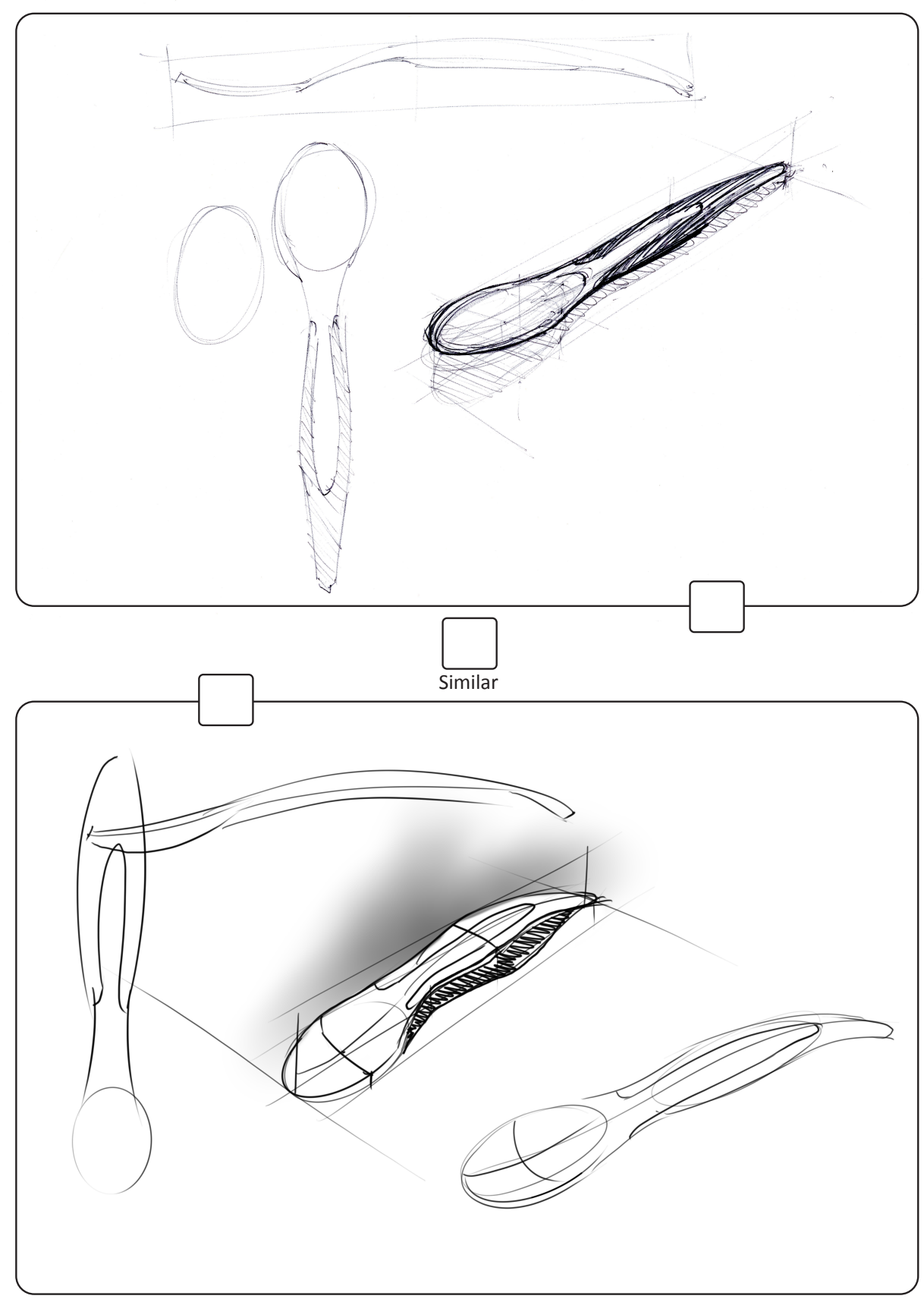

13 of 27 
Participant 7:

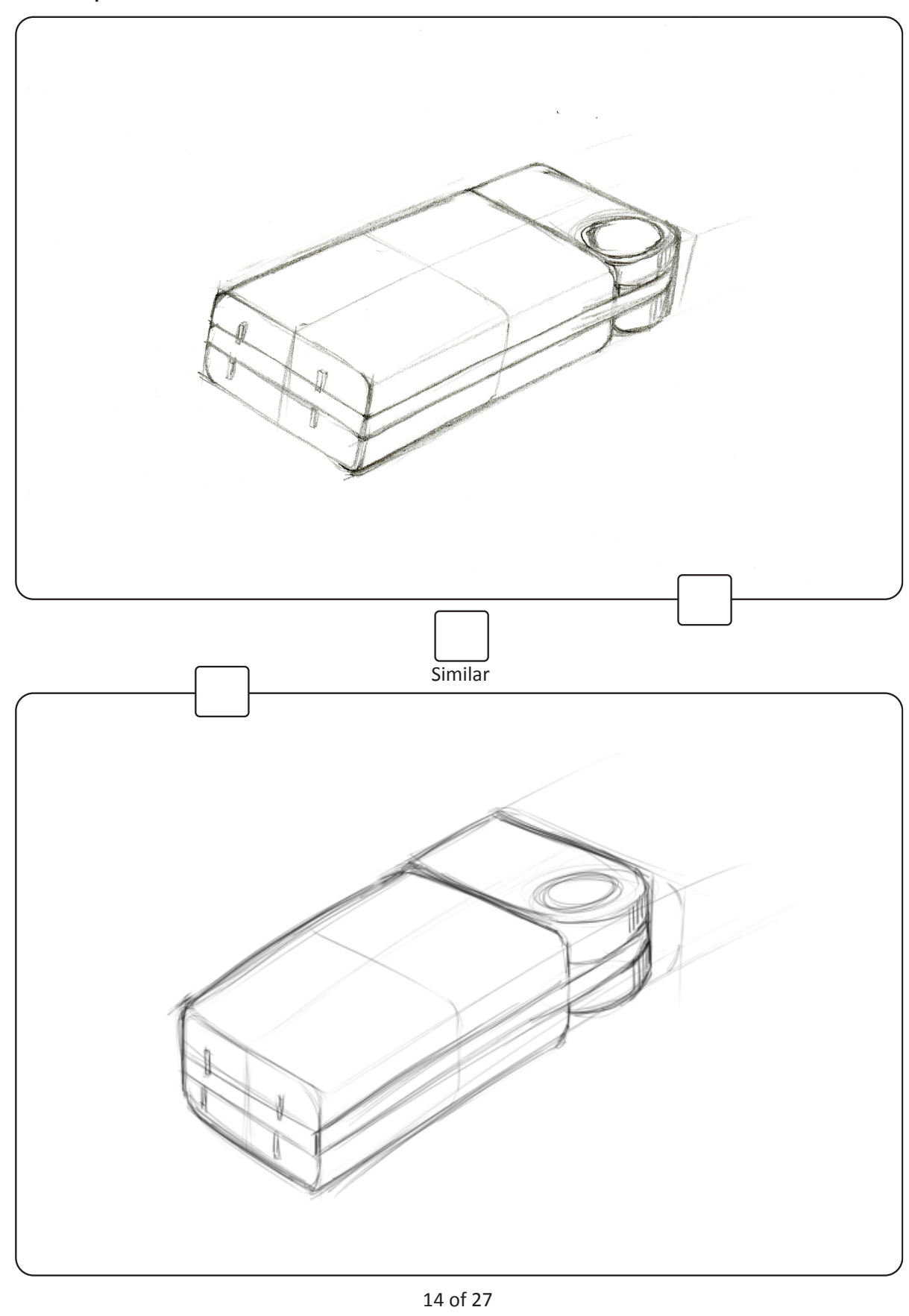




$$
\left[\begin{array}{l}
8 \\
B
\end{array}\right.
$$


Participant 8:

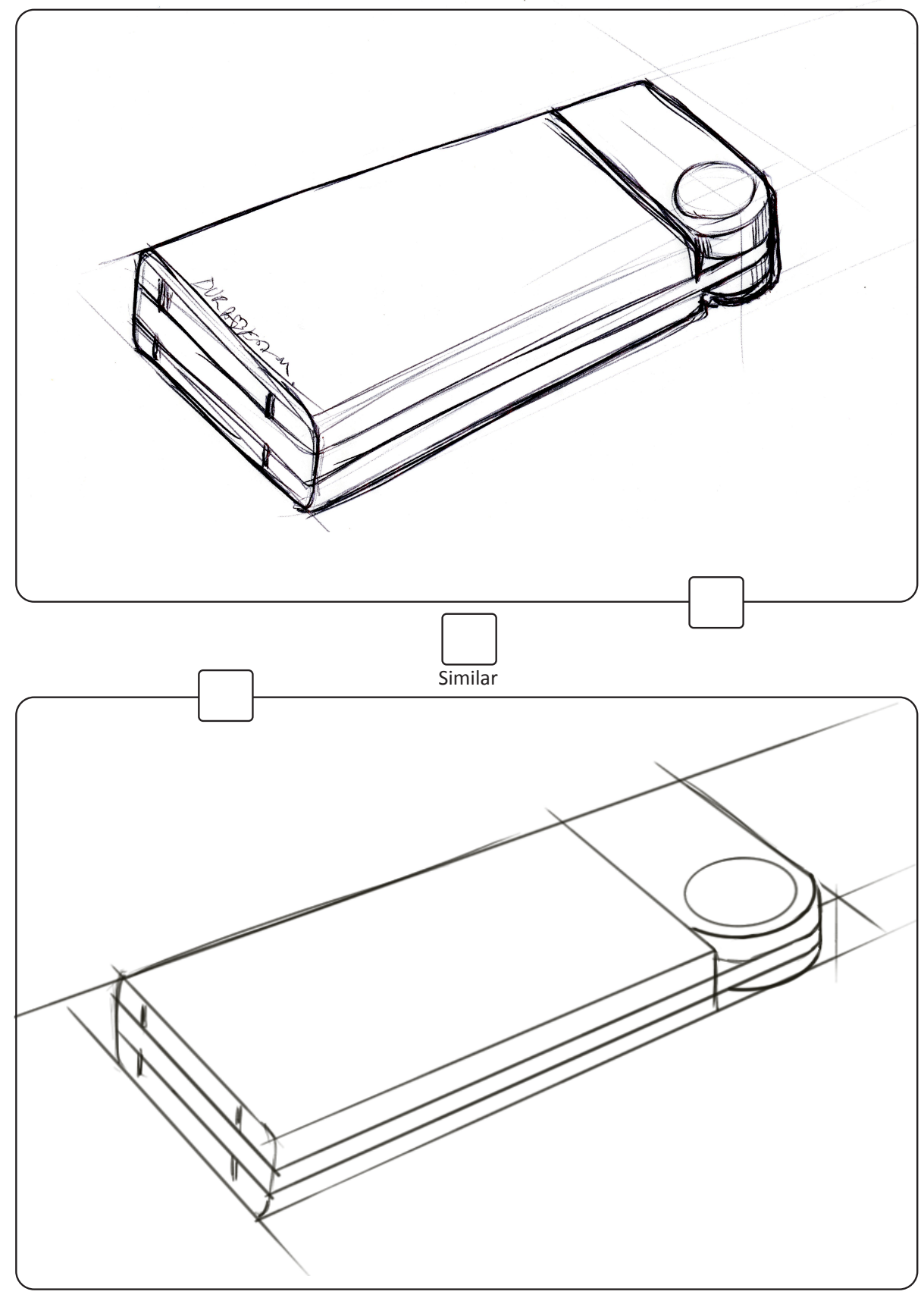

16 of 27 
Participant 8:

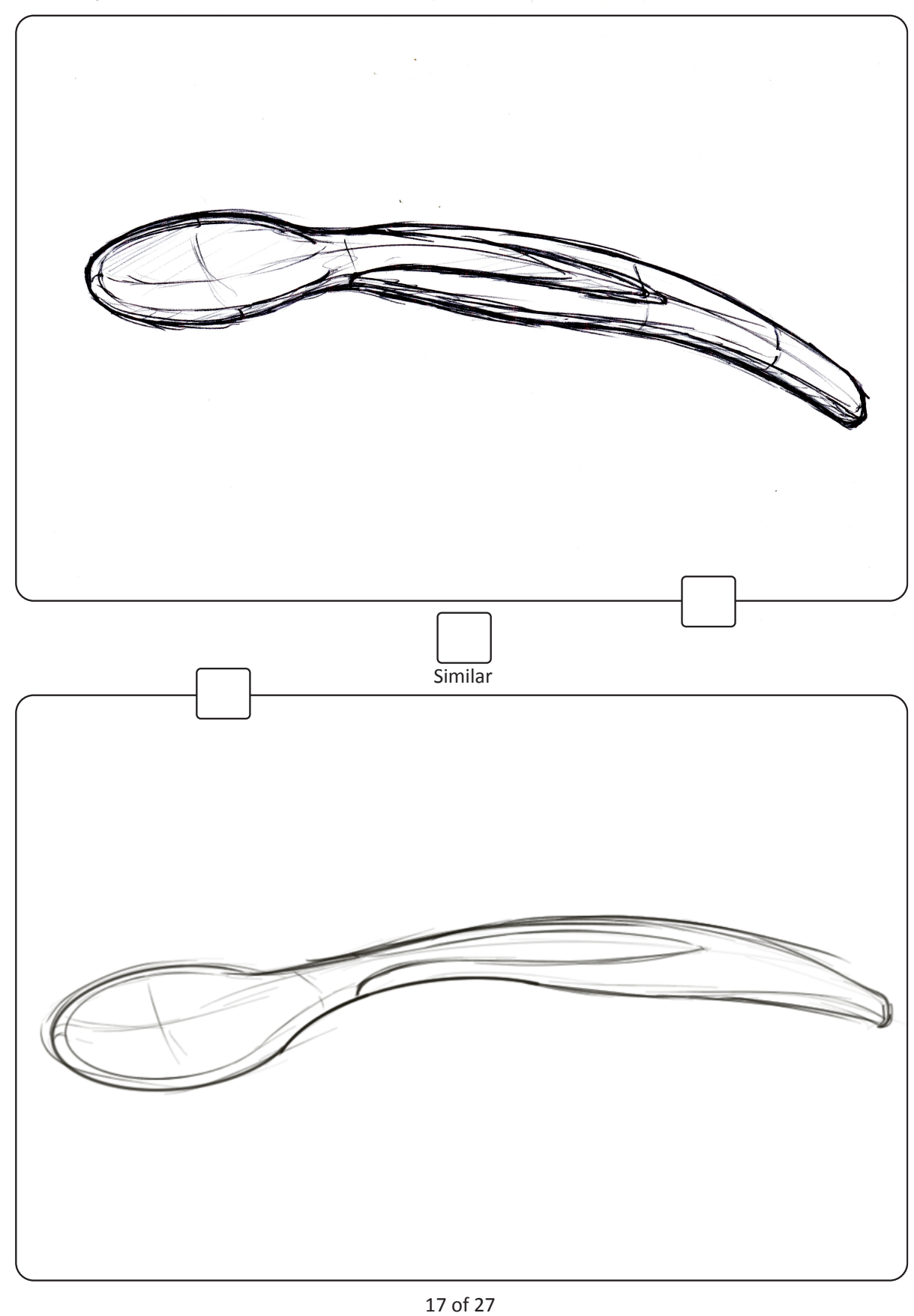


Participant 9:
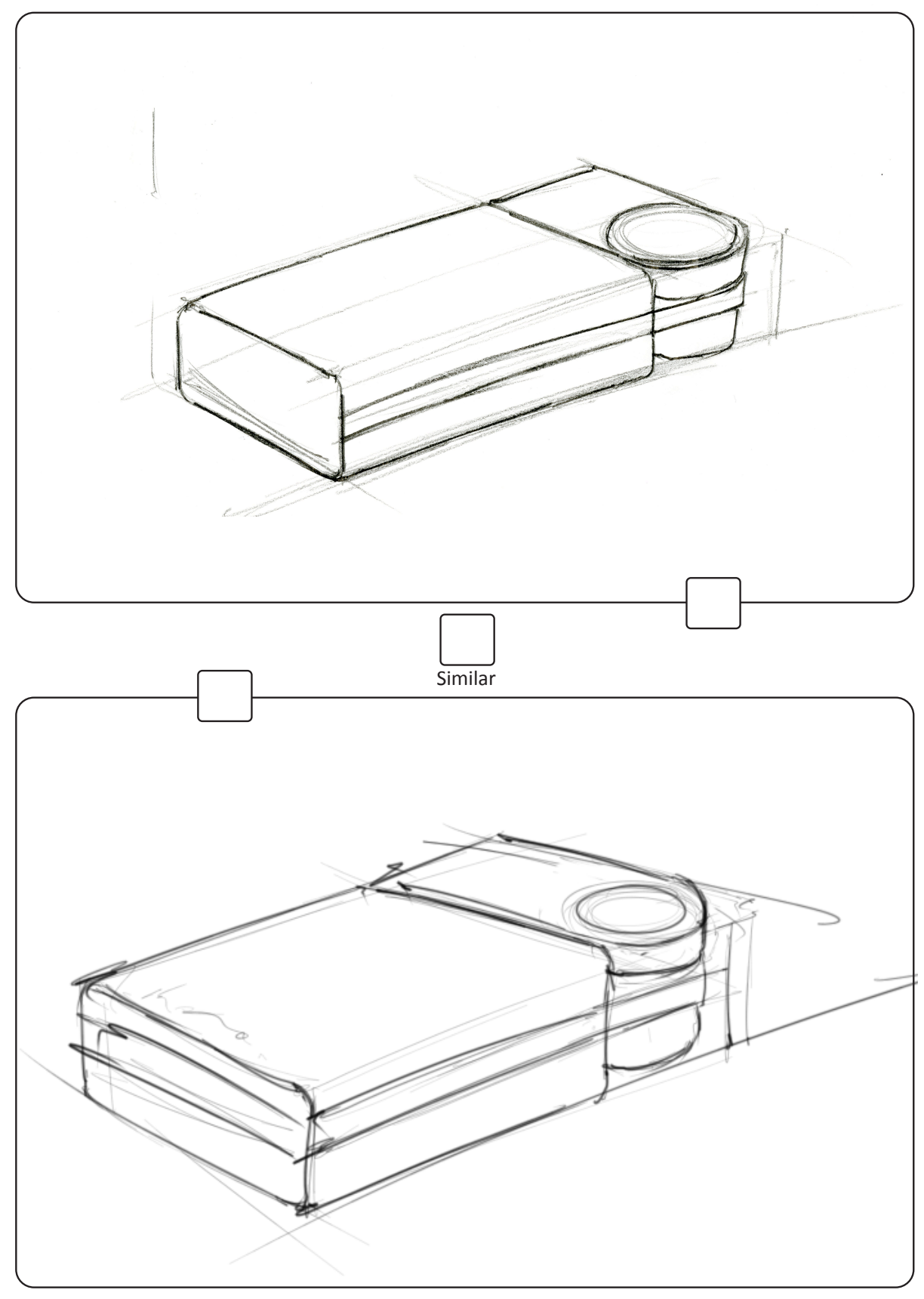

18 of 27 


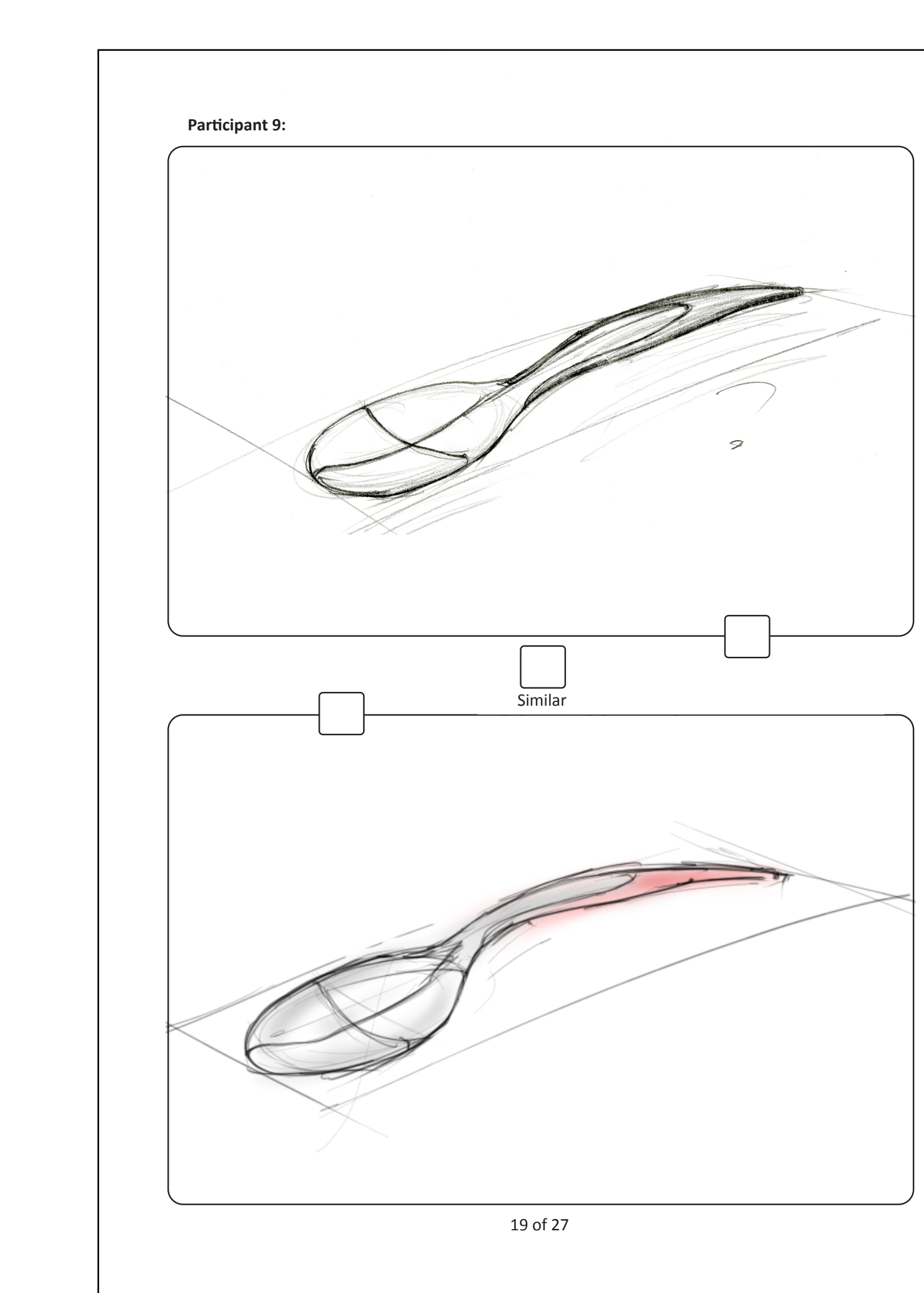




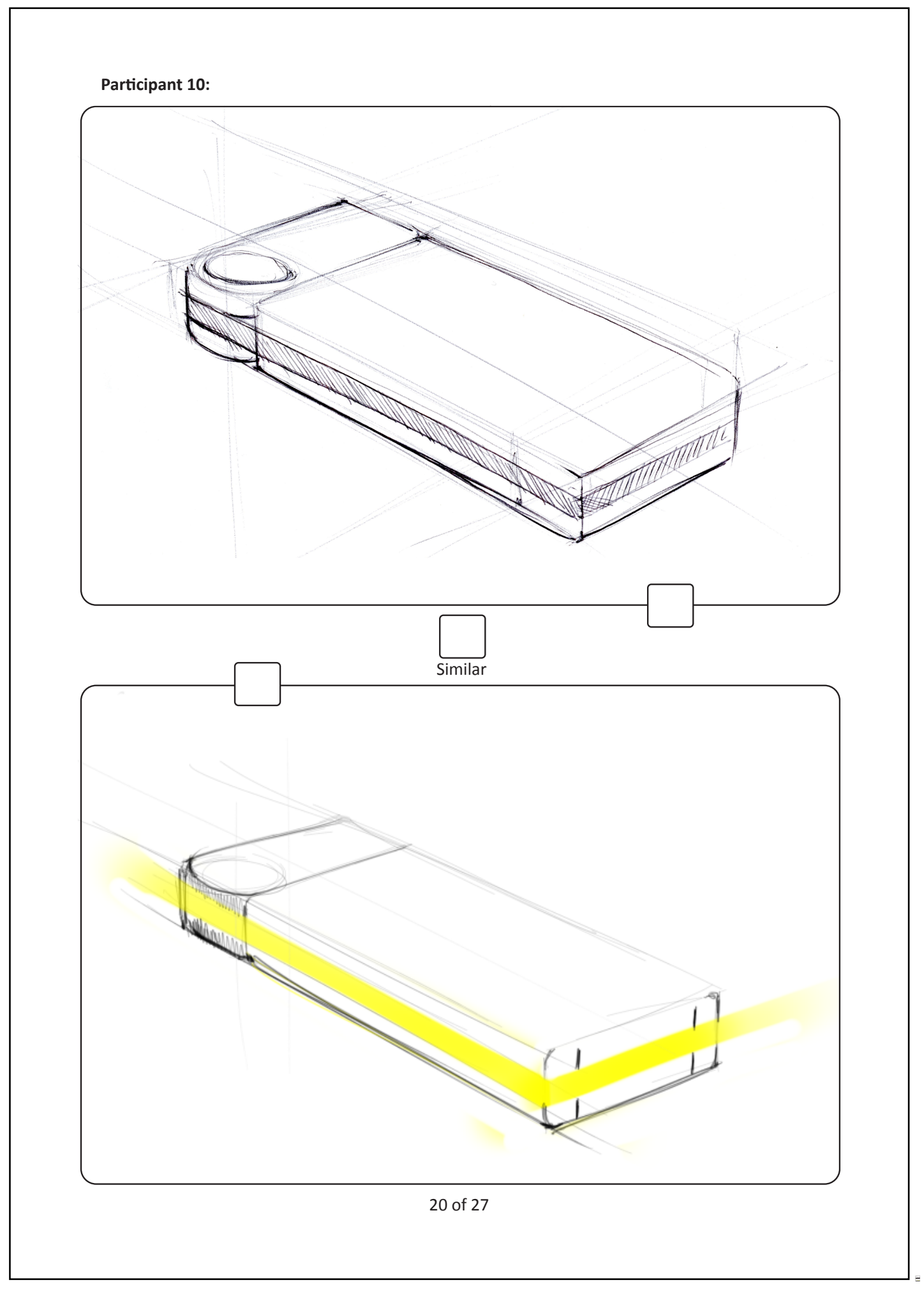


Participant 10:

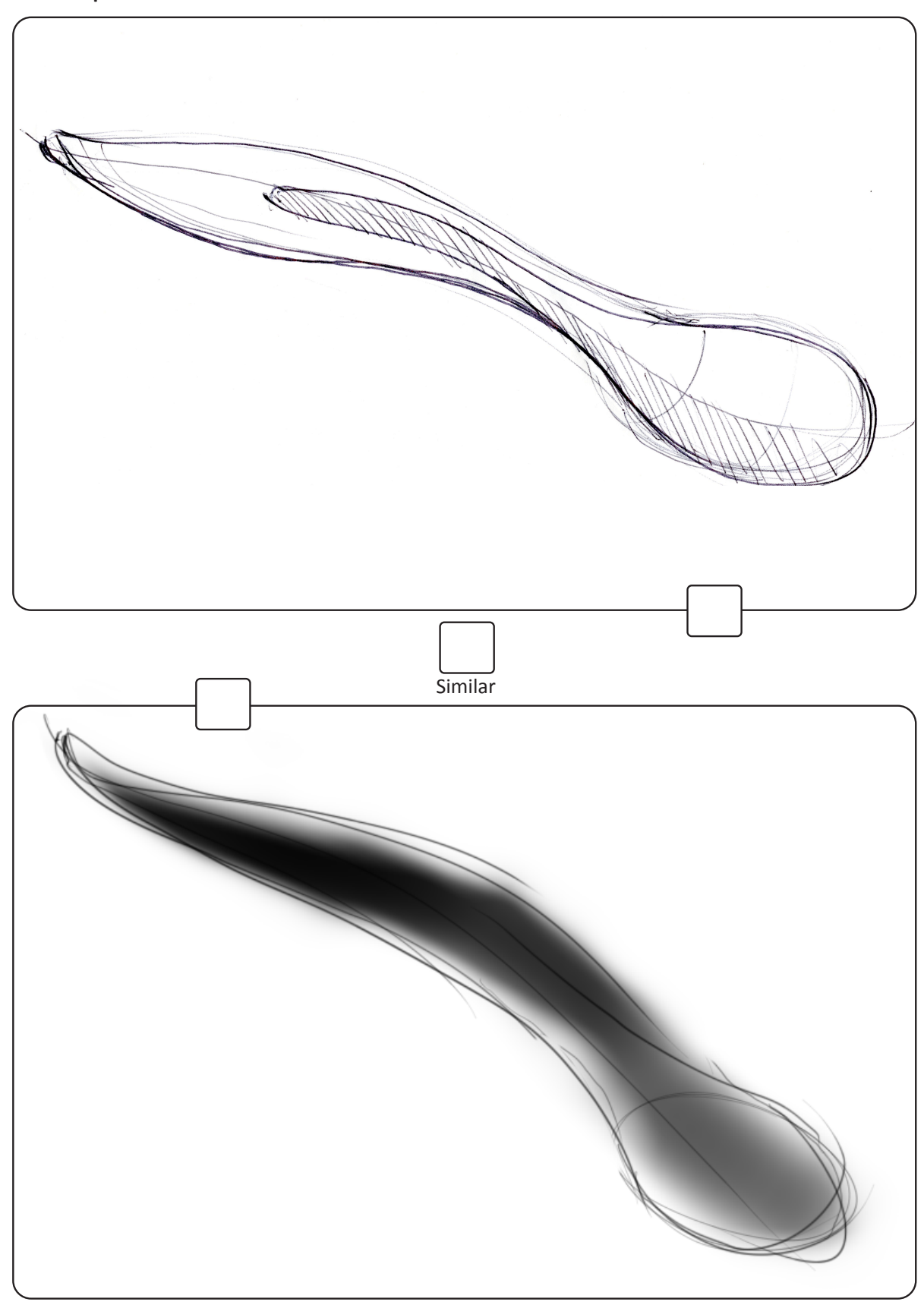

21 of 27 
Participant 11:

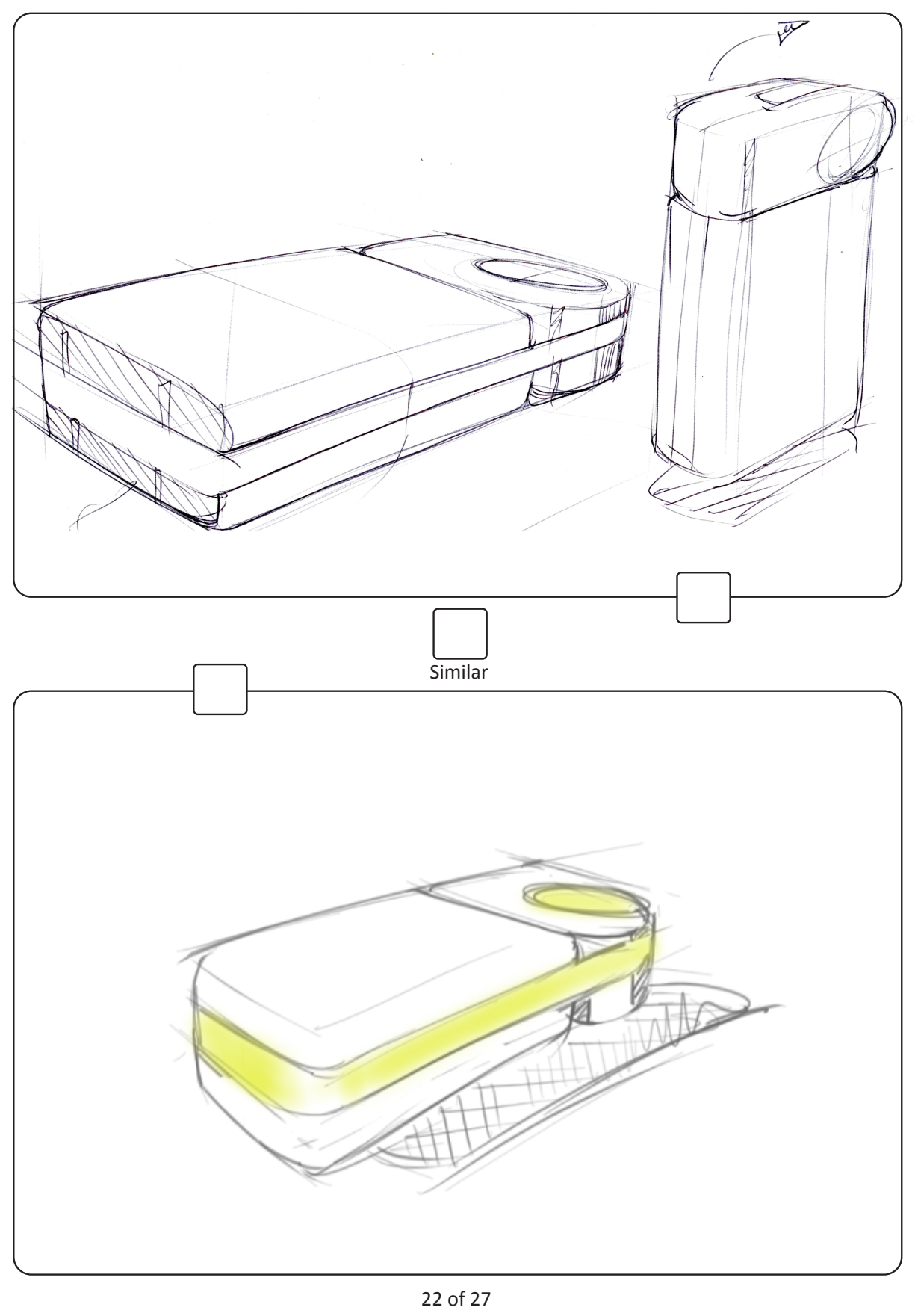


Participant 11:

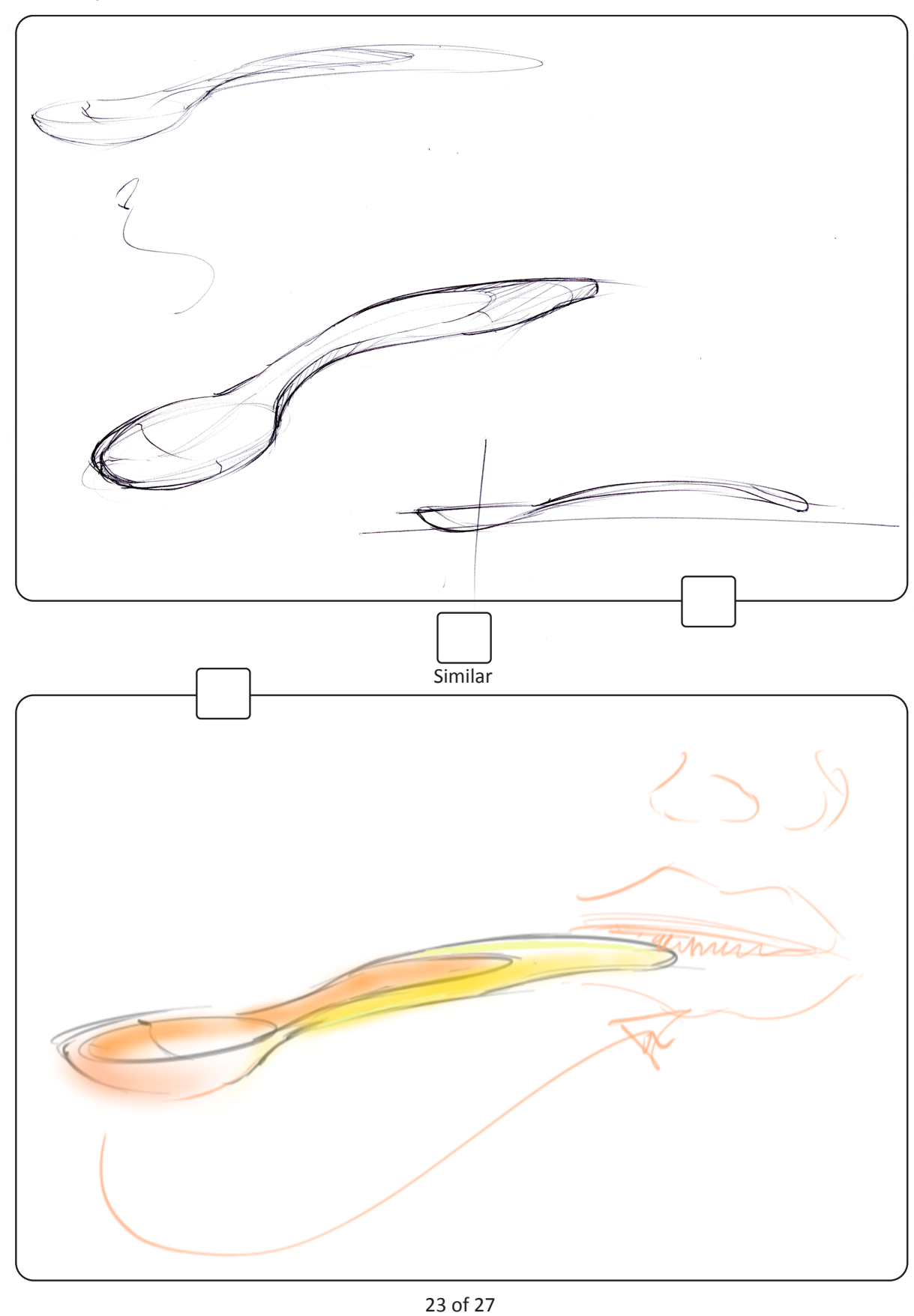




$$
\checkmark
$$


Participant 12:

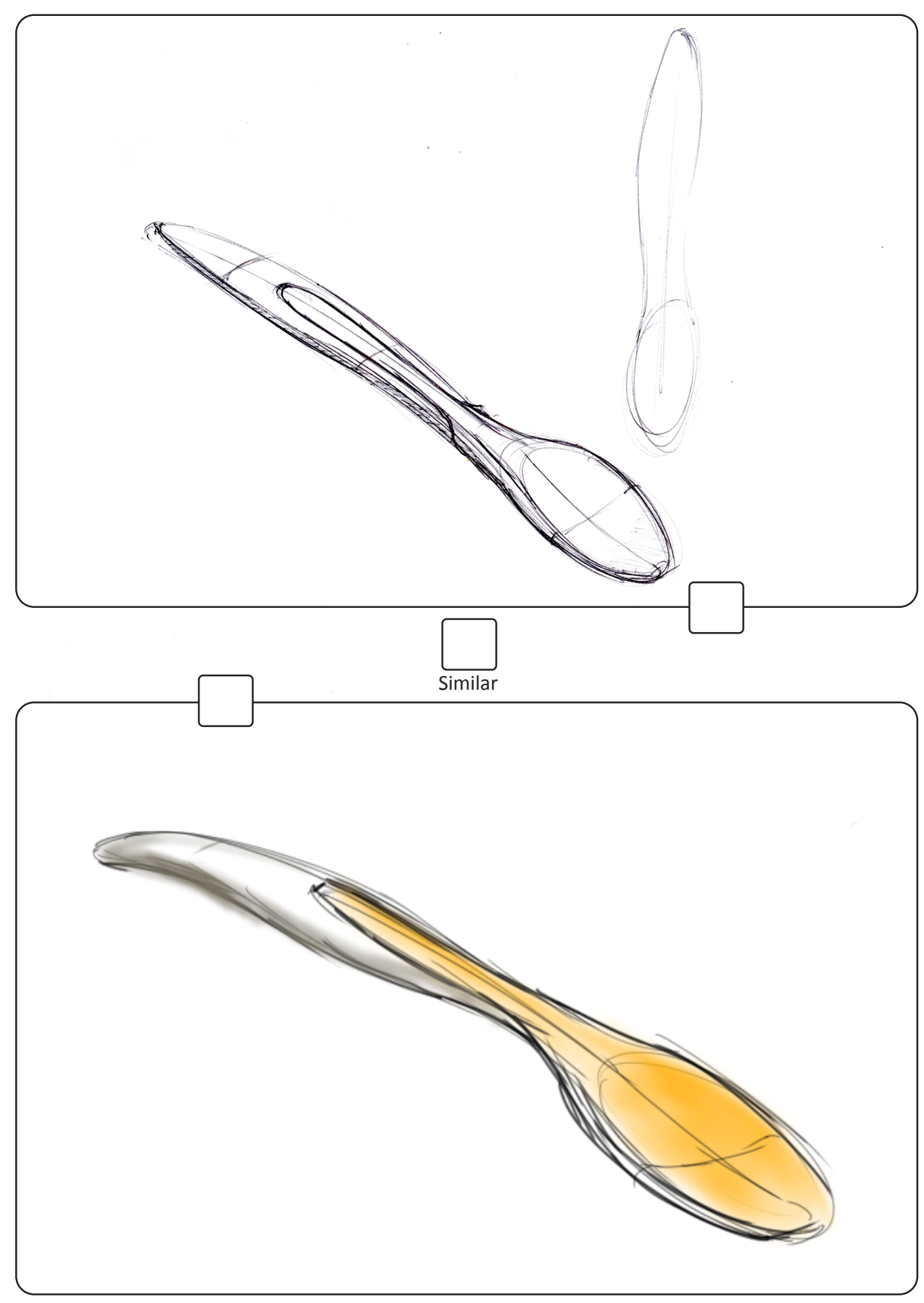

25 of 27 
Participant 13:

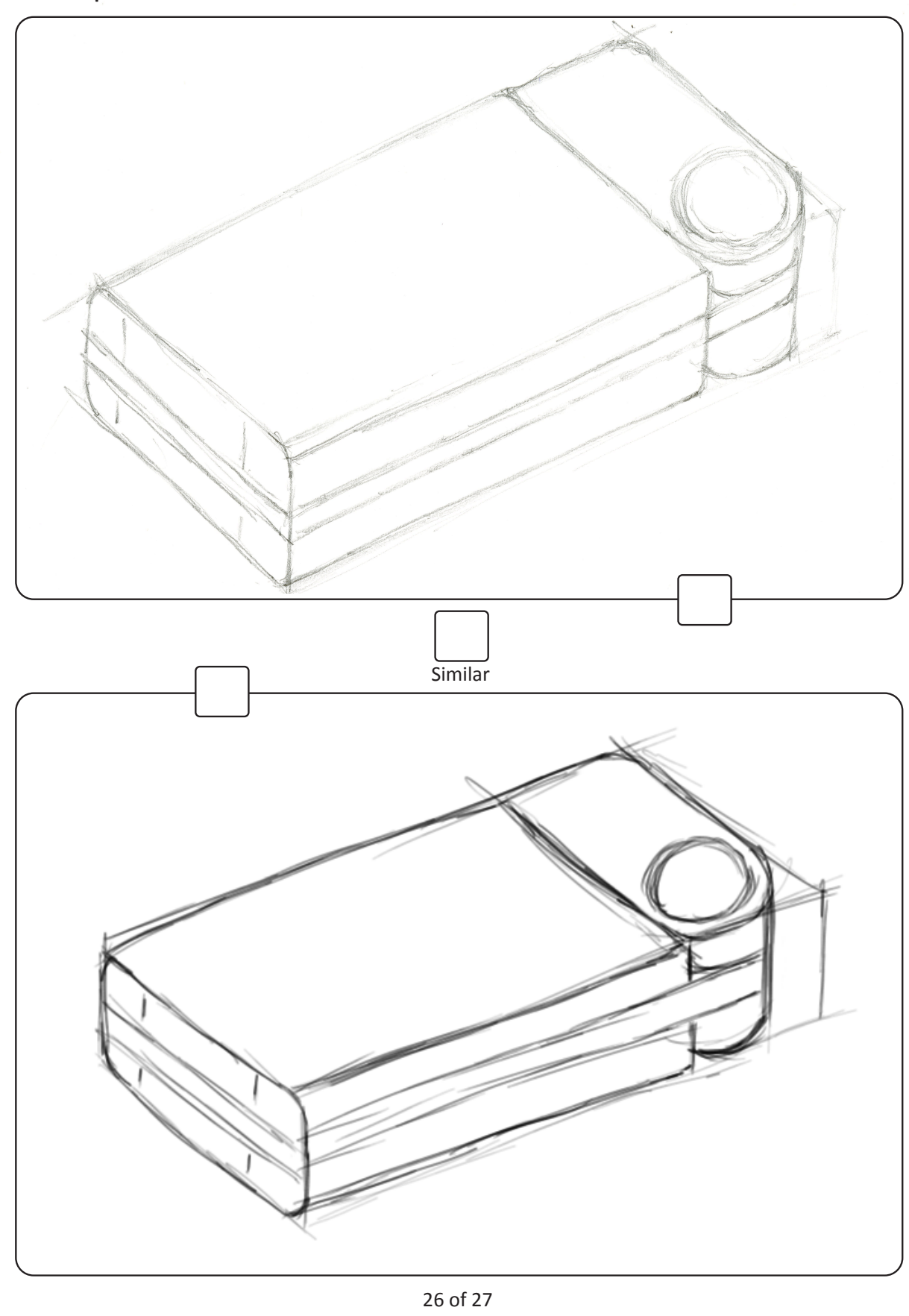


Participant 13:

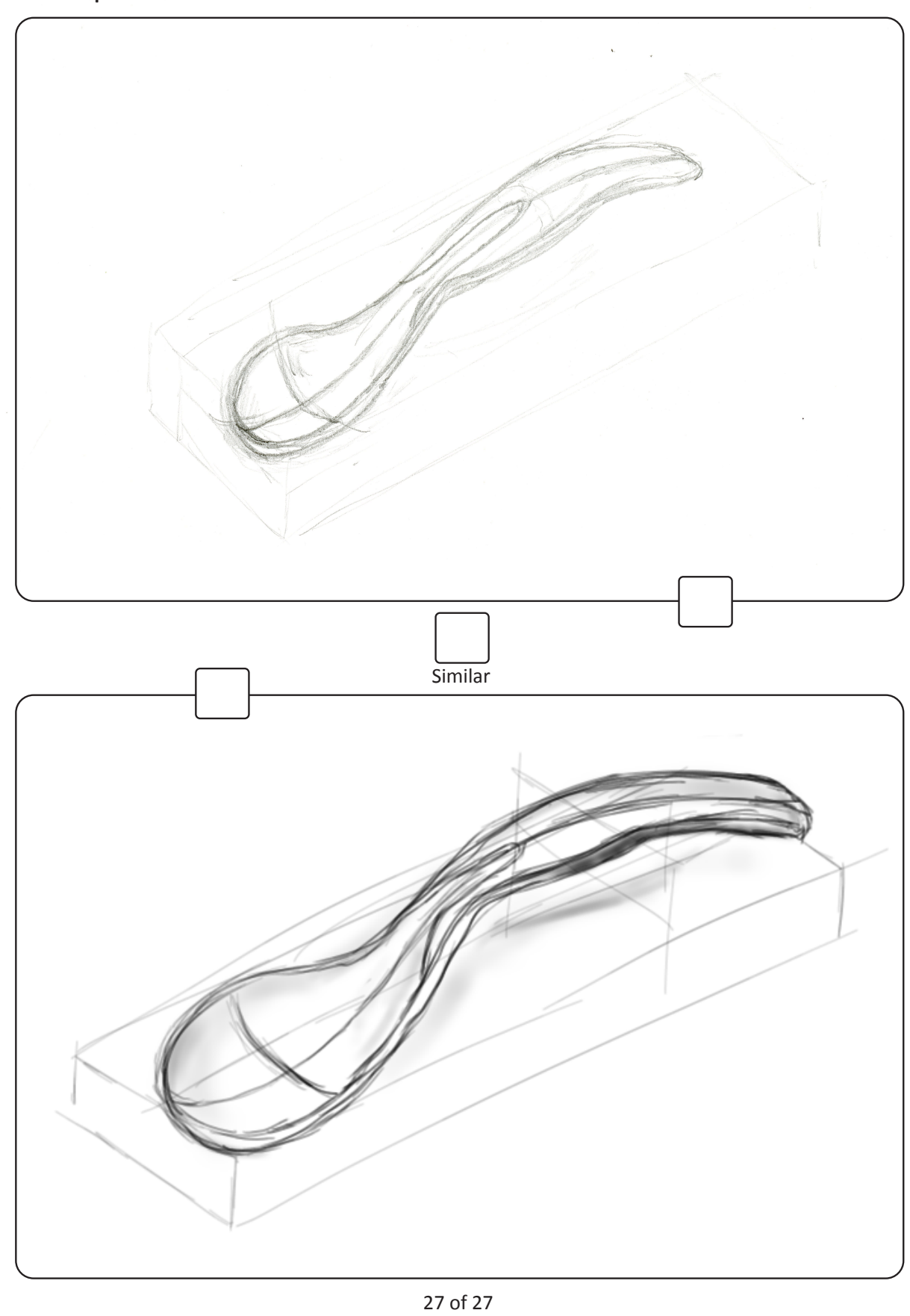




\subsection{Student Design Exercise Questionnaire}

Department of Design and Technology

Tel: +44 (0) 1509228315 Email: N.Al-Doy@lboro.ac.uk

Loughborough

University

\section{Design Exercise Questionnaire}

First name: $\quad$................................................. Surname:

Concept Generation via Digital Sketching:

Please list the strengths, weaknesses and software used in rank order when undertaking the pepper mill design exercise with the tablet PC.

Strengths: $\quad 2$.

Weaknesses:

2.

1.

Software used:

3.

Thank you for your assistance in this research 


\subsection{Student Focus Group Transcript Sample}

The focus group was carried out with the BSc group of students (seven students in total).

Date: $01 / 02 / 2010$

Location: Bridgeman Centre, Loughborough University, UK

\begin{tabular}{|c|c|}
\hline Interviewer & $\begin{array}{l}\text { All right, we are going to run for the next hour or so, a focus group, not asking specific } \\
\text { focus questions but quite open-ended questions so that we get a feel for opinion and } \\
\text { maybe it raises issues that we could not think about asking if we have got more } \\
\text { targeted and focused questions. So we are quite keen to see how you have got on with } \\
\text { the Tablet PC to date and, as I say, maybe eliciting some slightly unexpected answers } \\
\text { that we could not predict had we got prescribed questions. And that is about it really. } \\
\text { So I have got seven questions. We will finish by } 1: 30 \text {, which is the time that I gave you } \\
\text { in the e-mail. So without further ado then, we will make a start. So, they are open } \\
\text { questions and everybody can express an opinion if they have got one. So first one then: } \\
\text { how does sketching with a Tablet PC compare with pen/pencil sketching? }\end{array}$ \\
\hline Respondent & Not as good. \\
\hline Interviewer & So you feel that the Tablet PC is not as good as the pen/pencil sketching... \\
\hline Respondent & There is no feedback, no tactile feedback or resistance. \\
\hline Respondent & In what way? \\
\hline Interviewer & $\begin{array}{l}\text { Just general, you tell us, how does it compare? Good? Bad? Ugly? Indifferent? As } \\
\text { Anthony was saying, Anthony defined it by saying it is not as good. }\end{array}$ \\
\hline Respondent & $\begin{array}{l}\text { I just prefer that pencil resistance because there is practically no friction with the } \\
\text { laptop. You are just drawing on a piece of plastic, but with the pencil and paper, you } \\
\text { have got that resistance and you know ... just that feel of sketching, you know where } \\
\text { you are going with it. }\end{array}$ \\
\hline Interviewer & $\begin{array}{l}\text { So, somehow, the nature of the surface on the Tablet PC, it is not as receptive as } \\
\text { paper, a piece of paper. }\end{array}$ \\
\hline Respondent & $\begin{array}{l}\text { I think it is because you are not used to it as well, because we have always used pen } \\
\text { and pencils since the age of, like, three, like colouring in, not quite used to the texture } \\
\text { yet of it, so maybe with more ... if I have used that since the age of three, then I guess I } \\
\text { have used it enough and it will feel normal. }\end{array}$ \\
\hline Interviewer & Okay. \\
\hline Respondent & $\begin{array}{l}\text { I think it is definitely something you get used to, from an industry point of view; I think } \\
\text { you can create something that you can send out to clients or directors or other people, } \\
\text { maybe work colleagues, a lot quicker. }\end{array}$ \\
\hline Interviewer & On the Tablet PC? \\
\hline Respondent & You can get a lot more worked up and people can kind of feedback to it a lot quicker. \\
\hline Interviewer & Okay. \\
\hline Respondent & $\begin{array}{l}\text { It is because you can amend it quickly, you can add colour and do whatever. It is quite } \\
\text { versatile. }\end{array}$ \\
\hline Interviewer & $\begin{array}{l}\text { Okay, so you are a bit concerned about the surface that you are working on for the } \\
\text { Tablet PC and the feedback, but you are saying in terms of workflow, you can generate } \\
\text { stuff. }\end{array}$ \\
\hline Respondent & Yes, once you get used to it. \\
\hline Interviewer & So you are saying, what, more impressive and faster or ... \\
\hline Respondent & Yes, and if you are trying to impress clients which ... \\
\hline Interviewer & ... generally you are. \\
\hline Respondent & $\begin{array}{l}\text { Yes, you can create something, which you can e-mail and you can show to them quite } \\
\text { easily. }\end{array}$ \\
\hline Respondent & Without scanning. \\
\hline Interviewer & But forgetting about scanning because obviously you can correct something on paper \\
\hline
\end{tabular}




\begin{tabular}{|c|c|}
\hline & $\begin{array}{l}\text { and scan it relatively efficiently, is there something more fundamental about the Tablet } \\
\text { PC ... because actually to say I do not want to scan it ... }\end{array}$ \\
\hline Respondent & There is the undo button. \\
\hline Respondent & Digitally, black is black. Scanning, it is not always black is black. \\
\hline Respondent & You definitely lose some of the image quality. \\
\hline Respondent & $\begin{array}{l}\text { You have got this sort of higher contrast without PhotoShopping and getting, look, I } \\
\text { can make my sketch black and black on paper, but you have got sort of the contrast. }\end{array}$ \\
\hline Interviewer & Okay. \\
\hline Respondent & I do not know, more defined, more vibrant look. \\
\hline Respondent & More of a wow factor. \\
\hline Respondent & $\begin{array}{l}\text { And going back to what he said, I think maybe it is possible to create something that } \\
\text { does go more like paper, and does give you that feel that you usually expect with a } \\
\text { typical media. }\end{array}$ \\
\hline Interviewer & But in the case of the machines we are using ... \\
\hline Respondent & $\begin{array}{l}\text { In this current case, yes, I think that it seems a little bit ... the difference I think is it is a } \\
\text { bit too smooth and paper is kind of rough. That when you are putting a pen and pencil } \\
\text { against paper, you have got this sort of roughness texture against it, whereas you do } \\
\text { not get with plastic on plastic and I think that is what causes people to feel that it does } \\
\text { not feel so natural or they are saying that because it is making contact and it is pretty } \\
\text { accurate. It does feel like ... it is pretty good compared to a lot of other things. }\end{array}$ \\
\hline Respondent & $\begin{array}{l}\text { I think with anything, that is just a learning curve. You just spend more time with it and } \\
\text { you just get used to it. }\end{array}$ \\
\hline Interviewer & So maybe you can overcome that difference in texture with time? \\
\hline Respondent & Yes. \\
\hline Respondent & I do not think that is a problem ever. \\
\hline Respondent & $\begin{array}{l}\text { I do not think it is a problem for designers, but I think for someone that is not using it } \\
\text { so much, it may become a problem, for someone that is learning it initially. Like, pen } \\
\text { and paper, someone that has got the ability to sketch can just go out and sketch ... }\end{array}$ \\
\hline Respondent & $\begin{array}{l}\text {... but someone that does not know how to use a tablet, goes out and uses ... uses a } \\
\text { tablet but does not do so well. }\end{array}$ \\
\hline Respondent & What was the question again? \\
\hline Interviewer & How does sketching with a Tablet PC compare to pen/pencil sketching? \\
\hline Respondent & Who is saying undo? \\
\hline Respondent & Me. I actually do like that. \\
\hline Interviewer & So the fact that you can edit and get out of mistakes is good? \\
\hline Respondent & I think ... yes. \\
\hline Respondent & $\begin{array}{l}\text { I think it is about prior knowledge because you need to have ... with sketching you do } \\
\text { not need that prior knowledge on how to use it whereas with the tablet you need to } \\
\text { know how to use tools and it is just like with any kind of ... I guess ... but how to ... with } \\
\text { the SketchBook you need to know how to use it and it is just the kind of time } \\
\text { constraints and those quick things that we need to do, it was harder because you had } \\
\text { to kind of think about which one is which rather than rather than sketching. }\end{array}$ \\
\hline Interviewer & $\begin{array}{l}\text { So with a pencil and paper, you focus on perspective and shadow whereas with the } \\
\text { Tablet PC, you have still got those issues but you have also got the interface with the } \\
\text { software? }\end{array}$ \\
\hline Respondent & Yes. \\
\hline Interviewer & $\begin{array}{l}\text { It is not directly related to this question, but who uses Photoshop for sketching. So one } \\
\text { uses Photoshop, the rest of you use SketchBook Pro? }\end{array}$ \\
\hline Respondent & $\begin{array}{l}\text { I would normally use Photoshop but on the tablet, I normally use the control buttons } \\
\text { so I find it quite hard to ... without the control buttons, not to ... the shortcuts to do it } \\
\text { on the tablet, so on a big screen I would use Photoshop. On the little one, I would use } \\
\text { SketchBook. }\end{array}$ \\
\hline Respondent & You use it with an external keyboard do not you, so you can do the shortcuts. \\
\hline Respondent & $\begin{array}{l}\text { I do. I used to use Photoshop and then I realized it was pants for sketching and then, } \\
\text { thanks to Noor here, recommended SketchBook Pro and I have never turned back. }\end{array}$ \\
\hline
\end{tabular}




\begin{tabular}{|c|c|}
\hline Interviewer & A convert, actually a convert, but you are hanging onto Photoshop? \\
\hline Respondent & $\begin{array}{l}\text { I have not tried it because it did not work since SketchBook Pro would not work on my } \\
\text { laptop. }\end{array}$ \\
\hline Interviewer & $\begin{array}{l}\text { Okay, so at the moment, one Photoshop, everybody else, SketchBook Pro. Okay. So } \\
\text { anybody else on, how does sketching with a Tablet PC compare to pen/pencil } \\
\text { sketching? }\end{array}$ \\
\hline Respondent & $\begin{array}{l}\text { I think it is a little more comfortable for a long period of time, sketching on paper, just } \\
\text { because of the thickness of it. You can support your whole arm. }\end{array}$ \\
\hline Interviewer & $\begin{array}{l}\text { Okay, so you are saying because ... we have finished with this one now so I just grab } \\
\text { that ... it is the thickness of ... obviously when it is being flipped open ... I love this catch } \\
\text { so much. It is so easy to use. It is fantastic. So that thickness is problematic, is what you } \\
\text { are saying? }\end{array}$ \\
\hline Respondent & $\begin{array}{l}\text { If that is the thinnest it can be, if you have the extra battery pack or if you have it in the } \\
\ldots\end{array}$ \\
\hline Interviewer & Yes, sure. \\
\hline Respondent & $\begin{array}{l}\text { It is just kind of a pressure point on your wrist, if you rest your whole hand on it, } \\
\text { because you cannot spend a long period of time doing that. }\end{array}$ \\
\hline Interviewer & $\begin{array}{l}\text { So if you had ... I do not know, a couple of bits of MDF with a hole so you had a flat } \\
\text { surface... }\end{array}$ \\
\hline Respondent & Recessed desk. \\
\hline Interviewer & Recessed desk, thank you, I like it. \\
\hline Respondent & $\begin{array}{l}\text { I think another thing is the light on it, so it shines up so if you are sketching you can } \\
\text { easily see because it is a matte surface, you can see ... you can kind of sit how you want } \\
\text { to sit so you can sit properly, you can sketch for a longer time, whereas with the PC, } \\
\text { because you have got the glare, you have to kind of sit in one position which kind of } \\
\text { gives you that angle on the back so I find it is ... you can kind of be there for } 20 \text { minutes } \\
\text { but then you need a break for a little bit of time whereas you cannot kind of let it flow } \\
\text { constantly. }\end{array}$ \\
\hline Interviewer & Okay. \\
\hline Respondent & I swear I have a massively \\
\hline Respondent & January was yesterday. \\
\hline Respondent & Since January, beginning of Ja \\
\hline Respondent & Oh, the begin \\
\hline Respondent & $\begin{array}{l}\text { Honestly, I swear, I do not know if it is just due to the tablet or maybe it is I am just } \\
\text { weak and do not go to the gym enough, but, yes, just this leaning over thing. }\end{array}$ \\
\hline Respondent & It is just so you do not get the glare into it, you have to lean over that far. \\
\hline Respondent & $\begin{array}{l}\text { Well, I do not know if it is the glare thing. It is just the fact that you have to lean over. I } \\
\text { do not know, maybe when I am sketching, sometimes you feel that you can relax a } \\
\text { little bit more. With this, it just seems like... }\end{array}$ \\
\hline Interviewer & Does anybody else feel they have to be in an awkward posture? \\
\hline Respondent & Maybe it is because I use an external keyboard as well. \\
\hline Respondent & $\begin{array}{l}\text { I have the thing in front of me and I have this external keyboard above that and I will } \\
\text { literally be having my hand over that space far so I can zoom in and out and move } \\
\text { across the page, and maybe it is like that, that I am bent and it is killing my back. I do } \\
\text { not know. That is just my personal opinion. }\end{array}$ \\
\hline Respondent & $\begin{array}{l}\text { Position is definitely really ... it really differs because if you have got an A3 piece you } \\
\text { can sit properly in your chair whereas with the tablet, you do ... depending on where } \\
\text { you are sitting with the light, you do have to adjust and then kind of move it around } \\
\text { and then you have to adjust it again. }\end{array}$ \\
\hline Respondent & $\begin{array}{l}\text { You can actually adjust the piece of paper to fit you. The tablet will stay still and you } \\
\text { work around this fixed screen. }\end{array}$ \\
\hline Interviewer & So you are saying you spin the paper? \\
\hline Respondent & More so than the tablet. \\
\hline Interviewer & So you tend to spin a piece of paper to sketch ... \\
\hline Respondent & Yes, otherwise you have to spin yourself. \\
\hline
\end{tabular}




\begin{tabular}{|c|c|}
\hline Interviewer & ... so you do not tend to ... \\
\hline Respondent & It is because it has pads on the bottom. \\
\hline Respondent & I do occasionally but I do not massively. \\
\hline Interviewer & $\begin{array}{l}\text { And that is actually quite central ... I always think it is important to do that because it } \\
\text { gives you a better angle whereas, yes, I can see actually, that is quite ... }\end{array}$ \\
\hline Respondent & $\begin{array}{l}\text { I think that is so true but on top of that, with this undo feature, as you say, you can } \\
\text { undo so you sort of just go through that process a lot more. }\end{array}$ \\
\hline Interviewer & So you tend to just get on with it and knowing that you can undo it? \\
\hline Respondent & $\begin{array}{l}\text { Yes, and I think with that you ... with sketching, you sometimes ... when you have got a } \\
\text { line, you sort of do it slowly and then it becomes jagged and not very smooth, it does } \\
\text { not give that flair that you would get from something that you just drew quickly, and } \\
\text { with a tablet, you can just do that quickly and if it is wrong, you just undo it. }\end{array}$ \\
\hline Respondent & $\begin{array}{l}\text { I think that sort of equates to what you were saying before with the quality and } \\
\text { presentation to someone. The quality goes up because you have got this flair, and also, } \\
\text { when you are rendering, you can render and if something looks bad, you can go back } \\
\text { and try again and undo something, and with that, it sort of gives you this extra } \\
\text { confidence. }\end{array}$ \\
\hline Respondent & $\begin{array}{l}\text { It does, it makes you more adventurous with what you are putting down because you } \\
\text { know you can just change it with the touch of a button. }\end{array}$ \\
\hline Interviewer & $\begin{array}{l}\text { A marker is quite an unforgiving media. You put a marker there and it is set, whereas } \\
\text { with this... }\end{array}$ \\
\hline Respondent & Yes, and so therefore ... \\
\hline Respondent & I feel I go very conservative when I am using a marker or something unless ... \\
\hline Respondent & It is not very subtle, is it, if you go wrong, it is horrible. \\
\hline Interviewer & $\begin{array}{l}\text { Okay, good. Anymore? How does sketching ... remind you of the question: how does } \\
\text { sketching with a Tablet PC compare to pen/pencil sketching? }\end{array}$ \\
\hline Respondent & $\begin{array}{l}\text { Layering is an absolute Godsend. With paper, it is like paper and then paper and then } \\
\text { paper, so it is really nice to have that kind of different opacity. That is a real kind of } \\
\text { Godsend on sketching I must admit so you can do a baseline ... I can do boxing as you } \\
\text { do and then you do not have to rub it out or make it look messy. So presentation, } \\
\text { again, it is kind of work through that. }\end{array}$ \\
\hline Interviewer & $\begin{array}{l}\text { Actually, on one of the examples, the grinder ... I do not know whose that was but he } \\
\text { had changed the opacity of the crating he had used, still part of the presentation but } \\
\text { changed it to a layout. }\end{array}$ \\
\hline Respondent & $\begin{array}{l}\text { There is one other point, so I am sure you are going to go over it is the precision of } \\
\text { where the pen is to where the actual point is on the screen. It is sometimes slightly out, } \\
\text { you can set it but... }\end{array}$ \\
\hline Interviewer & $\begin{array}{l}\text {... it is spot on, with one piece of paper, but you are saying that that distance is } \\
\text { awkward. }\end{array}$ \\
\hline Respondent & $\begin{array}{l}\text { It is not distance but it is also the actual distance from where the pen is touching the } \\
\text { screen, it might be slightly off so if you have done a few lines, few shapes then you } \\
\text { want to start rendering, then you do a line and that is actually out by a few millimetres } \\
\text { because of the precision of the pen to the screen. It is a good thing that you go the } \\
\text { undo thing because you are going to undo and then you get closer over and over again } \\
\text { until you have actually got what you want. }\end{array}$ \\
\hline Respondent & $\begin{array}{l}\text { I find that when I am zoomed out and I do these little details, as you are saying, if it is a } \\
\text { mil out, even if it is one mil out, which is not a big amount, you are getting it } \\
\text { completely wrong so one of the things that I do to counteract that is just zoom in and } \\
\text { then that one mil on the page does not look like such a big distance. So that is a } \\
\text { counter to that problem, but I feel that that problem, like, if it was, as you are saying, } \\
\text { more accurate, then you would not need to do that and it would probably save me } \\
\text { time. }\end{array}$ \\
\hline Interviewer & $\begin{array}{l}\text { And it is a little bit artificial working in almost a macro mode all the time, not all the } \\
\text { time, but ... }\end{array}$ \\
\hline Respondent & $\begin{array}{l}\text { I find that with the macro mode, zooming in, you can be doing something but you do } \\
\text { not know what the big picture is so you can get the perspective wrong or you can get }\end{array}$ \\
\hline
\end{tabular}




\begin{tabular}{|c|c|}
\hline & $\begin{array}{l}\text { something not as precise as if you were zoomed out or if you had ... in a lot of ways it } \\
\text { allows you to get a fine detail that you struggle with when using a piece of paper. }\end{array}$ \\
\hline Interviewer & $\begin{array}{l}\text { OK. Anybody else on sketching ... how does sketching with a Tablet PC compare with } \\
\text { pen/pencil sketching? Moving on then, and there will be some overlap with these } \\
\text { questions because some of the issues will be applicable to more than one. What } \\
\text { impact has the Tablet PC had on your sketching ability? So, your ability to create half } \\
\text { decent representations of your design concepts or development? So, impact on your } \\
\text { sketching ability? Gone up? Gone down? About the same? }\end{array}$ \\
\hline Respondent & $\begin{array}{l}\text { I think I was referenced to the confidence as well as sketching, for the things you just } \\
\text { mentioned as well, that is how comfortable you are doing something or how ... }\end{array}$ \\
\hline Interviewer & So the edit thing makes you more confident which then improves your ability? \\
\hline Respondent & $\begin{array}{l}\text { Yes, improves your ability, because confidence shows ... I believe confidence shows in } \\
\text { what you do. If you are not really confident you get shaky lines and hairy lines as well } \\
\text { but ... and things where, if I had time to do it and I have got the confidence about } \\
\text { playing around with it, I feel things will come out better than things that I think, well, I } \\
\text { have got to do a quick sketch and then get it scanned so I will just do it on there, but } \\
\text { then the confidence is gone because of the precision of the pen and the things that we } \\
\text { just mentioned shows through. }\end{array}$ \\
\hline Interviewer & $\begin{array}{l}\text { Okay. Anybody else, impact that Tablet PCs have on sketching ability? Do you feel that } \\
\text { you can sketch better? Whose sketching improved? }\end{array}$ \\
\hline Respondent & $\begin{array}{l}\text { I can render better, like we said before with the whole quickly rendered ... so that } \\
\text { improves cause marker pens like we said are a nightmare even if you just put a grade } \\
\text { shade on something, it instantly looks a bit more 3D and nicer so that kind of improves } \\
\text { it a bit. }\end{array}$ \\
\hline Interviewer & What about the fundamentals of perspective? \\
\hline Respondent & $\begin{array}{l}\text { I think it kind of makes you go back to the basics because I find I am a little bit } \\
\text { uncertain on the ... because the screen is not any resistance. If it was on paper, I would } \\
\text { be happy just drawing the basic shape and getting perspective just by looking at it } \\
\text { because I am not on any tablet, I am not as sure about it. I kind of go back to the } \\
\text { crating and the perspective lines and ... }\end{array}$ \\
\hline Interviewer & So you tend to use more construction using the Tablet PC? \\
\hline Respondent & Yes, it takes you back to basics which I think improved my sketching. \\
\hline Interviewer & So just remind me why you are going back to basics with the Tablet PC? \\
\hline Respondent & $\begin{array}{l}\text { Because I am a little bit unsure about it, a bit ... because there is no resistance, or less } \\
\text { resistance, I feel I have to go through the structure of drawing rather to be able to do it } \\
\text { naturally. }\end{array}$ \\
\hline Respondent & \\
\hline Respondent & $\begin{array}{l}\text { So it is kind of like a knock off effect where it is improved your ... but I reckon because } \\
\text { of the Tablet PC I am better drawing on paper now. }\end{array}$ \\
\hline Interviewer & Why? That is interesting. \\
\hline Respondent & $\begin{array}{l}\text { I find with the torch one, I was doing my perspective lines because the angle of your } \\
\text { wrist when it is like that, I was getting curved lines instead of when I wanted a straight } \\
\text { line, because my wrist was up so I could not quite get the angle right. }\end{array}$ \\
\hline Interviewer & Right, so normally ... \\
\hline Respondent & Paper or tablet? \\
\hline Respondent & On the tablet because my wrist is up like that, I get like that more. \\
\hline Interviewer & Okay ... I will not use my pencil on the Tablet PC. What is going to sto \\
\hline Respondent & Yes. \\
\hline Interviewer & So you are trying to say you were doing that. Because the height... \\
\hline Respondent & $\begin{array}{l}\text { Luckily with SketchBook Pro you get this grid thing, which allows you to draw straight } \\
\text { lines. }\end{array}$ \\
\hline Respondent & It is quite time-consuming though, because you have got to kind of adjust it ... \\
\hline Respondent & But you can still kind of use a ruler on that. \\
\hline Respondent & Yes, that is true. \\
\hline Interviewer & So, actually using a plastic ruler on it? \\
\hline
\end{tabular}




\begin{tabular}{|c|c|}
\hline Respondent & Yes. \\
\hline Respondent & I do not use a plastic ruler. \\
\hline Interviewer & You do not? \\
\hline Respondent & Yes. \\
\hline Respondent & You can draw straight lines in between two points quite quick. \\
\hline Respondent & It is just having the keyboard ... \\
\hline Respondent & Yes. \\
\hline Respondent & ... because you have got the keyboard covered up by that. \\
\hline Respondent & True. \\
\hline Respondent & You need to have a keyboard, to do a straight line. \\
\hline Respondent & A rule does actually that though. \\
\hline Respondent & But that is only in Photoshop, correct? \\
\hline Respondent & Yes, in Photoshop. \\
\hline Interviewer & $\begin{array}{l}\text { Okay, so in terms of correcting those lines, somehow the ergonomics of using it can } \\
\text { cause problems because of the ... }\end{array}$ \\
\hline Respondent & Yes, because of the thickness. \\
\hline Interviewer & $\begin{array}{l}\text { Unless we use a recessed desk which will now be put into production. Okay. Any other } \\
\text { comments on impact on sketching ability? }\end{array}$ \\
\hline Respondent & $\begin{array}{l}\text { I am not really sure if my sketching on paper has improved or not through tablet use } \\
\text { but I definitely think that with the use of a tablet, your skills are going ... your odds are } \\
\text { increasing because it is a new media for yourself. I do not know how that translates to } \\
\text { paper because I do not do enough paper work anymore. }\end{array}$ \\
\hline Interviewer & $\begin{array}{l}\text { There is the skill in terms of using a new media, using SketchBook Pro or Photoshop } \\
\text { but I am just talking about fundamental ability to sketch a torch or a spoon. }\end{array}$ \\
\hline Respondent & $\begin{array}{l}\text { I think when I first went on the tablet, my stuff was pretty average and now it is better } \\
\text { than that because there is a learning curve with that. }\end{array}$ \\
\hline Interviewer & $\begin{array}{l}\text { Good. And you do not think that your sketching ability would have increased at such a } \\
\text { rate if you were just using manual techniques? }\end{array}$ \\
\hline Respondent & I could sketch, not saying in a very good standard before using the tablet. \\
\hline Interviewer & Yes, sure, of course. \\
\hline Respondent & $\begin{array}{l}\text { I do not know if that point has improved or not on paper since using a tablet but I } \\
\text { thought of that when I first went onto a tablet after ... to draw on paper, it was not } \\
\text { particularly good but very quickly it has improved. And I feel now that my sketches on a } \\
\text { tablet are superior to that on paper but I do not know if that translates back to paper } \\
\text { because now it is better than ... }\end{array}$ \\
\hline Interviewer & $\begin{array}{l}\text { But ultimately what you could present to a client or a tutor is better, you feel it is } \\
\text { better? }\end{array}$ \\
\hline Respondent & Yes, definitely. \\
\hline Interviewer & Yes, good. \\
\hline Respondent & $\begin{array}{l}\text { I found that the tablet has actually increased some excitement in co-sketching so by } \\
\text { having it you kind of want to try out different things so I put a lot more time into that } \\
\text { device than I would into sketching where you spend it on different things, but I found } \\
\text { that everyone who's kind of seen it wants to have a go at it, spend } 20 \text { minutes easily } \\
\text { just playing around with things and just that time has really kind of improved different } \\
\text { things. So I think it is the excitement with it and ... }\end{array}$ \\
\hline Interviewer & $\begin{array}{l}\text { You say "excitement," could have also mentioned enjoyment, is using this somehow } \\
\text { more enjoyable than sketching? Is that ... }\end{array}$ \\
\hline Respondent & $\begin{array}{l}\text { The reward is greater but it is quite hard to tell whether your ability is actually } \\
\text { improving compared to the output, it is easier to create something that looks better. }\end{array}$ \\
\hline Respondent & I think that is a great point, "enjoyable" because your work is better and so. \\
\hline Interviewer & Yes, sure, yes, yes. \\
\hline Respondent & $\begin{array}{l}\text {... because at the end of the day, even if I am on the tablet and I am producing } \\
\text { something that is bad, I get frustrated and annoyed and not happy whereas if you get a } \\
\text { good result, whether it is on paper or tablet, but it is more likely to be on a tablet, is } \\
\text { why you probably enjoy it more than you would doing sketching. }\end{array}$ \\
\hline
\end{tabular}




\begin{tabular}{|c|c|}
\hline Interviewer & $\begin{array}{l}\text { Okay, good. Anything else then on impact on the Tablet PC on sketching ability? All } \\
\text { right. So: what impact has a Tablet PC had on creativity? So do you feel you are more } \\
\text { creative? So we are not talking about sketching, we are talking about creativity, as } \\
\text { product design undergraduates. }\end{array}$ \\
\hline Respondent & $\begin{array}{l}\text { I think that is a difficult one to answer because we are constrained to what we have got } \\
\text { to do. We have not got really that much free time ... in my opinion, I have got not free } \\
\text { time... }\end{array}$ \\
\hline Interviewer & $\begin{array}{l}\text { In the context of working on whatever projects you have got, and I guess the pepper } \\
\text { mill exercise. }\end{array}$ \\
\hline Respondent & $\begin{array}{l}\text { I think it is good because it is Internet-based. You can go on the Internet, see what you } \\
\text { have got, import easily, have a sketch around it. It is all kind of there in one area, than } \\
\text { having to go and sketch something somewhere else and kind of having paper there and } \\
\text { Internet here and something else here. It is all kind of in one area, so creativity, I guess, } \\
\text { flows a little bit more because you have got everything... }\end{array}$ \\
\hline Interviewer & It is just one-stop design shop? It is all there in one package? \\
\hline Respondent & Yes exactly. \\
\hline Interviewer & Good, okay. Anything else, creativity, is it making you more creative, less creative? \\
\hline Respondent & $\begin{array}{l}\text { It might be better to join it to a desktop PC though because you have got that one } \\
\text { screen and you want to be able to drag things from the Internet and things but you } \\
\text { have to have the keyboard and the mouse to do that but that is hidden under the } \\
\text { screen, so if you actually had the screen, you could join it another laptop or another } \\
\text { computer, find it and drag it in then, that would probably be easier. }\end{array}$ \\
\hline Interviewer & So possibly combined with an external keyboard and an external screen maybe? \\
\hline Respondent & Yes, perhaps. \\
\hline Interviewer & Which were actually given as part of the re \\
\hline Respondent & What screens have you got? \\
\hline Interviewer & We have got a flat screen and a keyboard, but just two flat screens, two ke \\
\hline Respondent & I would say, I have never used an external screen on that. \\
\hline Interviewer & But do you have an urge to use on? I understand the context ... \\
\hline Respondent & I have got one spare. \\
\hline Interviewer & But you do not feel the urge to use it? \\
\hline Respondent & No never, but I have a Wacom Cintiq and I have that connected to the second one ... \\
\hline Interviewer & What size is that? \\
\hline Respondent & Twenty-one inch. \\
\hline Interviewer & $\begin{array}{l}\text { Okay, so like the monitor monitor that is interesting. But you are using that as a } \\
\text { monitor? }\end{array}$ \\
\hline Respondent & Just like yours. \\
\hline Interviewer & So you are using that as a screen, or are you using that as a monitor as well as a ...? \\
\hline Respondent & I never use it as a monitor. I use it only for sketching. \\
\hline Interviewer & Just drawing, okay. \\
\hline Respondent & $\begin{array}{l}\text { I turn it off and just use one screen. I have a 24-inch monitor, LG, beautiful, connected } \\
\text { to my desktop and I have this Wacom as well connected to the second monitor and } \\
\text { then, if I am using Photoshop then I will pull up the canvas on one side, then I will have } \\
\text { one on the Wacom so I can do whatever to it, and then on the other side, I have } \\
\text { navigator so I can zoom in and zoom out and move around. But during normal use I } \\
\text { just turn the Wacom off and just use screen. But on this HP device I have never, ever } \\
\text { had the inkling to connect it up... }\end{array}$ \\
\hline Interviewer & $\begin{array}{l}\text { So you feel it is kind of okay, what it is, this lump of stuff that you do not need anything } \\
\text { else hooked into it? }\end{array}$ \\
\hline Respondent & $\begin{array}{l}\text { No, I honestly do, I just never bothered but I do, as you say, have this external } \\
\text { keyboard, which is just a USB keyboard, stick it in and I do not think I can really sketch } \\
\text { without it. It is very difficult for me to sketch without the keyboard just because ... in } \\
\text { fact, one of the things I feel that ... it is just one button I need and that is the space bar, } \\
\text { to zoom in and zoom out and pan around on the SketchBook Pro. }\end{array}$ \\
\hline Respondent & What you can do is, there is a button on the back that is like a little flip up and down so \\
\hline
\end{tabular}




\begin{tabular}{|c|c|}
\hline & $\begin{array}{l}\text { you can assign space to that, so once you are on there, you just flip that space and then } \\
\text { that will come up. }\end{array}$ \\
\hline Respondent & Maybe I should do that then. \\
\hline Interviewer & Okay, lets just bring it back to creativity. Anybody else? \\
\hline Respondent & $\begin{array}{l}\text { Expand on that, just to be polite, I feel that I have my idea in my head but not always } \\
\text { because sometimes if you are doing a very complex surface shape, it is very difficult to } \\
\text { have that in your mind, I find, but in general, I have this idea of how I want this form to } \\
\text { be, already in my head, and it is just about translating that onto paper or to CAD. }\end{array}$ \\
\hline Interviewer & A physical manifestation? \\
\hline Respondent & $\begin{array}{l}\text { Yes, so that other people can see that, and I can actually see that and go, that is pants } \\
\text { or that is pretty good. So in terms of creativity, I do not really think that it makes a } \\
\text { difference but it helps... }\end{array}$ \\
\hline Interviewer & So you do not feel that the Tablet PC is increasing your personal creativity? \\
\hline Respondent & No. \\
\hline Interviewer & $\begin{array}{l}\text { Anybody feel it is? For instance, where ... the fact that you have got access to the } \\
\text { Internet and all other applications as well as sketching in one tool is useful? Anybody } \\
\text { else, any comment on creativity? Okay. Lets move on then. What impact has the } \\
\text { portability of the Tablet PC had on productivity, so the fact that you are going back to } \\
\text { one-stop design tool, everything is on it, it is highly portable, is it making you more } \\
\text { productive? }\end{array}$ \\
\hline Respondent & Yes. \\
\hline Interviewer & How? Why? \\
\hline Respondent & $\begin{array}{l}\text { My laptop is big to carry it around, cannot get it to the library and sometimes I spend a } \\
\text { lot of time in the library with all our course work and stuff, so just having that with me, } \\
\text { especially at this time when the library is so full and stuff and you can not find a laptop } \\
\text { or any kind of computer that has been great thing so you can change between } \\
\text { different tasks, so you can do that electronics revision for an hour and do mechanics } \\
\text { and then you can do some sketching so that has been really good and having that tool } \\
\text { there with you all the time if you wanted it especially having the batteries that you can } \\
\text { take off, makes it so light that it can just go into my handbag easily and stay safe. }\end{array}$ \\
\hline Interviewer & $\begin{array}{l}\text { Okay, so generally, it is light and it is easy to cart around. What about productivity } \\
\text { maybe related to sketching and having these applications on here? }\end{array}$ \\
\hline Respondent & $\begin{array}{l}\text { It is good with having all the tools on one thing. I have tried it on the train before, } \\
\text { having an A3 pad and then a few markers, pens and a few other bits and bobs and you } \\
\text { kind of take them on the table and do not make any friends, and there is stuff } \\
\text { everywhere and you are dropping things. With that, if you did it ... I have not tried to } \\
\text { use it on the train but you have got everything there so you do not have to ... you can } \\
\text { take it anywhere and just sketch away. }\end{array}$ \\
\hline Interviewer & $\begin{array}{l}\text { Has anybody been using it in that kind of context where you have got it with you and } \\
\text { you just want to do a bit of work? }\end{array}$ \\
\hline Respondent & $\begin{array}{l}\text { Planes, it has been perfect, from Geneva it was in my bag, and it was perfect for that } \\
\text { kind of ... just an hour, an hour flight so you can just do a bit of work. }\end{array}$ \\
\hline Interviewer & Which you would not possibly do if you got A3 pads and ... \\
\hline Respondent & $\begin{array}{l}\text { No way, with the little tables, like, this small, so that was just perfect size for any } \\
\text { papers. }\end{array}$ \\
\hline Respondent & $\begin{array}{l}\text { I have tried it on a train and it is rubbish because the shake and like this jot around far } \\
\text { more. }\end{array}$ \\
\hline Interviewer & We are getting a bit of difference in opinion here. \\
\hline Respondent & Yes. Maybe my flight was just better. \\
\hline Interviewer & I guess you did not have a lot of turbulence. \\
\hline Respondent & No, on the train. \\
\hline Interviewer & Oh, a train. I thought you said plane, sorry. \\
\hline Respondent & $\begin{array}{l}\text { I have just been jolting around and you cannot really get that involved in it. It is fine as } \\
\text { a laptop. It is great. }\end{array}$ \\
\hline Respondent & I took it to both Paris and Las Vegas thinking I am going to get loads done. \\
\hline & \\
\hline
\end{tabular}




\begin{tabular}{|c|c|}
\hline Respondent & $\begin{array}{l}\text { Not in the same trip. Okay, I took the Eurostar, smoothest ride, like, so smooth, did not } \\
\text { get anything done. Took it to San Francisco, Las Vegas, again, nothing happened. I do } \\
\text { not know if it is just because of Las Vegas, but on the plane as well, passed out, did not } \\
\text { do anything... }\end{array}$ \\
\hline Interviewer & All right, lets forget about the fact that you drink yourselves to oblivion. \\
\hline Respondent & $\begin{array}{l}\text { I have one MacBook and I usually take that for the e-mail, and the Internet and all the } \\
\text { others and it has got great wireless and I thought, okay, this time I am going to take HP } \\
\text { even though it is the worst laptop, take the HP because I can sketch on this and I am } \\
\text { going to do some amazing sketches and it did not happen. }\end{array}$ \\
\hline Interviewer & Was that because of your personal organization and state of mind ... \\
\hline Respondent & $\begin{array}{l}\text { Yes, maybe it is my state of mine. I could not sketch. I just did not feel that I could } \\
\text { sketch. I do not know, maybe ... }\end{array}$ \\
\hline Interviewer & In a public place. \\
\hline Respondent & $\begin{array}{l}\text { Yes, that was an issue, actually. I felt that ... I would get this tablet and people would } \\
\text { be like, yes, this guy is cool because he has got a tablet around me, but what is this } \\
\text { device; I have never seen it before. Okay, that is cool, but then I would be intimidated } \\
\text { on what I could do. Like, my father would be watching me and I would just be like, } \\
\text { okay, yes, I would just not sketch. So I felt that ... where it is being like you are in a } \\
\text { room or being in ... just expectation with the PC. }\end{array}$ \\
\hline Interviewer & $\begin{array}{l}\text { Yes, you are learning to use it, I guess, and increasing ... so, has anybody ... you } \\
\text { mentioned potentially on the train but did not actually ... has anybody found ... }\end{array}$ \\
\hline Respondent & See, I saw the potential. It did not work. \\
\hline Interviewer & $\begin{array}{l}\text { So, has anybody ... before a lecture or any context used it ... feel they can use it quickly } \\
\text { to sketch or you do not tend to do that with it? }\end{array}$ \\
\hline Respondent & Mechanics notes if you have got a little diagram, jot that down. \\
\hline Interviewer & But not so much for sketching concepts? \\
\hline Respondent & $\begin{array}{l}\text { I find it is a quick tool and I find sketching on paper is a lot quicker than using that. That } \\
\text { is more for building up something. I find, if I have only got } 10 \text { minutes, I would not pull } \\
\text { that out and ... }\end{array}$ \\
\hline Respondent & $\begin{array}{l}\text { There is a restrictive thing speed in moving around on the page, if you have got an } A 3 \\
\text { sheet, you have got to shrink it down and you are sketching something that is going to } \\
\text { be big and you cannot see what you do, you zoom in, like we said earlier. }\end{array}$ \\
\hline Interviewer & $\begin{array}{l}\text { Okay. Right. Okay. So what key skills need to be taught to use the Tablet PC effectively? } \\
\text { Now, I am talking about sketching, concept generation, and possibly some have used it } \\
\text { on combination with Pro/Engineer but what are the key skills that you need to be able } \\
\text { to use that as effectively as possible? So it is kind of a manual thing. Do you feel ... lets } \\
\text { spin it around a little bit ... could you be taught all of that stuff using this? So, if } \\
\text { everybody in the drawing class, first drawing class, semester one, first year, was given } \\
\text { one of these each ... }\end{array}$ \\
\hline Respondent & They would have to. They would be forced into getting used to resistivity. \\
\hline Interviewer & $\begin{array}{l}\text { I think what I am trying to say is, you mentioned everything in the first year, and that } \\
\text { was all manually based. Could we get away without doing that manual stuff? Could we } \\
\text { just give people one of these ... }\end{array}$ \\
\hline Respondent & Well, I think you could stop wasting time with markers, pencils and ... \\
\hline Respondent & ...Tipex. \\
\hline Respondent & Tipex and talcum powder and cotton, wool ... \\
\hline Respondent & But you keep going, you keep going... \\
\hline Interviewer & You were going to say something? \\
\hline Respondent & I agree that is absolutely a waste of time ... \\
\hline Respondent & And you could just go, look, use this pen, use this ... \\
\hline Respondent & But you need that foundation especially technically sketching line work. \\
\hline Interviewer & Actually do it manually. \\
\hline Respondent & Well, it helps having rendering and all that. \\
\hline Respondent & $\begin{array}{l}\text { I do not think there is any point in giving everybody, a hundred people, whatever, one } \\
\text { of those when you are just going to get basics lines. }\end{array}$ \\
\hline
\end{tabular}




\begin{tabular}{|c|c|}
\hline Respondent & Yes, of course. \\
\hline Interviewer & Yes, for sketching manually. \\
\hline Respondent & You can pick up in two minutes. \\
\hline Interviewer & $\begin{array}{l}\text { Can I really? So manual techniques, pencil, we need to understand a bit about } \\
\text { perspective about shadow but to use this ... we need that but we need to use the } \\
\text { software as well. }\end{array}$ \\
\hline Respondent & That is pretty easy to pick up. \\
\hline Respondent & $\begin{array}{l}\text { I think of it this way: pastels and markers are like software for the tablet. The pastel, } \\
\text { markers and paper is like software ... }\end{array}$ \\
\hline Interviewer & $\begin{array}{l}\text { I never really thought of it like that. I am completely enlightened. Okay, anything else? } \\
\text { Key skills need to be taught to use the Tablet PC effectively? Okay. The ultimate } \\
\text { question now then: What are your thoughts on the introduction of the Tablet PC to all } \\
\text { industrial strength product design students. So, again, going back to, everybody gets } \\
\text { one of these week one of the week that they enroll here and it becomes their design } \\
\text { tool, their design studio. }\end{array}$ \\
\hline Respondent & After freshers, you give it up after freshers otherwise it will be too ruined. \\
\hline Respondent & $\begin{array}{l}\text { I think, like we were just saying with that previous question, if they were forced into } \\
\text { using it, then they would get used to using it quite quickly and pick it up. }\end{array}$ \\
\hline Interviewer & $\begin{array}{l}\text { The position that we are trying to create is, it is almost ... it is a freebie, we give you } \\
\text { one each, is it a good idea or should ... }\end{array}$ \\
\hline Respondent & $\begin{array}{l}\text { Of course, if it was based on that drawing module, our first semester was just paper } \\
\text { work based things, and semester two was building up on that, using the Tablet PC, } \\
\text { then it might be a benefit. }\end{array}$ \\
\hline Interviewer & $\begin{array}{l}\text { All right. So even though you got these ... going back to an earlier point, even though } \\
\text { you have got these, you would still quite like to learn to sketch using bits of paper? }\end{array}$ \\
\hline Respondent & $\begin{array}{l}\text { Well, my sketching abilities when I came here was not exactly anywhere near passable, } \\
\text { let alone any good, so building up in the first place is always important. }\end{array}$ \\
\hline Respondent & $\begin{array}{l}\text { The PC might encourage complacency because you can have it undo so learn to get it } \\
\text { right the first time is really what you need. }\end{array}$ \\
\hline Interviewer & $\begin{array}{l}\text { What about in terms of its use with other applications such as Pro/E, switching } \\
\text { between sketching and Pro/E, somehow combining the two? }\end{array}$ \\
\hline Respondent & \\
\hline Respondent & well. \\
\hline Respondent & I would never $r$ \\
\hline Interviewer & Yes, 3D CAD renc \\
\hline Respondent & Yes. I would never recommend it beca \\
\hline Respondent & $\begin{array}{l}\text { However, if you did end up rendering something that you just put in Alias or Maxwell } \\
\text { you leave it go ... you can happily leave it going because it is quite a powerful little PC } \\
\text { as well. You can leave it going overnight and things while you use your regular } \\
\text { computer for other things... }\end{array}$ \\
\hline Respondent & $\begin{array}{l}\text { Or you could use a regular computer to render and then you can use this one for } \\
\text { anything else. }\end{array}$ \\
\hline Respondent & Yes, either way, yes. \\
\hline Interviewer & $\begin{array}{l}\text { All right. So potentially you have got mixed thoughts on the potential for using this as } \\
\ldots \text { giving everybody one of these and it becomes kind of the personal portable design } \\
\text { studio. It looks as if you would still need to have a screen ... }\end{array}$ \\
\hline Respondent & $\begin{array}{l}\text { This is the thing that I have felt massively. I think it is unfair to people who do not have } \\
\text { them. }\end{array}$ \\
\hline Interviewer & You have benefited from this research. That is another issue. \\
\hline Respondent & $\begin{array}{l}\text { As I was saying before I honestly feel that for anyone that does not have a tablet, it is a } \\
\text { disadvantage to them. }\end{array}$ \\
\hline Interviewer & $\begin{array}{l}\text { I am glad that you saying they are pretty cool piece of kit to have. They help you study } \\
\text { industrial and product design so really ... }\end{array}$ \\
\hline Respondent & $\begin{array}{l}\text { Yes. I have got my Cintiq but I feel for a portable device for note taking and sketching, I } \\
\text { am going to find something, either the iPad or find another tablet. }\end{array}$ \\
\hline
\end{tabular}




\begin{tabular}{|c|c|}
\hline Interviewer & Okay. You made a point before we got distracted, about ... \\
\hline Respondent & I do not think I can remember what it was. \\
\hline Interviewer & It is all right. Were you saying something to me? \\
\hline Respondent & $\begin{array}{l}\text { Yes, if you set a project that was actually around using that. You set a sketching } \\
\text { because there was a sketching ... DP2 I think it was, we had to hand in a perspective } \\
\text { and a general assembly drawing by hand. If you set this standard project where it has } \\
\text { to be done on the Tablet PC, then people will have to be forced into and encouraged to } \\
\text { use it and talking amongst each other on how to do things by encourage. }\end{array}$ \\
\hline Respondent & It might be easier than putting it all onto ... just drop it onto acetate and putting it on. \\
\hline Respondent & Thinking about ... DP2 or DP3 ... DP3 was the model, right? \\
\hline Interviewer & Yes. \\
\hline Respondent & And we had to do a drawing where it was like an accurate drawing ... \\
\hline Interviewer & Just a sketch, a sketch ... a proposal, I think it was, sketch proposal. \\
\hline Respondent & $\begin{array}{l}\text { Proposal in front, side view and a few others. Anyway, looking at the mark criteria for } \\
\text { that ... }\end{array}$ \\
\hline Interviewer & Yes, go on. No, I am sure there is a valid point coming up here. \\
\hline Respondent & This is relevant, I feel, things like losing marks for ... \\
\hline Interviewer & We have quality of line, perspective ... \\
\hline Respondent & With the tablet you may get perspective. Quality of line, you should not get ... \\
\hline Interviewer & No, you should not, no. \\
\hline Respondent & $\begin{array}{l}\text { Because you can undo, whereas on paper you cannot. Things like being symmetrical, } \\
\text { you should not be able to get it wrong because ... }\end{array}$ \\
\hline Respondent & You can mirror, copy and paste. \\
\hline Respondent & $\begin{array}{l}\text { You can mirror or you can use the mirror line on Sketch Book or whatever, so you are } \\
\text { not going to loose those marks there. What else? You know the criteria. }\end{array}$ \\
\hline Interviewer & Perspective. That is the one that you ... \\
\hline Respondent & $\begin{array}{l}\text { One area where, like, with the software you can still mess up on but apart from that } \\
\text { you should be ... apart from that it should be full marks, right? }\end{array}$ \\
\hline Interviewer & $\begin{array}{l}\text { It always is. Somebody in the previous group ... there was some command where you } \\
\text { could create a guideline so he was using a vanishing point on the Tablet PC and where } \\
\text { he wanted to start a line it was always creating a line so he could kind of sketch and } \\
\text { these lines were always going to a vanishing point which I thought was quite } \\
\text { interesting. }\end{array}$ \\
\hline Respondent & You can do that but you can still mess up perspective. \\
\hline Interviewer & Yes, sure you can. \\
\hline Respondent & $\begin{array}{l}\text { So that is still up to the person to get it right. But as I said, the rest of the stuff, you } \\
\text { should get full marks, so essentially someone with a tablet can get a lot higher grade } \\
\text { than someone that is just going to use paper and that is why I say I feel that it is almost } \\
\text { essential that someone has a tablet from ... }\end{array}$ \\
\hline Interviewer & $\begin{array}{l}\text { And that is quite interesting because the question is, what are your thoughts on the } \\
\text { introduction of the Tablet PC to all industrial product design students. You are saying it } \\
\text { is a major advantage to have one. }\end{array}$ \\
\hline Respondent & Yes, almost mandatory. \\
\hline Interviewer & Okay, right. \\
\hline Respondent & Okay, it is not mandatory. I just feel that you are bound to get. \\
\hline Respondent & It is a lot of money though, is it not? \\
\hline Interviewer & Yes, a couple of grand each, I think. \\
\hline Respondent & Well, this Netbook is starting to come out on a tablet. \\
\hline Interviewer & $\begin{array}{l}\text { And the cost will come down, of course. So any other points on introducing it to all } \\
\text { students? It seems to be generally positive apart from the cost of course. }\end{array}$ \\
\hline Respondent & Yes. \\
\hline Interviewer & $\begin{array}{l}\text { Okay, final question then: Is there anything else you would like to say about sketching } \\
\text { using the Tablet PC, anything we have not covered? }\end{array}$ \\
\hline Respondent & $\begin{array}{l}\text { The angle of the actual screen, going back to light and kind of being bent over. I think } \\
\text { we went over it when we were sketching and took some photos of it but some kind of }\end{array}$ \\
\hline
\end{tabular}




\begin{tabular}{|c|c|}
\hline & $\begin{array}{l}\text { prop for ... like, when you are doing engineering drawings, you kind of have the whole } \\
\text { piece of paper on that, so some kind of angle device that would stop light coming on it } \\
\text { would be good... }\end{array}$ \\
\hline Respondent & Apple will do one for the iPad. \\
\hline Interviewer & $\begin{array}{l}\text { But are you saying, when it is kind of in this mode ... hang on ... like that. Do you mean, } \\
\text { like that? }\end{array}$ \\
\hline Respondent & No, no, no. \\
\hline Respondent & $\begin{array}{l}\text { So when you are sketching normally, so it is down. You are like this so when you have } \\
\text { to turn it around so you have this hinge nearest you, you are sketching like that and } \\
\text { then, if you open it up a little bit, it will stop the light. }\end{array}$ \\
\hline Interviewer & Oh, I see, got it. So something like that? \\
\hline Respondent & Yes. \\
\hline Respondent & You just get some anti-glare cover though. \\
\hline Respondent & Yes, but it just kind of stop the back as well. \\
\hline Respondent & $\begin{array}{l}\text { I often thought that but I thought with a piece of paper you do not do that. You just } \\
\text { have it flat on the table anyway so it should not be an issue. }\end{array}$ \\
\hline Respondent & $\begin{array}{l}\text { Get an engineering drawing board and stick it on there, or, as I said, go get the iPad } \\
\text { accessories. }\end{array}$ \\
\hline Interviewer & Okay. Anything you would like to say about sketching using the Tablet PC? \\
\hline Respondent & It is good. \\
\hline Interviewer & It is good. You are very lucky to have them. \\
\hline Respondent & Oh, massively. \\
\hline Interviewer & If you have had them stolen ... \\
\hline Respondent & $\begin{array}{l}\text { Because there can be gestures, you have that in the design thing and it happened to } \\
\text { me, if you do that on the screen, it brings up the ... it is like a gesture control to bring } \\
\text { up the ... you know, the bit where you can write ... }\end{array}$ \\
\hline Interviewer & Oh, right, the little keyboard. \\
\hline Respondent & You can turn that off in the control menu. \\
\hline Interviewer & Okay. So, if you do a quick line, a quick shade, it brings up the keyboard on the screen. \\
\hline Respondent & Really? \\
\hline Interviewer & Right. So it is actually quite ... so, actually, if you got the cursor ... \\
\hline Respondent & It senses when the pen is close to the ... \\
\hline Interviewer & $\begin{array}{l}\text { Right, because I am a great fan of doing an ellipse, you get the pen moving and then } \\
\text { you touch it, so you are saying if you get a bit too close, even though it is not touching } \\
\text { the screen, it will make a mark. }\end{array}$ \\
\hline Respondent & Yes, it will still bring up the keyboard. \\
\hline Interviewer & Oh, it brings up the keyboard. \\
\hline Respondent & You can go back and forth because that means you want to scrub out or something. \\
\hline Respondent & $\begin{array}{l}\text { So marking up where you want and then do the line, so you get the idea and then do it, } \\
\text { it still brings up the ... because the pen is close to the screen so it is sensing where it is } \\
\text { going. }\end{array}$ \\
\hline Respondent & That is a bit of a trivial software thing though is not it. \\
\hline Respondent & I do not know because I do not have that. \\
\hline Interviewer & $\begin{array}{l}\text { So, we will discuss this over. Is there anything else you would like the say about } \\
\text { sketching using the Tablet PC? }\end{array}$ \\
\hline Respondent & No. \\
\hline Interviewer & $\begin{array}{l}\text { All right. So, the next session, I think, will be something like week } 14 \text {, week } 15 \text { of } \\
\text { semester two. I need to get you two guys back online. I think I have got a route to } \\
\text { doing that. Do not lose your machines. Make sure you are insured. }\end{array}$ \\
\hline Respondent & $\begin{array}{l}\text { I have got something to add. It would be really cool if we had ... instead of the space } \\
\text { bar rubbish, if you had multi-touch, but then, that could be a bad thing because your } \\
\text { palm and stuff would get in the way. The idea of pinching to zoom in and out ... }\end{array}$ \\
\hline Interviewer & Oh, right. \\
\hline Respondent & $\begin{array}{l}\text { And then to start using two fingers to move around, that could be really cool because } \\
\text { Wacom on the Bambo that cheap stuff, they have multi-touch and they have the ability }\end{array}$ \\
\hline
\end{tabular}


to sketch although I still rather pinch to zoom in and out in Photoshop is really quick and suddenly zoom in and suddenly zoom out. But that idea could be really cool on this tablet. And then also in Windows 7 , you have this thing where you can flick to, like ... if you are on a PDF or something or, like, on a website, it goes up and down which I find is really bad. If you ever go and find it out, I would say flick. It has a gesture, it is suppose to be a gesture with the tablet where you flick up and down and you can go up and down a page, but it is awful. I rarely use it. It is just not intuitive or anything.

Interviewer Okay.

Respondent And that is it.

Interviewer Fantastic. So, on that high informative note, thank you very much for coming along. Enjoy using your Tablet PCs. Look after them and we will rack your brains again, as I said, week 14, 15, something like that. All right. Thanks a lot. 


\subsection{Student Pre- and Post-Using the Tablet PC Questionnaire}

Department of Design and Technology

MTshire, UK, LE11 3TU

Tel: +44 (0) 1509228315 Email: N.Al-Doy@lboro.ac.uk

Loughborough

University

\section{Digital Industrial/Product Design Strategy Questionnaire}

This questionnaire will be used as part of a research study aiming to develop a curriculum for the study of digital industrial design (DID). Your honest opinions will be very helpful.

A. Background:

First name:

Surname:

B. Thoughts on the Digital Industrial/Product Design Strategy:

To what extent do you agree or disagree with the following statements?

1. Digital design methods are quicker than non-digital design methods.

$\square$ Strongly disagree $\square$ Disagree $\square$ Neutral $\square$ Agree $\square$ Strongly agree

Comments:

2. Digital design methods offer more portability than non-digital design methods.

$\square$ Strongly disagree $\square$ Disagree $\square$ Neutral $\square$ Agree $\square$ Strongly agree Comments:

3. Digital design methods are more effective for the presentation of proposals than non-digital design methods.
Strongly disagree
Disagree
Neutral
Agree
Strongly agree

Comments:

4. Digital design methods provide more opportunities to explore alternative solutions than non-digital design methods.

$\square$ Strongly disagree $\square$ Disagree $\square$ Neutral $\square$ Agree $\square$ Strongly agree

Comments: 
5. Digital design methods facilitate creativity more than non-digital design methods.

$\square$ Strongly disagree $\square$ Disagree $\square$ Neutral $\square$ Agree $\square$ Strongly agree
Comments:

6. Digital design methods are more productive than the non-digital design methods.

$\square$ Strongly disagree $\square$ Disagree $\square$ Neutral $\square$ Agree $\square$ Strongly agree
Comments:

7. Digital design methods facilitate the collaboration more than non-digital design methods.

$\square$ Strongly disagree $\square$ Disagree $\square$ Neutral $\square$ Agree $\square$ Strongly agree
Comments:

8. Digital design methods are easier to learn than non-digital design methods.

$\square$ Strongly disagree $\square$ Disagree $\square$ Neutral $\square$ Agree $\square$ Strongly agree
Comments:

9. Digital design methods contribute to the concept generation phase more than non-digital design methods.

$\square$ Strongly disagree $\square$ Disagree $\square$ Neutral $\square$ Agree $\square$ Strongly agree
Comments:

10. Digital design methods contribute to the design development phase more than non-digital design methods.

$\square$ Strongly disagree $\square$ Disagree $\square$ Neutral $\square$ Agree $\square$ Strongly agree
Comments:


11. Digital design methods contribute to the specification phase more than non-digital design methods.

$\square$ Strongly disagree $\square$ Disagree $\square$ Neutral $\square$ Agree $\square$ Strongly agree

Comments:

12. It is now viable to use a digital logbook whilst designing.

$\square$ Strongly disagree $\square$ Disagree $\square$ Neutral $\square$ Agree $\square$ Strongly agree
Comments:

13. It is now viable to design products using digital tools/media only.

$\square$ Strongly disagree $\square$ Disagree $\square$ Neutral $\square$ Agree $\square$ Strongly agree
Comments:

Thank you for your assistance in this research 


\subsection{Student Use of the Tablet PC for Designing Questionnaire}

Department of Design and Technology

Tel: +44 (0) 1509228315 Email: N.Al-Doy@lboro.ac.uk

Loughborough

University

\section{Use of Tablet PC for Designing Questionnaire}

This questionnaire will be used as part of a research study aiming to develop a curriculum for the study of digital industrial design (DID). Your honest opinions will be very helpful.

A. Background:

First name:

Surname:

B. Thoughts on the Use of Tablet PC for designing:

To what extent do you agree or disagree with the following statements? If you have not experienced the activity indicated in a question, please write 'N/A' (not applicable) in the 'Comments' section.

1. It was difficult to precisely match the position of the tip of the stylus with the cursor.

$\square$ Strongly disagree $\square$ Disagree $\square$ Neutral $\square$ Agree $\square$ Strongly agree Comments:

2. It was difficult to create faint lines and use them as a guide when using the Tablet PC.

$\square$ Strongly disagree $\square$ Disagree $\square$ Neutral $\square$ Agree $\square$ Strongly agree
Comments:

3. You would prefer it if the surface of the screen on the Tablet PC had a similar level of resistance to paper.

$\square$ Strongly disagree $\square$ Disagree $\square$ Neutral $\square$ Agree $\square$ Strongly agree

Comments:

4. The rubber feet on the Tablet PC made it difficult to rotate when sketching.

$\square$ Strongly disagree $\square$ Disagree $\square$ Neutral $\square$ Agree $\square$ Strongly agree
Comments:


5. The Tablet PC screen was too small for effective sketching

$\square$ Strongly disagree $\square$ Disagree $\square$ Neutral $\square$ Agree $\square$ Strongly agree
Comments:

6. The thickness of the Tablet PC made it uncomfortable to sketch with as it put pressure on your wrist.

$\square$ Strongly disagree $\square$ Disagree $\square$ Neutral $\square$ Agree $\square$ Strongly agree
Comments:

7. The ability to 'undo' previous work during concept generation hindered creativity.

$\square$ Strongly disagree $\square$ Disagree $\square$ Neutral $\square$ Agree $\square$ Strongly agree
Comments:

8. The stylus was too short for comfortable use.

$\square$ Strongly disagree $\square$ Disagree $\square$ Neutral $\square$ Agree $\square$ Strongly agree
Comments:

9. You were not able to sketch with the stylus at low angle on the screen.

$\square$ Strongly disagree $\square$ Disagree $\square$ Neutral $\quad \square$ Agree $\square$ Strongly agree

\section{Comments:}

10. You faced problems with screen glare while sketching.

$\square$ Strongly disagree $\square$ Disagree $\square$ Neutral $\square$ Agree $\square$ Strongly agree
Comments:


11. The Tablet PC was more difficult to use than pencil and paper.

$\square$ Strongly disagree $\square$ Disagree $\square$ Neutral $\square$ Agree $\square$ Strongly agree
Comments:

12. You were not able to use the full size of the Tablet PC screen because matching the position of the tip of the stylus with the cursor became more difficult towards the edges.

$\square$ Strongly disagree $\square$ Disagree $\square$ Neutral $\square$ Agree $\square$ Strongly agree

\section{Comments:}

13. Leaning over the Tablet while sketching created an uncomfortable posture.

$\square$ Strongly disagree $\square$ Disagree $\square$ Neutral $\square$ Agree $\square$ Strongly agree
Comments:

14. The line quality of the Tablet PC was better than that for paper-based sketching.

$\square$ Strongly disagree $\square$ Disagree $\square$ Neutral $\square$ Agree $\square$ Strongly agree
Comments:

15. You felt more confident using the Tablet PC compared to paper-based sketching because of the ability to 'undo'.

$\square$ Strongly disagree $\square$ Disagree $\square$ Neutral $\square$ Agree $\square$ Strongly agree

\section{Comments:}

16. It was easier to remove mistakes using the Tablet PC than when paper-based sketching.

$\square$ Strongly disagree $\square$ Disagree $\square$ Neutral $\square$ Agree $\square$ Strongly agree
Comments:


17. The quality of outcome was greater using the Tablet PC than when paper-based sketching.

$\square$ Strongly disagree $\square$ Disagree $\square$ Neutral $\square$ Agree $\square$ Strongly agree
Comments:

18. It was quicker to sketch with the Tablet PC than with paper.

$\square$ Strongly disagree $\square$ Disagree $\square$ Neutral $\square$ Agree $\square$ Strongly agree
Comments:

19. The Tablet PC helped you to quickly communicate your ideas to other people.

$\square$ Strongly disagree $\square$ Disagree $\square$ Neutral $\square$ Agree $\square$ Strongly agree
Comments:

Comments:

20. You were able to make quick amendments to your designs using the Tablet PC.

$\square$ Strongly disagree $\square$ Disagree $\square$ Neutral $\square$ Agree $\square$ Strongly agree
Comments:

Comments:

21. The Tablet PC helped you to impress clients.

$\square$ Strongly disagree $\square$ Disagree $\square$ Neutral $\square$ Agree $\square$ Strongly agree

\section{Comments:}

22. The colours used on the Tablet PC were more vibrant than those available with paper-based techniques.

$\square$ Strongly disagree $\square$ Disagree $\square$ Neutral $\square$ Agree $\square$ Strongly agree
Comments:


23. The Tablet PC made you more adventurous when generating concepts and developing them.

$\square$ Strongly disagree $\square$ Disagree $\square$ Neutral $\square$ Agree $\square$ Strongly agree
Comments:

24. The Tablet PC layering facility was very helpful.

$\square$ Strongly disagree $\square$ Disagree $\square$ Neutral $\square$ Agree $\square$ Strongly agree
Comments:

25. Using the Tablet PC increased the speed of your sketching.

$\square$ Strongly disagree $\square$ Disagree $\square$ Neutral $\square$ Agree $\square$ Strongly agree
Comments:

26. Applying colour and tone to your line-work was quicker and easier with the Tablet PC.

$\square$ Strongly disagree $\square$ Disagree $\square$ Neutral $\square$ Agree $\square$ Strongly agree
Comments:

27. Rendering using 3D CAD was quicker and easier with the Tablet PC.

$\square$ Strongly disagree $\square$ Disagree $\square$ Neutral $\square$ Agree $\square$ Strongly agree

\section{Comments:}

28. Sketches produced using the Tablet PC had a tendency to be less detailed.

$\square$ Strongly disagree $\square$ Disagree $\square$ Neutral $\square$ Agree $\square$ Strongly agree

\section{Comments:}


29. Your ability to sketch and draw using paper-based techniques has declined since using the Tablet PC.

$\square$ Strongly disagree $\square$ Disagree $\square$ Neutral $\square$ Agree $\square$ Strongly agree
Comments:

30. The ability to 'undo' using the Tablet PC increased creativity.

$\square$ Strongly disagree $\square$ Disagree $\square$ Neutral $\square$ Agree $\square$ Strongly agree
Comments:

31. The quality of your renderings produced using computer drawing packages (e.g. SketchBook Pro) improved using the Tablet PC.

$\square$ Strongly disagree $\square$ Disagree $\square$ Neutral $\square$ Agree $\square$ Strongly agree
Comments:

32. You became more productive when you used the Tablet PC.

$\square$ Strongly disagree $\square$ Disagree $\square$ Neutral $\square$ Agree $\square$ Strongly agree
Comments:

33. Sketching using the Tablet PC encouraged you to employ construction techniques such as crating when sketching in perspective.

$\square$ Strongly disagree $\square$ Disagree $\square$ Neutral $\quad \square$ Agree $\square$ Strongly agree

\section{Comments:}

34. Sketching using the Tablet PC improved your perspective.

$\square$ Strongly disagree $\square$ Disagree $\square$ Neutral $\square$ Agree $\square$ Strongly agree
Comments:


35. Use of the Tablet PC increased your excitement when collaborating through sketching with other people.

$\square$ Strongly disagree $\square$ Disagree $\square$ Neutral $\square$ Agree $\square$ Strongly agree

\section{Comments:}

36. The visual quality and appearance of your designs were enhanced by the use of the Tablet PC.

$\square$ Strongly disagree $\square$ Disagree $\square$ Neutral $\quad \square$ Agree $\quad \square$ Strongly agree Comments:

37. The work produced using the Tablet PC was of a higher level of presentation than that undertaken using paper-based techniques.

$\square$ Strongly disagree $\square$ Disagree $\square$ Neutral $\square$ Agree $\square$ Strongly agree

Comments:

38. The Tablet PC was easy to use for tracing and producing basic outlines.

$\square$ Strongly disagree $\square$ Disagree $\square$ Neutral $\square$ Agree $\square$ Strongly agree Comments:

39. The size of the Tablet PC screen limited your ability to see numerous previous ideas on the same page.
$\square$ Strongly disagree $\square$ Disagree
Neutral
Agree
Strongly agree

Comments:

40. The size of the Tablet PC screen encouraged you to think more carefully about what you sketch

$\square$ Strongly disagree $\square$ Disagree $\square$ Neutral $\square$ Agree $\square$ Strongly agree

Comments: 
41. Sketches produced using the Tablet PC appeared to be more precious in concept generation, which limited creativity.

$\square$ Strongly disagree $\square$ Disagree $\square$ Neutral $\square$ Agree $\square$ Strongly agree

\section{Comments:}

42. Being able to browse the Internet whilst generating ideas was a significant advantage of using the Tablet PC.

$\square$ Strongly disagree $\square$ Disagree $\square$ Neutral $\square$ Agree $\square$ Strongly agree
Comments:

43. The Tablet PC represented a stand-alone design tool that contained all that was required for effective designing.

$\square$ Strongly disagree $\square$ Disagree $\square$ Neutral $\square$ Agree $\square$ Strongly agree
Comments:

44. If not already in use, the Tablet PC was less convenient when short amounts of time were available for sketching.

$\square$ Strongly disagree $\square$ Disagree $\square$ Neutral $\square$ Agree $\square$ Strongly agree

\section{Comments:}

45. You were uneasy about sketching in public with the Tablet PC because of the potential for it to be stolen.

$\square$ Strongly disagree $\square$ Disagree $\square$ Neutral $\square$ Agree $\square$ Strongly agree
Comments:

46. If you had to work when visiting friends and family, you would prefer to take the Tablet PC rather than an $\mathrm{A} 3$ pad.
Strongly disagree
Disagree
Neutral
Agree
Strongly agree

\section{Comments:}


47. The weight of the Tablet PC affected its portability.

$\square$ Strongly disagree $\square$ Disagree $\square$ Neutral $\square$ Agree $\square$ Strongly agree
Comments:

48. You need to have 2D visualisation software experience to be able to use the Tablet PC effectively.

$\square$ Strongly disagree $\square$ Disagree $\square$ Neutral $\square$ Agree $\square$ Strongly agree
Comments:

49. You need to know the shortcuts in the $2 \mathrm{D}$ visualisation software to be able to use the Tablet PC effectively.

$\square$ Strongly disagree $\square$ Disagree $\square$ Neutral $\square$ Agree $\square$ Strongly agree
Comments:

50. Students should be taught sketching using paper-based techniques before using the Tablet PC.

$\square$ Strongly disagree $\square$ Disagree $\square$ Neutral $\square$ Agree $\square$ Strongly agree
Comments:

51. Students should be taught paper-based rendering before using the Tablet PC.

$\square$ Strongly disagree $\square$ Disagree $\square$ Neutral $\square$ Agree $\square$ Strongly agree Comments:

52. After sketching for some time, you get used to the smoothness of the Tablet PC screen.

$\square$ Strongly disagree $\square$ Disagree $\square$ Neutral $\square$ Agree $\square$ Strongly agree
Comments:


53. Students should not be taught paper-based rendering techniques as the Tablet PC makes them redundant.

$\square$ Strongly disagree $\square$ Disagree $\square$ Neutral $\square$ Agree $\square$ Strongly agree

\section{Comments:}

54. Students need to be taught how to use the virtual keyboard on the Tablet PC desktop.
Strongly disagree
Disagree
Neutral
Agree
Strongly agree

\section{Comments:}

55. The introduction of the Tablet PC to all industrial/product design students would have a motivating effect.

$\square$ Strongly disagree $\square$ Disagree $\square$ Neutral $\square$ Agree $\square$ Strongly agree

\section{Comments:}

56. Students should always have the option for using paper-based techniques to sketch in addition to the Tablet PC.

\begin{tabular}{|c|c|c|c|c|}
\hline Strongly disagree & Disagree & Neutral & Agree & Strongly agree \\
\hline
\end{tabular}

Comments:

57. The Tablet PC was not powerful enough for 3D CAD work.

$\square$ Strongly disagree $\square$ Disagree $\square$ Neutral $\square$ Agree $\square$ Strongly agree

\section{Comments:}

58. The Tablet PC screen was too small for 3D CAD work.

$\square$ Strongly disagree $\square$ Disagree $\square$ Neutral $\square$ Agree $\square$ Strongly agree
Comments:


59. Students about to start undergraduates degrees in industrial/product design should be encouraged to purchase Tablet PCs rather than laptops.

$\square$ Strongly disagree $\square$ Disagree $\square$ Neutral $\square$ Agree $\square$ Strongly agree

\section{Comments:}

60. Using the Tablet PC for designing introduced an element of fun.

$\square$ Strongly disagree $\square$ Disagree $\square$ Neutral $\square$ Agree $\square$ Strongly agree

\section{Comments:}

61. It was useful to use an external keyboard with the Tablet PC when sketching.

$\square$ Strongly disagree $\square$ Disagree $\square$ Neutral $\square$ Agree $\square$ Strongly agree
Comments:

62. SketchBook Pro was more suitable than Photoshop for the generation of line work.

$\square$ Strongly disagree $\square$ Disagree $\square$ Neutral $\square$ Agree $\square$ Strongly agree
Comments:

Comments:

63. SketchBook Pro was easier to use than Photoshop for the generation of line work.

$\square$ Strongly disagree $\square$ Disagree $\square$ Neutral $\square$ Agree $\square$ Strongly agree

Comments:

64. Photoshop was more suitable for rendering the line work than SketchBook Pro.

$\square$ Strongly disagree $\square$ Disagree $\square$ Neutral $\square$ Agree $\square$ Strongly agree
Comments:


65. Connecting the Tablet PC to a larger external screen was beneficial during 3D CAD work.

$\square$ Strongly disagree $\square$ Disagree $\square$ Neutral $\square$ Agree $\square$ Strongly agree
Comments:

66. The battery life of the Tablet PC was acceptable.

$\square$ Strongly disagree $\square$ Disagree $\square$ Neutral $\square$ Agree $\square$ Strongly agree
Comments:

67. The Tablet PC is pressure sensitive.

$\square$ Strongly disagree $\square$ Disagree $\square$ Neutral $\square$ Agree $\square$ Strongly agree

\section{Comments:}

68. Microsoft Journal software represented a viable alternative to a paper-based logbook.

$\square$ Strongly disagree $\square$ Disagree $\square$ Neutral $\square$ Agree $\square$ Strongly agree

\section{Comments:}

69. Using the stylus was useful with 3D CAD work.

$\square$ Strongly disagree $\square$ Disagree $\square$ Neutral $\square$ Agree $\square$ Strongly agree
Comments:

70. Having a device that enables you to adjust the angle of the Tablet PC screen while sketching would be beneficial.

$\square$ Strongly disagree $\square$ Disagree $\square$ Neutral $\square$ Agree $\square$ Strongly agree
Comments:


71. It would be beneficial if the Tablet PC could sit in a recess on a desk to make the screen flush with the surface.

$\square$ Strongly disagree $\square$ Disagree $\square$ Neutral $\quad \square$ Agree $\square$ Strongly agree

\section{Comments:}

72. Having an additional 'control' button that can be used when the screen covers the keyboard would be beneficial.
Strongly disagree
Disagree
Neutral
Agree
Strongly agree

Comments:

Thank you for your assistance in this research 